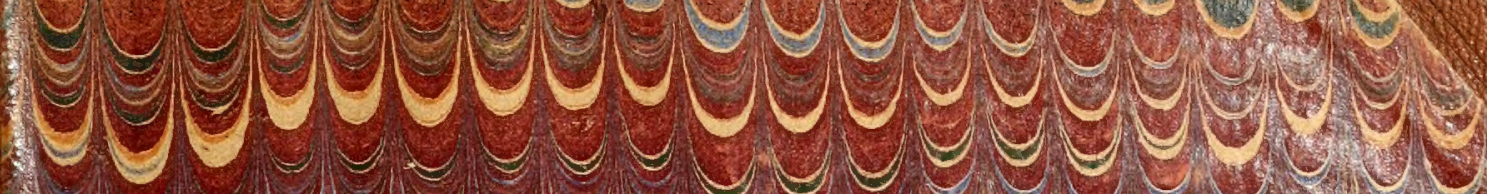

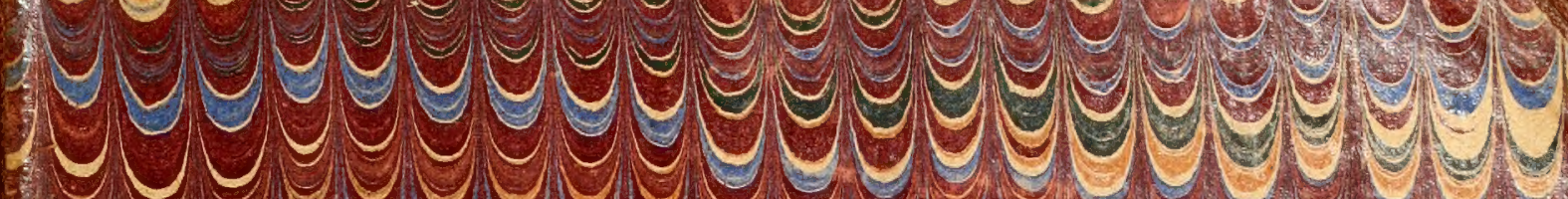
. Cy

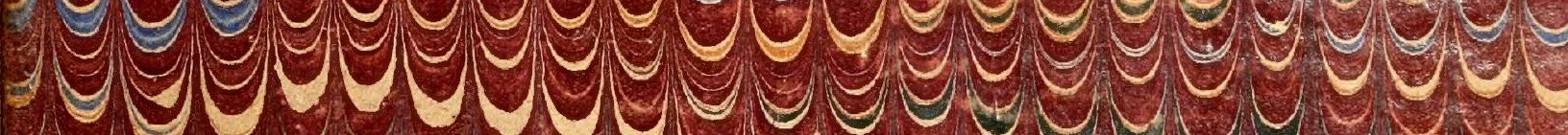

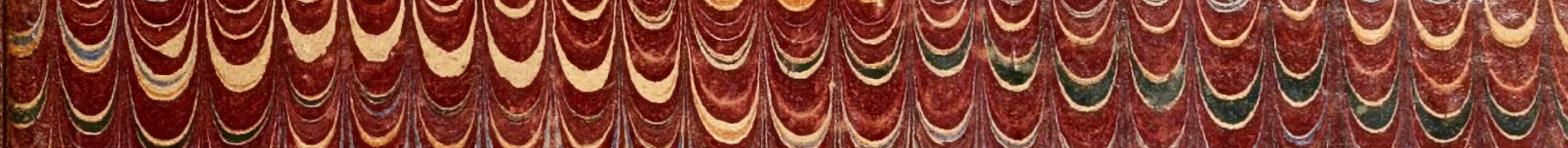
S

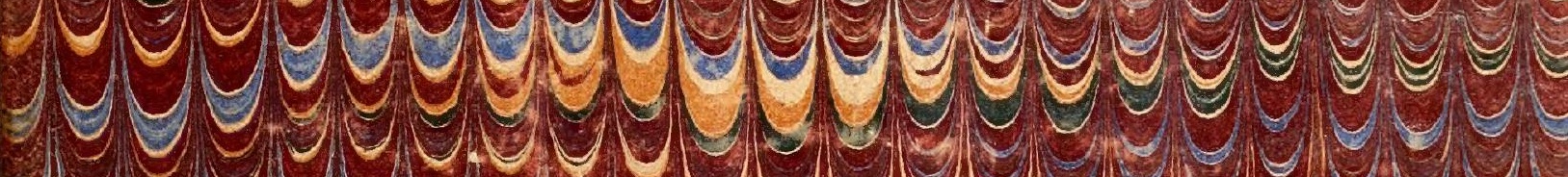

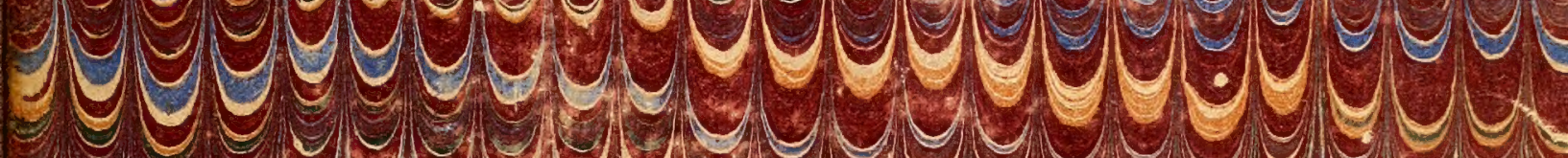

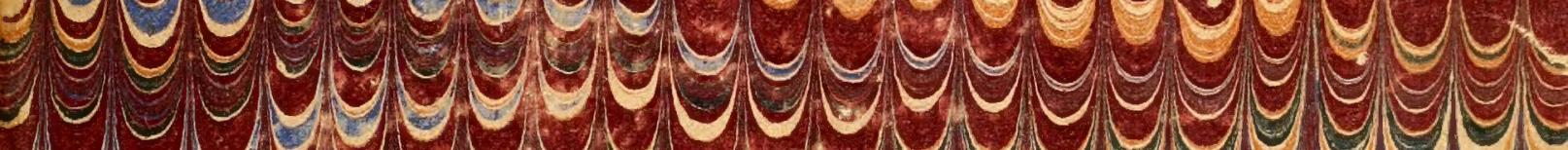
ry (a)

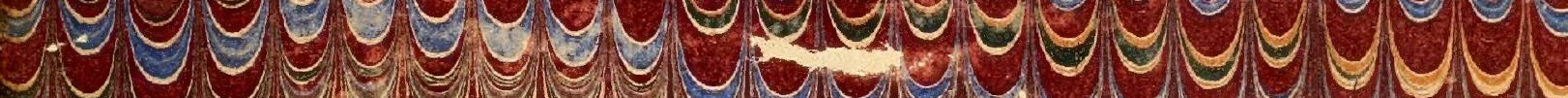

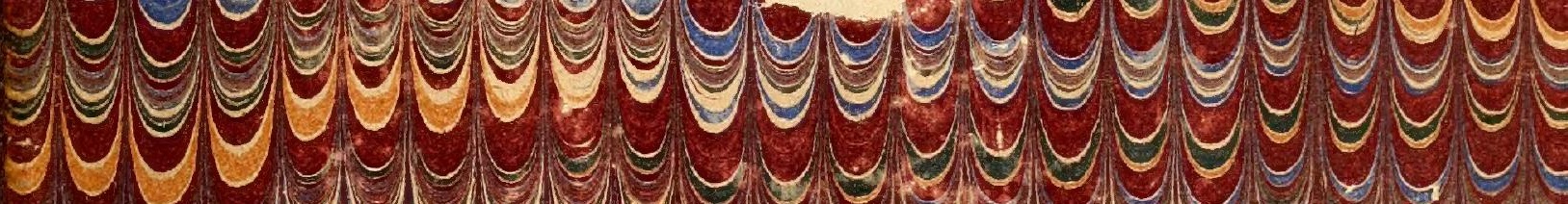

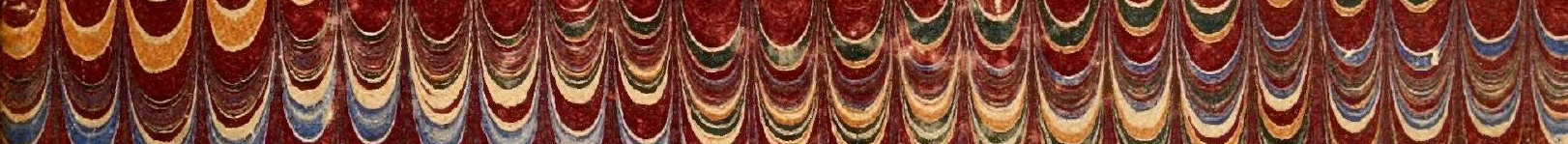
-

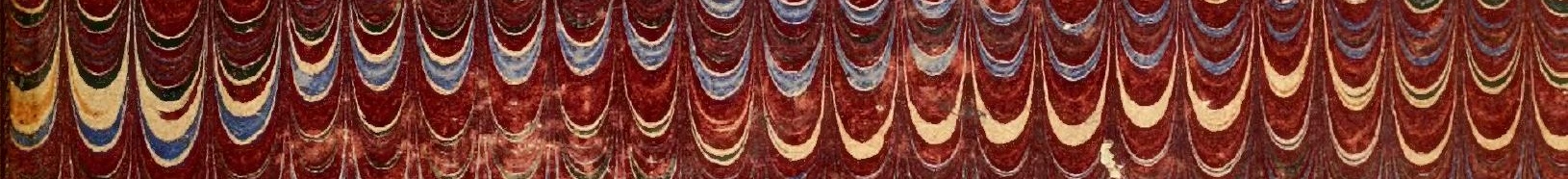
y y 8495 S ¿ 政

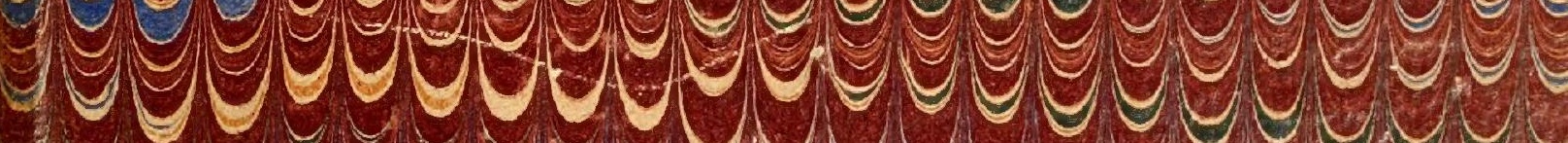
C

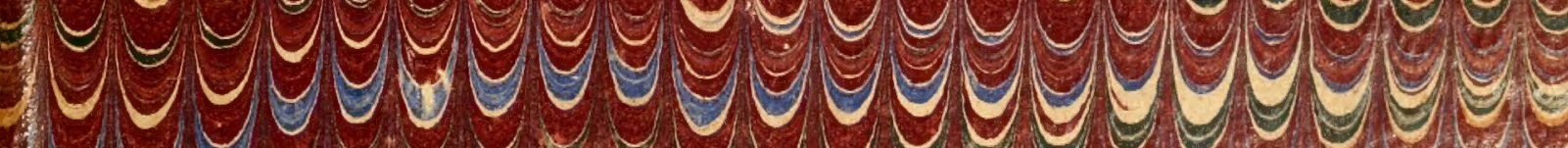

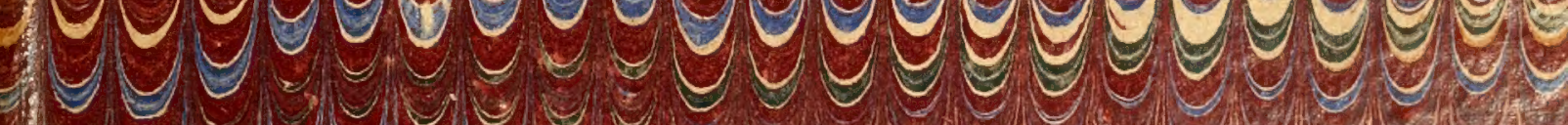
ac

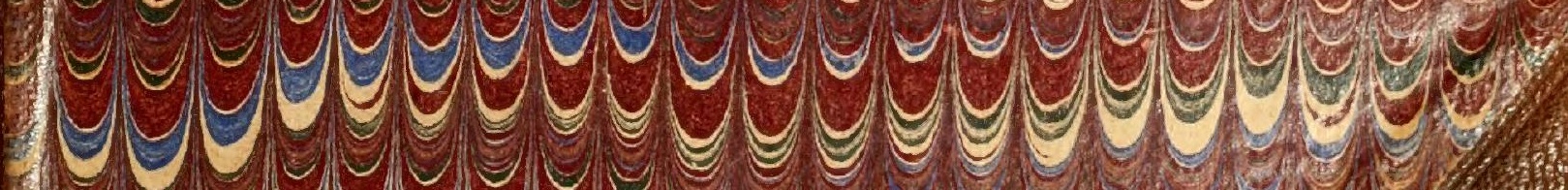




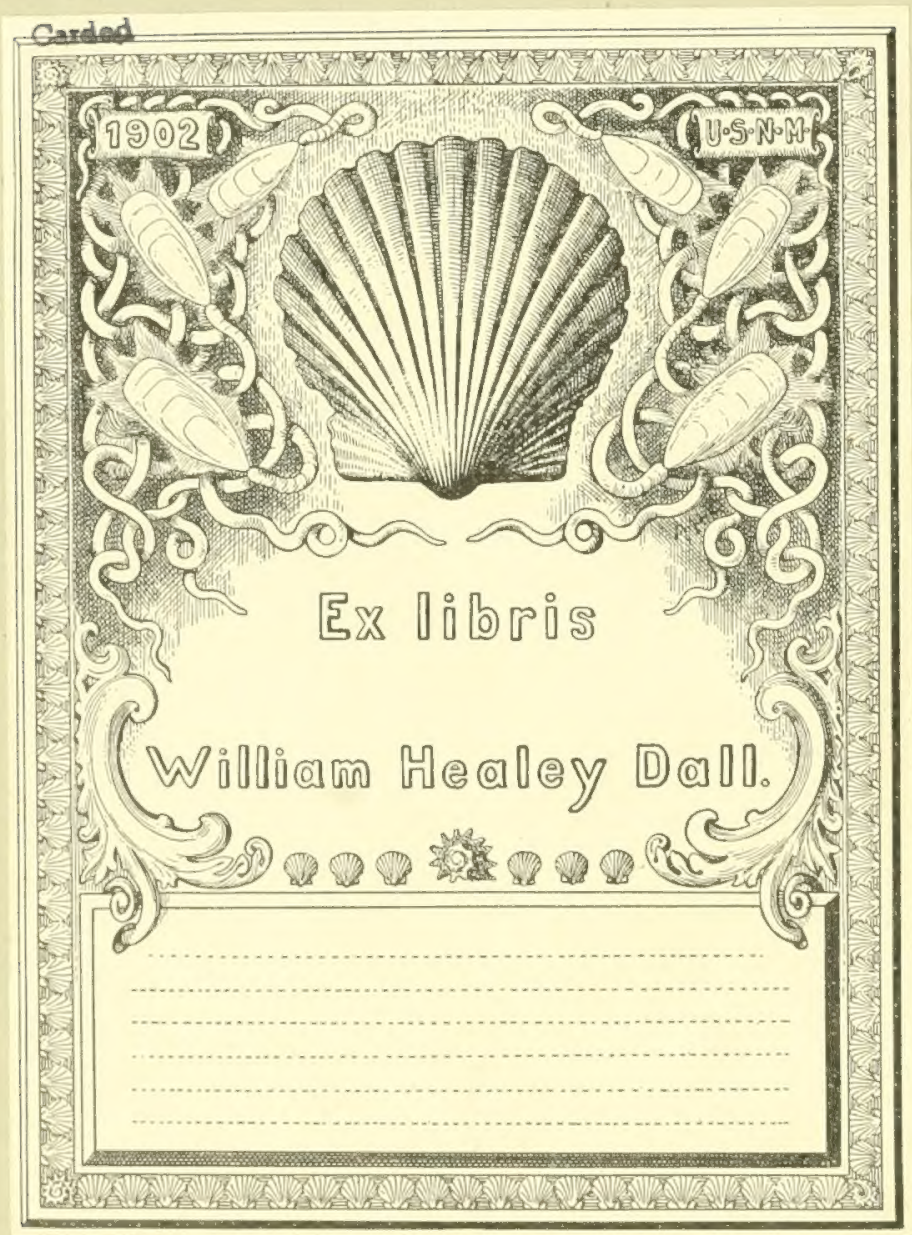


Division of Molluseles

Sectionel Librany 






\section{REALE ACOADEMIA DEI LINCEI Ano CCLXXVII (1879-80)}

\section{LE FORMAZIONI TERZIARIE}

NELLA

PROVINCIA DI REGGIO (CALABRIA).

M EM OR I A

2E. PROY.

G. $S$ G U E N Z A

Premiata al Concorso Accademico istituito dal Ministern di Agric., Ind. e Comm.

col r. Decreto 6 febbraio 1876.

ROM A

COI TIPI DEL SALVIUCCI

1880 


\section{REALE AOCADEMIA DEI LINCHI}

Anvo CCLXXVII (1S79-80)

\section{LE FORMAZIONI TERZIARIL}

NELLA

PROVINGIA DI REGGIO (CALABRIA).

M E MOR I A

NI I I : :

G. SWGU

RO II A

COT TEPI DEL SALVIUCCI

1879 
Serie 3." - Memorie della Classe di scienze fisiche, matematiche e naturali. Vou. VI. ${ }^{\circ}$ - Seduta del 4 febbraio $187 \%$. 
En général les kystèmes passent, les observations reatent. et chachun peut en tirer parti.. A. Farro, Recherches, géologiques dans les parties de la saroie ete.

\section{PREFAZIONE}

Nel movimento scientifico odierno, in cui le scienze naturali hanno preso si grande slancio e sì evidente predominio, la Geologia al certo mette più solide fondamenta, e prende parte attivissima nell'attuale progresso. Nell' Italia nostra vedonsi sorgere da per tutto esploratori più o meno solerti e laboriosi, che colle investigazioni loro danno un contingente abbastanza importante per la conoscenza del suolo italiano e dei fatti geologici rimarchevolissimi, di cui offrono doviziosa varieta la nostra penisola e le isole adiacenti.

Abituato a tali ricerche, ho portato le mie investigazioni sulla porzione meridionale della penisola italiana, che forma l'ultima estremita della parte continentale, esplorando per ora le formazioni terziarie della provincia di Reggio, che occupano buondato del suolo di quella regione, e la cui stratigrafia non credo sia nota al punto da somministrare gli elementi indispensabili alla conoscenza geologica di un paese; anzi bisogna lamentare che varî scrittori, e taluni di epoca assai recente, confondendo talune rocce secondarie con alcune delle terziarie di quelle contrade, per essersi lasciati guidare dai fallaci caratteri litologici, hanno intralciato talmente la matassa, da volere far credere sinanco alle più strane eccezioni delle leggi stratigrafiche e paleontologiche fondamentali, ritardando così di troppo la conoscenza geologica positiva di quell' ultimo estremo dell'Appennino, che colle sue svariate rocce e coi fossili numerosi che ci offre è chiamato ancor esso, e senza dubbio, a rischiarare potentemente la storia del suolo italiano.

Il suolo terziario della provincia di Reggio, formato da potenti masse di rocee svariate, costituisce una porzione ben importante di quella superficie: esso risulta da numerose e ragguaderolí zone, cho nel loro insieme rappresentano tutti quanta la 
serie terziaria colle distinte suddivisioni, nelle quali oggi si ripartono le tre grandi formazioni, cocenica, miocenica e plíocenica.

Abbondanti fossili e ben conservati nelle zone superiori permettono facilmente la ricognizione della loro eta; invece le zono meno recenti ci offrono dei resti in istato di conservazione più 0 meno cattivo, e le piu antiche in generale ne presentano di piì rari o ne mancano afliatto.

Esporre i risultamenti delle mie ricerche sulla serio terziaria del Reggiano, sincronizzando per quanto è possibile le varie zone di tale serie colle vicine e colle più classiche formazioni terziarie di Europa, ecco il compito che mi sono imposto in questo lavoro, sicuro che un tale studio, condotto con perseverante cura, dovea fornirmi importanti fatti, e quindi una sufficiente base per tirarne delle conchiusioni d'alto interesse.

Lungi dal perdermi in vane ed inutili speculazioni, uso invece ad amare l'osservazione, ad analizzare accuratamente i fenomeni ed a ricavare quelle conseguenze che da essi legittimamente derivano, io rifuggiro dall'addentrarmi in teoriche, le quali bene spesso non hanno che brevissima durata; o mi faro quindi ad esporre nel migliore ordine possibile i fatti attentamente studiati, lo osservazioni con esattezza compite, le relazioni che i terreni da me esplorati presentano con quelli di altri luoghi, i risultamenti cui sono arrivato mercè una castigata induzione.

Premetterò ai miei studî una storia critico-bibliografica delle rocce terziarie della provincia di Reggio, la quale dimostrerà quanto vario, strane e perfino contraddittorie opinioni sieno state emesse intorno a tali formazioni, e farà apprendere come sinora la serie terziaria è stata pochissimo conosciuta.

L'esame dettagliato dei terreni verrà preceduto da uno sguardo generale com1) lessivo sulla costituzione geologica del Reggiano e sulla topografica distribuzione delle roce $\theta$ dei varî periodi.

La parte descrittiva poi comincerà colla discussione della tettonica stratigrafica, fondata sull' esame di alcune sezioni naturali, scelte tra le moltissime da me studiate, 6 tra quelle in cui l'ordine di successione è il più evidente. In questa prima rassegna, dalla quale dovrì risultare eridente l'ordine cronologico di tutte le zone terziarie, a conture dalla più recente, accennerò benanco qualche carattere più rilevante, pel quale potrì venire assegnata l'età geologica cui ciascuna zona appartient.

Passerò quindi alla descrizione sistematica di tutti i piani terziarî, che ho riscontrato e studiato nel Reggiano; noterò i rapporti che essi presentano con terreni coetanei d'altri luoghi e specialmente d'Italia; darò uno sviluppo considerevolo alla parte paleontologica come quella che, pei grandi materiali ivi accumulati, morita la fiì grando cura da parte del geologo, e somministra i dati irrefragabili intorno l'età delle rocce e le condizioni, in cui esse si costituirono.

Alcune considerazioni $\theta$ conclusioni, alle quali naturalmente $\theta$ con evidenza conducono i numerosi fatti esaminati, porranno termine a questo lavoro, dimostrando chiaramente che la provincia di Reggio ha una costituzione geologica comparabile a quella delle altre provincie italiane; che le sue roceo non presentano niento di strano, non contraddicono menomamente, come si volle far credore, le leggi fondamentali della stratigrafia e della paleontologia; invece sono con esse in perfetto accordo, sicche potrebboro, se pur vo no fosse nopo, servir di conferma a quelle. 
A rendere piì intelligibili i risultati delle mie ricerche ò creduto opportuno di aggiungere a questo lavoro una serie di tapole illustrative.

Due frammenti della carta geologica della provincia di Reggio presi, l'uno nella parte settentrionale e l'altro nella meridionale, sul lato orientale il primo, sull' occidentalo il secondo, varranno a dare chiarissima idea della disposizione topografica e tettonica degli strati terziarî, ed una serie di sezioni rischiareranno tali conoscenze.

La carta geologica del Territorio di Reggio addimostra in parto quell'appianamento, che assume la regione superiore dell'Appennino reggiano, pel qualo il paesaggio di quella giogaia la forma specialissima e caratteristica.

Non poche tavole in ultimo saranno addette a rappresentare alcuni importantissimi fossili caratteristici dei varî piani terziarî, $\theta$ ad illustrare lo molte specie nuove.

E mio debito infine rendere cordiali e pubblici ringraziamenti a tutti coloro che in rarî modi e cou gentilezza somma hanno voluto coadiuvarmi nel difticile compitn che mi sono imposto. Quindi mille sinceri ringraziamenti ai sigg. barone G. B. Crea da Stilo, d. ${ }^{r}$ Michele de Mujà da Siderno, d. ${ }^{x}$ A. Ielasi da Bianco, arciprete A. Scordo da Ferruzzano, fratelli De Medici e G. Piromalli da Brancaleone, d. ${ }^{r}$ N. Paviglianiti, ing. F. Pariglianiti, ing. Ciraolo, ispettore delle ferrovie calabre, can. A. D'Amico, F. Pitea da Reggio e cav. P. Cordopatri da Monteleone. Ricordo da ultimo l'affettuosa assistenza prestatami dal sig. ing. G. Costantino, di cui deploro la recente perdita.

\section{STORIA BIBLIOGRAFICA DELLE ROCCE TERZIARIE DELLA PROVINCIA DI REGGIO.}

La bibliografia geologica e paleontologica riguardante le vaste formazioni terziari: del Reggiano è purtroppo ristretta per darci un'idea adeguata, nel complesso e nei dettagli, di terreni cotanto estesi, costituenti una serie si svariata e potente da rappresentare tutti i periodi dell'êra cenozoica.

Sono dordinario dei lavori speciali che essa ci offre, riguardanti un luogo solo, ovvero un solo terreno; e i lavori generali sono poco dettagliati, troppo comprensivi. per rispondere allo esigenze odierne di una completa conoscenza stratigrafica, litologica ecc. Le ricerche paleontologiche sono quasi tutte scompaguate dai correlativi studi stratigrafici e quindi riescono di ben tenue valore per la geologia.

E, bisogna pur dirlo, un grave ostacolo alla conoscenza esatta delle vaste formazioni terziarie delle Calabrie si è stato il difetto di fossili nelle rocce delle zono pii antiche, collegato colla somiglianza litologica di talune di esse con rocce di età secondaria. Per questi fatti appunto sono avvenute confusioni $\theta$ stranezze più 0 meno notevoli.

Io farò qui una rapida rivista delle pubblicazioni che conosco, riserrandomi di esaminare e discutcre nel corso di questo mio laroro taluno più importanti quistioni riguardanti l'eta di certe rocce terziarie. 
1630 Sin da oltre due secoli i mumerosi fossili della Calabria meridionale cominciarono ad attirare l'attenzione dei naturalisti, e lo Scilla nella sua importantissima opera, La Jana speculazione disingannata dal senso, discorre degli ammassi di conchiglie esistenti nelle colline presso Reggio, e delle volgari opinioni dell'opoca sua intorno a tali depositi.

Is:30 Dopo quel perioulo, ner quanto io sappia, non piil presto del 1836 comparvero dei lavori che riguardano la geologia della protincia di- Reggio: e fu il prof. L. Pilla che se ne occupò pel primo, segualando presso Gerace dell' arenaria in istrati fortemente inclinati, che riguardio siccome di epoea carbonifera $\left({ }^{2}\right)$; e nel seguente anno lia creduto di potere arralorare queste sue vedute per mezzo di alcuni fossili ani:-:-: mali e regetali $\left({ }^{2}\right)$. An più tardi il grès carbonifero di Agnana presso Gerace fu dichiarato dallo stesso itiliano scrittore siccome spettante al terziario medio.

[- :1 Nel primo congresso degli scienziati italiani il prof. L. Pilla presenta due spaccati trassersali del Regno di Napoli $\left({ }^{3}\right)$ : lo spaceato meridionale, traversa la provincia di Reggio dal Cipo Vaticano passando per Tropea, Nicotera, Monte Poro, Monteleone, Soriano, Serra, Monte della Colla, Monte di Stilo, Monosterace, Punta di Stilo. In questa sezione fia conoscere il granito e lo gneiss centrale, le filladi che lo ricuoprono: riguarda come giurassico il calcaro sopra Stilo, o cuindi rapporta al cretaceo tutte le arenarie al argille del terziario antico, tra le quali annovera quelle a combustibile di Agnana, riferendo all'epoea terziaria soltanto le sabbic o le marne del plioceno.

1840 Lo stesso prof. I. Pilla diede alla hee una Nota, riguardante la separazione della Calabria meridionale dal resto d'Italia all'epoca pliocenica, per mezzo di uno stretto tra Squillace e S. Eufemia, al modo stesso che oggi essa è disgiunta dalla Sicilia. In questo laroro dil titolo, Intorno alle separazione delle Calabrie settentrionale e meridionale $\left({ }^{4}\right)$, l'autore ritormando sull'eta dell'arenaria carbonifera di Gerace, vuol firla rimontare all'epoea del Macigno, allora creduto di cta secondaria, e riguarda siccome coetanei i gres di Valauidi riddrizzati contro i monti di gneiss, e ricoperti dalle marne terziarie orizzontali. Ricorda egli la fillade di S. Lorenzo e Fossato, il conglomerato di Pentedattilo, i caleari di Bora e di Capo delle Armi, che credo di epoen cretacen; quindi discorre del solleramento dei monti calabresi, che rapporta a due distinti periodi.

18.1 Il sig. Ii. A. Philippi in una lettera al prof. Bromn intitolata: Cenni geognostici sulla Calabrica, ed acconpragnata da mo schizzo di carta geologica, che per la provincia di lieggio credo sia più esatta e megrlio dettagliata della Carta del Collegno fubblicata di noi, parlando della geosnosia del Regrgiano s'intrattiene a dire del massiccio cristallino; e rignaria siccome rocec secondario le arenarie, i conglomerati e le argille delle zone terziarie antiche, e, quel che ì piì strano, giudica che it calcare giurassico di Canolo e d'altri luoghi sia sorrapposto a tali formationi.

1842 Il sig. 'I'chihatcheff" $\left(^{\circ}\right)$ esaminaudo li costituzione geologica del Napolitano, parla della distribuzione generale topografien delle formazioni terziarie; ma poco si cura della distinzione stratigrafica di esse, e solamento fib delle considerazioni sulle faune

(1) Bullettin de la Société géologiqune, vol. VII. 1. 306. - (2) Bull. rol. VIII. p. 198. - (3) Atti della prima riunione degli scienziati italiani. P'isa 1839 . - (') dnali geografici italiani pubblicati dal

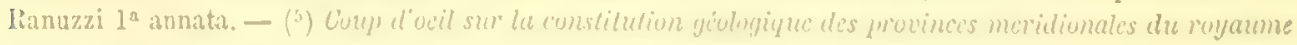
de Sieples. Beslin. 
diverse delle differenti zone del plioceno, riguardando quella di Terreti e Nasiti, per buon numero di specie estinte, diversa da quella di Monteleone ecc.

1843 Nel congresso di Lucea poi entmerando parimenti il Pilla le roce della Calabria, modifica ancora le sue ideo in rapporto alle arenarie carbonifere di $A$ guana $\theta$ d'altrove. riguardandole siccomo spettanti al terziario medio, senza indicare però le ragioni di tale apprezzamento.

1844 Il Plilippi nelle sue ricerche sui molluschi fossili, Fauna molluscomum Siciliae utriusque, dà per la Calabria nna serie di elenchi locali, i quali non hanno potuto influiro al progresso delle conoscenze stratigraficho; dappoichè l'autore non lua curato di tener distinte lo specio delle diverso zone per ciascun luogo, ed inoltre nelle sue ricerche si è limitato alle vario zono plioceniche. Così posso ricordaro benissimo gli elenchi di Terreti e Nasiti, Carnbbare, Pezzo, Monteleone, Monosternce, Valle Lamato ece.

Il Pilla nel suo, Saggio comparativo dei terreni che compongono il suolo d'Italia. è senza dubbio andato in un eccesso opposto a quello, cui l'aveano condotto lo pre. cedenti indagini: rapporta al terziario medio tutte lo menarie, i calcari, lo argille delle zone inferiori, cho prima avea rapportato al socondario, non che i gres carboniferi di Agnaua ed Antonimina, lo molasse ed arenarie di Valanidi od Annumziata, e quelle di Melito e di Stilo.

La carta d'Italia del Collegno riferisce al cretaceo il terziario antico.

Il D'Archiac, Histoire des progres de le Géologic de 1834 it 1815 Tom. II. 2 partio pag. 800, riassumendo quanto era stato seritto sulla Calabria sino a quell'epoca, conchiude cho non si aveano ancora idee bene stabilite.

1851 Il Philippi ha descritto tre clipenstri della provincia di Reggio, che spettano al mioceno di Monteleone: Ueber C. altus, C. turritus, und C. Scillae (').

Il prof. O. G. Costa ricorda un grosso dente di Carcharodon megalodon rinvenuto a Rombiolo presso Monteleone: Cenni intorno alle scoperte paleontologiche fatte nel Regno di Napoli duranle gli anni 1854-55.

Il lavoro più esteso intorno alle rocce terziarie del Reggiano è senza dubbio quello del sig. C. Montagna, intitolato: Gincitura e condizioni del terreno carbo. nifero di Agnana e dintorni. In esso trattasi estesamente della costituzione degli strati terziarî dei territorî di Gerace, di Agnana e di altri Iuoghỉ ma l'autore confondendo le argille scagliose terziarie di quelle contrade, colle argille scagliose ad Ammoniti, Turriliti e a numerosi fossili cretacei dei territori di Brancaleono o di Ferruzzano, credo che gli strati a combustibile di Agnana sieno sottostanti all'orizzonte ammonitifero, $\theta$ li riguarda perciò dí cpoca secoudaria, anteriore alla cretacea; e mentre crede di avere trovato negli strati a carbone una flora secondaria, che confessa non essere stata riconosciuta da competenti autoriti della materia, asserisce, ciò che d potuto verificare, che furono trovati nel carbone di Agnana ossa c denti di un mammifero ormaí indubiamente riconosciuti siccome spettanti all'Anthracoterium magnum, alla quale specie l'autore stesso li riferisco in altra sua opera. Con queste idee erronee la serie terziaria viene in gran parte dal Montagna rapportata alla serie dei terreni secondarî, e i fossili in essa raccolti per la maggior parte descritti 
dubitativamente siccome nuove specio. Sebbene i varî terreni esaminati dal Montagna lo saranno parimenti nel corso di questa Memoria, puro siu da ora è d'uopo anticipare l'importante fatto dimostrato dalla stratigrafia e dalla paleontologia, cioè che gli strati a carbnne di Agnana e di Antonimina spettano con sicurezza al mioceno inferiore, e propriamente al Tongriano del Dumont. E vamebbero a sufficienza l'Anthracoterium magnum riportato dal Montagna, el il suo Cerithium Melograni, raccolto alla base degli strati a carbone, che credo identico agli esemplari gentilmonte offertimi dal sig. ing. Gaetano Rota, raccolti precisamente nella medesima posizione stratigrafica, e spettanti senza dubbio al C. Margaritaceum Brocchi.

Il prof. 0. G. Costa nel medesimo tempo ricorda in una Nota, Intorno alle scoperte paleontologiche fatte nel regno di Napoli durante gli anni 1857 e 1858, numerose conchiglie di molluschi e di rizopodi raccolte nelle varie zono del plioceno del lato occidentale della provincia di Reggio.

Il sig. Montagna piì tardi pubblica un trattato geologico generale informato a nuore teoriche, Generazione della terra metodicamente esposta con nuovi prin. cipi di geologia, per mezzo delle quali intende infirmare le fondamentali leggi della stratigrafia e della paleontologia, e ritorna all'esposizione dei medesimi studî sui torritorî di Gerace, di Aguana ecc.; dai quali crede risultarne assolutamente la fallibilita dei canoni geologici meglio stabiliti, perocchè la serie dei terreni calabresi sarebbe per l'autore un complesso di eccezioni. Inrece, una dello piì rimarcheroli mie conclusioni, tratte dallo studio dei terreni della provincia di Reggio, si è, che questi sono perfettamente comparabili alle rocce dello altre regioni italiane ed europee: essi dimostrano alla loro volta che l'Italia non è la telua delle eccozioni che Ia scorza terrestre si è costituita dovunque sotto l'impero di leggi uniformi. Ai dotti il giudizio di cosi opposte idee.

1868 Anch'io mi sono occupato di varî argomenti riguardanti gli strati terziarî del Reggiano. Nolla mia ILemoria: La formation anclienne ('), parlo del plioceno antico 1869 dol Reggiano. In Una passeggiata a Reggio di Calabria ( $\left.{ }^{9}\right)$, discorro del plioceno e del quaternario, presento elenchi di fossili di vari luoghi e di diverse zone.

1869 In un'altri Nota, Da Reggio a Terret? $\left(^{3}\right)$, trattai del plioceno antico di quei colli o della fauma in esso mechinsa.

1869. In altra Nota dotermino cho un Clypeaster, inesattamento creduto il C. allus Iamk., giace nel plioceno calabrese: ò la Nota, Intorno alla posizione stratigrafica del Clypeaster altus (4).

1870 Talune specio plioceniche della Calabria meridionalo sono citate nella Memoria intitolata: Sull'antica distribusione geografica di talune specic malacologiche viventi $\left(^{5}\right)$.

1870 Nella Memoria critica: Dei brachiopodi viventi e lcriarib pubblicati dal prof. 0. G. Costa $\left({ }^{6}\right)$, sono ricordato delle specie plioceniche ed alcuma miocenica del Reggiano.

1870 Il sig. Manzoni $\left(d_{0}{ }^{r}\right.$ A. $)$ ha descritto molti briozoi degli strati terziarî recenti dei dintorni di Reggio nei suoi, Briozoi fossili italiani (Contribuzione $1^{\mathrm{a}}, 2^{\mathrm{a}}, 3^{\mathrm{a}}$ e $4^{\mathrm{a}}$ ).

(1) Bulletin de la Sociétó géologique de France, tom. XXV. p.ug. 165. - (2) Annali dell'Istru-

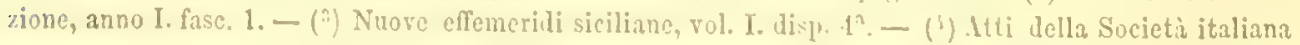
li scionze naturali, vol. XII. f. 3. - (5) Bullettino malacologico italiano, anno III. -- ( $\left.{ }^{6}\right)$ Ibid. 
1871 Il sig. G. von Rath da Bonn nel suo lavoro sulle Calabrie, Ein Ausflug nach Calabrien, ricorda bene spesso il pliocono di quelle contrade.

1872 Il sig. T. Fuchs da Vienma pubblica un lavoro stratigrafico intitolato: Geologische Studion in den Tertiarbildungen Sud-Italion, nel quale discorre soltanto del plioceno presso Messina e presso Gerace.

1872 Nei miei lavori paleontologici $\theta$ stratigrafici ho contiunto sempre a ricordare i terreni reggiani. In una enumerazione dei cirripedi delle provincio meriuionali d'Italia sono ricordate le specie pliocenicho dei terreni calabrosi : I Cirripedi tersiari dell' Italia meridionale (").

1873 In Una visita geologica a Brancaleone di Calabria ( $\left.{ }^{2}\right)$, oltre ai movi studî sul cretaceo, sono ricorlate aleune zone terziarie.

1873 I brachiopodi terziarî del Reggiano, quasi tutti pliocenici, sono descritti negli Studî paleontologici sui Brachiopodi terziari dell' Italia meridionale $\left(^{3}\right)$.

Parimenti i cirripedi pliocenici e miocenici possono tutti quanti trovarsi nella monografia intitolata: Ricerche pateontologiche intorno ai Cirripedi terziari della provincia di Messina, con appendice ecc. (").

La stratigrafia pliocenica della Calabria meridionale e l'entmerazione dei fossili di tali strati trovansi nogli Shudi stratigrafici sulla formazione pliocenica dell' Italia meridionale $\left({ }^{5}\right)$.

Il prof. Rath ancora si occupa del terziario delle Calabrie, ma nel Reggiano riconosce soltanto il plioceno rapportandovi dei conglomerati di più antica età. Il carbone di Agnana solo è por lui miocenico: Geognostisch-mineralogische fragmente aus Italien.

Il prof. Suess da Viemna uel suo laroro, Die brdbeben des sudlichen Italien, riguada assai sommariamente la serie stratigrafiea dei terreni calabresi, e quindi nessun dettaglio sulle formazioni terziarie forma parte di quel suo pregevolissimo lavoro.

1874. Nella mia Nota, Dell' Oligoceno in Sicilia, ho ricordato tale formazione presso Branculeone $\left({ }^{6}\right)$.

18 it Così ho parlato del plioceno di Calabria e della sua partizione nella Nota critica, Sulla relazione di un viaggio geologico in Italia per T. Huchs $\left(^{7}\right)$.

Il sig. Fuchs risponde parlando del plioceno calabrese e delle argille scaglioso $\left(^{8}\right)$.

Io replico trattando dei medesimi argomenti e toceando alquanto del mioceno $\left({ }^{9}\right)$.

Il Fuchs risponde parimenti $\left({ }^{10}\right)$, e quindi siegue una nuora mia risposta ed ultima, volta a discuter sempre del plioceno $\left({ }^{11}\right)$.

Sul pliaceno della Calabria ho parlato ancora nogli: Studi paleontologici sulla fauna malacologica dei sedimenti pliocenici depositatisi a grandi profonditi $\left({ }^{12}\right)$.

(1) La Scienza contemporanea, anno I. fase. 1. - (2) La Scienza contemporanea, ammo I. fisc. VI. (i) Bullettino malacologico italiano, vol. IV. n. 1, 2, 4, cce. - (i) Atti dell'decalemia Pontaniana di Napoli, vol. X. - (5) Bollettino del r. Comitato geologies 1873-77. - (9) La Scionza contemporanea. anno II. fasc. 1. - (i) Bullettino del r. Comitato geologrico 1874. - (\$) Bullettino del r. Comitato geologico, fase. 1 e 2.--(9) Bullettino del r. Comitato geulogico, fase. 3 e 1. - (10) Bull. del r. Culn. geul. (11) Ibid. - (1:) Bullettino della Socicti malacologica italiana 1875-76. 
Ho enumerato ancora diverse Verlicordic raccolte nel plioceno calabrese: Cenni intorno alle Verticordie fossili del Plioceno ilatiano (').

1sif, Dal precedente esame delle opere che riguardano in qualunque modo la geognosia della Calabria meridionale, risultano evidentissime le seguenti conclusioni:

1. Non r'ha un laroro che si occupi dell' esamo di tutta la serie terziaria cousiderata in tutta la provincia.

2. Ia serie eocenica e la miocenica, che sono sriluppatissime ed assai impoltanti, furono da molti scrittori riguardate siccome terreni secondarî.

3. I lavori paleontolorici si rapyntano tutti al plioceno; solo qualche specio mincenica è stata ricordata, una senza le nozioni intorno agli strati che la racehiudono.

1. I e numerose zone del misceno e dell'eoceno rostano tuttavia neglette ed indistinte; anzi guò ben asserirsi che le rocce svariatissime di questi due grandi periodi dellêra cenozoica restano tuttaria completamente sconosciute nella provincia di Regroio: $e$ se in qualche laroro si is accemato al minceno, ciò fu fatto quasi sempre senza addurre alcun documento stratigrafico o paleontologico.

\section{GAPO PRLJO}

Nozioni geornostiche generali

intorno all'estremo meridionale della penisola italiana.

\section{Generaliti, intorno alla costitusione topografica e geologica della provincia di Reggio.}

Quell'ultimo estremo meridionale della penisola italiana che si stacca dal restante della terra ferma per una considererole depressione o per un massimo restringimento, quasi un istmo tra i golfi di Śrquillace e di Santa Lufemia, e dalla Sicilia per lo stretto di . Iessina, costituisce geogralicamente la provincia di Reggrio.

Questa parte d'Italia quasi disgiunta dalle limitrofe provincie, non pertanto si mostra ad esse intimamente connessa jer la grande somiglianza nella costituzione gerlngica; e guantunque il mare la disgiunga dalla prossima Sicilia, è con essa sopratutto che si mostra somigliantissima nella natura litologica e geogeniea delle roece che la costituiscono; i cui strati possono ben a ragione riguardarsi siceome una rera continuazione di quelli che formano l'angolo nord-est della Sicilia, cosi interrotti o separati per l'interposizione del mare, in parte perchè rotti e denudati, in parte ancora perchie rilevaudn le loro testate verso i monti calabresi e siciliani, rengono a costituire in fondo allo stretto una sinclinale, e quindi una grande depressione orografica originaria.

(1) Rendiconto della r. Accalemia delle scienze fisiche e matem. di Napoli, fasc. 6, giugno 1876. 
La catena montuosa che percorre in lungo il Reggiano, quantunque per la depressione considererole tra S. Eufemia e Squillace topograficamente disginnta dai monti di Catanzaro, e dai Peloritani per lo stretto di Messina; pure essa forma realmente la continuazione geognostica di quella catena, la quale cosi estendesi ancora nella Sicilia. Difatti le primordiali rocce cristalline, che formano il nucleo dei monti della Calabria media, costituiscono parimenti l'asse della catena reggiana e dell'angolo nord-est della Sicilia, il che conferma geologicamente la continuaziome dell'Appennino attraverso l'istmo di Squillace e lo stretto del Faro.

Una giognia elevata in forma quasi di altipiano, percorre longitudinalmente la prorincia di Reggio arvicinandosi di più verso il lato orientale; dimodochè in generale i monti dal lato del Jonio sono molto più acelivi che dal lato del Tirreno. La parte centrale che forma l'Aspromonte si approssima rerso il lato meridionale, formando così la regione più elevata non esattamente al centro. La retta culminante è Montalto che s'innalza $1956^{\mathrm{n}}$ sul livello del mare; ad essa fanno corona una serie di vette di poco inferiori, dalle quali poi il smolo di tutta la regione si deprime grado grado verso la periferia.

La parte centrale è formata dalle rocce cristalline, alle quali si addossano intorno gli schisti lucidi paleozoici, che sopportano in taluni luoghi piccoli lembi di rocce secondarie, e quindi succede una larga cintura di roceo terziarie, che compie tutto il contorno della provincia; se non che in varî luoghi il centrale gneiss manda talune sue dỉamazioni verso la spiaggia, interrompendo così la zona terziaria, e costituendo coste erte e scoscese, orvero ripidi ed elevati promontori, che d'ordinario si protendono in mare formando dei veri capi.

Una grande diramazione delle primitive rocce cristalline dirigesi ad occidente nell'estremo settentrionale, e quindi corre rerso mezzogiorno per lungo tratto sulla costa, parallelamente alla catena centrale, dal golfo di S. Eufemia a Pizzo, Monteleone, Tropea, Capo Vaticano, Nicotera, ricoperta qua e là da lembi piì o meno estesi di rocee terziarie e quaternarie. Una seconda larga diramazione dello gneiss inoltrandosi rerso nord-ovest, invade anch'essa ma lunga estensione della costa da Palmi a Scilla. Un terzo ramo va all'estremo meridionale presso il Capo Palizzi; e sul lato orientalo non $\nabla^{\prime}$ ha che unica diramazione alla parte più nordica presso Squillace, doro la formazione cristallina va a costituire il Capo Stallittì.

Il cristallino nella provincia di Reggio occupa circa la metì della superficie: esso dividesi naturalmente in due zone, di cui la più antica estendesi sulla costa occidentale da presso Scilla a Palmi; dore forma quelle scoscese rocce quasi a picco elerate sul mare, costituite in gran parte da gneiss granitoide a grossi elementi, con mica nera e grandi cristalli di ortoclasio bianco o roseo, e traversate da numerosi filoni di granito bianco e grigio. Questa formazione cristallina antica s'interna sopportando la zona superiore e rocce di piì recente data; $\theta$ se da Scilla verso mezzogiorno, i Villasangioranni, Catona, Gallico non redesi presso la spiaggia, comparisce dappertutto nelle ralli, sottostante a terreni terziarî e quaternarî ( $\left.{ }^{1}\right)$. Somiglianti terreaí ricuoprono lo stesso gneiss granitoide in Sicilia sulla sponda opposta dello stretto del Firo:

(1) G. Seguenza, La formazione cristallina presso liallico (Prop. di Reggio-Calabria). 
ed anco ivi l'antico cristalliuo sporge a picen sul maro rerso il eapo Rasocolmo iniettato di filoni granitici, o s'inmalza sino alla vetta di monte Ciccia, dimodochè gri scogli di Scillir hanno il loro concatenamento geognostico colle roce dellangolo nord-est di Sicilia (').

La più antica zona del cristallino redesi ancoria estesa per lungo tratto sulla costa che suinterpone tra Nicotera, Capo Vaticano, Tropea, Briatico, Pizzo; ed anco ivi il granito s"inietta da pel tutto uello gueiss, e la formizione s'inoltra verso il centro della catena, dove il granito prende un grande sviluppo.

L'altra zona della formazione cristallima cho si sovrappone alla precedente è for"so piu rastamente rapresentata, e consta di materiali molto più svariati. Essa par che leboa ineludere la magnion parte del cristallino che estendesi a costituire il centro della caten reggiana e rarie sue diramazioni, e consla li gneiss di srariati aspetti de amfibolici o granatiferi, di pegmatite, di granito, di schisti micacei, di calcari cristallini; ai quali verso Cittunuora sottostanno dei serjentini, degli ashesti serpentinosi, del talco compatto (stentito), dell'oficalce, della dolomite. dell'amfibolite, ece. In taluni luoghi anco vi si vetono in seno alle rocee cristalline dei minerali metallici, siccome da s. Eufemia verso Aspromonte si associa a queste rocce la magnetite, e ad Olinadi ed a Torre Cavallo vi si trova dellit grafite.

Il prof. Gastaldi ha creduto necessario, studiando le Alpi oceidentali, di diridere il cristallino in due zone, le quali presentumo nelle Alpi i medesimi caratteri geognostici che oflirono in Calahria eli in Sicilia $\left({ }^{2}\right)$.

Ai terreni primitivi succedono gli schisti naleozoici, i quali variano molto di aspetto, probabilmente a norma dule zone direrse. eui spettano. Dordinario sono luedi, di color grigio più o meno intenso, orrero neri. In altra zona sono verdastri, ed in tal caso si associano ad una forma di protogino a grossi cristalli feldspatici, e sottostamno ngli schisti grigi; i quali spesso assumono una grande potenzi, che in qualche luogo può calcolursi di oltre $400 \quad 0500$ metri.

Quantunque nell'Italia merilionale in queste rocce non si sono scoperti dei fossili, pure, essento esse somigliantissine agli schisti paleozoici fossiliferi dello Alpi, è molto probabile che sieno a questi coetanee; c lo direrse raricti di aspetto, di struttura, di colorito, probabilmente spettano a zone diverse, che rappresentano dirersi periodi dell'êra primaria.

Sul lato occidentalo le filladi mancino quasi del tutto: appena cominciano a mostrarsi presso Valanidi, e si estendono ampiamente verso il lato meridionale sorrastando al cristallino più interno, e soltostando al terziario, che forma una larga zona sulla costa. Al capo Bova so ne rele qualche lembo, o poi ricompariscono rerso Agrnana, a Alammola, e si vedono molto estese ad occidente di Antonimina, di Gerace, di Stilo, di Guardavalle ecc.

Straterelli, ammassi o filoni di quarzo e di minerali metallici giaceiono negli schisti Incidi in molti lnoghi, ed in varie contrade si sono cavati la galena, la

(1) Contribusione allu grolngia dma morincia di Messina. Breve nota intorno le formazioni primarie e secundarie. Per G. Seguenza (1Bolletino del r. Comitato geologico, anno 1871).

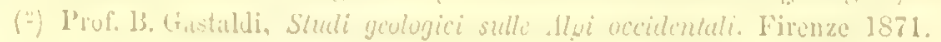


calcopirite, la blenda ed altri importunti minerali, che si associano al quarzo, alla baritina, al siderosio, alla pirite, al mispickel, alla leberchisa, all'azzurite, alla malachite ecc.

In un burrone, sulla sinistra della valle di Lazzaro sottosti alla fillade grigia uno schisto verdastro alternante con un grinito, che direbbesi protogino a grossi ele menti, la mica essendo sostituita da un talco verdastro, od il feldspato trovandosi in grossi cristalli. In seno a questa formazione estendesi, dall'uno e l'altro lato del burrone, un filone quasi orizzontale, costituito di calcare spatico intimamente commisto a fluorina e sparso di blenda, di galena e di pirite in proporzjone molto variabile.

Aleuni lembi di caleare compatto poggiano sulle filladi di varî lnoglui, e senza dubbio la maggior parte spetta alle formazioni secomarie, che nel Reggiano som poveramente rappresentate; ma la determinazione della loro etir riesce sovente in. possibile, mancando i caratteri paleontologici.

E importante notare che tali calcari mancano affitto sul lato occidentale. Al sui vedesi una breccia a grossi pezzi di calcare rossastro con frammenti indeterminabil di crinoidi; la quale giace al capo Bora sopria fillade nerastia, e senza dubbio essa roccia dere appartenere ad antica epoca scenniaria. Qualehe lembo di calcare somigliante mi fu dato d'incontrarlo presso Galati e presso Staiti.

Oltre Gerace a monte, sulla fillade di Agnana sporgono alte e scoscese le rocee calcnree di Canolo, alla base più o meno rosse e venate, sicchè ricordano bene il Lias medio di Taormina ( $\left.{ }^{1}\right)$; ma veruno indizio di fossili mi fu dato di scoprire. In alto, al calcare bianco si associa la dolomite, c vi si mecolsero dello Nerinee $\left(^{8}\right)$, delle quali una, sezionati naturalmente Iungo l'asse, mi fu gentilmente douata dal siguor dott. M. De Mnjà, ed lı potuto riconoscere che spetta probabilmente alli $N$. Goodallii Sowerby (N. Filangeri? Montagna). Da ciò risulta evidente che la parte superiore delle roace di Canolo appartiene al giurassico superiore, o propriamente alla formazione titonica: quindi è ben probabile che sia liassico il membro inferiore.

L'estensione maggiore di calcare autico trovasi poi a ridosso di Stilo, dove la roccia calcarea forma um ciglione che si cleva a 700 metii sul lirello del mare, e 300 sopra Stilo, estendendosi per ben 8 chilometri nella direzione da nord-est a sud-ovest. Il professor Sness vi ha scoperto orbitoidi e nummuliti $\left({ }^{3}\right)$ : il che può far credere clie almeno una parte di quella massa calcarea spetti ad un periodo del terziario antico; ma cio non potri definitiramente stabilirsi fino a che tali fossili nou sarano specificamente determinati.

Alla base di questa roccia e soprastante alla fillade è un deposito di limonite. cho da tanto tempo alimenta i forni della Mongiana.

Alcuni lembi di formazione cretacea, spettanti al Cenomaniano D'Orbigny (Roto. magiano Coquand), perfettamente riconoscibili pel gran numero di fossili che racchiudono, vedonsi alla marina di Bova, presso Brancaleone, e nol territorio di Ferruzzann,

(1) G. Seguenza, Contribusione alla gcolog. della provincia di Hessina.

(2) C. Montagna, Giacilura e condizioni del crreno carbonifero di Anana e dintorni. Generazione' della terra, pag 35 tav. II. XrV.

(3) Professor Vun Rath, Hemoric geognostico-geografiche sulla cillabria (Atti dell' Accademia Cosentina, vol. XII. fisc. 1). 
nei quali luoghi afforano in mezzo a terreni terziari di antica data ("). Argille indurite, scagliose, grigie o grigio-brune, alternanti con istrati marnosi e calcarei formano il terreno di questo periodo mesozoico, il quale ha l'identicissimo, litologicamente e paleontologicamente, in Sicilia, nel Messinese ed alle MIadonie $\left({ }^{2}\right)$, e nella provincia di Costantina in Africa $\left({ }^{3}\right)$. I fossili piì comuni che lo distinguono scno numerosi; ne accomerò soltanto taluni: Nautilus triangularis Montf., Amimonites rochomagensis Brong., A. Mantellii Sow., Turrilites Scheuchscrianus Bosq., Mactre Didonis Coq., Dosinia Delettrei Coq., Venus Dutrugei Coq., Crassatella Baudeli Coq., Cyprina trapezoiclalis Coq., Cardium I"auli Coq., C. regulare Coq.. Isocardia getulina Coq., Trigonia scabra Lamk., T. distans Coq.. Arca Delettrei Coq., A. terestensis Coq., A. parallela. Coq., Avicula gravida Coq., Janira tricostata Coq., Pecten Desvauxi Coq., Plicatula auressensis Coq., P. Fournelii Coq., Ostrea Syphax Coq., O. Rabellate Lamk., O. Deleltrei Coq., O. Africana Lamk., O. Overvegei Coq., O. vesiculosa Guer., 0. columba Lamk., Radiolites Nicaisei Cơ., IJolechppus serialis Desh., Epiaster Villei Coq., Periaster Fourneli Desh., Ilemiaster Batnensis Coc., II. Coquandi Seg., Il. Alricamus Coq., II. Homalensis Coq. (").

Le argille seagliose di questo terreno sono d'identica natura della così detta scaglia dell'alta e media Italia; ma esse talvolta somigliauo e molto a talune argille terziarie scagliose delle stesse o di ricine contrade, il che ha fatto nascere strane confusioni, che hanno indotto a più strane conseguenze.

Il piano Cenomaniano nella provincia di Reggio si presenta come isolato in seno alle formazioni terziarie, non connettendosi con altre zone cretacee; perche mancano nthatto di quest'epoca e le zone più antiche e le più recenti.

Ed eccoci ormai alle formazioni terziarie, delle quali mi sono specialmente occufato percorrendo la provincia di Reggio, e che formano l'oggetto del presente lavoro.

Cirea una metà della superficie di quella provincia è ricoperta dalle rocce ter. ziarie: esse occupano tutta quanta la depressione, che s'interpone tra Squillace e S. Eufemia; formano una zona non interrotta, che dallo gneiss del capo Stallitti si estende per tutto il lato orientale, poggiando ora sui piccoli lembi di calcare secondario, ora sulle filladi e talrolta anco sulle stesse rocce cristalline. La formazione cretacea di Brancaleone e di Ferruzzano non forma che incalcolabili interruzioni essendo assai ristretta l'area da essa occupata. In tutto questo lungo tratto orientale la zona terziaria subisce considereroli rariazioni in larghezza, restringendosi cioè molto ai due estremi verso Sant'Audrea del Jonio e Brancaleone, ed allargandosi poi al centro, verso Agnana, Gerace ed Antonimina.

Sul lato menidionale è lo gneiss del capo Palizzi $\theta$ la fillade ed il calcare giurassico

(') G. Seguenza, Sulle impontanti velasioni paleontologiche di talune rocce cretacee della Calabria con alcuni terreni di Sicilia e dell Africa sethentrionale.

(:) G. Seguenza, Contribusione allu geologia delln provincia di Messina. Breve nota intorno alle formazioni primaric o secondarie. - Sul crelaceo nedio dell ltalia meridionale (Atti della Societi ital. li scienze naturali).

$\left({ }^{3}\right)$ II. Coquand, Grologic ct palionlologie de le région sud de la province de Constantine.

(1) Vedi G. Seguenzat, Sul cieheceo metio dell'llalia meridionaie. Lettera ecc. (Atti della Societi italiatsa di scicnze natur, vol. X. fisc. II) 
del capo Bora, che interrompono per poco la zona di rocce terziarie; la quale si estende parimenti da quel lato, o poi incurvandosi al capo delle Armi non più intorrotta si protrae sin presso Scilla, dore sormonta il cristallino ai piani della Melia e così di seguito.

Una vasta estensione di rocce terziarie da ultimo ricomparisce a costituire la grande pianura tra Palmi e Nicotera, inoltrandosi molto nell'interno sin oltre Sino. poli, Oppido, Terranova, Radicena, Polistena, Laureana, e sin presso Cittànuova, ma in gran parte occultata dall'alluvione quaternaria; $e$ continuandosi quindi a settentrione, ma più ristretta ei interposta tra il cristallino della costa e quello del centro, e spingendosi verso Monteleone e Soriano e sin oltre Francarilla.

La formazione quaternaria è anch'essa importante pei suoi depositi marini di grande spessole, pel suo allurione che trorasi sino a grandi altezze. Essa è molto sviluppata in vicinanza della spiaggia, e ne ll'interno va divenendo sempre meno estesa o formata di lembi staccati, che d'ordinario coronano le vette delle collino.

Questa larga zona di roceo torziarie, che abbiamo veduto eingere da ogni dore il massiccio cristallino e paleozoico, consta di ma serie di rocce e di strati distintissimi e ben caratterizzati da faune differenti, da farli sincronizzare colle rocce italiane non solo, ma benanco cogli strati dei varî periodi terziarî delle altre parti di Europa; e forma una serie non interrotta e quasi completa di tutti i periodi della grande êra terziaria con regolariti meravigliosa ordinati.

Ponendo termine a queste generaliti devo toccare rapidamente di un fatto clie ha grande attinenza colle formazioni terziario, e che costituisce a mio credere un tratto caratteristico di grande importanza nella geologia reggiana.

Allorquando si percorre la porzione periferica della provincia di Reggio, cioè la regione bassa o mediocremente elerata, che in gran parte è costituita dalle formazioni terziarie, si vedono sempre delle colline più o mono disginnte, più o meno ripide a norma della loro litologica natura, le quali si elevano grado grado dalla spiaggia verso l'interno. Pervenendo all'elevazione di 700 metri ovvero di 800 In conformazione del suolo cambia completamente d'aspetto, il paesaggio mutasi d'un tratto: non più colline isolate, ma una sequela di pianure lievemente inclinate, che col leggiero declivio loro s'innalzano da ogni lato della regione d'Aspromonte (la centrale è la piì elevata della catena) pervenendo sino all'elevazione di 1200 motri o anco più. Ripidi e scoscesi burroni e profonde valli s'imabissano per ben $400 \quad 500$ metri in questi alta regione, contornando da ogni lato quegli altipiani e disgiungendoli profondamente. Tale è l'aspetto, tale la conformazione della regiono elevata della provincia di Reggio: regione da cui is cinta la parte centrale o piu prominente, la quale s'innalza sino a 1956 metri. Vediamo ora quale relazione lega tale conformazione colla costituzione geologica di quegli altipiani.

Già abbiamo veduto precedentemente che la giogaia contrale, che percorro longitudinalmente quest'estremo della penisola italiana è costituita dall'antichissimo grneiss, al quale lateralmente si adlossano le filladi. Talo è la costituzione dolla regione piì alta, tale l'ossatura dell'intiera catena, o tale si mostra la vasta regione dei pianalti esaminata nelle scoscese pareti delle sue ralli e dei suoi burroni; ma so ci facciamo ad esaminare il suolo di quello pianure elevate, lo troriamo soronte costituito di strati 
terziarî recenti, pressochè orizzontali, e non già di cristalline formazioni: è questa la precipua causa del fatto topografico esposto. Gli strati terziarî infatti hamno doruto ricuoprire ugualmente quella regione; le acque poi solcando qua e lì quei depositi, aprícno i buroni, profondarono le valli, denudarono buona parte di quell'alta giogaia.

Io non ho percorso che limitatamente quella elevata regione dei pianalti; ma da per tutto, dove l'ho risitato, mi si ò presentata colla costituzione sopra descritta: cosi In vidi nelle pianure, che si estendono sopra Canolo ed Agnana; cosi nei piani tra Gerace e Cittinova; così nella parte meridionale sopra Motta noi piani di Calcarelle; rosi nei piani della Melia sopra Scilla; nel medesimo modo fu reduta dal signor Mlagg. C. Carletti nei jiani sopra Reggio (Rerione Donato) allelevazioue di 1200 metri.

E conferma ben oridente di questo intimo ranporto tra la forma topografica esaminata e la geologica costiturionc, la scomparsa della foma appianata dove gli strati terziarî mancano, perchè furono tolti via dalla denulazione. Iri le rocce cristallino e paleozoiche ofhono un paesiggio completamente diverso, presentandosi in forma di erti o ripidi monti, di stretti dorsi, di piechi elerati: cosi possono osservarsi i territorî di sant'Alessio e s. Stefano sopra Gallico, quelli di Bagaladi, S. Lorenzo, Roceaforte del Greco; quello di Serra S. Bruno e via dicendo.

Questo fatto importantissimo, questa conformazione appianata delle elevate rogioni, intimamente legata alle formazioni terziarie più recenti, anzi dipendente da esse, dà campo a considerazioni e a deduzioni assai rileranti, che esporrò e m’ingegnero di apprezzare nel terzo capitolo di questo lavoro. L'aspetto intanto, la fisonomia del pacsaggio è tale da mettere in evidenza tutto quanto asserisco.

L'd upennimo calabrese, quantunque costituito nella sua nuassa dalle rocee cristalline, forma una giogaia di sorprendente uniformitit nel sno maryine superiore, che si disegna sull'orizzonte quasi linea retta, interrotta soltanto rerso la parte mediana, dal gruppo dell'Aspromonte, che si estollo al disopra dei pianalti e domiua gli elovati sentimenti pliocenici.

\section{Esame della successione stratigrafica dei terreni tersiarí, desunta dallo studio di una serie di sezioni nuturali.}

A rintracciare l'ordinamento tettonico delle formazioni terziarie del Regriano, io mi faro ad esaminare una serie importantissima di suzioni naturali, scelte tra lo molte che ln studiato, a fine di dimostrare con evidenza un tale ordinamento. Nell'esporre unesta parte importante delle mic ricerche, io seguiro un ordine inverso a quello cronologico, che adottero poi nella descrizione dei vâî tereni: quindi andrò dal superficialo al profondo, dal piì recento al piì antico.

Isungo la valle dello Stilino, che corre passando sotto Stilo o presso Mionosterace per Ia lunghozza di ben 10 clilometri lal primo paese alla spiaggia, redonsi sezionati in ordine di sorrapposizione gli strati terziarî dai più antichi ai pì moderni; se non che, taluni membri intermedî maneano aflatto, e talune importauti differeuze corrono evidentissime tra la serie di destra e furella di simistra della valle: lande ho reputato opportmo, alla intelligenza complota dell'ordinamento stratigrafien, di scegliere come sezinni generali le due maturali della vallo dello Stilaro, coadinvandole e complletandole nei dettagrli e nelle deficienze, per mezzo di molte sezioni prarziali. 
Un primo fatto che io devo segnalare, dipendente dal modo di disposizione stratigrafica dei terreni, si traduce in maniera assai evidente nel loro ordinamento topografico. Sul lato orientale della provincia di Reggio, i terreni dei periodi eocenico e miocenico si sncedono con ordino cronologico dai monti rerso lin costi; ciio non avviene sul lato occidentale, dove tale ordinamento topografico procede pressochè parallelamento alla catena, o meglio da sud-est verso nord-ovest. Una semplice osservazione dei duo frammenti di carta geologica cho seguono, persuade di tale differenza tra i dintorni di Reggio ed il territorio di Stilo (Vedi Tav. I. e IL.).

$\mathrm{Da}$ cid ne consegue necessariamente, che sul lato orientale le valli trasversali danno delle sezioni, che rappresentano tutti gli strati terziarî del lnogo; ed invece sul versante occidentale ogni valle non rappresenta che la sezione di alcuni pochi piani o anco di un solo. Cosi nelle valli presso Melito non vedesi che la potente arenaria del Bartoniano, presso Motta le valli sezionano le varie zono del Tongriano e. del Langhiano, oltre qualche strato dei piì recenti, montre poi tra Terreti od Ortì orride valli s’inabissano in seno ai conglomernti langhiani.

L'alluvione quaternaria è da per tutto la prima formazione che ci si presentia qualora si trascurano i depositi odierni. Essa si estende nelle basse pianure presso la spiaggia siccome nelle mediocremente elevate, e d'ordinario corona quasi tutte le vette delle colline, che formano i contrafiorti della giogaia principalo: cosi può vedersi nelle sezioni $1,2,3,4,5,8,9$, ecc.

Sul lato occidentale dolla provincia, cioè dal Capo delle Armi procedendo verso settentrione, vedesi sottostare immediatamente un sabbione marino viì o meno grossolano, o talvolta assai potente, che si eleva anch'esso a considerevole altezza, o che privo di fossili ordinariamente, ne presenta in qualche luogo di appartenenti a specie tuttora viventi nel prossimo mare, e spesso ritenenti ancora, più o men bene, i loro coloriti specifici. Le sezioni $3,4,5,8$, mostrano questa roccia nella sua normale posizione stratigrafica. E ben evidente che questa formazione rappresenta un membro marino del quaternario.

Ritoruando alla sezione 1, troviamo delle sabbie calcarifere in istrati orizzontali, ricehe di fossili, le quali si connettono con argille sottostanti, orizzontalmente stratificate e molto fossilifere anch'esse. Ia fauna di questi due membri è pressochè la stessa: è provalentemente costituita di specie viventi nel Mediterraneo, o costituisce percio una parto assai recento del plioceno. Sul lato occidentale poi, al posto di quello argille, trovansi delle sabbie quarzose con identica fimu: si possono consultare lo sezioni $1,4,5,6,7$.

Succedono da per tutto le marno più o meno sabbioso del vero plioceno, che racchindono una fauna di mari assai profondi: così nello sezioni $1,2,5,8,9,11,14$ questa zona ha i suoi strati alquanto inclinati.

Le sottostanti sabbie a pettini, che succedono in discordanza nella seziono 1 , e che sono associate a marno, colle quali talvolta alternano come nella sezione seconda, formano il più antico membro del plioceno, che redesi anco nelle sezioni $8,9,10$, $11,12,13,14$. Questo antico pliocono, di molta importanza per la provincia di Reggio, diviene rilevantissimo per la grando elevazione, a cui perviene.

Nelle due sezioni principali (la prima e la seconda che noi seguiamo) succede 
sotto il plioceno un potente conglomerato, il quale non solo i in discordanza col plioceno antico, ma benanco s"iuterpono tra essi una lacuma, la quale si manifesta quasi da per tutto nella provincia di Reggio: dimodochè il plioceno in rarissimi ed eccezionali luoghi pog yia sopra rocee che immediatamente lo precedono nella cronologia stratigrafica.

Difatti la sezione duodecima serve di complemento alle due principali predette, o mostra chiaramente quali altri membri sottostanno al plioceno, e s'interpongono percio tra questo ed il conglomerato.

Sotto le sabbie o le marne del plioceno antico, giace a Benestare un deposito di gesso, cho e potente ed esteso abbastanza. Sottosti a questa roccia dell'argilla brumastra e grigia con qualche raro fossile, la quale indubbiamente ha coetaneo mu deposito argilloso a cerizî presso Monteleone.

I cerizî e la roccir gessosa dimostrano chiaramente che trattasi del piano Messiniano del Miayer, di quegli strati detti anco mio-pliocenici, i quali sono stati recentemente studiati con cura in Italia. Questa determinazione viene convalidata dalla presenza di argille sottostanti a fauna tortoniana, rappresentate dagli strati 16 nella sezione $12\left({ }^{1}\right)$.

Soltanto presso Benestare io potei riconoscere il piano tortoniano, se se ne esclute qualche fossile raccolto a Monteleone, ed um brere lembo argilloso alla contrida Ambuti $\left({ }^{2}\right)$.

Seguono quindi dello sabbio d'ordinario bianche, riceho di grandi clipeastri e pettini, o racchiudenti degli striti grigi, spesso sormontati da un calcare a modelli di bivalvi. Questo importante membro del mioceno trorasi in molti luoghi, e rappresenta il piano Lilveziano, che risponde alle rocee di Leitha (Bacino di Vienna).

Questa seric superiore del mioceno, quantunque meno completa, vedesi poggiare sul conglomerato alla contrada Cudeli nei monti sopra Siderno (sezione 13).

Alla contrada Ambuti, a monte di Condojanni, ho potuto esaminare recentemonte una bella sezione, che comprende il plioceno od il mioceno sottostaute, colle sabio elveziane ricche di fossili e sorrastanti al conglomerato seguente.

11 potente conglomerato che succede oceupa precisamente il posto della roccia medesima, che redesi nei dintorni di MIessina ; ed è costituito come quella, ed è anche mivo di fossili ( ${ }^{3}$ ) (sezioni $1,2,6,7,8,10,11,12,13$, ecc.).

Vien poi, come risulta dallo sezioni 1, 2, una massa di argille grigio-scuro indurito, ilternanti con istrati di arenaria colorata al medesimo modo. Gli strati argillosi sono abbondanti di polipai spettanti al gonere Trochocyathus, e di conchiglio di Vaginella depressa; essi corrispondono evidentemente e per la posizione e pei fossili al piano Langhiano deI Mayer, al quale parmi si debba anco associare il conglomerato soprastante.

Sotto questi strati sono delle arenarie che alternano con nuovi conglomerati, e con argille più o meno sabbiose, come mostrano le sezioni 1 e 2. Fsso racchiudono una fauma molto importanto, quantunque mal conscrvata, ricea di Clipeastri, di Gorallarif, di Gasteropodi, eho rappresentano precisamente la fauna della collina di Torino

1) I'iì maturo csame mi fa associure al Tortonimo gli strati a cerizi.

(") Per equivoco liu da me chiamata tale contriuda Buti invece di Ambuti in un sunto di que-

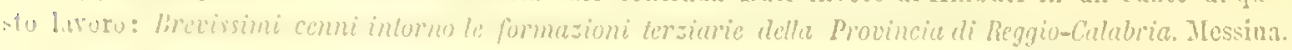

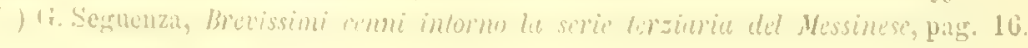


nelle sue sabbie serpentinose, nelle marne bleu e nel conglomerato inferiore. Dunque questo è il piano Aquitaniano del Mayer, che sul lato vccilentale viene rappresen. tato da un calcare a Briozoi e a Nullipore.

Succede quindi un' aremaria sotto Stilo, che è un vero granito rigenerato; i fossili ri sono rarissimi e vi si rinviene specialmente qualche grande Scutella. Questa arenaria, sul lato meridionale e sull' orientale della prorincia si associa al calcare, che è costituito di Briozoarî e Nullipore; il quale sovente par che la sostituisca completamente, come nelle sezioni 15 e 16. Questa zoma è evidentemente la superiore del piano Tongriano del Dumont.

Nelle sezioni principali, sottostanno all'arenaria a Scutella strati argillosi e molassici grigio-scuri senza fossili, i quali prendono un considerevole sviluppo presso Agnana ed Antonimina, come vedesi nelle sezioni 1, 2, 15; açuistano una fauna che ha le sue specie identiche in parte a quelle del Tongriano del Piomonte, o che talvolta ha l'identica nel Tongriano del Vicentino. Ad Agnana poi, alla base della formazione, vi sono strati di combustibile in mezzo ad arenarie, che divengono veri conglomerati in basso, siccome ha luogo nel Piemonte.

Argille scagliose con istrati di arenaria, di calcari, di marne, tutto colorato in varî modi, rosso, verde, grigio, bruno, costituiscono evidentemente il Flysch dei teileschi tanto sviluppato al nord delle Alpi e in Italia. Se non che, uno studio accurato di questa formazione dimostra chiarnmente (come rilerasi dalle sezioni 1, 2, 18) che la parte inferiore è ben distinta dalla superiore, la quale si associa per alternanza con un'arenaria silicen, che ad essa sovrasta (vedi sezione 17), e che in Sicilia alle Madonie racchinde ma fauma tongriana $\left({ }^{1}\right)$; mentre l'altra parte distinguesi per alternanza con istrati a nummuliti, ad orbitoidi, ad alveoline. Questa costituisce il Flysch eocenico, che forma il piano Liguriano del Mayer, l'altra è afiatto scevra di fossili in Calabria, se se ne eccettuino alcuni fucoidi clie rinvengonsi nelle marne bianche o verdastre esistenti alla base, come redesi nella sezione 18 , e forma il membro inferiore del Tongriano, molto sviluppato nei territorî di Ferruzzano, di Motta, di Ciminà, di Cirella, di Platì ece.

Alle argille variegate e scagliose succedono da per tutto delle arenarie micacee e dei conglomerati, che sovente alternano o che si mostrano distinte, siccome può vedersi nelle sezioni 1, 2, 19. Nessuno indizio di fossili in queste roces; ma la loro perfetta identiti colle arenarie e coi conglomerati cocenici di Sicilia $\left({ }^{2}\right)$, di Sardegna $\left({ }^{3}\right)$ e di altri luoghi dove sorrastano al calcare a grandi nummuliti, fa ben riconoscere in queste rocce il piano Bartoniano del Mayer, al quale spettano ancora le argille, cho a Stilo sottostanno ed alternano colle arenarie e col conglomerato, come ben dimostra la sezione 19.

A mio credere è probabilissimo che la elevata roccia calcarea, che sta a ridosso di Stilo, debba tutta intiera o in parte spettare alle formazioni terziarie per lo nummuliti e le orbitoidi in essa scopertivi dal prof. Suess da Vienua: ed in tal caso è dessa la più antica roccia cenozoica del Reggiano.

(') G. Seguenza, Dell Origoceno in Sicilia. - (²) G. Seguenza, Breviss. cenni int.ccc. - (3) G. Meneghini, Paléonlologie de l'lle de Sardaigne. 


\section{CAPO SECONDO}

\section{Descrizione sistematica dclle formazioni terziarie della provincia di Reggio.}

\section{FORMAZIONE EOGENICA.}

Senza dubbio, la base della grande serie teriaria della Calabria meridionale resta tultaria sconosciuta, o per lo meno velata dall'incertezza; e se mi sarà dato di emettere qualche opinione in riguardo al limite inferiore dell' eoceno, apportando qualche tenue documento in moposito, bisogna pur confessarlo che resta a studiarsi accurata. mente la quistione, essendochè il difetto di fossili è un gravissimo ostacolo alla soluzione del moblema.

E) il territorio di Stilo la contrada dore il terziario forma la serie meno incompleta e disposta con molta regolarita: le arenario, i conglomerati a le argille, su cui giace Stilo, joggiano fortemente inclinate sopra quella muraglia di calcare compatto che costituisce una giogaia o meglio un ciglione di parecchi chilometri, nel cui centro è il monte Stella, che si elesa 700 metri sul livello del mare e circa 300 sul livello del paese. Una passeggiera osserrazione nou mi ha dato indizio di fossili in quel calcare; inrece il sig. Sness, che la potuto esplorare quella erta roccia da tutti i lati, ri ha rinvenuto delle orbitoidi all' esteriore dal lato merilionale, e delle nummuliti nella massa centrale $\left(^{1}\right)$. Questa importante scoperta, a dire il rero, non potrà avere una precisa siguificazione, fiuchè quei fossili non sıranno specificamente definiti. Oggri clie le nummuliti non sono più i rizopodi caratteristici dell' eoceno, ma s'incontrano comunemente nel mioceno $\left(^{2}\right)$ e furono recentemente riconosciuto nel cretareo $\left({ }^{3}\right)$, nel giurassico $\left({ }^{(}\right)$, e sin nel carbonifero $\left({ }^{3}\right)$, bisogna in vero esser molto cauti nella determinazione d'una roccia a nummuliti. Malgrado ció, il calcare, di cui discorro, giace alla base di tutta la serie terziaria, e precisamente cone quello cle nella valle di S. Venera (prov. di Messina) compatto, rossastro, con rari nummuliti comincia la seric terziaria $\left({ }^{6}\right)$, come quello compattissimo che alle falde settentrionali di monte Pellegrino presso Palormo, poggia sui calcari cretacoi e racchiude varie specie di nummuliti. Potrebbe quindi il calcare di Stilo essero anch' esso terziario, siccome con sicurezza sono quelli di Sicilia testo accennati.

(1) E. Suess in (i. Tom Rath, Hemorie gcognosticongcografiche sulle Calabric.

(2) G. Michelotti, Deseription des foss. dos terrains miocines de littalie septentrionale 18:17; G. Michelotti, Étules sur le miocine infirieur 1861 ; Sismonda, Matériaux pour servir à la Pulionlologis du lesr. Lerto du Piumont. II. partie. 1871.

(*) Il sig. Stur comunicarami oralmente di aver raccolto nel mezzogiorno di Sicilia delle numInuliti in ruccin cretacen in inguiti.

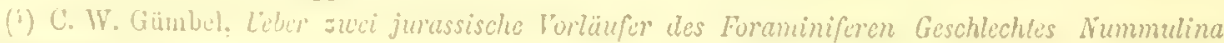
unit Orbilulites.

(5) H. I3. Braly, On a truc cartoniferous nummulite; V. AIoller, Die spiralgewnondenen Foraniniferen cles russischion hohlenkalls.

(i) (t. Seguenza, Brevissini cenni intorno la serie terziaria ecc. 
Nessun dato paleontologico d'altronde c'induce ad ammettere col sig. Rath ("), anco dubitativamente, l'età cretacea di quella roccia. Bisogua attendero quindi le nlteriori ricerche, che mi propongo di compiere al più presto possibile, per pronumciare sull'assunto un giudizio definitivo.

Intanto l'eoceno è abbastanza bene rappresentato dalle rocce che sicuramente vi riferisco. Difatti dalle più autiche argille di Stilo al calcare bianco a piccole nummuliti e ricco di alveoline, s'interpone ma serie abbastanza potente, la quale comprende argille, arenarie, conglomerati, argille seagliose, calcari ecc.

Il terziario antico o eocenico forma sul rersante orientale dei monti reggiani la zona terziaria più interna, la quale par che s'interrompa di tanto in tanto, orvero si avricini alla spiaggia là dore il cristallino si avricina anch' esso.

Sul lato meridionale si contium parimenti, venendo interrotto dalle rocce di capo Bova, e direi quasi si affaceia appena verso il lato occidentale, dove alla direzione di Lazzaro finisce, a quel che nare, per non comparire più verso nord.

1. Piano Parigino D'Orbigny (parte).

Sinonimi. Parigino Braser, Eoceno medio di varî autori. Parte della formazione nummulitica.

La roccia che nella provincia di Reggio io posso riguardare con sicurezza siccome la più antica tra le terziarie è un calcare a grandi e piccole nummuliti, non ancora trovato in posto, ma rinvenuto in massi isolati dal sig. maggiore C. Carletti che gentilmente me ne forni alcuni sagogi. Certamente ulteriori ricerche ci faranno scoprire in posizione questa importante roccia, raccolta nei dintorni di Reggio, dal lato meridionale.

Questo calcare è quasi compatto, alquanto poroso e sovente finamente granoso o un po cristallino, di color carneo, porta sulla superficie alterata dagli agenti atmosferici un colorito giallastro o rossiccio; in qualunque luogo della massa calcarea si operi la frattura scuopronsi numerose sezioni di grandi e piccole nummuliti, che annunciano chiaramente che il calcare risulta in gran parte dall'argregato di queste spoglie di rizopodi. Le maggiori tra esse giungono al diametro di 45 millimetri.

Io sono ben sicuro che questo calcare deve occupare la base della serie terziaria tutta che vado a descrirere, e potrebbe benissimo esser coctaneo della roccia calcarea, che giace a ridosso di Stilo. Nella valle di S. Venera presso Taomina, ed a Militello, nella prov. di Messina, come presso Lercara, a Termini-Imerese, alle falde di monte Pellegrino nella provincia di Palermo, un calcare compatto a grandi e piccole nummuliti giace alla base dell'eoceno $\left({ }^{2}\right)$; per' cui io non dubito punto che il calcare nummulitico trovato a Reggio debba stare alla base di tutte le formazioni terziarie.

Palcontologia. - Passiamo all' esame specifico delle nummuliti del calcare che esamino, ed alle conclusioni, alle quali esso ci conduce.

(1) Op. citata - (2) G. Seguenza, Brevissimi cenni intomo alla serie teriaria ecc. 
Elenco dei fossili raccolti nel calcare del piano Parigino.

Tipo. PROTOZOARII.

Classe. Rizopodj. - Ordine. Foraminiferi.

Nummulites. - 1. N. complanata Iamarck. = Camerina nummularia Britguière, I. millecaput Boubée. Questa specie, tra le. niì grandi del genere, è stata rinrenuta somra una grande superficie: Francia, Spagna, Srizzera, Bariera, Nizza, Dalmazia, Teronese, Vicentino, M. ${ }^{\mathrm{t}}$ Euganei, Majella (Abruzzi), Lercara (Sicilia), ecc. C. $\left(^{1}\right) .-2$. N. Tehihatelueffi D'Archiac = Nautilus lenticularis rar. $\alpha$. Fichtell et Moll. Questa specie è stata anco largamente riconosciuta, Vicentino, M. ${ }^{\text {te }}$ Bolca, MI. ${ }^{t i}$ Enganei, Bolognese, M. ${ }^{e}$ Gargano, Majella, Transilrania, Tracia, Sicilia, Crimea, ec. C. - 3. N. Molli D'Archiac = Nautilus lenticularis Fichtell et Moll. Trorata in Francia, in Transilvania, in Istria,

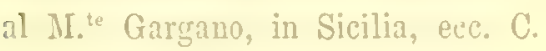

Queste tre sole specie io lio potuto riconoscere con sicurezza nel calcare nummulitico rinvenuto presso Reggio; esse sono a mio credere sufficienti a precisare l'etì della roceia che le racchinde. Difatti è ormai ben noto che da per tutto le grandi nummoliti caratterizzano la zona media della formazione eocenica: così nel bacino della Senna, nei Pirenei, nelle Alpi, negli Apennini, in Istria, in Crimea ed in Sicilia, si redono delle piccole specie negli strati piu bassi; le grandi specie giacciono negli strati medî, o gli strati superiori ne racchiudono anch' essi soltanto delle piccole $\left({ }^{2}\right)$.

La $N$. complanata difatti giace nell' coceno del Teronese e del Vicentino a caratterizzare gli strati medî della formazione, dove si associa talrolta con una fauna di molluschi che anpunto caratterizza il calcare grossolano del bacino di Parigi $\left({ }^{3}\right)$, 0 l'eoceno medio. In rarî luoghi poi essa trorasi insieme ad altre grandi nummuliti Iroprie anch" esse del secondo periodo dell' eoceno. Cosi la $N$. perforata che l'accompagna nel Vicentino $\left({ }^{6}\right)$, si associa ad essa nella contea di Nizza $\left({ }^{5}\right)$, a Kressemberg nel nord delle $\Lambda$ lpi (") e cosi in rarî altri luoghi.

La $\lambda$. lacvinata, che caratterizza nel bacino della Senna gli strati inferiori del calcaro grossolano, cioè la base dell' eoceno medio ( $\left.{ }^{*}\right)$, trorasi bene spesso associata ed in varî lunghi alla 1 . complanata; così al uord delle Alpi, a Kressemberg, Hollgraben $\left({ }^{2}\right)$ ece.

(1) A fine dindicare la rarita o labbondanza magriore o minore, colla quale una specie trorasi spara nella roccia che la contiene, impiegheru per breviti i segni C.c.r. R. che indicano, comunissima, conune, rara, rarissina. - (") Veli DD'Archiac ct Haime, Monographie des Nummules pag. 79, 80, 81. (:) Vedi L. Suess, Sur la strusture des dépits tertiaires du bicentin (Atti della Societi ital. di scienze nat. 'I'om. XI. fisse. III. 1865); F. Bayan. Sur les terrains tertiaires de la Vénétie (Bulletin de la Soc. géul. de France. Tom. XXVII. $2^{\circ}$ Sërie p. 458 e seg. $)$ - ( $\left.{ }^{4}\right)$ F. Bayan, op. cit. p. $400 .-\left({ }^{5}\right)$ L. BelIardi, Fussili nummulitici delle contea di Mizza. - $\left.{ }^{c}\right)$ C. W. Gümbel, Butrage zur Foraminiforen-fuunc der nurdalpinen Éräungebilde pag. 88 e 89 . - (i) D'Archiac et Haime, op. cit.: 1. Stoppani, Cursu di grologia. Vol. II. jrag. 473. - (s) C. WF. Gümlwl, op. cit. pas. 89. 
La $N$. Tchihatcheff trovasi associata d'ordinario colle grandi specie caratteristicho dell'eoceno melio: così nel Vicentino colla $\Lambda^{\prime}$. complanala $\left(^{1}\right)$, al monte Gargano colla $N$. lacvigata $\left({ }^{2}\right)$, nel Messinese colla stessa e colla $N$. perforata $\left({ }^{3}\right)$, in Crimea colla $N$. distans (*).

Parimenti I $N$. molli trovasi al monte Garguno insieme alla precedente ol alla N. laevigata $\left({ }^{5}\right)$.

A me sembra dai fatti enumerati che lo tre forme di nummuliti specificamento determinate, sieno sufficienti a definire che il calcare, di cui discorro, deve appartenere alla base dell'eoceno medio, e quindi al piano Parigino, nel senso ristretto del IIayer; e da ciò che siegue, e da quanto si conosce altrove, può asserirsi che osso debba giacere alla base dei conglomerati o delle arenario eoceniche, cho andremo esaminando.

\section{Piano Bartoniano Moujer.}

Sinonimi. Parigino D'Orbigny (narte), Eoceno medio di varî autori. Parte della formazione nummulitica.

a) Argille grigie. - E nelle vicimanze di Stilo che alla base di tutta la serie terziaria trovasi un potente deposito di argille grigio-scure, che non ho sinora osservato altrove, le quali si mostrano prive aftatto di fossili; esse nello zone superiori variano di colorito, direngono schistose ed in istrati grigi, bruni, rerdastri, alternano con arenaria micacea poco tenace, in basso rossastra, grigiastra in alto.

La potenza di tale deposito è difficilmente apprezzabile, dappoichè la parto media di esso è occultata da depositi posteriori, e specialmento da grindi ammassi detritici prodotti dal decadimento del calcare, che come immensa muraglia s'inmalza ripido e quasi a picco oltre 300 metri su quelle auticho rocce terziarie. Probabilmento 10 spessore oltrepassa i 250 metri.

La base di tali depositi, formata di argille grigio-scure, affiori da sotto la macerio calcarea verso il lato meridionale di Stilo, lì dore la rotabile che conduce a Pazzano s'incurva per traversare bentosto una grando spaccatura della muraglia calcarea. Iri tali argille si mostrano addossate ai fianchi di quella roceia, con evidente discordanza stratigrafica.

Là dove la via rotabile s'incurva doppiamente per condurre alla spiaggia, vedesi un'ottima sezione della parte superiore del deposito argilloso; la quale dimostra bene la connessione di questil zona colla seguente, per mezzo dell'alternanza dell'argilla variamente colorata e schistosa colle arenario e col conglomerato che imwediatamente sieguono.

Il difetto di fossili in questa roccia, e la mancanza di essa in altri luoghi, sono state le cause per le quali non ho potuto fare su questa zona ulteriori studî.

b) Conglomerato. - Succedo alle argillo descritte un potente conglomerato di ciottoli cristallini, il quale sorente alterna con arenarie in istrati più o meno spessi.

E questa la roceia che quasi da per tutto comincia la serie terziaria nella provincia di Reggio; dessa si mostra con molta rogolariti stratificata presso Stilo, dore

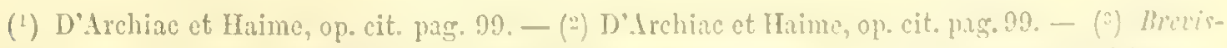
sini cenni intorno la serie tersiarie delle movincia di Hessina pag. 7. - (i) Didrehiac et Haime. op. cit. pag. 93. - (3) D'Arehiac et Ifaime, opr. cil. pag. 102. 
i suci strati sono inclinati fortemente, di oltre 50 gradi o colle loro testate formano l'elerazione su cui giace Stilo, estendendosi poi dal lato settentrionale verso Guardavalle, S. Caterina ecc. e dal lato meridionale rerso Placanica.

Questa roccia risulti dall'associaziono di ciottoli di vanissima grossezza, e quantunque presso Stilo non re ne sieno di troppo voluminosi, in altri luoghi perrengono qualche rolta alla grossezza di oltre un metro di liametro. I massi rotolati misti a sabbie, a ghiaic e frammenti di ogni rolume sono insieme riuniti e cementati in vario modo; sicehè la roccia si disgrega e decale piì o meno difficilmente, e talvolta conservaudo una consistenza abbastanza resistente, pol decadimento di una porzione rimane l'altra a formaro delle prominenze olevate, irregolari, spesso rariamente partite, come sul lato meridionale un bello esempio ci riene dato dalla roccia di Pentedattilo, che è formata dal couglomerato di cui discorro, e si presenta quinquepartita all'elevazione di 400 metri sul livello del mare.

Gli elementi di questa roccia sono formati di granito di vario aspetto, di pegmatite, di gneiss, di porfido dioritico, di quarzo, o più raramente vi si associano delle filladi e degli schisti rarî, siccome dei ciottoli di calcari compatti di epoche probabilmente secondarie.

Le rocee centrali dell'Apennino calabrese contengono, come già precedentemente ho esposto, i materiali degli elementi del conglomerato; se non che, il porfido dioritico, che in taluni hoghi trorasi abbondantemonte ed in grossi massi, era per me di origine affatto ignota, quando le importanti ricerche dol prof. Vom Rath sul porfido dioritico di Catanzaro( $\left.{ }^{1}\right)$ mi fecero con sicurezza conoscere la origine di questo elemento dol nostro conglomerato: ed infatti esso presentasi cosi rario nolla roccia di sedimento, quanto quel geologo lo trorara sul luogo di origine: dal rosso-chiaro al rosso-bruno, al verde-grigio, al verde-chiaro, vi sono tutto le intermedie gradazioni $\left({ }^{2}\right)$. E cosi ancora modificasi nella costituzione, sicche io non dubito punto cho tali massi porfirici nel conglomerato provengano da Catanzilio; anzi lo stesso conglomerato trovasi nei dintomi di Catanzaro $\left.{ }^{3}\right)$, e movendo verso mezzogiorno può seguirsi per tutto il lato orientale della provincia, e pel Jato meridionale sino ai monti che sorrastano al capo delle Armi; e per questo ben Iungo tratto esso forma la base del terziario, costituendo una zona potente, che sta rerso i monti addossata al cristallino orrero agrli schisti palcozoici.

Oltre che nel territorio di Stilo, io lio potuto studiare questa formazione in quelli di Precacuore, di Motticella, Staiti, Brancalcone, ed ancora rerso Pentedattilo e nei monti che dominano il capo delle Armi. In tutti questi luoghi il conglomerato assume forme bizzare e ripide, is solcato da valli e da burroni a pareti quasi verticali. Lungo la valle di Lazzaro, che scorre per bron tratto in mezzo al conglomerato, o specialmente nei bumi Iaterali, vedonsi assai comunemente grossi massi di porfido dioritico, del quale ho potuto ivi osservare e raccogliere numerose rarietà.

(1) G. Vom IRath, op. citita.

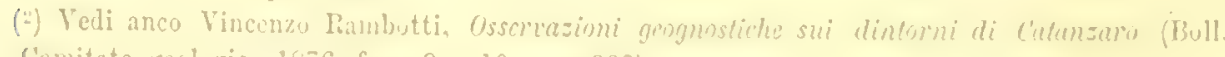
del $x$. Comitato geologrico 1576 , fasc. 9 e 10 pag. 3S8).

i) Veli liath e liambotti, op. citate 
Lo sriluppo del conglomerato cocenico è poco considerevole presso stilo, ma divieno grande a Pentedattilo e in tutto il lato meridionale della provincia, dore assume una potenza di oltre duecento metri.

Verun indizio di fossili, come è naturale, si è veduto in questa zona.

c) Arenaria. - Eccoci alla terza zona di questo periollo cocenico.

Là dove il piano Bartoniano è completo, sopra il conglomerato poggia una potente formazione di arenaria bene stratificata e concordante, la quale risulti di granelli grossolani di quarzo con molta mica, cementati ner ordinario debolmente, ma qualche rolti inrece con buona solidita. La roccia assume per lo più un colorito cliaro, biancastro o gialliccio, e rare volte grigio.

Straterelli di argilla grigia s'interpongono sovente ai grossi strati di arenaria, rendendo in tal modo poco solida la roccil, la quale per tule ragione decade facilmente.

A rendere ancor più frambile questa zona si aggiungono fratture e spostamenti, che traversano la roccia in ogni direzione, e la dividono e suddiridono in massi di svariato rolume, togliendo moltissimo alla sua maturale soliditi.

Presso Brancaleone ed al capo Zaffiro gli straterclli arwillosi, le fratture e gli spostamenti possono studiarsi in tutte le loro modificazioni ed accidentalita.

Questa zoma è abbastanza potente presso Stilo, dore mostra la sua connessione col conglomerato sottostante, alternando con esso, e con esso concordando nella stra. tificazione. Ivi alla parte superiore mostra degli strati calcareo-silicci chiari e schistosi. Le arenarie accompagnano il conglomerato dal lato nord verso Guardaralle S. Caterina, e dal lato sud si estendono verso Placanica e cosi via. Verso Roccella Joniea il conglomerato e le arenarie si appressano alla costa e si continuano andindo verșo Gioiosa Jonica, ed il teritorio di. Mammola. Io ho potuto rivederle quindi verson Precacuore, sopra Ferruzzano e Motticella, a Staiti e Brancaleone; e si finno anco vedere presso la costa ai capi Brnzzano e Zafiro. Quindi grande ol estesa massa o potente di arenaria può seguirsi dal torrente Amendolea verso i monti di Melito e della regione della Salina; pel quale lungo tratto meridionale questa zona si estenitr lungo la costa o lì presso, intermandosi el elevandosi considerevolmente.

In quest'ultima estesa regiome la potenza delle arenarie diriene dartero grande. c credo che possa calcolarsi di oltre 300 metri.

Questa zona non è più felice delle due precedenti per riguardo ai caratteri par leontologici, mancandori ogni indizio di resti organici.

La stratificazione concordante, la transizione e l'altornanza delle argille, del conglomerato e dell'arenaria testè descritte, mostrano evidentemente la loro connessiono e l'uniti del periodo. cui spettrno.

Essendo che veruno indizio, reruna traccir di fossili ho potuto scoprire nellu argillo inferiori, nei conglomerati, nelle arenarie; essendo che per un piano tanto importante per la sua potonza e per la sua estensione fit difetto il criterio pralconto. logico, solo la posizione stratigrafiea e le analogic litologiche nossono invocarsi pen la determinazione dell' età di tali rocce.

La Sardegna ci offre importanti fatti da companarsi ai sucsposti: iri al monte Galtelli il più antico terziario constar: 
1. Di nua breccia calcarea nummulitica, che poggia sul calcare ippuitioo, a smiglianza di quel calcare che presso Palermo alle falde di monte Pellegrino giace sul cretaceo ( $\left.{ }^{1}\right)$;

2. D'un calcare marnoso a nummuliti;

3. D' una puddinga nummulitica a ciottoli granitici:

4. D'un grès quarzoso, in alcuni luoghi sovrastante alla puddinga, i cui ciottoli granitici sono in basso, grado grado sostituiti da elementi calcari; sicchè finalmento essa si trasforma in breccia calcarea, che fa passaggio al calcare nummulitico ordinario, posto alla base della formazione $\left({ }^{2}\right)$. Un fatto paleontologico molto importante, che collera insieme queste rarie rocce (oltre la graduale transizione) sì è cho tutte racchiudono la medesima funa con poche variazioni; ri si raccolgono infatti le Vummulites complanata, distans, perforata, Lucasana, biaritsensis, granulata.

Ila tutti questi fatti hamo loro esatto riscontro in Sieilia, dove nel Messinese c nel Palcrmitano alla base del terziario è il calcare a grosse nummuliti ( $N$. perforute, N. lacvigata, N. distans, N. complanata, N. Gucttardi, N. Tchihatcheff, N. curvispira ecc.) $\left({ }^{3}\right)$.

Siffatto calcare nella rallo di S. Venera fa passaggio in alto ad una breccia calcarea sormontata da un conglomerato cho va perdendo i ciottoli calcarei, ed acquista invece ciottoli di rocce cristalline, e quindi succede potente massa li arenaria (").

Questa sorie messinese rispomle a capello con quella di Sarlegna.

$\Lambda$ 'Termini-Imerese poi suceedono ad un calcare compatto arenarie con argille, U. Ie due zono contengono pressochè le medesime specie di nummuliti ( $\left.{ }^{8}\right)$.

'Tutti questi fatti c'istruiscono bene sull' età della serie calalurese testè descritti, quantunque priva di fossili; essendochè l'ordinamento tettonico degli strati, la relativa posizione di essi con la serie soprastante, i caratteri tutti che li distinguono hanno un' esatta corrispondenza cogli strati nummulitici inferiori della Sarlegna e dolla Sicilia.

Spettaudo cosi la serie che esamino all'eoceno medio, io non dubito che debba rapportursi al piano Bartoniano del Mayer, che quasi commemente è d'altronde costituito di arenaric e talvolta anco di conglomerati: così mostrasi in Francia, in Svizzera, in Germania, in Austria, in Ungheria, in Russia (").

Le rocee che si rapportuno a questo piano non ragyiungono in genere grandi elevazioni sul livello del mare: nel territorio di Stilo non oltrepassauo i 400 metri, is Pentedattilo al in quei dintorni si elevano pressochè alla medesima altezza, e raggiungono i 650 metri nel territorio di Motta sui fianchi della valle di Lazzaro.

\section{Piano Liguriano Mayer.}

Sinmimi. Eoceno superiore degli autori (parte). Parte della formazione nummulitica.

(i) Argille scagliose. - Alle arenario dell'antico eoceno succedono quelle argille scagliose e variegate, che per la loro natura, ondo facilmente si rammolliscono

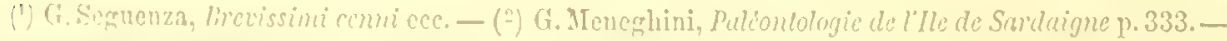

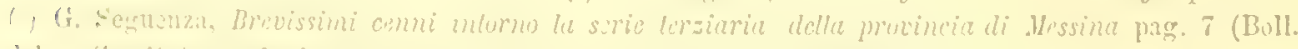

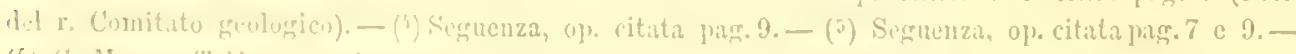

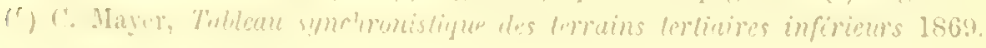


e si erodono, e per la loro conformazione, famo un meraviglioso contrasto con lo rocec, che le precedono e con quelle che le sieguono. Il contrasto spicca vie meglio la dore esse presentansi depresse ed appianate accanto a rupi erte, scoscese el elevate, costituite dalle arenario dell' eoceno e del mioceno.

Le argille scagliose, osservate con superficiale esame, scmbrano costitnire unica ed indivisa formazione, nella quale invero riesce d'ordinario assai malagevolo riconoseere una regolare stratificazione; che anzi il piì delle volte sembra inveco di non averne alcuna, ovvero che un potente rimestio dolla massa avesse scaucellato quella, che originariamente si ebbe.

Per varî caratteri le argille scagliose che sono in basso differiscono dalle superiori, especialmente perchè contengono calcari con nummuliti, cho unancano alla zona superiore; ed inoltre perchè i due membri delle argille sono disgiunti da un calcare bianco a piccole nummuliti, il quale lungi dal trovarsi in posto è sempre in frammenti, in massi isolati, sparsi sul suolo argilloso. Cio non ostante riesce assai malagerole assegnare $\mathrm{i}$ confini alle due zone di argille; dacchè gli strati superiori si sono col loro rammollimento dilatate e mescolate talmente cogli strati inferiori, che diviene quasi impossibile nella pratica il tracciare i limiti delle due formazioni. Le argillo scagliose infine coi loro calcari, colle arenarie, ecc. costituiscono chiaramente il Rysch alpino.

La loro distinzione in varie e ben caratteristiche zone, la ricognizione di ciascuma e l'importanza relativa, sono cose nonchè diflicili, quasi impossibili in Calabria, per l'ordinario rimescolamento a cui andarono soggette queste mobili rocce; cio non pertanto mi fu agevole riconoscere e determinare tutto, avendo gia lunganente studiato tali rocce in Sicilia, dove identica ne è la natura, la stratigrafia, e financo i minimi accidenti.

Un fatto topografico importante, che dipende dal disfacimento subito dalle argille scagliose, si è che allorquando queste rocce si trovano topograficamente intorposte tra le arenarie dell'eoceno e gli strati del mioceno o del plioceno, formano una noterole depressione, che s'interpone tra le arenarie ed il conglomerato eocenici, i quali s'innalzano ripidi a considerevole elevazione da un lato, e le arenario e i conglomerati mioconici presentantisi dall' altro colle testate dei loro strati molto potenti e tagliati a picco. Percio le argillo scagliose rengono a formare per la loro denulazione ma rera valle più 0 meno larga e profonda, che si estendo parallelamente alla catena centrale, lit dore l'ordinamento stratigrafico è regolarmente disposto da monte a valle: così sotto Stilo questa valle longitudinale redesi estendersi da un canto verso Guardaralle, dall'altro verso Stignano; similmente questo avvallamento può seguirsi tra i monti di Condoianni e Cimina. Somiglianti depressioni sono tra Gerace ed Agnana, come tra Zoparto e Casiguana, dove da un lato invece delle mioceniche sono le rocce plioceniche tagliate ripidamente. Quasi da per tutto sul lato orientale della provincia questa tale conformazione manifestazi più o meno distinta, formando una valle, che si estende dall' uno all'altro capo, ed interseca così le numerose villi trasiersali.

Le argille scagliose infexiori, che formano il piano Liguriano, sono sempre di colori varî e sovente misti a macchie più o meno grandi; sono brune, grigio-scure, rossoscure, verdastre, bluastre ecc.

Più o meno distintamente queste argille si dividono in Iminetto irregolari o si stemprano con molta diflicoltà nell'acqua. In seno alla loro massa si osserva un'intinitì 
di frammenti e di massi calcarei e piì rarnmente arenosi di aspetti variissimi. I calcari sono bianchi, grigi, verdi, rossi, hruni oce. ol compatti ed uniformi, ora con vene spaticlic, cil ora eristallini, talvolta brecciati. Questi frammenti offrono costantemente Ine fuece piane e prialiele, e talvolta una distinta stratificazione parallela a tali facce: onde non v' ha dubbio di sorta che quoi calcari e quelle arenarie sieno frammenti di strati, che erano interposti alle argille; if che riesce evidente in certi Inoghi, dore i frammenti della stessa natura si vedono allineati parallelamente ar altri allineati ancora, dimostranlo la successione di strati, che furono rotti. Quindi i hen chiaro che quei finghi sono stati profondamente tormentati e sconvolti in modo che i solidi straterelli internosti vemero rotti o frantumati, ed il movimento delle argille, che l'includerano, ne ha disperso nella massa fangosa i frammenti, che ripuliti per azione delle accue, si mostrano in grande abhondanza alla superficie del suolo.

Fra i calcari inclusi nelle argille liguriane se ne incontrano degli strati ricehi di piccole mumnliti, di orbitoidi, di alveoline e d'altri resti animali; ma bene spesso occorre che questi rizopodi, immersi sempre in roccia compatta, sono guasti e rotolati, spatici nell' interno, ed arrivano al punto da essere irreconoscibili, da confondersi con ciottoletti calcarei, la roccia sembraudo allora una rera breccia.

Io crodo beno che la zona inferiore o liguriana delle argille scagliose si debba trorare ovunque la zona superiore esiste; ma vuoi per la posizione soprastante, vuoi pel rammollimento e la diffusione arvenuta in quest' ultima, la prima spesso non si fa velere, perchè o ricoperta dall' altra, o con essa confusa.

Io ricoriterò soltanto i dintorni di stilo, cioè la valle trasversale sottostante, i territorî di Ciminì e di Cirella, le colline ad ovest di Ferruzzano, quelle sotto Brancaleone, dore pei calcari a numinuliti, che vi ho raccolto, non puo mettersi in dubbio lesistenza della zona argillosa inferiore. Dietro la stazione forroviaria di Brancalcone, oltrepassate le collino di arenaria che stanno immeliatamente presso, trovansi le argille scagliose, ed in seno ad esse dei calcuri al orbitoili, che credo debbano appartenero alla zona, di cui discorro. E evidente che questa zona comisponde esattamente nel Messinese e nel Palemitano in Sicilia a rocce esattamente identiche ('); anzi bisogna pur confessare che la comparazione delle argille scagliose calabresi con quelle del Messinese e del. Palemitano mi è stata assai utile a distrigare la difficilissima straLigrafia, che ha esatta corrispondenza in Calabria ed in Sicilia.

Vediamo i pochi dati paleontologici che ci somministrano queste rocee.

Palcontologia. - Le argille scagliose sono rocce prive affatto di ogni residuo orsanico; quindi è soltanto nei calcari nummulitici cho trovasi la piccola fauna, che caratterizza questo periodo.

Siccomo tali calcari sono stati da mo raceolti sotto Stilo e nel torritorio di Brancalcone soltanto, o quelli della prima contrala oflrono i fossili in cattivo stato, perciò indoteruinaljili, consegrue cho lo specio enumerate nol segruente catalogo sono state raccolte tutte presso Brancileone.

(1) Vedi G. Seguenza, Brevissimi cenni inlorno lu serie lepainria della movincia di Messina. Eocono. "Hona $2 .^{n}$ 
Elenco delle specie fossili dei calcari nummulitici delia zona $\Lambda$ del piano Liguriano.

\section{Tipo. PROTOZOARII.}

Classe. Rizopodr. - Ordine. Foraminiferi.

vommulites. - 1. N. curvispira Meneghini. Rapporto con qualehe dubio a questa specio alcuni esemplari. x. - 2. N. plan u I ta D'Orbigny. Molti esemplari parmi che con certezza vi apparteugano. C. - 3. N. Guettardi D'Arehiac et Haime. Rapporto con dubbio a questa specie alcuni esemplari in cattivo stato. c. Opereuliua. - 4. O. cana 1 ifera? D'Archiac. Rapporto con dubbio a questa specic un sol frammento. $R$.

Orbitoides. - 5. 0. dispansa I. e C. Sorrerby (Licophrys). Comunissima, forma quasi da sè sola nma roccia alla marina di Brancaleone. C.

Aiveolima. - 6. A. subulosa Montfort. c. - 7. A. sphacroidea Lamarck (Meloniles) $=$ A. melo. D'Orbigny (parte). C.

b) Calcare nummulitico. - Le argille seagliose or ora descritte si separano dalle soprastauti mediante un calcare nummulitico, che si distingue agevolmente per essere bianco e costituito dall' associaziono di piccole nummuliti con orbitoidi e molte alveoline. Questa zona clie io ho potuto osservare e studiare nella provincia di Palermo, a Termini-Imerese e Trabia dove è inolto sviluppata, assume una considerevole potenza, e consta di strati alternanti del calcare nummulitico sopraddotto e di marne bianche indurite; in altri luoghi poi l'ho potuto osservare sotto forma di piccolo strato appena spesso alcuni centimetri. Nel Regriano non l' ho veduto sotto quest' ultima forma; ma nelle basse colline di Brancaleone e nella ralle di Bruzzano mi si è presentato alla superficie del suolo argilloso, in massi o pezzi sparsi riconoscibili ai caratteri sopra accennati. Taluni grossi pezzi di calcare nummulitico ad alveoline, proprio di questa zona, vedonsi giacere alla contrada S. Giorgio presso Brancaleone sparsi sulle argille scagliose, che spettano in parte all'eoceno, in parte ad etil posteriore, ed in parte poi a pì̀ antica data, cioè all' epoca cenomaniana. Ed è curioso vedere appunto in certi burroni della contrada S. Giorgio, come, dal decadimento di queste argille scagliose di sì differenti epoche, risulti una miscela di materiali di eti sì diverse; $i$ fossili del cretaceo trovansi ivi commisti alle nummuliti dell'eocono, ed alle concrezioni ferruginose dell'oligoceno.

Questo calcare nummulitico ha la più esatta corrispondenza con la zona $1^{\text {a }}$ cocenica del Messinese e del Palermituno, secondo le ricerche da me fatte in Sicilia ('); ma ivi questa zona è molto beno sviluppata, e ricca di fossili ben conserrati e fitcilmento riconoscibili.

(1) Veli G. Seguenza. op. cit. 
Paleontologia. - I fossili di questa zona differiscono ben poco da quelli della precelente, essendochè sono delle piccole yummuliti ed orbitoidi, e vi sorrabbondano le alveoline.

Anco i calcari bianchi a nummuliti ed alveoline sono stati raccolti presso Brancalcone soltanto, per cui le specie, che enmmero, vengono da quella sola localiti.

\section{Elenco delle specie fossili raccolte nella zona B del piano Liguriano.}

Tipo. PRO'TOZOARII.

Classe. Rlzopod. - Ordine. Foraminiferi.

Nummurites. - 1. N. planulata D'Orbigny. C. - 2. N. striata D'Orbigny. C. Aveolina. - 3. A. subulosa Montfort. C. - 4. A. ovoidea Dorbiguy = A. elliptica D'Arch., A. subpyrenaica Leymeri. C. - 5. A. sphaeroidea Lamarek (Melonites) - A. melo D'Orbigny (parte). C.

Si vede bene dai fossili di questa zona che essa in realtà non è che uno di quegli strati, che si ripetono le tante volte in seno alle argille, ma che conviene distinguere per la grande abbondanza delle alveoline, e per lo sriluppo ben grande che esso assume in certi luoghi.

Le due zone riunite testè descritte, rispondono bene al Flysul delle Alpi $\left(^{1}\right)$ o di Intta l' Italia media e settentrionale $\left({ }^{2}\right)$, come di tanti altri luoghi d' Europa $\left({ }^{3}\right)$. Una porzione del Flysch invero è ritenuto oggi come distinto, e nou come parte della formazione eocenica; $\theta$ le mie osservazioni coneordano perfettamento con queste vedute, sicchè la zona superiore delle argille scagliose viene staccata dal resto per essere rinnita al mioceno, costituendo quel membro inferiore, che venno disgiunto dai Tedeschi col nome di oligoceno.

Sarebbe proprio vano l' esame dettayliato della posizione stratigrafica di ciascuma delle specio raccolte in questo piano; dappoichè sono esse tanto comuni quasi da per tutto nell' coceno, e cosi caratteristiche, che non può sorgere ombra di dubbio sulla loro etì. E ciò per le alveoline, come per lo nummuliti e per l’ unica orbitoide (').

(1) Vedi C. BInex, Tublian synehronislique des terrains terliaires $4^{\text {me }}$ édit. 1869 ; R. J. MIurchison, dlemoria sulle strullura geulugica delle .1/pi, degli Apennini e dii Carpazí.

(“) Vedi C. Mayer, op. citata; R. J. Murchison, op, citata; T. Taramelli, Sopra alcuni cchinili creberi e tersiuri del Friuli, o Sulla formesime cocunica del Friuli; F. Bayan, Sur les terrains lesliaires de la léntic; L. I'areto, Nole sur les sublivisions que l'on pourrail élablir dans les lerrains fertiaines de l'Appomin sepuntrional; Savi e Meneghini, Considerazioni sulla geoloyia stratigrafica delle Tuscrna.

(") R. J. Alurehison, op. cit.; C. Mayer, op. cit.

(i) Vedi D"Orbigny, Prodrome de pal, stratig: D'Archiac, Monogr. des numm. e Deser. aes anim. diss memme de l'Inde. 
La più grande somiglianza l'ha questo piano calabrese con gli strati coetanei di Sicilia, dove identica natura litologica, medesima costituzione, e medesime specie di fossili assicurano il sincronismo $\left({ }^{1}\right)$.

\section{FORMAZIONE MIOCENICA.}

Nello studio del mioceno reggiano sono stato di gran lunga piì fortunato di quanto non fui in quello dell' eoceno. L'essere assai rari i fossili degli strati del terziario antico, il riferirsi tutti alla classe dei rizopodi, lasciano tuttavia dei dubbî e delle incertezze, che in qualche modo dalla litologia e meglio dalla stratigrafia vengono resi men gravi. Non così dee dirsi della formazione miocenica; la quale più o meno ricca di fossili nelle sue zone srariatissime, si fa riconoscere agevolmente coi suoi ben noti caratteri paleontologici.

Una serie di strati veramente potente e molto varia ci offe nelle diversissime sue rocce, nella potenza cho acquistano sovente, nelle fanne diverse cho racchidono, i lunghi o distintissimi periodi di questa grande epoca terziaria. E difatti la serie reggiana si presta assai bene alla suddivisione in sei piani proposta dal sig. Mayer. Il Messiniano, il Tortoniano, l' Elreziano, il Langhiano, l'Aquitaniano, il T'ongriano sono rappresentati nella provincia di Reggio; e ciascuno di essi viene benissimo contraddistinto da una speciale fauna, composta da specie per lo pii già note, $\theta$ carattoristica del periodo miocenico, al quale appartiene, essendo comune alle rocce calabresi ed ai classici depositi cootanei.

Tra i fossili, che caratterizzano molto bene il mioceno che esamino v' hanno senza dubbio le specie del genere Clypeaster, le quali profusamente sparse, ci offrono l'importante fatto delle diversità specifiche in varî piani del mioceno; sicchè il Tortoniano, l'Elveziano, l'Aquitaniano, il Tongriano sono distinti da gruppi diversi di specie di Clypeaster. Gli altri piani non mi hanno offerto che alcuni frammenti indetermiuabili. Una specie trorasi anco nel più antico plioceno.

Impressionato da questi fatti notevolissimi, ho voluto dare nel mio lavoro un confacente sviluppo a questa parte paleontologica, illustrando tutte le specie di Clypeaster, che ho raccolto nelle mie ricerche o che da varì amici mi vennero offerti gentilmente $\left({ }^{2}\right)$. Nell'atlante annesso a questa Memoria rappresentando i clipeastri mi sono limitato a riprodure lo forme nuove.

La formazione miocenica occupa nella provincia di Reggio una superficio abbastanzil considerevole, di cui un'idea può aversi benissimo dai due frammenti di carta geologica annessi a questo lavoro; e mentre l'coceno estenlesi sul lato orientale e meridionalo soltanto, il mioceno invece incontrasi ovunque, e forse anco piì sviluppato sul lato occidentale. Ma qui pel completo manco di fossili sopra vaste ostensioni, divieno quasi irriconoscibile;

(1) G. Seguenza, Brevissimi conni ece.

(-) Alcuni di questi clipeastri mi furono ionati dal sig. dott. M. De MIuji che possiede importante collezione paleontologica di varì territori del Peggiano. 
c per la sua composiziono riesce assai facilmente confusibile cogli strati a'altri periodi, massime per le arenarie e pei conglomerati, cui somigliano molto quelli dell'eoceno.

Un importante fatto che risulta dallo studio stratigrafico del mioceno si è, che i piani superiori di questa grinde formaziono mancano generalmente, o non se ne tro. vano che lembi ristretti in taluni speciali lnoghi; cosi il Messinianu ed il Tortoniano vedonsi presso Benestare, Ambuti o Monteleone, l'Elveziano si associa a questi piani nei medosimi lnoghi, na in estensione prende uno sviluppo più considerevole.

In fine devo dire una parola in riguardo ai limiti che in questo lavoro sono assegnati al mioceno. Le zone inferiori cho furono in Germania denominato oligoceno, ho creduto piì opportuno di non separarle dal terziario medio; dappoichè in Calabria sono connesse col resto della formazione, e mi sembra inoltre non necessario il mo. dificare la primaria tripurtizione delle formazioni terziarie. Il Messiniano del Mayer, (gli strati che oggi si distinguono anco col nome di mio-pliocenici) che è un periodo distinto dal mio Zancleano, l'ho liunito anco al mioceno, perchè in Culabria l'ho trorato associato o concordante col Tortoniano, e mancante alla base del plioceno, meno in quei luoghi dove coesiste col Tortoniano. Questo fatto sarebbe contrario a quanto osservara il sig. Fuchs nelle sue ricerche tra Aucona e Bologna ("), per le quali proponera l'associazione al plioceno delle mame a gesso o zolfo (Messiniano) tanto sriluppate nell' Italia media ed in Sicilia.

Quanto alla fisonnmia che assume la formazione miocenica, importa ramimentare che in tutti i luoghi, dore ia serie inferiore e media si trovano associate e soprastanti all' eocono superiore, questo forma, come licemmo, appianamenti e depressioni; mentre quella ergesi in rocce clerate, scoscese e spesso tagliate a picco. Così formasi sul lato orientale, presso Stilo specialmente, quellir valle longitulinale gia accenuata, yer la forte depressione ilel Flysch, interposta tra l'antico eoceno a monte, $\theta$ lo ripidissime ell alte testate dei piani miocenici a ralle. Parimente sul lato occidentale velonsi le roce mioceniche formare altissime testate, che si allineano da nord-est a sudorest passando per Motta, elevandosi ripidissime sino all'altezza del monte Gonia, e soprastando a quegli appianamenti, che lo aryille seagliose formano ai loro piedi. Questi fatli possono benissimo osservarsi e nei due frammenti di carta geologica e nelle sezioni principali.

Nel discorrere del mioceno occorrerì di dorer trattare l'importante argomento dell'ctir relle rocee a combustibile di Agnanir e di Antonimina, etil che da quanto i stato publicato non si è ancora al caso di determinare; poichè or prestandosi fiducia al criterio litologico, or contando sulla pur troppo dubljia ricognizione di qualche fossile mal conservato, or fomlandosi sulla natura del combustibile e degli indizî di regetali, quelle roeee, come risultar dalla bibliograffi, sono state credute a rolta a volta e primarie e secondarie o teraiaric.

Guidato da serupoloso esame stratigrafico e farorito nelle mie ricerche dalla scoperta sli fosisili ben importanti sono ormai sieuro dell' eta tanto controversa degli

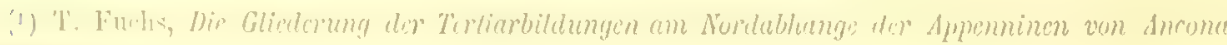
inis tivingine? 
strati a carbone di Agnana; i quali ben Inngi di riferirsi alle cti paleozoiche orrero alle mesozoiche, siccome da taluni tuttaria si opina, spettano con sicurezza al antico periodo del cenozoico medio.

\section{Piano Tongriano Dumont.}

Sinonimi. Eoceno superiore e Mioceno inferiore di rarî scrittori, Oliggoceno dei 'Tedeschị Membro superiore della formazione nummulitica.

a) Marne bianche a fucoidi. - Il primomenubro che comincia la serie di cui ora devo occuparmi è costituito da tre zone che si presentano più o meno distinte e sriluppate nei dirersi lnoghi, alla base delle marne a fucoidi, che famo passaggio agli schisti bituminosi soprastanti, in alto delle argille scigliose rariamente colorate. Il difetto di fossili in queste zone lascia purtroppo dei dubbî rigunado alla precisa loro eta, essendochè la loro natura petrografica le arvicina tahmente al sottostante flysch eocenico, che riesce sorente assai malagerole il distingnerle; ma in Sicilia, alle Madonie, io vi senopriva ma fama di molluschi e di comalli propuria del 'Tongriano ( ${ }^{1}$ ) e quindi bisogna riferirle a questo periodo.

Le marne a fucoidi sono sempre abbastanza dure, or bianche ed or piit o meno colvrate in rerdastro o in grigio; taluni strati sono compatti, a frattura concoide, e fanno passaggio ad un rero calcare, il quale sovente contiene della piromaea, che vi ò sparsa irregolarmente, e sotto forma di straterelli, di armioni, e di conerezioni di color cereo, grigiastro, gialliccio o brunastro; alternano con questi altri strati che si disgregano facilmente in iscaglie e costituiscono cosi delle marne scagliose bianchice o grigiastre.

Questa prima zoua, variabile in ispessore, sovente si offre, come il calcare nummulitico, in frammenti sparsi in seno alle argille; ma lia dore gli strati non furono rotti, le marne si redono in regolare stratificazione disposte alla base delli serie. Sotto la prima forma, cioè in frammenti sprarsi, redonsi quasi dormuque le argille scagliose appariscono; e per questo io potrei ricordare moltissime localita. Pel secondo caso il più bello esempio si ha presso Ferruzzano, dove queste rocce sono con molta regolarita disposte in ordine di successione, e non disturbate da sconvolgimenti.

b) Schisti bituminosi. - Un deposito di schisti più o meno bituminosi: in perfetta concordanza colle sottostanti marme, succede d'ordinario a 'quelle; anzi sorente le une fanmo passaggio agli altri, e a mio ereclere è unica la zona che le dne rocce costituiscono, o piir tosto è la medesimal roccia che si modifica per l'agginuzione dèl bitume.

La schistosità della roccia è eminente, e lungo i piani di frattura e nelle funditme si originano dei cristalli di gesso sovente in forma radiante, dei sottosolfuti di perossido di ferro, o della limonite dipendenti senza dubbio dill'ossidazione delle piriti sparse in quegli schisti.

Il bitume che essi racchindono varia molto in proporzione e tilrolta manca del tutto, in modo che questi strati si confondono coi sottostanti e costituiscono realuente nico membro della formazione.

(1) G. Seguenza, Dell Oligoceno in Sicilia (La Scienza contemporanea, anno II. fisc. I). 
A nord-orest di Fenuzzano gli schisti bituminosi redonsi nella posizione stratigrafica loro propria, e poi si osserrano nei territori di Stilo, di Motta ecc.

c) Argile seagrliose. - Sugli schisti bituminosi, dore questi esistono, e sulle marne a fucoidi dore mancano. si sormppone in concordanza una formazione Ii aruille scagliose abhastanza potente, di colorito molto uniforme e riro, che raria orlinariamente da un luogo all'altro, dal grigio semro al rosso piì o meno intenso. al rerde ece. Tali argille non racchindono dordinario straterelli calcarei, ma bensi costantemente stmerelli. anmoui, concrezioni di siderosio litoide, e talrolta a fuissima grana cristallina, il quale bene spesso trorasi gia conrertito in limouite bruna.

Tra siffatte concrezioni non posso fare a meno dal ricordarne aleune, sorente commi. di uma forma pressochè costante, che si arricina alla cilindrica, sebbene sorente radimo ulquanto restringendosi rerso un estremo, e colla superficie coprerta di gramuli di forma allumgata ('). Il colorito è sempre bruno, la grandezza rariabile c la forma ordinariamente troncata ai due estremi.

Straterelli di arenaria s'interpongono talvolta nella parte superiore di questa zoni, e sono affitto identici allarenaria che immediatamente sorrasta, lo che mostra In comnessione di queste due roce.

La potemza considererole di queste argille, che raggiunge talrolta lo spessore di (iltre ól metri. ed il posto superiore che esse oceupano, fir si che gli strati sottostanti che ri si conmettono, pel rammollimento e pel decadimento che esse subiscono incessantemente per azione delle acque, rengano quasi dorunque ricoperti e nascosti: " per tale miscela che quasi subiscomo le rocee di direrse zone, e per la grande somiglianza che esiste tra le dne zone di argille scagliose, riesce d'ordinario assai difficile distinguere le une dalle altre, e molto jiì tracciare i limiti di separazione: quantumque gli strati calcarei rariati e numulitici, che la zona inferiore racehiude. sieno valeroli caratteri distintivi.

Da tutto quanto lın detto è agerole rilerare il perchè raramente possano indicursi dei lnoghi dore sicumamente riscontrasi la zona eocenica delle argille scagliose. un invece le argille superiori or ora descritte costituscono una fascia leen appariscente fiiu o meno litrga, che siegue quasi dappertutto le arenarie e i comglomerati dell'eoceno medio, formando semure una depressione assai rimarcherole tra questi e le rocee mioceniche o plioceniche.

Io lo seguito questa zona sul lato orientale da presso Guardaralle, rerso Stilo, dove si mostra assai ben caratterizzata nella larga depressione sottostante, dirigendosi oltre Stignano, e cosi certamente si contiuna lambendo le arenarie e i conclomerati cocenici. duve l'eoceno superiore non si mostra. Io ne ho seguito l'andanento a GioiosaJonica, e quindi nei monti di Siderno, al Agnana, Gerace, sotto Antonimina, sopra

(1) Il prof. 0 . (i. Custa ha creduto questi corpi di origine organica, riferendoli a corna decidui ai ruminanti di genere cstinte e nuwo. hujo arer preteso che in essi usservasi uma particolare strutiura urganica micruscopica. M intitolandi) la presunta sprecie: Peleceros gramulatus (Vudi PaleontoL aqia del regno di Napoli. Vol. I. pag. 15 tar. 11. Il sig. C. Montacna riguardo pui tali concrezioni

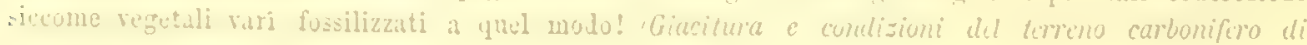
Iynana ecc. page. 25). 
Ardore e Benestare, specialmente nei territorî di Ciminà e Cirella, quindi nei monti di Bianco-nuoro tra Zoparto e Casiguana; da questo luogo in poi le argille scagliose assumono un grandissimo stiluppo in estensione ed in potenza giungendo sino alla costa, dimodochè i territorî di Bruzzano e di Ferruzzano sono quasi intieramente costituiti da queste rocce, che si estendono rerso Brancaleone, e sin oltre il capo Spartivento, e con grandi interruzioni sino alla marina di Bora ed alle Saline.

Da Lazzaro poi una zona delle argille seagliose superiori si estende nella chirezione sud-orest nord-est passando a sud di Motta ed elevandosi nei monti soprastanti, spianandosi sempre alla base dei grandi tagli a piceo, che fomano le testate dei calcari e delle arenarie del mioceno medio.

d) Arenaria silicea. - Sncede quindi un'arenaria specialissima e spesso potente, la quale ha tali caratteri e si mareati che riesce facilissimo di riconoscerla a prima giunta e distinguerla dalle arenarie di altre etì.

Essa è bianca ma diviene talvolta giallastra o rossastra, o bruna; i granelli di cui risulta, rariabili in grossezza e fino del diametro d'alcuni millimetri, sono di quarzo jalino, e ri manca del tutto la mica, il cemento è siliceo, la consistenza della roccia raria ancora molto, talrolta questa è assai tenace da sembrar quasi una quarzite, diviene in alcuni casi fragile ed anco friabile.

Questa formazione, come tutti gli strati massicci interposti o sorrapposti alle argille scagliose, trorasi fratturati in modo che mostrasi quasi ordinariamente sotto forma di massi o di frammenti isolati, sparsi qua e lì alla superficie del suolo argilloso. È soltanto nei territorî di Cimina, di Feruzzauo e di Brancaleone clıe io ho incontrato tale arenaria considerevolmente estesa e $n o n$ ispostata e non infranta.

Quiri forma quasi una rasta spianata su cui giace Ferruzano ed alla marina di Brancaleone una serie di collinette che corrono parallelamenteo al lido, dove questa zona assume il considererole spessore di oltre 50 metri.

Quasi dormque le argille scagliose afforano, redonsi alla loro superficie sparsi i residui di questa speciale formazione arenosa: cosi presso Stilo, Agmana, Gerace, Antonimina, IIotta ece.

Questa arenaria in taluni luoghi, come presso Brancalcone, alterna colle argille scagliose, e quindi si collega con esse, ed ha di comune con questa roccia il difetto completo di ogni indizio di fossili.

Le quattro zone descritte sinora alla base del mioceno, corrispondono colla piì grande precisione alla identica serie, da me descritta, vastamente estesa in Sicilia nelle prorincie di Messina e di Palermo, dove la caratterizzano i fossili mroprî del 'Tongriano (').

c) Arenaria con strati di combustibile. - Ad Agnana ed Antonimina gli strati a combustibile giacciono alternati con strati di arenaria più o meno grossolana, alla base della quale serie trorasi un conglomerato di piccoli ciottoli cristallini.

(1) G. Seguenza, Dell'oligoceno in Sicilia (Ta Scienza contemporanea, nuno II. fikce. 1, 
Gli strati del combustibile sono proe spessi, il magriore giungendo a 67 centimetri seconto il signor Montagna (").

Pui arersi un'idea della matura di questo carlone dicendo che è nero-brumo, uneo Incente, fragile e magro; che si associa a strati lumi o brunastri di sehisti Dituminosi; che talvultar sono molto chiari, ed allora sulla superticie di schistosita redesi una quantiti ininensa di fucoidi mal definiti ed indeterminabili.

Liarenaria i invece sotto forma di spessi strati, ora grossolana ed ora a fini uencenti di color grigio piu o meno intenso o chiaro.

Arendo visitato qual giacimento assai recentemente, e quindi in epoca in cui il combustibile non renisa carato, io non ho potuto studiarlo dettagliatamente nella sua striticralia; cii) non ostante intorno a questo deposito si lanno importanti e numerosi dati jubblicati dal signor C. Montagna. Dero inoltre alla cortesia del signor ing. G. Irotil, alcune infomazioni sull'assunto, ed alcuni fossili che sono preziosi incunenti per la determinazione cronologica di quelle roce.

In seno al combustibile si sono raccolti dei Panorbis e delle limnace (P. Ferrincundi Montalgna, L. Froncisci Montagna), ed innltre le ossa ed i molari dell'Anthracrerium magnum ( $\left.{ }^{2}\right)$, dellit quale specie un incisiro ed un canimo mi fu dato di studiarli nella collezione del signor ing. (r. Lota. Negli strati interposti al carbone varie specie di cerizi furono raceolti (C. pareulum, C.melograni Nontagna $\left({ }^{3}\right)$ ). Una specie che lo potuto esilninare, lacculta negli strati più bassi della formazione, appantiene crom sicurezzil al C. margaritacem Brocehi.

La formazione a cartuone in Agnaua come ad Antonimina viene sormontata da ma protente serie di strati marini di aremaria alternanti con strati argillosi o molissici, che nellat parte superiore direngono ruasi ancille scagliose o nolto schistose, semure di colnr arigio piir o meno intenso. Questo memoro superiore nei monti sopar Antonimina racchinde nunerosi fossili marini, e snecialmente dei pettini

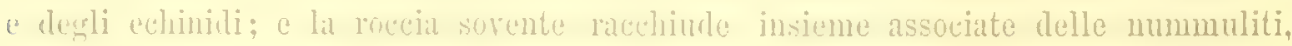

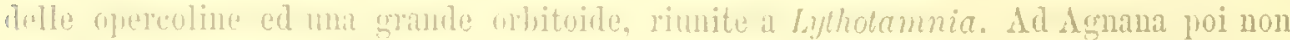
se ne rerlomo, mia assai juesso, al monte Petto, il signor dott. Michele De Muja ha raccolto nell'arenaria pettini e clipeastri irluntici.

Al Antonimina tuttar quanta questa zona assume una potenza che può valutarsi ri oltre foo metri, en importa notare che jvi nei monti soprastanti si elera sino allialte\%ar di sug metri circa sul livello del mare, estendendosi vastamente rerso il lato settentrionale, al di sopra del Monte S. Jejumio, dore per lungo tratto riene

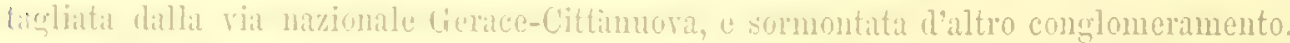

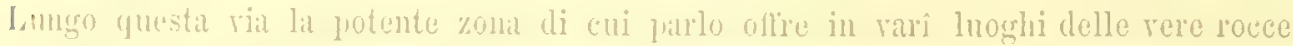
it Ainmmliti interposte alle arenarie ed alle arorille scagliose; le nummuliti sono piceole e quasi di miforme grandeztal, la rocesia ablonda molto di calcare. Cosi custituito questo membro del Tongriano, mostrasi molto sviluppato lungo questa regione; e quantunque lepeorrendo lit rotabile esso mostrisi interottamente, alternato colle rocee cristalline, pure apprarise sino lib ove la via raggiunge i pianalti, eleran-

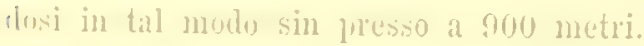

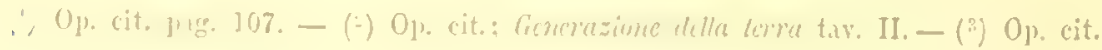


Quanto all'estensione topografica ed allo stiluppo di questa zona, è notevole che ad Aguana, ad Autonimina, oltre il Monte S. Jejunio, l'una e l'altro attingono il massimo; altrove io ho pututo riferirvi certe molisse ben poco appariscenti, che presso Stilo stanno tra le argille variegate e le arenarie a scutellu, e nel territorio di Motta sporgono da sotto i calcari a Briozoi, che somo, come vedremo, coetanei degli strati aquitaniani a Clipeastri di Stilo. In quest'ultime contrade gli strati spettanti a questa zona sour poco sviluppati, non offrono indizî di fossili, siccome presso Stilo, e si elerano a circa $600^{\mathrm{m}}$ sul livello del mare.

Non conosco sinora in altri luoghi la zona di cui mi ocenpo; a Motta ed a Stilo è soltanto per la posizione stratigrafica che io la rafíguro, essendochè la forma litologica stessa è alquanto dirersa, e manca omninamente il carattere paleontologico.

f) Arenaria a Scutella. - Gli strati che io mi fo a descrirere formano presso Stilo delle rocce, che, a dire il rero, meglio si collegano cogli strati aquitaniani anzichè colle zone precedenti: dorrébbero quindi associarsi più tosto al piano seguente; ma siccome quasi dappertutto in Europra la zona a Seutella giace, secondo lo stesso Mayer, nel piano Tongriano, ò pereio che alla serie, invero troppo raria e potente delle zone di già descritte, ri aggiungo l'arenaria a Scutella di Stilo.

Nella serie degli strati miocenici tagliati a picco, lungo la ralle che lougitudinalmente si estende sotto Stilo, orrero in quelle trasrersali che s'incassano in tali rocce, agli strati molassici della zona precedente succede mna speciale arenaria prira ordinariamente di fossili. Questa roceia spessa di oltre dieci metri, è costituita di strati piu o meno solidi, che risultano dall'aggregato di grani di qurrzo, di feldspato " di mica nera legati da un cemento calcareo, che diviene più abbondante in alto, rende la roceia tanto solida e cosi formata, che malagevole riesce distinguerla dal rero granito. Difatti è dessa un granito rigenerato, dipendente senza dubbio dal disfacimento delle rocee granitiche, tanto abbondanti nel centro della catena, e di cui graudi massi inalterati si comnettomo soprastando alla descritta aremaria, ed offrono ma costituzione a grossi elementi e quasi porfiroide, pei grandi cristalli di ortoclasio che racchiudono.

Nella parte superiore, più calcarea, s'incontra qualche rarofossile, ed in modo speciale nei dintorni di Stilo si raccolgono delle grandi Scutelle.

In tale territorio questa zona del mioceno inferiore si estende tagliata a picco sul lato orientale della valle che abbiamo rehuto correre parallelamente alla centrale giogaja e che può ben osservarsi sull'annessa carta geologica di quella contrada. Tali strati, ricoperti sempre dalle rarie zone del mioceno, inclinati d'ma rentina di gradi, affiorano soltanto là dove pei varî corsi di acqua l'intiera serie trorasi sezionati.

Laltezza massima sul livello del mare, che raggiunge questa zona nel territorio di Stilo, è di $300^{\text {na }}$ circa.

Quest'arenaria redesi considerevolmente sviluppata nei monti che sorrastano and Antonimina ed oltre S. Jejumio, nella quale regione perviene all'altezza di oltre 800 metri, acquista molto calcare e racchiude degli echinidi, e degli strati costituiti da una grande Orbitoide (O. Gumbelii n. sp.) e di mediocri e piccole nummuliti.

La formazione di eui discorro si presenta alqulunto modificatia sul lato meridiomale ed accidentale della provincia; iri infatti l'arenaria non risulta piir degli 
elementi di un granito disgregato, ma invece di soli granelli quarzosi con rariabile quantità di calcare, che talrolta diviene predominante. Anco qui la roccia si connette e par che faccia transizione ad un calcare pieno di Briozoi, di nullipore ecc; il quale per molti riguardi dere riferirsi al piano Aquitaniano, cui per la costante associazione, pel graduale passaggio, forse con piu ragione si dorrebbe associare l'arenaria della quale parlo.

Siffatta quistione potra venire risoluta dalla scoperta di nuovi e più importanti dati paleontologici, che non sono quelli somministrati da pochi esemplari di Scutella e da qualche dente di Carcherocton.

Nella regione delle saline qua e lì si manifesta bene sviluppata, e quindi va in costituire il capo delle Armi, nel traforo del quale furono trovati alcuni denti di squalidi di specie mioceniche.

In quel promontorio la roccia assume i caratteri d' una vera arenaria calcareosilicea, che fa passaggio ad un calcare più o meno granoso, ed assume la grande potenza di oltre 100 metri.

Si è creduto sinora che il capo delle Armi fosse costituito da roccie giurassiche, e come tale renne colorato nella carta del Collegno ed in tutte le altre di epoca posteriore, non esclusa lia recentissima del prof. Rath da Bom (').

Nel territorio di Motta dore il calcare a Briozoi mostrasi molto srilmpuato, juò in taluni luoghi redersi commesso inferiormente coll'arenaria di cui discorro, siccome tale commessione osservasi a Valanidi, dove l'arenaria sottostante al cal are aquitamimo poggia sugli schisti paleozoici.

Il piano Tongriano, nel modo che io lo considero costituito, è molto complesso, risultando da sei distinte zone, che prendono in taluni lunghi considerevole sviluppo; ma alcune di esse per ordinario appena si manifestano ed in soli frammenti; tali le marne a fucoidi, gli schisti bituminosi, l'arenaria silicea soprastante; sicchè di regola i due nembri appariscenti sono le argille scagliose colorate e l'arenaria ultima piu o meno ricca di calcare.

Un fatto rimarchevole intanto nella serie delle rariate rocee che formano questo fiano si e, che cliseuna di esse ha mo sriluppo estremamente rario da lnogo a luogo, assumendo poi in certi territorî una jotenza ed una estensione assai grande. Le marne a ficoidi e gli schisti bituminosi si redono stiluppati ed in posto a nord-orest di Ferruzzano, le argille di rariati colori assumono un grande sviluppo in potenza ed csstunsione nei territorî di Motta, di Ferruzzano, di Bruzzino, di Brancaleone, di Ciminà e di Cirella, nelle quali cinque ultime localiti l'arenaria silicea trovasi in posto srilupuata e potente. Le arenarie e molasse micace con combustibile assumono un grande sviluppo solamente ad Agnana, Antonimina ed oltre il Monte S. Jejunio, dove sono anco fossilifere. L' ultima di queste località, Stilo ed il capo delle Armi finalmente presentano jiù protente e meglio caratterizzata l'ultima zona, l'aremaria calcarifera.

La serie tongriana calabrese trova in Sicilia il più esatto riscontro, essendochè

1. Feili unera citatit. 
nelle provincie di Messina e di Palermo essa si offre sopra grandi estensioni sviluppata e costituita al medesimo modo $\left({ }^{1}\right)$.

Paleontologia. - La paleontologia del piano Tongriano si riduce a qquella delle arenarie a carbone, ed a qualche rara specie raceolta nell'ultima zona, essendoche le prime quattro zone sono aftatto prive di fossili se se ne esclude qualche fucoide gia ricordato.

Per tale ragione ho creduto opportumo di raceogliere tutte insieme in unico elenco le poche specie che mi renne fatto di ammannire, indicando la zona da dore ciascuna proviene.

Le localita fossilifere sono Agnana e i dintorni, Antonimina ed il suo territorio e i monti sopra S. Jejunio per la zona $E$; per la zoma $F$ i territorì di Stilo e di Lazzaro $\left(^{2}\right)$.

Come dissi, la zona superiore solamente per le sue Scutelle renne da me associata al Tongriano, dappoichè le sue relazioui topografiche e stratigrafiche l'associerebbero meglio agli strati soprastanti. Parmenti le zone pii basse, prive di fossili mimali, per la loro litologica fisonomia, meglio si associerebbero al Liguriano anzichè al Tongriano, ma esse rispondono a quegli strati che alle Madonie in Sicilia $\left(^{3}\right)$ lanno oflerto una fauma evidentemente tougriana: si è per questa ragione fortissima che io le ho associate a quest'ultimo piano.

Flenco delle specie fossili

raccolte negli strati del piano Tongriano.

'Tipo. VER'TEBRATI.

Classe. Mammiferi. - Ordine. Pachiderm.

Anthracoterium. - 1. A. magnum Curier. Questa sprecie del combustibile ri Agnana è stata esaminata e riconoscinta dal sig. prof. B. Gastalli siccome liferisce il sig. C. Montagna, il quale rapmesenta nelle tarole da lui pubblicate varî denti molari dell'Anthracolerium di Agnana ( $\left.{ }^{4}\right)$. Io stesso percorrendo quei luoghi ho potuto osservare tra gli oggetti raccolti, negli strati a combustibile, dal sig. ing. G. Rota un canino ed un incisiro ben conservati spettanti senza dubbio a questa specie. Zona $E$. negli strati a combustibile. 1. A.

Classe. Pesci. - Ordine. Condrotterigi.

Careharodon. - 2. C. megalo do $n$ Var. subauriculatus Agassiz. Due esemplari rotti, di cui uno di forma brere coll'estremiti corrosa, tratti dal calcare arenaceo

(1) G. Seguenza, Brevissimi cenni inturno la serie teraiaria della provincia di Messina. Dell' Oligoceno in Sicilia.

(2) Nell'enumerazione delle specie, a fine di abbreviare l'indicazione delle localiti, lo scelto i seguenti segni convenzionali: S., Stilo; 1., Agnana; An., Antonimina; L., Lazzaro, e suoi dintorni, come il capo delle Armi, M., tra S. Ejunio e i piuni della Melia.

(3) G. Seguenza, Dell'Oligoceno in Sicilia.

(4) Vedi C. MIontagna, Giacilura e condizioni del terreno carbonifero di Agnuna e dintorni. Tav. II. - Generazione della terra Tav. XLVI. tig. 1, 2, 3. 
dei dintomi di Capo delle Amni. Zona F. 1R. Is. - Var. siculus Gemmellaro. Un esemplare raccolto insieme ai precedenti. R. L.

Oxyohina. - 3. O. x y phod on Agassiz. Un esemplare completo colla radice della forma quasi esatta di un triangolo isoscele, più grande di tutti quelli sinora illustrati. tratto dal caleario arenoso dei dintorni di Capo delle Armi. Zonal F. R. L. - 4.0. D eso r i i Agassiz. Un esemplare ben conservato. Zona $F$. R. L, - 5. O. cras s a Agassiz. Un solo esemplare che cousertasi nell'lstit. tecnico di Reggio. 'Lona E. R. A.

Tipo. MOLLUSCH.

Classe. Gisteropodr.

Tousus. - 6. F. . . . sp.? Nella collezione del sig. ing. G. Rota ho resluto un fusus che non ho potuto studiare per determinare specificatamente; esso proriene dalla zona carhonifera di Agnana e somiglia al $F$. laxelamellatus Wichelotti. Lona li. strati a carbone. R. A.

Controum. - 7. C. margaritacen Brochi (Murcx). Alla base del deposito carbonifero di Agmana si è trovato un acemulo di cerizì spettanti a questa specie, dei quali ebbi l'agio di osservare e studiare rarî esemplari nella collezione del sig. ing. G. Rotil. Zona E. strati inferiori. c. A.

Pleuroromaria. - 8. P. neogenita n. spr. Tav. IV. fig. 1. L'unico esemplare che denomino così è in cattivo stato, e deformato dalla fossilizzazione, percui non mi permette di darne una completa descrizione. La conchiglia è trochiforme, cogli arrolgimenti conressi e oscuramente carenati al di sopra della linea della fissura, che è appena distinta; la superficie quantunque non ben conservata sembra non presentare scultura di sorta; la bise appianata juesenta una larga incavatura nella regione ombelicale, la çuale occultata dalla roccia nella parte centrale non ei jorge il destro di conoscere se sia ombelicata. Diametro 5 centimetri. '/ona E. strati marini. R. An.

Punorbis. - 9. L'. . . sp.? Negli strati a combustilile di Agnana furono trorati abbondanti i Plunorbis, che io stesso lio protuto esaminare nella collezione del sig. ing. G. liota, il cattivo stato di conservazione di queste tenui conchiglie non permette sicura determinazione specifica; il sig. Montagna chiamo questa specie P. Ferdinandi. Zoma E. strati a combustibile. c. A.

\section{Classe. Lanelibranchu.}

venus. - 10. V. dubia Michelotti. Rapporto con dubbio a questa specie un semplice morlello alquanto imperfetto. Zona li. strati marini. K. An.

'Tellins. -- 11. 'I'. I in eat a Montayna (Cycles). Riferiseo con dubbio a questa specic del IContagna taluni esemplari che provengono dagli strati interposti al carbone, dove egli anco li raceolse, ma la brevita della descrizione data dall'autore ed il difetto di figura lasciano molta incertezzil. Zonal li. 3.1.

Crasuatella. - 12. C. Michelotti Seg: = C. Parisienses Michelotti (non D'Orbigny) 'lav. IV. fig. :2. Comprando l'esemplare tipico di questa specie, raccolta nel mioceno inferive del Piemonte, colla specie prigina, si vede che la prima i più allungatia trastersalmente e le sue rughe concentriche sono imegolari e piu 
avvicinate, onde credo che la specie miocenica sia distinta, e quindi deblat mutar di nome. Vi rapporto un bel modello il quale consersa tuttavia qualehe frmmmento di conchiglia colle sue rughe trastorsali. Zona $E$. strati marini. R. An.

Carolita. - 13. C. A r d u in i Brongniart. Qualche raro modello. Zonil Fo strati marimi. r. An. - 14. C. La ura Brougu. (Fenericurdic). Vi rapporto qualche modello. Zona E. strati marini. 1". An.

Mrea. - 15. A. biangulina D'Orbigny = A. biangula Basterot. (non Defrance). liapporto con sicurezza a questa specie taluni esemplini della collezione del sig. ing. Rota, raccolti negli strati di arenaria interposti al carbone di Agnana. Zona E. strati marini. 1 . A.

vucula. - 16. N. Antoniminensis Seguenza. Tar. IV. fig. 5. Questa specie i aftine alla $N$ Joffreysii Bell. del plioceno (Vedi: Nuculidi terziarie dell' Italia meridionale). Zoua E. strati marini. R. An.

cima. - 17. L. miocenica Sismonda = L. gigantec Bellardi (non Deshayes). Rapporto a questa specie rarî esemplari piu o meno incompleti, che per la forma e per la scultura rispondono esattamente agli esemplari tipici del Piemonte coi quali li ho comparato. È senza dubbio questa specie che è stata creduta da alcuno la L. gigantea nel deposito carbonifero di Agnana, e quindi rapyortatil tale formazione all'epoca liassica. Zona E. strati marini. 1'. A? Au.

pecten. - 18. P. subasper ILontagna $=$ P. delecus Michelotti. Gli escmplari di Antoninina sono pir grandi di quelli di Dego, ma sembrami che ne abbiano tutti i caratteri, arendoli comparati ad un esemplare tipico fornitomi dal Michelotti. Ho rapportato poi questa specie alla forma deseritta dal Montigua pei caratteri assegnati dall'autore non solo, ma aneora per la localiti, arendo egli raccolto il $P$. subasper ad Antonimina. Tona $E$. strati marini. C. An. - 19. P. oblitus Michelotti. Rapporto con dubbio a questa specie alcumi esemplari la cui superficie non è ben conservata. Zona E. strati marini. 1. An. - 24. P. Ramond in i Montagna. Tar. IV. fig. $3,3 a, 3 b$. L ben distinto pel le costole curenate distanti, e per le numerose strie ralianti e concentriche, papillose nelle intersezioni. Zona L. strati marini. 1. An. - Var. dilatata. Distinguo così una forma piu allargata e colle costole piì allontanate. Zona L. strati marini. 1. An. - 21. 1'. miocenicus Michelotti. Vi riferisco due esemplari osservati nell'arenaria di Monte Petto. Zona L. strati marini. 1. A. - 22. P. simplex Michelotti $=P$. Tondi Montagna. Tav. IV. fig. 4. Questa è bella e distinta specie a pochi raggi larghi e senza alcuna scultura. Zona $k$. strati marini. $r$. An.

Janiura. - 23. J. areuata Brocehi (Ostrea) = J. fallax Michelotti, J. reperdila Michelotti. Rapporto una sola ralva e qualehe impronta a questa specie propria del mioceno inferiore. Zona $E$. strati marini. R. An. - 24. J. Grayi? Micheloti (Pecten). Vi rapporto qualche cattivo esemplare. Zona E. strati marini. 1. Au. Alcune impronte ed alcuni altri frammenti di Janire ho incontrato al Mlonte Petto e ad Antonimina, ma non è stato possibile di determinarle specificatinente.

Ostrea. - 25. 0. Brongniartii MIontagna. Anco questa specie ò molto dubluiat pel difetto di figura e per la breve descrizione. Io vi rapporto un solo esemprint

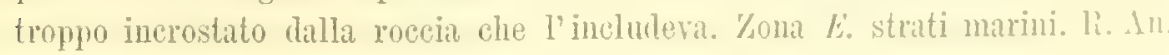


lipo. VliRMI.

Clasue. Axeluht.

Qualche indeterminabile resto spettante ai serusulidi. Zona E. r. An.

Classe. Brrozodrn.

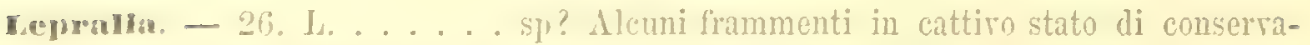
zione e quindi dificilmente definibili. Essi sono impiantati sul Periaster Capellinii e sul P. Cinlabrus. Zona E. strati marini, r. An. - 27. L. . . . . sp? Tre colonie snfra un frammento della Lima miocenica. Lo stato di conservazione molto cattivo non permette la determinazione. Kona E. strati marini. r. An.

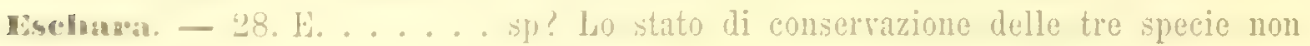
pormette la loro sicura doterminazione. Una per la forma delle cellule somiglia alla E. Iluueri Reuss. Zrona F. strati marini. 1". An. - 29. E. fistulosa? Reuss. Qualche frammento in cattivissimo stato. Yona L. strati marini. R. An. - 30. E. . . ..... sp? Ha qualche somiglianza colla E. stenostica Reuss. Kona E. strati marini. R. An.

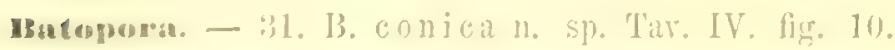

Questa specie distinguesi dalle conosciute pere essere d'una forma quasi regolare conico-celata e jer le cellule joeo sporgenti. Kona Li. strati marini. r. An.

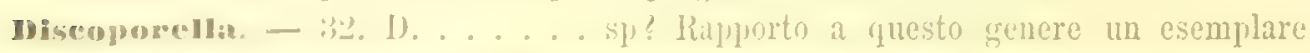
in cattivo stato fisso sul Periaster Cupellinii. La determimazione specifica non it prossibile. Zona E. strati marini. IR. An.

Tijo. ECHINODERMII.

Classe. Echinidi. - Ordine. Regordis.

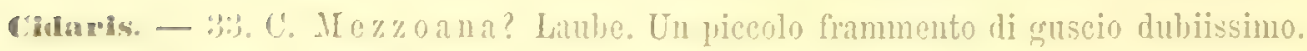
Tona lio strati marini. R. An. - Trorasi anco qualche radiolo irriconoscibile. che spetti probabilmente a questo genere.

\section{Ordine. Clupenstront.}

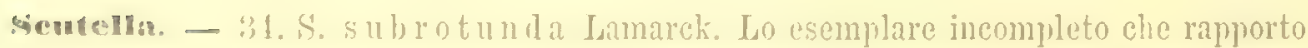
at questa specje cospisponde bene nei caratteri alla forma tipica, ma è più grande ni quelli di deege coi quali l' ho comparato. Giace nell'arenaria biancastra sottostante argli strati Aquitaniani del mioceno presso Stilo. Zoma l. R. S. - 35. S. Paulensis Merssiz. Tar. IV. fig. 11. Ralplorto a questa sprecio rarî esemplari molto grandi il cui diametro trastersale ì magringe del longitudinale (lumgal 1.10 mn

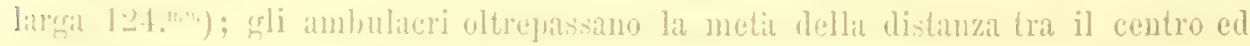
il margine, lo zone perifere banno una largheza che is quasi doppia della larshezal delle zone interporilere, le quali inoltre assumono una forma lineare poco 
assottigliata ai due estremi. Questa forma giace colla S. subrofunda nell'arenaria biancastria tongriana di Stilo. Zona $r .1 \%$. S.

Cypeaster. - 36. C. latirostris Agassiz. Rapporto con qualehe dubbio allit specie in discorso un esemplare in cattiro stato, deformato un poco dalla pressione. Proviene dall'arenaria presso Antonimina. Zona E. strati marini. R. An. 37. C. Antoniminensis n. sp. Tar. IV. fig. $6,6 a 6 b$.

Questa specie fu creduta da me dapprima siccome identica al C. mofunclus D'Arçhiac; ma arendo potuto raccoglierne rarî esemplari, mi sono convinto dellia sua distinzione, quantunque essi non fossero in ottimo stato di conserrazione. La mia specie differisce da quella del D'Archiac, per essere più distintamente pentagonale, cogli angoli ben mtondati e col margine lievemente incavato tra un angolo e l'altro, alquanto piu allargato e colla regione anteriore più ristretta, cousidererolmente più spesso al margine, cogli ambulacri pressochè dulla stessa forma e grandezza ma più aperti all' estremitì e colle zone porifere un po' più strette, con i tubercoli della superfieie più piccoli e molto più ravricinati. Qnesta specie potrebbe essere identica al $C$. pentagonalis Michelotti, ma nè la descrizione, nè le figure date dall'autore sono sufficienti a determinare la specie.

Questo Chpeaster caratterizza le molasse e le arenarie di Antonimina, dei monti sopra S. Jejunio, ed anco dei dintorni di Agnana, essendochè il sig. dott. M. De Mujà ha raccolto un masso di arenaria presso il Monte Petto il quale ne contiene alcuni esemplari.

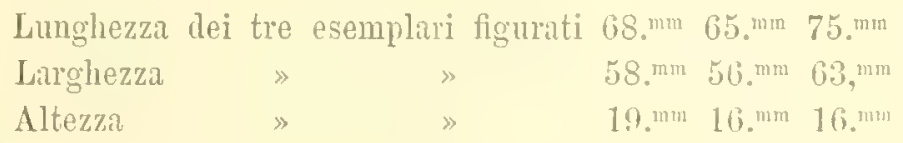

Zona $E$. strati marini e Zona F. c. An. MI.

\section{Ordine. Spatangomi.}

Eehinoiampas. - 38. E. hem is phaericus Lamarek (Clypeaster). Rapporto con qualche dubbio al Tongriano superiore un frammento di questa specie non raccolto in posto, ma aderente ad un pezzo di arenaria somigliante a quella che racchiude le Scutclle. Zona F. R. S. - 39. E. inflatus Laube. Un esemplare che lascia qualche leggiero dubbio, perchè fortemente compresso e deformato dalla fossilizzazione, ma la grandezza, la forma del contorno, gli ambulacri, ed i tubercoli conxispondono bene. Zona $L$. strati marini. Ir. An.

Periaster. - 40. P. Capellinii Laube. Questa specie comme ad Antonimina, raccogliesi sempre mal conserrata, perchè compressa; ciononpertanto la senltura e gli altri caratteri corrispondono con quelli della specie del Vicentino. Zona l: strati marini. c: An.

41. P. calablus 11. sp. Tay. IV. fig. 7.

Questa specie, affine alla precedente, si distingue benissimo per la forma allungata pressochè orale e troncata posteriormente: i petali posteriori sono meno divergenti, più lunghi e quasi uguali agli anteriori, i tubereoli dal lato inferiore più grossi, e piì rarricinati. 
Gli esemplari sono sempre compressi, e nou mostrano la fasciola laterale; se csisa manca realmente, questa specie sarebbe da riferirsi al genere Emiaster.

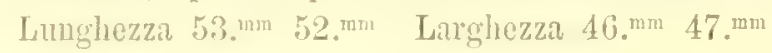

Zomi E. strati marini. c. An.

sohimster. - 43. S. . . . . sp? L' unico esemplare raccolto trovandosi in . cattiro stato, non può essere specificamente definito, ma esso somiglia allo S.lucirns Taube. Zona $E$. strati marini. R. An.

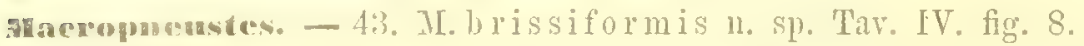

Questa specie è tanto afhine al $M$. Urissoides Laube, che fui sul punto di -associarlat an esso, difitti i tubercoli disugnalissimi, i petali profondi, la forma pressortic ovale ece. lo famo rignardare come tale; la fasciola nella specie (calab) insece di essere ai lati, tra i petali anteriori e i posteriori, convessa all' csterno, ì concara e si arricina quindi considererolmente verso il centro; la smapuinatura anteriore del guscio è molto più profonda e derira da un largo c profundo soleo al petalo impari, gli altri petali cousiderevolmente incarati sono prì lirevi.

Lumghezza del solo esemplare raccolto $68 .^{\mathrm{mm}}$

Larghezza "

Insicme trovai un riccolo esemplare. Zoua $E$. strati marini. R. An.

$$
\text { Clisse. Steluerini. - Ordine. Asterint. }
$$

Istroprecen. - $14.1 \ldots \ldots$ sp? Il solo articolo raccolto par che somigli molto all' A. laevis Desmoulins sp. Zona E. strati marini. R. An.

\section{Classe. Crinoidr. - Ordine. Brachiarir.}

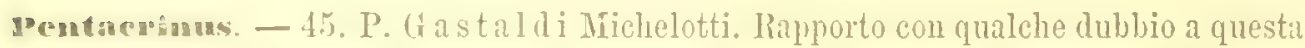
specic una colonnetta non ben conservata, formata da sette articoli colle facec alquanto concare, cogli spigoli ajpena rotondati e lateralmente compressa dalla fossilizzazione. Zona $l$. strati marini. R. An.

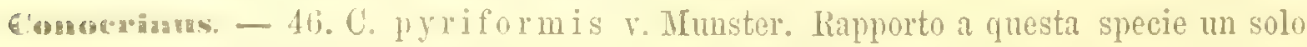
articolo, pel quale qualele dubbio si è affacciato. Zona $E$. strati marini. R. An.

'Tipo. CELENTERATI.

Classe. Antozoarit. - Ordine. Coralicaril.

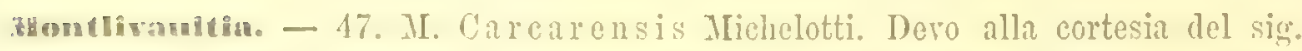
ing. G. Rotia un esemulare in buono stinto di conservazione spettante a questa specie, racenlto nei dintorni di Agnana. Zona $F$. strati marini. R. $\Lambda$.

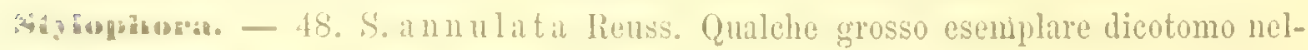
l'arenaria. 'Zuma li. strati marini. r. An.

Classe. Sinowinari.

Clions. - 49. U. . . . . sp? Malconservata, perfora un frammento di lima mincenicu. Konal L. strati marini. R. An. 
Tipo. PROTOZOARI.

Classe. Rizopodi. - Ordine. Foraminifers.

Pracopsilina. - 50. P. cenomana D'Orbigny. Molti esemplari fissi soma un frammento di Lima mincenica che assumono diverse forme somiglianti molto : quelle rappresentate dal Carpenter (') Tar. XI. fig. 12, 13, 14 della Lituola cenomana (Placopsilina) D'Orbigny. Zona E. strati marini. 1'. An.

Heceostegina. - 51. H. .....sp? Un solo maleonservato ed incompleto esemplare. Zona E. strati marini. R. An.

Dpeaculina. - 52.0. com planata Basterot (Lenticulites). La roccia molissicat in taluni strati ad Antonimina ed oltre il Monte S. Jejunio is sorente ripiena di questa specie. Zona $E$. strati marini. C. An. MI.

Vummulices. - 53. N. intermedia D'Archiac. Riferisco a questa specie la maggior parte delle nummuliti che troransi negli strati lnugo la via che conduce a Cittannova, e che giacciono tra il IIonte S. Jejunio e gli altipiani della MLelia. Zona E. strati mariui. C. M. - 54. N. G a r a n s e n s is Joly et Leym. Credo di trorire associata alla specio piecedente la forma scoperta a Garans presso Gaas (Laudes). Queste due specie troransi abbondantemente negli strati calcareo-arenosi e si associano bene spesso all'Orbitoiles Gumbeliz; esse, come dichiara il D'Arehiac. caratterizzano gli strati clel miocene inferiore. Zona $k$. strati marini. c. MI. 55. N. variolaria? Sowerby. In cattiro stato di conservazione e percio dubbia. Zona E. strati marini. C. An.

Grbituides. - 56.0. Gumbel i $11, \mathrm{sp}$. Tav. IV. fig. $9,9 c, 9 b, 9 c$.

Questa è una grande specie, sottile, m po' rigonfia rerso il centro, finamente granosa alla regione mediana, colla superficie finamente reticolata a maglie esagone, più o meno irregolari, con una camera centrale molto grande di forma lenticolare.

Le dimensioni di questa specie sono considereroli; il sno diametro ginuge sino a due centimetri. c. An.

Le ultime due specie si trorano presso Antonimina associate insieme, e costituiscono una buona parte della roccia in cui giacciono di mita all'Operculina. 57.0. gl l b u lina? Michelotti. Vi riferisco un solo esemplare che è un po diflerente perchè meno globoso, col margine meno distinto ecc. Zona L. strati marini. Ir. An.

Non fa d' uopo una lunga disamina dei fossili enumerati per internetare la loro significazione.

E primieramente la presenza di Limneae e di Planorbis negli strati a carbone anuuncia, seniza dubbio, che quel combustibile si accumuld nelle condizioni palustri in cui ordinariamente si costituirono tutti i carboni minerali; ma il mare invadeva a volta a rolta quei luoghi, e quindi gli strati a combustibile alternano con finma di estuario orrero con fauna prettamente marina. Finalmente una potente massia di

(1) Introduction to the sludy of the Firaminifera. 
aremaria a pettini, echinidi, forminiferi annuncia che il mare renira a cuoprire definitivamente quelle contrade.

Quanto all' eta lrecisa, quelle specie riportate nell' elenco ralgono benissimo a definira. Difatti l'Anhracolerium magnum del carbone ed il Cerithium margarilaceum sarebbero sufficienti a rapprortare questi zona al 'longriano. Il primo si conosce nel mioceno inferiore di Srizzera $\left({ }^{1}\right)$, di Francia ("), del Vicentino $\left({ }^{3}\right)$ e del Piemonte ( $\left.{ }^{4}\right)$; il sccondo trorasi parimenti nel Tongriano del Piemonte ("), del Vicentino( $\left.{ }^{\circ}\right)$, di Mayence (') ecc.

Gli strati marini superiori ci offrono la Venus dubia. la Crassatella Michelottii, l'Arca biangulinu, i Pecten suliasper, miocenicus, simplex, la Janira arcuata, la Honlivaullia carcarensis, la Shilophore annulata, Ia Aummulites intermedia che sono moprî del mioceno inferiore di Dego, Carcare, ece. nel Piemonte $\left({ }^{8}\right)$; come la Carditu Arduini e Laurae, l'bchinolampas inflatus, il Periaster Capellinii si trorano nel mioceno inferiore del Vicentino $\left(^{9}\right)$.

La zona $F$ joi viene da me associata al Tongriano come quella che rachiude messo Stilo le Sentelle, che troransi quasi dappertutto nel mioceno inferiore.

In questo piano come in tutti i precelenti dell' Eoceno mancano del tutto le specie identiche alle riventi.

\section{Piano hevitaniano Mayer.}

Sinonimi. Mioceno wedio degli autori (parte). Primo piano mediterraneo Suess.

Nelle srandi sezioni del mioceno presso Stilo succede alle arenarie a Scutella nn'alternanza di grossi strati di arenaria somigliante alla precedente, ma grigia, rerdastra, o brunastra con strati di conglomerato a ciottoli cristallini; e quindi in alto lo arenarie divengono sempre piì tenere e calcarifere ed alternano con strati marnosi e sorente con straterelli calcarei, dimodochè la porzione superiore oftre strati prominenti e strati incavati, secondochè sono piir o meno resistenti alle azioni meteoriche.

Questa serie, nel territorio di Stilo, succede ovunque alla precedente in relazione concordante; ma alla suil rolta ricoperta dille rocee più recenti, non si mostra d'ordinario che nei grandi tagli verticaki allineati lumgo la valle che si estende da Guardaralle a Stignano, e nelle valli trasversali, formando delle grandi muraglie inaccessibili, elerate quasi cento metri.

La potenza di questo piano raggiunge al certo $\mathrm{i}$ cinquanta metri ed in certi luoghi forse anco li oltrepassa. Sul lato orientale nella prorincia di Reggio è soltanto nel territorio di Stilo che io posso segnalare questa formazione, dove i suoi strati sono dappertutto fossiliferi, e caratterizzati da molluschi ed echinidi numerosi.

(1) Ieer in Gastalli, ('mmi sui verlebrati fossili del Picmonte. - (2) G. Michelotti, Étules sur

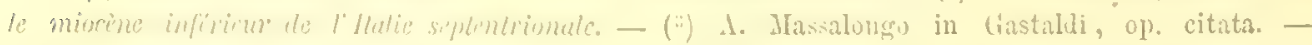
(b) I3. Giastalui, op. citatw (\&. Michelotti, op. cituta. - (5) Michelutti, Eludes sur le miocine infiricur

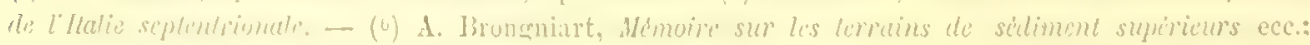

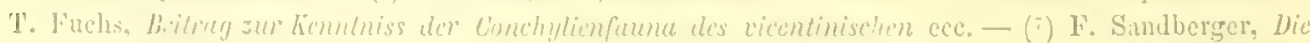

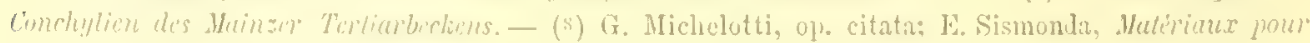

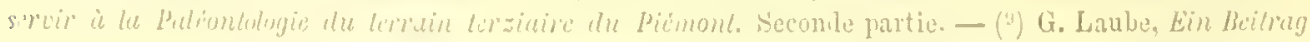

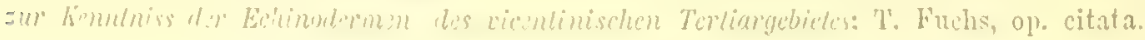


Sul lato meridionale ed occidentale poi, sulle arenarie delli zona ultima del Tongrimo poggia, come dissi rrecedentemente, e si comnette con esse pel gradazioni, m calcare compatto, bianco, grigiastro, o gialliccio, diviso in banchi da straterelli arenosi, quasi intieramente costituito da briozoi mal definibili, e specialmente da numerose cellepore, alle quali si associano sorente abbondanti Lylhothamiae(').

Questa roccia, potente e molto sviluppata nel territorio di IIotta, è un rero banco coralligeno in eni ai polipai si sostituiscono intieramente i briozoi e le Lythothammice, quindi una roceia costituitasi in considerevole nrofondita e di origine prettamente organica. Questa roccia suole adoperarsi nel Reggiano come pietria da taglio, per" costruire stipiti d'imposte, gradini ed altro, ma specialmente per' lastricare le strade, pel quale uso trasportasi anco a Hessina, dore specialmente s' impiega per la costruzione dei marciapiedi.

Le ragioni che mi guidarono a sincronizzare gli strati aquitaniani di Stilo col calcare a briozoi degli altri luoghi, si unificano duasi nella posizione stratigrafica di entrambi, che lio studiato da molto tempo ed aceuratimente nella provincia di Hessina.

La comparazione paleontologica riesee del tutto infruttuosa, essendochè il calcare a briozoi è privo affatto di resti di molluschi o ne conticne di rari ed indeterminabili, invece gli strati di Stilo sono ricchi di molluschi e di echinidi. Tale completa diversitì nelle due faune accenna alle diverse condizioni di esistenzi, e specialmente alla differente profondita delle acque in eui si costituirano i une diversi depositi; certo, gli strati di Stilo risultando di grossolani materiali aggregati, si costituirono a piccola profondita; quelli di Motta, calcarei e compatti, hamo dornto formarsi a profonditi considerevole; i primi infatti racchindowo una fauna littorale, i secondi colla loro ingente massa di briozoi dimostrano evidentemente li loro origine profonda.

Il piano Aquitaniano dunque con questi due diversi aspetti, o meglio colla sincronizzazione delle due rocce differenti e lontane, si oftre in varî hoghi considererolmente esteso.

Sotto forma di deposito littorale io $I^{\prime}$ ho seguito lungo la via che conduce da Guardavalle a Stilo; quella stradi è fiancheggiata sulla sinistra da altissimi tagli maturali in gran parte operati in seno alla roccia arenosa e nei conglomerati dell'Aquitaniano. Grossi e piccoli massi si staccano da quegli alti ciglioni, e rotolano giu nella valle, mettendo in eridenza i caratteristici fossili, e specialmente i grossi e rariati elipeastri.

Lungo la valle dello Stilaro si erge sulla destra la Timpa Melissuri, la quale offie insieme agli echinidi, numerosi e variati molluschi, per la maggior parte ridotti allo stato di modelli, ed alcuni colalli; tali fossili si raceolgono anco poco piu in basso, presso la rotabile che conduce a Stilo, siccome nei tagli che stauno di rimpetto sulla sinistra dell'alreo del torrente. Dilla Timpa Melissari dirigendosi verso mezzogiono si trarersa quella valle longitudinale che s' interpone tra i piani cocenici e le formazioni mioceniche. Quest'ultime tagliate a picco sulla sinistra, costegrgiano la valle formando elevati ciglioni, che si estendono verso Stignano, interrotti qua o lil dia ralli di erosione parallele allo Stilaro, che hamno alla loro roltil rrodotto colossali sezioni.

(1) Nullipore. Vedi A. W. W.aters, holes on fussil lithollammin (so-called mullipurar). 
Questi grandi tagli naturali, come può vedersi dalla seconda sezione, oftrono le testate delle rarie zone di eni risultano il mioceno inferiore ed il medio. Difatti in basse il Tongrimo, e sopra l'arenaria a Scutella si erge potente l'Aquitaniano, le eni roce decadento incessantemente, spargono di massi fossiliferi la ralle, nei quali or vedesi dominare i Pecten, or le Venus, or i Clipeastri ed ora una rariata miscela di fossili differenti, ed inrece sovente una specie soli o un solo genere costituiscono molti di quei massi: così bene spesso aleuni risultano dall'accumulo del Pectunculus obneulus, altri sono un rero impasto di grandi Pinne ece.

Sul lato meridionale e sull'occidentale, l'Aquitaniano assume l'altro facies già descritto, in cui la roccia è calcarea e i fossili sono briozoi.

Mir con tili caratteri comincia benanco a farsi vedere sul lato orientale; dore ho potuto nsservarlo soprastante agli strati fossiliferi del 'longriano in alto di Antonimina, siccome presso i piani della Melia, lungo la strida tra Gerace e Cittamova, ove giace nella melesima posizione stratigrafica, connettendosi inoltre per transizione cogli strati fossiliferi sottost mti; iri quindi raggiunge l'elerazione di quasi $900 \mathrm{~m}$. sul livello del mare.

Casi presentasi nelle colline sopristanti al torrente Ammendolea ed affiora qua e lit nella regione delle saline.

Ir è nel territorio di Motta che il caleare a briozoi assume il massimo sriluppo. Da presso Lazzaro infitti esso si estende nella direzione sud-orest nord-est, formando una zona ele oltrepassando Motta s"inoltra verso la contrada Leandro. In questa lunga esten-ine inferrotta di tratto in tratto, si ofre costituita di massi isolati e di vario volume dabla costa sin presso Motta; ed invece ma serie di ripidissime ed elevate colline calcaree la costituiscono sino al Leandro ed attorno le Serre del Corvo, dore si cleva rluasi sino a $7000^{\text {jn }}$ sul livello del mare.

Questal roceia lit dove poggia immediatamente sulle argille scagliose presentasi dislocata, rotta e sparsa in grandi e piccoli massi alla superficie delle argille stesse. Qnesta curiosia disposizione cle a prima ginntil potrebbe credersi doruta a grandi seonrolgimenti, deresi inrece attribuire al rammollimento delle argille, le quali dormuo quindi cedere sotto l'ingente peso degli strati calcarei, e questi rompersi (' sconrolgursi, siceome è accirduto per l'arenaria silicea della zona D. Con tali caratteri offresi questa formazione dia Motta seendendo rerso la costa; invece da quel paese dirigendosi in alto rerso nord-est il calcare a briozoi si presenta in posto e molto potente, formando enormi gradinate o grandi muraglie, che in parte decadute costituiseno mucchi gigantesehi di colossali rottami.

Come pnò velersi nell'annessa carta dei dintorni di Regoio, la zona di cui discorro s"interpone tra le argille scigliose, alle quali sovrasta, che si estendono lungo il linto sul-est, e le arenarie del mioceno medio, ehe si elerano ripidissime dal lato opposto, alle guili il calcare sottostit.

(buestar zona dunque, ehe da Iazzaro s'inoltra sino al Leandro, in cui il calcare a briozoi oflie il magrere svilupho, costituisee unit rera linea di demarcazione trat il 'Tongriane e l'Aquitaniano, siccome tril questo e il Langhiano, ehe rastamente cstendesi verso settentrione, costituito dit potente massa di aryila di arenarlia e di congrlomerati. In rarj altri luoghi l'Aquitaniano lungo il lato occidentale del Regrgiano affionat di: sutto questi strati. Cosi presson Valanili, all Almo, nol territorio di Palmi ece. 
Paleontologia. - I Inoghi fossiliferi nel territorio di Stilo sono molto estesi. e fra essi devono in primo luogo contarsi, la via che conduce a Guardaralle, is sezioni lungo lo Stilaro, la Timpa Melissari, la regione Milo e quelli che intercedono tra questa e Stignano.

La conservazione dei fossili è raria secondo la classe cui spettano e la matura della roccia. Le conchiglie dei molluschi o sono ridotte a soli modelli, orvero se conservate, riesce ben difficile la loro estrazione dalla roccia, soprattutto allorquando sono spatizzate. I coralli sciupati ovrero ridotti a modelli mal si prestano alla determinazione. Gli echinidi in genere, e specialmente i clipeastri sono ben couservati, questi ultimi contraddistinguono questo piario con forme commi e rariate.

È uopo qui ricordare, come si desumerà dal seguente elenco, che questa fama littorale risponde precisamente alla fauna della Superga, la quale giace ivi nei conglomerati e nelle arenarie serpentinose; e qui invece $\mathrm{i}$ conglomerati e le arenarie ripetono i loro materiali dal granito, ed in genere dalle rocce cristalline, che formano la centrale giogaja dell'A pemnino calabrese.

La fauna del calcare a briozoi non uni è nota, essendochè la doterminazione specifica di tali fossili riesce difficilissima e sovente impossibile in quella roccia compatta. Qualche nozione più importante puo aversi studiandoli alla superficie, dove gli agenti atmosferici, attaccando con maggiove energia la roccia, denudano quello spoglie animali c ce le offrono in qualche modo riconoscibili; ma la brevita del tempo ed i moltissini materiali di ogni zona che hanno richiesto assiduo ed incessante lavoro, non mi hanno permesso d'iniziare le ricerche per riconoscere i briozoi del calcare, i quali d'altronde richiedono assiduo e paziente studio, e non potranno dare che risultamenti incompletissimi.

Elenco delle specie fossili raccolte negli strati del piano Aquitaniano.

Tipo. VERTEBRA'T.

Classe. MaMmiteri.

Aleuni indeterminabili frammenti di ossa.

Classe. Pesci. - Ordine. Condrotterigit.

Carcharodon ("). - 1. C. megalodon Agassiz. Un solo dente raccolto presso Stilo; un altro nei monti sopra Palmi, nella roccia calcarea a Briozoi e Lythothamnia. R. - 2. C. rectidens Agassiz. Alenni esemplari raccolti sopra Palmi nella roccia sopradetta. $r$.

Oxyrhima. - 3. O. De s or i i Agassiz. Qualche esemplare dal territorio di Palmi. R. 4. 0. xyphodon Agassiz. Un esemplare dalle colline di Palmi. R.

(1) Tra i segni convenzionali l"ultima V. indica che la specie vive ancora. Eccetto qualche specie in cui è indicata la località, tutte le altre; che in questo elenco non portano rerım indic ozinne, provengono dal territorio di Stilo. 
Ordine. Teleostei.

Spluoerodus. - 5. S. a mu u latu s Agassiz. Varî esemplari nel calcare a Briozoi. c.

Tipo. MOLLUSCHI.

Classe. Gasteropodi.

BuIIa. - 6. B. . . . . sp. Dne modelli di una grande specie indeterminata. R. Cylichana - 7. C. B roc chi i Michelotti (Bulla). R. - 8. C. con roluta Brocchi (Bulla). R.

IIaromella. - 9. M. s u b o v u lat a D' Orbigny.=- M. ovulata (Grateloup.) Michelotti (non Lamk.) R.

mingicula. - 10. R. T o ur n o n e r i Morlet. Questa specie trovasi molto comumemente nel mioceno medio e superiore d'Europa. R.

Conms. - 11. C. betulin o ides Lamarck. Due grandi modelli. R. - 12. C. Ho ernesii Doderlein. $=$ C. Aldrovandi Hoemes (non Brocchi). R. - 13. C. Bergánsii Michelotti. r. - 14. C. ventricosus Bronn. r. - 15. C. Mercati Brocehi. R. - 16. C. Tarbellianus? Grateloup. Un modello. R. - 17. C. Puschí Michelotti. 1 - 18. C. antedilurianus"Bruguière. C. - 19. C. Brocelii? Bronn. Un esemplare in cattivo stato e quindi dubbio. R. - 20. C. catenulatus Sowerby. Alcuni modelli. R. - 21. C. Dujardini Deshajes. R.

Golnta. - 22. V. ficulina Lamarek. r.

Diva. - 23. 0. cylindracea Borson. R.

Ancilloria. - 24. A. glandiformis Lamarek. Diverse forme che suole ordinariamente assumere. e.

Colnmbella. - 25. C. nas o ides Gratelomp (Fusus). $=F$. politus Renier. Un solo esemplare. R.

vassa. - 26. N. plismatica Brocchi (Buccinum). R. - 27. N. incrassat: Muller (Tritonium). R. V.

Eburaa. - 28. L. e burnoides Matheron (Buccinum). r.

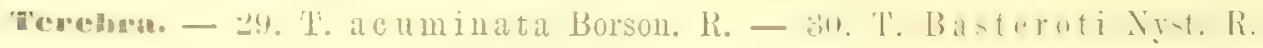

molium. - 31. D. denticulatum Deshayes. R.

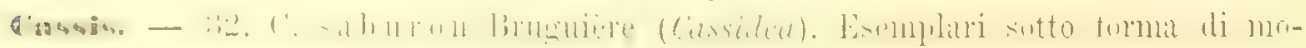
delli incompleti. r. V.

Minthroa. - 33. H. colnea Linneo (Murex). R. V.

myroistica. - 34. Mr. collu uta Agassiz (Purula). Rapporto a questa specie un usemplare incompleto o mal conservato, il quale sembra areme i diversi caratteri, ma costituirebbe una distinta varieti, perchè porta sugli arrolgimenti delle linee rilerate tra loro abbastanza distanti. R.

Grurex. - 35. MI. S is mo nd a e Bellardi. Varî piecoli esemplari, e qualemo grande. betl caralteristici. r. - 36. MI. . . . s]). Un escmplare in cattirissimo stato. R.

Vusus. - 37. F. glom oides Gené. Qualche modello. R.

abmella. - 38. R. marginata Martin (Buccinum). R. - 39. R. tuberosa Bomelli. Hi 
Triton. - 40. T. appenninicum Sassi. - Murex felicularis Var. Brocehi (non Linneo), Murex nodulosus Borson. Un esemplare in cattivo stato riferibile alla Var. B. Bellardi (Triton nodulosum Wichelotti). R.

Tasciolaria. - 41. F. tarbelliana Grateloup. Un sol modello alquanto dubbio. R.

Ficula. - 42. F. cond ita Brongniart (Pyrula). R. - 43. F. geometra Borsom (Pyrula). Un sol giovanissimo esemplare. R.

Cerithium. - 44. C. b is ule atum n. S1). Tar. IV. fig. 13.

Testa clongata cylindracea, longitudinaliter vix sublicata; anfractus planali, sulcis duobus cinctis, sulci bilineati; sulurae superficiale; anfractus ultimus sulcis plurimis ornatus. Os ovalis.

Questa specie ben distinta nou ho potuto studiarla che su di un solo esemplare rotto, ma la speciale scultura molto semplice la rende distintissima.

$$
\text { Lunghezza } 500^{\mathrm{mm}} \text { circa. Larghezza } 15 .^{\mathrm{mm}} \mathrm{R} \text {. }
$$

45. C. vulgatum Bruguiere. Un solo esemplare ben distinto. R. IT.

Xemophora. - 46. X. Deshayesii Michelotti (Phorns). r. - 47. X. cumulaus Brongniart (Trochus). r.

Natien. - 48. N. Sismond iana? D'Orbigny. Qualche modello in cattiro stato e perciò dubbio. R. - 49. N. e longat a? Michelotti. Un solo e dubbio modello. R.50. N. compressa? Basterot. Dubbî modelli.r. - 51. N. millepunctata? Lamarck. Rapporto un esemplare rotto a larghe e rare macchie. R. V.

Turritella. - 52. T. cathedralis Brongniart. Un frammento. IR. - 53. T. Rie ppelii Hoernes. R. - 54. T. vermicularis Brocchi (Turbo). Esemplari in cattivo stato. r. - 55. T. gradata Menke. r. - 56. T. Archimedis Brongniart. Modelli ed impronte. c. - 57. T. tele bralis Lamarek. R. - 58. T. subangulata Brocchi (Turbo). R.

Taroo. - 59. T. miocenicus Michelotti. Esemplari in cattivo stato ma riconoscibili. r.

60. T. erispatus n. sp. Tav. IV. fig. 12.

Testa parva depresso-conica; anfractus quinque transverse confertissine exquisite striali; duo ultimi, cingulo mediano rotundato carinati, superne linea impressa, inferne cingulis duobus, inferiore maiore, ornati; suturae mo/undatae subcanaliculatae. Anfractus ultimus inforne subangulatus; basis convexu. concentrice sulcata.

Questa piccola specie di turbo somiglia per la generale forma al T. pelorilunus Cantraine del plioceno, che è molto più grande; ma il T. crispulus è distintissimo per la scultura, costituita di linee d'accrescimento squisitissime e assai rarvicinate, che ne increspano la superficie, e prer varî altri caratteri indicati nella descrizione.

\section{Altezza $3 .^{\mathrm{mm}}$ Larghezza $3{ }^{\text {mm }} \mathrm{ll}$.}

Trochus. - 61. T. Michelottii n. sp. = T. Amodei. Michelotti (non Brongniart). Vedi fossili della formazione Langhiana. r. - 62. T. turgid u l us Brocchi. = T. Montagui WT. Wood. r. V. 
Classe. Scafoponi. - Ordine. Solenoconchi.

Dentalinm. - 63. D. fossile Linneo. Un solo cattiro esemplare. R.

\section{Classe. Lamelibranchi.}

Teredo. - 64. T. . . . . . . sp.? Di questa teredo s'incontrano dei tubi aggrupuati in gran numero, ed anco dei pezzi di legno mineralizzato contenente i suddetti tubi. Non ho potuto redere ancora la conchiglia per definime la specie; è forse la T. norvegica. Sp. c.

Pamopaca. - (35.). P. Menardi Deshayes. R.

Corbula. - 66. C.gib b Olivi (Tellina). - C. nucleus Lamarck. R. V. - Qualche frammento indeterminabile che spetta ad altra specie.

solecuntus. - 67. S. strigilatus Limneo (Solen). R. V.

Tellina. - 68. T. planata Lin. = T. complanata Gmelin. R. V. - 69. T. strigosa? Gmelin. Un solo esemplare mal conservato. R.

Troes. - 70. 1'. retula Basterot (Voms). R.

Genus. - 71. V.A gla urae? Brongniart (Corbis). Un solo esemplare in cattiro stato e quindi dublio. R. - 72. V. D ujardini Hoemes. R. - 73. V. orata Pennant. = V. radiata Brochi. R. V. - 74. V. scalar is Brom. R.

Cyulerea. - 75. C. Pedemontana Lamarck. 1. - 76. C. erycinoides Lamarek. c.

Dosinia. - 77. D. exoleta? Limeo (Venus). Un solo piccolo esemplare incerto. R. V. - 7S. D. lupiuns? Poli (Venus). Un modello R. V.

Astarte. - 79. A. scalaris Deshayes (Crassina). R.

Carlium. - 80. C. d is crepans Basterot. r. - 81. C.multicostatum Broc. R. Lucina. - 8:. L. columbella Lamarck. R. - 83. L. ornata Agassiz. R.

Diplodonu. - 84. D. rotundata Montague (Tellina). Qualche modello. R. V.

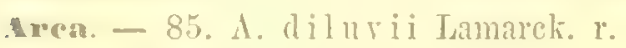

Fectunculus. - 86. P. stellatus Gmelin. (Vonus), r. V. - 87. P. insubricus Brocchi (Arca). r. - 88. P. obtusatus Partsck. Specie comunissima e ben conservati. C.

rytilus. - 89. M. fuscus Hoernes. L' unico esemplare raccolto è alquanto più largo di ciuello rappresentato dall'antore. R.

E"inna. - 90. P'. infundibulum n. sp. Tar. IV fig. 14.

Testa cuneato-infundibiliformis, subincurvata, valvae valde convexae, fere semiconicae ut aperturam subquadralam constituunt, medio longitudinaliter arcuatim rolundato-carinatae; margo anterior concavus, posterior subrectus: regio anterior oblique obsoleteque plicata, posterior costis paucis radiantibus.

Qnesta specie i ben distinta per la sua forma conico-piramidata, molto breve, spessa e per la grande convessiti delle valve, per cui ne risulta un' apertura proprio (puadrata, mentre la conchiglia d'altro canto assume una conformazione specialissima.

$$
\text { Lunghezza 69. }{ }^{\text {mm }} \text { Larghezza 70.mu Spessezza 74. } \text {.mm }^{\text {m. }}
$$

91. P. den udata n. sp. 'Tay. Y. fig. 1. 
Testa inflata, conica, subarcuata, trigono-subtruncata; valvine ecostatae, concentrice rugosae, margo anterior arcuato-concavus, posterior convexus.

Questa specie ha quasi la forma di un grande Mitilus e somiglia molto alla P. Brocchii D'Orbigny per la mancanza di costole, se ne distingue benissimo per la gibbosita delle valve e per la forma incurrata che assume.

$$
\text { Lumghezza 174. }{ }^{\mathrm{mm}} \text { Larghezza 121. }{ }^{\mathrm{mm}} \text { Spessezza 68. }
$$

92. P. peruula Chemuitz. - P. Maravignae Philippi. Rapporto non senza qualche dubbio a questa specie rivente una piuna molto comue nelle rocee aquitaniane del territorio di Stilo, la quale giacendo in roccia abbastanza solida, talvolta compattissima, difficilmente può estrarsi in buono stato, pure dagli esemplari quasi completi che ho potuto ottenerne bisogna conchiudere che essa non differisce dalla specie cui la rapporto. C. V. - 93. P. tetragoua Brocchi. Un bello e completo esemplare di forma piramidale a base quadrata parmi deblar riferirsi a questa specie. $r$.

Pecten. - 94. P. Tournalii Marcel de Serres. Rapporto a questa specie un grande esemplare molto maggiore di quelli rappresentati dall'Hoernes. R. 95. P. s o larium Lamarck. Un grande e bello esemplare. R. - 96. P. s cabrel1 us Lamarek. 1 .

Jnnirg. - 97. J. Besseri Andr. (Pecten). c. - 98. J. Beudanti Basterot (Pecten). 1. - 99. J.revoluta Michelotti (Pecten).r. - 100.J. Grayi Michelotti (Pecien). R.

Spondylus. - 101. S. Deslua Jesii? Michelotti. Una valva rotta di cui si rede soltanto l'interno. $\mathrm{R}$.

Ostrea. - 102. 0. plicata? Chemnitz. R. T. - 103. O. Boblay Deshayes. r. 104. O. ten u iplicata n. sp. Tar. XII. fig. 1. Vecli fossili degli strati tortoniani. 1".

Anomia. - 105. A. costata Brocchi. 1.

\section{Tipo. VERMI.}

\section{Classe. Anellidi.}

Qualche frammento di tubo appartenente alla famiglia dei Serpulidi. R.

\section{Classe. Briozoarin.}

Memuraniporar. - 106. M. L a cro ix i ? Sav. Una colonia di cattira conservilzione. R. V.

Lepralia. - 107. L. . . . sp.? Una colonia in cattivo stato che ricorderebue in qualche modo la L. Partschii Reuss. o la L. tenella Reuss. R. - 108. L. . ..... sp.? Mal conservata, somiglia alla L. semulata Reuss. R.

Celleporaria. - 109. C. polythele Reuss. (Cellepora). Si raccolgono delle grosse colonie distintissime per la loro forma arrotondata colla superficie irta di protuberanze. r.

compuaria. - 110. C. intermedia Michelotti. Vi riferisco un escmplare in cattiro stato, estratto da un calcare quasi compatto. Il sig. Mramzoni opina con buone ragioni che questa debba associarsi alla C. umbellata Defr. Li. 
Tipo. JCHI, Nol LRML

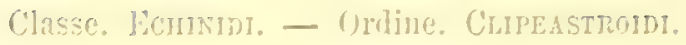

Crypeaster. - 111. (. p y ramidalis Michelin. liapponto a questa specie del fiano Aquitaniano una sola motir di un alto clypeaster raccolto alla 'limpa Melisari preses stilo. Lamico esenplare riferito dal Michelin viene dal calcare

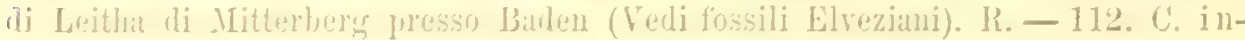

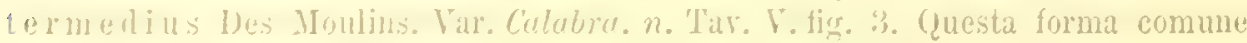
nell'Aquituniang di Stilo difierisee dalla forma tipica descritta dal Michelin, per were le aree anambulacrali non elevats, invece perfettamente piane ed a livello relle zone prifere; rilerante carattere, comune a tutti gli esemplari raceolti, che distingur prettinume questa varietal, d'altronde esattanente concordante col tipo in tutti gli altri caratteri e presentantesi variabile anche come ruello. Difatti varia molto nellaltez:a. Hella proninenza delle zone interporifere, ed allorche queste son molto oleratm, le aree ambulacrali riescono meno aperte alla base giunerono sino qubsi a chindersi. Ifo trovato questa forma aneo tra gli echinidi prorenienti die Liaselice.

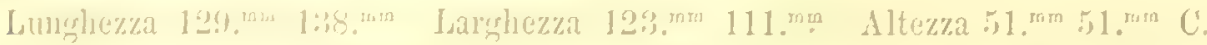
113. C. a cum inatus Lesor. Var. deriuns T'ar. V. fig. 2. Qualche esemplare

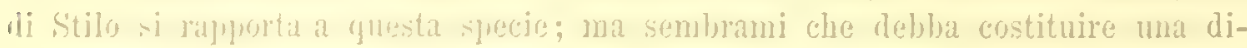
stinta varietid, jer ssere alruanto meno elevato ed acuminato, cogli ambulacri joii sporanti e più gibosi, col margine posteriore meno depresso, col peristoma juil piceolo di quanto lo rapruresenta il Michelin (").

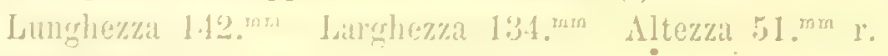

11.1. C. uetaliferus n. sp. Tiar. TI. fig. 2.

Questa specie somiglia alla precedente ed al C. gibbosus; dalla prima si distingue perche meno chata ars acuminata, dal secondo pel margine molto piiu grande. Cili ambulacri sono, petaloidi di forma pressreche romboidale, colla massima larshezzar alla motie della loro lunghezza, ed assottiogliati ugnalmente alle due estremita, incurrati joi in morlo che la parte superiore del guscio risulta appianatal. te son ruasi chinsi all'eatremiti inferione.

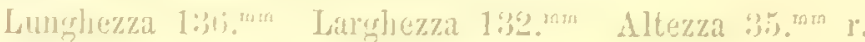

115. C. Stilens is n. - p. 'Tav. Y. fig. 4.

Questa forma is nolto affine alla juccerlentu; ma ne differisce considerevolmente per essere piil gribhosa, col mangine convesso e rigonfio cosgli ambulacri allungati

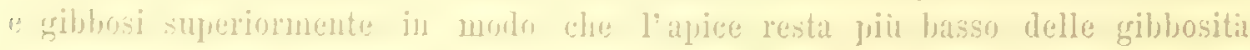

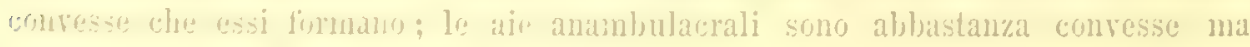
Ineno delle zone interjorifiere.

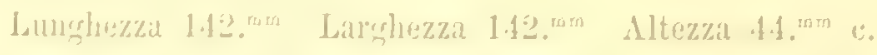

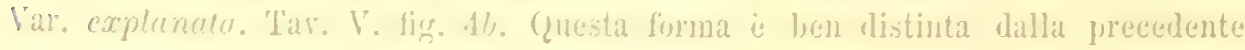
leel margine piu largo a meno sjesso. peegli ambulacri pii allungati e meno

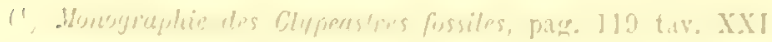


gibbosi ed invece per le aie anambulacrali tanto eonresse da ngungliare in elevazione le zone interporifere. $r$.

116. C. gibbosus Marcel de Serres. Rapporto a questa specie un solo esemplare molto sciupato e corroso, mancante di buonil parte del mareine, ma che pure è ben distinto. R. - 117. C. Michelotti A gissiz. Questa specie che per la conformazione generale, molto somiglia al C. Stilensis, se ne distingue eninentemente per essere largamente incirato alla base. Un solo esemplare. R.

118. C. ten u is n. sp. 'Tir. VI. fig. 3.

Sembra afline al $C$. marginatus per arere un largo margine e molto sottile; ma ne differisce moltissimo per essere ben distintumeute pentagono. perehe la porzione centrale rileratil non è appianata superiormente ma invece piramidata, pegli ambulacri di forma allungatit, sottile, semicilindriea, che si estendono sino ai tre quinti della distanza che passa tra il margine e l'apice, per la base non appianata, ma fornita di larga depressione che ha principio insensibile molto esternamente, pressochè come nel $C$. Nichcloltii.

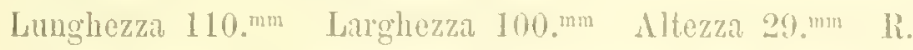

119. C. folium Agassiz. Rapporto a questa specie con qualche dubbio dne soli, piccoli e mal conservati esemplari, i quali per la loro forma e grandezza, por la depressione larga attorno la bocea, per la sottigliezza del largo margine. per la picciolezza degli ambulacri e prer altri caratteri parmi non difterire dal tipo. R. - 120. C. melitous is Michelin. Gli esemplari ehe rapporto a questa specie solno alquanto piu alti di quelli figurati dal Michelin o di forma un poco oblonga, cogli ambulacri allumgati. $x$. Var. clegans n. Titr. Vl. fig. 4. Chiamo cosi una forma poco piu alta, più regolamente pentigonla e cogli ambulacri considerevolmente piì larghi della nrecedente. $\mathbb{R}$.

121. C. planatus n. sp. Tar. VI. fig. 1.

Questa bella e grande specie, appianati inferiormente, si distingue per in grande depressione, pel margine largo e sottile, pre li regione degli ambulacri regolarmente convèssa, ma poeo elerata, per. gli ambulucri appianati e di forma allungata che si estendono poco oltre della meta dello spazio interposto tra il centro ed il margine.

\section{Lunghezza 173. $\mathrm{mm}$ Larghezza 173. ${ }^{\mathrm{mm}}$.1tezza $29 \mathrm{n}^{\mathrm{mm}}$}

Un solo esemplare. $R$.

\section{Ordine. Spatangolm.}

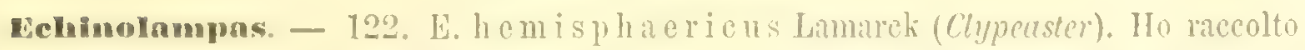
due grandi esemplari rotti, ma ben riconoscihili ai loto caratteri. li. - 123. E. scut if orm is Leske (Echinoneus). - Galeries scutiformis Iamarek, L. L'runcii Desmoulin, E. fungiformis Merian. Rinpporto a questa specie un grande ed orale esemplare che ha subito una compressione nel senso vertieale e percio ha il margine acuto; ma che in tutti gli altri caratteri comisponde alla specic cui l'ho riferito. K. 
Tipo. CHLENTERA'TI.

Classe. Antozoajiz. - Ordine. Zoantirir.

Ceratocyathus. - 124. C. verrucosus Michelotti (Trochocyalhus). R.

Trochocyathus. - 125. '1. Be lling erii ? Edwards et Haime. = Turbinolia Bellingeriana Michelin. R.

Fabculum. - 126. G. stylensis. 1s. sp. Tar. VII. fig. 1.

Qnesta è una grande specie coi lati taglienti e pressocliè ad angolo retto, colliasse maggiore del calice molto più basso del minore e pressochè il doppio, colla superficie rugosa trastersalmente, e colle costole appena distinte.

Larghezza 65. mm Altezza 52.mm Spessore $35 .^{\mathrm{mm}} \mathrm{R}$.

127. F. ext ens um Michelin. Ésemplari incompleti. R. - 128. F. de perd itum Michelotti. Qualche esemplare mal conservato. R.

Eupsammia. - 129. E. complessa Michelotti.r. - 130. E. Sismondiana Uichelin, (Turtinolia), r.

Ealanophyllia. - 131. B. praelonga Michelotti (Turbinolia). = Turbinolic cyllindrica Michelotti. r.

'R'urbinaria. - 132. T. e yath iform is Blainrille (Gemmipora). R.

Classe. Slongiaril.

Clionn. - 133. C. falunica Fischer. Alcune colonie sulle ostriche e i pettini. $r$.

Tipo. PROTOZOARII.

Classe. Rizopodi. - Ordine. Foraminiferi.

Dentalima. - 134. D........ sp.? Un solo frammento indeterminabile. spettante al gruppo delle levigate. R.

Cristcharia. - 135. C. cassis Lamarek. Un solo esemplare completo. R. V.

Babulima. - 136. R. in or nata? D'Orbigny. Vi riferisco rarî esemplari poco ben conservati, i quali potrebhero costituire ma ben distinta varietà, 0 anco una specie affine; perchè gli arvolgimenti sono più comprensivi, e la loro superficic è alquanto concava, carattere per cui si approssimano alla k. rotulata Lamk. 1 .

Anphistegins. - 137. A. vulgaris D'Orbigny. Gli esemplari raccolti sono in cattivo stato, ma rispondono bene, quantunque più piccoli, comparati a quelli tiprei dell'aquitaniano di Salicats. C.

Aperoulina. - 138. O. complanata Basterot. Qualche dubbio esemplare. R.

Meterostegina. - 139. H. papyracea 11. sp. Var. gigantec. 'T'ar. VII. fig. ¿2. Qnesta sprecie comunissima nell'elveziano, sarà deseritta in quella fauma. Lesemplare mieo e gigantesen raccolto a Stilo, diversifica ben poco dalla forma tipica, o ne costituisce la proposta varieti appianata e d'un grande sriluplo. Lunghezza 18."n Iarghezza $100^{\text {mm }} \mathrm{R}$.

deotulla. - 140. R. praecincta Karrer. Un solo esemplare incompleto. R. La fauna di cui ho enumerato le specie riconoscibili, si presenta a splendida 
conferma di quanto viene desunto dalla posizione stratigratica delle roce che la racchindono; difatti basta dare uno sguardo a quello insieme di forme specifiche per esserne pago oltremisura. Quasi tutte le specie conosciute sono note nella classica formazione della Superga, in quelle arenarie e conglomerati serpentinosi; ed io ricordo specialmente i Coni, le Ranelle, le Turritelle, i T'urhi, le Citeree, i Pettini, gli Echinidi, i Coralli ec. le cui variate specie sono ben note nel mioceno medio ( $\left.{ }^{1}\right)$.

È ancora beu notevole la proporzione tenue delle specie identiche alle viventi. In 140 forme specifiche se ne numerano soltanto 17 , cioè il dodici per cento cirea. Di queste forme virenti 15 sono Molluschi, 1 Briozoario ed 1 Forminifero.

\section{Piano Ijanghiano Parelo.}

Sinonimi. Hioceno medio degli antori (yarte). Lo Schlier degli scritturi teleschi.

a) Molasse. - Nel territorio di Stilo, sulle ripide rocce di arenarie calcarifere dell' Aquitaniano, si stende potente massa di argille grigio-bluastre; le quali fanno passaggio a strati induriti, sahbiosi e molassici, altemantisi con istrati di arenaria, rocce tutte che si collegano insieme per graduati passaggi, per uniformiti di colorito, per abbondanza di mica.

Queste rocce, che nell'insieme formano dei reri strati molassici, acquistano in taluni luoghi la considerevole potenza di circa 50 metri, e d'ordinario il loro lecadimento e l'erosione cagionata dalle acque fa sì che esse non possono restar tagliate a picco come le arenarie sottostanti, ma invece la loro sezione forma un piano inclinato su quest' ultime.

I fossili vi sono rari, ma sulla sinistra dello Stilaro ri ho trorato specialmenti Coralli monastrei, Pteropodi e Foraminiferi.

Le molasse langhiane si estendono di qua e di lit verso Stignano e rerso Guardavalle, sempre ricoperte dal conglomerato soprastante, che è molto esteso.

Nella salita che conduce a Guardavalle si osserrano, negli strati azzuri di arenaria langhiana, abbondanti conchiglie miste a coralli, tutti mal conservati, che pure completano in qualche modo la faun troppo limitata che raccogliesi sulla sinistra dello Stilaro.

Questa zona sul lato orientale nou la vidi altrove fnori del territorio di Stilo; sul lato occidentale è costituita al certo dalle molasse azzurre che s' incontrano sovente alla base delle arenarie e dei conglomerati della zona seguente, come redesi nelle valli tra Terreti ed Orti sino alla costa; ed ai Pantani sopra Lazzaro. D'ordinario alla base di tali molasse ed argille indurite azzurre trovasi un conglomerat. anch'esso bluastro, che sovente prende un considererole sviluppo, come puo bene osservarsi da chi percorre la via che da Vito conduce ad Orti, lungo quella ripich strada, che passa su d'una schiena elerata in mezzo a due orrendi burroni; si traversano successivamente e con ordine le direrse zone del quatermario e del plioceno,

(1) Vedi Michelotti, Fossili mivennici dell ullu Italia; Michelotli, Ëludes sun lo miocine: in-

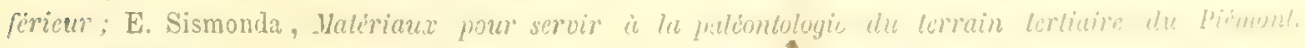
Seconde partie. 
pria di giungere al mioceno medio, ed allorchè si è perrenuti presso alla fine dell'erta saliti, si è già sul conglomerato che sta alla base delle molasse blu, ed è costituito di grossi ciottoli di rocce cristalline. In questi giacimenti non mi è riuscito sinora di raccogliere rerum fossile.

Rimpetto Stilo le molasse di cui parlai si elerano sino a circa 400 metri sul livello del mare; sopra Vito invece questa zona oltrepassa i 600 metri.

b) Conglomerato. - Un conglomerato molto potente forma la superiore zona di questo periodo miocenico; i ciottoli di cui esso risulta sono tutti di rocce cristalline, come di gneiss, pegmatite, siennite e principalmente di granito a piccoli e grossi elementi. Il volume dei componenti di questa roccia raria in tutti i modi, sino ad arere il diametro di m metro e mezzo, o d'ordinario alla base stanno delle semplici sabbie che per gradi passano al conglomerato, talrolta risultante da ciottoli tutti di grosso rolume, come accade di osservarlo presso Stilo, e spesso poi il conglomerato alterma con strati di arenaria.

Dorunque si oflre questa roccia è sovente ripidissima, orvero tagliata a picco; e bene spesso forma una serie di colline isolate e scerre di altro deposito, se se ne eccettui talora il plioceno che la ricuopre coi suoi strati marnosi o sabbiosi.

Vermo indizio di fossili mi fu dato di scuoprire in questa zona, che dovea necessariamente costituirsi sotto l'influenza di energiche azioni.

Lo sviluppo di questo conglomerato è molto considerevole nel Reggiano, ed è atfatto identico a quello riconosciuto in Sicilia siccome di eta miocenica $\left(^{1}\right)$. Esso si estende in una larga zona al di sopra dei piani precedenti nel territorio di Stilo (dove ho potuto seguirlo da oltre Guardaralle verso il monte Pellicciano, Camini, Riace ec.) costituendo il dorso di quella serie di colline che si dispone longitudinalmente, e forma un fianco della valle prodotta dall' erosione delle argille scagliose. Ho potuto rivedere la medesima roccia nelle colline sopra Siderno, nei monti sopra Portigliuola, S. Ilario, Condojanni, Ambuti, Ardore, e cosi via; ricomparisce essa al capo Spartivento ed al cano Palizzi, e poi rerso la marina di Bora. Sul lato occidentale piglia un grande sriluppo ed una regolare stratificazione e si alterna colle arenarie. Dal monte Gonia sopra Lazzaro si continua senza interruzione sino alle colline di Reggio, di Gallico e di Villa San Giovanni. Quest'insieme di strati che rappresenta tutto il mioceno medio pare che sul lato orientale della provincia non si elevi al di lì dei 550 metri sul lirello del mare; inrece al monte Gonia ra oltre dei 600 metri, ed assume una potenza di 200 metri o più.

Bene spesso accade nel Reggiano che la serie terziaria resti interrotta per difetto dell'Elveziano, del 'Tortoniano e del Messiniano, e quindi sul conglomerato di eui discorro poggia la formazione pliocenica. Quest'ultima, là dove è completa, porta alla base un conglomerato, spesso molto potente, che può facilmente confondersi col conglomerato langhiano; e quindi nel caso ordinario in cui la serie presenta la laguna soprulettil, riesce malagevole distinguere i due membri, che tanto somigliano per la litologica costituzione.

(1) (i. Seguenzal, Brevissimi cenmi intorno la seric tersiaria della movincin di Messina. 
Paleontologia. - I fossili del piano Langhiano qui appresso entmerati rengono dalle molasse di Stilo e di Guardaralle e sono quasi tutti, escludendone i foramiferi, in cattivissimo stato di conservazione ( $\left.{ }^{1}\right)$.

Elenco delle specie fossili
raccolte negli strati del piano Langhiano.

'Tipo. VERTEBRATI.

Classe. Mammiteri.

Nessun residuo.

Classe. Pescr.

Varie otoliti indeterminate. r. S.

Tipo. MOLLUSCHI.

Classe. Cefalopodi.

Aturin. - 1. A. Aturi Basterot (Nautilus). Di questa bella specie si è trorato un esemplare nel fondare le pile del ponte di Stilo, esso è posseduto dal prof. P. Mantorani. R. S.

Classe. Gasteropodi.

Seaphander. - 2. S. sublignarius D'Orbigny. = Bulla lignaria (Gratelonp) (non Lamarck) R. G.

Cypraca. - 3. C. a mygdal um? Brocchi. Un solo modello dubbio. R. G.

Itingicula. - 4. R. . . . sp. ? Un frammento specificamente molto dubbio. R.s. Diva. - 5. 0. cylindracea Borson. Un sol modello. R. G.

Amcillarda. - 6. A.glandiform is Lamarek. = Anolax inflata Borson, A. inflatu Bast. R. G.

Plos. - 7. P. polygonus Brocchi (Buccinum). Qualche modello. 1. G.

Porpura. - 8. P. elata Blainville. Un modello incompleto. R. G.

Cassis. - 9. C. saburo n Bruguière (Cassidea). Modelli incompleti. 1. G. V.

Fusus. - 10. F. glomoides Gené. Modelli ed impronte. r. G.

Fieula. - 11. F. elathrata Lamk. (Pyrula). c. G.

Xenophora. - 12. X. cumulaus Brongniant (Trochus). 1* G.

Vatien. - 13. N. Jos e p h ina Risso (Neverita). R. G. V. - 14. N. fusca! I) Blainville. Alcuni dubbî modelli. r.G. V. - 15. N. Dillwy n i i Palyraudeau. = Nacca fasciata Risso. R. S. T'.

viso. - 16. N. e burnea? Risso. Un grande modello dal quale riesce difficile il determinare se debba piuttosto riferirsi al N. Burdigalensis D'Orl. R. G.

(1) Ise localiti considarate nel seguente elenco sono Stilo S., Guarlaralle (i. 
Tumpordia. - 17. T'. Arohimed is Brongniart. r. G.

Turlur. - 18. T. carinatus Borson. r. S.

Truclaus. - 19. T. Michelottii n. sp. = T. Amodei Michelotti, D'Orbigny (non Brongniart). Questa specie ravicinata dal Michelotti a quella del Brongniart, hisogna che ne sia disgiunta. Essa è molto somigliante al $T$. rotellaris del Michelotti, dal quale dirersifica pel margine hasale meno rotondato, per la base alyuanto incarata nel mezzo, dore è una callosità molto più piccola, per le suture più profondate, pei cingoli rugosi e quasi granosi. Questa specie dunque i intermedia tra quella del Thehelotti ed il T. patulus, Brocchi. La specie del Vicentino d'altronde renne dal F'uchs rapportata al genere Turbo. R. G.

$$
\text { Classe. Scafopodi. - Ordine. Sorenoconchi. }
$$

Denralium. - 20. D. badense Partsch. c. S.

\section{Classe. PTERopont.}

Taginella. - 21. V. depressa Daudin. Questa specie quasi sempre compressa e mal conservata trorasi sparsa nelle argille grigie indurite, presso Stilo. Il prof. Mantorani la raccolse presso Reggio. c. S.

\section{Classe. Lamelibrancit.}

Tercho. - 2.2. T. . . . . sp.? Alcuni tubi calcarei spettanti a questo genere. ma specificamente indeterminabili, forse T. Norvegica Sp. x. S.

Nenera. - 23. N. cuspidata Olivi (Tellina). Rapporto con qualche dubbio a questa specie una impronta mal conservata. R. G. V.

solecuntus. - 24. S. . . . sp.? Un incompleto modello. R. G.

'china. - 25. 'T. serrata Brocchi. R. G. T. - 26. T. elliptica Brocchi. Un esemplare in cattiro stato. R. S.

Tenus. - 27. V. s cal a r is Bronn. Un cattiro esemplare. R. G. - 28. V. I u j a r d in i Hoernes. Aleuni modelli distinti per la forma, ma piì piccoli dell'ordinario. r. G.

Cytherea. - 29. C. pedem ontana Lamarek. R. S. - 30. C. erycinoides Lamk. c. G.

Dosinån. - 31. 1). exoleta? Limeo (Venus). Mal conserrata. R. G. V.

Carcilin. - :32. C. elongata Bromn. 1. G.

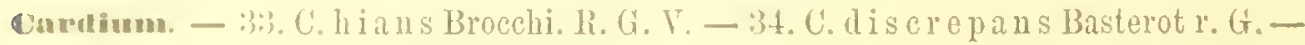
3... C. multicostatum Brocchi. C. G. - 360. C. taurinim Michelotti. R. G. 37. C. . . . . . sp.? Qualche frammento indeterminabile. I. S.

Axinus. - 38. $\Lambda$. angulatus? Sorrerby. Alemi modelli incompleti. $x$. G.

Lucina. - 39. L. columbella Lamarck. R. G. - 40. L. Agassizii Michelotti. r. G. - 41. I. Dujardini Deshapes. R. G. - 42. L. miocenica? Michelotti. Esemplari in cattivissimo stato. 1. G. - 43. L. spinifera Montagu (lenas). Var. hialclloides, R. G. V.

Ares. - 14. 1. Noe Limmeo. Un sol frammento guasto. R. G. V. - 45. A. dil uri i Lamarek. $r$. (i.

rectunculus. - 46. I. stellatus Gmelin. (Vonus). 1. G. V. - 47. P. inflatus? Brocehi (drea). Un modello molto dubbio. R. G. 
Vuenia. - 48. N. . . . sp.? Frammenti indeterminabili. R. S.

Pinna. - 49. P. Brocehii? D'Orbigny. Qualehe dubio frammento. R. G. 50. P. pernula Lamarck. Alcuni frammenti ben riconoscibili che sembrami non potersi disginugere dalla specie virente, $1 . G . V$.

cimea. - 51. L. Hoernesii n. sp. - L. strigilate Hoemes (non Brocehi). Tiav. VII. fig. 14.

Questa specie miocenica reme dall'Hormes confusa colla specie pliocenica, ma essa ne è perfettamente distinta. La descrizione nella fima dell'Elreziano. R. S.

Janira. - 52. J. Besseri Audr. (Pecten). r. G. S. - 53. J. Grayi Michelotti (Pecten). 1. G. S. - 54.J. 1. eroluta Michelotti (Peclen). ג. G. S.

55. J. subradiata 11. sp. Tar. VII. fig. 12.

Specie affine alla precedente ma molto meno convessa, appena costata. Sarì deseritta nella fauna dell'Elveziano. 1'. G.

Plenroncetia. - 56. P. cristata Brocchi (Ostrec). Frammenti. 1. G. S.

Dstrea. - 57. 0. tenuiplicata n. sp. Tar. XII. fig. 1.

Per la descrizione redi i fossili del piano Tortoniano. 1. G. S.

58. 0. Boblay Deshayes. 1. G. S. - 59.0...... sp? Frammenti indeterminabili forse di differenti specie. 1 . S.

Anomin. - 60. A. costata? Brocchi. Qualche dubbiissimo frammento. r. S.

Tipo. ARTROPODI.

Classe. Crostacei, - Ordine. Ostracont.

Cythere. - 61. C. Ha u e r i Reuss (Cypridina). Qualche esemplare ben caratterizzato per le fine e le grosse punteggiature di tutta la superficie.r. S.

62. C. subtrigona n. sp. Tav. VIII. tig. 2.

Per questa specie vedi la fauna elveziana e la torloniana R. S.

Tipo. VERMI.

Classe. AneluinI.

Serpula. - 63. S. . . . . spr.? Un solo esemplare indeterminabile. R. Gr.

Classe. BriozonRII.

Colleporaria. - 64. C. megalostoma? Reuss Alemi esemplari mal conservati perciò dubbî. r. S. - 65. C. polythele Reuss. (Cellepora). Come nell'aquitąniano $l^{\circ}$ G.

Cupularia. - 66. C. intel media? Michelotti. Rapporto a questa specie alcuni esemplari in cattirissimo stato, e quindi molto dubbî. r. G.

Tipo. ECHINODERMI.

Classe. Echinin.

Frammenti indeterminabili: fra questi alcuni spettanti al genere Clypeaster. r. C.... 
Tipo. CELENTERATI.

Classe. Axtozonrit. - Ordine. Zonxtarir.

Ceratocrathus. - 67. C. I a terocristatus Edwards et Haime (Trochocyathús). R. G. S. - 68. C. Tersicostatus Iichelin (Turbinolia). C. G. S. - 69. C. Ferrucosus Edwards et Haime (Truchocyathus). r. G. - 70. C. subcristatus Ldwards et Haime (Trochocyathus). R. G.

Trochocyarhus. - 71. T. pyramidatus Arichelotti (Turbinolia). R. G. 72. T. Bellingerii Edwards et Haime = Turbinolia Bellingheriana Michelin. 1. G. - 73. T. mitratus Goldfus (Turbinolia). Qualche raro e cattiro esemplare. IR. S.

74. T. Stilensis 11. sp. Tar. VII. fig. 4.

Polyparium conico-compressum, curvatum; basis attenuata, in totam longitudinem bi-vel tri-constrictum. Costae 48, prominentes, temuiter granulatae, maiores ninoribusque alternantes. Calix ellipticus, fossula parum profunda; columella e papillis compressis, confertis, numerosis constituta; septa tenues, lata, extus crassiuscula, gramulos crassos gerentes; paluli.....

Questa specie distinguesi bene per le costole prominenti, e pegli strozzamenti, or due ed or tre, che con costanza si osserrano sulla totale Iunghezza del polipaio; lo che gli dia l'aspetto di vari individui sorrapposti, come se l'uno si fosse sviluppato nel calice dell'altro. Il quarto ciclo non è sempre completo.

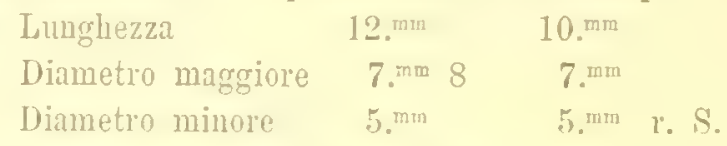

75. T. prismaticus n. sp. Tar. VII. fig. 3.

Polyparium prismalico-pyramidale, sexangulatum, compressum, curvatum. Costac sex angulosac, ceterae planatac. Calix exagonus, fossula profundata. Septa. lenues, exius crassiuscula, sex primaria prominentissima. Columella.... Paluli....

Questo Trochncyathus ì distintissimo per la sua forma di prisma esagono comjresso e curvo, dal clie ne risulta anco esagonale il calice. I tramezzi formano quattro cicli con pochi altri che iniziano il quinto.
Luughezza
15. nm (Base rotta) (Esempl. rotto)
Diametro maggiore
$9 . \mathrm{m}^{\mathrm{m}+\mathrm{n}}$
11.
Diametro minore
7. $\min$
6. $\mathrm{mm}$ r. G. S

Flabolum. - 70. F. atienla Michelotti (Turbinolia), r. S - 77. F. intermedium Edwards et Haine. r. S. - 78. F. extensum Michelin. r. G. S.

Corarotrochus. - 79. C. multiserial is Michelotti (Turbinolia). Un bellissimo esemplare. R. S.

Lupsummiat - 80. L. S ism ond ia na Miehelin (Turbinolia). c. G.S. - 81. E. compressa Michelotti. c. G. S.

Malnophyin. - 82. B. prat e longa Michelotti (Turbinolia). = Turbinolia cylinelrica Vichelotti. c. G. S. - 83. B. Meneghini F. Sismonda. r. S. 
Classe. Spongiamit.

CHona. - 84. C. falunica Fischer. Sulle ostriche. R. G. S.

Tipo. PROTOZOARII.

Classe. Rizopodi, - Ordine. Foraminiferi.

Yodosaria. - 85. N. a n o mala Reuss. Un esemplare incompleto. R. S. - 86. N. raphan istrum Limn. (Nautilus). = N. bacillnom Defince, D'Orbigny. I. S. V. 87. N. a cutecostata Silvestri. Due frammenti ben caratterizzati. R. S. 88. N. raphanus? Limeo (Noutilus). Un solo dubbio frammento. R. S. V.

Troudicularia. - 89. F. an un la ris D'Orbigny. Un sol dubbio frammento. R. S.

Dentalina. - 90. D. scabra Reuss. Esemplari corrispondenti assai bene alle forme rappresentate dall' antore. 1\% S. - 91. D. inermis Czizek. Esemplari alquanto più gracili.r.S.-92. D. pa u pe ra ta D'Orbigny.r. S. V. - 93. D. e legans D'Orbigny. Esemplari incompleti. r. S. V. - 9t. J). Scharbergana Neugeboren. Esemplari incompleti. c. S. - 95. D. Verneuillii D'orbiguy. R. S

Yomionins. - 96. N. scapha F. et M. (Nautilus). Esemplari ben caratterizzati. r. S. V. - 97. N. granos a D'orbigny. R. S.

98. N. formosa n. sp. Tar. VII. fig. 6.

Distintissima specie, finissimamente punteggiata, compressa, carellata, colla carena ottusa, rotondata, con un ombelico ben limitato, coll'ultima loggia rilerata al margine e colla faccia estrema triangolare, appianata, marginata. Ha qualche somiglianza questa specie colla mia N. subcarinata per la forma generale; ma questa manca di ombelico, ed invece ha la regione centrale prominente.

$$
\text { Diam. 0,3.mm Spess. 0,15.mm R. S. }
$$

Polystomella. - 99.P. su bum hilieata Czizek. R. S. - 100. P. Fichteliana D'Orbigny. R. S. V. - 101. P. erispa tumarck. 1. S. V.

Operculina. - 102. O. com p lanata Basterot. Un esemplare un po' dubbio. R. G. Vaginuliua. - 103. V. legumen Limeo (Nautilus). Due esemplari incompleti. R. S. V. - 104. V. badenens is I'Orbigny. Un frammento dubbio. R. S.

varginulina. - 105. M. ra pha un Lin. (Nautilus) var. parva. n. Forma piccola, appena incurrata ed ornata da acute coste longitudinali che si dispongono alquanto obliquamente, ed alcune si biforcano, r. S. V.

Cristellaria. - 106. C. . . . . sp.? Un esemplare rotto aftine alla C. concinna Reuss., ma le linee dei tramezzi si disnongono lasciando un'aria centrale. R. S.

Eobulina. - 107. R. rotulata Lamarck. (Lenticulites). Rapporto con qualche dubbio a questa specie ditersi esemplari di raria grandezza. 1 . S. V. - 108. R. cultrata Dorbigny. r. S. V. - 109. R. calear Gmelin. (Nautilus). Esemplari incompleti. c. S. V. - 110. R. imperatoria D'Orbigny. Nolto aftine e forse varietà della specie seguente. r. S. - 111. R. Vortex Ficht, et Moll. (Naulilus). r. S. V. - 112. R. a ustriaca D'orbigny. R. S. - 113. R. inoruata D'Orbigny. R. S.

Dolymorphina. - 111. P. digitalis D'Orbigny. Un solo esemplare alquanto 
diflerente dalle figure del D'Orbigny. R. S. - 115. P. a ustriaca D'Orbigny (Gutmelina). Un solo esemplare. R. S.

Uvagerơna. - 116. U. pygmaea Dorbigny. e. S. T.

Buliminn. - 117. B. Buchiana D'Orbigny. La forma molto comune che riferiseo a questa specie ne differisce alquanto per le sottili costole, che d'ordinario si estendono su tutta la superficic delli conchiglia. C. S. V.

Sphoeroilina. - 118. S. a ustriaca D'orbigny. Questa specie polimorfa presenti diverse delle sue numerose forme. C. S.

Pulvinulima. - 119. P. Partschiana D'Orbigny. R. S.

Itotadia. - 120. R. B e c carii Limeo (Noutilus). r. S. V. - 121. R. t e n u imargo Reuss. 1. S. - 122. R. a cul e ata D'Orbigny Var. Rapporto con qualche dubbio il questa specie un solo esemplare un jo' diverso dal tipo. R. S. - 123. R. praeeincta Karrer. c. S.

Orbulima. - 124. O. unirersa D'Orbigny. L̀ un solo frammento che virapporto. R.S.V. Globigerins. - 125. G. bulloides D'Orbigny. R. S. V. - 126. G. concinua? Reuss. Un dublio frammento. R. S. - 127. G. quatril oba D'Orbigny. R. S. 128. (t. triloha Reuss. 1\%. S.

Discorbina. - 129. D. solarium n. sp. Tar. VL. fig.9.

Elegante specie affine alla $D$. semiorbis Karrer, ma più appianata alla parte superiore, molto meno conressa dal lato opposto, e con varì particolari rappresentati nelle figure.

$$
\text { Diametro 0,7. }{ }^{\mathrm{mm}} \text { Spess. 0,18. }{ }^{\mathrm{mm}} \text { R. S. }
$$

Trumeatulina. - 130. T. Sel e ibersi Dorbigny. (Rotatina) r. S. - 1s'1. T. regularis Farrer. R. S. - 132. T. D utemple D'Orbigny (Rotalina). C.S. V. 133. 'T. Bad ens is Czizek (Rolalina) r. S. - 134. T. prop in qua Reuss. I miei esemplari sono per tutti i caratteri intermedi tra la forma tipica dell'antore e quella che ri rapporta Hantken. R. S.

135. 'I'. limbata n. sp. 'Tar. VII. fig. 7.

Afline alla Rotalina Ungeriana D'Orbigny, più conressa d'ambi i lati, collit depressione centrale appena accennata, e specialmente le logge formano un maggior numero di giri di spira, che sono naturalmente più stretti.

$$
\text { Diametro } 0,560^{\mathrm{mm}} \text { Spess. } 0,30^{\mathrm{mm}} \quad \text { r. S. }
$$

136. T. marginata n. sp. 'Tav. VII. fig., 10.

Afine allat precedente, eol margine più largo, colle logge dal lato superiore pii protuberanti, analogamente a quelle della $T$. hucida Renss ma meno oblique.

Diametro $0,4 . \mathrm{mm}$ Spress. $0,2 .^{\mathrm{mm}}$ R. S.

1:37. 'T'. B o ueana Dorhigny. Un solo esemplare. R. S. 1:38. 'l'. nu ue leata n. sp. Tar. VII. fige. S.

In qualche moto somigliante alla Rotalina Mortoni Reuss. ed alla Nonionina urnata Costa, colle logge più numerose, il margine rotondato, e porta un uncleo rotondato traslucido centrale sulla faccia inferiore.

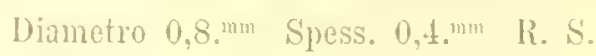

1839. 'T'. rariolata I)'orbigny (Anomalina). R. S. - 140. T. lobatula Walk, r. S. Y. - 141. T. commun is Roemer. R. S. 
Asterigerina. - 142. A. nlanorbis D'Orbigny. Qualche piccolo ed incompleto esemplare. R. S.

Siphonina. - 143. S. fimbliata Reuss.= Rotalina reticulate Czizek. r. S. Textilaria. - 144. T. carinata D'Orbiguy (Texheluria). Var. minor.n. Rapporto a questa specie una forma piccola, e sorente deformata, la quale somiglia a quella che vi riferisce Hantken, perchè manca di quei tali cordoni o rialzi che nella forma del D'Orbigny separano le logge. R. S.

Cassidulina. - 145. C. p unctata Reuss. x. S.

146. C. alata n. sp. Tar. VII. fig. 5 .

Questa Cassidulina è distintissima ner essere carenati e per Ia lamina che cinge la carena, siccome per la forma assai curva delle logge.

Diametro $0,40^{\text {min }}$ Spessore 0,22. . $^{2}$ R. S.

Cavulina. - 147. C. eylindrica? Hantk. Vi riferiseo con dubbio un solo frammento. R. S.

Plecanium. - 148. P. a b b reviatum D'Orbigny (Textularia). R. S. - 149. P. II aria D'Orbigny (Textularia) Var. inerme Reuss. Vi riferisco con qualche dubbio un solo esemplare R. S.

Emigenerina. - 150. B. nodosaria? D'Orbigny. L'mnico esemplare incompleto che lio raccolto è assai dubbio, essendochè nella parte inferiore parmi di forma più compressa del tipo a cui lo rapporto. R. S.

IBiloculims. - 151. B. a m p hiconica Reuss. R. S.

Quinqueloenlius. - 152. Q. badenensis D'Orbigny. Un solo e dubbio esemplare. R. S. - 153. Q. latidolsata Reuss. R. S. - 154. Q. concinna Renss. R. S.

Come risulta dal precedente elenco, le argille e le molasse soprastanti agli strati aquitaniani nella valle dello Stilaro racchiudono una fiuna costituita principalmente da coralli monastrei spettanti a specie ben note e proprie del mioceno medio torinese ('), a da Foraminiferi per la magrgior parte proprî del mioceno del bacino di Vienna e d'altri luoghi $\left({ }^{2}\right)$. Nella salita di Guardaralle ai molti coralli si associano i residui di molti molluschi, i quali confirmano i risultamenti a cui accenma la fauma zoofitologica. Difatti il mioceno medio di Torino $\left({ }^{3}\right)$, siccome il bacino di Viema $\left({ }^{4}\right)$ rachiudono quasi tutte quelle specie per la maggior parte caratteristiche del mioceno. II presso Stilo è da notarsi inoltre che le argille somo ricche di laginella; il quale fatto è segnalato dallo stesso Mayer siceome distintivo delle argille blu langhiane ('); è ben sicuro quindi che per la posizione stratigratica o per la fauna non $r^{\prime} h a$ dubbio di sorta intorno all'etit precisa di tale formazione.

Nella fauna precedentemente esaminata è da notare che il numero delle specie identiche alle virenti è già mroporzionalmente cresciuto. Si hamo infatti "ß1 forme tuttora viventi, dodici delle quali appartengono ai molluschi e diciannore ai foraminiferi: complessivamente si ha dunque il venti per cento di specie dei mari attuali.

Il potente conglomerato che sovrasta alle argille intieramente privo di fossili si

(1) E. Sismonda, op. cit. - (2) A. D'Orbigny, foraminifies du bessin de lienne; A. Reuss, Czizek, Karrer, Neugéboren, ecc. Opere varie e numerose. - (") G. Michelotti, Descriplion des forsiles ecc. -

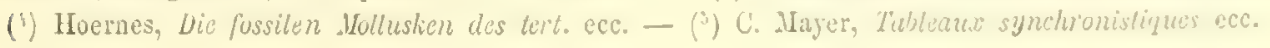


collega ad esse pel fatto che le accompagna dorunque; e poi sul lato occidentale della provincia si associano in tal modo, che riesce malagerole in taluni luoghi di trorare il limite delle due zone: laonde ho creduto convenerole di riunirle in unico piano, tanto piir she il conglomerato resta quasi dapertutto scerro degli strati elveziani posteriori, i quali si mostrano soltanto in luoghi speciali e molto ristretti.

Non posso trasandare intinto il fatto rimarcherole che osservasi in qualche luogo della provincia di Messina, cioè che i fossili del piano elveziano trovansi anco negli strati ultimi del conglomerato, che io qui, per ragioni stratigrafiche, associo al piano langhiano, lo che dimostrerebbe molta relazione tra questa roceia e gli strati elveziani. Tale fatto d'altronde non è che la conferma delle moderne idee intorno alle partizioni dei terreni in periodi, che le move scoperte ranno sempre meglio dimostrando siccome piì o meno sistematiche.

\section{Piano líteziano Mayer.}

Sinonimi. Mioceno medio (parte) degli autori. Secondo piano mediterraneo (parte) Suess.

a) Sabbie.-Quasi dapertutto, come gia ho accennato, il conglomerato superiore del mioceno mostrasi denudato da altro sedimento; e quindi per vaste estensioni nella morincia di Reggio la formazione miocenica si termina con questa zona; la quale sorente rieme poi ricoperta in discordanza dagli strati del più antico plioceno. Così presso Stilo, a Guardaralle, nei teritorî di Monosterace, di Riace, di Stignano, al Capo Spartivento, al Capo Palizzi ed in tutte le colline che si succedono lungo il lato occidentale tra Mnnte Gonia e Scilla.

Ia in taluni speciali Inoghi sul conglomerato compariscono potenti strati di sabbic fossilifere caratterizzate dovunque dai grandi Pettini, dai Clipeastri di forma elevata e piramidale, da abbondanti Eterostegine e da altri importantissimi fossili, che costituiscono una distinta fauna e ben caratteristica del piano miocenico che la racchiude.

Altrove manca del tutto la serie antica del mioceno sino al conglomerato langliano, e le sabbie fossilifere di cui discorro poggiano immediatamente sulle argille seagliose, come redesi evidentemente jresso Gerace alla contrada Pioca e presso Siderno a lialeo e Malnchia.

Queste sabbie seiolte ovvero leggermente cementate, fine o più o meno grossolane, hianclie orrero colorate in gialliccio, e raramente in brunastro, risultano da granelli quarzosi misti piu o meno a calcare e ricche di fossili, dai quali il calcare della rncoia derita.

Lo spessore di questi strati sabbiosi è rario, ma sempre poco considerevole, raggiungendo al massimo la potenza di circa quaranta metri.

b) Calcal c. - In taluni luoghi gli strati superiori di questo piano passano gradatamente ad una roceia calcarea jiù o meno compatta, ricca di modelli di bivalvi e di qualche gasteroporto; e non può a rero dire stabilirsi una precisa linea di demarcazione tra le sablie el il soprastante calcare, essendoche le prime d'ordinario si vamo carieando grado grado di calcite, finochè, quest'ultima predominando, la roccia diviene giù o meno resistente e talvolta proprio compatta, ma sovente anco cellulare e cavernosia per l'alteriatone e la distruzione di taluni dei fossili in essa racchiusi. 
A Benestare invece degli strati calcarei, o meglio soprastanti a strati sabhiosocalcarei, si osservano delle sabbie argillifere di color grigio-seuro, conservando i fossili stessi degli strati inferiori, e somigliando soltanto 'pel colorito alle argille tortoniane' fossilifere cui sottostanno. La zona calcarea di cui discorro manifestasi più o meno sriluppata e distinta secondo i varî luoghi, e lì dore sembra maneare, la porzione superiore delle sabbie, offresi sempre più carica di calcite.

Mentre in generale il piano elveziano manca nella prorincia di Reggio, perche vi fu quasi dapertutto denudato, in due ristretti territorî soltanto si mostra a priceoli lembi e staccati. Sul lato occidentale è specialmente sviluppato nel territorio di Monteleone, probabilmente sino oltre Francavilla, offrendo dovunque grande dovizia di variati fossili, ed estendendosi sempre a lembi disgiunti sino nel territorio di S. Giorgio MIurgeto. Sul versante orientale tali sabbie e calcari compariscono nel territorio di Gerace estendendosi considerevolmente dal lato nord e dal lato sud. In quest'ultima regione io ho potuto seguire il piano elveziano da S. Barbara presso Mammola ai Crudeli sopra Siderno, a Malochia, al colle di Falco messo Agmana, a Pioca sotto Gerace, ad Ambuti sopra Condojami e S. Ilario, poeo lungi da Portigliola e sino presso a Benestare. In tutti questi luoghi la roccia è ricea di fossili di tante diverse classi.

E utile dare un cenno dei caratteri e delle condizioni di giacimento dell'Flveziano nelle contrade dore ho potuto più o meno accuratamente studiarlo.

Nel territorio di Monteleone sono le sabbie che predominano, rariando considerevolmente nella diversa grossezza degli elementi che le costitniscono; esse divengono calcaree o marnose a norma dei luoghi e degli strati, o doruncue sempre ricche di fossili spettanti ai tipi dei Molluschi, dei Briozoi, degli Echinodermi, dei Rízopodi, tutti d'una perfetta conserrazione, predominandori in modo particolare i Peltini, le Terebratule, le Membranipore, le Lepralie, i Clipeastri di forma elerata, i Foraminiferi.

Sul lato orientale della provincia, a S. Barbara, i fossili vi sono scarsi e giacciono in seno alle sabbie più o meno cementate dal calcare. Alla contrada Crudeli sono sabbie fine e poco coerenti, che offrono qualche modello di biralve, qualche Clipeastro e numerose Eterostegine.

Il Colle di Falco e la limitrofe contrada Malochia offrono delle sabbie, che direngono calcaree alla parte superiore, e sono ricche di fossili, tra i quali sono importantissimi i resti dei Cetacei e dei Pesci, che si associano ai Lamellibranchi, ai Brachiopodi, ai Crostacei, ai grandi Clipeastri, ai Briozoi ed ai mumerosi Foraminiferi.

Le potenti sabbie che si estendono tra Gerace e la ralle a nord offrono piil rari fossili, ma di specie ugualmente caratteristiche, che in maggior copia racolgunsi in basso alla contrada Pioca.

Ed eccoci ormai alla contrada che io riguardo siccome la piu importante per lo studio dell'Elveziano. Nei monti che sorrastano Condojanni c S. Ilario havi ha formazione elveziana alla contrada Ambuti, che poco dista da Portigliola, giacenclo a sud-orest di quel villaggio; quel lembo di terreno sabbioso-calcarco offre grandu importanza per la dovizia di dati paleontologici non solo, wa ancorit e piì specialmente, perchè connettesi con strati sottostanti e sorrastanti che completano la scrie senza lasciare lacuna di sorta; it quale importante fitto non mi renne dato di osserrare sinora si precisamente in rerun altro luogo della provincia di lieggio. 
Alloriquando cominciava ad imprimersi il presente lavoro ed erasi gia litografata la tarola che rappresenta le piu importanti sezioni da me studiate nel Reggiano, io conoscera i molti fossili della contrada Ambutì, ma non area ancora esplorato la stratigrafia di quei luoghi; e quantunque fossi sicuro della posizione stratigrafica del piano sabbioso-calcareo di cui attualmente discorro, pure in verun posto mi era rinscito di constatare evidentemente le relazioni stratigrafiche tra le rocce elreziane e quelle che cronologicamente devono includerle.

Fu assai recentemente che mi venne dato di percorrere la ralle di Condojanni, esaminando le magnifiche sezioni che essa offre sopra ambo i suoi fianchi, ed in fondo, alla contrada Ambuti, la bella ed importantissima serie, che comprende gli strati elvezinu, e mostrasi completa dal Langhiano al Quaternario; cosa che manca in qualunque altro luogo del Reggiano, e sin nelle lunghe e piu complete sezioni della valle dello Stilaro, che ho scelto come tipo della nostra serie Cenozoica: difatti mancano ivi l'Elveziano, il 'Tortoniano, il Messiniano, e, come generalmente, il plioceno antico poggia sul conglomerato langhiano.

La sezione dunque della valle di Condojanni i destiunta a dimostrare e colmare la lacuna, che minifestasi quasi dapertutto, a completare le sezioni dello stilaro, e quindi la serie dei piani terziarî del Regogiano. Per cosiffiatta importanza ho creduto indispensabile di illustrare e di descrivere qui la sezione di cui discorro.

\section{Sesione lungo la valle di Condojanni}

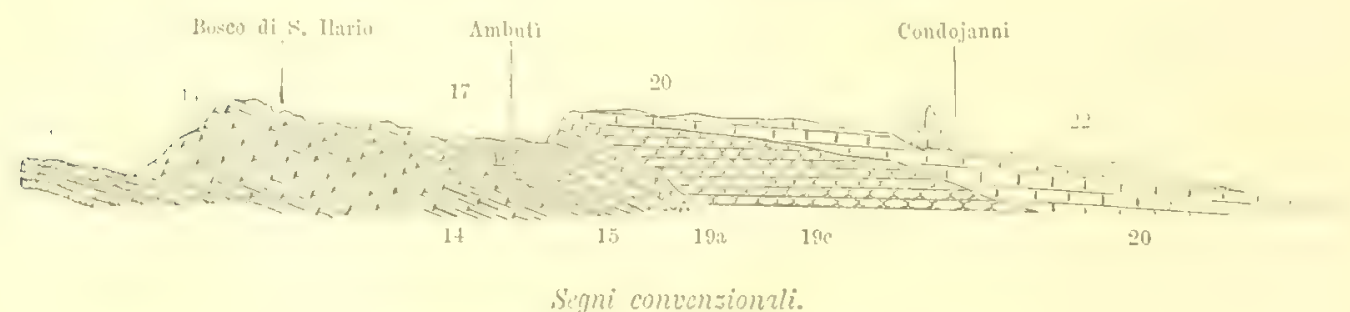

Segni convensionali.

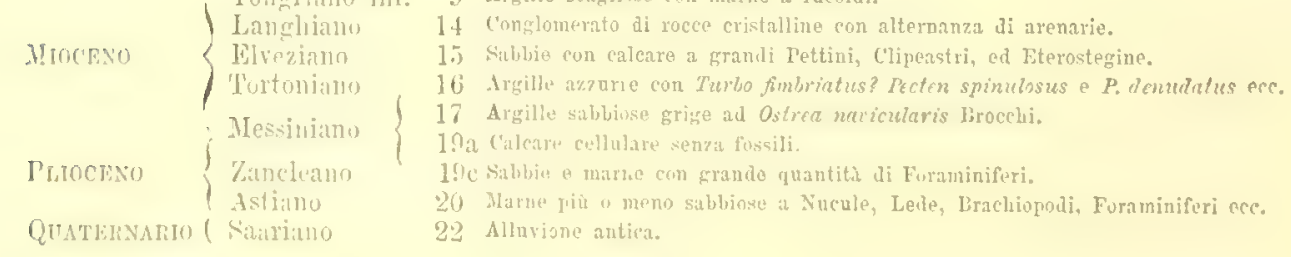

Nei territori di Ardore, di Condojami, di Gerace e nei limitrofi alla costa sucrode mil spianata jiù o meuo estesa, lia quale grado grado elevandosi si collega a basse collinette, dalle quali per successive e graduali elerazioni si passa ai monti, che indietreggiano tanto piir yuanto più vasta ì la pianura che suceede alla spiaggia.

Lal valle di Condojitnni shocéc abbastanza larga nella pianura, e presenta in tutta la sua lunghezza sino alla contrada Ambuti, dei restringimenti poco rimareheroli. Lat magrior parte di tale estensione i incassata nelle mane del plioceno, fiancheggiata in basso dia loggetti e da dimesse colline. Mano mano che s'interna, i fanchi si elerano sempere piu, le sezioni divengono grado grado piì ripide: cosi Condojanni 
situato sulla sinistra, si elera 130 metri sull'alveo del torrente, le marne dell'Astiano costituiscono quel poggio e tutte le colline sottostanti dall'mo e l'altro lato della valle, coronate qua e li dall'alluvione quatemaria. Piì in alto il colle che succente a Condojanni forma dal lato della valle un taglio ripidissimo, quasi rerticale, che si eleva pressochè 300 metri sull'alveo, ed offre quasi intiera la serie degli strati manosi e sabbiosi dello Zancleano, sormontati dalle mane astiane, che da quelli elevazione si estendono con lieve declirio sino alla pianura.

Continuando l'ascensione della valle, al termine della formazione pliocenica mutasi considerevolmente $1^{9}$ orografia, ed ai ripidissimi tagli del terziario superiore succede sull' uno e l'altro lato una rimarcherole depressione, due rere ralli secondarie, che mettono in bella eridenza la snccessione stratigrafiea dei piani, che in ordins discendente succedono al plioceno.

Tale serie molto importante è quella che attualmente ci rivuarda, e che può esaminarsi dettagliatamente inoltrandosi nella depressione che sta sulla sinistra della ralle alla contrada Ambutì. Quivi inoltrandosi, osservasi sulla destra come le mame plioceniche mostrano in alto le loro ultime testate, che si estollono ripidissime poggiando sopra una considerevole massa di calcare concrezionato; quello stesso che sotto l'antico plioceno trorasi tanto sriluppato presso Gerace. Questa roccia, jrira alfatto di fossili dorunque si presenta, si associa per rarie ragioni al mioceno.

A costituire la parte più elevata di quella depressione sporgono da sotto il calcare concrezionato delle argille grigie sabbiose, che contengono pinttosto abbondantemente ed in grandi esemplari l'Ostrea navicularis Brocchi, la specie che anco da se sola caratterizza alcuni strati argillosi soprastanti al Tortoniano presso il villaggio di Benestare. Ad Ambuti il gesso nou si fa redere, ma le argille ad Ostrec raprresentano indubitatamente il Messiniano. Difatti a questa roccia succedono delle argille azzurre meno sabbiose, che si estendono sul lato destro di quelia depressione e rerso la media altezza, e che sono scarsissime di fossili, avendori potuto raccogliere con molta parsimonia gli opercoli del Turbo fimbriatus? Borson, il Picten spinulosus v. Munster, il Pecten denudatus Reuss, la Pleuroncctia cristata (Brocchi), la Janirat calabra n. sp., l' Ostrea navicularis Brocchi, la Terebripora Archiaci Ficher. 'Tali specie troransi tutte nel Tortoniano di Benestare, delle quali le prime tre e la Janiru sono caratteristiche del mioceno.

Dal limite interiore di queste argille, indubitatamente tortoniaue, sino alla valle, la depressione della contrada Ambuti, ci oflre delle sabbie gialle piì o meno agglntinate e calcarifere, che si estendono sulla destra, e ricehe di fossili passano nelle assise superiori ad un calcare tenero e grossolano. I grandi Clipeastri di forma piramidale, i larghi Pettini siccome i piccoli, le Ostriche, i Brachiopodi, i mumerosi Briozoi ed i Foraminiferi spettano a quelle stesse specie che caratterizzano nelle rarie altre localita i diversi lembi di terreno coetaneo.

Sulla sinistra della depressione si vedono delle arenarie, sulle quali pogrgia la formazione elveziana, e quindi succedono ripide colline soleate da profondi burroni. e costituite da un potente conglomerato di ciottoli cristallini, che si ustende yel' lungo tratto formando monti elevati, come il Boseo di S. Ilario e i circostanti poggi. È questa la roccia che sovrasta alle argille langhiane, come vedesi atsai bene 
Lungo la ralle dello Stilaro, o nelle serioni 1. " 2.2 che la rapmesentano, e le accompagna dapertutto. Questo conglomerato privo sempre di fossili, come è naturale, renne dil me alssociato alle argile Inghliane perchè vi si comette, ed invece nel Reggiano vedesi gencralmente affatto denudato dagli strati clveziani; quantunque in talumi Inoghi di Sicilia tale conglomerato faccia graduata trausizione agli strati elreziani (i) ssiliferi.

Dopro arer traversato lia potente serie di colline costituite dal conglomerato, l'alreo del torrente s'incurva rerso sud-est, prendendo nel tratto susseguente una direzione pressochè perpendicolare alla prima, e lambendo colla destra le falde degli alti monti di conglomerato; wentre sulla sinistra si estende una rasta depressione, costituita come dordinario dalle argille seagliose del l'ongriano e del Liguriano, le quali costituiscono delle raste spianate, dei poggi a liere declirio, dei falsi piani dove ergonsi i due comuni di Ciminà e di Cirella.

Tra queste formazioni ed il conglonerato esiste una cousiderevole lacuma: mancano infutti le argille langhiane, tutto il piano aquitaniano ed i membri superiori e piii importanti del Tongriano.

Cosi la valle di Condojanni mostrando in bell'ordine la serie dei piani terziarî dal Sarriano al Langhiano, cioè della meta superiore dei terreni cenozoici, diviene di una grande importanza per la geologia del heggiano, che in questa serie superiore mostra dapertutto una rimarcherole lacuma.

La sezione di Condojami dunque è qui ammessa per non aver trorato posto nell'Atlante gia litografito, e perché bisognava al ogui modo assegnargliene uno pel la sua grande importanza.

Ni resti a dire finalmente di un'altra interessantissima località presso Benestare. Ivi le argille tortoniane sono ricehe di quella fauma tanto caratteristica che le distingrue, da rendere celebre il luogo. Sotto gli strati tortoniani si stendono delle sabbie grigie superiormente, e poi gialle e molto calcarifere. Qui dunque all' Elveziano si sorrappone il piano tortoniano come ad Ambutì.

Gili strati elveziani si elerano jroco sul lirello del mare, a Benestare come ad Ambuti, ed al colle Falce raggiungono orvero oltrepassano di poco i 200 metri.

Dalle cose predette risulta ad evidenza che il piano elveziano nella provincia di leggio, quantunque siavi dapuresentato da lembi staccati e ben poco estesi, pure oflire sin nelle fii lontane contrade una grande uniformita di caratteri litologici, che rengono ad associarsi dordinario agli stessi caratteri palcontologici, siccome risulta dal segruente clenco spevifico. Sono sempre dunque delle sabbie più o meno leggermente cementate, e variamente cariche di calcite e di fossili. Passeremo ora ad esaminare l'importantissima fauna, una delle più caratteristiche, offertaci dal mioceno in unesta estremil provincia italiana.

Pulconlologia. - La fauna elveziana adungue, quasi dapertutto uniforme, ispira mo grande interesse per le numerose specie caratteristiche di eni in gran parte si complone. Fassa ci oflie tra i Vertehrati taluni Mammiferi e i resti di numerosi Pesei che incontransi quasi in tutti i luoghi dove I'Heziano alliora; dei Molluschi sono talume poche limiglie che specialmente vi predominano, e le altre o vi mancano del 
tutto o vi hanno qualche raro rapnresentante; in generale ri sono scarsissimi i Giasteropodi e tra i Lamellibranchi ri abbondano i Pettinidi; dei Brachiopodi due specie redonsi quasi dapertutto.

Sono molto importanti, quantunque poco comuni, talune specie di Entomostracei di Cirripedi e di Anellidi.

La classe dei Briozoi acquista un interesse stragrande nell'blyezimo calabrese. per la numerosa rarieta delle forme earatteristiche che trovansi in mezzo alle cento specie che ri ho riconosciuto ( $\left.{ }^{2}\right)$.

Gli Echinidi sono rappresentati da grandi e variate forme di Clipeastri, che calratterizzano dorunque questo piano. I Coralli vi maneano quasi del tulto. I Foraminiferi invece ri sono dapertutto profusamente sparsi.

Quanto al modo di conservazione di tante ricehezze palcontologiche, notasi una grandissima differenza a seconda delle classi cui spettano. Cosi i denti dei Vertebrati vi somo conservatissimi, come tra i Molluschi le Lime, i Pettini, lo Ostriche, le Terebratule ecc., mentre i Gasteropodi e tutti gli altri Lamellibranchi sono stati completamente distrutti, ed è molto se nella roceia calcarea vi troviamo taluni modelli ed impronte, alle quali deresi la ricognizione delle poche specie enmerate nel seguente catalogo. Gli Entomostracei, i Cirripedi, i 13riozoi. gli behinidi ed i Goraminifori invece ri sono d'una perfetta conservazione.

I fossili enumerati nellelenco segnente sono stati ritecolti in rarie localiti, che verranno indicate coi segni convenzionali qui appresso stibiliti. Ambuti (Am), Benestare (B), Gerace (Contrada Pioca) (G), Malochia (Ma), Faled (F), Crudeli (C), S. ${ }^{a}$ Birlbara (Ba), Monteleone (ML).

Elenco delle specic fossili raccolte negli strati del piano liviveziano.

Tino. VERTEBlid'T.

Classe. Mlammarer. - Ordine. Cetacei.

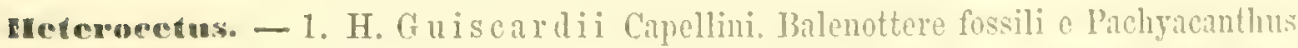
dell'Italia meridionale (Atti r. Aecademia dei Tineei 1876-1877) Tar. I. fig. 1-1\%. Questa importante specie di misticeto mi ha offerto ma cassa timpanica alquanto mutilata, spettante all' apparato auditivo destro, aflattn identica a quella rappresentata dal prof. Capellini, che insieme a rarie altre parti dello scheletro conservasi nel gabinetto geologico dell' Unirersiti di Napoli. Ii osso timpanico da me rinvenuto è alquanto più piccolo di quello illustrato dal Capellini; esso fur raccolto alla contrada Falcò nel territorio di Gerace, assai presso Sideruo superiore, di unita a molti frammenti di ossa mobihilmente spettanti allo scheletro del medesimo individuo. Lo scheletro posseduto dall'Unirersiti di Napoli ì stato raccolto presso Briatico, sul lato oceidentale della provincia di lieggio.

(1) I Briozoi e i Foraminiferi dell Elveziano della provincia di Regrgio e di tutti i piani seguenti, nonchè formar parte degli elenchi paleuntologici di unico lavoro, somministano suntelenti materiali per tante monografie distinte, di cui gli attuali clenchi non suno che i corrisponlenti sagsi. 
Altri ossami spettanti ad una Balenottera conservansi nell'Unirersita di Napoli e furono raccolti a Briatico e Pizzo. Il Capellini riferi quei resti al Plesiocetus Guropii Van Beneden, ma sconoscesi tuttaria a quale orizzonte spetta la roccia che li scmuministrò: è forse la elreziana stessa, orvero altra di piu recente età? R. F.

Ealacodelphis. - - . P. minutus Du Bus (') Mummiféres nouveaux du Crag d'Invers, Gernais et Van Beneden Ostcographie des Cétacés viv. et foss. p. $330^{\circ}$ tar. XX. fig. 22 e 23.

Qnestia specie può dirsi reramente caratteristica degli strati elveziani della provincia di Reggio, dappoichè nelle brevi ricerche paleontologiche da me fatte nelle varie contrade ho trorato i denti spettanti a questo cetaceo in tre distinte locaLiti, cioc a Malochia, a Faleo e ad Amlsuti, e probatilmente appartengono agli stessi indiridui i rarî e mal conserrati ossami raccolti di unita ai denti. r. Am. Ma. F.

Glasse. Pesci. - Ordine. Tereoster.

IBachyrlnyeus. - 3. B. teretipostris V. Beneden Recherches sur quelques poissons fossiles de Belgique (Bull. Acad. I. de Belgiqune 2e série, tom. XVI. 1071). 'Tra i rarì ossami che ho sottoposto all'esame del prof. Capellini fu da lui trorato un frammento di rostro spettante a questa specie; la quale, scoperta nel Belgio, oggi es stata rinrenuta in Toscana ed a Lecee, siccome gentilmente comunicavami per lettera il sullodato professore. R. F.

\section{Ordine. Controtterigil.}

Carcharalon. - 4. C. productus Agassiz. Vi rapporto un grande esemplare da S. Bariara presso Mammolia conserrato nella collezione del dott. De Mujà da Siderno; altri grandi esemplari insieme ad alcuni brevi e larghi, come quelli rappresentati dall' Agassiz nella tar. XXX. fig. 2 e 8 appartenenti ai lati mascellari furono da me raceolti a Malochia ed a Faleo r. Ma. F. B.

Oxyrhina. - 5. O. hasta lis Agassiz. Un solo esemplare mal consertato. R. Ma. 6. O. trigonodon Agassiz. Dne belli e ben conservati esemplari, molto somiglianti a ruelli figurati dall'A gassiz. R. MIa. H. - 7. O. x s p ho d o n Agassiz. Varî esemplari senza radici, alcuno di essi considererolmente convesso sulla parte medesima delia fíccia estema. r. Ma. F, - 8. 0. cras a $\Lambda$ gassiz. Riferisco prorvisoriamente a questa specie un grosso dente, piu grande di quello figurato dall'Agassiz, proporzionalmente più grosso e piu breve, ma che somiglia benissimo in tutti gli altri caratteri, sobbene il seno tra i rami della radice sia più profondo nell'esemplare calabrese. Il rinvenimento di altri esemplari somiglianti potra determinarei alla separazione di questa forma dalla specie di $\mathbf{\Lambda g a s s i z . ~ A n c o ~ q u e s t o ~ d e n t e ~}$ raceolto presso Ardore conserrarasi nella collezione del dott. MI. De Miuja. R. B. 9. O. tumidula Costa. Questa specie i ben distinta per la considerevole conressitit della laccia esterna dei denti; di essi ho raceolto varî esemplari della parte anteriore a delle laterali, lutti ben caratterizzati c. Mra. F.

(1) L'chregio sig. lrof. cumm. G. C'apellini ha esaminato e determinato i resti spettanti a questa (1) alli precelente specie, dol che gli faccio publolici ringraziamenti. 
camna. - 10. L. crassidens Agassiz. Un solo mal conservato esemplare. R. Ma.

Ddontaspis. - 11. O. d u bia Agassiz. Vi riferisco vari denti alquanto tra loro diversi per rapporto alla forma, probabilmente pel direrso posto che occuparano nelle mascelle, e colla superficie priva di strie. 1. F.

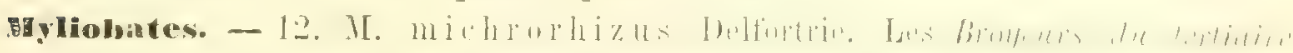
aquilanien (Actes de la Société Limnèenne de Bordeanx. Tom. XXYIr. 29" liv. pag. 15 tar. X. fig. $37 \AA, a, b)$.

Rapporto a questa specie una piastra dentaria inferiore alquanto mutilata ed erosa, la quale fu esaminata dal sig. car. Roberto Lawley e dal sig. mrof. Arturo Issel, i quali furono concordi nel riconoscere in questo fossile il $1 \%$. michrorhizus ed entrambi gentilmente vollero commicarmi le loro 0sservazioni. R. Am.

Detoluares. - 13. O. Seguenziae R. Lawley (M. S.) in lettera 23 agosto 1877. Tar. VII. fic. 11. 111, 11\%.

Di unita alla placea dentaria della precedente specie ho raceolto contemporaneamente la piastra inferiore dimezzata ed crosa, che rappresento nell' Atlante e che il car. R. Lawley ebue lia cortesia di studiare. Egli la rapportara al genere Octobates e riguardara siccome nuova specie, che mi dedicava. Invero il solo incompleto esemplare sinora raccolto è in troppo cattiro stato per renire descritto; mi limito quindi a darne per ora alcune figure, sperando che la scopertia d'individui migliori renga tosto a darmi l’agio di fornire una completa deserizione. R. Am.

Nei vari giacimenti dell' Elreziano della provincia di Regrio si raceolgono ancora varie forme di otoliti, che restano specificamente indeterminate.

Tipo. MOLLUSCHL.

Classe. Gasteropod.

Conus. - 14. C. Hoernesii Doderlein - C. Ahrovandi Hocrnes (non Brocehi) R. Ma. - 15. C. fuscocingulatus? Brom. Un dubbio modello. R. M.

meilaria. - 16. A. glandiform is Lamk. =- Anolax inflate Borson. Modelli ed impronte solamente. c. Am.

Dniseia. - 17. O. eithara Brocehi (Buccinum $)=0$. cithara Sowerby. Una solit impronta ben riconoscibile. R. Am.

Turritella. - 18. 'I'. Arehimedis Bronginiart. Riconosciuta da impronte nellit roceia calcarea. r. $\mathrm{Am}$.

'Trochus. - 19. T. rotellaris Michelotti. Inmonte e modelli nel calcare. 1 . Am.

Classe. Limetitbrineth.

Psammobia. - 20. P. uniradiata Brocchi (Tellina). NLodelli nella roccia calcarea. 1. Am. Ma.

Tellina. - 21. T. tumida Brocehi. Un modello incompleto. Qutestir specie è comunissima nel calcare a modelli del Messinese. R. Ma.

venus. - 22. V. Haueri Hoernes $=1$. dglaurce Hoemes (non Corbis Agluarac

Brongn.) Comune nell'Elyeziano messinese. R. Am.

23. V. insign is n. sp. Tar. VIIL. fig. 1. 
Questa grande specie è stata incontrata sinora nell'Elreziano sotto forma di modelli assai grandi, analoghi a quelli che stole offrire la precedente. Le impronte esteriori siccome gli esemplari incompleti, mecolti nel Tortoniano, dimostrano come sia una distintissima specie per la diversa scultura; difatti la superficie delle ralve oftre delle costole spianate concentriche, le quali sono disginute dia solchi profondi pressoche di ugual larghezza e forniti da varie lamelle alquanto rilerate e parallele alle costole; quest'ultime presentano inoltre delle lierissime pieghe che inradiano dall'umbone. Lo spessore delle ralve è assai grande, il margine ì interiamente dentellato.

Lunghezza 105. mar Larghezza 85. Spessore 65.mn r. Am. Ma. F. 24. V. multilamella Iamk. R. Am. V.

Clnma. - 2̆. C. austriaca Hoernes. Dne piccoli modelli ben riconoseibili. R. Am. - 26. C. gry r hoiles r. Am. V.

Cordita. - 27. C. Jonanneti Basterot. Trovasi d'ordinario in forma di modelli. 1. Am, B. G. Mil. F. Ba. - 28. C. pudista Lamk. Rapporto con qualche dubbio a questir sprecie un modello un po' gibboso. R. Am.

Cardium. - 20. C. d is e re pans Basterot. Grandi modelli. r. Ma. C. - 30. C.hians Brocehi. Un sol modello R. Mi. V. - 31. C. turon i cum Mrayer. Alemi modelli r.Am. IIa. - B. C. C.multicostatum Broe. r. G. - 33. C. fragile? Broc. R. Ma.

Area. - :34. A. umboula tamarck. Varì modelli. 1". Am.

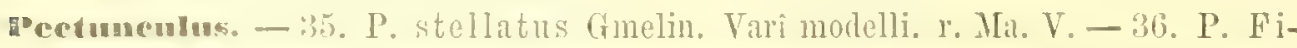
ehteli Deshayes. Rapporto a questa specie numerosi e grandi modelli. c. Am. B. Mr. Ba.

Limen. - 37. L. subauriculata? Montagu (Pecten). Vi riferiseo un piecolo frammento molto dubbio. R. B. V. - 38. Is. strigilata Broçhi (Ostrea). Varî esemplari incompleti, che rispondono pure esattamente alla specie del Brocehi propria del plioceno. 1. B.

39. L. Hoernesii n. sp. = L. strigilate Hoemes (non O. strigilala. Brocchi). 'Iar. VII. fig. 14.

Basta osserrare le figure dell'Hoernes, da lui date per rapresentare la specie del bacino di Viemna, riferita alla specie del Brocehi, per convincersi che quella differisce considerevolmente dalla specie pliocenica; la quale ha costole radianti molto più mumerose, assai sottili, ed appena rilevate, laddove nella specie miocenied le costole sono distintissime, prominenti ed in numero di gran lunga minore. I miei esemplari rispondono esattamente alla specie di Vienna.

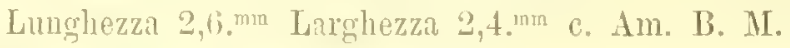

Decten.-40. I. s c a buellus Lamarck. Questa comunissima specie presenta numerose variazioni, alcune delle quali credo che sieno state riguardate siccome distinte specie. l'Ostrea dubia del Brocchi è probabilmente la stessa forma. C. Am. B. MIa. I'. Ba. M. - 41. P. substriatus D'Orbigny. Rare impronte. R. Am. B. 42. 1. similis Iaskey. $=P$. pullus Cantraine, P. pygmaeus anct. (non v. Munster). $1, \Lambda m . V$.

Jumina, - 4:3. T. 13esseri Andrzejowski (Pecten) = Pecten arenicole Eichwald, P. Angelicae l)ubois de Montperenx. Questa specie molto comune nell'ilveziano 
delle Calabrie, oftre ivi esemplari giganteschi, considererolmente piir grandi dei maggiori illustrati dall'Hoermes. C. Am. B. G. Ma. F. C. Ba. M. - 44. T. B endanti Basterot (Pecten). Questa specie si raceoglie abbondantemente ed in ottimo stato di conserrazione di unita alla mecedente. C. Am, B. Ma. I. M.

45. J. Gray i Michelotti (Pecten). I pochi esemplari raccolti rispondono con alcuni tipici della Superga. r. B. Ma, - 46. J. xevoluta Michelotti (Pecten). Io rapporto a questa specie un solo esemplare, il quale comparato cou alemi della Superga vi risponde esattamente, e solamente è alquanto mono gibboso. R. Mir.47. J. Rollei Hoernes (Pecten). r. Am. Ma. M.

48. J. Calabra.n. sp. Tav. VII. fig. 13.

La specie che io propongo sia distinta con questo nome, molto somiglia alla J. revoluta Nich. ed al $P$. Felderi Fuchs, e pei suoi varî caratteri sembrami intermedia tra le due. Sulla valva inferiore le larghe costole sono aprena distinte da un solco superficialissimo o meglio da una semplice linea, c meglio appariscono al margine rentrale della conchiglia e ramo sraneudo gradatamente rerso la regione cardinale, sulla quale per considererole spazio mancano affatto, sicenme difettano sui lati anale e boccale. I' apice è meno gibloso e rivoluto di quello della J. revoluta, nè sporge, o poco, oltre il margine cardiuale. Lat raltra superinere è alquanto concara, le costole radianti sono cirea docici, ben distinte, alpiannte, disgimnte da spazî ngualmente larghi e ramo stanento rerso la regione cardimale, dore all'apice redesi una lieve gibbosità. La superficie è ornata da esilissime strie concentriche rilevate e più distinte presso il margine.

Lunghezza 40. ${ }^{\text {mm }}$ Larghezza 44 . $^{\text {mm }}$ Spessore $26 .^{\text {mm }}$

Questa bella specie trovasi ben conserrata e talrolta colle valve rimite. C. Am. B. Ma. M.

49. J. subladiata n. sp. Tay. VII. fig. 12.

Questa specie si avvicina anco al P. Felderi Fuchs per Ia mancanza quasi completa di costole sulla valva inferiore, la quale intanto è ben poeo convessa a fronte della specie del Fuchs: il suo umbone non sporge al di lit del cardine, le costole non si offrono che sotto forma di lierissimi indizî appena percettibili soltanto in aleuni individui, ed ugmalmente su tutta la valva; la ralva superiore è appianata e leggermente conressi, colle costole circa al numero di seclici, ben distinte presso il margine, seblene poco sporgenti e quasi appiamate, che svaniscono gradatamente rerso la regione cardinale. In ambo le valre la superficie interna è ornata da sottili e prominenti costole disposte per paio siccome nel $P$. cristatus.

Oltrechè la forma poco convessa fa distinguere questa dalle sprecie aftini, la convessità delia valva superiore, la forma ovato-rotondata la differenziano dalliz precedente, che ha concava la ralra superiore ed è piì larga che lumga.

Lunghezza 45. mm Larghezza $4.0^{\mathrm{mm}}$ Spessore 15 .mm

Questa distinta Janira reme da me raccolta a valre disginnte. 1. Am. 13. 50. J. pumila 1. sp. Tav. XI. fig. 56.

Questa specie passa dall Elveziano al Tortoniano; per la sua descrizione redi le specie tortoniane. C. Am. B. II. 
Plemoncerta. - 51. P. cristata brocchi (Ostrea). Raramente raccogliesi intiera, dordinario incontrasi in frammenti. r. Am. H. Ma. - 52. P. fenestrata Forbes $($ lecten $)=$ P. inacquisculplus Tiberi, P. Ihilippii Acton, P. Acloni r. Iartens, P. concentricus Forbes, $P$. antiruatus Plilipii. Qualche frammento ben riconoscibile. R. MI. $V$.

unmites. - 53. H. tenu is n. sp. 'T'ar. VIl. fig. 15.

Testa parve, lenuis, subcuneata, valve inferior tola alnata, valva superior cotus concentrice strialo-sublamellose. ariculis inaequalibus.

Qnestir specie ì veramente rimarchevole per essere considerevolmente inequilatera: dall'un lato le orecehiette sono tagliate si obliquamente da formare quasi nima retti col margine della conchiglia, mentre poi al margine opposto, al di sotto delle orecchictte, trotasi una forte sinuositi.

\section{Lunghezzal 15.m Larghezza 15. mm}

Li unico a completo esemplare raceolto è fisso nell'interno di una ralva di lecten sertirellus. R. Am.

spoudylus. - 54. S. crassicosta Lamarck. Un modello interno ed aleuni frammenti, 1. Am. Nar.

Ostren. - nis. (1) navicularis Broccbi = Ostrea Pillue Meneghini, 0. cochlear rar. Hocrues. Questil specie giunge talrolta a grandezze molto considereroli e sovente acquista una grande solilita, presentandosi sempre in individui isolati, ele jortano la fiussetta ligamentare disposta pressochè verticalmente, laddore l'O. cochlear is agreregata e collit lossetta orizzontale. c. Am. H. G. MI. - 56. 0. Boblayei Deshayes. Si racengono grandi esemplari ed intieri. r. Am. G. Ma. - 57.0. p l icatula Cimelin. Pami alquanto diversa dalla specie virente. r. Am. Ma. V.

58. (). tenuiplicata n. sp. 'Tar. XIl. fig. 1. Vedi l'elenco delle specie tol-

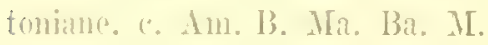

59. 0. acuticosta 11. sp. Tar. XII. fig. 2. Trorasi in belli esemplari nel Tortoniano. Yeeli quelle elenco prer la descrizione. r. B.

Aamiar. - bo) L. costata Brocehi. r. Am. - 61. A. striata Brocehi. Piccoli esemplari ma ben caratterizzati. c. Am. B. M. - 62. A. patelliformis Limneo. Un solo ben caratterizzalto esemplare. R. Am. V.

Classe. Blischopon!.

Terelorantula. - 6i3. 'T'. Costa e Segnenzil = T. sinuosa (parte) Davidson, T. bipliculu Custa, Jhilipli, (non Sowerhy). Questa specie curatterizza in Calabria il jiann alseziann, e non trorasi mai in altri orizzonti greologici. Per equiroco, nel mio laroro sui Brachiopodi terziarî dell'Italia meridionale, ho riguardato questa sircome specie pliocenical. 'Trovalsi commemente insieme alla seguente Rhyncho. nolle in qualsi tutte le localitit. Ise varieta dilatala e planala sono commi, la rar. insignis is molto litrit. c. Am. H. (t. Ma. F. 13a. M.

Cistonu - 0.1. C. costulata Sechenza (Argiope). Un solo esemplare ben conservatu e completer. R. I3.

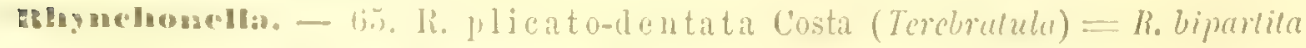

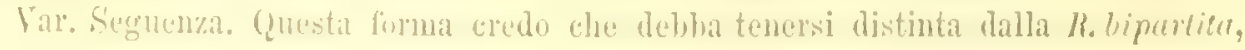


essa è costantemente più piccola, ha il seno rentrale molto meno profondo, e porta delle pieghe più o meno prominenti ed estese, le quali talvolta in certi individui tendono a scomparire, e percio sono appena accentiate sul margine rentrale. c. Am. B. Mra. MI.

Tipo. A RTROPODI.

Classe. Crostacei.

Dei crostacei superiori in questo piano nou s'incontrano clre rari frammenti indeterminabili.

Ordine. Osrricont.

IBairdia. - 66. B. subdeltoidea r. Munster (Cythere) $=$ B. subleloidea Jones. Questa specie è senza dubbio di sorta l'ostracode più comune che incontrasi nell'Italia meridionale, esso traversa benanco molti piani e trovasi tuttavia virente' nel Mediterraneo. c. Am. B. Ma. AI. V. - 67. B. areuata r. Munster (Cythere) = B. arcuata Bosquet. Alcuni esemplarí ben caratterizzati raccolti in una sola località $x$. B.

Cythere. - 68. C. plicata r. Munster. Ma. - 69. C. plicatula Reuss (Cytherina). Questa specie presenta direrse rariazioni. 1. Ma. - 70. C. similis Reuss (Cypridina). Rapporto a questa specie un solo e completo esemplare. 71. C. subtrigona n. sp. 'Tav. VIII. fig. 2.

Questa specie per la forma generale soniglia molto alla C. Francquuna Bosquet, ma è più ristretta posteriormente, non troneata ma rotondata e con lievi indizi di dentelli; il margine anteriore porta cinque dentelli piì piccoli e di forma liù allungata, i quali si comettono con dentelli piccolissimi, che ormano il margine dal lato della regione inferiore, e parte del margine iuferiore stesso, il quale nc resta sfornito solo nella parte centrale. La carena porta quattro denti assai piccoli o distanti tra loro. La superficie delle valve è punteggiata da punteggiature rarricinate ed impresse.

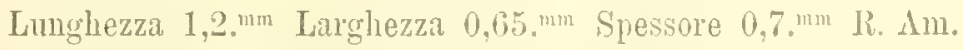

72. C. microtubereulata 11. sp.

Questa forma ha molta affinità colla C. tubcrculalu Sirrs rivente, dalla quale distinguesi benissimo pei caratteri seguenti. La conchiglia è molto piccola, ai duce estremi ugualmente larga e rotondata e con m margine depresso, la regione anteriore è più compressa, ed al margine porta quattro piecoli denti ed allungati; il margine posteriore ha sei denti brevi triangolari, il margine inferiore ed il superiore sono quasi retti e paralleli; verso la regione inferiore si eleva una carrena longitudinale abbastanza prominente che stanisce agli estremi; i tubercoli che ornano la superficie delle valve sono piir rarriciuati e più numerosi di quelli della C. tuberculala. R. B.

73. C. coro nata Roemer. Questa specie presenta importanti varietal, tra le quali ne ricordo ma della contrada Malochia, veramente rimareherole: essia ricorda bene la forma di Ortenburg che il dottor I. G. Egger ha illustrato rifurendola allia specie del Roemer, e credo che i caratteri di tale Cylhere si riassumono meglio dicen-

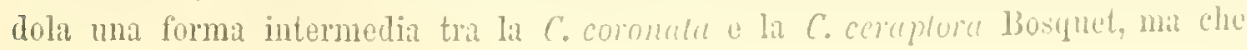




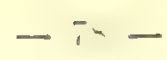

meglio a associa colla prima per l'insieme della forma generale. Per taluni carattari joi potreblue in rero specificamente discrimerersi. c. Am. B. Ma. - 74. C. 1) unctata Y. Munster. I miei esemplari rispondono alle figure deI Renss. r. B. MIa.

Cornerella. - 75. U. cumpressa ron Munster (Cythere) $=$ Cytherina compressa lienss, Cigherella compressa. Bosquet. 1. B. Ma.

\section{Ordine. CITRITEIJ.}

Iatunus. - 7ij, 13. coll carus Bronn. Rari frammenti riconoscibili, che conservalno il colorito rosion con costole biancastre. r. Am. B. II. Y. - 77. B. stelIar is brocthi (Lepus). Lur. miocenica Seguenza. Questa ríccola forma del $B$. stellaris trorasi ormuque nelle sabbie elreziane di Calabria, sempre fissa sul Clypeaster pyramiulis Michelin, sul P. scalrellus Lamk., sulla Juniru Rollei Hoernes, sulla Junira besseri Audx., sull Ostrea biobayi Deshares ece. ece. Tra i molti esemflari racolti si osserria un graduale jassagrio ad alcuni, che mancano totalmente di costole. e che furmano un'altra distinta rarieti che chiamo lar. simplex, la quale ger tale transizione legrasi eridentemente alla forma che forta forti e prominenti costole. colla quale trorasi insieme associata. C. Am. B. G. Mit. F. .II.

Sesmpellum. - 78. S. Mo linianum Segnenza. Rapyorto con sicurezza a questa specie un picerio tergo in cattivo stato, il quale cin nou pertanto presenta ben eridenti i caratteri della specie, e solo ne ditferisce per essere molto più piccolo, arendo una lumghezza che ì circa metia di quella che raggiungono gli esemplari del Dudenese da me illustrati. Vedi Ricerche paleont. Cirrip. ters. mov. al Messinu (Atti Ace. Pontaniana rol. X.) R. B.

Tipro. TERMII.

Classe. AxelLid.

Ditrupa. - 79. D). in enria (Renier) Brocchi (Dentalium). Questa specie molto conmue i variabile moltissimo in grandezal. conme pel sno andamento, per la imegolarita che sorente presenta ecc. A giudicare dalla struttura della conchiglia, c dalle consucte irregolaritil che ofire si è certi che trattasi del tubo di un anellide, che spetta jercio al gencre Ditrapa. C. Im. B. II.

Serpular. - 80. S. alticulata n. sl. Tar. Vill. fig. 3.

Chiamo cosi ma serpula aderente al monomia che distinguesi pel carattere rilerantissimo di risultare d'una serie di nodi disginnti per mezzo di considereroli restringimenti, da dore la denominazione di articolata. R. Am.

s1. S. disco-le elix n. sp. Tar. VIII. fig. 5.

Conchiglia arrolta a spirale piana, con noterole regolarita relativa ad una spogria di semplinte, la quale is a plianata al centro jel modo come si rimiscono gli arrolginesti, l'ultino soltanto si ralza al di sopra del piano degli altri formando un margine irregralanente guadrangolare, perche depresso superiormente; ed incltre costituisece inturno a sè una incrostazione sottile sulla conchiglia alla 'flale arlerise; gli arvolgimenti sono segnati inoltre da linee di accrescimento sottili, inegulari, Hessuve. Questa specie impiantata sulla Janira Beudunti, viene 
da me riferita al genere Scrpula con qualche dubhio, essendochè oggi i serpulili si ripartono in numerosi generi, la ricognizione dei quali riene troppo mal determinata dallo studio dei soli tubi calcarei. r. Am.

Troransi ancora altri tubi, probabilmente di Sropule, che pel loro cattivo stato 1 o creduto meglio di trascurare.

vexmilia. - 82. V. miocenica n. \$p. Tav. VIII. fig. 4.

Conchiglia triquetra, rariamente flessuosa, fornita d'un carena che si cleva sul dorso in forma di lamina spessa irregolarmente ondulata, che sporge sulla boeca in forma di dente; la superficie è segnati da legrgiere, irregolari e Hessuose linee di accresciments, l'apertura è esattamente circolare; le pareti nella loro parte piu spessa sono care e concamerate per mezzo di numerose lamine trasrersali. Questil in rero è una di quelle numerose specie triquetre, che in parte spettano al genere Serpula, ed in parte al genere l'emilia, e clue la loro ricognizione specifica nonchè generica imbarazza sinanco i zoologi più abili nella determimazione delle specie rirenti.

Il carattere delle pareti cave e tramezzate in questa specie mi è sembrato rimarcherolissimo e di molta importanza. C. Am. B. MIa. MI.

Classe. Briozonir.

Snlicornnrin. - 83. S. fal ciminoides Johnston. Othe tutte quelle numerose variazioni tanto hene illustrate dal Renss e da altri. R. Am. B. II. V.

serupocellaria. - 84. S. elliptica Reuss. R. MI.

Miriozoon. - 85. M. truncatum Pallas. Un solo ramo. R. Am. $V$.

Acrea. - 86. A. sica Conch. Fissa su di un frammento di Chypeaster. R. Am. V.

Terebripora. - 87. T. A rehiaci Ficher. Mi uniformo all'opinione ralerolissima del sig. A. Manzoni nel riguardare questo Briozoo perforante siccome illentico alla specie dell'eoceno, ma a dire il vero resta in me qualuhe dubbio. Cili esemplari da me raccolti sono delle colonie che perforano la Janira Beudanti, e rispondono a capello colla figura data dal Manzoni per le colouie del plioceno di Castrocaro. 1. Am.

Fustra. - 88. F, dentieulata n. sp. Tar. VIII. fig. 6.

Riferisco a questo genere un briozoo importantissimo per la sua formi, che trorasi in piccoli frammenti sottili, i quali portano sopra ambe le fitece delle cellule orato-oblonghe, imbricate, col margine sroltato in fuori, inspessito rerso la regione superiore, e formito elegantemente tutto intorno di denti prominenti, allungati, non assottigliati. c. B.

yembranipora. - 89. MI. L a cro ix i Sarigny (Flustra). Questa specie presentasi considerevolmente variabile nella conformazione e grandezza delle cellule, essa sovente incrosta intiere conchiglie, costituendo ma clegante reticolazione. Il Reuss ed il Manzoni sono proclivi a riguardarla siccome Ia ./. reliculum Michelin. Inerosta la J. Besseri, la J. Beudanti, la J. Calabra, il Clypeaster pigamidalis, la Celleporaria polythcle ecc. c. Am. B. Ma. Mr. V. - 90. M. diadema Reuss $=1 \%$. Lacroixii var. diadema Reuss. Dai pochi esemplari esaminati parmi che questa forma sia ben distinta dalla .1\%. Lucroixii. Incrosta la $C$. 


$$
\text { - : }
$$

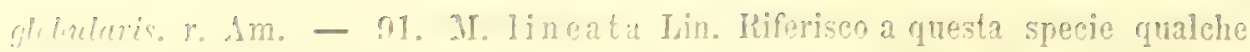

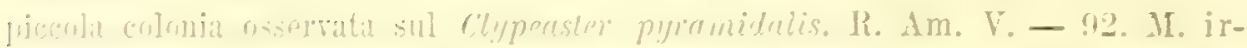

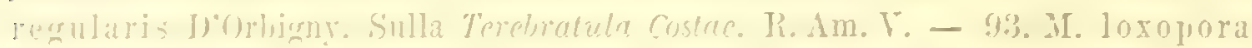

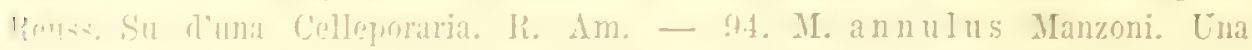

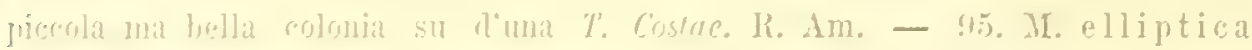

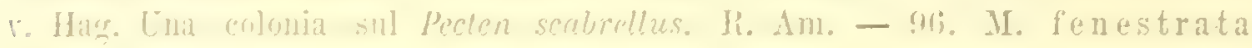
IRens: Lina colonia un ben conservata sulla J. Beudanti, alquanto dubhia. R. Am.

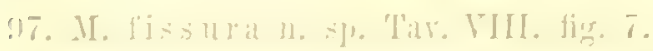

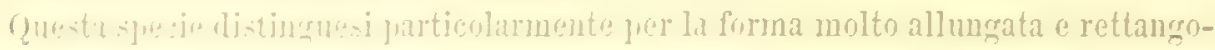
lare relle cellule, le quali sone intieramente aperte e ciascuna porta una porzone

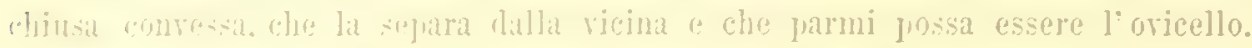

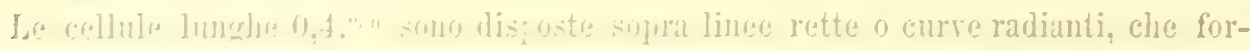

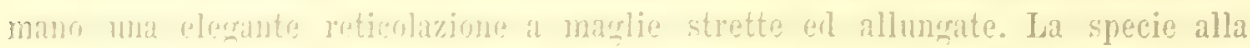

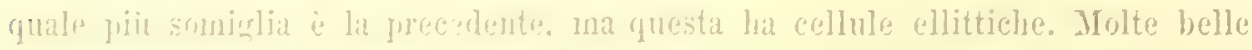

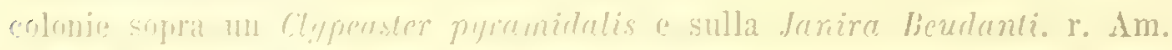

98. M. Ponilleti Aulonin. Rifurixen con qualche dubjo a questa specie una colonia che eriace su di un' ostren naviculeris. R. Am. V.

(19). ML. Hicurnis n. su. Tar. VIJT. fige. 10.

renesta forma is afline alla puecelente jure sembrami ben distinta per le sue ceeflule di forma trigona con un margine rilerato che porta un ovicello di forma wata. troncato inforomente somontato da due srandi aviculari orato-acuminati. Won pose tacere che rusesta suecio si modjica considerevolmente e che nella medosma culonia ferlemlo gli oricelli e talrolta alcuni avienlari, e le sue cellule

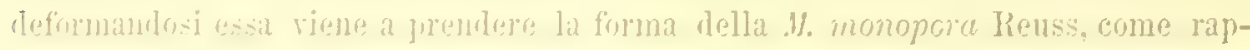

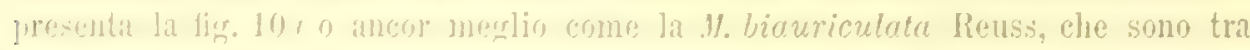
loro molto affini e forte nom altro che varietia dolla specie seguente.

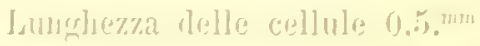

Di questa bebla forma trovansi grandi colonie sul Pecten scubrellus e sulla J. lieuarmit. Ins. Is.

100. M. alpondiculata Rouss. (questa risjonde esattamente alle figure date

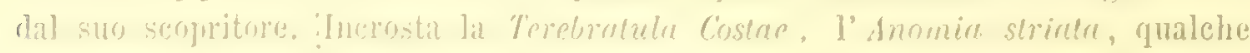

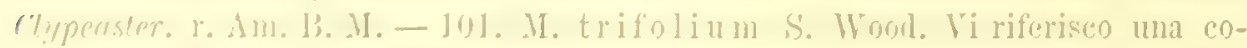

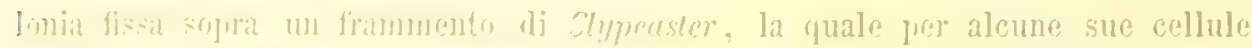

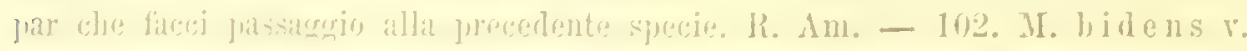
Harg. ()-servata sul Pecton scabrollus; sulla J. Reulanti, sulla T. Costac c. Am. B. 10\%. U. ogivalis n. su. Tar. VIII. fig. o.

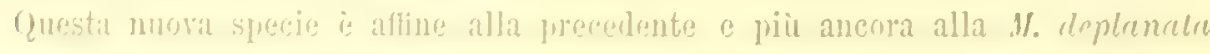

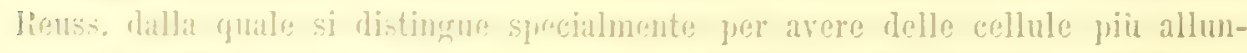

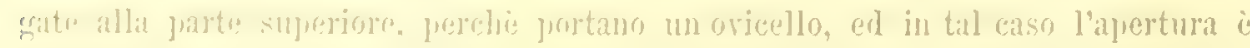

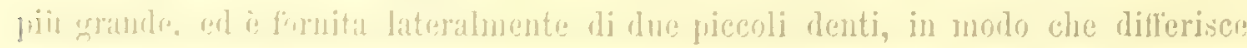
mella conformazione rla ruella delle cellule non jurolifere.

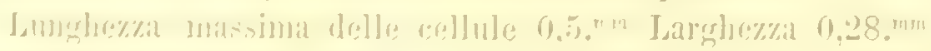

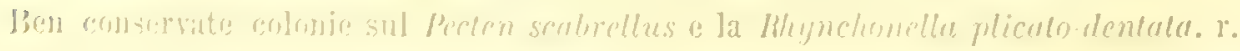

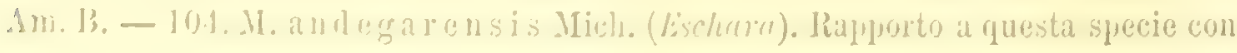


sicurezza alcune colonie, in cui talune cellule trasformate in aviculari sono di forma alquanto diversa, con un'apertura centrale. Risponde precisamente agli esemplari del Crag, soltanto gli avieulari inrece di rari forami ne banno un solo e grande al posto di quelli. Tali colonie incrostano rarie Celleporarie. R. 13. - 105. II. graeilis Reuss. Di questa bella specie conserro grandi colonie, che iucrostano rari esemplari del Chpeaster pyramidalis. I. Am. M. - 106. M. papyracea Reuss. Una piccola colonia sulla. T. Costac. R. Am. - 107. II. angulosa Reuss. Questa specie dall'eoceno è soprarrissuta sino ai mari attuali. Sul Pecten scabrellus, su d' un' Ostrea e d'ma Celleporaria. r. Am. B. Mia. V. - 108. MI. stenostoma Reuss. Molto affine alla precedente. L' ho trovati sul Pecten scabrellus e sull'ostrea navicularis. I. Am. B. - 109. II. formosa Reuss. Bella e ristintissima specie per la forma ellittica e regolare delle cellule marginate e fornite d'una bocea con due denti robusti, laterali. Riunisco a questa specie col nome di far. conferk (tav. VIII. fig. 8) una forma che difierisce soltanto dal tipo per arere le cellule che reciprocamente si comprimono e si deformano, in modo che la specie perde uno dei suoi piu rileranti caratteri, quello cioè di offrire le cellule disgimnte e dí forma assai regolare. Pure tra la rarieti e la forma tipica ri si osserrano tutte le gradazioni, ed inoltre gli altri caratteri nelle due forme sono identici. Questa rarietà, dal lato morfologico, oflendo un legame più intimo tra la .1. formosa ed altre specie, mostra a mio gindizio inammisibile il genere Jollia Lamouroux, che comprenderchlue questa e le specie analoghe. Trorati incrostante la T. Costae e l'ostrea navioularis con ambe le forme. I. Am.

renrolin. - 110. L. Barrand e i Reuss. Sulla Junira Besseri. 1. Ma. - 111. L. plemropora Reuss. Sul Pecten scabrellus, e sulla Janira Beudanti. 1. Am. MI. - 112. L. ciliata Limneo (Cellepora). 'Iroransi direrse rarietì, cosi quella che risponde alle figure date dal Busk pei fossili del Crag, e quella rappresentata dal Manzoni. Osserransi sul Pecten scabrellas, sulla Tercuratula Costae, e sulle Celleporarie. c. Am. Ma. V. - 113. L. inam oena Reuss. Incrosta il P. scalrellus, la Janira Beudanti, l'Ostrea tenuiplicala, Ia Terebratula Costae, lo Celleporarie. c. Am. MIa. - 114. L. decorata Reuss. Grandi e belle colonic sui P. scabrellus, Janira Beudanti, J. Calabra, Terebratula Costae, Clypeaster. c. Am. B. M. - 115. L. megalota Reuss. Sul Pecton scabrellus. 1. Am. 116. I. coccinea Jonston. D'ordintrio li forma che incontrisi nell' Élveziano avvicina molto alla figura data dal Reuss. Vedesi sul P. scabrellus, sulla T. Costae, sulla Janira Calabra, sul Clypeaster..... e sulle Colleporarie. Tar. gracilis. Forma allungata fissa sulla Janirce Culabra. C. Am. I3. MIa. II. V. - 117. I. resupinata Manzoni. Vi riferisco con qualche dubbio alcune colonie che incrostano la Terebralula Costae. r. II. - 118. L. ansata Jonston. Troransi numerosissime forme e tutte quelle varietil rappresentate dal Reuss, dal I3nsk e dal Manzoni, talvolta in grandi e conservatissime colonie sui P. scabrellus, Janira - Besseri, J. Calabra, Clypeaster pmamidalis. C. Am. I3. Mat. M. V. - 119. Is. biaperta Michelin. L' unica colonia che vi rapporto conviene colla figntia del Manzoni e incrosta la Terebratula Costee. R. AI. - 120. L. cras s ila lu ra Manzoni. Belle e ben conservate colonie sul Pecten scabrellus, sulla Janira beulanti. 
r. Am. - 121. L. Gonversi Renss. Una colonia sulla Janira Besseri. R. Ma. 122. L. s c hizogaste $1^{\circ}$ Reuss. Risponde meglio alla forma data dal Reuss anzichè a quella del Manzoni, la regione della feuditura rentrale è ancor più prominente che quella della forma del bacino di Vienna. La prima colonia incontrata presenta le serie delle cellule alquanto disgiunte ed allontanate, dimodochè la gindicai un'llypothoa; i trovati posteriori fecero rettificare il mio giudizio. Trovata sulla Terebratula Cosae. R. Am. - 123. L. Sturi Reuss. Alcune piccole colonie sul di un frammento di Clypeaster e sulla Terebratula Costae. R. Am.

124. L. formosin 11. sp. Tav. VIII. fig. 12.

Questa bella Lepralia è affine allia precedente della quale potrebbe essere una insigne varieti. Essa pel modo di associarsi delle cellule ricorda la $L$. complicutu, per la suntura invece la L. Sturi. La bocea è orata e non già trasversa come in quest'ultima, gli ariculari, uno o due per ciascuno indiriduo, sono grandissimi estendentosi dalla boeea sino all'oricello della cellula sottostante.

Lunghezza massima d'una cellula 0,6 . mu Larghezza 0,43 . ${ }^{\text {mm }}$

Incrostinte lin Terebratula Costae. R. Am.

125. L. rugulosa Rens's. Colonie che incrostano la T. Costae ed un'Ostrea. R. Am. - 129\%. L. violacea Jonston. Una colonia rechia e molto calcificata, alquanto. dubbia, sulla Janive Besscri. R. ML. V. - 127. L. otophora Reuss. Corrisponde precisamente agli esemplari tipici del bacino di Vienna e non alla furma data dal Manzoni. Inerostia il P. scabrellus. R. M.

128. L. braclicejliala 11. sp. = L. ofophora Manzoni (non Reuss). L'unica colonia di questa forma, incrostante $1^{\prime}$ Ostrea navicularis, mi fa decidere a riguardarla siccome distintir dalla specie del Reuss. li. Am.

129. L. gastropora Reuss. Ho trorato molte colonie incrostanti il Clypacaster pyrcomidulis, ehe eredo rispondano alla specie del Mioceno di Viemna. I. MI. 130. L. pustulosa n. sp. Tar. VIIL. fig. 14.

Questa specie distinguesi per le grandi cellule orate colla bocca ellittica e tubercolitia al margine, colla superficie ornati di grosse pustole, che la caratterizzano assai bene.

Lunghezza d' ma cellula 0,8 . mm Larghezza 0,6 .mm

Inerosta il P. scabrellus. R. Am.

131. Is. minutissima 11. sp. Tav. VIII. fig. 13.

Cellule piccole, glohoso-orate, alcune delle quali portano lateralmente breve ma grosso e rotondato ariculare con doppio forame; la bocea è rotondata con un largo intaglio in basso; talume cellule portano un grande e rotondato oricello che si slarga alquanto trasversalmente. Somiglia questa specie alla $L$. incisa Reuss, gli aviculari ed altri particolari ne la distingnono.

Isughezza massima d'una cellula 0,48 . in $^{2}$ Larghezza 0,27 . $^{\mathrm{m}}$

Incrosta l'Ostrea... R. Am.

132. I. tenella Reuss. Specie affine alla L. linearis. Io ho potuto riconoscervi le varie forne che incontransi nel bacino di Vienna, inerostanti il P. scabrellus, il Clypeaster myramidalis, le Celleporarie cec. r. Am. M. - 133. I. linearis Hassal. Sulla Janire Besseri. 1R. Ma. V. - 134. L. leticulata Busk. Sul P. 
scabrellus. R. Am. V. - 135. L. pertus Jouston. Esemplari analoghi a quello rappresentato dal Manzoni nei suoi Briozoi mediterranci; solamente le perforazioni sono un po' più piccole e più numerose. Incrosta la $J$. Calabra ed il $P$. scabrcllus. R. Am. - 136. L. arrecta Reuss. Sul P. scabrcllus. R. MI. - 187. L. scripta Reuss. Questa specie presenta considereroli variazioni, studiate dal Reuss e dal Manzoni, che troransi tutte ed insieme ad altre nell'Elreziano di Calabria, incrostanti il P. scabrellus, la J. Besseri, la J. Rollei, l'Ostrea navicularis, la Terebratula Costae, la Bhynchonella plicato-dentata, lo Cellepararia ece. o. Am. Ma. M. V. - 138. L. innominata Coneh. Una sola colonia sulla J. Calabra. R. Am. Y.

139. L. elegantissima 11. sp. Tar. VIII. fig. 11 .

Questa magnifica Lepralia spetta al proposto gruppo delle Cribrillina Gray; essa ha i suoi più prossimi parenti nelle C. radiata (Moll.) e C. fagularis (Johnst.) virenti, ma più si approssima a quest'ultima che vive alla Florida. La specie miocenica manea di ariculari nella colonia da me studiata, e percio differisce dalla L. radiata, e fornita di oricelli nella maggior parte delle cellule e pereio distinguesi da entrambe le specie sumominate. Numerosi particolari cle la contradistinguono risultano meglio che altro dalla figura.

Lunghezza d'una cellula $0,51 . \mathrm{mm}$ Larghezza $32 . \mathrm{mm}$

La colonia da me rinvenuta incrosta la Rhynchonella plicato-dentata. R. Am. 140. L. raricostata Reuss. Questa bella specie del bacino di Vienna trovasi nel nostro Elveziano di unita alle tante altre comuni ai due depositi. Sul Pecten substriatus e sul Clypeaster ..... 1. Am. B. - 141. L. serrulata Reuss. Raccolta aderente al P. scabrellus ed alla J. Besseri. c. Am. MIa. M. - 142. I. I egularis Reuss. Varie colonie un pochino dubbie, che incrostano una ralva dell' Ostrea acuticostata. 1: B. - 143. I. incisa Reuss. Una bella colonia sulla J. Besseri. R. Am. - 144. L. Partsehii Renss. Sul P. scalrellus. 1. M. 145. L. Reussiana Busk. Concorda bene colla figura datil dal Mranoni. Su d'un frammento d'Ostrea. R. Am. - 146. L. monoceros lienss. Precisamente rispondente alla forma del brcino di Vienna, questa specie è tra le più comuni del nostro Elveziano, dove forma belle colonie sulle seguenti specie: $P$. scabrellus, Janira Besseri, J. Beudanti, J. Rollei, J. Calabra, Chypeaster pyra. midalis, Terebratula Costae, Celleporaria polythele ece. C. Am. B. Ma. M. - 147. L. Brongniartii Audoun. Trovasi la forma tipica e la rarieta rapresentata da Manzoni nei fossili di Castrocaro. Sulla Janira Isesseri. r. Ma. Y. - 148. L. vaseula MLanzoni. Una colonia mal conservata sulla Janira Beutanti. IR. M. 149. L. Haueri Reuss. Belle e rimarcheyoli rarieti di questa specie redonsi sul P'. scabrellus, sulla Janira Besseri, sulla Terebralula Costae. I. Am. B. Mla. M. 150. L. crassa Reuss. Una sola dubbia colonia su d'un frammento d' Ostrea. R. Am. - 151. L. goniostoma Reuss. Sul P. scabrellus e la Terebratula Costae. 1. Am. B. MI. - 152. I. insignis Reuss. Inerosta la Janira Besseri. R. Mra. - 153. L. planiceps Reuss. Sul P. scabrellus. 1. M. - 154. I. cuceulata Busk. Soniglia molto alla forma rappresentata dal Manzoni tra i fossili di Castrocaro. Aderente alla Janira Beudanti ed alla T. Costae. 1. An. V. - 155. L. 
I uceru ula Minzoni. Questa grande specie, in ma delle due colonie da me incontrate sull Terebratula Costae, oftre alcume cellule con uno, orvero due ariculari ai lati, pel quale carattere sono stato $u$ po' indeciso intorno alla esattezza della Ceterminazione; ma per questo solo fatto, convenendo la mia Lepralia per tutti gli altri caratteri colla suriferita, non mi sono creduto autorizzato a disgiungere questa dalla specic del Manzoni. 1. Am. B. - 15b. L. obelisens Manzoni. Raprorto a questa sprecie una sola colonia, che mi lascia qualche incertezza. Sull'ostrea..... R. B.

Celleponaria. - 157. C. p.ol y the le Reusis. Questa specie forma delle masse mammellonate non rare nell' Lilreziano di Cilabria. c. Am. B. - 158. C. globularis Brom. Qualche volta aderente al P. scabrellus. I. B. Ma. M. - 159. C. systoIostoma Manzoni. Rari ma ben riconoseibili esemplari. r. Am. B. - 160. C. retusa Manzoui. Alcuni esenulari fissi sulla Janira Besseri. r. Ma.

IBatopon. - 161. Batopora rosula lienss. Un solo ben conservato esemplare. R. B.

Eschrara. - 169. L. macrochila Reuss. Questa specie si accorda esattamente colle figme date dal Manzoni. C. Am. B. - 163. E. und ulata Renss. Possiedo dei rani commessi al altri rotondati quasi cilindrici : mo di questi è fisso sulla T. Costac. r. Am. B. - 164. H. poly stomella Reuss. Rapporto a questa specie ma forma di eschara che laseia in me qunche dubbio. c. Am. B. - 165. E. tessulata Reuss. R. M. - 166. E. conferta Reuss. 1. An. B.

167. E. variolata n. sp. 'I'ar. VIII. fig. 15.

I rami di questa specie sono assai compressi, le cellule orato-fusiformi hanno una larga bocea, rotondata smarginata anteriormente, la superficie oftre qua e là irregoliamente disposte delle infossature. Ben dirersit da tutte le specie mioceniche.

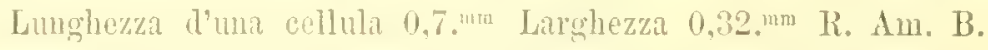

atetepora. - 168. R. collulosa Linneo. Piccoli frammenti. r. Am. B. V.

Vimenaria. - 169. V. cueullata Reuss. Eschara costata Reuss, E. Reussii Stol. Gli esemplari che jossiedo hauno formi molto conipressa. 1. Am. B.

Cupularab. - 170. C. Ha il ingeri Renss. Rapporto con dubbio a questa specie m esemplare alerente alla roceil, ehe mostrasi scoperto dal lato inferiore. R. B. - 171. (....... sp.? Non è possibile di definire la specie di Cupulariu, che sotto forma di modello o impronta della fuccia inferiore trorasi in questo fiano, ess 2 ha il grande diametro di 13 millimetri in media, ricorda quindi per la grindezza lia C. intermedia Michelotti o la C. umbellata Defrance, che d'altronde rengono confuse insieme dal Manzoni. r. Ma.

Corisa. - 172. C. Ho ernesii Reuss. Tenui e ben conservati esemplari.r. B. M. 173. C. Edwards i Reuss. Lsemplari concordanti con quelli di Viema. r. B. MI.

Hornem. - 174. H. lippolythus Defrance. I miei pochi frammenti si avicinano molto alle figure date dal Busk. 1 . B. - 175. H. frondiculata Lamonroux. Pochi frammenti di rechi rami. r. B. V.

176. Hornera Reussi in. sp. 'Tik. VIIL, lig. 16.

Questa bella sprecie è afline all'/l, asperula Renss, dalla quale si distingue specialmente per arere piu rarricinati i tubi che la costituiscono, e per arere la 
faccia posteriore ornata di costole piir grosse, meno numerose, qua e la interrotte e sporgenti in forma ottusia o acuta, in modo che la superficie ben conservata is spinescente.

\section{Lunghezza dei rami figurati $3,4 . \mathrm{mm} \quad 3,3 . \mathrm{mm}$}

Trovasi una varieta più gracile. c. B.

Idmonca. - 177. I. pertus a Reuss. Risponde esattamente alla specie del bacino di Viemna. c. Am. B. - 178. I. cancellata Goldfuss. (Retepora). Vi riferiseo qualche ramo. R. B.- 179. I. concara? Reuss. Questa specie comune molto. somiglia grandemente alla forma cui dubitativamente li rapporto, ma sempre incrostata e quindi in cattivo stato. La forma generale, l'andamento e la disposizione delle cellule ricordano proprio tale specie, la faccia prosteriore è appianat con linee curve di accrescimento. C. B.

Fulisparsa. - 180. F. rarians Reuss = Pushuloporb anomala Reuss (Parte). I miei esemplari rispondono esattamente od in tutti i particolari alle figure date dal Reuss per quelli di Crosara. c. B. - 181. F. biloba Reuss (IIonnera). Vi riferisco alcuni piccoli esemplari. 1'B.

Guralonleora. - 182. E. attenuata Stol. Qualche piecolo esempline un po'ubljio R. B. - 183. L. anomala Reuss (Pustulopora) (Parte). I mici esemplari rispondono bene alla restrizione apportata alla specie dal dott. Manzoni. r. B.

Pustulopora. - 184. P. p ulchella Reuss (Cricopora) = Enthalophora pulchella Reuss. Parmi che gli esemplari di Benestare rispondano bene a quelli de] bacino di Vienna, e solo variano alquanto nella gracilita delle colonie. c. B. 185. P. palmata Busk. Qualche esemplare un po' compresso, e dubbio 2. B. 186. P. c la v u la Reuss. Due soli esemplari ben distinti e mal conserrati. R. 13.187. P. sub compressa Reuss. Vi riferisco un solo escmplare ben distinto per la considerevole compressione e per essere coperto di numerose ed arricinate cellule, R. 13.

Spiropora. - 188. S. pulch elia Reuss (non Cricopora pulchella Reuss). Due ben distinti esemplari, che rispondono esattamente a quelli di Crosara. Io sono perfettamente d'accordo col dottor Manzoni nel riguardare questo Briozoo siccome perfettamente distinto dalla Pustulopora pulchella Reuss. I. B.

Tubulipora. - 189. T. fo li a ce a Reuss. Di questa specie raccolsi belle e grandi colonie che incrostano il P. scabrellus, la Janira Besseri, I'Ostrea Boblayi, il Clypeaster pyramidalis ece. c. Ma. M. - 190. T. flabellaris Fabr. = Dinstopora plumula Reuss. Sulla Ditrupa incarva e la Terebratula Costae. 1. Am. II. V. - 191. T. p I uma Reuss (Defrancia). Alcuni esemplari sul Clypeastiv' pyramidalis. R. II.

Diastopera. - 192. D. flabellum Reuss. Riferisco a questa specie, che deve forse associarsi alla $D$. simplex Busk, dne esemplari poco ben conservati, fissi sulla Terebratula Costae e sul Clypeaster pyramidalis. R. Am. B. - 193. D. sparsa Reuss. Sul P. scabrelles e sulla T. Costae ece. 1. Am. B. M.

Discoporella'. - 194. D, echinulata Reuss (Tubulipora). Sul P. scabrellus e sul Clypeaster....... I. Am. II. - 195. D. formosa Reusis (Defrancia). Varî esemplari che lasciano qualche dublio. l. Am. It. 
Necto. - 196. A. echinata V. MImster (Cellcpora) = Diastopora chinata Renss. Alemi esemplari aderenti alla Tercoralula Costac ed al Chypeaster pyramidalis. 1". Am. Mr.

Ibarinella. - 197. P. proligera Busk. Rapporto con dubbio a questa specie una sola colonia trovata libera ed alquanto incrostata. R. 13.

Ceriopora. - 198. C.g I b u l us Reuss. Rari esemplari esattamente identici a quello figurato dal Reuss. r. M. - 199. C. arbus cul um Renss. Qualche piccolo esemplare coi forami più radi di quelli della precedente specie. R. B.

Hetcropora. - 200. H. stellulata Renss. Bella specie incrostante la Janira Besseri ed il Clypeaster pyramilulis. 1. Am. MIa.

\section{Tipo. ECHINODERJI.}

Classe. Faninin. - Ordine. Rerolari.

Cinnris. - 201. C. tessurita Meneghini. Var. major. Un solo radiolo, R. B. 202. C. rosaria Bromn. Qualche frammento di radiolo. Secondo il professor Meneghini la C. hirta Sismonda dee arersi come sinonimo di questa specie. R. B. 20:8 C. siguata Sismonda. Un qualche radiolo. R. B.

Ordine. Cripeastroid.

Cigpenster. - 204.C. pyramidalis Michelin = C. allus Philippi [non Leske (Echinanus)] ('). Tar. I.. fig. 1, 1 ${ }^{\circ}$

Questa specie, la piì grande del genere, è ancora la più comune del piano Elreziano calahrese, essa è distintissima per la sua forma molto elevata ed esattamente piramidale. Io crelo che il Philippi uel suo lavoro intorno i Clipeastri di IIonteleone abbia riguardato questa siccome il $C$. altus Lamk. che è specie molto meno elevatia e diversa per molti caratteri. Questa specie non è stata sinora raccolta, nex quanto io sappia, che a Mitterberg presso Baden nel calcare di Leitla, e quindi al medesimo livello stratigrafico dore comunemente s'incontra in Calatria. c. Am. G. Ma. F. MI. Var. brevior Tar. IX. fig. 16, 1c. Questa forma

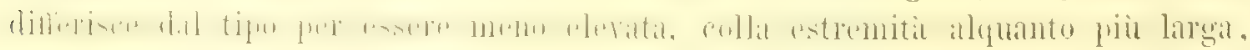
cogli ambulacri meno appianati. 1. Am. G. F. ('.

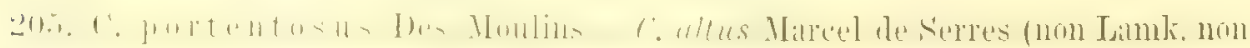
Philippi), C. turvins Agassiz (non Philippi), C. Agassizii Sismonda. Tar. IX. fig. 3.

A questa specie io riferisco dne soli esemplari raceolti a Monteleone. La forma slanciata ed alquanto obliqua la fa distinguere assai bene dalle affini; gli ambulacri sono molto allungati e molto più prominenti e più stretti di quanto lo sono nella precedente specie. E stata raccolta a Dax (Landes), ad Eisenstadt (Ungheria), a Malta ece. R. MI.

Var. clatior 'Tar. IX. fig. 3. Chiamo cosi un Clipeastro di forma ancor piì elevata della tipica rapuresentata dal Michelin, conviene del resto con quella in tutti gli

(3) Ucber C'mnaster allus, C. Lmilus, C. Scillac (Palacontugraphica With. Duncter und Herm yon Meyer lisal. 
altri caratteri. R. MI - 206. C. alticostatus Michelin. Rapporto qualche esemplare a questa specie alquanto diverso dal tipo rappresentato dal Michelin. perchè alquanto più basso e meno depresso al margine posteriore. Si è raccolta in Corsica, a Santa Manza, a Raubstallbrunnen tra Baden e Tostan (Austria) Ir. Am. II. - 207. C. altus Leske (Echinantus) $=$ C.altus Lamarek (non Philippi), Scutella pyramidalis Risso, Echinites campanulatus Schlotheim. Tar. VIII. fig. $17,17 a, 17 b$.

Intorno a questa specie par che sianvi state opinioni varie, dappoichè questo nome fu imposto, da varî scrittori, a diversi Clipeastri, e gì il Philippi avea chiamato con tale nome il $C$. pyramidalis. Gli esemplari che io ri rapporto soun esattamente identici a quello descritto e figurato dal Michelin ('), che risponde alla figura dello Scilla. L' esemplare che ho da Monteleone è un po' guasto e rotto, perciò nell'Atlante ne ho rappresentato uno da Baselice molto bello, fornitomi dal prof. G. Guiscardi. Raccolto a Bordeanx (Gironda), Dax (Landes', Oran (Algria), San Miniato (Toscana), Isole di Corsica, Capri, Malta, Creta ecc. R. ML.

208. C. insignis n. sp. = C. turritus Philippi. Tar. IX. fig. $2 \pi, 2 c, 2 \pi$.

Ho mutato il nome a questa specie, essendochè quello di tarritus impostole dal Philippi è stato precedentemente dato a varie altre, e potrebbe quindi ingenerarsi confusione. La specie è proprio distintissima per la sua forma conico-concara, elevata, arrotondata all'apice, e quindi esattamente campanulata; la loase è perfettamente piana con cinque solchi profondi, che si addentrano sempre piu sino al peristoma, situato in fondo ad una stretta caviti quinquepartita dai cinque solchi. Gli ambulacri sono molto allungati da superare i due terzi della distanza che intercede tra l'apice ed il margine, ristretti gradatamente all' estremiti inferiore, e distintissimi per essere estremamente appianati e quindi ben poco sporgenti sul resto della superficie.

Altezza 74. ${ }^{\mathrm{mm}}$ Diametro maggiore 124. ${ }^{\mathrm{mm}}$ Diametro minore 112. ${ }^{\mathrm{mm}}$

Il Philippi ebbe questa specie da Monteleone, ed io parimenti. r. MI.

Var. acuminatus Tar. IV. fig. 2, 2b. Questa forma differisce dalla precedente pel margine piì sottile, per la parte elerata più gracile e per l'apice piu stretto. Altezza $80 \mathrm{~mm}^{\mathrm{mm}}$ Diametro maggiore $130 \mathrm{~mm}^{\mathrm{mm}}$ Diametro minore 122. ${ }^{\mathrm{mm}}$ R. M. Am. 209. C. Philipp i n. sp. = C. Scilla Philipri (non Desmoulins) Tar. X. fig. 1, 1 .

Anco questa specie non può conservare il nome che si ebbe dal Philippi, perchè era stato imposto precedentemente ad altra, per cui ho seguito il consiglio di dedicargliela. Il Clypeaster che esamino ha forma intermedia tra la precedente e lit seguente specie. Dalla prima differisce specialmente per essere ili forma conica, regolare o alquanto conressa, e nou già concara, coi pori genitali più distanti; dalla seconda pel contorno ovale nou angoloso, per la forma conica non convessa, pegli ambulacri meno estesi e meno prominenti.

Altezza 68. $\mathrm{mm}$ Diametro maggiore 132..$^{\mathrm{mm}}$ Diametro minore 126..$^{\mathrm{mm}}$

Il Philippi ed io abbiamo aruto questa specie dal territorio di Monteleone. c. MI.

(1) Monographic des Cly peastres fussiles. 
Var. melia. Tar. X. fig. 1n, 1b, 1c. Forma meno elevata, più rotondata e quindi assai vicina alla specie seguente.

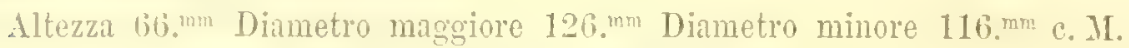
210. C. Reidii Wright Var. clepressa. Tar. X. fig. 2, 2u, 2b. La raricti che accenno ha una forma alquanto piì depressa della tipica, e si distingue dalli precerlente specie per una maggior graudezza degli ambulacri, siccome per una conressiti maggiore della superficie e pei pori genitali distanti molto.

Alteza 62. Diametro maggiore $1366^{\mathrm{mm}}$ Diametro minore 12...$^{\mathrm{mm}}$

Qnesta specie è lroprơ dell' Isola di Malta. L'unico esemplare che figuro è di Baselice, e conservasi nel grbinetto geologico dell' Unirersità di Napoli: rendo adunque grazie al carissimo amico mol. G. Guiscardi, direttore di quel gabinetto, che ha voluto mettere a mia disposizione tutti gli echinidi di quella localita. Dal Reggiano possicdo qualche esemplare dubbio, perchè in catliro stato. R. M.

211. C. formosus n. sp. Tir. X. fig $4,4 a, 4 b$.

Questa specie è assai affine al $C$. insigmis, del quale è meno elerato, regolarmente conico, non concaro, col margine abbastanza acuto, sottile e considererolnente grande, perehè gli ambulaeri sono stretti e piecoli, e i pori genituli arvicimati. Tutti questi caratteri lo distinguono dal C. Philippii. Dero anco questa specie al prof. Gruscardi; essa proviene dall'Elveziano di Baselice: non l'ho sinora incontrata con sicurezza nel lieggiano e ri rapporto dubbiamente qualche frammento.

Altezza 60.mm Diametro maggiore $120 .^{\mathrm{mm}}$ Diametro minore $114 \mathrm{~m}^{\mathrm{mm}} \mathrm{I}$. M. 212. C. mar ginatus Lamarek. Gli esemplari che rapporto a questa specie sono deformati dalla fossilizzazione, e sembrano a prima giunta dirersi dal tipo di Lamarck illustrato dal Michelin; ma uno studio minuzioso dimostra che non fir d'nopo alIontanarli dia quello, al quale stanno naturalmente collegati. r. Am. B. Ma.

Var. cenuipelalus. Tar. X. fig. 3, 3r. Questa forma ̀̀ un anello estremo, che differisce dalla forma tipica per avere gli ambulacri piì stretti e percio non cosi anrotondati come in quella.

Altezza $360^{\mathrm{mm}}$ Diametro maggiore $150 \mathrm{~mm}^{\mathrm{mm}}$ Diametro minore 140 . mm

Il C. marginalus i stato raccolto nel Mioceno di Dax (Landes), Santa Manza (Corsica), Malta ece. 1. Ma.

\section{I'IPO. CELENTERATI.}

Classe. Antozonris, - Ordine. Zonntari.

Crypanmia. - 213. C. Marasita? Michelin (Lithodendron). Con grandissimo dubbio riferisco a questa specie alcuni forami che troro in rarie Celleporarie mal conservate: Ia forma e la disposizione pressochè equidistanti di tali forami mi fanno credere the sieno dipendenti dalla distruzione dei poliperiti di una Criptengiel I. I3.

Classe. Spongiamir.

Clioma. - 214. C. fal unica Fischer. Rapporto a questa specie una Cliona abhastanza comune, che perfora le Ostriche, Ia Janira Besseri o la Terebratula Costas c. Am. B. Ma. 
215. C. tubulos a n. sp. Tav. XII. fig. 29, $29 a$.

Questa è ben distinta specie, perchè le cellule sono riunite in modo da formare dei veri canali pressochè esattamente cilindrici, retti o curri, che presentano ben rari restringimenti, e si ramificano qua e là. Gli osculi sono circolari, disposti su d'una linea retta, curra, o leggermente flessuosa; di grandezza rariissima nella medesima colonia e disugnalmente distanti, talmi possono appena osserrarsi ad occhio nudo, ed altri pervengono quasi al diametro di un millimetro. Questa specie perfora la Janira Besseri. c. Am. Ma. (Vedi fossili tortoniani).

Tipo. PROTOZOARIL.

Classe. Rizupodi. - Ordine. Foraminiferi.

Lagenn. - 216. L. grlobosa Walker (Serpula) = L. globost Reuss, Enthosolenia globosa Williamson. r. Ma. V. - 217. L. marginata Walker. (Sermula) $=$ L. marginata Reuss, Enthosolenia marginata Williamson, Oolina compressa D'Orbigny. 1. Ma. $\mathrm{V}$.

Nodosaris. - 218. N. raphanistrum Linneo (Nautilus) = Nautilus bacillum Parkinson, Defrance. C. Am, B. V. - 219. N. scalaris D' Orbiguy $=$ N. in. falu Costa, $N$. contracta Costa, $N$. sulcata Costa, N. siphunculoiles Costa. 1 . Ma. V. - 220. N. longicanda D'Orbigny $=N$. sulcatu D'Orbigny, N'. tenuicostata Costa, N. Reussi Costa. 1. Ma. V. - 221. N. marginuloides Silrestri. r. Am. Ma.

Clandubina. - 222. G. I a e vigata D'Orbigny. . B.

Lingulina. - 223. L. costata D'Orbiguy. 1 . B.

Frondienlaria. - 224. F. rom bo idal is Dorbigny. 1. Am. B. - 225. F. alata D'Orbigny. r. B. V.

226. F. cordata n. sp. Tar. IX. fig. 5.

Questa specie distinguesi assai bene per la forma compressa, sottile, e dilatata in modo da presentarsi quasi arrotondata, con nu considererole incaro in basso, che la rende di forma esattamente cordata; Ia superficie poi è ornata da squisitc linee rilevate, pressochè rette e radianti.

Lunghezza 4. ${ }^{\text {mm }}$ Larghezza $3,90^{\mathrm{mm}}$ R. Am. B.

Dentaliun. - 227. D. brevis D'Orbigny. r. B. V. - 228. D. Vernenilli i D'Orbigny. r. B. - 229. D. consobrina D'Orbigny. R. M. - 230. D. elegans D'Orbigny. r. B. V. - 231. D. Orbignyani Nengeboren. 1. B. - 232. 1. crebricosta? Nengeboren. c. B. - 233. D. bifur cata D' Orbigny, 1. Am. 234. D. urnula D'Orbigny. r. B. - 235. D. acuta D'Orbigny. c. B.

yonionina. - 236. N. commun is D' Orbigny. 1. Ma.- 237. N. B oucana D'orbigny. R. II. - 238. N. Soldanii D' Orbigny. 1. B.- - 239. N. punctata D'Orbigny. 1. Ma.

Polystomella. - 240. P. obtusa D' Orbigny. r. Am. Ma. - 241. r. crispa Lamarck. c. Am. B. Ma. M. V.

Amphistegina. - 242. A. Camp belli? Karrer. Un solo esemplare molto dubbio. R. An. 
Heternstoma. - 243. H. costata Dorbigny. r. Am. Ma.

244. H. paptracea n. sp. Tar. II. fig. 4, $4 a$.

Distinguesi dalla precedente per essere grande, sotțile, ordinariamente flessuosa, in modo che la surerficie risulta irregolarmente ondulata; essa è inoltre prisa di costole, liscia, e mostra appena appariscenti le linee dei tramezzi, che separano le logge.

Lunghezza 6.mm Larghezza $5 .^{\mathrm{mm}}$ Spessore 0,2 mm

Questa specie è importantissima, per essere caratteristica, ahjondante ed esclusiva di questo piano miocenico. Essa giace dapertutto ore compariscono le sabbie elreziane nella morincia di Regrgio, e talrolta la roccia ne è completamente ripiena. In taluni giacimenti supera il diam. di un cent. C. Am. B. G. Ma. F. C. Ba. I. Earogontiase. - 245. M. li irsuta DOrbigny. r. B. T. - 246. M. raphanus Linneo. c. B. T. Tar. crebricosta. Tar. LX. fig. 6. Chiamo cosi una forma che mesenta magrior numero di costole, più sottili, incurrate, che fanno allontanarla cousiderevolmente dal tipo. c. B.

Vamulina - 247. T. linearis Montagu. Riferisco con qualche dubbio a questa specie jochi esemplari. r. B. Am. Y.

Cristellaria. - 248. C. Cassis Ficht. et Moll. r. B. V.

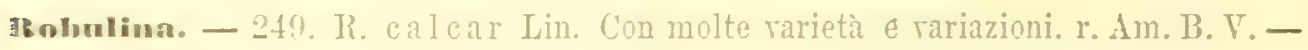
250. R. cultrata Dorbignr. Forse è da amorerarsi tra le molte rarieta della precedente. c. $1 \mathrm{~m}$. B. I. - 251. R. similis D Orbigny. IIolto ricina alla precedente. c. B. - 252. R. nitida Reuss. Qualche esemplare un po" dubbio R. B. 25\%. R. rotulata Lamareh (Lentioulies). r. B. M. T. - 254. R. inornata DOrbign. C. Am. B. - 25\%. R. subangulata. Reuss.r. B. - 256. R. rorter Ficht. et IIoll. 1. B. T: - 257. I. imperatora D Orbigns. r. Am. B. 255. R. intermedia DorbignY. r. Am. - 259. R. obtusa Reuss. r. B. 2030. 1. striolata Czizek. Var. Oltre le strie, porta delle granulazioni. r. B. 2601. R. ornata Dorbign?. Tarieta. r. B. T. - 262. R. echinata D'Orbigny. Varietà C'zizi. Colla superficie granulata. 1. Am. B. MI.

Polsmorphisa. - 263. P. orata DOrbigny. r. B. - 2b4. P. anceps? Philippi, r. B. - 265. P. communis Dorbigny. Tar. r. B. - 266. P. problema Dorbigny. Tar. 1. B. - 267. P. a equalis Dorbigny (Globulina). r. B. 268. P. gibba Dorbigne (Globulina). r. Am. B. - 269. P. punctata D'Orbigny (Globulina), r. Am. B.

Irigerina. - 279. U. DYgma ea Dorbigny. 1. Ma. T.

IBulimin. - 271. B. Bu chiana Dorbigny. Tar. r. Ma. V. - 272. B. pupoides Dorbigny. R. Ma

Sphocroidina. - 27:3. S. a ustriaca Dorbigny. Ti s’incontrano direrse rarietá delle tante che sono state lescritte. $r$. 13. Ma.

Palvinulina. - 274. P. Partschiana D" Orhigny (Rotalia). R. B. - 275. P. acutimargo lieuss (Rotalia). r. B - 27(i. P. Kahlembergensis Dorbigny (Rolulina). r. II. - 277. P. re janda Fichtel et Moll. r. Am. V.

Motalia. - 278. R. Meceari Linneo (Yautilus). r. Am. 13. M. T. - 279. R. Soldanii Lorbigny (Rotulina). 1. 13. V. - 280. R. Jraecincta Karrer. r. Am. 
Orbulina, - 281. O. universa D'Orbigny。 c. Am. B. Ma. V.

GIobigerina. - 282. G. bulloides D'Orbigny. c. Am. B. M. V. - 283. G. quatriloba D'Orbigny. c. Am. B. - 281. G. triloba Reuss. c. Am. B. Ma. M. - 285. G. Aradasi i Seguenza (Rotalina). Forma identica a quella del Plioceno recente, che somiglia alquanto alla G. cretacea D'Orb. C. Ma.

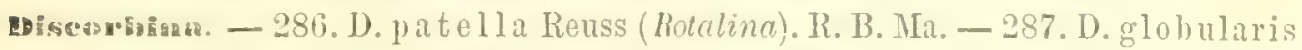
D'Orbigny. R. B. V. - 288. D. semior b is? Karrer. I molti esemplari da me rapportati a questa specie, ne offrono la forma molto somigliante; ma i particolari della superficie vi sono appena accennati in taluni, e quasi del tutto mancanti in altri. Cio dipende probabilmente dallo stato di conservazione. c. B. MI.

Trunentulins. - 289. T. lo batula Walker. c. Am. B. Мra. IT. V. - 290. T. variolata Dorbigny (Anomalina). I. Ma. - 291. T. badenensis D'Orbigny (Anomalina). r. B. Ma. - 292. T. A kneriana D'Orbigny (Rotalina). r. B. 293. T. elegantissima n. sp. Tav. IX. fig. 7, 7a, 7b.

Questa specie ricorda un pochino la T. Dutemplei, ma distinguesi molto beno per essere considerevolmente incarata sopra, ed appianata in basso, per le numerose e distinte concamerazioni, segnate da una punteggiatura speciale.

Diametro maggiore $0,82 \mathrm{~mm}$ Spessore 0,28 . $\mathrm{mm}^{\mathrm{mm}}$. MIa. B.

294. T. I ucida Reuss. Vi rapporto dne esemplari che mi lasciano un po" di dubbio. Questa specie è molto affine alla T. Ungeriana. R. Ma. - 295. T. Ha idingeri D'Orbigny. (Rotalina). 1* B. - 296. T. affin is Czizëk (Rotulina). r. B. - 297. T. Badensis Czizëk (Rotalina). Associasi a qualche varietà. r. Am. B. - 298. 'T. D utemple i D'Orbigny (Rotalina). c. Am. B. Ma. M. 299. T. Ungeriana D'Orbigny (Rotalina). 1'. B. V. - 300. T. Brongniartii D'Orbigny (Rotalina). R. Am. Ma.

301. T. spirata n. sp. Tav. XIV. fig. 4. Vedi yer la descrizione i forminiferi del Tortoniano. r. B.

302. T. vortex 11 . sp. Tar. IX. fig, $8,8 a, 8 b$.

Questa forma molto somiglia alla T. lucida Reuss, ma è molto piir elerata, di forma conica, appianata inferiormente, col margine assottigliato ed acuto, e coll'apice considerevolmente ristretto.

Diametro maggiore 0,66.mm Spessore 0,22. ${ }^{\text {nnm }} \mathrm{r}$. B.

2acomaina. - 303. A, colonata Parker et Jones. r. Ma. V.

Panuhima. - 304. P. a riminens is D'onbigny。 r. Am. B. V.

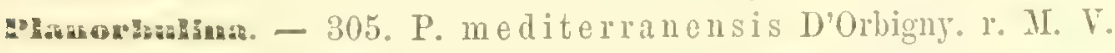

Astcrigerina. - 306. A. planorbis D'Orbigny. IR. I3.

Textiaria. - 307. T. calinata D'Orbigny (Textularia). 1. B. V.

Tuivuina. - 308. V. pectinata Hantk. Vi rapporto un piccolo osemplare. R. MI.

Bolivinn. - 309. B. antiqua D'Orbigny. 1. B.

Cassiñuna. - 310. C. punctata Reuss. 1. B. Ma. - 311. C. oblonga

Reuss. r. Ma.

Esitcaia. - 312. L. Soldani i Parker et Jones. r. Am. B. V.

Ciatengas. - 313. C. commun is D Orbigny. r. Am. B. Мr.

picenniana. - 314. P. laevigatnm Dorbigny (Textularia). r. Am. - 
315. P. acutum? Reuss (Tertularia). Sono dubbî gli esemplari riferiti a questa specie. 1. Am. - 316. P. subangulatum Dorbigny (Textularia). r. Am. M. 317. P. Ha ueri D'Orbigny (T'exulceria). r. B. - 318. P. abbreriatum Dorbigny (Textularia). r. B. V. - 319. P. sagittula Defrance (Texhularia). r. B. V. - 320. P. troehus (Limeo). 1. B. V.

321. P. a cum inatum n. sp. 'Tav. X. fig. 5, 5a, 56 .

Questil specie distinguesi per essere molto assottigliata all'estremità inferiore. per le numerose caritì, e per la sezione pressochè eircolare.

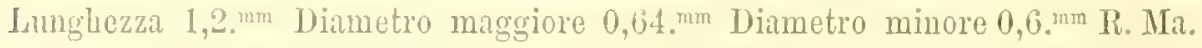

Gaudeyina. - 322. G. chilostoma Reuss. r. Ma. - 323. G. textilaroides? Hantk. lituporto a questa specie rari esemplari non ben conservati, i quali presentano rarie anormaliti, ma parmi che nei caratteri specifici rispondano alla specie di Hantkell. 1. B.

vuhcenlaria. - 324. N. papillosa 11. sp. Tav. X. fig. 6, 6a, 6b.

Questa specie distinguesi per arere li superficie irta di papille e segnata da irregolare punteggiatura impressa; del resto è molto rariabile di forma, e trobasi fissa sul $P$. scabrellus. sulla Terebratula Costae ecc.

Diametro maggiore nei più grandi indiridui $2,8 .^{\mathrm{mm}} \mathrm{l}$. Am. B. MI.

Aveolina. - 325. A. me lo D'Orbigny. 1 'Am。

Riloculina. - 326. B. bulloides Dorbigny. 1 . Am. V. - 327. B. inornata Dorbigny. 1. Ma. - 328. B. simplex Dorbigny r. Ma. - 329. B. a uph iconlica Reuss. 1. B.

Quinqueloculina. - 330. Q. Buch ian a Dorbigny. r. B. Ma. - 331. Q. Akneriana Donbigny. 1. Am. - 332.Q. Ungeriana D'Orbigny. 1. Am. - 333.Q. concinna? Reuss.r. Ma. - 334. Q. Josephilla D'Orbigny.r. Am. - 335. Q. Schreibersi D'Orbigny. r. Am. B. - 336. Q. asperula Seguenza. R. B.

La fauna importantissima fin qui descrittia non la d'nopo d'interpretazioni a di commenti: essa tutta intiera e nelle singole classi che la costituiscono, depone perfettamente in farore, o meglio in accordo della posizione stratigrafica di gia stabilita; difatti cssa è miocenica per eccellenza, e lo attesta il maggior numero delle specie di tutte le classi, riconosciute nelle contrade e nei terreni miocenici più classici di tutta Enopra.

Difatti, tra i Vertebrati, sono specialmente i resti di pesci che si appartengono a specie ben note, le quali sono comunemente sparse nel Mioceno.

I Molluschi sono jer la maggior parte caratteristici del Mioceno, e la famiglia dei Pottinidi che ri predomina is lapresentata da suecie rariate, che caratterizzano a merariglia tutti i lembi dell'Elveziano calabrese.

'I'ra gli Articolati ricordo specialmente gli Entomostracei rappresentati da specie propric tel Mioceno d'Austria, di Francia e del Belgio.

Mia quello, tra i gropui di fossili, che a mio arviso deve attirare molto l'attenzione dei palcontologi, nonche dei geologi, è la classe dei Briozoi; la quale per le mmerose ed imprortanti forme di questo piano reclama un laroro monografico accurato; cio non pertanto io ri ho riconoscinto oltre cento specie distribuite in ventotto generi. Lo forme slecifiche sono prer la maggiol parte note per gli studî del compianto prof. 
A. Reuss e dell'egregio sig. dott. A. Manzoni; esse furono raccolte quasi tutte nel bacino di Vienna e specialmente negli strati di Leytha, che possono prendersi a tipo del piano elveziano del Mayer.

Tra gli Echinodermi merita speciale attenzione il gruppo dei Clipeastri, il quale si offre in questa zona con forme grandi e per la maggion parte elevate, completamente diverse da quelle che ho enumerato nelle fiune dei piani Tongriano ed Aquitaniano. Le specie note caratterizzno a meraviglia questa zona, incontrandosi dapertutto nel mioceno d'Europa, siccome nel Regrgino i Clipeastri associati ai Pettini caratterizzano quasi tutti i lembi dell'Elveziano.

Anco i Foraminiferi formano un importante grupno e ben caratteristico, nel quale le centorenti specie che ri figurano sono state quasi tutte riconoscinte dil D'Orbigny, dal Reuss, dal Karmer ece. nel bacino di Vienna ed in modo speciale negli strati di Leytha. L'/leterostegina papyracca è una particolire e grande forma. comune dapertutto nell'Eliceziano della prorincia di lieggio.

Da quanto è stato esposto puo ben conchiudersi al siucronismo degli strati calabresi, di cui discono, con rarî terreni miocenici d'Europa.

E primieramente, risulta erideutissimo como tali strati abbiano la massima somiglianza cogli strati di Leytha del bacino di Vienna, arendo comune con essi quasi tutta intiera la fauna; difatti i Moiluschi $\left.{ }^{1}\right)$, talumi Échuolermi, gli Entomostracei $\left({ }^{2}\right)$, i Briozoi $\left({ }^{3}\right)$, i Foraminiferi $\left({ }^{4}\right)$ attestano colla più grande chiarezza il sincronismo dei due terreni:

Sul continente italiano abbiamo gli strati calcarei superiori della Snperga, le marne e le sabbie serpentinose nutime di quelle colline, del Monferrato e di Serraralle, somiglianti più o meno per la litologica costitnzione, e molto più per li fauna, agli strati descritti, rappresentanti nel Regriano il piano elveziano del Majer" (").

Altri lembi di terreni calcarei sparsi in vari luoghi della Toseana sono stati oggetto di controversia tra i geologi sin da tempi abbastanza antichi; ma gli studî del prof. Capellini ( $\left.{ }^{\circ}\right)$, del sig. Fuchs $\left(^{7}\right)$ e d'altri hamo dimostrato trattarsi di ma formazione coetanea ed analoga al calcare di Leytha. Pure il prof. De Stefani recentemente ha creduto che tali calcari potessero comprendersi nel plioceno, ma tosto in altro suo lavoro ha fatto buone le idee del Fuchs e del Capellini; però tuttavia non si è sicuri, a mio arriso, che tali strati, che si connettono col sarmatico, studiato con tanta cura da quest'ultimo geologo, rappresentino l'Elreziano in 'L'oscana.

Oltre il Reggiano, nelle Provincie merilionali, gli strati elvezinui affiorano in varî lnoghi: così nella provincia di Lecee, la così detta pietra leccese rappresenta l'Elveziano; e basterebbe ad attestarlo li bella Terchratule Costec, che ri si raccoglie abbondantemente in esemplari conserratissimi; e meglio ancora gli abbondanti

(1) Vedi: Hoernes, Die fuss. Hollusten. - (*) Meusis, Die fose. Entomostracen des Ustirr. Tentiarbechens; Bosquet, Descript. des entom. foss. ecc. - (") Reuss, Die Cossilen Pulypmien des Wiener herliarb.

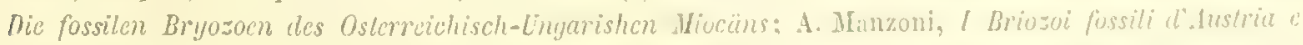

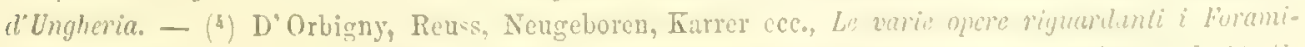

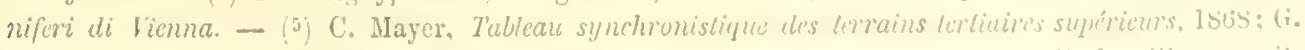
Michelotti, Descriple des foss. miace de l'llalic sept. - (i) La formazione gussosa di bustellime mariltima. - (') Relasione di un viaggio grolugico in Ihalie. 
resti di mumerosi Squalidi ilnustrati si bene dal prof. Costa; lo hamo dimostrato $d^{\circ}$ altromde i recenti studi del prof. Capellini $\left({ }^{1}\right)$.

Nella prorincia di Catanzaro il prof. Lorisato par che abbia trorato l'Elreziano in qualche luogo e col frcies stesso, col quale si presenta d'ordinario nel Reggiano, cioè riceo di Clipeastri dirersi; ma lo studio delle specie di rarie localitì di quella Irorimeia gentilmente comunicatemi dal suddetto professore. mi fa riconoscer tutti i Clipeastri che nel regegiano giacciono presso Stilo nel piano aquitaniano, e quindi Inolti lembi ricehi di tali Echinidi dorersi rapportare a tale epoca.

Ma sui monti che sorrastano a Catanzaro l'Elreziano è proprio identico a quello della prorincia di Reggio, contenendo la Terebratula Costae ed altri fossili caratteristici.

Calcari coetanei frar che esistano anco in Sardegna, da quanto ne dice il professor Ireneghini $\left({ }^{2}\right)$, sia per la litologia o per la stratigrafia, ma più ancora per la fauna, che racchiule Pettini, Litofugi, Eterostegine ed altre specie caratteristiche.

Corrispondono marimenti questi strati calabresi a quelli della seconda zona del mioceno messinese $\left({ }^{3}\right)$, ed ai calcari teneri ed a modelli di Siracusa ('); e le faune colle loro specie comuni attestano chiaramente tale rarricinamento.

Gli strati miocenici di Malta ci offrono una fauna. che ben si accorda colla descritta, per le specie iri raccolte nelle ultime due zone. Cosi i Clipeastri calabresi vi hanno dirersi rapuresentanti $\left({ }^{5}\right)$; la fauna dei Mollusehi vi corrisponde benissimo, e il sig. Fuchs vi ha raccolto un buon numero di specie identiche alle nostre ${ }^{6}$ ), fra le quali trorasi la Terebratula Costae (“). specie tanto sparsa nelle Calabrie, e perfettamente caratteristica di questo riano.

La fauna abbastanza ricea dell'Elreziano da occasione inoltre a considerazioni dialtro ordine che andrò breremente srolgendo.

E dapprima se si considera tale fauna comparando fra loro quelle delle direrse localitia esaminate, anco le più lontane, in generale si resta merarigliati della grande somiglianza o piì tosto della perfetta identità. Così ad esempio le specie che raccolmnusi a Monteleone sincontrano quasi tutte nelle contrade diverse che giacciono sul lato orientale della jrovincia; e questa perfetta corrispondenza ri esiste per tutte le classi dei Iolluschi cosi che pei Crostacei, pegli Echinodermi, pei Foraminiferi, siccome risulta ad eridenza dalle indicazioni di localiti enumerate nel precedente elenco. Considerata poi la fauma in se stessa, fir d'uopo comchiudere che essa non i una fanna littorale, ma che inrece il mare in cui si formarano quei depositi calcarco-salubiosi, in cui rireano rigogliosamente quei grandi Clipeastri di mita ai

Lalenothere fossiti o Puchyacunthus dell' lalia mevidionale. - Della pielra leccese e di alcumi

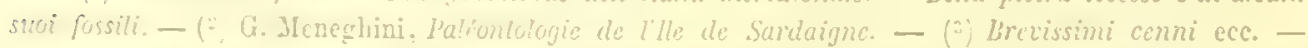

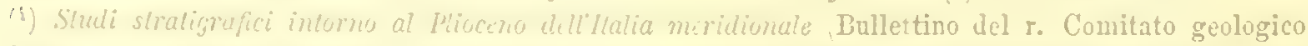

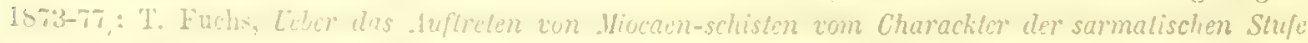

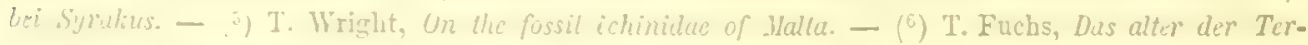

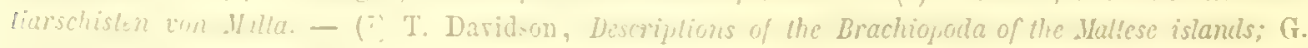

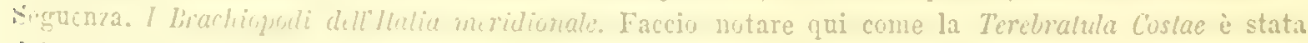
dal Davidern e dal Fuchs confusa culla T. sinuose Brocehí io, poiche la distinsi nella mia monografia. incori in on altro errore crelendula propria del piano Zancleano, laildore essa caratterizza dapertutto l'thruiano. 
numerosi e variati Pellini allo belle e gigantesche Janire, alle molte Ostriche, cui si associarano dei Gasteropodi non pochi e molti altri Lamellibranchi, offriva tali condizioni da dare alimento insieme a profusissimi Brachiopodi, ad una ricea faun di Briozoi che inerostara ogni maniera di conchiglie, ad una rariatissima congerie di Foraminiferi che colle sue spoglie andara a costituire parte non liere dei sedimenti; le quali ultime classi attestano eridentemente uma considererole profoudita delle acque. ore manifestarasi tanto rigogliosamente la rita nei rariati grupi degl'Tnvertebrati. cui si associarano ancora numerosi presci e tra questi predominarano i giganteschi Squali, coi quali conrirerano anco i grandi Cetacei.

Comparando la fauna elreziana della Calabria meridionale colla rirente si riconosce che essa racchiude un numero di specie ben considererole identiche a quelle tei nostri mari, di cui la proporzione già si elera oltre il 20 per cento, considerata complessiramente tutta la fauna. Difatti iu 336 specie 69 spettano a forme tuttaria rirenti; cioè in 52 Molluschi ve ne sono 8 che hanno jrotratto la loro esistenza sino ai mari attuali; di 13 Artropodi ne rirono ancora 2; di 122 Termi ne rirono 23 specie; di 12 Echinodermi nessuna specie si è conserrata sin oggi, e di 121 Protozoarii ne persistono 36 specie.

Un'altra quistione ben rimarcherole riene agerolmente risoluta collo studio degli strati elreziani, che troransi in rari luoghi del Reggiano. I geologi austriaci sono stati lungamente indecisi intorno alla successione stratigrafica dei calcari di Leytha, colle sabbie ed argille di Baden, credendo piì probabile che tali rocce fossero esattamente del medesimo orizzonte, e che quindi si sostituisseroa ricenda, e spiegando le differenze litologiche e paleontologiche per mezzo delle condizioni direrse in cui i due depositi si costituirono. Il Marer inrece sostiene che le rocee di Leitha formano un distinto piano (I'Elreziano) sottostante al Tortoniano, rapresentato nel bacino di Tienna dalle argille di Baden. Or tali redute appunto rengono pienamente confermate dai terreni calabresi, dore a Bunestare ad Ambuti ed altrore, agli strati elveziani si sorrappongono le argille tortoniane somigliantissime e coetanee a quelle di Baden.

\section{Piano Tortomiano.}

Sinonimi: Mioceno superiore degrli autori (parte). Seconto piano moliterranco (parte) Susas.

Dopo arer percorso molte contrade del Reggiano, le mie ricerche reiterate mi arevano gia messo in conoscenza della bella serie miocenica coi suoi rariatissimi piani sino alle sabbie del periodo elveziano; ma tuttaria in rerun luogo mi era occorso di riconoseere il piano tortoniano si bene caratterizzato in tauti luoghi di Sicilia. Desideroso di potere studiare anco in Calibria gli strati superiori del terziario medio, andara fra me stesso pensando quali fossero teoricamente i luoghi da esplorarsi con maggiore probabilita di riuscita, e conrinto che il mioceno superiore renue dapertutto denudato nel Reggiano, io ritenera, che se qualche lembo fosse rimasto, bisognara andarlo a cercare presso i depositi di gesso, che in Sicilia, come nell'Italia continentale, seguano ordinariamento nelle formazioni terziarie il limite tra il mioceno ed il plioceno. Cosi pensando, andai tosto arl esplorille il piu gran deposito gessifero di quella provincial, che grace nel territorio di Benestare, e fui 
lietissimo di trovare accanto alle estese rocce di gesso gli strati tortoniani, caratterizzati da una rieca fiuma.

Le ricerche ulteriori lungamente protratte mi hanno fatto scoprire qualche altro lmmo del Tortoniano, al quale bisogna attribuire ben poca importanza, sia per la breve estensione che occupa, siccome pei rari fossili che racchiude; ma tali studi mi hanno conrinto sempre meglio che nel Reggiano generalmente il mioceno si arresta al conglomerato Langhiano, ed in taluni rari luoghi alle sabbie elveziane, a che il rincontrare strati più recenti è una rera eccezione.

Questo difetto generalissimo del mioceno superiore in tutta la provincia di Reggio, seguito dalla generale distribuzione del plioceno antico, che d'ordinario poggia sul conglomerato Langhiano, ì tale un fatto, che acquista a mio modo di vedere, un' importante significazione. Pria di srolgere le mie idee in proposito è indispensabile esporre i risultati delle ricerche sul plioceno, e quindi mi riservo tale esame alla fine del compito.

Il villaggio di Benestare giace più in alto di Boralino, sopra elerate colline, in aprica e ridente posizione; il plioceno che dal piano si eleva grado grado inoltrandosi sino a considererole distanza dalla spinggia, giunge sino oltre quelle colline, che hamo le loro rette costituite dai suoi piì antichi strati marnosi, sui quali si ergono i fabbricati di Benestare. Oltrepassato il rillaggio, il suolo si abbassa gradatamente e ra a costituire una larga depressione, ai fianchi della quale ergesi verticalmente un potente conglomerato rosso, sul quale ramo a poggiare le più antiche marne plioceniche, che coromano le vette delle circostanti colline. Un rasto e potente deposito di gesso cristallino suecede al conglomerato in ordine discendente, e si estende cingendo la valle dal lato sud e dal lato ovest, dore si erge in erte prominenze e di unita al conglomerato ra assai lungi.

Le argille scagliose variegate del mioceno inferiore si estendono sul fondo della valle sottostando alle rocce gessose, o dore queste mancano, vengono fuori da sotto il conglomerato.

Nel centro dell'arrallamento, alle argille scagliose si addossano sabbie elveziane jiì o meno calcarifere in gran parte ricoperte dagli strati tortoniani, i quali d'altro canto si estenlono sulle argille scagliose stesse.

Ia formazione tortoniana adunque occupa presso Benestare una buona porziono della superficie di quell'avvallamento testè descritto; essa consta di argille azzure finissime che si stemprano assai bene nell'aequa, sono molto ricche di fossili, o negli strati superiori divengono brumastre e contengono solamente qualche esemplare di Ostrea navicularis Br. Sopra gli strati argillosi si addossa in alto della valle, un banco di grossolane sabbie cementate da rariabile quantiti di gresso, che in qualche luogo diviene molto albrondante.

Tale roceia assume lo spessore di sei o otto metri, o racchiude abbondante yuantiti di fossili voluminosi, che hamo subito una epigenesi veramente rimareherole. Sono dei Gasteropodi associati a graudi Lamellibranchi, che conservano per la maggior parte ambo le ralve riunite, a si mescolano a qualehe Echinide; e tutti questi solidi gusci tromusi convertiti in selenite cristallina, la quale is ora opaca e bianca e talrolta abbastanza traslueida, olliendo sempre la facile sfaldatura in direzione 
perpendicolare alla superficie. Questa talvolta è ben conservata sino a mostrare l'orna mentazione delle specie, come nel Clypeastor marginalus, nella Cardita Jouanneli, nei Peltuncoli, nei Cardii, nei Peltini ece. talvolta è crosa, e si mostria più o meno scabra.

Queste sabbie fossilifere formano adunque uma zona ben distinta dalle sottostanti argille, ma connessa ad esse per una fauma evidentemente tortoniana.

Le argille intanto formano la parte principale di quel piano, e racehiudono mu fauma variatissima e molto ricea. Esse raggiungono ma potenza di circa venti metri, si stemprano facilmente nell'acqua, e i piani inclimati che costituiscono sono mofondamente solcati dall'azione delle acque piorane; le quali rengono a modmre dei burroni coi fianchi molto ripidi, che damno uni fisonomia aftatto identica a quella dei coctanei terreni del Tortonese, fisonomia completata dal colorito azzurro-grigio intenso delle argille.

La stratificazione di tali terreni è lievemente inclinata, e sembra parallela, concordante coi sottostanti strati dell'Elrezinno.

Un altro lembo assai limitato della formazione tortoniana trorasi ad Ambuti direttamente sorrastante alle sabbie fossilifere dell'EIreziano, e riconerto dalla serie pliocenica, come è stato rappresentato nella precedente sezione (velli formazione elveziana). Quivi il Tortoniano riconoscesi più che d'altro dalla sua posizione stratigrafica e dalla sua natura litologica. Difitti sono delle argille grigio-azzmre piì o meno sabbiose, in generale prive di fossili, che assumono la potenza di circa trent: metri e si estendono in quella depressione, che ho descritto precedentemente, trinsrersale in rapporto alla valle di Condojanni sulla eui sinistra afliorano gli strati dell' Elreziano. Salendo lungo tale depressione ed oltrepassate le sabie clreziane, le argille del Tortoniano si estendono soprastanti, solcate da profondi burroni e formanti poggi e colliuette, appiamamenti e depressioni, che si segnono per uni zona poco larga, lungo la via che conduce a Portigliola e sin presso alla ralle che precede quel villaggio.

In qualche eccezionale lnogo di quella contrada tali argille, che sono piì sabbiose negli strati superiori, offrono rari fossili, gli opereoli di un Turbo, aleune Ostriche ed alcuni Pettini, tutti di specie che troransi a Benestare e la maggior parte caratteristiche del mioceno.

Altro breve lembo di argille tortoniane redesi presso il colle di Fulcò poco lungi da Sideruo superiore. Iri tali argille grigiastre si addossano lateralmente agli strati elveziani, e si famno riconoscere ner qualche raro Pettine in frammenti che offrono soltanto alla base; come il Pecten denulatus ed il $P$. cristatus. L'estensionc di tali rocee è poco considerevole al colle di fialco.

Dai dintorni di Monteleone provengono taluni fossili che si appartengono senza dubbio al periodo tortoniano, cosi il Ifurex Dortonensis, l'Astrea crenulata Goldt ed altri. Or siccome presso Monteleone l'Elveriano ì molto sriluppato e riceo di fossili, devesi necessariamente inferire che anco ivi il Tortoniano estende qualche suo lembo sopra gli strati elveziani.

E qui fa d'uopo ricordare ancora che nel territorio di Monteleone, tenimento di Cessaniti, trovansi degli strati a lignite alternanti e sormontati da strati fossiliferi. 
di cui taluni lacustri con Planorbis e Bithynia racchindono il combustibile, ed altri marini ricchi di Cerizî. Il prof. O. G. Costa ha ricordato tali depositi nei Cenni intorno alle scoperte palcontologiche fatte nel regno durante gli anni 1854 e 55 nelle quali ba benanco descritto taluni Cerizî di questo giacimento.

Questa formazione a me sembra doversi riferire al Tortoniano, quantunque sull'esempio del Mayer, nella Promemoria da me pubblicata ("), abbia riguardato tali depositi siccome Messiniani, essendoche in essi abbonda fra gli altri il Cerithium lignitarum, specie che caratterizza secondo il Mayer stesso gli strati più bassi del Messiniano. Cosi trorasi insieme il C. Duboisii, il C. minutum, il C.articulatum di Costa che è molto affine al C. pictum, e qualche altro.

I miei ulteriori studî compiti sul mioceno della provincia di Messina mi fanno mopendere verso l'idea che il Messiniano del Mayer debba associarsi al Tortoniano, dappoiche a me pare che $i$ depositi lacustri o di estuario che rapportansi al primo non sieno che facies diverse e coetanee dei depositi marini, sempre identici a se stessi, che si riferiscono al secondo, cosi parmi risultare dai rarî lnoghi del Messinese. Gli strati sabbiosi e marnosi con ammassi di gesso, che sorrastano sempre agli uni ed agli altri depositi e che teminano la serie miocenica, sarebbero quelli che bisogna riferire al Messiniano, qualora fosse conveniente di conservare questo piano siccome distinto, lo che parmi venire contrastato dai rapporti stratigrafici.

Dall' esame sinora fatto risulta evidente che la formazione tortoniana nel Reggiano è pochissimo sviluppata, non presentandosi che sotto forma di brevissimi lembi, di cui il più importante è quello che giace presso Benestare, essendo il più esteso ed il solo che offre ma ricea fauna.

Non può esservi dubbio di sorta, da quanto è stato detto intorno all'Elveziano ed al Tortoniano, e specialmente sul ristrettissimo loro sviluppo nella provincia di Reggio, che una rastissima denudazione si operò sul finire della grande epoca miocenica, per la quale le due formazioni vennero distrutte quasi interamente, solo restandone dei frammenti incalcolabili sopra ambo i rersanti, ed anco a grandi distanze, testimonî parlanti della generale distribuzione degli strati di questi due periodi, pria che la denudazione avesse esercitata la sua rapina. Ma tuttocio viene confermato con luminose prove dallo studio del plioceno, che estendesi invece dapertutto nel Reggiano; ̀̀ perciò che io mi riservo a discutere questi importantissimi fatti, di alto momento per la geologia dell'Italia meridionale, nelle conclusioni ultime deI mio lavoro.

Paleontologia. - Chiunque si fa a razzolare nelle argille di Benestare si accorge a prima giunta che trattasi di depositi tortoniani, il facies di quella fauma uonchè i distintivi tutti del deposito sono assai caratteristici e rispondono con presisione a quelli molto uniformi, che gli strati tortoniani offrono nonche in Italia, dapertutto in L̇uropa.

I fossili, quantunque di perfetta conservazione e profusamente sparsi, pure sono per lo piì rolti, ma per l'ottimo stato anco un frammento riesce determinabile.

(') G. Seguenza, Brevissimi conni intorno le formazioni tersiaric della provincia di Reggio-Calabria. 
La fauna vi è assai doviziosa: ne sia testimonio il seguente elenco ricco di oltre 900 specie, raccolte nel breve tempo di tre esplorazioni, impiegando appena alcune ore per ciascuna.

Tale fauna è costituita dall'insieme di molte classi. I Vertelorati ri hanno lasciato pochi resti di soli pesci, nei Molluschi abbondantissimi predominano principalmente i Gasteropodi. Tra gli Artropodi gli Ostracodi vi hanno una parte considerevole. così i Briozoi e taluni Vermi. Parimenti tra i Celenterati, gli Antozoarii e le Spugne perforanti. I Foraminiferi poi hamo preso in tali depositi un immenso sviluppo.

Da tale insieme bisogna conchiudere che non trattasi d'una fauna littorale, ma invece di un deposito di mare considererolmente profondo, che può rapportarsi presso a poco alla zona coralligena, e la natura molto fina del deposito attesta in favore della profondità delle acque.

Non così è a dirsi degli strati superiori formati di sabbie grossolane cementate dal gesso cristallino: in esse la fauna è costituita da poche specie di MIolluschi, la maggior parte di grandi Bivalvi, e di qualche Echinide. Tali fossili colle valve riunite, bene conservate, e trasformate in gesso attestano un deposito littoraneo, siccome la roccia che li racchinde.

I depositi tortoniani di Ambuti del colle di Falco, siccome quelli di Monteleone non racchiudono che pochi resti animali.

Gli strati a Cerizî di Cessaniti presso MIonteleone mostrano evidentemente colle alternanze, che quel deposito costa di strati di estuario caratterizzati dalla grande abbondanza di Cerizî, e di strati lacustri, in cui giace la lignite, contradistinti dai Pianorbis e dalle Bithynie.

Io ho voluto enumerare a parte le poche specie contenute in questi strati, la cui età precisal non è colla massima certezza definita, o per meglio dire non è ancora definitivamente stabilito che essi debbansi associare al Tortoniano, siccome parmi invero molto probabile.

Elenco delle specie fossili raccolte nel piano Tortoniano (').

\section{Tipo. VERTEBRATI.}

Classe. Pescr. - Ordine. Condrotierigit.

Odontaspis. - 1. 0. dubia Agassiz. Un sol dente ben caratteristico e ben conservato quantunque mancante dei piccoli coni laterali e della radice. $R$.

Cnleocerdus. - 2. G. Pantanelli Lawley. Anco di questa specie, nelle argille tortoniane di Benestare, non ho trovato che un solo dente, che, a dire il vero, è conservatissimo, R. $\left({ }^{2}\right)$.

(1) Le specie enumerate in questo elenco provengono quasi tutte dalla ricca localitì di Benestare, alcune poche sono da Ambutì e da Monteleone, di quest"nltime sarà sempre indicata la provenienza, nelle prime sarà sottintesa.

(2) Devo alla cortesissima gentilezza del sig. cav. R. Lawwley la deferminazione dei resti di pesci qui sopra enumerati. 
Ordine. 'T'eleostes.

Pagrus. - 3. T. . . . sp.? Un piccolo dente emisferico renne riguardato dal Lawley siccome rappresentante di tal genere, ma nella lettera di cui mi onoro sogginnge che potrebbe spettare ad un Sargus, overo riferirsi al Chrysophys Agassizii. E. Sismondia. li.

Un altro frammento di dente potrebbe spettare a varîgeneri, ma somiglia ai moltissimi che redonsi sulle mascelle del Cantharus Ûciunensis Lawley.

A questi pochi resti si devono aggingere, tra i fossili ittiolitici, numerose e comuni forme di Otoliti, che restano tuttaria specificamente indeterminate per difetto ki studi comparativi.

\section{Tipo. MO L L U S C H I.}

Classe. Crfalorodi.

Loligo. - 4. L. rulgaris? Limeo. Alemi piccoli denti remnero dal sig. Lawley riguardati siccome estremiti di mandibole di questo cefalopodo, essendo identici ai moltissimi che si raccolgono nel plioceno toscano ad Orciano e nel Sienese; ma a dire il rero parmi azzardata la determinazione specifica d'un cephalopodo fondata sull'esame delle sole estremitì delle mandibole.

Classe. Gasterorodi.

Acteon. - 5. A. ping is D'orbigny. Piccoli esemplari. R. - 6. A. semistriatis Ferrusic. R.

Scaphander. - 7. S. Iignarius Limeo (Bullu). Pochi frammenti. R. V.

HBula, - 8. B. utriculus Brocchi. R. V. - 9. B. miliaris Brocchi. Alemi frammenti. R.

Utriculus. - 10. U. Lajonkerianus Basterot (Bullina). Un bello e caratteristico esemplare. R. - 11. U. tru u o atul u s Bruguière (Bulla). Frammenti. R. V.

Cylichnar. - 12. C.esube ounlus? D'Orbigny (Bulla) = Bulla conulus Hoemes (non Deshayes). Frammenti dubbî. R. - 13. C. umbilicata Montagu. Due buoni esemplari. R. V.-14. C. clathrata? Defrance (Eulla). Un frammento dublio, $R$.

15. C. nana n. sp. 'l'at. XI. tig. 1, 1a.

Teste minime, ovato-subcylindracea, utringue obliquissime lruncata, spiraliter tenuissime rare striatu, postice umbilicata; regio antica prominens, os postice strichum antice elargatum ovalum, labrum sinistrum simplice subrectum, dextrum flexuosum, columellu fortiter arcuata; umbelicum superficiale.

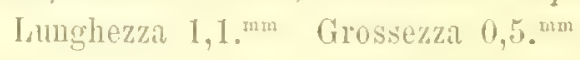

Dalle sprecie terziarie o riventi che io conoseo questa è ben distinta per l'insieme dei suoi caratteri e sprecialmente per la conformazione della bocea, la quale stretta ed in firma di fenditura per breve tratto nella parte superiore, si allarga tosto in forma orato-illungata per la grande curratura del lato columellare, perlochè duesta frecolil specie assume tille andamento nella forma da somigliare alquanto alle Philine, da costituirne cioè una forma prossima a quel genere. R. 
Trisia. - 16. T. retusa Sowerby (Cypraca). Rapporto con qualche dubbio a questa specie alcuni esemplari i quali presentano l'apertura un po' più laterale di quauto è negli esemplari inglesi. R.

Erato. - 17. E. Ia evis Donovan (Voluta) = Voluta cypracola Brocchi. 1. V.

Marginella. - 18. M. m i i a ce a Lamk. Piì piecola della rivente. R. V. - 19. M. Deshayesi i Michelotti. Lisemplari ancora più grandi di quelli del Tortonese.c. 20. M. Benestarens is 11 . sp. Tir. XI. fig. 2, 2थ.

Testa ovato-oblonga, spira brevissina mammillate: labrum inlus metio incrassalum, extus crasse et late marginatum; plicae columellac quatuor crassae: apertura stricta inferne vix latior.

\section{Lunghezza $14 .^{\mathrm{mm}}$ Larghezza $90^{\mathrm{mm}}$}

Specie molto affine alla M. marginata Bou., dalla quale si distingue benissimo per essere più allungata, per avere la spira molto più breve, appena sporgente e mammillata, ed il labro ancor più ingrossato.

angieula. - 21. R. margillata Deshayes (Auricula). E m solo esemplare che io riferisco con qualche dubbio alla nomimata specie del Deshajes. R. - 22. R. a uriculata Menard. Due esemplari più grandi di quelli che pescansi nel Mediterraneo, ma che corrispondono esattamente in tutti gli altri caratteri. R.V.

23. R. calabra n. sp. Tav. XI. fig: 3.

Questa è specie grandemente affine alla $R$. conformis Monterosato, ma si distingue bene per avere l'ultimo arrolgimento proporzionalmente più brere e piu globoso, per le suture meno profonde, per la piega posteriore molto arricinata alle anteriori, e per una smarginatura profonda alla regione anteriore della bocca. ma il più importante carattere si è quello della mancauza assoluta di una cuartil piega, che distingue la specie virente interponendosi tra la posteriore e le anteriori.

\section{Lunghezza $5,6{ }^{\mathrm{mm}}$ Larghezza 3,5 . $^{\mathrm{mm}}$}

Var. R. ornata. Linee spirali impresse, ed indizi più o meno distinti di numerose costole longitudinali. c.

Mirm. - 24. M. s crobiculata Brocthi (Voluta). Raccolte anco le Var. B. e C. del Bellardi. I. - 25. M. striatula Brocchi (Voluta). Insieme raccogliesi anco la Var. A. Bellardi.c. - 26. MI. B ors on i i Bellardi= M. cancellata Bonelli, M.elegans Michelotti.C. - 27. M. recticosta Bellardi, Gli esemplari di questa specie presentano delle rariazioni nel numero e nella prominenza delle costole, alcuni offrono indizio di strie presso le suture. c. - 28. II. pyramidella Brocchi (Volula). I nostri esemplari presentansi piì o meno costati per lo lungo, cogli arrolgimenti striati nella porzione superiore. c.

29. M. minima 11. sp. Tar. XI. fig. 4.

Testa ovalo-obloniya, spira brevis, oblusa. Infraclus convexinsculi, posticc marginati; ultimus magnus, antice productus gradatim attcnuatus, 2/3 longitudine vix brevior; medii transverse laeviler plicali, plicae crussae, conliguar, obsoletae. Suturae profundalae. Superficies lacvissime. Os angushum elongatum. Labrum sinisirum aliquanlulum flexuosum, simplice, lacre; columella quatriplicata, plicae aculae, prominentes, mediae majores.

Lunghezza 5, 5. $0^{\text {mm }}$ Larghezza $2,60^{\text {mm }}$ 
Questa piccola specie è ben caratterizzata dalla sua forma e dalle pieghe longitudinali negli arrolgimenti medii, e piì ancora dalla brerità della spira, che è inoltre ottusa, e da un cordoncino poco prominente che trovasi al margine posteriore degli arrolgimenti. r.

30. MI. bicoromata n. sp. Tav. XI. fig. 5.

Testa parva, ovato-oblonga, spira breviuscula, obtusa. Anfractus subplanati, plicato-costati, postice bicoronati, propter series duas granulorum. qui ornan! costarum fincm; ullimus magnus, untice productus, gradatim in canalem brevem altenuatus, $3 / 5$ longiludinis vix brevior"; suturac profundatac. Superficies regulariter, transverse striata, striae impressae, paucae super costas excurrentes. Os angushm, oblongo-sublanceolatum. Labrum sinistrum arcuatum, simplice; columella triplicate, plicae obtusae, antica minor.

\section{Linghezza 5. ${ }^{\text {mm }}$ Larghezza $2,30^{\text {mm }}$}

Questa bella mitra is assai ben distinta sopratutto dalla sua ornamentazione, essendoche le costole o pieghe prominenti che l'ornano finiscono alla parte posteriore di ciascuno avvolgimento con dne granuli o tubercoli piu o meno rotondati e prominenti, che formano due serie, quasi due corone. Ne ho raccolto un solo esemplare. Ir.

Conus. - 31. C. Berghausii Michelotti. Esemplari in cattivo stato e sempre rotti. c. - 32. C. fuscocingulatus Brom. Esemplari parimenti guasti.c. 33. C. Mercati Brocchi.c. - 34. C. $n$ is us D'Orbigny $=$ C. puncticulatus Grat. (non Lamarck). r. - 35. C. rentricosus Bronu. r. - 36. C. pyrula Brocchi. R. - 37. C. striatulus Brocchi. r. - 38. C. Brocchii Bronn= C. deperditus Brocchi (non Brug.). Vi riferisco con qualche dubbio una piccola spirale mancante di tutta la parte anteriore. R. - 39. C. antediluvianus Bruguière. Esemplari ben conservati ma rotti. c.

Plenrotoma. - 40. P. coromata MLnster. Si raccolgono diverse varietì. c. 41. P. contigua Brochi. (Murex [Pleurotoma]). Oltre la forma tipica si raccolgono insieme molto più rare dne distinte varietà. L'una var. granosa offre dei grannli ben distinti all' intersezione dei cingoli colle linee flessuose d'acerescimento, l'altra var. lamellosa ha quest'ultime linee rarricinate e lamellose. C. 42. P. turicula Brochi (Iurcx). Qualche raro esemplare commisto ai uumerosi della precedente specie. R.

Surcula. - 43. S. intelmedia Brom (Plcurotoma). Un solo esemplare. R. 44. S. Mercati i Bellardi. = Pleurotoma sinuata Bellardi. c. - 45. S. dimidiata Brocchi (Jurex [Pleurotoma]). R. - 46. S. Lamarckii Bellardi. Esemplari beu couserrati.c.

Genota. - 47. G. Craverii Bell. = Perrotoma Partschii Bell. e Mich. Esemplari abbondanti, ma sempre rotti. C. - 48. G. M unsteri Bell. e Mich. (Pleurotoma). Con qualche dubbio vi rapporto alcuni frammenti. R.

Drillis. - 49. D. Scilla Bell. = Drillia interposita Bellardi (M. S.), Pleurotoma interposita Seguenza (non Desh.). R. - 50. D. Paretii Hayer (PleuroLoma). Abbondante e ben conservata. C. - 51. D. obtusangula Brocchi (Murcx [Fusus]). 1. - 52. D. sejuucta Bellardi. R. - 53. D. modiola Jan. 
(Fusus). Un solo frammento. R. - 54. D. crispata Jan. (Plcurotoma). Esemplari della forma tipica del mioceno tortonese. R. - 55. D. ordita Bellardi. Varî esemplari incompleti. $\mathrm{R}$.

56. D. Luciae n. sp. Tav. XI. fig. 6 .

Questa specie è affine alla D. crispata, ma più si arricina alla D. biflosa Bellardi. Essa è composta di quattro avvolgimenti, oltre del nueleo embrionario che è rotto e sembra analogo a quello. della D. crispata; la parte anteriore di ciascuno arvolgimento è leggermente concara e porta un cingolo posto circa ad ${ }^{1} /$ is di distanza dalla sutura, la carena è acuta, la parte posteriore degli arrolgimenti è appianata o leggermente convessa e porta alla meta due esilissimi cingoli molto ravricinati. Le linee di acerescimento sono inoltre appena discernibili.

Lunghezza $4{ }^{\mathrm{mm}}$ Larghezza $1,7 \mathrm{fm}^{\mathrm{mm}}$

57. D. globulifera n. sp. Tav. XI. fig. 7 .

Chiamo cosi varî frammenti d'una specie certo affine alla mia D. consangrinea, ma diversa per l'apice globoso, per la carena degli avrolgimenti piu sporgente e piì acuta, inoltre sulla meti posteriore di ciascun avvolgimento non v'ha che un solo cingolo presso la sutura. R.

58. D. sigmoidea Bromn. (Pleurotoma). c.

59. D. minor n. sp. Tav. XI. fig. 8 .

Testa parva elongato-turrila, apex oblusus, rolundatus. Anfractus sex vel septem convexi, postice vix depressi, ultimus antice depressus, productus, tolius longitudinis dimidium subaeguans. Superfacies laevissima, longitudinaliter costata, costac prominentes, rotundatae, postice th ad basim evanescentes; interstitia majora. Os clongatum.

Lunghezza $7 .^{\mathrm{mm}}$ Larghezza $2,8{ }^{\mathrm{mm}}$

Questa specie assai affine alla precedente ne è pure distintissima per l' apice ottuso di forma assai diversa e globoso, per gli arrolgimenti molto piu conressi, per le costole più sporgenti rotondate, che si terminano bruscamente alla parte posteriore degli arvolgimenti, e non souo flessuose, mancano da ultimo in questa specie le linee trastersali che si osservano sul canale della $D$. sigmodea. 1 .

Ciavatula. - 60. C. Sotterii? Michelotti (Pleurotoma). Un solo piccolo frammento molto dubbio. R. - 61. C. Coppii Bellardi. I pochi esemplari raccolti furono comparati colla forma tipica del Tortonese, e solo in alcuno di essi sono poco distinte Ie nodosita degli arrolgimenti. $R$.

62. C. monsleonensis n. sp. Tay. XI. fig. 9.

Questa è specie molto affine alla P. spinosa Grat. ma ha la superficie con diversa scultura, cioè ricoperta da sottili costole trassersali molto rarricinate, inoltre è meno gracile, e coll' ultimo avvolgimento proporzionalmente più grande; per lo costole spirali somiglia in qualche modo alla P. Schreibersii. Hoernes, ma la nostra è più svelta, cogli arvolgimenti più incavati, e colle spine che sono appariscenti soltanto alla parte posteriore degli arvolgimenti.

Lunghezza 22. ${ }^{\mathrm{mm}}$ Larghezza 12 . $^{\mathrm{mu}}$

Questa specie riene da Monteleone. R. - 63. C. Schreibersii Hornos. (Pleurotoma). Ho raccolto pochi esemplari mal conservati, che appartengono con 
sicurezza a questa bella specie del bacino di Vienna. R. - 64. C. granulatocincta? IIunstel (Pleurolomu). Rapporto con molto dubbio a questa specie, e come rarietì di essa, nu solo esemplare, che è meno angoloso nell'nltimo avrolgimentn, ma somiglia bene nella rariata scultura. 1 . - 65. C. Jouanueti Grat. (Pleurotomi). Un solo esemplare. IR - 66. C. semimarginata Lamk. Pleurotoma. Grandi e ben conservati esemplari. C.

bolichotoma. - (i7. D. cataphrata Brochi (Murex [Pleurotoma]). Raceogliesi la forma grande e tipica. C.

Ohigoroma. - 198. O. panu us Basterot (Pleurolomu). R.

asmotoma. - 69. H. scaberima 11. sp. Tar. XI. fig. 10.

Questa specie difterisce dalla $/$. reticulata, alla quale piì somiglia, per molti anteri. E più larga, le costole piì prominenti e meno numerose, vengono intersecate da eingoli lamelliformi, e nelle intersezioni sporgono delle prominenze cuasi spiniformi; gli arrolgimenti sono più conressi, più breri, con minor numero di cingoli, le suture sono più mrofonde. L'apice somiglia a quello della 11. reticulala, ma è meno gracile, ed ha la superficie finamente ed elegantemente reticolati.

$$
\text { Limghezzil 15. mm Larghezza 2.8. }{ }^{\text {mm }} \mathrm{K} \text {. }
$$

70. H. turritelloides Bellardi (Plezrotoma). Piceoli ma distintissimi esemplari. r.

mangelia. - 71. M. contracta Bellardi. R. - 72. M. angusta Jan. (Pleurotoma). Un solo frimmento. $R$.

genphitonna. - 73. R. hispidir Bellardi. R. - 74. R. hispidula Jan. (Plererotoma). 1. - 75. R. plicatella Jin. (Fusus). Vi rapporto alcuni frammenti. R. 76. R. ble ris n. sp. T'ir. XI. fig. 11 .

Questa specie è molto attine alla $R$. nana Scacehi dalla quale distinguesi bene per essere più piceolin, piì breve, coll'nltimo arvolgimento piì lungo della spira, che è formata d'un minor numero di giri, le cui costole sono più gracili, ed esilissime le linee trasrersali, siccome l'apice lerigatissimo è formato d'arrolgimenti piir conressi, disgiunti da suture piu profonde.

\section{Lunghezza 3.m Larghezza $1 .^{\mathrm{mm}} \mathrm{r}$.}

77. R. brachystoma Philippi (Pleurotome). Diverse variazioni.c. V.

78. R. harpulactorm is 11 . sp. 'Tar. XI. fig. 12 .

Specie afline allit R. harpula (Brocchi) e più ancora alla R. Columnae (Seacchi); ma ha gli arrolgimenti quasi angolosi alla meti, dove le costole sottili sono più sporgenti, la superficie liscia, meno tahuni rari indizi di linee trasversali.

Lumghezza 7,7."mn Litrghezza $3 .^{\text {nnn }} \mathrm{R}$.

Atomen - 79. A. Iy pothetica Bellardi (Raphitoma). Un solo esemplare. R.

Mival. - 80. (). cylindracea Borson. Un solo esemplare. R.

Ancillaris. - 81. A. glandiformis Lamarek : Anolax inflata Bors, Ancil. laria influta Bast. S'incontra commemente la forma a spira breve, ottusa, rotondatil; la rarictit al spira acutir è meno comune. C. - 82. A. obsoleta Brocchi (Buccinum). Comunissima questa specie offre raramente quella varieti allungata che si rappresentil dall'Hoernes nella fig. $t$ della tar. VI. C. 
Columbella. - 83. C. nassoides Grateloup (Fusus). Var. A. Bellardi. Tav. XI. fig. 17 (dpice). La forma tipica manca nel Tortoniano calabrese. La rar. A. abbonda, essa è breve, rentricosa, colla bocca ristretta, e coll'ultimo arrolgimento che è ormato da forti strie spirali. To opinara che questa forma doresse specificamente disgiungersi; ma uno studio accurato sulla conformazione dallo stato primitivo della conchiglia, rivelatoci dalla forma dell'apice, mi ha dimostrato completa somiglianza tra il tipo e la rarietid. C.

84. C. inflata 1. sp. Tav. XI. fig. 13, $13 a$.

Questa specie è affine alla C. nassoides, dalla quale si distingue per essere molto più rigonfia e d'una grandissima soliditi, per l'angolo spirale considererolmente più largo, pel canale più breve, il quale porta clelle forti costole trasversuli, per una distinta angolositi cle separa nell'ultimo arrolgimento la porzione apuianata dalla depressa, per la bocea piu Iarga, per l'apice costituito da due arvolgimenti pressochè di egual diametio, essendo il primo globoso, ladilove nella C. nassoides è formato da tre avrolgimenti convessi e regolarmente crescenti.

Lunghezza 23. ${ }^{\mathrm{m}}$ Larghezza 13.

Questa specie trovasi anco nel Tortoniano messinese. 1".

85. C. interposita n. sp. Tar. XI. fig. 14, 14a.

Io ho riguardato dapprima questa forma siceome una piccola rarietid della précedente, ma più mimuzioso esane me l'ha fatto distinguere. Difatti questa Columbella assai più piccola è molto meno assottigliata nella spirale, e costituita da otto arrolgimenti, invece di undici o di dodici, alquanto più conressi, la superficie presenta numerose o lievissime pieghe o costicine longitudinali; l'apice è nolto più grande quautunque la conchiglia raggiunga appena in lunghezza i due quinti della precedente specie, esso è formato da due arrolgimenti molto convessi e pressochè uguali, il primo dei quali non è glohoso come nella Columbella inflata.

Lunghezza 14. ${ }^{\mathrm{mm}}$ Larghezza $5,5$. mm Un solo esemplare. R.

86. C. Calcara Seguenza. Tar. XI. fig. 18 (Apice). Specie affine alla C. subulata, ma piccola e proporzionalmente piu breve. Comme nel plioceno d'Altavilla presso Palermo. R. - 87. C. B ellard i Segnenza. Tar. XL. fig. 20 (Apicc). Specie più gracile della $C$. subulata e diversa anco per li forma dell'apice. R. 88. C. minor Scacchi Tar. XI. fig. 19 (Apice). Questa specie risponde esattamente pei caratteri dell'apice e tutti gli altri, alla forma vivente del Mediterraneo, taluni esemplari soltanto sono meno gracili. c. V. - 89. C. colrugata Brocchi (Buccinum). Tav. XI. fig. 16 (Apice). Pochi e ben distinti esemplari. R.

90. C. colonata n. sp. - C. thiarch Hoemes (non Bellardi). Tar. XI. fig. 15, 156.

Testa parva, ovato-oblonga, spirce clale, acuitiuscula; anfractus septem, tres primi convexi, esquisite transverse striati, qualuor ultimi planati, costati; costac prominentes, aculae, rectae, postice super suluram productac anfractuumque coronantes; anfractus ultimus antice, ubi costae cvanescunt, depressus, produchus, et dimidiam tolius longitudinis superans. Os ovalo-oblongum; labrum sinistrum simplice, antice compressum, extus vix cressiusculum, intus denticulatum. Superficies laevis, canalis extus spiraliter sulcalus.

Lunghezza 6,4 . "mm Larghezza 2,8. 
Questa specie è affine alla $C$. costulata (Cantraine) (C. Halyeti Jeffreys vivente), In quale ha gli arrolgimenti conressi, le costole piì gracili e flessuose ed altri carattcri che ben la distinguono dalla mia, che parmi corrispondere esattamente ad una specie del bacino di Vienna, che l'Hoernes riferì erroneamente alla C. thiura Bellardi. c.

Bisogna ancora distinguere due rarietit.

Var. A. gracilior. Folma piì allungata, più gracile. R.

Var, B. striala. Tar. XI. fig. 15a. Superficie striata spiralmente. 1 .

Bros - 91. P. po\ygonus Brocchi (Buccinum). Esemplari piuttosto piccoli. C. Vasser - 92. N. prismatica Brocchi (Buccinum) 1. - 93. N. serraticosta Bronn (Buccinum). Identica agli esemplari del plioceno. Questa è specie aftatto diversa dalla N. pusilla (Phil.), che ha strie impresse, spirali, rarricinate, ed in quella del Brown sono invece cingoli molto meno numerosi. c. -94 . N. graunlaris Borson. C.

95. N. crenaticosta n. sp. Tav. XI. fig. 21.

Testa ovata, parva, longitudinaliter costata, costac 10 prominentes, interstiis duplo minores, nodoso-crenatae. Anfractus septem, tres primi laeves, ecostati, convexi, caeteri convexi, costati, postice aliquantulum planulali, spiraliterque striati; striae intermptae, ad interstitia evanescentes, super costas nodibus connexas, ad basim continuale; anfractus ultimus dimidium totius longitudinis vix superans. Os orbiculato-ovatum; labrum sinistrum extus varicosum, crenatum, intus denticulamom.

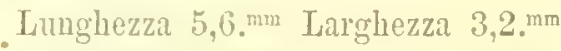

Questa specie è molto affine alla precelente dalla quale si distingue benissimo pegli arrolgimenti più convessi, pel minor numero di costole, pei caratteri delle strie spirali ecc. Somiglia anco alla $N$. serraticosta, ma si distingue pei medesimi caratteri. l.

96. N. turbinella Brocchi (Buccinum) c. - 97. N. Brocchii Mayer $=N$. costulata Brocehi (Buccinum) (non Renier). Specie ben dirersa dalla $N$. costulata Renier virente. La specie che esamino è molto variabile, sopratutto nello sriluppo delle coste longitudinali, che sono pinttosto delle pieghe, nei nostri esemplari miocenici tali pieghe sono poco appariscenti e quindi la specie sembra fare passaggio alla seguente. C. - 98. N. semistriata Brochi (Buccinum). I. V.

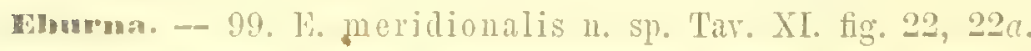

Teste ovate, solida, spire prominers, acuta. Anfractus 10 convexi, laeves, ultimus marimus globoso-ovatus, postice rotundalo-planatus, antice plica crassa cum callositute columellae coniuncta. Suturae superficiales, haud canaliculatae, planoconcavae, contiguac. Os ovatum, labruin sinistrun simplice, callum lebri dertri crassum.

Luughezza 42. ${ }^{\mathrm{mm}}$ Larghezza $27 .^{\mathrm{nm}}$

Questa specie par che sostituisea la E. eburnoides (Math.) del Tortoniano del Nord dell'Italia e del bacino di Vieuna, dalla quale differisce per non arere le suture scanalate, per essere piì globosa, cogli arvolgimenti più convessi, specialmente messo le suture, col labro simistro non progettato in fuori, il quale carattere da 
alla ma specie ma forma più globosa, e l'inverso imprime all' E. cburnoicles una fisonomia ben particolare e distintiva. 1 .

Var. oblonga. Distinguo così un esempline di forma piì allungata e che forse potrà costituire una distinta specie. $R$.

Terebar. - 100. T. fuscata Brochi (Buccinum). Offre nel mioceno regogiano lo rarie forme piì o meno allungate, che costituiscono diverse variazioni. c. - 101. T. acuminata Borson. Esemplari incompleti, ma che oftrono le diverse rariazioni che suole presentare la specie. $x^{\circ}-102$. T. pertusa Basterot $=$ Buccinum strigilaum Brocchi (non Limeo). Anco di questa le diverse fariazioni.r. Var. crispata. Una varieta importante di questo giacimento, che forse dorrebbe specificatamente distinguersi, offresi cogli avvolgimenti incarati verso la regione anteriore, col cordone posteriore prominente e rotondato, colle pieghe longitudinali sinuose più fortemente e pressochè doppie in numero. r. - 103. T. Basteroti Nyst = Buccinum duplicalum Brocchi (non Limeo). R. - 104. T. Scarabelli Doderlein. Comparati gli esemplari col tipo della collezione Doderlein. I.

Cassis. - 105. C. saburon Bruguière (Cussidect). Gli esemplari del nostro mioceno sono senza strie spirali sull'ultimo artolgimento e formano la Var. u Cocconi = Cassis laevigata Defi., la quale suole commemente rinuirsi alla $C$. saburon, ma che potrebbe ritenersi distinta, quantunque par che sianvi auelli intermedii tra le due forme r. V. - 106. C. mammillaris Grateloup. Soltanto grossi frammenti del labro sinistro. 1".

Oniscia. - 107. 0. calabia n. sp.

Io sono d'arviso che l'unico esemplare rotto e qualche frammento di Oniscia da me raccolti nel Tortoniano di Benestare mal si rapportimo alla specie del Brocchi (0. cithara); di fatti in tali resti comparati al tipo del Brocehi si osserta che le costole sono più strette, meno arrotondate, e più distanti, percio in minor numero e separate da più larghi interstizî, inoltre rerso la parte posteriore non si terminano in forma di nodo arrotondato, ma bensì acute e spinescenti, e gli avvolgimenti sono angolosi in linea delle spine e ben appianati posteriormente, ripiegandosi sempre al margine, che ra a ricuoprire l'arrolgimento seguente sino quasi all'angolo, lasciando appena renir fuori le spine: ladklore nell' 0 . cilhark, ogni arrolgimento è poco appianato posteriormente, nè vịene cosi ricoperto dal precedente. Quindi mella forma calabrese la spirale è meno sporgente, l' angolo spirale è molto più aperto, inoltre i solchi trastersali sono 1000 profondi.

Tali caratteri differenziano bene questa dalla specie del Brocchi, io propongo quindi il nome di O. calabra. R.

Cassidara:a. - 108. C. echinophora Lin. (Buccinum). Sempre dei frammenti. 1. V.

Cuthria. - 109. E. cornea Linneo (Murex).r. V. - 110. F. magna Bellardi. Esemplari rari e grandi ma rotti, pure ben riconoscibili. 1\%. Var. striatc R.

Follia. - 111. P. Bellardiin. sp.

Specie affine alla P. exacuta Bell. dalla quale sopratutto differisce per le costole trasversali nodoso-squamose, le quali sono altematiramente magriori e minori. Potrebbe anco essere una distinti rarietid della specie del 'T'ortonese. r.

Crave!! - 112. C. Ilipsteini Michelotti (Fusus). Gli esemplari del Regriano 
sono meno solidi di quelli del Modenese, e d'ordinario più gracili: tale rarieti i stata descritta dal prof. Comi. c.

Tusus. - 113. F. crispus Borson. Questa forma viene dal Bellardi rimita al F. rostratus, ma gli esemplari che io conosco del plioceno e del mioceno, offrono, oltre dei caratteri speciali, uno stato embrionario afratto diverso, pel quale fatto soltanto non ì possibile di associarli specificatamente al $r$. rastralus. R. 114. F. longiroster Brocehi (Jhrer). Sono alcuni frammenti, che io rapporto a questa specie molto comune nel plioceno. R. - 115. F. Valenciennesii Grateloun. Tarî esemplari ben caratteristici rappresentano questa specie. r. 116. F. lamellosus Borson. Alcuno vorrebbe credere questa specie identica al F. pulchellus Pliil., ma essa ne è ben distinta per l'apice dirersissimo, formato cioè th quattro arrolgimenti regolarmente crescenti, convessi e lisci. c.

Murex. - 117. M. torularius Lamarck = M. brandaris e \%. cornutus Brocehi (nom Limeo), M. pseudcuranduris D'Ancona. C.

118. M. Bellardii n. sp. Tit. XI. fig. 23.

Testu subfusiformis, clongalu. Anfraches regulariler convexi, gibboso-robundati, postice vix subplanali, ullimus antice parum depressus, $3 / 4$ longitudinis subaequans; suturae superficiales; superficies transverse costato-striata; costulae parval aliisque minoribus striisque confertis intermixtac, ac super varices omnes crcurrentes. Furices compressae, solidele, ad suturas contignae ot in tres series regulures, contontas dispositue, utrinque costuto striatae, ad marginem laciniatae, prope suluras laciniae maxime prominentes, triangulares, aculae, postice carinatue; nodus unus. varicibus interpositus, valde prominens, rolundalus. Os obliruum, orbiculato-ovalum, angustum; peristoma productum; cauda recta lata: conalis cleuszos.

Lunghezza 43. man Larghezza 26. mm

Questa ben distinta specie, che declico al chiar. prof. L. Bellardi, nella generale forma somiglia moltissimo al $N$. Teranyi Panlueci, dal quale è ben distinto per la superficie costato-striata e per le varici alquanto solide e non gia sottili c foliacei. $\mathrm{l}$.

119. M. rutis Borson. Alemi esemplari rotti beu riconoscibili. R. - 120. M. 'I'apluan if Bellardi. Taluni frammenti che rispondono bene alla descrizione e courengono o lle figure dell'autore. r. - 121. M. dertonensis Bellardi. Un solo ben conservato usemplare raccolto a Monteleone. R. - 122. M. craticulatus Brocchi. Un incompleto esemplare. R. - 123. M. fun i culosus Borson. Qualche raro frammento. R.

'yphis. - 124. 'T'. horridus lyocehi (Murcx). R. - 125. T. fistulosus Brocchi (Murex). Belli o ben conservati esemplari. c.

manella? - 126. Li. malginata Mintin (Buccinum). c.

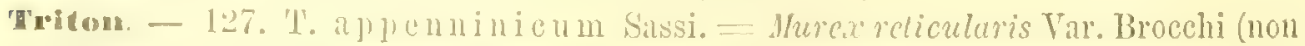
Limneo). Mrurex nolulosus Borson. Soltanto alcuni esemplari riferibili alla Var. 13. Bellardi (Triton nochelosum Michelotti) r. - 128. T. u is tort u m Brocchi (Mhrex). Vi rifurisco alcumi frammenti. R. - 129. T. O le a r ium Limn. Un solo frammento del margine bocenle. I. V. - Frammenti indeterminabili di altre specie. 
Fasciolaria. - 130. F. tarbelliana Grateloup. Pochi esemplari incompleti, ma pure ben caratterizzati. R.

131. F. Calabra n. sp.

Sono rarî esemplari incompleti che si approssimano per la forma generale e per le costole rigonfie, arrotondate e quasi nodiformi alla $\mathrm{F}$. ctrusca D'Aneona del plioceno, dalla quale la mia specie differisce per essere piì gracile abbastanza e per avere le costole spirali grandi e piccole che si alternano regolarmente. I.

Ticula. - 132. F. geometra Borson (Pyrula). Un sol frammento dubbio. R. 133. F. intermedia Sismonda (Pyrula). R. - 131. E. condita Brongniart $($ Pyrula $)$. Alcmi frammenti ben riconoscibili. 1.

Purpura. - 135. P. exilis Partsch. Un solo esemplare deformato. R.

Cerithium. - 136. C. minutum M. de Serres. Un solo esemplare rotto. R. 137. C. gran ulinum Bonelli. È questa una delle piu comuni specie di questo giacimento. C. - 138. C. Bromn i Partsch. Vi rapporto con qualche dubbio pochi esemplari trovati tra i moltissimi della precedente specie. 1 :

Triforis - 139. T. perversa Limneo (Trochus). R. V.

Ceritholum. - 140. C. scablum Olivi (Murex). Varieta con numerose rarici e piccoli gramuli. r. V. - 141. C. Sehwartzii Hoernes (Cerihium). r. 142. C. spina Partsch. (Cerithium) Pochi esemplari alquanto dubbî. 1.

143. C. sculptum n. sp. Tar. XI. fig. 26.

Questa elegante specie è distintissima: essa ha qualche somiglianza col C. Schuarli, dal quale se ne separa a prima giunta per arere gli arrolgimenti appianati e forniti di numerose linee trastersali, presentando inoltre delle piccole e leggiere pieghe longitudinali, che specialmente affettano li parte posteriore degli arvolgimenti, e spesso somo scancellate o mancano del tutto pii specialmente negli arrolgimenti ultimi. L'apice è conico costitnito da quattro arrolgimenti convessi e levigati. Lunghezza 3,7. mm Larghezza 1,2. mm

Questa specie è comune nel 'l'ortoniano del MIessinese. R.

Cerithiopsis. - 144. C. tub ercularis Montagu (M/urex). R. I.

145. C. bicarinata n. sp. Tar. XI. fig. 27.

Distintissima specie, che ha gli avrolgimenti molto breri e disgiunti da suture assai profonde, mentre essi sporgono fuori portando due carene acute intersecate da costole longitudinali, al numero cirea di dieci, acute e sporgenti come lo carene stesse. L'apice è anch"esso distintissimo, per essere grande, di forma guasỉ cilindrica, e costituito da tre arrolgimenti lisci, alti e conressi.

\section{Lunghezza $1,60^{\text {tum }}$ Larghezzal $0,7 .{ }^{\text {num }}$}

È unico l'esemplare che ho descritto siccome nuova e distinta specie. R.

Chenopus. - 146. C. pes-pelican i Limneo (Strombus). Vi rapporto un esenplare molto piccolo ed incompleto, il quale ne ha i caratteri piu importanti, e percio potrebbe costituire una Var, minor; ma dubito che debba specilicamente disgiungersi. R. V. - 147. C. pes-graculi Brom. Specie che credo ben distinta dalla precedente.c.

Strombus. - 148. S. coronatus Defrance. Soltanto alemi frammenti poco riconoscibili. r. 
Cancellaria. - 149. C. uns if form is 11. Sp. Tar. XI. fig. 28.

Teste parva, avato-oblonga, spira clata. turriculala, obtusiuscula. Anfractus sci convexi, postice subplanati, ultimus dimidiam longinulinem superans, prim duo lacves; suturae profundatae. Superficies clathrata, costae longitudinales acutce 11, cirgulos transversos parum minores (tres in quoque anfractu, in ullino vero unlecim) decussantes; ad interselionem papilla acuta praeditae. Os obovatum; columelle uniplicald, vix umbilicala.

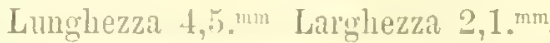

Questil specie assai piccola distinguesi benissimo per la sua forma molto alInngata e quasi cilindrica, pel la seultura e per l'unica piega della columella. R. 150. C. Italiea D'Aneona. Var. crispata. n.

Chiamo cosi una cancellaria che somiglia molto nella forma alla $C$. Italica D'Ancona, ma è piì grande, nell'ultimo arvolgimento ai cingoli se ne interpongono altri due o tre minori, e le csili linee di accrescimento estremamente ravvicinate e quasi lamelliformi rendono i cingoli e tutta la superficie increspata. Inoltre lo stato embrionario dellir conchiglia è af̉atto diverso, essendo costituito ta oltre due arrolgimenti regolarmente spirali e conressi; invece nella $C$. Italica esso costa quasi di un solo giro di spira, che è gibboso al centro.

\section{Limghezza 15. mm Larghezza 10. . $^{\text {. }}$}

Di questa forma che potrì costituire più tardi una specie distinta ho raccolto un solo esemplare. R.

151. C. mitraeform is Brocchi (Voluta) R. V. - 152. C. cancellata Linueo (Voluta). Vi rapporto un esemplare un po' diverso dai viventi. R. V. - 153. C. II chelini Bellardi e Michelotti. R. - 154. C. calcarata Brocchi (Voluta). R. - 155. C. spinifera Grateloup. Le costole sono più o meno rade. r. 156. C. Westiana? Grateloup. Aleuni frammenti molto dubbî. R. - 157. C. seriata Brom. R. - 158. C. raricosa Brocehi (Voluta). R. - 159. C. lyrata Brocehi (Voluta). 1'.

Kenophora. - 160. A. infundibulum Brocehi (Trochus). Alcuni frammenti 1. - 161. X. Deshayesii Michelotti. R. - 162. X. testigera Brom. (Trochus). R.

Solarinm. - 163. S. simplex Bromn. 1. - 16t. S. semisquamosum Bronn. Specie ben caratterizzata e distinta, che trovasi anche nel plioceno r. - 165. S. millegranum Lamk. R. - 166. S. or au uliferum Bronu. R. - 167. S. fallaciosum Tiberi. Un piccolo frammento. R. V.

Isirmontia. - 168. B. minima n. sp. Tar. XI. fig. 29.

L'mica conchiglia incompleta a cui impongo questo nome, è distintissima per essere arrolta in ispirale fliana, per arere la porzione embrionale della forma emIrionaria dei solari, e costituita da due giri di spira lisci e convessi; la parte ndulta della conchiglia, certamente incompleta, non forma che nn mezzo arrolgimento, il cquale i lisgrimto dal resto o bastantemente allontanato, rettangolarmente bicarenato, e con una lamelia prominente sopra ciascuna carena, ed clegantemente pieghettata e dentellata. Dal lato ombelicale l'arvolgimento ì quasi appianato con una linea rilevata che cinge l'ombelico, dal lato opposto invece ì 
alquanto convesso e porta due linee spilali. La superficie è finissimamente pieghettata tutta in traverso; la sezione è circolare tenclente al quadrato.

Diametro 1,2. . $^{2}$

169. B.? zanclea Philippi. Un esemplaretto ben distinto. R. V.

Segmenzia. - 170. S. monocingulata Seguenza (Trochus) = Omphalius monocingulatus Jefrreys, S. monocingulatu Jeffreys (M. S.), S. formosa Jeffreys. Vi riferisco alcuni frammenti in cui è ben distinto anco l'apice. R. V.

vatica. - 171. N. millepunctata Lamarck. La forma tipica è poco comme. 1 . V. - Var. minor. E una piccola forma comunissima. C. - 172. N. a uropunctata Meneghini. Specie molto comune che tra i numerosi esemplari mostra graduati passaggi alla piccola forma della precedente. C. - 173. N. pliocenica Seguenza. Pochi esemplari, tra i quali alcuni mostrano affiniti colla precedente. r. - 174. N. Dill w y i i Payrandeau = Nacea fasciata Risso. 1. V. - 175. N. crassa Nyst. Affine alla $N$. praesolida Brignone, c. - 176. N. fusea De Blainville. Forma piccola C. V. -177 . N. pseudo-epiglottina Sismonda $=N$. epiglottina Bronn (non Lamarck). Forse questa è una estrema forma della precedente. $r$.

178. N. plobleman. sp. Tar. XI. fig: 30 .

Questa specie è discntibile; affine alla N. Guillemini Payr. virente, ma più globosa, colla spira alquanto piu sporgente, coll'ombelico più largo e molto profondo, cinto da una scanalatura profondamente impressa, che circonda un cordone calloso, poco prominente, che si connette colla callositi esterna più spessa e piu sporgente. Pei caratteri dell'ombelico, per essere maggiomente globosia e pel difetto di depressione sulla regione posteriore degli arvolgimenti, distinguesi beuc dalla $N$. fusca.

$$
\text { Lunghezza } 19,5 .^{\mathrm{mm}} \text { Larghezza } 18 .^{\mathrm{nm}} \mathrm{c} \text {. }
$$

179. N. minor n. sp.

Testa parva globoso-ovata, spira parum prominula, obtusa, robundata. Umbilicus parvus, e callositate convexo-subplanata, sinuosa ob̈tectum, fissuramque latiusculam reliquens.

Lunghezza $7 . \mathrm{mm}$ Larghezza 6,5 .

Questa specie per la sua piccolezza, per la forma globosa e non depressa, per l'andamento particolare del callo, che ricopre in gran parte l'ombelico, non pud confondersi con altre, ed è ben dirersa dalla N. Josephina Risso. C. - 180. N. redempta Michelotti. Alcuni riconoscibili esemplari qquantunque rotti. r.

Eulima. - 181. E stenostoma Jeffress. Riferisco a questa specie due escmplari incompleti e dubbî. R. V. - 182. E. subulata Donovan (Turbo). Qualche esemplare piccolo. $r$ V. - 183. E. Eichwaldi Hoemes. Un solo esemplare R. - 18.1. E. lactea D'Orbigny. Esemplari completi identici a quelli del plioceno, $r$. 185. E. breviuscula n. sp. 'Tav. XI. fig. 31 .

Testa brevis, conica, curviuscula; anfrachus 8 planati, suturis superficialious vix distincti; apex obtusiusculus; anfractus ullimus anlice subangulabus, convexus; os orale. 
La mia specie miocenica si approssima alquanto alla virente $E$. merostoma Brusina, ma ne è distintissima pẹrchè piir piccola, piì gracile, coll'apice ottuso, e specialmente per gli arrolgimenti più alti. Raccolto un solo esemplare. R.

viso. - 186. N. eburaea Risso. Una piccola forma simile a quella comune nel Plioceno. 1 .

Eulimella. - 187. E. Scilla e Scacchi (Helania). Alcuni frammenti. R. V.188. E. confusa Segrenza. Molto affine alla precedente, ma piiz gracile. r. 189. E. subumbilicata Grateloup. (Actacon) = Turbonilla subumbilicate D'Orbigny. Un frammento. R. - 190. E. a cicula Philippi (Eulima). Frammenti. R. V. - 191. H. Tentricosa Forbes (Parhenia). Belli e completi esemplari.r. V. - 192. E. obscura Renss (Turbonilla). Un incompleto esemplare. R.

Turbonilia. - 193. T. subllicata 11. sp. 'Tav. XI. fig. 32.

Uu solo esemplare della forma della Odostomia (Eulimella) superfuc Monterosato, ma ancor piir gracile, con sottili ed oblique pieghe longitudinali appenia distinte e mancanti del tutto sugli ultimi avrolgimenti.

\section{Linghezza 5. mm Larghezza $1,4 . \mathrm{mm}$ R.}

194. T. dimidiata Doderlein. Alemi framenti, comparati col tipo della collezione Doterlein. $R$.

195. T. minima n. s1\%. Tar. XI. fig. 33, 33u.

Questir specie per la sua forma generale ricorda la Eulimella acicula Philippi colle sue variazioni; ue differisee intanto per le tenui pieghe longitudinali, rette, più o meno distinte e prominenti, le quali al mumero di dieci o di dodici vanno sranendo sugli ultimi arrolgimenti e scompariscono sorente del tutto nell'nlimo. Lapice rivoluto dei snoi due arrolgimenti presenta il primo solto forma di un globetto o di un granulo arrotondato molto sporgente al di sopra del secondo, che è molto conresso. Qnesta specie varia molto oltrechè per la distinzione delle costole, per la lunghezza relativa degli arrolgimenti, che sono appianati o leggermente convessi.

$$
\text { Lunghezza 2,4. mu Larghezza } 0,6 \text {, mm } 1 \text {. }
$$

196. T. Lanciae Libassi. (Chemailsia). Comparata cogli esemplari tipici del plineno d'Altavilla. I. - 197. T. varicosa Doderlein. Identica al tipo della collezione Doderlein. r. - 198. 'T. costellata Gratelonp (Acheon). 1. - 199. T. decussata Bonelli. Risponde agli csemplari del Piemonte. c. 二200. T. gracilis Broceli (Turbo). Belli esemplari e ben conservati. R. Var. dubia Tar. XI. fig. 3.1. Riguardo come varieta di questa specie un frammento nol quale gli arrolgimenti sono un $100^{\circ}$ piir alti, le costole meno gracili e più oblique. R.

201. 'T'. nucleata n. sp. 'Tiv. XI. fig. 35, 35a.

Questa specie i affine alla T. pusilla Phil. (Chemmitzia): essa ha gli avrolgimenti convessi, le suture profonde, le costole sottili, circa quindici, la superficic levigatissima, l'apice proprorzionalmente grande è depresso molto da direnire quasi lenticolare, gli avvolgimenti suoi sono tre e erescono celeremente.

Lunghezza 2,2. ${ }^{\mathrm{mm}}$ Larghezza $0,7 . \mathrm{mm}$ R.

202. 'L. oxilis Segucuza. Comparata cogli esemplari pliocenici d'Altavilla. Si distingmo per le poche costole o per la grande graciliti. r. - 203. 'I'. elegans 
Seguenza. Simile uel Plioceno. Aftine alla $T$. clegantissima dalla quale diversifica per gli arvolgimenti meno breri, c per le costole piu gracili, che lasciano percio interstizî molto più larghi. R.

Pyrgulina. - 204. P. enricosta n. sp. Tav. XI. fig. 36.

Un solo incompleto esemplare, meno gracile della $P$. interstinctr Mont. alla quale in qualche modo si approssima, cogli avvolgimenti convessi, le suture profonde, con gracili costole longitudinali, ravvicinate, oblique, flessuose.

Lunghezza 1,7. nm Larghezza 0,8. ${ }^{\text {rm }} \mathrm{l}$.

205. P. formosa 11. sp. Tar. XI. fig. 37.

E questa una forma affine alla $P$. inclistinta, dalle varie forme della quale distinguesi pegli arrolgimenti conressi, pel loro numero minore, per le suture assai profonde, per le costole assai sporgenti ece.

$$
\text { Lunghezza 2. }{ }^{m m} \text { Larghezza } 0,8 .{ }^{m+1} \mathrm{R} \text {. }
$$

206. P. fenestrata Forbes (Oclostomia). Esemplari ben distinti. r. - 207. P. pygmaea Grateloup (Actaeon). Esemplari conservatissimi. I. T. - 208. P. decussata Montagu (Turbo). Un solo esemplare. R. V.

Odostomia. - 209. 0. conoidea Brocchi (Turbo). Tar. XI. fig. 53 (Apice). c.V. 210. 0. angulata n. sp. Tav. XI. fig. 38, 38 .

Questa specie distinguesi assai bene pel forte angolo che porta alla base dell'ultimo arrolgimento, essa è affine alla precedente, ma ben distinta per l'angolo suddetto e per l'angolo spirale più aperto, siccome per la forma generale esattamente conica. Per tali caratteri è vicinissima alla 0 . unictentata vivente, ma la specie miocenica è acuta, ha un nucleo molto piccolo, gli arvolgimenti sensibilmente piit alti, l'ultimo piì fortemente angolato.

$$
\text { Lunghezza 2,8. }{ }^{\mathrm{mm}} \text { Larghezza } 1,60^{\mathrm{mm}} \mathrm{l} \text {. }
$$

211. 0. S is mou dae Seguenza = Acteon honleolum E. Sismonda (non Arricula hordeola Lamk.). Tar. XI. fig. 52 (Apice). Identica agli esemplari tipici del Plioceno dell' Astigiano, prossima alla 0 . conoidea, dalla quale è distinta pegli avrolgimenti convessi, I'ultimo non angoloso.r. - 212. O. planulata Jan. (Pyramidella). R. - 213.0. acuta Jeffreys. R. V.

214. 0. Ven us 1 . sp. Tar. XI. fig. 39, 39u.

Specie che per la forma generale ricorda bene l'Aclis Frounfeldi, ma la distingue sopratutto l'apice rivoluto proprio delle odostomie. Gli avvolgimenti, escluso l'apice, sono tre alti e convessi, le suture sono profoudate e la hocca ovale, dimodochè l' ultimo giro della spira è quasi disginuto e porta un largo ombelico.

\section{Lunghezza 1. ${ }^{\text {mu }}$ Larghezza 0,3 mm}

È questa ma forma ben distinta pei vari caratteri qui sopra descritti. li. 215. 0. striata Hnernes, R.

Mathilda. - 216. II. quadricariulta Brocchi (Turbo). Qualche frammento. R. V. - 217. I. elegantissima 0. G. Costa (Trochus). Var. lenuisculpu. Chiamo cosi questa forma miocenica, che conriene in tutti i caratteri colla specie del Costa, ma oflre piì sottile scultura, specialmente nelle costelle lungitudinali, che sono gracilissime. R. V. 
Aclis. - 218. A. Fran feldi Hoernes (Acme). Vi riferisco un solo esemplare coll'apice rotto. R.

Comiscus. - 219. C. miocenicus n. sp. Tav. XI. fig. 40.

Questa elegante e distinta specie ha nel Plioceno e nella fauna rirente una forma molto somigliante, che è il C. glacilis Jeftreys, dal cuale distinguesi specialmente pegli arrolgimenti fortemente convessi che tendono ad appianarsi alla parte posteriore, e che sono disgiunti da suture molto profonde. L'apice è ottusissimo, le costole longitudinali molto sporgenti e soltili, al numero di 12 , disgimte da interstizì più larglii. L'ultimo arvolgimento presentasi leggermente angoloso alla parte anteriore ed alquanto appianato, come osservasi in talune specic di Scalarie.

\section{Lunghezza 2,2."mn Larghezza 0,6 .}

Raccogliesi questa bella specie con una certa rarita nelle argille tortoniane di Benestare, dove conserva assai costanti i suoi caratteri. $r$.

Scalaria. - 220. S. rissoides n. sp. Tav. XI. fig. 41.

Testa parva elongata, solida; anfractus 8 convexiusculi, primi laeves, qualuor ultimi costati; costae 10-12 crassiusculae, interstitiis minores, postice subevanescentes, anfractus ullimus antice obtuse angulatus, ccostatus, depressus, subplanatus. Superficies transverse punctato-striata. Os obliquum, orbiculato-ovatum, poristoma distinctum, crassiusculum; labrum sinistrum extus crasse varicosum, fortiter striatum, labrum dextrum fissuram ombelicalem constituens.

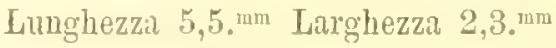

Questa specie per la sua generale forma breve e fornita di poche e rade costole, siccome per la grande solidita e picciolezza insieme, ricorda proprio talune rissoe, essa offre una certa analogia colla $S$. hellenica Forbes, ma questa è molto piu gracile ed ha numerose costole, pei quali caratteri la mia specie distinguesi anco dalla S. Scacchii Hoernes coetanea del bacino di Vienna. R.

221. S. I a n c e olata Brocchi (Turbo). Var. miocenica. Questa forma comparata cogli esemplari pliocenici si presenta diversa pegli avrolgimenti un po' convessi, e per le costole che svaniscono presso le suture. Si raccolgono ben conservati esemplari. r. - 222. S. varicula Seguenza = Chemnitzia varicula Foresti (non Chemnitzia varicula S. Wood). Questa specie è affine alla precedente, e distinguesi per essere meno gracile, cogli arvolgimenti più brevi, e colle costole più regolari, e più strette. Conviene cogli esemplari pliocenici. R.

223. S. raricosta n. sp. Tav. XI. fig. 42.

Forma affine alla S. torulosa Brocchi, dalla quale è ben distinta per essere meno gracile, ornati di regolari strie impresse, pegli avvolgimenti molto conressi, per le poche costole assai strette e prominenti, ed anco per essere molto piccola. L' unico esemplitre raccolto è incompleto e presentasi qua e lit varicoso. $R$.

224. S. lamellosa Brocchi (Turbo). Un bello ma piecolo esemplare. R. 225. S. Trevelyana Leach. Aleuni frammenti dubbî. R, V. - 226. S. ven us ta Libassi. Specie del pliocene d'Altarilla presso Palermo. Affine alla S.pseuloscalaris Brocehi. ${ }^{*}$. 
227. S. filicosta n. sp. Tav. XI. fig. 43.

Questa specie ricorda bene la S. pulchella Bivona; ma ne è ben distinta per la forma più suella, pegli avrolgimenti più alti, per le suture meno profonde, pelle costole, che quantunque lamelliformi, sono pure in forma di esili fili perchè poco sporgenti, ed assai minori in numero, riducendosi talora esilissime in alcune varietì che la specie oftre; il nucleo embrionario è piu allungato pressochè cilindrico, opaco e bianeo.

$$
\text { Lunghezza 2,5. }{ }^{\mathrm{mm}} \text { Larghezza 1,2. }{ }^{\mathrm{nm}} \mathrm{r} \text {. }
$$

Turritella. - 228. T. Riep peli Hoernes. Pochi esemplari rotti e detriti. r. 229. T. Brocehii Brom. Un solo frammento. R.

230. T. in a equ isculpta n. sp. Tav. XI. fig. 44 .

Questa specie più piccola e più gracile della $T$. tornata (Brocchi) ha una speciale scultura: gli avvolgimenti sono appena convessi, quasi appianati e disgitunti da profonda sutura, ciascuno porta due cingoli presso la sutura posteriore, disgiunti da uno strettissimo solco, al centro tre cingoli più grossetti e più allontanati, alla regione anteriore altri cingoli minori, che altermano con quattro molto piccoli.

$$
\text { Lunghezza 35. }{ }^{\text {mm }} \text { Larghezza } 11 .^{\text {mm }}
$$

Un solo esemplare. R.

231. T. Archimedis A. Brongniart. Questa specie molto comme offre a Benestare mumerose graduali variazioni. C. - 232. T. bicarinata Eichwald. Oltrechè nelle argille, questa specie trovasi piì comıue negli strati gessiferi soprastanti, dove la conchiglia è trasformata in selenite cristallina. 1. - 233. T. turris Basterot. Var. minor. n. Riguardo tali, molti piccoli esemplari piu gracili della forma tipica. R. - 234. T. subangulata Brocchi (Turbo). Le diverse varieta. c. -235 . T. exasperata Doderlein. Comparati i frammenti raccolti cogli esemplari tipici della collezione Doderlein. R. - 236. 'T. marginalis Brocchi (Turbo). Un solo esemplare incompleto. R.

suiqunria. - 237. S. anguina Lin. (Serpula). Un piccolo esemplare ben distinto. R. V.

Vormetus. - 238. V. gigas Bivona p. Var. granulatus. Questa forma molto comume nelle argille tortoniane di Benestare differisce dalla vivente del Mediterraneo per avere tutte le costole e le costicine interposte, che ormano la superficie, fortemente e distintamente gramuate; anzi puo ben dirsi che ogni costola grande o piccola che sia risulta d' ma serie di granuli piì o meno allungati nel senso della direzione delle costole stesse. Per tali caratteri costanti nei numerosi esemplari raccolti io credo che questa forma miocenica potrebhesi specificamente disgiungere dalla vivente, denominandola V. granulalus. C.

Caccum. - 239. C. trachea Montagu. R. V.

Setin. - 240. S. golobosa n. sp. Tav. XI. fig. 45.

Questa è specie molto affine alla S. fulgida Adams, dalla quale distinguesi per essere più rotondata, pegli avrolgimenti più convessi, per le suture piu profondate.

$$
\text { Lunghezza 1,1. }{ }^{\mathrm{mm}} \text { Larghezza } 1 . \mathrm{mm} \mathrm{r} \text {. }
$$

Rissoina. - 241. R. obsoleta Partsch. Due incompleti esemplari. R. 
Misson. - 242. R. cancellata $\mathrm{Da}_{\text {a Costa }}($ Turbo) $=$ R. cremulata Michand. R. V. 213. M. r eticulata? Montagu (Turbo) = R. Becany Hanley. Un frammento R.V.244. R. Venus Dorbigny. r. - 245. R. cimex Lin. $($ Turbo) $=$ R. calathi seus Lasckey, R. granulata Pliil. R. T. - 216. R. Montagui Payraudeau. R. V. - 247. R. Zetlandica Montagu $($ Turbo) $=$ R. carinata Aradas. R. V. - 248. R. Laches is Basterot. Diverse variazion. Var. lacvis Hoemes. Senza costole. C. - 249. R. scabrella Doderlein. Comprata col tipo della collezione Doderlein. 1. - 250. R. diadema Doderlein. Identica al tipo di Doderlein. Assai mrossima alla specie precedente. Trovasi anche nel plioceno. $R$. - 251. R. Testae Aradas $=R$. reticulatu Philippi, R. Abyssicola Forbes et Hanley, R. Partschii Hoernes. Specie molto distinta e comune dal mioceno ai mari attuali. c. V.

252. R. obliquisculpta n. sp. Tar. XI. fig. 46 .

Testa parva, ovato-conica, anfractus quatuor, duo primi lacves, convexi; cateri convexo-subplanati, spiraliter tenuissime striati, oblique plicali, postice angulato-submarginati, planati; ultimus maximus luplo spira longior, antice angulato-carinatus, convexus. Suturde impressae. Os clargatum, magnum, ovatum. Linghezza 2. Larghezzi 1,7. ${ }^{\mathrm{mm}}$

Questa specie per la forma, per la scultura per tutti i suoi caratteri è distintissima. $R$.

Turton. - 253. T. rugosus. Limueo. Rapporto con qualche dubbio a questa specie un solo e grosso opercolo, raccolto di unita ai molti delle specie seguenti. R. V. - 254. 'I. fimbriatus Borson. Sempre in frammenti e quasi distrutto. c. Var. subramulosc Doderlein. Rapporto a questa rarieta qualche esemplare piceolo e granoso sughi arrolgimenti superiori. r. - 255. T. speciosus Michelotti. Quest'altra elegantissima specie molto comune si trova anch'essa quasi distrutta, e non ci oftre che pochi frammenti riconoscibili. C.

Trovansi inoltre, e ben conservate, due specie di opercoli di Turbo, che cortamente si appartengono alle due precedenti specie. C.

256. T.? reticulatus 11. sp. Tir. XI. fig. 47.

Testa parve globoso-depressu: spira haud prominons, convexiuscula, subplanala; anfractus tres, ultimus maximus; superficies tenuissime reticulata; umbilicus profundus; labrum columellare incrassatum; os orbiculare.

\section{Altezza 1,3. mm Larghezza 2. ${ }^{\text {mm }}$}

lapporto provrisoriamente, perche con dubbio, al genere Turbo questa specie, che parmi delha pei stroi caratteri sprettare ar un gruppo distinto, forse a quello cui si appartiene il Tromellensis Segnenza, e la virente specie di Granata, che ì ancor più alline al T. reliculatus: ma quest'ultimo è mofondamente ombelicato, cillittere che manca in quelle due specie.

Ho raceolto due soli esemulari. Rr.

'Mraciusus. - 257. '1'. lo tellaris Michelotti. Specie distintissima e caralteristica del mioceno. $x_{0}$ - 258. 'l'. . . . . . sp.? Due esemplari assai vicini al rivente $T$. Adansonii, colla base concentricamente solcata, colla spira meno elevata. $R$. 259. T. scabrellus n. sp. 
Questo troco è molto affine al $T$. exasperatus, dal quale distinguesi specialmente per essere ombelicato, e per la dirersa scultura, ogni arrolgimento portando delle linee oblique, sottili, rilerate, ed essendo marginato anteriormente e posteriormente per mezzo di un cingolo granoso, a grani piccoli e distanti; delle linee spirali ornano la superficie e portano delle papille prominenti la dore s'intersecano colle linee oblique, formando così una superficie ben reticolata e scabra. Var. semiornatus. Gli ultimi arrolgimenti mancano delle linee spirali, che si scancellano gradatamente e talrolta in parte.

$$
\text { Lunghezza 6,2. mm Larghezza 4,1. }{ }^{\mathrm{m} m \mathrm{r}} \mathrm{r} \text {. }
$$

260. T. peregrinus Libassi (Solarium). Incompleti esemplari che rispondono bene a quelli del plioceno. R.

circulus. - 261. C. striatus Philippi (Valvata?). Un solo esemplare. R. V.

Areorbic. - 262. A. Woodii Hoernes. R.

Crepidula. - 263. C. $n \mathrm{ng} u$ iformis Lamarck. r. V. - 264. C. gibbosa Defrance. c.

Calyptraca. - 265. C. chinens is Lin. (Patella). Un frammento. R. V.

Capulus. - 266. C. sulcatus Borson. (Hipponic). Specie caratteristica del mioceno. Un solo esemplare. $\boldsymbol{R}$.

\section{Classe. Scafopodr. - Ordine. Solmaconchy.}

Dentalium. - 267. D. Badense Partsch. R. - 268. D. in a equa le Bromn. Una delle piì comuni specie del Tortoniano di Benestare. C. 269. D. ina qui costa n. sp. Tar. XI. fig. 48,48 .

Testa magna, soilda, elongatu, conico-subpiramidata, vix incurvata. Costae 8-10 longitudinales, crassae, mominentes, semicylindricae, saepius linea impressa bifidae. Interstitia majora, subplanala, inacqualia, costis minimis $1-1$ praedita.

\section{Lunghezza circa $700^{\text {mm }}$ Larghezza $100^{\text {mm! }}$}

Questa specie è molto affine al D. elephantinum, dal quale distinguesi per essere quasi retto, per la forma, grossezza e numero delle grandi costole, siccome per la grande irregolaritì degl'interstizî e delle piccole costole che le percorrono. C.

270. D. prismaticum n. sp. 'Tar. XI. fig. 49,49 .

Testa mayna, solidissima, conico-subprismatica, curviuscula. Costae $8-10$ longitudinales, acutae, postice prominentes, antice unguliformes. Interstitia planata, costella una vel duabus ct rarior tribus signata.

Lunghezza oltre $60 . \mathrm{mm}$ Larghezza $6,5.5 \mathrm{~mm}$

Specie distintissima per la sua forma prismatica, e per le costole che rella parte anteriore della conchiglia sono veri angoli ottusi, risultanti dalla superficie piegata in forma esattamente prismatica, e nella parte posteriore poi sporgono in forma acuta. c.

271. D. dentalis Linneo. c. V. - 272. D. Michelotti. Hoernes. Con qualche variazione nella sporgenza delle costole. 1. - 273. D. laevigatum Ponzi. r. Sipinouocientahium. - 274. S. tetragoun Brochi (Dentalium) = Dentalium 
quinquanguare Forbes. $x$. V. - 275. S. intermedium Coppi (Dentalium). Questa specie è molto affine al D. Jani Hoernes. R.

Melonyx. 276. H. ventricosa Bronn (Dentalium) $=$ Gadus ventricosus. DoderIein, Creseis gadus Broun, Dentalium gadus Cocconi, D. Otivi Scacchi, Gadulus Olivi Jefir. r. V. - 277. H. gadulus Doderlein (Gadus). Questa specie è comune anco nel plioceno. $\mathrm{r}$.

278. H. tenuis n. sp. Tav. XI. fig. 50.

Specie molto somigliante alla $H$. Ieffreysii Monterosato, vivente e fossile del plioceno, dalla quale differisce per essere più gracile, più piccola e meno gibbosa nella regione mediana.

\section{Lunghezza $3 .^{\text {inm }}$ Larghezza $0,7{ }^{\mathrm{mm}} \mathrm{r}$.}

Cadulus. - 279. C. cyathus De Cristofori et Jan. (Creseis) = Dentalium ovulum. Var. altenuata Monterosato, C. cyathus Monterosato, Seguenza. Un solo esemplare identico alla forma che occorre nel plioceno. $R$.

Classe. Pteropod.

Iyalaen. - 280. H. . . . . sp.? Alcuni indeterminabili frammenti. R.

Cleodors. - 281. C. pyramidata Lin. $($ Clio $)=$ C. lanceolata De Blainville. Molti frammenti ben riconoscibili, specialmente le estremita posteriori. $r$. V.

Cuvieria, - 282. C. conica n. sp. Tav. XI. fig. 51.

Testa conico-subcylindracea, fragilis, inferne truncata, clausa, parumque convexa. Superficies laevis.

I pochi esemplari raccolti sono dei semplici frammenti, tra i quali quello figurato è una porzione della conchiglia dal lato posteriore, che non presenta alcuno indizio di restringimento alla parte anteriore, ed ha in tutta la sua lunghezza una sezione circolare. $R$.

\section{Classe. Lamelibranchi.}

xylophaga. - 283. X. dorsalis Turton (Teredo). Una valva incompleta. R. V.

Corlsula. - 284. C. gib ba Olivi (Tellina) $=$ C. nucleus Lamark. c. V.

Neacra. - 285. N. crispata Seacchi (Corbula). Un solo frammento. R.

Thracia. - 286. 'T. pubescens? Pult. (Mya). Vi rapporto provisoriamente un piccolo frammento, che presenta la rugositi particolare di questa specie. R. V.

Solen. - 287. S. vagina Linneo. Un frammento. R. V.

Symdosmia. - 288. S. o vata? Philippi (Erycina). Qualche frammento. R. V.

Mactra. - 289. M. subtruncata Da Costa (Trigonella $)=$ M. triangula Ren. Una valva sola. $\mathrm{K}$. V.

vrvilia. - 290. E. pusilla Philippi (Lrycina). c.

Tellima. - 391. '1. serrata Brocchi $=$ T. Brocchii Cantraine. R. V. - 292. T. planata Lin. = T. complanatu Gmelin. Alcuni frammenti. R.

Tapes. - 293. I. retula Basterot (Venus). Negli strati superiori sabbioso-gessiferi trasformata in gesso. R.

vonus. - 294. V. umbonaria Lamarck. Qualche raro frammento. R. 
295. V. insignis n. sp. Tav. VIII. fig. 1 (vedi fossili elveziani). Nelle argille tortoniane si rinvengono grossi frammenti ben conservati. $r$.

296. V. grandis n. sp.

L'unico esemplare di questa grande specie è stato raccolto negli strati sabbioso-gessosi superiori di Benestare: esso è trasformato in selenite cristallina e corroso alla superficie, perciò non è possibile di darne completa descrizione.

La forma di questa conchiglia somiglia molto a quella della Cytherea Pedemontana, ma è ancor più grande, più allungata trastersalmente, cogli omboni molto più piccoli, la superficie poi è ornata di grosse ed elevate costole concentriche. Lunghezza 100. mm Larghezza 133 . $^{\mathrm{mm}} \mathrm{R}$.

297. V. ponderosa n. sp.

Non possiedo che frammenti raccolti nelle argille di Benestare: da essi si riconosce che trattasi di una grande specie e molto solida, le cui valve hanno Io spessore di un centimetro presso l'apice, la forma generale è convessa, rotondato-orata, con apici fortemente incurvati con una larga lunula cordata, lia superficie è ornata di lamine concentriche, rilerate, pieghettate, che alternano con una due o un maggior numero di lamelle interposte; delle linee o esili costole irradiano dall'apice ed ornano tutta la superficie intersecando le concentriche lamelle. R.

298. V. plicata Gmelin. Pochi frammenti e qualche piccolo esemplare. R. V. 299. V. multilamella Lamarck (Cytherea). c. V. - 300. V. scalar is Bronn. Un sol frammento. R. - 301. V. ovata Pennant = V. radiata Brocchi. r. V. 302. V. rudis Poli := Cytherea Venetiana Lamarck. r. V.

Dosinis. 303. - D. orbicularis Agassiz. Qualche frammento. R.

Cytherea. - 304. C. erycinoides Lamarck. Trovasi anco negli strati gessiferi sopra le argille, trasformata in selenite. $1 .-305$. C. pedemontana Lamarck. Raccogliesi anco negli strati gessiferi trasformata in selenite. R.

Circe. - 306. C. minima Montagu (Venus) = Venus Cyrilli Scacchi, Cytherea Sismondae Calcara. c. V.

Crassatelln. - 307. C. concentrica? Dujardin = Astartc Murchisonii Michelotti. Rapporto dubbiamente a questa specie una ben conservata valva di Crassatella, la quale per essere molto piì grande delle figure date dall'Hoernes e dal Michelotti, coll' ombone un po' più prominente, alquanto più fina la scultura, ne è realmente dubbia l'associazione, nè altro può dirsi intorno a questo argomento se non si raccoglieranno molti esemplari della Crassatella calabrese. $\mathbb{R}$.

verticordia. - 308. T. tra pezoidea Seguenza. Questa distinta specie che tuttora vive nel Mediterraneo è comparsa fin dal periodo del mioceno superiore, e trovasi non molto rara a Benestare. r. V.

Isocarda. - 309. I.c or Lin. (Chama). Molti frammenti, che vi rapporto con dubbio.c.V. Ho raccolto negli strati sabbioso-gessosi un esemplare d' Isacardia con ambe le valve trasformate in gesso, che sembra diverso dalla precedente specio.

Kelliella - 310. K. milia $x$ is Phil. (Venus?) = Kellia abyssicola Forbes, Kelliella abyssicola M. Sars. Questa piccola e tenue specie trovasi un po'raramente, e viene da taluni riguardata come forma giovane della precedente. $r$. 
Chnma. - 311. C. gryphoides Linneo. Una sola ralva. R. V.

Carditn. - 312. C. Jo u a n eti Basterot. Nelle argille questa specio raccogliesi in frammenti, nelle sabbie gessose soprastanti trovasi più abbondante in esemplari completi colle valre riunite e trasformate in gesso cristallino. c. - 313. C. scahricosta Michelotti. Un solo frammento. R. - 314. C. Indista Lamaret. ILlto abbondante, ma quasi sempre in frammenti. C.

Cardimm. - 315. C. discrepans Basterot. In frammenti roluminosi ed assai spessi. Qualche gigantesco esemplare trasformato in gesso negli strati sabbiosi superiori. $x^{-}$- 316. C. pectinat u m Limeo. Un solo frammento. R. V. - 317. C. multicostatum Brocehi. In frammenti. r. - 318. C. fragile Brocchi. Piccoli frammenti.r. - 319. C. turonicum Mayer. Un solo frammento. I. 320. C. fasciatum Montg. Tre valve. R. V. - 321. C. exigum? Gm. = C. subangulatum Scacchi. Direrse piccole ralve, quantunque più compresse parmi potersi riferire a questa specie. $1 . \mathrm{V}$.

Diplodonta. - 320. D. trigonula Brom. Una piccola valva. R.

Aximus. - 323. A. ferruginosus Forbes (hellia).R. V.

Lucinse. - 324. L. borealis Lin. (Vomus) = Tellina vachula IIontagu. Un frammento. R. V. - 325. L. Broui i Mayer. Un solo frammento. R. - 326. I. spinifera Montagu (lenus). c. V - 327. L. dentata Basterot. R. - 328. L. Agassiz i Michelotti. x. - 329. L. c o 1 um b ella Lamarck. Una sola ralva ed un frammento. $R$.

cepton. - 330. L. lamellosus n. sp. I'av. XI. fig. 55, 55a.

Questa tenue specie somiglia per la forma al L. Clarchie Clark; ma è più allungata trasversalmente, cogli omboni più prominenti, colla superficie ornata di regolari e numerose costole concentriche, le quali sono tenuissime elevate.e lamelliformi. Il dente mediano è grosso, prominente e trigono, dei laterali appena discernibile quello che è dal lato boceale.

$$
\text { Lunghezza 1. mm Larghezza 1,3. }{ }^{\text {mm }} \mathrm{R} \text {. }
$$

Area. - 331. A. helvetica? Mayer. - 332. L. nitidum I'urton. Una valva rotta. R. V. Rapporto con molto dubbio a questa specie alemi frammenti. R. 333. A. cuculliform is Eichwald. Una sola valva. R. - 334. A. diluvii Lamarck. Da non confondersi colla specie vivente del Mediterraneo, che è l'A. Polii Mayer. C. - 335. A. Syracusensis Mayer. Specie che per la forma generale ha molta somiglianza coll'A. pectinata Brocchi.x. - 336. A. clathlata Iefrince. I. - 337. A. dichotoma Hoernes. Una sola ralva. R. - 338. A. pectuneuloides Scachi. Due valve $R$. V.

Lmopsis. - 339. L. Aradasii l'esta (Pectunculus) = L. clegans Michelotti (II. S.), Trigonococlia Semperi Mayer. Questa specie varia considerevolmente in grandeza ed in forma, essendo talrolti meno allungata e quindi quasi orbicolare. Gli esemplari miocenici corrispondono a quelli tipici del plioceno d'Altavilla. c. 340. L. C'alabra 11. sp. 'Tar. XI. fig. 54, 5ta.

Teste ovalo-rotundule, convexa, influta. obliqua, inaequilateralis, sulcis conscntricis, regularibus, profundiusculis, angustis, lincisque radiantious, promimulis. dichotomis. eleganter reliculato-subgranosa; umbones parvi, acuti; area 
parvula; dentes 8-10, postici obliquiores; margo indequaliter denticulalus, denticuli medio minimi, lateraliter majores, postice cum plicis internis connexi.

Lunghezza 6,2. ram Larghezza 5,7 . ${ }^{\text {mm }}$ Spessore 4.mm

Questa specie comunissima a Benestare è molto affine alla Trigonocaclia Bronni Mayer, dalla quale parmi che differisea per essere costantemente molto conressa, pei denti che con rarita raggiungono il numero di dieci, per le linee radianti sottili non valide, e per la superficie non veramente granosa. Del resto potrebbe la mia nuova forma essere benissimo una varieta di quella del Mayer; a risolvere una tale quistione è affatto indispensabile uno studio comparativo, degli esemplari delle due forme, che non mi fu dato di compiere.

La L. calabra è uno dei più comuni fossili del Tortoniano di Benestare. C. 341. L. anomala Eichwald. Una sola valva. R. - 342. L. pygmae Philippi (Pectunculus). Specie molto ben distinta, comune nel plioceno, 1 .

Pectuneras. - 343. P. stellatus Gmlin (Venus). Ho raccolto nelle argille soltanto dei frammenti poco riconoscibili e dei giorani esemplari, nelle sabbie gessifere soprastanti si trorano grossi esemplari con ambe le valve riunite trasformate in gesso. r. V. -344 . P. insubricus Brocchi (Arca). Un giorane esemplare dubbio. R.

Nucula. - 345. N. Mayeri Hoernes. Alcuni dubbî frammenti. R. - 346. N. u ucleus Lin. (Arco). Frammenti più o meno grandi ed aleune valve intiere. R. V.

Fucinelia. - 347. N. calabra Seguenza. Un solo osemplare con ambe le valve riunite. $R$.

Iedre - 348. L. Ho ernes i i Bellardi $=$ L. clavata Hoemes (non Nucula clavata Calcara). Un frammento solo. R.

Lembulus. - 349. L. commutatus Phil. (Nucula). Diverse varieti di forma e di scultura, tra le quali annorero il L. consaguineus Bellardi (Leda). C. V. 350. L. B on ellii Bellardi (Leda). Sempre in esemplari rotti. c. - 351. L. peraffinis Seguenza (Leda). Specie molto prossima alla L. messancnsis Seg., dalla quale differisce pel l'angolo cardinale meno aperto, e per le strie concentriche esilissime alquanto oblique delli superficie.c.

Yoldia. - 352. Y. Philippii Bellardi. Alcuni esemplari corrispondono al tipo. Var. striata. Chiamo cosi tutti gli altri individui, che presentano rare strie impresse, somiglianti a quelle della Y. nitida (Brocchi). 1. - 353. Y. nitida Brocchi (Arca). Più rara della precedente ed in frammenti. r. - 354. Y. sinuosa Seguenza. Questa specie è affine alla $Y$. frigida Torell, dalla quale distingmesi per essere trasversalmente più allungata, per la piega più larga c più rotondata, nonchè per le dimensioni maggiori.c. - 355. Y. frigida Torell. Aleune valve che riescono identiche comparate cogli esemplari riventi dei mari nordici. r.V.

Nalletia. - 356. M. B ellardi Seguenza. Una sola ralra, comparata cogli esemplari raccolti nel plioceno di Sicilia. R.

Eimea. - 357. L. strigilata Brocchi (Ostrea). Identica alla forma pliocenica.c. 358. L. ovata S. Tood. Riferisco con dubbio alla specie del Crag inglese nua piccola valva. R. V. - 359. L. crassa Forbes (Lima) = Limea Sarsii Lorèn. Una mezza valva ben distinta R. V. - 360. I. . sp? Un frammento 
che ricorda la L. clliptica Jeflreys virente, ma le costole sono più grosse, più rotondate. R.

Eceten. - 361. P. latissimus Brocchi (Ostrea). Un grosso frammento. R. 362. P. scabrellus Lamarck= Ostrea dubia Brocchi. c. - 363. P. Malrina e Dubois. R. - 364. P. substriat us D'Orbigny. R. - 365. P. spinulosus r. Munster. Alcuni frammenti da Benestare e da Ambuti. R. - 366. P. similis Laskey $=$ P. pullus Cantraine, $P$. pygmaeus anct. (non r. Munster). R. V. 367. P. denudatus Reuss. Escmplari abbastanza grandi. Benestare, Ambuti, Falco. r. - 368. P. elegans? Andr. Un frammento dubbio. R.

Jamira. - 369. J. burdigalensis Basterot (Pecten). Numerosi frammenti.c. 370. J. B e u danti Basterot (Pecten). Soli frammenti.r. - 371. J. Rolle i Hoernes (Pecten). Un sol frammento dubbio. R. - 372. J. a du uca Eichwald (Pecten). Un frammento. R. - 373. J. Gray i Michelotti. Alcuni frammenti. R.

374. J. Calabra n. sp. Tav. VII. fig. 13 (redi fossili elveziani). Molti frammenti dalle contrade Ambuti e Benestare. c.

375. J. pumila 11. sp. Tav. XI. fig. $56,56 a, 56 u, 56 c$.

Testa parva, rotundato-sublrigona, 15 costata, costae prominentes, triangulares, interstitiis subaequales, in utrisque valvis similes, superne obtusiusculae, laeves, ad latera squamulis arcuatis imbricatisque scabrae; interstitia laevia. Valva superior plano-concava ad umbonem comvexiuscula; inferior convexa. Auriculae subacquales radiatim costatae.

Lunghezza $150^{\mathrm{mm}}$ Larghezza $16,50^{\mathrm{mm}}$ Spessore $5,70^{\mathrm{mm}}$

Questa è una ben piccola specie comune, la quale distinguesi benissimo dalle forme affini pei caratteri delle costole, che non somigliano per niente a quelle di specie, che per la forma si arvicinano. c.

neuronceta. - 376. P. cristata Brocchi (Ostrea). Specie comune in frammenti a Benestare ed Ambuti.c. - 377. P. fellestrata Forbes (Pecton). Pei sinonimi vedi i fossili elveziani. R. V.

Spondylus. - 378. S. crassicosta Lamarek. Due valve e rarî frammenti. R. 379. S. gaederopus Limeo. Un solo frammento. R. V.

Dstrean. - 380. 0. navicularis Brocchi (redi fossili elreziani). c. - 381. 0. digitalina Dubois. Alcune valve superiori, giovaui, dubbie. $R$. - 382. 0. neglecta Michelotti. Un piccolo esemplare e tenue, di color roseo. $R$.

383. 0. a cuticosta n. sp. Tay. XII. fig. 2, $2 \alpha$.

Testa magna, solida, obovato-subtrigona, utraque valva crasse lamellosa, radiatim costata, costae dichotomae, latae, validae, prominentes, trigonae, plus minusve angulosae, ad marginem subproductae, ad intersectionem lamellarum crasse nodoso-squamosae: interstia parva, margo fortiter undulatus, prope cardinem crasse plicatus. Valva dextera convexiuscula, ad umbonom convexa; sinistra parum convexa vel convexissima et quidem valde crassa, parte adfissa parva. Carlo majusculus, canalis limidium latitudinis aequans, concavus, profundalus: marginibus prominontibus, sulcis impressis. Impressio muscularis ovate.

$$
\text { Lunghezza 100."mm Larghezza } 900^{\text {mm }}
$$


Questa bella ostrica è distintissima per avere ambe le valve ornate di grosse e prominenti costole dicotome, nodoso-squamose lì dore intersecano le lamelle della superficie, siccome per la grande larghezza del canale del cardine. Questa specie pel margine fortemente oudulato, per le costole carenate spetta alla sezione dell' 0. plicata (Sezione carinatae Raulin et Delbos). $x$.

384. 0. tenuiplicata n. sp. Tar. XII. fig. 1. $1 a, 1 b$.

Testa parva, tenuis, ovata, utraque valua extus plicis tomuis, depressis, dichotomis, confertissimis, subsquamosis, radialim dispositis praedita, intusque radiatim striata, margo prope carlinem tenuissime crispatus. l'alva dextera concaviuscula ad umbonem convexo-gibbosa, concentrice squamosa; sinistra regulariter convexa; concentrice squamoso-lamellosa, parte adfissa maxima vel parva. Curdo parvus, canalis $1 / 3$ latibudinis supcrins, parum profundatus, brevissimus, marginibus prominontibus, sulcis profundatis. Impressio muscularis ovato-oblonga utrinque profunde emarqinatè unde videtur sub-bipartita.

Lunghezza 19. ${ }^{\text {mm }}$ Larghezza 17. ${ }^{\mathrm{mm}}$ Spessezza $8 .^{\mathrm{mm}}$

Questa piccola ostrica è distintissima per le sue dimensioni poco considerevoli e per tutti i suoi caratteri, e specialmente per le sottili pieghe dicotome, che ornano la superficie di ambe le ralse.

安 veramente rimarchevole che questa specie siasi conservata dall'Aquitaniano insino al Plioceno. e.

Anomia. - 385. A. Burdigalensis Defrance. Gli esemplari miei rispondono a quelli del bacino di Vienna, della collina di Torino ec.; ma sembrami che non possano in verun modo rapportarsi all' A. costala del Brocehi alla quale li riferi l'Hoemes. r. - 386. A. ephippium Lin. Riferisco a questa specie numerosi giovani esemplari, che potrebbero forse appartenere ad altra. c. V. - 387. A. a c uleata Montagu. Alcuni pochi esemplari. r. V. - 388. A. striata Brocchi. Un frammento. R.

\section{Classe Brachioponi.}

Rerebratula. - 389. T. sinuosa? Brocchi (Anomia). Rapporto con dubbio a questa specie numerosi frammenti assaí spessi, spettanti alla regione cardinale d'una grande terebratula. Essi potrebbero invero appartenere anco alla T. ampulla (Brocchi). c.

Cistella. - 390. C. I a e v is Seguenza (Argiope). Un solo ben conservato esemplare. R.

\section{Tino. ARTROPODI.}

Classe. Crostacer.

Dei crostacei superiori soli frammenti indeterminati.

Orline. Ostraconi.

Cypris. 391. C? recta Reuss (Cytherina). Vi rapporto con qualche dubbio due sole valve. $R$.

392. C? angulosa 11. sp. Tar. XII. fig. 3.

Questa specie si arricina in qualche modo alla C. Cabu Desmarest, dalla 
quale differisce bene per essere meno allungata, meno rigonfia, e più angolosa, sopratutto per un angolo ben distinto che presentasi alla regione antero-superiore e che manca alfatto nella specie sopradetta. La superficie forma una prominenza rerso il centro della valva, la quale è bianca con sette punti traslucidi, in tutto il resto ì come macchiettata.

Lunghezza $0,9{ }^{\mathrm{mm}}$ Larghezza $0,60^{\mathrm{mm}} \mathrm{R}$.

Mairdia. - 393. B. subdeltoidea F. Munster (Cythere). c. V. - 394. B. arcula Bosquet. r.

Cythere. - 395. C. Kostelensis Reuss (Cypridina). Qualche sola ralva. R. 396. C. pun ctata $\mathrm{r}$. Munster (Cypridina). I miei esemplari sono esattamente rappresentati dalle figure del Reuss. c. - 397. C. Haueri Reuss (Cypridina). Il znio unico esemplare è un po' diverso perchè gibboso al centro delle valre. R. - 398. C. asperrima Reuss (Cypridina). Oltre la forma tipica incontrai una raricti, nella quale la forma è più allungata, ed inoltre la regione centrale presenta delle elerazioni arrotondate (due o tre) e la superficie è un po' meno spinosa. 1. - 399. C. Histrix Reuss (Cypridina). Le spine sono bipartite e talune tripartite. Var. clongata. Forma piùr gracile colle spine più lunghe. c. 400. C. corrugata Reuss (Cypridina). In taluni esemplari la scultura è più fortemente marcata e le fossette sono cinte da rialzi piu prominenti, costituendo in tal modo una vera rarieti. r. - 401. C. plicata v. Miunster (Cypridina). L'esemplare che vi rapporto si riferisce meglio alle figure date dall'Egger. $\mathrm{R}$. 402. C. striato-punctata Rocmer. Questa specie ofle esemplari che convengono bene colle figure date dall'Egger. Var. elongata Egger. Anco di questa forma qualche esemplare. R. - 403. C. Jon esiana Bosquet. Un solo esem11are. R. - 401. C. plicatula Reuss (Cypridina). Forma e scultura alquanto variabile in modo che $s^{9}$ incontrano delle modalita che più o meno somigliano alle figure rarie date dal Reuss, dall'Egger e dal Bosquet, ma più si arricinano a quelle di quest'ultimo autore, e portano costantemente al margine anteriore dei piccoli dentelli acuti. c.

405. C. seminulum n. sp. Tav. XII. fig. 4, $4 a$.

Questa specie si avvicini per la forma allungata alla precedente, ma ne è distintissima per tutti i caratteri. La forma è allungata molto, un po'curva e pressochè ugualmente larga in tutta la lunghezza, cogli estremi arrotondati, il posteriore soltauto alquanto angoloso e sporgente; la superficie regolarmente convessa non presenta depressioni o appianamenti marginali, la scultura è fatta da piccoli incari allineati in superficiali solchi di forma curra non paralleli al margine superiore.

Luughezza 1. um Larghezza 0,5. ${ }^{\mathrm{mn}}$ Spessore $0,4$. mm $\mathbf{R}$.

400. C. gibboso-foveolata n. sp. Tav. XII. fig. 5, 5a.

Aftine alla vivente C. quatriclentata dalla quale distinguesi per essere molto piì rigonfia, e per la senltura costituita d'incari più grandi, pii ravricinati, più angolosi, piì profondi, ed anco per la generale forma pii regolare, perchè il margine superioro e l'inferiore sono pressoche esattamente paralleli.

$$
\text { Lunghezza } 0,7 . m \mathrm{~m} \text { Larghezza } 0,4 .^{\mathrm{mm}} \text { Spessore } 0,4 .^{\mathrm{mm}} \mathrm{x} \text {. }
$$


407. C. s ca bra r. Munster (Cypridina). Questa forma bella e distintissima per la speciale scultura trovasi comme e costante a Bencstare. c. - 408. C. E d w ards i i Roemer (Cypridina). Gli esemplari calabresi sembrano intermedi tra quelli rappresentati dal Reuss e quelli figurati dal Bosquet. I dentelli dei margini anteriori e posteriori sono poco prominenti. R.

409. C. subtrigona n. sp. Tav. VIII. fig. 2.

Vedi per la descrizione l'elenco dei fossili elveziani. Nel Tortoniano oltre della forma tipica s'incontrano delle varieta. Var. marginato-striate. Tar. XII. fig. 6, 6a. Questa forma si distingue per la scultura della superficie quasi cancellata, pei dentelli dei margini anteriore e posteriore piu numerosi, che si connettono colle striature radianti che affettano ambo i margini. 1 .

410. C. semiluuata n. sp. Tar. XII. fig. 7 .

Questa forma è distintissima quantunque abbia una certa somiglianza grossolana colla C. Haueri Roemer, dalla quale basterebbe la sola carena per distinguerla eminentemente. La forma generale è quasi esattamente quella di un semicerchio coll'angolo anteriore rotondato, il posteriore acuto ed alquanto prominente. La superficie regolarmente convessa e liscia si presenta con rare punteggiature e molto presso al margine inferiore $v^{\prime \prime}$ ha una carena arenata prominente priva affatto di sporgenze, di dentelli ec.

$$
\text { Lunghezza } 1{ }^{m m} \text { Larghezza } 0,6{ }^{\mathrm{mm}} \mathrm{R} \text {. }
$$

411. C. ceraptora v. Munster (Cypridina). Di questa bellissima specie possiedo due conservatissime valve, che sono anco fortemente trashcide. Una lieve ditterenza si osserva tra questi esemplari e le figure date dal Bosquet, cioe la piu elevata prominenza della carena è meno sporgente. $R$.

412. C. flabellata n. sp. Tar. XII. fig. 8.

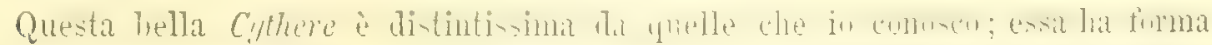

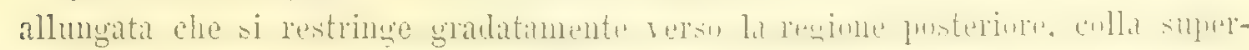
ficie regolarmente convessa, ma appianata verso i margini, e ornata da una scultura specialissima che direi squamoso-foreolato-rugosa. Il margine anteriore appianato, regolarmente arcuato è sottilmente radiato-striato ed ollie qualche lievissima sporgenza, e coi medesimi caratteri si comette il margine superiore, che conservasi tale per soli due quinti delia sua lunghezza. Il margine posteriore è rotondato-troneato, e plicato-crenato e con tale forma continuasi il margine superiore pei tre quinti della sua lunghezza. Il margine inferiore quasi retto presenta nella sua parte centrale quattro dentelli allontanati. In ricinauza dell'angolo infero-anteriore la superficie offre ma prominenza abbastanza elevata.

Lunghezza 1. mm Larghezza 0,5 . $\mathrm{mm}$.

413. C. tetraptera n. sp. Tar. XII. fig. 9, 9a.

Questa specie per la sua forma generale ricorda la C. Nicheliniana Bosqunot, ma ne è distintissima per molti particolari. La regione posteriore è uneno ristretta e meno prominente, rotondata e col margine formito di dentelli spiniformi, tra i quali uno più valido e più lungo. La regione anteriore è più regolarmente arcuata, la metà dal lato della regione inferiore è dentata, invece finamente crenata l'altra meta. La carena si termina in un aculeo, ed alla regione mediana posteriore della 
valva v'ha una lamina elevata che all'estremo diviene triangolare. Un'altra carena è poi di forma arcuata dal lato della regione superiore. Mancano infine quegl'incavi che nella C. Micheliniana cingono la carena d'ambo i lati.

Lunghezza 1,2.ma Larghezza 0,6 . wu Spessore 0,6 . . $^{\mathrm{mm}}$

Raccolto un solo esemplare intiero. $R$.

Foxoconeha. - 414. L. p unctatella. Reuss (Cypridina). Questa specie risponde esattamente alla forma del bacino di Vienna descritta dallo scopritore. R.

415. L. obliquata n. sp. Tav. XII. fig. 10.

Questa specie è affine molto alla virente L. impressa Baird (Cychere), ma se ne distingrue perchè ha una scultura foveolata molto meglio distinta, perchè più regolare ed uguale per tutta la superficie, solamente ne sono prife due porzioni depresse che cingono soltanto le due regioni estreme l'anteriore e la posteriore.

Lunghezza 0,8 . $^{\mathrm{mm}}$ Larghezza $0,50^{\mathrm{mm}} \mathrm{R}$.

Testoleberis. - 416. X. tum id a Reuss (Cytherina). L'unico esemplare ed intiero che ho raccolto risponde bene alla descrizione e figura del Reuss, e certo fa d'uopo rapportare la specie al genere cui la riferisco. 1 .

Cytherella. - 417. C. compressa v. Munster. L' unica ralva che raćcolsi ha delle linee irregolari alla superficie, che io riguardo siccome accidentalmente prodotte da superficiale erosione. R. - 418. C. Jo ñesana. Bosquet. Riferisco con qualche dubbio a qnesta specie una sola ralra, la quale ha le due estreme regioni un po' più rotondate, e la superficie finamente punteggiata. $R$.

\section{Ordine. Cirrtpedi.}

EaIanus. - 419. B. concarus Brom. Frammenti che conserrano un colorito rosso-bruno con raggi bianchicci. $R$. V. - 420. B. . . sp.? Una valra indeterminabile. R.

Scalpelluas. - 421. S. Molinianum Seguenza. Un tergo incompleto, in cui sono assai marcate le linee radianti. Vi riferisco inoltre nn frammento di una delle piccole ralve. $R$.

\section{Tipo. VERMI.}

Classe. Aneluini.

asygmoluram

Denomino cosi numerosi frammenti di un tubo di anellide, che trorasi sparso in abbondanza nelle argille di Benestare. Tali frammenti giungono sino alla lunghezza di quattro centimetri, hanno un diametro variabile che raggiunge al massimo inove unillimetri, la loro forma è pressochè cilindrica, raramente si assottiglia pochissimo verso l'estremo posteriore; la parete che lo costituisce ì d'una grande soliditi e ragginnge il considererole spessore di due millimetri; la superficio ì trasfersalmente ed imegolamente rugosa.c.

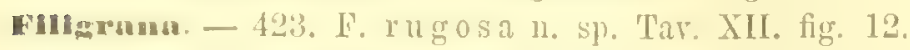

I tubolini calearei di questa specie sono flessuosi più o meno e si associano insieme formando delle masse analoghe a quelle della virente Scrpula fligrana 
Lin. dalla quale distinguesi perchè i tubi sono annulato-rugosi e portano inoltre di tanto in tanto anelli più rilevati. $x$.

Dirorbis. - 424. S. cornul-arietis? Philippi.

L'unico esemplare che ravricino a questa specie del Mediterraneo ando smarrito e quindi non ho potuto bene studiarlo e compararlo, perlochè il ravvicinamento è nolto dubbio. R. V.

425. S. obtectus n. sp. Tav. XII. fig. 10.

Questa specie è poco elevata e mostra soltanto l'ultimo giro della spirale, il quale è molto allargato e lascia un ombelico stretto e profondo, imbutiforme; attorno l'ombelico la conchiglia è carenata, e la carena dal lato interno è cinta da un solco.

\section{Diametro $1,5 . \mathrm{mm}$}

Incontrasi fisso sull'Ancillaria glandiformis. 1 .

Ditrupa. - 426. D. in eurva (Renier) Brocchi (Dentalium). Specie comunissima, variabile molto di grandezza e di forma. C.

Serpula. - 427. S...... sp. ? Tubi trasversalmente rugosi, e con talune angolositì oblique.

Al genere serpula si rapportano inoltie varî frammenti di tubi di forma e di caratteri diversi, che non possono determinarsi precisamente per la pochezza del materiale raccolto.

\section{Classe. BrtozonriI.}

Sallcornaria. - 428. S. far ciminoides Jonston. Questa polimorfa specie io la riguardo siccome il Reuss nelle ultime sue pubblicazioni ed il Manzoni. Nel nostro Tortoniano essa offre sillatte numerose forme e molto srariate. C.

Cemcllarise, - 429. G. punctata 1. sp. Tav. XII. fig. 13, 13a.

L'unico esemplare che io denomino così ha considererole analogia colla $G$. prima Renss, dalla quale differisce perchè ciascun intermodo è proporzionatamente più lungo, perchè più allungate sono le cellule, le quali inoltre hamno la regione dell'apertura alquanto incurrata lateralmente ed in senso opposto per le due di crascun paio. Una linea retta rilerata si estende sopra ambo i lati disgiungendo le due serie di cellule e due ordini di punteggiature accompaguano ciascuna linea parallelamente. R.

Bnetridiun. - 430, B. Manz oni i n. sp. Tav. XII. fig. 14, 14a.

Questa specie è ben distinta dalle conoscinte, le sue cellule hamo una forma ovata con una prominenza superiore, che sporge meglio verso la faccia posteriore della colonia, anteriormente ciascuna cellula porta una porzione convessa orale: l'apertura è trastersalmente ovale. Una linea ondulata impressa disgiunge sopra ambe le facce le due serie di cellule. Un solo esemplare. R.

Acten. - 431. A. sica Couch. Di questa specie ho trovato qualche colonia sul Peclen latissimus. R.

Terebripora. - 432. T. A r chiaci Ficher. Per questa specie redi i fossili dell'Elveziano. Trovasi comunemente perforante le conchiglie di molti MLoluschi, come Conus Mercati. Fusus longirostris, Turritella lornata, Pechunculus slellatus: 
siccome è abbondante sui coralli, quali il Flabellum cxtensum var., il Ceratotrochus 12 costatus ece; ma commemente redesi sparsissima sull' Ostrea navicularis, tanto a Benestare quanto ad Ambuti. C. - 433. T. Orbignyana Fischer. Questa distinta forma trorasi anch' esșa sparsa a Benestare sulle seguenti specie: Conus....... Ancillaria glandiformis, Eburna meridionalis, Natica auropunctata, $N$. redempta. c.

434. T'. tou us n. sp. Tar. XII. fig. 15.

Questi forma di cui incontrai runa sola colonia su d'un frammento di Yenophoru distinguesi per essere molto gracile e piccola, per la lunghezza doppia o poco pii dei canali che rimniscono le cellule, per la forma strozzata e raria delle cavitì che queste hanno lasciato nella conchiglia che perforano ec. $R$.

apatipora. - 435. S. laxa n. sp. Tav. XII. fig. 16.

Rapporto con dubbio a questo genere un Briozorio perforante, il quale non presenta alcuna cellula sul tragitto degli esilissimi canali di cui è costituito, i quali si ramificano ordinariamente ad angolo acuto e con irregolarita, e più raramente ad angolo retto, ed i rami sorente si anastomizzano tra loro, il quale carattere manca nelle specie sinora descritte. Le cellule stanno in prossimita dei canali alteruando con poca regolariti, esse si presentano sotto forma d'una semplice escarazione circolare, nella quale non mi fu dato di scuoprire i brevi canali che doreano metterle in relazione coi canali principali. $\Lambda$ Benestare questa specie perfora molte conchiglie come: Conus....... Ancillaria glandiformis, Murex rudis, Fasciolaria tarbelliana, Ranella marginata, Eburna meridionalis. C.

Menulornipors. - 436. If. irrogularis D'Orbigny. Sulla Fasciolaria tarbetliana. R. V. - 437. Ir a perta Busck. Qualche colonia sulla Fasc tarbelliana. R. - 438. M. loxopora Reuss. Identicissima agli esemplari del Bacino di Vienna; sul Murex torularius e sulla Ranella mìrginata. 1 . 139. II. crispa n. sp. Tav. XII. fig. 18.

Questa specie è molto somigliante alla 11 . trifolium S. Wood sia per l'andamento generale come per la superficie granulosa delle cellule, ma le cellule sono irregolarmente orali, l'apertura orato-rettangolare e cinta d' un margine increspato, e quel che più importa mancano affatto gli aviculari. Incrosta il Dentalium inaequicosta. R.

440. M. bidens $v$. Hag. Trovasi incrostante un frammento di conchiglia indeterminabile. $\mathrm{R}$.

441. M. ogivalis n. sp. (Vedi fossili elveziani, tar. VIII. tig. 9). Inerosta l'Ancillaria glandiformis, ed il Pectunculus stellatus. 1. - 442. M. andegavensis Michelin. Una colonia sul Mhex Bellardii. R. - 443. M. calpens is var. Una colonia molto simile alla virente. R. V. - 444. M. semiaperta leuss. Sulla Turritclla bicarinata. R. - 445. M. gracilis lienss. Poche colonie sullo Stromuns coronatus e sul Hurex Bellardii. 1. - 446. M. jrap y racea Reuss. Sulla fiscinlaria tarbelliana. li. - 417. M. angulosa Renss. Sull' Ancillaria glandiformis e sul Murer mulis: 1. V. - 448. M. stenostoma Reuss. Sulla insciolaria tabellinane. R 
cepralin. - 449. L. ciliata Linneo (Cellepora). Aleune colonie stl d'uni Col. leporaria. R. V. - 450. L. in amoena Reuss. Qualche colonia su d'unil Celleporaria. R. - 451. L. ansata Jonston. Diverse rarietil sullo Strombus coronatus e sul Murex torularines. r. V.

452. I. radiato-porosa n. sil. Tiar. XII. fig. 19.

Chiamo così una lepralia miocenica che il Manzoni riguardo siccome identica alla L. tetragona Reuss (Cellepora), e che l'autore piu tardi giustamente associo alla $L$. ansata Jonst. Ho voluto rappresentare la forma che trovasi in Calabria siccome un jo' dirersa dalla miocenica del Piemonte figurata dal Manzoni. Difatti le cellule delle mie colonie offrono un maggior numero di solehi poriferi radianti, e molto sporgente la prominenza centrale. Incrosta la fasciolaria tarbelliana, ed il Murexo torularius. 1 .

453. L. otophora Reuss. Qualche colonia sulla Eburna meridionalis. R. 454. L. brachicephala n. sp. = L. otophora Hanzoni (non Reuss). Sembrami dorersi distinguere questa dalla precedente forma. Sul Dentalium inaequicosia. R. 455. L. radiato-foréolata n. sp. Tar. XII. fig. 20.

Bella forma radiato-costata, nella quale le cellule orali quasi appianate sono elegantemente ornate di costole prominenti che irradiano da un forame centrale, e sovente si comnettono con una serie di fossette marginali. Sotto la bocea, di forma trastersalmente orata, havri costantemente un ariculare in forma di protuberanza ovata con un forime circolare orvero orale. $\mathrm{H}$.

456. I. regularis Reuss. Grandi colonie sul Pccten latissimus. R. - 457. L. obelis cus Manzoni. La forma che io riferisco a questa specie può riguardarsi come una rarieti. Essa ha la bocea elargata orato-quadrangolare, ma la forma delle cellule è meno rigonfia e le fossette marginali sono piu grandi e rassomigliano a quelle della precedente specie. Una sola colonia sopra un frammento di Pettuncolo. R. - 458. L. violacea Johnston. Le colouie sono più o meno calcificate ed incrostano l'Ancillaria glandiformis, l'Eutria magna, la Turritella bicarinata, il Dentalium inaequicosta. c. V. - 459. L. squamoidea Reuss. Una colonia sul Dent. inaequicosta. R. - 460. L. l ugosula Reuss. Sul Murea: rudis. R. - 461. L. granoso-porosa Reuss. Sul Murex torularius. R. 462. L. an is ostoma Reuss. L'nnica colonia che vi rapporto raria molto uella forma della bocca, che raramente assume quella rappresentata dall'autore. Sul Carlium discrepans. R. - 463. I. reticulata Busck. Sul Conus ..... e sullo Strombus coronatus. r. V.

Celleporaria. - 464. C. re ru cus a Renss. Rapporto con molto dubbio a questa specic alcuni esemplari di Celleporaric ramosa mal conservati. 1. - 465. C. globularis Bromn. Oltrechè a colonie isolate trorasi questa specie incrostare la Ditrupa incurva, altre Cellepordrie ec. 1. - 466. C. crass a MIanzoni. Qualche piccola e dubbia colonia. R. - 467. C. Systolostoma Manzoni. Pochi frammenti con cellule a grossi pori. R. - 468. C. pulchir Michelotti. Uni colonia sul Cardium discrepans. R. - 469. C. edax Busk. Questa specie propria del Crag inglese e vivente nei mari settentrionali si presenta a. Benestare in ben conservati esemplari, i quali hamo la conformazione di quelli inglesi, e 
presentano un canale curvo, mostrando che le cellule si aggrupparono inerostando dapprima mu tubo di una Serpula orrero la conchiglia d'un Vermetus. r. T.

Cumulporer. - 470. C. trausilvanica (Reuss. M. S.) Manzoni. Io credo poter rapportare a questa specic di belle forme rarie colonie che incrostano la Turritella bicarinata, il Dentalium indequicosta ed il Celrdium discrepans. r.

471. C. granosa 11. sp. Tar. XII. fig. 21, 21 .

La nuora forma di Cumulipora da me rinvenuta a Benestare è distintissima e. non lascia dubbio di sortil sulla definizione generica, essendochè le sue cellule ricordano quelle di ma Lepralia, e la loro irregolare disposizione, che influisce a dar loro sovente un imegolare sriluppo, ricorda bene le Celleporaric.

Ciascuma cellula è pressochè pentagona, una quasi sempre irregolarmente sviluppata, la parete che la costituisce è compatta ed imperforata colla superficic levigata e splendente quasi coperta da una vernice, quantumque sparsa di grossi ed irregolari gramuli parimenti lisci e splendenti. La bocea è orata a rovescio, angolosa in basso, e porta da un lato un aviculare globoso, prominente con apertura orata, il quale manea sorente e con più raritì si offre sopra ambo i lati. Un altro aviculare poi di ben diversa forma esiste costantemente al centro Iella cellula, esso è orato-oblongo, disposto trasrersalmente, alquanto ristretto nel mezzo, acuminato ad un estremo, con un margine sottile rilerato e bipartito da un tramezzo piu o meno prominente e distinto, e con apertura variabile. Gli oricelli, come rappresenta la fig. 21 a sono grandi, globosi, rugosi alla superficic e con un piccolo intaglio sulla fronte.

Questa bella specie forma delle piccole colonie che appena ragginngono i tre millimetri; tra le poche che ho raccolto una sola mostra il corpo su cui le cellule si fissarono ed ì uma Morginulina raphanus. I:

IBafopma. - 472. B. rosula Reuss (Cellepora). È questo uno dei briozoi più comuni che raccolgonsi a Benestare nelle argille tortoniane e sempre in perfettissimo stato di conservazione. C.

Grbituliporg. - 473. 0. exeentrica 11. sp. Tar. XIL. fig. 22, 22a.

Le belle e grandi colonie di questa distinta specie, che giungono sino al diametro di sette millimetri, sono di forma molto compressa ed appianata, con un contomo pressochè reniforme, nella parte incarata del quale sta il centro e l'origine della colonia. Le cellule molto numerose sono disposte concentricamente attorno il punto d'origine della colonia, e formano inoltre come delle serie sopra linec rette o poco eurve dal margine inferiore al superiore; inoltre esse ingrandiscono frogressivamente dal centro ai margini, conservando sempre una forma globosa o globoso-orata, coll'apertura circolare. Talune fra esse, irregolinmente distribuite nella colonia, o formanti delle serie anco irregolari, o più ordinariamente in vicinanza dei margini, divengno prolifere, ed allora acquistano una grandezza piì che dopriti, mua forma ovata, che nella parte inferiore è gibbosa e nella superiore si apre la bocea pressochè semicircolare; la superficie di tali cellule è rugosia.

Trovasi questa specie a Benestare molto ben conserrata. 1 .

Hemieschara. - 474. H. traperoidea Renss. Riferisco al questa sprecie dell'oligoceno un sol frammento. R. 
475. H. varians n. sp. Tar. XTI. fig. 23.

Riferisco a questo genere col nome sopradetto taluni frammenti in cui le celIule sono ovali cinti da grandi perforazioni, con una grande bocea ovale circondata di solchi di rarie lnughezze disposti parallelamente al margine. Alla base della cellula è un ariculare che si manifesta per una grande apertura rariabile, triangolare e talvolta lanceolata. R.

Eschara. - 476. E. undulata Renss. Pochi frammenti hen riconoscibili. 1:- 477. E. monilifera M. Edwards. Pochi ma distintissimi e ben conservati frammenti. R.

478. E. reticulata n. sp. Tav. XII. fig. 24.

Questa distinta specie mostrasi in frammenti di rami abbastanza compressi nei quali le cellule di forma allungata e pressochè rettangolari sono disposte con molta regolarita sopra linee rette e parallele. La parete della cellula appianata presenta alla superficie una elegante reticolazione a maglie un po' disuguali, in fondo a ciascuna delle quali apresi un largo forame, e perciò la parete è perforata. La bocea circolare si apre sopra una prominenza che costituisce un corcine rotondato attorno ad essa. Immediatamente sotto la bocea vi ha mincaro profondo, orale, in fondo al quale apresi un largo forame anch'esso ovale, e tra questo, e la bocca un secondo di forma semilunare.

Questa specie ha molta analogia colla E. diplostoma Phil. alla quale io credera poterla riferire; wa il carattere che più nettamente la distingue è quello della reticolazione della superficie, e della perforizione di tutta la parete. R.

Cupularia. - 479. C. u m b ellata Defrance. Sono abbondanti i frammenti d'uma grande Cupularia che io rapporto alla C. umbellata, ma non ho rinvenuto esemplari intieri. c. V. - 480. C. Haidingeri Renss. Questa specie oltrechè in abbondanti frammenti trorasi in esemplari intieri e ben conservati. e. -481 . C. canariensis Busk. Trovasi in frammenti rispontenti alle figure e descrizioni date dal Manzoni. r. V. - 482: C. Re us si i Manzoni. La piccola e convessissima forma distingue questa specie, che è la più comune del giacimento di Benestare. C.

cumalites. - 483. L. androsaces All. Troransi i soli frammenti molto ben, conservati. $x$.

Sclenaria. - 484. S.? miocenica n. sp. Tar. XII. fig. 25, 25u.

È un semplice frammento rappresentato dalla sua faccia inferiore nella fig. 25a, che io con molto dubbio rapporto al genere Selenavia, che, a dire il rero, non conosco nemmeno in natura. La forma del frammento dimostra chiaramente che xi appartiene alla famiglia dei Selenariidi, il difetto di pori vibraculari me lo fit rapportare al genere Selenaria. In questo briozoario le cellule sono rimarcherolissime perchè si presentano di due forme. Sono tutte di forma orale orvero oratopentagona, le une colla parete concara, puntegriata, marginato-crenata e con una grande apertura in alto, elargata, biangolosa e troneata in basso; le altre presentano una superficie appianata, leggermente convessa ed irregolarmente fugosa " scabra, con una boeca in forma di arco, talyolta molto curvato, quasi a ferro di cavallo; tali cellule zoocciali sono irregolarmente distribuite in mezzo alle altre. e la loro dicersi forma e costituzione io non saprei ad altro attriburite se nom 
all' invechiamento delle cellule stesse e yuindi alla loro calcificazione, dalla quale arrebbe origine l'ispessimento della parete per la sorrapposizione d'un materiale irregolarmente rugoso alla superficie.

La ficcia inferiore della colonia (fig. $25 a$ ). è solcatia e rugosa. R.

Crisis. - 485. C. e burne a Limeo (Sertularia). Alcuni delicati e ben conservati esemplari. R.V. - 486. C. Edwardsi Reuss. R. - 487. C. Hoernesii Reuss. Esemplari ben caratterizzati. 1 .

488. C. maloginatan. sp. Tar. XII. fig. 26.

Denomino così l'unico esemplare rapmresentato nelle tavole, nel quale ciascun tubo zooeciale presenta un margine dal lato esterno più o meno sviluppato e distinto. R.

Inomern. - 489. H. froudiculata Lamouroux. Pochi rami mal conservati. R. V. - 490. H. concatenata Reuss. Un piccolo frammento di Hornera somiglia in tutti i caratteri alla specie sopra citata, ma per la pochezza del materiale si restn incerti della determinazione. $R$.

491. H. Reussii 11. sp. Tar. VIII. fig. 6.

(Vedi fossili elveziani). Qualche raro frammento. R. 492. H. simplex 11. sp. Tar. XII. fig. 27, 27a.

Questa bella sprecie è molto afline alla $/ I$. serrata Reuss, dalla quale differisce per essere piì gracile, per un minor numero di cellule zooeciali, perchè le pieghe della faccia posteriore sono meno divergenti, e la superficie è seguata da linee impresse che s"intersecauo in modo da chindere degli spazî irregolarmente romboidale-allungati, che ricordano in qualche modo quanto si osserva sulla faccia posteriore delle reteprore. $R$.

Immoner. - 493. I. spica 11. sp). Tav. XII, fig. 28, 28 .

Questa specie è molto affine alla I. lineala Hag, dalla quale differisce per essere più gracile, per essere trigona colla faccia posteriore un $10^{\circ}$ conressa, e striata esihuente come in quella specie. R.

494. I. carinata? Roemer. Un piccolo frammento che risponde alle figure date dal Manzoni e mostra distintissime le strie della superficie. R. - 495. I. d is t i c h a? Goldf. Vi riferisco un fiammento che lascia dei dubbî. R. - 496. I. fenestrata Busck. In mezzo agli esemplari della specie seguente ne ho trorato due corrispondenti alli forma del Crig d'Inghiltera. R. - 497. T. pertusa Renss. La più comune delle Idmonce di questo giacimento, la quale presentasi con tutti i caratteri che la distinguono nel bacino di Vienna. r.

Fuipparsa. - 408. F. varians Reuss. Un ben distinto esemplare. R.

Lontalophana. - 499. E. at tenuata Stoliczka. Un solo conservatissimo esemplare. R.

mustuloprora. - 500. P. pule hella Reuss. Esemplari ben distinti.r. - 501. P. noboscina Manzoni. Una sola colonia assai ben conservata. R. - 502. P. sparsa Reuss. Pochi e mal conservati esemplari. R.

Mesentenipura. - 50:3. MI. e udesiana? ML. Edwards. Un esemplare dubbio. R?.

Tubulipona. - 504. 'I'. foliacea Reuss. Le colonie allargate lobate e divise che riferiseo a questa specie lasciano in me lieri dubbî intorno all' esattezza della determinazione. Incrostann il Pecten latissimus. R. 
Diastopora. - 505. D. sparsa Reuss. Una sola colonia. $R$.

Aceto. - 506. A. rugulosa Reuss. Una bella e distinta colonia, analoga a quella rappresentata dal Manzoni, incrosta il P. latissimus. I.

Defrancia. - 507. D. simplex F. A. Roemer. Riferiseo con sieurezza a questa specie dell'oligoceno di Sollingen un esemplare ben conservato di Benestire, dalle argille tortoniane. R.

Ceriopora. - 508. C. globulus Reuss. R.

Tipo. ECHINODERMI.

Classe. Sterlerind. - Orline. Asteridr.

Crenaster. - 509. C. Soldani Moneghini. Riferisco a questa specie molti scudetti o ossicini di forma e di grandezza varia che rispondono benissimo alla descrizione che ne dì sulla faccia conressa il prof. Neneghini, sinanco in alcuni osserransi le papille nere lucide ricordate dal Soldani, solamente poco alupezzabili sono le crenature della cornice scaualata, ma ciò parmi potersi attribuire alla poco buona conservazione degli esemplar'i posseduti. r. - 510. C. oluatus Jenighini. Vari ossicini piccoli tubercolati sulla faccia convessa parmi che si riferiscano alla specie qui ricordati. 1: - 511. C. erenulatus Michelotti (M. S.). Riferisco a questa forma due ossicini puì piccoli degli esemplari faroritimi dal sig. car. Michelotti raccolti nel mioceno medio, e che somigliano ai precedenti per la forma, wa hanno la superficie convessia come squamosil con aleuni tubercoli ad un'estremiti. R. - 512. C. foreolatus Meneghini. Un solo scudetto risponde, quantunque più piccolo, alla descrizione data dall'autore e somiglia perfettamente a due scudetti della collina di Torino di dimensioni granilemente maggiori. $R$.

\section{Classe. Fchinidi. - Ordine. Rerulate.}

Cidaris. - 513. C. Inusteri E. Sismonda. Tarî radioli raccolti, quantunque diversi nel numero delle serie di spinette, parmi che presentino tutti i caratteri che il prof. Meneghini ha assegmato allia rariabile specie. Il margine articolar. si presenta, allorchè ben conservato, piì distintamente crenulato dia un lato, siccome accuratamente l'ha descritto il sullodato prof. Meneyhini. r.

Centrostephnnus. - 514. C. primigen ius 11. sp.

Il piccolo materiale che io denomino cosi dimostra trattarsi d'una specio molto affine al vivente $C$. longissimus Plil. (Diadema) = Diadema europaeum Agassiz; sono difatti frammenti piccoli del gruscio e pezzetti di radioli, quest'ultimi comjarati colla specie virente d' Europa mostrano le seguenti differenze. Il ribordo al collaretto è profondamente soleato longitudinalmente, laddore ucl longissimus ì appena striato, la faccia articolare la il margine più fortemente crenato, i rerticilli in tutta la lunghezza dei radioli sono più lunghi. I.

Ordine. Chipeastrojn.

Crypenster. - 51ě. C. marginatus Lamarek. Nelle argille tortoniane li Benestare troransi dei frammenti di questa specie ben riconoseibili. Nelle sabbite 
gessifere soprastanti questo bello cchinide si raccoglie in esemplari trasformati in selenite cristallina. $r$.

Ordine. Spatangoid.

Riesce affatto impossibile la determinazione anco generica dei piccoli frammenti e di qualche radiolo spettanti a quest'ordine, raccolti nelle argille tortoniane.

\section{'Tipo. CELENTERATI.}

Classe. Antozoarit. - Ordine. Alcionaril.

Isis. - 510. 1. melitensis Goldfuss. Rapporto a questa specie con dubbio un sol piccolo articolo alquanto irregolare ed a strie incurate. R.

Ordine. Zositaril.

Trochocyathus. - 517. 'I'. mitratus Goldfuss (Turbinolia). R. - 518. T. granulatus Goldfuss (Turbinolia). Alcuni frammenti un po'dubbî. 1R. - 519. T. Bellingerii Edwards et Haime = Turbinolia Bellingeriana (Michelin). Un frammento di dublia determinazione. R.

DeItocyathus. - 50. I). italieus Hichelotti (Turtinolia) $=$ Stephanophyllia itulica Michelin, U. ilalicus II. Edwards et H., Renss. ecc. Questa specie trovasi a Benestare in snli e rallissimi frammenti. R.

Eemesus: - 521. H. fungiaeformis Philipyi = Hemicyahus crassicostahus Seguenza. 'Trovansi lari frammenti. r.

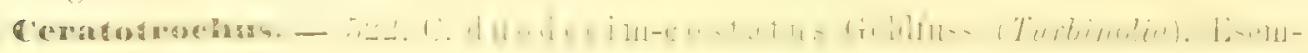
plari sempre rolti. c. - 533. C. multiserialis Michelotti (Turbinolia) Var. mullicostalus. L'esemplare unico che denomino cosi ha molta analogia colla bella varieta raupresentata dal heuss nella fig. 7 della tar. IV. (Die fossilen Korallen des Osterreichischen Ungarichen miocüns. 1871), ma la forma calabrese si distingue per avere oltre le 18 costole interrotte e tulsercolate, altrettante costole minori alternanti con quelle, anch'esse angolose, ma meno interrotte e non tubercolate. $\mathrm{L}$.

Conotrochus. - 524. C. ty p us Seguenza = Ceralotrochus typus Sismonda, Conotrochus typus Reuss. Esemplari ben conservati identici a quelli comunissimi del plioceno. li.

Fhablum. - 525. F. extens um Michelin. Var. costata. Questa forma viene da me associata al $F$. exiensum, quantunque se ne distingua per essere alquanto meno compressa, e per arere cinque o dieci costole sporgenti. Forse la scoperta di esemplari intieri e ben conservati che io non raceolsi la farebbero erigere al rango di specie. c. - 526. E. in terme d i um Ldwards et Haime. R. - 527. F. lio is y a num fidwards et Hame. Un frammento assai dubbio. R. - 528. F. acutum Edwards et Haime. Alcuni esemplari incompleti. 1.

Mellastronen. - 509. H. IR u usana M. Edwards et Haime. Un solo esemplare in ceattivo stato di conservazione. Tr.

stephnophylla. - 530. S. agaricoides Risso (Fungia) = S. imperialis Michelin. Renss. S. agaricoides Sismonda. Trorasi in ben conservati frammenti. R. - 
531. S. elegans Bromn (Fungia) $=S$. elegans Michelin. M. Edwards et Haime. Reuss, Sismonla. Belli e ben conservati esemplari intieri. r.

Bahnophylla. - 532. B. i lo egularis Seguenza. Esemplari sempre rolti. c.

Porites. - 533. P. incrustaus Defiance (Astrea) = P. incrustans M. Fidwarts el Haime, Seguenza, Reuss cce. Vi riferisco con dubbio alemi piccoli frammenti. Ir.

Classe. SrovginRIJ.

chona. - 534. C. falunica Fischer. Questa specie trorasi molto commementc e perfora ogni specie di conchiglie, come Coni, Ancillarie, Murici. Pettuncoli. Ostriche, Terebratule ece. C.

535. C. tubulosa 11. sp. Tar. XII. fig. $29,29 a$.

(Vedi fossili elrezini). Nel Tortoniano questa specie trorasi ahbastama sparsa. essa perfora l'Ancillaric glandiformis, i Coni, i Pelluncoli, il Elubellum extensum ecc. c.

536. C. rermicularis n. sp. Tar. XII. tig. :30.

Questa comune forma distrusse gran numero di conchiglie del gitcimento di Benestare. Essa presentasi sotto forma di solchi superficiali e Hessuosi, che direngono sempre più profondi verso un estremo, dore apresi un forame circolare che si continua nell'interno della conchiglia sotto forma di tenue, lungo e flessuoso canale. Vedesi sopra Ancillaric. Coni, Terebre, Turrilelle, l'elluncoli sul Flabellum ertensum ece. C:

537. C. micropora 11. sp. Tar. XII. fig. 3l.

Chiamo così una perforazione assai sottile, visibile per mezzo di ma lente di ingrandimento, costituita di forami rotondi, disnguali, rarricinati, el irregolarmente distribuiti, i quali si continuano in esili camali nell'interno della conchiglia, d'oldinario perpendicolari alla superficie. 'Trorasi sulle Ancillarie, su i Coni sulle Natiche e sopra altre conchiglie. c.

538. C. oostoma Tar. XII. fig. 32.

Denomino cosi talune perforazioni di forma orato-allungata, che si osserrano di unita alle precedenti specie perforare i Coni, le Ancillarie cd altri resti. 1.

Tipo. PROTOZOARII.

Classe. Rizopont. - Orline. Fornuniferi,

Magena. - 539. L. rulgaris Williams := L. Laevis Wrilliams, Phialina puriformis Costa, P. propinqua, ovata, longirostris Seguenza. Si raceolgono direrse rarieti e specialmente la Var. semistriate Wrilliams. c. V. - 5.10. L. ol'nata Segnenza. (Ovulina) $=$ L. favose Rouss. R. - 541. I. catenulata Williams = Ovulina reticulata Seguenza (non Lagenula reliculata Maegill.). R. V. - 542. L. c y lindracea Seguenza (Phialina). r. - 543. L. Gemmella ri i Seguenza (Phialina) r. - 5.4. L. filicosta Renss. R. - 5t5. I. I yelli i Seguenza (Amphorina) R. - 546. L. 1 neida Williams R. T. - 5.77. T. marginata Waleher. 1. V.

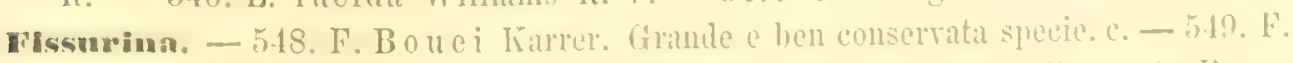
laeyigata Reuss. r. - 550. F. Biancale Seguenza. R. - 551. F. a cuta Reuss. 


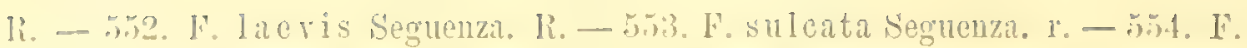
Hateheli Seguenza. R. - 55s. F. carinata Reuss. R. - 5ab. F. alatil lieuss. R. - 557. F. tubulosa Seguenza. r.

558. H. punctata n. sp. Tav. XIL. lig. 1.

Alquanto somigliante alla precerlente, questa specie si distingue per un doppio margine, per una prominenza posteriore e per le grosse punteggiature della superficie. R. - 559. F. squa mos 0-marginata Parker et Jones (Lagena). Questa specie vive in Australia ed estata trovata fussile nel mioceno di s. Domingo. R. V. 560. F. radiato-marginata Parker ot Jones (Lagena). L'unico esemplare che vi riferisco è alquanto dubbio, essendochè sono appena accennate le linee radianti. Questir specie vive in Australia e fu trorata fossile nel terziario medio di Bordentux. R. Y.

Tousaria. - 561. N. raphanistrum Linneo (Nautilus). Questa grande e comune specie offre le sue numerose rariazioni nel Tortoniano di Benestare. C. Y. 562. N. raphanus Limeo (Naulilus). 12 V. - 563. N. longicanda Dorbigny. Questa specie ofire tutte le forme rarie descritte dal Silrestri. C. V. 564. N. proxima Silrestri. Alcmi pochi esemplari. r. - 565. N. a culeata 1) (or). Forse una delle rarieti della precedente specie. R. - 566. N. aspera Silvestri. Con dubbio rapporto a questa specie, siccome varietà, un esemplare in cui la forma ovale delle logge, la maniera della scultura rispondono bene; ma Io strozzamento che disgiunge le cavitì è poco sriluppato. R.

567. N. typus u. sp. Tav. XII. fig. 2.

Questa specie che, per la sua ordinaria regolariti, può prendersi a tipo del genere, non mi è nota tra quelle descritte, essa si assomiglia in qualche modo alla Var. laevigute della $N$. monilis Silvestri; ma nel giacinento di Benestare essa non offre reruna trunsizione rerso quest'ultima, le sue logge sono pressochè sferiche con un lieve rialzo mediano, e crescono con molta regolarita, disgiunte da uno strozzamento forte, che costituisce tra una carità e l'altra un breve canale; la superficie è liscia.

$$
\text { Lunghezza 1. }{ }^{\mathrm{mun}} \text { Diametro 0,1."nm } \mathrm{c} \text {. }
$$

568. N. pupa Karer. Un solo esemplare che rispoude appuntiuo alla figura data dall'autore. R. - 569. N. irregularis D'Orbigny. Aleuni frammenti. R.

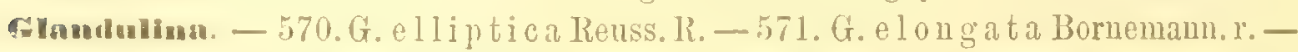
572. G. Ia vigata I'Orbigny. Questa forma abbastanza comme presenta graduali variazioni nei.vari suoi caratteri. e. V. - 573. G. inflata Bornemann. Con diverse varietì. Questa forma viene riguardata sorente siccome da amnettersi alla precedente specie. C. - 574. G. o btus is sima Renss. R. - 575. G. glob) ul us. lieuss. r.

Ingunina - 576. L. costata D'Orbigny. L' unica specie di questo deposito i comune e variabile in istretti limiti. C.

Frondiendurda. - 577. F. s eulpta? Karrer. Una delle forme di frondicularia del mioceno di Benestare si arricina molto alla specie sopria nominata, ma più compressa ed appianatia e colle strie poco mumerose ed assai brevi. R. - 578. li. a cuminata Costa. Un solo esemplare. R. - 579. F. rhomboidalis D'orb. Consilerevolmente variabile. c. V. 
580. F. cordata n. sp. Tar. IX. fig. 5. Specie assai ben distinta per la forma e per la seultura (Vedi fossili elveziani). R.

Dentalima. - 581. D. a cuta Dorbigny. Questa specie essendo molto comune, presentasi altresi molto variabile e specialmente nella forma e nel numero delle costole, clie in talune forme divengono piì numerose e rarrisimate. C. - 58. D. pungens Reuss. I miei esemplari rispondono meglio alle figure date dall'Hantken, anzichè alla originale del Reuss. R. - 583. D. Schwartii Kirrer. R. 584. D. bifureata D’orbiguy. Gli esemplari che ri riferisco convengono colla figura data dal Reuss. c. - 585. D. a cuticosta Reuss. Questa bella specie presentasi in esemplari conservatissimi, ma quasi sempre rotti. C. V. - Var. Hoemesii Neugeboren (non Ifuntken). Taluni esemplari piò gracili ed allungati si rapportano a questa forma, che eredo non torersi disgiungere dalla specie del lieuss. r. - 586. D. urnula D' Orbiguy. Esemplari intieri e conservatissimi. R. 587. D. nodosa D'Orbigny. Belli esemplari ed esattamente rispondenti al tipo. C. - 588. D. cornicula D' Orbigny. Alcumi frammenti. R. - 589. D.

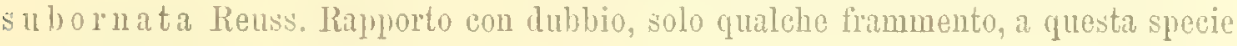
della creta, ma esso potrebbe forse aprartenere alla D. aciculata I'Orbigny, che ha le carità più convesse. $\mathrm{R}$.

590. D. semicostata n. sp. Tav. XILI. fig. 3.

Questa bella specie è molto affine alla D. seminuda Reuss od alla D. semilaevis Hantken; essa è intanto ben distinta da entrambe perchè manca di pungiglione posteriore, ed inrece è oltusa e rotonlata, perchè ha le logge più conivesse e le anteriori rotondate e quasi globose. Le tenui costole mancano completamente sull'ultima loggia, che è levigatissima e splendente, e si estendono su tulta li superficie o sino a metà della penultima loggia.

$$
\text { Lunghezza 2,2. }
$$

591. D. gutifera Dorbigny. Soli frammenti. r. - 592. D. pup iform is Karrer. L'unico esemplare che ri rapporto, diflerisce alquanto per arere le logge, che crescono un 110' più celeremente. R. - 593. D, elegans D'Orbigny. Pochi frammenti. R. V. - 594. D. seripta D'Orbigny. Frammenti che mancuno dei segni proprî della superficie. 1 . - 595. D. indifferens Reuss. Escmplari che rispondono esattamente ai caratteri assegnati alla specie. Var. globigera. Chiamu cosi una forma, che si distingue per arere le logge anteriori più rotondate, culasi globose. r. - 596. D. Sehal hergana Neugeboren. R. - 597. D. intermedia Hantien. 1. - 598. D. Reussii Nengeboren. Si trovazo le diverse forme rappresentate dall'antore, cioè a dire le valietà a logge più o meno convesse. c.

599. D. solida n. sp. Tar. XIII. fig. 6 .

Questa specie è affine molto alla precedente, dallia quale differisce per essere: opaca, più solida, meno gracile, più grande e colle cellule non convesse, orrero. pochissimo. La estremiti posteriore è ottusa e rotondata.

\section{Lunghezza 5.: Dianetro 0,7.}

600. D Haidingeri Neugehoren. Esemplari inticri e ben conservati. r. 601. D. Benestarensis n. sp. Tar. XIII. fig. 4.

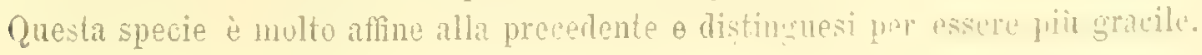


per le logge non convesse, e le ultime tra queste crescenti col medesimo rapporto delle precedenti; dal che risulta la grande regolariti di questa forma.

Lunghezza 1,5..!m Larghezza $0,2 . \cdots n$ li.

602. D. Verneulli D'orbigny. R. - 603. D. inermis Czizek. Qualche incompleto esemplare. - 604. D. in ornata D'Orbigny. Qualche frammento. R. 105. D. Ferstliana Czizeh. Varie forme analoghe a quelle figurate dall'autore. r. - 606. D. Roemeri Neugeboren. Specie variabile come riene rappresentata dalle molte figure date dall'antore. c.

(i07. D. crassicauda 12. sp. Tav. XIII. fig. 5.

Questa specie è athine alla precedente ed alla D. Bottcheri Reuss, ma distinguesi benissimo da entrambe per essere meno gracile, specialmente nella regione posteriore, perchè le logge sono appianate e disgiunte da suture superficialissime ed appena risibili; perlocchè la conchiglia prende un aspetto ben diverso, appare più compatta e sembra formata quasi d'un sol pezzo.

Lunghezza $1,9 \mathrm{~mm}^{\mathrm{mm}}$ Diametro $0,3{ }^{\mathrm{mm}} \mathrm{l}$.

608. D. Orbignyan Neugeboren. Specie anco aftine alla precedente, variabile come rappresentano le figure date dall'autore. c. - 609. 1). mucrouata Neugeboren. Le diverse forme rappresentate dall'autore. c. - 610. D. gomphoides Costa. Un solo individuo di forma tipica. R.

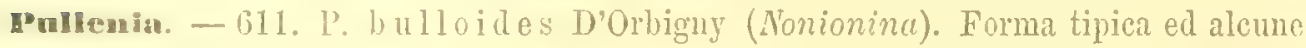
variazioni. $r$.

Burseotina. n. gen. - Conchiglia globosa molto analoga a quella delle Pulleniu, ma nelle ultime logge offrente un ingrandimento straordinario in modo che nell'ultimo estremo della spirale diviene elargata e prominente, portando un'apertura in forma arcuata alla parte superiore dei tramezzi. Per quest'ultimo carattere il nuovo genere distinguesi dal precedente e dal segnente, che portano l'apertula alla base dei setti.

612. B. calahra n. sp. Tav. XIII. fig. $7 ; 7 a, 76$.

Conchiglia quasi in forma di senre per la grande prominenza dell'ultima loggia, che si termina con un margine sporgente e ad areo. Liapertura occupa oltre un terzo della larghezza della lamina che chinde l'nitima cavitì. La superficie è sottilmente striata parallelamente alla spirale. Le caviti sono appena distinte all'esterno.

$$
\text { Lunghezza } 0,4 .^{\text {mm }} \text { Iarghezza } 0,3 .{ }^{\text {mm }} \text { Spessore } 0,3 \text {. }^{\text {nm }} \mathbf{R} \text {. }
$$

Tonioninse. - $61 \%$. N. com mu is. D' Orbigny. Oltre la forma tipiea, ve ne ha una più piccola, colla curena un po' rotondata, e di forma più breve, che costituisce una rarietà. e. Y. - (j14. N. Boueana D'Orbigny. Alla folma figurata dal D'Orbigny si associano pere sradazione altre forme, in eni le logge sono piu o meno appianate. r. - 615. N. umbilicata D'Orbigny. L'unico esemplare elue rifcriseo a questa specio ì $u n$ molello di limonite, che somiglia a molti che io abbi dalla Toscana. R. V. - Gl6. N. falx Czizek. Forma molto affine e forse varieta della seguente. r. - - 417 . N. Soldanii D'Orbigny. Comunissima specie ed alquanto variabile. C. $r$.

Molystomelna. - til8. P. cristra tamarek. Piì o mono convessa e quindi colla carena meno o più aleuti. C. V. - 619. P. Fichteliana D' Orbigny. R. - 
620. P. rugosa DOrbigny. Gli esemplari che ri riferisco portano un maggior numero di raggi. $R$.

Vammulites. - 621. N.? granosa $12 . \mathrm{sp}$.

Riferisco con molto dubbio a questo genere un solo esemplare specialissimu pei suoi caratteri, e che dnolmi di non aver potuto bene studiare, perchè andò smarrito. La N.? granosa io posso compararla alla N. Madaraszi Hantken: essa i, come quella, compressa, appiauata ed ornata di grossi gramuli disposti spiralmente sulla superficie, ma formanti una semplice serie e non gia una serie doppia; il diametro era di circa due millimetri. $R$.

Amphiscegina. - 622. A . . . sp.? Di questo genere non possiedo che un dubbio ed incompleto esemplare, il quale ricorda in quálche modo $1^{4} \mathrm{~A}$. Compbelli líarrer. R.

Iretcostegina. - 623. H. costata D'Orbiony. Esemplari mal conservati e corrosi, forse prorenienti dal sottostante Elreziano. R.

Dsecadiun. 624. P. oratum 11. sp. Tar. XIII. fig.8.

La mia specie si avvicina per la forma.al $P$. subovatum Karrer, essa ne differisce per una leggera prominenza laterale nella regione posteriore, all'origine delle logge; ed inoltre per la disposizione dei tramezzi che separano le carita. Ia quale molto si approssima a quella del P. simplex Nengeboren.

$$
\text { Lunghezza } 0,6{ }^{\text {mm }} \text { Larghezza } 0,4 \text { mm } \mathrm{R} \text {. }
$$

Marginnlina. - 625. M. p upoides n. sp. Tar. XIII. fig. 9, 9 a.

È questa una bella specie, che sta proprio quale anello intermedio tra i generi Dentalina e Marginulina; difatti è affine alla D. brevis D'Orbigny, ma la disposizione alquanto involgente delle prime logge e l'apertura che tenle a rivolgersi dal lato convesso della conchiglia mi hanno deciso a riporla tra le marginuline. Essa è distintissima per la sua forma conica nolto regolare, percio abbastanza acuta posteriormente, poco curva, formata di logge breri, che crescono con molta regolarita, e portano una linea trasversa che le biparte; la bocea radiata è quasi centrale.

Lunghezza 1,5. . $^{\text {nm }}$ Diametro 0,5 . $\mathrm{mm}$ h.

626. II. contraria Czizek. Un solo incompleto esemplare, che quantunque un $100^{\circ}$ meno gracile, pure non può riferirsi che a questa specie. R. - 627. M. splendens Hantken. Aleune delle rariazioni rappresentate dallautore. li. - 628. Ir. pediformis Bornemann. Diverse variazioni. R. 629. M. nodosa n. sp. Tar. XIII. fig, 11, 11a.

Specie molto allungata e compressa, articolata, perehè strozzata alle suture, colle logge di forma pressochè quadrata, essendo le suture della lunga porzione retta perpendicolari ai margini; una breve porzione posteriore anch'essa larga e rotondata all'estremita s'incura bruscamente e risulta di tre logge obliquamente disposte.

$$
\text { Lunghezza 1,2. } \text {. }^{\mathrm{mm}} \text { Larghezza } 0,2 . \text {. }^{\mathrm{mm}}
$$

La mia specie a prima gimuta potrebbe sembrare molto aftine alla .1\% regularis D'Orbigny, ma ne è assai diversa per essere molto compressa in tutta la sua estensione. laddore quella è a sezione circolare. R. 
630. MI. Hirsuta I'Orbigny. C. T. - 631. ML. criste lla rio ides Czizek. Questa comune specie oftre le ste rariazioni nel numero delle logge, e nella scultura più o meno pronmeiata. C. - 632. M. s p in u los a Karrer. Riferisco con qualche Aubhio a questa forma alcuni pochi esemplari, che hanno breri le logge, globosa cliscia soltanto T'ultima. R. - 633. MI. raphanus D'Oribigny. E questa una delle foraminifere piì abbondantemente sparse nel giacimento di Benestare, e raria molto nel umero e nelli prominenza delle costole, nella lunghezza e distinzione delle logge, nella curratura della conchiglia, e così ria via. C. V. - Var. crebricosta n. (vedi fossili dell'Elreziano). Tar. IX. fig. $6 c^{\circ}$

Vaginulina. - 634. V. legum e n Limneo (Nautilas). Riferisco dubbiosamente a questa specie nari ben conservati esemplari. 1. V. - 635. V. lens Costa. Un solo esemplare. R. - 636. V. linearis Montagu. Riferisco a questa specie taluni ben conservati esemplari, non marginati sui lati, colla superficie levigata, che offre talune linee longitudimali piì distinte sulla regione posteriore. $r$. V.

Crostellaria. - 337. C. sul cata Costa (V'aginulina). Questa bella specie, abboudante nel plioceno messinese, quantunque sia quasi retta, o appena curra nella larga legione posteriore, pure presenta nel sno primo stadio un arrolgimento spirale completissimo, perlocchè bisogna necessariamente annetterla al genere Cristelluria. Dopo questo primo stadio, la conchiglia si srolge retta, ricoperta di solchi longitudinali più o meno regolari, colle suture poco oblique, ravriciuate, impresse, e più profonde nella regione anteriore, specialmente l'ultima che separa l'ultima loggia, la- quale è più globosa, poco costata, orvero del tutto liscia. r. 0:38. C. legumen n. sp. Tar. XIII. fig. 12, 12a.

Questa specie ha una certa analogia nel suo primo starlio colla C. crepidula F. et M.; ma nello stato adulto sembra più tosto una Marginulina. Essa è compressa molto nella regione posteriore, ma l'estremo anteriore è a sezione quasi circolare, le logge crescono rapidamente in altezza, e l'ultimil è di forma orata. La superfieie è liscia. Molto somiglia alla M. temuis Bornemam, ma questa è a sezione circolare.

Limghezza $1,4^{\text {mm }}$ Larghezza 0,2 . $^{\text {nm }} \mathrm{R}$.

1339. C. articulata 11. sp. Tar. XIII. fig. 10, 10a.

Questa cristellaria è molto somigliante alla C. vaginalis Reuss, ma se ne distingue por arere le logge piì convesse e piì brevi, le suture più profonde, e l'ultima caviti proporzionalmente più grande e più globosa.

Lunghezza $1 . \mathrm{mm}$ Larghezza $0,40^{\mathrm{mm}} \mathrm{K}$.

1540. C. pygmaea Reuss. Riferiseo a questa specie un esemplare solo, il quale differisce alquanto per essere m po' piu gracile. R. - 641. C. lata Renss. Un individuo corrispondente alla figura data dal Karrer. R. - 642. C. italica D'Orbisury. Dne esemplari ben caratteristici. IR. V. - 643. C. aureola Farrer. Due individu. 12. - 644. C. arenata 1)' Orbigny. 1. - 645. C. cymboides Dorbigny. Un tipico individuo, lR. - 640. C. ren iformis D' Orbigny. Varia alquanto nell'alteza e nel numero delle logge. 1 - 6.47. C. Beyrichii Bornemann. Un solo esemplare dubbio, per arere un minor numero di logge apparenti, che pereio sono piir larghe. R. 
648. C. paucisepta n. sp. Tar. X. fig. 13, 13\%。

Questa particolarissima specie la forma pressochè rettangolare cogli angoli rotondati, non è troppo convessi, è giblosa nella regione centrale e fornita di una stretta lamina marginale. Le logge risibili sono quattro, disgiunte da suture impresse ben profondate, le quali sono joco curve e disposte l'una perpendicolarmente all'altra, lasciando nua grande aia centrale; la superficie è levigatissima.

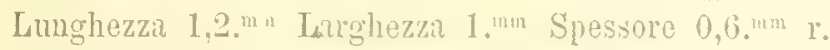

649. C. c r'as a D'Orbigny. Esemplari esattamente rispondenti al tipo. r. - 650. C. cassis Lamarck. Forma immensamente rariabile, che perciò si presenta piir o meno convessa e talrolta gibbosa, colla lamina marginale di rariissima larghezza, colla regione centrale liscia o granosia, colle suture più o meno impresse e talvolta rilevate in forma di costole, che direngono anco granose. La fig. 14 della tar. XIII. rappresenta una raricti a lamina marginale stretta. C. V.

651. C. disco-graulata 11. sp. Tar. XIII. fig. 15.

Questa specie è molto affine alla precedente, dalla quale distinguesi sopratutto per essere più regolare e piì rotondata, siceome costantemente compressa co colla lamina marginale stretta; inoltre le logge si restringono molto rerso il centro e molto s'incurrano ad areo, contormando il disco centrale che i piir o meno granulato.

Diametro :3."'m Spessore 1."1n r.

652. C. I enticula Reuss. Un solo esemplare. R.

PPanularla. - 653. P. s e m il un a D Ort. (Cristcllaria). Un solo tipico esemplare. R. 654. P. Ia $\theta$ ris n. sp. Tar. XIII. fig. 16, 16\%。

Questa è molto affine alla precedente specie: essia distinguesi per la lamina marginale dentata, per un nucleo centrile grande e sferico, per le ultime logge che si rimiscono formando uno sperone verso la regione posteriore, per la superficie lerigatissima e priva di linee radianti.

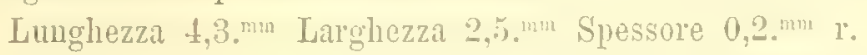

655. P. a uris Defrance. r. V. - 656. P. ang ustata Costa (Frondicularia). Var. 11. Riferisco a questa specie due soli esemplari, che parmi si allontanino alquanto dal tipo per avere una lamina marginale più larga, e strie radianti un po' più numerose. R.

657. P. falcata n. sp. Tav. XIII. fig. 17.

Bella specie affine alla precedente. Essa è suella curvata in arco, speronata, radialmente striata nella meta posteriore, e con istrettissima lamina marginale. La forma più gracile ed un maggior numero di logge la distinguono bene dalla precedente.

Lunghezza 4,1.mm Larghezzil 1,1.mm Spessore 0,1. ma $R$.

Robulinn. - 658. R. simplicissima n. sp. Tiar. XILI. fig. 18, $18 \%$.

Questa specie è molto affine alla seguente, dalla quale differisee per arere la carena ottusa e rotondata, e per essere di forma ovalc, non orbicolare, oltre a cio la parete che chinde l'ultima loggia non presentasi inearatia in rerun molo. ma invece conressa alquanto.

Lunghezza 0,7 . 
659. R. simplex D'Orbigny. La forma tipica fa graduato passaggio ad una, chu porta una piceola aia centrale mal definita. c. - 660. R. subangulata Reuss.r. (ib1. R. Iueida n. sp. 'I'ar. XIII. fig. 19, 19 .

Di forma orale, questa specie somiglia alla Cristellaria lenticula, dalla quale: distingnesi per le logge piu larghe, per la carena ottusa e rotondata. La superficie è levigatissima. Potrebbe essere forse varietia della $R$. simplicissimi.

Lunghezza 1,3. ${ }^{\mathrm{mm}}$ Larghezza $10^{\mathrm{mm}}$ Spessore $0,50^{\mathrm{mn}} \mathrm{r}$.

602. R. e urisepta n. sp. Tar. XIII. fig. 20, 20a.

Specie ben distinta pel modo come si presentano i tramezzi sulla superficie, cioè in forma di linee che si allargano dal margine verso il centro, dore raggriungono considerevole larghezza, s' incurrano bruscamente, e riunendosi insieme costituiscono una bizzarra figura a cinque braccia.

Lunghezza 1. ${ }^{\text {mnn }}$ Larghezza $0,9^{m m}$ Spessore 0,4 . ${ }^{m m} R$. 603. R. confusa 11. sp. Tar. XII. fig. 21, $21 a$.

La Robulina che denomino così è una piccola specie con sei tramezzi regolarmente curvi, che lasciano un' aia centrale circolare, e si manifestano per suture impresse, che disgimgono logge alquanto conresse.

Lunghezza 0,7. mm Larghezza 0,5.

Questa specie è forse una rarietì della seguente, dalla quale distinguesi per arer le suture regolarmente curve, essendo in quella lievemente flessuose. $\mathrm{R}$.

b6t. R. semiinpressa Reuss. r.

665. R. obtusimargo n. sp. Tav. XIII. fig. 22, 22a.

Anco questa ì uni forma molto afline alla precedente, ma più rigonfia, col margine più ottuso e colle logge più inrolgenti.

Lunghezza 1."m Larghezza 0,9.mm Spessore $0,5 . \mathrm{mm} \quad R$.

666. I. a ustriaca D'Orbigny. R. - 667. R. inornata Dorbigny. Variabile molto per grandezza, e per la relativa grandezza del disco centrale. C. - 668. R. limbata Bornemann. R. - 669. R. aicuato-striata Hantken. Vi riferisen ancora quei tali individui che hanno le linee radianti meno curre: essi si collegano alla forma tipica per gradazione. C. - 670. R. depauperata Reuss. Varia pel numero delle logge come riene rappresentatia dall'autore. $\mathrm{h}$.

671. R. gravida n. sp. 'Tir. XIII. fig. 23, 23a, 23b, 23c, 23l, 23e, 23 .

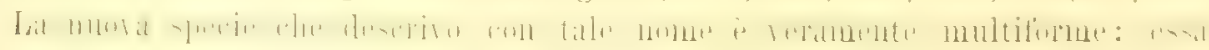
distingnesi per essere molto convessa, dal quale carattere ha origine il nome; perche le logge si dispongono attorno una grande aia ceutrale che varia molto in diametro, e le suture si profondano più o meno. Varia poi nel numero * nella forma delle logge, nel margine carenato o rotondato, nell'aia centrale piu o meno grande, nella superficie liscia, orrero gramosa al centro, o in parte esilmente striata. In mezzo a tanta viriabiliti possono benissimo distinguersi come varieta le seguenti forme fiù mareate. Var. A. paucisepla fig. 236, 23c. Quattro logge le cui suture sono disposte perpendicolarmente al margine cirenato. Var.

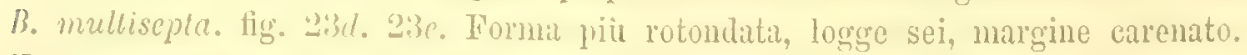
Var. C. discoulea lig. 2:3/. Diseo grandissino, logge cinque, strette, allungate e curve, margine carenato. Var. D. anormalis. Forma piì compressa, e piir o 
meno anormale nello sviluppo, sopratutto delle ultime logge. Tutte le descritte rarietà si collegano più o meno chiaramento pei caratteri comuni assegnati alla specie, nonchè per forme intermedie, quantunque esse sieno sì distinte da potersi riguardare siccome specie direrse.

Diametro della Var. A. 1,3. mm Spessore della stessa $0,8 . \mathrm{mm}$

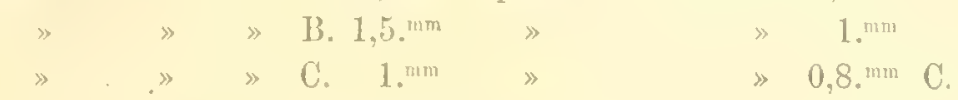

672. R. rostrata n. sp. Tar. XIII. fig. 24, 24 a.

Questa specie è affine alla precedente, ma più compressa, senza carena o con questa appena accemnata; le logge esterne sono da quattro a sei, s' incurvano molto e l'ultima molto compressa sporge in forma triangolare acuta formando cosi la conchiglia alquanto rostrata, pel quale carattere essa somiglia alla $R$. deformis Bornemann.

Lunghezza $1,3{ }^{\mathrm{mm}}$ Larghezza $1,0{ }^{\mathrm{mm}}$ Spessore $0,8{ }^{\mathrm{mm}} \mathrm{r}$.

673. R. vortex Fichtell et Moll (Nautilus). Questa comunissima specie presentusi variabile nella curvatura ed arvicinamento delle linee di sutura delle logge, nella grandezza della conchiglia, e nella carena piì o meno acuta. Var. Laminifera. Questa rarietà è più grande ed alla carena è cinta d'una lamina. C. V. - 674. R. imperatoria D’orbigny. Questa forma viene sovente associata alla precedente, essa difutti differisce per avere il disco centrale. 1 .

675. R. serpens n. sp. Tar. XIII. fig. 25, $25 \alpha$.

Questa forma sembrerebbe a prima ginuta da annettersi alla $R$. vorlex, ma essa se ne distingue nettamente, per arere il margine rotondato e non carenato. Oltre a ciò, le linee suturali non sono regolarmente incurvate, ma angolose, e l'ultima porzione sulla regione marginale s'incurva lievemente in senso contrario, dimodochè risultano stranamente flessuose e divengono molto divergenti sul margine, che resta leggermente lobato, per essere alquanto incarato la dove termina un tramezzo.

Lumghezza $1 .^{\mathrm{mm}}$ Larghezza $0,9{ }^{\mathrm{mm}}$ Spessore $0,4 .^{\mathrm{mm}} \mathrm{x}$.

676. R. clype iformis D'orbigny. In taluni esemplari lo linee suturali sone rilevate in forma di costole, come rappresenta il D'Orbigny, in altri poi sono appianate. r. V. - 677. R. radiata Bornemann. r. - 678. R. I im bosa Reuss. Gili esemplari che vi riferisco sono alquanto dubbî, e meglio rispondono alle figure date dall'Hantken. r. Le tre precedenti specie sono certamente molto afhini. e parmi che trovansi graduati passaggi che le rarricinano. - 679. R. cultrata D'Orbigny. Questa specie variando molto nello spessore relativo, nel numero delle logge, nella larghezza della lamina marginale e del disco centrale, raggiunge soventi fiate dimensioni gigantesche. C. V. - 680. R. similis D'Orbigny. MIolto affine alla precedente, e forse varieti di essa. $r$.

681. R. tenuis n. sp. Tay. XIII. fig. 26, 26a.

Questa è forma affine alle due precedenti pel piccolo ed appianato disco centrale. che si distingue per essere molto compressa cl assottigliata al margine, e piu ancorit per le sottili linee settali, che sono rette aflatto, orvero lierissimamente incurvate.

Lunghezza $1,6 . \mathrm{mm}^{\mathrm{m}}$ Larghezza $1,3 . \mathrm{n}^{\mathrm{nm}}$ Spessore $0,7 . x$. 
lis:. R. ritrea n. sp. Tils. XIII. 1ig. 27, $27 a$.

Qutesta bella specie è costante nei suoi caratteri, ed è ritrea perchè lerigata e traslncida. Le logge esterne sono sei, di forma triangolare, le linee settali quasi rette che si allargano al margine, e s'ineurrano poi fortemente al centro per cingere e delimitare un'aja centrale, che non può riguardarsi come un rero disco, perchè del medesimo aspotto del resto della conchiglia, non isporgendo al disoria della superficie generale. La lamina marginale è stretta d'ordinario, ma talyolta si allanga abjoastanza.

Lunghezza 1,9.m Larghezza 1,7. mm Spessore 0,9. •.

683. R. curvispira n. sp. Tar. XIIL. fig. 28, 28a, 286, 280.

Conchiglia fornita di larga lamina marginale, rigonfia al centro e gradatamente assottigliata al margine; le lngge apparenti sono da sette a nove, le linee suturali impresse sono fortemente incurate al centro in modo analogo che nella $R$. vortex. della quale la mia specie è molto piì grande.

Lunghezzil 2. mm Larghezza 1,7.mm Spessore 0,9.m $\mathrm{r}$.

Var. gibba fig. 28\%, 28c. Lamina marginale larga ma meno distinta; regione centrale più rigonfia. Li.

1i8t. Ir. stellata n. sp. Tar. XIII. fig. 29.

Affine alka $R$. cultrata; dalla quale distinguesi per essere più compressa, ma principalmente pel numero maggiore delle logge, che sporgono alla periferia in forma di angoli auti o più o meno ottusi e variamente prominenti; le linec suturali poi, piu curvate e maggiormente oblique, sono al numero di dodici.

Lunghezza 2,2. ${ }^{\mathrm{mm}}$ Larghezza 2. $\mathrm{mm}$ Spessore $0,7 \mathrm{~mm}$ c

685. R. dubia n. sp. Tar. XIII. fig. $30,300$.

Questa forma è afhne alla precedente, ma è distiuta perchè più conressa, senza disco centrale, con minor numero di logge (sette a nove) che sono meno angolose al margine.

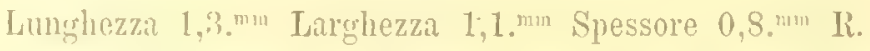

1866. R. ornata D'0rbigny. La forma tipica i molto rara. Var. incerta. Il numero delle logge appariscenti è maggiore, la lamina marginale piì larga. le costole concentriche piu numerose e più sottili. Var. cincter. Le logge in maggior numero del tipo, la lamina marginale mancaute, le costole concentriche non interrotte, piir numerose, che si estendono sino alla penultima loggia.r. V.

(i87. R. curricosta n. s]). Tiar. XIII. fig. 31, 31\%.

Conchiglia orhiculato-ovata, con ma stretta lamina marginale, con uu disco contrale di mediocre larghezza, e sporgente; con otto logge esterne a pareti alquanto concave, colle line suturali curve e prominenti in forma di costole. Pere quest'nltimo carattere questa specie è ben distinta dalle conosciute.

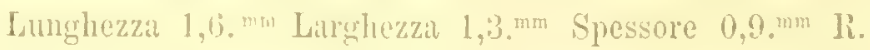

688. R. princops Jornemam. Un solo esemplare alquanto piu conresso del tipo. R. - 689. R. cal car (Jimeco) Gmelin (Nautilus). Lat più comune tra le foraminifere di Benestare, questa sprecie presentasi unolto rariabile. sia nel numere delle logge esterne, sia nel munero e nella grandezza delle spine marginali. In 
rapporto a questa ma forma, che porta una lamina marginale irregolarmente dentellata e che chiamo Var. lacern, ed un' altra col margine intiero non spinoso che dico Var. integre C. T. - 690. R. ecli inata D'Orbigny. La forma tipica, quale vedesi figurata nell'atlante del D'Orbigny, è ben rara; invece trovasi molto abbondante la rarietà in cui le scabrezze delia superficic sono sostituite da costole concentriche, che exapresentata dallo Czizek, e che io denomino Var. curvicosta. Altra forma molto rara è la Var. hevis, che è piccola ed a superficie sfornita di scabrezze e di costole concentriche. C.

691. R. formosissima 11. sp. Tar. XILE. fig. 32, 32u.

Conchiglia molto compressa, incarata e scabra al centro, concentricamente costata e con una larga e sottile lamina marginale, con otto logge apparenti, triangolari, convesse, disgiunte da suture larghe e molto profonde. Ciascuna loggia ć fornita di sei a otto costole, che si elevano in forma di lamine sottili e prominenti; la loggia ultima è alquanto prominente, radialmente costata, maggiormente conressa, la lamina di chiusura della quale, è allungata, molto stretta, in forma ellittica; l'apertura ì in forma di fenditura.

Questa rara specie ricorda a prima giunta la K. ariminensis D'Orbigny, dalla quale ne è distiutissima per essere discoidale, molto, più compressa, per la larga lamina marginale, per la grande depressione centrale, per la strettezza della parete anteriore dell'ultima loggia.

Lunghezza 2,2. ${ }^{\mathrm{mm}}$ Larghezza 2. ${ }^{\mathrm{mm}}$ Spessore $0,7 .{ }^{\mathrm{mm}} \mathrm{R}$.

692. R. dilecta n. sp. Tar. XIII. fig. 33,33 .

La mia specie è affine alla precedente ed alla Cristellariu undulatu Karrer, ma da entrambe sopratutto distinguesi per essere fortemente convessa nella regione centrale, pel quale carattere anco discostasi molto dalla $h$. uriminensis D'Orbigny, che syetta al medesimo gruppo. La $R$. dilecta è di forma orale, sempre considererolmente conressa, con una lamina marginale stretta, formata da sei logge apparenti, disginnte da profonde suture ed ormate da grosse lamine concentriche incomplete, che maneano sull'ultima loggia; la quale è chỉsia anteriormente da ma lamina alquanto concara, di forma stretta molto ed allungata; l'apertura poi è in forma di fissura radiata.

Lunghezza 2,3. ${ }^{\mathrm{mm}}$. Larghezza 2. ${ }^{\mathrm{mm}}$ Spessore 1. ${ }^{\mathrm{mm}} \mathrm{C}$.

Var. denuddia. Manca in gran parte delle lamelle concentriche. 1.

Polimorphina. - 693. P. a ustria ca D'Orb. (Gulluline). Forma molto ricina alla seguente.r. - 694. P. problema D’Orb. (Guttulina). Raccolgonsi direrse modificatzioni.r.-695. P. nodosaria Reuss. A questa specie riferisco un solo esemplare che differisce alquanto dal tipo per esser meno regolare e colle suture meno profonde. R. - 696. P. a cuta D'Orbigny. R. - 697. P. complanata D'Orbigny. R. - 698. P. ovata D'Orb. IR. - 699. P. cylindriua Bormeman. R. 700. P. lanceolata Renss. Varieta di forma allungata. R. - 701. P. sororia Reuss. R. - 702. P. dimorpha Bornemant. R. - 703. P. teneral hilrur. Un esemplare solo e rotto. R. - 70.t. P. tub u losa D) Orbigny (Globulinu). Un

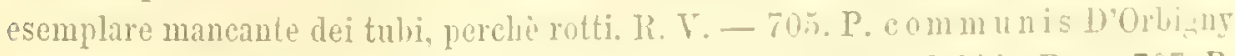
(Gullulizu). C. Y. - 706. P. discreta Renss. Cn esemplare dubbio. R. - 707. P. 
inaequalis Renss. R. - 708. P. depauperata Renss. R. - 709. P. obtusa Bornemann. Un esemplare dubbio. R. - 710. P. lactea Walker et Jacob. R. . . 711. P. lata Bomemanm. R. - 712. P. gibba D'Orbigny (Globulina). Presenta molte rarietir descritte dall'Egger: taluna si approssima alla G. acqualis D'Orbiguy. c. - 713. P. punctata D'Orbigny (Globulina). R. - 714. 1'. rugosa D'Orbigny (Glubulina).R. - 715. P. le prosa Reuss. R. - 716. P.tub erculata D'orbigny (Glubulina).r. - 717. P. spin os D Dorbigny (Globulinu). Due esemplari piu commessi del tipo. R. - 718. P. e ostata Egger. R.

Uvigevian. - 719. U. Ir y g m a a D'Orbigny. Si trorano numerose variazioni. c. V. 720. U. cochlearis Karrer. Specie gracile e molto variabile nella lunghezza e negli altri caratteri. C. - 721. U. urnula. D'orbigny. A questa specie riferisco una forma che è molto analoga a quella del Dorbigny, ma che ne differisee per arere la superficie funamente striata nella totaliti o quasi per jntiero. (. - 722. U. asperula Czizek. Uua rarietì quasi costata. R.

Dimorghina. - 723. D. tuberosa? D'Orbiguy. Varî esemplari rotti, molto duluhî, r. V.

Bulimåna. - 724. B. B uchian a D'Orbigny. Var. Calabra.11. Tav. XIII. fig. 34. E questa una forma che si allontana considerevolmente dal tipo, al quale l'associo in considerazione delle forme diverse e ben lontane che oggi sogliono a quello rapportarsi dai vari serittori. Questa varietì è allungata molto, quasi regrolarmente conica ed acmminata alla sua posteriore estremiti, le logge sono disposte molto regolarmente e sembrano ordinate, oltrechè a spirale, sopra tre serie, dimodoche sembra quasi una Reussiu. r. V. - 725. B. ac uleata D'Orbigny. Qualche esemulare un po' lubbio. R. V. - 726. B. imperatrix Karrer. Bella e distinta specie di cui ho raccolto due soli esemplari. R. - 727. B. pupoides D'Orbigny. Var. brevis. 1. La forma di questa buliminu è piu tozza del tipo figurato dal D'Orbigny. 1: V. - 7:8. B. ovata D'Orbigny. Variabile nella lunghezza in modo he per gratazioni si passa ad una forma breve che chiamo rar. infa1a. C. - 729. B. tenera Renss. Anco questa raria molto. r.

730. B. bulbiformis n. sp. Tar. XIIL. fig. 35 .

Distinguesi questa specie per la forma obovata, beu convessa ed arrotondata nella regione anteriore, acuminata posteriormente, colle suture superficiali appena impresse e percio poco visibili. Quest' ultimo carattere la disgiunge nettamente dalle specie affini.

$$
\text { Lunghezzil } 0,5 .{ }^{1, m} \text { Larghezza } 0,3 .^{\mathrm{mm}} \mathrm{R} \text {. }
$$

73i. B. calcarata n. sp. 'lav. XIII. fig. 36.

Questa specie ha messochè la forma della B. maryinatu Dorbigny, alla quale somiglia ance perehe teminasi posteriormente con un breve aculeo, talvolta tripartito, ma le logge in minol numero alle suture nom sono crenato-marginate. inrece regolarmente conresse, e circandate da suture profonde.

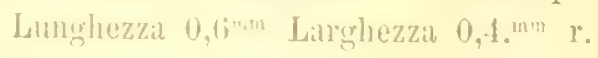

73.. B incrassata Linner. Var. chnemlu. n. Chiamo così una rama forma, identica a quella del Karrer ma più allungata. R. - 733. B. p y u la Dorbigny. La forma tipica è ben rara, invece s'incontrano spesso le due segnenti modificazioni. 
che credo debbansi amnettere alla specie del D'Orbigny. Var. lalu. n. Di forma piu larga, colla regione posteriore non prominente ma quasi appianata. r. - Var. spinasa. n. Colla regione posteriore più o meno prominente e fornita d'una, due o tre piccole spine. Questa forma ricorda per le spine posteriori la B. caudigera D'Orbigny, ma invece di essere ovata sí allarga regolarmente dalla regione anteriore verso la posteriore, assumendo una forma conica e non già una forma ovata. C. V.

virgulius. - 734 V. Schreibersi i Czizek. Forma molto nota, perehè trorasi in dirersi piani. 1 .

Sphneanoina. - 735. S. a ustriaca D'Orbigny. MLolte delle forme numerose che somo state descritte e figurate dal Reuss e dallo Czizek. c.

PuIvinuliua. - 736. P. umbonta Renss. Specie ugualmente convessa d'ambo i lati. R. - 737. P. Partschiana D Orbigny (Rotalina). C. - 738. P. Boueana D'Orbigny (Rolalinu). R. - 739. P. repanda Fictel et Moll. (Tanelilus) R. V. - 740. P. Menardii D'Orbigny. (Rolulina). 1. V. - 741. P. erinacea Karrer. Distintissima specie appianata e liscia superiormente, convessa e papilloso-scabra inferiormente. C. - 712. P. scaphoidea Reuss (holalina). C.

Eotolia. - 743. R. inflata Seguenza (Rotalina). Questa rotalia è una forma che forse dovrebbe riumirsi alla $R$. Beconrii Linn. (Noutilus), dalla quale differisce soltanto per essere molto convessa d'ambo i lati e talrolti dal lato della bocca, giungendo sovente ad essere molto globosi e pressochè sferica. Oltre a cio conserva costantemente piccole timensioni, poco maggiore di un millimetro al massimo, siccome trovasi nelle argille quaternarie di Catania. Per tali caratteri distinguesi costantemente dalla $R$. Beccurii, verso la quale non mostra gradazioni. C.

744. R. punctato-granosa n. sp. Tar. XIII. fig. 37, 37, 37 .

Specie affine alla $R$. Beccorii ed alla $R$. viemnensis D'Orbign na ben distinta da entrambi. Basterebbe la seultura per distingnerla dalla prima, difatti la superficie è distintissima perchè ornata di granuli rotondati, poligonali, al lungati, irregolari, disgiunti da interstizî stretti, flessmosi; nei quali trovansi delle perforazioni. Oltre a cio la conchiglia è molto piu convessa al centro e si assottiglia verso il margine, pel quale carattere la mia specie somiglia molto alla $R$. Vienmensis; ma quella mauea del disco centrale, che è sostituito da una grande superficie più o meno scabra e scolpita da intagli profundi, irregolari, curvi, flessuosi, ramificati, che si comettono poi con aperture, che in forma d'intagli irregolarmente frastagliati e flessuosi, continuano le suture delle logge. La scultura della superficie è anch' essa distintissina, siccome nella mia specie le suture delle logge sono molto meno oblique.

Diametro 2,1.mm Spessore 1,4.ma C.

745. R. ammoniformis D'orbigny (Rolaliur). Anco questa è forma molto affine alla $R$. Beccurit, ma più compressa, e diversa jer altre ragioni. R. V. 746. R. simplex Dorbigny (Roualna). C. - 717. R. grata Renss. 1.-718. R. orbicularis D'orbigny (Gyroidina). Un solo esemplare. R. V. - 749. R. praecincta Karrer. Specie molto affine alla precedente. Ir. 
750. R. lobata n. sp. Tar. XIII. fig. $38,38 \pi, 38 \%$.

Per Ia forma grenerale la $R$. Cobuba somiglia alla precedente, ma essa la le logge conresse, le suture profondate, in modo che la conchiglia risulta distintamente lobata.

\section{Diametro $0,5 .^{\mathrm{mm}}$ Spessore $0,34 .^{\mathrm{mm}} \mathbf{R}$.}

751. R. conoidea Czizek (Rotaline). Gli esemplari che vi riferisco si presentano di forna alquanto meno conica, ma variabili in modo che disposti in serie, da un canto questa va a confondersi colla forma tipica, dall'altra si hamo individui fiù depressi alla parte superiore e di forma pressochè emisferica. Alla parte inferiore poi le logge non sono così appianate come sembra dimostrarlo la figura della forma tipica. c. - 752. R. Soldani i D' Orbigny (Rotulina). Sopratutto l'infossamento alla regione superiore distingue questa dalla precedente specie. C. V. - 753. R. Broekiana? Karrer. Un solo esemplare dubbio riferisco a questa specie. R.

Orbalima. - 754. 0. un i fersa D'Orbigny. C. V.

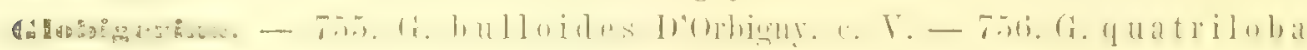
D'Orbigny. r. - 757. G. triloba Reuss. R. - 758. G. biloba D'Orbigny. c.

Disconhina. - 759. D. grauosa 11. sp. Tar. XIV. fig. 1, 1a, 1b.

Questa specie ha certa analogia colla D. turris Karrer, è come quella irregolarmente granosa, ma le logge appariscenti sulla faccia inferiore sono undici e sono disginute da irregolari intagli, che continuano le suture verso la regione centrale, ed al centro della loro rimione ne risulta un' apertura radiata.

Diametro 0,8.mn Spessore 0,3."mm $R$.

760. D. vestita 12. sp. Tar. XIII. fig. 39, 39a, 39b.

Questa specie ricorda in qualche modo per la forma generale e compressa la I. outus.l D'Orbigny; ma ne è distintissima per non essere perforata, perchè le logge sono cinte da ogni lato da un margine largo e rilerato, e dal lato concaro è una specie d'incrostazione rugosa che le ricuopre interamente al centro lasciandone vedere una piccola zona di ciascuna verso il margine.

$$
\text { Lunghezza } 1,3{ }^{\text {nm }} \text { Larghezza } 1,10^{\text {mm }} \text { Spessore } 0,5{ }^{\text {mm }} \mathrm{r} \text {. }
$$

761. D. perforata 11. sp. Tav. XIV. fig. 2, 2a, $2 b$.

Questa specie è rariabile di forma, perchè visse senza dubbio sopra rarî corpi, e dalla forma depressia e rotondata si passa a forme più o meno contorte ed oblonghe nelle quali sorente si manifestano due lunghe prominenze sopra opposti margini, perehè la conchiglia sembra aver prediletto dei gracili allungati oggetti per fissarvisi; siccome lo dimostra la regione inferiore, che presenta un infossamento longitudinale, ed il resto della superficie più o meno appianato. La regione superiore i convessa varibilnente: essa offre la prineipale caratteristica della specie riposta nella perforazione delle pareti delle carita, fatti per mezzo di grossi pori e rarricinati. Le logge al numero di dieci nell'ultimo arrolgimento dellit spirat sono esternamente distinte per mezzo di zone prive di pori.

Janghezia 1,2. mm Larghezza 0,7 . $^{\mathrm{mm}}$ Spessore $0,4 .^{\mathrm{mm}} \mathrm{r}$.

762. D. obtusa D'Orbigny (Rotalina). 1 .

763. 1), minuta 11. sp. Tay. XIV. fig. 3. 34, 34. 
Questa specie e molto affine alla D. squcmulu Reuss, dalla quale distinguesi benissimo per essere grossolanamente punteggiatil, piu elerati, col lato concavo invece alquanto convesso, e le cinque logge che su di esso appariscono nella forma del Reuss, sono intece al mumeno di sette nolla mia specie.

Diametro 0,4. min $^{\mathrm{m}}$ Spessore $0,2 \mathrm{~mm} \mathrm{k}$.

764. D. minutissima n. sp. Tav. XIV. fig. 4, 4a, 4h.

Questa minutissima specie puo in qualche modo paragonarsi alla D. slellutu Renss, dalla quale si distingue eminentemente per la sua maggior convessità. per le logge più numerose e molto più strette ed allungate, per la faceia inferiore appianata e non concava.

Diametro 0,2."m Altezza $0,1 . .^{m} \mathrm{R}$.

Trumeatulina. - 765. T. Sehreibersi Dorbigny (Rolalina). Varia considererolmente nella convessitz dalia spira, la quale è inoltre piì o meno prominente; varia benanco nella forma della regione anteriore, ora più ora meno prominente al centro, e variamente distinti i lobi che rresentano le logge all'interno. C. V. - 766. T. Haidingeri D'Orbigny (Rotulina). Specie alla quale io riuniseo una forma che non differisee in altro dalla forma tipica se non nel numero delle logge apparenti sulla regione anteriore le quali invece di sei sono sette orvero otto. C. V. - 767. T. Ballensis Czizek \{ Roulinu). Specie molto alfine alla precedente. c. - 768. T. py grmea Hantlen. Riferisco con qualche dubbio a questa specie un solo esemplare 1 .

769. T. marginata r. sp. Tar. VII. fig. 10 (redi fossili langhiani). R.

770. T. a ffin is Czizek (Rolulina). Vi riferiseo un solo esemplare. R. - 771. T. Dutemplei D'Orbigny (Rolalina). Questa is specio molto rariabile nella convessitì tanto della regione superiore quanto dell' inferiore; raria altresi nella profondita delle suture, e quindi nella distinzione delle logge, che tallolta restano quasi del tutto indistinte. C. - 772. T. propindua Reuss (Rotaliu). Alline alla precedente, distinta specialmente per una specie di diseo centrale e pror la maggior profonditi dei solchi che disgiungono le logge. r. - 773. T. lucida Reuss. Vi riferisco pochi esemplari. $\mathrm{R}$.

774. T. spirata n. sp. Tar. XIV. fig. $\check{3}, 5(1,5)$

Questa forma molto comune ì afline alla precedente, dalla quuale si distingue - per la regione superiore piu elevatá e di forma pressochè conica, por le logge più oblique e piu curve, pel milrgine piu acuto, per la spira a giri piu stretti e piì numerosi.

\footnotetext{
Diametro $1,4$. mm Altezza 0,4 ." $\mathrm{C}$.

775. 'T. formosa n. spr. Tar. XIV. fig. (3, Gu. (6),

Questa elegantissima specie disting uesi dalla T. Ungeriunu, alla quale molto si avricina, per un numero alyuanto maggrore di logge fornite di grosse punteggiature, e cinte sopra ambo le ficee da un margine depresso, levigato, non punteggiato. La conchiglia porta allia periferia una linnina stretta e sultile.

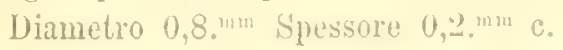

776. T. Ungeriana D'Orbigny (Rolalina). Specie molto costante nei suoi caratteri. C. T. 
777. 'T. A kneriana D'Orbigny (Rotnlime). Qualche esemplare un po' dubbio. R. 778. 'T. rortex u. sp. Tar. IX. fig. 8, 8\%, 86 (redi Foraminiferi dell' Elreziano). C.

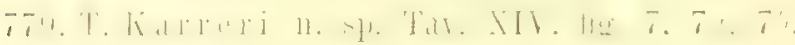

Questa specie è molto analoga alla T. Dutemplei D'Orbigny, e si arvicinerebije per la forma alla Rotaliu pruccinctu Karrer, ma essa è più elevata di entrambe, troneata alla parte superiore in modo che ha proprio forma di un cono tronco; ¿̀ alquanto convessa alla parte inferiore. Le logge inoltre sono molto piu numerose, circa quattordici, siccome piu unmerosi sono anco i giri della spira che si manifesta alia parte inferiore della conchiglia.

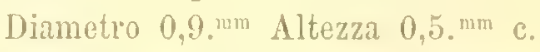

Var. depressiusculu. Meno elevata, colla hase appianata o alquanto concara. c. 780. 'T. lobatula D'Orbigny. Variabile e più o meno deformata. c. V.

781. 'T. badenensis D' Orbiguy (Anomalina). Specie che soffre alquanto di deformazione. C. - 782. T. rariolata D'Orbiguy (Anomalina). r. V.

Anomalina. - 783. A. austriaca D'Orbigny. Pochi esemplari. R. - 784. A. rotula D'Orbigny. Var. ammomifomis. 1n. Arero chiamato questa specie, sin da lungo tempo d. cmmoniformis, ma un esame più accurato mi mostrò che essa realmente poco si allontuna dalla specie del D'Orbigny, e ciò per essere un po' più spessa e per arer logge appariscenti nell'nltimo giro di spira al numero di diecisette, e disginnte da suture piì profonde; questi caratteri mi decisero ad associarla all' $A$. rolala conservando come nome di rarieta quello precedentemente impostole. $c$.

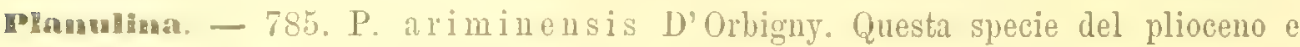
dei nostri mari era già comune nel periodo tortoniano. C. V.

Spiriluma. - 786. S. punctata Reuss (Operculina). Credo poter riferire a questa specie un individuo molto giorane. La struttura perforata di tale conchiglia, la sua costituzione uniloculare la rimandano al genere Spirillina. IR.

LPlnorlualina. - 787. P. mediterranens is D'Orbigny. Identica e rariabile come la rirente dei nostri mari. C. Y.

Asterigerist: - 788. A. planorbis D'Orbigny. Esemplari molto piccoli. $\mathrm{r}$.

Siphonins. - 789. S. fimbriata Reuss. Qualche piccolo indiriduo. R.

Textilnan. - 790. T. carinata D'Orbigny. Questa comune specie presentasi più tosto rarmente coi caratteri assegnatigli dall'antore, cioè con un cordone prominente, che disgiunge tra loro le logge, invece è molto comune la varietì che manca di tale rialzo al margine interno delle $\log g e$, e che riene assai bene rappresentata dalla taw. VII. fig. 8 nell' opera dell' Hantken: Die faund der Chunulinu Sauboi Schichlen. C. - 791. T. pectinata Reuss. Questa specic varia consilerevolmente nella sporgenza esteriore delle logge. C. - 792. T. pa la Czizek. Questi specie à più allargata della jrecedente, ha le logge appianate, ina parmi che alcuni individui stabiliseano delle gradazioni tra le due forme. $r$.

vuluulina. - 793. V. peetinata IFinticn. Questa bella specie risponde esattamente al tipo descritto ed illustrato dall'autore. C.

Bolivian. - 794. B. antiqua D'Orbigny. Variabile come rappresentano le figure date dall'Egger, r. 
Cossidulunn. - 795. C. punctata Reuss. Le punteggiature di questa specie. nei numerosi miei esemplari, non sempre si distinguono bene. C. - 796. C. margareta Karrer. r. - 797. C. oblonga Reuss. r.

Roberdin. - 798. R. austriaca Reuss. Var. muticu. n.

Riferisco come varictì della forma del bacino di Vienna un esemplare solo, il quale manca del mucroue pasteriore, quella regione percio è alquanto prominente ma non speronata, nel resto parmi che la conchiglia convenga colla specie del Reuss. R.

Chilostomella. - 799. C. oroidea Reuss. Un solo ma ben caratterizzato esemplare. R.

Orbitoides. - 800. 0. malgiuata Michelotti. I'unico esemplare che rapporto con qualche dubbio a questa specie, comparato cogli esemplari tipici della collina di 'Torino, mostrasi identico nei suoi caratteri e soltanto un po' diverso pel margine un po' meno distinto. $\mathrm{R}$.

Lituola. - 801. L. canariensis D' Orbiguy. Rapnorto al questa sprecie un esemplare che si allontana alquanto dalle varie forme figurate dagli autori; ma, vista la grande variabilita di queste spoglie, credo potersi riferire anco la mia che è allungata nel senso dell'asse della spirale. $R$. V.

Clavulina. - 802. C. commuis D'Orbigny. c. - 803. C. irregulatis Costa. Questa non è forse che varieti della precedente. c. - 804. C. cylindrica Hantken. Oltre la forma che risponde al tipo dato dall'autore trorasi una grande varietà più irregolare, che chiamo Tar. mijor. n. C.

rlecanium. - 805. P. cuneatum n. sp. Tav. X'. fig. 5 (redi fossili dell'Elreziano). R. -- 806 . P. sagittula D'0rbigny (Tembluria). Varia moltissimn in. lunghezza e diviene sorente irregolare. C.

807. P. costatum n. sp. Tar. XIY. fig. 8, $8 a, 86$.

Specie affine alla precedente per la forma generale e per la sporgenza delle logge in forma di costole trastersali, ma distintissima per essere sempre piccola, colla superficic meno scabra, colle costole pir strette, con una carena longitudinale mediana molto ottusa sopra ambo le ficce, dal che risulta la sezione romboidale; i margini sono irregolarmente dentellati, l'apertura è in forma di fenditura breve e stretta.

\section{Lunghezza 1. ${ }^{\mathrm{mm}}$ Larghezza 0,7. ${ }^{\mathrm{mm}}$ Spessore 0,5. ${ }^{\text {mm }} \mathrm{r}$.}

808. P. Bronniánum Dorbigny ('éxtuluria). R. - 809. P. acutum Renss (Textularia). Esemplari rariabili in lumghezza. 1.

810. P. irregulare n. sp. Tar. XIV. fig. $9,9 u, 9 b$.

Questa specie si distingue soluatnito per essere compressa considerevolmente nella regione posteriore e carenata ai margini. Grado grado rerso la regione anteriore la comuressione diminuisce e nell'ultima porzione s'inverte, cosi le carene direngono sempre yiù ottuse e scompariscono del tutto sulle ultime logge; anteriormente le suture divengono sempre più profonde, lo logge più convesse; l'apertura è allungata e curra.

Lunghezza 2,6."m Diametro 1,4, . $^{\text {mm }}$ c. 
811. P. Partsehii Czizek (Turhuluit). Un solo esemplare. R. T. - 812. P. rugosum Reuss? Riferisco questa denominazione specifica per una certa somiglianza che ha il mio mico esemplare colla specie del Reuss. R. - 813. P. Spayeri Renss? Anco questo is run rarricinamento nolto dubbio tra i miei esemplari e la specie oligocenica del Renss. 1: - 814. P. subangulatum D'orbiguy. Specie relativamente costante nei suoi caratteri, la piì comune del genere. C. - 815. P. Haueri Dorbigny. c. - 816. P. abbreviatum D'Órligny. Distintissimo per la forma breve e dilatata. C. V.

817. P. tuberiforme n. sp. 'lar. XIV. fig. 10, 10u, 106.

Questa specie è molto distinta per la conformazione arrotondata di tutte le sue parti, dimodochè una sezione trasversale è pressochè circolare, le carità sono poco convesse, ma le nltime due sono molto grandi ed arrotondate, le suture poco profunde; la bocea ì lineare, in forma di fenditura curvata ad arco. Lunghezza 1. mm Diametro $0,50^{m m} \mathrm{R}$.

Cavalurya. - 818. G. badenens is Reuss. Un solo esemplare ben caratteristico, R. $V$.

Higenerian. - 819. B. agg 1 utinans D'Orbigny. e.

Vubeculan pia. - 820. N. papillosa n. sp. (vedi fossili clveziani, tav, X. fig. 6). Qualche esemplare forse proveniente dall'Elreziano. R.'

Cornuspira. - 821. C. foliacea Philippi (Orbis). Specie ben nota, molto compressa, ed a giri culeremente crescenti. R. V. - 822. C. plicata Czizek. (Operculina). Un solo usemplare rotto. R. - 823. C. involvens Reuss (Operrulina). La specie più comnne del genere. c. - 824. C. Bornemanni Reuss. Specic distinta per essere marginata. c.

Avealina. - 825. A. me lo D'Orbigny. Dalla forma compressa alquanto si passa per" gratazione ad una forma proprio sferoidale. $r^{\circ}$ - 826. A. Ha u e r i D'Orbigny. Un solo e distintissimo esemplare di perfetta conservazione. $R$.

Spirolocuina. - 827. S. nitida D'Orbigny. Un solo esemplare. R. V. - 828. S. canaliculata D'Orb. Specie molto piecola e ben distinta per le logge scanalate. C. V. - 829. S. hadenensis Dorb.c. - 830. S. dilatata D'Orb. R. - 831. S. excarata D'Orb. Distinguesi per lo spessore consilererole, per la forma quasi circolare, per la profonda escavazione sopra ambo le filcee. C. 832. S. crassa 11. sp. Tdy. XIV. fig. 11, $11 \%$.

Questa sprecic è affine alla precedente, dalla quale si distingne per essere molto pii grande, meno escarata sopria ambo le facce, dove le logge in minor numero sono appianate; lia uni forma che più si arvicina alla circolire, ì molto spessa c l'apertura ristretta i di forma quasi esattimente triangolare.

$$
\text { Lunghezzil 1,4."mm Larghezza 1,3. mm Spessore 0,5. }{ }^{\mathrm{mm}} \text { R. }
$$

mocubina. - 833. B. simplex 1)orbigny. Specie molto vicina alla B. bul-

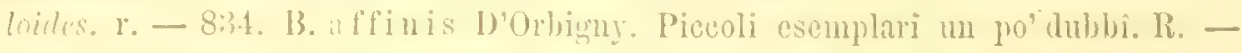
835. B. bulloides D'Orbigny. Specie sovente compressa dalla fossilizzazione

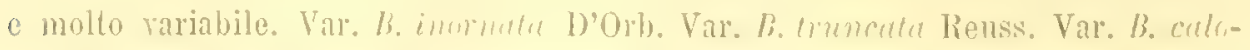
stomn Kirrer. Ia forma tipica ì comune, rare invece sono le rarietil. c. V. 436. B. lobata Reuss. Un solo esemplare ben distinto. R. 
837. B. Iarvata Reuss. Var. brevinscula. n. Questa forma si distingue dal tipn illustrato dal Reuss per essere alquanto puiu breve, e per aver la loggia minoro piì allargata. r. - 838. B. I un ula d'Orbigny. Vi riferisco taluni dubhî usemplari. r. - 839. B. an phiconica Renss. Specie variabile nella forma rlelle logge. C. - 840. B. depressa D'Orbigny. Qualehe dubbio esempline. R. V. 841. B. disgiunta n. sp. Tar. XIV. fig. 12, $12 a, 12 b$.

Questa distinta sprecie somiglia in qualche modo alla B. oyclostoma Iicuss, ilillia quale distinguesi bene per essere molto più gibbosa, colle due logge pressocho emisferiche e disgiunte da un solco ben distinto. La regione dell'apertura invece di esser prominente e marginati, è depressa ed incarata. L'apertura i proporzionaluente molto piccola, di forma trasversalmente ellittica, e porta un dente in formal di T. Lunghezza 0,59. mm Larghezza 0,6. ${ }^{\text {nm }}$ Spessore 0,68.

842. B. ventricosa Reuss. I pochi esemplari raccolti rispondono bene allo figure date dall' antore. R. - 843. B. contraria D'Orbigny. Questil comunc specie trovasi in graudi e ben distinti esemplari. C.

Troboculina. - 844. T. gib ba D'Orbigny. Specie distintissima per la sua format triquetra. C. - 845. T. a ustriaca D'Orbigny. MFolto affine alla precedente. 1. 846. T. inor nata D'Orbigny. R。 - 847. 'T. selene Karrer. r. - 848. T'. inflata D'Orb. Ben distinta per le sue forme arrotondate. c. - 849. T. scap ha D'Orbigny. V'ha di questa specie ma varietà più allungata, che io non saprei disgiungere dal tipo. c. - 850. T. anceps Renss. Var. inflata. H. I'unico esemplare che credo dover riferire alla specie del Reuss è meno compresso, e quindi lo rapporto ad una distinta rarietì. $R$.

851. T. striarella 11. sp. Tar. XIV. fig. 13, 13a, $13 b$.

Molto affine alle due precedenti specie. La mia distinguesi per aveive la loggia centrale piccola, non prominente, ma invece profondata per una ricurvatura del margine delle circostanti logge; sull'opposto lato della conchiglia la suturia delle due maggiori logge è lievemente flessuosa e profondata; la superficie è ormata da strie curve disposte nel senso longitudinale; l'ultima cariti si protende in un breve e stretto rostro, ehe porta un'apertura ellittica con un dente bifido.

Lunghezza 1,6. ${ }^{\text {mm }}$ Larghezza $1,1{ }^{\text {mm }}$ Spessore $0,7{ }^{\mathrm{mm}} \mathrm{r}$.

852. T. consobrina Dorbigny. Due ben distinti esemplari. R. - 85\%. T. nitens Reuss. Vi riferisco due minimi esemplari che parmi convengano in qulasi tutt'i caratteri colle figure dell'antore. R. - 854. T. pulchella Reuss. L'elegante seultura formata di costelle longitudinali distiugue bene questa snecie. $\mathrm{l}^{\circ}$

Quinucloculina. - 855. Q. longirostrat D'0rbigny. La quinta piecola loggia in taluni individui diviene piccolissima e tende a scomparire. 1 . - 856 . Q. Partschii D'Orbigny. Esattamente identica a quella del bacino di Vienua, mostrando sinanco le linee longitudinali rilevate nella parte che avvicina l'apertura. R. - 857. Q. Akueriana D'Orbigny. 1. - 858. Q. Bucluiana D'Orbigny. La più comme quinqueloculina di Benestare. C. - 859. Q. Ungerialla I)'Orbigny. C. - 860. Q. oblonga Montagu (Serpula). Parmi che questa comune sprecere sia identica alle forme che presentansi tra le viventi. c. - 861. Q. concinna? Reuss. L'unico esemplare che rapporto a cuesta forma difierisce alquanto per 
arere $u$ j10 angulose le due mincipali logge; del resto l'andamento generale della conchiglia is proprio identico a quello della specie, cui la rapporto con dubbio. R. 862. Q. triangularis D'Orbigny. Qualche esemplare dubbio. R. V. - 863. Q. II a u e r in a D'Orhigny. Un solo ben caratterizzato esemplare. R. - 864. Q. ten u is Czizek. E dubbio l'unico esemplare che vi rapurto, perchè le logge sono meno distinte, ma la forma e l'apertura rispondono bene. R. V. - 865. Q. Haiding e ri D'Orbigny. Oltre la forma tipica, raccogliesi una varieta in cui l'ultima grande Inggia non rienopre del tutto la terz'ultima, perciò al margine ne compariscono tre, di cui la piu antica mostrasi più o meno estesamente. 1 . -866 . Q. badenens is D'Orbigny. Parmi doversi riferire a questa specie un solo piccolo esemplare. R. 867. Q. Schroekingerii Karer. I miei esemplari mancano di strie longitulinali; in tutto il resto convengono bene colle figure date dall'autore, ed in modo speciale è da segnalarsi la esatta forma dell'apertura e del dente. $r$.

Var. Calabra 'T'ar. XIV. fig. 14. 14a, 14b. Chiamo cosi uma commissima foruna di Quinqueloculina, la quale differisce abbastanza dal tipo del Karrer, ma che sembra in taluni esemplari offrire delle transizioni verso quella forma; inoltre l'apertura allungatia quasi in forma di fenditura rettangolare con un lungo, retto e gracile dente è proprio quella della specie del Karrer, ma la forma di Benestare difterisee dalla tipica per essere più allargata, assumendo una figura romboidale, o differisce ancora più per arere le due maggiori logge rotondate piì o meno sul dorso; per lo che i due spigoli prominenti che sogliono limitarlo si ottundono piiu o meno, e nelle forme estreme si arrotondano, assumendo in tal caso la conehiglia un aspetto assai direrso. In questa varieta si osservano sovente delle strie longitudinali che affettano il dorso delle grandi logge, o sono in prossimita di quella regione. C. -868 . Q. Juleana D'Orbigny. K. 869. Q. contolta Dorbigny. R. - 870. Q. asperula Seguenza. Identica alla forma che racoggliesi nel plioceno e nel quaternario. C. - 871. Q. foeda Reuss. Raceogliesi la forma ristretta e la forma allargata. r. - 872. Q. Bon eana D'Orbigny. M' insorge qualche dubbio intorno all'unico esemplare che vi rapporto, essendochè le logge centrali sono più grandi di quanto le rappresentò il D'Orbigny. R. - 873. Q. Schreibersii D'Orbigny. r. - 874. Q. Josephina D'orbigny. Variabile molto nella forma, nel numero e nella prominenza delle costole longitudinali. C.

Specic fossili dei depositi lignitiferi di Cessaniti presso Monteleone.

Tipo. $\mathrm{MOI}_{\Delta} \mathrm{I}_{\Delta} \mathrm{USCH}$.

Classe. Tasteropodi.

Cerithium. - 1. C. lignitarum Fichwald. Grande specie considerevolmente rariabile, che presenta perciò forme svariate più o meno gracili. c. - 2. C. I) uboisii Hoernes $:=C$. plicalum Dubois de Montpereux (non Lamk.), $C$. quadricinchum O. G. Costa. Anco questa specie è variabile molto nel giacimento 
presso Monteleone. c. - 3. C. minntum M. de Serres. Questa specie presenta nel medesimo giacimento una forma piccola, che, pei varî suoi caratteri le si deve associare. c.

4. C. obliquistoma n. sp. Tar. XI. fig. 25.

Testa parva, conico-pyramidata, anfractus decem subplanati, sutura impressa discreti, cingulis duobus striisque exilissimis lineisque incrementi nrnati; plicis longitudinalibus octo, ad intersetionem cingulorum gramulos prominentes rotundatos preditae. Anfractus ullimus antice convexissimus, cingulis lenuibus, paucis, striisque plurimis alternantibus signatus: canalis brevis: os ovatum obliquissime positum, postice canaliculatum; labrum dilatatum. fortissime arcuatum; margo columellaris, presertim postice, callosus.

Lunghezza 15,5. mm Larghezza 7,5."1um

Questa distintissima specie è molto bene caratterizzata dalle ntto pieghe longitudinali, ornate da due granuli per ogni avrolgimento, da due eingoli, da numerose strie esilissime per ogni anfratto, e dalla bocca orata, ma disposta assai obliquamente. Spesso la conchiglia conserva intero il margine boceale, e varia poi nella grossezza relativa e nella prominenza delle costole e dei granuli. Questa specie trovasi molto comune nel Messinese. 1 .

5. C. articulatum Costa. Tar. XI fig. 24. Questa specie distinguesi benc dal C. subthiara D'Orb. dal C. pictum Bast. pei due grossi cingoli o meglio cordoni, che stanno ai margini degli arvolgimenti, portando dei nodi appenia sporgenti, che in talune forme mancino del tutto. Il Costa raccogliera questa specie nel medesimo lnogo donde io la possiedo. La specie è molto variabile per varî caratteri, in generale molto allumgatia, conserva un colorito rosso-bruno disposto a macchie oblique sui cingoli; è questa la forma tinica.

Var. brevis. n. Forma meno allungata, suture meno scanalate, cingolo anteriore meno distinto. Questa rarietà si presenta rariabile anco nel colorito, cioè oltre il coloramento moniliforme, come nella format tipica, si presenta talvolta coi cingoli scolorati e nel resto colorata uniformemente in aranciato.

Var. tricingula. n. fig. 24a. Qnesta forma è breve o allungata con in terzo cingolo mediano sugli avrolgimenti, e varia molto quanto alla disposizione ed alla forma delle macchie ferruginose, le quali in taluni indiridui si presentano in forma di linee oblique ravvicinate sui cingoli. c.

Eythinia. - 6. B. stagnalis Basterot (Turbo) = Paludina stagnalis Hoernes. È nella lignite, e nelle argille ore stanno queste racchinse, che trorasi sparsa abbondantemente la specie che rapporto alla nominata. c.

Classe. Ia Metimbancm

Solen. - 7. S. subfragilis? Eichwald. Un solo frammento, che oftre il cardine e l'impressione muscolare, insieme al margine anteriore completo. 1 .

Presso Palmi un calcare piì o meno cellulare, che sorente acquista della sabbia e muta struttura divenendo arenaceo o sabbioso, affiora qua lit alle falde e sui forti declivî degli altipiani della Corona, sottostando al calcare cellulare del Messiniano, sulla quale roceia mostransi la serie plioceniea e la quateruaria 
marina ed alluriale. Tale roccia compatta o cellulare, ma assai resistente nelle assise superiori, diviene molto tenera in basso, variando anco nel colorito dal giallo al giallo-brumo, al rossastro. Essa sottostando al calcare del Messiniano, par che debbar riferirsi all'orizzonte del calcare a modelli del Hessinese, e quindi al periodo Tortoniano.

Siflatta conclusione viene convalidata dai fatti paleontologici; con i fossili quasi tutti allo stato di modelli, come nel calcare del Messinese, vi corrispondono benissimo e specialmente sono notevoli ed importanti i Litodomi, e le comuni specie dei Coralli, quali l'lleliastrea Reussana e la Porites incrustans.

I fossili di questo giacimento ho voluto riminli nel seguente distinto elenco per enumerarli a parte.

Elenco delle specie fossili raccolte nel Tortoniano di Palmi.

'l'ipo. MOLLUSCHI.

Classe. G A S T E R OPODI.

Iranotis. - 1. H. Volh in ie a Eichw. Impronte esteriori di perfetta conservazione e modelli interni. 1 .

\section{Classe. LAMELLiBRANCH.}

דenus. - 2. V. uml onaria Lamk. Un grande modello. R.

Ares. - 3. A. umb oulata Tamk. Varî modelli. r. - 4. A. lactea? Lin. Un dubbio modello. R. V. - 5. A. elatlurata Defrance. Impronte e modelli. r. 6. A. la bata Lin. Modelli varî. e. V.

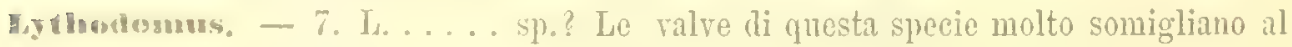
I. arilmsis Hoernes, una lir regione boccale è piì sporgente. R. - 8. L. appendiculatus Pluilipi. Con molta riservatezza riferisco a questa specie vivente in Amorica i modelli raccolti presso Palmi, che sono affatto identici a quelli comunissimi del Messinese, dit me accuratamente comparati cogli esemplari viventi. r. r.

Altui mal conservati modelli di Litolomi troransi nel calcare di Palmi, e ricordano le mumerove specie di tal genere, che raccolgonsi nel calcare coetaneo del Messinese.

Lima. - 9. L. s q u a mos a Lamk. Impronte e modelli ben riconoscibili e numerosi.c.V.

Eecten - 10. P. Reussi Hoerues. Modelli ed impronte commi di piceole dimensioni. c. - 11. P. clegans Andrz. Modello interno ed impronta esteriore. R. 12. [?. Segtemradiatus Muller. Un solo modello colle linee radianti ben forti. R. V.

Manuires. - 13. H. Defrancei? Michel. Riferisco a questa specie con molto dubbio una semplice impronta. R.

'Tipo. ECHINODHRMIT.

Classe. Echinidi. Ordine. Regolari.

Cidaris. - 14. C. tessurata Meneghini. Var. major. R. 


\section{Tipo. CELENTERATI.}

Classe. Antozodrit. Ordine. Zodntam.

Meliastraca. - 15. H. Reus a

Questa importante specie presentusi in esemplari ben conscrvati o non rari nol calcare di Palmi. c.

Ponites. - 16. P. incrustans Michelin. Riferisco a questa specic una comunissima forma, che costituisce parte importante della roceia, pure essa trorasi costantemente in cattivo stato di conservazione. C.

17. P. stratiform is $11 . \mathrm{sp}$.

Chiamo cosi una grande porite, che risulta dalla sorrapposizione du uumerosi strati del polipaio. Tali strati, spessi alcuni millimetri, si mostrano distintissimi; essi sono inoltre fortemente piegati, Hessuosi e compiono una serie di ondulazioni ben larghe, conservandosi pressochè paralleli. Da quanto pù̀ desumersi, essendo l'esemplare mal conservito, i calici devono avere un diametro di circa due mill. $\mathrm{R}$.

La ricca fauna esaminata nei precedenti elenchi, costituita dal rimarchevole numero di 893 specie animali, non ha d'uopo di delueidazioni o schiarimenti: essal parla eloquentemente al paleontologo, il quale a prima giunta ri riconosee quell'insieme di Molluschi, di Crostacei, di Coralli, di Rizopodi caratteristici dell'epoca tortoniaua, una fauna insomma completamente identica a quelle che s'incontrano negli strati del mioceno superiore delle piì classiche localitì d'Italia ed anco di tutta Europa.

Così gli strati del Tortonese e del Modenese sono quelli specialmente che ollirono nella loro fauna il maggior numero di specie comuni coi depositi di Benestare; i Molluschi, i Coralli e i Rizopodi sono specialmente i gruppi che richiamano l'attenzione del paleontologo a questo riguardo. Le opere del Michelotti ( $\left.{ }^{1}\right)$, del Sismonda $\left({ }^{2}\right)$, del Bellardi $\left({ }^{3}\right)$, del Doderlein ( $)$, del Coppi ( $\left(^{5}\right)$ enumerano e descrivono le mumerose specie che si raccolgono in quei glacimenti.

Il bacino di Viema presenta anch'esso nei suoi strati superiori un gran numero di specie che sono comuni col nostro Tortoniano, el anco qui bisogna segnalare i Molluschi, i Coralli, ed in modo specialissimo i Briozoi, gli Ostracodi ed i Foraminiferi, che per la maggior parte sono stati raceolti nel mioceno superiore di Vienna. I signori Hoernes $\left({ }^{6}\right)$, D'Orlbigny $\left({ }^{7}\right)$, Reuss $\left({ }^{8}\right)$, Czizek $\left({ }^{9}\right)$, Neugeboren $\left({ }^{10}\right)$.

(1) G. Michelotti, Description des fussiles des lorrains lerliaires miacénes de l'llulie scplentro. nale. - $\left({ }^{3}\right)$ E. Sismonda, Synopsis melhodica Pedenontii fossilium. - Malériaux pour servir à la paléun-

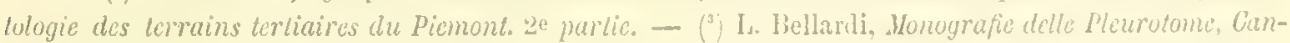
cellarie, Mitre e Columbelle fossili del Piemonte. - I Molluschi dei lerreni tersiari deb Piemonte e dellu Liguria. - (") P. Doderlein, Cenni geologici intorno la giaciluru dei terreni miocenici dell' latia cintralc. (5) F. Coppi, Calalogo dei fossili tersiari del Modenese. - (") M. Hoernes, Die Possilen .Wolluschen des lertiar. Beckens von Wien. - (O) A. D'Orbigny, Forminiferes foss. du bassin tertiaire de lienne. (1) A. Reuss, Aeue Foraminif. aus den Schichten des osterreichischen Terliar beckens. - Die liust.

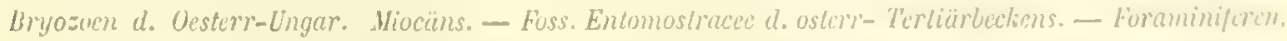

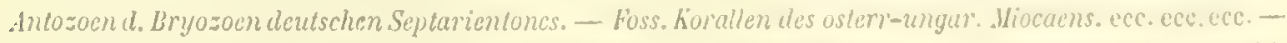
$\left(^{3}\right)$ Czizek J., Beilr. z. Kenntn. d. foss. Foraminifuren d. Wiencr Beckens. - ( ${ }^{10}$ ) Neugeluoren. (J. I.) Die Foraminiferen ans d. Orin. d. Slichosteyier v. Oherbhugy. 
Karrer ('), Fuchs ("), Manzoni (") hamno illustrato con somma cura quella fauma. Nolti altri lembi in Italia di terreni miocenici hanno col Tortoniano di Benestare comune la famna. Cosi gli strati (li Sogliano descritti accuratamente dal Manzoni (") e poi riesaminati dal Fuchs $\left({ }^{5}\right)$; probabilmente vi sono coetanei taluni dei numerosi giacimenti miocenici della Sarkegna studiati dal Ia Marmora e dal Meneghini ("). siccome alcuni depositi della Corsica illustrati dal Locard e dal Cotteau ( ${ }^{3}$ ).

In Sicilia sono molti lnoghi dove il Tortoniano è fossilifero, e la fauna ha la massima somiglianza con quella del Tortoniano del Reggiano, dappoicchè v'ha la magrgior parte di specie comuni ai depositi sincroni delle due vicine regioni.

Così nel Messinese le argille e le molasse fossilifere di Sampiero, di Rometta. di Patti e delle valli di Spadafora $\left({ }^{8}\right)$, nel Palermitano le argille di Ciminna $\left({ }^{4}\right)$, jresso Sirneusa il calcare tenero che riene estesamente impiegato nelle costruzioni siccome pietra da taglio $\left({ }^{10}\right)$, nel Vizzinese e nel Licodiano le marne con fama tortoniana da recente scoperte dal sig. I. Cafici, che si collegano colla serie messiniana soprastante $\left({ }^{11}\right)$.

Tra i piu rilevanti depositi coetanei al Tortoniano di Calabria, che ho precedentemente esaminato, fuori d' Italia si rapportano rarî giacimenti della Francia, e specialmente fa d'ropo ricordare le molte contrade del bạcino del Rhône con tanta cura recentemente studiate dal sig. F. Eontannes, dopo che una serie di celebri geologi l'aveano gia illustrato sin da lingo tempo. Là il 'Tortoniano si connette coi varî piani del mioceno e del plioceno, che lo precedono e lo sieguono, siccome con molta cura ha dimostrato il Fontannes $\left({ }^{13}\right)$.

E pur tacendo di molti altri lnoghi meno rimarchevoli, non trasanderò al certo il Iontano Portogallo, dove il Tortoniano fa bella mostra della sua fauna malacologica studiata già da Pereira da Costa $\left({ }^{23}\right)$ e dimostrata quasi intieramente identica a quella del bacino di Vienna e d'altri lnoghi.

E qui fureblo d'uopo di un dettagliato esame comparativo tra le fanne tortoniane speciali dei diversi luoghi enumerati e quella della Calabria meridionale testè descritta: ma per ragione di brerità io lascio un tale agevole compito al lettore, e mi contento di ricordare soltanto, che un'associazione cosi rariati e numerosa di spoglie animali, che non era stata giammai studiata, presenta un certo numero di

(1) Karrer F. Die miocenc Foraminiferen-funna von Kostey intr Bumat. ecc. ecc. - (") 'T. Fuchs. 11. Farrer., Geol. Stulien. in d. Terliarbild. d. Wiener. Beckens. - ( $\left.{ }^{3}\right)$ 1. Manzoni, I Briozoi fossili del mioceno d'Austria e l'Ungheria. - (") A. Manzoni, Fossili di alcuni lembi miocenici. - ( $\left.{ }^{5}\right)$ T. Fuchs., Die Giliederung der Tortiarbildungen am Nordabhange der Appenninen von Ancona bis Bologna. - (") A. De La Marmora, Voyage en Sarduigne. Paliontolugie par Mr. lo prof. Meneghini. - (") A. Locard et (i. Cottean, Descriplion de la faune des terrains lertiaires noyens de la Corse. - ( G. Seguenza, Nolizie succinte intorno alla costiluzione gcologica dei lerreni del distretto di Hessina. - Studi stral. int. alla formazione pliocenica (Boll. del 1 . Comitato geolog.) - ( j S. Ciofalo, bi una nuova specie fossile del mioreno di Ciminne. - Alcune osservazioni sul mioreno di Ciminna. Iettera alling. P. Zezi. (10) G. Seguenza, Stuli stratigraf. int. alla fumas. plioecn. dell llalia nevidionale (Boll. del r. Comitato geolog.). - (") I. Cofici, La furmasione gessosa del Vizzinese e del Licodiano (Provincia di Catania),

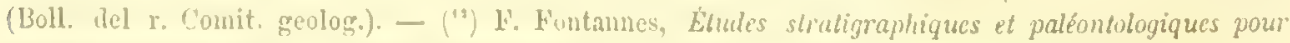

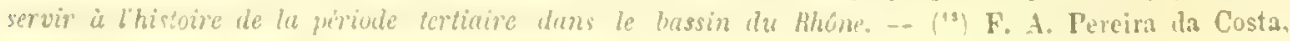
Gasteropodes dos deprositos lerciarios de lormont 
specie nuore, che puo valutarsi a quasi un sesto (141 sopra 893) del totale, essendo le altre riferibili a specie già conoscinte, e appartenenti alla fauna tortoniana dei piu classici luoghi d'Europa, se se ne escludono alcune pochissime, le quali non elano state pria d'ora trovate nel mioceno superiore.

Passo quindi a considerare la fauma tortoniana del Reggiano nella sua costituzione, esaminandola complessivamente nei suoi piu rilevanti caratteri. E dapprima parmi assai rimarchevole il numero complessivo delle specie che la costituiscono, il quale si eleva ad 874, per un solo lnogo, ed è tanto più grande proporzionatamente quanto piu limitato è il terreno che somministra i fossili, trattandosi quasi dell'unica e ristrettissima localiti di Benestare, dove il Tortoniano fossilifero credo che non raggiunga in superficie un mezzo chilometro quadrato.

Tale ricchissima fanna (') risulta costituita dal seguente numero di specie per ciascuna classe: Pesci $3\left({ }^{2}\right)$, Molluschi: Cefalopodo 1, Gasteropodi 262, Pteropodi 3, Lamellibranchi 106, Brachiopodi 2, Crostacei: Entomostracei 28, Cirripedi 3. Anellidi 6, Briozoi 81, Echinodermi 7, Corallarii 23, Spongiarii 5, Rizopodi fo-" raminiferi 336.

Un assembramento cosi variato di organismi marini, in ottino stato di conserrazione, ci dà l'agio a discorrere intorno alle condizioni di loro esistenza, e quindi intorno al mare in cui si costituivano quei depositi di finissima argilla.

E dapprima i Molluschi, che formano il gruppo maggiore, tanto importante e cosi caratteristico ci offrono tra le 387 raccolte 90 specie, ciò̀ il $23 \%$, tuttora viventi nei mari attuali le quali hanno quindi traversato i diversi periodi del plioceno e del quaternario. Dunque senza alcun dubbio sono ben 297 le forme che non si conoscono allo stato di vita. Tra le viventi talune sono proprie delle acque poco profonde, ed altre note come abissicole; della prima categoria mi basta ricoldare lo Scaphander lignarius, l'Euthria cornea, il Cerithiolum scabrum, In Natica millepunctata, la Rissoa Montagui, la R. cimex, il Turbo rugosus, la Venus ovata, e di profondita piu o meno considerevoli sono invece l'Erato laevis, il Solarium zancleum, la Seguenzia monocingulata, la Natica fusca, l'Eulimella Scillae, la Pyrgulina pygmaea, la Mathilda elegantissima, il Siphonodentalium tetragonum, la Verticordice trapezoidea, l'Arca pectunculoides, la Limea crassa, ecc.

Dal quale fatto evidentemente risulta che le argille tortoniane di Benestare si depositarono a mediocre profondita, la quale conclusione d'altronde viene confermata dall'esame di ogni elasse della ricca fauna ivi scoperta. Difatti se si considerano complessivamente anco gli stessi Molluschi si riconosee che essi spettano quasi completamente ai Gasteropodi ed ai Lamellibranchi, alle quali classi si agrgiungono ben pochi resti di Pteropodi e di Brachiopodi.

Trascurando quelle classi che vi sono rappresentate da poche specie sparse con molta parsimonia, bisogna pur considerare nella fauna di Benestare i Briozoi, gli Antozoarii, ed i Rizopodi che vi sono largamente rappresentati.

(') Nell'esame che siegue tengo conto soltanto delle specie del grande elenco; che pettano tutte alla località di Benestare e pochissime ar Ambuti e Falcò. - (9) liestano escluse da questo numero le molte specie a cui acconnano gli otoliti, che nello stato attuale non possono determinarsi. 
I Briozoi ci offrono ottantuna specie, ma queste sono sparse con molta parsimonia, dovemlo spignlare con molta cura fra tutti i resti d'ogni maniera di fossili e grande ufuntitir del piccolo residuo sabbioso delle argille per ragranellare poche e sparute rolonie. Cii dimostra, concortemente ai Molluschi, che non trattarasi se non di mediocri profontiti. I Coralli quasi tutti dei Curiofillidi e dei Turbinolidi accennano anch'essi in tili batimetriche condizioni; e i Foraminiferi, al numero ben grande di 336 specie, non contenendo in abhondanza nè le orbuline, nè le globigerine abitatori degli abissi, coneordano colle esposte redute; quindi il mare delle argille tortoniane di benestince dorea essere al certo di frofonditì mediocre.

Al di sopra delle argille abbiamo detto griacere un banco sabbioso cementato da gesso cristallino. Or i fossili in esso contenuti sono trasformati in gesso clivabile e ben conservati, tanto che si determinano agevolmente le specie, e i Lamellibranchi offromo d'ordinario le valve rimite.

Questa piccola fauna è costituita da qualehe Turritella, dalla Cardila Jouanneti, da grandi Venus e Pectunculus, da alcmi Peltini e da qualche Clipeastro; trattasi insosmma d'uni fama evidentemente littoranea, quindi i fossili e la matura del deposito concordemente dimostrano essersi originati a piccola profondita, e percio fa d'uopo ammettere un inalzamento del fonto marino, il quale già par che aresse subito m'analoga oscillazione alla fine dell' epoca ulveziana, dappoicchè i depositi sottostanti al Tortouiano racchiudono quasi dapertutto abbondanti Brachiopodi e profusissimi Briozoi, che eridentemente accennano a maggior mrofonditi delle acque, divente pereiò sempre più basse fino all'ultimo periodo dell'epoca tortoniana.

Se ciò viene dimostrato evidentemente dalla serie stratigrafica di Benestare, viene poi luminosamente confermato dagli strati tortoniani del territorio di Monteleone, tore. come fu detto precedentemente, gli strati marini di estuario, ricchi di varî Cerizì, e gli strati lacustri lignitiferi si succedono e si alternano, indicando cosi l'oscillare e l'inalzarsi progressivo del fondo sottomarino.

Cosi ancoria ad un deposito di mare poco profondo è da attribuirsi la formazione calcarea presso Palmi, come ben lo dimostrano i suoi fossili.

Da ultimo parmi ntile ricordare i rapporti che la fama tortoniana del Reggiano, cosi ricca di specie, offe colla fauna marina vivente. I rapporti più importanti e piì immediati ci rengono espressi dal numero delle specie comuni alle due cpoche, tali sono quelle appunto, che perdurando e propagandosi nei tempi successivi hamo protratto la loro vita sino ai nuri attuali, addimostrando cosi di fronte alle mumerose forme estinte una rimarchevole resistenza alle cause che limitano ciascuna forma specifica in un leterminato periodo geologico.

Delle tre specie di pesci nessuna è vivente; il Cefalopodo, a cui fu dubbiamente rapportata l'unica specic, vive tuttaria: di 262 Gasteropodi se ne conoscono nei nostri mari soltanto 50; dei tre Pteropodi un solo; di 106 Lamellilianchi ne rirono tuttora 35 specie; nessuno dei due 13rachiopodi; di 28 Crostacei Fntomostracei soltanto una specie ì superstite; di tre Cirripedi uno; di sei Anellidi un solo; di 81 Briozoi se ne conoscono nei nostri mari 14; delle sette specie di Echinodermi e delle 23 spettanti ai Celenterati nessuma è sopravrissuta; invece in 336 Foraminiferi se ne sono scoperti 69 virenti nei mari attuali. 
Quindi complessiramente abbiamo che delle 874 specic fossili del Tortonian calabrese 176 hanno traversato i diversi periodj del terziario superiore o del quaternario e si sono associate alla fauna vivente.

Un altro fatto importante deriva dal fucies della fauma che esamino, concordemente alla costituzione generale della fauna tortoniana tutta di Europa, che dimostra ad evidenza un clima più caldo dell'attuale; difatti i numerosi Coni, i rariati e grandi Pleurotomili, le Marginelle, le Ficula, le T'rebra, gli Strombus, le Cancellariu e tanti altri generi addimostrano che tale fauna somiglia di pii nel suo insieme alla fauna dei mari caldi anzichè alla mediterranea; lo che prova con sicurezza, quantn fu già dimostrato, che le acque dal mare tortoniano in Europa e quindi il clima di quel periodo erano piì caldi degli attuali delle stesse regioni.

6. Piano Messiniaño (Mayer).

Sinonimi: Mioceno superiore e Plioceno interiure (parte) di vari autori. Strati niu-pliocenici e formazione gessoso-solffera di altri.

Il prof. C. Mayer da Zurico ha chiamato Messiniano un piano geologico, sul finire della lunga epoca miocenica (1), costituito da strati di varia natura, sorente da depositi di estuario e lacustri, che l'autore erroneamente ha roluto credere coetanei agli s'rati zaucleani dell' Italia meridionale, che si depositarono in mare piu o meno profondo e che oramai sono ben riconosciuti siccome di eta posteriore e sicuramente pliocenica.

In Italia a tale piano si rapportano gli strati gessosi a Congerie e Cardi che il prof. Capellini scopriva in rari luoghi della Tosenna, nel Senegalliese, presso Ancona, e che dimostrara sincroni agli strati con analoga fauna di Talncuhia, di Crimea e della Valle del Rodano $\left({ }^{8}\right)$.

Tale correlazione venne riconosciuta e convalidata dal sig. Fuchs, e parmi evidente che questo prezioso orizzonte corra dall'uno all'altro estremo la penisola italiana e l'adiacente Sicilia, che se non dapertutto quella fauna caratteristica viene a determinare le rocce che ri spettano, la posizione stratigrafica e la litologica costituzione si associano a precisare quasi sempre il posto cronologico di tali depositi. Cosi sembra ormai evidente che la zona gessoso-solfifera di Sicilia bisogna rapportarla a tale periodo e riguardarla siccome la continuazione di quei depositi messiniani gessiferi che interrottamente si estendono sull'uno e l'altro lato dell'A ppennino. I molti studi pubblicati e specialmente le ultime ricerche accurate e minuziose del sig. Stohr lo dimostrano chiaramente $\left({ }^{3}\right)$.

(1) C. Mayer, Catalogue systématinue ot descripuf des fossiles des lemoins tertiaires qui se trouvent au Musie federal de Zwich: Deuxième Cahier. - (^) Vedi. G. Capelliui, Notizie geologiche o. palcont. sui gessi di Castellimu marillma (Nnoro Cimento, vol. X11. I'isa 1860): Giacimonti petrulifuri di Valachia ecc. (Mem. dell'Accad. delle scicnze dell' Istitutu di IJulogna. Ser. Na tom. V'II. Bologna 1860): Varne glauconifere dei dinforni di Bologna: La fomazione gessosa di Casbellina marittimn wer. 1874. Gli strati a Gongeric o le marne computte miocmiche dei dintomi d'. Incona: Il calcume di

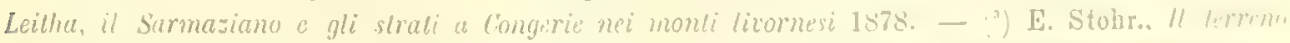

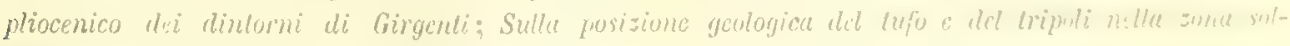
ffrra di Sicitia. Boll. del r. C'umititu reulow. 
Nella provincia di Reggio, come già ho dimostrato, la formazione miocenica si potente, si estesa e si variata offie un fatto rimarchevole quanto alla distribuzione doi snoi varî piani: essi presentano. una latitudine che scema grandemente dal Langhiamo agli strati più recenti. Difatti le rocce langhiane, e specialmente il conglomerato, quasi compiono il perimetro dell' intiera provincia, sebbene interrottamente: invece lo sabbie ed i calcari elveziani sono molto limitati nella loro topografica distribuzione, e come già accenuai si mostrano soltanto in due opposte regionj, il territorio di Gerace sul lato orientale, e quello di Monteleone sul versante accidentale; il Tortoniano poi si limita a piccoli lembi nelle sole contrade di Benestare. Ambuti e Cessaniti: il Messiniano con analoga limitazione si fa vedere sulle stesse aree, esso non offre allo studioso verumo elemento paleontologico, che valga a precisare e definire la sua etì, e le condizioni in cui quelle roce si andavano costituendo; soltanto la posizione stratigrafica arvalorata anco da qualche dato litologico sono i soli caratteri che possono invocarsi per determinare l'età delle rocee che credo dover riferire al periodo Messiniano.

Difatti gli strati che io vi rapporto giacciono sulle argille e sulle sabbie gessifere a fauna tortoniana, e sopportano i più antichi sedimenti pliocenici, come osservasi presso Gerace, a Benestare, nelle colline di Siderno ed al Capo Spartirento.

Ma mentre in molti luoghi del suolo italiano si vanno scoprendo rasti lembi di argille e di marne gessifere, ricche della caratteristica fauna a Cardî e Congerie. per la quale riesce agevole sincronizzare tali rocce coi depositi messiniani della Francia, dell'Austria-Ungheria, e del mezzogiorno della Russia, nella provincia di Reggio sara molto se potremo esser sicuri che le rocce gessose e calcaree che io vi riferisco sieno veramente e precisamente di tale eta, non arendo potuto, per quanto io conosca il suolo del Reggiano, trovare la caratteristica fauna, oggetto di tante discussioni e di si importanti deduzioni; fa d'uopo quiudi che io mi rassegni a dare la sola descrizione litologica dei brevi lembi di roce messiniane.

Nella prememoria sulle formazioni terziarie del Reggiano pubblicata nel inaggio del 1877 (') io rapportara al Messiniano, oltre la formazione gessosa, talumi strati argillosi ad Ostrea nuvicularis, che a Benestare sorrastano alle argille tortoniane; ma piu tardi avendo rinvenuto tra gli strati suddetti e i gessi una formazione sabbiosa cementata dalla selenite cristallina e fornita d'una fauna indiscutibilmente tortoniana. bisogno che tali strati, e quindi le sottostanti argille ad ostrece navicularis, renissero associate al Tortoniano.

Amettera ancora al Messiniano, in quel breve schizzo, la formazione lignitifera del territorio di Monteleone, la quale viene ben caratterizzata da una fauna ricca di Corizii, fra i quali il grande $r$. limniturum. Or tale fauna più opportunamente bisogna che si riferisca al Tortoniano, come gia ho fatto nel presente lavoro; e quindi sono i gessi che resterebbero isolati a costituire da se soli il piano messinjano, qualora io $110 \mathrm{n}$ vi avessi annesso un calcare sovrastante, che nel mio succinto lavoro figura siccome il membro piu antico del plioceno. 
Il calcare che oggi vi annetto è privo anch'esso di fossili, e quindi il IIessiniano sarebbe rappresentato a mio giudizio dagli ammassi di gresso connessi a strati marnosi in qualche luogo, e dal calcare che altrore c'iamai concrezionato ('). Eccomi alla descrizione.

a) Ammassi di gesso. - Nella serie stratigrafica di Benestare, come rappresenta la sezione ruodecima, il gesso succede agli strati tortoniani formando ammassi giganteschi che si estendono a costituire scoscesi dirupi ed elevate colline che si ergono sul lato orientale del comune di Benestare, e si estendono vastamente verso il territorio di Platì ma bentosto il gesso viene ricoperto da un potente ammanto di conglomerato, che costituisce la parte principale di quella elevata regione, e quindi scomparisce sotto un deposito sì spesso, ma sporge qua e là dove il suolo si arvalla profondamente, dore esso mostrasi orribilmente acclive e scosceso, dove la denudazione ha tolto via la soprastante roccia dalla quale sembra sporgere in molti luoghi.

Così traversando quelle colline mi è occorso di rirederlo in talune contrade e sino alla distanz di circa dieci chilometri da Benestare, là ove nella direzione Nord-Ovest il conglomernto e le ripide colline che esso forma finiscono bruscamente per cedere il posto alle argille scagliose del Tongriano, che si estendono sotto forma pianeggiante o di colline arrotondate, ivi la roccia gessosa sporge fuori poggiando sulle argille variamente colorate e sopportando l'immane roccia aggregata dai voluminosi ciottoli granitici. In quel luogo la serie miocenica è ridotta ai suoi due termini estremi, che pel difetto dei piani intermedî troransi ad immediato contatto, è cosi che il gesso poggia direttamente sulle argille scagliose.

Isa roccia gessosa adunque nel territorio di Benestare oltrechè si mostra molto potente nello spessore, dere occupare una superficie molto grande per aftiorare alla rimarcherole distanza rettilinea di dieci chilometri.

Quanto ai caratteri che presenta bisogna rimarcare anzi tutto che la selenite di cui discorro servando dorunque struttura cristallina non si presenta mai stratificata ed assume invece la conformazione di colossali ammassi, che risultano savente come dall' associazione di grandi mammelloni a superficie grossolananente rugosa. La frattura offre il distinto sfaccettamento a larghe lamine, che s'intersecano tral loro con varia ed irregolare orientazione, il colorito ne è bianco o grighastro e d'ordinario senro per miscugli di corpi estranei.

Con identici caratteri la formazione gessosa affiora benanco in un burrone che stendesi ad ovest presso il capo Spartivento, e la il gesso eristallino vedesi sporgere di mezzo alle marne del plioceno antico.

Nelle colline sopra Siderno il gesso comparisce in qualche luogo sottostante al plioceno, ma cambia ivi di struttura assumendo quella compatta o finissimamente saccaroide, e divenendo di color giallastro o grigiastro e comuettendosi con depositi sabbiosi e con potente formazione di marne molto bene stratificate.

Le rocce gessose conosconsi ancora nel territorio di Mileto. 
b) Calcare cellulare. - La roccia che io denomino calcare cellulare è quella stessa precisamente che pei terreni messinesi io avea denominato calcare consrezionat), e che nalle precedenti pubblicazioni associara al plioceno (\$).

Orgi, nure e più minuziose ricerche, compite specialmente nella provincia di ILessin., hanno modificato considerevolmente le mie redute, facendomi credere piì conreniente l'associazioue del calcare cellulare al Messiniano anzichè allo Zanclean. Difutti nel ILssinese tale rocia siegue dapertutto la formazione gessosa. ripiegandosi. contormandosi ed inflettendosi insieme e concordemente ad essa.

In Calbria non saprebbesi detorminare la posizione relativa del calcare di cui tiatto iil rimporto alla furmazione gessosa, e potrebbesi anzi credere che l'uno sostituisin l"atri, essondochè non redonsi mai associate nel medesimo luogo: cosl a Benostar. th altrove esisto il vesso e manca il calcare, e viceversa a Gerace e ad Ambuti il calcare è seomparnato dal gesso.

$\mathrm{P}_{i} \cdot{ }_{\mathrm{n}} \mathrm{n}$ MIessina invece il calcare si associa alla roccia gessifera sorrapponendosi schinn ad essa e inostrandosi cosi d'un periodo posteriore.

Il calane cullulare costituisce una formazione rimarchevolissima per la sua grande irreglaniti. esso presentasi sotto forma di ammassi sinuosi, rovinosi, forniti di prominenze, di lapressioni, e sfornito d'ogni indizio di struttura e di forma stratifica'a, seblene in tuluni lnoghi vi si comette inferiomente con un calcare assai tenero, eninentemente stratificato.

Esso è più o meno tenero e talvolta quasi friabile, sparso di carità irregolari di piccolo diametro e talvolta aneo grandette sino ad alcuni centimetri: tali cellule in alcuni casi sono tapezzate di inerostazioui cristalline ovvero da esili cristalli di calcare e più raramente di celestina, come osservasi in qualche lnogo del Messinese; il colorito ì bianco niveo, ovrero roseo, rossastro o gialliceio.

Un fitto rimarchevole in riguardo a questa roccia è quello della completa assenza d'ouni resto paleontologico, e tale carattere is immancabile nel Regriano come nel Messinese.

Un'ultima considerazione risulta il mio credere evidente dai fatti tutti che ho enumerato. Difitti la costituzione del calcare ed il difetto di resti organici dicono abbastanza per potere riconoscere in questa formazione un deposito chimico, che ripete probabilmente la sua origine da sorgenti calcaree: e tale conclusione viene anco arralolata dal fatto della irregolarità di conformazione e di distribuzione di tale deposito, essendochi esso mostrasi in certi speciali luoghi e piu ordinariamente manca, il plioceno percio che tanto vastamente si estende, poggia quasi dappertutto sopra rocce di piu antica eti.

Il liogo dove pii largamente estendesi il calcare che esamino è presso Gerace, cioè nelle colline che s' interpongono tra questo capoluogo e la spiaggia; la via nazionale lo taglia in molti luoghi ed in varie direzioni, ed è lì che puo osservarsi il contatto tra il calcare ed i piis antichi strati pliocenici. Siffatto contatto par che mostri uma discordanza tra le due formazioni, ma la grande irregolaritì della superficie caleare lascia dubhiosa e mal definita una tale deduzione.

\footnotetext{
(1) U. Segnenza, brevissini cem inlornu le furmazioni terziario lella Provincia di Reggio-Calabria.
} 
Il calcare cellulare dalle basse colline di Gerace si estende verso settentrione mostrandosi qua è là nelle colline di sidemo, nelle piò elevate presso i Crudoli e sopra Gioiosa-ionica; dal lato meridionale poi si vede aneora sotto forma li lembi isolati che ho potuto seguire per lungo tratto sino ad Ambutì ed Ardore.

Probabilmente dorrà riguardarsi siccome coetanea al calcare cellulare la roceia calcarea del Salto della Vechia. Intorno a questo argomento non ho da addurre alcun dato importante.

Altrove parmi non avere incontrato il calcare cellulare, ultimo membro della potente e variata serie miocenica.

I brevi lembi della formazione messiniana del Reggiano, la completa mancanza di fossili e la loro stessa posizione, per la quale appena affiorano, non dauno alcun agio al geologo di compiere un accurato studio stratigrafico delle rocee che la costituiscono; ed è già abbastanza se dalle contrade esplorate e dai pocbi lembi scoperti io ho potuto precisarne la cronologica posizione, e guidato dai bei larori e numerosi, intorno alla formazione gessosa italiana, che hanno veduto la lice in que. sti ultimi anni, sono riuscito a riconoscere nei piccoli lembi calabresi, la continuazione di quella formazione gessosa, che alla base del plioceno si continua per tutta la penisola italiana sull'uno e l'altro ver'sante dell'Appenuino e sviluppasi vastamente in Sicilia, dove al centro ed al mezzogiono caricandosi di zolfo costituisce la ricca zona solfifera, di cui hanno scritto, sin da tempi abbastanza lontani, numerosi geologi, e recentemente il Mottura (') e lo Stohr $\left({ }^{2}\right)$ che hanno compiti studi dettrgliati di quei terreni e massimamente l'ultimo che ue esaminò tanto aceuratumente la fauna microseopica.

È qui dunque, in Sicilia, che il tipo della formazione messiniana, potente, variata nei suoi strati, doviziosa di cristallizzazioni direrse, poggia sugli schisti silicei o tripoli e sulle marne bituminose dimostrati entrambi dallo Stohr siccome di etir tortoniana, e ciò meliante studio accurato delle ricehe faune, che racchiudono ablonndanti Foraminiferi, Radiolarî e Diatomec.

A questi recenti studî e minuziosi sono venuti ad aggiungersi molto opportunamente le importanti e recentissime scoperte del sig. I. Cafici, il quale scopriva nel territorio di Vizzini, soprastanti agli strati gessiferi, le marne lacustri a piccoli Cardii e Congerie e sottostanti le marne tortoniane ricehe della caratteristica faum con Pleurotomidi, Cancellurie, Murichli. Nasse. Coni. Ancillario, Mitre. Denulii ec. ec. I quali fatti sempre meglio dimostrano il sineronismo di tutti i lembi della formazione gessifera italiana.

La provincia di Messina poi, che è la prossima al Reggiano, oftre molto sriluppata e potente la formazione gessosa $\left({ }^{3}\right)$, che variata molto negli strati che la costituiscono, si termina col calcare cellulare potente, vastamente esteso, e perfetta-

(1) Sulla fornazione solffora al Sicilia Menorie della r. Accudemia di seienze di Torinu (S rite 11 'Lomo $\mathrm{XXV}$. - Appendice alla . Henoriu sulla formazione tersiaria della zona solffera di Sicilia (Memorie del r. Comitato geologico, Vol. II).

(*) Il terreno pliocenico dei dintorni wi Girgenti (Boll. del r. Comitato guolog.) - Sulla pusisione genlogica del tufo e del tripoli nella zona sulfifore di Sicilin (Boll. del r. Cumitato geol. 1875:Die Radiolarenfauna der Tripoli von Grolle. Provinz Girgenli in Sicilien (Palaeont. o graphica).

') G. Seguenza. Brevissimi cena intorno lu serie Lraiariu della Provincia di Vessinu. Vedi p. 18. 
mente identico a quello del Regriann; mentre poggia sulle argilis compatte e sabbiose con fituna tortoniana. Uli strati gessiferi sono sabbiosi, manosi, calcarei, e di tripoli, c tali roce predominano nellordine in eui troransi qui enumerati, anzi pare che spesso le marne famo graduale transizione verso i tripoli, siccome a Grotte fu osservato dallo Stohr. Il gesso raramente vi è stratificato, compatto o saccaroide. d'ordinario inrece trorasi sparso in seno agli strati rari in forma di ammassi colossali e di ogni dimensione sino alla furma di piccoli arnioni, che risulta dall'aggregato di grossi o piccoli cristilli, sorente associati a ferro li lancia e spesso sporgenti allu superficie degli aggregati, e non mancano i casi in cui il gesso si presenta in cristalli isolati rolumiuosi e sorente assai belli.

Nel Messinese il gesso intade anco gli schisti silicei, mentre bene spesso giace nelle mane. Ciò accennerebbe che sin dal periodo superiore del Tortoniano esso comincio a deporsi in queste contrade, il quale fatto concorda colla scoperta a Benestare d'una fuma tortoniaua in istrati sabbiosi cementati dal gesso.

La formazione gessosia del Messinese presenta assai spesso i suoi strati flessuosi e ripiegati in mille moli, come d'ordinario zresentansi i coetanei della zona solffera, lo quali curvature rengono concordemente seguite dal calcare concrezionato cellulare. mentre gli strati pliocenici soprastanti fanno un rimarcherole contrasto presentandosi ordinariamente appianati.

Il solfo unanca del tutto uel IIessinese e solo comincia a mostrarsi presso Calatabiano, in sul limitare di questa colla provincia di Catania. La Celestina invece si mostril talvolta in nitidi cristalli mel calcare cellulare e presso Rometta in un calcare soprastante alle aryille tortoniane, nel quale ha sostituito per epigenesi il calcare delle grandi bivalri e dei coralli poliastrei. Gli schisti silicei offrono dei pesei ben conservati come qualli che si raccolgono nei tripoli della zona solffera, e risultano come quelli kall'acenulo di Foraminiferi, di Radiolarii e di Diatomeo. Uno studio uicroscopico delle rocee di questa zona verrì pubblicato di unita allo studio dei terreni messinesi di cui preparo da ben lungo tempo i materiali.

Quanto alla considerevole estensione che assume il Messiniano in questa provincia dirò che sul lato orientale esso manca, nei dintorni della cittit, di quei grandi ammassi di gesso che lo distinguno dapertutto, e solamente racchinde la Srlenite in eristallini isolati, affiomanto da S. Nicandro sino a Larderia. Quindi ricomparisce ai Giardini ricchissimo di strati, li ammassi e di cristalli di gesso, estendentosi rerso Calatabiano dove come dissi mostra dei eristalli di zolfo. Sul lato settentrionale poi la formazione messiniana pò segruirsi lumgamente senza intermzione. Dalle ralli della Castanea si accompagna rerso Sillec u la selenite offre i suoi massimi depositi presso il villagrio Gesso: «uindi si continua al Serro, a Calvaruso, presso Saponara, nelle valli di Fondico muro o di Spadafora, a Rometta, a Gualtieri ed a S. Filippo, ricomparisce a Bafia ed a Patti, quindi a S. Stefano e poi aneo presso Tusa, compiendo cosi il giro della parte littoranea della provincia.

Nel porre termine alla deserizione della importantissima serie dei terreni miocenici del leggiano mi ì d'uopo accennare talune deduzioni moito rilevanti, che derivano naturalmente dai fatti precelentemente esposti. 
Gli ultimi tre piani mioceniei mostrano ad eridenza colle loro relative fame ehe la profonditit del mare ando mano mano decrescendo. lo che importa che il fondo sottomarino si andò rialzando grado grado. Noi vediamo infatti l'Ëlreziano molto riceo di Brachiopodi e di numerosi Briozoi che accemano a cinsiderepole profondita, il Tortoniano abbondante specialmente di Gasteropodi e di Lamellibranchi che dimostrano scemamento di profonditi, ridotta poi ad esser hen piccola nell'ultimo periodo in cui vive una fauna littorale e si depongono elecgli strati grossolanamente sabbiosi. Ma il gesso che succede accenna gia ad un deposito probibilmente d'acqua poco profonda e d'ordinario lacustre, ed íl calcare cellulare sopuastante non può essere che d'analoga origine. Tutto cio redesi bene, come dicemmo, a Bentestare e ad Ambuti.

Se volgiamo gli sguardi sul lato occidentale bisogna correre nel territorio di IIonteleone, e lì riconoscendo pressochè la medesima serie viene confermato il medesimo movimento ascensionale. Agli strati di mare profondo dell'Elveziano fanno seguito strati marini, di esturio e litenstri del Tortoniuno, che accemnano ul oscillazioni ed a definitivo imnalzamento del fondo marino.

In tal modo i sedimenti miocenici degli utimi periodi spinti fuori dalle accuc andarono soggetti all'azione delle onde ed alla erosione uneteripa. i quali agonti ne operarono la demudazione, che dorea essere più energica e quasi completa per le rocce più recenti, jerchè superficiali e meno estese, più mite invece per quelle di meno recente età che sono più profonde: difitti l'Elreziano is al certo più sviluppato, lo è meno il Tortoniano, meno ancora il Messiniano, tutti tre del resto non si mostrano che in luoghi speciali, formando dei ristretti lembi che eloquentemente ilimostrano la grande e generale denudazione avrenuta, per la quale i sedinenti plioce. nici poggiano assai sorente sul conglomerato langhiano, che cinge quasi tha tutt i lati la provincia reggiani.

Ma al cominciare dell'epoca pliocenica, come redremo, succedera un morimento inverso nell'Italia meridionale come altrove; e quindi lo rocce emerse e gii denudate si riimmergevano, esponendosi cosi lentamente e per una seconda volta alI'azione distruttiva delle onde, che dovera certamente demdare una buona porzione ancora di cid che eria rimasto nell'emersione. Ed eceo ad un primo periodo ed alle prime cause di distruzione, suceederne un secondo ugrtilmente importante pel rinnoramento di analoghe azioni distruttrici; eceo una ralerolissima ragione che spiega a sufficienza la ristrettissima estensione, la divisione in piccoli lembi c staccati degli ultimi piani del mioceno, tanto più limitati quanto più recenti; eceo da ultimo una nuora e ralerolissima ragione per delimitare il mioceno, per segmare la linea di demarcazione tra questo ed il plioceno. Difatti colla fine del Messiniano ha termine un'epoca di ascensione, dando lnogo ad un'epoca di depressione rimarchevolissima, quale si è la pliocenica; quindi a parte le considerazioni in rapporto alle faune, la natura e l'origine dei sedimenti, le condizioni assai diverse in cni si formarono, a disgiungere il mioceno dal plioceno intervione questa rimarcherole inrersione del lento movimento del fondo sottomarino, tanto piu che non soltunto la provincia di Reggio, ma evidentemente si muore all' unisono la Sicilin intiera, le altre provincie tutte della penisola italiana e probabilmente le vicine e le lontane regioni circummediterranee. 
Eeco perche a mio avviso la moposta di coloro che rogliono annettere il Messiniano al plioceno non ì sostenibile, invece ì darrero nu fatto per se stesso rimarchevolissimo il cominciare a deprimersi del suolo sopra vasta superficie, e piu importante ancora per le numerose, variate, e rileranti conseguenze.

\section{[II. FORMAZIONE PLIOCENICA.}

Chi si fa a percorrere la provincia di Reggio in ferrovia sull'unica linea ReggioCatanzaro, che costeggia il suo littorale, si avrede bentosto che quasi dapertutto si elevano delle colline plioceniche ora dimesse e con lieve pendio e regolare, ed ora elevate e gigntesche, ergentisi a grandi altezze, denudate, frastagliate e solcate in mille modi da valli e da profondi burroni. Qua sono potenti rocee marnose che le formano. e là invece sabbie e conglomerati che più spesso si associano alle prime, sottostando. sovrastando ovvero alternando con esse. Il colore bianco niveo che le distingue ordinariamente si modifica talrolta in giallastro, in grigiastro o in altro modo; ed in certi luoghi tu redi la formazione pliocenica a lembi staccati, o perchè interrotta dall'affiorure di terreni più antichi, o perchè ricoperta da depositi moderni; in altri Juoghi piu sovente continuarsi in esteso per lunghi tratti, talrolta poco discosta dalla spiaggia, altrove estesanente inoltrata nell'interno, elevandosi a rimarehevoli alterze.

Sulla costa occidentale le cose passano diversamente: per lunghi tratti tu redi ergersi a picco sulla spiaggia roce colossali: sono le rocce cristalline che assumono quell'aspetto imponente, e contrastano invece con quella forma orografica taluni tratti variamente estesi, nei quali alla spiaggia succedono delle pianure più o meno raste, ovvero per lieve declivio si passa a colline dimesse, che si elevano per gradi; qua è il quaternario alluriale o marino che assume tale conformazione, e dore questo manca, affiora il plioceno in lembi sempre di breve estensione, restando altrore ricoperto.

Sulle masse cristalline inrece la formazione pliocenica si estende rastamente, e si estolle ad altezze molto rimarchevoli anco poco lungi dalla costa. Chi si fa ad esplorare poi le elevate regioni dei monti regriani, chi percorre quei pianalti e chi traversa quelle giogaie, s'imbatte qua e li nelle rocee plioceniche, che si presentano con fossili abbondanti e ben conservati, e si elerano ad altezze inusate, poggiando sulle rocee di qualunque età.

Il terziario superiore adunque è senza dubbio il terreno neozoico più estest della provincia di Reggio. Esso forma quasi una zoua irregolare, raramente interrotta, che largamente cinge da ogni lato tutta quanta la provincia sin presso la spiaggia ed internandosi in taluni luoghi sin nella parte centrale, sulla clevata regione dei pianalti: lale fatto sarelne stato ancora più appariscente se potenti depositi quaternarî, specialmente sul lato occilentale, non si fossero sorrapposti qua o la occultando per considerevoli estensioni la formazione pliocenica.

Uno dei tratti più rimarchevoli, e senza dubbio importantissimo, della storia del plioceno calabrese, si è quello risultante lalla grande elevazione sul livello del mare, alla quale esso perviene. Difatti sormontando tutte quante le rocec di ogni 
ragione e di ogni età si fa vedere quasi dapertutto, costituisce le basse colline come le vette degli alti monti, si mostra sul lido marino come al centro rlella catena, ricomparisce dovunque con rariati caratteri, ma sempre con una fisonomia sua propria che $10 \mathrm{fa}$ riconoscere a prima giunta.

Gli strati dei rarî piani eocenici e miocenici si mantengono in generale ad elevazioni poco considerevoli, e solo eccezionalmente in taluni luoghi raggriungono ma elevazione massima di cirea 900 metri sul livello del mare nella proviucia di cui discorro. Cosi io posso ricordare benissimo dai lnoghi da me stesso risitati, che il conglomerato bartoniano c le rocec che l'accompagnano a Pentedattilo si elera appena a $360^{m}$, presso Stilo nom oltrepassa i $450^{\circ}$, e nel territorio di Motta, dore guadagna la massina elevazione, raggiunge appena 650m alla contrada Malascì.

In quel medesimo territorio le argille seagliose del Flysch, ed il calcare a Briozoi, con altri membri interposti, che formano il mioceno inferioro ('Tongriano) non ascendono al di la di questa elevazione; mentre sopra Antonimina e lungo la rotabile Gerace-Cittimora le arenarie a combustibile cogli strati sorrastanti a Pettini, Clipeastri, Nummuliti ed Orbitoidi, che formano un membro dello stesso Tongriano, si elevano sino a cirea $900^{\text {m }}$.

Il mioceno medio poi tra Stilo e Guardavalle ginnge oltre a $500^{\mathrm{m}}$, mentre presso Reggio a S. Auno e ad Orti si cleva a $600^{\mathrm{m}}$, e fin quasi a $700^{\mathrm{m}}$.

È imbile passare in rassegna i luoghi dove si trorano gli strati dei rarî periodi del mioceno superiore, dapoicchè essi in verum lungo raggiungono i $600^{\mathrm{m}}$.

Il plioceno invece è la sola formazione terziaria che si estolle sopra tutte lo altre: esso dalla spiaggia s"inoltra sin presso al centro della catema; sulla costa, e sovente nell' interno, forma da se solo alte colline; ma internandosi ed elevandosi ra sormontando le formazioni di tutte le età: così a Gerace, ad Ambutì e in altri luoghi sorrasta al calcare concrezionato; a Benestare giace sul gesso messiniano e sulle sabbie e marne tortoniane; nelle colline solua Siderno a frerace ed altrove poggia sugli strati dell'Elreziano; nei territorî di Stilo, di Guardavalle ece. siccome a Gallina, Valanidi, S. Agati, Nasiti, Terreti, Orti presso Reggio sormonta le scoscese ed alte colline del conglomerato langhiano; nel territorio di Stilo redesi qua e lit sul Langhiano e sull'Aquitaniano; nei monti che dal Capo delle Armi si estendono rerso Notta e più in alto, poggia sui varì nembri del Tongriano; nei dintorni di Stilo e presso Mrelito può redersi e sul Liguriano o sul conglomerato bartoniano, mentre poi alla marina di Brancaleone le mane plioceniche poggiano in qualeho luogo sul Cretaceo medio. Più ordinariamente poi nelle regioni elevate vertesi sorrastare all antichissime rocee, di cui è formata quella catena centrale: ad Agnana infitti e nei monti sopra Cauolo e sopra Motta giace sormontanto le filladi palleozoiche, siccome più vastamente estendesi sulle roece cristalline, così a Parigliana, a Cataforio, it Gallico, a Terreti, nei piani sopra Reggio (regrione Donato), nei piani sopra Seillat (Piani della Melia) ece. ece. In tal modo il plioceno del Reggiano redesi quntsi ormune, giace su tubte le formakioni, ricomparisce quasi a tutte le altezze dallar spiaggia alla centrale grogaia. L per ricordare talune delle altezze fiù ragguarderoli relativamente alle varie regioni, io nominero le poche seguenti: tra Stilo e crurdaralle si elera a circa 500 metri, nei piani della . Lelia raggiunge i $600^{\text {m; }}$ nelle 
colline che sorrastano a Canolo io ho riconosciuto i suoi più antichi strati a circa noo' mentre poi il membro più recente del plioceno nei piani sopra Motta trorasi a mille metri di elerazione, ed alla Regione Donato gli strati più antichi ragcrimgono l'elevazione ben rimarcherole di 1200 metri sul livello del mare.

La parte centrale di cuesta porzione estrema dell'Appennino, che forma la regrone dell'Aspromonte, costitnita lit un gruppo di monti, che s'inalza sul livello cencrale della ciogaia, si stacca in modo rimareherole da questa; la quale assumento superiormente una forma appianata serve di base al grupuo centrale che si estolle sino all'elerazione di 1958 in sul livello del mare.

Chi è ahituato a contemplare lo direrse conformazioni orografiche in rapporto alle diverse cause originarie o consecutive che le hanno determinato, non può restare indiflerente al limirare aneo da luugi questo estremo meridionale della catena italiana, siccome ne fui colpito io stesso sin da lungo tempo. Colui poi che arendo sormontato erti balzi e scoscesi burroni sarà gimuto all'elerazione di un migliaio di metri, da qualungue lato sia che ascenda la catena reggiani, si trorerà finalmente con sua grande sorpresit, su d' una rasta spianata, profondamente frastagliata in mille modi, e d'ogni lato cinta da valli profonde. Difatti i numerosi lembi di questo pianalto molto esteso portino d'ordinario i nomi locali di pinni o compr: cosi per addurre qualche esempio riconderò i piani della Melia tra Gerace e Cittanora, i piani di Aspromonte sopra Scilla, i piani sopra leggio, i campi di S. Agata, i campi di Sclani a cosi ria via.

La causa di tale conformazione nou sta riposta certamente nelle rocce cristalline, che formano la parte principale di quelle regioni elevate e centrali, ma, come si riconoser agevolmente acecendo sui luoghi, principalmente nei depositi pliocenici, i quali elevandosi sino a mille e millednecento metri, coi loro strati pressochè orizzontali, colla potente massa delle loro moce, colmando le disuguaglianze delle antiche formazioni, hamn dovuto costiture una spiamata, originariamente vasta, ma frastagliata poi dall' azione corrosiva delle aeque, che apportò sopra grauli tratti la completa denudazione del plioceno, ridonando ai terreni cristallini ed ai paleozoici quella forma a superficie irresolare che è loro propria.

Sono poche joi lo nozioni litologiche generiche che io devo dare intorno alla costituzione del pliocenn regriano. Iu warne, come già accennai, formano la parte principale dei diveri piani: esse sono quasi sempre molto calcaree e generalmente bjanchissime, orrero foruite d' una tinta sempre assai leggera, e per la commistione di materiali juiu o meno fini, fanno passaggio a vere sabbie, talvolta perfettamente sciolte quarzose, tall' altril cilcaree, e nell' uno e l'altro caso possono presentarsi cementite. E ordinariamente alla base della formazione che si presentano bene spesso dei conglonerati assai potenti, in eni varissimo è il volume dei ciottoli, che si associano piir o meno ar clementi sabiosi.

[l calcare is una mecia reramente eccezionale nel plioceno reggiano, e non vi si trova che in frammenti o in picenli lembi incalcolabili, in cui d'ordinario abbondano i Brachiopodi e i Colalli, come sopna rasta scala osservasi nella ricina provineia messinese.

Lar natura marusia della magrior farte hei nepositi, ma più ancora la costituzione 
delle faune che racchiudono, dimostrano nella generaliti dei casi, che le rocce plioceniche di cui discorro si denositarono in un mare assaj profondo; e basterebue per tale conchiusione l'analisi microscopica, la cuale discnopre ma miriade di Foraminiferi, che colle loro spoglie formano sovente una grall parte della massa rocciosa: il perchè questa viene caratterizzata e riguardata siccome di matura identica a quel fango, direi quasi vivente, che viene tratto dalle graudi profondita oceaniche, ricchissimo di spoglie di Rizopodi, e specialmente di Globigerine, siccome si presentano dorungue le marne plioceniche.

Le altre classi di fossili, dove esistono, confermano perfettamente tale risultamento generale, e specialmente i Molluschi, di cui un buon numero, creduto di specie estiute, rien oggi trovato in parte rivente ed abitatore degli abissi mediterranei ed nceanici.

Questi potenti depositi di grandi profondità plioceniche contrastano a merariglia cogli strati precedenti del Tortoniano, che dimostrano una fama littorale, o almeno di una profonditit poco considerevole, wa più ancora colle rocce che immediatamente li precedono, quali gli strati messiniani, formatisi dorunque in estuarî orvero in seno a laghi, paludi o lagune. E tale contrasto, che piì o meno nettamente si appalesa dorunque in Italia, promi sia una ragione di piir per seguare il limite tra il mioceno ed il plioceno, coll'amettere al terziario medio anco il Messiniano.

Non mancano intanto nel plioceno calabrese i luoghi dove gli strati dimostrano per la loro costituzione e per la loro fauna un deposito proprio littorale o d' uma mediocre profondita. Così non è da discutere sul conglomerato che comincia la serie, essendo questa una roceia eminentemente littorale. Nei rari periouli poi di quell' eproca, come di qualunque altra, doreano necessariamente esistere le coste, e percio dobbiamo trovarri oggi i lepositi littorali; solamente sta a vedere se furono rispettati dalla denudazione e se sia agerole rinreniri, o se affiomo da sotto gli strati piu recenti che poterono ricuoprirli. Il fatto sta pni che quantunque non siano comuni i depositi littorali, e meglio ancora i depositi di media profonditi, pure si possono indicare in taluni luoghi per ciaseun piano, e sopratutto pel piano superiore, che mostra dovunque essere le acque direnute generalmente poco profonde.

Finalmente l'esame stratigrafico del plioceno calabrese conduce matmalmente alla divisione in tre distinti piani geologici, che sono lo Zancleno (Segnenzi), l'Astiano (Pareto), il Siciliano (Doderlein). Queste tre formazioni, che rappresentano tre distinti periodi dell' nltima grande epoca terziaria, sono discordanti e distinte per fune considerevolmente diverse. Nella sezione prima e in varie altre vedesi chiara la discordanza.

Da ultimo veugo segnalando iu fatto palcontologico unolto rimareherole, fecondo d'importanti deduzioni. Tale fatto in modo comprensivo o generale pno cnunciarsi così: Le faune plioceniche della Calabria offrono nella loro generaliti delle differenze assai considerevoli colla classica fama del plioceno dell'alta Italia. Esso meglio che negli altri piani, manifestasi ad evidenzal nel plioceno madio civè nell' Lstiano.

La condizione di diversa profonditi delle aeque in eni contemporaneamente si costituirano tntti i depositi pliocenici, è la principale cagione di tanta diflerenza, a ci sarì agevole constatare in seguito per ciascum piano come cessando tale citusia

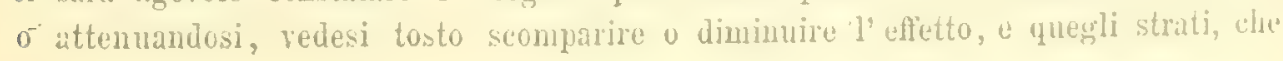


eccezionalmente si depositarono a medie o picenle profonditi, presentare tosto in parte o completamente la classiea fiuna pliocenier. Risultamento brillantissmo, che mentre Ia un canto ci dimostra ad evidenza la precipua cagione dellar grande dillerenza tra lia fauna plioeenica dell' alta Italia e quella dell' Italia neridionale, ei addita in rinest? nltima il complemento necessinio della prima.

\section{Pano Zincheano Seguenzet.}

Simenimio. Plipeno inferiores o antico di varî serittori.

a) Conglomerato. Il menuro inferiore del plioceno ì costituito da un conglomerato ali ciottoli cristallini, molto variabile nei stoo caratteri e nella sua potenzal. Lisso risulta costantemente dall' associazone di ciottoli granitici per la magriol parte, che si riuniscono a ciuttoli di sehisti cristallini rarî, di yegnatite, di sienite, di diorite ec. con ma considerevole quantiti di ghiaie e di sabbie grossolane.

I ciottoli cristallini bene arrotondati sono nel medesimo luogo di rarissimo volume, dalle jiù piccole dimensioni pervenendo sino alla ram grossczzid di parechi metri di clianctro; da lnogro a lnogo poi e' è anco grande rariabilitit, in moto che il conglonerate si riduce talvolta ad min rero sabbione e raramente ad nu cumulo di massi colossali. Isa gradnzone intermerlia, in eni gli elementi magrori ragriungrono al più un mezzo metro di diametro, ì quella cho si osserva commenente.

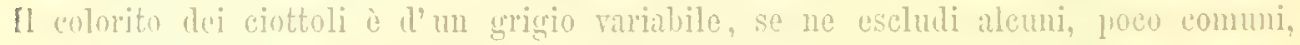
di color rosso mattone, formati di pegmatite di diorite od altro, perloceche il colorito

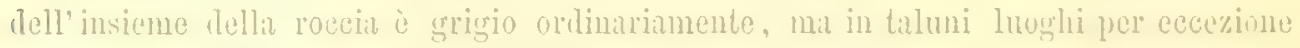
diviene rosso o rosso-brumo, ed in tal caso $i$ ciottoli tutti sono colorati estermamente dallosside di ferro.

I fosili come è naturale mancano generalmente in questa rocuia, ma in qualche liogo se ne raccolgono dei frammenti, come at Gerace.

Quinto allia stratificazione, il conglomerato pliocenico, non di rado la puescuta ben distinta, sopratutto in qualche lnogro dore s"interealano degli strati sabbiosi. Ma sovente non a possihile di riconosentri neanco un indizio di rem stratificarione, specialnente allorelie risulta costituito di elementi molto mrossi.

r. importante notare anco un fatto cecezionale che onserrasi presso Portiglinla. Lungo lia vil ehe conduce a quel villaggio si traversano per lungo tratto le subbive e

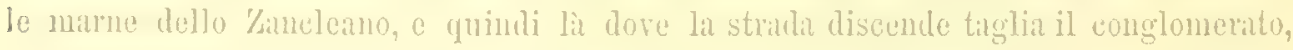
e con sorpresil si vedono in seno ald esso potenti strati di marua identica anla supratstante e colla medesima fama mieroscopicar. Ciò dimostra ad evidenza l'etir plioceniea del conglomerato.

Il decalimento di questa roceja arvenc sopra rasta scala, appunto perelé i snoi elementi non sono collegalti e mattemuti insiene da verum cemento, ma sono sol-

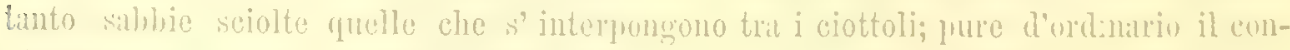
glomerato si mostra formando delle gramil pareti tagliate a piceo, e redesi lungo to balli o su pei monti costituire masse imponenti, il cui spessone ramabile raggriunge talloolta i 50 metri.

Jallia descrizione fatta del conglonnerato pliocenico risultil un' importante somishlianza, e molto grande, col conglomerato langhiano, il quale difficilmente potrì con 
sicurezza renir distinto dalla smile roccia plioceniur, se non si constatil l.z suai posizione stratigrafica. Cio è ben naturale, dacchie non juo rivocarsi in rubbio, che in gran parte i rar: conglomerati terziari più recenti delle Calabrie ripetono i lon materiali dai più antichi. Inoltre concorre un altro fitto a rendere molto più diffeile la distinzione. La grande denudazione arvenuta alla fine del lungo periodo miocenien arendo asportato generilnente il Messiniano, il Tortoniano e l'Filreziano, lit dove il conglomerato pliocenico mancin, le marne zancleane poggiano sul conglomerato langhiano; lo che accalde bene spesso, ed in til caso, rer la lacuna esistente, quest' ultimo trovasi al posto del primo e la rieggnizione diviene datvero ardul, pereni hisogna affidarsi a dati d'importanza minore e stuliare il problema con molta cura. Cosi l'erosione alla superficie del conglomerato, la diseordanzil colle sopristinti marne. la presenza sorente di strati argillosi o molassici in seno alla roceia dimostrann l'etir miocenica della stessa; mentre gli oprosti caratteri c la concondanza colle mame, che specialmente si puo osservare esattirsima in alcuni luoghi, dimostrano che trattasi della formazione plioecnica.

Quanto noi alla distribuzione topocrafica di questo primo rappresentante del plioceno, io diro dapprima che parmi proprio cridente, che esso won trorisi miformemente distribuito alla base dellil formazione, e che percio le mane o th sabbie soprastanti poggino bene spesso soprar altre rocce e sovente, come dissi, sul conglomerato langhiano.

Io reputo siccome spettante a questo membro aleuni strati sabbiosi con grandi massi inchusi, che troransi nelli valle dellinmunziata a nord di Regrgio. siccome nei burroni a sud delli Valle Amendolea, ed al Cipo Palizzi, dore roce analoghe e con grossi massi sottostanno alle mame zancleane.

Ifa il conglomerato di cui discorro sviluplasi con regolinitic e potentemente sul lato orientale della prorincia. Difatti redesi con sorprendente regolariti sottostare in concordanza colle marne zancleane lungo la valle al di lim di Giolosa-fonica. Torrente del Messinese; ivi il conglomerato si urge a pieco sulla valle e nella parte superiore è colorato in rosso. Da quel luogo andando verso sud il conglonerato pliocenico trorasi estesamente sriluppato, così nelle colline di Siderno, alla contrada Crudeli, quindi a Gerace ed a Portigliola; poi sriluppasi in modo rimareherole il Benestare, dore diviene di colore rosso-vivo e dia li si estende ampiamente e.potentemente, costitnendo i monti sopastanti, e sino a molta distanza ricuoprendo lo grandi masse di gesso messiniano.

b) Sabbio e Ifarne. Due rocec ben diverse e d'orlinario hen distinte formano il membro più importante e superiore dello \%incleano, cioè le sahbie o le marne.

Le sabbie zancleane sono sempre quarzose e d'orlinario perfettamente sciolte, bianche, grigiastre, orrero giallice, ma pel miscuglio di fossili in quantiti rariabile divengono piil o meno calcarifere e talmalta auco cementate e ricele di materia calcarea, siccome in taluni luoghi somo decgli strati di rerd arenaria alternanti con istrati sinbiosi.

Variabile ne è grandemente lil funcra delle salbie le quali da un canto fanno talvolta transizione verso il couglomerato per la grossezza dei matcriali che le 
costituiscono, altra rolta assai fine e calcarifere si arricinano e si collegano alle marne, ma più ordimariamente sciolte, costituite di granelli piccoli e quarzosi sono rere sabbie mobili.

Le marne poi formano ma roceia molto ben nota in Calabria pei suoi caratteri tutti e pel suo particolare aspetto: essia è molto estesa, sopratutto sul lato orientale. e forma delle colline aride, infinttusse, sovente ripidissime e disginnte da profondi burroni ingenerati dall'azione erosiva delle aeque. Questa principale raccia dello Zilucleano i più sorente bianchissima, ma spesso passa al grigiastro, al viallastro, e talvolta is zonati pralellamente alla stratificazione. Quanto alla sua costituzione essa ì sempre ricea di calcare, e fir passaggio a vere rocce di calcareo tellero, si stempera fiù o meno facilmente nell'acqua, c ner levigazione dà un residuo sabbioso variamente abjondante, costituito in parte da fina sabhia quarzoso-micacea, ed in parte dai gusci calearei di Foraminiferi rariatissimi, tra i quali predominano le Gmbigcrine e le omuline; ma i teneri gusei di questi Protozoi galleggiano allorchè la marna viene stemperatib nell'aequa, e quindi rengono da essa asportati o più non si trovano nel residuo della lerigazione; andrebbero quindi intieramente perdnti se non si ponesse cura di racoglierli alla superficie dell'itequa stessa.

Queste marne ealcaree, siccome gia dissi precedentemente, sono dei reri fanghi depositatisi nelle profonditi ocenniche, affatto identici a quelli dei mari odierni, dimodochè la loro massa risulta jar la maggior parte formata dall'aceumulo di organismi, e quella parte considerevole di calcare che all'analisi meccanica della roceia non si presenta sotto folma di gusci, è dil riteuersi siccome tritume dei gusci stessi dei rizopodi.

Le sabbie e le marne non formano due distinti membri dello Zancleano, ma costituiscono invece due diverse forme litologiche che assume la medesima zona; difitti occorre sovente di vedere la sostituzione dell' una roccia all'altra, tanto nel tempo come nello spazio.

In taluni lnoghi infatti le marne si alternano colle sabbie, come pno redersi a Gerace; in certi altri le mame sostituiscono le sabbie in ordine topografico e ri si nota sovente la graduale transizione tra le rocee. Cosi a Vigna di Mare, Terreti, Nasiti presso Reggio, lo Zancleano è eninentemente sabbioso; mano mano che si studia in contrade piì meridionali si osserva che fa passaggrio alle marue, finchè presso Melito tra il Cupo Palizzi ed il Capo Spartivento ece. diviene costituito esclusiramente di marne potentemente svilumbate.

Ila alla distinzione litolosica el alla concernente transizione, che ho stabilito, si collega un altro fatto d'interesse geologico molto piin rilerante. Lo Zancleano nei suoi strati non contiene sempre la medesima fanna: in talmi luoghi le sne rocee sono ridondanti di fossili srariati in srin parte spettanti ai Mollusehi, ed invece più comunemente l'occlio nulo le trora prive di resti organici, e bisogna il microscopio per ricunoservi quell'immensa serie di Foraminiferi, che forma gran parte della roceia, senza mescolari ordinariamente a resti di Molluschi. Tale marcatissima distinzione della fanua segue quasi costuntemente la dirersa qualiti della roccia; dimodoche le sabbie sono L'ordinario siacimento dei Molluschi, lo marne invece risultano dall'accumulo inmenso di foraminiferi. Rarissimanente occorre di raccogliere taluni 
Molluschi nelle marne, e troransi talvolta delle sabbie costituite quasi per intero da soli Foraminiferi. Ecco adunque lo Zancleano con due distintissimi facies, che per la natura delle roce e per lo diverse faune ci offrono ad evidenza i depositi degli ahissi oceanici e i sedimenti delle piccole profonliti: i primi reri anmassi orgauici, i secondi, rocce di aggregazione.

Ma naturalmente tra i depositi costieri e quelli delle grandi profondita doveano costituirsi anco dei sedimenti a profonditi intermedie, i quali collegando insieme $j$ primi ai secondi, necessariamente partecipar doveano rlegli uni e degli altri. Difatti nella formazione zancleana troriamo rocce sibbioso-marnose, Ie quali offrono una fauna mista di Molluschi, di Foraminiferi o d’altre classi, che dimostra la mediocre profonditi delle acque in cui rivea, e dore si originarono i depositi che la racchindono. Ed eceo un terzo facies dello Zancleano, ancor esso abluastanza distinto. quantunque intermedio tra $\mathrm{i}$ due per le circostanze originarie rivelatici dai caratteri litologici e paleontologici.

Queste tre maniere di presentarsi dello Zancleano possono talvolta incontrarsi ordinati successivamente nella disposizione topografica: ed io posso adiure come esempio molto istruttivo a tale riguarlo, quello stesso che precedentemente ricordara per provare il passaggio dalle sabbie alle mame. Sulle piamme della Melia, che giacciono sopra Scilli, elevate scicento metri sul livello del mare, si estenlono grossolane sabbie dello Zancleano: sono esse viche delle spoglie di Molluschi costieri o si estendono amplamente associandosi a mame sui monti e lungo le valli, che sovrastano a Villa San Giovanni. Quelle sabbie a lembi staccati si rireclono qua c là, e compariscono ricchissime di fossili soprat gli Arehi nuesso Regrio alla contradu Vigna di Mare, o così ria via sino a Terreti e Nasiti, celebri localitì sopra legegrio, dove le sabbie si fammo più fine, ai Molluschi lamellibranchi si associano i Brachiopodi, ed una ricea fanna di Briozoi e di Foraminiferi, cio che mostra trattarsi di sedimenti originatisi in mare più profondo. Continuando l'esame rerso mezzogiono, come gia dissi, si passa grado grado alle marne estesamente sriluppate, che formano i sedimenti di alto mare del periodo Zaneleano. Così dagli strati della Melia e di Vigna di Mare in seno alla formazione cristallina, e pressochè costieri, si passa ai depositi della zona coralligena di Terreti e Nasiti, e quindi alle marne della regione pii meridionale, che sono i funghi degli abissi oceanici.

Il piano Zancleano oltrechè si presenta nel Reggiano molto sviluppato in potenzal ed estensione, è desso che si eleva sul lirello del mare ad altezze rimarcherolissime, anzi costituisce i sedimenti piu alti della catena dell'Aspromonte. Difatti dal lato orientale le sabbie e le mirne zancleane nei territorì di Stilo e di Guardaralle si elevano sino oltre quattrocento metri; nei piani sopra Agnana e Canolo raggiumgono norecento metri, che vengono oltrepassati poi nei piani tra Gerice c Cittanorit. Verso il lato meridionale il plioceno antico pal che non raggiunga considerevoli elevazioni; invece sul lato occidentale perricne alla massima altezza; a Terreti grimgu costituendo l'alta spianata di Monte Govi sino a 749 metri, ad Orti redesi i 746 metri, ai piani della Melia sopra Scilla oltrepasia i seicento, e perriene al massimo di milleduecento metri nei piani sopra Reggio, alla regione Donato.

Lo spessore dei depositi Zancleani is consilerevole, raggiungendo in taluni luoghi 
la potenza di circa 300 metri, sia sotto forma di sabbie, sia ancora colla forma piu comm ri marue, potenza che diviene poi imponente se a queste rocce si aggiunge ancora quella del conglomerato. Bisogna visitare le colline che si ergono ripide sopra Siderno ed oltre Gioiosa-Jonica per restare sorpreso della vastiti di quelle marne nivee, che si estollono talvolta ripide en inaceessibili con una potenza sorprendente. Cosi nei territorî di Condojanni, di Benestare ed altrore sul lato orientale; ma non meno jotenti sul lato occidentale sono i gircinenti dei piani della Melia messi in ovilenza dai profomli e lunghi buroni che riescono nella Valle di Fiumara, siceome le sabbie di Terreti, di Nisiti e d'altri luoghi.

Volendo dare un cenno ilella topografica distribuzione dello Zancleano, cecomi a ricortare i piu importanti luoghi. Nei territorî di Grardavalle e di Stilo si mostra molto esteso e sale sino nei dintorni di quest' ultimo comune sormontando e le mioceniche e le roce coceniche tutte. Livi che tra Stilo e MLonosterace sotto forma di sahhic grossoline racehinde una fanna di Pettini, di Ostriche ece. che distinguesi siccome la più littoranea di tutta quanta Ia provincia. Da quegli estremi confini il plioceno antico si continua verso mezzogiorno quasi senza interuzione, ma d'ordinario sotto forma di lembi consecutiri più o meno rasti: cosi nei territorî di Stignano, di liace, di Rocenlla Jonica cee. dore sono specialmente le marno che assumono un grande sriluppo. Tali rocee pero divengono continue, assai potenti, e si elevano e s'intermano molto come dicemmo, associandosi al conglomerato sottostante nei territorî di GiojosaJonica, Siderne, Agnana, Gexace, Portigliola, Contojanni, Ardore, Benestare, Bianeo.

Le argille seagliose e le arenaric di antichi perionli terziarî formano quindi ma considerevole intertuzione, e poscia le mane zancleane ricompariseono alla marina di Brancalenne, sormontano il conglomerato miocenico al capo Spartirento e formano le ripinte colline costegsianti la spiaggia simo al capo Palizzi, internandosi più o meno. Subisce poi considereroli interruzioni prodotte da rocee piì anticho che si estendono Limn alla costa; dimothechè il plioeno forma dei lembi staceati alla marina di Borat, presso la fimmina Ammendolea e nei dintorui al Melito. E mentre sulla costa meridionale sono lo rocep piir antiche che predominano, appena oltrepassato il capo delle Armi ln Zancleano scomparisce sotto unomi depositi di rocee piir recenti, quindi ricomparisce sriluppatissimo nel ternitorio di lieggio: a Talanidi, Crallini, S. Agati, Parighiana, Nasiti, Terreti, Arohi, Orti ece. Nelle valli ehe precerlono Villa S. Giorami se ne vertome dei piceoli lembi che poggiano sulla formazione cristillina; quindi esso sriluppasi rastamente nella valle di Fiumara, dove coronando i monti che lia fiancheggiano s'inoltri a formare gran farte dei piaui della alelia. Nella regrone poi piu elevata si fir rulere nei pianalti sopra Regrgio, come gii dissi jrecedentemente, all'elevazione di 1200 metri, alla regione Donato.

Finalmente nel mio ipprezzamento trovo di grande riliero e di molta importanza i carathri desumti dalla forma elue assume nelle Calabrie lo Zancleano. La sua

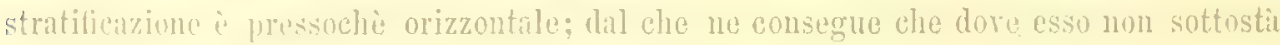
ad altri trirenj, come acearle nelle regioni elevate, lit sua superfieie si presentir spianata, o quineli la contrada acquista la forma di pianalto, i sedimenti dell'antico plinceno colla lorw inolta potenza arendo colmato di strati orizzontali le ineguaglianze dei terreni uristallini e li pio reconto eth. 
Ma siffatte spianate si mostrano costantemente a piecoli lembi, a brani sparsi qua e là, e disgiunti da larghe valli, da profondi burroni e talvolta da grandi estensioni di terreno variamente accidentato, mostrando ad evidenza che esse non sono che i frammenti, i resti d'una vasta spianata che estendevasi in largo e in lungo cingendo il centrale Appennino dell'Aspromonte. Difatti i piani della Melia trorann la loro continuazione in un punto pressochè matematico, la roccia che ergesi sopra Orti, anch' essa spianata alla sommith, e poi il Monte Govi sopra Terreti colla medesima conformazione, e così via via. Sul lato orientale al modo stesso si redono lembi sparsi, sempre piu elevati, mano mano che si avricinano alle regioni centrali: e per addurre qualche esempio ricorderò $\mathrm{i}$ lembi di sabbie e mame zancleane che orribilmente scoscese s' inalzano sopra Agnana di fronte all'alta roccia che ergesi presso Gerace, entrambi colossali frantumi degli strati zancleani che si estendono nelle spianate sopra Canolo, raggiungendo oltre $900^{\mathrm{m}}$ di elevazione. La denudazione adunque è quel complesso fattore cha ha eroso ed asportato massa di rocce cosi ingente, che ha tolto via la continuazione di quegli strati, formanti i minimi e Iontani lembi rimasti a testimoni duraturi, cioè quella continuazione che colmara gl'immensi vuoti; è dessa che ha modotto cosi le larghe valli, che ha profondato i burroni, che ha solcato e corroso in ogni luogo i sedimenti dell'antico plioceno.

Dovrei riservarmi a trattare dei rapporti stratigrafici dello Zancleano coll'Astiano nel seguente paragrafo, dopo aver descritia quest' ultima formazione; ma interessami molto di mettere in evidenza, pria di por termine alla descrizione dello zancleano. come esso si presenta distinto, separato, e perfettamente discordante dal soprastante plioceno Astiano.

E di vero, tenendo in calcolo quanto fu detto precedentemente, il plioceno antico ascende sino ad elevazioni considerevoli, assumendo l'evidente forma dei resti sparsi di un'immensa spianata, a strati pressochè orizzontali, che venue distrutta, o tra i cui sparsi frammenti non resta che il gran vuoto dell'immensa massa di rocce asportate. Così per addurre un esempio palpabile e facilmente accessibile, ricorderò uno di quelli precedentemente addotto. Il geologo che si farà a risitare le alte colline che corrono a distanza dalla spiaggia, lungo la costa che da Reggio dirigesi verso settentrione. deve necessariamente accorgersi che i terreni di Nasiti, Terreti, Monte Govi si collegann colla roceia di Orti, cogli ampli strati dei piani della Melia, originariamente formanti un tutto uniforme, che le larghe e profonde valli, e gli orridi burroni che s'interpongono devonsi alla denudazione, la quale tolto via il plioceno, ha interessato anco il mioceno e sovente ha messo allo scoperto la sottostante formazione cristallina.

Vediamo ora qual posto occupano in rapporto agli strati zancleani le rocce dell'Astiano. Chiunque conosca la originaria e consecutiva topografia dello Zancleano non pud non addarsi tosto della discordanza rimarchevole tra le due formazioni. Ed io ricorderò i fianchi della valle dell'Annunziata presso Reggio, lì sulla destra, presso Vito ed al di sopra: vedonsi le marne astiane estendersi sotto gli strati quaternarî e fiancheggiare in qualche luogo le sabbie zancleane; lo stesso dicasi del lato sinistro della valle e delle marne di 13otte. Ma quella ralle risulta dalla denudazione; in alto di essa si ergono le rocce di Terreti e di Monte Govi tagliate a picco; dunque gli strati astiani si deposero allorchè le depressioni in seno agli strati 
zancleani erano gla formate. Ecco perchè sovente i frimi non mostrano relazione di sorta coi secondi, invece si sviluppano accanto ad essi; ecco la migliore delle discordanze. Pure in molti luoghi occorre di vedere le due formazioni sovrapposte erl allora palesemente discordanti. Mi basta di ricordare la sezione prima tra Monosterace e Stilo, e rarî luoghi dei dintorni di Reggio.

Questa curiosa maniera di sriluppo delle due formazioni cioè che l'una si è deposta generalmente nelle depressioni o meglio nei vuoti che la denudazione produsse nell'altra, ha indotto in gravi errori rarî geologi. Cosi. il Fuchs la creduto che presso Gerace le marue che stanno in basso del paese, sormontate talvolta da sabbie non sieno che la continuazione rotta e scoscesa delle rocee che stanno al di sopra. ed invece queste sino all'ultimo strato sono zancleane, quelle invece astiane. La costituzione litologica diversi, i fossili diversi, la diversa successione stratigrafica 10 attestano al evidenza: a Gerace insomma, come nei dintorni di Reggio, come nella Valle dell'Anunziata, come dapertutto nella frovincia, l' Astiano si costitui dopo che lo Zancleano renne profondamente denudato, e quindi dovette deporsi nelle depressioni originatesi.

Or siccome la demudazione dovea necessariamente esercitarsi pii energica verso la periferia, i lembi dello 'Zancleano da essa rispettati 's' incontrano nell' interno. e i ruoti prodotti all' esterno troransi colmati dall'Astiano: cosi presso Gerace. Siderno, Monosterace, Ardore, Bovalino, Bianconuoro ece. e sul rersante occidentale parimenti, come si osserva a Gallina, nella Valle dell'Annunziata, a Villa San Gioranni eec. in somma nel Reggiano quasi dorunque.

Siffatta disposizione coadiurata dall'analoga natura delle rocee delle due formazioni, e benanco talrolta dai fossili littorali, racchiusi nel membro antico che sta piì presso dell'antica costa, dai fossili abissicoli rachinsi nel membro più recente. concorre a rendere completa la illusione, facendo credere che l'mo sia la continuazione dell'altro; e bisogna perseverante esame, e di molti luoghi, per convincersi di yuanto io eredo di avere dimostrato.

II mio egregio amico prof. P. Mantovani ha potuto osservare la discordanzi tra i due membri in qualche luogo dei dintorni di Reggio; ma ne fu dubbioso per qualche altra contrada. Hgli notava inoltre come l'Astiano che incontrasi sulla sinistra della rotabile presso T'erreti. non olfre rapporti di sorta collo Zancleano che si Alera poco al di lia a costituire il Monte Govi.

Questo filto rientra nella generale interpretazione che jo ne ho dato, e non pui sfliegarsi senza ammettere 1 ma perfetta discordanza tra i due tereni. Come può mai mifiatti concepirsi la deposizione dell'A stiano della rotabile Regrio-Terreti, se non si ammette la precedente demdazione dello Yaneleano, che in istrati orizzontali costituisce li presso l'alto Monte Govi, c che dovea estendersi amplamente e direi quasi indefinitamente?

Io termino facendo notare che la distinzione di questo membro antion del flioceno nella urovincial di Regyio, come in Sicilia, viene corrobors's da fatti molto rilevanti, che stamno in comessione colle relarioni stratigrafiche, colls distribuzione topografica, coi risultamenti paleontologici. I primi due ordini di doemmenti furoun whiu precelentemente esaminati: scguiranno $i$ fatti relativi alla paleontologia. 
I lavori del Capellini, del Foresti, del Manzoni dimostrano che anco nell'Ttalia unedia bisogna distiuguere e separare un plioceno antico; ed in modo speciale ricordn le ricerche sul plioceno di Castrocaro, e specialmente lo studio dei mumerosi Briozoi. dal quale il Manzoni ne ricavara esser quella una veria fama intermedia, per le specie di cui è costituita, tra la Tortoniana e l'Astiana. Per tante ragioni dunque bisogna distingnere un plioceno autico, che, a causa di prioriti, fi d' nopo chiamare Zancleano. Il Mayer, senza buone ragioni invero, ha voluto mutare talre denominazione in quella di Messiniano, riferendovi taluni depositi varî di cxemania. d'Austria, di Francia ed anco dell'alta Italia; ma un esame comparativo ha dimnstrato di poi chiaramente, che gli strati messioiani del prof. di Zurigo non som sincroni degli strati zancleani, e solamente il conglomerato, primo membro di questi. par che sia coetaneo ai conglomerati che terminano quella serie: del resto ho dimostrato come tale roccia non possa disgiungersi dall'antico plioceno. Da cio consegue che la denominazione imposta dal Mayer non puo ritenersi pel nostro antico plioceno. come quella che non ranta prioriti, e, cio che è peggio, pecca di macronismo.

Paleontologia. - Nel dare uno sguardo sommario e generale alla famia tanto importante dello Zancleano calabrese, fa d'ropo esaminarla dapprima nei tre distinti facies, coi quali il terremo si presenta; essendochè i fossili sono appunto quelli che formano il primario, il piu importante fattore di questa triplice distinzione, dipendente dalle fisiche circostanze in cui ogni strato si costituiva e precipuamente dalla profondita, attestata a meraviglia da essi.

E primieramente non fa d'uopo in questo esame tener calcolo delle zone in cui 10 Zancleano si riparte; essendochè, come dimostrai, le marne e le sabbie non custituiscono che unica zona nella quale le dne rocee si altermano, si succedono, si rimutano e si sostituiseono in tutti i modi.

Il conglomerato che mantiensi distinto, non racchiude che in qualche luogo soltanto dei rariframmenti di fossili, d'altronde spettunti a specie proprie delle soprastanti sabibie. Il primo facies che naturalmente si presenta a considerare è quello in cuila roccia grossolanamente sabbiosa offre una fama che meglio si avvicina ad un'associazione dei Molluschi littorali. Io assumo come tipo di tale natura le sabbie fossilifere giacenti tra Monosterace e Stilo, dove le specie sono poco numerose ma profusissime, dimodochè raccolgonsi in grande quantitì. I generi che costituiscono questa piccola fauna sono i seguenti: Perna, Lima, Limea, Pecten, Janira, Hinnites, Spondylus, Ostrea, Anomia, che colle loro specie ancor viventi attestano la piccola profondità del mare in cui vivea quell'associazione di Lamellibranchi. Lo altre classi animali vi hanno scarsissimi rappresentanti.

Altri luoghi dove lo Zancleano presenti precisamente i medesimi caratteri di In deposito littorale, come redesi a Stilo, io realmente non ne conosco; ma i giacimenti che più vi si approssimano sono quelli dei Piani della Melia e di Testa del Prato o Vigna di Mare sopra gli Archi: in questi due lnoghi ai fossili di Stilo, cioè alle medesime specie di Molluschi, si associano in quantiti poco considererole i Crostacei, i Briozoi, gli Echinidi, tra i quali specialmente i Briozoi dimostramo che nou

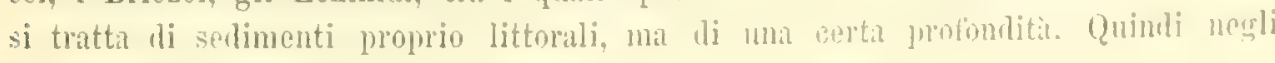


accennati depositi si ha realmente un vero intermedio tra la forma littorale a soli Lamellibranchi, che costituisce il primo facies, e i depositi di cui trattero tosto, che formano il secondo aspetto o facies dello Zancleano.

Senza che manchino i Molluschi dei depositi testè descritti, la fauna si accresce di molto per l'aggiunzione di varie altre classi animali, mentre d'altro canto la roccia risulta di sedimenti molto pii fini: è cosi che lo Zancleano acquista un nuoro aspetto in molte contrade, e si per la roccia come per la fauna costituisce realmente un nuovo facies ben distinto dal primo.

La fama si accresce di abbondante numero di Brachiopodi spettanti ai generi Terebratula, Terebratulina, Megerlia. Argiope, Rhynchonella, Crania. Dei Crostacei abbondano grandemente i Balani e qualche altro genere di cirripedo vi è raro. (ili entomostracei vi sono sparsi con qualche abbondanza. Ma la classe che merita la principale attenzione, si è quella dei Briozoi, che assume un grande e rimarchevolissimo sviluppo. Non $\mathrm{r}^{\prime}$ ha fossile sul quale tu non vi osservi le colonie di nua qualche Membranipora e di ben numerose Lepralie associate a tanti altri generi the virono costantemente fissi; non $r^{\prime}$ la pizzico di sabbia nella quale tu non trovi i ramuscoli delle Salicornarie, delle Scrupocellarie, ovvero Eschare, Crisie, Idmonce, Hornere, Filisparse, Tubulipore e bene spesso molte di queste insieme. Sulla valva inferiore d' un Hinnites crispus ho potuto numerarvi oltre quaranta specie di Briozoi tutte esattamente determinate perchè conservatissime.

Questa fauna di alto interesse per la nostra geologia, per gli studî da me sinora fatti si compone del numero rimarchevolissimo di oltre centocinquanta specie ripartite in trentadue generi.

Si aggiungono ancora degli Echinidi in iscarse proporzioni, tra i quali è rimarchevole una grande specie di Clypeaster (C. pliocenicus); ed in fine compariscono i Foraminiferi in proporzioni abhastanza cousiderevoli.

E qui bisogna ricordare, quantunque non esclusiva di questo piano, l'Amphistegina Hauerina, specie estremamente comune nelle sabbie zancleane, che diviens sempre piì abbondante nelle assise superiori, dove talvolta giunge a tanto da costituire quasi da se sola la roccia sabbioso-calcarea, cosi a Terreti e sopra Gerace: In tal caso si ha appunto in Calabria, come si ripete in Sicilia, ad Altavilla presso Palermo ed a Giardini presso Messina, una roccia in tutto identica, e coetanea alla roccia lenticolare di Parlascio, di S. Frediano, di Castrocaro e di altri luoghi di Toscana e del Bolognese.

Quest'associazione cosi variata di spoglie animali dimostra un mare che dovea avere una alquanto considerevole profondita. Difatti il Balanus tulipiformis che vi è profusamente sparso vive nella zona coralligena; la grande fauna di Briozoi, i Brachioprodi e i Foraminiferi concordemente dimostrano che trattasi di sedimenti formatisi al una certa profondita, che ben può esser quella della zona coralligena, essendo questa spessissimo assai ricea dei rappresentanti di tali classi.

I luoghi dove questo facies dello Kancleano si presenta colla sua forma veramente tipica sono due, ed essi per tale fatto diverranno veramente celebri: intendo dire 'lerreti e Nasiti, che stamo sulle alte colline poco lungi da Reggio.

Cosi ancoril vedonsene lembi a S. Agata, presso Valanidi e sugli altipiani della 
Regione Donato. Le rocce su cui si erge Gerace e quelle che ripide s' innalzano al di sopra di esso, si connettono col facies che esamino; così ancora quelle che si estendono sui piani che sovrastano ad Agnana ed a Canolo.

Sin da qualche tempo fu fatta l'osservazione che nei depositi di Terreti non trovansi dei Gasteropodi, ma il Costa $(0$. G.) risitando quei luoghi asserisce di aver trovato dei Vermeti. La mancanza dei Gasteropodi è un fatto generale che si estende nello Kancleano di tutta la Provincia di Reggio e parimenti in Sicilia; ma essa non è assoluta: io vi ho raccolto varie Scalarie e qualche Patella, che però vi sono di una rarita grandissima. La S. retusa è la meno rara ed in belli esemplari. Il difetto accennato non si limita soltanto ai Gasteropodi, ma bensi a molti gruppi di Lamellibranchi: difatti consultando il seguente elenco si vede che questa classe è rappresentata da abbondanti Pettinidi ed Ostreidi, e da qualche resto di altro gruppo affine; vi manca perciò la maggior parte delle famiglie.

Questo difetto e quello dei Gasteropodi, costanti dapertutto nel plioceno antico del Reggiano, rendono la fauma dei Molluschi estremamente incompleta perchè rappresentata da poche famiglie. A volere indagare la causa del difetto di tanti diversi gruppi, io credo di vedere nella costanza assoluta del fenomeno un fatto importante, pel quale non puo ritenersi originaria tale mancanza, essendochè i tre facies dello Zancleano e le loro gradazioni intermedie addinostrano abbastanza le variate condizioni fisiche e specialmente di profondità in cui si deponevano quegli strati; or non è credibile che in tanta diversità del mezzo, dallo deboli profondita littorali alle grandissime dell'alto mare, i Molluschi fossero sempre rappresentati dai Pettinidi, dagli Ostreidi e talvolta dai Brachiopodi, senza che si fossero mai associate a veruna profondità nè i Gasteropodi nè le aumerose altre famiglie dei Lamellibranchi. Da cio io sono indotto a conchiudere che tali gruppi doveano esistervi, ma che le loro spoglie non si conservarono.

Varî fatti più immediati parmi che vengano in appoggio a questa conchiusione: 1. I Molluschi esistenti sono di quelli le cui spoglie trovansi meglio conservate dapertutto nei sedimenti; difatti le Lime, i Pettini, le Ostriche, le Anomie, le Terebratule trovansi sempre in perfetto stato; e viceversa i gruppi che mancano sono quelli che bene spesso incontransi allo stato friabile. 2. Non di rado poi occorre di trovare impronte e modelli di Gasteropodi e di Lamellibranchi non rappresentati. e quantunque questo sia un fatto non comune, pure esso non attesta meno la distruzione avvenutavi dei resti di quelle famiglie. $30^{\circ}$ E un fatto ovvio quello d'incontrare dei sedimenti sabbiosi, nei quali sono conservatissimi le Lime, i Pettini. le Ostriche, le Anomie, le Terebratule, e tutti gli altri Molluschi si vedono in abbondanza ridotti allo stato, come suol dirsi, di calcinazione, cioè friabilissimi. Ma $v^{\prime}$ ha ancora di più: nei dintorni di Messina si puo proprio assistere alla scomparsal delle spoglie di quei tali Molluschi. Le sabbie quaternarie in certi luoghi sorrabbondano di fossili conservatissimi; più in lit tu vedi che i Pettini, le Ostriche, le 'Terebratule e i loro affini si conservano parimenti; ma gli altri gruppi si alterano, si disgregano, cadono in polvere. Percorri ancora qualche tratto di suolo, e quelle spoglie mancano intieramente, restandovi solamente i Mitilidi, i Pettinidi, gli Ostreidi, i Brachiopodi. Mancano adunque a mio vredere tanti gruppi di Molluschi 
nelle sabbic zancleane, non perchè in quei mari non vissero, ma perchè le loro spoglie non si couservarono. I fatti e le ragioni testè addotí possono probabilmente applicarsi in molti altri casi; e per recare un esempio ricordero le sabbie elveziante nelle quali come nelle zancleane non si redono conservati che Pettini, Ostriche e $^{-}$ Terebratule; ma ivi sono piu commi le impronte e i modelli di Gasteropodi e di varî Lamellibranchi, quindi piì immediata la prova dell'esistenza di tutti i gruppi nella fauna che risse a quell'epoca nei mari italiani.

Se da questo esame generale dei Molluschi e della Ioro varia conservazione passiamo agli altri gruppi, troviamo pochi resti di mammiferi che sono indetermiuabili, pochi denti di Squalidi ben conservati, ma con la radice distrutta; tra i Crostacei i Cirripedi sessili molto commi sono d'una conservazione perfettissima, sinanco col loro colorito siccome gli Entomostracei; dei Vermi, pochi Serpulidi in perfetto stato: quindi lo sterminato numero dei Briozoi che invade tutta la formazione e che oftre tntte le specie imparegiabilmente ben conservate, dimodoche per l'abbondanza e pel buono stato di essi lo Zancleano calabrese, specialmente nelle localita di 'Terreti e Nasiti, costituisce uno dei migliori giacimenti dei Briozoi terziarii italiani; quindi gli Echinidi e i Foraminiferi anch'essi in perfetta conservazione.

Un'ultima osservazione rigurda i coralli. Questa importantissima classe non mi ha offerto nello Zancleano che qualche incompleto modello; ed io, messa anco in calcolo Ia profonditi alla quale si depose lo Zameleano a Briozoi, sono di parere che questi fossili venuero distrutti siccome i Gasteropodi e gli altri gruppi dei Molluschi.

Il terzo facies dello Zancleano ì distintissimo, è il più esteso, e viene caratierizzato bene dalla natura della roceia, che ì una marna calcarea, talvolta piu o meno sabbiosa, che non presenta quasi mai dei fossili visibili ad occhio nudo.

La famia microscopica che la roccia racchiude e che costituisce buona parte del suo rolume è l'altro carattere distintivo. Qnesta fauna è quasi intieramente ed esclusivamente formata da Foraminiferi; ma bene spesso a tali resti si associano yuelli di molti Entomostracei. È ben raro il caso in cui la roccia contenga qualche fossile visibile ad occhio nudo, e sempre trattasi di un Pettine di un Ostrica o di qualche Brachiopodo. Così mi è occorso di raccogliere dei frammenti della Janira Rabelliformis, dell'Ostrea tenuiplicala e della Rhynchonella bipartita nelle marne che si estendono in colline sulla sinistra del forrente Amendolea. A dare un cenno dell'immenso ammasso di Foraminiferi contenuti in tali strati io ricordero che sono di perfettissima conservazione. Cio non toglie che buona parte della roccia possa risultare dal tritume di tali spoglie, come sicuramente risulta. Appena la marna viene stemprata nell'acqua vedonsi galleggiare numerose Orbuline e Globigerine, di unita a molte altre tenui specie. Questi due generi formano d'ordinario la parte principale della grande massa di questi organismi abissicoli, e percio quelle marne tanto potenti e cosi estese sono, come io dicera precedentemente, veri fanghi costituitisi a grandi profondita e che deveno riguardarsi siccome depositi d'origine organica, cioè identica a quella dei fanghi legli abissi oceanici attuali. Oltre le orbuline e le globigerine vi abbontano molto le nodosarie, le tentaline le robuline, e molti generi affini, mentre ri sono rari i generi a conchiglia agghtinante, e rarissimi 
quelli a conchiglia imperforata, come sarebbero le biloculine. Ie triloculine. Is quinqueloculine e gli analoghi generi.

Nelle marne delle molte localita, che ho potuto studiare al microsconio, vi ho riconosciuto una meravigliosa uniformità della fauna dei Rizopodi, la quale costituita sempre dalle medesime specie predominanti, risponde a capello alla coetanea fauna delle molte localita siciliane da me esaminate. Nel paziente ed accurato esame microscopico occorre ben di raro incontrare di unita alle Foraminifere qualche spicula silicea degli Spongiarî, ovvero qualche guscio di Radiolario e di Diatomea; invece presso Ardore, ho incontrato una marma zancleana, che oltre ad essere ricca di Foraminiferi delicatissimi e di perfetta conservazione, racchinde una quantiti ben grande di spicule silicee di diverse forme appartenenti agli Spongiarî, una fanna importantissima di Radiolarî associata a molte forme di Diatomee. - I resti silicei di Spongriâ̂ sono molto variati; r"hamno spicule semplici rette, ve n'la ad ancora e stellate, v'hanno scheletri reticolati. Queste numerose forme dimostrano evidentemente grupji svariatissimi di spugne e fra essi certamente gli Esattinellidi ed altri abitatori deyli abissi oceanici. I Radiolarî anmunciano una fauna pliocenica di molto interesse. la quale è costituita di forme in parte identiche a quelle dei Tripoli della zona solfifera di Sicilia tanto bene studiate dal sig. ing. Stolr $\left({ }^{1}\right)$, ed in gran parte direrse, ma molto analoghe a quelle quanto ai generi cui spettano.

Questo facies distintissimo dello Zaneleano è considererolmente sviluppato in potenza ed in estensione. Le marne zancleane difati si mostrano quasi dapertutto alla periferia della morincia, e lì stesso dove lo Zancleano è sabbioso le marne benc spesso sorrastano o alternano con le sabbic, come a Gerace. $\Lambda$ voler seguire lo sriluppo delle marne zancleane, ricordero i pii importanti luoghi. Il territorio di Guardaralle e quello di Stilo ci offrono uno sriluppo grande di questa roceia che vi è anco potente: essil is sparsa in lembi più o meno estesi, e si continua verso Stignano, Riace e così via per assumere un'estensione ed nno spessore grande nei territorî di Roccella Jonica e di Gioiosa Jonica, siccome nei monti di Siderno e di Agnana; quindi si continua a Gerace a Portigliola nei monti di Ardore encatenandosi colle potenti mame di Bianconuovo. Succedono poi quelle di Brancaleone che passando sul Capo Spartivento, formano quella serie di colline presso la spiaggia che si continua sino oltre il Capo Palizzi; quindi ricompariscono interrottamente qua e là e piì sriluprate presso il torrente Amendolea, e poi al di la di Melito, e quindi nei dintorni di Regrgio. a S. Agata, a Valanidi, sopra Gallina, e così via ria riconpariscono poi ad Ortì nelli Valle di Fiumara estendendosi sui Piani della Melia e rerso i Piani della Corona: oltrepassati i quali, amplamente si allargano nel territorio di Palmi, in quello di Seminara ed in tanti altri, formando una cintura attormo la rasta pianura quaternaria di Gioia.

Un ultimo argomento da trattare riguarderebbe la distinzione delle mame zancleane da quelle astiaue, colle quali facilmente si confondono, perehi molto somiglianti e perchè sorrapposte. Questiz distinzione rivsece agevole invocando i caratteri paleontologici; allorchè maneano i dati stratigratici: ed io rimando la trattazione piu

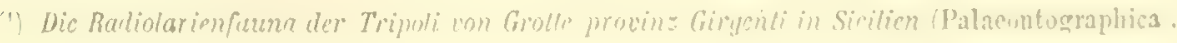


aranti. flove dirò dell Astianc. Per ora contentandomi di accennare come in generale là dove esictono le due formazioni, l'Astiano, essendo piì recente, occupa il posto che più si approssima alla costa, e, come precedentemente dissi, riempie o si adagia nelle depressioni esistenti nello Zancleano, il quale viceversa si mostra piu internamente e si estolle in colline elevate. Cosi ad esempio l'Astiano di Monosterace, di Siderno, di Gioiosa-ionica giunge sin presso la spiaggia, e le marne zancleane invece si elevano sui monti.

Pria di venire alla enumerazione delle specie, che saramno riunite in unico elenco, è d'uopo dire qualche parola intorno alle località fossilifere. E primieramente ricorderò che da quanto è stato detto sinora, in qualunque luogo e sotto qualunque forma si presenti lo Zancleano è sempre fossilifero: se non che le marne che sono tanto estese non ci offrono che Rizopodi ed Entomostracei. Ricorderò quindi che il primo facies, o facies littorale del plioceno antico, vedesi presso Stilo; i depositi dei Piani della Melia e di Testa del Prato sono intermedî tra i sedimenti littorali e i coralligeni. Il secondo facies si offre a Gerace e piu in dentro nei piani sopra Canolo ed Agnana; quindi si manifesta sul lato settentrionale a Valanidi, S. Agata, Terreti e Nasiti. Comunissime poi sono le marne a Foraminiferi che rappresentano il terzo facies. Di questi diversi luoghi sono i fossili enumerati nel seguente elenco. e di taluni altri che mi hamno fornito le marne di cui ho studiato la fauna.

\section{Elenco delie specie fossili raccolte negli strati del piano più antico del Plioceno - Zancleano Seguenza (').}

Tipo. VERTEBRA'T'.

Classe. Mammifert.

Neterocetus? - 1. H...... sp.

Indico in questo modo i resti di una Balenollera che conservo nelle mie particolari collezioni e che io stesso ho estratto dalle sabbie zancleane che costituiscono le colline presso Terreti. Essi consistono in una vertebra incompleta del diametro di tredici centimetri e dell'altezza di otto, ed in varî pezzi di una mandibola che insiememente presi formano una lunghezza di cinque decimetri e mezzo. Allorquando mi feci a discavare questi residui di Cetaceo, io non vi giungera che troppo tardi, dappoichè dal medesimo luogo erano stati estratti considereroli quantità di ossami delle quali mi fu dato osservarne una parte soltanto, costituita da vertebre, costole, una mascella, ed altro $\left({ }^{2}\right)$; dal che io ne conchiudeva che

(") Le localiti verranno indicatc coi seguenti segni: 'T., Terreti e Nasiti nelle colline presso Reggio: 2.. Testa del Prato, o cone altri dice Vigna di mare, sopra gli Archi presso Reggio; A. S. Agata: S. Stilo cioè tra Stilo o Monosterace; Va., Valanidi; M. L'iani della Melia sopra Scilla; G., Gerace: Ar. Ardore: Po., Portigliola; Me., Valle del Messinese presso Gioiosa-ionica; Pa., Palmi; Se minara; B., Benestare. Delle prine sei localiti la fauna è delle sabbie, di Gerace ho stadiato le sabbic "le marne, degli ultimi sei luoghi lo marne soltanto.

(") Vedi G. Seguenza, Da Reggio a Terreli 
in quel luogo giaceva intiero lo seheletro di quel cetacco, siccome quei tanti che sono stati diseppelliti negli strati pliocenici dell'alti e media Italia.

Devo alla solita cortesia del prof. G. Capellini l'esame dei pochi residui di questo cetaceo, che gli hanno suggerito la incerta determinazione generica qui sopra riferita. R. T.

Importa molto notare intanto che nelle sabbie di Terreti, frammenti di ossa di vario rolume se ne incontra sovente, sebbene corrosi ed indeterninabili.

\section{Classe. Pesci. - Ordine. Connrotemengir.}

Carehnoodon. - 2. C. sulcidens Agassiz = C. lamia Bonp., C. Rondeleti Muller et Henle, C. Caifassii Lawley, C. cruscus Lawley. - Sono ormai parechi anni (1875) che paragonando i denti di Carcharodon, che incontransi sovente negli strati pliocenici del Messinese, con quelli della specie mediterranea ebloi a convincermi che i fossili erano identici a quelli del $C$. Rondeletii, e con tal nome li annunciai in qualche mio lavoro (vedi Bullett. del r. Comitato geologico $187 \mathrm{~s}$ fascic. $3^{\circ}$ e $4^{\circ}$ p. 83). Più tardi il sig. Lawley arendo a sua disposizione numerusi denti fossili del plioceno toscano, che avea riferito a diverse specie dell'Agassiz, si convinse, dal confronto colle intiere mascelle di un C. Rondeletii, che le varit forme da lui possedute erano da rapportarsi alle diverse regioni dellapparato dentario dell'unica specie che tuttora vive nel mediterraneo, e che quindi, trovando le diverse forme da lui precedentemente denominate $C$. productus, $C$. w'galodon, C. angustidens, C. sulcidens, C. Caifassii sulle mascelle del medesimo individuo, li riuni insieme sotto l'unica denominazione di $C$. etruscus. 'Tale nome a me sembra superfluo, a deve necessariamente andare in sinonimia, essendochè varî altri ce n'erano gìì, quantunque aleuni fossero dati ad una speciale forma di denti. E per ragione di priorita a me pare che debba darsi la preferenza al nome dell'Agassiz ( $C$. sulcidens), come quello che con sicurezza spetta alla specic di cui parlo, sła perchè i caratteri corrispondono precisamente coi denti delle mascelle superiori, sia ancora perchè l'autore si ebbe tali denti dal jlioceno di Castel Arquato. Nè il Sismonda nè il Costa parlano di questa specie; il Gemmellaro invece rinvenne alcuni esemplari in Sicilia, i quali gli offrirono il carattere di una dentellatura a denti bifidi, tale carattere con poca costanza e con molta irregolarità si osserva nei molti denti che possiedo. Questi varî denti, di diverse forme, si riferiscono alle varie descritte dal Lawley e riconosciute siccome spettanti alle diverse regioni della bocea. Molti di questi denti mi renneru esibiti dal sig. ing. F. Paviglianiti, e movengono da S. Agata. I. R. A. V.

Dxyrhina. - 3. 0. hastalis Agassiz. Un sol dente grande e ben conservitu che trovai insieme ai molti spettanti alla precedente specie. R. $\Lambda$.

ธamms. - 4. L. erassidens Agassiz. A questa specie riferisco taluni pochi denti. varí di forma e sopratutto di diversa curvatura, a norma della posizione che occupavano sulle mascelle. I. R. A.

maja. - 5. R. antiqua Agassiz. Ripporto a questa specic non altro che uni sola placea dermica, la quale per la sua forma conica areuata, pel suo allargamento 
alla base e pei diversi particolari ele la contradistinguono moltissimo somiglia allia figura data dal Lawley alla tay. II. fig. 1g, quantunque il mio fossile sia mancante in gran parte della porzione elargata della base. $\mathrm{l}$. P.

\title{
T'ino. HOLLUSCHI.
}

\author{
Classu. G A S T E R O P O D I.
}

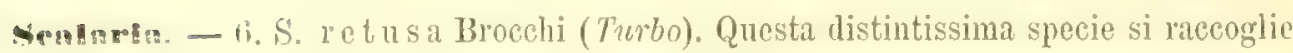
in belli e conservatissimi esemplari nell'antico plioceno di Nasiti e di altri lnoghi. r. T. S. - 7. S. Turtona e Turt. Var. tenuicostate Michaud $=$ S. planicosta Biv. R. P. V. - 8. S. pulehella Bivona. Un solo incompleto esemplare. R. P. V. - 9. S. lamellos a Brocchi (Turbo) Var. gracilis. n. Questa forma che io riferiseo come varietà della specie del Brocehi è piì piccola della tipica; colle suture piu profondate, alquanto più gracile, colle costole più smilze. Un solo esemplare raccolto presso Gerace. R. G.

10. S. Aspromontana n. sp. Tav. XIV. fig. 14 .

Questa specie molto somiglia alla precedente, dalla quale distinguesi bene pegli avrolgimenti poco convessi, per le costole in minor numero, che son dodici, le quali sono larghe e rivolte in dietro, in modo che $i$ denti acuti, di cui il loro margine è fornito, vanno fino a toceare la costola precedente, restando cosi tral uma ed altra costola qualtro interstizi, siccome quattro forami, presso a poco. sebhene meno perfettamente, come arviene nella S. pumicea. alla quale questa nuova specie somiglia appunto per l'accennato ultimo carattere. Le costole inoltre sono prominenti alla parte posteriore degli avrolgimenti, dove formano delle sporgenze alquanto acute, colle quali si terminano.

\section{Lunghezza 23. ${ }^{\mathrm{mm}}$ Larghezza $11,50^{\mathrm{mm}}$ R. 'I'.}

11. S. Rhegiensis n. sp. Tav. XIV. fig. 15.

Questa bella specie è anch'essa molto prossima alle due precedenti, ma le sue costole sono piu numerose e piin sottili, leggermente svoltate, le lamelle di cui ronstano sono più grossolane, la hase, o regione anteriore dell'ultimo arvolgimento, ¿ appianata, ma colle costole ben distinte, e con una carena marginale prominente c nodosa, che ben la disgiunge dal resto dell'avrolgimento. Inoltre gli avrolgimenti sono convessissimi, le suture assai profonde, e due ordini obliqui di rarici prominenti scorrono su due linee opposte della spirale.

\section{Lunghezza 21,5. $\mathrm{mm}$ Diametro $150^{\mathrm{mm}}$}

Un solo esemplare raccolto presso Valanidi. R. Va.

Datritn. - 12. P. coerulea Lamarek. Qualche esemplare non ben conservato. R. T. P. V.

\section{Classe. Lamfinmkanom.}

Saxicava. - 13. S. norvegica? Spengler (Alya) = Panopea Norvegica K. H.. P. Bivonae Phil. Riferisco con qualche dubbio a questa specie vivente nei mari |fol nord un solo molello in medioce stato di conservazione. R. Va. V. 
contipes.- 14, L. grandis n. sp.

Questa specie è affine al L. transversus Bronm, ma se ne distingue molto belke per la sua grandezza pressochè quadrupla, per la regione boccale meno prominente, quantunque ben angolosa, e quindi la porzione anteriore considerevolmente più stretta della posteriore. La forma generale della conchiglia è rotondato-quadrata di una lunghezza pari alla larghezza, che misura 33. ma Gli apici sono adunchi, relativamente piccoli. La superficie è concentricamente striata da linep impresse non molto ravvicinate, risultanti dalla particolare costitnzione della conchiglia, che si mostra all'esterno come formata dalla sorrapposizione di tenui lamelle imbricate.

Questa specie ben distinta renue da me trorata presso S. Ginseppe di Gallico, R. R.

Modiola. - 15. M. adriatica Lamk = Mililus Cavoline Scacchi. Rapporto con qualche esitazione alla nostra specie virente ma modiola molto comme, che prer la sua grande fragiliti raccogliesi sempre in frammenti. c. T. P. A. V.

Avieula. - 16. A. media? Sowerby. Vedesi su d'una Ostrea l'impronta d'una valra di Avicula, sulla quale l'Ostrea erasi fissata, nerlocchè malamente riconoscesi la specie. R. T.

Perna. - 17. P. Soldanii Deshayes. Soli modelli. x. T. S.

Mims. - 18. L. s quamosa Lamarck. 1. P. V. - 19. L. inflata Chemn. (Pecten) R. T. V. - 20. L. Loscombii.G. B. Sow。=lobullate (Turton) Phil. Raccolto qualche esemplare di grandi dimensioni colla scultura assai forte. r. T. P. Y.

Limea. - 21. L. crassa Forbes (Lima) $=$ Limea Sarsii Loveln, Lime scrbrelle M. Andrew. R. T. S. V. - 22. L. elliptica Jefir. Un solo frammento. R. 'T. V. - 23. L. orata S. Wood. Riferisco a questa specie del Crag inglese mu piccola Limea che pel considerevole restringimento della regione cardinale somiglia molto bene a quella; le costole sono jiin grosse ed in minor numero chu nella specie precedente e si scancellano sui liti. 2. T. P. V.

Pecten. - 24. P.multistriatus Poli (Ostren) = Ostrea pusio Limneo. c. T. P'. A. V. - 25. P. valius Limeo (Ostrea). C. T. P. A. V. - 26. P. substriatus D'Orbigny. Riferisco a questa specie una forma non troppo rara, piccola, colle costole meno scabre e piu appianate di quanto l'ha il P. pusio. l. T. P. A. S. M. - 27. P. o percula is Limeo (Ostrea). Più comunemente in questo piano s'incontra una varietà, che non raggiunge mai grandi dimensioni, a costole leggermente solcate, convesse regolarmente e separate da piccoli interstizî. C. T. P. A. S. M. V.28. P. scabrellus Lamarck. Specie eminentemente variabile nella grandezza. nella convessità delle valve, nella prominenza delle costole, nella sporgenza delle lamelle trastersali e quindi nella scabrezza della superficie; potrebbonsi percio istituire numerose rarieti, fra cui ve ne la una piccola a costole sporgenti. strette e poco scabre. Questo Pecten è al certo la piu comune specie ai questo piano. C. T. P. A. S. M. G.

29. P. subspinulosus n。 sp\%

Questa specie è intermedia tra il P. opercularis Lin. ed il P. spinulosus Mrnster: ma meglio si arrieina al primo per la formia, il mumern delle costnle ere. 
Ogni costola è percorsa longitudinaimente. quasi sempre da tre linee irte di squamette prominenti.

$$
\text { Lunghezza 49. }{ }^{\text {rm }} \text { Larghezza 46. mи } \mathrm{R} \text {. 'T. }
$$

30. P. pestelis Limneo (Ostrea). r. T. P. A. MI. V. - 31. P. inflexus Poli (Ostrea $)=$ P. adspersus Lamck. r. T. P.A. V.-32. P. flexunsus Poli (Ostrea)

P. polymorphus Broun. R. T. V. - 33. P. tigrinus MInller, Qualche rara ralia di questa specie, che rive nei mari del norl. R. T. Y. - 34. P. latissimus Brocchi (Ostrea). Di questa grande specie si raccolgono conservatissimi gli esemplari. c. 'T. P. S. MI. - 35: P. denudatus Reuss. Alcuni rari frammenti. R. 'T'. S. - 36. P. similis Lasker $=$ P. pullus Cantraine, P. pygmaeus anct. (non r. Munster). Questa piccola specie ben conservata e comune oftre indizî delle macchie che sogliono ormarla rivente. c. T. P. A. M. V.

Janirs. - :37. J. flabelliformis Brocehi (Pecten). Specie sparsa abbondantemente ed in grandi esemplari, e costituente in yuesto piano talrolta quasi da sp sola intieri strati e potenti banchi. Var. sulcata. n. Questa forma si distingue per" le costole più prominenti e più convesse e per gli spazî intercostali in forma di solehi. C. I. P. A. II. S. G. - 38. J. Alesii Philippi (Pecten). Questi specie nou juò confondersi menomamente colla precedente, siccome taluno pretende; $i$ soli frammenti da me racolti in Calabria si distingnono a prima gimuta. ‥ S. M. R.

39. J. Jaericostata n. sp. Tar. XIV. tig. 16 e $16 a$.

Questa specie è molto afline al $P$. Leythaianus Partsh del mioceno, ma è perfettamente distinta per essere piu convessa, per avere un minor numero di costole. cioc ventidne, le quali sono più strette e più sporgenti, mentre i solchi che le lisgiungono sollo piu larghi e molto profondi. Le linee concentriche sono piì sporgenti negli interstizi che seprarano le costole. e quasi scancellate sulle costole stesse.

\section{Lunghezza $633^{\mathrm{mm}}$ targhezza $700^{\mathrm{mm}} \mathrm{l}$. T. P. S.}

40. J. Rhegiensis 11. s1. Tar. XIV. fig. $17,17 a, 17 b=P$. medius Philippi (non Lamarck.).

Questa conchiglia ì realmente molto ricina al P. medius, ma comparata cogli 'xemplari della specie virente distinguesi per le costole più larghe e piu sporgenti, pel solco che le biparte più distinto, per le linee concentriche lamelliformi, sprorgenti emeglio distinte e per vari altıi particolari. I1 Philippi arendo raccolto a Termeti taluni semplari di questa specie. la confuse colla vivente del imare liosso.

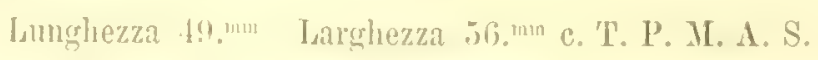

41. J. maxima Limeo (Ostrea). Una sola valva rotta hen riconoseibile. R. T. I. 12. J. bipatita 11. s1. - Vola marima Var. bipartila Foresti. Questaforma we incontratsi nel plioceno antico di Calabria, parmi distinta dalla specie precerlente jer le costole molto jiin prominenti e hipartite. r. T. P. M. - 43. . . Incoliea Limneo (Ostrea). La forma tipica vi è molto rara. Var. striatissima Foresti. Qnesta forma sempro molto piccola, incontrasi commemente. c. T. P. U. A. S. Va. V. 
-1enronectia. - 44. P. fenestrata Forbes (Pecten) $=$ Peclen inequisculplus Tiberi, P. Philippii Acton, P. concentricus Forbes, P. antiquatus Phil. Esemplari assai ben conservati. 1 . T. P. II.

Hunites. - 45. H. crispus Brocehi (Ostrea) = II. Cortesii Defrance. Grandi belli esemplari. La valva inferiore è sparsa di lamelle concentriche, sporonenti to rilevate. Riferisco a questa specie una piccola valra in cui le lamelle sono molto grandi e prominenti. r. T. P. S. - 46. H. Ercolanianus Cocconi. Dne valve che per le loro numerose e piccole costole rispondono bene alla descrizione ed alla figura del Cocconi. R. Va. - 47. H. la erinseulus Philippi. I pochi esemplari da me raccolti rispondono bene in generale alla figura e alla descrizione del Philippi, ma sono molto più grandi e con costole numerose sottili e interposte alle maggiori. L'esemplare del Philippi par che sia un giovane.r.T. Ta

glicarula. - 48. P. mytilina Philippi. R. T. P. MI. A.

Spondylus. - 49. S. crassicosta Lamarek. Si raccolgono esemplari giganteschi. 1". T. P. - 50. S. gaedelopus? Limeo. r. 'T. P. V.

Ostuer. - 51. O. cochlear Poli. Vi riferisco quella forma, piccola, sottile e colla fossa ligamentare orizzontalmente disposta, che risponde esattamente alla specic rivente. C. T. P. A. M. S. G. Va. Y. - 52. O. naricularis Brocchi = O. Pillar Meneghini. Per questa specie che viene generalmente associata alla precedente: vedi cio che fu detto a proposito dei fossili tortoniani. In questo piano raggiunge grandi dimensioni e diviene sorente di soliditi rimarcherolissima e di forma ordinariamente molto allungata. c. T. P. M. A. S.

53. 0 . minima

E questa una piccolissima e ben distinta Ostrea, la quale grandemente somiglia all' O. neglecta Michelotti, ma è piccolissima, raggiungendo appena la lunghezza di tre millimetri. La sua superficie è levigata ed ondulata concentricamente con irregolarita, l'apice è incurvato lateralmente. Questa conchiglietta conserva spesso un colorito rosso più o meno shiadato. che talvolta diviene quasi scarlatto, e sovente si dispone a zone concentriche, che altemano con zone più chiare o bianche. v. G. Ar. R. Pa. Se.

54. O. edulis Lin. La forma che ri riferisco è molto scal)ra, in grandi esemplari e comuni, probabilmente quella stessa varietì ricordata dal Cocconi. c. 'T. P. M. S. V. - 55. 0. Lamarekii Mayer = O. Cortesiana Cocconi. O. fallaciosa Mayer, O. exasperata Mayer. In veriti queste diverse forme parmi che presentino troppo lievi differenze per tenerle distinte, perlocchè mi associo all'opinione del prof. C. De Stefani, che le riunisce in unica specie, r. T. P. S. 56. 0. cataplasma Mayer. Sembrami potere riferire a questa specie qualche esemplare di mediocri dimensioni. R. T. - 57 . 0. lamellos a Brocchi. Hsemplari d'ordinario di mediocre grandezza, qualche rolta molto grandi. c. 'L. P. II. S. Va. - 58. 0. Boblay i Desh. Questa specie che per tutto trovasi nel mioceno, in Calabria sale sino al plioceno antico. dore offresi comunemente in esemplari molto grandi. c. T. P. S. - 59. 0. plicata Chemn. Questa specie che si raccoglie in esemplari di varie grandezze. è diversa nella forma delle costole radianti. r. T. P. S. M. V. 
60. O. ten u iplicata 11. sp. Tar. XII. fig. 1,1 a. 16 (redi fossili del Tortoniano). ‘. 'T. T. M. S. A.

61. O. A qu itanica Mayer. Questa specie presentasi sovente colla superficie colrosa sino alla quasi completa scomparsa delle prominenti costole. r. T. P. M. S.

Anomia. - 62. A. e phippium Lin. Questa specie presenta molte rarietà e numerose rariazioni. C. T. P. M. A.S. V. - 63. A. or b ic ul a ta Brocehi. Anco questa forma doveblbe probabilmente associarsi alla precedente siccome opina il sig. Cocconi insieme ad altri. 1. T. P. T. - 64. A. costata Br. 1. T. P. - 65. A. pate Lliform is Lin. I. S. M. V. - 66. A. striata Br. Questa specie per la sua striatura radiante è distintissima. c. T. P. M. A. S. - 67. A. a cu leata Montagu. Forma assai piccola una distinta per le spine che ricuoprono la sua superficie. c. A. I.

Classe. Brachiopom.

Terebrstulu. - 68. T. Calabra Seguenza. c. T. P. A. Va. - 69. T. Philippli Segnenza - T. grandis. Var. complanata Philipui. C. 'T. P. A. Va.

rereluratulina. - 70. T. sinuosa n. sp. $\left.{ }^{(}\right)$.

Questa specie credo che sia ben distinta dalle conoscinte per molti caratteri. tra i quali ricordo la simmosita della linea di congiunzione delle valve, una rimarcherole depressione lougitudinale sulla grande valra, e le costole, tra le quali alcune maggiori, rilevate in mezzo a molte minori eee. r. T. L. Va.

71. T. caputserpentis Lin. (Anomia). Vi riferisco con dubbio qualche giorane esemplare. R. A. G. V.

Megerin. - 72. M. eusticta Philippi (Orthis) = Terebratula lucinoides Costa, Megerlia? orbicularis Meneghini (M. S.), M.? orbicularis Davidson. M. eusticta Seguenza. A mio credere, giudicando dai numerosi esemplari esaminati, che prorengono da molti luoghi, questa specie assai variabile nella forma e nell' ornamentazione la dato origine alla istituzione delle rarie specie che riporto nella sinonimiat, perchè con sicurezza le riguardo come identiche, o variazioni della forma tipica. C. T. P. A. Va. - 73. M. truncata Linneo (Anomia), Var. granosa n. Questa Megerlia è molto importante: essa è piu piccola del tipo a cui la riferisco, ha la superficie fortemente granosa e prica intieramente di costole, le quali in qualche esemplare soltanto si famo vedere debolissime. È questa una rimarcherole forma che dorreblue forse disgiungersi specificamente dalla comune forma vivente. c. A.

matidia. - 74. P. anominides Sc. Orthis anomioides Phil. Qualche raro esemplare. 1 : G. $\mathrm{Y}$.

arompe. - 75. A. decollata Chemn. (Anomia). Varie forme come tra i viventi. r. T. I'. 1:. 1. 1

Cistena. - 76. C. la eris? Seg. Un esemplare che non ì in perfetto stato, ma che per la sua forma ricorda assai bene la mia specje mincenica. R. G.

mhymchonella. - 77. R. bipartita Brochi (Anomia). Questa specie presenta

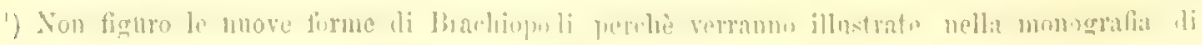

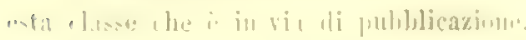


molte rariazioni nella larghezza, nello spessore, nella profonditi del seno ilorsale cue. Var. subplicata. Col margine rentrale leggermente pieghettato, c. T. R.

Crania. - 78. C. a 11 oma la Muller (Patella) = Anomia turbinata Poli. Qualche rara valva. R. P. V.

\section{'lipo. A R'TROPODI.}

Classe. Crostaceil.

Di forme appartenenti a gruppi superiori s'incontrano frammenti indeterminahili.

Ordine. Ostracons.

Dontacypris. - 79. P. mytiloides Norman. (Cyhere). I pochi esemplari che riferisco sono alquanto dubbî, perchè di forma alquanto friiu snella, collia regione posteriore più aenta, si arvicinano quindi alla $P$. sagillula T'ery. Ne costituiseo perciò una distinta varieta che chiamo Val. pliocenica. 11. 1. G. Po. V. 80. P. compressa n. sp. Tar. XIV. fig. 19, 19 a.

Questa specie è molto aftine colla $P$. trigonella Sars rivente nei mari del nord. dalla quale io la distinguo per essere piu breve ed alquanto piì rotondata alla estremità posteriore. Inoltre è rilerante il caratiere della sua magoior compressione. Lunghezza $0,90^{\mathrm{mm}}$ Larghezza 0,4 . mm Spessore 0,2. mn R. 'T.

Bairdim. - 81. B. subdeltoidea Munster (Cythere) = Cychere subdeltoidea Renss, B. subdeltoidea Jones. In questo piano lil comunissima specie si presenta di grandezze variissime ed offive tutte quelle rarieti e rariazioni che sonu state illustrate dal Terquem nei fossili di Rodi, e dal Brady tra le forme virenti. Cosi si rimarcano quelle modificazioni che presentano dei dentelli margrinali piì o meno sviluppati. C. A. G. Ar. Pa. Se. Po. V. - 82. B. counplatnata Brady. Gli esemplari che vi riferisco rispondono precisamente alle figurc date dall'autore, e presentano poche rariazioni. Vive nei mari d'Inghilterra. e. G. Ar. Pa. Po. Se. V. - 83. B. obtusata Sars. Agli esemplari che rispondono bene alla forma tipica di Norvegia se ne associano commemente altri che formano una distinta varieta, che chiamo Var. producta 11. Essa ditlerisce per avere l'angolosita posteriore piu sporgente, più distiuta e quasi acuta. Vive nei mari del nord: Norvegia, Inghilterra, Ibridi. c. G. Ar. Pa. I'o. Se. V.

Macroeypris. - 84. M. minna Baird (Cythere). Vi riferiseo un solo esemplare. Questa specie rive in Norvegia, in Inghilterra, alle Isole Sketland. li. Po. V. 85. M. Calabra n. sp.

Difterisce dalla precedente jer essere di forma piu snellat, perche la regione dorsale non è troppo gibhosa e quindi d'uma curvatura meno forte; ma le valve sono convesse al centro e depresse agli estremi. Inoltre i pii piecola.

Lunghezza 1,5. ${ }^{\text {nm }}$ Larghezza $0,00^{\mathrm{mm}}$ Spessore 0,5. ${ }^{\text {nn! }} \mathrm{h}$. Se.

Covhere - 86. C. cieatricosa Reuss (Cypridina). r. T. Al. A. - 87. C. convexa Baird. Questa comme specie rivente è molto rara nello Zancleano. IR. Ar. I. 88. C. elongata n. sp.

Questa specie ricorda alquanto la C. bisinualu 'L'rquem, specialmente per le ralve rigonfie verso la regione centrale dore in essa sono ancor piil rigontie; mal 
si listingue assai hene per essere piu allungata, quindi di forma piu snella. oltre cuc è piu larga anteriormente e più stretta all'estremita posteriore.

Lunghezza 0,7." Larghezza $0,2{ }^{\mathrm{nm}}$ Spessore $0,350^{\mathrm{mm}} \mathrm{r}$. Po.

89. C. terebrata Terquem. I rarî esemplari che rapporto a questa specie presentano una patina calcarea, che ne nasconde i caratteri, ma talvolta si scrosta questa investitura e comparisce la grossolana perforazione. In qualche esemplare l'incrostazione manea del tutto, ed allora parmi che la conchiglietta per la forma. per lo spessore, pei grossi forami conviene bene colla specie del plioceno di Rodi. c. 'T' - 90. C. histrix Reuss (Cypridina). Var. scaberrima. n. Questa Cythere si allontana dal tipo miocenico per arere le spine più rarricinate e poco dirise o partite; per tali caratteri par che sia intermedia tra il tipo e la $C$. asperrime del Reuss. r. Ar. Se.

91. C. soroleula u. sp. Tar. XIV. fig. 18, 18 .

Questa bella specie è affine alla $C$. fornicala 'Terquem, è molto solida e si distingue per essere meno conressa e meno gracile, e per la scultura formata di grandi incavi angolosi, disuguali, irregolarissimi, che si allungano mano mano verso l'estremo anteriore e finalmente ne cingono il margine.

Lunghezza 1.mm Larghezza 0,5 .mm Spessore 0,4 .mm r. T. P.

12. C. scabra r. Munster (Cypridina). Ho raceolto qualche esemplare che risponde bene alla forma virente dell'Atlantico e del Mediterraneo illustrata dal Brady. Var. minor. n. Chiamo cosi una piccola forma dello Zancleano in cui lo scabrezze della sunerficie sono meno prominenti, e le estremita della conchighia pii rotondate, coi dentelli marginali quasi mancanti. r. G. Pa. V. - 93. C. Ldwards i Roemer (Cypridina). Var. radiato-plicale n. Questa forma noncredo che possa disgiungersi dalla specie eui la rapporto. Essa differisce pertanto considererolmente, per arere una scultura piì fortemente pronunciata, per la regione anteriore onata di pieghe ben distinte, radialmente disposte, e pei dentelli marginali un po' diversi. $R$.

94. C. pliocenica. 11. sp.

Sono dolente di non arere potuto rapnrescntare nell'Atlante questa specie atsali ben distinta, che è tra le piì comuni del plioceno antico. Essa per la scultura formata da ineavi irregolari ed angolosi ha ma certa somiglianza colla $C$. anIntaropora Reus's, ma ne è molto diversa per la superficie considerevolmente seabra e spinescente, per una forte carena che si elera sopra ciascuna ralva presso la regione inferiore o ventrale, col margine pieghettato e dentato, terminandosi posteriormente con una valida spina. La forma generale è allungata. e ciascuma valva molto gibhosa, porta una prominenza rotondata presso la regione centrale; inoltre presenta nella sua Imghezza quasi uguale larghezza, dilatandosi alquanto ai due estremi, che divengono appianati e radialmente costati, l'anteriore col margine areuato is fornito di molti piecoli denti pressochè wguali, il posteriore angoloso ai lati e presso al centro è fornito di denti molto disuguali: alcuni di essi dal lato rentrale sono molto sporgenti.

Lunghezza 1,6.10m Larghezza $0.8 . \mathrm{mm}$ Spessore $1,2.0 \mathrm{~mm}$

Var. minor. Questa forma differisce soltanto jer essere piccola u per il juco 
sviluppo dei dentelli marginali e delle spine della smperficie. C. G. Pa. Se. Ar. Po. 95. C. subtrigona n. sp. Tar. VIII. fig. 2, tar. XII. fig. 6.

Una sola ralra, spettante forse alla varietic (redi fossili dell'Elveziann en Ostracoli del Tortoniano). R. Ar.

96. C. semilunata n. sp. Tav. XII. fig. 7.

Ho raccolto nello Zancleano un esemplare completo e ben poco direrso di quelli del Tortoniano (vedi Ostracodi tortoniani). R. Po.

97. C. radiatopora n. sp. 'Tír. XVI. fig. 48.

Questa bella specie a costole radianti raceogliesi non rara nelle marne zan- cleane (per la descrizione redi i fossili astiani); ma piì comunemente s'incontril la seguente rarieti alla quale fa grarluato passaggio. Var. sculpta n. Questa forma ne è molto distinta; le costole si estendono per tutta la superficie, cosi le fossette che s'interpongono negl'interstizî delle costole la ricuoprono quasi pur intero, e sono d'una maggior grandezza. Le ralre sono più ristrette alla regione anteriore, i margini appianati si restringono ancora e nella regione anteriore si manifestano superficiali solehi paralleli al margine areuato, mentre nella postrriore sonvi dei dentelli. Questa forma che parmi non potersi disginngere dalla tipica, quantunque abbastanza diversa, somiglia moltissimo alla $C$. Parkeri Brady vivente nei mari d'Anstralia. c. G. Al. Po. Pa. Se.

98. C. calcarata n. sp.

Questa Cythere per la sua forma generale ricorda la C. foliacea ilel Siciliano. ma si restringe di più e diviene angolosa e quasi speronata alla regione posteriore, l' anteriore ben larga è regolarmente areuata; la conressiti delle valre porta ma prominenza centrale stretta e rotondata, una carena rerso il lato rentrale, e delle spine e scabrezze dal lato posteriore. La scultura della superficie ¿ ben dirersa, mancano le squamette imbricate e presentasi finamente granosonrugosa, con indizio di lierissimi solehi radianti alla regione anteriore.

Lunghezza $0,8 .^{m m}$ Larghezza $0,40^{m m}$ Spessore $0,40^{\mathrm{mm}} \mathrm{R}$. G.

99. C. tetraptera 11 sp. Tar. XI. fig. 9, 9a.

Specie che viene dal Tortoniano ed oflie speciali varieta nello Zancleano (vedi fossili tortoniani). Var. angustate n. Colle valre alquanto piì strette, le due ali o carene sopra ciasenna sono pii robuste, piì sporgenti e piir estese, a queste si associano delle costelle poco appariscenti, che altermano con esse. Var. dentate n. La maggior carena nella prominente estremita posteriore presenta tre grossi denti; l'altria carena è piccola e si associa ad altre due o tro costelle analoghe, $1 . \mathrm{Pa}$.

Cyrucridea. - 100. C. sim ilis n. sp. Tar. XIV. fig. 20, $20 \%$

Questa forma fu creduta a prima gimta da me siccome la C. prenctillata 13rarly; ma piì maturo esame me la fece distinguere, per essere piì compressa el un po" prominente all'estremo posteriore, e per avere inoltre la scultura poco appatriscente e finissima.

Lunghezza 0,8.mm Larghezza $0,50^{\mathrm{mm}}$ Spessore 0,3 , $^{\text {rnm }}$ R. T.

101. C. Iu cida n. sp. Tav. XVI. fig. 51, 51a. Var. minor. n. Riferisen sicenme varieti della nominata snecic astiana (vedi fossili astiani) un sol piccolo 
esemplar che oltre la statura molto minore ha l'angolo posteriore piit ottuso e meno prominente. R. G.

102. C. exilis n. sp. Tav. XVII. fig. 49, 49 a

Questa specie propria del Sarriano presentasi rarissima anco nello Zancleano. R. Pa.

Iyolutes. - 103. I. bartonens is Jones. Var. monosteracensis n. Tar. XVII. fig. $29,2 ? a$.

Qnesto importante Ostracode non è raro troplo nello Zancleano. esso non differisee gran che dalla forma vivente nei mari del nord. r. Ar. V.

104. I. compressa n. sp. Tar. XVII. fig. 30, 30a.

Per la descrizione di questa specie vedi gli Ostracodi del plioceno superiore. Var. antiqua 11. Oltre la forma rappresentata nell'Atlante, che trovasi nel plioceno antico come nel recente vi ha nello Zancleano una forma jiì rigonfia alla regione mediana che distinguo come varietit. c. Al. G.

Loxneonelia. - 105. L. implessa Baird (Cythere) = Cythere carinata Brady, $C$. rhomboilea Fischer, L. rhomboidea G. O. Sars. Alcuni pochi esemplari nelle sabbie, comune invece nelle marne di Portigliola. c. Po. A. V.

Xestoleberis. - 106. X. depressa G. O. Sars. Questa specie molto comune nel Quaternario è abbastanza rara nel plioceno antico. r. Po. V.

Cythenellar. - 107. C. complessa v. Munster. Un solo esemplare. R. P.

108. C. bipartita n. sp.

In importante specie che denomino così ha una certa somiglianza colla vivente C. scoticr, specialmente guardata nella sua larghezza, pure essa ne è distintissima pei seguenti caratteri. Ogni valra presenta una rimarcherole depressione o incavatura alla regione mediana, in modo che la sua convessita si presenta come divisi in due porzioni, che stamno alla regione anteriore ed alla posteriore, dove è massima cone in tutte le specie; di modo che la conchiglia guardata nel stio spessore si presenta abbastanza convessa, ma fortemente strozzata nella regione mediana, ben rotondatil all'estremo posteriore, il quale porta il maggiore spessore a circa un sesto della lunghezza totale della conchiglia. Ciascuma valva ben arcuata alle dne estremiti, si presenta ristretta alquanto alla regione posteriore; la superficie è finamente junctato-rucrosa.

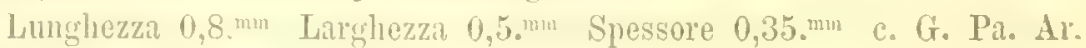
109. C. consanguinea us.

Questa specie che trorasi insieme alla precedente ne differisce molto per essere assai compressal, e leggermente ristretta alla regione mediana. Le valve s'incurvano alquanto e si restringono alla regione posteriore più che nella precedente specie; la superficic loro è appena rugosetta.

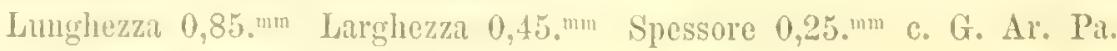
110. C. lucirla n. sp.

Questa specie ha nella vivente C'. lacvis Brady la piò affine, alla quale somiglia srandemente per la forma, ma ne differisce per la forma generale piu rotondati, c) piu ancora perehe il massino spessore è circa ad un terzo della totale lunghezza lella conchighia, e quindi ai unagini è considerevolmente assottigliata. 
La superficie delle valve è lucida.

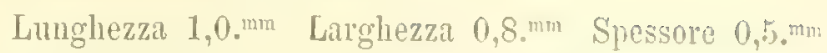

Var. oblonga. 11. La forma rotondata che è la tipica perchè la piú comune si collega per gradazioni insensibili ad uma forma piì o meno allungata che meglio si avvicina alla $C$. laevis, e che io mopongo come rarieti.

Lunghezza 1,1. mm Larghezza 0,7.wn Spessore 0,5。m c. G. Pr. So.

$$
\text { Ordine. Cirripedi ('). }
$$

Balanus. - 111. B. tim tinnabulum Linneo (Lepas). Qualche conchiglia e qualche valva dell'opercolo. R.T. V. - 112. B. tulipiformis Ellis=Lepes tulipa Poli. Esemplari di tutte grandezze ed anco molto roluminosi. Var. arenarin Seguenza. Costato e di variabilissima grandezza. C. T. P. M. A. S. Va. V. - 113. 13. sentorum Segnenza. Sugli sendi del Balanzs concavus. r. P. T. - 114. Is. spongicola Bromn. Var. pliocenica Seguenzal. C. T. P. II. A. S. G. Va. V. - 115. B. perforatus Bruguière. Molte forme e rariazioni, ovate, globose, coniche ece. Var. Altavillensis Seguenza. Un enorme gruppo di grossissimi halani, che spettano a questa rarieti si conserva nella collezioue (lel sig. dott. Michele I)e Mijia e proviene dai dintorni di Ardore. Analoghi gruppi ma più piccoli si raccolgone a Stilo. C. T. P. M. S. V. - 116. B. conearus Bromn.= Lepas tintimabulum Brocchi, Costa, Calcara (non Linneo). Varieti numerose, costate 0 no, di dimensioni variissime e sinanco gigantesche. C. 'T. P. II. A. Va. G.S. V. - 117. B. stellar is Brocehi (Lepas) $=$ - B. corrugatus Darwin. c. T. P. A. M. Va. S.118. B. I arw inii Var. Calabra Segnenza. 1. T. T. - 119. B. Mylens is Seguenza. E comune una piccola varietì. c. T. P. A. Mr. V. - 120. B. b is ul cattus Darwin. Questa specie, propria del Crag inglese, mi ha offerto un solo sendo esattamente rispondente alla forma tipica. R. S.

Pachylasma. - 121. P. gigan te um Philippi (Chthamahus). Un solo sendo. R.P. T. verruea. - 122. V. stromia MInller (Lepus). Var. lacvis. La forma costatia in questo piano ì estremamente rara; la rarietil levigata invece trovisi piir tostn comunemente; taluni indiridui conservano l'opereolo, essa aderisce at virie conchiglie di Molluschi, quali le varie specie di Pecten e Janire e sull' llinmites crispus. c. T. P. M. V.

Sealpelum. - 123. S. magnum Darwin. La sola caratteristica ralva, cioes il lato carenale. R. T?

Tipo. VERMI.

Classe. ANELIIII.

Psymolnanchus. - 124. P. protens us Auctorum. Riferisco con molto dubhin alla specie mediterranca dei tuibi joco rugosi trasversalmente, poco curri o thessllosi. r. T. P. V.

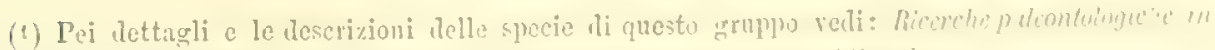

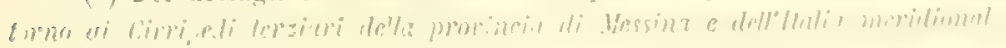


Eprorbis. - 125. S. Pagenstecheri Quatrefages. Vi riferisco qualche esemllare. 1. P. V.

126. S. plicatus 11. sp.

Conchiglia convessa, di cui non si vede che l'ultimo arvolgimento; ombelico piì tosto stretto dal quale irratiano delle grosse pieghe che si allargano e svaniscono rerso la periferia, i solehi che le disgimgono sono stretti e profondi.

$$
\text { Diametro 2,1."m Spessore } 0,9 . \text {."1m }
$$

Aderisce alla Janira flabelliformis. R. P.

Ditupa. - 127. D. incula Ren. (Dentalium), r. T. P. G. A. Al.

Eerminas. - 128. V. miocenica n. sp. 'Tiav. VIIL. fig. 4 (vedi fossili elveziani).

Questa specie par che risponda illa forma miocenica, avendo la porzione aderente concamerata come in quella. c. T. P. M. A. Ge.

12n. V. prerforata n. sp. Tar. XV. fig. 1 .

Tubo triquetro, aderente, flessuoso, carena sporgente in forma di spessa lamina; sni lati sono due altre carene minori, le quali portano ai lati dei forami in forma d'intagli trasversali ravricinati e disposti con molta regolarità. I'apertura è cireolare, le carene sporgono poco oltre di essa. Aderisce alle Janira fabelliformis, \%. Iacvicostata e rarî Pettini. r. T. P.

131). V.calyptrata Grube (Serpula) $=$ V. calyptrata Phil. Riferisco con molto Aubbio a questa specie un comme tubo ordinariamente avvolto a spirale, spesso e traspersalmente rugoso, aderente ai Pettini, alle Janire ecc. c. T. P. M. A. V. 131. V. y unquelineata Phil. Anco questa un po'incerta. x. T. P. MI. V.

Eomatoceros. - 132. P. triquetroides D. Chiaie (Serpula) $=$ P. tricuspis Gr. Sui pettini ed altri corpi. c. T. P. M. A. V.

Serpuala. - 133. S. compressa Quatref. Questa specie risponde bene agli esemplari virenti. Sulle Janira esui Pecen. c. T. P. M. V.-134. S. verm ic ular is Lin. Questa specie ì comune sui Balani, i Pettini, le Janira ecc. I. T. P. V.

\section{Classe. Briozon rit.}

Salicornaris. - 135. S. far ciminoides Jolnston. Questa longeva, commissima e prolimorfia specie trorasi molto commemente sparsi nell'antico plioceno calabrese, dove offre le sue numerose rarieti, or esilissime, or più or meno incrassate, ed is estremamente varia nella forma delle cellule e delle loro aperture. C. 'I'. P. M. A. G. S. P'o. P'a. Mr. Se. V.

Gentaria. - 136. C. cereoides Solander et Ellis. Questo raro briozoo non si allontana dalle forme miocenicle, nè dalle forme viventi nel Mediterraneo. I". '?. I'. I.

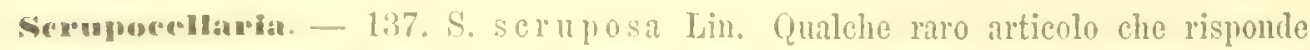
alla forma virente. I. 'T. V. - 1:38. S. Hliptica Reuss (Bactrilium). Questa comune sprecie presentasi piì o meno gracile e con tutte quelle modificazioni indicate dal sno seopritore. C. 'I'. P., A. G. Po. P'a. Ar. Se.

Cubcren. - 139. C. Boryi Aulonin (Crisia) $=$ C. zelanica, C. palagonica, C. bumpi lnusk. 'Tall. XIV. tig. 21, 2la. Alcuni piceoli rami di questa specie mi 
avevano fatto credere ad una mova forma, ma pii accurato esame e la scopertal della medesima specie nello stretto di Nessina, ma in forma jiù minnta, mi fecero certo che trattasi in rero della $C$. Boryi varietir maggiore. La forma incontrata nello stretto di Messina giace alla profonditi della zona coralligena di unita al Balanus tulipiformis ed al Pachylasma giganteum. R. P. V.

Uyriozoon. - 140. M. truncatum Pallas. Questa notissima e comume specic trovasi con rarita nel plioceno antico. I. T. P. MI. S. G. V.

Iippothon. - 141. H. flagellum Manzoni. Una piccola colonia sull' Ostren Lamarckii ed ma piì estesa sul Balanus concavus. R. T. P. V.

Actera. - 142. A. sica Conch. Sui Pecten scrabellus, Ostrea navicularis, Terebratula calabra, Alegerlia eusticla. 1.' '1. P. V. - 143. A. a ng gina Hinks. Sul Pecten scabrellus 1. 'T. M. V.

Terelonipora. - 144. T. A rehiaci Fischer (vedi j fossili tortoniani). Io resto sempre dubbioso intorno alla specie del mioceno e del plioceno d'Italia associata dal Manzoni a quella dell'eoceno, dappoichè nella nostra le cellule sono più allontanate, e quindi più lunghi i tubi che le rimiscono. Sull' Ostrea navicularis: $1:$ S.

Membranipora. - 145. M. catenularia Jameson = 1. peduncolatu Manzoni. Una sola colonia sulla interna superticie del Pecten labissimus. R. P. V. - 146. MI. aperta Busk. Variabile nella forma delle cellule; questa forma si aftï bene alla figura data dal Manzoni. Incrosta le specie seguenti: Balamus concavus, B.tulipiformis, Pecten scabrellus, Janira Rabelliformis, J. Thegiensis, Anomia ephippium, Terebrabula calabra. I. 'T'. P. II. - 147. II. ir'egularis D'Orbigny. Aneo questa forma convicne bene colla figura del Manzoui. Sul Peclen scabrellus e sulla Janira flabelliformis. R. T. P. V. - 148. M. Fleming i i Busk. sul Pecton -scabrellus e sulle Junira Rhegiensis, J. iacobea, J. flubelliformis. 2. T. V. - 149. II. lineata Lin. Questa forma variabile offre sul marrgine dell'apertura talvolta i granuli che accemno alle spine orali, che in taluni rari casi si conservano ancora. Spesso essa assume la forma rapportatari dal Manzoni. Osservata sul Balanus tulipiformis, sul Pecton latissimus, sul P. opercularis, sull'Ostrea cochlear, e sull'Ostrea... r. T. P. M. S. V. - 150. M. diadema lieuss. Questa forma, che il suo scopritore ha riunito alla $1 \%$. Lacroixi, raceogliesi in magnitiei esemplari sul B. concavus, la Janira fabelliformis, l'Ostrea cochlear. Lin., l'Inomia ephippirm, la Terebratula calabra, la Negerlia eusticta, e parmi che essa si approssimi maggiormente alla $\%$. lineata per le sue spine orali, che sono molto regolarmente disposte sul margine fornito di granuli assai distinti. 1. T. P. - 151. II Lacroixi Sarigny. Questa specie comume incrosta sovente tutte intiere le varic conchiglie. Trovasi sulle seguenti: Balanus concavus, tulipiformis, spongicola, perforalus, Pecten scabrellus, pesfelis, latissimus, Janira flabelliformis, Ostrea cochlear, Boblayi, Anomice ephippium, Hegerlia eusticta, od anche sopra ciotloli. c. T. P. M. V. - 152. M. Po uille ti i dudonin. Le poche colonie rispondono esattamente alla forma del Crag e giacciono sulla J. fubelliformis o su qualche Ostren. R. P. - 153. Mr. fenestrata Reuss. Variabile e più o meno irregoline; giace sul Balanus concavus, sul Pecton hatissimus, sulla Janira flabelliformis. 1. 1'. - 
154. MI. anculos a Reuss. Questa, che ì la più comune tra le membranipore, dell'antico plioceno, raria considerevolmente secondo l'eta e perciò lo stato di calcificazione. La più comme forma del plioceno calabrese costituisce nua ben distinta varicti in cui le cellule trasformate in aricularî sono in numero poco minore delle ordinarie e quindi quasi regolarmente alternanti con esse. Incrosta le specie seguenti: Balanus concavus, tulipiformis, perforalus, Pcclen scabrellus. opercularis, latissimus, pesfelis, Janira flabelliformis, Rhegiensis, iacobea, Ostrea Boblayi, cochlcar. Tercbralula calubra, ed anche dei ciottoli. C. T. P. M. S. G. V. - 155. M. anmulus Manzoni. La specic presenta tutte quelle diverse variazioni che sono state indicate dall'antore. 'Trorasi sul Pecten scabrellus, I'. latissimus, Anomiu cphippium, A. striata, Ostrea ... e sopra ciottoli. 1. T. P. G. 1. - 156. M. stenostoma Reuss. Qualche colonia dublia. R. 'T. 157. M. exagona n. sp. Tar. XV. tig. 3.

Denomino cosi aleune piccole colonie in cui le cellule sono appianate, esagone o irregolarmente angolose, e portano un'apertura centrale arrotondata variabile in grantezza ma sempre piccola. Dulito che questa possa essere una forma della precentente specie, ma non ho trorato passaggi graduali. Trovasi sulla Janira fabelliformis e sull'Ostrea...

Diametro d'una cellula 0,3 .mm R. P.

158. M. Rosselli Audouin. Quelle poche colonie che vi rapporto lamno larga apertura alle cellule. Incrostano il B. Concavus e la Janira flabelliformis. I. T. P. V. - 159. M. in e omp ta Reuss. Riferisco a questa specie una membranipolia comune del plioceno antico, la quale ha le sue cellule orato-ellittiche e non pressochè rombiche come quelle della precedente, ciò non pertanto io non posso dissimulare la grande affinitit che scorgo tra queste due forme. Incrosta Pecten opercularis, P. scabrellus, Janira fabelliformis, Ostrea cochlear. c. 'T. P. - 160. M. hidens Hagenow. Rare colonie e picele che incrostano le segnenti conchiglie: Balanus concavus, tulipiformis, Pceton scabrellus, Janira flabelliformis. 1'. 'I'. P. - 161. II. formos a Renss. Questa bella specie è molto rara nel plioceno antico e trovasi sul Pecten scabrellus, la Janira fabelliformis, l'Ostrua . . . . R. T. P. - 162. M. a nd ega reus is Michelin (Eschera) Var. incisa. 1. Tav. XV. fig. 2. Denomino cosi una Membranipora che incrosta spesso assai largamente rarie conchiglie, quali il Pecten latissimus, il P. scabrellus, la Janira fabelliformis, nstrec cec. In essia la forma delle cellule un po' rariabile risponde precisamente a quella del Crag inglese figurata e descritta dal Busk; se non che le cellule rhe in quella sono trasformate in aviculari, ofriono rari forami sulla membrama che le chinde completamente, e nella nostra invece tali cellule sono piri rade e si presuntano eome intagli considerevolmente lunghi, perche sono d'ma grandeza maggiore ed invece di forami portano una larga e lunga fenditura. Una piecola colonia per la forma delle cellule molto si arvicina alla M. cxilis Manzoni, che forse donrà rignardarsi come modificazione della stessa. r. T. P. V. - 163. II. gracilis V. Munster (Cellepora) $=$ IT. gracilis lieuss. Questa forma che il sig. Waters vuole rimita alla precedente io ererto di dover tenere distinta prer un aspetto hen diverso col quale si presenta, dipendente dalla diversa conformazione 
delle cellule, dal margine di esse prominente, ed inoltre dal difetto di collutu che sieno trasformate in ariculari. Sul Balanus concovus, il Pecten scubrelleus. 1'Ostrea Boblayi. 1. T. P. - 164. M. palyyacea Theuss. Anco questa parmi distinta dalla \%. andegavensis alla quale l'associa Waters. Aleme colonic sulla Janiva Rabelliformis, e $1^{\prime}$ Ostrea cochleas". 1'. '1'. 1'.

Jepralia. - 165. L. formosa n. sp. Var. biamale. Tar. XIV. fig. 22.

Le colonie che denomino cosi mostrano evidentemente i caratteri della specie che raceolsi nel mioceno, ma se ne distingrono pella grandezza massima deghi avieularî, i quali hamno origine in contatto allovicello della cellula precedente, estendendosi sino oltre l'apertura: sono dne in ogni cellula, quasi sempre, ma d'ol'dinario disugnali in grandezza e non di rado manea l'oricello. Tali caratteri comunicano uno speciale aspetto allia colonia. Incrostia le Janira lacvicostala e flabelliformis ed il Balanus concavies.

Lunghezza d'una cellula 0.7 . nm 1 . T. P. M.

166. L. decoata Reuss. E questir tra le più comuni forme del plioceno antico del Reggiano; essa raria considererolmente ofliendo delle colonie mancanti di oricelli ed altre in cui ogni cellula ne è fornita. Gli ariculari sono mo o due per ciascuna celluliz. Le perforazioni sono rariabilmente manifeste. Vedesi sulle specie seguenti: Balamus concuvus, tulipiformis, perforabus, Peclen scabrellus. opercularis, latissimus, pesfolis. Janiva lacvicostala, Rhegionsis, flabelliformis, iacubea, Ilinnites crispus, II. lacvinsculus, Ostrea..... Anomia cphippirum. Terebratula calabra, T. Philippii, Hegerlia ensticta, Rhynchonella bipartita, ed anche sopra ciottoli. C. T. I. MI. - 167. I. coceinea Johnston. Tar. antiqua n. Questa comunissima specie si juesenta con caratteri considererolnente diversi nel plioceno antico delle Calabrie, allorchè si compara colle colonis che raccolgonsi negli strati recenti. Difatti nel plioceno antico le cellule sonn costantemente più jiccole, la scultura della superficie manea quasi del tutto. orrero è appena aceennatit, e solamente sono bene manifeste e profoule le crenature o incari marginali, siceome nella figura data dal lienss. La forma joi globoso-orata delle cellule is ben rara e ma tanto rigonfia quanto nella forma niù recente, invece ì conunissima una forma pressochè conico-ololonga. Varia molto inoltre per la grandezza degli aricularî e per la posizione piu alta a piì bassa di essi. In talune colonie le cellule sono tutte prolifere, in altre mancano tutte di ovicelli, re ne ha pure sorente alcune in cui le cellule molifere sono miste allu sterili. Le conchiglie su cui griace questa Lepralia sono tutte quante lo specie che si raccolgono nel plioceno antico di tutti i luoghi, non eselusi il clypeuster pliocenicus e l'Echinolampas sculiformis. C. T. P. M. V.

168. L. grandis n. sp. 'lay. XY. fig. 4

Cellule grandi orato-coniche rialzate ed irresolarmente associate insieme, collit superficie perforata; ai lati ciascuna cellula porta tuo o due avicularí aliformi. triangolari, più o meno sporcenti; l'apertura è ovale quasi troncata anteriormente c porta ai margini una serie di spine orali, che ri hamo lasciato le papille sulle quali orano impiantate. Questa specie è affine a rarie altre, mil si distingue bene dat tutte. Per l'apertura, le spine orali e liz posizione rilernta delle cellule 
somiglia alla L. disgiunta, ma la struttura della parete o gli aricularîne l'allontanano, quest" nltimi e le spine orali la distinguono dalle $L$. annulatopora e lucernula. L' unica colonia raccolta giace sulla Janira flabelliformis e nessuna delle sue cellule i) prolifera.

\section{Lunghezza d'uma cellula $1,50^{\text {mun }}$ R. 'T'.}

169. L. fulgurans MIanzoni. Questa specic nelle sue rariazioni numerose si appiana, c tende a perdere un ariculario o anco amberlue. Giace sulla Janira fabelliformis. R. T. P. MI. G. - 170. L. stren $n$ is Manzoni. Riferisco a questa specie una sola colonia allerente al una Janira flabelliformis; essa conviene ahbastanza colla figura data dal MLanzoni melia sua Ter zo Contribusione, specialmente pel suo abito e pei grandi pori marginali profondamente canalicolati; gli aricularî in molte cellule sono riclotti a più piccole dimensioni e con piccola apertura. Var. laciniate 1. Tav. XV. fig. 5. In riferiseo a questa specie una forma, che ritengo dubitativamente come insigne rarieta. la quale per l'abito e i grandi avicularî che cingono lapertura ricorda hene la forma tipica, ma oltrechè i forami marginali sono poco stiluppati, e superfeiali, il margine dell' apertura non is intiero ma diviso in otto lobi di cui i due anteriori sono piuttosto piccoli, e ricordano bene quelli che si nsservano nell'esemplare di Castrocaro, gli altri sei invece sono divisi da profondi intagli ed acquistano una forma allungata. Le colonie giacciono sul Pecten scabrellus e sulla Janira fabelliformis. R. P. Var. T. - 171. L. surgens Manzoni. Questa bella e distinta specie è poco rariabile: e risponde bene agli esemplari di Castrocaro. Incrosta Balanus concrvus. Pecion scabrellus, P. latissimus, danira Mhegiensis. Ilinnites crispus, Terebratula Philippii, Megcrlia custicta. c. T. P. M. - 172. L. innominata Conch. Questa Lepralia per la su rariahiliti viene rariamente rappresentata dagli autori; essa mar che porti talvolta grandi avicularì come nella seğuente specie, alla quale sembra far pissagrio, come opina Waters. Sui Peclen opercularis, scabrellus, latissimus, Janira Rabelliformis, Ostrea Boblay. 0. plecata, ece. I. T. P. II. V. - 173. L. scripta Reuss. Questa specie è anche essa molto variabile nel numero e la prominenza delle costole, sicenme nella presenza o assenza dei grandi arienlari e degli oricelli piu o meno carenati; r'hanno colonie in cui questi organi mancano quasi del tutto er altre in cui si vedono in pressochè tulte le cellule. Quasi sempre si constata ma grande regolariti nella forma e nella disposizione delle cellule di ogni colonia. Questa specie is tra le più comuni di questo piano e pereio incontrasi sopra quasi tutte le conchigrle dei rarî griacimenti. C. 'T. P. MI. V. 174. L. planicosta n. sp. =L. scriple? Manzoni. Ho creduto di dorer distinsuere questa forma dalla precedente. essa viene rappresentata dal MLanzoni tria i fossili di Custrocaro alle figure 25,25 ed associata dubitativamente alla $L$. scripte. Io che ho potuto esaminare numerose colonie di questa forma abbastanza comme in Calabria, ho riconosciuto che distinguesi sempre per le cellule molto appianate, per le costole mumerose, poco sporgenti e disgiunte da linee impresse, inoltre d'ordinario nell'associazione e nella forma delle cellule notasi ma irregolariti molto grande, a ditlerenza della specie precedente, ciasema cellula percio assune sorente ma diversa forma ed irregolare, e spesso diviene molto allungata nella 
sua porzione posteriore. Incrosta i Pecton scubrellus, latissimus, pesfolis, dunirc flabelliformis, Hinnites crispus, Ostrea cochlear ece. c. T. P. M.

175. L. Cala bra n. sp. Tav. XV. fig. 6, 6a.

Le cellule di questa specie sono piccole, quadrato-rombiche, quasi perfettamente piane e disposte in quinconce con grande regolaritil a costanza; la parete ì fortemente perforata, e ciascuma cellula porta una prominenza incrassata, tubulosa, perforata al di sotto della bocca, ed un solo ariculare prominente che disposto sulla destra ovvero sulla sinistra della cellula e senza mancare mai, si ripiega verso l'apertura, la quale è di forma semicireolire, coi margini prominenti, che portano cinque granuli poco appariscenti, inservienti all'inserzione di altrettante spine orali; nell'aviculare si aprono the forami, l'uno triangolare e l'altro semilunare; l'ovicello è molto prominente, globoso, alquanto allungato trasversalmente e colla superficie irta e rugosa per le prominenze di cui è fornita.

Dimensioni delle cellule 0,5 . $^{\mathrm{mm}} \quad 0,4$. $^{\mathrm{mm}}$

Questa specie è mirabilissima per la grande costanza dei suoi caratteri: essa ha costantemente il poro vibriculare centrale e un unico aviculario che non fa mai difetto. Le colonie che essa costitnisce hanno due aspetti diversissimi, in un caso mancano del tutto gli ovicelli e la colonia sembra un pavimento a pezzi quasi quadrati regolarmente disposti; spesso però tutte le cellule divengono prolifere e si hanno in tal caso delle colonie di aspetto molto diverso, perche in esse predominano gli ovicelli globosi e molto sporgenti sopra le cellule appianate; più raramente poi le colonie risultano di cellule prolifere miste a cellule sterili. La descrizione di questa specie puo farla giudicare una varieta della L. ciliata, ma essa invece a mio gindizio ne è distintissima, le cellule, costantissime nella loro grandezza, sono molto più piccole, appianate e non convesse, di forma quadrato-romboidale, poco variabili, gli ovicelli allungati trasversalmente, granulati ecc. ece. Trovasi sulle specie segueuti: Balanus concavus, B. tulipiformis, Pecten scabrellus, Janira flabelliformis, Hinnites crispus, Ostrea .... 0. cochlear. c. T. P. M. 176. L. ansata Johnston. Questa specie presenta tutte quelle variate morlificazioni che sono state descritte e figurate dal Reuss, dal IIanzoni e dir altri; la parete delle cellule è più o meno perforata e gli aviculari ridotti talvolta ad un solo, mancano del tutto in certe colonie o in parte di esse come noto il lieuss nei giacimenti miocenici. Trorasi sulle specie seguenti: Balanus concavus, tulipiformis, perforatus, Pecten scabrellus, opercularis, pesfelis, latissimus, Janira Rhegiensis, J. flabelliformis, maxima, Hinnites crispus, Ostrea Boblayi, cochlcar, Rhynchonella bipartita. c. T. P. M. V. - 177. L. areolata? Reuss. Piccola e duhbia colonia sul $P$. scabrellus. R. 'T. -178 . L. re supinata Manzoui. Parmi che questa specie presenti delle gradazioni verso la comune forma della $L$. cocciner del plioceno antico di Calabria. Sul $b$ be lanus tulipiformis e qualche altra specic. 1. T. P. MT. - 179. L. 13rollgniartii Aud. = L. capituta Reuss. La forma del mioceno parmi che sia lieve modificazione della specie virente. Nel plioceno antico questa specie oflice tutte le modificazioni conosciute, sicchè verlesi tanto colle cellule contigue, quanto con ispazî punteggrati intercellulari, silcome la figurò il Manzoni tra i fossili di 
Chstromo. Tromasi sulle conchiglie di Balanus lulipiformis, Pecten scabrellus, Janira flabelliformis, Hinmiles crispus, Ostrea Doblayi. O. cochlear, D. . . . . . Terebratula Philippii. r. T. P. M. T. - 180. L. biaperta Michelin. Identica al fossile di Castrocaro, d'ordinario con due ariculari per ciascuna cellula. Difficilmente si riconosce allorchè la colonia inrecelhando si calcifica. Sul $B a-$ lanus tulipiformis, Pecten scabrellus, Janira fllabelliformis. J. iacobea. J. maxima, Negerlia eusticta, sogra ciottoli. T. T. P. M. - 181. L. planata Manzoni. Essendo dordinario incrostate le colonie di questa specie. gli ariculari raramente presentano distinta e larga apertura. Sul Balanus tulipiformis. Pecten scabrellus, P. opercularis. Janira fabelliformis. r. T. If - 182. L. micans Janzoni. Belle e conserrate colonie sui Pecten scabrellus, P. opercularis, Janira Rhegiensis, \% Rabelliformis; I. iacober, Hinniles crispus. Ostrea ... O. cachlear, Rhynconella bipartita. Megerlia eusticta. r. T. P. M. 183. L. congesta n. sp. Tar. XT. fig. 7.

È questa una forma affine alla L. minutissima ed alla $L$. incisa, entrambe del mioceno. Distinguesi dalla prima per la forma più allungata delle cellule e per lapertura che presenta ma fenditura esilissima alla parte anteriore. bastantemente estesa, che si allarga all'estremita terminandosi in un forame. Quest'ultimo carattere la distingue dalla seconda specie, dalla quale allontanasi inoltre perchè talune celIule sono fornite lateralmente dun ariculario sporgente con ristretto forame. Nelle colonie inrecchiate la fenditura alla parte anteriore si allarga molto. In talune cellule troransi gli oricelli. Sul Balanus tulipiformis, e sui Pecten scabrellus, opercularis.

Lunghezza d'una cellula mrolifera 0,7 ma Larghezza 0,4om R. T. P. 184. T. marionensis Manzoni. Risponde bene alla figura dell'autore. R. T. II. - 185. L. Linearis Hassal. Incrosta le seguenti specie: Peclen scabrellus. opercularis, Janira iacobea, J. pubellifurmis, Ostrea .... 1. T. P. V. - 180. L. tenella Reuss. Questa specie risponde bene alle forme mioceniche descritte dal Renss. Trovasi sui Balanus tulipiformis, B. spongicola, Pecten scabrellus, P. apercularis, P. pesfclis, P. latissimus, Janira flabelliformis, Rhegiensis, Ostrea cochlear. D . . . . Terebratula Philippii. c. T. P. 187. L. rulgaris Moll. Wi riferisen ma colonia incrostante l'Ostrea Boblayi. R. P. V. - 188. L. tum id a Janzoni. Una piccola colonia sul Pecten scabrellus. Non sono conrinto della conrenienza di riunire questa alla precedente specie come fa il Waters. R. T. M. - 189. L. ciliata Pallas. Le varie forme che s'incontrano sono state illustrate dal Manzoni; tra esse è molto rara la rarieti figurata nella Terza Contribuzione tar. III. fige. 14, la quale si allontana molto dal tipo. Incrosta Balanus concavus, B. tulipiformis, Pecten scabrellus, P. pesfelis, Janira flabelliformis, J. maxima. Ostrea cochlear, 0.... Celleporaria. r. T. P. Y. - 19n. I. ple uropora Renss. Ti riferiseo con qualche dubbio una ríccola colonia che inerosta la Itegerliu custictn. 1R. T. - 191. L. IIorrisiana Busk. Belle colonie ora sterili ed ora fornite di oricelli sul Pecten latissimus, ?. repercularis, Ostrea cochear, O. . . r. T. P. - 192. I. crassilabra Manzoni. Distinta eprecie esattanente identica alla forma di Castrocaro. Le 
sue colonie giacciono sul Balanus concuvus, il Pecten latissimus, l'Ostrea.... r. T. P. - 193. L. cribrillina? Manzoni. Riferisco a questa specie, con grave dubbio, una colonia mal conserrata che incrosta il Pecten scalocllus. R. 'T. - 194. I. rarecostata Reuss. I miei esemplari convengono piì o meno bene colla forma tipica del bacino di Viema, dalla quale parmi differisea quella che vi rupporta il Manzoni. Sul Pecten scabrellus e la Janira flabelliformis. 1. T. P.

195. L. mitrata n. sp. Tar. XV. fig. $8,8 a$.

Questa specie somiglia alla $L$. innominala ma ne è ben distinta perchè le cellule sono piì grandi, ormate di costole prominenti in piccolo unmero, radianti, e disginnte da solchi profondi, perlochè il margine è fortemente crenato. Alcume cellule sono fornite di oricello mitreforme, il quale non è liscio ma irregolarmente costato e papilloso. L'apertura ha un peristoma inspessito considerevolmente, che presenta dei grauli in numero di quattro, sui quali s'inserirano les spine orali, due di esse restano occultate nelle cellule prorriste d'oricello. Var. radians 11. Tar. XY. fig. 8a. Le grosse costole che ormano i zooecii irradiano dal centro della superficie della cellula e sono disgiunti da soluhi piu larghi e più profondi. Trovasi sul Pecten latissimus, P. scabrellus, Ostrea Boblayi. Nelle colonie da me osservate nessuno ariculario si presentò. Una cellula prolifera è lunga 0,7 . mm r. T. P. 196. L. vaseula Manzoni. Poche e belle colonie sulla Janira flabelliformis e 1' Ostrea Bollayi, esaltamente identiche al tipo di Castrocaro. R. T. P.

197. L. eximia n. sy. 'Tav. XIV. fig. 2:

Cellule regolarmente disposte, di forma pressochè rettangolare, convessa, ornita di costole parallele poco numerose, che si estendono ai due lati perpendicolarmente ad una leggiera carena longitudinale mediana; l'apertura ì trasversalmente allungata e larga; l'oricello i orato a rovescio e lerigato. Questa bella e distintissima specie nou può renir confusa con altre per la sua originaliti: per quanto mi sappia essa non ha afini, se non nelle formazioni cretacee.

Lunghezza d'una cellula prolifera 0,57.mn Larghezza 0,31.

Le poche colonie raccolte incrostano l'Hinnites crispus, o l'Ostrea..... . '. 'l'. 198. L. Serulata Renss. Questa bella specie miocenica mi la oflerto tre grandi colonic, identiche a quelle che si raceolgono nel mioceno elveziano: esse incrostano Ia Terebratula Calabra e la T. Philimpii. R. T. - 199. Ls. rariolosa Jonhst. Var. 11. Le colonie che riferiseo a questa specie del Cring inglese hano le serobiculature marginali più o meno manifeste, la superficie delle cellule leggermente verrucosa, e due promineuze alla parte posteriore della bocea, come la varietir figurata dal Busk. Sulla Janira maximu. r. P. - 200. L. rentricosa Hassall. L'unica colonia, che incrosta l'interno di una valva di $P$. scabrellus, presenta nelle frominenze del margine orale, nella forma e caratteri tutti delle cellule e degli oricelli la maggior somiglianza colle forme del Cray inglese. K. 'L'. V.

201. L. adplessa n. sp. 'Tar. XY. 1ig. 10.

Questa specie si arvicina alla L. ventricosa, ma è ben distinta. Due o tre gribnuli alla parte posteriore dell'apertura che è piccola e rotondata, servono all'inserzione delle spine orali. Il labbro è rivolto in fuori alla parte anteriore e si 
allarga e s'inspessisce ai lati, allorchè la cellula è sormontata dall' ovicello, il quale è sempre molto piccolo. Le cellule in questa specie somo sdraiate sulla superficie che incrostano, e formano delle grandi colonie ramificate o meglio a larghi lobi.

Lunghezza d'mua cellula prolifera 0,7 .mm Larghezza 0,4 .

Incrosta il Pecten scabrellus. r. T. - 202. L. p y r if o r m is S. Wood, Non senza esitare io riferisco questo nome per talune poche colonie quasi circolari, che incrostano il Peclen scabrellus il P. pesfelis e la Janira flabelliformis, e che sono alquanto incrostate; pure la conformazione delle cellule e degli ovicelli corrisponde alla specie del Crag, l'apertura ì alquanto più larga. I. T. P. - 203. L. obolisens Manzoni. Riferisco a questa specie rarie piccole colonie, che per la forma e disposizione delle cellule e posizione degli ovicelli, parmi fi si debbano rapportare, quantunque soltanto in alcuna ho potnto appena scorgervi le punteggiature marginali. Trovasi sul Balanus tulipiformis, Pecten scabrellus, P. opercularis, Jenira flabelliformis, Ilinnites crispus, Rhynchonella bipartita. 1. T. P. 204. L. gib bosula Manzoni. Specie ben distinta per la forte perforazione delle pareti. S'incontrano grandi colonie ora provviste ed ora sfornite di ovicelli. Vi distinguo tre rarieti. Var. adpressa. n. Le cellule sono siraiate sulla superficie del corpo cui aderiscono. Var. erech. n. Cellule rilevate. Var. bidentata. n. L'apertura porta ai lati due denti più o meno sviluppati e rivolti in dentro, i quali restringono talrolta abbastanza l'orifizio. Giace sui Pecten scabrellus, P. pesfelis, Janira flabelliformis, J. Rhegiensis, Ostred cochlcar, 0. Boblayi, Ilinnites crispus. r. T. P. II.

205. L. macrocephala n. sp. Tav. XV. fig. 9.

Affine alla $L$. obcliscus, si distingue per avere la bocea ovata, piccola, colle labbra molto spesse, pegli ovicelli molto grandi ed allorchè vi esistono, l'apertura c le labbra si allargano molto. Sotto il labbro r'ha una prominenza poco manifesta, non perforata. Le cellule sono poco rialzate e formano piccole colonie.

Limghezza d'una cellula prolifera $0,8{ }^{\mathrm{mm}}$. Larghezza $0,5 .{ }^{\mathrm{mm}}$ R. 'T. P. 206. L. monoceros Reuss. Questa distintissima specie del Mioceno è comune assai nel plioceno antico delle Calabrie, dove si presenta cogli stessi caratteri e ben poco variabile. Gli ovicelli sferici si osservano soltanto sopra talune colonie. Trovasi sui Balanus tulipiformis, B. spongicola, B. perforatus, Pecten scabrellus, P. pesfelis. Janira fabelliformis. J. laevicostala, Ostrea cohlear, O. . . Anomia ephippian, Celleporaria. c. T. P. M. - 207. I. obvia? Manzoni. Rapporto con molto dubbio a questa specie qualche grande colonia in cui le cellule hamo molti caratteri che l'avricinano alla specie di Castrocaro: l'apertura si avricina molto ma is più irregoline, l'oricello meno largo e più lumgo. Snl Pecten scabrellus. r. P. - 208. L. It a ueri Reuss. Aneo questa risponde alla forma miocenica; essa varia negli omamenti e nel grado di seultura delle cellule, essendochè in molte colonie uquesta è quasi intieramente scomparsa. Incrosta le segnenti specie: Pecten scabrellus, P. pes/elis, I. lalissimus, Janira flabelliformis, Ilinnites crispus. Ostrea cochlear, Terebratula Philippii. c. T. P. M. 209. I. Iata 13usk. Forma delle colonie sorente estese. che incrostano le 
seguenti specie: Balanus concavus, B. tulipiformis, B. spongicola, B. perforatus. Pecten scabrellus, P. opercularis, P. latissimus, Janira flabelliformis, Ostrea . . r.T. P. M. V. - 210. I. c up u lata Manzoni. Il sig. Waters vuole riunita questa alla precedente specie; io la tengo distinta perchè mi mancano le transizioni. Le cellule delle poche colonie trovate nel plioceno antico sono piî piccole di quelle che io ho raccolte viventi nello stretto di Nessina, incrostanti la Columbella rustica. Giace sul Peclen scabrellus. R. P. V. - 211. L. rugulosa Reuss. Somigliante molto agli esemplari di Castrocaro. Sui Bulanus tulipiformis, B. spongicola, Pecten scabrellus, P. latissimus, P. opercularis, Janira lacvicostata, J. flabelliformis, Ostrea cochlear, 0. plicata. r. T. P. M. - 212. I. ceratomor plua Reuss. Questa specie rispoude bene alla forma del mioceno d'Austria, essa griace sui Pecten scabrellus, Janira fabelliformis. Hinnites crispus, Anomia ephippium, Terebratula calabra. r. T. P. M. - 213. L. I igulata Manzoni. Una colonia sul Pecien scabrellus. R. T. V. - 214. L. rudis Manzoni. Questa specie mostrasi considerevolmente rariabile nella forma delle cellule più o meno allungate, nel margine anteriore dell' apertura piì o meno ingrossato, . nell'assenza quasi ordinaria, o nella rara presenza dei larghi oricelli e finalmente nel grado rario di perforazione della parete. Inerosta le seguenti specie: Balanus concavus, Pecten scabrellus. P. opercularis, P. pesfelis, Janira flabelliformis, J.Jacobea.c. T. P. - 215. L. u m bouata Manzoni. Credo di dorere riferire a questa specie una Lepralia in varie colonie in cui il labbro inferiore dell'apertura è fornito d'una prominenza molto elevata; l'apertura è meno ristretta della forma tipica. Trovate sull'Echinolampas scutiformis varie colonie che incrostano la interna parete. 1 . P. - 216. L. Pallasiana Moll. Io riferiseo a questa specie una delle pii belle Lepralio dello Zancleano, che fa d'ordinario delle grandi incrostazioni, costituite da larghe cellule poco convesse, a parete pertorata da larghi pori, posti in fondo d'ineavi maggiori; l'apertura è grande, marginata, troncata in basso e ristretta in mezzo. Incrosta le specie seguenti: Balanus concavus, B. tulipiformis, Peclen opercularis, Janira flabelliformis, Ostrea Boblayi, Anomia ephippium, Chypeaster pliocenicus. 1. T. P. V. - 217. L. reticulata Macg. Rarissima tra le Lopralic dell'autico plioceno ealabrese sulla Janira phbelliformis, e la L. pertusc. R. T. P. V.

218. L. pratens is n. sp. 'Tir. XV. fig. 11, 11 $a$.

Dopo l'accurato studio che ho fatto di qnesta specie, parmi mroprio indubitato che le sue magoiori affiniti essa l'abbia colla specie precedente, tanto comune tra le rirenti del Mediterraneo. Essa intanto ne i ben distinta, forma delle colonie circolari o cllittiche di sei a otto millimetri di diametro, nelle quali sli zooecii sono disposti sopra linee rette o poco curve, che irradiano da un punto centrale, che nou è al centro della figura, e mano mano che si arricinano allat periferia tali linee si dividono e suddividono con rera dicotomia come ho cercato di rappresentare nelle due figure. Lic cellule, piccolissime al centro, ingrandiscono gradatamente e raggiungono la maggior grandezza al contorno della co. lonia. La forma loro ì convesso-oratil, e spesso sono molto sprorgenti in modn che un profondo soleo separa due ricine serié. Gli ovicelli troransi nella magrgior 
parte delle cellule e mancano specialmente in quelle più esterne; essi sono di forma ovata a rovescio. Lil bocea is rotondata con un intaglio poco distinto, e con una prominenza rotondata solto il labbro, la quale è più sviluppata nelle cellule piir piccole.

La lunghezza degli zooecii, trascurando gli ovicelli, va da $0,25 . \mathrm{mm}$ a $0,6^{\mathrm{mm}}$

Le varie colonie che lo raccolto incrostano il Pecten scabrellus, la Janira pabelliformis, l'Ostrea cochlear ec. r. P. '1'. M.

219. L. pertusa Lsper. I miei esemplari ricordano le diverse modificazioni illustrate dal Manzoni; essi incrostano il Balanus tulipiformis, il Pecten scabrellus, la Janirc flabelliformis, l' Ostrea .... R. 'T. P. M. V. - 220. L. sy stolos toma Manzoni. Qualehe colonia dubbia sul Pecten pesfelis ed il P. opercularis. R. T. M. 221. L. chilopora Reuss. La forma che io riferiseo a questa specie del mioceno d'Austria risponde bene, eccetto lievi differenze, alla figura data dal suo scopritore; ma è ben diversa dalla forma di Castrocaro che vi rapporta il Manzoni. La mia Lepralia ha la bocea un po' variabile in grandezza e sovente piì stretti di quanto lo mostrano le cellule figurate dal Reuss, inoltre il labbro inferiore non sempre mostra o ben poco una sporgenza mediana come in quelle. Le colonie incrostano le seguenti specie: Balanus concavus, "Pecten scabrellus, Janira flabelliformis, Tcrebratula Plilippii. 1. I'. P. M.

222. L. trigonata 11. sp. = L. chilopora Manzoni (non Reuss.). Chiamo cosi la Lepralia che il Manzoni riferì alla $L$. chilopora, e che parmi assai diversa dalla precedente. Vi lapporto intanto con qualche dubbio alcune colonie che incrostano una grande Ostrea. R. T.

293. L. deltostoma n. sp. Tav. XV. fig. 13.

Cellule ovali colla parete perforata, apertura triangolare, coll'angolo inferiore acuto che sorente si protende avanti, il peristoma ì più o meno riroltato in fuori, l'oricello è globoso, mressochè sferico. Le colonie di questa bella specie oftrono alcune cellule centrali sterili, e le altre, molto mumerose, sempre fornite del Ioro ovicello.

Lunghezza d'una cellula $0,6 .^{\text {mm }}$ Larghezza $0,3$. .mm $^{2}$

Questa forma di Lepralia ricorda a prima gime la specie precedente, ma le cellule ovali perforate ne l'allontanano molto; essa incrosta il Balanus tulipiformis, Pecten scabrellus, Janira flabelliformis, Ostrea . . . . 1. T. P. M. 224. I. tuba Nanzoni. Una piccola colonia sulla Terebratula calabra. R. T. 295. I. stellata n. sp. Tav. XV. fig. 12, $12 a$.

Le collule sono piccole tubulose erette, con un'apertura pressochè circolare e disposte sempre con molta regolariti sopra linee rette, lasciando profondi e larghi interstizi tra una serie e l'altra; gli ovicelli di cui la maggior parte delle cellule sono fornite sono globoso-sferici, ma bene spesso si allumgano alla parte superiore e divengono piriformi o si deformano altrimenti, ed in tal caso sovente otirono mn' apertura superiore. spesso dal lato della bocea sono smarginati overo intagliati, ed ì notevole come la magrior parte delle colonie othie i suoi ovicelli distrutti. Le serie di cellule sono disposte in ogni colonia con grande regolariti, esse sono sempre retie, sei piu lunghe partono da un centro corrispondendosi a 
due a due sulle medesime rette, e divergenlo tutte ugualmente por angoli di lion: tutte le altre serie di cellule si dispongono con esatta equidistanza parallelimente alle sei principali, in modo da riempire gli spazi da quelle lasciati.

Lunghezza d'una cellula 0,5 ."mm Larghezza 0,2."mm

Questa Lepralia per la forma delle cellule senza oricello si arvicina alla L. crassu Reuss, ma ne è da quella distintissima per molte ragioni. Trovo questa specic incrostante il Balanus concavus, i Pecten opercularis, $P$. scabrcllus, $P$. latis. simus e la Janira flabelliformis. C. T. P. M.

Celleporaria. - 227. C. tubigera Busk. Questa specie è al certo la piì comune tra quelle che raccolgonsi nel plioceno antico di Calabria; essa costiunisce delle piccole e delle grandi masse irregolari più o meno arrotondate che aderiscono ad ogni specie di conchiglia. c. T. P. MI.S. V. - 228. C. e dax Busk. I'unico esemplare che ri rapporto è cilindraceo, con un forame che lo percorre nella sua lunghezza, e quantunque in non buono stato, per la picciolezza, la forma e la posizione della bocca in ciasema cellula, io credo poterlo bene associare alla forma del Crag inglese. R. P. V. - 229. C. polythele Reuss. Riproduce bene le figure date dal Manzoni, e costituisce anco delle masse in forma di more. R.T.P. 230. C. retusa Manzoni. R. T. G. - 231. C. ramulosa Linneo.x. T. P. G.Probabilmente altre specie dorrebbonsi distinguere, ma in questo genere sono troppo ardue le difficoltà che s'incontrano nell'apprezzamento dei caratteri, sopratutto pel cattivo stato degli esemplari fossili.

Wschara. - 232. E. foliacea Lamk. Questa specie vivente trovasi in piccoli frammenti nel plioceno antico. r. T. P. M. V. - 233. L. Sedg w ich ii Edwards. Pochi frammenti sono quelli che riferisco con qualche dubbio a questa specie. r. 'T. P. 234. E. pertusa Edwards. Questa bella e distinta specie si presenta nel nostro plioceno con tutti i caratteri coi quali raccogliesi nel Crag, vi si trovano difatti degli esemplari conservatissimi con molte cellule prolifere. r. T. P. M.

235. E. microtheca n. sp. Tav. XV. fig. 14.

Questa specie forma delle espansioni sottili, ramificate, che risultano dall'associazione di numerose piccole cellule, le quali variano nella forma globosa, presentando spesso due prominenze ai lati dell'apertura, che è di forma arrotondata, d'ordinario sormontata da un oricello globoso-orato più o meno intagliato alla fronte, con due sporgenze alla base dove s'inserivano due spine orali; tali ovicelli spesso sono distrutti alla loro parte anteriore.

Lunghezza d'una collula 0,43 . $^{\mathrm{mm}}$ Larghezza $0,3{ }^{\text {mm }}$

La E. microtheca è una distinta specie, che parmi non possa renil confusa colle gia note per la picciolezza e i caratteri delle sue cellule, che in numero stragrande sono associate con poea regolarita sopra ciascuna faccia del polizoario. r. 'T. P.

E. quatrilatera n. sp. Tar. XV. fig. 15.

Di questa Eschara io non ho trovato che un solo frammento, di forma sottile ed appianata, le cui cellule quadrangolari e quasi quadrate presentano una grande regolarita nella loro disposizione, con una apertura semicircolare intagliata inferiormente, con un grande aviculario e colla superficie quasi appianata punteggiato-lugosa. Tali caratteri distinguono dalle specie conosciute la descritta, ma 
essi d'altro canto ricordano la $L$. ansata in una delle sue numerose forme; per ammettere un tale ravvicinamento sarebbe d'nopo riguardare il fossile descritto siccome lo stato escariforme della L. ansata. Ta raceolta di nuori materiali relativi potrit rischiarare un tale argomento.

Lunghezza d"una cellula 0,7 .mm Larghezza 0,5 .

236. E. li chenoides Lamark. Di questa specie trovansi bei pezzi di perfetta conservazione, alcuni dei quali ofirono rari oricelli. r. T. P. V. - 237. E. mon ilifera M. Edwards. E questa la più comme Eschara del nostro plioceno inferiore; essa presentasi in rami beu conservati, mal riconoscinti allorehè sono invecchiati, essendoche si calcificano eccessivamente facendo scomparire la distinzione delle cellule. In alcuni rami ho potuto rarvisarvi delle rare cellule prolifere, che offrono i grandi oricelli solcati radialmente; in tal modo riconoscesi perfetta la comispondenza colla specie del Crag inglese. c. T. P. M. G. - 238. E. und u lata Reuss. Qualche raro ma ben caratteristico esemplare. R. P. - 239. E. cerricornis Lamarck. Questa specie, rarissima a Castrocaro, è invece molto comune nell'antico plioceno di Calabria. c. 'T. P. M. A. G. V. - 240. E. col u m n a r is Manzoni. Questa bella specie, di forma cilindracea, sembra-caratteristica di questo piano. I'. 'I. P. G.

Binusira. - 241. B. Savarti Aud. Questa importante e comune specie par che debba associarsi alla $B$. delicutula Busk del Crag d'Inghilterra; essa risponde esattamente alla forma di Castrocaro descritta dal Manzoni. c. T. P. M. V.

Melicerita. - 242. M. Charleswarthii M. Edwards. Questo bel briozoario è un importante acquisto per la nostra pliocenica fauna, ed inoltre aggiunge ancora un dato ai tanti caratteri di ravricinamento che evidentemente esistono tra il plioceno inferiore dell'Italia meridionale ed il crug corallino dell'Inghilterra. I miei esemplari rispondono esattamente alla descrizione e alle figure date dal Busk pei fossili del Crag. r. 'T. P.

Icmiesehora. - 243. H. imbell is Busk. Ecco un'altra specie propria del Crag inglese. R. T, P.

Retepora. - 244. R. cellulosa Lin. Questa specie è la comunissima tra le riventi del Mediterraneo.r. T. P. MI. G. V. - 245. R. simplex Busk. Un po' dubbiamente riferisco questa specie. I. T. P. G.

Cupularia. - 246. C. Re us siana Manzoni. Di questo genere ho raccolto duc soli frammenti che riferiseo alla nominata specie. R. T. P.

Crisia. - 247. C. fistulosa Heller (non Busk) $=$ C. Haueri Reuss. Per questa specie dorrebbesi ritenere il nome dato dal Reuss. R. T. T. - 218. C. Edwardsi Reuss. Secondo il Manzoni e il Waters questa specie dorrebbe forse associarsi alla C. elongata M. Edwards. I. T. P. - 249. C. Hoernesi i Renss. E questa la forma di Crisia che vedesi comunemente nel plioceno antico delle Calabrie. e. 'L, P', II, S, Po, Me, Pa. Se.

Almoner. - 250. I. crassa n. sp. Tar. XV. fig. 16,16 a.

Questa specie, che parmi non potersi associare a reruma delle gia note, si distingue perche costiluisce una spogrlia di forma allungata, ma ablastanza larga e spessa; le largho serie di rooecii costano d'un variabile numero di tubi, da cuattro 
a sette, e sono disposte molto obliquamente e con poca regolariti ; la faccia posteriore è convessa abbastanza, con linee longitudinali appena discemibili e fornita di solchi e di rughe e piegature trastersali di accrescimento di varia ed irregolare grandezza.

Lunghezza del ramo figurato $9 . \mathrm{mm}$ Larghezza $2, \%$ m $\mathrm{m}$ R. P.

250. I. conferta n. sp. Tav. XV. fig. 17, $17 a, 17 b, 17 \mathrm{c}$.

Questa $\boldsymbol{i}$ (lmonea forma eleganti cespugli a ramificazione dicotoma, cle per la brevita dei rami e la loro divergenza molto forte acquista mo speciale aspetto; le serie zooeciali sono ben poco oblique, molto rarvicinate, e constano ciascuna di cinque cellule; la faccia posteriore del briozoario i poco contessa, quasi appianata, ed offre leggieri solchi di accrescimento arcuati, trastersali, irregolari.

Dimensioni dell'esemplare figurato: Larghezza 1. ${ }^{\mathrm{mm}}$ Lunghezza 2,3. $\mathrm{mm}$

Questa bella specie è distinta per la forma generale del briozoario, nonchè pel ravicinamento delle serie zooeciali, dal quale carattere ne ho derivato il nome specifico. r. T. P.

251. I. producta n. sp. Tar. XV. fig. 18, 18a, 18b, 18c.

Questa forma è molto affine alla precellente, della quale potrebbe essere in rero una insigne rarietiv. Essa distingnesi pei rami più gracili, pel la superficie posteriore piì convessa e con rughe trasversali piin forti, per le serie zooeciali meno rarricinate, più sporgenti e formati da quattro cellule.

Lunghezza dell'esemplare della fig. 18:2. mm Larghezza 1. ${ }^{\mathrm{nm}}$

Questi ultimi caratteri delle serie di cellule dàno un direrso aspetto al briozoario, il quale d'altronde ha un portamento analogo a quello della specie precedente. c. T. P. G.

252. I. ir egularis Meneghini. Di questa specie qualche solo frammento ben caratterizzato. R. P. V. - 253. I. lineata (Hag) Reuss (MI. S.) Manzoni. Anco questa specie rispondente alla figura data dal Manzoni è estremamente rara. R. P. V. - 254. I. gracilis Meneghini. Riferiseo a questa specie una forma fossile abbastanza comune, la quale ha d'ordinario le serie zooeciali molto corrose; la faccia posteriore è appianata orrero alquanto convessa e la figura del briozoario risulta più o meno distintamente triangolare. Var. teretiuscula. n. Questa è meno distintamente trigona. Var. crilis. n. Forma ancor piu gracile colle serie di celInle più strette e piì rarricinate. c. T. P. V. -255 . I. trif or is Heller. Arolto affiue alla precedente; questa specie distinguesi per avere tre zooecii in ciascuma serie. R. T. S. V. - 256. I. concara Reuss. Riferisco a questa specie dell'antico Terziario di Crosara, e trovata rivente a Napoli dal Waters, alcuni pochi esemplari del plioceno antico, i quali sono alquanto concari orvero piani sulla faccia posteriore. r. T. P. G. S. V.

Iornera. - 257. H. froud iculata Tamk. Sono rari molto i frammenti riferibili a questa specie; taluni formano una distinta rarieti per arere la faceia posteriore più scabra, inoltre perchè irta di papille. r. T. P. V. - 258. H. striala M. Fdwards. Qualehe frammento che risponde agli esemplari del Cring ed alle figure date dal Manzoni. R. T. - 25.?. H. Reuss i i . sp.: - It. hippolithus (Reuss) IIanzoni. Questa specie come bene osserra il Itanzoni non corrisponde alla $/ 1$. 
hippolitha di I)efrance e dei vari antori; la scultura diversa e ben distinta ne la separano a dirittura ed i pereio che mi sono deciso a denominarla in onore del leuss che la raccoglieva nel primo nel bacino di Viema; gli esemplari del plinceno di Calabria rispondono henissimo a rquelli illustrati dal Manzoni. r. 'T. P.260. H. hippolithus? Defrance. Riferisco con molto dubbio a questa specie taluni frammenti, che quantunque sulla loro superficie non oftrano la seultura indicata dal Busk, pure taluno di essi spettando alla porzione basale mostra eridentemente l'ahito di quella specie. R. T. - 261. H. serrata Reuss. Var. plincenica 11. Tar. XV. fig. 19, 19a. È questa l'flornera pì comune che raccogliesi nello Zancleano calabrese, essa differisce ben poco dalla forma trorata nell' antico terziario di Crosara, illustrata dall'autore; alquanto piiu gracile, colle pieghe divergenti della superficie posteriore alquanto meno distinte, forma una varieti pliocenica, che ben poco differisce dal tipo del Vicentino. I. 'T. P. A.

262. H. simplex n. sp. Var. impressa n. Questa forma del mioceno superiore mi ha offerto qualche frammento nel plioceno, il quale mostra la scultura pii fortemente impressa e quindi costituisce una rimarcherole rarietì. R. 'T. 263. H. oylindracea n. sp. Tav. XV. fig. $20,200,21$.

Questa rarissima Hornera forma un briozoario pressochè cilindrico, la superficie anteriore ofire $\mathrm{i}$ zonecii disposti in quinconce con molta regolariti, ciascuno di essi è delimitato da due linee rilevate longitndinali, l'apertura circolare presenta un margine alquanto rilerato e sporgente sulla superficie; dne serie di doppie cellule poi si dispongono longitudinalmente ai lati e i zooecii sporgono colle loro estremità orali alquanto più degli altri e damno al briozoo una dentellatura ai due margini rara e breve. La superficie posteriore è un po' meno convessa ed ornata da linee rilevate, longitudinali, dicotome, che mettono capo ali zooecii delle serie laterali o pressochè analoghe a quelle che oftre l'Idmonea vibicata Manzoni. La superficie tutta è finamente punteggiata. Var. prominens n. fig. 21. Questa speciale forma differisce dalla precedente perchè tutti i zooecii hanno l'estremità superiore molto piì prominente, di modo che il briozoo acquista ben altro aspetto e sembrerebbe dorersi riferire pinttosto al genere filisparsu; ma essa non può disgiungersi dalla specie in esame, perchè conserra tutti i caratteri di scultura della superficie anteriore e posteriore, siceome la specialissima disposizione delle due serie di cellnle marginali, nelle quali i zooccii si associano a due a due. In questa rarieti notasi ancora una ninore regoluiti nella disposizione zooeciale. Lunghezza dell'esemplite della fig. 20: 1, 9.mm Larghezza 0, 9, man R. T. P.

mosparsa. - 264. F'. va rians Reuss. Non v'ha dubbio alcuno che gli escmplari da me riferiti a questiz specie rispondano bone a quelli dei varî piani del mioceno, r. T'. P., S.

265. T. lata. 11. sp. Thr. XV. fig., 22, 22a.

Questo grande e bello briozullio si sarebbe tentati a urima giunta di associarlo alla precerlente specie, dialla quale ne ì ben distinto. Fortemente compresso o dilatato, ha le face appiamate orvero alquanto concasa l'anteriore e un po' conressa la posteriore; i zooecii numerosi sporgono molto sulla superficie comune ed in forma di tubi ciliulrici a larga apertura, del diametro stesso della cariti 
e sono poco ordinatamente distribuiti, quantunque pressoehè equidistanti; la superficie estema è segnata da numerose sughe trasversali arcuate c da più fine striature parallele, intersecate da linee longitudinali e da esilissime pieghe appena discernibili. Gli esemplari che possiedo sono per la maggior parte coll'estremità bipartita.

Lunghezza del ramo figurato 5,8 ${ }^{\mathrm{mm}}$ Larghezza dello stesso 5,9 $\mathrm{mm}$

Questa mia specie si avvicina alla $F$. tipica Manzoni, ma la forma cilindrica dei zooecii, la sporgenza e la disposizione loro ne la distinguono a prima giunta. $\therefore$ I. P. H. A. (i.

Eatulophora. - 266. E. a no mala Reuss. Vi rapporto la forma che il Manzoni ha illustrato e talune altre a quella molto affini. I. T. P.A.

Postulopora. - 267. P. rugulos Mamzoni. Esemplari di forma varia, ma più gracili di quelli illustrati dal Manzoni. 1. 'L'. P. A. - 268. P. proboseina? Manzoni. Un sol frammento non ben determinato. R. P. M. - 269. P. probos cidea Johnst (Pustulipora). Belli e distinti esemplari ramosi. r. 'T. P. M. V. - 270. P. clavata Busk. Di questa specie propria del Crag inglese si raccolgono magnifici rami perfettamente dicotomi. I. 'T. P. M. G. - 271. P. clavula Reuss. Belli esemplari che rispondono a quelli illustrati dal Mauzoni e dal Reuss, ma la maggior parte di essi ha forma compressa 1. P. 1'. - 272. P. clava eformis Busk. Riferisco a questa specie un solo esemplare molto ingrossato alla parte superiore, e che parmi offrire nei suoi zooecii i caratteri assegnati dall'autore. Ii. T. Y.

Tulunipora. - 273. T. palmata Smith. Rapporto a questa specie alcune poche colonie che trovo staccate dal corpo cui aderivano orvero impiantate sopra frammenti indeterminabili di conchiglie. R. T. P. I. G. V. - 274. 'I. ventricosa Busk. Di quest' altra specie nordica conosco un solo esemplare. R. P. V. 275. T. serpens Lin. Uni molto caratteristica colonia di questa specie l' ho trovata sull' linnites crispus ed altre sul Pecten scabrellus e sulla Janira Rabelliformis. r. T. P. T. - 276. T. foliacea Reuss. Tar. XV. fig. 24. Gli esemplari che io riferisco a questa specie discordano molto da quello che vi rapporta il Manzoni, che d'altronde dichiara apertamente non convenire colla figura del Reuss; i miei invece parmi che si aceorlino con quella, essi formano delle grandi espansioni incrostanti, che si dividono e suddividono in larghi lobi arrotondati, colla superficie tntta irta di tubi rarvicinati, equidistanti, piì o mene prominenti, verticali, o meglio leggemente inclinati. Qnesta specie incrosta il Balanus tulipiformis, il Pecten scabrellus, il P. latissimus, la Janira flabelliformis, la Megerlia custicta. Y. T. P. M.

277. 'I'. seriatopora n. sp. 'l'ar. XV. fig. as.

Questa bella specie distinguesi eminentemente da tutte le altre: essa forma delle colonie di piceole dimensioni per lit picciolezá rimarcherole delle cellule. Ie colonie formauo delle espansioni incrostanti antogamente alla precedente specie, edivise come quella in ramificazioni ed in lobi, che assumono forme piu allungate e piir snelle; la superficie è coprerta di cellule obliquanente disposte, molto ravicinate ed ordinate in serie, che si associano parallelamente, disponemlosi 
sopra ciascuma espansione sotto forma pinmata più o meno regolare. Tutti questi caratteri distingnono e deteminano con precisione la nuora specie. Dimensioni dell' esemplare figurato:

Lunghezza 3. ${ }^{\text {mn }}$ Larghezza $3 .^{m m}$

Le poche colonie possedute inerostano il Pecten scabrellus, 1' Hinnites crispus, l'ystrea cochlear e l'Echinolompas scuhformis. r. T. P. M.

278. 1. Habellaris Fabr. Questa comune specie olfre numerose forme nelle sue varie colonie, che incrostano Balanus concaus, B. hulipiformis. B. spongicola. Peclen scabrellus, P. opercularis, P. pesfelis, P. latissimus, Janira fubelliformis, J. Rhegiensis, J. incober, Ilinnites crispus, Ostrea cochlean, 0 . . ec. e. T. P. M. S. V. - 279. 'T. p hal angea Couch. Incrosta le seguenti specie: Pecten scabrellus, Janira Rheyiensis, J. flabelliformis, Ostrea cochlear, O. . . . r. T. P. V. 280. 'T. fas e ic ulata r. su. 'Tav. XV. fig. 25.

Questa magnifica specie appartiene al gruppo delle Tubulipore composte, secondo il Mauzoni. Difatti da un ceppo comune irradiano i tubi molto allungati ed associati insiene formanti delle serie a doppio ordine, che costituiscono delle lamine elevate, incurvate, variamente flessuose, che si dividono e si suddividono mano mano uhe si allontanano dal punto centrale originario e s'inspressiscono verso la periferia acquistando talfolta una terza serie di collule. La forma d'insieme che acquista la colonia tende presso a poeo alla circolare, nella quale le lamine riescono irradianti con molta irregolariti, dappoichè in origine i tubi partono da un ceppo commue e le lamine che esse costitniscono in numero di quattro o cinque, che e immediatamente si moltiplicano per suddirisione, si spingono in alto divergendo come i rami di un albero, ma bentosto le due più basse s'incrirano e con esse tutte le altre in vario grado: quelle due prime vanno a cingere uno spazio più o meno arrotondato attorno il ceppo comune e toccandosi colle loro estremitic si anastomizzano, e seguite poi dalle altre nel loro andamento, vanno a disegnare alla intiera colonia uno spazio pressochè circolare. Diametri di due colonie: 12. ${ }^{\mathrm{mm}}, 13,4{ }^{\mathrm{mm}}$

Questa mia specie è affine alla T. limilliata Reuss dalla quale differisce per la forma generale, per la mancanza di tubi centrali isolati, per un nmero assai maggiore di raggi tubuliferi ec. Inerosti le specie seguenti: Balanus concavus, B. spongicola, Pecten scabrellus, P. opereularis, P. pesfolis, Janira flabelliformis. Ilinnites crismus, Ostrea plicata, Echinobumpas sculiformis. 1. T. P. M.

Diastoponst. - 281. D. 1 a tiu a Smith. I miei esemplari in vero non sono esattanente quali li deserive il Manzoni, ne perfettanente convengono colle figure dello Smith e llel Busk ma conviene a mio credere associarveli come forme intermedie. Inerostano: Pecten seabiellus. I'. opercularis, P. pesfelis, Janira fabelliformis, J. maxima, Ostrect cochleat, 0. plicata ec. r. T. P. M. T. - 28:. D). latumarginata I)' Orb. Questa che is lil specie più comure del plioceno callabrese, parmi corrispondere bene alla ligura data lal sig. Waters, quindi mi appiglio alla sua definizione specilica. Giace sulle speeie seguenti : Balanus concavres, B. spongicola. Peclen scalrellus, P. opercularis, P. pes/clis, Janira faLelliformis, Ostrea ... Echinolampas scutiformis. c. T. P. M. Y. 
283. D. simplex Busk. Io troro i miei esemplari concordanti colle figure delle colonie viventi date dal Busk, e non saprei associare questa forma alla D. flabellum Reuss, come fu il Waters. 'Trovasi sulle segnenti sprecie: Bulunus concevus, B. tulipiformis, Pecten scabrellus, P. pesfolis, P. latissimus, Janira furbelliformis, Ostrea cochlear, Ostrea.... r. T. P. V. - 284. D. conges ta? Worbigny. Vi rapporto dubbiamente alcune colonie mal conservite che criaceiono sul Pecten scabrellus. R. T. V. - 285. D. flabellum Reuss. Vi rapporto qualche raro esemplare. R. P.

Discoporella. - 286. D. radiata Aud. (Melobesia). Mostrisi con rariti sopura: Balanus concavus, Pecten scabrellas, Janira flabelliformis, Jomaximu, Ostrea cdulis, 0.... Echinolumpas scutiformis. r. T. P. T. - 287. D). verrucaria Fabricius. Belli e conservatissini esemplini soura le seguenti conchiglie: Balanus perforatus, P'ecten scabrellus, Junira fabelliformis, Terebratula Philipprii ec. I. T. P. M. V. - 288. D. hispida Flem. = D. echimulata Reuss. Questa specie è talvolta ben conservati nel deposito del plioceno antico. Trovasi sui Balanus tulipiformis, B. perforans, Pecten scabrellus, P. pesfelis. Janira fabelliformis, Terebratula Plilippii ee. I. T. P. M. V. - 28?. D. stell if o rm is Reuss. Riferisco a questa specie miocenica aleune piccole colonie, che sembrami abbiano i caratteri proprii della specie del Renss. Sopria Balenus tulipiformis. Pecten scabrellus, P. pesfelis, Janira Rhegiensis, J. flabelliformis ee. I. T. P. II.

Arecto - 290. A. repens Wood. Questa specie primi che risponda bene agli esemplari del Crag, sembrami diversa pero dall'A. major a cui l' associa il Busk. Trorasi sulle conchiglie di Balanus concavus, Pecten scabrellus, P. cpercularis, P. pesfolis, Janira fabelliformis, J.laerionstata. Himites crispus, Ostrea cochlear, 0....ec. C. T. P. M. V. - 291. A. dilatans W. 'Lhompron. Di questo genere è questa la spuecie più comme del plioceno antico di Calabria; essa forma delle grandi colonie, che espandono largamente le lono ramificazioni sopra estesa superficie, ciascuna delle quali dilatasi più o meno largamente alla sua estremiti. Incrosta mumerose conchiglie quali le seguenti: Balanus concavus, B. tulipiformis. B. perforatus, Pecten scabrellus, P. opercularis, Janira laevicastata, J. Nabelliformis, Jo iacobea, J. Khegiensis, llinniles crispus, Ostrea cochlear, O. elulis, O. Boblayi, Anomia ephippium ut. c. T. P. M. V. - 292. A. castroearens is MLnzoni. Questa distintissima specie forma delle colonie allatto identiche a quelle di Castrocaro, e i zooccii sono solidi e conformati esattamente come nel tipo. Trorasi sul Pecten scabrellus, sulla Janira Rhegionsis, sull' Cstrea navicularis, sull'O. cochlecir, sul .Y!riozoon truncatum e sui ciottoli. r. T'. P. M.

Patinellat. - 293. P. proligera Busk. Riferisce a questa specie del Crag titluni esemplari del nostro plioceno, i quali mi lasciano ynalche dubloio; uno tra essi essendo costituito dall'associazione di varie colonie ricorta in qualche modo la figura a del Busk. R. 'T. P.

294. P. Manzonii. n. sp. 'Tay. XV. fig. $2 t^{3}, 26 a, 26 b$.

Chiamo cosi un unico briozov raccolto at Terreti, il quale presenta i seguenti caratteri: forma irregolarmente conica e molto allargata, prira di pectuncolo, 
solcato-striata all'esterno, colla superficie superiore appianata per oltre cinquanta lamine radiunti di varissima estensione, le quali partendo dalle pareti si dirigono verso il centro raggiungendolo soltanto alcune, e le altre restandosi a raria distanza, risultando tutte dall'associazione in unico ordine di tubicelli pressoche retti e rerticali.

\section{Larghezza 5,2..$^{\text {rnm }}$ Altezza 1,9. . $^{\mathrm{mm}}$}

Questa specie è distintissima dalla P. cyathiformis Manzoni, sopratutto pel gran numero di cellule ehe racchinde: nè credo che le convenga bene il genere Patinella, alla quale io la rapporto provvisoriamente, sembrandomi quasi evidente che questa non sia congenere alla precedente specie sulla quale il genere renne fondato. R. T.

Domopora. - 295. D. truncata Jameson (Millepora). Alcuni esemplaretti ricordano bene colla loro costituzione questa specie virente nei mari del Nord. Ii. I'. I', Y.

Frondipora. - 296. F. reticulata Blainville. Di questa specie occorrono soltanto piccoli frammenti, che farebbero credere colle loro forme, più grandi delle riventi, non solo a specie, na anco a forma generica diversa. r. T. P. A.S. V.

Cerioporat. - 297. C. globulus Reuss. 10. T'. P. G.

meteropora. - 298. H. clavata Busk. Vi riferisco enn dubbio un esemplare pinttesto voluminoso, globoso, a superficie rotondata. R. P.

\section{Tipo. ECHINODERMI.}

Oasse. Echinidi. - Ordine. Rerolari.

Charis. - 299. C. sosalia Bromn. Un frammento del guscio, ben caratterizzato dai grossi tubercoli forati e crenati tutto in giro. R. T. - 300. C. Soldauij Meneghini. Alemi frammenti di guscio e di radioli. R. T. - 301. C. If unsteri E. Sismonda. Vi riferisco taluni pochi radioli di cui alcuno che è completo nell'estremita jarticolare offre le caratteristiche crenature. r. T. P. Va. - 302. C. marheritifera? Meneghini. Qualche articolo molto dubbio. R. 'T. - 303. C. tessurata Meneghini. Questa piecola specic, assai ben distinta per la forma e scultura dei suoi radioli, a la più comme e parmi caratteristica di questo piano inferiore del plioceno. c. 'T'. P'. M. S. G. Va.

Borocidaris. - 304. 1), pa p il 1 a ta. Leske, Cidaris) Cidarites hystrix Lamarek, C.aflinis Phil, Dorociuluris abyssicole $\Lambda$. Agassiz. Riferisco a questa specie tanto variabile varî radioli che difteriscono nel numero e nella prominenza delle costelle serghettate, I: 'I'. P. II. V.

Centrostephamuss. - 305. U. longispinus Philippi (Diadema) - Diadema ezroprezm Agrissiz. A mio eralere sin dill'antico plioceno questa magnifica sprecie is comparsa nella regione metiternanea, dippoichè in tutti i lnoghi fossiliferi di questo piano si raceolgono i frammenti dei lunghi radioli, che per la loro struttura e gli altri caratteri tutti rispondono bene nel ralfironto colla specie vivente. r. 'T. I'. M. (T. S. I'.

Eehinus. - 306. L. mierotuloreulatus Blainville - Psammechinus 
microtuberculutus Agassiz, E. miliaris Risso (non MInller), E. pulchellus $\Lambda$ gassi\%. Var. pliocenica. Alemi esemplari di mediocre conservazione racolti in rari luoghi si offrono abbastanza somiglianti alla specie cni li riferiseo; solamente i tubercoli delle maggiori serie sono alquanto più grossi. r. T. I’. V. - 307. L.. Romanus Merian. Un solo esemplare. IR. P.

Stirechinus. - 308. S. precursor. n. sp.

Questo echinide ha molta somiglianza all' mico congenere sinora conosciuto, 1o S. Scillae, tauto comme nell'Astiano dell'Italia meridionale, ma esso distinguesi bene pei caratteri seguenti: la forma generale ì somigliante molto, mentre i solchi che disgiumgono le serie di tubercoli sono appena accennati, i tubereoli sono grossi e prominenti, quelli delle serie interambulacrali sono molto più ravicinati di quanto si osserrano nell'altra specie, e cio arriene per la relativa bassezza delle placche interambulacrali; invece i tubercoli delle serie ambulacrali alquanto piu piccoli degli altri sono più allontanati e cio per una particolare disposizione delle placche, le quali invece di essere altissime, come nella specie tipica, sono bassissime, e portano i grossi tubercoli altemativamente, essendo la placca senza tubercolo ancor piu bassa della tubercolatia per cccezione si osserva di tanto in tanto che due placehe consecntive portano i tubercoli; i tre paia di pori che porta ogni placea sono pel li bassezza di questa molto ravricinati; i granuli sporadici sparsi su tutte le placche sono più piccoli di quelli dell'altra specie e se ne associano molti assai piccoli.

La nuova specie è evidentemente un anello intermedio tra lo $S$. Scillcce ed il genere Echinus, tanto più che è di molto attenuato il carattere precipuo sul quale il genere renne fondato, per cui mi sembrano esatte le osservazioni del Dujardin, che lo riguarda siccome un gruppo non distinto da caratteri valevoli.

Un solo esemplare. R. P.

\section{Ordine. Cutpeastroldi.}

Clyperster. - 309. C. pliocenicus n. sp. = C. allus Seg. (non Lamarck). Tar. XV. fig. 27, 27 (r, $27 u$.

Questa specie è molto vicina al C. aluus, e distinguesi per essere meno elevata, ma sopratutto pel margine molto piì largo ed alquanto appianato; gli ambulacri sono quindi meno estesi ed inoltre meno sporgenti. Essa oltrechè ì molto ben distinta pei suoi caratteri, raggimge dimensioni proprio gigantesche, trovandosi esemplari della lunghezza pressochè di due decimetri. Fi proprio caratteristica del piano inferiore del plioceno, e trovasi bene spesso la dove lo Zancleano si fa vedere. c. T. $P$.

Cchinocyamus. - 310. E.pusillus Inller (Spatangus) = Fibularia tarentinu Lamk., F.equina Aradas, Echinocycmus parthenopaeus Costa. Riferiseo a questa specie molto rariabile qualche esemplare raccolto nelle sabie di questo piano. li. T. P. Y.

311. E. Costa e n. sp. - Costa, Monografia degli Echinociami. Tir. II. fig. 6 e 7. Questa specie non descritta nella monografia postuma del Costa, ma snltanto figurata, è ben distinta dalla precedente per essere poco attenuata alla regione 
anterine, pegli ambulacri poco estesi e con pori grossi e distintissimi, siccome pei grandi tubercoli dhe ornano tutta la superficie. Es sempre molto piccola arendo il maggior diametro al massimo di millimetri 2,5. r. T. P. M. A.

Ordine. Spatangoidi.

Echimolampas. - 312. E. scutiform is Leske (Echinuncus) = Galeriles scutiformis Lamk. Echinolampas Francii e scutiformis Des Moulin. Scilla. Tav. XI. Figure superiori.

Gli esemplari ben conservati, ma incompleti, che io riferisco senza esitare a questa bella specie, mi renne fatto di comprarli accuratamente cogli esemplari dell' $E$. sculiformis del mioceno di Malta, e mi sono dovnto comrincere che essi non presentano difierenze apprezzabili; dal che sembrami potersi conchiudere che questa sprecie dal mioceno fa passaggio al più antico plioceno.

Le dimensioni degli esemplari pliocenici sono pressochè nguali a quelle dei miocenici. r. P.

\title{
Classe. Crinomin.
}

Comocrinus. - 313. C. Segr u enz a i Meneghini =- Bourghetrcrinus sp. Seguenza. Riferisco al questa specie pochi articoli, che quantunque abbastanza gracili, pure, attesa la variabilità della specie pliocenica, parmi che possano rapportarvisi. r. A.

Rhimocrinus? - 314 . sp. ind.

Denomino cosi qualche articolo molto somigliante ai moltissimi, che si trorano nell'Astiano messinese, e che il Meneghini ha caratterizzato in tal modo (I crinoili terzicri pag. 2:3); solamente ì da notare che gli articoli raccolti nello Zancleano calabrese si presentano lineati e forniti di scabrezze alla superficie esterna, laddore sonn lisci quelli dell'Astiano messinese. Sarù forse la specie di Calabria diversa dia quella dell'Astiano? Bisegua attendere che abbondanti materiali vengano a rischiarare l'argomento, R. A.

\section{TIPo. CELENTERATI.}

\author{
Classe. Antozon rir. - Ordine. Zoantaril.
}

Fiabelium. - 315. F......sp.?

Di questa classe nou altro resto ho scoperto che un modello grandioso di Flabellum, che conserva ancora parte del polipaio, ma ì troppo incompleto per essere riconoscinto specificamente; pure ricorda per la forma generale il $F$. Sucssi Reuss o qualche altra specie afline, ma è di quello molto più grande. R. T.

\section{Classe. Srongiarit.}

chons. - Una considererole quantiti di conchiglie dei denositi zancleani trorasi perforata da numerose colonic di Clione varie, le quali restano per ora indeterminate, essendoche fanno difetto nella mia hiblioteca importanti monografie di tal genere, siccome mi mancano le collezioni relative. Trovansene in tutte lo località fossilifere. 
Tipo PRo'TozoAlit.

Classe. Rizopodr. - Ordine Foriminifers.

Lagena. - 316. L. globosa Walk. (Serpula) = Oolina lacvigala Dorbigny. Entosolenia globosa Williams, Ooline simplex Reus's. Questil specie si jresenta con varie modificazioni. e. G. Pat. Ar. V. - 317. I. apiculata Reuss (Oolina) $=$ L. centrophora, decrescens. elliptica, frumentum heuss. Rilra nello Zancleano. r. Pa. Ar. - 318. L. emaciata Reuss. Distinta per la forma allungatior. G. 319. L. cuenrbita n. sp.

Questa specie è aftine alla precedente per la forma generale, ma costantemente presenta una leggiera curvatura. L'estremiti anteriore ì ingrossata e segnata da solchi che irradiano dall' apestura, dalla quale anco si protende un tubo che scende nell'interno, sino oltre la meti della conchiglia.

\section{Lunghezza 1,2. ${ }^{\mathrm{mm}}$ Diametro $0,3 .^{\mathrm{mm}} \mathrm{r}$. Pa. (r. Se.}

320. L. rulgaris Williams. Questa oftre moltissime forme. Per la sinomimia dei Foraminiferi precedentemente accennati vedi i cataloghi che precenono. c. Pa. G. Po. Ar. V. - Var. semistriate Williams. 1. Se. V. - 321. L. clavata I)Orbigny (Oolina). Vi rapporto una forma sracile intermedia tra le due illustrate dal Reuss. R. Pa. T. - 322. L. gravillima Segnenza (Amphorina) $=$ A. acuminata, A. distorta. Seg. Associo in mica specie queste poco diverse forme. c. Po. G. Pa. V. - 323. L. distoma-polita Park. et Jones. Forma in doppio cono che rive nel mare Rosso e in Anstralia. R. Pa. V. - 324. L. striata D'Orbigny (Dolna). Distinta per le funissime strie longitudinali. 1. Se. V. 325. L. cylindracea Seguenza (Phiulina). c. G - 3:06. L. Gemmellarii Seguenza (Phialina). r. Pa. G. - 327. L. suleata Seguenza (Oolina) = Oolina rillardeboana D'Orbiguy. Y. Pa. T. - 328. L. Tyelli Seguenzil (dmphorina). Questa specie varia nella sua generale forma. r. Po. V. - 329. L. lucida Williams = Enthosolenia marginate Var. Incida Will. Varia per gradazioni sino alla Var. quadrata. Will. 6 Pa. G. Se. Po. Ar. V. - 330. L. marginata Walker (Serpula $)=$ Oolina compressa D'Orbigny, Entosolenia marginata Williams. Questal specie compressa e carenata è molto variabile, e senza dubbio delle sue numerose forme si sono istituite molte specie che derono al certo renire sopuresse. C. Pa. G. Se. Me. Po. AF. V.

Fissurima. - 331. F. carinata Renss. r. G. Se. Ar. Pa. - 392. F.apiculata? Renss. Qualche esemplare troppo dubbio. R. Se. - 333. F. alata Reuss. 1. Se. 334. F. latimarginis 11 . sp.

Questa specie di forma pressochè circolare, leggermente prominente dal lato dell'apertura, difterisce dalle note per' la grande lamina marginale che cinge uni cavita relativamente piccola, nella quale si protende un tubo che ha origine dlalla bocca.

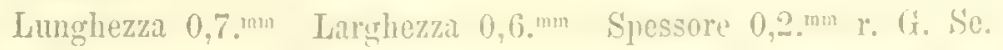

335. F. longirostris Seguenza. Specie tenuissima e vitrea. R. (i. - \$336. F. radiata Seg. Assai bella e distinti per lo linee radianti che oruauo la limima 
marginale. Affue ma diversa della Foonate Will. (Lagena) del Crag, la quale i) earenata, ma non offre lamina marginale. R. Pa.

vollosnoia. - 337. N. raphanistru un Linneo (Nautilus). r. G. Pa. Po. Ax. V. 338. N. conica Silvestri. x. G. - 339. N. raphanus Lin. (Nautilus). r. Pa. Ar. Y. - :340. N. longicauda D'Orhigny. S'incontrano tutte le rarie forme note. Var. imperfecte-costata Silvestri. c. T. P. G. Pa. Ar. V. - 341. N. proxima Silvestri. Specie ben distinta perche costituita da due sole logge costate. r. G. - 342. N. pupoides Silrestri. Bella e ben distinta specie non rara. Var. rcostufe. n. Questa ha forma identica al tipo, e manca soltanto delle fine costole. U. I’. U. Ar. - 343. N. gemina Silvestri. Questa specie molto importaute presenta quelle varie modificazioni, che furono riconosciute ed illustrate dal Silvestri, per le quali par che faccia transizione ad altri generi, ed a me sembra, che essa si colleghi con una Frondiculuria, del quale passaggio discorrerò parlando di quest'ultima. c. Ar. G. Pa. Ar. Se. V. - 344. N. fusiformis Silvestri. Bella specie assottigliata ai due estremi, e con fine costole longitudinali. r. G. - - :35. N. interupta Silvestri. r. Ax. P0. - 346. N. subtertenuata Schwager. Qualche indiriduo ben caratterizzato. 1 . Pa. - 347. N. aspera Silvestri. r. G. Pa. Ar. - 348. N. papillosa Silvestri。 1..Ar, - 349. N. hispida D'Orbigny. Ofire le numerose rariazioni si bene illustrate dal Costa, dal Silvestri ece. c. G. Pa. Ar. V. - 350. N. mon ilis Silvestri. Questa specie è realmente molto rariabile nella forma e nella scultura. Var. laevigata Silv. $=N$. scabriuscula Costa. r. Al. V. - 351. N. $10 \mathrm{ng}$ is e at a D'Orbigny $=$ N. culmen Costa, N. calamus Silrestri. Trovasi in piccoli frammenti. 1 . G. Ar. Po. V. - 352. N. o vienla D'Orbigryy $=N$. furcimen Silvestri, N. gracillima Costa. r. G. Ar. Se. V. - 353. N. II ariate Dorionny. Le logge di questa tenuissima specie sono alquanto piu globose della forma tipica. $1 . \mathrm{Pa}-354$. N. antenn ula Costi. Ordinariamente rotta. $\mathrm{r}$. G. Pil. Po. V. - 355. N. suba equal is Costa. c. T. G. Ar. Pa. Se. V. :36. N. incerta Silvestri. r. Pa. - 357. N. simplex Silvestri. Specie importante a due sole logge. 1. Pa. - 358. N. Iadicula Linneo (Naulilus). Questa spuecie colle sue logge che in gran parte si ricuoprono reciprocamente mostra una rera transizione tra le Nodosurie e le Glanduline. R. G. V.

Ehabdogomimu. - 359. R. tricarinatuan D'Orhigny (Vaginulina). Questa bella specie propria del plioceno italiano e vivente nell'Adriatico, ha servito qual modello generico al D'Orbigny. r. G. Ar. V.

Gandulina. - 360. G. laevigata D' Orbigny. Qnesta specie è molto variabile nei snoi caratteri e quindi si è rappresentatia con molte forme direrse. c. Me. Po. Se. Pal. G. V. - 361. G. olotusissima Renss. Ti riferisco pohi esemplari che concordano bene colle figure date dallantore. Ir. Ar. $36 \%$. G. olliptiea lieuss. Questa specic presenta le rarie forme figurate dal Reuss cl inoltre talune colle suture più profondate. c. (i. Se.Ar. - 363. G. apiculata Costa. Un solo individuo. R. G. - SG. G. discreta Reuss. Gli esemplari che vi riferiseo sono varî per la forma piì o meno allungata nonehè per la rariabile profonditil dei restringimenti alle suture dell'ultima o delle ultime due logge, e per la forma più o meno acuti della regione posteriore. r. Se. G. Ar. 
Uingubina. - 365. L. carinata D'Orbigny. R. T. V.

Frondicularia. - 360 . F. laevigata Karrer. Rappiortu a questa specie alemi pochi esemplari raceolti al Ardore di unita alla seguente, che forse potrebbu essere una distinta varietà della stessa. Tali esemplari portano un minor nunero di logge della forma tipica, conformate come in quella e propriamente somigliano di più alle ultime e mancano delle strie longitudinali sulle prime logge. r. Ar. 367. F. filicostata 11 . sp.

Questa specie è molto somigliante alla precedente per Ia conformazione grenerale. come per la forma delle logge, ma ne differisee pei seguenti caratteri. Una primi serie di logre in quella sono con m angolo piir aperto delle susseguenti, mentru nella mia sono pressochè uniformi se ne eccettui le primissime, lo che importa che la conchiglia si assottiglia di più alla regione posteriore. La lamina marginale è yia larga, sottilissima e tanto diafima che apnena si vede nelle preparazioni al balsamo. La superficie è percor'sa da costole filiformi e ben prominenti, che scorrono non interrotte da un capo all'altro della conchiglia; il loro numero è estremamente vario ma sempre ben limitato, non oltrepassano la diecina e si ridneono talvolta sino ad una sola che scorre nel inezzo. Lo spessore è ben piccolo ma rario.

Lunghezza 3."m Larghezza 0,7. .m Spessore 0,1:3. mm

Questa Frondicularia è d'una varibilitì estrema, dalla forma allargata e counpressissima, che è la piì comune e che riguarlo come tipiea, si passa per grali a forme sempre più ristrette, nelle quali lo spessore ammenta, le logge si alluugano e ranuo mutando di forma, perechè si accorciano le due prominenze laterali e sembra moprio che la conchiglia faccia transizione rerso la Nodosuria geminu Silvestri, che trovasi non raramente nel medesimo giacimento, c. Ar.

368. F. Medelongensis Karrer. Aneo questa specie miocenica trovasi nel plioceno antico. 1\%. G. Ar. - 369. F. compressa Costa. Specie dello Zaneleano di Messina. e. G. Se. Ar. Pa. Po. - 370. F. inaequalis Costa. Aneo questa ì una forma del plioceno antico di Messina; essa presentasi anco senza le irregolariti che redonsi nella figura del Costa. 1 . G. Al. - \$37. F. a cuminatal Costa Specie identica anch'essa a quella dol Messinese. r. Ar. I’a.

372. F. acuminato-striatan. su.

Somigliante molto alla frecedente per Ia forma generale, ma no dillerisee per essere più esattamente romlica, per le logge piil numerose, piì strette, colle suture rette, e sopratutto per munerose linee rilerate, che percorrono longitudinalmente la regione posteriore della conchiglia. R. Pa. Se.

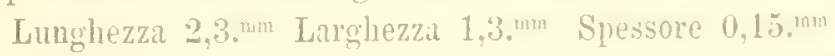

373. F. denticulata Costa. Questa forma presenta anco nel Regriano tutte quelle modificazioni che offre nel Messinese. Var.a. e Var.b. Costa. c. G.Al. Pa. 374. F. a lata D'Orbignr. Questa specie dal Soldani trorata in rarî luoghi del plioceno italiano, virente nell'Arriatico, e racenlta recentemente tra i viventi de]le . Intille, si presenta in Calabria in grandi e conservatissimi esemplari. r. G. Ar. Po. I.

Denfalina. - 375. D. acuta Dorligny. Oltre la forma tipica ri rapporto ma forma più robusta con costole più numerose e lavvicinate; che in vero ne í noltu diversa e la dico Var. major. n. l. T. S. G. Po. Mr. Pa. - ".7tr. I). ninula 
Dorbigny. Questa specie oltre la forma rappresentata dal Dorbigny, si presenta con quella indicata dal Costa (Foram. đli Messina Tar. I. fig. 299), cinè con quattro o cinque logge inrece di tre. r. G. Pa. - 377. D. s eminuda Renss. R. G. T. - 378. D. pungens Renss. r. Se. Pa.Ar. Po. - 379. D. suluata (Nilsson) Fan-den broeck. I miei esemplari rispontono albbastanza lene a quelli pescati alla Barbada e descritti dal sig. Vau-den Broeck. r. G. Ar. Pa. V. 380. D. a ciculatis Costa. I. G. Pa. Se. - 381. D. clegantissima D90rbigny. Questa bella e molto gracile conchiglia trorasi conservatissima in esemplari assai belli. c. Pa. Ar. V. - \$32. D, a ciculata D'Orbigny. Anco questa i ben conservata. c. G. Se. Pa. - 38:3. D. nodosa Dorbigny. Erammenti ben riconoscibili. l'. U. Ar. Pa. Po. Y. - 384. D. cornicula Dorbigny. c. 'I'. P. A. Po. V. - 385. D. strigosa Costa. c. G. Se. Pa. - 386. 1). Adolphina D"Orbignt. In rero questa specie non si distingne dalla Nod. monilis di Silvestri se non per essere curra. c. Ar. - 387. D. discreta Reuss = Norlosaria ovuluris Costa. Parmi che la specie del Costil non debba disgiungersi da quella del Reuss. r. Se. Pa. P0. - 388. D. subinflata Costa (Morlusuria). Qualche esemplare molto prossimo alla specie mecedente, ma colle aviti di forma meno glohosa. R. Pa. - 389. D. guttifera D'Orbigny. Esemplari conserratissimi colle logge piir o meno allungate. c. G. Ar. Pa. V. - 390). I). c legans D'orbigny. r. Pa. Ar. Y. - 391. D. nepos Costa. Differisce dalla precedente per arere le logge meno convesse e più allungate. r. (i. - 392. D. Subtilis Nengeboren. Si approssima alla precedente ma le suture sono molto oblique. r. Al. 393. D. Reussii Neugeboren. x. Ar. - 394. D. Haidingeri Neugeboren.r. Ar. - 395. D. consobrina D'orbigny. Esemplari completi e distintissimi. $l$. Ar. - 396. D. pauperata D’Orbigny. R. Ar. T. - 397. D. brevis D'orbigny. Un sole caratteristico esemplare. R. Pa. - 398. D. Scarbereana Neugei. Quilche esemplare che risponde precisamente al tipro. r. G. $39 ! \%$. 1), fillum 11 . sl\%

Questa forma è estremamente sottile e rassomiglia molto alla I). (muis Neugeh. dalla quale si clistingue per essere quasi retta. e per le logge poeo distinte jiì brevi.

$$
\text { Lungheza } 1,60^{\mathrm{mm}} \text { Diametro } 0,1 . \mathrm{mm} \text { R. } \mathrm{G} \text {. }
$$

400. 1). ealcarata $1 \mathrm{sp}$.

Questa specie distinguesi lalle molte forme allini. per la sua forte curratura e pel polcroso sperone; le logge smo convesse, specialmente le anteriori, le suture poeo oblicque.

Lunghezzil 2,4."m+1 Diametro 0,4.nm r. Pa. Ar. G. Se.

401. 1). Buntarensis 11. sp. Thiv. XIII. fig. 4.

Riferiseo al questa forma del mioceno la più comme tra le dentaline dello Zancleano (redi per la descrizione i fossili del 'turtoniano). c. G. Pa. Ar. - 402. I). Varneuilli Dorbigny. Questa furmal afline alla precedente i meno comme. r. G. Pa. Ar. - 403. 1). mucronata Nengeboren. $r$. U. Se. - 404. D. adunea Costa. Guesta specie i molto afline alla /\% aculicurula lieuss, dalla quale alppena difterisce per essere alquanto pii graeile e posterionnente più cura. r. 6 . 
Ar. Pa. Po. - 405. D. Boneana D'Orbigny. Esemplari intieri e distintissimi. r. Pa. Aro - 406, D. commun is 190rbignr. 1". G. Pa. Se. V. - 407. 1) annulata (Reuss) Van-den Broeck. Ho raceolto qualehe exemplare identico an quello figurato tra le specie della Barbada. 1". Se. V. - 408. I) seripta D'orbigny. Mancano le piccole lineette della superficie. r. Ar. Pa. - 409. D. Wadenensis D'Orbigny. La grande obliquiti delle suture, e la forma allungata delle logge distinguono bene questa specie. $r$. Ar.

410. D. macrocephata n. sp.

Conchiglia distintissima per essere costituita da quattro logge gracili allungatn e disginte da un forte restringinento, e di una yuinta globoso-orata anteriormente rostrata; rostro centrale.

$$
\text { Lumghezza 0,1.m! Diametro 0.2."m R. Pa. }
$$

411. D. inornata D'orbigny. I. 'T. P. Pa, V. - 412. D. obliqua D'orbigny. r.Pa.G.Ar. V. - 413. D. Foerstliana Czizek. R. (t. - 414. D. Roemeri Nengeboren. r. Ǵr. Ar. - 415. D. Urbignyan a Neug.r. Gr.

416. D. solida n. sp. Tar. XILI. fig. 6r. Vedi fossili tortoniani. r. Ar. 417. D. indifferens Reuss. G. Ar. - 418. D, gomploides Costar. Esemplari colle logge un $10^{\circ}$ meno convesse. 1\% G. Pa. Ar.

419. D. coruiculata n. sp. - Costa. Foram. mess. T'ar. I. fig. :茫.

Questa suecie è aftine a molte altre e distinguesi perche si assottiglia poco posteriormente, nonchè per le logrge non conresse e per le suture appena distinte ed oblique.

Lunghezza 2. Diametro 0,42.mm c. Me. (i. Po. P'a. Se. Ar.

420. D. opaca 13. s1\%.

La forma di questa specie ricorda unella della D. crassicamla per essere poen assottigliata posteriormente e coll'estremita arrotondata; ma essa i pii curra, colle suture poeo oblique ed appena discernibili, opaca e come formata d'm sol jrezzo. Lunghezza 2,8. mu Diametro 0,5.5. ${ }^{\text {mm }} \mathrm{x}$. Pa.

421. D. rostrata n. sp. - Costa. Foram. messiu. 'Tar. I. fig, 3:.

Questa specie può compararsi alla D. inornuta D'Orb., dalla quale ditterisee pel lungo rostro, pelle logge poco convesse. pell'estremiti posteriore piil assottigliatia ma sempre rotondata.

$$
\text { Lunghezza } 2,4 .{ }^{\text {min }} \text { Diametro } 0.3 .40^{\mathrm{mm}} \mathrm{r} \text {. }
$$

422. D. recta 1 . \$1\%

Conchiglia gracile, retti, formata da 13 logge disgimte da suture impresses; le ultime caviti creseono celeremente, in modo che la conchiglia diriene gribbosa presso la regione anteriore, en is ottusa o rotondatia posteriomente.

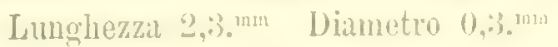

Questa specie somiglia un po'alla I). debilis Hants, ma i più gracile, piì retta. con doppio numero di logge e sopratutto colle suture apnena oblique. R. Par.

Penllenia. - 423. P. complessa n. sp. liar. XVII. fig. 14, 14\%.

Per questa specic redi i fossili Astiani. r. Po. B.

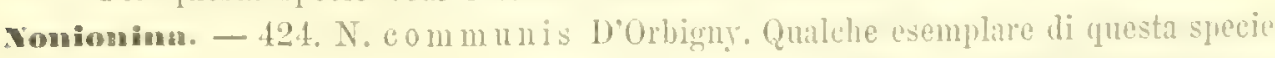
trovasi a Portigliola. r. Po. - 425. X. scaplia Fich. e Moll. (Nautilus). 3. 
Ar. Po. Y. -426. N. umbilicatula Mont. (Noulitus). r.t. Po. Y. - 427. X. Soldani Dorbigny. Ir.

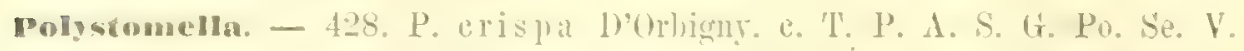

Amphistesina. - 429. A. Ha ueriua I'Orbigny. Riferiseo a questa specie del mioceno d'Austria, come ha fatto il Manzoni, la comunissima Amphistegina dello Zancleano di leggoio. Essa oltrechè rariabilissima, non conviene benissimo colla specie del D'Orbignr, sopratutto per la prominenza centrale d'ambi i lati, che non is mai cosi sporgente come la rapuresentano le figure date dall'antore. Del resto raria in grandezza, in ispessore, nel numero delle concanerazioni ec. ec. l'rorasi aboudantissima negli strati superiori dore talrolta forma una roccia licea di calcare e quasi intieramente custituita da essa. Roccia cosi formata redesi a Terreti, a Gerace ec. ed in Sicilia ad Altavilla, a Calatabiano ec. In taluni di questi luoghi la roccia assume un aspetto allatto identico alla coetanea roccia lenticolare di Parlascio e di S. Frediamo in 'loscann. C. 'L'. P. A. S. Ta. II. G. V. Nelle marne di Portigliola trorasi una piecola dmphistegina in cui le lince radianti sono molto forti. Forse è una insigne varietir della precedente.

Ianoinulina. - 430. MI. cfi. subbullata Hants. L'unico esemplare raccolto differisce ben joco dalla nominata specie. le logge che precedono l'ultima sono un no'meno globose, le suture alquanto meno mofonde. R. G. - 431. MI. regularis dorbigny. R. Ar. - 432. M. similis Dorbigny. R. G. - 433. M. glabla W' Orbigny. Specie considererolmente rariabile. 1 . G. Se, Pa. Al. Po. V. 434. M. Litums J'Orhigny. Un esemplare che risponde bene per la forma curva. per li forma delle logge, ed ha l'ultima poco prominente. R. Pa. V. 135. M. triangularis Dorbigny. R. U. Ar.

436. M. compressa n. sp.

Questa forma somiglia moltissimo alla . I. indifferens Hanth e ne differisce soltanto per arere le logge meno convesse e meno alte, presentandosi d'altronle colla forma allungatia e molto compressa di quell'altra. r. G.

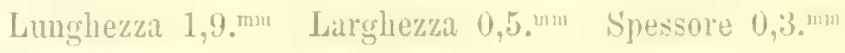

4:37. M. siliqua 11. sp.

Questa ha wrande somiglianza nella sua generale forma, come nell'andamento " conformazione delle sue logge, colli $\%$ nodosa del '́ortoniano, ma se ne distingue benissimo perehe i suoi margini non damo come in quella una sezione rutondata, mil invece angolosa perchè formano due veri spigoli acuti. La regione posteriore snole in ynesta specie incurrarsi di piu che nell'altria.

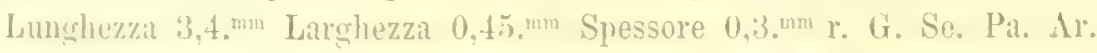
4:38. MI. hirsuta Dorbigny. c. G. Pa. Ar. T. - 439. M. cristellarioides Czizek. 1. G. Pa. - 4to. M. spillulosa Karrer. 1". G. Po. l’a.

4.11. M. striata n. sp.

Questa per la furma somiglia bene alla .\%. siliqua, molto compressa come guella, coi margini in forma di spigoli taglienti, ma ragrange ma lunghezza molto magriore ed ha la superticie ricoperta di linee rilevate, longitudinali, irregolari e rariamente sviluprate.

Lunghezza 5,6. mu Larghezza 0.6. mm Spessore 0,5.mm c. Po. Pa. Ar. G. 
442. M. striatissiman. sp.

Specie in forma linerre perchè quasi retta e di ngual larghezza in tuita la sua lunghezza, un pochino eurva soltanto all'estremiti posteriore, che porta un minimo sperone; compressissima uniformemente, in modo che il suo spessore is uguale dorunque, al margine come alla regione mediana. I margini sono rotondati; le suture abbastauza oblicque, len poeo distinte; la superficie i ornata longitudinalmente dia linee rilevate, rarricinate, uniformemente distrilunite.

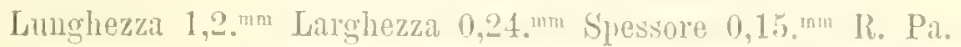

443. M. raphanus D'orbigny. Molto variabile in tutti i suni caratteri. Tar. crebricosta 11. (vedi specie elreziane). C. T. P. G. Se. Po. Pa. Ar. V.

444. M. Costae n. sp. - Nodosaria spinulosa. - Costa. Foram. di Messina p. 11. Tar. I. fig. 28.

Questa specie è molto afline alla M. raphanus, ma distinguesi per arcre le costole in forma di lamelle prominenti, le logge disginnte da suture piü profonde. l'ultima sovente più piccola con un canale sporgente e poco laterale, la regiunc posteriore d'ordinario spinulosi. Riferendo questa specie al genere Harginulina lo dornto mutare anco il nome specitico. c. G. Ar. Po. Pa. Se.

Vaginulina. - 445. V. italica Costa. Specie comme nel IIessinese. c. Al. Po Pa. G. - 446. T. badeneusis Dorbigny. r. Ar. G. - 4t7. T. lens Costa 1. G. Pa. - 448. V. clavata Costa.r. Pa.

Corstellaria. - 449. C. su leata Costa (V'aginulina). Tedi fossili tortoniani. r. Se. Pa. - 450. C. crepidula Ficht. e Moll. (Naulilus). 1. G. Pa. Po. V. - 451. C. compress a D'Orbigny. Un solo esemplare che risponde hene allia specie del bacino di Vienna. R. G. - 452. C. irregularis Hantk. Vi spettano eridentemente taluni esemplari che rispondono bene al tipo descritto dall'autore. 1. G.- 453. C. cymboides D'Orbigny. 1. Pa. G. - 45t. C. elongata Dorbigny. r. G. Ar. - 455. C. simplex D90rb. R. T. - 456. C. latir Reuss. R. A. 457. C. italica D'Orbigny. Bella e distinta specie che presenta delle rariazioni. r. G. Pa. Ar. V. - 458. C. a reuata D'Orbigny. Varia siecome la rappresenta il sig. Hantk. r. G. Ar. Se. - 459. C. ren iform is D'Orbigny. La forma tipiea è ben rara, invece un po' comune una che denomino Var. pliocenica. no, la quale è più allargata e quindi meno snella, colle logge grandi, più larghe e meno numerose. c. G. Ar. Pa.

460. C. minuta n. sp.

Questa mia specie ì intermedia tra la C. variabilis Renss o la C. peregrimu Sehw.; per la forma si approssima alla prima, ma ha tre o quattro logere appatrenti, una lamiua marginale che la cinge tutta come nella seconda, ma piu stretta. e l'apertura divisa in piccole lacinie acute.

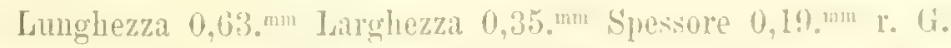

401. C. galeata? Reuss. Non senza dubbio rappinto a questa specic aleuni esenphiti. R. G. - 462. C. concinna Reuss. R. G. - 463. C. crassa I) Orbigny. Alenni esemplari dubbî. R. Ar.

4iit. C. Hessanensis n. sp.

Questa specie essendo comune nello Zinneleano messinese, sin dia lungo tempo 
e. stata da me cosi denominatio. lissa is una specie molto bella di aspetto esi arricina alla $C$. arenuria Lírrer trorata nel terziario di Luzon. La mia specie intanto è distintissima pei caratteri seguenti. La forma d’insieme è ovata abbastanza conressa, colle cariti nuasi appianate e disginute dia suture alquanto profondate; I'ultima loggia si termina quasi appianata o lievenente convessa e nou gria ilrotondatia come in quell'altra. Il dorso è carenato e cinto di spine piu a meno Iunghe, acuminate e diafane. La superficie è ricoperta di granulazioni disugruali abbastanza grosse che si dispongono specialmente sulle suture, laddore nella $f \%$ arenaria troransi invece sulle logge. L'ultima loggia o le ultime sono sfornite di gramuli.

Lunghezza 2. ${ }^{\text {mm }}$ Larghezza 1, $6^{\text {mm }}$ Spessore 1. mm r. Pa. $\dot{G}$.

165. C. striatissima n. sp.

Questa bella e distintissiua specie è rotondata dapmrima, quindi diviene oratuacuminatit perche le ultime logge si srolgono su d'una retta. Essial è molto compressa ed uniformemente, meno alla regione centrale che è un po" piu rigonfia: il dorso è carenato, ma privo di lamina marginale; le logge sono un po' convessse. lo suture alquanto profondate circa otto o nove. Ia superficie è elegantemente mata da squisite stric concentriche che non si estendono sulle ultime due logge, che si restringono terminando cosi la conchiglia in forma acuminata.

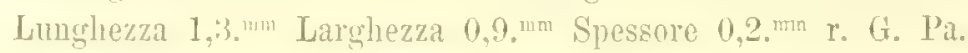

t6i. C. cassis Lamareli. Si trovano diverse forme delle molte che snole presentare. R. A. G. Ar. Pa. Se. V. - 467. C. Josephina D'Orbigny. Qualche esemplare in cuile logge hamno magevior larglezza della forma tipica. Var. gramulato Karrer. Colla forma precedente. r. G. Pa. Se.

Planularia. - 468. P. semiluna D' Orligny. Gli esemplari che vi riferiseo hanno le logge meno strette, e percio in minor numero. $1 . G$. Ar. - 469. P. auris Defrance. C. G. Ar. T. - 470. P. similis Costa (Frondicularia). r. Pa. Se. 171. P. simplex n. sp.

Questa bella specie quantunque più larga della Cristellaria lanceolata D'Orl. pure ne ha l'andamento generale, ma si fa distinguere perche manca della lamina marginale: inoltre sono poco risibili e il rigontiamento alla regione posteriore e le costole che ormano tale regione. La sua superficie i liscia, c piane le logge, ed un minimo sperone manifestasi posteriormente.

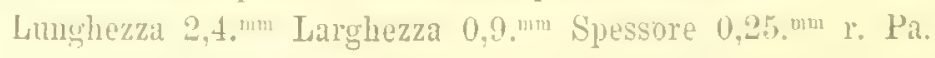

172. P. longinsula Costa (Frondiculuria). r. Pa. - 47\%, P. I anceolata D'() rbigny. 1: Ar. Pa. - 474. P. Cymba D'Orbigny. Qualebe esemplare soltiuto. R. G. T. - 475. P. angustata Costa (Frondicularia). is questa al certo. la più comune specio di questo genere. c. G. I'al. - 476. P'. restrata D'0rbigay. Qualche individuo rotto e m jo"dubio. R. Pa. - 477. P. typica Costit (Fondicularia). r. G. Pa. - 478. P. subfalcata Costa (Fronclicularia). r. (i. Pra.

179. P. faluata 1n. sp. Tiar. XII. fig. 17.

Per questa bella specie vedi i fossili iel Tortoniano. Nello Zancleano raccolsi soltanto alcuni frammenti. li. G. 
Robuliua. - 480. Li. simplex Dorbigny. Var. pauciscpla n. Questa speciale rarietì differisce per un minor numero di logge apparenti. r. G. Ar. L'. Pa. G. Ar. - 481. R. austriaca I) Orbigny. C. (x. Pa. Ar. - 182. R. inornata, D'Orbigny. 1. T. Pa. Po. Se. G. Ar. - 483. R. depanperata Rouss. Riferisco con dubbio a questa specie una piccola forma poco comme. 1. Pa. Se.484. R. vortex Ficht. e Moll. (Noutilus). r. (t. Pa. Se. V. - 485. R. imperatoria D'Orbigny. l'. G. Se.

486. R. serpens n. sp. Tar. XIII. fig. 25. Veri i fossili tortoniani. c. (x. Se. Pa. - 487. R. rotulata Lamk. La forma tipica è meno rata. Var. pliocenice 11. Sepimenti pii curvi e più ravricinati. r. T. P. A. G. Ar. Se. Po. Pa. T.488. R. clypeiformis D' Orbigny. r. T. G. Ar. Pa. V. - 489. R. radiata Born. r. Pa. - 490. R. eultrata D'orbigny. Varia molto nella larghezza della lamina marginale ed in altri caratteri. c. T. A. S. G. Ar. Po. Pa. Se. V. - 491. R. similis D'Orbigny. r. G. Ar. Se. Pa.

492. R. tenuis n. sp. Tav. TIII. fig. 26. Tedi fossili del Tortonimo. r. (t. 493. K. stellata n. sp. T'ar. XIII. fig. 29. Vedi foraminiferi del Tortoniano. r. Se.

494. R. ornata D'Orbigny. R. Ar. V. - 495. R. calcar D'Orbigny. Oltre la forma tipica con vario numero di spine r'ha la Tar. lacerd n. e la Tar. $m$ tegra n. c. G.Ar. Pa. Se. 'T. P. V. - 496. R. echinata D'Orbigny. La forma tipica è meno comune, invece abbonda più la Yar. curvicosta n. che fu illustrata dallo Czizek, e che invece di rugositì o granulazione porta delle costole o linee concentriche. c. T. P. A. S. G. Pa. Po. Ar. Se.

497. R. dilecta n. sp. Tar. XIII. fig. 33. Var. compresse n. Chiamo così una forma meno rigonfia che con larità raccogliesi nel pllioceno (vedi fossili tortoniani). R. G. Pa. - 498. R. ariminensis D'0rbigny. R. G. Ax. - 499. R. Helenae Karrer (Cristellaria). Alemi individui di questa Robulina risponIono precisamente alla forma miocenica illustrata dal Karrer, ma i più se ne allontanano alquanto, costitueudo la seguente distinta varietà. Tar. ilalica n. Questa forma differisce daI tipo, perchè porta delle lamelle rilevate concentricho alla periferia, cioè presso il margine; tali lamelle sono più o meno distinte e d'ordinario irregolari. 1 . G. Po.

TIabellina. - 500. F. foliacea H. Brady. Credo di potere riferire a questa specie, pescata dalio Challenger uelle profondita oceaniche, alcuni esemplari raccolti nell'Astiano. R. Ar. V.

501. F. striolata n. sp.

Questa che io cosi denomino è somigliante molto alla precedente nella forma, ma ne differisce per avere la superficie interrottamente e sottilmente striata nel senso longitudinale.

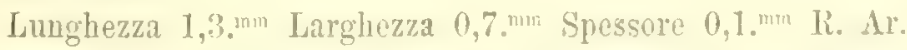

Porymorphina. - 502. P. gutta D90rbigny. r. G. V. - 503. P. oblonga IVil. liamson. r. G. V. - 504. P. in a equa lis Reuss. Un solo ben distinto esemplare. R. I'. - 505. P. co m mun is Dorbigny (Guttulina).r. T. L. Y. - 506. P'. compressa D'Orbigny. r. Ar. Pa. I. 
507. P. involvens $\mathrm{n}$. sp.

Questa conchiglia ha una certa analogia colla P. ovata D'Orbigny, dalla quale difterisee pel minor numero di logge, pella forma piu allungata, pel grande sriluppo delle ultime due cavita, che si estendono sopra gran parte delle altre, ma sopratutto questa specie si distingue dalle affiu perchè è distintamente carenata ai lati, assumendo proprio la forma d'una mandorla ma fortemente convessa sulle due opposte ficce.

Lunghezza 1,8. mu Larghezza 0,8.mm Spessore 0,6. nm 1. Pa. Se. G. 508. P. Soldani 109higny. Un solo individuo. R. G. - 509. P. variata Jones, Parcker et Brady. r. T. P. - 510. P. a ug usta. Reuss. R. T.

Ellipsoidina. - 511. E. sphoeroidalis n. sp.

Questa specie distinguesi bene per Ia forma quasi esattamente sferica, essendo solo un pochino prominente ed in grado pressochè insensibile alla regione dell'apertura. La superficie is d'una levigatezza e Jucidezza grandissima. r. Ar. 512. E. abbreviata Segnema. Questa è di forma orato-rotondata. r. G. Po. 513. E. ellipsoides Segnenza. La forma ellissoidale distingue questa specie. c. G. Pa. Po. Me. - 514. E. o blonga Seguenza. Questa ha forma oblongo-cilindricea. C. (t. Pa. Me. B.

Uvigeriun. - 515. U. pygmaea I'0rhigny. Insieme alla forma tipica v'la una varietà piu grande in cui le costelle sono meno distinte. 1. A1. Pa. G. Me. V. 516. U. angulosa Williamson $=U$. trigona. Seguenza. 1. Ar. V. - 517. L. urnula D'Orbigny. Var. r. G. - 518. U. asperula Czizek. r. Ar.

Pleurostomella. - 519. P. Costae 11. s1\% - O. G. Costa. Foram. mess. Tav. II. fig. 9.

Il Costa ha dato una figura soltanto, nella quale nou è rampesentata la bocea, non ha poi descritto nè denominato la specie; la quale è distinta dalle conosciute e specialmente dalli $P$. cocena. Gumb. e P. alternans Schwag, che sono le piì affini, per arere le logge molto prominenti e che crescono con maggiore rapidità.

$$
\text { Lunghezza 1,6.mm Dianctro 0,4., nm } \text { c. G. Pa. Ar. }
$$

520. P. cylindracea 11 . sp.

Conchiglia cilindrace-fusiforme, piì o meno allungata, colle estremità assottigliate, specialmente la posteriore. Le logge al numero di quattro poco convesse c rlisginnte da suture poco profonde ricordano nel modo di loro associazione in qualche maniera la firgulina squamela 1)'0rb. La prima sporge appena all'estremita posteriore in forma di un granulo arrotondato, le altre sono ben allungate, e si dispongono dall'uno e l'altro lato, in modo che le suture risultano obliquissime. L'apertura ì in forma di fenditura arenata.

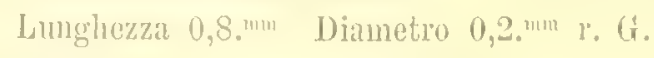

51. I’ nodosaria n. sp.

Conchiglia oblongo-cilindracea, 111 109 curva, colle estremita rotondate, alquanto prominenti al centro; lo logge sono pochissimo convesse, disgimnte da suture superticiali poco oblique, lappoiche le logete restano libere-su tutta la circonferenza e solamente si restringono da un lato e sempre cou reciproca alternanza. 
Lal prima loggia sporge dall'estremiti posteriore in forma rli m piccolo e breve sperone, le altre nella loro magyione altezza non stuperano mai la larghezzi, l'ultima invece è lunga, di forma cilindrica, o raggriunge cirea la metì della lunghezza totale della conchiglia. I'anertua è di forma lineare $11 n 0^{\circ}$ curva.

\section{Lunghezza 1,2.mm Diametro 0,55. mm R. Pa.}

522. P. inflata n. sp.

Questa specie ha analogo andamento della precedente, quanto alla disposizione delle logge, ma è di forma orata, colle logge più consesse, colle suture piiu profonde e meno oblique, dimorlochè alla prima ispezione sembra proprio una Glandulina: la prima loggia sporge in formi di piccolo sperone rotondato, l'ullimit globoso-orata supera la metil della lunghezza totale del guscio; l'alternanza nello sriluppo delle logge, l'obliquiti delle suture, la forma di fenditura cura dell'apertura determinano con certezza il genere.

$$
\text { Lunghezza } 1,2 .{ }^{\text {mm }} \text { Diametro } 0,9 \text {, }
$$

Var. oblonga n. Differisce dal tipo per la forma jiù allungata, e perchè la prima loggia non isporge in forma di sperone. $r$. G. Pa. Ar.

523. P. intolvens $\mathrm{n}$. sp.

Conchiglia orata, acuta ad ambe le estremiti, colle logge inrolgenti jn modo che delle quattro che precedono l'ultima appena, ue resta scoperta jiccola porzione; la convessitì delle logge è poco considerevole, le suture impresse; la prima cariti sporge in forma di breve sperone, l'ultima grandissima supera i due terzi dellat lunghezza totale del guscio, ed assume ma forma ovato-conica. L'apertura is lineare e curva.

Questa particolarissima specie e caratteristical ha una certa somiglianza colla P. acuta Hantk dalla quale distinguesi assai bene pex" la poca convessitit en estensione delle logge e per contro dallo sviluppo grandissimo dell'ultima, nonchè per la forma dell'apertura.

\section{Lunghezza 0,8 . nm $^{2}$ Diametro $0,3 . \mathrm{mm}$}

Var. inflata 13. Forma più rigonfia, ultima loggia più grande.

Var. elongata n. Forma allungata e piì gracile, coll'ultima logggia meno estesa, e quindi piì manifeste le altre. 1 . G. Pa.

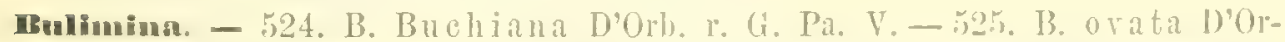
biguy. R. T. G. Ar. V. - 526. B. tenera lienss: r. G. - 527. 13. pyrulat D'Orbigny. Oltre la forma tipica raceogliesi la var. lata (vedi fossili tortoniani). c. G. Pa. Se. Ar. V. - 528. B. mutabilis Costa (Guttulina). Insieme alla precedente specie racogliesi questa e la segnente. r. G. I'a. Ar. 529. B. nirunella Costa (Gullulina).r. G. Se. Pat

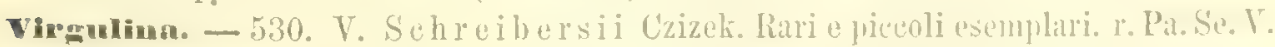

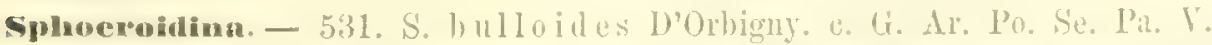

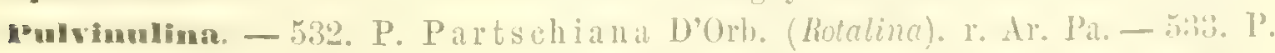
Karsteni Reuss, c. T. A. V. - 534. P. Menalii Dorbigny. C. T. I. T. 535. P. Bou eana D'Orbigny (Rotulina). Un bello esemplare tipico. R. L'o. 536. P. communis D'Orbigmy (Rotalina). 1. C. Y. - 537. P. a uricula Fich. et Moll. (Naulilus), Questa forma ì molto sparsa. c. G. Mr. Se. L'a. I'o. I. 
Itoralia. -- 538. R. Becearii D'Orb.r. T. P. S. V. - 539. R. ammoniformis D9orbigny. R. T. V. - 540. R. Soldanii D’Orbigny. r. G. Pa. Ile. V.

Orbulina. - 541. O. universa D' Orbighy. C. T. P. A. S. Va. M. G. B. Ar. Pil. Pri. Mis. Ile. Yr.

Grobigerinn. - 542. G. bulloides D'Orb. C. T. P. A. S. Va. M. G. B. Ax. Pa. Po. Se. Me. V. - 543. G. helicina D' Orbigny. r, T. P. A. V.541. G. regular is D'Orbigny. r. 'T. A. - 545. G. quatriloba D'orbigny. r. B. Se. G. - 546. G. congl o merata Schwager. Credo sia identiea a questa nna comune forma del leggiano. c. B. Me.

547. G. difformis $\mathrm{n}$. sp.

Questa specie fresenta tre logge maggiori che spiralmente si collegano con altre minori, ma essa distinguesi per avere l'ultima cavitì allungata e compressa a diflurenza delle precedenti che sono globose.

Lunghezza 0,8. ${ }^{\mathrm{mm}}$ Larghezza $0,5{ }^{\mathrm{mm}} \mathrm{C}$. Pa. Se. Ar.

548. G. Aradasi i Seguenza (Rotalina). r. G. - 549. G. triloba Reuss. c. 'T. A. Pe. Ar. P0. B. M[e. Se. - 550. G. seminulina Sehwager. Risponde questa alla specie di Kar-Nicobar. c. B. Me.

551: G. gomitulus 1. sp. Tar. XVII. tig. 16. Vedi fossili astiani. 1. Ar. B. Se.

552. G oroidea u. sp. Tar. XVII. fig. 39. Vedi fossili siciliani per la descrizione di questa specie. r. B. Me. Se. Ar.

Discorbina. - 553. D. restita 11. sp. Thr. XIII. fig. 39, 39a, 396. Tar. pliocenica 12. Le logge in questa forma sono più grandi, il margine che le cinge dal - lato della spirale molto piì stretto (redi fossili tortoniani). I. T.P.

554. D. globularis D'Orb. C. A. Pa. Se. V. - 555. D. globigerinoides? Parck. et Jones. Chiamo così un solo esemplare molto somigliante a quella specie del bacino di Parjgi, attendendo muovi materiali per lo studio e pel confronto. R. 'T'.

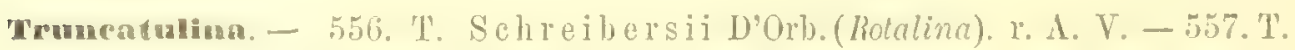
Haidingeri I' Orbigny (lobalina). V'edi quanto fu detto pei fossili tortoniani. Ir. Ar. Pa. V.

558. I. spirata 11. sp. Tar. XIV. fig. 5. Var. gibba n. Questa rarietil del plioceno ì considerevolmente più gibluosa. c. T. A. G. - 559. T. affin is Czizek (Rotulina). I. Gil. Pa. Ar. - 560. 'T. Dutemulei D'Orb. (Rolalina). Oftre tiverse varieta. C. T. P. A. G. Ar. Pa. Po.

561. 'T. formosa 11. sp. Tay. XIV. tig. 6, 6a, 6b. Vedi fossili tortoniani. 1. G. Ar. Se. - 562. 'T. peraffin is Costa (Rotalinc). Specie affine molto alla seguente. non marginata e senza incaro centrale. r. Pa. - 563. T. Ungeriana D'Orbigny (Rotalina). r. G. Po. V.

564. '1'. rortex n. sp. 'Tar. IX. fig. 8, 8a, 8b. Tedi fossili elveziani.c. Pa. 565. 'T. Helicina Costil (Nonionina). c. G. Ar. Pa. Po. Se. - 566. T. 10batula DOHo. I. 'I. I'. A. G. Pa. Ar. Po. Se. V. - 567. 'I. refulgens Montf. r. 'T. A. G. V. - 568. 'T', badenensis D'orbigny (Anomalina).

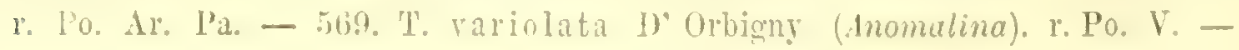


570. T. tuberosa Fich. et MO11. (Nculilus). Questa specie i stata dal Soldani rappresentata nelle rariatissime forme ch'essa suole assumere. r. G. Y.

Anomalina. - 571. A. coronata Parek. e Tones. Bella e distinta sprecie tuttavia vivente. r. T. V. - 572. A. polymorpha Costa. I pochi esemplari che vi rapporto sono della forma rappresentata dal Costa nella sua fig. 9 ; essi adhimnstrano di essere rissuti aderenti. Questa specie ha molta somiclianza colla precedente. r. Se. - 573. A. rotula D'Orbigny. Questa è ben rara nello Kancleano. r. Se. Ar.

Planulks. - 574. P. ariminens is D'Orbigny. C. G. Ar. Pa. Po. Se. V.

Rianorkuhina. - 575. P. retinaculata Parker e Jones. Questa sprecie vive fissata sulle conchiglie nei mari delle Indie, secondo quanto ne scrivono gli autori. L'esemplare che io vi rapporto incrosta la superficie interna della valva superiore di una Janira fubelliformis, ed esso prar che costi di vari individui colle ramificazioni intralciate, colla superficie perforata, granoso-rugosi. Differisee il mio esemplare dalla figura data dagli antori, perchè non mostra all'esterno i segni dell'ordinamento spirale; ma cio può renire attribuito allo stato adulto degrl'individui. R. T. V.

Asterigerina. - 576. A. planorbis D'Orbigny. r. Ar. Pa.

Bolivina. - 577. B. p unetata D'Orbigny. r. G. Ar. Po. Se. V.

Schizophora. - 578. S. calabro-sicula 11. sp.

Questa specie è somigliante molto alla S. hacringensis Gumbel, o si distingue dalla forma eocenica, perche le logge della porzione posteriore formano in mezzo un angolo meno aperto, come più curvate sono quelle della regione anteriore. Inoltre i margini non sono intieri come in quella, ma irregolarmente dentellati. La forma generale poi è abbastanza variabile mostrandosi piu o meno allungata.

Lunghezza 1,8. mm Larghtezza 0,1.mm Spessore 0,5."mm

Questa specie è comune nello Zamcleano messinese. 1. G. Al. Po. Pa. Se.

Lituola. - 579. L. scorpiurus Montf (Nodosaria). r. G. V. - 580. L. dubia D'Orbigny (Nodosaria). Un piccolo esemplare. r. G. V.

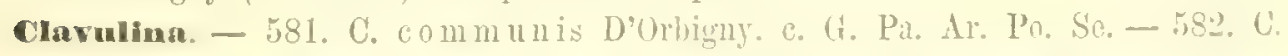
irregularis Costa. c. G. Se. Pa. - 583. C. cylindrica Hantk. Probaljilmente dere a questa associarsi la Glandulina rudis Costa. 1. G. Po. P’a.

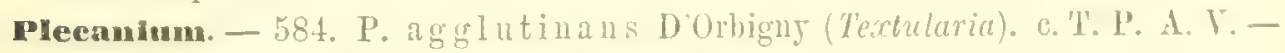
585. P. sagittula D'Orbigny (Textularia). 1. 1. Po. V. - jsib. P. alubleriatum D' Orb. (Textularia). 1. T. P. Ar. Po. V. - 5s7. P. Partschij Czizek (Textularia). R. P. Se.G. V. - 588. P. gibbosum I)'Ork. (Textularia). R. P. G. Ar. Po. Pa. Se. B. V.

589. P. subacutum. n. sp.

Questa è specie molto somigliante al P. acutum Reuss (Teruluria), dal quale differisce per essere un po'meno acuto, ma specialmente per arep" l'apertura piì ristretta, e la regione anteriore in lnogo di essere rotondata i carcenata come sono i due lati.

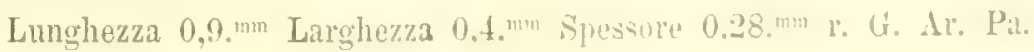


Bigenerima. - 590. B. nodos a ria D'orhigny. r. A. V. - 591. B. agglutinans D'Orbiguy. 1 . Ar.

vabecularia. - 592. N. papillosa 11. sp. T'ar. X. fig. 6, tia, 6b (redi i fossili elveziani).

Questa forma del mioceno trovasi meno rugoso-papillosa alla superficie, del resto presentasi analoga e rariabile come in quel piano. Trorasi sul Pecten scabrellus ed altre conchiglie. r. T. P.

Biloculina. - 593. B. tubulosa Costa. R. G. Ar. - 594. B. compressu D'orbigny. IR. Se, V.

Troiloculina. - 595. T. a ustriaca D'Orbiguy, Due soli esemplari. R. T. Ar.

Quimpucloculina. - 596. Q. triangularis D'Orbigny. Un solo esemplare. R. T'. V. - 597. Q. as perula Seguenza. Questa specie a dire il vero la ben altril struttura dei congeneri: la sua rugosa superficie Io attesta manifestamente. r. Ar. G. P0, Pa. Se.

\section{Ordine. Radiolariı (').}

Conosphaena. - 598. C. plutonis Ehrbg. Specie trovata nel mioceno e virente nel Mediterraneo. $r$. Ar. V. 599. C. mucrouatan. sp.

Reticolizione molto disuguale, alcune maglie molto grandi ed altre piccole, tutte arrotondate. Tre valide spine poco meno lunghe del diametro del guscio. c. Ar. 600. C. e chin in 11 . sp,

Piccola specie a maglie molto larghe, rotondate, e pressochè uguali, irta di spine che sono lunghe una metì del raggio. 1 . Ar.

601. C. microspina n. sp.

Piccolo guscio con perforazioni minute, irto di brevissime e numerose spine. 1' Al.

Irchosphners. - 602. H. rudis n. sp.

Specie coperta di rade e grosse prominenze troncate ed irrogolarmente angolose. R. Ar.

Ialiomma. - 603. H. hexacanthum Mruller. Bella e ben nota specie del Mediterraneo. r. Ar, V.

604. H. mucronatum. us. sp.

Forma non troppo regolare; perforazione molto rarricinata e come radiante; sette lunghe spine, rageri interni molti. c. Ar.

605. H. cfr. modestum Stohr. Questa forma differisce per avere le perforazioni più ravricinate. $r$. Ar. - 606. H. cfr. horridum Stohr. Si allontama alquanto da questa forma miocenica. 1 . Ar.

Eeliodiseus. - (007. H. pliocenious n. sp.

Giuscio fornito di grandi, rarvicinate, rotondate perforazioni, che sono pressochè

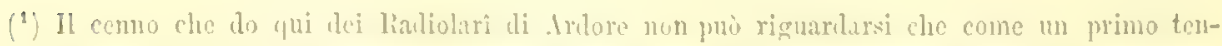
tativo. I) altronde le nuove denominarioni secifiche levono rifenersi come provvisorie, non awento iu gotuto consultare tutta la biblicgratia in noposito, e moponendomi di fare piu tarili un lavoro speciale intorno a tale gruppo. 
uguali; porta due spine opposte piir o meno disuguali, la magroiore supera il diametro del guscio; sfera interna con quattro raggi. e. Ar.

Tedrapyle. - 608. T. octoacantum Mnll. Tirente nel Mediterraneo. I'. Ar. V. 609. T. cfr。 quadriloba Ehrog. r. Ar.

Iommatocampe. - b10. H. trina eria Stohr. Differisce alquanto dial tipo per avere le perforazioni piu grandi e più ravricinate alla parte centrale.

Actinonma. - 611. A. diacanthus n. sp.

Guscio scabro e appena spinuloso alla superficie, perforazioni grandette, rarvicinate e circolari, due grandi spine in opposizione, di cui una d'ordinario piì lunga. Sferule interne irregolari con cinque o sei raggi. c. Ar.

612. A. Stohrii n. sp?

Guscio con larghe ed arricinatissime perforazioni, superficie irta di piccole e numerose spine; quattro grandi aculei disposti in croce. 1 . Ar.

613. A. pliocenicum n. sp.

Distinguesi per una reticolazione a maglie grandissime, rotondate e poco disuguali, e per numerose spine assai robuste della lunghezza del raggio del guscio. r. Ar.

614. A. hirtum n. sp.

Maglie assai larghe, irregolari e disuguali, spine numerose, circa meti del riggio che rendono la superficie irta. 1 . Ar.

615. A. entaclinia Ehrog. Questa specie differisce alquanto sol perche non si presenta di forma esattamente sferica. r. Ar. - 616. A. ellipticum Stohr. Questa specie miocenica presentasi nel plioceno di Ardore con forma molto prossima alla sferica. 1\%. Ar. - 617. A. efr. Schwageri Stohr. Molto attine a questa specie. r. Ar.

618. A. simplex u. sp.

Manca di spine, i fori sono regolari, piccoli ed arricinati, sei raggi si mostrano tra l'esterua e la seconda sferula. r. Ar.

Cyrtocnlpis. - 619. C. cfr. ur una Stohr. Questa forma pliocenica è molto affine alla miocenica: ha il margine crenato, la perforazione piu fina e i fori molto numerosi e rarricinati. 1'. Ar.

620. C. longidens n. sp.

Forma orata molto regolare, perforazione fina e regolarissima, denti lunghi. acuti, uguali cireondanti l'apertura. c. Ar.

Carpocnnium. - 621. C. lagena 11. sp.

Orato, regione posteriore prominente, fori larghi e ravricinati, denti marginali triangolari, acuti. $1 . \mathrm{Al}$.

622. C. min imum. us. sp.

Affine al $C$. campanula Stolr", con perforazione niù larga e piu larga apertura. r. Ar.

623. C. spinescens n. sp.

Questo è in forma di coppa con larghe ed arricinate perforazioni, con ampia apertura a margine dentellato e colla superficie irta di spinc poco mumerose mat valide. 1 . Ar. 
cophophacna. - 624. L. chi. amphora Stohr. Questa specic è molto affine alla nominata. ma offre talune differenze. r. Ar.

Lithomelisan. - 625. L. mediterranea Muller. Presentil tahne lieri difterenze. I'. Al'. V.

Anthocyrtis. - 626. A. Ehrenbergii Stohr. Var. pliocenica n. Questa forma differisce dal tipo per una perforazione piir larga, ha i denti marginali irregolari, e porta delle spine su d' una linea che cinge eșternamente il margine dentato. c. Ar.

627. A. sphoeroidenm 11. sl\%

Forma globosa quasi sferica, prominente alla parte posteriore, che si termina in un lungo ed acuto sperone; l'apertura è molto ristretta con un labro alquanto sporgente; i fini sono mediocri e ravricinati. 1 . Ar.

Diefyomitura. - (i28. 1), punctatella n. sp.

Forma molto allnngata e gracile, costituita da cinque articoli e da un anello posteriore, gli articoli molto convessi, portano fine perforazioni disposte in serie circoliri, che mancano sulla porzione anteriore di ciascmo articolo. C. Ar. 1029. D. cristallina 11. sp.

Forma molto allungata, articoli conressi e quasi carenati; ogni articolo ha una serie circolare di fine punteggiature e di strie disposte nel senso longitudinale della conchiglia. C. Ar.

630. D. ventricosa Stohr. La forma che vi riferisco è una varietà un po' meno ventricosa alla regione modianil. c. Ar.

Eueyntidiun. - 631. E. a c tr min at um Elırbg. c. Ar.

(632). E. doliolum n. sp.

Guscio allungato-ellissoidale; sei articoli disgiunti da suture impresse, quasi appianati; un anello posteriore con un piccolo pungiglione, apertura un po ristrettil, c. Ar.

(i3). E. tenu iporum u. sp.

Guscio di forma molto allungata, costituito da sei articoli, di cui i primi quattro molto conressi e disgiunti da suture profonde, gli altri due appianati con suture impresse: I regione posteriore porta un anello con un pungiglione. La perforazione ì fina e molto ravicinati i pori. C. Ar.

634. E. pliocenteum n. sp.

Guscio di tre articoli, i due anteriori globosi, il posteriore molto piccolo, pressochè sferico, con un forte ed acuto sperone. La bocca ristretta e regolarmente dentata, con denti uguali, acuti; perforazione fina. C. Ar.

635. E. tripartitum nosp.

'Tre articoli regolarmente crescenti, finannente perforati, convessi, disgimnti da suture protonde. Posteriormente im anello con piecolo sperone. Apertura larga, margine irregolarmente crento. c. Ar.

(i3). H. calyx $11 . \mathrm{sp}$.

Guscio formato di tre articoli, piecolo il posteriore, orato-acuminato, il secondo, conico, il terzo quasi cilindrico, che si restringe como il precedente alla regione 
anteriore in modo brusco, e l'apertura guindi is di minor diametro, col margine intiero. La perforazione più tosto fina. c. Mr.

Pterocaninan. - 637. P. diceras ns, sp.

Questa specie distinguesi per the grandi e solite prominenze marginali incurrate ed acuminate. La sul forma è conica; i forami mediocri, rarricinati e pressochè uguali. r. Al:

6:38. P. char ybdeum Mnller. Credo di dovere rapportare a questa specie vivente del Mediterraneo la forma a tre prominenze del giacimento di drdore. r. Ar. M.

Acanthomern. - 43!) A. regularis n. spr.

Riferisco questa e la seguente specie con dubhio al genere Acanhomotrr. usendoche entrambe portano al centro una reticolazione a larghe maglie o disugmali, pel quale carattere si avvicinano all'A. costuta . Inller del Mediterranen. Guesta ha otto larghi e lunghi raggi, che presentano delle solcature; la regione centrale presenta delle pieghe radianti al numero di rentiquattro. 1 . Al.

(j40. A. longispina n. sp.

Questa specie è fornita di sette spine valide e molto lunghe, le quali. alk medesima distanza dal centro, e verso la meta di loro lunghezza, portano tutte delle prominenze laterali flessuose, irregolari e ririate analogamente a diverse specie che attualmente rirono nel IIediterranen, ma piu somiglianti a quelle della A. mucronata IÏ̈ller. La regione centrale reticolata presenta al margine numerose e breri pieghe radianti.

Tremadorliseus. - 641. T. plincenicus 11. sip.

Questa specie somiglia al T. cllipticus Stohr, ma ne è hen distinta, perehè lo porzioni concentriche di cui il guscio è costituito sono più strette e piì numerose, le perforazioni più grandi. c. Ar.

Derielanydium. - b42. P. dilatatum n. sp.

Affine al P.limbatum. Ehrog. ne differisee sopratute perchè mancal di quelle settazioni alla regione centrale, e per le perforazioni ravicinate. c. Ar.

643. P. irregulare n. sp.

Questa è specie distintissima per le irregolarita che presentano nel loro contorno e nel loro sviluppo le porzioni concentriche e le partizioni loro, nonchè per la maniera di perforazione. c. Al.

EuchitoniR. - 644. E. triangulum 12. sp.

Questa è molto affine all' $E$. acuta Stohr., ma se ne distingue hene per la forma triangolare ad angoli rotondati, e non acuti come in quella, nonchè pei segmenti assai distinti e concentrici di ou sono formate le porzioni, che dal centro irradiano verso gli angoli. l: Al.

Stylactis. 645. S. triangulum Eihrog. c. Ar. V.

Spongurus. - b46. S. cylindricus Haeck. L. Al. V.

Spongocyelin. - 647. S. cireularis n. sp.

Questa forma parmi distinta per essere proprio circolare. r. Ar.

Dietyocha. - 648. D. aeuleata Ehrbg.

Vi riferiseo qualche esemplare con un po' di dublo. 1 . Ar.

Lidnocireus. - 649. L. dentato-punetatus no sp. 
Questa speoie distinguesi henc per la forma sattamente cireolare, pei dentelli arvicinati e regolarissini, che ormano il margine interno, per le finissime punteggiature che manilestansi al margine esterno. $r$. Ar.

La fauna testè esaminata, nel suo insieme riesce reramente rimarchevole ; e qualltunque molto riceil, da parte di talune elassi, non puo farsi a meno di dichiararla incompleta allorche si considerano i Molluschi, rappresentati soltanto da pochissime famiglie, essendone escluse completamente tutte le altre, come gili osservammo, cereande di indagame le cagioni.

Questo fatto non è di poco rilievo, dapoichè il tipo dei Molluschi essendo tanto incompleto, non è comparabile ntilmente colle faune somiglianti o coetanee di altri paesi, nè tampoco colla fauni virente. Difatti i generi che lo rappresentano comunemente sono Lima, Limea, Peclen, Ianira, Pleuronectia. Spondylus, Ostrea, Inomia, Torebratula ec. Qnesti generi le sui spoglie resistono a meraviglia nella fossilizzazione, sono anco quelli le cui specie par che sieno dotate di maggior vitalita; difatti molte di esse si vedono traversare parte dellat serie miocenica e tutto il plioceno, orvero quest'ultimo ed il quaternario sino ai mari attuali; cosi al esempio sono nel primo caso le Pleurnnectio cristatu e duodecim-lamellate, "nel secondo il maggior numero dei Pettini che comparisce nello Zuncleano e vive tuttavia. Cio dimostra abbastanza la vitalitit delle specie di questi generi, che arendo tralrersato molti perjodi geologici non possono percio esser caratteristiche di alcuno. Perciò la proporzion delle specie tuttria riventi deve necessariamente elevarsi; e quindi sotto questo punto di visti la fauna dei Molluschi zancleani calabresi non i comparabile colle laune coetanee dell'alta e media Italia; dore, per quanto ne conoseo, ai Pettinidi ed alle Ostreide si agginngono i Gasteroporli e gli altri gruppi di Lamellibanchi. Tale e il plioceno antico del Bolognese studiato dal prof. Capellini e dal dott. Foresti: come quello di Castroaro cosi bene illustrato da quest' ultimo.

Devo allit cortesia del sig. car. R. Lawley ma importante raccoltir di fossili della pieta lenticolare di Parlascio e di s. Frediano in Toseama, dalla quale lo riconoscinto colla massima eridenzia che trattasi di depositi coetanei allo Zancleano calabrese; difutti i resti dei Mollusehi sono tutti di specie che trovansi in tale terreno, ed inoltre la comune Amphistegino forma in quei luoghi della Toscana la parte principale della roceia.

Se dai pochi Molluschi, che formano una fauma tanto incompleta nello 'Zancleann della provincia di Reggio, pud trarsi tanto poco partito nel sincronizarvi le formazioni di altri lnoghi, non arriene cosi se rivolgiamo uno sguado alla prossimat Sicilia; ove vedesi il plioceno antico con tale una completa somiglianza di caratteri litologici c palcontologici da riconoscerlo a prima giunta siccome la vera continuazione dello Zaucleano calabrese; ove trovansi tutte le stesse specie di Molluschi, e di altri Possili; oro i depositi oflrono i tre distinti fucies, tra le quali le marne a foraminiferi cstesissime; ove tutto si ripete colla piil completa identitit e nella provincia di llessinat e in quella di Palermo, siecone a Siratera, a Caltagrione el altrove.

Ma della nostrat filunil, i Molluschi, come risulta dalledenco, non ne formano (he la minor frorzione: varic altre classi sono amplamente rappresentate, e possono alla loro volta somministrare documenti importantissimi. Cosi per non ricoriare i 
gruphi che hamno minore importanza, mi atterro ai Cirrinedi ell ai Briozoi. I primi offrono dei Balani di mumerose forme jrofusamente sparse, le quali si ripetono cogli stessi caratteri dapertutto in Sicilia, e credo parmenti nell" Italia media u settentrionale. Ma la classe che parmi debha con ragione richiamare l'attenzione dei Palcontologi si è quella dei Briozoi, sia per Ia dorizia delle specie ehe essisci oflie, sia per la varietà di forme, come per le sprecie caratteristiche. Hi gia le fame dell'vilveriano e del Tortoniano, precedentemente esaminate, offrono due esempli importantissini intorno al ralore paleontologico e stratigratico di tali organismi. Difatti i Briozoi olveziani e tortoniani della provincia di Reggio abhiamo veduto corrispondere a meritviglia colle faune coctanee del bacino di Vienna. Non meno caratteristica ci si presenta la ricea fauna dei Briozoi zancleani, la quale risulta dal rimareherole numero di oltre 160 diverse forme, distribuite in $3: 2$ generi. Il primo rarvicinamento the si presenta naturalmente a chicchesia è quelio della fiuma di Castrocaro così maestrerolmente illustrata dall' esimio sig. Manzoni; a sonza che io mi facci ad cummerare le specie che sono comuni ai due depositi, dirò soltanto che delle 85 specie trorate a Castrocaro sono pochissime quelle che non si redomo nel Regriano, e a dippiù se ne vede invece un ummero mressochè doppio di quelle che sono comuni ai due depositi. Pei Briozoi dunque non puo esservi più perfetta somiglianza di quella accennata, essendochè una fauna così riccil come si è quella di Castrocaro, trovasi quasi per intiero trasportata in Calabria; mai puo ben ritenersi che le nlteriori ricerche faranno scuoprirvi sicuramente quelle altre floche specie non trovate sinora, essendochè i miei studî derono riguardarsi sicome affrettati, aruto riguardo al breve tempo in cui furono compiuti, di fronte all'abjondante materiale esaminato, proveniente da tutti i luoghi e da tutti i piani terziarî del Reggiano. Il sincronismo adunqune tra il classico deposito del Bolognese studiato dal Manzoni e lo Kancleano calabrese. grazie ai Briozoi, non mò essere dimostrato con maggiore evidenza.

Un altro ravicinamento riesce quanto importante, altrettanto evidente. Il Manzoni nelle conclusioni tratle dallo studio dei Briozoi di Castrocaro ricorda che delle venti specie di Briozoi della roccia pliocenica di Parlascio da lui posseduti, diciannove sono comuni ai due depositi; lo che dimostra nel miglior modo possibile la loro coetaneità, e quindi riesce evidente il sincronismo tra lo Zancleano calabrese e lia così detta pietra lenticolare di Parlascio e di S. Frediano in 'l'oscanta, cle risultil dall'associarione di sterminato numero di Amphistegine, a somiglianza completa degli strati ultimi del plioceno antico di Calabria e di ficilia.

Quantunque non abbia che appena iniziato l'esame dei Briozoi zancleani di Sicilia. pure posso affermare sin da ora, che essi sono, come bisognava attendersi, specificamente identici a quelli delle Calabrie; in tal modo si dimostra ancora una volta, che lo Zancleano di Sicilia in tutto riesce identico a quello di Calibria, anzi ne i lia continuzione.

Dai fatti esposti viene sempre meglio confermata la conclusione che ne tracta il Manzoni, alla quale io pienamente mi associo, cioè che la classe dei Briozoi. al pari di qualunque altra classe animale, vale benissimo colle sue specie il eteruninare l'età di un terreno qualunque, o se finora lo studio li tali fossili ì state trascurato, oggi la loro importauza lo richiama ad un'attiva fase, dalla quale se ne trarrano ntilissimi risultamenti. 
Frori d'Ttalia io accemnero come coetaneo allo Zancleano le sabbie a Pettini e Balani nei dintorni di Montpelier, e poi il Crag corallino inglese. In quest'nltima formazione il Manzoni riconoscera renti specic identiche a quelle di Castrocaro, le quali sono anco comuni agli strati reggiani; ma inoltre io devo ricoldare altre importanti forme e mumerose che viemmeglio ravicinano le rocee calabresi ai lontami deprositi inglesi. Ecco le specic di aggiungere: Hembranipora Porilleti, M. andegavensis, lepralia Morrisiana, L. pyriformis, Lo variolosa, L.ventricosa, L. Pallasiana, Celleporaria ellan:, Eschara pertusa, E. monilifera. Helicerila Charlesuartii, Ilemieschara imbellis, Hornera hyppolithus, Pustulopora clavata, Dinstopora simpleir, Allecto repens, Pulinella proligera. Feco delle forme importanti, e talune di esse comuni. che ravicinano viemmeglio gli intichi strati del plioceno inglese al plioceno inferiore dell'Italia meridionale.

Il Manzoni segnalara ancora una relazione importante tra i Briozoi di Castrocaro e quelli miocenici del basino di Vienua, egli riconoscera in ottantatre specie del primo lnogo, ventidue comuni ad ambe le formazioni; dal quale fatto rilevara che i Briozoi di Castrocaro formano un insieme davremo intermedio tra la fanna miocenica e l'ordinaria pliocenica; ed io constato parimenti tali rapporti nella ricea fauna dei Briozoi reggiani. Si legga infatti l'elenco, ed alle specic comuni a Castrocaro ed a Viemna si redono far seguito altre specie molte, che hanno aruto esistenza nel mioceno, sia dell'Austria come della Calabria stessi. Piacemi ricordare siflatte forme molto importanti : Membranipora diadema Reuss, H. fenestrata Reuss, H. stenostoma Renss, I\%. incompla Reuss, M. formosa Reuss, H. gracilis r. MInst., lepralia tenella Renss, L. pleuropor Reuss. Lo scrmulata Renss, L. monoceros Reuss, L. ceralomorpha Reuss, L. chilopora Reuss, Eschura unduluta Reuss, Crisia Bilwardsii Reuss, C. Iloemesii Reuss, IIornera hippolythus Reuss, IJ. servatu Reuss, Filisparsu variuns Renss, Finulojhoru unomula Renss, Pustulopora clamula Reuss, Tubulipore foliacen Reuss, Discoporella stelliformis lieuss. Leco una serie d'importanti forme. che agriungono senza hublo ralore raguarderole alle gia note relazioni tra questa fauma e quella del Tortoniano di Vienna.

Wr eccomi finalmente a dare un ultimo sguardo alla fiumi zancleana, per vedert in anali relazioni ussa stia colla fauna virente. Il totale delle specie risulta da 1 Mimmifero, 4 Pesci, 7 (iasteropodi, 55 Lamellibranchi, 11 Brachiopodi, 322 Crostacei entomostrace, 13 Cirripedi, 11 Anellidi, 165 Briozoi, 16 Echinodermi, 1 Anto-

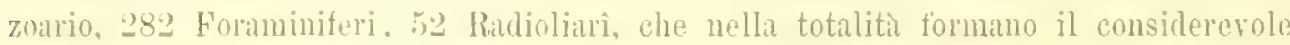
mumero di 650 sprecie.

. Di ogni classe si conosce il seguente numero di specie, che traversando gli ulteriori periodi geologici tromensi virenti nell'epoea attuale. L' unico mammifero. quantunque non ispreciticato, is probabilmente estinto; i Pesci, delle quattro specie che presentano, una is rivente ancora nel Mediterimeo; delle sette specie di Gasteropodi ne virono soltanto tre; i Lamellibranchi sono al numero di einquantacinque, dei quali ventisette sono virenti; di undici Brachiopodi ce ne sono einque nei nostri mar. Ia comparazione dei Crostacei ei fa conoseere dieci specie di Lintomostracei viventi tra le trentadue zancleane; di tredici Cimipedi ne vivono ancora otto. (ili Anellidi dnbbiamente determinati dai loro tubj calcarei ci mesentano in undivi 
specie sette identiche a quelle del Mediterraneo; la grande fauna dei Briozoi in centosessantacinque forme specifiche ne ofle sessantatre che sono sopnarrissule ai periodi posteriori. Vivono infine delle ultime classi quattro Echinodermi sopra sedici, probabilmente l'unico corallo è estinto, gli Spongiarî sono indeterminati, dei Foraminiferi, al numero di dnecentottantadue, sono in rita ancora norantotto specie, dei einquantadur. Radiolarî ne virono tuttaria sette. Nel totale admque abbiamo seicentocinquanta forme specifiche, delle quali uella natura rivente se ne sono incontrate sincra soltanto duecentotrentatre.

Dai dati qui soprì esposti se ne ricara che i Vertebrati hanno nello Zancleano il venti per cento di specie tuttavia riventi, i ILollusehi il quarantotto per cento. gli Artropodi il quaranta per cento, i Vermi il quaranta per cento, gli Echmodermi il renticinque per cento, i Protozoarî il trentuno per cento; e complessiramente considerata tutta la fauna si ha che le specie pervenute sino ai mari attuali raggiungono la proporzione del treutasei per cento. Si ha quindi un proporzionale anmento ben considerevole delle specie viventi, dacchè il Tortoniano non ne rachiude jiin lel quinto e lo Zancleano ce ne oftre oltre del terzo.

\section{Piano asitano Parelo.}

Sinonimi. Terreno subappennino D' Orbigny: formarione plivectica propriamente dett? dai varî autorí.

Ta formazione Astiana che raprresenta il sccondo periodo dell'ejoca pliocenica. si mostra in Calabria come in Sicilia (') perfettamente distinta dal piano Zaneleano. rappresentante del primo periodo. La discordanza, come si rede nella prima sezione. e la fauna differente, distinguono benissimo le rocee delle due età; jume, per la grande analogia litologica, bene spesso riesce malagerole la distinzione dei dne piani. allorehè mancano i dati paleontologici.

Sono le marne le rocé principali e predominanti, ed in molti luogli le snle. che costituiscono la formazione astiana lella provineia di Reggio wi sono subordinate bene spesso delle sabbie e più raramente dei calcari; ma né l' ma nè l'altra di tali roce occupa un posto stratigrafico determinato; dal che riesce malageroh ripartire in zone il piano astiano.

Le marne sono d'ordinario calcaree e pii o meno griviastre, rariabili molts nella consistenza e nella finezza degli elementi; dimodochè dalle masse a pasta finissima si passa per gradazioni alle forme terrose e più o meno sabhiose. Qualumgut di queste varieta presenta anco delle gradiaioni nel colorito a fit piasagugio al bianco, tende al gialliccio, e talvoltal anco al bruastro, e sempre si stempral agevolmente nell'acqua formando con essil una pasta molto buona, che viene in tanti luoghi adoprati per la fabricazione dei laterizî. Se questa tale roccia, dopno osserte stata rammollita Tall'acqua, si stempra completamente in essa, e poscha si liscia tutto in riposo, allorchè la massa terrosa si depone lasciando limpido il liquido sopranmotante, si rede su di esso galleggiare una massa molto considerevole di tenuissime spoglie di Foraminiferi spettanti alle specie più piecole piu gracili c piu delicatr.

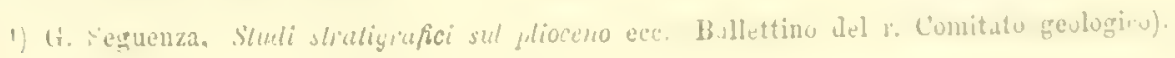


Se poi si passa alla levigazione del materiale stemprato, si attiene un residuo sabbioso più o meno abbondante costituito quasi per intiero di spoglie di Foraminiferi associate al ogni maniera di resti animali, e specialmente alle conchiglie di piceoli Molluschi ahissienli.

Così sono costituite le marne astiane di tutti i lnoghi del Reggiano, dimodochè nelle loro rariazioni presentano alen che di costante che le ta riconoscere.

Le sabbie sono quarzose, ma contengono quantita variahili di calcare o di marna costitniti dagli abboudanti fossili che racchindono; in qualche raro caso le sabbie restauo cementate dal calcare e formano come prer esempio a 'Timpra di l'enda presso Siderno una roccia calcareo-arenosa piì o meno solida e resistente.

Il calcare astiano poi è darrero una raritì nel Reggiano: esso è or tenero en or compatto, risultando dall'associazione di Coralli insieme ad altri fossili, ovvero dall' accumulo d' immenso numero di Brachiopodi.

Le sabbie ed i calcari, come io gia dicera, sono due rocee subordinate alle marne e poco sviluppate, che non formano speciali orizzonti, perchè non oceupano costantemente la stessa posizione stratigratica e non esistono che in taluni speciali luoghi.

L'Astiano di questa provincia, come in generale di tutta l'Italia meridionale, si presenta con un abito ben diverso del plioceno classico dell'alta Italia, e la differenza è costituita precipuamente dalla fauna, che annuncia un deposito di mare profondo, e che diversifica grandemente dalla fauna, tanto ben nota, descritta dal Brocchi e da una rimarcherele serie di scrittori contemporanei.

Lo mi astengo dal dire lungamente intorno al plioceno astiano di Calabria, arendone già parlato in esteso in rari miei lavori, e più specialmente negli Shuli sul plioceno ('), e solamente mi atterro a talme considerazioni più rileranti ed ai fatti speciali della regione che studio.

Osservo dapprima come il piano che esamino, per la grande uniformita di caratteri riconoscesi ovunque agerolmente; ma al vedere si enorme dirersita tra la fauna della formazione che studio e quella del comune plioceno dell'alta e media Italia, si aftaceia maturalmente il dubbio se tra questi due terreni siari perfetto sincronismo.

Lo eredo che le prove che ho potuto addurre a questo rignardo sieno proprio decisive ; ed esse possono ridursi a due capi principali.

Conoscendo bene che l'ordine cronologico in Calabria come in Sicilia porta lo Lancleano immediatamente anteriore alla formazione in esame, essendoche quest'ultima porgia quasi generalnente sullo Zancleano, si hamo i seguenti fatti :

$1^{0}$ Ad Altavilla nella provincia di Palermo si ha lia serie zancleana piu caratteristica; in basso potenti marne bianche a foraminiferi, in alto delle sabbie calcarifere ricche di quella fauma tanto imprortate precedentemente esaminata, nella quale i Pettinidi. gli Ostrejdi, i Brachiopndi, i Balani, i Briozoi e lia comunissima Amphistegina sono i gruppi che predominano, le specie souo quelle stesse che redonsi dapertutto in Calabria come in Sicilia; quindi lo \%amcleano di Altavilla non puo essere meglio

(') Stuli struligrafici sul pliseno dellulu meridimale Bullettino del r. Comitato geologico anui 1873 e secti. 
caratterizzato. Su di esso giaceiono deerli stmati mamoso-sahbiosi ricehissimi di fossili, i quali rispondono completamente alla fauna caratteristica del plioceno classico rell'Astigiano, del Piacentino, del Bolognese, della Tosena ecc. ('). Questi strati dunque sono precisamente al posto degli strati marnosi, che rastamente si estendono in Sicilia ed in Calabria rachiudendo ma fauna diversissima da guella d'Altavilla: sono essi dunque coetanei, e il loro diverso facies evidentemente lo ripetono dalla diversa profonditì alla quale si enstitumono. Gli strati d'Altarilla doveano formarsi in vicinanza della costa ed a mediocre profondita, inrece le marne comuni si costituivano a profonditì assai grande.

$2^{\circ}$ Il secondo fatto, che convalida il primo confermando pienamente le conclusioni, fu da me scoperto sul limitare della prorincia di Messina con quella di Catania. La nella pianura di Calatabiano si elera una serie di colline plioceniche. le quali al basso sono formate di strati marnosi e calcarei delio Zancleano, che racchiudono benanco una roccia affatto identica alla pietra lenticolare della Toscama, in alto risultano di strati calcarei, arenacei ed in ultimo di marne sabbiose. L' esame della fauna racchitisa negli strati superiori da un risultamento, a mio crestere, dei più brillanti che possa mai attendersi dallia paleontologia. L'associazione degli organismi ivi sepolti e ben couservati è granle, e risulta dall'assembramento di specie numerose che hanno i loro identici negli strati superiori d'Altavilla e ri altre moltissime che rispondono alle specie rachiuse nelle commi marne di mari profondi. Li tu vedi con sorpresa che le due fame si trovano insieme commiste nel nedesimo strato: ai Gasteropodi pressochè littoranei ed ai Lamellibranchi loro compagni tu vi trovi associati a profusione e Trochi, e Turbi, ed Arche, e Nucule, e Limopsis, e Lede, e Dentalii, e Cadulus, e Pteropodi, e Brachiopodi vari rappresentati da specie abitatrici delle profondita più o meno grandi; ri si associano coralli rariati. Briozoi numerosi, Foraminiferi a profusione, e le conchiglie più delicate intiere c conservatissime dimostrano che tutti quegli animali vissero insieme, che quei depositi dalla loro origine non furono mai turbati, e che la naturale spiegazione di quella miscela sta riposta certamente nel ritenere che quella fauna risse ad una media profondita, dore quegli strati si costituivano. Dunque qui, meglio che il ragionamento, sono i fatti stessi che ci apprestia la natura i quali parlano per mostrarci la fauna di Aitavilla e quella delle commi marne nonchè coetanee, coabitatrici e commensali ( $\left.{ }^{2}\right)$. Ma questi due fatti non sono rimasti isolati, bensì li vedremo quasi identicamente ripetersi in Calabria.

Da quanto sinora ho esposto chiaro appare che la formazione astiana nell'Italia meridionale si presenta generalmente con un fucies di mare profondo, che fir un rimarcherole contrasto coi depositi notissimi dell'alta Italia; ma qua e lia si notano sedimenti più o meno variati nei quali la fama è anch' essa differente, e cosi manifestansi diversissimi fucies originatisi a profondita varie, perchè a varie distanze dalle coste.

Il primo e generalissimo aspetto che assume il nostro Astiano is quello dei

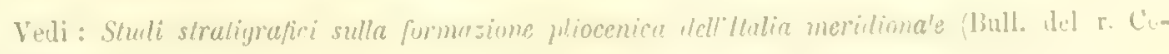
Initato geologico!.

(1) Vedi: Sturi struligrafici (Bull. Lel r. Cumitito geologino 
mari molto profondi: sono, come dissi, delle marne calearee lia cui massia mincipale e costituita dalle spoglie di Foraminiferi, tra i quali moltissimo predoninano le orboline e le Globigerine; la fauna dei Molluschi che rachiudono e costituita dit speciali gruppi di Gasteropodi, di Solenoeonchi, di Lamellibranchi e li abbondanti Pteropodi, di specie proprio abissicole, alle qutali non altri resti si associano che pochi frammenti di Cidariti, ed abbondanti Coralli spettanti agli Isidiani, Cariofilliani, Turbinoliani, Oculiniani, Eussammiani e Dendrofilliani.

Qnesto primo e distintissimo facies, che forma la generalita del deposito astiano. si estende implanente sul perimetro della provincia, ed io lo chiamerò facies degli abissi.

Un seconto aspetto si osserva in taluni depositi sabbiosi o sabbioso-calcarei nei quali la fauna id dirersissima dalla precedente: essa risulta principalmente di abbondantissini Brachiopodi tra i quali predominano la Tercbraula minor e la 'T. Scillae. di pochi Lamellihranchi, di Cirripedi sessili, di Éntomostracei, di Colalli e di grande qunatiti di Briczoi e di Foraminiferi. Io chinmo questa considererole modificazione dell'Astiano, facies a Brtchiopodi. Fissa giace in taluni luoghi sottostante alle marne, come a Valanidi rresso Reggio; ed in altri termina la serie, come a Teuda presso Siderno e nelle colline sottostanti a Germce.

I'la anco nel territorio di Reggio m rappresentante littorale dell'Astiano, e quantunque fornito d'una fauna troppo porera di forme, pure si tratta gia d'un terzo froies dai due precedenti distintissimo. Noi dintorni di S. Cristina, la formazione astiann è formata di marne azzure, che divengono sempre più sabbiose negli strati superiori. I fossili che vi si racolgono suno quasi tutti Molluschi spettanti ai seguenti greneri: IJuminea, Surcula, Drillia, Nassa, Fusus, Ranella, fCassidaria, Turvitella, Chenopus, Natica, Dentalium, Corbula, Mactra, Thracia, Cardium, Lucina, Axinus, Pecten, Ostrea, Anomin ece. e rappresentati da specie quasi tutte estranee all:Astiano dei mari profondi; e quantunque non possa tale fauna dirsi prettamente littorale, perchè rarie specie non sono tali, pure essa si approssima di molto a quella, ed io la tengo in sua rece, chiamando tale forma dell'Astiano, che conosco soltanto a S. Cristina, facies littorale. Dessa infatti è quella che più somiglia nella sua grande poverta paleontologica al plioceno classico; e tutte le sue specie. poche eccettuate, si trovano nell'Astiano d'Altarilla.

II ancora $r$ ' ha un quarto aspetto dell'Astiano calabrese, di altissimo interesse. che puo dirsi l'associazione ed il compendio dei tre precedenti.

Il prof. P. Mantorani mio egregio amico esaminando il plioceno dei dintorni 1 R Reggio, fra gli altri luoghi faceva delle importanti osservazioni intomo agli strati pliocenici che si stendono sulla fronte della spiauata, sulla quale ergesi il villaggio di Gallina ('), additando cosi una contrada di altissima importinza per vini rignardi. ma sopratutto pegli strati superiori, e per la faun che racchindono.

Sulle arenarie e le argille del Langhiano molto inclinate che costituiscono l'elevazione di Gallina, poggiano in discordanza gli strati pliocenici quasi orizzontali, che

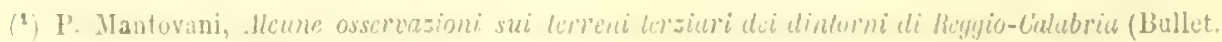
tel r. Comilato geologicu 18 is $\mathbf{n} .11$ e 12 ). 
sono costituiti dall'alternanza di calcari o di sahbie ricechi di Brachionori, di cirripedi, di Briozoi ecc. spettanti all'Astiano del fucies a Brachiopori.

In alto della serie trovansi strati marnoso-sabbiosi, nei quali il Mantorani, che li distinse colla lettera $\hat{C}$. ha creduto di scorgervi lepositi coctanei delle sabbic quaternarie di Carrubbare, perche, egli dice, rachiudono in stesse fruma, saluo minor ricchezza di specie.

Io inrece in quegl'importantissimi depositi vi ho scoperto una fauma tanto rieca whe li renderi celebri, e che è costituita di tali specie da dichiararli cridentemente astiani. Tale fauma risulta dall'associazione di numerosissime sposlie di animali spettanti a tutte le classi, ed associate in tale numero e così grande che sembramo mourin pigiate insieme nella roccia; eppure esse sono di tale una conservaione, che si trasgono fuori intierissime sino le più delicate Hyaleae. A dare un' idea dolla crindo quantità di organismi lúuniti in quegli strati mi basteria solo di rienrdare che poltando le mie ricerche sopra ma lumghezza di un paio di metri, pes la tenuswinna profondità ed altezza di pochi decimetri, io ri raceoglieva quasi settecento specio di Molluschi, ed insieme grande quantità di resti delle altre classi, che rengono tutte specificamente enumerate nel seguente elenco. Ma ciò che sorprende riemmaggiormente si è che la fauna di cui parlo risulta tanto ricea, perchè costa dall'associazione delle fanne che troransi separate nei tre dirersi facies dell'Astiano calahrese. Qua infatti sonri Gasteropodi e Lamellibranchi della fauna littorale di S. Cristina o di Altavilla, qua i Brachiopodi, gli abbondanti Briozoi, i Cirripedi, gli Entomostracei, i Coralli e i Foraminiferi del facies a Brachiopodi di Talanidi, Siderno, ecc.. qua i resti di numerosi Pesci, di Gasteropodi e Lamellibranchi abissicoli, di Coralli (3) di Foraminiferi del comme facies dell'Astiano degli abissi; qua insomma ripetesi precisamente quella tale associazione e rarietit di gruppi che ho scoperto lier lit prima rolta a Calatabiano, coi depositi della quale località gli strati marnoso-sahbiosi di Gallina hanno la massima somiglianza, avendone comme il maggior numero di specie. Questi fatti di altissimo riliero dimostrando li media profonditi delle acque in cui si costituirono gli strati di Gallina, come quelli di Calatabiann, confermano irrevocabilmente il sincronismo delle rocee. che si presentano coi tre distinti facies precedentemente esaminati, delle cui faune a Gallina sono insiome associate la maggior parte delle specie.

Cosi i depositi di Gallina riescono del pii alto interesse paleontologico o geologico, e costituiscono un facies the io direi misto.

Due criterî ralerolissimi parmi che concorrano a distingureve l'Astiano dalln Zancleano; la discordanza stratigrafica, o le diflerenze paleontologiche.

Quanto al primo carattere io facera gia notare, come nou solimente le marne astiane a stratificazione piì o meno inclinata si mostrano cliscordanti dalla formitzione zancleana, come redesi nella prima a seconda sezione, ma quello cho fiu interessa a mio giudizio si è che gli strati dell'Astiano si sieno deposti dopnoche lo Zancleano subl una grande denudazione; in modo che essi occupano ordinariament. le depressioni, mentre lo Zancleano si cleva a gramli altezze formando rlello spianate the non vengono ricoperte dall'Astiano. Casi accade delle marne astiane della contratil Botte e di Vitn presso Regein, whe rieunprono il pliocenn antion demudatn. mentre 
poi questo si cleva a costituire la suianata di monte Gori, formata dalla successione di strati pressoche orizontali, che furono risparmiati dall'azione denudatrice. Nello stesso modo jo riguardo l'associazione delle roce plioceniche del territorio di Gerace. 11 deposito marnoso-sabbioso su cui ergesi que] capoluogo ha tutti i caratteri dello Cancleano invece le marme che si estendono in basso a costiture quelle colline sono astiane, e cosi ria via dorunque i due piani si trovano a contatto. Una dillicolta insorge talvolta nella distinzione dei due piani, allorehè essi conrengono esattilmente nella litologiea costituzione, cioe allorqundo sono costituiti completamente di marne, che riescono talvolta identicissime. Questib ed analoghe cireostanze hanno fatto credure a gradazioni, a trausizioni tra i dne terreni, o piuttosto hanno ingenerato delle confusioni tra le marne e talrolta anco tra le sabbie delle due etid. Ma il carattere migliore che possa inrocarsi per la distinzione delle marne astiane dalle zancleane si è il seguente, che io adotto come il piu costante. Le marne zancleane rostitnite dall'immenso acenmulo di Foraminiferi mancano completamente di Molluschi, le malne astiane inrece sono dorunque caratterizzate da Molluschi abissicoli, ed in modo speciale ri predominano generalmente le Arche, le limopsis, le Nucule, le Led", che si associano poi a mumerosi altri generi.

Alla discordanza dei due piani si associa per la distinzione il carattere paleontologico; dappoichè le faune presentano rimarchevoli differenze, quantunque quellit dello Zanclenno sia molto incompleta pel difetto del maggion numero dei gruppi di Molluschi. Pure se si trascurano tali gruppi, e la comparazione si fa soltanto trit quelli asistenti in ambo i terreni, dere necessarianente convenirsi che si oflie una differenza molto importante, sopratutto se si tiene in calcolo, come è ben ragionerole. nou solo la presenza o l'assenza delle specie, ma ancora il grado di loro frequenza. Si gnardino infatti gli elenchi, specialmente per la parte che riguarda i Brachiopodi, i Cirripedi, i Briozoi, o si sara couvinti delle differenze marcatissime che presentano le the finne.

Il prof. P. Mantorani nota che negli strati sabbioso-calcarei di Gallina, redonsi talune specie che non si trovano generalmente nell'Astiano, e che fanno passaggin dal piano inferiore: tali sono il Pecten latissimus, la Janira pabelliformis, la Meferlice eusticte, la Rhynchonella bipartita, le quali, esclusa la prima, sono state anco da me raccolte, quantunque con molti parsimonia, nell'Astiano di aleuni speciali luoghi di Sicilia e di Calabria. Da questo fatto il prof. Mantorani crede che sieno renuti meno in gran parte le differenze paleontologiche che distingnono i due piani. Ma no, si rassicuri il mio egregio amico, delle differenze ne troverit a iosa comparando shi clenchi paleontologici dei due piani, che io do in questo lavoro.

Quanto alla potenza che l'Astiano assume in Calabria, bisogna pur eonvenire che ussa è molto variabile, ma che in taluni luoghi diventa reramente considererole. calcolandola io apmossimativamente di quasi 200 metri: cosi arriene presso Valanidi, cosi a Bianco-nuoro, at Ardore, a Gerace, ece.

Da vltimo io aceemerò in breve la topografica distribuzione dall'Astiano nella jrovincia di Regrgio.

L'estensione di questo piano ì molto importante; i snoi strati siegruono quasi sempre lo Zancleano, e Io accompannano sino ad altezze considerevoli. 
Sono in gran parte le rocee di questo piano che formano quella rona depressat che costituisce quasi un istmo tra Squillace e S. Eufemia. Quindi è sul lato orientate che l'Astiano assume un grande sviluppo e la maggiore estensione; iri infitti dal lato meridionale del capo Stallitti sino oltre Bianco-moro esso si presenta sriluppatissimo e quasi non interrotto per una estensione cosi grande, e solo si modifica nei diversi luoghi quanto allo sriluppo in larghez\%a, essendoelè forma una zona lungo la casta che dalla spiaggria s'inoltria più o meno nell'interno. Solna una superficie così vasta in generale non si osservano che marne sempre fossilifere, che raggiungono in taluni luoghi una potenza rimarchevolissima.

Quantunque io non abbia seguito passo a passo tanto estesi formazione, posso pure accennare i più importanti lnoghi visitati, e ricordare le monificazioni che in essi l'Astiano subisce. E dapurima nei territorî di S. Cateriua e di Guardaralle parmi che esso assuma uno sriluppo considererole. Il territorio di Monosterace che succede immediatamente è anch'esso vastamente occupato dall'Astiano, che ì stato per la prima rolta esplorato dal Philippi, e che è riceo della fuuna submarina. Ksso si continua verso Sud presso a poco coi medesimi caratteri, variando solamente nel colorito che da bianchiccio si fa brunastro, ma grado grado ritorma nel bianco rerso Riace dove contiene ricea fauma di minute sprecie. Così continuasi nei territorî di Rocella-ionica e di Gioiosa-ionica, dove pami che poco si estendia rerso l'interno poggiando sopra potentissime marne dello Zancleano. I Siderno poi dal lato di mezzoriorno le solite marne fossilifere si commettono con un calcare arenoso con facies a Brachiopodi, e sottostanno inoltre a potenti sabbie col medesimo facies, che si estendono dill'altro lato della valle, sormontando le potenti marne zancleane del territorio di Gerace, e ricche di fossili estendendosi sin messo al paese. Ancor molto esteso e ricco è l'Astiano dei territorî di Boralino c di Ardore, ma aneor piu rastamente si vede costituire quei monti che somrastano a Bianco, che per la candidezza della roccia colpiscono sin da lungi il tiandante e valsero a dare il nom* al paese. Quelle rocce alla fauna abissicola comune aggiungono delle grandi Verticordie, che reclamano l'attenzione del paleontologo.

Dalla valle che succede a Bianco-nuoro per tutta la costa meridionale l'Astiano non si fa redere menomamente, se non ì forse qualehe priccolo lemlo verso il Salto della Vechia. Poi al Capo delle Armi comincia a mostrarsi con un caleare a crustacei el echinidi che riempie le cavitil e le fenditure della roccia tongriana, e cun una marna a Cirripedi poco sviluppata.

Dei piccoli lembi calcarei o marnosi si famo vedere poi a Cosentino, nella valle dell'Olireto e nei monti messo Motta alla contrada Landro; quindi da Valanidi si estende amplamente verso Gallina, costituito in hasso da strati calcareo-sabbiosi molto potenti del facies a Brachiopodi, ed in alto dalle solite mane con fiuna abissicola; le quali negli ultimi strati direngono molto sabbiose presso Gablina ed aequistano quel facies misto dato da una ricchissima fauma e di alto interesse geologico, siccome abbiamo veduto precedentemente. Dei piceoli lembi " poea spessi con somigliante fauna si fanno redere lungo la rotabile liegrio-Terreti, lia dore la via si ritorce più rolte sopra se stessa, e sopra lo Zaneleano di lesta del l'rato. Le marne ordinarie si redono quindi in lembi staceati a Botte, a Vito. dose 
s' imalzano sino alla Porticella sopmastante ex in qualche altra contrada dei dintorni di Reggio.

L'Astiano viene rappresentato a Pezzo da saibie e calcare a Polipai e Cirripedi peduncolati, e sotto forma di sabbie fine marnose incontrasi sulla rotabile che conduce a Fiumara. Un ultimo lembo parmi poterlo poi segnalare sui piani della Melia, dove, in un pendio degli stessi rivolto a Sud, si osserrano strati marnosi con Ncilu excisus. Quindi presso S. Cristina e piì in la sono i depositi, di eui wia clissi a lungo, che conteugono una fama pressochè littorale.

Paleontologia. - Dalla fama che giace racchiusa nelle comuni marne dell'Astiano dell' Italia meridionale io me ne sono estesamente occupato in varie jubhlicazioni ('), e dopo quegli studî variati ho dovuto conchiudere che tale fauna. per lo innanzi pochissimo conosciuta, estremamente diversa da cuella classica dell'alta Italia, perchè propria delle grandi profonditi del mare pliocenico, deve ritenersi siccome il complemento necessario dell' altra che visse a piccole e medie profondità; dimodochè sti strati pliocenici dell'alta Italia racehindono solo una parte della fauna pliocenica, l'altra essendo contenuta neyli strati dell'Italia meridionale. Cosi le due faune non solamente sono dimostrate sincrone, ma sono anzi riconosciute come parti di un tutto, che si completano quindi a vicenda, comprendendo l'insieme degli animali che vissero all'epowa astiama nelle diverse profonditì dei mari italiani.

La fama delle marne calabresi adunque riesce del pii alto interesse, sia per le considerazioni qui sopra accemnate, sia ancora per la ricehezza e rarietia di forme che essa racchiude. Sono in essa rapuresentate tutte le classi di animali marini di profonditi più o meno grandi con una ricchezza rimarcherole, sopratutto se si accresce dell'importante materiale somministrato dall' Astiano a facies di Brachiopodi - più ancoria da quello a facies misto, con la quale addizione la fama tende ad usser completa.

In essa trovansi accennati i Cetacei; i Pesci vi hamno lasciato resti che ricordano numerose specie, alcuni denti, abbondantissimi otoliti. Dei Molluschi si ha nua serie assai ricea ed istruttira. Le famiglie e i generi che per vầ righardi piì interessino sono i segnenti. 'l'ra i Ciasteropodi: Bullili, Philine, Bulla. Scaphander. Cylichna, Acteon, Metrginelle, una nuosa e comune Ringicule, Mitro, Pleurotomidi. Sureule, Drillu, Clinure, Aphenitome, Homotome, Hangelia, Rephitoma, Columbelle. Nasse, Trophon, Clavelle, Solariun, Natica, Eulima, Turbonille, Scalaria. Rissoidi, Thrbo, Trochidi, Scissurella, Fissurellidi, Prunchurella, Rimula, Emarginulu, Solenoconehi, Dentalium, Siphonodentalium, Ildonyx, Cadulus. Dei Pteropodi: Hyalea. Creseis, Embolus. Tra i Lamellibranehi: Neaem, Symlosmia, l'enus, Verlicurdir, Cardium, Lucina, Area, Limopsis, Nucinella, Nucula, Leda, Lembulus, Yoldiu, Siliculu, Neilo, Tindurie, Limea, Pecten, Peuronectia, Ostrea, Anomia. Nei Brachiopodi: Tercuratula, Megerlia, Argiope, Ih/ynchonellu.

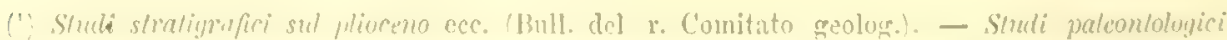

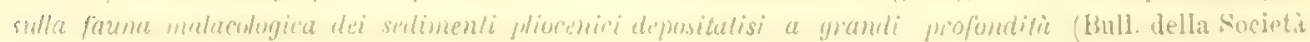
malicologica italiana, 1sis) 
Ad una fauna di Molluschi ricca e rariatissima quale si i laxceennata, si associano numerosi resti delle altre classi. Dei Crostacei infatti abbiamo gli Entomostracei con molti generi e specie, i Cirripedi, importanti ner le verruche a pei generi peduncolati. Tra i Vermi sono i Briozoi che con numerosi gencri e specie richiamano molto l'attenzione dello studioso. Desli Echinodermi r"hanno anen delle specie comuni. Dei Celenterati ricorderò specialmente le Isis, i Cariofillini, i T'urbinolidi, gli Eupsammidi, i Dendrophillidi; e poi la grande serie dei Foraminiferi con molti generi e numerose specie, che rappresentano il tipo dei Protozoarî.

Se poi questa fauna viene smembrata, siccome la natura stessa ce la presenta. nei diversi fucies coi quali abbiamo rechto presentarsi l'Astiano, e che vencono precipuamente determinati dai diversi gruppi di fossili che rachindono, si perriene a quelle conchinsioni riguardanti la profonditi diversa in cui si costituirono gli strati o i membri dell'Astiano, che offrono diflerente fucies che già precedentemente acrenmai.

La fauna delle marme infatti, che risulta costituita quasi esclusiramente di Ifolluschi, di Coralli, e di Foraminiferi, dimostra ad evidenza la granle profonliti in cui quelle rocee si formarano. Gli elementi migliori che si hamo a questo riguardo ci rengouo dalle esplorazioni che ormai incessantemente si compiono per riconuscere gli abitatori delle grandi profondita oceaniche. E dopo le pesche latte dal Porcupine, dal Vulorous, dal Challenger e gli studî pubblicati da dotti inglesi (Jettreys. Garpenter, Thomson, Duncan, Watson, Brady, ece.) si sa dapprima che le marne ad Orbuline e Globigerine sono identiche ai fanghi delle grandi nofonlitì oceaniche; in secondo luogo alcuni dei molti Coralli da me illustrati e che caratterizzano l'Astiano dell'Italia meridionale, fra i quali ricoldo specialmente qualche specie del tanto conmune genere Cerulocyalhus, furono ol pescati rirenti a grandi profondita: in terzo luogo soprabutto i Molluschi contenuti nelle marne, per la maggior parte crealuti estinti ed invece mano mano che le ricerche progrediscono, riconosciuti sempre in maggior numero virenti ed abitatori di considerevoli profondita. Così per accennare qualche gruppo ricordero speciahnente i Trubo, i Trochidi, i Dentalidi, le V'erticondir. e più particolarmente le Nuculu, le Lembuhus, le Yoldia, le Neilo, le Terebratula. le Wallhcimia, le Bhynchoncla eec. che mano mano si ramo pescando pieni di rigogliosa vita a quelle profonditi dore non hia guari crederasi impossiljile l' esistenza d'organismi rirenti.

Il secondo facies, quello a Brachiopodi è riceo anco di Briozol e di F'oraminiferi, accennando cosi ad una certa considerevole mofonditi, che risponderebbe al mio giudizio a quella della zona coralligena, dove attualmente vive buon numero delle specie che trovansi nelle rocee a Brachiopodi dell'Astiano.

Il fucies hittorale non è perfettamente tale perchè, come gria dissi, comprende alcune specie che virono a considerevoli profonditì.

Nel fucies misto abbiamo un'associazione di forme darvero rimarchevoli, numerose e molto variate, che certo, oltre una media frofonditi delle acyue, condizioni speciali d'esistenza hamo potuto fare convirere.

$\dot{E}$ in questa fauna mista che troviamo oltre il sincronismo di tutte le precelenti, la coctaneita col plioceno classico, col quale essa ha molte sprecie comuni, che mancano affatto negli altri depositi della stessa età, ma di diflerente aspetto. 
La fuuna di cui attualmente ci occupiamo cominciò ad essere studiatia con cura ed illustrata dal Philippi, il quale percorrendo la Sicilia e la Calabria la ricomobbe in molte contrade, e ne descrisse rarie importanti specie di Molluschi ('); più tardi rennero studiati i Pteropodi $\left({ }^{2}\right)$, i Brachiopodi $\left(^{3}\right)$, i Cirripedi ("), i Coralli ( $\left(^{5}\right)$, i Foraminiferi $\left({ }^{\circ}\right)$; quindi riprese le ricerche su tutte le classi dei Molluschi, che somministrarono una serie rimarchevolissima di nuove forme credute dapprimia estinte, trovate poi in parte viventi $\left({ }^{7}\right)$. Or il nuoro studio, che da lungo tempo compio sulle molte contrade fossilifere del Reggiano, mi ha fatto riconoscere che ri si trorano presso a poco le stesse specie raccolte nell'Astiano della prorincia di Messina; ruindi nell'elenco che siegne credo opportuno di descrivere accuratamente ed illustrare soltanto quelle muore forme, che sinora non furono scoperte nei terreni messinesi; quelle altre poi che sono comuni alle due regioni, accennate soltanto, o brevemente caratterizzate, verranno quindi piu tardi, in altro mio lavoro riguardaute il Messinese, amplamente descritte e figurate.

Le località fossilifere più importanti, dore furono raccolti i fossili enumerati nel. seguente elenco, suno state descritte indicando la distribuzione topografica dell'Astiano; ma qui è d'uopo ricordarle in ordine al grado loro d'importanza paleontologica. E sotto tale punto di vista il principale giacimento di fossili astiani si è quello di Gallina a facies misto, col quale si collegano per identica natura, piccoli lembi giacenti sulla via presso Terreti ed a Testa del Prato. Fra loro poco dirersi sono i giacimenti delle marne dei mari mofondi, pure si succedono nell'ordine seguente: Monosternce, Riace, Sideruo, Ardore, Bovalino, Gerace, Bianco-nuoro, e Crioiosa-Jonica sul lato orientale: Vito, Botte, Valle di Fiumara, Piani della Melia sul lato oceidentale. Quindi tra i lnoghi a fauna di Brachopodi abbiamo, sottostanti alle marne. le rocee di Valanidi, di Gallina, della ria Reggio-Terreti, e di Pezzo; soprastanti a tali rocee, le sabbie di Tenda presso Siderno e del territorio di Gerace. Finalmente S. Cristina ra ricordatil come localiti distinta per la fauni piu prossima alla littorale.

(1) Enmmeratio molluscomum Siciliae 1814.

(2) G. Seguenza, laleont. nal. dei terreni terziuri ece. Pleropoli enl Eteropodi. - Studi palenn. sulla fauna malacolog. dei selim. plioc. dep. a grandi profondilit. Pleropodi. - (") I Brachiopodi bev-

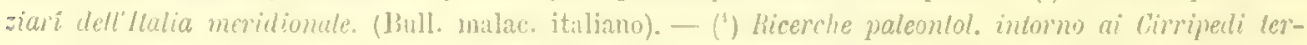
siari della prov. di Mssina. - (") Disquisizimi palconlolugiche intorno ai Corallavi fossili dei terr.

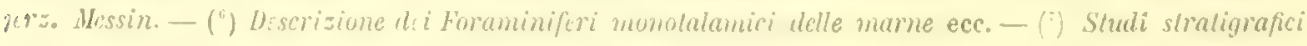
intorno la form. plior: Bull. del r. Comit. geologe.. 
Elenco delle specie fossili racolte nemli strati

del piano Astiano (').

Tipo. VERTEBRATI.

Classe. MAMnifer.

Delphinus. - 1. D. . . . sp. I I'unico residuo di mammifero che in hn raccolto nel piano Astiano si è un dente in cattivo stato di conservazione. che rapporto con qualche dubbio al genere Delphinus, ma che nou può determimarsi specificamente. R. S.

Classe. Pescr. - Ordine. Condrotterion.

Carcharodon. - 2. C. sul cidens Agassiz. Nei depositi di mare profoudo di questo piano troransi anco sorente denti conserratissimi di questa specie. che è da ritenersi identica alla vicente del Meditermaneo. Vedi le osservazioni nel catalogo dei fossili zancleani. r. R.

Oxyroma. - 3. "O. Desorii Agassiz. Riferisco a questa specie alemi pochi denti poco curvi, che parmi convengano bene colle rarie figure che sono stałe pubblicate da diversi scrittori. Vi rapporto inoltre un piccolo dente di forma triaugolare mult, allargato alla base e fornito di radice, Ia quale si presenta apuianata dal lato interno e fornita d'un ben distinto e profondo soleo mediano: tale dente raceolto a Riace fu da me riguardato per lungo tempo, dai caratteri accennati, siccome spettante al genere Otodus, ma essendomi provristo di una testa dell'O. Spullanzanii Ratinesque. e notando le grandi differenze che passano tra i denti delle direrse regioni delle mascelle, fui sorpreso nel vedere che quelli che stamo nelle parti piu interne delli bocca sono piccoli, brevi, triangolari, allargati e somigliano in tutto al mio piceolo fossile, essendo sinanco appianati nella faccia interna della radice e solcati analogamente; da ciò ho conchiuso che tal dente deve riferirsi alla specie stessa cui gli altri con sicurezza appartengono, 1. R. Ga. Ri.

นaиma. - 4. L. crassideus Agassiz. E un solo il dente che riferisco a questa specie; esso è fortemente curro in dentro, coll'estremità rolta in fuori. $\mathrm{l}$. R.

Oulontaspis? - 5.0.... sp.? Un solo piccolo ed assai gracile dente riferisco con dubbio a questo genere. R. Ri.

\section{Ordine. 'I'EIEOSTEI.}

Sphoerodus. - 6. S. cinctus Agassiz. Due soli denti riferisco a questa specic con qualche dubbio, l'uno nero l'accolto a Siderno, l'altro piceolo e grigio-seuru trorato a Galliua. R. Ga. S.

(') Le localiti varie dell'Astiano fussilifero, nel quale le specie di questo elenco sono state raccolte verranno indicate colle seruenti lettere: lieggio e lintoni, R.; Pezzo, P.: S. Ciistina. C.; Gallina, Ga.; Cosentinn. Cu.; Bianco-nıovu, B; Buralino, Bu; Ardore, 1 ; Cierace, lie.; Siderno, s.; rioiosa-Jonica, (r., Riace, Ri; Valanidi, Va.; Monosterace, MI. : Valle Lam tto, L. ; Vito presso Jieggio. Vi. 
In la chasse dei pesei più che dai denti e da qualche rara vertebra, che troransi sparsi con molta parsimonia nell' Astiano, viene profusamente rappresentata dagl'Ittiotoliti, che dapertutto laccolgonsi ahhondantemente e con variatissime forme, dal che a prima giunta e chiaramente emerge che quei resti fossili rappresentano numerose specie, e spettanti al certo a gruppi dirersissimi e molteplici. Quantungue siano molti gli serittori che abbiano fatto cenno di questi corpi, che si conserrano cosi hene nelle rocce di tutte le etat, come l'Agassiz, il Sismonda, il Pictet, il Costa, il Lawley, pure disgraziatamente non si è progredito di un passo solo nella ricognizione degli Ittiotoliti. In questo studio paleontologico il metodo di comprarione colle specie riventi nonchè utile el importantissimo, come per qualunque classe di fossili, diriene attatto indispensabile per tale natura di resti ittiologici, se vuolsi pervenire alle determinazioni generiche e meglio ancora alle distinzioni specifiche. L' importanza di tale studio cresce a dismisura all'apparire di si enorme quantita di tali fossili, ell io mi sono associato all' egregio sig. dott. L. Coceo per procurarmi mano mino una ricea collezione di Otoliti delle specie ittiologiche rirenti, a fine di perrenire colla loro comparazione, fatta sopra numerose specie ed abbondanti esemplari, non solo alle determinazioni generiche, ma benanco alle distinzioni specifiche ed agli importanti criterì intorno al grado di rariabilita di tali organi. Ma tuttaria, bisogna fur confessarlo, silmo ben lungi dall' arere raggimuto un primo grado di conoseenze a questo riguardo; di modo che i risultamenti che qui appresso espongo, e che sono stati ottenuti mercè l'esame e la comparazione di tutti gl'Itliotoliti raccolti nell' Astiano della provincia di Reggio, quantunque pochissimo soddisfacenti, mure raplresentando quelli d'un primo tentativo bisogna che sieno compatiti. I numerosi a rariati Otoliti dell'Astimo della provincia di Reggio ci offrono in primo luogo ma rarieta di forme rimarcherolissime, che accennano a munerosi generi ed a gruppi el a famiglie diverse. Quanto alle grandezze essi interessano per le gradazioni variate e numerose che troviamo tra estremi considerevolmente lontani. Cosi ve ne ha di quelli che oltrepassano di poco un millimetro di lunghezza e si sale gradatamente sino ai maggiori che raggiungono quasi i tre centimetri; o quantunque noi abbiamo doruto convincerei dalle specie viventi sinora raccolte, che non vi ha alcum rapporto costante tra la grandezza della specie e quella del suo otolite, potendo questo essere piccolo molto in ispecie relativamente granle, pure dai roluminosi otoliti che comunemente s'incontrano bisogna conchiudere che trattisi di specie molto grandi. Dalla comparazione poi cogli otoliti delle specie riventi fitta dal dott. Coeco risulta, che lelle numerose specie astiane nessuma risponde precisamente alle specie viventi th noi possedute, nn che cinque sono ricinissime e potrebbero forse non essere che lievi modificnzioni o virietit delle forme meditermee. Lo specie viventi cosi prossime sono le seguenti: Pagellus aceme Uw., Sparus sargus Lin., Clupea spratus Briim, Phycis Mediterrancus De Laroche, Jhullus ruber Lae. Inoltre molte forme troriamo, che per la loro somiglianza con queste specie deronn certamente essere congeneri. Da ultimo l'esame comparativo di tutti i materiali racolti in questo piano ci conduce ar ammettere oltre cinquantis specie tra loro piu o meno distinte. 
Tipo. MOLLUSCHI.

Classe. Cefatopont.

Loligo. - 7. "L. vulgaris? Lin. Ti rapporto, come ho fatto pol Tortoniano, alcuni resti che si riferirebbero secondo il sig. Lawley all'estremita delle mandihnlu di questo cefalopodo. Per me r'hanno ancora gravissimi dubbî a questo riguardo. r. Gia. I. ().

Classe. (iasteropont.

Atranta. - 8. A. Peronii Lesueur = A. Costue Piraino. Un solo esemplate ben conservato e ritreo. R. Ga. V.

Mexia. - 9. A. Firminii Payr, (Auricula) = Ovelelle punctate 1Bir. 11.. Auricula Bivonae Phil. Un solo individno. R. Ga. V.- 10. A. myosotis I) rapl. (Auricula) $=$ Auricula dubia Cantraine. Ih. Ga. V.

Seutulum. - 11. 'S. G us on ii O. G. Costa (Anculus) = Patellodede vitrea Cantr. R. Ga. V.

Gadinia. - 12. "G. Garnoti Payr (Pileopsis). Ir. Ga. Y.

Philine. - 13) 'P. scabra Muller' (Bulla) = Bullaca angustatu (Bivona p.) Phil. Questa che è la più comune tra le specie dell'Astiano di Calabria, oftre rimarchevoli rariazioni nella forma piì o meno allungata, siccome nelle linee punteggiate che l'ornano. c. Ga. V. - 14. "P. Loreni Maln. Tre esemplari soli di questa Philine vennerc da me raccolti, e dal Jeffreys identificati alla specie del Malm, riguardandola siceome varieta della precedente; a me sembra distinta sopratutto per la fina scultura. R. Ga. V.

15. "P. retieulum n. sp. Tar. XVI. tig. : ; $3 u$.

Elegantissima specie alquanto affine alla $P$. catona, dalla quale distinguesi. quanto alla forma, per essere anteriormente alquanto più stretta, ed un po' sinuosa rerso la regione posteriore, coll'apertura meno elargata, meno inarcata la columella, e col margine finamente dentellato; ma la scultura sopratutto ne è distintissima, essendo costituita da tre ordini di linee rilevate, sottili, equidistanti e pressochè di uguale grossezza, che s'intersecano ad angoli uguali cioè di cjo.`: formando una elegante reticolazione a maglie esagone.

$$
\text { Lunghezza } 3,30^{\text {mm }} \text { Larghezza } 2,4{ }^{\text {mun }} \text { R. Ga. }
$$

16. 'P. punctata Clark. (Bullaca). 1". Ga. T. - 17. "P. quadrata S. Woond (Bullaea). Si raccoglie in esemplari piccoli più comunemente, ed in esemplari grandi con una scultura piì forte. c. Ga. $\mathrm{T}$.

18. "P. involvens n. sp.

Questa specie è affine molto alla precedente ma listinguesi pei caratteri segnenti. La sua forma generale è più rotonclata e globosa, il labro al lato posteriore s'incurva, e sporge ensiderevolmente formando una sinuositic che si protende al di lit dell'apice della conchiglia, che invece di essere largamente infossato forma uno stretto incavo ed alquanto profondo. Daltronde la conchiglia

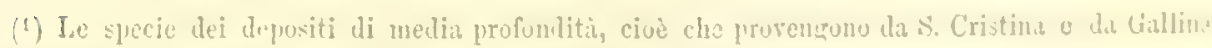
sono segnate con un asteriscu ") prorché si riculuscano a prima griunt. 


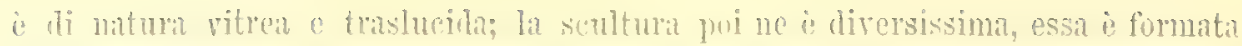
di linee spirali impresse meno rarvicinate a molto sottili, con punteggiature finissime, che si enmettono colle esili strie di accesesmento ben manifeste.

$$
\text { Lumghezza 5,8.mm Latrughera 4,7.m R. Ga. }
$$

ścophander". - 19. "S. Iignarins Lin. (Bulla). Questa specie non raggiunge grandi dimensioni ed è lara. r. Ga. V.

20. 'S. Jeffreysi i n. sp. 'lav. XYT. fig. $1,1 a, 1 b$.

Qnesia specie is alfine allat jrecedente dalla quale distinguesi per lia forma globosir e costantemente piccolia per la columella piì arcuata e quindi per l'apertura moltu piis alliugata alla regione anteriore e ristretta invece posteriormente. dore la estremitit della conchiglid si restringe e manea di quell' infossamento mopnio della specie virente. La scritura risulta di linee spirali più allontanate e piì, finamente puntegriate.

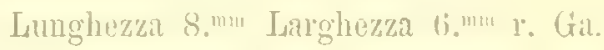

Gsemplari un po'più grandi ineompleti. Uno completo lnngo 12. mm largo 9. mu 1. Gà. 21. "S. ina un is a uptus Seg. (M. S.). = : S. liomarus Seguenza (non Loren). Tar. XVL. fig. 2, 2ैa.

Signifieai con tal nome nellil mia collezione, sin da parecehi anni, uno Scaphamler che raceolsi a Galatibiano e che piu tardi ho creduto identico allia specie vivente S. librrmins: rnecolto oril abbondantemente nel plioceno di Calabra lo dovuto convincermi che trattisi realmente di specie affine alla sopradetta, ma listinta di importanti caratteri. Di fatti la specic pliocenica è più stretta, eoll"aperturia meno allargita interiormente, ì inoltre più solicla, colla callositi cólumellare più spessia irregolarmente grinoso-rugosia l'estreniti posteriore porta un piecolo e profondo ombelico, mentre è largo e superticiale nellia virente. La superfieie is segnata da linee spirali irregolari, con funtegsiature appena aecennate e discermibili al microsenpio, tali linee sono molto ramicinate alle due estremiti della conchiglia. Questa specie è costantemente più piccolia.

$$
\text { Lunghezza mass. 15. mm Larghezia 9." C. Ga. 13. S. }
$$

Maminea. - 20. 'H. Faricosil Ponzi (Bullaca) H. varicose Seguenza. Di forma globoso-otatil, distinta per le linee spirali segnate da grosse punteggiature. 1i. 1,1. ('.

Bmulla. - 23. "B. grandis 14. sp. Thav. XVI. fig. t.

Testa globoso-ovala, magne, furtiler transubrse striato-punctata. labrum aicuenum, columellu feruesu, velue simunu, callo dilatabo, incrassato, suepius rugoso-tuberculato practitr.

Questir crande specio is ben distinta per lir formal quasi globosia, pere l'assenzat di ombelico, per lit formal ctellil columellia e la callositì che la investe, e per lir scultura custituita da lines spirali fortemente puntegginte, che ornano tutta lil superticie.

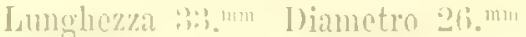

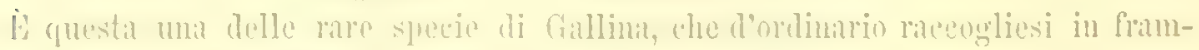
menti e con moltit ranitit in esemplari intieri. r, Gia.

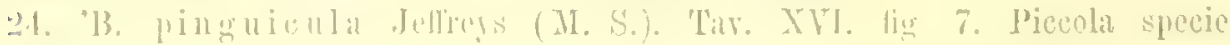


slobosa, nitida, mbelicata alle due estremita, che presentumn anco qualehe stria ipirale.

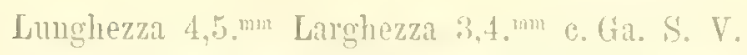

25. "B. semila eris Jeft'. (II. S.). Tar. XVI. fig. 5. Śpecie orata, piecola, di forma un po" cilindracea, ombelieata e striata alle due estremita. Var. globosa 11. Forma più breve e piì rotondata.

$$
\text { Langhezza 5,6. mu Larghezza } 3,4 . \mathrm{mm} \text { c. Ga. V. }
$$

26. 'B. c ylindracea n. sp. Tar. XVI, fig. 6.

Qnesta forma è molto somigliante alla precedente, dalla quale ne differist: soltanto perehè meno ristretta alle due regioni estreme, fo cuiunti fi forma meno rotondata e quasi cilindracea. Potrebbe essere anco una distintil rarieti.

\section{Lungheza 7. mm Diametro 5. man}

Si raceoglie molto raramente. R. (tia.

27. "B. utriculus Brocehi. c. Gii. V.

Actacon. - 28. "A. tornatilis Lin. (Voluea) =- Tomatelle fasciale Phil. Cal-

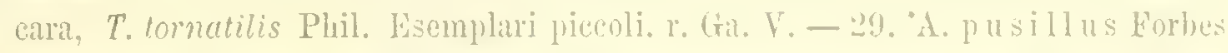
(Tornatella). Grandi e belli esemplari. Var. bistriato-punctuta. Negl' interstizî delle ordinarie strie se ne forma un'altria piin sottile parimente punteggiata e la seultura diriene elegantissima. c. Ga. V. - 30. "A. globulinus Forbes (Tornutclla). Specie trovata anco nei mari di Sicilia. r. Gia. V.

31. "A. foveolatus u. sp. Tav. XVI. fig. 8, 8a.

Testa ovato-cylindracea, anterius producta. spira obtusa. brevissima, suburaclata, anfractus quatuor, ultimus maximus cylindracens, postice subangulatus. subplanatus; superficies spiraliter sulcato-foveolate, columellae plica crassa. labrum parum arcualum. os clongato-sinualo-angulosum.

Questa specie è distintissima per tutti quanti i suoi caratteri. La forma cilindracea, mominente alla regione anteriore, con una spira unolto oftusa e mevissima è reramente rimarcherole. Specialissima ne è poi la seultura formatil da solchi sprirali, che lineette curve, trasversali e rijevate diridono in ma serie:

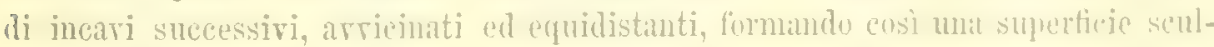
turata con molta eleganzat.

$$
\text { Lunghezzil } 6,8,8 \mathrm{~mm} \text { I)iametro } 8,4,4 \mathrm{~mm}
$$

Raceolto mu solo esemplare. R. Gir.

32. "A. exilis Jeffreys. Usemplari ben completi dimostrano che la specie varia. essendo or più ell or meno grateile. r. Gir. V.

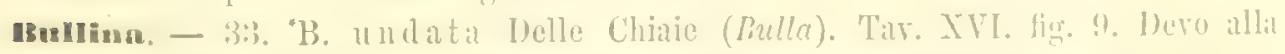
solita cortesia del sig. Jellireys la determinazione di yuesta specie. 1. Gra. L:

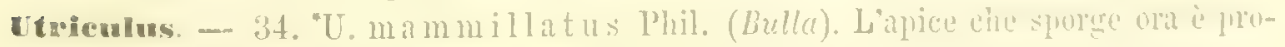

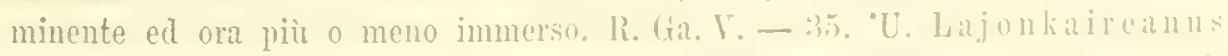
Basterot (Bullu). R. Ga. - 36. "U. tru ne a tul us Bruguière (Bullu). - Bullu scrui-

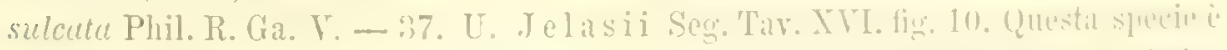

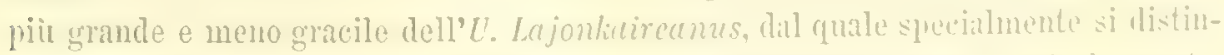
gue per arere gli arrolgimenti subangolosid depressi ed anplianati pristeriormente.

$$
\text { Lunghezal 5.2. min Diametro :3.4."nin R. B. }
$$


Tomatina. - :38. "T. spirata Brocchi ( Vohuta). Questa specie ha la carena della regione posteriore degli avrolgimenti prominente ed acuta, il solco al di lit di tale carena ben profondato, e delle strie oblique sulla carena suddetta più o meno distinte. r. Ga.

Cyliehna. - 39. "C. subappennina I'Aneuna (M. S.) (Bulla). = C. subappennima Seguenza. Questa specie is rimarcherole per la sua grande solidità; essa somiglia per lia forma alla piccola $C$. nitidula, ma ha dimensioni che le fanno oltrepassare talvolta la lunghezza di un centimetro. C. U’a. - 40. 'C. nitidula Lorèn. c. Ga. V. - 41. "C. umbilicata Mont. (Bulla). r. Ga. V. - 42. "C. al ba Brown (Volvaria). Questa specie propria dei mari del Nort fu trovata prima nel Messinese, ed ora a Gallina. C. Ga. B.S. V. - 43. "C. cylindracea Pennant (Bulla). C. Gia. S. B. V. - 44. "C. conroluta Brocchi (Bulla). Fsattamente cilindrica coll'apertura piir stretta della specie precedente. r. Ga. - 45. "C. o besiuse ula Brugnone. Specie molto affine alla $C$. ovala Jeftreys, ma parmi realmente distinta come vuole il stuo scopritore, perchè puì rigonfia, più angolosa allit regione posteriore, dove le linee d'acerescinentu la rendono scabra. r. Ga. S. 46. "C. ovata Jeffreys. Questa specie è commissima nell'Astiano messinese, molto rara invece nel Reguiano; vive nel Nord-Atlantico. r. Ga. Vi. V.

47. "C. voirula eformis n. sp. 'Tar. XVI. fig. 11.

Testa ovatu, antice rotundalu, postice subacuta: columella subarcuata, fissuram umbilicalem constituens; os strictum, arcuatum, antice elargatum, postice. tradatim altenuatrum.

Questa specie è distintissima per la sua forma, che non jresenta alcuna troncatura alla regione posteriore, la quale invece sporgente o quasi acuta, olfresi intagliata dalla bocea che si continu sempre più stretta sino alla parte estrema. Questo carattere ricorda beme il genere Volvula, e pereio questa specie is Ih rignardarsi siccome un rero anello di congiunzione tra questo e le Cylichm.

Limghezza 5." Diametro 3. ${ }^{\text {mum }}$ R. Ga.

Orula. 48, - O. spelta Lin. (Bulla). Molto rara. 1. Ga. V.

Oypraca. - 49."C. .... sp.? Un giovane esemplare non riconoscibile speuificamente. 1\%, Ga.

o'roivin. - 50. "T. e uroprea Mont. (Cypraen) = Cypruen coccineila Lk. Esenflari piecoli e grandi. c. Git. V.- 51. "I'. pu l ex (Solender) Gray, Esemplari molto variabili. r. Ga. V.

5.). "T. gribba 11 . sp.

Credo dorel" disgiungere questa forma dalla precedente specie pei seguenti caratteri: Essa i molto giblossa, col dorso liseio e fornito d'una larga e superficiale solcatnra longitudinale. Le costelle sono esili e svaniscono mano mano verso la regione dorsale, invece divengono più grosse e piu sporgenti attorno la regione boceale. Ultre la forma giblosid, la grandezar molto magrgiore distingue anco questa specie. Lunghezza 15. mu Larghezza 11. mm $\mathrm{r}$. Ua.

5:. "T. a ffin is I) ujardin (C!pruen). (Questa specie che riene dal mioceno, distinencsi per la forma m jo' oblongat e pel superticiale soleo dorsale. Alcuni esemflari conservano un colorito roseo, r. Ga. 
Erato - 54. "E. Iaevis Donovan (Voluta) = Voluta cypraeola Brocehi. Specie variabile molto in grandezza ed in folma. Si distingnono le forme seguenti. Var. brevispira n. A spira poco prominente. Var. elongala n. A spira sporgente, ed a conchiglia di forma allungata. Var. incrussulu n. Spira breve, conchiglia anteriormente allungata. C. Gia. V.

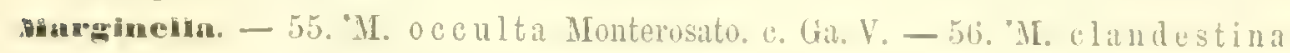
Brocehi (Volula). r. Ga. Tr.

57. 'M. ovula e form is n. sp. Tav. XVI. fig. 12.

Questa specie per la sua generale forma molto somiglia alle ovule, e d'altro canto è affine molto alla.$\%$ occulu, dalla quale si distingue bene, per essere di tripla lunghezza, per essere un po' più snella, per l'estremitì posteriore più prominente e pel labro meno inspessito. Questi caratteri ne famo una bella e bnona specie.

Lunghezza 4,8. ${ }^{\mathrm{mm}}$ Larghezza 2,8.m C. Ga. $^{\text {man }}$

58. "M. Philippii Mouter. $=$ M. minula Phil. (non L. Pfeili.).c. Gra. V. 59. "M. miliaria Lin. (Volut(t). R. Ga. V. - 10. "H. secalina Phil. r. Ga. R. M. V.

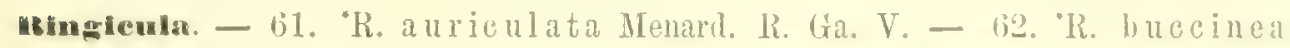
Brocchi. Var. Una forma piceola ed alquanto allungata, qualche esemplare ha indizio di costelle longitudinali ed accenna pereio al passiggio alla Var. incemedio Foresti. r. Ga.

63. "R. biplicata n. sp. Tar. XVI. fig. 13,1:a.

Questa specie nella forma generale somiglia molto alla precedente, dalla quale ne è tanto distinta da spettare ad altra sezione generica, dappoichè la columella porta due sole pieghe bene sriluppate e manea intieramente della terza, pel quale rilevantissimo carattere è molto aftine alla specie seguente. Dalla $R$. buccinea distinguesi inoltre per la spira più prominente, per la callositi columellare pochissimo estesa, pel labro meno ingrossato, per la sul generale sottigliezza. La superficie è levigata, e solamente vi si scorgono tenuissime linee di accrescimento.

Lunghezza 9,2."m Larghezza 5,2. ${ }^{\text {mu }}$

Var. influta n. Forma rigontia. Var. elongete n. Forma più snella. C. Ga. 64. "R. I eptooheila Brugnone. R. Ga. V.

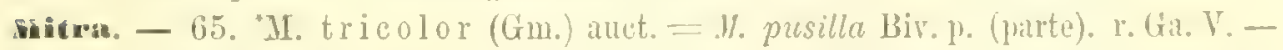
66. "II. Sayignyi Payr. 1". Ga. V. - 67. "H. e benus Lamarck. Furma breve, e rar. plicatula. r. Ga. V. - 68. "M. pyramidella Brocehi (lioluta).r. Ga. - 69. "M. I utescens Lamk. 1'. Ga. V. - 70. "Mt. 'striatula Brocchi (Voluta). Un sol griovine. R. Git. - 71. "Mr. flus iform is Brocehi (bolula). Alemi giovani esemplari. 1". Gia. - 72." M. obsoleta Broceli (l'alula). Un solo individuo distintissimo per la seultura, la quale juo indicarsi cosi: Solchi longitudinali e trastersali rendono la superficie come tagliuzata in quallelli. R. Lia.73. "M. cupressina Broceli (Ioluta). r. Ga.

74. II. filicosta n. sp. Specie amaloga alla $\%$ cupressinu, ma distintissima pegli arrolgimenti quasi aplianati, per le costelle rette, strette. ed in lorma di filo, legl' interstizì larghi e finameute clatrati. R. B. Bo. 
Conns. - 75. C. an tedilurian us B3rug. Un solo incompleio esemplare. R.B.76. "C. striatulus Brochi.r. Ga. - 77. "C. mediterraneus Brug. Esemplari rotolati e enrosi. R. Ga. V. - 78. "C. p y rula Brocehi. Un bello a conservatissimo esemplare. r. Ga.

menurodoma - 79. P. lot a ta Brocchi (Murex). Un solo esemplare incompleto. R.IB.

Surcula - 80. "S. no dulifera Phil. (Meurotoma). Questa bella e distinta spevic ha la superficie juiva di solchi e di strie, invece l'ha perfettamente lerigata, ed ogni arrolgimento offre uma serie di nodi arrotondati o alquanto allungati. Var. plicifere n. I noduli sono considerevolmente allungati in forma di pieghe obliçne. Var. distinck n. Noduli pliciforni che mancano nell' ultimo arvolgimentn. Un solo esemplare a S. Cristina. 1". Ga. Ge.S. G. Ri. M. C. - 81. "S. dimidiala Brocehi (Murex). Un solo esemplare mal comserrato e rotto. Var. minor n. Chiamo così ma forma piccola e gracile. r. Ga. - 82. S. proma a Philippi (Pleurofoma). Questa bella specie distingnesi dalla precedente sopratutto per la scultura costituita da grosse linee rilevate spirali, che divengono sottili e rade nella regione posteriore concava degli avrolgimenti. Valr. difformis n. Tav. XVI. fig. 14. Forma più gracile, carena meno sporgente, ultimo arvolgimento quasi mancante di nodi. Var. unifurmis n. Carena sugli avvolgimenti piia sporgente, pieghe nodiformi piu grosse e più sprorgenti. r. Ri. MI. - 83. "S. tol"quata Phil. (Pleurotomu). Specie molto rara e ben distinta per la sua forma e scultura e per le pieghe nodulose che affettano le carene degli avrolgimenti. R. S. M. (Phil.). Ga. V. 84. S. Monosteracensis 11. sp. Tay. XVI. fig. 15.

Tista ovalo-fusiformis, gradate; anfradus 10 carinati, carina prominens subacula, suturae anticae propinquiores et illeo pars antica anfracti brevior. quae convexa, cingulo majore aliesque minoribus plicisque ouliquis ornata: pars postica lata, concava, lincis spiralibus expers, practer cingulum prope carinam, aliumque al suturam, lineisque obliquis, incurvis. cxllibus elegunter omate; anfractus tres primi regulariter converi, carina carentes, lacvissimi; ultimus mugnus $3 / 3$ totius longitudinis subaequans, antice depressus, productus; cauda brevis, cingulis trinsversis majoribus minoribusque altemantibus, lineisque obliquis confertis pradedita. Os ovalo-oblongum: labrum sinistrum simplice.

\section{Lunghezza 16. smm Larchezza 8. "mu}

La forma generale di questa specie rieorda alquanto quella della Drillia modiola, ma ì più breve, colle carene meno sprorgenti, o con una distintia scultura. li. II.

Thoinia - 85. " D). sygmoidea Brom (Pleurotoma). Manea nei depositi di mare profonto assai. Var. major 11. V'hat a Gallina uma forma molto grande, yuasi Iolphiamente lunga, ed m jo' meno gracile, che chiamo var. major. C. Gia. 81i. "D. pumila no. sp.

Questa forma it grande analogia colla D. minor hel Tortoniano di Benestare, ma pure risultar distintissima; la sua forma generale è più breve, più brevi an-

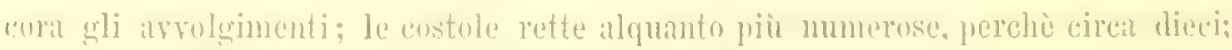
lo stato embrionario i perfeltamente distinto costando di tre arvolgimenti regolarmente erescenti a convessi. La superficie della conchiglia è levigatissima.

$$
\text { Lumghezzil 5.mm Diametro 2..3. }{ }^{\mathrm{mm}} \text { R. Ga. }
$$


87. "I). galerita Philippi (Pleurotoma) $=$ P. Rochella Bell., P. subasperum Brugnone. Questa specie varia molto nella forma generale, che i piì o menn allungata. Oltre la forma tipica, Var. minor n. Piu piecola e colle pieghe sulla carena degli arvolgimenti meno mumerose. G. Ga. Bo. - 88. "I), morlio lia Jan. $($ Fusus $)=$ Pleurotoma carinate Bir. f. (non Lk.), P. acuta Bell. In questa sprecic la carena è molto prominente ed assottigliati. R. R. Ge. Ga. Bo.

89. D. confusa nt. sp.

Questa forma che io disginngo dalla precelente, distingnesi assai hene per essere molto pii gracile, e colla carena deghi arrolgimenti meno frominente e non assottigliata. E a questa forma che si rapporta un esemplare vivente della collezione Benoit, e non alla precedente. Bisognerebbe istituire delle ricerche per sapere se non si debba, come è probabile, applicare a questa la lenominizione del Birona. R. R. Ge. Ri. Ga. Y. - 90. "I). erispa Seg. (Pleurotoma) = D. crispala Var. A. Bell. La forma più grande è molto meno graeile, e lá senltura piu grossolana di questa Drillia mi fanno credere conveniente di mantenerla distinta, tanto più che la rera D. crispata caratterizza il Tortoniano e questa tronasi quasi dapertutto nell'Astiano. R. Ga. - 91. "D. Loprestiana Calcara (Pleurotoma $)=$ Pleurotoma Trecchi T'esta, P. Tarentini Phil. Questa specie fu per lungo tempo creduta identica alla $P$. crispala. Tive nei nostri mari dove ì ben rara. Tra i fossili ho raccolto pochi esemplari identici atfatto ai viventi. $R$. Ga. S. G. L. V. - 92, "D. emendata MIonterosato. = Peurotoma Renierz Phil. (non Seachi). 1. Ga. S. V. - 93. 'D. consanguinea Seg. (Pleurolomn). (Qnesta sprecie ì molto affine alla precedente, ma ne è ben distinta per arerc l'nltimo arvolgimento più grande, i cingoli spirali piì vadi ed in minor numero, un solo sottile sulla regione posteriore concava degli arvolgimenti, mo sporgente molto presso la suturia. R. Bo. Ga.

rela. - 94. "B. septangular is Mitg. (Murex). Tar. B. seculina Phil. (Ileurotoma). R. Ga. V.

rachesis. - 95。 "L. minima Montg. (Buccinum). R. Ga. V. - M1\%, "L. mammillata Tisso - L. minima Var. 1 Monteros. R. Ga. V. - 97. "L. Iincolata? Tiberi (Nesaca). Un sol frammento. R. Ga. V. - 98. "L. candidissima Philippi (Buccinum). Esemplari incompleti lon distinti. R. Gia. V. - 99. "L. Folineae (Delle Chiaie) Phil. (Buccinum) = Fusus granulatus Calcara, B. Lefebvrii Marav. R. Ga. V. - 100. "L. areolata Tiheri. I. Ga. V. - 101. 'Id rulpee ula Monts. = L. recondila Brugnone. Qualche frammento un $\mathrm{pos}^{9}$ dublio. R. Gir. V. 102. L. costulata 11. Sp.

Testa elongata subgracilis; apice obtusinscula, anfractus septem convexi. duo primi apicem subglobosum formantes, lacvissimi, ferruginei; quingue serperntes costati, costac prominentes, decem, interstilia subaequantes, lulle vel aumenliacae; ultimus ovatus antice depressus, dimidium longitudinis subsuperens: os ovatum, babrum arcustum, quatridentatum; canalis brevis.

Lunghezzal 6,5, mm Diametro :3,"mm

Questa specie è molto beu distinta, poichè ha la superfece levigata " privat completamente di linee spirali, invece ie unatil di costole longitudinali che si 
presentann di un colore aranciato più o meno intenso, siccome l'apiee, che è sempre piì scuro. Qualche esemplare oftre il colorito uniformemente aranciato. r. Ga.

Climure. - 103. "C. Gallinae n. sp. Tav. XVI. fig. 16.

Testa ovato-fusiformis, gradalu; anfractus 8 carinati, carina oblusa, subrolundata, suturae posticae propinquiores, pars antica unfracti major, planatosubconvexa, transverse striata, striis impressis prope carinam magis distinctis; oblique plicato-costata, plicis in anfractus ultimus evanescentibus; pars postica planato-concaviuscula, lineis spiralibus expers, lineisque tenuissimis obliquis incurvis ornato; anfruches tres primi regulariter convexi, curina carentes, lacvissimi; ultimus "/: Inngitudinis totius subcequans, antice depressus, proaluchs: cauda brevis, lineis spiralibus super eum magis impressis, lineis incrementi lemibus. Os ovalo-oblongum.

Lumghezza 13,2."m Larghezza $6,2$. m."

Questa specie per la sua scultura, che risulta di semplicissime linee impresse è perfettamente distintil ; la ristinguono benanco le pieghe oblique, la regione posteriore degli arvolgimenti che è alquanto concava ecc. R. Ga.

104. 'C. ten u is culpta Seguenza (Pleurotoma).

Testo ovato-fusiformis. spira parum longa parumque riculn; anfractus $8 \mathrm{ca}$ rinati, carina obtusa, subrotundate. suburde posticae propinquioris; anfrachus cmbrionales tres, convexi, lacees: anfractus ultimus antice inflatus, ad basim caudae valde depressus, dimidium longiudinis superans; cauda brevis; pars postion anfractuum planata, al carinam late marginata: suturae impressae. linerres: superficies totu transverse tenuissime striate, striae prominentes, majores minoribusque altornantes, lineisque obliquis decussantibus granosis. Os ovatum sub-angulosum: columella parum contorta; cauda dextronsum obliquate.

$$
\text { Lunghezza 13. }{ }^{\text {mm }} \text { Larghezza } 6 .^{\mathrm{mm}}
$$

Var. infalo n. Forma più breve, ultimo avvolgimento più rigonfio.

$$
\text { Lunghezza 13. }{ }^{\mathrm{mm}} \text { Larghezza 7,2. }{ }^{\mathrm{mm}}
$$

Var. mejor 11. Forua grande, senltura poco appariscente.

\section{Linghezza 20. ${ }^{\text {mm }}$ Larghezza $9,6 .^{\mathrm{mm}}$}

Questa specie is molto affine alla C. subutionum Bell., dalla quale l'autore la listinse indicandone i preeipui varatteri. La tenuissima scultura e la mancanza di fieghe e di costole eredo che caratterizzano assai bene la mia specie. r. Ga. 105. C. clathrata n. sp. 'Tav. XVI. fig. 17.

Questa specie per la forma si arricina alla precedente, ma la spirale c̀ piì hreve, la carena sugli arrolgimenti è ancor meno distinta, la porzione anteriore degli avvolgimenti piì convessa ed ornata da cingoli e costelle longitudinali sporgenti, che colle loro intersezioni costituiscono un reticolo distintissimo e aratteristico; la parte posteriore alquanto eoneava o ornata da linee oblique, sporgenti, flessuose; i mimi guattro arrolgimenti sono convessi e levigati. Un solo giovine esemplare.

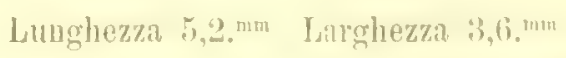

La scultura distintissima separa assai bene questa dalle altre specie. $R$. S. 
Psendotomn. - 106. 'P. breris Bellardi (Pleurotoma) = Pleurotome abbreviald Bonelli. Questa specie comparata cogli esemplari del Piemonte risponde esattimente. Essa conoscevasi soltanto nel Tortoniano, quando io lit raceolsi a Calati-

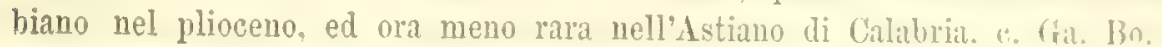

Aphuntomn. - 107. "A. Bella di i n. sp. Tar. XVI. fig. 18.

Questa specie è molto affine all' 1 . Pecchioli Bell., dalla quale io la distingun pei seguenti caratteri. Essia è un 110' meno gracile nella forma generale, it le costole in maggior numero nodose sulla ottusa carena. la scultura risulta da linep spirali impresse, piu forti sulla coda; i nodi alla colmmella sono ben prominenti. il posteriore più grande; il labro ì soleato internamente.

$$
\text { Langhezza 10,8. ma Jarghezza 5.5.) ann } \mathrm{h} \text {. (iit. }
$$

108. "A. If arini Libassi (Hitra) = Rnrsoniu Murini Monterusato. In questa specie allungata le pieghe columellari sono oblique o ben poco sporgenti. R. Ga. V. - 109. A. Philippii 11. sp. = = Peurotoma lmp.rati Philippi (nou Seacchi), A. Imperali Seguenza. Questa specie compramtil con quella dello Scaechi si mostra diversa; essa intanto somiglia molto all's. Bellurdii, e si distingue da questa per la scultura appena risibile, essendo le linee spirali ben marcate soltanto sulla coda; inoltre i due granuli sullit colmmelli sono appena accennati. r. Ga. R.Bo.- 110. "A. Gracei Philipui (Columbella) = Hera ohnirlea Cantr. 1\%. columbellaria Scacchi, H. leontocroma Brusina. Questa specie che fu riguardata come Nitra da varî scrittori pei due granuli della sua columella, parmi chr non spetti realmente alle Columbellu e che invece trovi il suo rero posto tra le Aphanitoma del Bellardi; difatti il suo portamento generale, lo stato embrionario, la forma dell'apertura che è molto stretta el allungata, le pieghe colnuellari, Ia lievissima depressione sulla parte anteriore dell'ultimo arrolgimento e la scultura stessa mostrano evidentissimo il legame tra questa e le precedenti specie. L'A. Graeci è molto rariabile nella Iunghezza della spira e nella presenza o assenza di pieghe longitudinali. Var. cingulate n. Tav. XYI. fig. 19. Chiamo cosi una forma allungata, colla spira piò sporgente, priva di pieghe longitudinali " fornita invece d'una scultura ben piì distinta, in modo che le linee spirali sonn quasi dei cingoli. C. Ga. V.

Crathurella. - 111. "C. e marginata Donoran (Murex) = Murex grecilis Mont. Pleurotoma gracilis Phil. R. Ga. V.

Homotoma. - 112. "H. zanclea Seguenza (Defranciu).

Questa specie è veramente elegante e somiglia alla II. humens Boll., lialla quale distinguesi per essere più piccola, di forma più larga, colle pieghe longitudinali più oblique e flessuose, colla porzione posteriore degli arvolgimenti appianata.

$$
\text { Lunghezza 9. }{ }^{\text {mn }} \quad \text { Larghezza } 50^{\text {mmi }}
$$

Var. Iata. n. Di forma piu allargata. 3. Ga. Bo.S.-113. "H. reticulata henim

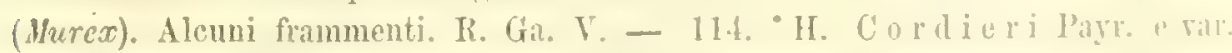
hirta. Rapporto qualche esemplare ed alcuni frammenti a questa specie ed allit

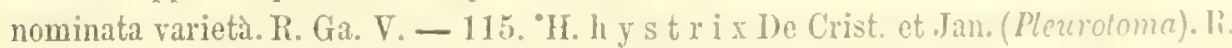
Ga. V. - 116. "H. purpurea Nont. (Murer). Un solo esemplare. R. Ga. V.- 
117. "H. c I egans Donotan (Murex) = Murex linearis Mont. K. Ga. V. - 118. "H. Leufroy i Tichand (Pleurotoma) $=$ Pleurotoma Cyrilli Costa, P. inflata Phil. R. Ga. V. - 119. "H. infla ta De Crist. et Jan. (Pleurotoma) $=$ P. volutella Valencien, P. virgatum Bir. f. R. Ga. V. - 120. "H. textilis Brocchi (Murex). Pochi ben distinti e conservati esemplari. K. Ga. - 121. "H.stria Calcara = Meurotoma semipliceltu Bonelli. Un esemplare rotto ma ben conservato. R. Ga.122. "H. a n ceps Eichw. (Pleuroloma) $=$ P. teres Forbes, Fusus La Viae Calrara, P. minutum Aradas. Questa specie si presenta considerevolmente rariabile, e gradatamente si avricina per alcuna delle sue modificazioni alla $\mathrm{H}$. intermedia Foresti. $x$. Ga. V.

123. "H. cincta n. sp. Tav. XVI. fig. 20.

Questa specie è molto affine alla $/ \%$. anceps, ma a mio giudizio ra distinta dalla forma meno gracile, perchè gli arvolgimenti sono piu brevi e percio relativamente più larghi, i cingoli sono più sottili e piir sporgenti, sopratutto uno mediano che rende spesso quasi carenati gli arvolgimenti, gl'interstizî molto piu larghi ece.

$$
\text { Lunghezza 10,6."m Larghezza 5.mm 1. Ga. Bo. }
$$

124. "H. multicingula n. sp. Tav. XVI. fig. 21.

Anco questa è specie prossimia alla $H$. anceps, dalla quale distinguesi assai bene per la forma e l'andamento dei cingoli, che sono molto numerosi, poco prominenti, e ravvicinatissimi in modo che gl'interstizî divengono minimi. La forma degli arrolgimenti è convessa e profonde le suture. Tutti i caratteri indicati quindi distinguono molto bene questa dalle due precedenti specie.

Lunghezza 15. ${ }^{\mathrm{mm}}$ Diametro. $6^{\mathrm{mm}} \mathrm{r}$. Ga.

Daphnells. - 125. "D. Roman i Libassi (Plourotoma). Tre belli esemplari ed un firmmento. R. Ga.

พnnatis. - 126. "M. Bertrandi Payr (Pleurotoma) = Pleurotoma coeruluns Philippi. Pochi esemplari conservatissimi, in cui si osservano le faseie colorate. R. Ga. V. - 127. M. multiline olat a Deshayes (Pleurotoma) $=$ Pleurotoma pusilla Scacchi, P. subcaudata Bivona f., P. Bivonae Maravigna. Qualche esemplare che conserva le zone colorate. R. Ga. V. - 128. "M. costata Donoran $($ Murex $)=$ Pleurotoma conrctata Forbes, P. prismaticum Brugnone. c. Ga. V. - 129. M. ten uicostata Seguenza (Raphitoma). Questa specie è affine alla M. rugulosc Phil., dalla quale è distinta per essere di forma più allargata, colla spira più breve, gli avvolgimenti ben carenati alla parte posteriore, l'ultimo più grande in forma conica, le costole più strette, piì prominenti, più flessuose ed in minor numero: la scultura esilissima e costituita da strie alternatiramente piin piccole e molto rarvicinate, che dàno alle costole una crenatura molto elegante.

Lunghezza 6..$^{\text {nm }}$ Larghezza $3,10^{\text {min }}$ R. Ga. S.

130. "M. clathrita De Serres (Pleurotoma) $=$ Pleurntomu mule Phil., P.cancollatu Calcara, P. grenum Phil, r. Ga. V.

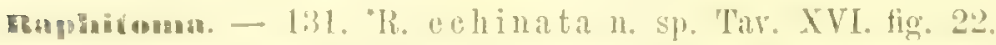

l'este oblongo-fusiformis, anfractus 7, duo primi convexi, laeves, cacteri medio carinati. plicae longitudinales ad carinam spinescentes. pars antica 
anfracti convexiuscula, linea transversa super plicas magis prominula, pars postica planalo-declivis, lacvis, plicisque obsoletis vel cvanescentibus, anfraclus ultimus $3 / 5$ totius longinudinis superans, antice depressus, produclus, inneisque transversis paucis, super costas 14 magis distinctis. Os ovato-oblongum.

Lunghezza 9.m Larghezza $50^{\mathrm{mm}}$

Questa specie somiglia alquanto alla $R$. hispida Bell., wa ha la superficie levigata, con poche e rade linee trasversali, e grosse pieghe longitudinali, che spolgono in forma di spine acute sulla carena. R. M. Ga.

132. 'R. hispidula Jan. (Pleurotoma). Qualche raro esemplare. 1., Bo, Ga. 133. 'R. nu perrima Tiberi (Pleurotoma) $=P$. decussubrm Phil. Holto atinu" alla precedente, ma ritenuta distinta dal Bellardi, dal Monterosato e da altri. Vas. subangulata n. Gli avrolgimenti alquanto angolosi verso la metì. e. Gi. V.134. "R. nevople ura Brugnone (Pleurotoma). K. Ga. - 135. "R. turgida Forbes $($ Pleurotoma $)=$ Pleurotoma nana Scacchi. Un solo esemplare incomplete. R. Ga. V. - 136."R. megastoma Blugnone (Plenrotoma). Un soloconserłatissimo esemplare. R. Ga. - 137. "R. submarginata Bonelli (Pleurotoma). Due belli esemplari. R. Ga. - 138."R. sulcatula Bonelli (Pleurotoma) e Var. Calcbra n. Alla forma che eredo risponda bene alla tipica si aggiunge l'altra che riguardo come varietà, e differisce per la carena piì prominente e pei cingoli alternatiramente maggiori. 1 . Ga. - 139. "R. attenuta Mont. (Hurex). Si raccolgono le varie modificazioni che suole presentare questa specie. 1. Ga. V. 140. "R. brachystoma Phil. (Pleurotoma) = Pleurotoma cancellina Bonelli. Pleurotoma granulifera Brugnone. R. Ga. V. - 141. 'R. Harpula Brocehi (Murex). Un solo esemplare in cattivo stato. R. Ga. - 142. "R. Col um na Se Scachi $($ Pleurotoma $)=$ Fusus costatus Philippi. In belli e conserrati esemplari,alcuni dei quali per lievi crenature sulle costole par che accennassero ad una transizione verso la precedente specie. c. Ga. Bo. M.

Columbella. - 143. 'C. costulata Cantraine (linsus) =- Buccinum acruticostatum Phil., B. Testae Aradas, C. Haliacti Jelitr. 1. Ga. S. Bo. Gre. V. - 144. "C. spmicostata Cantraine (Fusus). Questa specie affine alla precedente, per le costole più grosse, più ravricinate, non in forma tagliente, e fler le forti stric rilerate trasversali distinguesi bene. r. Ga. - 145. "C. seripta Lin. (Imux) Aurex conulus Olivi, Buccinum Linnaci Payr. c. Ga. V. - 146. "U. Liervillij Payr. (Mitra) $=$ Purpura corniculata Risso. Questa e la precentente specie conservano le macchie colorate che areano allo stato di riti. I: (ia. I.

147. "C. elegans u. sp.

Questa forma è intermedia tra la $C$. soripta e la C. Iurgidula, essenton pii breve della prima e più gracile della seconda. Gli arvolgimenti sono aplianati, le suture impresse; l'apertura ie ristretta perelic il labro si rettifical approsimambi inoltre verso la columella: questa disposizione ingenera sull'ultimo arvolgment" una certa irregolarita o leggiera giblosita. La columella presenta dei granuli. il labbro internamente is dentato, con grossi e ravieinati denti. Lal colorizione in molti esemplari si conserva e forma un disenno molto elegante, dal yuale

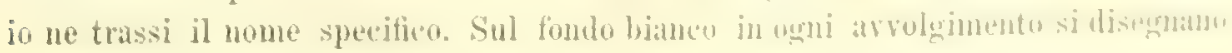


delle macchie quadrate, e più o meno irregolari, di colore rosso-bruno, che si dispongono equidistanti sopra due zone contigue alle suture, ed una zona a queste intermedia offre una reticolazione moltó grata, a maglie ellittiche e dello stesso colore. Sull' nltimo avrolgimento tre zone a macchie si altermano con altrettante zome reticolate.

$$
\text { Lunghezza 13. }{ }^{\mathrm{mm}} \text { Diametro 6. }{ }^{\mathrm{mm}} \text { c. Ga. }
$$

148. 'C. turgidula Bellardi. Gli esemplari che riferiseo a questa specie rispondono benissimo a quelli del Piemonte, ma sono alquanto piì piccoli. c. Ga. 149. "C. s e mic a u a t a Bonelli. Var. inflata n. Un solo esemplare alquanto piii rigonfio del tipo. R. Ga. - 150. "C. B o l's on i Bellardi. Vi rapporto un solo bello esemplare, il quale convenendo in tutti i caratteri, solo ne differisce perchè dal lato del labro il breve canale non è perfettamente distinto. R. Ga.151. C. s ubulata Brocchi (I/urex). In grandi e conservati esemplari. c. Ga. S.152. C. Bellardi i Seguenza. Forma piu gracile della mecedente e diversa per l'apice e per rarî particolari. $r . G a .-153 .{ }^{\circ} \mathrm{C}$. m in or Scacchi $=$ Buccinum mmus Philippi, B. Scrcchi Caleara, B. politum Cantraine. r. Ga. V.

Gycienasis. - 154. "C. ne ritea Lin. $($ Buccinum $)=$ C. Italica Issel. c. Ga. V.155. "C. pellucida Risso (Cyclope). r. Ga. T.

Fasmar. - 156. "N. mutabilis Lin. (Buccinum). R. Ga. V. - 157. N. obliy uata Brochi (Buccinum). Un sol frammento. R. Ga. - 158. "N. cornicu$1 \mathrm{~m}$ Olivi (buccinum) = Buccinum Calmentii Payr. R. Ga. V. - 159. "N. semistria a Brocchi, con diverse varietà, C.R.C.Ga. R. G. M. L. V. - 160. "N. Brocelıii Unrer. = Buccinum constulatum Brochi (non Renier). Specie variabile nel grado di gracilita, come nel ravio grado di sriluppo delle pieghe oblique, per cui semhra fur jassaggio alla precedente. C. Ga. C. A. Ge. S. B. Bo. G. Ri. MI. L. - 161. "N. Cuvieri Payraud (Buccinum) $=$ Bucrinum subdiaphanum Biv., B. variabile Phil., Nessa costulata (Ren.) Weinkauff. Molto rariabile nella forma e nelle pieghe, come la virente. Tar. simplex $\mathbf{n}$. Chiamo così una distinta forma piccola e rigonfia, priva affatto di costole e colle strie spirali fortemente impresse. c. Ga. V.- 162. "N. reticulata Lin. (Buccinum). R. Ga. V. 163. "N. turbinelloides n. sp. 'Tar. XVI. fig. 23.

Questa specie è molto affine alla N. turbonella Brocchi, ma distintissima per la forma piu brere e quindi meno gracile, per l'nltimo arvolgimento proporziomalmente piir grande o che porta ma scanalatura alla parte anteriore precedente il canale; le strie impresse trasversali sono poco sensibili sugli arrolgimenti, e direngono profondi solchi alla parte anteriore dell'ultimo, l'apice della conchiglia i molto più voluminoso, costituito da quasi cinque arrolgimenti convessi e levigatissimi; gli arrolgimenti costati che sieguono sono quattro.

$$
\text { Lunghezza 8,5。m Larghezza 4,8. } \text {. }^{\text {mm }}
$$

Specie molto bella e distinta. c. Ga. S.

164. "N. musira Brocchi (Buccinum). Alemi frammenti. R. Ga. - 165. N limata Chemu. (Buccinum). Questa specie molto comme a Gallina. presentasi li forma allungata, jiecola e con seultura forte; invece essa è d'ordinario breve w a fina seultura nei depositi di wrandi mofondita. C. Ga. C. S. R. Ge. Ri. M. V. - 
166. 'N. renovata? Monterosato $=: N$. prismaticu Monts. (non Broceli). Rayporto con dubbio a questa forma alcuni esemplari.r. Ga. V.- 167. N. w i thr a ta Brocchi (Buccinum). r. Ga. - 168. "N. asperata Ćnconi. Piccola specie a distinta per la scultura; taluni esemplari presentano delle rarici. r. Ga. 169. 'N. pusilla Philippi (Buccinum). 1"Ga. - 170. "N. iucrassata Mull. $($ Tritonium $)=$ Buccinum ascanias Bruguière, B. macula Mtg., B. coccinelln Lamk., B. Lacepedei Payx. Un solo esemplare di forma breve. R. Ga. V. 171. "N. ang u lata? Brocchi. E un esemplare proprio intermedio trat la pretecedente specie e quella del Brocchi. R. Ga.

17.2. " $\mathrm{x}$. con i c a a 11 . sp.

Questa specie è atline alla $N$. limate ed alla $N$. incrassala, ma distinguesi per essere breve, conica, cogli arrolgimenti poco convessi, quasi appianati, colle costole prominenti e ben delimitate, più strette degl'interstizí; le linee spirali sono analoghe a quelle delle specie afhini.

Lunghezza $10,4 .{ }^{\mathrm{mm}}$ Diametro $7 \mathrm{~mm}^{\mathrm{mm}} \mathrm{R}$. Ca.

173. "N. pum il a n. sp.

Questa è specie ben distinta, della forma generale e della grandezza della $N$. pusilla, ma da essa ben diversa pegli arrolgimenti appianati, disgiunti da suture profondate, ornati da costole rette, prominenti, larghe quanto gl' interstizî, ed al numero di circa quattordici; le linee trasversali sono fortemente impresse.

Lunghezza 9. ${ }^{\mathrm{mm}}$ Diametro $4 .{ }^{\mathrm{mm}} \mathrm{R}$. Ga.

174. N. spinulos a Philippi (Buccinum). Distintissima forma per l'appianamento degli arvolgimenti nella parte posteriore, pei forti cingoli, e per le costole rilevate e rariabili in numero ed in grandezza, che sono fornite di spine nelle intersezioni. Var. spirata n. Spira piì allumgata. C. Ge. Ri. M. L.

Cassis. - 175. "O. saburon Bruguiere (Cassidea). Soli frammenti. R. Cra. T. 176. "C. la erigata Defrance $=$ Euccinum areola Brocehi (non Lin.). Con sole strie ai margini degli arrolgimenti. Taluni ritengono questa come rarieta della precedente. R. Ga.

Casstuara. - 177. "C. thyrena Chemu. (Buccinum). R. Ga. B. Y. - 178. "C. e chinophora Lin. (Buccinum). R. Ga. B. C. Ge.S. V.

179. 'C. tenulicincta n. sp.

È una piccola Cassidaria più globosa dolle due precedenti specie, che distinguesi specialmente per avere gli avrolgimenti molto più convessi, la scultura di gran lunga più fina, cioe formata di piecoli, distutissimi ed arvicinati cingoli, che alternano con altri esilissimi talrolta doppî. Le numerosissime, esili e disuguali linee di accrescimento rendono finamente increspati i cingoli. I'n solo esemplare.

\section{Lunghezza 30. ${ }^{\mathrm{mm}}$ Diametro $210^{\mathrm{mn}}$ R. Ga.}

1'allis. - 180. 'P. D' Orbigny i Payr. (Buccinum) = Pisania nodulosu Bivona p. R. Ga. V. - 181. "P. Hileata Broceli (Ihurex). Piu rigontia della precedente. r. Ga. - 182. "P. scabra Monterosato. R. Ga. Y. 183. "P. bieolor Cantraine (Murex) = liurex fasciolarioides Forbes. Buccinum leuensonum Plilippi.r. Ga. T. - 184. "P. f"usulus Brocehi (I/urer). 
Un solo esemplare. R. Ga. - 185."P. Spadae Libassi (Murex). Qualche frammento. R. Ga. V.

Lurhria. - 186. 'E. cornea Lin. (Murex) = Fusus lignarius Lamk. R. Ga. I. Taranic. - 187. "T. cirrata Brugnone (Pleurotoma) = Bela demersa Tiberi. 1. Ga. S. V.

Trophon. - 188. "L. vaginatus De Crist. et Jan. = Murex carinatus Bir. p. M. carinalus Scacchi. Raccogliesi di molte dimensioni. c. Ga. C. R. S. Bo. M. V. 189. "T. multilamellosus Phil. (Murex). Costelle piu o meno arricinate e sporgenti. Var. clegans 1. Con rare e scancellate strie spirali. c. Ga. R. Ge. S. Bo. L. V. - 190. "T. muicatus Mig. (Murex). r. Ga. V. - 191. "T. squamulatus Brocchi (Murex). Questa specie, spinosa sulla carena, è distintissima dalla precentente per la forma dell'apice. 1. Ga.

Musus. - 192. 'F. pulchellus Philippi. Questa forma par che si comnetta colla seguente; il Monterosato ve l'associa. c. Ga. Ge. S. M. V. - 193. "F. rostratus Olivi (Murex). Molto rariabile. c. Ga. R. M. C. V. - 194."F. longiroster Brocchi (Alurex). In belli esemplari, c. Ga. C.

wurex. - 195. 'M. Broc chi M Monterosato = M. craticulalus Brocchi. R. Ga. V. 196. "M. corallinus Scachi = Fusus lavalus Phil. (non Bast.), Murex aciculatus anct. (non Lamarck). R. Ga. V. - 197. "M. scalarioides De Blainville $=$ M. distinctus Jan. Un solo esemplare. R. Ga. V. - 198. "M. Edwards i Payr. (Purpura). 1. Ga. V. - 109. "M. scalaris Brocchi. R. Ga. - 200. "M. Blainvilli Payr. = M. crislulus anct. (non Brocchi), M. Broschii Cantr. $r$. Ga. V. - 201. "M. eristatus Broe. Un frammento. R. Ga. - 202. M. H oernes ii D'Ancona. R. Ga. - 203. "M. rudis. Borson. R. Ga. - 204. "M. eriuaceus Lin. = . decussulus Gm. R. Ga. V. - 205. "M. lamellosus (Jan.) Phil. (l'usus). Esemplari a carena bene sporgente. R. Ga. V. - 206. "M. torularius Lamk. Soli frammenti. R. Ga.

Distorass. - 207. "E. leticulatus De Blainville (Triton) = Ranella lanceolata Menke, Tritonium Iurriculalum Desh, Cumia decussata Bir. f. Pochi frammenti. R. Ga. V.

Itanclls. - 208. 'R. gigantea Lamarck = Murex reticularis anct. (non Lin.). Un bello e conservatissimo esemplare presso Ardore. r. Ga. A. C. R. V.

Won. - u09. "T. nodiferus Lamarek = Trilonium mediterrancum Risso. R. Ge. Ga. V. - 210. T. appeninicum Sassi. = Murex nodulosus Borson. Un solo frammento. R. S. - 211. "T. e utacens Lin. (Murex). Un frammento. li. lial. I:

suseionuia. - 2l:. "F' fimbriata Brochi (Mnea). Qualche esemplare mal conservato, R. Ga.

4:bvelia. - 213. C. fil os a Seguenza, Questa specie somiglia considererolmente al Fusus gracilis dei mari del Nord, ma ne è distintissima perchè piu piccola, coll'avvolgimento ultimo piì depresso alla regione anteriore, pel nucleo di forma assati diversa e regolare, per la scultura non fatta da linee impresse, ma come da fili rilerati che alternano sorente con altri minori. 
veptunca. - 214. N. contraria Lin. (Murex). Grande specie dei mari del Nort. r. C. V.

Buconum. - 215. 'B. Humplu e ysianum var.=B. striatum Philippi. Esemplari incompleti. e. Ga. V.

Cerishum. - 216. "C.v ulgatum Bruguière. Esemplari rotti. 1. Ga.V.-217. "C. varicasum Brochi. Esemplati rotti. R. Gia - 218. "O. rupestre Risso= C. lividulum Risso, C. Mediterraneum, C. fuscatum 0. G. Costa, C. dolium Veink. (non Brocehi). l: Ga. V.

Cerithiolum. - 219. "C. scabu um Olivi (Murex). = C. lima auct. C. Ga. V. 220. "C reticulatum Angl. $x$. Ga. V. - 221. "C. pusillum Jefir" $=C$. Schwartii Tib. (non Hoernes). R. Ga. V. - 222. "C. lacteum Plil. (Cerithium) = C. niveum Biv. p., C. clegans auct. (non De Blainville). c. Ga. V. - 223. "C. spina Partsk. K. Ga.

Triforis. - 224. "T. pelversa (Lin.) auct. (Trochus). Var. Benoiticna Aradas. R. Ga. V. - 225. "T. a dversa Montg. (Mhrex). R. Ga. V.

Cerlthiopsis. - 226. "C. tubercular' is Montg. (Hurex) = Cerithium pygmaeum Phil, C. acicula Brus. 1. Ga. V. - 227. 'C. bilineata Hoernes. (Cerithium) = C. Coppolae Aradas. R. Ga. V. - 208. "C. scal ar is Monterosato. R. Ga. V. 229. 'C. Metaxa e Delle Chiaie (Murex) = C. Crosseanum Tiberi, C. subcylindricum Brus. R. Ga. V.

Chenopus. - 230. "C. Serresianus Michand (Rostcllaria). B̀ questa tra le piu comuni specie del plioceno calabrese. C. Ga. C. A. B. Bo, Ge. S. Ri. M. V.

Cuncellaria. 231. - C. ly rata Brocchi (Voluta). Un solo esemplare. R. Ge.232. "C. coronata Scachi. R. Ga. V. - 233. "C. Broechii Crosse= Volutu piscatoria Brocchi. Qualche piccolo esemplare. R. Ga.

Lamellaris. - 234. "L. perspicua Lin. (Helix). Un giovane individuo. R. Gil. V. Solurium. - 235. "S. fallacios 11 'Tib. = S. stramineum auct. (non Lamk.). R. Ga. V. - 236. "S. s e mis qu a mos um Brom. Specie assai distinta, col margine assottigliato, dal lato dell'ombelico marginato e con un cingolo che l'orni ad una certa distanza; gli avvolgimenti, alquanto convessi, sono elegantemente nenati da quattro o cinque solchi e da numerose linee oblique che l'intersecano. c. Ga. - 237. 'S. contextum Seguenza. Specie affine alla precedente ma pii convessa d'ambo i lati, col margine finamente crenato, senza cingolo; ombelico più stretto, base concentricanente solcata; avvolgimenti ornati da solehi spirali e da linee oblique molto ravvicinate ed esilissime.c. Ga. - 2:38. 'S. Alleryi Seguenza $=S$. moniliferum Tiberi (non Bromn). Assai ben ristinta lahla specic del Bronn, perchè offre meta di cingoli granosi, e per la forma generale moltu più rigonfia al margine. $r$. Ga. $V$.

239. "S. G allinate n. sp.

Questa bella e grande specie, ha wna certa analogia pel sno gencrale indimento col S. caracollalum Lamk. che è sparso nel mioceno; ma la specie pliosenica ò molto più elevata a quasi di forma conica, colla base o regione anteriore molto meno convessa e quasi appianata. Gli arrolgimenti si deprimono un poco posteriormente, sono spiralmente soleati con regolarità; le linee oblique su di essi 
sono poco risibili; l'angolo marginale è piiu acuto, $i$ due cingoli marginali della baco meno prominenti ed appianati; le pieghe attorno l'ombelico molto piu fine el irregolini. Un solo esemplare.

$$
\text { Alteza 12. }{ }^{\mathrm{mm}} \text { Diametro } 22 . \mathrm{mm} \text { R. Ga. }
$$

Variea-240. "N. millepun ctat a Lamk. = N. stercus-muscarum Gm., Noced punctala Rissa. h. C. Ga. V. - 241. N. maculata Desh. = Naced maximn Risso, N. Ilebraed Martin. R. C. V. - 242. N. tigrina (Defrance) auct. Questa ¿ ben distinta dalle precedenti e conserva a $\mathbf{S}$. Cristina le macchie rare, larghe e rubiginose che ne ornano la superficie. La bocea è dilatata, l'ombelico amplo, sottile il callo. c. C. Ga. V. - 243. "N. plioceniea Seg. Specie di forma glohosa molto aftine alle precedenti. Un solo esemplare un po'dubbio. R. Ga.. - 24t. "N. fl amm $u$ la ta Reg $=N$. filosa Plil. (non Reeve), N. fulminea (Risso) Tib. (non N. fulminea Gm.). N. Sagraiana MIonterus. (non D'Orbigny). Un solo esemplare a Siderno, comume invece a Gallina. c. (ia. S. V. - 24t. "N. catena Da Costa $($ Cochlea $)=N \cdot$ monilifera Lamk. Qualehe esemplare un po' dubbio. R. C. Ga. S. V. - 246. "N. f usca De Blainville $=N$. sorlide Phil. (non Swainson), N. Brocchiana Phil. Varia in grandezza e nella prominenza della spira. C. Ga. C. R. Ge. S. Ri. M. V. 247. N. pseudoepiglottina Sismonda. Probabilmente- è varietà della precedente. 1. 13i. M. - 248. "N. intermedia Philippi $=$ N. Alderi Forbes, N. pulchella (Risso) anct. c. Ga. Ri. V.-249. N. macilenta Philippi. R. Ga. V. 250. "N. Guillemini Payr. = N. marmorata Risso. Conserva indizî dei colori. c. Ga. V. - 251. "N. intricata Donoran. = N. Valenciennesii Payr. R. Ga. V. - 252. N. Montacuti Forbes. Vivente nei mari del Nord.c. Ga. Ri. V.253. "N. Josephinia Risso (Neverita) $=$ N. glaucina Philippi. R. Ga. V.

Nulhuse - 254. 'E. polita Lin. $($ Turbo $)=$ Rissoa Boscii Parcr. R. Ga. V. 25\%. "E. K'hilippii Weink. = E. distorta auct. (non Desh.). R. Ga. V. 25(i. "H. s ul, ulata Donovan (Turbo) = Melania Cambessedesii Payr. R. Ga. V.257. "W polygira Seguenza. Distintissima pei suoi numerosi arvolgimenti. r. (Ha. V. - 2.)8. "T. Jeffreysiana Brus. (Leiostraca). R.Ga. V. - 259. "E. intermedia Cantraine. = E. nitida Phil. (non Lamk.). R. Ga. V. - 260. "E. ennica Seg. Bella specie, meno graeile dell' F. Jeffreysiana. r. Ga. - 261. "H. fus iformis Seguen\%al. Specie assai distinta dalla $E$. slenostomu Jeffr. per la forma allungata ed assottigliata della regione anteriore. $R$. Ga.

Culinella. - 262. "E. Seillae Seacehi (Melania). R. Bo. S. Ga. Ri. V. 263. "E. superflua Monter. R. Bo. Ga. S. V. - 264. "E. acicula Philippi (Mclania). K. (ia. V.

Terbonuna. - 265. "T. striatula (Lin.) anct. (Turba) $=$ Turritella potamoides Cantr. Melania pallida Phil., Parthenia varicosa Forbes. R. Ga. V. 266. "T. Lanca Libassi (Chemnitzia). R. Ga. V. - 267. "T. varicosa Donder1. Alumi frammenti. K. Gat. - 268. "T. a moen a Monterosato (Odostomia) = O. (Turbonilla) venusta Monter. (non Issel). R. (ia. V.

269. "T. magnifica n. sp. 'Tar. XVI. fig. 25.

Questa bella specie è molto affine alla T. plicatula Broc. (Turbo), ma distinguesi hene per avere le costelle quasi seancellate, gliavrolgimenti proporzionalmente 
pii brevi, specialmente l'ultimo; essi sono un po' ingrossati alla parte anteriore, e sporgono ciascumo un por al di fuori del seguente, divenendo cosi a superficie alquanto coneara; l'ultimo arrolgimento poi is angoloso, e presenta uni fissurar ombelieale.

$$
\text { Lumghezza 11. mum Larghezza } 8,40^{\text {mm }}
$$

Var. simplex. Costelle quasi nulle. r. Ga.

270. "T. oliliqueplicata n. sp.

Questa è afline alla precedente, o distinguesi henissimn pegli arrolginenti piani. per le pieghe regolari sottili ed obliqumente disposte; laddore nella prexentente sono molto irregolini, più numerose, pressoche perpendicolari alle suture, c la superfieie è striata spiralmente, mentre in questa i levigatissima.

Lunghezza 5. ${ }^{\mathrm{mm}}$ Diametro $1, \breve{s}^{\mathrm{mm}}{ }^{\mathrm{m}} \mathrm{l}$. Cra.

271. "T. delicata MIonteros. = chemmitsia gracilis Pliil. (110n 13rocchi). li. Ga. V. - 272. "T. elegant issima Montg. (Turbo) = 0. lactea (Lin.) Jeflr., Melania Campancllac Phil. R. Ga. V.

273. "T. scalariformis n. sp. Tar. XVT. fig. 24.

Questa specie comparata colla precedente ne somiglia un poco per la senttura. essendo fornita di costelle rarricinate e spesse, piì larghe degl' interstizî, ma essil è distiutissima per la forma più brese, pegli arrolgimenti ahbastanza conressi. Lunghezza 7.mm Larghezza 2,6 . mm $\mathrm{I}$. Ga.

274. "T. ble ris $\mathrm{n}$. $\mathrm{sp}$.

Questa per la sua forma generale soltanto si arvicina mu poen allia $T$. sculnriformis, ma è ancor meno gracile, cogli arrolgimenti molto convessi c colle stlture profoudate. L distintissima poi per le costelle sottili e numerose. el inoltru per le strie spirali impresse, che mancano sulli regione anteriore dell'ultimn avvolgimento. La contessiti e brevitir degli arvolgimenti, la forma quilsi ghubosa dell'ultimo, e l'apertura molto hreve rendono questa specie particolarissima. Var: obsolete n. Mancano quasi intieramente negli ultimi tro arvolginenti le costole c le strie spirali.

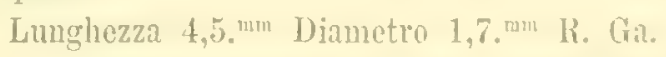

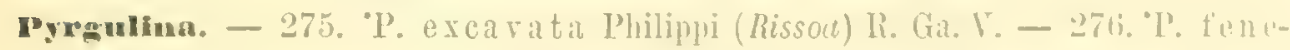
strata. Forbes (Odostomia). R. Ga. V. - -77 . "P. Hrerieula Monteros. (Ohlustomia) $=0$. Moulinsiana Nonter. (non Fischer). li. Ǧa. V.

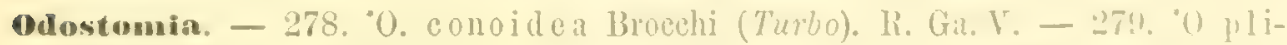
eata (Montg.) Jefli. R. Ga. V. - 280, O. unidentata deflir. Tire nei milli

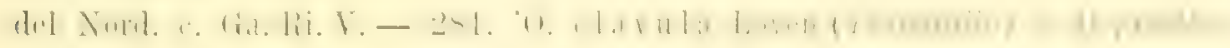
Brugnone. R. Ga. V. - 282. O. S'ismondac Segnenza = Acteon homdedum

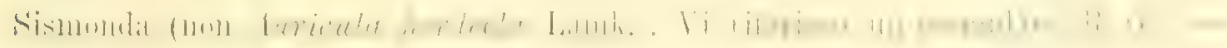
283. "0. thiara Seguenza. Un esemplare rispondente alla forma lanecolta an . 11tavilla. 1. Ga. - 281. "0. sutulalis IBonelli (Auriculu). Un pemplate duhbio. R. Ga. - 285. 0 . pallida Montog. (Turbo). Individui alquantu püi rigonfî. K. Gia. V.

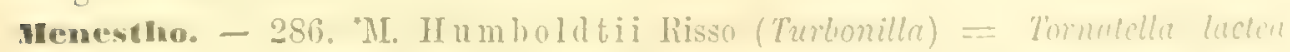
Michaud, T. cluthruta Phil., Rissoe reticulete Callearia. R. (ial. I. 
gyaramindIa. - 287. "P. plicosa Bronn. Pochi esemplari. r. Ga. - 288. "P. minuseula Momiterosato. R. Ta. V.

mathilda. - 989. "M. quatricarinata Brocchi (Turbo). R. Ga. V. - 290. MI. elogutissima O. (G. Costa (Trochus). Un solo individuo incompleto. R. Bo. V. Arlí - 291. "A. Walleri Teffr. R. Cra. V. - 292. "A. 11 mbilicaris Sesnenza. Arvolgimenti molto convessi, suture assai profonde, ombelico e linee spiJali, più o meno manifeste la distinguono dalla precedente. R. Ga.

293. "A. bi cincta 11 . sle.

Specie distintissima, ma che si avvicina alquanto all' Aclis supranitida, della quale ne è molto piì rigonfia. Oltre i tre a quattro arvolgimenti poco conressi e levigati, ehe costituiscono l'apice cilindraceo, la conchiglia costa di sei avvolgimenti brevi, molto convessi, e che crescono celeremente, e sono disgiunti da suture molto profonde. Ine cingoli sottili ma prominenti scorrono sulla regione anteriore degli arvolgimenti, e divengono meno distinti sull' ultimo, il quale $\dot{e}$ regolarmente convesso alla regione anteriore e presenta un largo e profondo ombelico e la bocea quasi circolare.

Lumghezza 3. ${ }^{m m}$ Diametro $1,5$. mm $^{\mathrm{m}}$ R. Ga.

Sealaria. - 294. "S. communis Lamarek. Tr. Ga. V. - 295. "S. Turtonate Turt. - S. cleguns Risso, S. tenuicostata Michaud, S. planicosta Bivona p. Qualche incompleto esemplare. R. Ga.S. V.-296. "S. pseudosealar is Brocchi (Turbo). R. Ga. - 297. "S. penusta Libassi e rar. Seguenza. La specie e la virieta sono forme distinte. R. Gr. - 298. 'S. Tre vel y an a Leach. r. Ga. V.2909. 'S. soluta Tiberi. K. Ga. V. - 300. "S. frondieula S. Wood. r. Ga. B3o. V. - 301. "S. Salicensis Seguenza. Specie affine alla S. hispidula Monterosatn, ma piir grande, colle costole lamelliformi accartocciate e spinescenti alla parte posteriore. Due ben conservati esemplari. R. Ga. - 302. S. pulchella Biv. 1. Un solo esemplare che meglio somiglia alla forma detta S. Schultzii Weinch. R. 130. V. - 303. "S. erenata Lin. (Turbo) = S. crenulata Kien. Due soli esempliri. R. (ar. V. - 30.t. S. plicosa Phil. R. L. - 305. "S. Coceoi Sesucnza. R. (*a. - 306."S. Bombiceiana Coceoni. Questa specie molto affine alla mia S. Coccoi ed alla S. Corulosa (Brocchi), per la superficie striata spiralmente rien distinta bene dalla prima; le grosse rarici e le costole prominenti alla parte rentrale degli arrolgimenti la famno disgiungere dalla seconda. Trovasi in conservati esemplitri. 3. Gr.--307. "S. Iong is s ima Seguenza. Questa specie è alangitissima, cilindrion. engli avbolgimenti convessi, esilmente striati, marginati; con enstole strette, oblique, Hessunse. R. B. (Hi. - 308. "S. corrugata Brocuhi (Turbo). Var. calabra n. I hei e grandi esemplari ehe riferiseo a questa spe-ie differiseono dalla forma tipica per essere di forma più allargata, e per gli avonlgimenti alquanto convessi. r. (ia. - 309. "S s ub lamellosa Seçuenza. P'iu iecela, più gracile, piir aeuta della s. lamellosa (Brocehi), con minor uumero li motole, e senza le linee esili, lamelliformi, longitudinali e trasrersili ehe ca-

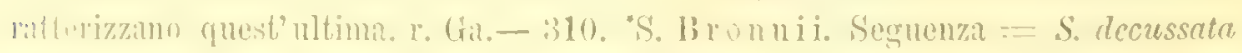
Brom, Coceni (non Lamack), s, amoend Foresio (non I'hilippi). Un solo frammentn. li. (ria. 
311. 'S. II antovani n. sp.

Questa gracile ma solida specie è molto prossima alla S. sublamellosa, ma ì di quella molto più gracile, con maggior numero di costole sottili e di strite spirali, e presenta delle varici qua e li sriluppate irregolarmente, ed ì anco piu assottigliata all'apice.

$$
\text { Lunghezza 11. mm Diametro 3,3. }{ }^{\text {mm }} \text { R. Gar. }
$$

Turrella. - 312. T. com $\mathrm{m} u$ is Risso. R. Ga. V.- 313. T. tricarinata Broc$\operatorname{chi}($ Turbo $)=$ T. terebra auct. R.C. V. - 314. "T'. triplicata Broceldi $($ Turbo). c. Ga. V.- 315. "T. subangnlata Brocehi (Turbo). Le diverse rarietid. c.C.Gia316. "T. striatissima Doderlein. Pochi frammenti. R. Ga. - 317. "I". tolnata Brocchi (Turbo). R.Ga,- 318. "T. rermicular is Brocehi (Turbo). R. Gu.

Vermetus. - 319. "V. gigas Birona p. = V. Arenarius, anct. Serpula polyphragma Sassi. c.Ga. V. - 320. "V. intortus Lamarck (Serpulu). Ordinariamente di piccole forme. C. Ga. - 321. "V. triqueter Bir. 1. Ga. F. 322. 'V. Seguenzianus dradas e Ben。 c. Gil. V. - 3233. "V. semisurecetus Biv. p. 1. Ga. V. - 324. "V. subeancellatus Biv. 1. li. Gia. V.

coccum. - 325. 'C. trachea Montg. (Denulium) $=$ Odontilium rugulosum Phil. l. lit. Y.

Skenea. - 326. "S. planorlb is Fabricins (Jelix) = Helix depressa Montagn. r. Ga. V.

setia. - 327. "S. amabilis Monts. = Rissoce pulcherrima anct. (non Jeflr.). R. Ga. V. - 328. "S. pr ulcherrima Jefil" (Rissoch). Gli esemplari raccolti, comparati con quelli dei mari d'Inghiltera, conispondono precisamente. R.Ga.Y.329. "S. fulgida Adams (Holix), R. Ga. V.

peringiella. - 330. "P. Schlosscriana Brusina (C'ingula). r. Ga. V.

IsarIeia. - 331. "B. Inbla Montagn (Turho). c. Ga. V.

Ixissoins. - 332. "R de cussata Montagu (Turbo). 12. Ga. - 333. "R. pusilla Brocchi (Turbo). r. Ga.

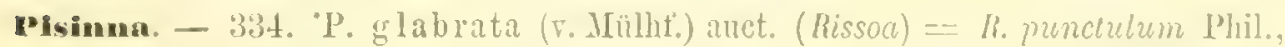
R. sabulum Cantraine, R. Mandralisci Aradas. Un solo esenuplare ben conservato. R. Ga. V.

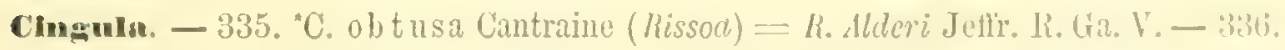
"C. obtus ispira Segnenza. Afhine alla precedente, avrolgimenti meno convessi. ultimo ottusamente angoloso, fissura ombelicale. R. Gia. - 337. C. grianulu Philippi (Rissoa) = Rissoa (Cingula) aemula MIonterosato. Un solo e rotto esemplare. R. Ga. V. - 338. 'C. rudis Phil. (Rissoa). 12. Gia. Y.

Nunia. - 339. A. elegantissima Segnenza (Rissua) = R. abyssicula var. obtresa Jeffr. Bella e distinta specie, fornita d'una scultura più fina tella specie seguente. R. Ga. V. - 340. 'A. Testae Aratas = R. reticulald Phil.. li. ubyssicola Forbes et Hanley. R. Ga. V. - 341. "1. scabra Philippi. R. Ci.l. V. 3.12. A. costata Adams $($ Turbo $)=$ R. exigua Michaud, R. carinale P'hil. R. Ga. V. - 343. A. Iineata Risso = R. rugosula Arudas, Lo corrugulu Brus. r. Ga. V. - 344. A. Montagu Payr. (Rissua) = A. Surdoa lisso, Risare

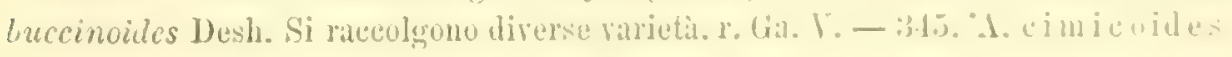


Forbes (Rissoa $)=$ Rissoa sculpta Phil., R. intermedia Arad. r. Ga. V. - 346. "A. bieingulata Seguenza (Rissoa). Vivente nello stretto di Messina, e fossile nui dintorni di Messina. R. Ga. V. - 347. A. laches is Basterot (Turbo). Specie romune nel mioceno. 1. Ga. - 348. "A. calathus Forbes et Hanley. Vive nei mari kal Nord. R. Ga. V. - 349. "A. sororcula Granata (Rissoa). R. Ga. V. 350. "1. reticulata Montagu (Turbo) $=$ R. Beani Hanley 1. Brocchii Weink. 1. Ga. Y. - 351. "A. cimex Limeo $($ Turbo) $=R$. calathiscus Laskey, Alvaniu luropaca Risso. Rissoce granulata Phil. c. Ga. V. - 352. "A. subcrenulata Śchw. (ms.) $=$ R. grenulata var. minor Phil., R. Oceani (D'Orb.), Jetli", r. Ga. V. - 353. "A. cancellata Da Costa (Turbo) $=$ R. cremulata Michand. r. Ga. V. - 354. "1. clathrata Phil. R. Ga. V. - 355. "A. diadema bolerlein (Rissoa). Specie distintissima per le pieghe longitudinali e trasversali che al loro incontro portano delle prominenze acute. Var. Cingoli a prominenze spinescenti, piî̀ piccole ed in maggior mmero. c. Bo. A. Ga. S. - 356. "A. lactea Mich. R. Ga. V.

:35. A. reticulato-punctata n. sp.

Questa specie è afline alla precedente, dalla quale è ben distinta per essere pii rignontia, cogli arvolgimenti pii convessi, colle suture abbastanza impresse, ma non quasi camalicolate come in quella. La scultura poi forma una reticolazione molto fina, in cui le linee longitudinali e le trasversali sono uguali, e i vuoti cle lasciano somigliano a punteggiature.

$$
\text { Lunghezza 4,5. } \text {, }^{\text {mut }} \text { Diametro } 3,3 \text {. }{ }^{\text {nm }} \text { R. Ga. }
$$

abson. (') - 358. "R. violacea Desm. 1. Ga. V. - 359. "R. splendida Eichw. $=$ R. omatr Phil. r. Ga. V. -360 . "R. variabilis v. Müllh. $=$ R. costata Desm. Questa specie comunissima presenta le direrse rarietà, e gli ornamenti colorati della superficie troransi sorente conserrati nel riceo deposito di Gallina. 6. Ga. K. - 361. 'R. costulata Alder. = R. subcostulate Schw., R. decoratu Phil.r. Gat. V. - 362. "R. Sultzeriana Sismonda. R. Ga. - 363 "R. ventricosa Desmant. r. (ia. V. - 30t. "H. simil is Seacehi. Qnesta specie presenta diverse varietil, frat le quali aleunil senza costole. 1" Ga. V. - 365. "R. pulchella Phil.

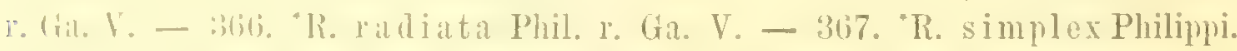

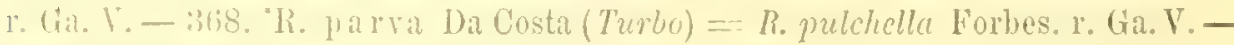
stis. H. oblonga besmaret. R. Ga. V. - 370. R. auriscalpium Lin. (i'urluo). li. (kit. V.

Mera. - 371. "H. tenella Jeffr. (Lacuna). 1. Ga. A. Bo, S. V.

Matronina - "372. 'L. neritoides Lin. (Turbo). R. Gia. V.

37 . Is. peregrina $13 . \mathrm{sp}$.

(Que'stal Lillorina ì atfine allpuanto alla L. rulis, ma ben distinta pegli arvolgimenti meno convessi. pelle suture non frofondate e più ancora per la soultura costituita da cingoli riluati, che divengono alyuanto nodosi irregolarmente per le linee di aceresemento. I cingoli sono meglio manifesti sull'ultimo

(') Le muneruse slucir di liksoidi. in qusto e nei seguenti piani, mi hanno consigliato di ri-

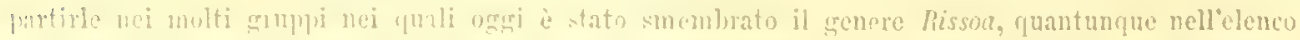

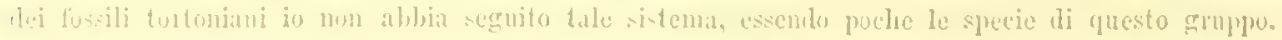


avrolgimento, due verso la base formano cunsi dne callene, perchè sono piii rilevati. Oltre i cingoli, sonori delle linee che in vario mumero w essi s'interpongono.

\section{Lumghezza 11,5., nm Diametro 9,5.}

Gli esemplari raceolti conservano un colorito lrunastro. li. Ga.

APrasianema. - 374. "P. costatum Broechi (keritu). Var. putulum e var. minutum = Fossarus clahratus Philipui. La prima varieti ì la piu comune. l’. Ga. V. 375. "P. cinctum n. sp.

Questa specie quantunque mostri molta affiniti colla precedente, pure si lascial distinguere benissimo pei numerosi caratteri differenziali; e primieramente la spirale, che è piu prominente, non cresce cosi celere come in quella, le suture non si profondano mai, l'ombelico manca, ed in sua vece si stemle in quella regione una callosita, che lascia appena una lievissima fissura; ma ancora fiu rilevanti caratteri si hamo dalla seultura: i cingoli sollo prominenti, rotondati te regolarissimi; essi affettano anco la regione appianata posteriore degli arrolgimenti ed ormano la regione tutta ounbelieale; le costelle lamelliformi che s'interpongono obliquamente ai cingoli, sono anch'esse sviluplate con grante regolarita; la superficie tutta finalmente è oluata da esilissime linee spirali, che non mancano nemmeno sugli stessi cingoli.

\section{Lunghezza 8. ${ }^{\text {mm }}$ Diametro 8. ${ }^{\text {mm }}$}

Esemplari pio o meno mutiliti. Ir. Ga.

PHasianel1a. - 376. "P. pulla Lin. (Turbo). 1. Gal. V. - 377. P. tenuis Michant. r. Ga. V.

Trachysums. - 378. T. delicatum Phil. (Cyclostoma?) = Janhine delicala Seguenza, Architer cutemulata? Jelin. (110n Costa), Trachysma delicatum Jeffr. Sottile ed elegante specie scoperti virente nei mari del Torit. R. Ri. P. V.

Turbo. - 379. "T. rugosus Lin. 1" Gia. T. - 380, "T. fimbriatus? Borson (Trochus). Tra i varî opereoli iella precedente sprecic ne trorai uno spianato dal lato esterno, che frami rupportarsi all T. fimbriatus conosciuto tanto nel mioceno quanto nel plioceno. R. Gra.

381. "I'. graulutus 11 . spr.

Questa specie ha certa analogia col T. speciosus Michelotti del miocenu. ma è più piccola, più stretta, colla regione anteriore piana el angolata, coi grianuli che ornano gli avvolgimenti ottusi, proe sporgenti c lisposti in serie spirali. di cui una, formata di granuli più grossi e postil presso la suturi posteriore. curona ogni arrolgimento.

$$
\text { Lunghezar 13. mu Dianetro } 14 .^{\text {mu }} \text { R. (ial. }
$$

382. "T. peloritanus Cantraine =: T. eryehrimus Galrani, Trechus filosus " glabratus P'hilipui. Questa inpiortante specie trorata visente nell'Atlantico è prupria del plioceno dell'Italia meridionale. Troransi aneo la Val. filose e lal lar. glabrata. r. Ga. R. A. Bo. Ge. S. G. Y. M. L. T. - B8\%. "I. mamilla Andrzeiowski (Jonolonta). Questo Thurbo del mioceno e lel plioceno furmil una ben distinta specie fornita di tenui strie sprirali; usso nou fuò raplurtarsi al 
genere Monodonla o nitro della famiglia dei Trochidi. c. Ga. V. - 384. 'T. romettensis. Seguenza Piceola specie lerigatissima. c. Ga. V.

onivis. - 385. "). T'inei Caleara (Honalontu) = Honodonle limbala Philippi, Cruspedotus Tinei auct, O. Tinei Segnenza. R. Ga. V.

Crnuculus. - 386. "C. col'allinus Gmelin (Trochus) = Monodonta Conturii Payrand. R. Ga. T. - 387. 'C. cruciatus Lin. (Trochus) = Honodonta Wieilloti Payramt. r. Ga. T. - 388. "C. J us sien i Parraud. (Honodonta). r. Ga. V.

Trochas. - :is9. "T. magus Lin. Molti giovani esemplari. r. Ga. V. - 390. "T'. lotulus Brochi. 1" Ga. - 391. "I'. fanulum Gm. R. Ga. Y. - 392. 'T. Guttal a ri Philippi. R. Ga. I. - 393. 'T. Ferm on i Payrandean. R. Ga. T. - 394. "T. varius Lin. - T. Roissyi. R. Ga. V. - 395. "I. villicus Phil. R. Ga. T. - 396. "T. turbinoides Desh. $=$ T. helicoides Phil. 1. Ga. V. - 397. "T'. Adansonii Payr. r. Ga. V. - 398. T. gemmulatus Philipui. r. P. V. - 399. "T. turbinatus Born. Un frammento che conserra le machie colorate. R. Ga. T. - 400. 'T. angulosus Segueuza . (Architen). R. P. V.

401. "T la evissimus n. sp. Thav. XVI. fig. 27.

Specie affine al T.exilis Phil, dal quale distinguesi molto agerolmente pegli avrolgimenti piu contessi, e levigatissimi, mancando ogni indizio di strie, per l'ombelico più svilupluato e più profondo, e per l'ultimo avolgimento relativamente più grande.

Lunghezza 2,7.mm Diametro 3."mm r. Ga.

102. 'T. solarioides Seguenza. Questa specie ì distintissima, molto depressa, levigata, ombelicata, coll'ombelico crenato. In cattivo stato, si spolverizza assai facilmente. c. (xa. - 403. "T. pex egriu us Libassi (Solarium) =- Trochus (Margarita) peregrinus 1 Ionterosato, Seguenza. Specie molto bella ed elegante pei cingoli spinescenti di cui is ornati. c. Ga. - 404. 'T. reticulatus Philippi (Solurium $=$ Trochus reticulatus Jefrreys., T. (Hargarilu) reticulatus Seguenza. Questa sprecie fu trorata vivente nei mari del Nord. R. L. V. - 405. T. margin ulatus Philipui. Bella specie, che presenta numerose varieta e variazioni. r. Ri. S. R. - 406. "T. cinctus Philippi. Specie affine alla precedente pegli arrolgimenti crenati sopra una carena posteriore, per la forma generale, pel largo ombelico crenato somigliante a quello dei solarî; ma differente per la profondita delle suture, pel largo appianamento alla regione posteriore degli avvolgimenti e per molti particolari, tra i quali specialmente i numerosi cingoli che ornano la superficie dechi avrolgimenti, come la base, e che variano in numero siccome in prominenza. Var. amabilis $\cdots$ T. amubilis Jefri. La carena posteriore degli arrolgimenti diviene piir sporgente, i cingoli numerosi spariscono, restandone uno alla base degli arrolgimenti, due sull'ultimo. Var. depressa n. Coi caratteri della precedente, na a forma molto bassa. Questa specie conserva delle macehie rosse piir o meno regolmmente distribuite siceme le descrisse il Philippi. Altra rolta ho pubblicato questa specie trovata a Calatabiano col nome di $T$. amabilis Jeftr; allora non ne rinvenni che qualche esemplare e taluni frammenti, oggi la raccolsi abbomdantemente a Gallini, dove presenta le rarjeta ricordate, tra le quali la piir 
abbondante, risponde precisamente alla specie che il Philippi scopiva a Militello. Le altre si collegano ad essa colla massima evidenza, e sjettano chiaramente alla forma dei mari del Nord. (T. amabilis). Grazie alli gentilezza del prof. A. Aritdas, io ho potuto comparare i miei fossili con un individuo tipico racolto a Militello, e devo alla somma cortesia del sig. J. G. Teffleýs varî esemplari del suo T. amabilis del Nord, coi quali ho potuto firre acentatimente i miei confironti. Cosi considerata, la specie deve portare il nome datole dal Philippi, perchè anteriore, e la forma descritta dal Jeffreys deresi ritenere siccome rarieta di quella. c. Ga. V. - 407. "T. Ottoi Philippi. Specie distintissima, che oflre anco impoltanti rarietì, ma è molto rara nel Reggiano. Var. major. Lisemplari griganteschi. r. Ga. S. B3o. V.

408. "T. distinctus M. sp. 'T'av. XVI. fig. 28.

Più piccoloassai, ma di forma molto piiu elevata del $T$. Ottoi, al quale somiglia alquanto pegli arvolgimenti appianati, per Ie suture largamente profondate, per due ordini di prominenze che arvicimano le suture; ma ne è distintissimo per la forma conica più alta, per le linee rilerate alquanto oblique che riuniscono in ciascuno arvolgimento i granuli per le due serie marginali. La base convessa ha dei solchi concentrici grossi ed in piecol numero. La hocea è quadrangolare, pii larga che alta, il Iabro è flessuoso; la columella un po'obliqua.

\section{Lunghezza 5,4."mm Diametro 4,2. min R. Gar.}

409. "T. conulus Limn. R. Ga. V. - 410. "T. zizpphinus Lin. o vall. Turbinoides Lamk. R. Ga. V. - 411. "T. dubius Philippi. R. Ga. V.-112. "T. I a ugieri Parreand. R. Ga. V.-413. "T. Gualterianus P'hil. = T. laevinatus Phil. (non Gm.) R. Ga. V. - 414. "T', millegranus Philippi = T. miliaris Brocehi. C. Ga. A. S. V. - 415. "T. Coceh i D'Aneona (MI.S.). Specie largimente conica e con largo ombelico, con iscultura analoga alla precentente. La forma ratecolta a Gallina costituisee la Var. coronalus 11. I eingoli degli arrolgimenti sono appena granosi, invece uno di essi presso ciascuna sutura è plicato-granoso. R. Gia. 416. "T. marginatus. 12. sp.

Questa specie ha la forma generale del T. sizyphinus, cooli arrolgimenti alquanto convessi, i superiori cingolato-granosi, gli altri lisci con qualche stria impressa presso le suture. Un cingolo angoloso, striato, e crenato necli avrolgimenti posteriori, liscio negli altri, cinge il margine anteriore legli anfratti. La base è convessa, striata concentricamente da strie finissime, variabili, che ingrinssano attorno la regione ombelicale, ed uma maggiore sta presso il marcoine all'esterno. Var. crispatus n. Gli arvolgimenti sonn strati, il cincrolo marecinale increspato. Var. dilatalus n. Forma piì allargata, cingolo più prominente.

$$
\text { Lunghezzat 9. mu Larghezza 8,5. ำ r. Ga. }
$$

117. "T. grianulatus Born. Vill. Laevis Brugnone. Vi riferisen un sol frammento. R. Ga. V. - 418. "T. suturalis Plhilippi. I". S. M. L. V. - 119. "I'. Hullatus Philippi. Questa specic comunissima nellistiano di M[essina, ì hen lama ne] liengiano. r. I'. K. Gie. - 120. 'T'. Say y nus Seguenza. Specie hen distintir pre te suture largamente profondate, pegli arvolgimenti piani c carenati presso le suture. Var. striatulus. 11. Con esili strie rilevate spimali che ormano gli arrolgimenti. li. 
Ga. - 421. 'T. turgidulus Brocchi = T. Montagui W. Vood. R. Ga. V.122. - "T. tumirulus Amdas. 1". Ga. V. - 423. "I'. cxasperatus Pennant $=T$. cremulatus Brocchi. Var. granulatus n. Questo Trochus va riunito con molto dubhio alla specie del Pennant, ma attesa la grande varialjilita di quest'ultima, tale rarricinamento può accettarsi. In questa nuova forma i cingoli risultano di granuli arrotondati perfettamente distinti, ma negli ultimi avvolgimenti variano, o altermando con altri minori non granosi, orvero perdendo tutti la gramulazione, e sino la forma di cingoli. r. Ga. R. K.-424. "T. par rulus Phil. M[olto afline al segnente. $r$. Ga. $=425$. "T. striatus Lin. Con diverse varieta. e. Ga. V. - 426." 'I'. muidentatus Phil. Qualche esemplare un po' dubbio. R. Ga. V. Cireuhus. - 427. "C. striatus Phil( Valvatu?) = Solarium Philippii Cantr. 1. Ga. V. G'yelostrems. - 428. "C. I u c i l u m Seguenza. Speeie grandetta e levigatissima colle suture poeo profondate. R. Ga. - 129. 'C. Cutle rian um Clark. (Shenea).R.Ga.V.

semuenzia. - 430. S. monocingulata Seguenza (Trochus) = Omphalizus monocingulatus Jefí., Seguenziu monocinguluta Jeffi.. (M. S.), Seguenzid formosu Jutli. Questa magnifica specie è assai ben distinta. Var. cleguns Seguenza. Linee d'accrescimento ben appariscenti. r. Bo. A. Ri. M. L.

scissmella. - 431. "S. erispata Fleming. = S. striatula Plilippi. Alcuni esemplari di forma proprio tipica li ho raceolti a Gallina; ma questa specie raria poeo nella frominenza della spira, e dallo studio fatto sugli esemplari vivi e fossili di vario provenienze e sulla figura e la descrizione del Philippi io sono venuto alla conclusione, che la S. usperce Phil. è una distinta specie. r. Grit. V. 439. "S. a spera Philippi. Tar. XVI. tig. 31. Spira più elorata e prominente di quanto lo è nella precentente specie, ultimo arvolgimento più rigonfio, regione anteriore degli avvolgimenti piì alta assai, regione posteriore molto convessat, ombelico più alerto, senltura somigliante, ma meglio distinti. Io ho ritenuto sinora whe alla S. aspera doreasi riferire la forma seguente, che credo distintissima e che tho raceolto insieme a questa; i recenti studî me ne dissuasero. r. Ga. V. 433. "S'. eximia n. sp. 'lav. XVI. fig. 32.

Questa hella specie è più grande della prececlente; essa difterisce poi da quella ner molti caratteri: la regione anteriore dell' ultimo arrolgimento è molto più convessa el elegantissimamente reticolata jer costelle radianti e per cingoli ad usse uguali, entramhi esilissimi e ravricinatissimi nella precedente; l'ombelico riducesi and una semplice fissura onbelicale, mentre nella precedente la regione circostante s'infossia gralatumente per costituire un ombelico clargato; la fenditura sulla carena si estende per oltre un quarto dell' nltimo arvolgimento, la rima es cinta da duo lamello poco sporgenti, lo sono invece molto nelle S. crispulu ed usperu. La regione posteriore deghi avrolgimenti è appianato-convessa, mentre nell'altra is fortenente convessit; le costelle incurvate siegnono l'andamento di quelle della recoione anteriore tanto nella forma che nella distanza, ma in tale superficie aprena vi si scorgono indizî di linee spirali.

\section{Alteza 2,9..$^{\text {mm }}$ Diametro $3,5 .{ }^{\mathrm{mm}}$}

Questa specie non puo riferirsi alla s. aspere Ph., che deve avere la parte posteriore degli arvolgimenti molto convessa, la scultura delli base molto più tenue 
di quella della regione posteriore degli avvolgimenti, como risulta dallia deserizione e dalla figura date dall'antore. c. Gro.

434. "S. ten u is u $1 \mathrm{p}$ ta n. sp. Tar. XVI. fig. 2n.

Questa distinta forma è più grande della precedente, insieme alla quale si raccoglie e dalla quale agevolmente distinguesi, perchè nella forma generale è meno globosa, meno elerata la spirale, più convessa la parte posteriere degli arrolgimenti, brevissima la parte anteriore, la regione anteriore dell'ultimo arvolgimento è poco rigonfia e pressochè ugualmente couressa quanto la posteriore. Lai scultural è esilissima: sulla regione posteriore degli arrolgimenti costa di finissime line oblique, e di più sottili linee spirali; sulla regione anteriore dell"ultimo arvolgimento, che porta un angolo presso la scanalatura, le linee oblique si contimuno colla medesima intensita, le spirali sono più distinti of fra loro molto allontamate. Liombelico è formato da una fessura ombelicale profonda. Lia hocea it rotondato-angolosa.

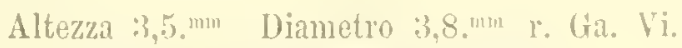

435. S. argutecostata n. sp. Tiv. XVI. tig. 30.

Questa specie somiglia molto alla precelente, dalla quale distinguesi pera arere la spirale piu elevata, le suture piu profonde, lat rogione anteriore ilell' ultimn arvolgimento meno tumida, assumendo cosi una forma pressochè conica; ma sopratutto la distingue la seultura, che ì ben uguale per lit regione anterioru come per la posteriore, e formata da linee oblique prominenti col acute, le quali sono intersecate da esili linee spirali molto piu soltili e rarricinate.

Altezza 3,1. ${ }^{\mathrm{mm}}$ Diametro $4,4 .{ }^{\mathrm{mm}} \mathrm{R}$. S.

Inalioris. - 436. "H. la mellosa Lamarck. R. (tia. V.

Crepidula. - 437. "C. unguiformis Lamk. = Co candida Risso, r. Lia 1. 438. "C. Monliusii Michand z.- C. fornicata Phil.' (non Lamk.). R. Ga. V.

Calyptraen. - 43?. "C. Chinensis Lin. (Palella). C. Gia. V.

Capulus. - 440. "C. H ungaricust Lin. (Patella). r. Gia. V.

mrocehia. - 441. "B. Bellardii Biondi. 12. Gr. T.

rissurella. - 442. "F. costaria (Basterot) Philippi. l. Ga. T. - 443. F, neglecta Desh. - Patella Graeca Brocehi (non Lim.), F. italica Defiance. Vall. W.

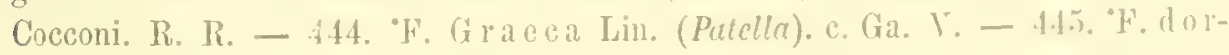
sata Monts. R. Ga. V. - 446. "F. gib bit Philippi. c. Ga. V.

Fissurisepta. - 447. F. papillosa Seguenza. Tive nei mari del Nord. R. P’. V. Puncturella. - 448. P. noachina Timeo (Patelle). Vive nei mari del Tord. R.R. I monuda. - 449. "R. ca lu 1 iformis Pechioli. Grande e ben distinta specie Var. depressa n. Forma poco elevata. c. Ga.

Crepiemarginula. 11. gen. Conchiglia orale convessa o conica, coll'apice rivolto indietro, ed incurvato verso il margine posteriore, a carita semplice; csisa porta al suo margine anteriore un intaglio o fenditura, che si continua con uma callositit lineare interna, che ra sino all'apice, ed all'esterno con un camale eorrispondente, trasversalmente striato. Apertura ovale, che viene in parte clinsa da unit lamina appianata, che stendendosi orizzontalmente aderisce coi suoi mareini alle pareti posteriori c resta libera pel margine anteriore. 
Quest" sener", "nme chianmente apurare dalla costituzione della conchiglia, e un rero intermedio tra la fimiglia dei Caliptreidi e quella dei Fissurellidi. Esso ha infitti l'indanento d'una Emurginula, sia per la folma, come per la fenditura marginale e pel solco dorsale, ma la lamina che chinde porzione dell'apertura i froprio come nelle Crepiclule.

450. - "C. reticulata 11. sp.

Testa parva, solida, ovato-elliptica, regulariter convexa; apex prope marginem posticum: sulcus superfuciulis: superficies tenuiter esquisite clathrata; margo crenalus.

Conchiglia ovato-ellittican, poco elevata, regolarmente convessa, coll'apice che va sino al margine posteriore; soleo dorsale poeo profondo e stretto, con linee trasversali arcuate e distanti; superficie elegantemente reticolata per due serie di linee che l'ornano, le linee sono sottili e prominenti, le une irradiano dall'apice alla periferia, le altre disposte concentricamente le intersecano formando un reticolo molto bello. Il margine della concliglia è finamente crenato. La lamina che chiude parte della boeca s'inserisce ad una certa altezza dal margine ed è alquanto convessa.

Non ho trovato sinora che un solo esemplare incompleto di questa specialissimil conchiglia.

$$
\text { Altezza 2,3.mm Larghezza 3.7. }
$$

Frianramula. - 451. "L. fissula Lim. (Patclla) - E. elata Libassi. r. Ga. V. 4.2. "H. confusa Seg. Specie che vire nello stretto di MIessina. r. Ga. R. V. -

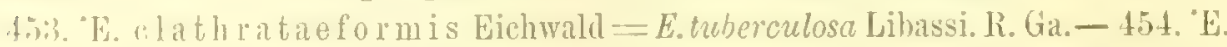
con ica Schum. $=E$. Costce Tiheri. R. Ga. V. = 455."E. pil colus Michaud =E. capuliformis Pli1.. R. Ga. V. - 456. 'E. cancellata Philippi. R. Ga. V. 457. "H. A driatica O. G. Costa. r. Ga. V. - 458. E. decussata Phil.r. L. 159. "H. elongata O. G. Costa. r. Ga.T. - 160. "E. Huzardi Payr = E. depressa. Risso. R. Ga. V. - 461. "E. solidula 0. G. Costa. r. Ga. V.

Trotume. - 462. 'T. un icolor Forbes (Lottia) = T. virginea anct. (non Mull.). c. Ga. V.

Datalla. - 46i3. "P. coerule a (Lin.) auct. Qualche esemplare. r. Ga. V. - 464. 'P. Lusitanica Gm. - P. punclala Lamarck: R. Ga. V.

Chiton. - 465. "C. olivacens Spengl. = C. squamosus Poli (non Lin.), C. sulcalus Risso, C. Sicu'us Gray. 1. Ga. V. - 466. "C. miocenicus Michelotti. I a compararione di questo Chion con quello del mioceno medio dimostra lievi diflerenze. c. Ga. - 467. "C. corallinus Risso = C. rubioundus O. G. Costa, C. scytodesma Seacehi, C. Freclundii Forbes, C. pulchellus Phil. (non Gray), C. Philippii Issel. R. Ga. V. - 168. "C. Cajetanus Poli. r. Ga V. - 169. "C. Altavillensis Seguenzil :- C. squamosus Libassi (non Linneo). Questa grande e hella specie si distingue per essere ricoperta da grosse squame ellittiche. Le valve sono moltn spesse e solide, le valve estreme sono dentellate ed intagliate. Raccolte poche valve a Gallina, che rispondono bene con quelle di Altarilla. r. Ga.

acanthoehutes - 470. $\mathrm{A}$. discrepans Brown (Chiton) $=$ A. communis lisso. r. Git. Y. 
Classe. Sol.enoconchi.

Dentalimm. - 471. D. De lessertianum Chenu = D. strialum Phil. (non Lamk.), D. sulcalum Scacchi (nou Lamk.), D. Philippii Monteros. Questa specie è molto comune nell'italia meridionale. C. Ga. R. C. S. B. Bo. A. M. Ge. 472. 'D. elephantinum Linneo. È difficile negli esemplani incompleti di distinguere questa dalla precedente specie. C. R. Ga. B. Bo. A. Ge. Si. Ri. M. L. V. - 473. D. badense? Partsk. Con dubbio ri riferiseo qualche esemplare. R. R. - 474. "D. Passerinianm Coceni. c. Ga. A. Bo, - 475., 1), Panormeum Chenu = D. Lessoni G. B. Sow. (non Desh.). r. (ria. K.

476. "D. polyedrum n. sp.

I pochi esemplari incompleti di Dentalinm che riunice sotto yuesto nome si distinguono beuissimo per la loro format, la quale invece di exsere come d'ordinario conico-cilindracea ì piramidato-prismatica, colle facce perfottamente piante e separate da spigoli ben netti. Le farce sono cirear 14 a disugualissime. Lal superficie è levigata e lucida.

Lunghezza presunta 25."mu Diametro 2,5."'m! 1". Gia.

477. 'D. v ulgale Da Costa--D. Tarentinum Lamk. 1. (Fia. V. - 47S. '1), I aerigatum Ponzi. r. Ga. - 479. "D. agile Sars. =- D. incertum Phil. (non Desh.). Nel plioceno dei mari profondi is questa ma delle specie commissimu e caratteristica. C. R. C. Ga. B. A. Bo. (re. S. G. Ri. M. T. Vi. T.-480, 'D). rubescens Desh. Distinto per la fenditura. R. Lia. V.

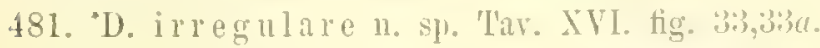

Questa specie è più gracile e più assottigliata delle due precelenti, presental leggiere ed irregolari strie di acerescimento, la sua formal poco enra si ollire sempre sviluppata con irregolaritì, la fenditura is breve e si allarga regolarmente in forma triangolare.

Lunghezza 32. ${ }^{\mathrm{mm}}$ Diametro 2,4. ${ }^{\mathrm{mm}} \mathrm{r}$. Ga.

482. D. filnm G. B. Sow. $=$ D. gracile Jeffi. (non Meek.). Un solo esemplare. R. Ga. V.

Siphonodentalimm. - 48\%". S. triquetrum Brochi (Dentalium). Qualche esemplare molto grande di unita ad altri di ordinaria statura. l. (ta. 13. $\Lambda$. Bo. Ge. - 484. 'S. tetragonum Brocehi (Dentalium) = D. quinquangulare Forbes. c. R. C. Ga. B. Bo. A. Ge.S. (A. Ri. MI. Ti. V. - 485. 'S. Lofotens II. Sars. r. lia. I.

Helonyx. - 486. "H. rentricosit Bromn (Denlalium) =- Dentuliun coarchtum Lamk. (parte), Creseis gulus Bronn, Dentalizm Olivi Scacehi. Combulus ventricosus Doderlein, Gadulus gadus Appelins, Denalium gadus C'oceoni (nn) Montg.). Questa specie, che il Jeffrers trorava virente nei mari di (irvenlandia. è comune dapertutto nel plioceno italiano. Essa trovasi nella provincia li lieggio molto rara, ma è comune invece a Gallinit dove raceogliesi in usemplari conservatissimi. c. Ga. S. Bo. B. T. - 487. H. ga dulus Doterlein (Godulus).

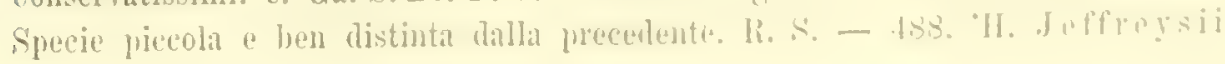


Monterosato $=$ Cadulus subfusiformis Jeffreys (non Sars). Questa piccola e gracile specie tropasi ben consertata a Gallina. r. Ga. i.

Carlalus. - 48?. C. diplocouns Seguenza. Questa sperie ricorda la precedente nella forma gencrale, ma spetta a quest'altro gruppo, ed inoltre presenta un brusco rigonfiamento verso il mezzo, dal quale carattere riconoscesi a prima giunta. r. S. Vi. - 490. "C. c yath us De Cristofori et Jan. (Creseis) = Dentalium ovulum. Var. attenuata Monterosato. 1. Ga. S. A. Bo. - 491. "C. o r u l um Philipui (Dentalium). Specie assai distinta per la forma globoso-orata, levigatissima, ad iperture circolari, la posteriore ornata da elegante dentellatura, a denti piccolissimi e prominenti. Tar. gibba. Più rigonfia e maggiormente gibbosa. c. Ga. A. (re. S. Ri. M.

419. C. Salicens is 11. sp. = C. ovulum Var. Salicensis Seguenza. Questa forma che io associara alla specie precedente, devesi disgiungere; essendochè il margine all'apertura posteriore non is finamente dentato, inrece presenta delle oscure e larghe crenature. Quanto alla forma, distingnesi; perchè si restringe più bruscamente alla regione posteriore, che diviene assottigliata e prominente. r. Bo. A.

Classe. Pteroponi.

Myanen. - 493. "H. tridentata Forschal (Anomia) = H. connea Lamarck. In esemplari conservatissimi a Gallina. c. Ga. V. - 494. "H. peraffinis Seguenza. Esemplari di perfetta conservazione ma molto fragili. c. Ga.V. - 495. "H. scilla e Seguenza. Specie globosa, e ben distinta per la gibbosità della regione rentrale, per la convessitì e caratteri delli regione dorsale. R. Ga. -- 496. "H. Cal at a bia ne n s is Seguenza. Piccola e distinta specie nolto allargata, tricostata, con apertura allungata e stretta. R. Ga. - 497. "H. inflexa Lesueur" = $I$. uncinatr Hoening, II. vaginella Cantrane. Questa specie nel griacimento di Gallina presenta delle rariazioni, in cui le pieghe dorsali tendono a sparire. c. (ia. V. - 498. 'H. trispinosa Lesueur = H. mucronaia Quoy et Gaim., II. clepressa Bir., Diacria trispinosa anct. 1'. Ga. B. V.

Creorion's. - 499. "C. p y ramidata Lin. (Clio) = C. lancenlata Blainville. C. Ga. B. Bo. S. Ri. Y. - 500. "C. e uspidata Lamk. (Hyalcea). Qualche frammento. R. Ga. V.

Crescis. - 501. "C. subulata Quoy et Gaim. = C. spinifera Rang. c.Ga. V. 5). "C. al cicula lang. = C. spiniformis Benoit. 1". Ga. V.

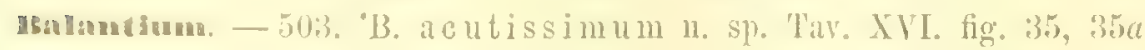

Questa specie ha ma certa analogia di forma col B. Pedemonanum (Mrayrr), ma is distintissima perchè piu gracile, più assottigliata gradatamente alla rewione posteriore, che risulta molto piì acuta. Gili spigoli laterali sono molto taglienti; e la conchigha risulta sensibilmente piir incurvata. Tnoltre la superticie inferiore e la superiore sono quasi uguali, ugualmente convesse, e regroLmmente incurvate, senza considerevoli angolositi o depressioni, se non che in riginaza dei margini laterali una lieve e graduale depressione si arrera, e sulla finccia superiore si manifestano alla regione mediana gl'indizî di due superfi- ialisimi solchi longitudinali. Le piome trasversali sono sottilissime, poco curve 
e divengono sempre piu tenui rerso la regione posteriore, dove nell' nltima porzione spariscono del tutto.

$$
\text { Lunghezza 22. }{ }^{\text {mm }} \text { Larghezza 8,4. }{ }^{\text {mm }} \text { Spessore 5,8. mm }
$$

Specie fragilissima, ben distinta, che raccogliesi in esemplari piì o meno mutilati. r. Ga.

Cuvieria. - 504. 'C. striolata n. sp. Tar. XVT. lig. 36.

A prima giunta direbbesi che questa sia la $C$. astesana Rang: ma essa ne it benissimo distinta, perchè di forma meno gracile, quantunque somigliante; inoltre il margine orale non presenta pieghe di sorta orvero angolosita, di modo cle la bocca risulta di forma jressochè circolare. La superficie ì levigata e lucente. ma guardata con una lente di forte ingraudimento essa si presenta striata pre lo lungo e trasversalmente, mostrando cosi ma finissima reticolirione.

\section{Lunghezza 9. mm Diametro 4.}

La scultura parmi che distingua molto bene questa specic dalle affini. Lissal trovasi anco a Messina. R. Gia.

Spirialis. - 505. 'S. globulosa Seguenza. R. R. Ga. - 506. "S. dirersil Monterosato. Somiglia alla $S$. reticulalce, ma ha la spira più breve; le suture sono crenate. R. Ga. V.

Embolus: - 507. "E. rostralis Sonleyet (Spirialis). Un solo conserratissimo esemplare colla bocea completa e fornita del caratteristico rostro. R. Ga. V. 508. "E. bellerophina 11. sp. 'Tar. XVI. fig. 34,34 , 34\%.

Questa è distintissima specie, che colla sua forma generale ricorda il gener. Bellerophina, estremamente sottile e fiagile, abbastanza rigonfia, colla spirale ben appariscente e concara, che cresce lentamente nei suoi arrolgimenti larghi a lerigatissimi. L' ombelico è stretto e frofondo; la bocea semilumare, cioè stretta e curra in forma d'arco semicircolare.

\section{Diametro $2.8 .0^{\mathrm{man}}$ Altezza $1,9, \mathrm{~mm}$}

Questa temue specie colla sua forma ricorda davrero il genere Bellerophim del Cretacen. r. Ga.

\section{Classe. IAMELLiBRANCH.}

Xyiophusa. - 509. "X. dolsalis T'urton (Teredo). R. S. Gia. V.

Eastrochaena. - 510. "G. dubia Peun. (Mya) $=$ G. Polii Philippi. R. (ra. I.

Petricols. - 511. "P. subcalinata 11. sple

È una sola ralva raccolta a Gallina che io chiamo cosi. lissa ì di forma nom molto inequilatera, trasversalnente orato-oblonga, colla resione boceale rotondata, colla regione anale rotondata e quisi angolosid, con una cilrena molto ottusa che dall apice scorre sino all' angolositit marginale. I a superficie presenta delle lamelle concentriche alquanto spesse. yuasi regolarj e rilevate; gl' interstizî piii larghi offrono una fina e scancellata reticolazione per linee ennentriche e radianti. I due denti cardinali snmo prominenti e molto solidi.

Lunghezza 9,5, mm Larghezza 13,6. ${ }^{\text {mm }}$ R. Ga.

Vencrupis. - 512。"V. irus Lin, (Donnx), R. (ria. V.

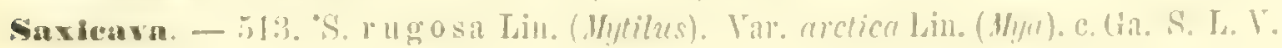


Sphenia. - 514. "S. carinata n. sp. Tav. XVI. fig. 37, 37a.

Io denomino cosi uma sola valva rinvenuta a Gallina, la quale è di forma pressochè quadrangolare, come rappresentano le figure, col lato boccale rotondato esporgente, col lato anale sinnoso-troncato, formando un angolo prominente ed acuto col margine ventrale. Da questo angolo si eleva una carena prominente fortissima che si estende sino all'apice, il quale è molto gibboso. La regione o margine undinale è pressochè retta, e presenta un intaglio sotto l'apice.

Lunghezza 17.mu Larghezza 21. mm R. Ga.

Corbula. - 515. C. gib ba Olivi (Tellina) - C. nucleus Lamarck. c. Ga. V.

Veacer. - 516. N. crispata Scacchi (Corbula). Una ralva incompleta ed altri frammenti. R. Ga. B. - 517. N. euspidata Olivi (Tellina) = Inatina brevirostris Brom. R. (ia. B. V. - 518. "N. rostrata Spenglex $($ Mya $)=$ Anatina longirnstris Lamk., $N$. attenuata Forbes, $N$. renovati Tiberi. r. Ri. Ga. G. V. 519. "N. obesa Lorèn. Alemi frammenti un po' dubbî. R. Ga. V. - 520. "N. lamellosa MI. Sars. $=N$. jugosu S. Wood. Una ralra rotta molto piiu grande della vivente. R. (ra. V.

in1. N. tenuilatmella no sp. Tar. XVI. fig. 38, 38\%。

Questa ben distinta speeir per la sua forma si arvicina alla $\Lambda_{*}^{*}$ obeso, ma il rostro è piì breve; per la scultura somiglia un poco alla $N$. lamellosa, ma t $^{\circ}$ lamelle nella mia specie sono tenuissime, molto numerose e di sorprendente regolaritit. L'apice non è molto prominente, invece perfettamente arrotondato. L'interno delle valve presenta delle sottili linee radianti. L'incaro cardinale per l'inserione del lignmento è piccolo. È specialissimo poi il dente laterale. il quale is assai gramle e sotto forma di una lamina sottile che ha origine dall'interno del margine, prende la conformazione di una raschetta semicircolare, e cio che piì importa trorasi ugualiswimo sopra ambe le valve, anzichè in una sola.

Lunghezza 7. mm Larghezza 9.5. ${ }^{\mathrm{mm}}$ Spessore 6. ${ }^{\mathrm{mm}} \mathrm{r}$. Ga.

52.2. "N. costellata Desh. (Corbula) = N. sulcatc Lovèn, N. Actoni Tiberi. Inatina radiata Calcarit, Corbula rostrato-costellata Acton. R. Ga. V. - 523. "N. Plilippi Sesucuzal = Corbula costellata Philipui (non Desh.). Questa specie per la hrevitil del rostro, e per varî particolari della scultura distinguesi bene dalla precedente. r. Gia. S. Ri. M. I.

Doromya. - 524. "I'. grianulata Nyst et West. (Coroula) = P. anatinoides Forlos, Cumingia Parthenopaea Tiberi. c. B. Ga.S. V. - 525. 'P. neacroides Segnenza. Specie distinta per la forma gilbbosa e pre le papille o punteggiature della superfieie disposte in linee radianti. R. Ga. V.

Thracia. - 526. 'T'. convexil W. Wood (Mya) $=T$. ventricosa Phil., T. Maravignae Aradas e Calcara. R. C. Y. - 527. "T. corbuloides Deshayes. R. Ga. V.

solen. - 528. 'S. siliqua Lin. R. Ga. V.

Solcenurus. - 529. "S. candidus Renier. R. Ga. V. - 530. "S. strigilatus Lin. (Solen). Un frammento. R. Gar. Y.

Syndosmis. - 531. "S. alla W W. Wood (Mactra) = Erycina Renieri Philippi. r. Ga. S. V. - 5is. "S. longicallis Scacchi (Tellina). Specie che incontrasi

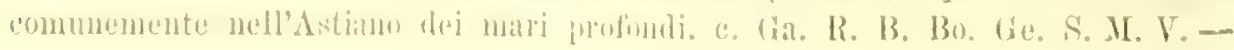


533. "S. similis Philippi (Enycina). c. Ga. II. L. - 5:34. "S. prismatiual Montg. (Ligula $)=$ Tellina stricta Broce. Erycina anqulosa Bronn. E. Aralue Biondi. R, Ga. Y.

Gutraxin. - 535. "L. elliptica Lamk. R. Ga. T".

Nrotrse - 536. "NL. glanca Born. = M. helvaced Philipui. Alemi frammenti. R. Ga. V. - 537. "II. subtruncata Da Costa (Trigonella) = M. Mridngule (Ren.) auctorum. c. Gia. V.

Ervllia. - 538. "E. castanea MIg. (Donax) = Erycina pusilla Philippi. 1. Ga. V.

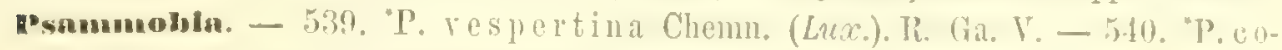
stulata Turt, $=P$. discors Plilipni. R. Ga. T.

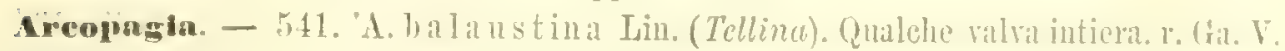

Touna. - 542. "T. exigua Poli = T. emuis Da Costa. 1". Gal. V. - 54:3. "T. o rata Brocehi. Frammenti. R. Ga. - 544. "T. pulehella Lamk. R. Ga. V.545. T. donacina Limeo $=$ T. variegata Poli. R. Gá. V. - 546. "T. pusilla Philippi. 1\% Ga, V.

Gupes. - 547. "T. edulis Chemn. (V'ems) = V. rhomboides Penu. Qualche frammento, K. Gar. $\mathrm{T}$.

Cotherea. - 548. "C. Chione Lin. (Venus). Qualche giorine. R. (ia. V.

Dosinia. - 549. "D. exoleta Lin. (Venus) R.Ga.V.- 550. "D. lincta I'ult. (V'onus). R. Ga. V. - 551. D. lupiuns Poli (Venus). R. Ga.V.

Venus. - 552. 'V. l' udis Poli - Cytherea vonetiana Lamk。 l. Gia. V. - 5.53. "V.

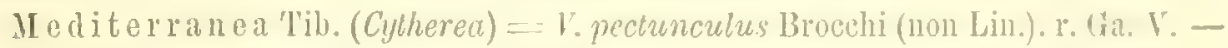
554. "V. orata Penn. = V. radiale Brocehi. c. Ga. V. - 555. "V. Bro ong nat ri Payr. = V. biradiata Risso.r. Ga. V. - 5.56. "V. Mess an en is Segnenza. Specie molto affine alla $V$. effossa per la forma e per la seultura, ma distintissima per la lumula non infossata. r. Ga. P. Va. R. - 557. "V. casina Limneo. R. Ga. Y. 558. 'V. multilamella Lamarek. $=V$ r rugosa (Bronm.) Phil., V. cygmus Weink. (nou Lamk.). c. Ga. V. - 559. "V. Rusterucii laỵ. = V. cygnus Arad, et Benoit (non Lamk.), V. Joenia Benoit c Granata. c. (Fa. B. V. - 560. 'T. verucosa Lin. r. Ga. V.

Circe. - 561. ${ }^{\circ}$. minima Montg. (Venus) $=$ V. Cyrilli Sculcehi, Cylhered Sismondue Calc. - 562. "C. solida Brugnone (MI. S.). Rotundato-trigona, levigatia. coll'apice prominente. $\mathrm{R}$. Ga.

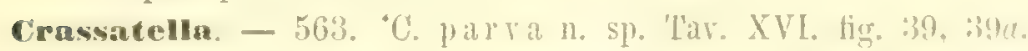

Questa forma ì ben distinta dalla C. planala, che è l'unica specie congenere che vive nel Mediterraneo; essa ie di firma molto piu allargata trasversalmente. cogli apici meno prominenti e meno acuti, colle costelle trastersali, più pronunciate e ben distinte su tutta la superticie.

$$
\text { Lunghezza 8,0. }{ }^{\text {mun }} \text { Larghinezza } 9,5 .{ }^{\text {num }} \mathrm{K} \text {. Ga. }
$$

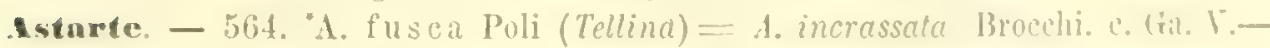
565. 'A. sulcata Da Costa (Pecuenculus). Con molte varieta di forma e di seultura. c. Ga. V. - 566. "A. triangularis Mitg. (Huctre). Varietic a margim crenato e a margine intiero. 1 . Ga. V. - 567. 'A. bipartita Philippi (Lucina?). R. Ga. V. 


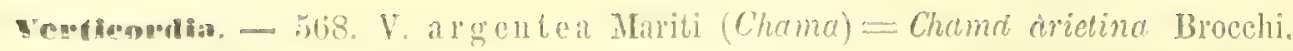
Perchiolic argentea Meneghini. c. 13. Ge. - 569. "V. a euticostata Philippi (llippagus) $=1$. cardiformis $\mathrm{S}$. Wool. Trovasi dorunque nel plioceno depositatosi a grandi profonditi. r. R. Ga. B. Ge. Bo. G. Ri. L. V. - 570. 'V. granulata Seguenza. Si e rimasti molto indecisi sulla esistenza di questa specic tra le viventi, e la forma prossima, pescata a diverse profondità ed in rarî luoshi, si eredeva dia talumn doversi piu tosto riferire alla specie seguente; ma dal confronto or ora fatto dal sig. Jeftreys dei miei esemplari tipici con quelli dell'Atlantico risulta che la forma atlantiea deve associarsi a questa. R. Ga. V. - 571. 'T. trapezoidea Seguenza. Il sig. march. di Monterosato ha pescato questa specie nel Mediterrmen, e ne ha riconoseiuto la esatta corrispondenza cogli esemplari fossili di Fiearazzi e di Altavilla. r. Ga. V. - 572. "V. arenosa (Rayneval) E. L. Appelius (Pechioliu). Grande e distintissima specie. c. B. Ga. S. G. Ri. MI.

rielliella. - 57:5. K. milial'is Phil. (Venus?) = Kellia abyssicola Forbes. K. abyssicola MI. Sars. U. R. Ga. Ri. Vi. V.

Isocandla - 57t. "I. col Lin. (Chama), R. Ga. V.

Chuma. - 575. "C. gryphoides (Lin.) auct. C. Ga. V. - 576. C. circinata Monterosato. Specie che abita i fondi coralligeni.. Ga. V. - 575." C. gry p li in a Lamk. = C. sinistrorsa Weink. (non Brocehi). R. Ga. V. - 578. "C. dissimilis Brom. Sprecie molto distinta dalle precedenti per la forma delle lamelle che l'ormano. l'. Ga.

Aordita - 579. "U. colb bs Phil. = C. minuta Seacehi. r. Ga. V. - 580. "C. trapezia Lin. (Chama). R. Ga. Y. - 581. 'C. calyculata Lin. (Chama). C. (ra. V. - 582. "C. crassicosta Lamk. R. Ga. - 583. "C. a euleata Poli (Chama). C. Ga. V. - 584. 'C. intermedia Brochi (Chama). R. Ga - 585. "U. rhomboidea Brochi (Chama).r. Ga. - 586. "C. pectinata Brochi (Chama). r. Ga. - 587. "C. leroluta Seguenza. Tar. XVI. fig. 40,40a. Bella specie, aftine alla C. Jounneti ilel mioceno; ma molto piccola. R. Ga. - 588. "C. Partschii Goldt. La forma che riferisco a questa specie è piccola, rotondata e con numerose costele granose; conviene mediocremente colla specie miocenica. 1". (ta.

Cardium. - 589. 'C. erinacem Lin. In grandi e belli esemplari. r. Ga. V. 590. 'C. ochinatum Jiu, - C. mucronatum Poli. R. Ga. V.

591. "C. l unulatum n. sp.

Chiamo cosi una sola ralva di Carliam raceolta a Gallina, la quale per la sura generale forma o scultura ha certil somiglianza col C. echinatum, ma ne è eminentemente distintis. Lal forma i pii rotondatis, le costole sono al numern di 25 e le papilie rhe le crmano in forma di cucchiaio, piu allargate alla regione anteriore; ma il arattere presipun che serve a distinguere questa forma si c quello d'una lunula cordato=ovatia, gramde, levigata e profondamente incavata.

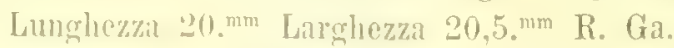

592. "C. tuberculatum Lin. R. Ga. V. - 593. "C. hirsulum Brom. Questa bella e distinta specio trorasi nel mineeno come nell'Astiano di molti lunghi. 
c. Ga. - 594. "C. papillosum Poli= C. planatum (Ren.) Broceli, C. Polii Payr.c.Ga.V. - 595. "C. fasciatum Montag. r. Ga. V. - 596. "C. min imum Philippi.r.Ga.V. - 597. "C. parrum Philippi. r. Ga. V. - 598. "C. roseum Lamk. $=$. nodosum Turton, C. scabrum Plilippi. r. Ga. V. - 599. "C. Lamarckii Reeve $=C$. glaucum Brnguière, C. rusticum Lamk. (non Lin.), C. clule auct. (non Lin.). R. Ga. V. - 600. 'C. Norvegicum Spengl. - C. laevigalum auct. (non Lin.). 1. Ga. V. - 601. "C. fragile Brocchi $=$ C. striolatum Calcara. R. Ga. - 602. "C. pectinatum Lin. Vire nei mari di regioni più calde. $R$. Ga. V. - 603. "C. multicostatum Brocchi. Trammenti. R. B.

Diplodonta. - 604:"D. lo otundata Montg. (Tellina). R. Ga. V. - 605. "D. intel"media Biondi. r. Ga.V. - 606. "D. apicalis Philippi (Tellina) $=$ D. trigona Scachi, D.trigonula anct. (non Bronn.). R. Ga. V.

Axinus. - 607. "A. flexuosus MItg. (Tellina). Insieme alla forma tipica trovasi la Var. = Plychina biplicatc Phil. Trovasi in esemplari conservatissimi. c. Ga. V. - 608. A. granulosus Jefir. Var. rotundatus. 1. Ga. V. - 609. 'A. Croulinensis Jeffr, c. Ga. V. - 610. "A. ferruginosus Forbes (Kellia). r. Ga. V. - 611. A. rostratus Pecchioli (Lucina). Questa specie è molto distinta per essere molto grande, d'uno spessore considererolissimo, colla simosita anale poco marcata, cogli apici acuti e rostrati. 1. C. Ga. B. A. Ge.

Jagonin. - 612. "J. reticulata Poli (Tellina) = Lucina peclen Phil. (nou Lamk.).r. Ga. V.

Gueinn. - 613. "L. spinifera Montg. (Venus). Var. dilatala n. Chiamo così una forma larghissima ed a strie concentriche assai sottili.c.C. Ga. A. V. -614. 'L. Bronnii Mayer. Oltre la forma tipica r'ha una rarietà. Var. major n. Varî esemplari grandi ed alquanto imegolari. c. C. Ga. A. - 615. "L. bo real is Lin. (lénus) $=$ Tellina radula Montagu. 1. C.Ga.A. V.

616. L. Aspromontana Seguenza. Tar. XVI. fig. 41,41त.

Questa specie è molto affine alla precedente, dalla quale è perfettanento distinta. Allorchè adulta, è molto conressa, cogli apici acuti più prominenti, con una piega che scorre sulla regione anale, e che quantunque non molto prominente, pure è ben distinta, la lunula lanceolata è più profonda e più acuta, le linee concentriche della superficie sono elevate, lamelliformi, ma molto irregolari, alcune maggiori sono variamente distanti, e negli interstizî se ne interpongono molte minori irregolari e variabilissime. Questa specic per la irregolarita delle lamelle concentriche, per la piega anale el altro, somiglia alquanto alla L. incrassala Dubois, comune nel mioceno; ma se ne distingue specialmente per la lunula lanceolata e non fortemente profondata.

Lunghezza $45{ }^{\mathrm{mm}}$ Larghezza $47 \mathrm{.mm}^{\mathrm{mm}}$ Spessore $25{ }^{\mathrm{mm}}$ C. C.

117. 'L. circularis n. sp.

Questa specie ha forma pressochè circolare, e molto si arricina alle due precedenti; ma ne è distintissima per la seultura, la quale formata di solchi concentrici, ricorda precisamente quella della bosinia exoleta. Liapice ì piccolo, poco sporgente, acuto, incurvato: la lunula ì caratteristica, breve, larga, triangolare. 
profondata; due renti divergenti centrali ed uno molto solido o sporgente laterale costituiscono il cardine.

Lunghezza 25. ${ }^{\mathrm{mm}}$ Larghezza 25,4. ${ }^{\mathrm{mm}}$ Spessore 14. ${ }^{\mathrm{mm}} \mathrm{R}$. Ga.

Horipes - 618. "Li. I a cteus (Lin.) Poli (Tollina) = Lucina leucoma Turt., L. Desmaresti Payr. r. Ga V. - 619. "L. fragilis Ph. (Lucina) = Lucina bullata Reere. 1. Ga. V. - 620. "I. divaricatus (Lin.) auct. = Lucina commutata Phil., L. pellucida Caruana. 1. Ga. V.

Atornia. - 621. "B. cur bu lo ides Phil.= Evycina crenulata Scacchi. r. Ga. V.622. B. Geoffroyi Paymudeau (Evicyna) $=$ B. complanata Philippi. R. Ga. V.

Fontneuta. - 623. "M. substriata Mont. (Ligula)= Kellia Spatangi Brus. r. Ga. V. - 624. "II. ferruginosa Mtg. (Mya). R. Gia. V.

Arer. - 625. "A. Noae Lill. r. Ga. Y. - 626. A. tetragona Poli. r. Ga. V. 627. A. barbata. Lim. c. Ga. Y. - 628. A. pectinata Broc. Alcuni esemplari piccoli. R. Gi. - 629. "A. Polii Mayer" = A. antiquata auct. (non Lin.), A. diluvii auct. (non Lamarek). Piccoli esemplari. R. Ga. V.-630. "A. lactea Lin. = A. Quoyi Payl.c. Ga. V. - 631. "A. p ul chella Reeve=-- A. imbricata Poli (non Bruguière). x. Ga. V. - 632. A. scabra Poli $=$ A. nodulosa Miuller. c. Ga. V. - 633. "A. aspera Phil. c. Ga. B. Bo. A. Ge. S. Ri. M. L. 034. "A. obliqua Phil. (non Reere).c. Ga. Ge. Bo. S. Ri. L.V.- 03ă. "A. pectunculoides Scrcchi. r. Ga. Vi. V. - 636. "A. Altavillensis Seguenza. Questa ì perfettamente distinta dalla precedente, per la forma più allungata trasversalmente, jer la simuositi mediana, nonchè ner le linee radianti. R. Ga.

Dectunculus. - 037 . "P. binaculatus Poli (Arca) $=$ P. siculus Reeve, P. glycimeris Phil. (non Lin.). c. Ga. V. - 638. 'P. pilosus (Lin). auct. R. Ga. V. 639. '1'. violacescens Lamk. r. Ga. V. - 640. "P. insubricus Brocchi (Arca). r. Ga.

Limopsis. - 641. 'L. Aradasii Testa (Pectunculus) = Trigonocoelia Semperi Mayer, L. elegans Michelotti (M.S.). Qnesta bella e grande specie del mioceno e del plioceno mi ha offerto a Gallina soltanto rari e piccoli esemplari. R. Ga. 642. "L. a urita Brocchi (Arca). Questa specie, che raggiunge dimensioni rimarchevoli in taluni luoghi, trovasi nel Regriano quasi eselusivamente a Gallina. Var. radiatce Ponzi. Fornita di linec radianti. Questa forma è molto rara. C. Ga. S. V.0.13. 'L. minuta Philippi (Pectunculus). Questa è la Limopsis, che incontrasi dorunque uel plioceno dei mari profondi, o che nella prorincia di Reggio è sparsal profusamente. C. Gia. R. B. A. Bo. Ge. S. G. Ri. M. L. V. - 64t. "L. Re invarti i Cantraine. Specic piu allungata e più convessa della precedente, linee concentriche e radianti piu ravricinate, superficie quasi granosa. Var. obsolete $n$. Ise linee radianti appena discernibili. 1 . Ga. - 615. "L. anomala Eichwald (Pectunculus). La forma pressochè romboide o irregolarmente quadrangolare, la superficic fortemente clatrata distinguono benissimo questa specie, che non è da confondere, come taluni hamo fatto, colla l. pygmaca. c. Ga.

6.16. Is. clathrata Seguenza. Tar. XYI. fig.42,42\%.

Questa specie è alline alla L. minuta; ma ne diversifica perchè oruata da linee concentricho o radianti, che sono disposte a maggior distanza, e formano una 
superficie clatrata ben distinta, per le valve poi piit convesse, i denti in maggior numero (12 o piii), il margine fortemente crenato, e le crenature molto grosse. Lunghezza 5,3."m Larghezza 3,3. ${ }^{\text {r.m }}$ r. Ri. Bo.

647. L. fragilis Seguenza.

Questa specie è più rotondata della $L$. minuta, ed ha la scultura esterna della $L$. calabra; all' interno è radialmente striata e piì fortemente alla regione posteriore. Lunghezza $5,80^{m m}$ Larghezza $3,90^{m n}$ R. B.

648. 'L. tenuis Seguenza $=L$. anomala Lonterosato (non Eichw.). Vi riferisco un solo esemplare molto dubbio. R. Gr. V. - 649. "L. pygmaea Philipri (Pectunculus) $=$ L. pygmaea Seg., Trigonocoelia anomala Mayer (non Eichw.). Questa distintissima specie è affatto diversa dalla $L$. anomala, e riesce agerole riconoscerla alla sua forma abbastanza contessa, più larga cle lunga, ed alla scultura risultante da costole concentriche, rilerate ed abbastanza allontanate. Var. major n. Sono esemplari relatiramente molto grandi. 1. Ga. S. Bo.

Vucinella. - 650. N. ort is S. Wood (Pleurodon) = Pleurodon miliaris S. Wood., Nucinella miliaris S. Wood (non Deshayes). Questa distintissima specie del Crag inglese fu da me trorata a Calatabiano in Sicilia; ma recentemente io la raccoglieva in esemplari più grandi presso Reggio alla contrada Gallina. r. Ga.

vucula. - 651. "N. placentina Lamk. Questa grande specie trorasi in tutte le zone del plioceno. r. Ga. - 650. "N. nitida Sowerby. Qualche esemplare. r. Ri. Ga. V. - 653. "N. nucleus Iimeo.r. Ga. V. - 65.4. "N. umbouata Seguenza. R. Ri. Ga. - 655. N. trigona Seguenza. c. Ri. G. - 656. "N. suleatil Bromn $=N$. Polii Philippi. Specie comunissima in tutti gli strati del plioceno dei mari profondi. C. C. R. Ga. B. Bo. A. Ge. S. G. Ri. M. L. V. $-657 .{ }^{\circ} \mathrm{N}$. decipiens Phil. $=N$. conuis Seguenza (non Montagu). Var. A. - N. Acgeensis Forbes. Var. B. inflata. 1. Ga. S. G. Ri. II. L. Bo. V.

658. "N. confusa n. sp. Tar. XVI. fig. 43, 43 a.

È questa una distinta specie, che pure ho trorato confusa cogli esemplari della N. decipiens; essa si distingue precipuamente per essere meno inequilatera, per l'apice incurrato rerso il centro della conchiglia anziche verso la regione boccale, pei denti molto più larghi, prominenti e ravvicinati, nonchè per la formi pressochè ellittica.

Lunghezza 4,7. ${ }^{\mathrm{mm}}$ Larghezza $7,30^{\mathrm{mm}} \mathrm{r}$. Ga.

659. "N. inflata n. sp. Tav. XVI. fig. 44 , 44 .

Questa piccola specie è affine alla seguente; ma lia gli apici molto rigonti. una forma meno inequilatera e molto piu giblosa, oltreche la regione boceale non. è angolosa, ma rotondata.

Lunghezza 2,7. nm Larghezza 3,2. mm Spessole 1,8m R. Ga. 660. "N. delphinodonta Jirh. Vivente nei mari del Nord, e trovata recentemente nel Mediterraneo. R. Ga. V. - 661. N. corbuloides Sermenza. I: Ri. Vi. - 662. "N. glabra Phil., e Var. clata Seg. c. G. lii. Gia.

ceda. - 663. "L. H o e ruesi i Bellardi =- L. clavala Hocmes (non Caleara). R. Ga. 664. L. eus pidata Phil. (Nucula). Bella sprecie concentricamente lamellosil. r. S. Yi. 
耳cmanulas. - 665. 'L. commutatus Philippi (Leda) $=$ L. deltoides Risso, Nibcula striata Bronn., $N$. minuta Scacchi. ${ }^{\circ}$. Ga. L. V. - 666. L. in a equilaterus Seguenza (lecla). R. B. - 667. "L. trigonus Seguenza (Leda):=Nuuula striata Philippi (non Lamarck). Questa specie somiglia al L. concavus Broun e si distingue per essere più gibbosa, e per le costole concentriche lamellose. c. Ga. A. Bo. Ge. L. - 668. "L. concarus Brom (Nucula). r. C. Ga. 669. L. gibbus Seguenza (Leda). r. A. Bo. - 670. "L. Messanensis Seguenza $($ Leda $)=$ L. acrminata Jefrr. (non Sow). Si raccolgono le numerose rarietà che questa presenta nel plioceno dei mari profondi, dore trovasi dapertutto abbondantemente. Var. inflatus n. Forma molto rigonfia raccolta a Gallina. c. Ga. R. B. A. Bo. Ge.S. Ri. M. Vi. V. - 671. L. seminulum Seg. (Leda). r.A.Bo. - 672. 'L. Nicotrae Seg. (Leda). c. Ga. - 673. 'L. pustulosus Jeflreys (Lela). Vive nell'Atlantico e nei mari artici. c. Ga. A. Bo. V. - 674. 'L. pusio Philippi (Nucula). Vive nell'Atlantico e nei mari artici. c. R. Ga. B. Bo. A. Ge. S. G. Ri. M. Vi. V.

voldin. - 675. "I. frigida Torell = I. nana Sars. r. Ga. Ri. A. Vi.V. - 676. I. pellucida Philipni (Nucula). Questa specie è perfettamente distinta dalle altre, e speciale sinoria all'Astiano del lato orientale della provincia di Reggio, le molte forme che si sono al essa rapportate di rarî lnoghi e terreni non le appartengono. r. A.Bo.S.Ri. I. - 677. Y. I u cida Loven. R. Ri. V. - 678. Y. c o n fusa Seguenza $=$ L. pellucida Seguenza (non Nucula Phil.), Y. lucila Seguenza (non Loven). r. B. A. Bo. S. Ri. M. - 679. 'Y. ten us Philippi (Nucula) $=$ N. pygmaeu Philippi (non v. Munster). R. S. M. A. Gallina comunissima. V. - 680. 'Y.abyssicola Torell = Leda $($ Yoldia $)$ producta Monterosato, Yoldia striolata Brugnone. R. Ga. A. 130. V. - 681. Y. meridional is Seguenza. R. A. Bo. - 682. "Y. oblonga? Jeffreys $(L c d a)$. Riferisco a questa specie alcuni pochi esemplari. R. (Gia. V.

shicula. - 683. "S. ovata Jeflreys. = Phaseolus ovatus Jeffreys. Dopo avere trovato questa specie nell'Astiano di Calatabiano in Sicilia, l'ho raccolto nella provincia di Reggio. R. Ga. V.

Malletia. - 184. "Mr. Bellardi Seguenza. R. Ga.

vello - 685. N. dilatatus Philippi (Nucula). I. A. Bo. S. Ri. M. L. - 686. "N. exeisus Philippi (Nucule). Questa specie rive nei mari del Nord, ed è sparsa profusamente nelle roceie marnose e sabbiose dell'Astiano dei mari profondi. C. R. Ga. B. A. Bo, Ge. S. G. Ri. Mi。 T, Vi, V.

Tindaxia. - 687. "T. solida Seguenza e Var. minor n. La rarieta è di forma piecola griva di esterna seultura. 1', A. Ga. Bo.

Modiolaria. - 688. "If. costulata Risso (Modiolus) $==$ M. subpictus Cantraine. L. Ga. V. - 1899. "M. subclarata Libassi (Hodiola) = Hodiola gibuerula Cailland. R. Ga. I'. - 6900. "M. Uiseors Limneo. Vive nei mari del Nord. R. Ga. T.

Modioln. - 691. ML. phascolina Philiphi = M. laevis Dan. e Sandri. Questa fragilissima speciu allo stato fossile, racoghiesi pure in esemplari conservatisinti. it. li. i

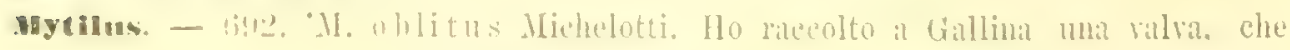


parmi convenga bene colla specie miocenica ricordata. R. Ga. - 693. "Mr. gallnprovincialis Lamk. Un giorine ed un frammento. R. Ga. V.

Aviculs. - 694. 'A. tarentina? Lamk. Frammenti troppo dubbî. R. Ga. V.

Lima. - 695. 'L. squamosa Lamarck. 1'. Gia. V. - 696. "L. inflata Chemn. (Pecten). R. Ga. V. - 697. "I. tenera Turt. R. Ga. V. - 698. "L. Losenm b i i (Leach). G. B. Sow. = L. bullata (Turt.) Phil. R. Ga. V. - 699. 'L. excarata Chemn. Grande specie dei mari del Nord. R. Ga. V.

Limea. - 700. "L. crassa Forbes =- L. Sarsii Lorèn, L. scabrella M" Andrew. R. Ga. V. - 701. L. strigilata Brocchi (Ostrea). R. B. - 702. L. retic u l a t a Seguenza. Specie analoga di forma alla L. elliptica Jefir., colle costole piu prominenti, crenate e piì distanti, e con linee concentriche squisite. R. P.

Pecten. - 703. "P. multistriatus Poli $($ Ostrea $)=P$. sentis Reeve, P. pusio anct.r. Ga. S. V. - 704. 'P. varius Lin. (Ostrea). Ga. V. - 705. "P. opercularis Lin. (Ostrea) e Tar. = Ostrea sanguinca Poli, P. Audouinii Payr. C. Ga. B. S. G. M. V. - 706. "P. pesfelis (Lin.) anet. = Ostrea elonguta Born., O. corallina Poli. r. Ga. V. - 707. "P. infllexus Poli (Ostrea) = P. adspersus Lamarck, P. Dumasii Payr. r. Ga. Y. - 708. "P. pes-lutrae Linneo $($ Ostrea $)=P$. septemradiatus AIüller. Vire nei mari del Nord. c. Ga. V.709. "P. flexuosus Poli (Ostrea) = P. polymorphus Brom. R. Gra. V. 710. "P. Brue i Payr" = P. leptogaster Brus. R. K. S. Ga. V. - 711. "P. com mutatus Monterosato = P. gibbus Phil. (non Tamk.), P. Philippii Rècluz (non Michelotti). R. Ga. V. - 712. 'P. scabrellus Lamk. c. Ga. - 713. 'P. Hoskynsii Forbes - P. imbrifer Lorèn, P. fimbriatus Phil. R. Ca. S. M. V. -

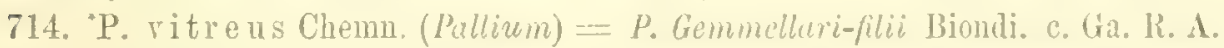
Bo.S.G. Ri. Co. V. - 715. "P. similis Laskey - P. pullus Cantraine, P. pygmaens auct. (non V. Munster) or. Ga. V. - 716. "P. Testae Biv. IR. Gra. V.

Janira. - 717. "J. J a c o be a Lin. (Ostrea). r. Ga. B. S. V. - 718. "J. flabelliformis Brocchi (Pecten). R. Ga. G. - 719. T. Alessii Phil. (Pecten). R. G. Ri.

Plennonectia. - 720. "P. fenestrata Forbes (Pecten) = Pecten incieruisculptus Tib., P. Philippii Acton, P. concentricus Forbes, $P$. antiquatus Philippi. 1\% Gra. II. L. V. - 721. P. d nodecimlamellata Bronn (Pecten). Questa distintissima specie passa dal mioceno al plioceno, ed è caratterizzati dai raggi distanti e dalla superficie ormata di strie elevate, lamelliformi. 1. Bo. A. Ge. M. 722. "P. difform is Seguenza. Tav. XVI. fig. 45, 45a, 45b.

Qnesta specie è analoga alle due precedenti; ma distinguesi per essere più conressa, traslucida e come membranacea, mentre la precedente è bianca ed opaca. la esterna scultura d'una valra è proprio quella del P. Ilosckinsii; nell'altra sono delle linee esilissime concentriche rilevate, che facilmente scompariscono, inoltru sono delle linee impresse radianti in corrispondenza delle interne costole, le quali sono molto pii ravvicinate che nella precedente specie, e lasciano un margine largo che esse non inradono. Questa conchiglia viene rigurdata dal Jeftreys siccome illentica al P. Iloschinsii. I. Ri. Ga. M.

723. P. cristata Brom (Pecten) $=$ Ostren neruronectia Brochi. Questa errande 
e bella specie manca nell'Astiano di tutta la provincia di Reggio, eccetto la valle di Finmara dove trorasi in belli esemplari. $x$.

minnites. - 724. "H. la e vi us culu s Philippi. Vi rapporto alcuni esemplari un po" dubbi. Tedi fossili zancleani. R. Ga. - 725. "H. crispus Brocchi (Ostrea). Qualche frammento. R. Ga. - 726. "H. Ercolauianus? Cocconi. Un frammento. R. (tar.

Sponalylas. - 727. 'S. gaederopus Limeo. R. Ga. V. - 728. "S. Gussonil Costa. R. Ga. T.

plieatura. - 729. "P. mytilin a Philippi $=$ P. crossidentata Bronn. Trovasi in grandi e belli esemplari. r. Ga.

Ostrea. - 730. O. navicularis Brocchi. Questa specie, comunissima nel piano precedente, i rarissima nell'Astiano della prorincia di Reggio. Io l'ho trovata apJena rapmesentata da qualche individuo nella valle presso Villa S. Giovauni ed a S. Cristina. R. C. P. - 731. "O. cochlear Poli. R. Ga. R. S. V.

73\%."0. platicardinis n. sp.

Questa conchiglia per la conformazione conressa della valra inferiore, e appianata della superiore, per le lamelle distanti che si osservano sulla superficie di entrambe, facilmente può renire confusa tra le diverse forme che assume l'O. cochlear: ma colpisce a prima giunta la forma allargata del cardine, il quale inoltre è appianato e lungo, il canale è poco piì di un terzo della larGhezza e lievemente incarato, i margini perfettamente piani, i solchi poco profonduti. Ai lati del cardine la conchiglia i fortemente increspata. All' esterno la ralra inferiore presenta larghissime pieghe o ondulazioni radianti; anco la ralfa superiore è più o meno oudulata. r. Ga.

733. "0. tenu i l l i ata n. sp. Tar. XII. fig. 1, 1a, 1b. (Vedi i fossili tortoniani). E veramente rimarcherole come questa specie nel Reggiano dagli strati aquitaniani passa per tuti i piani successiri sino all'Astiano senza manifestare modificazioni rimarcheroli. R. Ga.

734. "O. lamellosa Brocchi. Ho raccolto qualche esemplare gigantesco di questa specie. r. Ga. - 735. "O. laticardinis Seguenza. Specie che caratterizza molto bene l’Astiano nel Messinese, ma è piu rara nel Reggiano. r. M. Ga.

Anomia. - 736. "A. ephipgium Limneo. Nei depositi di mare assai profondo raccogliesi spesso una piccola e traslucida forma, che forse riferiscesi alla Var. squamula Philippi. r. Ga. S. V. - 737. "A. costala Brocchi. Riferiseo a questa specie alcuni esemplari che prami jossano essere semplice rarietì della precedente. 1. Ga. - 738. "A. a culeata Montagu. r. R. Ga. Vi. V. - 739. "A. patelIiform is Lin. = "A. pecliniformis Poli. 1. Cia. V. - 740. "A. striata Brocchi. Questa specie è costante nella sua scultura, che risulta di linee radianti arricinatissime, non mi pre che ri si possa riferire nessmma delle forme viventi. R. Ga.

\section{Classe. Brachioron.}

TereJnratula. - 7.11. "T. Scilla e Seguenza. Questa specie trovasi in belli e grandi resemplari. c. R. Ga. Va. Ge. Si. Co, - 74. "T. Regnolii Meneghini. Vi riferiseo solo alemi frammenti delle due valve. pereio com qualche dubbio. R. Cia. - 
743. "T. vitrea Born. (Anomir).r. R.Ga. A. Bo. Ge. S. G. Ri. L. Co. V. - 744. "T. minor Philippi. c. R. Ga. Ge. S. Co. T. - 7t5. T. sphoenoidea Philippi. r. R. Ge, S. I. Co. V.

Waldheimia. - 746. "W. cuthira Phil. (Terebrahuln). Io artotto nuovanente per questa specie la denominazione del Philipni, appunto perchì rinasce in no il dubbio che questa possa essere distinta dalla W. cranium vivente nei mari del Nord. A Gallina raceogliesi in esemplari ahbondantissimi e di perfetta conserrazione. c. Ga. M.Ge.Co.L. - 747. "W. septigera Lovèn (Terebratula) $\pm W$. peloritana Segnenza. Vive nei mari del Nord. c. Ga. V. R. Ge. Co. V. - 748. "W. Davidsoniana Seguenza. Riferiseo rarî esemplari a questal specie, ma senza averne potuto esamimare l'apparecchio apofisario. $r$. Ga.

Terebratulina. - 749. T'. caputserpentis Linneo (Anomia). r. Ge. R. S. Var. V. - 750. "T. granoso-radiata Segnenza. Specie a grosse costole, dicotome. granoso-rugose. R. Ga.

Tereloraciln. - 751. "T. se p tata Philippi (Terebratula). Si trovano diverse varieta. r. R. Ga. S. Va. Co. L.

Megerlia. - 752. "MI. e usticta Philippi (Terebrutula). Questa specie distintissima è assai comme nel piano precedente, e rara nell'Astiano. \% Ga. - 753 "M. trulucata Limneo (Anomia). R. Ga. R. Ge. S. Co. T.

Cistella. - 754. "C. cuneata Risso (Tercbratula) = T. Soldaniana Risso, Orthis pera v. Mulfho, T. scobinate Cantraine. R. Ga. V.

sraiope. - 755. A. decollata Chemnitz (Anomia) = Terebratule debuncalu Philippi. 1. Ga. R. Ge. S. V.

Rhynchonella - 756. "R. bipartita Brochi (Anomia). Molte variazioni. L. Ga. L. - 757. R. sicula Seguenza. Oltre la forma tipica raccolsi una forma molto stretta. 1. S. V.

Cramia. - 758. "C. a nomala Miüller (Patella $)=$ Anomia turbinatu Poli, C. 1hingens Philippi. R. Ga. Ge. V. - 759. "C. lamollosa? Seguenza. Una sola valva inferiore. Ii. Ga.

Tipo. ARTROPODI.

Classe. Crostacei. - Ordine. Toracostracei.

Si raccolgono nel calcare e nelle marne dei frammenti di crostacei superini. che per la maggior parte spettano certamente al nominato ordine; ma la lorn determinazione riesce impossibile pel modo come sono frantumate le grandi specie, e soltanto una molto piccola parmi che sia in grado da potere essere studiata e comparata colle forme conoscinte.

Ordine. Ostracons.

Pontocyuris. - 760. 'P. sagittula Terquem. Rarricino a questa spucie un solu esemplare, il quale so ne discosta alquanto solo, perehè le protuberanze accellnate dallo scopritore sono poco risibili. R. Ga. Vi.-761. "P. dactylus Liggel' (Bairdia). Gli esemplari che riferiseo a questa specie non mesentano punteggiature. 1. Ga. Ri. - 762. P. lueida lieuss (Cypherina). li a questa formi 
mincenica che io ho potuto meglio riferire l'nuico esemplare raccolto a Gallina. R. Ga. - 763. "l) trigonella Sars. Specie che rive nei mari del Nord. 1.. Ga. Y.

Baindia. - 764. "B. subde lto id ea Munster (Cythere) $=$ Cytherina subdeltoidea Reuss, B. subdelloilea Jones. Questa comme specie, che è comparsa nelle Calabrie sin dal periodo elveziano e vive tuttora nel IIediterraneo, presenta nel plioceno delle forme considerevolmente variabili e sorente abbastanza direrse, come una rarieta piccola e più stretta, che direi Var. minor, ed altre piì o meno rotondate, piì o meno angolose, più o meno rigontie, slargate ece. Delle quali forme varie corrispondono a quelle viventi illustrate dal Bradr, ed alle fossili figurate e deseritte dal Terquem. C. R. Ga. Va. A. Bo. Ri. V. - 765. "B. obtusata G. 0. Sars. Un solo esemplare abbastanza piccolo raccolto a Gallina, molti a Vito. Var. producta n. Abbastanza comune. Vedi fossili zancleani. La specie rive nei mari settentrionali. c. Gil. Vi. T. - 766. B. complanata Bradr. La forma tipica vi è rara. Var. sinuata 11. Il margine ventrale è più curvato, la regione anteriore piu rotondata, la forma generale alquanto più compressa. Questa rarietà è jii comule e raggyiunge maggiori dimensioni. e. Vi. V.

767. B. recta n. sp.

La Baindia che chiamo cosi, ì molto ben distinta per la sua forma allungata, retta, col margine ventrale allpena incavato, abbastanza compressa e colle regioni estreme rotondate. l'anteriore essendo pressochè uguale alla posteriore. Le dimensioni di questa specie sono minori di quelle delle precedenti.

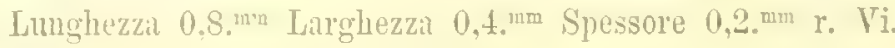

varuevpris: - 768. M. calabla 11. sp.

(Vedi fossili zancleani). Nello Zancleano ho trovato un solo individno, invece nell'Astiano questa specie è comune, e quindi ho potuto ben comparare questa colle aftini. Eissa è alquanto più gracile della $\%$. minna, colla regione posteriore meno acuta, ma piì acuta di quanto è nella Cytheridẹis decora Brady, colla quale la mia specie ha srande somiglianza. Ma il carattere più rilerante della mia specie si è quello della gibbosita delle valve alla regione centrale e della forte depressione che esiste alle due regioni estreme, per uni essa è rigonfia in mezzo a compressa alla regione anteriore e posteriore; quindi la sua forma generale risulta ben diversa dalle due affini sopra nominate.

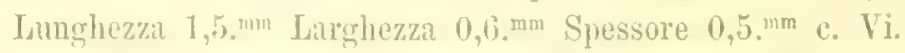

Cythere. - 769. "C. punetata r. Munster" = Cytherina punctata Rocmer. Cypridine punctata lienss. lifferisco a questa forma mio-pliocenica un solo esemplare. 1R. Ga. - 770. "C. cicatricosa Reuss (Cypridina). Anco questa specie mi ha oflerto pochi esemplari. R. Ga. Va. - 771. "C. convexa Baird. Questa specie, che vive uei mari del Nord e forse anco nel Mediterraneo, nei molti esemplari da me raceolti si mostra rariabile nella prominenza e distinzione delle dentellature che ollre la regione posteriore; le quali sonu sempre meno manifeste di quanto le rapresentano le figure date dal Brady, ed io mi associo at questo scriltore sulla convenienta che $v^{9}$ la forse di rimire questa alla precedente specic. c. Ga. Vi. V. - 772. "C. W is inuata? T'erquem. Gli 
esemplari che riferisco a questa sprecie sono molto solidi, e presentano poco appariscenti le due sinuosità. r. Ga. Va.

773. C. I umilis n. sp. Tar. XVI. fig. 46, $46 a$.

Questa Cothere viene da me distinta perchè più gracile, quantunque di analoga forma delle precedenti; difatti è più piccola, più allungata, più compressa e finamente punteggiata.

Lunghezza 1. ${ }^{\text {mm }}$ Larghezza $0,5{ }^{\text {mm }}$ Spessore 0,25 . $^{\text {num }}$ R. Ga.

774. 'C. a virostris n. sp. 'Tar. XVI. fig. $47,47 \%$.

Specie ben distinta per la sua forma orato-allungata, colla regione anteriore regolarmente areuata, colla posteriore sinuato-jostrata, non molto convessa, colla superficie ornata d'una reticolazione molto gracile ed a piccole maglie.

Luughezza 8. $\mathrm{mm}$ Larghezza 3,8. ${ }^{\mathrm{mm}}$ Spessore 2,3. $\mathrm{mm}$

Questa specie pei suoi caratteri è molto ben distinta. R. Ga.

775. "C. sororoula n. sp. Tav. XVI. fig. 18,18a.

Var. minor. n. Questa bella specie ̀̀ affine alla C. fornicata Terquem, come dissi precedentemente; molto solida, essa si distingue da quella per essere meno convessa e meno gracile, nonchè per la scultura formata di grandi incavi angolosi, disuguali, irregolarissimi, e per un solco che cinge il margine anteriore. Essendo più piccola e un po' diversa nella scultura, la distinguo come varietà dalla forma zancleana. Vedi fossili zancleani. Var. obliterata. Mancano i solchi sulla regione anteriore, i dentelli marginali sono appena accennati. R. Ga. Vi. -776 . C. scabra r. Munster. Risponde meglio alla forma vivente illustrata dal Brady. ed ha inoltre $\mathrm{i}$ margini molto spinescenti. r. Vi. V. - 777. C. plicatula Reuss (Cypridina). Un solo esemplare ben distinto di questa specie fu raccolto a Valanidi ed alcuni altri a Vito; tutti rispondono ai virenti descritti dal Brady. R. Va. Vi. V.

778. C. radiatopora n. sp. Tav. XVI. fig. 48, $48 a$.

Conchiglia di forma ovato-cuneata, che si assottiglia considerevolmente al. l'estremo posteriore, che pure termina arrotondato e cinto da dentellature d'una estrema picciolezza; ogni valva è carenata dal lato ventrale e cinta da un margine spianato traslucido, che si allarga alle due estremita e presenta esilissime striature radianti. La porzione centrale nella sua meta posteriore è longitudinalmente solcato-puntata e i solchi convergono rerso l'estromità posteriore.

Lunghezza 1. ran Larghezza $0,58{ }^{\mathrm{mm}}$ Spessore $0,2 .{ }^{\mathrm{mm}}$

Var. inornata n. La superficie delle valve manca dei solchi radianti e delle punteggiature, $\theta$ presenta una depressione mediana trasversale che biparte ogni ralva. La $C$. Jurinei Munster ha qualche somiglianza grossolana colla mia specio, mil ne differisce moltissimo per tutti i particolari accennati. c. Ri. Vi.

779. C. Bradyi n. sp.

Questa mova e distinta specie puo venire confusa a prima giunta con quella modalita della $C$. Jurinei dal Brady trovata e descritta tra le forme viventi, e ciò tanto per l'andamento generale delle valve, quanto per la scultura; ma essa è perfettamente distinta, oltrechè per la forma pì allungata, perchè la riunione delle valve forma un margine molto sottile ed acuto, perchè molto convesse al 
centro, csse si reprimono e si appianano alla periferia, laddove nella $C$. Jurinci il margine é ottuso, anzi rotondato. La scultura è tenuissima, formata da sottili linee longitudinali e da fine punteggiature impresse disposte in serie negli iuterstiri.

Lunghezza 0,5. ${ }^{\mathrm{mm}}$ Larghezza $0,2 .{ }^{\mathrm{mm}}$ Spessore $0,2 \mathrm{~mm} \mathrm{~h}$. Vi.

780. C. Ceratoptera? Bosquet Var. devians n.

Riferisco con molto dubbio a questa specie una forma di Cythere piu breve. alquanto diversa nei suoi particolari caratteri, e colle spine meno sviluppate. pel quale fatto meglio si affì alle figure date dal Terquem per la forma del plioceno di Rodi. R. Vi.

Crtheridea. - 781. "C. foreolata n. sp. Tar. XVI. fig. 49, 49a.

Conchiglia solida, orato-cuneata, che si restringe rerso l'estremo posteriore, ed inrece ì bastantemente allargata anteriormente, colle estremiti rotondate, colla superficie convessa regolarmente e ornata da fossette, che mostrano una certa regolarita, e si allineano parallelamente ai margini della conchiglia.

Lunghezza 1. mun Larghezza 0,59.mn Spessore 0,49.mn R. Ga. Va.

782. "C. punctato-compressa n. sp. Tav. XVI. fig. 50, 50u.

Conchiglia pressochè egualmente larga in tutta la sua lunghezza, molto compressa, coll' estremiti anteriore rotondata, colla posteriore un po sporgente e leggermente sinuosa, colla superficie segnata da sottili punteggiature.

Lunghezza $1,04{ }^{\mathrm{mm}}$ Larghezza $0,54{ }^{\mathrm{mm}}$ Spessore $0,37 .{ }^{\mathrm{mm}}$

Per la grande compressione questa specie è assai ben distinta dalle altre conoseiute. l. Ga.

783. C. I u cida n. sp. Tav. XVI. fig. 51,51a.

Questa specie somiglia alla C. zellandica Brady, ma ne è distintissima, perchè $\| 11$ po' piì allungata, coll'estremiti posteriore un po' più sporgente, e sopratutto molto compressa; ha inoltre la superficie lucida.

Lunghezza 1,04. mm Larghezza 0,58. mm Spessore 0,41."m R. Ri.

784. C. tenuis Renss (Cytherina). Vi rapporto un esemplare solo, che parmi convenire colla specie miocenica. R. Va.

785. C. exilis 12. sp. Tar. XVII. fig. 49.

Per questa specie vedi fossili siciliani. Vi rapporto taluni pochi esemplari. R. Vi. 786. "C. minima n. sp. Tav. XVII. fig. 2, $2 a$.

Questa piccola specie ricorda bene la C. punctillata Brady, ma ha il margine ventrale un po'incarato, la superficie ornata di due specie di punteggiature, una finissima, entrambe a punti più rarvicinati di quanto si osserva nella specic vivente dei mari del Nord.

$$
\text { Lunghezza } 0,50^{\mathrm{mm}} \text { Larghezza } 0,31 . \mathrm{mm} \text { Spessore } 0,160^{\mathrm{mm}} \mathrm{R} \text {. Ga. }
$$

Iyoustes. - 787. I. bartonens is rar. monosteracensis n.

Questo fossile è più comune nel Siciliano (vedi fossili di quel piano). Var. brevis n. Forma molto pii breve quasi orata. r. Vi. V.

Ioxoconeha. - 788. "L. impressa Baird (Cythere) = Cythere carinate Brady. C. rhomboidea lischer, L. rhomboidea G. O. Sars. Questa, che è la Loxoconcha piu comune che io ho raceolto nel plioceno, risponde bene alle figure 
date dal Brady, e tra gli esemplari varî che possiedo ve ne sono di quelli che spettarono ad individui femine, ma questi sono in mumero molto minore des maschi. c. Ga. Va. Vi.

789. 'L. fabacea n. sp. Tav. XVI. fig. 53,53a.

Questa è forma affine ma ben distinta dalla precedente; è più allungata e col margine rentrale siccome col dorsale pressochè retti e paralleli, colle estremita strettamente marginate, colla superficie coperta di grosse punteggiature ravvicinate.

Lunghezza 0,75."nn Larghezza 0,41 . $^{\mathrm{mm}}$ Spessore $0,3{ }^{\mathrm{mm}} \mathrm{r}$. Ga.

790. 'L. l e g u men n. sp. Tav. XVI. fig. 52, $52 \alpha$.

Pii lunga della precedente, coi margini ventrale e dorsale alquanto flessuosi. cogli estremi pressochè uguali e strettamente marginati, colla punteggiatura più fina.

Lunghezza $0,8{ }^{\mathrm{mm}}$ Larghezza $0,4{ }^{\text {mm }}$ Spessore $0,27 \mathrm{~mm}^{\mathrm{mm}} \mathrm{R}$. Ga.

791. 'L. maculato-punctata n. sp. Tav. XVII. fig. 1, $1 a$.

Conchiglia rotondato-ovato-rombea, largamente marginata, ai due estremi sopraintto, verso la regione centrale delle valve molto conressa. La sostanza della conchiglia è opaca, bianca, la superficie finissimamente punteggiata, e sparsa di larghe protuberanze appena prominenti.

Lunghezza 0,8..$^{\mathrm{mm}}$ Larghezza $0,6{ }^{\text {inm }}$ Spessore $0,4{ }^{\mathrm{mm}} \mathrm{R}$. Ga.

792. 'L. tamarindus Jones (Cytherideis) = Cythere laevata Normann, L. longipes Sars. Tra gli altri, un esemplare è considerevolmente più largo, e senza dubbio spetta ad indiriduo femineo. 2 . Ga. V.

Xestoleheris. - 793. "X. depressa G. O. Sars. I miei esemplari rispondono a capello colle figure e colla descrizione del Brady. c. Ga. V. - 794. "X. angustata Terquem. Questa comme specie presenta delle variazioni nella lunghezza. nel grado di ottusità ecc. C. Ga.

795. X. spinulosa n. sp. 'Tay. XVII. tig. $3,3 a$.

Questa bella specie è molto affine alla Cytherina setigera Reuss; ̀̀ ritrea, traslucida, col margine rentrale quasi del tutto retto, coll'estruniti anteriore in forma di angolo retto un po' ottundato, colla superficie liscia e sparsa di rare ed esili spinette, regolarmente distribuite.

Lunghezza $0,73 .^{\mathrm{mm}}$ Larghezza 0,43 . $^{\mathrm{mm}}$ Spessore $0,46{ }^{\mathrm{m} m \mathrm{n}} \mathrm{R}$. IR.

796. "X. aurantia Baird (Cythere) = Cythere nitida Lilljebory, C. virulis Zenker, $X$. aurantia G. O. Sars. Riferisco ben pochi esemplari a questa piccola specie, i quali hanno la forma degli esemplari maschili ed una punteggratula un po' dubbia. 1. Ga. Va. V.

797. X. producta n. sp.

Questa è forma molto affine alla X. testudo del Saariano, una ben distinta. Alla regione ventrale è come quella, appianata, ma meno gibbosa alla regione dorsale; la regione posteriore rotondata, l'anteriore rostrata, il rostro sporge bruscamente ed è più tosto ottuso. Ia punteggiatura della superficie ì assai fina.

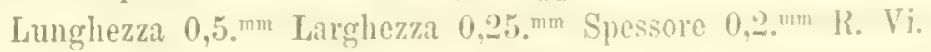

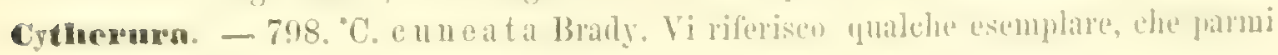


convenga bene e nella forma e nella scultura coi viventi dei mari del Nord. Yar. tencisculpta n. Scultura molto fina, sperone posteriore più valido. Trovasi a Vito. R. Ga. Vi. V.

Cytheropteron. - 799. C. Iaevis n. sp.

La conchiglia è nella forma generale pressochè romboidale, e ciascuna valral quasi cumeata; la regione anteriore í cinta da ma porzione appianata, e da margine arcuato; la regione posteriore si restringe e porta un'estremita appianata e dentellata; le ali sono molto prominenti; la superficie i levigata.

Lunghezza. 0,8. ${ }^{\text {nm }}$ Larghezza 0,5. mm Spessore 0,7. ${ }^{\text {mm }}$ R. Vi.

Paraloxostoma. - 800. "P. ens if o l' $\mathrm{m}$ is Brady. Qualche esemplare, che risponde precisamente alle figme date dall'antore. R. Ga. Va.V. - 801. P. areuatum Brady. Un solo esemplare che vi riferiseo con dubbio. R. Va. V.

Cytherella. - 802. "C. compressal V. Munster. Questa specie che è stata figurata da molti scrittori, è stata rappresentata in modi assai differenti, da far credere che probabilmente si sieno confuse diverse forme: cosi il Munster, il Reuss. il Bosquet, l'Egger ece. la rappresentano piì o meno diversa, ed io dero dichiarare che i miei esemplari meglio convengono colle tigure dell'Egger. 1. Ga. Ri. Vi. 803. C. bipalita n. sp.

Questa forma ì descritta precedentemente tra i fossili dello Zancleano. c. Vi. 804. C. hispida n. sp. Tar. XVII. fig. 4, $4 a$.

Questa specie ì molto analoga nella forma alla precedente, colla superficie raramente punteggiata e scabra perchè irta di piccole spine, che divengono più numerose e piu prominenti verso le regioni estreme.

$$
\text { Lunghozza } 0,1 \text {. mn Larghezza } 0,58 \text {. }{ }^{\text {mm }} \text { Spessore } 0,500^{\text {mn }} \text { R. Ri. }
$$

Ordine. Cirripent.

Balanus. - 805. "B. tulipiformis Ellis = - Lepas tulipa Poli. In questo piano è affatto identico al vivente. C. Ga. Ge.S. V. - 806. "B. calceolus Pallas. Vive in Africa, alle Indie, raro nel Mediterraneo. R. Ga. V. - 807. "B. s cutorum Segnenza. R. Ga. - 808. B. concavus Brom = B. tintinnabulum 0. G. Costal (non Lin.) 1. Ga. V. - 809. "B. spongicola Browu. Var. pliocenica Seguenza. r. Ga. V. - 810. "B. perforatus Bruguière. R. Ga. V. - 811. "B. stellaris Brocchi (Lepas) $=$ B. corrugatus Brocchi. Questa specie ì in frammenti insieme agli opercoli. r. Ga. - 812. "B. my lensis Seguenza. Questa specie l'ho raccolta di unita a molti scudi. r. Ga. S. V. - Di quasi tutte queste specie negli strati di Gallina, calcarei, marnosi e sabbiosi, insieme alle conchiglie, più ordinariamente intiere, si raceolgono gli scudi e più raramente i terghi.

Acasta. - 813. A. muricata Segnenza. Solo qualche ralva. R. Ga.

Coronula. - 814. C. bifida Bronn. Di questa importante forma ho raccolto soltanto qualche compartimento. R. 13.

Esachylusma. - 81\%. P. griganteum Philippi (Chtamalus). a Pezzo presso Villa S. Giovanni v'ha un calcare quasi completamente costituito di questo grande Cirripedo, che si presenta colle valve disgiunte, fra le quali non maneano gli sendi e i terghi. e. P. Va. Y. 
Verruca. - 816. "V. stromia Miller. Sul Pecten scabrellus.r. Ga. V. - 817. "V. Zanclea Seguenza. Alcume valve disgiunte. r. Ga. R. G. Ri. M. - 818. T. Romettens is Seg. Valve disgiunte. r. R. Ri. G. V. - 819. 'V. crebricosta Seguenza. Valve disgiunte, l. Ga. G. Vi.

Icpas. - 820. L. signata n. sp.

Dò questo nome ad un piccolo seudo, raccolto a Vito presso Reggio, il quale ¿̀ della forma d'un triangolo scaleno, cogli angoli rotondati, della lunghezza circa di tre millimetri e della larghezza di due, colla superficie levigata, che porta tre linee impresse profondamente, che irradiauo dall'angolo piì ottuso e sraniscono verso i margini. R. Vi.

Scalpellum. - 821. S. zancleanum Segnenza. A Pezzo presso Villa S. Gioranni le grandi valve di questa bella specie troransi associate insieme per costituire una roccia calcarea. c. P. R. - 822. S. Michelottianum Seguenza. Le ralve di questa specie, conservatissime e di dimensioni maggiori di quanto si osserrano nel MLessinese, sono state raccolte nei dintorni di Reggio ed al Capo delle Armi. r. R. - 823. S. magnum? Darwin. Rapporto dubbiamente a questa specie alcune valve rotte e rare che ho raccolto nelle mame di Bianco nuovo. R. B. Bo.

Scillaelepas. - 824. S. carinata Philippi (Pollicipes) - S. carinata Seguenza. Questa specie è rarissima nel Reggiano, laddove è estremamente comune nel Messinese. R. P. - 825. S. ornata Seguenza. Anco questa specie vi d̀ molto rara, intece comunissima nel Messinese, come la precedente. R. P.

\section{Tipo. VERMI \\ Classe. ANeLlidi.}

Psyamolurgnchus. - 826. "P. firmus 11. sp. Tav. XIl. fig. 11, 11a. (Vedi fossili del Tortoniano). Vi riferisco un solo esemplare di S. Cristina, lungo oltre sedici centimetri, il quale sembra proprio somigliante alla specie miocenica; e solo ne differisce alquanto per la superficie un po' meno rugosa, e per: la spessezzil della parete alquanto minore. Del resto è il caso di dovere ricordare come gli Anellidi assai malanente si lasciano determinare dalle loro conchiglie, e bene spesso la loro ricognizione specifica ì allatto impossibile. R. C. - 827. "P. protensus auctorum. Riferisco alla specie mediterranea una conme forma che parmi convenga bene con quella. c. Ga. V.

spirorbis: - 828. "S. na utiloides Lamk. Alcuni individui sopura m ramo di Lophohelia. 1. Ga. V. - 829. "S. laeris Qtrfgs. 1". Ga. V.

830: 'S. plicatus n. sp.

Vedi fossili zancleani. Alcuni esemplari aterenti all' 0 . cochleur ed ai radioli della Dorocidaris papillata. r. Ga. - 831. 'S. granulatus Lin. (Serpula). Rapporto con qualche dubbio a questa forma alcuni esemplari aderenti al $P$. opercularis, che presentano due solchi, e quindi tre carene. r. Gia. V.

Ditrupa. - 832. "D. subulata Desh. (Dentalium). Questa specie, abbondantc nello stretto di Messina, nell'Astiano ì comme a Gallina solamente. r. Gia. V. - 
833. 'D. incurтa Ren. (Dentalium). R. Ga. - 834. D. ? siplunculus Costa (Modosaria). Il tubo calcareo, nodoso, che il Costa ha roluto rapportare ad um Foraminifero, a mio credere spetta indubitatamente ad un Anellide, e prorrisoriamente lo rapporto al genere Ditrupa, sperando che ulteriori studî renissero al rischiararci intorno alle sue affinita zoologiche. x. S. G. Ri.

Vermun. - 835. 'V. pe r forata n. sp. Tar. XV. fig. 1. (Yedi i fossili zancleani). Trorai qualche esemplare aderente ad una Celleporaria. R. Ga. - 836. 'V. cal I p trata Grube (Serpula). Qualche raro esemplare dubbio. r. Ga. T.-837. 'V. infundibulum auctorum. Qualche esemplare raro di cui uno ben conserrato. fisso nell' interno della maggiore ralra di una Terebralula Scillae. 1\%. Ga. T.

serpula. - 838. "S. velmicularis Lin. 1". Ga. V.

\section{Classe. Briozoarit.}

Salicomaria. - 839. "S. farciminoides Johnston. Si raccolgono le unmerose forme che suole presentare. C. Ga. Ta. A. B. F.

840. 'S. mammillata n. sp. Tar. XTII. fig. 5, 5a.

Articoli brevi, ingrossati, ed assottigliati agli estremi. Cellule disposte regolarmente in quinconce, non marginate, incarate al centro con apertura circolare in fondo all'incaro, la quale porta un largo intaglio alla parte inferiore. Uno o due pori ribraculari, rotondi o semilunari. Superficie mammellonata a mammelloni disuguali ed irregolari, lisci, e lucidi. Specie distintissima pei suoi caratteri * spettante ad un grupno che forse potrebbe elevarsi al rango di genere.

Lunghezza della colonia figurata 3 .m Diametro 1,3. mm R. Ga.

Cellaria. - 841. C. cereoides Sol. et Ellis. Un solo frammento mal conserrata. P. Ti.. I

scrupocellarin. - 842. "S. elliptica Reliss. R. Ga. Va. - 843. "S. scruposa Lin. (Cellularia). Vi riferisco con dubbio qualche raro frammento. R. Ga. V.

vyriozoon. - 844. "M. truncatum Pallas. Specie ben nota e sparsissima. c. Ga. Ta, V.

IIppothor. - 845. 'H. flagellum Manzoni. Sull' Ostred cochlear. r. Ga. V. Actea. - 846. 'A. sica Couch. Sul Pecten scabrellus, r. Ga. T.

Membrniporn. - 847. "M. lineata Lin. Su d'una Anomia. r. Ga. V. - 848. M. angu 10 s a Renss. Raccogliesi aderente alla Fissurella costaria, al Turbo rugosus, al Balanus concavus, al Pecten opercularis, alla Janira Jacobea, all' Ostrea... ecc. c. Ga. T. - 849. "M. a n u lus MIanzoni. Incrosta un tubo di Serpula. r. Ga. 350. 'II. cal pen is Busk. Sul Pecten opercularis e sull' Ostrea cochlear.r.Ga.V.851. "Ir. pa pirace a Reuss. Incrosta il Pecten opercularis e 1"Ostrea cochlear. r. Ga.

Cepralla. - 852. "L. decorata Reuss. Sull'Ostrea cochlear. R. Ga. - 853. 'L. coceinea Johnston. In questo piano questa specie, comunemente sparsa, divienc somigliante alla rirente, perchè le cellule s'ingrandiscono e la scultura diriene abbastanza jronunciata. Inerosta le seguenti specie: Bulanus tulipiformis, Pecten opercularis, P. pesfelis, Ostrea naviculuris, 0. cochlear, Anomia ephippium, T'erebralula minor, T. Scillae. C. Ga. V. - 854. 'I. stren nis Manzoni. Sul Pecten pesfelis. IR. Ga.- 85\%. "L. sureres. Manzoni Var. Ta piceola colonia che vi 
rapporto, presenta gli arieularí piu in alto, l'apertura della cellula alquanto piu allungata. Aderente al Pecten opercularis. R. Ga. - 856. "L. in nom in ata Couch. Sull'Astarte fusca, e sull' Ostrca cochlear. R. Ga. T. - 857. 'L. scripta Reuss. Sulla Terebratula Scillae. 1". Ga. Y. - 858. 'L. ansata Johuston. Sull'Ostreu navicularis, 0. cochlear, Anomia ephippium. 1. Ga. V. - 859. "L. B rongniarti i Audouin. Var. È una sola colonia che incrosta la Janira Jacobea, e spetta ad una rarietà molto prossima a quella illustrata dal Manzoni. Te cellule sono considererolmente allontanate, e gli spazî interposti, dirisi in molti piccoli compartimenti. che sporgono in forma convessa. Gli aricularî mancano sorente. R. Ga. V. 860. "L. planata IIanzoni. Var. La colonia che vi riferisco ha in molte cellule' obliterati gli aricularî. Sulla Janira Jacobea. R. Ga. - 861. "L. schizogaster Reuss. L'unica colonia che ri riferisco ha caratteri tali nelle sue cellule, che si lega colla forma dell'autore e con quella considererolmente dirersa illustrati dal Manzoni. Sull' Ostrei cochlear. R. Ga. - 862. 'L. violacea Johnston. Una colonia sola che incrosta quasi per intiero l'intemo della ralva inferiore dell'Ostrea cochlear. R. Ga. V. - 863. 'L. rulgar' is Moll. La colonia che vi rapporto ricorda bene le forme rirenti illustrate dal Waters. Sul Pecten opercularis. R.Ga. V. - 864. "L. ciliata Pallas. Sul Peclen operculcris. R. Ga. V. - 865. "L. Nor risiana Busk. Una ben caratteristica colonia sopra un frammento di Pettuncolo. R. Ga. - 866. "L. Pallasiana MLoll. Una colonia priva di aviculari incrostante un tubo di Serpuld. R. Ga. V. - 867. 'L. Ma lus ii Audnin. Qualche colonia sull' 0. cochlear. R. Ga. V. - 868. "L. renusta Eichw. Questa bella specie, a grandi ed assai distinte cellule, non mi ̀̀ occorso di raccoglierla in tutta la serie miocenica, nè nel plioceno antico, e solamente si fa redere nell'Astiano calabrese; laddore nel bacino di Tiemn giace nel mioceno, e a Castrocaro nel plioceno antico. Raccolta incrostante i Peclen opercularis, $P$. pesfelis, Ostrea cochlear. r. Ga. - 869. "L. obria Manzoni. Sulla Janira Jacobaea. Le cellule non offrono ordinariamente le perforazioni delle pareti, che rengono indicate nelle figure date dal Manzoni. R. Ga. - 870. L. Gattyae Lands. Una colonia sul Pecten opercularis R. Ga. V. - 871. 'L. lata Busk. Una grande colonia che inerosta un radiolo di cidarite ed un piccolo balano che vi aderisce. R. Ga. V. - 872. "L. reticulata Macg. Sul Pecten opercularis e sull' Ostrea... Var. distincta. 11. Questa Lepralia è a piccole collule disposte in serie, coi margini fortemente punteggiati, colla superficie granoso-perforata, cogli oricelli granoso-rugosi, e cinti al margine da larghi forami. 2. Ga. V. - 873. "L. crassa? Reuss. Questa specie molto somiglia alla forma miocenica descritta dal Reuss, ma trattandosi d'una sola colonia, tale determinazione richiode una conferma. Sul Pecten pesfelis. R. Ga.

874. "L. colonata 11. sp. Tav. XVII. fig. 6.

Piccole cellule orato-rettangolari alquanto convesse e disposte in serie, con una prominenza mediana, che porta un poro vibraculare. La parete delle cellule è perforata da forami angolosi e ravricinati che la riducono ad una specie di reticolo. La bocca è quasi semicircolare, l'oricello è rotondato-globoso, prominente, eircondato da grossi, ravvicinati e profondi incari; la superficie è irta da prominenze' 
in forma di lamine imegolari a molto elevate, che s'intersecano in rari modi " rimmon aspetto molto curioso agli ovicelli. Sul Pecten fexuosus.

Lumghezza d'una cellula prolifera 2,5. ${ }^{\mathrm{mm}}$ Larghezza $1,4 .{ }^{\mathrm{mm}} \mathrm{R}$. Ga.

Celleporarin. - 875. "C. tubigera Busk. Riferiseo a questa specie la più comume Celleporaria che trovasi nell' Astiano, associandomi pero completamente a quanto osserva il Manzoni. Essa forma delle colonie di raria grandezza. pii o meno arrotondate, che si raccolgono libere orrero aderenti alle conchiglie. $c$. Ga. Va. S. V. - 876. 'C. systolostoma Manzoni. Questa specie l'ho trorata raramente in masse libere, più spesso incrostante la Turritella triplicata, la Balanophyllia italica ecc. e sempre molto tenera. r. Ga. V. - 877. "C. retusa Manzoni. Qualche rara piceola colonia d'ordinario aderente a conchiglie. r. Ga. V. - 878. "C. ramulosa Lin. r. Ga. Va. V. Probabilmente altre specie in cattivo stato di conservazione non somo riconoscibili.

Eschara. - 879. "F. lichenoides Lamarck. R. Ga. V. - 880. "H. foliacea Lamarck. 1. Ga. V. - 881. "H. monilifera M. Edwards. Questa specie sì comune nel plioceno pii antico, diviene rarissima nell'Astiano: non we ho trorato che due soli rami. R. Ga. - 882. "E. undulata Reuss. Questa che ha origine nel mioceno insieme alla precedente, è rarissima nell'Astiano. R. Ga. - 883. "E. cervicornis Lamarck. Questa specie invece comme tra i virenti, si aumenta nell'Astiano. c. Ga. Va. V. - 884. "E. coscinophora Reuss. Var. pliocenica n. Tav. XVII. fig. 7, 7a. La bella Eschara che io denomino cosi, sembra a prima giunta distinta dalla forma miocenica sopratutto per la gracilità dei suoi rami, i quali d'ordinario non portano sopra ciascuma faccia che tre serie di cellule e più raramente quattro ordini, e qualche volta cinque. Le cellule presentano le loro estremità superiori incurve e prominenti, e raramente sono ben circoseritte in tutta la loro periferia: l'infossamento centrale presenta talrolta unica apertura grande o piccola. oltre le due superiori, orrero rarî forami molto variabili in numero ed in grandezza, talvolta molto piccoli, e disposti in m incaro molto allungato e non gia circolare come uella forma miocenica, ed in mumero molto minore che in quella. r. Ga. - 885. "E. c ol $1 \mathrm{~m}$ nar is Manzoni r. Ga. Va.

mimustra. - 886. B. Sarartii Auduin. Anco questa specie comune nello Zancleano, diviene rarissima nell'Astiano, R. Ga. V.

IRetepors. - 887. R. cellulosa Linneo. 1. Ga. Va. V.

Cupuisia. - 888. ${ }^{\circ} \mathrm{C}$. $u \mathrm{mb}$ bllata? Defrance. Quantumque abbia raccolto abbitstanza esemplari di Cupularia, sono pure indeciso sulla determinazione specifica, specialmente perchè la maggior parte presenta una larga apertura delle cellule per la mancanza della parete anteriore, pur esistendori gli altri caratteri. Questa differenza puo forse attribuirsi allo stato di conservazione? r. Ga. V.

Crisia. - 889. 'C. fistulosa Heller (non Busk.) = C. Haucri Reuss. R. Ga.V.890. "C. Edwardsi Reuss. r. Ga. Ta. - 891. 'C. Hoernesii Reuss. c. Ga. Va. A. B.

Imoner. - 892. "I. pertusa Reuss. Questa distinta specie viene dal mioceno. - comparisce sin nell'Astiano. 1. Ga. - 893. "I. atlantica Forbes. Gli esemplari che riferisco a questa specie, parmi che convengano bene colle figure date 
dal Manzoni. 1. Ga. Ta. I.- 894. 'T. concara Reuss. Questal suecie fir trurata rirente a Napoli dal Traters, $x^{\circ}$ Ga. Ta. V. - 895 . 'I. trif ol' is Heller. R. Gia. Via. Y.

896. "I. bacillaris n. sp. Tar. XVII. fig. $8.8 \%$.

Questa specie distinguesi perchè è compressia lateralmente e con un solchett longitudinale su ciaseun lato; tale compressione fa si che la colonia in forma di bacchette la il suo maggior diametro d'aranti in dietro, e ogni serie di cellule i costituita da tre tubicelli.

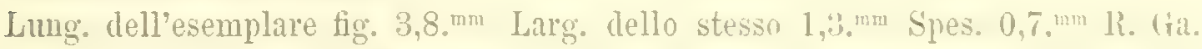
897. 'I. irregularis Meneghini. Un solo ma distinto ramoscello. R. Ua. V.

Iornera. - 898. "H. striata M. Horrards. Questa specie rara nel plioceno antico. trovasi sparsa commemente nell'Astiano. c. Gra. Ta. - 899. "H. flondiculata Lamk. Oltre la forma tipica, rarricino a questa specie a titolo di Var. rugosa una IJomera che ha la faccia posteriore rugosa per mumerose prominenze. c. Ga. Ya.A. B. V. - 900. "H. hyp polithus Defrance. La forma cle io vi riteriseo corrisponde alla miocenica illustrata dal Reuss e dal Manzoni. c. Ga. Va. 901. "H. c oncatenata Reuss. Due soli rami che rispondono bene agli esemplari di Crosara illustrati dall'autore. R. Ga. Ta.

Fuisparsa. - 902. "F. ralians Reuss. 1'. Ga. - 903. "F. tubulosa Busk (Hornera). Il Busk riguarda questa come rarietil dell' $H$. violacea, l' Water's lal separa associandola al presente genere. Io ri riferisco alcuni frammenti un poci dủjỗ. Essa rire in molti mari. R. Ga. Va. V.

Entalophora. - 904. E. a nom a la Renss. Due soli grieili rami riferiseo a questat specie, che trovasi sempre rara nel Reggiano, tanto neI mioceno quanto nel plioceno. R. Tra

i'ustulopora. - 905."P. deflexa Conch. (Tubulipor"a) $=$ P. deflexa Jolnst. Un solo ramo bifido. R. Ga. T. - 906. P. subverticillata Busk. Un solo ramo dicotomo colle cellule appianate e ben circoseritte siccome le dimostrano talune delle figure date dall'autore. R. Ta. - 907. 'P. r'ugosa D'Orbigny (Erialo. phora $)=P$. rugulesa Manzoni. 1. Ga. Ta. - 908. "P. proboseina Manzoni. R. Ga.

Tubulipora. - 909. "T. flabellaris Fabl. Abbastanza lara in questo piano. I. Ga. Y.

Dinstoporn. 910. - 'D. latomarginata D'Orbigny. Questa specie virente incrosta direrse conchiglie. l: Ga. V.

Discoporella. - 911. "D. hispida Fleming. Tnerostir il Pecten pesfelis ed altre specie. r. Ga. V.

Mecto. - 912. A. castrocale 11 is Manzoni. Una sola colonia sul Balanus tulipiformis. R. S. - 913. 'A. majol' Jonst. Rapporto al questa specie poche colonie che incrostano il Pecten opercularis. R. Ga. V. - n14. A. repens Wood. Una colonia molto estesa, che giace sul radiolo d'una Culnvis. R. Gia. V.

Ceriopoxa. - 915. C. globulus Reuss. Qualche esemplare soltanto, grlobuliforme. R. Ga. 


\section{Tipo. ECHINODERMI.}

Classe. Echinidi. - Ordine. Regolari.

Charis. - 916. "C. Desmoulinsii E. Sismonda. I miei pochi radioli par che rispondano abbastanza bene colla descrizione data dal Meneghini. Un solo frammento parmi distinto e forse spetta ad altra specie, per avere i granuli della superficie solcati nel senso dell'asse del radiolo. 1. Ga. - 917. "C. Mr unsteri E. Sismonda. Molti radioli e qualche frammento di guscio ofliono i caratteri assegnati dal Meneghini a questa specie. r. Ga. S. Ri.

Possiedo frammenti poco considereroli di radioli spettanti certamente ad altre specie.

Dorocilnois. - 918. "D. papillata Leske. (Cidaris) = Cidaris histrix Lamk. Cidaris Stohesii Agassiz, C. affinis Phil., Lejocidaris hystrix Desort, D. papillate Agassiz. Oggi con buone ragioni, cioè pei graduati passaggi che si notano, si rogliono associare insieme le pretese specie enumerate nella sinonimia, ed io possedendo varî esemplari che rappresentano alcune di tali forme, oltrechè vi notai le accennate gradazioni, ebbi a restar sorpreso nell'accorgermi che taluni dei radioli presentano l'estremita articolare fornita di grosse crenature ben distinte, e che il tubercolo in tal caso offre attorno le corrispondenti crenature, mentre poi nello stesso individuo la maggior parte dei radioli sono sforniti dal benchè menomo indizio di crenature. Questo fatto è molto rilerante, dappoichè per esso l'importanza grande che si è attribuita al carattere delle crenature viene attenuata di molto, e forse anco scancellata del tutto; ed io per questo fatto sarei proclire in credere che la precedente specie non sia che una delle forme che assume la 1. papillata, alla quale realmente somigliano moltissimo i radioli e la rariabile loro scultura. r. R. Ga. Va.A.S.G. V.

919. "1). aspern ima n. sp.

Denomino così i più comuni radioli che trovansi nell'Astiano dell'Italia meridionale, associati agli scudetti che costituivano il guscio di questo echinide, che non di rado raccolsi intiero nel Messinese, a conobbi quindi che esso raggiunge dimensioni molto maggiori della precedente specie.

Le dificrenze che io noto nei radioli sono le segnenti: la scultura quantunque analoga alla precedente specie, pure si presenta molto più forte cioè le costole assai sporgenti e fornite di seghettature o spine acuminate rivolte in su: la grandezza è notevole, e alla regione inferiore si presenta un ingrossamento piii o meno mareato, del resto l'estremitil articolare, ordinariamente sfornita di crenature, ne ra fornita in molti casi, come nella D. papillala.

is sicuramente questa la forma rappresentata dallo Scilla nelle rarie figure della lav. XXIV. della sua celehre operia.

Questa forma che io distinguo, potrebloe essere una insigne varieti della precedente. 'Lialvolta nelle mame s'incontrano dei cilindretti di limonite che semIrano chiodi rugginiti: essi sono a mio credere i radioli di questa specie cosi

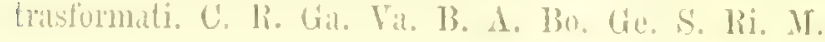


IRnblocidaris. - 920. R. oxyrine Meneghini. Possiedo un sol frammento di radiolo che risponde precisamente alla descrizione ed alla figura data dall'antore. R. S.

Centrostephanus. - 921. 'C. 1 ong ispinus Philippi (Diadema) = Diadema europaeum Agassiz. Frammenti dei radioli. r. Ga. V.

Echinus. - 922. "E. pulchellus Agassiz (Psammechinus). Di questa piccoli specie s'incontrano esemplari intieri, che convengono esattamente coi viventi del Mrediterraneo. 1. Ga. R. V. - 923. "L. acutus Lamarck. Riferisco a questa specic taluni frammenti, che rispondono esattamente per la scultura e per tutti gli altri caratteri. R. Ga.V. - 924. L. melo Lamarck. Anco questa specie oftre un porzione di guscio. R. Va. V.

925. E maximus n. sp.

Questa specie molto grande, forse anco maggiore dell'E. melo, col quale ha lat massima affinità, trovasi nelle marne sempre in frammenti, sicchè non è possibile darne una completa descrizione e delle tigure. Diro quindi soltanto che le placehe di questa specie hamno tutte un'altezza proporzionalmente maggiore di quella dell'affine, che i tubercoli nelle aie interambulacrali sono più nmerosi e più prominenti, siccome nelle aie ambulacrali, ed inoltre i pori sono disposti assai presso al margine delle placche, laddove nell' $E$. melo trovansi molto in dentro. 1. S. A. Ri. - 926."E. .... sp.? Qualche frammento di altra specie s'incontra a $Y^{\prime}$ lanidi, tali resti accennano a forma alquanto depressa con renti ordini di grossi tubereoli e molto ravricinati, poco disuguali: inoltre le placche interambulacrali presentano molti granuli disuguali. R. Va. Gria.

Strechimus. - 927. S. Scilla e Desmoulins (Echinus) = Echinantus costatus Agassiz, Stirechinus Scillae Desol. Questa specie distintissima i rara nel Reggiano, mentre è commissima nel Messinese. l. h. P. Va.

\section{Ordine. Spataxgornt.}

Spatangus. - 928. S. . . Sp.? Rapporto a questo goenere aleuni firamenti troppo piccoli perehè possano specificarsi. R. A.

\section{Classe. CrinoIdr.}

Conocrinus - 929. C. Seguenzai Meneghini. Non altro che qualche rarissimo articolo molto gracile io posso riferire a questa specie plioceniea. R. Va. Vi.

\section{Tipo. CELENTERATI.}

\section{Classe. Antozonri. - Ordine. Alcionarir.}

Juncells. - 930. J. antiqu u Seguenza. Un solo esemplare presso Gallico. R. R. Isis. - 931. T. melitensis Goldfuss. Specie molto comme nel plioceno astianu del lato occidentale della provincia di Reggio. c. R. P. - 932. I. pe lolitana Seguenza. Questa specie è ben distinta pei suoi lunghi e gracili articoli, collit superficie liscia e splendente, quantunque superficialmente soleati, colle estremitic allargate. colla base espansil. radiciforme e ramificatio. Gili esemplani abbombinti 
dei dintorni di Reggio, sono assai sovente giganteschi. ma sempre relativamente gracili. c. R. Ge.

(133. I. com pressa Seguenza.

I pochissimi esemplari, o articoli, di questa specie raccolti nella provincia di Messina, spettano ad una rara rarietà, la quale è mal caratterizzata dal sno nome, essentochè la compressione degli articolì è un carattere che appena mò assegnarsi alla rarietì suddetta. I caratteri specifici dai numerosi esemplari raccolti bisogna che sieno modificati come siegue: Articoli calcarei alquanto breri, cilindracei, sorente irregolarmente angolosi, curri, compressi, solcati ece.; superficie solcata da linee larghe impresse, flessuose, curve e che tendono sovente a direnire spirali; estremitì articolari più o meno dilatate, appianate - leggermente concare, ma che divengono piu o meno prominenti al centro, e talrolta acuminate; inoltre, numerose e ravricinate lamelle concentriche che segnano tutta la superficie articolare, e presentano i loro margini crenati per molti solchi che irradiano dal centro. Questi caratteri si connettono coll'intima struttura degli articoli, i quali risultano da strati concentrici e sovrapnosti, che facilmente si staccano, seg'nando nettamente i rarî neriodi d'incremento, laddore nella precedente specie la struttura è molto compatta. La base è dilatata e ramificata estendendosi in espansioni radiciformi come nell' I. peloritana; ma nella specie in esame tali espansioni sono molto più spesse e più solide. Gli articoli ramificati sol10 molto rari.

La costituzione, l'aspetto delle superficie articolari, la struttura lamellosa e la conformarione degli articoli distingnono bene questa specie. c. R. S. Ri. M.

Ordine. \%OANTARII.

Caryophyllia. - 934. 'C. clarus Scacchi. Un esemplare da Reggio è molto grande ed un $10^{\circ}$ direrso dal tipo per la base più larga, le costole più sporgenti, la superficie scaberrima ece. r. R. Ge. Ga. V. - 935. C. Zan clea Seguenza. Tariabile come nel Messinese. l. R. - 936. C. geniculata Seguenza. La forma molto allungata e flessnosa distingue bene questa specie; ma tra i numerosi esemflari retesi variares sino a divenire conica invece di cilindracea. c. R. -937 . C. compressa Secruenzal. Un solo e ben caratterizzato esemplare. R. R.

Ceratocyathus. - 938. C. simplex Seguenza. Un solo esemplare distintissimo. R. R. - n39. C. le etus Seguenza. R. R. S. - n40. C. conulus Seguenza. R. K. - 91. C. Romettensis Segnenza. r. S. - 942. C. compressus Segnenza. R. R. - 943. C. elegans Seguenza. c.S. - 944. C. Scilla Seguenza. r. R. - 945. C. ponderosus Seguenza. Insieme alla forma tipica raceogliesi ma varieti minore di forma quasi esattamente conica. C. R. S. Ri. - 946. "C. communis Segnenza. Questa specie molto rariabile oftre nel Reggiano numerose modificazioni, molte delle quali possono raprresentare distinte varietì. C. R. Ga. Ge. S. Ki. - 947. C. atfin is Segmenza. R. R. - 948. "C. polymorylus Seguenza. Questi piccola specie è distintisima, nei numerosi esemplari, coi quali ordinariancnte si presenta cl oflre quelle variazioni mumerose che gli valsero il nome che la distingue. Difatti le costole vedonsi piì omeno prominenti, orvero 
scompariscono del tutto, i tramezzi ed in corrispondenza i paletti sono in numero estremamente rario ecc. C. Ga. A. Ri. G. Bo. - 949. C. poly e di us Seguenza. Specie considererolmente rariabile. c. R. S. M. - 950. C. acuticostatus Seguenza. Costole angolose promimenti ed acute. C. B. G. Ri. M.

Stephanocyathus. - 951. "S. e legans Seguenza. Eccetto i giorani, questa specie raccoghiesi quasi sempre in frammenti; presso Vito ho raccolto eleganti esemplari intieri e numerosi ed esemplari gioranissimi di due o tre millimetri. S'incontra anco lat Var. S. subspinosus. c. R. Ga. B. S. G. Ri. Bo. M. - 952. S. umbrella? Ponzi (Trochocyathus). Rapporto a questa specie un grande esemplare intiero, ma incrostato di limonite e cristallini di gesso, quindi non è ben riconoscibile. R. A.

Troehoeyathus. - 953. 'T'. tetracyclus

Polyparium oblongo-conioum, compressiusculum. plus minusve curvalum, Basis parva truncata. Costae 48 inferne subaequales, convexac, fortiler granu. latae, superne prope calicem magis prominentes, subacutue, granulato-denticulatae. Calix ellipticus, fossula parum profunda; columella e lamellis parcis. granulato-plicatis, in seriem digestis constitula: septa tenues, lata, extus crassiuscula, primaria, secundariaque lationa ac prominentiora, paluli lati, tenues, pexuosi, granulos crassos gerentes.

Lunghezza 10. mm Diametro maggiore 11."mm Diametro minore 9. ${ }^{\text {mm }}$

Questa specie pliocenica, che ho trorato abbondantemente anco a Calatabiano. in Sicilia è affine molto con varie specie del Tortoniano e particolarmente coi T. crassus, T. mitralus, e sopratutto col T. f'uchsi Reuss; dalle quali speciu parmi che si distingua per la fina gramulazione delle costole, le quali sono sporgenti e piì rerso il calice mostrando lievi differenze; i tramezzi e i paletti molto sottili, siccome le lamelle che formano la columella. c. Al.

Doneyathus. - 954. "P. striatus Philippi (Cyathina). E un solo esemplare che io riferisco con sicurezza a questa specie che rire nel Mediteraneo. R. Ga. V.

vemesus. - 955. E. fungia eform is Philipi = Hemicyathus crassicostatus Segrenza. Ben rari frammenti. R. A.

Desmophyllum. - 956. D. giganteum n. sp.

Polyparium magnum, clatum, solidum, conico-compressum, sub-clavatum; costae 24 prominulae, superne in cristas acutas irregulares prominentes; superficies tenuiter gramulato-rugosa. Calir ellipticus, profundus: septa cries incrassata, primaria, secundaria, tertiariaque majora, quinariis adnata.

La grandezza di questo polipaio è ben rimareherole, esso quantumque rotto alla base è ben piì lungo di un decimetro ed il suo calice mutilato dorea almeno arere un asse maggiore di otto centimetri.

Questo Desmophyllum ì il più grande che io conosea, esso dillerisce dal (1). crassum Seguenza ner essere piu compresso e per arere $2+$ costole distinte; chr presso il calice sporgono molto sotto forma di creste acnte; questi caratteri Io distinguono aneo dal D. maximum Segruenza. IR. S.

A questo genere spettano fiammenti indeteminabili di altre sprecie probalilmente identiche arl alcune rel Messinese. 
Fabellum. - 957. F. messanense Seguenza. Soli frammenti poco bene riconoscibili. 1. A. Bo. - 958. "F. siciliense Edwards et Haime. Gli esemplari sono ordinariamente piccoli e più o meno rotti, comparati con quelli del plioceno di Palermo rispondono benissimo. Var. crassitheca $\mathrm{n}$. La forma che io denomino cosi presentr nella meti inferiore delle costole prominenti, ha le creste laterali più forti e spessissima la muraglia di unita all'epitecio. Questa modificazione risponde benissimo alle figure date dal Reuss pel $F$. siciliense del mioceno austroungarico. Di questa speciale forma ne conoseo un solo esemplare da Santa Cristina. 1. Ga. C. - 959. 'F. exteusum Micheliu. Var. pliocenica n. La forma importante che denomino cosi parmi non possa disgiungersi dalla specie miocenica cui la riferisco; essa infatti pei suoi caratteri importanti conriene colla specie miocenica, ma differisce da quella del colle torinese e dalla rarietì costata del Tortouiano di Benestare. Difatti i due spigoli laterali sono armati da cresta che diriene assai larga presso il margine, le due creste hanno i loro margini irregolarmente dentato-crenati e disposti su d'una retta, mentre tanto negli esemplari del torinese quanto in quelli di Benestare essi formano un angolo più o meno ottuso; inoltre la superficie è fornita di numerose costole larghe e appena rilerate, alternatiramente più distinte. I. Ga. - 960. "F. compressum? Lamarck (Fungia). A leuni incompleti esemplari parmi che possano spettare a questa specie. ma resterì sempre il dubbio finchè non potrò comparare i fossili coí rirenti dell'Oceano indiano. Nei miei esemplari sempre rotti le costole numerose che ornano la superficie sono pochissimo sporgenti, larghe, leggermente convesse e portano m sottile soleo mediano. R. Ga. V. - 961. "F. Michelini Fdwards et H. = F. cuncalum Michelin (non Turbinolia cuneata Goldfuss). Vi riferisco due esemplari soli di cui uno giorane e l'altro deformato alquanto. R. Ga. - 962. laciniatum Philippi (Phyllodes). Sempre incompleto. R. Ga. Ri.

Conotrochns. - 963. "C. t y pus Seguenza = Ceratorrochus typus Michelotti; Conotrochus typus Reuss. Questa bella e comnne specie del mioceno e del plioceno che mi ha dato oceasione a fondare il genere è stata riportata dal Michelotti (in Sismonda) nel genere seguente; ma il Renss lı creduto di mantenere il mio genere, e credo che il completo e spesso epitecio valga bene a distinguerlo. C. Ga. A. Bo. Ge. G. Ri.

Centotrochus. - 964. C. anceps (in Sismonda) Michelotti. Alla base alcune costole sono un po' prominenti. R. R.

cophohelin. - 965. "L. Defrancei Edwards et H. Questa specie trorasi sparsa con rarita nella prorincia di Reggio, e probabilmente dorrà rimirsi alla vivente L. prolifera. r. Ga. R. Ge. S. Ri. M. - 966. -L. prolifera Pallas (Madrepora). R. Ga. V.

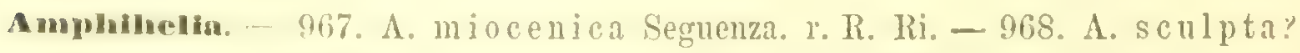
Seguenza. R. Ge. II. - 969. "A. oculata Limeo (Madrepora). Questa specie comme nel Mediterraneo comineia a mostrarsi sin dall'Astiano. r. Ga. V.

Dipfolnchis. - 970. 1). reflexa Michelotti (Oculina). C. R. Ri. M. = 971. D. Dorerleiniana Seguenza. c. R. Ge. M. - 972. D. Sismondiana Seguenza.

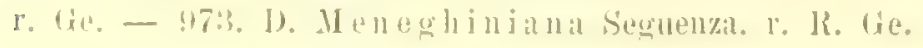


Cradocora. - 974. "C. Prevostana Edwards et Haime= Caryophyllia coespitosa Bronn (non Lamk.), C. Prevostiana Edw. et H. Qualche poliperito isolato. R. Ga. - 975. "C. stellaria Fdw. et H. $=$ C. plexuosa Ehrenberg. Piccoli cespugli formati da pochi poliperiti. R. Ga. V:

Bähophyllik. - 976. "B. irlegularis Seguenza. Questa specie si presenta così variabile e sorente sriluppata anormalmente, siccome arriene nel plioceno messinese. c. Ga. R. A. Bo. - 977. "B. italica Michelin (Caryophyllia). Riferiseo con un po'di dubbio a questa specie un solo esemplare rotto, che nei tramezzi e nella columella, come nella forma generale, conviene colla specie ricordata, e solo ne differisce alquanto per le costole un po' meno sporgenti e meno regolari, ma ngualmente granose. R. Ga. V.

978. 'B. complessa n. sp. Tar. XVLI. fig. 11, 11a.

Polyparium conico-aglindraceum, rechum, compressum; basis lata. Epilccium solidum plicatum. Costue ultra epitecium perforato-granosac. Calix cllipticus, fossula parum profunda; columella transverse elongala, e lamellis plicatis confertis constiluta, septa crassa, recta.

Polipaio retto, elerato, compresso, sopratutto presso del calice, assottigliato alquanto alla base. L'epitecio spesso, trasrersalmente rugoso occulta intierameute le costole nella porzione che ricnopre, restando ad una certa distanza dal margine del calice. Costole larghe, ravvicinate, perforato-rermiculate e granose. Calice ellittico, coll'asse maggiore poco meno del doppio del minore. Fossetta profonda. Columella quasi appianata, ellittica, molto sviluppata e costituita da numerose bacchette rarvicinate. Quattro cicli completi di tramezzi spessi, disuguali, poco larghi, pochissimo sporgenti, non curvi, coperti di granuli, che verso il margine si associano formando delle rugositi radialmente disposte.

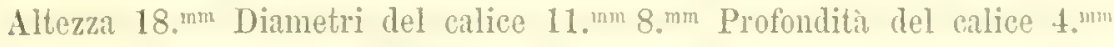

Questa specie distinguesi assai bene per tutti i snoi caratteri dalle specic conosciute. R. Ga.

979. '13. circularis 11. sp. Tar. XVII. fig. 10, 10a.

Polipariun, parvum, conicum, curvum. Costae crenato-granosae, Calix circularis"; fossula profundata; columella parva e lamellis paucis, tenuibusque constituta; sepla exlus crassa, intus tenuissima; tertiaria curvala secundariisque coniuncta.

Polipaio piccolo, conico, curro, elevato, non compresso, colla base bastantemente assottigliata. Senza epitecio; costole prominenti, ravricinate, poco disuguali, irregolarmente crenato-granose. Calice quasi circolare; fossetta molto grofonda ; columella molto piccola, formata di poche sottili lamelle. Quattro cicli completi di tramezzi, spessi all' esterno e saldati insieme, non prominenti, sottilissimi all'interno; quelli del terzo ciclo currati e saldati con quelli del secondo, piccoli e rari granuli sulle loro superficie.

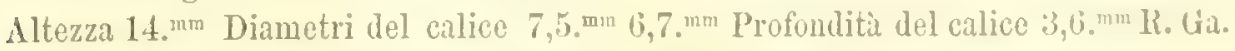
980. "B. car yophylloides n. sp. 'Tav. XVII. fig, 9, 9a.

Poliparium pedunculatum, conicum, fortiter curvatum. Costac tonuiter granosae et perforatae. Calix subelliplicus; fossula profunda; columelle clongate 
e lamellis flessuosis, contortis, confertisque constitutu; septu prominentia, latu, cxhs crassa, reptr, quaternaria curvinescula tersiariisque coniuncla.

Polipaio, conico-allungato, fortemente curvo, poco compresso, assottigliato gradatamente alla base, che risulta gracile e peduncolata. Superficie della muraglia priva di epitecio. Costole numerose, poco sporgenti, appianate, disuguali, finamente granose e perforate, coi granuli formanti due o pii serie. Calice ellittico ad assi poco disugrali, profondo. Columella appianata, molto allungata, e formata di lamelle contornate rarricinatissime e molto numerose. Cinque cicli di tramezai disuguali e molto prominenti, l'ultimo ciclo incompleto; i tramezzi spessi all'esterno e sottili all'interno; larghi, colla superficie coperta di granuli molto sporgenti. disposti in linee curre parallele al margine; dodici tramezzi molto più grandi e sporgenti, con ciascuno di essi se ne comnettono ai lati altri due saldandosi pel" mezzo dei granuli; i tramezzi in generale sono poeo emri, ma quelli che piì s'incurtano costituiscono il quarto ciclo e rolgono rerso quelli del terzo convergendo e saldandosi tra loro a due a due.

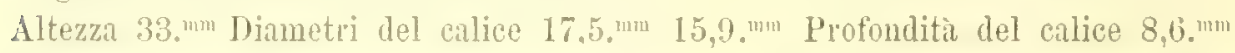

Questa specie è eminentemente distinta per la forma conico-peduncolata, ma fiu ancora per la disuguaglianza e prominenza dei tramézzi, caratteri tutti che a prima giunta la fanno credere una rera cariofillia. R. Ga.

Dendrophyllia. - 981. "D. colnigera Lamarck, (Cariophyllia). Questa specie trorasi in pezzi pii o meno lunghi rispondenti ai rami affatto identici ai viventi. A Giallina ho raccolto u» esemplare che sembra proprio una Balanophyllia, analoga alla B. praelonga: ma lo studio comparativo mi fa rapportare questo fossile siccome un giorane individuo della specie di cui discorro. r. P. R. Ga. Ge. T.

Ennilopsammin. - 982. E. Seilla e Seguenza (Coenopsummia) = Enallopsammia Scillac Michelotti (in Sismonda). Questa magnifica specie e gigantesea caratterizza gli strati astiaui del Messinese e del Reggiano, presentandosi sotto formi di grossi ceppi e di rami piì o meno giorani, che sembrerebbero distinti. C. P. R. Ga. Ge.

Astroides. - 983."A. calycularis Pallas (Hadrepora). Troransi dei poliperiti disginnti e cou gemmazioni laterali. Lo Scilla alla Tavola XVII. fig. B rappresenta un magnifico ceppo di questa specie fossile del Capo di Milazzo. r. Ga. V.

\section{Classe. Spongiarit.}

Criona. - Come lio doruto dire per lo \%ancleano, mi accontento di ripeterlo qui e per tutti i piani che sieguono, dappoiche alle gravi difficoltà di specificare le Cliona si agriungono le altre insormontabili, cioè difetto di opere e di collezioni delle specie virenti che in gran numero sono state giil descritte. Molte conchiglie, specialmente di Gallina e di qualche altro lnogo sono niì o meno perforate da mumerose o variate Cliona. 
Tipo. PROTOZOARII.

Classe. Rizorodi. - Ordine. Foraminifert.

Lagena. - 984. ${ }^{*}$. glo bosa Walker (Serpula) = Serpula lacvis-globosa Walk., Oolina lacvigata D'Orbigny, Entosolenite globosa Will., Ooline simplex Renss. r. Ga. V. - 985. L. a piculata Reuss (Oolina). R. Ri. Vi.-986. I. e maciata Reuss. R. Ri. - 987. "L。 c lavata D'Orbigny (Oolince). r. Ga. Vi. V. - 988. "L. vulgaris Williamson. =L. Lacvis Will., Phialina oviformis Costa, P. puriformis Costa, P. propinqua, ovala, longirostris Seguenza. Si osservano molte delle variazioni che suole presentare allo stato di vita. Var. semistriala = Phialinu longissima Seguenza. Anco questa è forma molto tariabile. r. R. Ga. Ri. A. Vi. V. 989. L. affin is Seguenza (Phialinu). R. R. - 990. I. elongata Costa (Amphorina). R. R. - 991. L. gracilis Costa (Amphorina). R. R. Vi. - 992. L. gracillima Seguenza (Amphorina). R. A. Vi. V. - 993. L. ten u is Bornemann. Forma allungata, quasi troncata inferiormente, con un cercine all'apertura, con sei costole alla base. 1. Vi. V. - 994. L. striatula Seguenza = O. striatula Seguenza (non D'Orb.). R. A. - 995. 'L. su I cata Seguenza (Ovulinu). r. Ga.996. L. tenuistriata Seguenza (Phalina). r. R. - 997. L. striata D'Orbigny (Oolina). r. Vi. V. - 998. L. Gemmellarii Seguenza (Phialina). 1. R. 999. L. cilindracea Seguenza (Phialina). R. R. - 1000. L. Ha idingeri Czizek. Var, globosa n. Forma globoso-depressa, costelle piì grosse ed in minor numero. R. Vi. - 1001. L. L y elli i Seguenza. 1. Vi. V.

1002. L. decorata n. sp. Tav. XVII. fig. 12.

Conchiglia globoso-ovata, che si termina in un canale cilindrico fornito di lamelle prominenti trasversali; la regione posteriore è fornita anch'essa d'una prominenza in forma cilindrica. La superficie è ormata da piccoli incavi contigui i cui margini rappresentano una reticolazione, od è fornita di prominenze che la rendono aspra. Lunghezza $0,5 .{ }^{\mathrm{mm}}$ Diametro $0,25 . \mathrm{mm} \mathrm{R}$. R.

1003. L. I u cida Williams. (Entosolenia). La forma compressa di questa come di altre specie e l'apertura non del tutto circolare di talme, costituiscono i caratteri di transizione fra le Lagena e le Fissurina. Var. quadrata Will. $x^{\text {. Ri. }}$ A. V. - 1004. L. appendiculata Will. r. Vi. V. - 1005. 'L. marginata Walker. Questa specie si presenta dapertutto colle numerose e differenti rarietà. C.R.Vi. Ga. M. Ri. A. V.

Fissurima. - 1006. F. recta Seguenza. R. Vi.

1007. F. diaphanan. sp.

Ancor piì allungata della $F$. cavinata, vitrea, diaphana, con mn eanale interno, e con forti perforazioni della parete. $\mathrm{R}$. Vi.

1008. F. solida Seguenza. c.R. Vi. - 1009. F. simplex Seguenza. R. R. 1010. "F. latistoma Seguenza. 1. Ga-1011. F. a euta Seguenza (non Reuss). r.R.-1012. F. Pecehi oli i Seguenza.r. R. - 1013. F. com mu is Seguenza. c. R.Ri. - 1014. F. obvia Seguenza. 1. 1. 1015. F. ovata Segueuza. r. l.. 1016. F. bic andata Segnenza. I. R 
1017. F, foliacea n. sp. 'Lav. XVII. fig. $13,13 \alpha$.

Questa specie parmi che abbia nella $F$. pterocephak del MLessinese la specie piu affine, pure ne è da quella distintissima per la forma piì allungata e per essere compressissima.

Luughezza 0,51. ${ }^{m m}$ Larghezza $0,36 .{ }^{\mathrm{mm}}$ Spessore $0,18 . \mathrm{mm}$ R. A. 1018. F. rugosa Seguenza. 1. A. - 1019. F. Costa e Seguenza. 1. A. - 1020. F. radiata. Seguenza. r. R. - 1021. F. regularis Seguenza. c. Ri. R. A. 1022. F, Lyelli i Seguenza. x. A. - 1023. F. Peloritana. Seguenza. r. R.

Le specie riportate in questo c nel precedente genere hamo d' uopo d' un riesame accuratamente fatto sopra abhondanti materiali, perchè vengano ridotte al loro reale ralore. Mi è maneato il tempo necessario per tale studio.

Vodosnoin. - 1024. N. raphanistrum Lin. (Ncuutus) = Nautilus bacillum Parkinson, N. grossecostatn, intermentu, doholum Costa. Questa vi è in belli e conservati esemplari, 1. Bo. Ri. Vi. V. - 1025. N. raplan us Lin. (Nautilus) =N. propinqua Costa. r. Ri. V. - 1026. N. con ica Silvestri. Questa specie è stata bene illustrata dal Silvestri essendo stata pria descritta e figurata malamente dal Soldani. r. Ri. - 1027. N. longicauda D'Orbigny. c. Vi. V. - 1028. "N. hispida D'Orb. R. Ga. V. - 1029. N. papillosa Silvestri di piccolissime dimensioni r. Vi. - 1030. N. glabla D'Orbigny. r. Va. A. T. - 1031. N. s ubaequal is Costa. 1. Ri. T. - 1032. "N. lougiscata D'Orbigny. Bella specie, che trovasi sempre in frammenti per le sue lunghe logge e per la sua fragilità. r. Ga. Va. V. - 1033. N. aute un la Costa. Questa non è da confondersi colla D. ancemula D'Orbigny, essa è lerigata su tulta la superficie, retta e più snella, r. R. Ri. Va.

Gandulima, - 1034. "G. la evigata D' Orbigny. Si associa a diverse rarieta. r. Ga. Ri. A. Bo.Vi. V. - 1035. G. o vi form is Terquem. Qualche esemplare che risponde bene. R. Vi. - 1036. G. cfr. obtusa Costa. Le suture sono un po'più profondate, la regione posteriore si termina con un piccolo sperone. R. Ti. 1037. G. acuminata Costa. r. Vi. - 1038. G. a piculata Costa. r. Vi. 1039. G. gracilis n. sp.

È affine alla G. acfualis Renss, ma ancor di forma più gracile, troncata anteriormente da foramo cireolare, colle suture appena impresse, poco visibili, colla regione posteriore fornita d'un piceolo sperone.

\section{Limgliezza 1.mm Diametro $0,3,3$, , mm R. Vi.}

1010. G. Uiseretar Renss. Una varictib nu pomeno gracile. R. Ri. Vi.

Lingulina. - 1011. "Ts. calinata I) Orbigny. Forma allargata. l. Ga. Ri. V.

Dentalinas. - 1042. I), pungens lienss. 1". Ri. - 1043. "D. obliqua Lin. (Nonetilus). 1. Gia. V. - 104t. I). substriata D'Orb. r. Ri. V. - 1045. D. a ciunlaris Costa. c. R. - 1046. I). strigosa Costa. c. R. - 10.17. "1). orularis Costa. 'T'alvolta un po' curra, sorente rotta in pezzi. c. Gia. 1. Bo. G. S. M. 1048. D. subiullata Costa. Molto alline alla precedente; logge in minor numero e meno globose. r. li. - 1049. 'D. inornata 1)'0rlo. r. Ri. Ga. V. 1050. D. communis D'Orb.r. Ri. V. - 1051. D. Orbiguyana Nengeboren. r. Ri. - 1052. D. Badenensis D'Orbigny. R. R. 
Bullenir. - 1053. P. bulloides Dorlo. (Nonionina). r. R. Ri. V.

1054. P. compressa 11. sp. Tav. XVII. fig. 14, 14u.

Questa specie ha qualehe somiglianza colla $P$. compressiusculu Reuss, ma ne è ben distiuta perehe porta cinque logge, le quali sono meno arrolondate, e la conchiglia nella sua forma generale risulti piì compressia. r. Vi. R. Ri. S. M.

Momionina. - 1055. N. Soldauii D'0rb. P. G. Ge. V. - 1056. N. unbilicatula Montagu. r. A. V. - 1057. N. commu is D'Orbigny. Gli esemplari raccolti non hanno la carena ben acuta come la rapluesenta l'autore. r. Va. V.

Polystomella. - 1058. "P. crislia Lamarek. e. Ga. R. Ri. A. Bo. Va. T. 1059. P. Fichtelliana D'Orbigny. R. R.

Amphistegina. - 1060. A. Ha u erilla Dorbigny. E noterolissimo como questa specie tanto abbondante nello Zancleano, sino a costituire da se sola intieri strati, nell'Astiano si presenti poi in un modo reramente anormale. Nel riceranre le rocce tutte dell'Astiano non oceorre mai d'incontrarne m indiriduo solo e poi nella contrada Gallina in seno a strati i più recenti e i più caratteristici dell'Astiano trorasi profusamente sparsi. Ma questo fatto. ha attinenza evidente, anzi è un caso speciale dell' introduzione che osservasi nella merlesima contrada di specie zancleane negli strati astiani, la quale anomalia richiede ma interpretazione. c. Gar.

Opereunina, - 1061. O. am monoides Gronovins. Vi riferisco mu solo esemplare che mi riesce un 10' dubbio. R. Va. V.

Croistellaria. - 1062. C. concinna? Reuss. Rapporto con qualche dubbio a questa specie varî esemplari raccolti. 2 . Vi - 106:3. C.crepidula F. et MI. (Youlilus). r. S. Va. V. - 1064. C. cass is F. et M. (Kunilus). G. G.V. - 1065. C. navicular is MIontf. (Scomtimus). Domelubesi probabilmente associare alla mecedente. c. G.

Eobulina. 1066. R. simplex D'Orbigny. l. Ta. - 1067. R. inorinata Dorb. r. R. Ri. Va. - 1068. "R. cultratta Dor'bigny. La larghezza della limina marginale è molto rariabile. c. R. Ga. S. Ri. M. Ti. V. - 1069. R. f'estouata Costa. Qualche esemplare. R. Vi. - 1070. R. similis D'Orb. I. G. Ri. - 1071. "R. rotulata Lamk. r. Ga. V. - 1072. "R. voltex Fich. el Moll. (Munilus). Oltre lil forma tipica direrse varietiv. 1. Ga. Va. A. Bo. Ri. V. - 1073. R. calear. D'Orb. Oltre la forma tipiea ma rarieti ineme. I. Tr. Ri. G. A. IBo. T.

Polymorplnima. - 1074."P. commun is d"Oribgy (Gultulines). 1". Ga. - 1075. P.

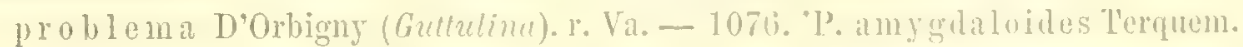
r. Gia. - 1077. P. guttal I)'Orb.r. Va. V. - 1078. P. compressil D'Orhigny. r. Ga. R. A. Bo. - 1079. P. oblonga Williamsono 1. A. I30. Vi. V.

vvigerina. - 1080. U. pygma ea D'Orb. S' incontranole rarie forme che suole assumere, tra le quali una varietil allungatia l. Va. Ri. 1. Bo. Vi. I. - 1081. 'L. angulosa Williamson. 1. Ga. T. - 1082. U. asperula Czizek. Lin solo e bello esemplare. R. Ri.

Plemestomelln. - 1083. P. obtusan 11 . sp.

È afhine alla mia $P$. infletu dello Zancleano e quinti molto somiglia ad una Glandulina; essa è di forma orato-oblongal ottuka a rotondata posteriormente,

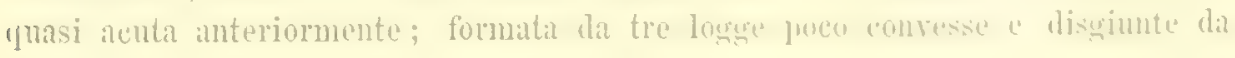


suture alquanto impresse e poco obliquamente disposte in rapporto all'asse, con alternanza d'inclinazione. L'apertura $\dot{e}$ in forma di fenditura arcuata.

$$
\text { Lunghezza 0,8. }{ }^{m n} \text { Larghezza } 0,44{ }^{\mathrm{mm}} \mathrm{r} \text {. Vi. }
$$

Bunminn. - 1084. B. imperatrix Karrer. Questa magnifica specie, che ho trorato nel Tortoniano, fa passagrio all'Astiano. 1. Ga. Ri. - 1085. B. o rata D'0rbigny. x. Ri. A. Bo. Vi. V.- 1086. B. marginata D'Orbigny. Formaallungata. R. Va. V: - 1087. B. Buchiaua D'Orb. Yo. V.-1088. B. pyrula D'Orbigny. Si raccolgono forme diverse che costituiscono differenti varieta. 1. Ri. Va. Vi. V. - 1089. B. tenera Reuss. Forma variabile come la miocenica.r. Vi.1090. "B. 1lülla Costa (Gutulina). Questa specie è affine alla precedente, e con sicurezza nua Bulimina, essa distinguesi per la forma molto allungata. c. Ga. Va. A. Bo. R.

Virgurus. - 1091. V. Iongissima Costa (Polimorphina). Questa specie per la sua gracilita si distingue bene dalla $V$. Schreibersii Czizek e si approssima alquanto meglio alla V'. squamose D'Orb. ma sembrami anco da questa distinta. r. Va. Vi.

sphoeroulina. - 1092. 'S. bulloides D’Orbigny. 1. Ga. Va. A. Bo. V. - 1093. S. a ustriaca Dorbigny. r. Va. Ri. Vi.

Porvimulina. - 1094. "P. Parts chiana D'Orbigny. Specie molto sparsa nell'Astiano. E. R. Ga.S. Ri.M.Vi.- 1095. "P. Karsteni Reuss. Y. Ga.V. - 1096. P. elegans D'Orb.r.Va. V. - 1097. "P. Menarkii D'Orb. c. Ga. Va.V. - 1098. P. Micheliniana D'Orb.r. A. V. - 1099. "P. repanda Fich. et Moll. (Nautilus). R. Ga. V. - 1100 "P. commun is D'Orb. l. Ga.V. - 1101. "P. a uricula Ficht. et Moll. (Nautilus). c. Ga. R. V.

Exotulia. - 1102. R. Beccarii D'Orb. r. Va.V.- 1103. R. Soldanii D'Orb.r. Ri. $\nabla i . V$.

Orbvina. - 1104. 'O. un iversa D'Orh. C. R. Ga. Va. B. A. Bo. S. Ge. Ri. M. Vi. V. Globigering. - 1105. "G. bulloides D'Orb. C. R. Ga. Va. A. Bo. Ge.S. Ri. MI. V. - 1106. "G. lielicina D'0rbigny. Questa specie parmi che si connetta indissoluhimente colle forme che il Renss descrisse sotto i nomi di G. concinna e G. diplostoma alle quali fa passaggio negli abboudanti esemplari che possiedo. c. Ga. Ri. V. - 1107. 'G. regularis D'0rb.r.Ga. Ri. - 1108. G. triloba. Reuss. c. Ga. Ri.A. Bo.- 1109. "G. Aladasii Seguenza (Rotalinn). Questa forma molto si avvicina alla Globigerina inflata ed alla G. Cretucen D'Orb. c. R. Ga. Ri. Vi. Va. - 1110. G. r ub r it Drorb. Il sig. Vanden Broeck figura questa forma nei suoi Foraminiferi della Barbade. I miei esemplari sono identici a quelli e solo ne differiscono per la mancanza dell'apertura in ogni loggia.r. Ri. V.

1111. "G. goun itulus n. sp. Tav. XVII. fig. $16,16 \pi$.

Questil specie come bene rapnresentano le figure is distinta per avere le logge compresse non glohose, le suture non molto mofondate o dispioste ortogonalmente, in modo che questi caratteri la distinguono bene dalle altre.

\section{Jungheza 0,7.mm Larghezza 0,62. ${ }^{\mathrm{mm}}$}

Qnesta Globigerina is comune nell'Astiano. c. Vi. R. Ga. Ri. G. 1112. G. oroidea n. sp. Tar. XVII. fig. 30. Questa specie è descritta nei fossili siciliani, essa è comme in quel piano. r. Vi. 
Discorbina. - 1113. "Do gr o bularis D'Orbigny. c. R. Ga. Va. A. Bo. V. 1114. D. perforata 11. sp. Tar. XIV. fig. 3, 3थ. Alla ntova forma trovata nel mioceno rapporto questa pliocenica. c. Va. A. Bo.

Trumeatulina. - 1115. "T. lobatula D'Orb. E molto rariabile. c. R. Ga. Va. A. Bo. S. Ge. Ri. Vi.V. - 1116. "T. refulgeus Doorb.r. Ga. Va. Ri. V.1117. '1. tuberosa Fich. et Moll. (Naulilus) $=$ T. rariubilis D'Oris., T'. inmormalis Costa. Vedi fossili zancleani. r.Vi.V. - 1118. "T. D utemplei D'Orb. (Rotalina). c. R. Ga. Va. V. - 1119. T. I u cida Reuss? r. S.

1120. T. spirata n. sp. Tav. XIV. fig. 4, 4a, 4b. Questa forma è comme nel Tortoniano e giunge sino all'Astiano. R. R. - 1121. T. a ffin is Czizek (Rotalina). Alcuni esemplari un po'più compressi del tipo. 1. Vi. - 1122. T. Le licin a Costa (Nonionina), c. Vi. R. - 1123. T. Ungeriana D'Orbigny. e. Vi. R. V.

1124. T. peraffinis Costa (Rotulina). 1. Vi. Va.

1125. T. formosa n. sp. Tar. XIV. fig. 5, 5a, 5b. Anco questa viene dal mioceno. r. Ri. - 1126. T. badenensis D' Orbigny (Anomalina). r. R. Ri. 1127. "T. variolaria D'orbigny (Anomalimn). r. Ga. V.

Anomnlina. - 1128. A. polymorpha Costa.r.Ga. - 1129. "A. coloulatil Parkel et Jon. c. R. Ga. Ri. Vi. V.

Plannlina. - 1130. P. ariminensis. c. R. Ri. Va. A. Bo. Vi. V.

Siphonina. - 1131. S. fimbriata Renss. - Rotulina reticulata Czizek. r. Ri.

Bolivina. - 1132. B. punctata D'Orbigny. r. A. Vi. V.

Chilostonella. - 1133. "C. ofoilea Renss. r. Ga. V. - 1134. "C. cylindriea Reuss. Questa e la precedente specie rengono dal mioceno dore li raccogliera il Reuss. R. Ga.

Polytrema. - 1135. 'P. l'u bra Lamarck. Questa specie è comune anco nel Mediterraneo. r. Ga. V.

Implostiche - 1136. "H. compressa 11. sp. Tar. XVIT. fig. 17, 17 a.

Questa specie è della forma di una Lingulina perchè abbastanza compressa e risultante da quattro logge irregolari, crescenti e disposte in linea retta o leggermente curva. Risulta quasi intieramente dall'associazione di granelli quarzosi e quindi la superficie è granoso-scaberrima.

Lunghezza 1,6. mm Larghezza 0,52. mm Spessore 0,45. ${ }^{m m} \mathrm{r}$. Ga. Va.

Lituola. - 1137. L. canariens is D'Orbigny. 1. Ri. V. - 1138. L. globigeriniform is Parker et Jones. 1. Va. V.

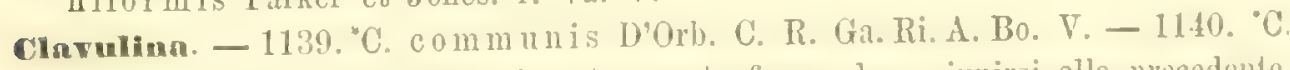
irregularis Costa. Probabilmente questa forma deve rimirsi alla precedente. C. R. Ga. Ri. A. Bo. Vi. - 1141. "C. cylindrica Hantken. Trovasi anco la Var. inflata. 1. Ga. A. Bo.

plecanimm. - 1142. P. pala Czizek (Texularia). Alemi esemplari se ne allontanano considerevolmente per essere più spessi, colle logge più larghe e pianissime. $x$. Ga. Vi.-1143. P. spinulosum Reuss (Textularia). 1. R. Ta.-114. 'I'. a b breviatum D'Orb.(Texiularia).r.Ga.Va.A.Bo.V.-1145. P. subangulatum D'Orb. (Texlularia).r. Va. - 1146. P. gibbos um Dorb. (Textularia). 1. Ga.Va. A.V. 1147. 'P. tuberiforme n. sp. Tar. XIV. fig. 9, 9r, 96. Descritto tra le specie 
del Tortoniano. r. Gr. - 1148. P. Partschii Czizek (Texiularia).r. Vi. V.1149. P. sagittula Defrance (Texuluriu). c. Ga. R. Ta. A. Bo. Vi. Ii. MI. V. 1150. "P. irregulare n. sp. Tar. XIV. fig. 7, 7a. Deseritto tra le specie tortoniane. r. Ga. A. - 1151. P. agglutinaus Dorh. (Texhuhuiu). 1. Ga. Tas. Ri. Vi. V. - 115. 'P. Mariae D'Orb. (Texhulurin).x. Ga. - 1153. "P. rotulllatum? Costa (Tertularin). Riferisco a questa sprecie un solo esemplare ehu parmi puì̀ compresso e più allungato. R. Ga. - 1154. P. g ibbos um Dorbigny (Texhluriu) = Textuluriu obnesa D'Orbigny. r. Vi. V.

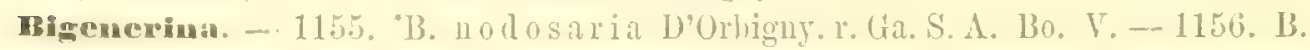
agglutinans Donbigny. Distintil specie, che risponde bene alla forma del bacino di Vienna.r. Ri.

Conmuspira. - 1157. C. foliacea Phil.(Dibis). c. R.S.Ge. MI. Vi. V. - 1158. C. calinata Costa. 1* Ri. Vi.

Planispirina 11. genere.

Conchiglia discoidale molto compressa, costituita da logge ordinate a spirale piana, ugualmente risibili d'ambo le facce; le carità allungate ed incurrate da formare un arco di nn quarto o di un terzo di circonferenza; lil dore una loggia s'innesta coll'altra il margine presenta una sinuositi orrero un angolo ottuso, in molo che il perimetro della conchiglia non is perfettamente tondeggiante, ma jiù o meno angoloso. Lapertura è allungata in forma di feuditura come nelle Cornuspiria.

Questo nuovo genere è hen distinto ed intermedio tra le Cornuspira, alle quali somiglia molto por la forma e per l'apertura, e le funerina, alle quali si approssima per la disprosizione delle logge; ma distinguesi bene dalle prime perchè la conchiglia è custituita di molte logge, dalle seconde per la grande compressione della conchiglia, l'allungamento delle carita, la forma dell'apertura.

A primo aspetto la opacitì e la forma pianissima della couchiglia puo farla confondere colle Cormuspira, ma il carattere esteriore più rilerante, allorchè le logge non si distinguono bene all'esterno, è quello della preriferia angolosa. 1159 . P. comm unis 11. sp. Tav. XVIT. fig. 18, 18 .

Questa specie ha quattro o cinçue angolosita ben rotondate alla periferia, il suo margine è gradualmente o lievenente ingrossato a ben arrotondato nel suo spessore; la conchiglia presentasi quindi leggermente e gradualmente incarati rerso il centro; le logge sono quasi invisibili all'esterno, e solamente per le angolositi marginali quelle dell'nltimo giro di spira danno indizio della loro estensione. Questa specie è comunissima nell'Astiano di Messina.

$$
\text { Diametro 2, 1. mm Spessore 0,8.1mm } \text { r. S. Ri. }
$$

1160. P. cariunta n. sp. Tar. MYII. fig. 19.

Questa forma i ben distinta, quantunque somigliante nella forma generale alla precedente. 11 earattere ben rilerante si e che il margine si assottiglia, si demime bruscamente per costituire una lamina che sporge in forma di carena. Le logge sono piit o meno risibili allesterno.

Diametro 1,5.mm Spessore 0,2.mm 1. A. 130. Ri.

menculina. - 1161. 'B. contratia Dophigny. 1. (ia. - 1162. 'B. bulloides. 
Insieme alla forma tipica s'incontrano varie forme che a quella si collegano. c. Ga. R. S. Ri.Ge. Vi. V. - 1163. B. tuhulosa Costa. Questa ì ben distinta specie, perchè l'apertura è sormontatil da m breve tubo. r. R. Ri. A. Bo. 1164. B. In nula D'Orb. r. S. M. - 1165. B. cirenmelausa Costa. c. A. Bo. G. S. M. Ri. Vi. - 1166. "B. amphiconica Renss. 1. Ga. A. Bo. Qneste tre ultime forme sono troppo affini. - 1167. B. depressa D' Orbigny, r. Vi. V.

spiroloculina - 1168. "S. excavata D'Orbigny. r. R. Ga. - 1169. S. canaliculata D'Orbigny. r. R. Ri. Vi. V. - 1170. "S. limbata D'Orbigny. F. Ga. V. 1171. S. tenu is. Czizek. R. Ri. V.

Quinmuelocnlima. - 1172. "Q. triangularis. Dorb, Con diverse varietit. c. R. Ga. Va. 1. Bo. B. Ri. S. M. Vi. V. - 1173. Q. incrassata Karer. Var. I. S. M1174. Q. seminulum Lin. (Scrpula). Un solo esemplare. R. Ga. V. 1175. QQ. a sperula. Seguenza. C. R. Ta. A. Bo. S. Ri. Vi.

Fatto un esame minuzioso el accurato della fauna dell'Astinno calabrese, vediamo in breve quali rapporti passano tra essa e quella di altri lunghi.

Faceio notare dapprima, che pei Molluschi e pei Cirripedi, m tale paragone d stato già fatto per molti el importanti luoghi d'Italia. Nel lungo elenco, dia me dato negli Studî sul plioceno dell' Ituliu merisionule (') sono messe a raftionto le famno astiaue di molti luoghi della Calabria, della Sicilia, e dell'alta Italia, ed in quell'eleneo is gia fatta la distinzione in tre facies dell' Astiano tutto, e vi si osserva la enrispondenza completa delia fauma di quoi lunghi che ofrono facies identico.

Un tale esame, ricsce molto piì concludente, perche più completo, dall'elenco che precede. In esso sono enumerate le specie di tutte le classi di fossili, a cominciar dai Vertebrati sino ai Protozoi.

Un primo esame sommario ci fa conoscere che tútta la fuma astiana del Reggiano costa di 1 Mammifero, di 5 Pesci, ai quali bisogna ancora annettere la grande fauna rappresentata dagli abbondantissimi Otoliti, di 1 Cefalopodo, di 463 Gasteropodi, di 22 Solenoconchi, di 16 Pteroporli, di 232 Lamellibranchi, di 19 Brachiopodi, di 45 Crostacei ostracodi, di 21 Cimipedi, di 13 Anellidi, di 77 Briozoarî, di 13 Echinidi, di 1 Crinoide, di 54 Antozoarî, di 190 Rizopodi.

Fauna così ricca è rimarchevole per rarî riguardi, e per la varietì dei gruppi, che essa racchinde, e pei numerosi generi o per le variate specio che la compongono, e per le forme nuove che ci oflie.

Le varie classi di Molluschi riescono del piì grande interesse per le molto specie che le recenti esplorazioni hanno scoperto nelle grandi profonditì dei mari. I Cirripedi peduncolati formano un gruppo che enratterizza al merariglia l'Astiano dei mari profondi, tutte le specie essendo eschusivo di quel periodo.

I Briozoarî interessano alla loro rolta, perchè oflirono delle forme che meglio approssimano la fauna astiana all'attuale, restando un gran numero di specie dello Zancleano proprie e caratteristiche di quella formazione.

E tralasciando i gruppi di minore entita e che meno interessano, ricordoro sopra

(1) Stuli stratigrafici ece. (Bull. (imm. geologr 


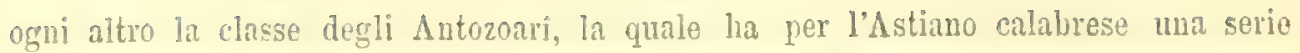
di forme abhastanza rariata ed importante che non oltrepassa menomamente i limiti stratigrafici di quel terreno.

I Foraminiferi poi costituendo quasi per intiero quelle marne, offiono campo illimitato allo studioso, che rolesse, direi quasi, dedicarvi intiera la sua vita.

Ecco adunque una fauna astiana cho per la sua varietà ed abbondanza di forme si presta a merariglia au ogui maniera di confronti e di studî.

Il mimo confronto che conviene istituire è quello coll'Astiano della provincia di Messina. Qua come in Calabria noi troviamo che si presentano quattro facies di. stinti. Quello degli abissi è il commissimo, non è raro quello a Brachiopodi, il littorale ri si rede per reri eccezione, il facies misto, come già dissi, si mostra a Calatabiano. Così essendo, bisogna comparare la fauna reggiana colla messinese nel modo come smembrate ci si offrono in natura, e tosto si rede che le specie di una regione si'propagano nell'altra conservandosi distinte nei diversi facies.

Abbiamo così che la fanua dell'Astiano nelle due provincie è completamente identica; solamente poche specie locali si aggiungono alle moite comuni alle due regioni.

Nella fauna mista di Gallina, tanto somigliante a quella di Calatabiano, ci si offrono abbondanti elementi comuni coi depositi astiani di Altavilla $\theta$ dell'alta Italia. Ecco l'anello di congiunzione tra i depositi littorali e quelli dei profondi mari dell'epoca astiana. Per darne un'ilea concreta ricordo le specie seguenti di Molluschi, che troransi a Gallina e che sono comuni a quasi tutti i giacimenti dell' Astiano classico:

Scaphander lignarius, Bulla utriculus, Cylichna subapennina, C. convoluta, Ringicula buccinea, Mitra strialula, $1 \%$. Obsoleta, Surcula dimidiata, Dryllia sigmoidea, D. crispa, Pseudotoma brevis, Raphitoma nevropleura, R.turgida, R. megastoma, R. brachystoma, R. harpula, R. Columnae, Columbella turgidule, C. subulata, C, Bellardii. Nasse clatirata, N. asperala, Pollia fusulus, Trophon squamulatus, Fusus longiroster, Cancellaria lyrala, Scalaria Bombicciana, Tumitella subangulate. T. Cornata, Rissoina pusilla, Turbo mamilla, Trochus palulus, Dentalium Passerinianum, Siphonodentalium triquetrum, S. tetragonum, Helonyx. ventricosa, lenus multilamella, Isocardia cor", Chama gryphoides, $\ell$. dissimilis, Cardita intermedia, C. crassicosta, C. rhomboidea, C. Purtschii, Cardium hirsutum, C. pectinatum, Aximus rostratus, Lucina Bronnii, Pectunculus insubricus, Limopsis aurita, Lembulus concevus, Ostrea navicularis, Inomia striata.

Le specie enumerate non formano certamente un gruppo costituito quale potrehbe attendersi dall'esplorazione per esempio di un lembo del plioceno classico, cho racchinde una fauna veramente littorale, nella quale d'ordinario vi sono profusi i grandi Pleurotomidi, i Coni, le numerose Cancellario e cosi via via; ma pure è quanto può sperarsi dalla fauna, dalla quale quelle specie sono tolte, da una fauna in cui associati conriveano o gli organismi delle mediocri profonditì e gli animali abissicoli; ¿ quanto soddisfa al bisogno. I,e specie ricoriate dimostrano benissimo"l'assunto, la loro associarione e pliocenica per eccellenza e con lievi mollificaioni, secondo i luoghi, si riconosco durunque nei plioceno littorale. Cosi lo specie enumerato dimostrano, 
che è astiano il giacimento da dove prorengono, astiano lo numerose specie che con esse vissero e con esse giacciono sepolte, e quindi astiani tutti i sellimenti a diverso facies, che racchiudono queste uftime; dimostrano quindi il sineronismo legli ultimi strati di Altavilla, o dei tanti terreni pliocenici dell'alta e melia Italia colle nostro marue e sabbie gia descritte. Fico come la faum mista di Gallima, al pari di yuella di Calatabiano, costituisce un trorato paleontologico dif grands portata, fecondo di utilissimo applicazioni, di conclusioni importanti.

La comparazione poi della ricea nostra fauma astiana colla rirente ci di dei rapporti che non possono essere costanti; dappoichè osteso le esplomzioni sullo grandi profonditi oceaniche, e condotte con perseverante lavoro, e direi quasi senza interruzione, si assiste di continuo al fatto imponente di velere rivivore le specio plioceniche credute per lo imanzi estinte.

Ed è precisamente il plioceno dell'Italia meridionule, cho si formo a grandi profondita, che ra soggetto a tali mutamenti di mpporti tria la sna fama e quella vivente. Tali fatti e le relativo considerazioni ci parlano della probabile variazione che subiranno i risultamenti ottenuti da questo esame, e che in ria prortisoria vado qui esponendo.

Il numero proporzionale delle specie tuttarial viventi in rapporto al totale, per ciascuna classe dal precedente elenco risuita come siegne:

\begin{tabular}{|c|c|c|c|c|c|c|c|c|}
\hline Pesci & un. & 5 & viventi & 1 & Cirripedi & пищ. & 21 & riventi \\
\hline Gasteropodi & $»$ & 463 & $»$ & 291 & Anellidi & $»$ & 13 & $»$ \\
\hline Solenoconchi & $»$ & 22 & » & 9 & Briozoi & $»$ & 77 & $»$ \\
\hline Pteropodi & $》$ & 16 & $»$ & 9 & Echinidi & $\gg$ & 13 & $»$ \\
\hline Lamellibranchi & $i \gg$ & 232 & $»$ & 153 & Crinoidi & $》$ & 1 & $\gg$ \\
\hline Brachiopodi & $»$ & 19 & $»$ & 10 & Antozonrî & $»$ & 54 & $»$ \\
\hline Ostracodi & $»$ & 45 & $»$ & 15 & Rizopodi & » & 190 & 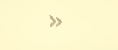 \\
\hline
\end{tabular}

Quindi complessivamente si ha um totale di 1175 specie animali di cui 652 hamno i loro rappresentanti nei mari attuali.

$\mathrm{E}$ volendo tradure queste cifre in dati paragonabili, convicne ridurle in rapnorti eentesimali; si arrì cosi per le classi di sopra enumerate:

\section{Specie viventi}

\begin{tabular}{ll|ll} 
Pesci & $20: 100$ & Cirripedi & $43: 100$ \\
Gasteropudi & $63: 100$ & Ancllidi & $61: 100$ \\
Solenoconchi & $41: 100$ & Briozonri & $58: 100$ \\
Pteropodi & $56: 100$ & Echinidi & $38: 100$ \\
Lamellibranchi & $66: 100$ & Antozonrî & $16: 100$ \\
Brachiopodi & $53: 100$ & Rizopodi & $46: 100$ \\
Ostracodi & $33: 100$ & &
\end{tabular}

Per cui del totale della fama si ha il 55 per cento di specie rirenti.

Mra ciu non basta: bisogna ancora esaminaro con molta attenziono quali sono i mari e le diverse condizioni fisiche in eni virono tuttavia molte telle specie, che nell"epoca plioceniea, nel periodo astiano, vissero in Calah)ia associats: alle tanto

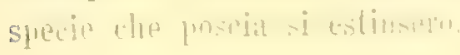


Di quolla ricca fauna abbiamo giì veduto come considererolo si è il numero dello specie, the si conoscono tuttaria viventi, e queste si ripartono naturalmento in due gruppi: l'uno, di quelle abitatrici del Mediterraneo; a l’altro, delle specie che virono in altri mari.

Anco qui le esplorazioni fatte a profondità più o meno considerevoli hanno influito non poco ad accrescere il numero delle specie mediterranee, e con esse quelle che sono comuni a questo mare ed alla fauna astiana, ordinariamente a speso dolle specie atlantiche.

Così a voler parlare solo dei Molluschi, eho è il gruppo meglio conosciuto, ricorderò che al 1870 io pubblicava una Nota rignardanto lo specie astiaue tuttavia viventi nel Nord-Atlantico ('). Da quell'esame risultava che nell'Astiano di mare profondo dell'Italia meridionale trovansi ben sedici specie, che oggi vivono nei mari äIughilterra, di Norregia ecc. tali sono le seguenti: Pleuroloma modiolu, Columbella costulata. Natica Hontacuti, Aporrhais Hacandreas, Techura Fulva, Puncturella noachina, Fissurisepla papillosa, Emarginula crassa, Leda cxcisa, L. lucida, Limopsis aurita, Limea Sarsii, Lima excavata, Pecten tigrinus, Wüldheimia septigera. W. cranium.

Ma per le scoperte posteriori di queste sedici specie, șette furono trovate nel Mediterraneo, o quindi si ridussero a nove quelle del nostro $\Lambda$ stiano che virono sul. tanto nei mari settentrionali; e di tale limitato numero la prorincia di Reggio ne possiede solamente sette, le altre due non essendori state rincontrato sinora.

Intanto le mio ulteriori ricerche hanno di molto aumentato il numero dello specie che sono comuni all'Astiano calabrese ed all'Atiantico settentrionale, e non ancola scoperte nel Mediterraneo, quantunque talune di esse furomo pescato recentemente sulle coste del Portogallo o della Spagna. Tali specie sono: Cylichna alba, Veptrunea contraria, Natica Montacuti, Odostomia unidentata, Scalaria Trevelyana, Setia pulcherrima, Trachysma delicatum, Troshus marginulatus, T. cinctus, T. Ottoi, Seguenzia monocingulata, Punchurella noachina, Helonyx ventricosa, I'erticordia acuticostata, Lembulus pustulosus, L. pusio, Neilo excisus, Mo liolaria subclavata, Lima excarda, Pecten pes-lutrae, Terebrabula sphoenoidea, Waldheimia septigera, Ihynchonella sicula.

Eceo una buoma serie di Mollusehi, che manea al Mediteraueo, e di cui uma buona porzione, nella fauna vivente, forma tuttaria parte esclusira degli abitanti dei mari del Nord.

Queste specio norliche potrebbero accenuare al un mare o ad un clima più freddo dell'attuale; ma bisogna esser cauti nell'ammettero come sicura una tale deduziono, specialmente perche trattasi di dopositi dei mari profondi, dove nel Mediterraneo si vanno scroprendo lo specie nordiche, o perehè i sediuenti coetunei littorali colla loro funa accennano invece al un maro più caldo dellattuale.

(1) Sullunlica distribusione geogrufict di talune specie malaculugiche viventi (Bullettino malacoIogico italianu 1870 ). 


\section{Piano Siciliano Doderlein.}

Sinonimi. Pliostoceno Iyell. Plioceno superiore o recente di varî autori. Parte itel Qunternario secondo altri.

Abbiamo in questo piano il cosi detto plioceno superiore orvero pliostoceno del Lyell, che il Doderlein ha proposto di chiamaro Siciliano perchè molto sviluppato e ben caratterizzato in Sicilia.

Due ben distinti aspetti assume questo piano nella Calabria meridionalo, cho vengono distinti e dalla natura del deposito o dalla cliversiti della fauma.

Sul lato orientale questa zona non ì che appena rappresentata, o quindi assumo pochissimo sviluppo, ma colla sua rimarchevole potonza e coll sua olevaziono dimo. stra che costitui una potente formazione c vasta, che venne interamente denudata, restando solo a testimonio quel lembo estremo che vado a descrivere. Presso MIono. sterace, sugli strati astiani, come ben dimostra la prima sezione, si elerano a considerevole altezza delle marne, che poggiano in discordamza sugli strati astiani suddetti, formando delle ripide colline, a striti orizzontali, solcate e scoscese per l'azione delle acque. Alla parte superiore esse alternano e vengono sormontato da strati sabbiosi, e gli uni e le altre racchiudono una fuur quasi littorale molto somigliante, o molto aftine a quella che vive nel nostro Mediterraueo.

Questi strati sono formati di marno sabbiose azzurre, cho si stemprano ficilmente nell'acqua; esse raggiungono lo spessore di circa 80 metri, e si elevano a 170 motri sul livello del mare.

Sul lato orientale questo piano non lo conosco in verun altro luogo, nè sotto Ia forma colla quale presentasi a Monostorace, nè con altri carattori.

Si estende invece sul lato occidentale una roccia arenosa ad elementi piì o meno fini o grossolani, cementata di variabile quantiti di calcite, c ricca d'un fauma cho ¿̀ bon diversa da quella che racogliesi nelle argille grige di Ionosterace: li infatti predominano i Gasteropodi e i Lamellibranchi littorali; nelle sabbie lel lato occiden. tale invece il predominio è sopratutto pei Briozoi, e per altri gruppi o specic che accennano a profonditi un po'considerevolo del raro in cui si deponevano quello sabbio quarzose, quantunque grossolane.

Ma questi caratteri non si mantengono orunque immutabili, che anzi per gradi si passa dai sedimenti della zona coralligona ai depositi veramente littorali.

Difatti il piano di cui discorro si mesenta messo la spiaggia a P'ezzo, cioè ricino Villa S. Giovanni dove oftre tutti i caratteri di sedimento della zona coralligena, risultando dall'assembramento d'immensa quantiti di Briozoi, quali le Retoporia, le" Escharia, le Homera, le Idmonea, incrostate da grin numero di Lepralia, di Membranipora, di Diastopora, di Tubulipora, di Mlecto, di Celleporaria, o di laute altre variato forme, tra i rami e gl'interstizî dei quali spargonsi a profusiono le spoglio dei MolInschi, dei Cirripedi, degli Anellidi, dei Coralli, legli Echinidi o cosi via ria: no risulta una roceia costituita quasi per inticro da spoglie animali, in cui i Briozoi pre. sentano un grande predominio sulle altre classi, o formano esi un insieme rerumente rimarchevole e caratteristico. Tillo e con siffati carattori si prescutir il plioceno recente nelle basse colline su cui ergonsi Pezzo e Villa S. Giovami, doro assume una 
potenza ben poco rimarcherole, non oltrepassando al certo, nei luoghi dore ho po. tuto esaminarlo in tutto il suo spessore, i dieci o i quindici metri. La sua stratificazione è leggermente inclinata, e pende verso la sfiaggia, i suoi strati poggiano sul calcare coralligeno dell'Astiano e sono ricoperti dall'allurione quaternaria, clse forma in quelle contrade rasto e potente deposito.

Se rogliamo secruire altrore il plioceno superiere bisogna che rolgiamo i nostri passi verso il lato meridionale, dore amplamente si estende, clerandosi a considerevoli altezze. Difatii da sotto le sabbie marine quaternarie viene fuori estendendosi lia dore queste mancano o funono denudate. E comincia a rivelersi alla contrada Pantano nelle colline sopra Pellaro, dore costituito sempre di sabuie cementate lerfgermente, muta alquanto per la minore abbondanza dei fossili e specialmente dei Briozoi, o per la comparsa dei Brachiopodi, che si associano alle altre classi.

Un altro lembo redesi a Jiotta, dore la roccia acquista maggiol quantità di calcare e con csso maggior tenacità. Iri redesi sottostare in discordanza agli strati quaternarî marini, mentre pogegia solua l'antica formazione tongriana.

Ia la gramle massa del plioceno recente si estunle sulle colline ancor più elerate che sorgono ad est ed a unrd-est di Motta, e da quelle alture si spinge a costituire quasi uniformemente il suolo degli altipiani, che si difatano piu internamente. Dalla Rerione Leandro e da sopra S. Basilio si estende lungo le Serre del Corro e verso Pietramoliun, intemanlosi rerso la regrone Calcarella.

Su quelle alture gli strati sono d'ordinario abbastanza inclinati; le sabbie, ce. mentate furtemente, acquistano loene spesso i camtteri d' una rera arenaria, e i fossili poco abhondanti nel generale, direngono fiu numerosi in certi luoshi, accusando sempre e dormuque in quelle elevate regioni dei depsiti pressochis littorali.

Il filioceno recente su anelle estese pianure non is ricoperto d'ordinario da vemu altro terreno, se non da mu letrito euperficiale, overo dal terreno vegetale; ma nelle colline alquanto fiì dimesse esso scompare sotto il potente ammanto delle sabbie quaternarie.

In qualche linogo ben raro, nei monti che sorrastano a Jotta, riesce di redere sporgere da sotto quelle safjbie le marne dell'dstiano co'loro Brachiopodi caratteristici, ma in generale in tutta quella vastu regione gli strati del plioceno recento porriano sulle filladi paleozoiche, e per breve tratto sul calcare a Briozoi dell dquitaniano.

IIa il fatto fiir rilerante di questa formazione, che dere necessariamente attirare gli sgrumi scrutatori del geoloso, es quelio dell"elerazione rimareherolissima, alla quale essa perviene. F difatti nei honi che sorrastano a Mrotta ed a Fossato si ha una altera di oltre mille metri sul livello del mare; elevazione reramente rimareherolisima, come io dicera, per un deposito che rachinde una fauna poo dirersa dalla melitermanea.

Difatti is Ier coiffutta elerarione, es prella ancora masgriore del plioceno antico, che hisogna conchindere al lento e recente elevarsi della catena dell'A spromonte, sommersa ancora nella stia magrince jurtione alla finc del plioceno recente.

Ma sircome l'antien plio ano lelle elerate rergioni è formato di depositi di mare profondo, ed invece il blioceno recente costituito di sabbie littorali mentre raggiunge 
minore altezza, bisogna necessariamente conchiudere cho il morimento di depressione cominciato collepoca pliocenica e giunto al un massimo rimareherolissimo, si ì or. mai inrertito, ed il morimento inverso che lo sostituisce, il movimento ascensionale, era già cominciato da me pezzo, allorquando il Plioceno recente si deponera.

È questa la piì importante, Ia piì rimarcherole delle conclusioni a cui conduce Io studio del plioceno recente.

Pria di por termine all'esame di tutto quanto riguarda gli strati che riferiseo al Plioceno recente, è necessario considerare brevemente lopinione li coloro che riguardano tale formazione siceome spettante all'epoca quaternaria.

E nrimieramente ricordo come per la posizione stratigrafica. e per la faum la formazione che studio è coetauea alle argille di Ficarazzi ed al calcare tenero della pianura di Palermo, alle argille e sabbie di Livorno e di Valle Biaia, alle argille dei dintorni di Catauia, alle sabbie cementate dei lintorui di Nessina ece.

A dire il rero l'associare ma zona di strati al gruppo superiore piu tosto cho all'inferiore non è quistione per me di grande importanza, dorendo nevessariamente qualunque strato o gruppo di strati presentare analogie ed alliniti colle formazioni che l'includono, se queste le precedono e le siegriono immediatamente nell'obline crunologico; ed io sarei ugualmente propmso a rimire al Quatermario gli strati che ogsi associo al plioceno, tanto più che la fama che ricchintono somiglia molto niiu alla quaternaria anzicliè alla pliocenica; ma la discordamza col Quatermario da un canto e dall'altra parto la grande eloraziono alla quale s'innaliano seguendo molto dia vicino il plioceno, sono le principali ragioni che mi autorizzano a riunire a questiultima formazione gli strati controversi.

Paleontologia. - Le argille sabbiose di MIonosternee offrono ma fuma di mediocre profondità costituita di Gasteropodi, di Lamollibranchi, di rari Pteropoli di pochi Briozoi e di Foraminiferi.

Le sabbio cementate del lato oceidentale della prorincia ci presentano ma famma, cle come giì redemmo si modifica grado griulo dalle regioni piu basso allo piì clerate; nelle primo il predominio della fauma l'hanno i Briozoi, i quali colle loro ramificarioni intralciate formano un insieme roramente rimarcherole, al quale si associano Molluschi, Cirripedi, ed altri resti, cho acconmo eridentemente allia profonditì della zona coralligona. MIa in regioni piu elevate i Briozoi ramo diminuendo, e mano mano In fauna si riduce nelle massime alturo al un insiemo di Mrolluschi costicri.

L'elenco che siegue comprende principalmento i fossili di due localitil estreme, cioè quelli delle argille di Monosterace o gli altri dei depositi a Briozoi di Pezzo. Lo localitil di Notta e dei piani soprastanti mi hanno fornito poche specie, sia per la scarsezza dei fossili che racchindono, sia pel brero tempo che ho potuto impiegarvi per tali ricerche. Lo stesso dicasi della contrida Pantani.

I segni conrenzionali pel le localiti sono i seguenti: Monosterace, If; Villa S. Gioranui, Ti; Pantani, Pa; Motta, MLo, intendendo con questultimo anco i liani elevati che s'internano sopra quel comune; Arehi, Ar, cioe alcuni piccoli lembi che sono sopra quella contrada; Reggio, $R$, qualeho lembo sulle colline rerso 'Terreti. 
Elenco delle specic fossili raccolte nel piano Siciliano.

Tipo. VERTEBRATI.

Classe. Pesct.

Per le ragioni precedentemente addotte, i rarî llictoliti, poco comuni, raccolti in questo piano, e specialmente melle argille di Monosterace, non sono specificamente definibili.

Tipo. MOLLUSCHI.

Classe. Gasteropodi.

Balla. - 1. B. utriculus Brocchi. R. M. V.

Actacon. - 2. A. tolnatilis Lin. (Volua). Qualche giovine esemplare. R. II. V. curriculus. - 3. U. truncatulus Bruguière. (Bullu). r. M. V.

Cylichna. - 4. C. nitidula Lorin. 1. M. V.-5. C. umbilicata MItg. (Bulla).

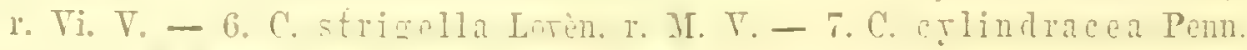
(Bulla). R. II. T.

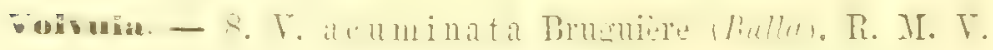

Trivia. - 9. T. Europ a a Montagu (Cypraea). R. Vi. V.

Erato. - 10. E. la eris Donoran (Toluta). r. Ar. V.

Wurenciun. - 11. M. Philippii Monts. c. Vi. V. - 12. M. clandestina Brocchi (Voluta). c. Vi. V.

Axingicula. - 13. R. a uriculata? Menard (Marginella). R. MI. V.

sitra. - 14. MI. e beu us Lamarck. r. Vi. M. V. - 15. II. I utescens Lamarck. r. Ti. V. - 16. Mi. tricolo1 Gm. r. Ti. V.

Drinlia. - 17. D. confusa n. sp. Vedi fossili astiani. r. R. V. - 18. D. Loprestiana Calcara (Pleurotome). R. II. V.

Fiomotonu. - 19. H. anceps Eichw. (Pleuroloma). R. II. V.

Aphanitoma. - 20. A. Grae i Philipri (Columbella), r. Vi. Ar. R. V.

Mnngelia. - 21. MI. clathrata M. de Serres (Pleurotoma). r. Vi. V.

Raphitoma. - 22. R. Columna Seachi (Pleurotoma). r. R. Vi.

Coinmbelln. - 23. C. rustica Lin. (Yoluta). R. Ar. V. - 24. C. scripta. Lin. (Jurex). r. R. V. - 25. C. minor Scacchi. r. R. V.

Gucionassn. - 26. C. ne lite a Lin. (Buccinum). 1. MI. V.

vassa. - 27. N. limata Chemn. (Buccinum). c. Vi. M. Ar. R. V. - 28. N. pris matica Brocchi (Buccinum). r. II. - 29. N. pusilla. r. R. - 30. N. incrassata Muller (Tritonium).r. R. V. - 31. N. Cu vieri Payraudeau (Buccinum). c. Vi. V. - 32. N. musira Brocchi (Buccinum). r. Vi. - 33. N. semistriata Brocchi (Buccinum). c. M. R. V.

Cassidaria. - 34. C. echinophora Lin. (Buccinum). r. M. V. - 35. C. thyrroua Chemn. (Buccinum). r. MI. Y.

Euthrla. - 36. E. cornea Lin. (Hurex), c. M. V. 
Pollia. - 37. P. D'0 rbign y Payraudeau (Buccimum). r. Vi. V. - 38. P. bicolor Cantraine (Hurex), r. Vi. V.

Fusus. - 39. F. rostratus Olivi (Murex). c. Vi. MI. R. V. - 40. F. pulchellus Pliil. r. Vi. Al. r.

Trophon. - 41. T. muricatus MLontagu (Murex). r. M. V.

Murex. - 42. M. b randaris Lin. r. M. V. - 43. Mr. trunculus Tin. c. Vi. V.44. M. erinaceus Lin. r. Vi. V. - 45. MI. cristatus. Brocchi. R. R. 46. M. Edwards i Payr. (Purpura). r. Vi. M. V.

Hanella. - 47. R. gigantea Lamk. 1. Vi. V.

Epidromus. - 48. E. reticulatus Blainville (Triton). c. Vi. V.

Triton. - 49. T. Partheu paeus V. Salis (Uurer).r. Vi. V. - 50. T. cor rugatus Lamk. r. Vi. M. V.

Bufonaria. - 51. B. scrobiculator Lin. (Murce). r. Vi. V.

Bвисcinum. - 52. B. "undatum Lin. Vire nei mari settentrionali. 1. Vi. M. V.53. B. Humpleysian n Bennet rar. ventricosa. r. Ar. V.

Cerithium. - 54. C. vulgatum. Brug. c. Vi. MI. V.

Cerithiolum. - 55. C. reticulatum Da Costa (Strombiformis). C. Vi. M. R. V.56. C. sc a b r u m Olivi (Hurex). C. Vi. M.Ar. R. V. - 57. C. pus ill um Jefi. (Turritella?) C. II. V. - 58. C. lacteum Phil. (Corithium). c. Vi. V.

Triforis. - 59. T. perrersa Lin. (Trochus), e var. Benoiliana Aradas. c. Vi. Ar. V. Cerithiopsis. - 60. C. tubercularis Mfont. (Hurex). r. Vi. Ar. R. V.

Chenopus. - 61. C. pespelicani Lin. (Strombus). r. II. V. - 62. C. Serrosianus Mich. (Kostellaria). c. MI. V.

Solnrium. - 63. S. Alleryi Seguenza. R. Ar. T.

Finten. - 64. N. millepunctala Lamk. c. M. V. - 65. N. intricata Donovan. R. M. V. - 66. N. fusca De Blainv. c. Vi. M. V. - 67. N. intermedia Phil. c. MI. V. - 68. N. Montacuti Forbes. Vire nei mari del Nord. l. II. Ar. V.

Enlimella. - 69. E. a cicula Phil. (Helania). 1. MI. V. - 70. E. Scillae Scacchi (Melania). 1. Vi. V. - 71. E. nitidissima Montg. (T'urbo) r. M. V.

Turboniln. - 72. T. striatula Lin. (Turbo). R. MI. V.

Pyroulina. - 73. P. brevicula Monterosato. R. MI. V.

Odostomia. - 74. 0. cono idea Brocchi (Turbo). r. M. V. - 75. 0. rissoides. Hanley. r. M. Vi. V. - 76. 0. a cuta Jefir. I. M. V.

Mathilda. - 77. M. quatricarinata Brocchi (Turbo). 1. Mr. V. - 78. M. olegantissima O. G. Costa (Trochus). r. Ar. V.

Scalaria. - 79. S. communis Lamk. r. Yi. V.

Turritella. - 80. T. commun is Risso. C. MI. V. - 81. T. tricalinata Brocchi (Turbo). c. MI. V. - 82. T. triplicata Brocchi (Turbo). C. Vi. Ar. I. M. V. vermetns. - 83. V. subcancellatus Birona. c. Vi. li. V. - 81. V. triqueter Biv. p. r. $\Lambda r^{\circ}$. V.

Inrleia. - 85. B. rubra MIont. (Turbo). r. M. R. V.

missoins. - 86. Ir. B r ug u iere Payr. (Risson). r. Vi, V.

usson - 87. R. a uriscalpium Liu. (Tumon). Y. Vi. R. V. - 88. R. simplex 
Philippi.c. Vi. V.-89. R. similis Scacchie rar. c.Vi.R.V.-90. R. rariabilis r. Mühlf. (Turbo). C. Vi. R. V. - 91. R. inconspicua Alder. r. M. Al. V. 92. R. splendida Fichw. x. M. V. - 93. R. radiata Phil. r. M. V.

Arrania. - 94. A. lactea Michaud. r. Vi. V. - 95. A. cancellata Da Costa (Turbo). c. Vi. Ar. V. - 96. A. subcrenulata Schw。r. Vi. Ar. V. 97. A. reticulata Mtg. (Turbo). r. Ar. V.-98. A. clathrata Phil. (Rissua). r. Ar. V. - 99. A. bicingulata Segnenza (Rissoc). r: Ar. V.

100. A. turritelloides n. sp. Tav. XVII. fig. 20.

Testa clongato-turrita, apice obtusiusculo; anfrucus septem, convexi et rocunduti: primi duoluevissimi, caeteri cingulis spiralibus, prominentibus, allernatime majoribus ornali; os ovato-subtrigonum.

Questa Rissou per tutti i suoi caratteri i distintissima da quante io ne conosco; la forma turrita, la scultura formata da cingoli spirali maggiori e minori alternanti la fanno somigliare ad una vera Turritella. La bocea però è propra delle lissou, di forma orata, alquanto angolosa e quasi trigona.

$$
\text { Lunghezza 2,15. }{ }^{\text {мл }} \text { Diametro } 0,95 .^{\mathrm{mm}} \mathrm{R} \text {. Vi. }
$$

101. A. cimer Lin. (Turbo). c. Vi. Ar. V. - 102. A. cimicoides Forbes (lissoc). I. Vi. Ar. M. V. - 103. A. Testae Aradas (Rissoci). c. M. V. - 104. A. punctura Montagn (Turbo), c. M. V. - 105. A. Montagui Payr (Rissoa). C. Vi. M. Ar. R. V. - 106. A. tenuicosta Segnenza (Rissoa). r. Vi. V.

Cingula. - 107. C. o btusa Cantraine (Rissoa). 1. MI. V. - 108. C. granulum Philippi (Rissoa) $=$ C. acmulc Monterosato e var. r. Vi. Ar. V.

Lisinna. 109. P. glabrata (v. Müllf.) auct. (Rissoa). r. Vi. V.

Setar. - 110. S. a ma bilis MInnterosato. r. Vi. V.

Mittorina. - 111. L. neritoides Lin. (Turbo). r. Vi. V.

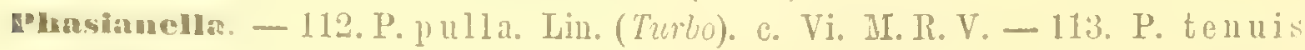
Micland. r. Vi. V.

Turbo. - 114. T. x ugosus Lin. c. Vi. M. Ar.V. - 115. T. s anguine us Lin. c. Vi. V.

Dlivia. - 116. 0. Tine i Calcara (.110nodonta), r. Vi. MI. V.

Cinnenlus. - 117. C. corallinus Gm, (Trochus). c Vi. V. - 118. C. cruciatus Lin. (Trochus). c. Vi. Ar. V.

Trochus. - 119. 'T. conulus Lin. Var. 1. Ar. R. V. - 120. T. Zizyphinus Lin. c. Vi. V. - 121. T. Gualterianus Philippi. c. MI. Vi. V. - 122. T. millegranus Phil. c. Vi. M. Ar. V. - 123. T. turgidulus Broceli. c. Vi. V. 124. T. striatus Lin. C. Vi. MI. R. V. - 125. T. exasperatus Penn. C. Vi. II. V. - 126. 1'. magus Lin. C. Vi. MI. V. - 127. T. Guttadauri Philippi. 1. M. V. - 128. 'T. Ottoi Phil. 1. Vi. V. - 129. T. elegantulus Philippi (Delphimule). Trovato a Pezzo, dove il Philippi l'avea raccolto. R. Vi.

Circulus. - 130. C. striatus Philippi ('alvater?) 1. Vi. V.

scissurens. - 131. S. crispata lileming. 1. Ti. T. - 132. S. tenuiseulpta

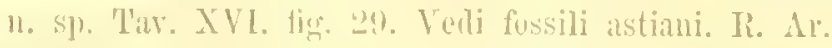

muliotis. - 133. H. lamellosa tamk. e. Vi. V.

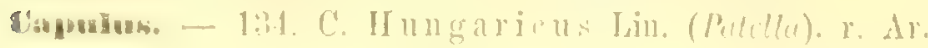


Calyptraca. - 135̃. C. chinensis Lin. (Palclla) e rar. depressa. C. Vi. II. Ar. R. V.

Dropilidium. - 136. P. ancyloides Forbes (Patclla). r. Ar. V.

Fissmerella. - 137. F. costaria (Bast.) Phil. 1. Vi. V. - 138. F. gibba. Phil. c. Vi. V. - 139. F. dolsata Monteros. r. Ar. R. V.

Fissurisepta. - 140. F. papillos a Seg. r. Vi. V.

Emarginula. - 141. E. fis u ra Lin. (Patelle). r. M. Vi. Ar. V. - 142. E. con ica Schum. r. M. V. - 143. E. adriatica 0. G. Costa. r. Vi. V. - 14.4. L. s 0lidula O. G. Costa. r. Vi. V.

Chiton. - 145. C. olivaceus Spengl. 1. Vi. V.

Acanthochites. - 146. A. discrepans Brown. (Chiton) l. M. V.

\section{Classe. Solenoconchi.}

Dentalium. - 147. D. Delessertianum Chenu. C. IT. - 148. D. rulgare Da Costa. c. M. R. V. - 149. D. norem-costatum Lamk. r. M. V. 150. D. Panormeum Chenu, r. M. V. - 151. D.agile Sars. 1. M. T.

Siphonodentaliun. - 152. S. tetragonm Brocehi (Dentalium). ‥ M. V. IIelonyx. - 153. H. subfusiformis II. Sars (Siphonodontalium). I. R. V. Cadulus. - 154. C. o v 1 u m Phil. (Dontalium). l丷. R.

Classe. Ptrioponi.

Emboins. - 155. E. rostralis Souleyet (Spirialis). r. M. V.

Spirialis. - 156. S. retrorersus Fleming (Fusus). c. II. V. - 157. S. dirersa MIonterosato. r. M. $T$.

Clcolora. - 158. C. pJramidata Lin. (Clio). c. M. Ar. V.

Classe. Lametubmanchi.

Xylophaga. - 159. X. dorsalis Turton (Teredo). r. M. Ar. V.

Gastrochoena. - 160. G. dub ia Penn. (Mya). 1. Vi. M. V.

Venernpis - 161. T. irus Lin. (Donax).r. Vi. V.

Snxicara. - 162. S. Iugosa Lin. (Hylilus). Var. arcticu. Lin. c. II. V.

Corbula. - 168. C. gib ha Olivi (Tellina). U M. Ar. T.

Corbulomya. - 164. C. meditelranea 0. G. Costa (Corbula). r. Vi. V.

Thracia. - 165. T. papy racea Poli (Tellina). r. M. V.

Cochlodesmn. - 166. C. praetenu is I'ult. (Myga). r. . II. V.

Syndosmia. - 167. S. alba W. Wood (Maclra) e rarietì. L. IL. V. - 168. S. prismatica Mont. (Ligula). I. ML. V.

Lutraria. - 169. L. elliptica Lamk. l. Vi. V.

mactra. - 170. M. colallina Tin. I. M. V. - 171. M. Subtruncata Ila Costa. c. M. V.

Mvroiliar. - 172. E. castanea Mont. (Donax). C. Ti. M. M1. Mo. V.

vesniesna. - 173. M. colil ea Poli (Mactra). r. M. Y.

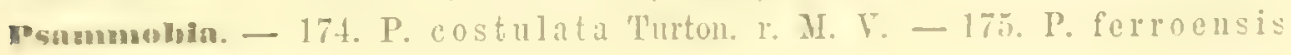
Chemn. (Tellina). (: Vi. M. V. 
Tellus. - 176. T. dona cina Lin.c.MLAr. V. - 177. T. distorta Poli. r. M. V. 178. T. pusilla Phil. c. M. V. - 179. T. pulchella Lamk. r. Vi. Ar. V. Areopagia. - 180. A. crassa Penn. (Tellina). r. II. V.

venus. - 181. V. verrucosa Lin. r. Vi. V. - 182. V. casina Lin. rodr. V. 183. V. Rusteruei Payr. 1. Ar. Vi。. V. - 184. V. effossa Bir. r. Al. V. 185. V. Messanens is Seguenza (r. fossili astiani). r. Ar. R. - 186. V. gallina Lin. c. .I. V. - 187. V. rud is Poli. r. R. V. - 188. T. Brougniartii Payr. l: Vi. V. - 189. V. opata Penn. C. Vi. Ar. R. M. T.

Dosinia. - 190. D. exoleta Lin. (lenus). c. MI. Ar. V. - 191. D. lup iu us Poli (l'enus). r. MI. Y'.

Cytherea. - 192, C. Chiolle Lin. (V'cmus). 1'. M. V.

Crprina. - 193. C. islandica Lin. (V'enus). Vive nei mari del Nord-Atlantieo. i. I. Y.

Ciree - 194. C. minima Mont. (Tenus). Con varietà. C. Ti. II. Ar. R. V.

Crassatella. - 195. C. p lanata Calcara (Astarle). 1. MI. V.

Astarte. - 196. A. fusca Poli (Tellina). c. Vi. M. Al. V. - 197. A. sulcata Da Costa (Pectunculus). c. Vi. MI. Ar. R. V. - 198. A. triangularis Mont. (Mactra). Le due rarieta a margine crenato ed a margine-intiero. c. MI. I. V. 199. A. bipartita Phil. (Lucina?). r. Vi. M. V.

Isocardin. - 200. I. col Lin. (Chama). r. II. V.

Telliell. - 201. Ir. miliaris Phil. (Venus?). C. MI. V.

Chama. - 202. C. grtphoides Lin. r. Yi. M. R. V.

Cypricardia. - 20\%. C. lith ophagella Lamk. R. Ti. V.

Corlitn. - 201. C. aculeata Poli (Chama). 1. II. R. T. - 205. C. colb is Phijl. ¿. II. R. I.

Cardiun. - 206. C. c chinatum Lim. e Var. C. Deshayesii Parr. c. MI. V. - 207. C. papillosum Poli. (. Vi. M. V. - 208. C. fasciatum Mout. r. M. V.209. C. exigum Gm. 1. M. T. - 210. C. Lamarki Reeve. C. Ti. M. R. V. 211. C. oblongum Chemn. c. M. V. - 212. C. No rog icum Spengler. c. II. V.

Diplodonta. - 213. D. a picalis Phil. (Tellina). c. Ti. II. Ar. V.

Axinus. - 214. A. croulineusis Jettr. 1. M. V. - 215. A. fer ruginosus Forbes (kellia). 1. II. V.

woollis. - 2I6. W. digitaria Lin. (Telline). C. MI. Ar. R. V.

Incina. - 217. Lo bolealis Lin. ('enus). c. MI. V. - 118. L. spintifera Mont. (Tenus). c. M. Y.

Jagonia. - 219. J. reticulata Poli (Tellinu). r. Vi. Ar. V.

Moripes. - 220. L. lacteus Lin.) Poli (Tellina). r. Ar. T. - 221. L. divaricatus Lin. (Tellina). r. Vi. MI. V.

rellia. - 622. K. suborhicularis Montag. (Mya). r. Ar. V.

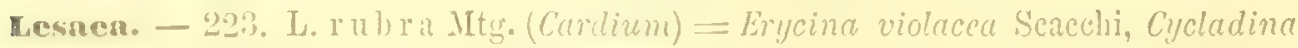
Adansonii Cantraine, Bornia seminulum Philipui. I. U. T.

vontacents. - 224. M. bidentata Montag. (Mya). 1. M. V.

septon. - 225. L. nitirum 'Turton. c. II. V. 
Area. - 226. A. tetragona Poli. c. Ar. Vi. Ar. T. - 227. A. barbata Tin. r. Ar. V. - 228. A. la ctea Lin. c. Vi. Ar. V. - 229. A. aspera Phil.r. R. 230. A. obliqua. Phil. r. Ar. R. V. - 231. A. lulehella Reere = A. imbricate Poli (non Bruguiere). r. Vi. V. - 232. 1. pectunculoides Scace. r. II. Ar. Ii. Y.

Comopsis. - 233. L. aurita Brocchi (Irca). r. II. Ar. R. V. - 234. I. miun ta Phil. (Pectunculus) r. R.V. - 235. L. p y g ma e Phil. (Pectunculus). r. R. 236. L. tenuis Seg. 1. Vi. V.

Pectumenlus. - 237. P. bimaculatus Poli (Arcu). c. M. Ar. R. Pa. V.238. P. stellatus Gmelin (Venus). c. M. R. V. - 239. P. violacescens Lamk. c. MI. V.

Vucula. - 240. N. sulcata Bromn. 1. II. V. - 241. N. nucleus Lin. (Area). 1. MI. V. - 242. N. n itida G. B. Sow. M. M. V. - 243. N. pla cen tiua Lamk. r. M. - 24t. N. decipiens Phil. Var. Aegeensis Forbes. I. M. V.

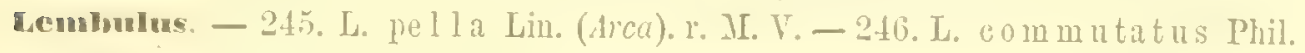
(Mucula). c. Vi. MI. T.

Voldin. - 247. Y. ten u is Phil. (Nucula). r. M. V. - 248. T. frigida Torell. R. M. $\mathrm{V}$.

Modiola. - 249. M. bar bata Lin. (Mytilus). r. Vi. V. - 250. Mr. p la a s colina I'hil, ı. Vi. M. Ar. R. V.

Nytilus. - 251. M. galloplovincialis Lamk. c. Vi.'V.

Lima. - 252. L. squamos a Lamk. 1. Vi. V. - 253. L. hi ans Gm。 (Ostreu) r. Vi. V. - 254. L. Loseombii G. B. Sow. 1. Vi. MI. V.

Limes. - 255. L. nivea (Ren.) Brocchi. r. M. Y. - 256. L. subauriculata Mont. (Pecten). c. M. V. - 257. L. o vata. S. Wood. Vive nei mari del Nord. R. R. M. V.

Pecten. - 258. P. multistriatus Poli (Ostrea). c. Pa. Vi. 1r. V. - 259. P. valus Lin. (Ostrea). c. Vi. MI. Ar. IR. Pa. V. - 260. P. opereularis Lin. (Ostren). Con diverse varieti. C. Vi. M. M L. Al. Pa. V. - 261. P. I) es f el is Lin. (Ostrea). r. Pa. Vi. Ar. V. - 262. P. pes-1utrae Limneo (Ostrea). (unesta specie rire nei mari del Nord. C. M. Ar. Pa. V. - 263. P. inflexus Poli (Ostrea). c. M. Vi. V. - 264. P. commutatus Monteros. r. Vi. V. - 205. P. striatus Muller.(non v. Munster). R. Vi. V. - 266. P. vitreus Chemn. (l'allium). r.M.Pa. V.-267. P. Testa e Birona. 1. M. Pa. V. - 268. P. sim il is Laskey.u. M. Pa. V.

Janira. - 269. J. iacobea Lin. (Ostrea). c. Vi. MLo. M. Ar. Pa. V. - 270. J. maxima Lin. (Ostrea). l. Vi. M. V.

Pleuronectia. - 271. P. fenestrata Forbes (Peclen). r. Al. V.

Spondylus. - 272. S. ga e d e rop us Lin. c. Yi. V.

PIyeatula. - 273. P. mytilina Phil. $x$. M。

Ostren. - 274. O. ed ul is Lin.c. Vi. V. - 275. O. Cylu u si Payr. r. Vi. V.276. 0. cochlear Poli. c. Vi. Pa. V.

Anomia. - 277. 1. ephippinm Lin. c. Vi. M. MI0. Ar. Pa. V. - 278. A. orbiculata Brocchi. 1. Vi. MI. V. - 270. 1. aculeata Mront. 1. M. V. - 280. A. patellifolm is Lin. c. M. Pa. V. - 281. A. striata Brocchi. l: M. 
Classe. Brachiopodr.

Terebratula. - 282. T. Scilla e Seguenza R. Pa. - 283. T. ritrea Born. (Anomia). r. R. Pa. V. - 284. T. mimor Phil. r. Pa. Vi. R. V.

wallheimia. - 285. IV. septigera Lorèn. Vive nei mari del Nord. 1 . Pa. V. Terebratulina. - 286. T. caput-serpentis Lin. (Anomia). c. Pa. Vi. Ar. R. V. negerlia. - 287. M. trun cata Lill. (Anomia). 1. Al. Pa. V.

Arsiope. 288. A. decollata Chemi: (Anomia). r. Ar. Pa. V.

Cistello. - 289. C. cistellulia S. Wood (Terebratule). R. Vi. V.

Tipo. A RT ROPOI) I.

Classe. Crostacet.

Dei crostacei superiori, frammenti indeterminabili.

Ordine. Ostricodi.

Pontocypris. - 290. P. s aggittula 'Terquem. Valr. Calabra n. La rara forma che denomino cosi, differisce dal tipo per arere il margine inferiore alquanto piin inearato, e le promineuze presso gli angoli meno distinte. R. II.

Bairchia. - 291. B. subdeltoidea Vou Munster (Cythere) $=$ B. subcleltoidea Jones. Si raccolgono, insieme alla forma comune, altre diverse varieti, fra le quali una di forma piceola, ed altra allungata che ricorda la Var. angusta 'Terquem senza somigliarla perfettamente. r. Mi. V. - 392. B. obtusata G. O. Sars. Qualche esemplare risponde alle figure date dal Brady. Var. angulosa. n. Tav. XVII. fig. 21. L'angolo postero-inferiore ì un po' più sporgente. r. MI. V.

Cythere. - 293. C. punctata Reuss (Cypridina). Gli esemplari che vi riferisco parmi che rispondano bene al tipo miocenico. I. M.

294. C. triggonata n. sp. Tav. XVII. fig. 22.

Questa specie molto somiglia alla $C$. inflata 'Terquem', dalla quale differisce per essere piir compressa, e di forma piu trigona, con m margine stretto e fornito di sottili strie radianti, colla superficie fornita di folta e sottile punteggiatura. Lunghezza 0,73 . $^{\text {mm }}$ Larghezza 0,4 . m.n $\quad$ R. II.

295. C. fove olata n. sp. Tav. XVII fig. 23.

Affine alla C. bisinuate 'Terquem, dalla quale differisce sopratutto per la scultura formata d'infossature piuttosto grandi; la regione anteriore is strettanente marginata.

$$
\text { Lunghezza } 0,750^{\mathrm{mm}} \text { Larghezza } 0,300^{\circ} \mathrm{mm} \quad \mathrm{R} \text {. M. }
$$

296. C. su ba e clualis n. sp. 'lay. XVIl. fig. 24 e $24 a$.

Forma pressochè ellittica. margine anteriore arenato, regione posteriore somi-. gliante e quasi nguale all'anteriore, ma alquanto piu stretta, entrambe fornite d'un margine pinttosto largo ed appianato. Superficic regolarmente conressa e fortemente puntegriata.

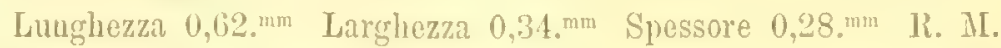

297. C. asperima Reuss (Cypridina). I conservatissimi esemplari raccolti rispondono bene al tipo miocenico d'dustria, taluni soltanto sono piì allungati di 
forma e presentano spine piu lunghe, ma si collegano ai primi per gradazioni intermedie. c. II.

298. C. rarepunctata n. sp. 'Tir. XVII. fig. 23 e $25 \pi$.

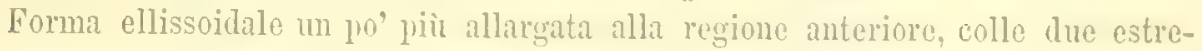
mità marginate, margine appianato e foruito d'una serie d'infossamenti regolari c regolarmente circoscritti. L' esterno delle valve è regolarmente convesso, colla superficie lerigata e fornita di rare muntegriature.

Lunghezza 0,5. mm Targhezza 0,25. ${ }^{\text {mm }}$ Spessore 0,25. m. $^{\text {m. }}$ R. M.

299. C. rostrata 11. sp. Tav. XVII. fig. 26 e 26 .

È questa affine alquanto per la forma alla C. fornicala Terquem; dalla qualt" distinguesi per essere meno convessa, per la prominenza posteriore piì sporgente e più acuta, per la superficie finamente reticolata; le valve presentano un margine distinto, il quale si allarga molto alla regione anteriore formando una cintura depressa.

Lunghezza 0,68. mm Larghezza 0,31.mm Spessore 0,17. $\mathrm{mm}$ R. IT.

300. C. foliacea n. sp. Taw. XVII. fig. 27 e $27 n$

Questa specie è ben distinta per la regione anteriore molto larga col margine arcuato, e per la regrione posteriore ristretta, in morlo che la forma generale risulta cuneiforme; la superficie convessa si appiana rerso le regioni estreme, ed è rugoso-papillosa, e tali prominenze divengono più sporgenti, lamelliformi e si associano ordinandosi parallelamente al margine sulla regione anteriore, la qualc risulta quasi fogliettata.

Lunghezza 0,73. ${ }^{\mathrm{mn}}$ Larghezza $0,45 . \mathrm{mm}$ Spessore 0,35. mm R. M.

301. C. cordiform is Terquem. Gli esemplari che rapporto a questa specie rispoudono abbastanza bene alle figme date dall'autore, e mi fanno chiaramente riconoscere come la specie del Terquem è molto affine alla mia C. subtrigona. l. MI. 302. C. parva 11. sp. 'liar. XVII. fig. 28 e 28a.

Piccola specie di forma cuneata, stretti posteriormente e molto larga, col margine areuato anteriormente, appianato e radiatamente pieghettato. Superficic convessa, piì elevata alla regione posteriore, dove si ofrrono due pieghe longitulimali poco distinte, e ormati da piccole rarricinate infossature.

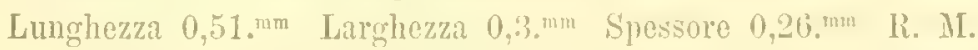

303. C. Edwards i Roemer (Cypridina). Poco diversa dalla forma miocenica, earene longitudinali alquanto oblique, margine anteriore con rari dentelli. r. MI.

Crtheridea. - 304. C. subrostrata? Costa (Cytherina). Riferisco con dubluio a questo genere ed a questa specio una sola valva, che ha forma alquanto piì. allungata di quella illustrata dal Costa. R. II.

Iyoloates. - 305. I. bartonens is Jones. Var. Monosteracensis. 11. 'T'ur. XVII. fig. 29 e $29 a$. Sembra a me che querta forma non possa specificamente disgiungersi dalla rivente dell'Atlantico e dei mari del Nord; essa infatti parmi che difleriscal soltanto per arere langrolo infero-posteriore piu distinto e percio ben mareato.

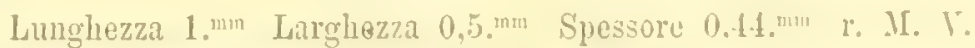

306. I. compressa n. sp. Tar. XVII. fig. 30 e $30 a$. 
Specie affine alla precedente per la forma generale, ma molto più compressa. coi margini superiore ed inferiore pressochè retti e paralleli, in modo clie le valve si restringono lievissimamente rerso la regione posteriore; Ia quale si termina troncata obliquamente e con un angolo ben prominente e rotondato alla regione infero-posteriore. La superficie è lerigata.

Lunghezza 0,83 . $^{\mathrm{mn}}$ Larghezza $0,360^{\text {mnt }}$ Spessore 0,2.mn R. M.

Loxoconelas. - 307. L. implessa Baird (Cythere) $=$ L: rhomboidea G. O. Sars. Di questa specie che si raccoglie in abbondanza, si trotano le diverse modificazioni dipendenti dal sesso, dall'etì e dalla rariabilitit della specie. c. II. V. 308. L. granu lata Sars. Riferisco con dubbio a questa specie qualche esemplare. R. M. V. - 309. L. elliptica Brady. Anco questa mi offerse esemplari dubbî e radi. R. M. T. - \$10. L. tamarindus Jones (Citherideis) = L. longipes G. O. Sars. Questa sprecie parmi risponda benissimo alle figure del Brady, soltanto il margine distinto è alquanto piì largo. I. M. V.

xestoleberis. - 31 i. X. a urautia Baird (Cythere) $=$ Cythere nitida Lilljeborg. Riferisco a questa specie qualche raro esemplare. IR. M. V. - 312. X. depressa G. O. Sars. Qnesta specie risponde bene al tipo.c. M. V.- :313. X. angustata Terquem. Rapporto con dubbio a questa forma qualche raro esemplare. R. Ir.

314. X. pustulosa n. sp. Tav. XVII. fig. 31 e 31 .

Questa specie per la forma può dirsi proprio intermedia tra la $l_{\text {. a }}$ arantia e la X. pyriformis Terquem, rariando considerevolmente uella gibbosita, specialmente della regione posteriore, ma mantenendosi anco in questo carattere intermedia tria le due. La superficie poi è speciale perehè irta di pustolette equidistanti e non molto ravricinate.

Lunghezza $0,57 .{ }^{\mathrm{mm}}$ Larghezza $0,34 .^{\mathrm{mm}}$ Spessore $0,35 .{ }^{\mathrm{mm}} \quad$ c. $\mathbf{M}$.

Cytherura. - 315. C. striata G. O. Sars. Qualche raro escmplare. R. MI. V.

Parodoxostoma. - 316. P. hibernicin m? Brady Riferisco con molto dubbio a questa specie un solo esemplare. R. II. V.

Cytherella. - 317. C. Brad yi n. sp.

Questa specie èmolto afline alla C. scotica Brady ed alla C. pulchra Brady. Si avvicina alla prima per la forma generale e per la punteggiatura poco manifesta della superficie, alla seconda somiglia di più per avere il margine posteriore prominente, per Ia somiglianza del contorno ed anco per la forma generale, ma distinguesi per essere piiu breve, 'e per arere la maggiore spessezza assai presso il margine posteriore, dove, guardando la conchiglia di profilo, si vede che la superficie forma un'angolosita sopra ciascuna valva.
Lunghezza 0,75 .
Larghezza 0,48 .
Spessore 0,31 .
R. II. V.

318. C. Calabra n. sp. 'Tar. XVIL. fig. 50 e $56 a$.

Questa specie importante o ben distinta, è rarissima in questo piano, ed invece abbondante nel Quatemario, pereiò ì ivi che la descriro. R. H.

\section{Orline Cirrsped.}

Balauns. - 319. B. tulip iform is Hllis. 'Trovasi in esemplari completi mancanti sempre degli opercoli. r. Pa. r. 
Exehylaswn. - 320. P. gigantenm Pliil. (Chlamalus). Si trora in valvedisgiunte. 1. Vi. Pa. T.

veruea. - 321. V. stromia Ifuller. Questa specie grince in esemplari grandi, conservatissimi, sorente forniti del loro opercolo. mresso Pezzo, dove trovansi aderenti a rarie conchiglie e Briozoi, ma più spesso al Hytilus galloprovincialis, ed alle Relepora. r. Vi. MI. Ar. R. Pa. V.

'lipo. VERMI.

Classe. $\Lambda$ Nehridom.

Psygmolnanchus. - 329. S. p lo otensus Gmelin. (Serpula). Vi riferisco qualche tubo poco flessuoso, e con superficiali ed irregolari solehi trasversali. r. MI. V.

Fuigrana. - 323. F. implexa Berkeley = Serpula flograna Lim. Trovansi dei grandi ammassi di questa specie a Pezzo presso Villa S. Gioranni, c. Vi. V.

Spirorbis. - 324. S. corrugatus Montagu (Serpula). Un esemplare. li. M. V. 325. S. gran u atus Lin. (Serpula). 1. Al. V. - 326. S. Lacvis Quatrfy. 1. Yi. II. Y.

Ditrupa. - 327. D. incurta Renier (Dentalium). I. MI. R. Pil. - 308. D. subu lata Deshayes (Dentalium). I. M. Pa. Mo. R. IT.

Clnsse. Briozodrin.

Salieormarin. - 329. S. farciminoides Johnston = Tubularic fistulosa Linneo, Cellaria salicornia Lamk. Qnesta polimorfa specie presentasi sempre e dapertutto colle sue rariate forme. c. M. Vi. Pa. Ar. V.

Serupocelraria. - 330. S. serupea Busk. M. M. V. - 331. S. scruposa Lin. (Sertularia). In reriti, come ben dice il Manzoni, queste specie poco difleriscono dalla S. elliptica Reuss, molto comme nei precedenti piani. r. Vi. V.

Myriozoon. - 332. Mr. tru u a $t$ um Pallas (Millepora). Comunissimo tra i riventi rel Mediterraneo. r. ri. Ar. Kr. Pa. V.

mippothon. - 333. H. catenularia Jameson (Tubipora) = II. catomularia Fleming. Trovasi sul .bytilus galloprovincialis, sulla Retcpora cellulosa Lin. e sui ciottoli. r. Vi. V. - 334. H. divaricata Lamouroux. Raccogliesi non troppo raramente sulle Nullipore e sulla Modiola phaseolina. 1. Vi. V. 335. H. flage 11 u manz. La maggior picciolezza delle cellule, e la lunghezza grande degli esili canali distinguono bene questa dalla precedente specie. Incrosta le Nullipora e la Modiola phaseolina. c. Vi. Ar. V.

Acten. - 336. A. sica Conch. Sulle Nullipora o sulla Eschara foliacea. r. Vi. Ar. V. - 337. A. anguina Lin. (Sertuleria). Sull' Escharre Poliacea e sulle Retepora. 1: Ti. V.

Calocere. - 338. C. Bory i Audouin (Crisia) = C. Boryi Busk. Si trorano raramente i frammenti dei gracili fusticini di questa bella specie, che ho trosato rivente nei fondi coralligeni dello stretto di MLessina. 1. Vi. Y.

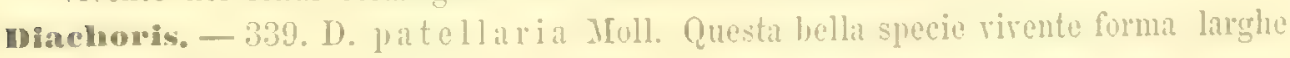
incrostazioni sulle villipora. r. Ti. IT.

gembronipora. - :30. M. aperta Busk. Questa specie pami irlentificarsi 
bene colla forma eosi denominata dal Manzoni. Sulle Retepera e le Nullipora. r. Vi. - 341. M. irrogularis Smith. Aneo questa concorda colla forma che vi riferisce il Manzoni. r. Vi. Y. - 342. M. I ineata Lin. Mollo variabile. conserva talrolta sinanco le spine orali. Incrosta le Retepora, le Eschara, le Nulliport, il Myriozoon truncatum. c. Vi. V. - 343. II. P ou illeti Busk. La mia risponde molto bene alla forma del Crag inglese. Incrosta un' Lschara e l'Anomia ephippium. r. Vi. - 344. M. Rosselli Aud. Qualche colonia sulla Janira maxima. I. M. V. - 345. MI. angulosa Reuss. r. Ar. Pa. V. - 346. MI. annulus Mamoni.r. Pa. - :34. II. Smithii. Manzoni. Questa fu trorata dal Manzoni a Pezzo presso Villa S. Giorami. r. Vi. - 348. M. calpells is Busk. Sul Mytihes edulis e la Lischara foliacea r. Vi. V. - 349. M. papyracea Reuss. Risjonte hene come al tipo cosi alla figura e descrizione data dal Waters. Sul Pectunculus bimaculalus e sulla Janira jacobea. r. Ar. II.

Lepralia. - 350. L. coceinea Jonst. Le colonie di questa specie nel Plioceno recente presentano le cellule grandi e colla superficie fortemente scolpita come nelle viventi; esse incrostano la Modiola phaseolina, il Mytilus galloprovincialis, il Myriozoon trunciatum, le Retepora e le Nullipora. c. Vi. V. - 351. L. innominata Conch. Le cellule, come arviene d'ordinario in questa specie, sono irregolari e rariabili molto nella forma. Incrosta la Hodiola phaseolina, la Janira maxima, e lo Nullipora. r. II. Vi. V. - 352. L. seripta Reuss. Sulle Nullipora. Questa specie presenta delle rariazioni per le quali fa credere che dehbasi realmente associare alla precedente siccome ppina il sig. Waters. 1* Vi. Ar. Pa V. - 353. L. planicosta n. sp. (redi fossili zancleani). Questá forma illustrata dal Manzoni parmi distinta dalla precedente per le cellule allungate, alphianate, fornite di costole radianti rarricinate e umerose. Sul Mylilzs gulloprovincialis. $\mathrm{x}$. Vi. - 35t. L. a n s a ta Johnston. Diverse forme e rarieti. Sul Myriozoon truncalum, sul Pecten opercularis, sulla Janira maxima ecc. I. Mr. Ar. Vi. V. - 355. L. Bronguratii Aulonin. Varie forme di quelle che suole assumere tale specie, tra esse ì rimarcherole una che presenta assai pronunziate c quasi regolari le pieghe trasversali. Sulla Modiola phaseo'ina, sul Iyytus galloprovincialis, e sulle Nullipore. 1. Vi. V. - 356. L. riolacea Johnston. Trovasi sul Pectunculus bimaculatus sul Pecten opercularis, sulla Janira marima. sul Mytilus galloprovincialis, su d'una Serpula, sul Myriozoon Iruncalum. x. MI. Vi. Ar. V. - 357. I. ciliata Pallas. Sul Hytilzes galloprovincialis, sulla Eschara foliacea, e sulle dullipord. 1. Vi. V.

358. T. Calabra 11. sp. (verli fossili zancleani). Iíferiseo a questa specio, non senza dubbio, qualche colonia osservata sulla Hodiola phaseulina. R. Vi. - 359. L. Morrisiana Busk. Sulle Repera. r. Vi. - 360. L. Malusii Audouin. Iiproduce esattamente la forma del I'lioceno antico, come quella vivente. Incrocrosta l'Anomia ephippium, le lietepora e lo kulliposid. c. Vi. T. - 361. L. linearis Hassal. Grandi colonie costituite da cellule larghe ed appiamate. Sulle Retepora e le Nullipore. 1. Vi. V. - 362. L. reticulata 13usk. Variabile molto come negli strati quaternarî c nelle colonie viventi. Trovata sul Peclunculus bimaculatus sul Pecten operculuris, sulla Junira maxima, sul Mulilus galloprov. 
e su molti Briozoi muosi. c. Vi. M. V. - 363:?. I. encullata Busk. Questa specie ricorda presso a poeo la forma virente illustrata da Waters. Incrosta le Nullipora. r. Vi. V. - 36t. Is. pelotusa Johnston. Incrosta rarie specic di Briozoi: Eschara, liyriozoon. Reteporu, ec. r. Vi. V. - 365. L. tencra Reuss. Riferisco a questa specie miocenica una colonia che incrosta l' Anomiu ephippirm. R. Vi. - 366. L. rudis Manzoni. Sulle Retepore. r. Vi. - 367. L. ligulata Manzoni. Sul Mytilus gallomorincialis. r. Vi. - 368. L. Peachi i Johnston. Riferisco alla specie dol Crag inglese alcune colonie che incrostano il Mytilus galloprovincialis e la Lischara cervicornis. I. Vi. V. - 369. L. rentricos a Hassal. Questa specie incrosta lia Modiolu phaseolina. l'Eschara foliacea, le Nullipora, le Retepora ec. c. Vi. V. - 370. L. obelis cus Mauzoni. Riferisco a questa specie qualche colonia impiantata su d' un Balano. R. Vi. 371. L. Iata Busk. Trorata sul Pecten opercularis. R. M. V. - 372. L. cupulata MLanzoui. Sul Trochus exasperatus. 1. Vi. V.

373. L. stellata? n. sp. Aleme colonie di Lepralia, non troppo bene conservate, ricordano per la disposizione delle cellule la nominata specie zancleana, ma tale ravricinamento non è sicuro. 1 . Vi.

374. L. thiara u. sp. Tar. XVII. fig. 57 (redi fossili quaternarî). R. Ti.

375. L。 intricata 11. sp. Tar. XVIL. fig. 32.

Questa forma è veramente rimarchevole. Le sue piccole collule sono come squamette incrostanti, che hanno una carena mediana più o meno distinta, da dove irradiano cinque o sette costole irregolini e prominenti. Ia bocea piu o meno arrotondata trovasi sorente infossata allorchè le cellule sono piir sporgenti. Lo sviluppo delle colonie e l'ordinamento delle cellule è d'ordinario irregolare. Incrosta il Mytilus galloprovincialis. $\mathrm{r}$. Vi.

Celleporaria. - 376. C. tubigera Busk. Questa specie si presenta colle molte sne variazioni conoscinte nel plioceno e nei mari attuali. C. Vi. M. Ar. Pa. V. 377. C. c o ron op us S. Tood. Quintunque dubbiamente, pure dalla forma allungata e ramosa sono indotto a riguardare questa specie come identica a quella del Crag inglese, ed alla comune di Ficarazzi esaminata dal Manzoni. 1. M. Vi. V. 378. C. Hassalii Johnston. Questa specie ì stata illustrata assai hene e deseritta minutamente dal Manzoni. c. Vi. V. - 379. C. digitata Waters. 'Trovata dall'autore virente nel golfo di Napoli. Incrosta l' Eschare? cerviconis. l. Vi. V. - 380. C. Iobatula Waters. Vive nel golfo di Napoli. r. M. V. 381. C. systolostoma Manzoni. Varia considererolmente siccome noto lo seopritore. Inerosta le Nulliporce e lia Janive Jacobca. c. M. Vi. - 38:. C. I'amulosa Lin. Distinta e gracile forma. C. Vi. V.

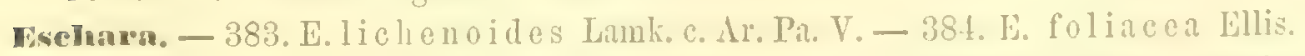
Questa specie comunissima is Pezzo presso Villa S. Giorami occorre qualche volta in forma incrostante in un solo strato alla maniera di una rera Lepralict sicome la incontro virente nel golfo di Napoli il Waters. C. Vi. Ar. Pa. V. -

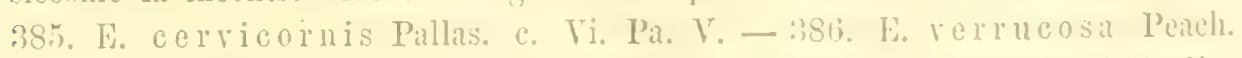
Questa specie anch'essia virente nel Mediterineo is stata illustrata e lettagliattamente descritta dal IVaters. 1. Vi. Ir. V. 
metepora. - 387. R. cel1ulos a Lin. Nella localita di Pezzo questa specie abbondantissima fra le tante, si presenta sovente conservatissima, staccata dalla roccia sabbioso-calcarea che l'include, ed incrostata da mille altri Briozoi. C. Yi. Ar. Pil. T.

Crisia. - 388. C. fistulosa Heller. Trorasi come le altre specie in piccoli frammenti. c. Vi. V. - 389. C. el ongata. M. Edwards. Trorasi di unita alla Var. angustala Waters. r. Vi. M. V. - 390. C. eburnea Lin. r. Vi. V.

Iomones. - 391: I. atlantica Forbes. r. Vi. V. - 392. I. notomala Busk. Riferisco a questa specie con qualche dubbio pochi esemplari. r Vi. V. -393. I. irregularis Menegh. Qualche solo ramo nelle argille. R. M. V. - 394. I. Me in ghini Heller. Questa specie si presenta in belle ramificazioni sorente impiantate sulle Retepora e circondate e protette dalle stesse, in modo che sono rimaste perfettamente libere e quindi non impigliate nella roccia. c. Vi. V. 395. I. concava Reuss. Trovata rivente dal Waters nel golfo di Napoli. R. M. V.

Pustulopora. - 390. P. proboscidea E. Forbes. Qualche rano. r. M. V.

Alecto. - 397. A repens Wood. Sul Mitilus galloprovincialis, sulle Retepord e le Nullipora. r. Vi. Ar. Pa. V.

Tubulipora. - 398. T. flab ellaris Fabr. Sul Mytilus. r. M. Vi. T. - 399. T. phalangea Couch. Sul Myriozoon e sulle Nullipora. r. Vi. T. - 400. T. serpens Linn. Sul Mytilus, sul Myriozoon e sulle Nullipora. r. Vi. V. 401. T. palmata Smith. Sul Mytilus, sulle Retepora e le Nullipord. 1. Vi. V. 402. T. ventricosa Busk. Sulle Nullipora. R. Vi. V.

Diastopora. - 403. D. latom a rginata D'Orb. Aderente ai Mytilus ed alle Nullipora. r. Vi. Ar. V. - 404. D. simplex Busk. Sul Mytilus e le Retepora.r. Vi. V.

Discoporellar. - 405. D. radiata Aud. Sulle Nullipora. 1. Vi. Ar. Pa. V. 106. D. verrucaria Fabr. Sulla Modiola phaseolina e sulle Retepora. r. Vi. II. V. - 407. D. hispida Flem. Sul Mytilus galloprovincialis. r. Vi. V. 408. D. mediterranea Blainville. Sulle Relepora e le Nullipora. r. Vi. V.

Fromdipors. - 409. F. reticulata Blainv. Questa comunissima specie del Mediterraneo trovasi in belli e conservati esemplari nei depositi di Pezzo. c. Vi. V.

Ceriopora. - 410. C globulus Reuss. Vi rapporto con qualche dubbio una sola colonia. R. MI.

\section{'I'ipo. ECHINODERMI.}

Classe. Foninin. - Ordine. Regolari.

Dorocidaris. - 411. D. papillata Leske. (Cidaris). Frammenti di guscio e di radioli. 1. Vi. Ar. V.

Ordine. Ctipeastroidi.

Fehinocyamus. - 412. H. pusillus Muller (Spatungus) = Fibularia equnna Aradas, fibularid larentina. Lamk. r. M. Vi. V.

Ordine. Spatangoidi.

Dne Echinidi di quest' ordine mecolti nei piani sopmin Mottal, sono specialissimi perchè conservano aderenti cel in ottimo stato tutti i gracili radioli; pure, 
essendo incompleti, la loro determinazione specifica riesce impossibile, quantunque sia evidente che l' mo spetta al genere Echinolampas e l'altro al genere Schizaster.

Tipo. CELENTERATI.

Classe. Antozon rir. - Ordine. Zoantarir.

Corallinm. - 413. C. r u brum Lin. r. Vi. V.

Astroides. - 414. A. caly cularis Pallas (Madrepora). r. Vi. V.

Classe. Spongiarit.

Varie spugne perforanti da studiarsi.

Tipo. PROTOZOARIE.

Classe. Rizopodi. - Ordine. Forduniferi.

Lagema. - 415. L. globosa Walker (Serpula) = Oolina lacvigala D'Orb.. EnLosolenia globosa Williams. Varie forme piil o meno globose. r. IC. V. - 416. L. v ulgaris Williamson. = Phialina oviformis Costa L.lacvis MIontg. (Vermiculum), Phialina propinqua, ovata, longirostris Segnenza. Questa specie presenta quella variabilita che suole addimostrare si vivente che fossile, e tra le tante forme che vi riferisco ve ne ha taluna molto allungata e gracile. Var. semistriata Will. c. M. V. - 417. L. emaciata Reuss. Uu solo esemplare che ricorda presso a poco la figura data dall'antore. R. MI.

418. L. maculato-punctata n. sp. Tiv. XVII. fig. 33.

Questa specie ricorda per la sua forma e la punteggiatura la L. oxystoma Reuss e si distingue per la punteggiatura più forte e piì rarricinata cl inoltre per talume macchiette bianche sparse su tutta la superficie.

Lunghezza $0,85 \mathrm{o}^{\mathrm{mm}}$ Diametro $0,560^{\mathrm{mm}}$ r. M.

419. - L. clavata D'Orb. Una forma considerevolmente allungata. R. II. V.420. L. striata D'Orbigny (Oolina) $=$ L. gracilis Will., L. gracilicosta Reuss. Questa bella e distinta specie è variabilissima nella forma più o meno globosi ovvero allungata. c. M. V. - 421. L. Gem mell arii Seg. (Phialina). r. M. 422. L. cylindracea Seg. (Phialina). r. II. - 423. L. filicosta Reuss = L. striata Will.; L. perlucida Will. (parte), L. inlervupte Will. Distinta pel lungo tubo e le rare costole. r. II. V. - 424. L. sulcata Segnenza (Oo'ina) = Oolina Isabella D'Orb., O. ravicosta D'Orb., Phialina lagena Seg'uenza, O. Villardeboana D'Orbigny. r. II. V. - 425. L. gracilis Williams. = L. confustissima, L. lepida Reuss. Qualche esemplare ben mareato. 1. MI. V. - 126. I. apiculata Reuss (Oolinu) $=$ Ourelina caudigera Seg. Fisemplari di forma piu 0 meno globosa. r. M. V. - 427. L: c a u d a ta D'Orbigny (Oolinci). R. M. V. 428. I. distoma-polita Parker et Jones. Forma molto rariabile in gracilitit. r. M. V. - 429. I. distoma Parker et Jones. IR. M. V.

430. L. decorata n. sp. Tar. IVII. fig. 12 (redi i fossili dell'Astiano). Uún solo esemplare. R. M. - 431. L. melo D'orb. (Oulim). L. II. V. - 43.. L. scalariformis Will. (Entosolenia). 1. M. Y. - 433. L. marginata Walk. 
(Serpula $)=$ Oolina compressa D'Orbigny, Fissurina simpler, delloidea, communis ed altre forme, Segnenza. Questa specie immensamente rariabile olive diverse delle sue forme. c. II. V. - 434. L. I u cịa Will. (Enlosolenia) = E. marginata var. quatrata Will. I. MI. V. - 435. L. lagenoides Will. (Entosolenia). 1. M.V. 4:30. L. ma re inato-radiata n. sp. 'Tar. XVII. fig. 35.

Questa specie analoga alla L. marginata presenta un tubo prominente e delle linee che irradiano dalla base a difterenza della L. radiato-marginata nella quale le linee irridiano dal centro verso tutta lia periferia.

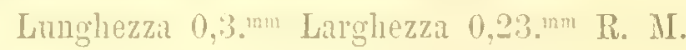

437. L. marginato-perforata n. sp. Tar. XVII. fig. 34.

La conchiglia è li forma orato-compressa, marginata, prolungata in forma di tubo alla regione anteriore e colla lamina che la costituisce perforata da grossi forami. Una rarietì più piccola presenta più minute perforazioni.

Luugluezza $0,37$. mm Larghezza $0,24$. . $^{\text {nm }}$. r. MI.

Nissurina. - 4:38. F. s quamoso-marginata Parker et Jones (lagena).r. Mr. V. 439. F. diptera n. sp. Tar. XVII. fig. 36.

Questi esile conchiglietta si distingue per la sua natura ritrea e trasparente, per l'interno tulo, e pel prolungamento della lauina marginale in due ali in forma di acmminati speroni, che si dirigono posteriomente dirergendo. Lo spazio interposto è oceupato da due dentelli.

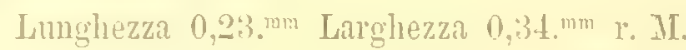

Todossura. - 440. N. raphanus Lin. (Nautulus). R. MI. V. - 441. N. longicauda D'orbigny. Tar. Questa è la forma a tenui costole. R. MI. V. - 442. N̦. antenn ula Costa. Vi riferisco con dubbio taluni esempliuri incompleti e frammenti. r. M. V. - 443. N. s ubaequalis Costa. r. MI. V.

444. N. nerforata n. sp. Tar. XVII. tig. 37.

Questa specic ricorda per la forma la precedente, ma le sue logge crescono con molta regolarita; lil prima ò arrotondata, l'ultima è un pos sporgente alla regione anteriore, ma il carattere che ben la differenzia è la forte perforazione. Lunglezza $1 .{ }^{\mathrm{mm}}$ Diametro $0,25 . \mathrm{mm} \mathrm{l}$. MI.

445. N. radicula Lim. (Yautilus). Ouesta specie par che facci passaggio alle Glundulina siecome dimostrarono i sigg. Parker et Jones. r. N. V.

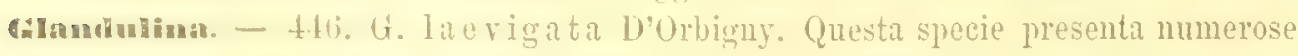
rariazioni nella forma piir o meno glohosia 0 allungata. c. M. T. - 447. G. ad un ea Costa. Vi riferiseo un solo esemplare un pro' meno gracile. R. MI.

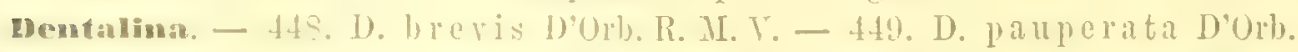

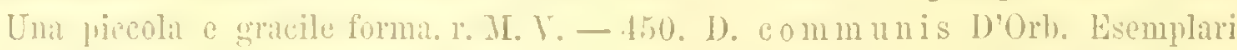

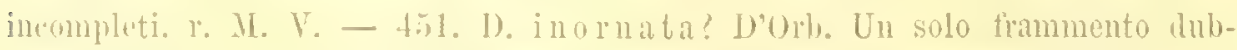
hio. li. IL. V. - the. I). nodosa Dophigny. Alemi frammenti. K. M. V. -

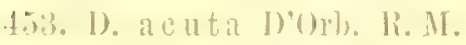

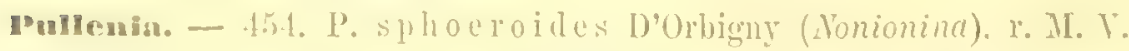

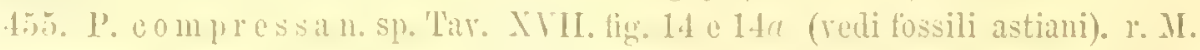

Vonionina. - 456. N. Soldani D'Urbigny. 1. Mt. V. - 457. N. umbiliea. tula Montagu. r. Mr. V. - tos. N. subealinata Seguenza. R. M. 
Polystomella. - 459. P. crispla Limn. La forma tipica colle sne rariate modificazioni. C. MI.T. - 460. P. macel1a Fich. et MIoll. (Nautilus). 1. M. V. - 461. P. subumbilicata Czizeck. Due esemplari che rispondono molto bene al tipo, una lieve differenza si nota nella estenzione un po' minole dei solchi che trasversalmente segnano la superficie nelle direzioni dei tramezzi. r. M. - 462. P. striatopunctata Fichtel et Moll. (Nautilus). 1: M. V.

463. P. minima n. sp. Tav. XVII. fig. 38 e $38 a$.

Questa piccolissima specie porta circa dodici logge apparenti, lievemente convesso all'esterno e disgrimte da superficiali solchi punteggiati che imadiano un po'obliquamente. Il margine della conchiglia presentasi un po'assottigliato e quindi ottusamente carenato. La regione centrale leggermente infossata e cinta da una serie di piccoli incari elegantemente disposti che caratterizzano bene questa specie.

Diametro 0,1.mm Spessore 0,04.mm R. II.

Amphistegina. Alcuni mal conservati esemplari sembra che appartengano a questo genere, ma sono indeterminabili. R. II.

Maraimulina. - 464. M. glabla D'Orbigny. M. M.V. - 465. M. sinilis I)'Orbigny. R. M. - 466. MI. contraria Czizek. Rapporto a questa specie un solo esemplare, il quale differisce alquanto dalla forma tipica solo perche ha le tre nitime logge alquanto più globose. R. M.

Cristellaria. - 467. C. cre pid u la Fichtel et Moll. (Aculilus). Forma molto allum gatil. 1. M. V. - 468. C. a reuata D'Orbigny. Belli e distintissimi esemplari. r. M. - 469. C. virgata D'Orbigny. R. M. V.

Roluulina. - 470. R. eultrata D'Orbigny. R. M. V. - 471. R. calcar D'Orlo. Forma quasi priva di prominenze marginali. R. M. V. - 472. R. rotulata Lank. R. M. V.

Polymorphina. - 473. P. la etea Walker et Jacoh) (Scrpula). Varie modificazioni. c. ML. V. - 474. P. commun is D'Orb. (Gullutina). 2. ML. V. - 475. I'. amygdaloides Terquem (nou Reuss). I miei esemplari rispondono bene colle figure dell'antore. 1. M. - 470. P. gutta D'Orbigny. R. M. V. - 177. P. oblonga Williams. R. IT. T. - 178. P. complessa D'Orbigny. Colle logre quasi globose non allungate. 1. M. V.-479. P. compla na ta D'Orhigny. Forma intermedia tra la miocenica del bacino di Viema e la pliocenica del Crag inglese. r. Mr. - 480. P. tubulosa D'orbigny. Qualche esemplare porta l'apparato dei tubi molto sriluppato e completo. r. M. V.

vvigerina. - 481. U. p Yg maca Dorhigny. Diverse forme trovansi insieme nel medesimo giacimento. r. II. V. - 482. U. nodosa D'Orbigny (Stegrina). r. M. V.

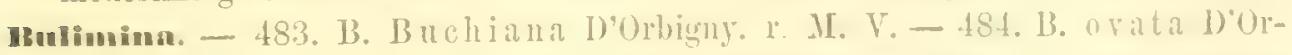

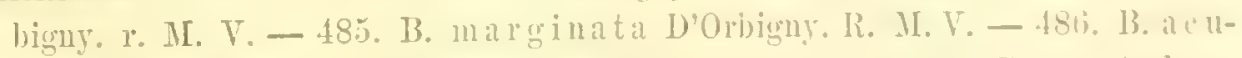
leata Dorbigny. $=$ B. spinosa Seguenza. r. II. V. - 187. B. lustulosia Costa. Riferiseo con qualclue dubbio a questa speeie un solo escmplare alquanto più rigonfio. R. II. - 488. B. pylula D'Orbigny. Di unita allat forma tipica si vedono delle forme che ammerano una grachaione rerso talume moditicarioni o più brevi e globose o più allungate. c. ML. V. - 489. 13. 1 r unella Costa (Gutlulina). Molto rariabile. c. MI. - 490. B. mutabilis Costa (Gultulina). M. M. 
Spheroidina. - 491. S. bulloides D'Orbigny. I. M. V.

Enlvinulina. - 492. P. punetulat a D'Orb. (Rotalina), r. M. V. - 493. P. auricula Ficht. et Moll. (Nautilus). x. MI. V.

IBotalia. - 494. R. Becurii D'orbiguy. Variabile molto nei diversi caratteri. C. II. Pa. V. - 495. R. a m m on if or m is D'Orbigny. Questa è forma che dorrì associarsi alla precedente dalla quale differisce ben poco. I. M. V. -496 . R. Soldani DOrb. Bella e distinta specie. r. MI. V.

Orbulina. - 497. O. universa D'Orb. Taria in grandezza. C. M. V.

Clobigerona. - 498. G. bulloides D'Orbigny. C. M. V. -499. G. Aradasii Seguenza (Rolalia). c. MI.

500. G. gomitulus n. \$p. Tav. XVII. fig. 16 e 16a. (vedi fossili astiani). r. M. - 501. G. helicina Worbigny. r. M. V.

502. G. oroidea n. sp. Tav. XVII. fig. 39.

Questa specie si distingue per la forma oroidale, essendo costituita esteriormente da due sole logge poco difterenti e disgiunte da una sutura poco profonda e non da un rero restringimento.

Lunghezza 0,84. ${ }^{\mathrm{mm}}$ Larghezza $0,64 \mathrm{~mm}^{\mathrm{mm}} \mathrm{x}$. M.

Discorbina. - 503. D. globularis D'Orbigny(Rotalia). C. I. V.

Truncatulinas. - 504. T. 10 bat u la D'0rbigny. Variate forme. c. M. V. - 505. T. refulgens D'Orbigny. r.M. V. - 506. T. tuberosa Dorbigny. R. M. V. 507. - T. Ungeriana D'Orbigny (Rotalina). I. M. V.

planuliar. - 508. P. a riminens is D'Orbigny. R. M. V.

Planomburins. - 509. P. mediteranens is D'Orbigny. r. M. V:

Siphonina. - 510. S. fimbriata Czizek. R. M. V.

Molivina. - 511. B. punctata D'Orbigny. R. M. V.

'Textilaria. - 512. 'I. g' rínulata Costa (Textularia). Un solo esemplare. R. Mr.

Cassidulina. - 513. C. l a evigata Dorbigny. R. MI. V.

DPecanium. - 514. P. saggitiula Defrance (Textularia). C. M. V. - 515. P. agglutinans Dorbigny. r. M. V. - 516. P. pygmaeum D'Orbigny (Testularia). R. MI. I.

rsigencrina. - 517. B. nodosaria D'Orb. r. M. V.

Cornuspirs. - 518. C. foliacea Philippi (Orbis). R. M. V. - 519. C. carinata Costa (Operculina). r. MI.

HBloculiua. - 520. B. bulloides D'Orbigny. c. M. Vi. V. - 521. B. elongata J'0rb. r. M. V. - 522. B. I un u la D'Orbigny. Vi riferisco un solo esemplare. R. M. - 523. B. ampliconica Reuss. Riferisco molti esemplari a questa specie; essi sono somigliantissimi alla forma miocenica e passano alla $\mathrm{B}$. commessa Costa, che parmi sia una modificazione della specie del Reuss. c. M. 524. B. Clepressa D'Orbigny. Questa specie presentasi d'ordinario un po' gibhosa al centro e sembra percio fare transizione rerso la precedente. r. M. V.

Spipaloculins. - 525. S. rotumeta D'Orbigny. 1.M.V. - 520. S. excarata D' Orhigny. R. M. Vi. - 527. S. canaliculata D'Orbigny. I. M. V. 528. S. nitida d'Orbigny. R. M. V. - 529. S. planulata Dorbigny. r. M. V.

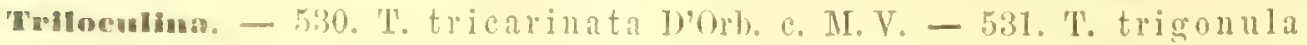


Lamk. c. M. V. - 532. T. inflata D'0rl. I. MI. T. - 533. T. selene? Karrer. Riferisco con dubbio a questa specie qualche esemplare. R. MI. - 534. T. oblonga MIontagu (Serpulce). C. MI. V.

Quingueloculina (') - 535. Q. triangular is D'Orb. Si raccolgono le diverse modificazioni che suole presentare questa specie. C. M. V. - 5\%36. Q. pulgaris D'Orbigny. R. II. V. - 537. Q. plana D'Orb. R. M. V. - 598. Q. bulloides D’Orb. R. M. V. - 539. Q. a sperula Seguenza. 1. M. - 540. Q. I yra Dorb. c. M. V. - 541. Q. Herrusacii Dorb. c. M. V. - 542. Q. depressa D'Orbigny. r. M. - 543. Q. Sehrookingerii Karrer. E un solo l'esemplare che io riferiseo a questr specie, ma esso offre esattamente tutti i caratteri assegnati dall'autore alla specie suddetta. Si redono infatti assai hen marcate le linee longitudinali e le piccole pieghe trasversali. Le incaleolabili differenze che ho potuto notare sono la forma alquanto piu allungata della conchiglia, uno sriluppo un po' minore delle logge mediane e l'apertura nu po' piu allungata e con essa il lungo dente lineare; tali differenze sono di lievissimo conto, esse si notano quasi tra gl'individui di tutte le specie. R. II. - 5t4. Q. I ucida Karrer. Riferisco a questa forma con qualehe dubbio un solo esemplare. Questa e la precedente specie sono proprie del mioceno. R. I. - 5.5. Q. costata D'Orbigny. c. MI. V. - 5t6. Q. I ulehella D'Orls. MLolto variabile nella forma generale. c. M. V.

Terminato l'esame della fauna del plioceno superiore, le conclusioni che da esso ne derivano si possono ben presto enumerare.

Dapprima Ia fauna delle argille di Monostemce ricorda promin quelli delle argille di Ficarazai presso Palermo, siccome quella delle sahbie di Valle Biaia anzi no è proprio identica; ed invece il graude deposito di Briozni di Villa S. Giorami, quantunque non trovi in altro luogo un assembramento coetaneo cho gli somigli; pure esso collegasi con depositi sincroni del Messinese, che offrono gli stessi Briozoi sparsi con una certa parsimonia e che in tutti i loro caratteri sono identici aftinto ai depositi arenosi che si estendono da MItta Ferso gli altipiani soprastanti.

Sia nell'uno come nell'altro facies, che assume nel Reggiano il plioceno superiore, sono da notarsi i due fatti che caratterizzano dorunque la fauna di quel periodo. In primo luogo la proporzione delle specie non ancoria conoscinte virenti is molto piccola; ed io, trascurando le altre classi, ricordero soltanto i Molluschi come quelli che nella natura virente sono meglio stuliati; accenno percio clalle argille di Monisterace le seguenti specie: Dentalium Delessertianum, Nucula plucuntina, ditomia striata, e dei giacimenti sul lato occilentale questo altre: Raphitoma Columnae. Nossa musiva, Rissoa turrilclloides, Trochus elegantulusec. In secondo lworgo r' ha un certo numero di specie che più non vive nel prossimo matre; la maggiol parte anzi í

(') Nella determinazione delle specie del Dorbigny spettanti a questo gentere mi som ralso

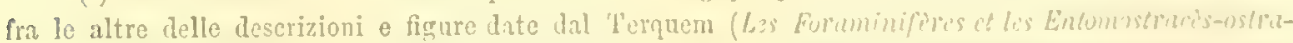

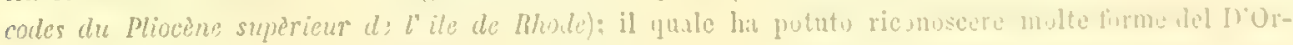

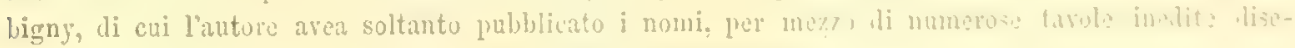
gnate dillautore e i corrispondenti esemplani di loraminifori. 
propria dei mari settentrionali. Dei Molluschi ricordo le specie segnenti: Buccinum undatum, Nafica Iontaculi, Trochus Oltoi, Fissurisepta papillosa, Cyprina islanaica, Limopsis minulu, Pecten pestutrae, IIallhoimia septigera, Cistella cistellula.

Oltre i Molluschi, rarî altri grupli di fossili ofriono considerevole interesse: tali sonn i Briozoi di Villa S. Giovanni; i quali mostrano un vero legame tra la fanua pliocenica e la quatermaria, siccomo ben lo riconobbe il Manzoni che esaminò pel primo quelle importanti spoglio; tali sono ancoria gli abbondanti Entomostracei e i Foraminiferi numerosi delle argille di Monosterace, gli uni e gli altri formando dei gruppi, che eridentemente dimostrano la transizione tra le fume del precedente periodo e del seguente.

Siflatti risultamenti sono di tale natura da arvicinare troppo il membro di cui discorro alla formazione quaternaria, e se mi è convento di riunirlo al pliocono per la gramle elevazione a cui perviene di unita a quest'ultimo, per l'esame della fimma csso, come gili precedentemente manifestai, si connette meglio al quaternario anziche al plioceno.

\section{FORMAZIONE QUATERNARIA.}

\section{Piano Sariano Mayer.}

Sinonimi. T'erreni quatemarî, e post-terzinui di varî scrittorí.

Quella massa rariata di terreni che generalmente comprendonsi sotto la denominazione di quaternari, non formano un tutto, che naturalmente si separa e completamente disgiungesi lai terreni pliocenici; che anzi da quanto fu detto precedentemente, si arguisce con evidenza, che da questi si passa a quello por gradazioni rivelateci e dalle comrizioni stratigrafiche e dai caratteri paleontologici.

Quindi si appongono bene coloro, come il Mayer ed altri, che riguardano il guateruario siccome il rappresentante d'un ultimo periodo della grinde epoca teriaria; e tale meglio che altrove ci riene climostrato da quella sorie di depositi marini, che in Sicilia el in Calabria fanno seguito, senza interruzione di sorta, agli strati pliocenici.

I terreni che riferisconsi al quaternario nella proviucia di Regoio come in Sicilia sono di due ben distinte nature: gli uni sono dei selimenti marini, pii o meno riechi di fossili; gli altri sono depositi continentali, in cui ordinariamente manca ogni resto d'organismo.

I depositi marini vedonsi ordinariamente sottostare ai depositi terrestri, che sono percio di data posteriore, o formano per la loro stessa natura una zona prerfettamente distinti.

É chiaro quimdi cho si lanmo due distinti periodi dell' eposa quaternaria, marino il primo, terrestre l'ultimn.

Facentomi pertanto al szaminare i clepositi quaternarî marini del Regogiano, io mi sono imbattuto in taluni caratteri dischuntivi, che li divilono naturalmente in the formazioni. In che estendesi sulle colline, raggingendo considerevoli altezze; l'altra che velesi jurce nelle basse regioni, che cingo le filde dei monti costituendo 
dei poggi molto dimessi d'ordinario appianati alla sommita. Na inoltre una ben dislinta diversita tra le due formazioni ci riene data dalle fiune cho lanchiulono. Io quali presentano talune ben mareate dillerenze, che esuminero piii taril.

Intanto a me sembra sufticiente la lisposizione topografica lei due terreni per la completi dimostrazione delli loro differente etì.

Difatti chi si fa a visitare l'amena contada sulla quale grited il villagrgio li Gallina traversa una serie di terreni terziarî molto importanti, clıe si collogano ai rarî strati del Quatemario, dimostrando trit essi rimarcherolissime relazioni.

La pianura che si steude dalla base della collina alla spingsia, è costituita da un potente deposito di allurions del solito colore rosso-loruno; ma questo, ai piedi del monte su cui ergesi Gallina, cale il posto al un terren. grossolanamento sab. bioso, di origine marina, ricco di fossili alla contralia Ravagnese.

Traversata la bassa pianura, appena cominciasi l'ascensione del ripilo colle di Gallina, mutasi tosto la natura e l'aspetto del terreno, essendochè ben piì antica si is quella roccia. Strati argillosi e molassici alternanti costituiscono quasi per intioro quell'altura: essi spettano al mioceno laughiano. L’altura rieue ripianata dil strati alternanti calcareo-marnosi e sabbiosi, che ripupiendo le sinnositi e le depressioni rappresentano molto bene, colla ricca fauna ele contengono, il piano Zancleano ed Astiano, quest' ultimo specialmonte nei suoi strati superiori marnoso-sabbiosi riesce d'interesse specialissimo, siccome precedontemente dimostrai.

L'allurione quatemaria rosso-irma stulesi uniformenente sulle precedenti rocee e forma il suoln dellallia splitnita su cui giace il ribente villaggio di Gallina. Ma dopo aver traversat, (quellaltipiano, inoltrindosi in mazo allo colline cho sinalzano ancora al disopra della spianati in sontra la piu intum verso la regione Badia. sí c̀ gia in seno ad una formarione quateruatia marina costituita d' nu sabbione ricco di fossili, analogo in vero a quello che stendesi alle falde del monte. A fronte di questi due dopositi viene ben naturale il domantarsi: Sedimenti marini cosi ar. vicinati, entraubi imlubitatamente quaternarî, per la fuma che racehiudono, mil a livelli molto dirersi possono riguardari come coetanei, cioè ritenersi siccome lem\}i di uno stesso deposito? A me sembria evidentemente di no. Infatti la stratificazione in entrambi i pressochè orizzontale, pure l'altezza sul livello del mare del terreno basso è di 80 metri, di quello alto ì invece di 324 metri nolla sua parte piì elevata, giacendo a 250 metri lik spianata di Gallina su cui esso pog gia : cio importa una differenza di ben 254 metri, tra $\mathrm{i}$ due terreni quaternarî, intanto quello ì di origine lit:orale, questo accema, pei suoi fossili, ad un mare piì profondo. Tonendo in caicolo tutti questi dati bisogna ritenere per furmo che i due depositi non sono coetanei, che bisoguò assolutamente che per primo si fosse deposto quello che oggi ha rnggiunto maggiore elevarione; anzi fu necessario che il sedimento piir antico fosse emerso perche al una distanza verticale considerevole, quale si it quella di 254 metri, potesse costituirsi un leposito che la tutti i caratteri dei sedimenti littomali. Quindi ne consegrto che il movimento ascensionale comineiato nel periodo pliscenico si è continuato per tutto il periolo quaternario, e con molta energia: limo dochè i bassi sedimenti, quenli che occupano i dimessi poggelti della pianura, snno ghi ultimi rappresentanti murui di quell' enoca, cho si costiturono quandn gria la 
massa principale doi depositi quatemarî era non solo omersa ma avea raggiunto altezze rimarcherolissime, come vedremo in seguito. La disposizione delle due zono del Quaternario marino si apprende molto bene dall'annessa sezione tratta dallo studio della vallo di S. Agata, e che rappresenta il sinistro lato di quella valle, comprendendori tutta la regione che stendesi da presso il rillaggio omonimo sino alla spianata di Gallina ed alla bassa pianura che le succede sino alla spiaggia.

\section{Sezione sul lato sinistro della valle di $S^{a}$ Agata.}

Direzione Est-Orest. - seala 1:50,000.

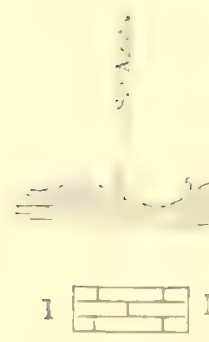

Doppia per le altezze.

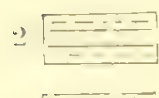
Mroceno
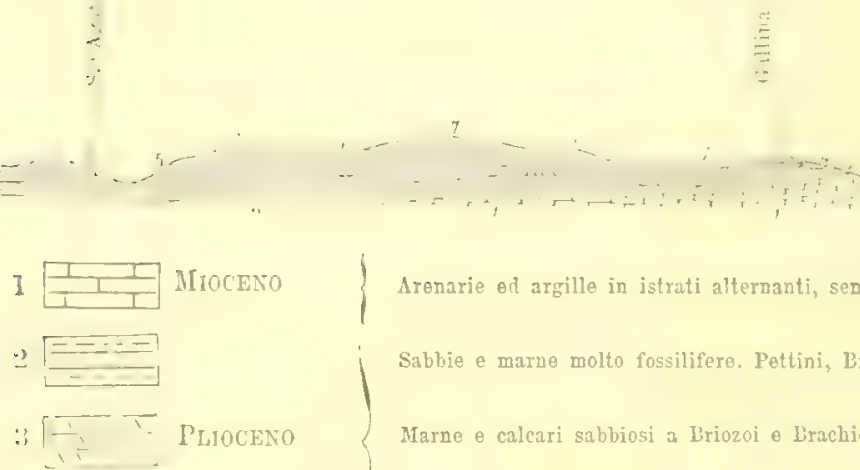

|

Arenarie ed argille in istrati alternanti, senza fossili.

Langhiano

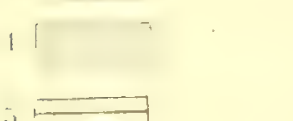

S Marne e calcari sabbiosi a Lriozoi e Drachiopodi. (Ter. Scillae, ec.) ,

Salibie con strati marnosi a fauna mista e ricca.

Astiano

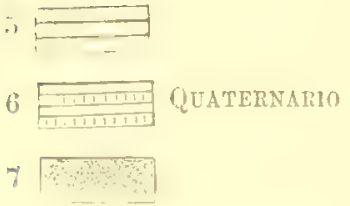

Sabbie grossolane ricche di fossili; con ispecie settentrionali.
Sabbie fossilifere con Strombus coronatus e specie dei mari caldi.
Allurioni antiche

Saariano

Queste importanti conchusioni vengono convalidate dall' esame acemrato delle faune dei due depositi, le quali presentano rimarcherolissime differenze che conducono poi a deduzioni di alta importanza.

Quanto abbiamo esaninato o discusso intorno al Quaternario del territorio di Gallina, con pocha variazioni, puo ngualmente dirsi di tutto quel tratto cho da Scilla estendesi sino al Capo delle Ami, siccome di altri lnoghi e d'altri tratti del lato occidentale. Sul lato meridionale e sull'orientale il Quaternario marino ri è rarissimamente rappresentato, nè l'alluvione antica vi è troppo comunemente sparsa.

Dalle cose predette ne consegue che il Quaternario marino resta naturalmente diviso in due periodì che vengono meglio confirmati e caratterizzati dai fatti paleontologici.

Qunuto poi ai depositi terrestri, generalmente noti col nome di allurioni antiche, per la loro speciale origine costituiscono una formazione a parte, dirersa dai depositi marini, o che richiedono accurato studio perchè si decida se siano o 110 sineroni con quest"ultimi.

a) Sabbie marine inferiori. Is formazione quaternaria piì potente $c$ e giìl rimarcherolo. noll'Italia merilionale esenza dubbio qunla di cui imprendo a 
trattare, e nel Reggiano come vedremo, quantunque non ocenti una superficie rera. mente rasta, pure per la sua potenza e per la grande clevazione cui raggiunge offre speciale interesse.

Il Quateruario inferiore adunque costa d'una roceia sabbiosa d'origine marina, priva ordinariamente di fossili, $i$ quali divengono inrece abbondantissimi in taluni Inoghi speciali. Questo deposito è costantemente formato di fina sabbia quarzosia, sovente pì o meno grossolana e mista di gliaia e di ciottoli anch'essi silicei, che talrolta costituiscono un vero conglomerato, che rimpiazza l'ordinaria roccia.

Il sabbione marino di cui parlo assumo una rimarchevole potenza, si eleva sino a grandi altezze, e manifestasi soltanto sul lato occidentale della nroviucia.

È importante notare l'aspetto imponente che assumono le colline e i monti costituiti dalle sabbie quaternarie: essi d'ordinario si estollono giganteschi per la grande potenza della roccia ed offrono appunto la conformazione di un mucchio di sabbia che scoscende incessantemente, coi fianchi molto acclivi e solcati qua e là dall' azione delle acque, colla cima molto ristretta, ovrero in forma di schiena; ond'e che offrono inoltre un triste aspetto per la loro ariditi. Tali si presentano i monti a nord di Reggio e quelli che sovrastano a Pellaro.

A voler seguire il suo sviluppo bisogna cominciare ad esaminarlo dal Capo delle Armi dore esso manifestasi ai fianchi sormontando il calcare tongriano.

Sul lato meridionale assume poco sviluppo; invece le colline che esso forma dal lato di settentrione si collegano con una serie di prominenze che sormontando le varie formazioni terziarie s'inoltrano nell'inter'uo e raggiungendo al di sopra di Motta la rimareherolo elevazione di 830 metri sul livello del mare, tra Motta e S. Lazzaro assume il piì grande sviluppo in potenza poichè oltrepassa senza dubbio Io spessore di 200 metri. Quindi si continua a lembi staccati piì o meuo estesi nelle alte colline sopra Pellaro, Valanidi, Boretto, Gallina, Reggio, dovo seemdendo assai presso la spiaggia, forma a settentrione della citta, oltrepassata la valle dell'Annunziata, una serie di colline elevate, scoscese, aride sino oltre gli Arehi, assumendo aneo ivi una potenza di oltre 200 metri. Più in là il Quaternario marino nella bassa regione affiora in taluni luoghi soltanto, essendo sriluppatissima l'alluvione quaternaria, che dapertutto lo rienopre. Nella regione elerati poi queste antiche sabbie mariue quaternarie non si mostrano piu in lembi ravicinati o disposti con qualche ordine, ma bensi in picoli e rari frammenti, sovente molto allontanati, resti della grande denudazione subita, testimonî ilell'estensione origrinaria del Quaternario marino. Cosi manifestasi a S. Auno, ad Orti, a Calanni, ai L'iani della Melia ee., quindi oltrepassata la grande pianura di Palmi ricomparisee nel territorio di Monteleone.

In tanta e sì vasta estensione, le sabbie quaternarie sono d'ordinario prire completamente di fossili, e soltanto ne presentano in talune spociali localiti. Cosi io faccio cenno dei dintorni di S. Lazzaro, di Motta, di Pavigliana, di Gallina, dei dintorni di Reggio, dove in molti luorhi lo sabbie yuaternarie sono fossilifere, degli Archi e finalmente di Monteleone. Tra questo localiti merita speciale menzione la contrada Corrubbare presso Reggio per la dovizia di fossili che presenta, inoltre per essere divenuta celebre, essendo probabilmente stata esplobata dapprima da Agostino 
Scilla ("), renne molto più taxdi ricereata con cura dal Philippi, che pubblicò un elenco delle spoglie di Molluschi ivi raccolte $\left({ }^{2}\right)$, quiudi da me, che mi occupai in varie pubblicnzioni delle diverse classi ni fossili che raccolsi in quella ricca localitì $\left({ }^{3}\right)$, e recentissimamente dal prof. P. Mantosani in un suo laroro geologico sui dintorni di Reggio, ove dava auch'egli nn elenco di fossili raccolti a Camubbare (").

Di tale localiti io levo aucora ricordare come gli strati fossiliferi del Quaternario sono varî: alla superficie è un deposito di ciottoli abbàstanza roluminosi misti a ghiaia; succedono quindi le sabbie molto fossilifere, e queste alla loro volta sorrastano a strati costituiti di materiali viì fini, che formano dei banchi marnososabbiosi, nei quali tra i fossili piì appariseenti vedesi la gigantesca Modiola grandis Phil. che in realti non ì che una grande forma della M. modiolus Lin. virente nei mari settentrionali.

Un'altra importante particolariti dei dintorni di Regogio, che è indispensabile di ricordare, si is lir scoperta di un Elefante fatti lal mio egregio amico sig. ingegn. G. Costantino. Ad oriente di Regurio, presso la rotaisile che comuluce a Terreti, faceasi un discaro per lik conluttura di acque, il quale reniva eseguito in seno alle sabbie quatemarie. Oru al ma certa profonditi senoprivasi un deposito fangoso che in forma di grande lente giacera in seno alle sabbie, e in mezzo a quel fango era il grande mammifero. Dapprima renivino fuori due enormi difese poco curre che misuravano una lunghezza di circa tre metri o mezzo: esse giacevano tuttaria in posizione sul cranio, che fu trovato intiero o colle mascelle superiori, mancavano le inferiori, e quantunque siasi usata la massima diligenza nell' estrarre si importanti resti, pure la loro distruzione comincio bentosto, e tutto andavia in polvere, se non mi fossi adoperato ad indurire e preserrare cosi dalla distruzione $i$ denti gia pel la maggior parte ridotí a lanine staccate. Oltre il teschio si rinvennero altre ossa ed insieme qualche vertebra, che fecero presumere che ivi giaceva l'intero scheletro dell'Elefante; ma le condizioni del luogo e sopratutto la soprastante ed elevata roccia sabbiosa non permisero la continuazione del discavo. La sezione terza indica il giacimento dell'Elefante sopradetto, e, come vedesi, sotto l'alluvione quaternaria giace potente massa di sabbie marine, solto la quale stendesi il banco arrilloso che conservò i resti di quel pachiderme.

Quanto riguarda joi la stratificazione delle sabbie marine quatemarie inferiori è da dire che essa non manifestasi sempre con eridenza, specialmente lia dove le sabhie sono grossolane, fanno passaggio arl un vero conglomerato e mancano di ogni specie di cemento; ma più comunemente la stratificarione è ben distinta e gli strati sono orizzontali, ma più spesso inclinati in vario grado e pendono verso la spiaggia.

Tutto quanto sinora ho detto riguarda le sabbie inforiori che si stendono lungo

(') A. Scilla, La vana speculnzione disingannata dal senso. Napoli 1670.

(') R. A. Philippi, Einumeratio mullussorum Siciliae Vol. II.

(") G. Seguenza, Lna messegygieta a Riggio di Calabria. 1869 (Anuali dell'Istruzione anno I fase. 1

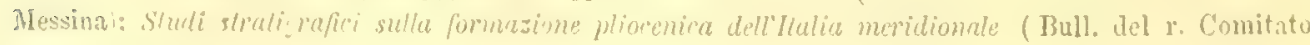
geulog. 157:3-76

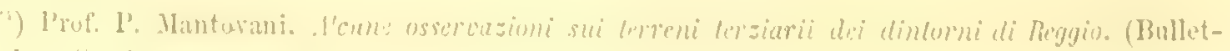
tino del r. Comitato grenlug.. 1879). 
il lato occidentale della provincia di Regyio, e che riggiungono, giona ripeterlo, la grande elevazione sul livello del mare di 830 metri.

Se si rivolgono le iudagini sulla costa meridionale, il Quatemario in parola non si fa vedere o vi giace in lembi incalcolabili presentandosi livertutto ripide roccie dii etì più 0 meno antica.

Il lato orientale va sfornito anch'esso di sabbie somiglianti a quelle tanto sriluppate sul lato occidentale, e solamente vi si notano minini resti di rocte che credo sincrone delle sabbie suddette. Così io posso acceunare come tali le sabhir fine, giallo-brumastre, che notansi nelle colline di Siderno, e che possono bene stndiarsi lungo la via che conduce daila marina al rillaggio superiore; in esse mancano ordinariamente i fossili, e soltanto in qualche luogo si raccoglie con molta liarità il Cardium Lamarckii.

Credo che debbansi riferire a questo periodo degli strati calcareo-arenosi, che giacciono presso la marina di Riace, e che più estesamente redonsi sparsi in forma di massi staccati giacenti sulle matne astiane tra Riace e lo Stilaro. In questil roccia dominano le Cladocore, e le conchiglie dei Molluschi conservano tuttavia il proprio colorito: cosi il Turbo rugosus, lo spondylus gacleropus ece.

6) Sabbie marine superiori. Fu già dimostrato precedentemente che la zona quatemaria marina superiore ha per suo principale distintivo la posizione molto bassa relativamente a quella della zona precedente, che si eleva sino sugli alti monti; è perciò che la prima l'abbiamo vedut i stendersi alle falde dell'alta spianati di Gallina ed aflorare proprio sul limitare della pianura col monte; ma non ì in questir sola localitì che essa manifestisi, costituisee invece una serio di collinette e meglio di poggetti poco sporgenti, a lievissimo declivio, solcati qua e lir dall'azinne delle acque, $i$ quali da Ruvagnese si diriggono verso il lato meridionale costeggiando le falde dei monti.

Siffitto deposito è vario nella sua costituzione, quantunque sempro sabbioso: alla base è formato ordinariamente dir sabbie molto fine, che divengono sompre piit grossolane in alto, c finalmente ra a terminarsi sempre con un rero conglomerat? di grossi ciottoli poco potente.

In qualche luogo, come a Boretto, le sabbie fine si mescolano nelle assise inferiori a materia argillosa, ed acquistano qualche grado di coesione. La stratifien. zione del deposito è manifestissimu, regolare e pressochi orizontule. Il colorito is rimarchevole, essendo ordinariamente brumastro, con vario gradazioni che tendono piir 0. meno al grigio.

Le localita fossilifere da me esplerite sono quelle di Boretto e di Raragneso: la prima delle quali merita molta considerazione per la grando abhombanza di fossili variati che offre.

E qui sorge un dubbio a riguarlo di due altre localitì fossilifere cioc Carrubbare, che io già ascrissi alla zona inferiore, e Musala che rapporto alla superiore.

La localitì di Carrubbare di eni grii ho dato precedentemento un cenno storico, giaco sulla destra del torrente Calopinace poco Iungi da Rogyio: per la mea elerazione di quei ricchi depositi fossiliferi sembra a prima giunta che essi si connettann 
con quelli di Raragnese e che ne sieno perciò coetanei; ma jiù immediatamente le sabbie di Carrubbare si collegano invece colle sabbie della zonat inferiore che formano tutte le colline circostanti e sorrastanti, estondendosi ed eleviudosi da un canto sino alla Porticellar, e scendendo poi al di là del torrente Annunziata sino alla spiaggia, dore, come redemmo, costituiscono i più spessi deñositi quaternarî dei dintorni.

Cosi il Quateruario antico verso Boretto, Gallina ecc. trovasi in alto e lungi molto dalla spiaggia; presso Reggio vi si apmessa, comprendendo il deposito di Carrubbare; più in là è sviluppatissimo sulla costa.

Queste ragioni, derivate dulla topografica conformazione dol Quatornario antico, non sembrano invero molto soldisfacenti, o almeno non sono tali da convincere shicchessia; ma i dati più importanti a dimostrare che gli strati fossiliferi di Carrubbare spettino al Quaternario inferiore sono a'altro ordine, e rengono somministrati dai fatti paleontologici, siccome vedremo.

E per tali dati ancora che io sono indotto a riguardare siccome depositi della zona superiore le sabbie fossilifere di Musala.

Queste sono grossoline, ghiaiose, perfettamente sciolte, bianeastre e costituiscono delle collinette che scoscendono incessantemente, offiendo una serie importante di fossili.

Tali depositi offrono una certa analogia di giacimento con quelli di Ravagnese e di Bovetto, in quanto che trovansi sul limitare della spianata di Campo, formata dall'alluvione antica, e degli alti monti che si ergono ripidi al di là.

Cosi la zona marina superiore del Quaternario io la riconosco soltanto nelle vicinanze di Reggio, c i suoi fossili nelle tre località di Bovetto, di Ravagnese e di Musala, siccome è probabile che vi spettano gli strati fossiliferi sotto l'alluvione tra Palmi e Gioia: altrove nella provincia non mi è occorso di osservarla.

c) Alluvioni antiche. Sopra i depositi marini testè descritti giace l'alluvione antica costituita da un fungo rosso-bruno misto più o meno a sabbia, a ghiaia, a ciottoli di variissimo volume, e talvolta a strati alternanti di grossi ciottoli, che in tanti casi formano la massa principale lel deposito terrestre.

Alla parte superiore sovente vedesi uno strato abbastanza spesso di sola argilla brunastra, ovvero bruna e talvolta nero-bruna, che ricorda nei snoi varî caratteri il Loess dell'Europa centrale. Tale strato è rappresentato benissimo nei dintorni di Reggio, e può studiarsi molto bene nella soprastante spianata del Cimitero.

Questa formazione terrestre si mostra sino a considerevoli altezze sul livello del mare; ma in quelle elevate regioni d'ordinario si present: a lembi staccati, che sovrastano a formazioni varissime che coronano le vette dei monti, come ricuoprono le alte spianate. Ma la regione dove l'alluvione antica è sviluppatissima si è quella delle basse e modie pianure: ivi d'ordiuario estendesi amplamente, occultando le tante variate formazioni marine.

Sul lato occidentale infatti tu veli l'allurione costituiro dei lembi staccati presso Motta, a 'Terreti, a S. Auno, ad Orti e così scendendo sulle colline meno elerate, finche nelle regioni più basse assume un predominio rimarcherolissimo ed insieme una potenza considerevole, e redesi formare per intiero la spianata che stendesi a mezzogiomo di Rergio tra la spiargeria o i monti, inalzandnsi mano mano sulle 
colline di cui ricuopre quasi sempre le Fette, forma la spianata del Cimitero od ancor più vastamente redesi sviluppatil tra Reggrio e Villa S. Giovami. Lungo tutto questo tratto costituisce qua e li delle vere terazze che si sciglionano a varie al. tezze; così gli elevati appianamenti presso Reguio, sopra Gallico e Villa S. Giovanni riescono di utile ammaestramento a questo liguardo. La più rasta estensione di suolo ricoperta dall'alluvione è senza Uubbio, nella provineia di Reggio, la grande pianura che si dilata a nord-est di Palmi.

Sul lato meridionale poi e sull'orientale l'alluvione antica trovasi distribuita con molta limitazione; difatti sono ben rari i luoghi dove possa arlditarsi un lembo di questo terreno sulla costa meridionale, ed io come esempio ricordero le colline plioceniche, che si estendono sull'uno e l'altro lato del torrente Amendolea, che Fedonsi coronate dall' alluvione, e verso la Baronia ece. Sul lato orientale bisogna correre sino al territorio di Bianco e di Boralino per trovarne qualche lembo che poi vedesi pì̀ esteso verso Ardore, Gerace, Siderno, e bene sviluppato a Riace, MIo. nosterace e cosi via via.

I depositi terrestri qui descritti non mi hanno offerto alcun residno organico, verun resto della faura terrestre contemporanea; ma bisogna qui ricoldare come il prof. P. Mantovani abbia seoperto prosso Regrio i resti dell' in lustria umama. Nella spianata che sovrasta alli citti come gia dissi è molto sviluppato quello strato di fina argilla bruna, nel quale furono raccolti ol ulensili vari di pietra e cocei diversi, che l'egregio mio amico ha rinvenuto e curato di descrivere.

Finalmente nel por termine all'esame dei depositi terrestri, credo indispensabile trattare di talune quistioni che si connettono direttamente colla cronologia di tali terreni.

E primieramente il fatto positiro da segnalare in orline alla stratigrafia, si è quello della sorrapposizione dei depositi terrestri alle sabbie quaternarie marine, come dipertutto può constatarsi nei dintorni di Regroio: tale fatto dimostra che le alluvioni antiche segnano l'ultimo periodo dei devositi quatemarî, e che quindi esse andaronsi costitnendo alloriuando gli strati marini ultimi emergevano dalle acque.

Ira dacchè io esploro le provincie di Messina e di Reggio, mi sono sempre proposto la soluzione di un problema, che si presenta molto naturalmente a chi è uso meditare sullorigine e la cronologia delle rocee.

Le alluvioni antiche mancano di fossili ed inoltre hanno sempre analoga costituzione, perlochè famo difetto i dati litologici siccome i paleontologici per sanere se esse spettano ad unica età, se debbano comprendersi in unico periodo.

Il dato stratigrafico juvocato di sopra non è un fatto gencrale, e i depositi terrestri, come i marini, poggiano sovente sopra rocce di dirersissime oti, che d"ordinario non sono quelle che cronologicamente le procedono: quindi a rigore sono dimostrate quatemarie quelle alluvioni che porcriano sul Quaternario marino, che è il più recente deposito.

D'altro canto a me sembra evidente che esploramlo i rarî lembi dell'alluvione antica mano mano che dalle regrioni clevate si scende alle meno alte, e yuindi alle hasse ed ai piani, si acquista la convinzione che tali depositi terrestri si collegano per insensihile gradazione cogli ana?nghi cho oggigiorno lepo-itano i nostri torenti: ne i. sufficiente prova la difficoltil che si sperimenta bene spesso ib tracciare i limiti tra 
le alluvioni antiche e le moderne. A mio credere quindi lit furmarone conosciuta generilmente col nome di alluvione antiea o quaternaria, si ando deponendo mano mano che il morimento ascensionale mettera all' asciutto le terre che cmergerano dal mare, e quindi per tutto il lungo periodo trascorso sin oggi. Bisogna percio ammet. tere che progredendo la emersione, $i$ depositi terrestri più antichi, mentre venivano da un canto denudati, perche spinti in alto, si sottracvano mano mano alla azione ulteriore dei torrenti.

E questa evidentemente la maniera per la quale costituivasi l'allurione antica, per cui velesi $0 g_{3} \mathbf{i}$ scaglionata dalla pianura sino a rimarehevoli altezze: c̀ per lo stesso meccunismo onde areano origine le terraze, tanto bene sviluppate in Sicilia, c cosi bene apprezzahili anco nella provincia di Reggio.

Questa ricognizione nella maniera d'origine della formazione alluviale, mentre da un canto mette in evidenza le ragioni percui le alluvioni antiche collegansi per gradazioni colle moderne, d'altra parte dimostra che le une e le altre formaronsi al medesimo modo, e se r'hir differenza rimarcherole tra queste, è la grande mole degli antichi depositi. Le cagioni che la determinarono sono poi da ricercarsi nelle condizioni climatologiche del periodo in cui quei terreni costituirousi.

Ma fino a questo punto, colle ragioni addotte, riesce soltanto evidente l'origine delle allurioni antiche ed il laro graauale deporsi sino a collegarsi colle alluvioni moderue: resta ancorn a determinarsi qualo sia il periodo geologico in cui comincio la loro formazione.

Da quanto è stato detío risulta evidente che i niì antichi depositi terrestri, dorousi trovare i più alti sul livello del mure. Or nella provinela di Regrgio per quanto io abbia espluato non mi renue fatto d'incontriane ad un livello superiore a quello cui pervengono le sabbie del Quaternario marino inferiore, che è elevato, come dissi, di ben 830 metri, e d'ordinario le vette di tale deposito marino sono coronate d'alluviune. Da ruesti fatti e da quelli precedentemente esposti deriva dunque a rigor di logica che nel Reggiauo non $\nabla$ 'hanno depositi terrestri precedenti l'epoca quatemaria; anzi i piì antichi seguirono immediatamente la formazione delle sabbie inferiori del Quaternario.

Questa conclusione conduce ad un' altra egualmente esatta. Ho dimostrato precedentemente come $\mathrm{i}$ depositi marini dol Quaternario si ripartono in due zone clue sprettano a due ben distinti periodi: abbiamo veduto infatti che allorquando il mare 'fuaternario battesa al piedi delle colline, come di quella di Gallina e delle altre con essa allineate, a vi deponeva le sabbie fossilifere di Raragnese e di Boretto, i potenti depositi sabbiosi del Quatenario inferiore erino già emersi in gran parte es su di essi grii si accumulava da gran tempo il terreno di alluvione. Ciò importa che l'alluvione rquatemaria che ammantil le clorate sabbie inforiori costituivisi nel tempo in cui il mare deponera le salbbie marine ultime di Ravagnese, Boretto eec. E indubitato yuinli che parte dei lepositi terrestri sonn esattamente coetanei degli ultimi depositi marini, e unesti confermano un tale sieurissimo risultanento per mezzo del loro colorito brunastro, che pare abbiano riceruto dai torenti, i quali dopo were formato i depositi cerrestri, si searicavano nel mare quatemario arichi di argilla colorata a quel modn.

Mil gli strati fossiliferi ultimi aftiorano sul limitaro dello basse reginni coi monti, 
e dia quel livello, talora alquanto elevato, sino alli spiagria si stumio vista o $10-$ tente furmazione terrestre, la quale è ripartita in terrazzi, o va a collegarsi insen. sibilmente colle alluvioni morlerne.

Tanta massa di sedimenti alluriali è sicuramente posteriore agli ultimi depositi marini che ricuopre; quindi lia formazione terrestre di cui mi occupo, cominciata i costituirsi appena s'inizio l'emersione delle sabbie inferiori, si continuo lungamente dopo l'emersione delle sabbie recenti, e si fu quest'ultimo il periodo in cui si formarono i terrazi.

Dopochè avremo esaminato i fatti paleontologici, ci sarì più agevole rintracciare le cause precipue che determinarono l'accumulo di cosi ingento materiale, quale si i quello che costitnisce la grande mole dei terreni quaternarî sì terrestri cho marini. Difatti tanta massa di rocee aggregate ripete principalmente la sua origine la immani correnti terrestri, le quali si legano alle conlizioni ed ai mutamenti climatolivgici, e questi riflettendo sulle fauno dei divorsi periodi si traducono in fatti permanenti che ci vengono rivelati dallo studio dei fossili.

Paleontologia. - La partiziono in due zone del quaternario marino, alla quale ci condusse lo studio di tale terreno, fa d'uopo che renga ancora seguita nell'importante esame paleontologico, il quale alla sua rolta verri in appoggio o confermerà validamente tale divisione, dandoci inoltre l'agio di trarre delle conclusioni molto rilevanti.

Le sabbie quaternarie marine della zona inforiore sono sprorristo di fossili nella loro maggiore estensione, e solamente in taluni luoghi speciali ne ofrono, d'ordinario in poco abbondante quantita di specie, se si esclude la localitì di Carubbare, che no è invece abbastanza ricca. Le localiti fossilifere adunque che sono state da me esplorate sono le colline presso la stazione di S. Lazzaro, le sabbie di Motta, gli strati sabbiosi che formano le elcrate collino che stanno piì in alto li Gallina: gli strati di Pavigliana, varie località nei dintorni di Reggio, tra le quali prinegria quella di Carrubare, gli strati sabbiosi presso gli Arehi, le colline di Gallico, e finalmente i dintorni di Monteleone. Sul lato orientale poi qualche fossile si raccoglie a Sillemo e presso Riace.

La zona superiore delle sabbie quaternaric aftiora ricen di fossili a Boretto c Ravagnese, ed io vi attribuisco inoltre le colline di sabbie di Musali, cho si stendono sul limitare della spianata alluviale di Campo sopra Villa S. Giorami.

La conservazione dei fossili in ambe le zone è perfottissima in quasi tutte le località, e solamente in alcuna dell'inferioro vedonsi i Gasteropodi e taluni generi di Lamellibranchi che hanno subito un'alterazione più o meno considerevole. Nell? zona superiore le conchiglio dei molluschi conservauo spesso il lon colnrito abhastanza bene; dimollocho la disposizione delle machio o dei rarî disogni che oftre la superficio del fossile pud studiarsi bene, ed usufruirsi nell'accertamento dello determinazioni specifiche.

Se si rirolge uno sguardo complessivo allo faune delle due zone quaternaric, si riconoscono i seguenti filti:

$1^{\circ}$ Le due faume solno costituite presso a poco al medesimu modo, rinè risul- 
tano dall'associazione delle medesime classi, che vi concorrono quasi nelle medesime proporzioni. Tengono il primo posto i Molluschi, e vengono quindi in ordine d'importanza i Foraminiferi, i Briozoari, gli Eutomostracei, gli Echinodermi, gli Antozoarî, gli Anellidi, i Cirripedi e, per qualche resto ben raro, i Vertebrati.

$2^{\circ}$ Le due faune possono dirsi alquanto riche pel considorevole numero di specie, di varie classi, delle quali risultano.

$3^{\circ}$ Sono ben poche le specie che non si conoscono rivonti.

$4^{\circ}$ Le specic tuttavia riventi appartengono per la maggior parto al Mediterra. neo; talune vi maneano e sono proprie di altri mari.

I caratteri fin qui enumerati sono comui alle fanne delle lue zone del Quaternario; ma esse compariscono ciò nou pertanto assai diverse allorquando si osservano comparativamente, ed una serie di caratteri differenziali dimostrano ad evidenza come le due zone stabilite siono realmente distinte, e rapresentino due periodi cho importa non confondere. Così, per accennare alcuni di questi duti differenziali, ricordo il dicerso predominio dei generi di una medesima classe o di una stessa famiglia: ad esempio i Pettini a i generi affui, e i Buccini, pì o meno comuni nelle sabbie inforiori ed invece ben rari nelle superiori; e vicerersa i Coni, le Tormatine, le Cassis ecc. che vedonsi non raramente in queste ultime e mancano affatto alle prime. Un secondo carattere è al certo quello delle differenze specifiche che sono abbastanza numerose, ma la cui maggior parte non hanno grande importanza, venendo istituite tra specie che vivono tuttavia nel Mediterraneo, e determinate dalle condizioni diverse di profondità 0 altro in cui i due depositi si costituivano; pure queste differenze imprimono alle. due faune facies considerevolmente diversi. Una terza differenza risulta ancora tra specie comuni alle due zone, essendo rare nell'una ed abbondanti noll'altra, o viceversa. Queste differenze nel rario grado d:llo svilunpo specifico, sono anch' esse di considerevole importauza, o valgono molto ad imprimere un particolare facies alle due fune. Mi basta addure un solo esempio: il Pechunculus violacescens, comunissimo nel Mediterraneo, ma raro abbastanza nella zona inferiore, è invece profusissimo e spesso colle valve riuuite nelle sabbie superiori di Bovetto e di Raragnese.

I fatti differenziali tostè ricorlati sono a parer mio di poca importanza a froute iell'altro rilevantissimo che vado a sernalaré, richiamando l'attenzione dei geologi non meno che dei paleontologi, poichè trattasi di un trovato, per quanto io mi sappia, sconosciuto sinora e fecondo d'importanti deduzioni riguardanti gli ultimi periodi genlogici delle regioni circummediterranee. È cosa ai paleontologi ben nota sin da lungo tempo como talune specie fossili in Italia, nergli strati pliocenici e nei quaternarî, trovandosi oggi ancor tra le viventi, non juì vivono nel Mediterraneo, ma trovansi emigrate verso i mari settentrionali. Io mi sono occupato altri volta di un tale importante argomento enumerando ma serie di specie plioceniche di varie contrade italiane, viventi oggi nei mari d'Inghilterra, della Scandinaria ecc. ( ${ }^{1}$ ); ma ormai quella lista ha subito considerevoli riduzioni per lo accurito ricerche fatte nel Mediterranco, dove si vanno scoprendo continuamente delle specie credute esclusire dei mari nordici. Is gri precedentemento, in questo lavoro, discorrendo dull'stiano, ho

(1) Sullantica distribusione geografica di hlune specie malacologiche vimuli. Nota di G. Seguenzat (Bullettiuo malacologico italiano Anno III. 1870). 
segnalato talune specie della provincia di Reggio, che, sconnsciute allatio nel Mediterraneo, sono state pescate nei mari d'Inghilterra, di Nurvegia ovrero in regioni ancor più settentrionali. Tale fitto abbiamo veduto ripetersi nel plioceno superiore o Siciliano, dove sono state enumerate talune poche specie dei mari settentrionali, ed ori vedremo, nell'elenco che siegue, continuarsi ancora e ben distinto nella zoua inferiore del Quaternario, dove, fra le altre, si raccolgono delle grundi specie nordiche, come ad esempio il Buccinum undatum, la Modiola modiolus, la Cyprina islandica ecc. Or continuando un tale esame, ci troviamo di fronte ad una fauna, nel Quaternario superiore, cho è priva completamente di specie che nella fauna vireuto sono confinate nei mari settentrionali. Ed eccoci già ad una differenza ben marcata ed assai importante tra il Quaternario inferiore al il superiore: quello partecipa della fauma nordica, questo invece ne è affatto privo mancando compintamente di ogui rappresentante esclusivo di quelle fredde regioni.

Intanto l'esame accurato della fauna della zona superiore del Quateruario, nel mentre da un canto ci mostra gia la scomparsa di quelle specie che vissute nel periodo precedente nelle nostre regioni trovansi oggi confinate nei mari nordici, ci addimostra contemporancamente quel fatto, a mio credere molto rilevante, che rengo qui additando ai paleontologi ed ai geoloçi, e che acquisterà al certo magriore importanza, allorchè ruella fanna verrà ricereata ed esplorata con molta assiduiti:

Traltasi della comparsa di specie che piu non vivono nel Mediterranco, ma che abilano oggi mari piru caldi.

La localitì di Boretto, dove la fiuna del Quaternario superiore si presenta abbondante e ricca, dove io sin da molto tempo mi sono assicurato del fatto che qui vengo esponendo, ̀̀ destinata al certo a divenire importante e ad acquistare rinomauza.

Ben si sa come sin da tempi molto antichi, scrittori varî abbiano voluto proclamare la identificazione di specie fossili con ispecie che vivono nei mari più caldi. I terreni tcrziarî soprattutto a cominciare dai Parigini hanuo somministrato specialmente nelle loru conservatissime cnvehiglie i materiali per siffatte identificazioni, che più tardi sono state mano mano rettificate riconoscendosi le marcate diflerenze che le specie fossili uffrono a fronte delle analoghe viventi dei mari tropicali.

Ma in tempi a noi più vicini furono lo specio del mioceno e del plioceno italiano, oggetto di tali identificazioni; così il Brocchi el altri scrittori anco molto più recenti ce ne offrono molti esempî. Puro quelle numerose specie del Mare rosso, dell'Oceano indiano o d'altri mari tropicali, cho vollero tripiantarsi nei nostri terreni terziarî si sono andati dileguando grado grado, riconoscendosi ormai in genere cho i fossili miocenici o pliocenici creduti a prima giunta siccome identici ai congeneri dei mari caldi, non sono che specie analoghe, sovente molto affini, ma prre perfettamento distinte. Delle tante specie di Molluschi viventi nei mari tropicali o creduto fossili nei nostri terreni terziarî che cosa rimane dunque al giomo d'oggri? Nulla o pressochè nulla, qualche rarissima spiecio tuthria reputata identica ad una forma dei mari caldi riene dubitativamente ricordata dai paleontologi.

Quindi non è più ammissibile l'emigraziono di specio plioceniche, verso le rogioni culde, se non per qualche caso raro ed eccerionalo; ed inrece, come già abbiamo 
veduto precedentemente, è bon dimostrato e per molte specie astiane, siciliane, dol Quateruario inferiore l'emigrazione verso le regioni settentrionali.

Il caso admuque che io presento, quasi preconizrato da tanti scrittori colle loro identificazioni di specio fossili con forme tropicali, si offre proprio nuovo, essendo dichiarate insussistenti quelle identificazioni, e con nuovo aspetto per le circostanze che lo accompagnano.

Trattasi d'una fama del Quaternario superiore, quindi della più recente tra le faune fossili, la quale risulta di numerose specie viventi tuttavia nel prossimo mare. Tra flueste, talune se ne incontra che più non vivono nel Mediterraneo, ma che invece oggi formano parte di faune di mari molto più caldi.

Il piccolo numero di tali specie tropicali io l'ho veduto accrescersi mano mano col reiterare le ricerche, e certamente diverrì più grande in prosieguo.

A fronte delle numerose disillusioni avute per le specie tropicali plioceniche, importa moltissimo la esattezza di determinazione delle specie quaternarie che identifico con quelle dei mari caldi. Diffidando perciò delle mie limitate conoscenze a questo riguardo, e mancando di molti mezzi opportuni, ho domandato l'ainto di uomini competentissimi, che si sono prestati volentierosi e beneroli, e quindi offro loro pubblica testimonianza di affetto e li riconoscenza specialmenie al prof. 'A. Issel dell'Universiti di Genora, e ai sigg. Watson e Smith. Quest'ultimo specialmente mi ha reso grande servizio comparando i miei esemplari fossili cogl'identici viventi, che conservansi nel Museo britannico di cui ne è direttore.

Comprovata cosi indubitatamente l'esistenza nel Quaternario superiore di specie tropicali, ne risulta una nuova ed importante difierenza tra questa zona e la precedente, la quale offre invece delle specio emigrate verso il norl.

Sorge qui nuovamante la quistione delle due importanti localita fossillifere cioè Carubbare e Musala, per definire paleontologicamente a quale delle dette zone quaternarie si appartengono i loro strati. Pami ovidente che i fossili coufermino quanto ho dedotto dalle condizioni topografiche. Limportante localiti di Carrubbare, tanto ricea di fossili, oftre delle specie nordiche tra le quali primeggiano i grandissimi esemplari della Modiola modiolus, che trovansi negli strati piu bassi formati di sedimenti più fini: inoltre io non ri ho incontrato veruna specie tropicale: eceo i due fatti orma decisivi per riporte gli strati di questa localiti nel Quaternario inferiore.

La località di Musala presenta invece i dati paleontologici proprî del Quatermario recento, ciò̀ difetto di specie nordiche ed associazione di talune specie tropicali alle moltissims mediterranee.

Un ultimo fatto da esaminare si è quello offertoci dalla presonza di specie estinte n sconosciute tra le viventi. $\mathrm{L}$ ben piecolo il numero di tali specie, tanto nella zona superiore quanto nella inferiore; na nella prima mi sorprese la riapparizione di qualche specie plioconica, pel quale fatto nel principio delle mio visite a Bovetto fui indotto a riguardare quel doposito siccome spettante al plioceno superiore. Per addure qualche esempio di questo rimarehevole fatto io ricorderd tra i Molluschi la Mitra scrobiculutu (Brocchi), tria i Briozoarî la Cupularia umbellata (Defr.), che oggi pare si conosea vivente. La hrima si oflie nel Quaternario con una varietà costantemente molto piccola, la quale risponde henissimn nei suoi caratteri alla specio pliocenica, 
offrendo benanco quello variazioni di scultura presentate dalla forma tipici. Nel Rorsgiano intanto nemmeno il plioceno offre questa specie, e bisogna scendere sino al Tortoriano per rinvenirla, come risulta dai precelenti elenchi. Pure nell'Italia meriliunale io la conosco nell'Astiano d'Altavilla; ma è affitto sconosciuta e nol plioceno superiore della stessa provincia di Palermo e d'altri luoghi, come nella zona inferiore del Quaternario. La C. umbellata nel Reggiano incontrasi nel Tortoniano di Benestare e poi nell'Astiano di Gallina; manea affatto e nel plioceno recente e nol Quaternario inferiore anco in Sicilia, per riapparire poi coi medesimi carattori ed anco colle stesse dimensioni nel Quaternario superiore di Bovetto.

Una mia maniera d'interpretaro quest'ultimo fatto mi farò ad esporla dopo avere enumerato i resti paleontologici delle due zone del Quaternario.

Ed eccomi ora a presentare l'elenco delle specie che ho potuto riconoscere negli strati del Quaternario reggiano; ed affuchè si possano viemmeglio apprezzare i rapporti e le differenze tra la fauna della zona inferiore e quella della recente, ho disposto ed ordinato le localiti dei due periodi in dne gruppi distinti, preceduli da segni convenzionali che si riferiscono ai due membri del Quateruario.

Da questo elenco si vedrì come la fauma del Quaternario è abbastanza ricca, c vi hanno rappresentanza molte classi del regno animale. Tra queste talune vi figurano per qualche specie, quali i Mrmmiferi, i Pesci, i Cirripedi; altre vi sono contenute con varia abbondanza, e prima per la ricchezza si è al certo il tipo dei Molluschi, rappresentato da tutte le classi, meno che dai Cefalopodi; i Crostacei abbondano soltanto nel gruppo degli Ostracodi, che si offre con forme variate, tanto piì imporkanti quanto meno studiate nelle nostre rocce e noi nostri mari.

Degli Anellidi sono i soli Serpulidi che vi hanno lasciato i loro tubi calcarei, mal definibili specificamente.

Del tipo dei Vermi, altro importantissimo gruppo si è quello dei Briozî, che prosentasi con una serie ben considerevole di generi e di specic. Gli Echinidi e gli Antozoarî vi sono poco abbondanti; invece i Foraminiferi sono sparsi in taluni luoghi, specialmente là dove i sedimenti divengono più fiui, con grande profusiono e si presentano con numerose e rariate forme.

I segni che derono convenzionalmente indicare le localitì nel seguento clenco sono: $R$, Reggio e suoi dintorni: - Gu, Gallina; - P, Pavigliana; - . M, Monte leone; - Bo, Bovetto; - Ra, Ravagnese; - M, Musala; - Pa, Palmi. 
Elenco delle specie fossili che costituiscono la fauna delle due zone del Quaternario.

N.B. In rquesto elenco la siuonimia è trascurata nelle specie ricordate precedentemente. Inoltre due segni vengono stabiliti per indicare il giacimento delle specio nelle due zone del Quatersario, cioè faccio precedere da (i) le localiti della zona inferiore, e da (s) le indicazioni riguardanti la zona superiore.

\section{Tipo. V ERTEBRATI.}

Classe. Mammiferi.

Elephas. - 1. E. armeni a e us Falconer. In prossimitì di Reggio, dal lato nord-est, presso la rotabile che conduce a Terreti venue scoperto lo scheletro di un Elefante, che dubitativamente io riferisca alla specie sumominata. Dirigera taluni discari, che eseguiransi in quelle colline per la conduttura domportanti masse d'acque, il mio egregio amico sig. ing. G. Costantino, di cui si deplora la recente perdita, quavdo sotto imponenti strati di sabbie rennesi a scoprive l'immane scheletro, che giacera iu una specie di accuniolo faugoso di forma lenticolare suttostante a grande massa di sabbie quaternarie, alla loro rolta sottostanti all'alluvione antica. Nel discaro renuero fuori dapprima le difese, che furono misurate della Innghezzi di oltre tre metri e mezzo, ma sgraziatamente caddero tosto in frammenti e quindi in polrere per lo stato di cativa conservazione, e poi si andò discuoprendo il teschio maucante delle mascelle inferiori, e qualche vertebra in seguito el altre ossa che accennarano alla probabile esistenza dell'intiero scheletro, ma i discavi non poterono inoltrarsi in quelle sabbie mobili e quindi non si ebbero altre parti scheletriche.

La disposizione degli strati quaternarî nei quali fu scoperto quest'Elefante redesi bene nella sezione terza. Le sabbie, nelle quali ì inclusa una grande lente argillosa, che rachiludera lo seheletro, sono indubbismente mane; in esse io vi Lo raccolto dei Pettini, dei frammenti di Balani, dei Briozoi ecc. i. R. R.

\section{Ireterocetris?}

Riferisco dubitatiramente a questo genere l'unico resto di cetaceo raccolto nella zona inferiore; esso e il corpo di una vertebra abbastanza grande, raceolta nelle sabbio di Ravagnese ed oggi conservata nelle collezioni dell'Istituto tecnico di Roggio.s. R. Ra.

\section{Classe. Pesci.}

Gli Otoliti sono i soli resti che rapresentano questa classe; come le specie degli altri piani bisogna che sieno assogugettate allo stulio comparatiro generale. i. c. R. - s. Nelli zona superiore ai molti ittiotoliti si associa qualche rertebra parimonti indeterminata. c. Bo. Ra.

Tipo. MOLLUSCHI.

Classe. Gasteropod.

Seutulum. - 2. S. Gussonii O. G. Costr (Ancylus). \&. R. Bo, V. 
Philine. - 3. P. scabra Muller (Bulla). i. R. R. V. - 4. P. catena Montagu (Bulla). S. R. Bo. V.

Bulla. - 5. B. utriculus Brocchi, s. R. Bo, V.

Maminea. - 6. H. hydatis Lin. (Bulla). Aleuni giorani. S. r. Bo.V.

Actaeon. - 7. A. tornatilis Lin. (Volue $)$. S. 1. Bo. V.

8. A. Bovetensis n. sp. Tir. XVII. fig. 40.

Questa specie di forma orato-oblonga, colle suture profondate, distinguesi pei forti solchi spirali della regiono anteriore, pel difetto di essi nella regione posteriore degrli arrolgimenti, per la spirale prominente; l'apertura è allungati, angolosa, pressochè romboilalo. Molto piccola, essa è più allungata o a spira più frominente della precedente specie.

$$
\text { Lunghezza 2,8. }
$$

Utroiculas. - 9. U, truncatulus Bruguière (Bulla). i. 1. R. - s. r. Bo, V. 10. U. mammillatus Philipi (Bulla). i.r. R. - s. R. Bo. V.

Tornatina. - 11. T. Ku ockeri Smith = Utriculus spiratus Seg. (non Brocchi) (Bulla). Qnesta specio che io aver confuso col fossile del plioceno vive invecs sulle coste occidentali dell'A frica e fu riconoscinta dall'autore. S. 1. Bo. V.

Cylichna. - 12. C. uitidula Lovìn o vir. major. i. I. R. - S. c. Bo. Ra. V. 13. C. mubilicata MItg. (Bulla). i. 1. R. - e Var. pyriformis. - . c. Bo. Rr. V. - 14. C. strigelia Lovin. i. r. R. V. - 15. C. striatula Forbes (Bulla) $=$ B. (Cylichna) Hoernesii Veink., C. cuneata Tiberi. S. c. Bo. V. - 16. C. Joffreysi i Weink=Bulle ovulata Auct. s.r. Bo. V. - 17. C. cylindracea Penn. (Bulla). s. r. Bo. V. - 18. C. al ba Brown. Un solo rotto osemplare. s. r. Bo. V. - 19. C. obesinscula Brugnone. s. R. Bo.

Volvuln. - 20. V. vacumillata Bruguière (Bulla). S. r. Bo. V.

Cyohoma. - 21. C. Boretensis n. sp. Tar. XTII. fig. 4141 a.

Questa forma è affine alla C. gibbosa, ma più piecola, più stretta agli estremi, con doppia carena trasversa poco visibile, coll'apertura più larga, col labro ab. bastanza curro e privo di crenature.

$$
\text { Lunghezza } 11 \text { mm }^{\mathrm{mm}} \text { Larghezza } 6.5 .^{\mathrm{mm}} \text { ค. r. Bo. }
$$

Trivia. - 22. T. e ur opaca Mont. Cypraca). i. R. R. - S. 1. M. V. - 23. T. pulex Solauder (Cymaer). s. R. M. V.

Cypraea. - 24. C. achatidea Gray. S. R. M. V.

Iraronella. - 25. M. o c culta Nonteros. i. R. R. V. - 26. M. clandestina Brocchi (Voluta).i.c. R. V. - 27. M. Philippii Monter. i. c. R. - - c. c. Bi. Y.

Geingicula. - 28. R. auriculata Menad (Harginella). i. R. R. V. - 29. R. conform is Monts. s. r. Bo. V.

mitra. - 30. M. e benus Lamk。 i. r. I. - s. r. Bo. V. - 31. M. Iutescens Lamk. i. r. R. V. - 32. M.tricolor (Gm.) anet. ‥ r. Bo. V. - 33. II. Bromii Mi-

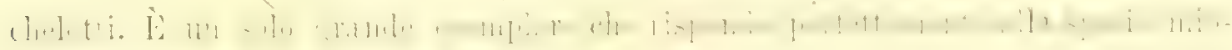
pliocenica. S. R. ML. - 34. M. scrobiculata Brocehi (Murex). La forma che riferisco a questa speciu è sempre molto piecola, ma rispomide bene alla forma del Brocehi, costituendo cosi una varietit ammiserita. - r. c. 13o 
Conus. - 35. C. meditorranous Bruguière. i. r. R. V. - 36. C. testudinalius Martini. Var. Tuluni esemplari raccolti e comparati coi viventi esotici dol British museum, si possono rapportare ad una varieti di questa specio che vive alle isole del Capo Verde. i. 1. Bo. Ra. V.

37. C. subventricosus n. sp.

Questa specio è assai vicina al C. ventricosus del plioceno, e si distingue per l'estremiti della spira acuminata e più prominente, pegli arrolgimenti scanalati e con forti strie impresse, per le suture piì profondate, per la superficie ornata da grosse e rare linee spirali che sono più manifeste e più avvicinate alla parte anteriore. La forma generale della conchiglia poi è più allungata e pereiò un po' meno ventricosa.

Lunghezza 40. ${ }^{\text {mm }}$ Diametro 22. ${ }^{\text {mm }}$ s. r. Bo. Ra.

38. C. Rherginus 11 . sp.

Questa specie i molto ben distinta per la forma esattamente conica, dell'ul. timo arrolgimento, per la spirale bassissima e prominente al centro, sopratutto negl'individui giorani, somigliando cosi al C. virginalis Brocchi, dal quale è ben distinto per' la spira molto breve, per l'ultimo arvolgimento meno angoloso, colla superficie striala spiralmente, ma più fortemente alla regione anteriore.

$$
\text { Lunghezza 30. }{ }^{\text {mm }} \text { Diametro } 16{ }^{\mathrm{mm}} \text { s. } 1 \text {. Bo. Ra. }
$$

39. C. Mantovani n. sp.

Conchiglia orato-conica, spira breve, conica, leggermente convessa; arvolgimenti segnati da un solco abbastanza profondo, il quale porta all' esterno una linea profondata; le suture sono molto profonde: l'ultimo avvolgimento è conicoconresso e listintissimo per la scultura, essendo ornato di cingoli che alternano con linee spirali; $i$ cingoli e le linee divengono sempre più forti e prominenti verso l'estremo anteriore.

\section{Lungherza 35. ${ }^{\mathrm{mm}}$ Diametro $18 \mathrm{~mm}^{\mathrm{mm}}$}

Questa sprecie mi venne fornita dal prof. P. MIantorani dell' Istituto tecnico di Reggio al quale la dedico. s. R. Ri.

I tre Coni nltimi che descrivo come nuove specie non poterono dal sig. Smith nel British muscum venire identificati con ispecie virenti, pure io li ho descriti come nuove, restando alquanto dubbioso, e ficendolo quasi prorvisoriamente.

Surcula. - 40. S. similis Biv. f. Afline, ma diversa dalla S. undatiruga Bir. P. S. R. M. V.

Driun. - 41. D. confusa n. sp. Vedi fossili dell'Astiano. i. R. R. V. - 42. D. Loprestian a Calcar (Pleurotoma). i. R. R. V. - 43. D. incrass a ta Dujardin (Pleurotoma $)=P$. Maravignac Biv. f., P. clegans Scace. (non Defi.). . . r. Bo. V.

Bela. - 44. B. secalina Phil. (Pleurotoma) -. R. Bo. V.

Clathurella. - 45. C. grateilis Mtg. (Murer). i. r. R. - - r. r. Bo. M. Ra. V.

Homotoma. - 46. H. rudis Seace. (Pleurotomu). i. R. R. V. - 47. H. I inearis Mtg. (Murex). i. r. R. - s. r. Bo. V.

Mangelia. - 48. M. costata Donor. (Iturex). s. r. Bo. V. - 49, M. rugulosi

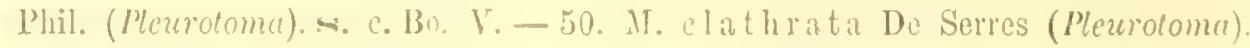
s. I. Bn, V. 
Baphitoman. - 51. R. altenuata MItg. (Jurcx). i. I. R. - - R. Bo. V. 52. R. blachystoma Phil. (Plenrotoma). s. C. Bo. V. - 53. R. costulitta De Blainville (Pleurotoma) (non Risso) - Pleurotoma striolute Seacehi. - - l. Bo. Ra. V. - 54. R. Columna Sicuechi (Pleurotoma). i. R. R. - s. IR. Bo. Aphanitome? - 55. Grabi Phil. (Colnombella). i. l. R. V.

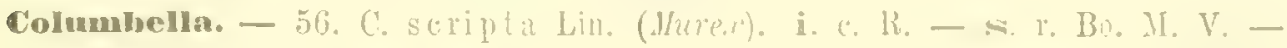
57. C Gervillii Pilyr. (Jitra), i. 1. R. V. - 58. C. mino it Scaledi. i r. R. s. e. Bo, V. - 59. C. costulata Cantraine (Fusus). S. R. MI. V. -60 . O. rustica Lin. (Volula), i. P. R. - s. R. M. V.

Cycomassa. - 61. C beritea Lin. (Brecinum). i. 1. R. - s. r. Bo. R. M. V. Nossa. - 62. N. limata Chemu. (Buccinum). i. c. R. Mt. - - s. c. II. V. 63. N. reticulata Lin. (Buccinum). s. r, Bo. V. - 64. N. inusi: a IBrocchi (Buccinum). i. r. R. Mt. - 65. N. Inerussatir Muller (Tritonizm). i. 1. L.․ r. Bo. II. V. - 66. N. pyoma Lamk. (Ranella). i. R. R. V. - 67. N. Cuvieri Pityrand. (Buccinum). i. c. R. - s. I. Bo. Rr. II. V. - 68. N. In utabilis Linu. (Buccinum). i. c. R. - s. 1. Bo. Ru, V.

Terebra. - 69. T. corrugata Lamk, var. Regina Desh. Un esemplare clie conserva anco i colori. Vive alla Gininas. S. R. M. V.

Cassis. - 70, C. saburon Bruguiere (Cussileu). S. R. Bo. Y. - 71. C. undulata Lin. (Buccinum) = Cussilech sulcosa Bruguidre. È costantemente una forma piceola, più o meno granulosa sni disersi arvolgimenti, e fornita di grossi tubercoli disposti in dne o quattro serje sullia parte posteriore dell'ultimo. s. r. Bo. Ri. T.

Cassidaria. - 72. C. echino phota Lill. (Buccinum). i. 1. R. V.

Cuthria. - 73. E. cornea Liu. (Murero). i. c. R. Btt. - \&. 1. Bo. V.

gollia. - 74. P. D O bygu Payr. (Buccimum). \&. R. Bo. MI. V. - 75. P'. scillin? Monteros. S. r. Bo. V.

Fusus. - 76. F, rostratus Olivi (Murex). i. c. R. V.

Trophon. - 77. T. un uricatus Monter. (Murex). i. c. R. V. - 78. 'I'. Bar. vicensis Julnston. i. R. R. V. - 79. T. multilamellosus Phit. (Mure, ${ }^{\prime}$. s. R. Bo, V.

Mures. - 80. M. brantaris Lin.s. I: Bo. Ri. V. - 81. II. trumeulus Lin. i. c. R. - s. c. Bo. Ra. V. - 82. Mr. eriulceus Iin. i. I. R. - - i. B. B) V. - 83. M. Edwardsi Paylitud. (Purpura). i. r. R. - $\rightarrow$ R. Bo. II. V. - 84. II. corillinus Senchi, i. r. R. - s. I. Ho. V.

rymula. - 85. P. panninitana Monterosos. R. Bo. V.

Epidromms. - 86. E. reticulatus De Blainv. (Triton). i. r. R. V. - - - ro.r. V. Triton. - 87. T. corrugatus Iamk. -1 . II. V. - S8. T. ficoides Reere T. samier Alamson. Questa splecie rivo al Sumegal. s. r. R.ı. II. V. - S9. T. pat renopens $r$. Sali: Un gioranissimo imlivituo. A. R. Bo. V.

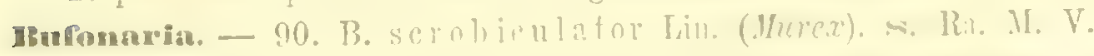

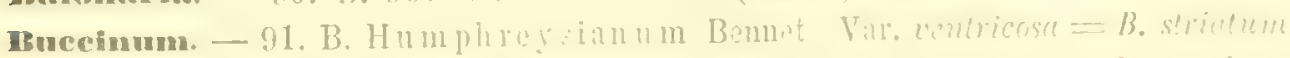

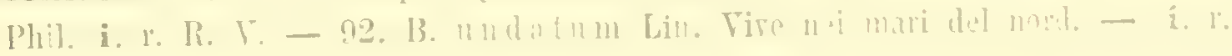
R. MIt, Y 
Ronprerg. - 93. P. hemastoma Lin. (Buccinum), i. R. MIt - s. R. Bo. Ra. V. Cenoithium. - 94. C. vulgatum Bruguière. Con diverse varictà. i. c. R. Mt. s. c. Bo. Ra. V. - 95. C. rupestre Risso = C. Puscalum. 0. G. Costa i. $r . R .-N . r . R i$. V.

Cerithiolum. - 96. C. scabrum Olivi (Murer). Con molte rarictid. i. C. R \&. C. Bo. Ra. Mr. V. - 97. C. pusillum Jefreys (Turrilella?). i. C. R. $\therefore$ 1. Bo. V. - 98. C. Iacten Phil. (Cerithum). i. c. R. - S. r. M. V. Triforis. - 99. T. perversa Lin. (Trochus). i. c. R. - s. c. Bo, M. V.

Cenothiopsis. - 100. C. tub ereularis Mont. (Hurex). Con varietì. i. r. R \&. r. Bo. V. - 101. C. M otaxie Dello Chiaio (Murex). i. R. R. - s. R. Bo. V.

Strombus. - 102. S. corouatus Defrance. Esemplari piccoli e frammenti. i. r. R. IIt. - s. Raccogliesi abbondintemente in buoni esemplari, che sono sempre molto piccoli in ripporto alla grando forma del plioceno o parmi che abbiano anco qualche differenzuccin, come ad esempio la spira più promisente. c. Bo. Ra.

Chemopras. - 103. C. pespelecani Lin. (Strombus), i. 1. R. - s. r. Bo. V.

Cancellaria. - 104. C. cancellata Lin. (Voluta). i. I. R. - s. c. Bo. Ra. V.

Solarium. - 105. S. fallaciosum Tiheri. S. R. Bo. V.

Adeorbis. - 106. A. subcarinatus Mont. (Helix), i. r. R. V.

Nates. - 107. N. millepunctata Lamk. i. c. R. NIt. - s. 1. Bo. Ra. V. 108. N. Hebraea Mirtyn (Nerita) N. maculatu Desh. S. I. BN. V. - 109. N. flinmulata Req̨. i. r. R. - s. r. Ra. Bo. V. - 110. N. fusea De Blainville. i. r. R. - s. r. Bo. V. - 111. N. intermedia Phil. i. c. R. - s.c. Bo. V. - 112. N. Guillemiui Paylutud. i.r. R. - s. i. M. Ra. Bo. V. 113. N. Montaenti Forbes. Vive nei mari del nord. i. r. h. - s. R. MI. V. - 114. N. macilenta Phil. i. c. R. - s. r. Bm, V. - 115. N. orientalis Gmel $=N$. canrence Seg. (non Lamk.). La furma è proprio di questa sprecie ma i colori presentano delle machie diveroamente disposte, che ricordano la $N$. Fanel Adam. Vive alle Indie. s. 1. Bo. Ra. II. V. - 116. N. porcellaua D' Orbigny $=N$. mummilla Seg. (non Lin.). Questa specie di perfetta consersazione, comune dapertutto in questr zona, è la più frequente delle formo esotiche dei mari caldi, che giacciono in questo deposito. Vire alle Canaric. s. c. Bo. Ra. M. V. - 117. N. intricata Donoran. i. c. R. V. - 118. N. Josephinia Risso (Neverita). i. I. IR. - s. 1. Bo. V.

verita. - 119. N. viridis Lin. s. r. Bo. Ra. V.

Eulima. - 120. H. Philipp i Weink. i. r. R. - 121. E. bilinoata Aller. i. r. R.

Eulimella. - 122. E. a cicula Philippi (Melania). i. 1. R. V. - 123. E. ventricosa Forbers (Purthenia). i. I. R. V.

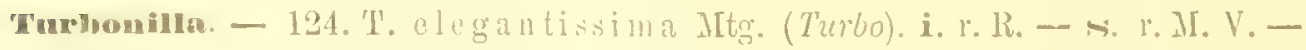

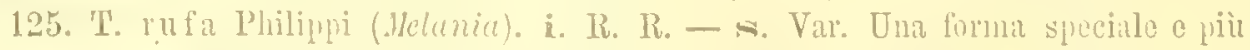
gracile giace colla tipica. c. Bo. V. - 126. T. amoena Monts. -. R. Bo. V.

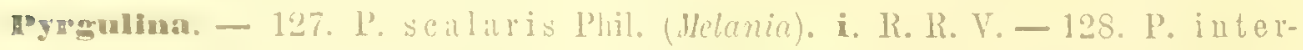
stinctal Jlty. (Turbo). m. l. I30. V. - 129. P. monozona Brusinia (Olostomia).

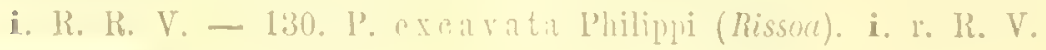

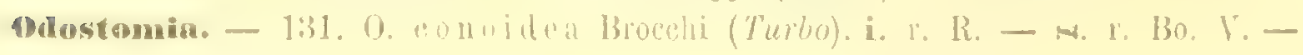


132. O. polita Bir. r. Bo. V. - 133. O. rissoides Itanleg. Colla rar. dubia. i. r. R. - s. r. Bn. II. V.

134. O. la evissima n. sp. Tilt. XVII. fig. 42.

Testa orata, laevis, lacida; lineace spiralis at incrementi tenuissimae, de. cussatae; anfractus tres converi; suture profundatae; apex obusus; ultimus maximus inforne proluches, fore $3 / 4$ tolius longitulinis aequans; Os ovalum, superne aculum.

Questa specie pel piccolo mumero degli avolgimenti, pu la grandezza relativa dell'ultimo, per" le suture molto yrofonde distinguesi assiu bene dalle atlui. L'O. achatina Seg. che è la specie piì alline lia le suture non profontate, un' ovoluzione più rapida ed è piì mracile.

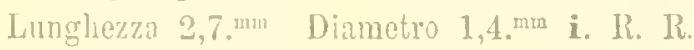

135. 0. confusa 13. sp. 'Tar. XVII. fig. 43.

Questa Odostomia ha unolte aflui ; essa intanto si arricina di piì per la conformazione generale alla O. plicata, dalla quale no è hen distinta per la convessitit degli arrolgimenti, per" la profonditi delle suture, per un liovo indizio di ombelico, per la maggior lunghezza dell'ultimo arvolgimento, che è ben convesso alla regione anteriore. Lunghezha 1,8. ma Diametro 8.rmm s. r. Bo.

136. 0. a euta Jefrr. i. 1. R. - s. c. Bo. V. - 137. O. plicata Mltg. - . R. Bo. V. - 138. O. clavula Lovèn (Turbonillu). s. 1. Bo. V. - 139. O. pallik a Montagn (Turbo). i. r. R. V. - 140.0.0 bliqua dldex. s. 1. Bo. V. 141. O. Warreni Thompson (Risson). i. r. R. - s. r. Bo. V.

Mathula. - 142. M. eleginutissima 0. G. Costa (Trochus). s. IR. Bo, V. 143. M. retusa? Brugnone. Un ulubio lrammento. s. R. Bo. V.

Acirsa. - 144. A. subdecussata Cintraine (Scalaria) $=$ Turrilclla Philippii Aradas. s. R. Bo. V.

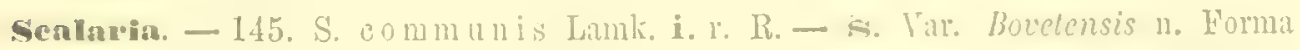
a costole più sporgenti e lamelliformi. r. 130. V. - 146. S. Turtona e 'lurton (Turbo). s. r. Bo. V. - 147. S. Cantrainei Weinck. Un frammento dubbio. $\therefore$ R. Bo. V. - 148. S. soluta Tiberi. \&. 1. Bo. V.

Turritella. - 149. T. commun is kisso. i. C. R. - s. c. Bo. Ra. V. - 150. T. tricarinata Brocehi (Turbo). i. c. R. - s. c. Bo. T. - 151. 'L'triplicata Broceli (Turbo). i. C. R. Mit. - - M. C. B. M. V.

Soliquarin. - 152. S. anguin a Lin. (Serpula). i. 1. 1R. V.

vermetus. - 153. V. gigas Bir. 1) i. C.MLt. - i. I. M. V. - 15t. V. triqueter Biv. p. i. r. R. - s. o. M. V. - 155. V. semisurectus Bir. p. N. c. II. V. - 156. V. subcancellatus Bir. 1. s. c. II. V.

Coecum. - 157. C. trachea Iltg. (Dentatium). i. 1. R. - - . 1. 130. V.

Rissoa. - 158. R. oblonga Desm, i. 1. R. V. - 159. R. monodonta Biy. i. r. R. V. - 160. R. parra Da Costa (Turbo). i.r. R. T. - 161. R. ratiata Phil. i. r. R. - s. Bo. V. - 102. R. simplex Phil. i. c. R. V. - 163. R. p 11silla Phil. i. c. R. Y. - 164. R pulehella Phil. i. c. R. - - r. 130. V. 165.R. inconspicua Alder. c valr. laevis. i. c. R. - - c. c. Bo, V. - 166. R. simblis Seacehi e lirerse rarietid. i. c. I. - - I. II. V. - 107. Ir. costulat a 
Alder. i. r. R. V. - 168. R. ratiabilis r. MIubli. (Turbo), i. C. R, - - e. e. Bo, II. V. - 169. R. spleudida Eichw. i. r. R. V. - 170. R. violacea Desm. i. r. R. - s. r. Bo, V. - 171. R. Fentricosa Desm. i. r. R. V.

Arrania. - 172. 1. Incted Micham (Rissua). i. 1. R. V. - 173. A. cancellata Da Custa (Turbo). 1. C. 12. - - - r. Bo. M. V. - 174. A. subcrinu-

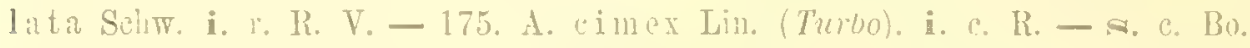
M. V. - 176. A. bicingulata Spunema (Rissoa). i. 1. R. V. - 177. A. reficulata MIontg. (Turbo). i. e. R. V. - 178. A. cimicoides Furhes (Risson). i. r. R. - S. r. II. V. - 179. A. Zetlandica Montagn (Turbo). i. r. R. V. - 180. A. sulpsoluta Arulas (Rissou). H. Ro. V. - 181. A. punctura Montg. (Turbo). i. c. R. - s. r. Bo. V. - 182. A. Montagu i Payratud. (Rissout). i. C. R. - N. e. Bo. Mi. V.

Cingula. - 183. C. semistriatil Monty. (Turbo). i. I. R. V. - 184. C. granulum Phil. (hisson). Con varietid. i. c. R. V. - 185. C. obtusa Cantiane (Rissoa) $=$ R. Alleri Forbes. i. 1. R. - s. r. Bo. Rit. V

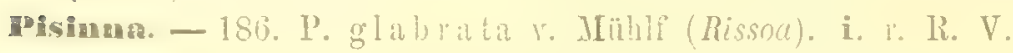

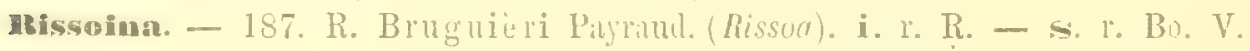

Setia. - 188. S. Ins a Philipni (Truncatelle?). i. R. R. - s. r. Bo. V. - 18 ?. S. amabilis Monteros. i. R. R. V.

Mela. - 190 H. tenella Jefir. (Lucuna). i. R. R. - s. r. Bo. V.

Mittorina. - 191. T. neritoides Lin. (Turbo).s. I. I30. MI. V.

Plnasianella. - 192. P. pull a Lir. (Turbo), i. c, R. - - r. Bo. V. - 193.

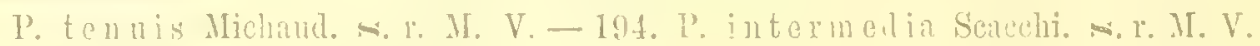

Tarlyo. - 195. T. rugosus Limeo. i. e. R. Mt. - s. I. Bi. M. V. - 196. 'T. sanguinens Lin.s.r. r. U. V.

OHivin. - 197. 0. Tino i Culcari (Monodonta). i. R. R. V.

Clanculus. - 198. C. colrallinus Gm. (Trochus). i. c. R. Mt. - s. 1. Bo. MI. V. 149. C. Uluciatns Lin. (Trochus). i. C. R. - s. I. Bo. M. V. - 200. (\%.

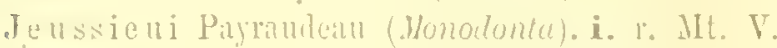

Trochus. - 201. T. ennlilus Lis, i. c. li. MI. - s. 1. Bo. Ra. M. V. - 202. 'I'. zizyphinu: Lin. i. c. R. MIt. - r. Bo, M. T. - 203. T. (tualterianus Phil. (Trochus). i. c. R. - s. r. Bo. M. V. - 204. T. millegrau us Phil. i. c. R. V. - 205. T. I il ugeri Payr. s. 1. Bo. M. V. - 206. 'I'. striatus Lin. i. C. R. - - - c. Bo. M. V. - 207. T. exasperatus Penn. i. c. Mt. R. - s. r. Bo. M. T. - 208. T. turgi u us Broccli. i. c. R. - s. r. Bo. V. - 209. T. tumidulus Aradis. i. r. R. V. - 210. T. granulatus B3oru. $\therefore$ R. Bo. V. - 211. T. magns Lin. i. C. NIt. R. - \&. l. Bo. V. -212. 'T. Gutaduur Phil. i. r. R. V. - 213. T. Fermonii Parr. i. r. R. $\therefore$ R. IR. MI. V. - 214. T. Ad ansonii Payro i. c. R. T. - 215. T. rarius Lin. s. r. Ri. V. - 210. T', umbiliearis Lin. i. 1. R. V. - 217. 'T. Ri-

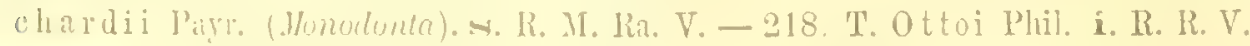

Cimculus. - 219. O. Striatus Phil. (Fuluata?). i. 1. li. V.

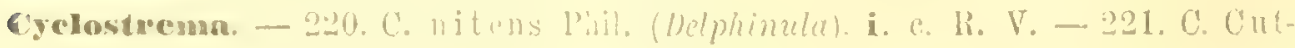

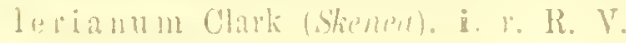


Scissurellar. - 222. S. erispata Flem, i. R. R, r.

Maliotis. - 223. H. lamellosin Lamk. i. c. Mt. R. V.

Crepidula. - 224. C. Monlins i i Michant. s. R. II. V.

Calyutrater, - 225. C. chinensis Lin. (Patella). i. C. R. - s. r. Ra. M. V.

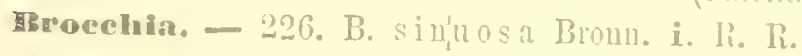

Capulas. - 227. C. In ungaricus Lin. (Patelle). i. c. R. V.

Fissurella. - 228. F. costaria. (Basterot) Phil. i. 1. R. - s. r. Bo. II. T. 229. F. gibba Plilipri. i. e. R. V.

Emarginula. - 230. F. fisstura Liu. (Putella), i. l. R. - s. 1. 1T. V. - 231. E. solidula 0. G. Costa. i. r. R. V.

Tecture. - 232. T. un icolor Forbes (Lollit). i. I. R. V.

Pratella. - 233. P. coerulea Lin. i. r. R. Ga. - s. r. Ra. II. V. - 234. P. aspera Lamk. S. I. M. V.

Chiron. - 235. C. olivacaeus Spengl. i. r. R. V. - 236. C. Poli Philipui (non Deshayes), i. 1. R. V.

ceanthochites. - 237. A. fascienlaris Lin. (Chilon). i. r. R. Y.

\section{Classe. SolenoconciI.}

Dentalium. - 238. D. vulgare Da Costa. i. c. R. - s. r. Bo. V. - 239. D. dentalis Lin. i. c. R. - S. C. Bo. Ra. V. - 240. D. norem-costatum Lamk. s. r. Ra. V. - 241. D. rubescens Deshiyes. i. l. R. - s. 1. Bo. T. 242. D. agile Sars. s. 1: Bo. V.

Siphonodentalium. - 243. S. lofotellso Sars. i. R. R. V.

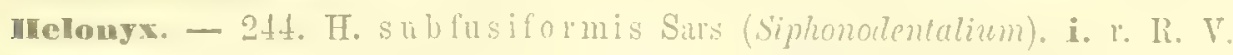

Cadulus. - 245. C. cyathus? De Crist. ot Jan. (Creseis). i. R. R.

\section{Classe. Pteroponi.}

Embolus. - 240. E. rostralis Souleyet (Spirialis), i. r. R. - - r. r. Bo. V. Spiroralis. - 247. S. lotroversus Fleming (linsus). i. c. R. V.

Hyalaca. - 248. H. trispinosa Les. . I. Bo. V. - 249. H. quallillentata Los. Riferisco a questa piccola specie, che vivo nolle Indie occilentali, pochi esemplari che per essere troneati posteriormente, pei quattro dentelli di cui il margine è fornito, prex la forma globosa o pegli altri caratteri par che ben si allicano a quella forma rivente. Ho potuto comparare i miei eseduplari con alcuni dulla collezione Benoit provenienti lal mare Rosso. s. r: Bo. V.

Cleadora. - 250. C. pyramiata Lin. (Clio). i. C. R. - s. C. Bo. MI. V.

\section{Classe. Inamedibranchi.}

Xylophnga. - 251. X. dorsalis 'Turt. (Teredo), i. r. R. - s. c. 130. V. Gastrochacna. - 252 . G. dubia Penu. (My/u). i. 1. R. - s. r. Bo. V.

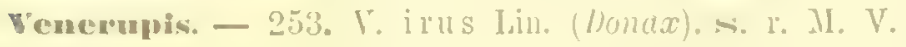

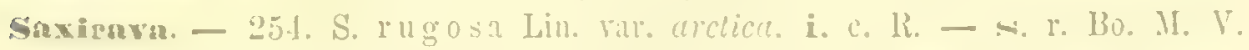

Corlunia. - 255. G. g ibba Olivi (Tellina). i. c. R. - s. c. Bo. Ril. V.

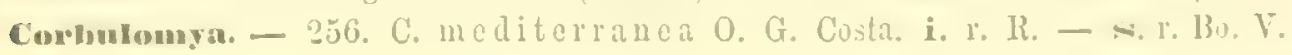




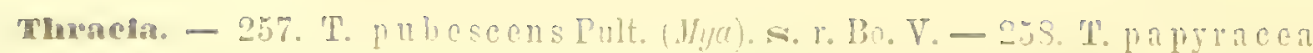
Poli (Tellinu). i. 1. R. Y. - 259. T'. courexa W. Wool. (Mya). i. r. IIt. R. - - r. Bo, T. - 230. T. eorbuloides Desh. s. r. Bo. T. - 261. T. distorta Inontg. (U!jue). N. 1. Bo. V.

verera. - 202. N. eucpilata Olivi (Tellina). i. R. R. - s. r. Bo. V.

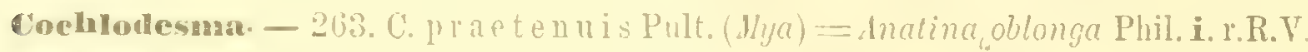
Pondora. - 264. P. in a equiraltis Lin. (Tullina). i. I. R. - s. 1. Bo. V. Solen. - 265. S. ensis Lin. i. c. R. V.

Solecurtus. - 266. S. strigilatus Lin. (Solen). s. r. Bo. T. - 267. S. can. diolus (Ren). Brocchi, i. c. R. V. - 208. S. antiquatus Pult. (Solen). i. c. R. - s. C. I30. Ra. T.

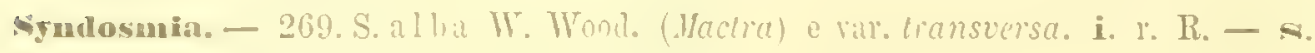
r. Bo. Ra. T. - 270. S. llismatica Mtg. (Ligula). i. r. 1R. - s. 1. Bo. V.

Lutraria. - 271. L. elliptica Lank. i. 1: MIt. $\nabla$.

Mactra. - 272. M. corallina Lin. i. r. R. - s. r. Bo. V. - 273. M. solida l.in. i. e. R. T. - 27t. II. subtrucala Da Costa (Trigonella). i. a. R. IIt. - - . c. Bu, Rir. T.

Erovilia. - 275. E. castanea Mnntagu (Donax.) i. C. R. IIt. - s. C. Bo. Ra. V. Donax. - 276. D. renusta Poli. i. r. R. - s. r. Bo. Y. - 277.D. polita Poli (Tellina). i. 1. R. - s. r. Bu. Ra. V. - 278. D. semistriata Poli. s. r. Ra. V.

Psammolbia. - 270. P. costulata Turton. i. 1'. R. - s. r. Bo. MI. T. - 280. P. ferroens is Chemn. (Tellina). i. C. R. - s. C. Bo. T. - 281. P. respertima Chemn. (Lax). s. 1\%, Bo. Ra. V.

Tellina. - 282. T. planata Liu. s. B. Bo. V. - 2S3. T. nitida Poli. i. C. R. - s. c. Bo. V. - 284. T. compressa Brocchi. Vire sulle coste d'Algeria. -. r. Bo. Ra. V. - 285. 'I'. Ionacina Lin. i. c. R. - s. c. Bo. Ra. V. 286. T. distorta Puli, i. r. R. - s. r. 130. Ri. V. - 287. T. pusilla Pliil. i. c. R. - s. c. Bo. T. - 28s. T. pulehella Lamk. i. c. h. - s. c. Bo.

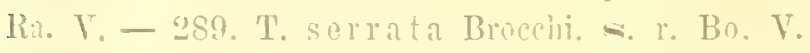

Arcopagia. - 290. A. crissa Penn. (Tellina). i. 1. R. - s. r. Bo. V. - 291. A. bal a llstina, Lin. (Tellina). S. Y. Bo, Y.

Tapes. - 292. T. decussatus Lin. (lenus). - - c. Bo. V. - 293. T. edulis Chemn. (lemus.) ‥ C. R. - s. C. B . II. V.

Venus. - 294. Y. rerrucosa Lin. i. C. Mt. R. - S. c. MI. V. - 295. V.casina Lin. i. c. R. MIt. - s. r. Bo. M. V. - 296. T. Rusterucii Payr. i. C. R. MIt. - s. c. Bo. M. V. - 297. V. efiossa Bir. i. r. R. - s. c. Bn. II. V. - 298. V. Gallina Lin. i. c. R. - s. c. Bo. Ra. V. - 299. V. Brongniatii Payr. i. c. R. - s. c. Bo. V. - 300. V. orata Penu. i. C. Mt. R. - - U. 13o. Tha. M. V. - 301. V. rud is Poli. i. C. R. - s. c.Bo. M. T. - 302. T. Ifediterralnea Tils. (Cyherea). i. C. R. - - s. C. Bo. Ra. V.

Dosinia. - ¿03. D. a goleta Lin. (lenus). i. C. Itt. R, - - e. Bo. MI. V. 304. D. lineta Plilt. (lenus). i. (. R. - - . c. Bo. MI. V. - 305. D. lupinus Poli (lenus). i. r. R. - - - c. 130. Rr. V.

Gyerea. - 300. C. Chione Lin. (Tenus). i. C. Mt. R. - s. C. Bo. Ra. M. V. 
Crpring. - 307. C. islandion Lin. (Tenus). Vironei mari del Nord. i. r. R V. Circe. - 308. C. minima Montign (f'enus). i. c. R. - N. C. Bo. Ra. V.

Crassatella. - 309. C. planata Calcim (Astarte). i. r. I. V.

Astrute. - 310. A. Cusca Poli (Tellina). i. c. R. - S. H. M. V. - 311. A. suleata Dia Costa (Pictunculus). i. c. R. MIt.- - r. M. V. - 312. A. trian. gularis Nontg. (Hactra). Colin vilietì a margine non crenato. i. c. R. - s. r. Bo. M. V. - 313. A. hipretita Philiph (Lucina?). i. r. R. - S. I. I3. II. Y.

Chama. - 314. C. gryphoikes Lin, i. 1. R. - - . 1. Bo. Ra. T.

Copricnrolis. - 315. C. lithophagolla Lamk. = Venempis Romani Culcaria. i. R. R. V.

Cardita. - 316. C. antiquata Lin. (Chama). i. 1. R. V. - 317. C. a culoati Poli (Chama).i. r. R. - s. r. Bo. V. - 318. C. tra lezia Lin. (Chama) i. r. Bo. V. - 319. C. corhis Phil. i. r. R. V.

Cardimm. - 320. C. aculeatum Lin. s. r. Bn. V. - 321. C. erinaceum Lin. i. I. R. - S. 1: Bo. M. V. - 322. C. e chinatum Liu. a la rar. Meshayesii Payr, i. c. R. MIt, - S. c. Bo. Ri. MI. V. - 323. C. pan e icostatum Sow. s.1. Ra. V. - 324. C. tuberculatum Lin. i. a. Mt. R. - s. r. Bo. Ra. V. 325. (. papillosum Poli, i. c. R. Mt. V. - ‥ c. 130 Ra. M. V. - 326. C. fasciatum Iontagu. i. r. R. - s. r. Bo. Ri. V. - 327. C. roseum Laink. i. r. R. - s. r. Bo. Rr. MI. V. - 328. C. minimum Phil. i. r. R. - 心. r. IR. V. - 329. C. oxigum Gm. = C. subangulatum Scatchi. i. r. Ir. s. r. Bo, V. - 330. C. Lamalki i Reere. i. C. Mt. R. - s. C. Bn. It. V. 331. C. oblongum Chemn, i. c. R. V. - s. C. Bo. M. V. - 332. C. Nolregicum Spengler, i. c. R. - s. e. Bo. Ri. II. V.

Diplodouta. - 333. D. rotundata Mnntagu (Tellina). i. r. R. - S. 1. Bo. V. 334. D intermedia Biondi. i. l. R. V. - 3:5. D. an icalis Phil. (Tellina). i. c. R. - s. r. M. V. - 336. D. Sarigny i? Vaillant. L'unica Falva che riferisco a questa specic sembra più larga e meno globosa della vivente del mare Rosso; la ruale d'altronle è molto rariabile. $\rightarrow$. R. Bo. V.

Axinus. - 337. A. flexuosus MItg. (Tellina). A. R. Bo. Y.

woodin. - 338. W. digitalia Lin.(Tellina). i. C. R. - - ‥ Bo. M. V.

Jagonia. - 339. J. reticulata Puli (Telliná). i. r. R. - s. r. Br. R. . II. V.

Lucina. - 340. L. borealis Lin. (lenus). i. c. I. - s. c. B3o. V. - 341. I. spinifera Montuga (I'enus). i. c. R. - r.e. B30. V.

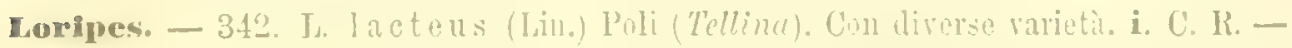

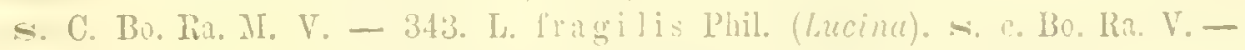
344. L. livaricatus Lin. (Tellina). i. c. R.- - s. c. Bo. Lit. II. V.

345. L. Snithit 11. En. 'Tay. XVll. fig. 44.

Specie analoga al L. transversus (Brocehi), piil allunsata trasiersalmente, col lato anteriore prominento ed angolesn.

\section{Lunghezza 19.m Larghezza $23.50^{\mathrm{mm}}$}

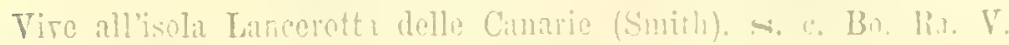

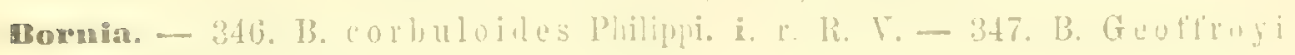
Paymuleau (Erycime). A. R. Br. V. 
Kenno - 348. K. suborbicularis Montagu (Wya) = Bornia infala Phil. i. r. R. V.

Screchin. - 349. S. exigua Brugnome. S. R. Bo.

Montreuta. - 350. M. bidentata Montagu (Mya). i. 1. R. - s. 1: Bo. T. 351. M. substriata Montagu (Ligula). s. r. Bo. V.

Repton. - 352. L. nitilnm Turton. i. c. R. - s, r. Bo, V.

Area. - 353. A. Noae. Lin. i. r. R. - s. x. Bo. Ra. V. - 354. A. tetragona Poli. i. c. R. - s. r. Bo. MI. V. - 355. A. barbata Lin. i. r. R. - s. r. II. V. - 356. A. Polii Mayer. i.r. R. - s. r. Bo. V. - 357. A. diluvii? Lamk. Quest' Arca moltissimo somiglia ad una varietit rigonfia della speeie mio. cenica, ma ha jure qualche carattere che la differenzin. s. r. Bo. - 358. A. lactea Lin. i. c. R. V. - s. r. Bo. M. V. - 359. A. pulchella Reeve= A. imbricate Poli (non Brug). S. R. Ra. V. - 360. A. scabra Poli i.r. R. s. I. Bo. M. V. - 361. A. ol, liqun Plit. (non Reere). i. r. R. - s. r. M. V. - 362. A. peatunculoides Sencehi。 i. 1.R. - S. I. Bo. MI. V.

Pecrumenlus: - 363. P. bimaculatus Poli (Area). i. C. It. R. - s. r. Ril. II. V. - 364. P. pilosus Lin. (Arce). i. c. R. - s. c. M. Bo. V. - 365. P. yiolacesceus Inamk. i. c. Mt. R. - s. C. Bo. Ra. V.

Lmopsis. - 366. L. a $n$ rita Brocchi (lrca). i. r. R. - s. 1. Bo. V. - 367. L. minuta Phil. (Pectunculus). i. r. R. V. - 368. L. tounis Seg. $=$ L. anomala. Monterosato (non Eichw.). i. R. R. V. - 369. L. pygma a Plil. Var. major. i. r. R. - s. I. M. V.

Nucula. - 370. N. sulcata Bromu. i. 1. R. - s. 1. Bo. M. V. - 371. N. uиcleus Lin. (Area). i. r. R. - - r. Bo. M. V. - 372. N. nitida G. B. Sow. i. r. R. T. - 373. N. decipiens Phil, Vatrageensis Eorbes. i. R. R. - s. r. Pi... Y

Lembulus. - 374. L. lella Lin. (Arca). i. 1. R. - s. c. Bo, Ril. V. - 375. I. commutatus Phil. (Nucula). i. C.R. V.

Yoldia. - 376. Y. ten uis Pliil. (Nucula). i. r. R. V.

Modiolarin. - 377. M. discols Linn. (Mytilus). S. I. Bo. V. - 378. M1. ma!morata Follies (Mylilus). \&. R. Bo. V.

Modiola. - 379. M. modiolus Lin. (Mylilus). Specio vivente noi mari del Nori. Si riecolgono esemplari gignteschi. i. r. K. V. - 380. M. barbata Lin. (M!) tilus). s. r. 130. M. V. - 381. M, pllaseolina Phil. i. c. R. - - . r. M. V.

Mytilus. - 382. M. Gallopropincialis Lamk. i. c. MIt. R. - s. r. Ka. V.

Pinna. - 383. P. noljilis Linn. i. R. IR. V. - 384. P. pernula Chemn. 1. In, Y.

Lman. - 385. L. s fu anosir Lank. i. c. R. V. - 386. L. tanera Turton. i. r. R. V. - 387. L. Losenmbii (t. B Sow. i. r. R. - s. r. Bo. V.

Limen. - 388. I. niren (Ren.) Brocehi. i. r. IR. V.

Pecten. - 389. P. mullistratus Poli (Ostrea). i. o. Mt. R. P. Ga. - N. r. II. V. - 300. P. ratius Lin. (Ostret). i. e. R. Mt. - - r. MI. V. - 391. P. operenlaris Jin. (Ostra) a rill. P. senguineres Poli. i. C. Mt. R. Ga. P. -

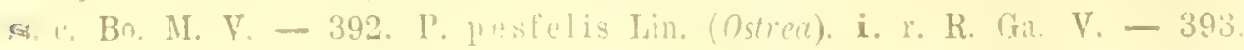


I'. pestutrae Limn. (Ostrece). Vive nei mari del Nord. i. C. IR. 1'. Ga. T. 394. P. inflexus Poli (Ostrea). i. c. R. Ga. V. - 395. P. floxuosus Poli (Ostrea) $=P$. polymorphus Bronn. - r. r Bo. M. V. - 396. P. tignrinus IIuller: Specie clei mari del Nori. Raccolsi diverse varietit. i. r. R. V. - 397. P. Bl'u i Payraul. -i. r. R. V. - 398. P. commutatus Monterosato. i. I. R. - - - r. Bo. Ri. V. - 399. P. striatus Mullor (non r. MLuster) = P. Turnaboni BBomli, P. vimulosus Phil. s. R. II. V. - 400. P. ritreus Chemm. (Pullium), i. r. R. - - r. Bo. V. - 401. P. Testae Birona. i. r. R. V. - 402. P. similis Laskey. i. c. R. - s. r. Bo, V.

Jauira. - 403. J. Jacobata Lin. (Ostrea). i. C. Mt. R. P. - s. c. Bo. Ra. II. V. Var. simplex n. Piccola, con costole leggermente soleate, u rrive alliatto di solchi. i. r. R. - s. I. Bu. Ra. - 404. J. maxima Lin. (Ostrea). i. l. R. V. spomilylus. - 405. S. gatederopus Lis. i. c. Mt. R. - s. l. lia. Bo. M. V.

Ostren. - 406 0. edulis Lin. i. e. R. MIt. - c. B. Bo. Ra. V. - 407. U. Cyru us i Payr. i. r. R. Mtt. - r. r. Bo. V. - 408. O. cochlear Poli. i. c. R. P. Mt. Ga. - s. r. Rn. V.

Anomia. - 409. A. eplippium Lin. Con mumerose varietir. i. C. R. Mt. Ga. s. c. Bo. M. V. - 410. A. or bieulata Broceni. i. 1. P. - S. r. M. V. - 411. A. patelliformis Lin. i. r. R. - s. r. M. V. - 412. A. striata Brucch. i. R. P. Ga.

Clisse. Brachiopodi.

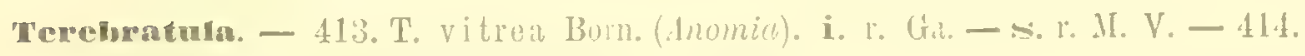
T. minol Phil. i. I. R. Git, - «. I. Ho. M. V.

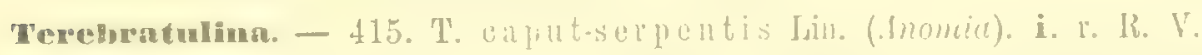

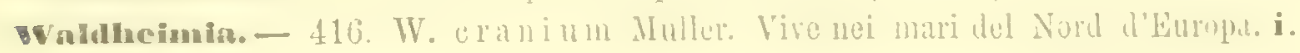
r. R. Gial. V.

Megerolan. - 117. M. truncata Lin. (Anomict). i. l' R. V.

Argiope - 418. A. deeollata Chemn. (Anomici). i. r. R. - - . I. Bu. II. V.

Cistolla. - 419. C. cuncata Misso (Terebratule). i. r. R. - s. 1. Bu. Il. V.

Tino. A RTROPODI.

\section{Classe. Crostacei.}

Dei Crostacei superiori sompro frammonti indeterminahili spuciticamente, tiunto nella zona inferiore quanto nella superiore

Ordine. Ostraconi.

Paracypris. - 420. P. polita G. O. Sars. Vato Mubia n.

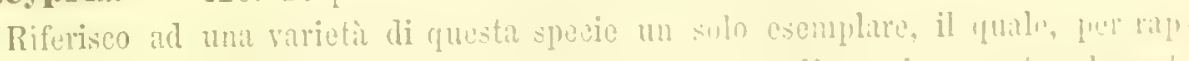

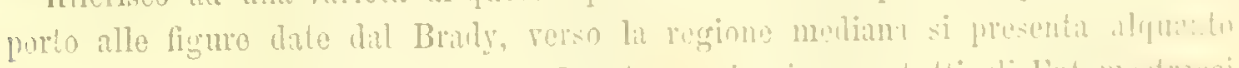

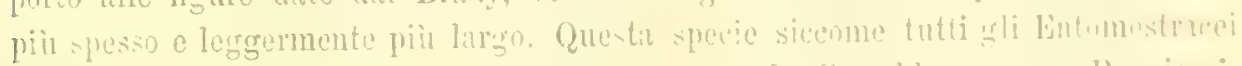

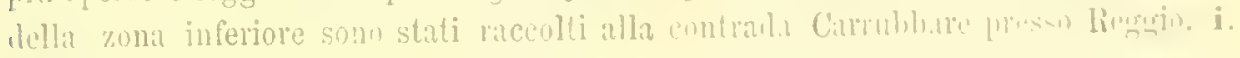
R. IR. $V$. 
Pontocypris. - 421. P. sagittula Terquem. Var. Calabran.

Por questa forma che probabilmente dovai distinguersi specificamente vedi gli Eutomostracei del plioceno superiore. i. R. R.

422. P. variolata n. sp. Tav. XVII. fig. 45.

Questa è specie molto somigliante alla $P$. semulate, dilla quale ne è pure distintissima per essere ben più acuta alla sua estremitì posteriore, per due angoli distinti sulla regione dorsale, ner un seno più profondo alla regione ventrale, e per la superficio sparsa di numerose prestolette irregolarmente distribuite.

$$
\text { Lunghezza 0,57.m Larghezza } 0,3 . \mathrm{mm} \text { i. r. R. }
$$

423. P. mytiloides Noman (Cythere) = Cythere avence Norman, Cypris serrulata G. O. Sars. I pochi esemplari raccolti rispondono bene alla forma virento dei mari del Nord. i. r. R. - s. R. Bo. V. - 424. P. trigonella G. 0. Sars. Qualche raro esemplare, i. r. R. V.

Baimular. - 425. B. subdel toidea. Von Munster (Cythere). Questa specie comune cd estesamente sparsa presenta in ambe le zone delle varieti di grandezzil e di forma, tra le quali una gracile. i. c. R. Ga. - s. c. Bo. Ra. V.

426. B. reniformis n. sp. Tav. XVII. fig. $46,46 a$.

Specie molto affine alla vivente $B$. Bosquetiana Brady, dalla quale difforisec per avere forma alquanto più allungata, colle due estremitic un po' più ristrette e quasi esattamente uguali, più incavato il margine ventrale, lo spessore della conchiglia è rimareherole alle due estremitì e pressochè uguale e di poco inferiore allo spessore della regione mediana.

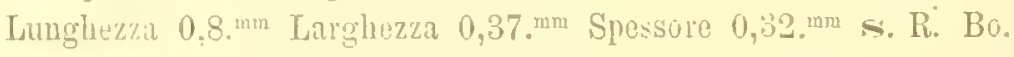

Cythere. - 427. C. subiaqualis n. sp.

Questa specie lia qualehe analogir nellil suib lorma grenerale ed anco nella scultura, colla $C$. villosu Sars, ma ne differisce per molí particolari, dir forma è piu allungata, l'estremitì posteriore al(yuinto più ristretta dell'anteriure, od ambo quelle regioni cinte da un mangine stretto el appianato; la superticio delle valve convossa presenta su ciascuna una prominenza ottusa verso la regione supero-posteriore ed ¿ ornata da infossature augolose, ben marginate, e contigue, più piccole di quelle della specie cit. La congiunzione delle valve forma una carena prominente ed acuta.

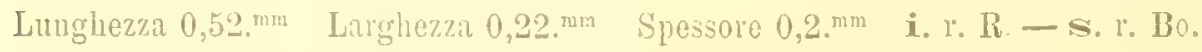
428. C. oblonga Brady. Questa specie risponde precisamente alla forma rivente nel Mediteranoo e nei mari settentrionali. i. r. R. V. - s. Oltre la forma tipica la Var. eximia n. Questa forma í hen distinta perchè più ristretta all' estremiti posteriore che ì ben arrotondatia, l'anteriore inrece è dilatatia c fornita l'un margine arenato el aplianato, entrambe finissimamente dentellate al margine, l'ornamentazione della superticie is considerevolmente più sottile. r. Bo. V. 129. C. interposita 11. sp.

Questa è vicina alla preculente ed allia C. costata Blady, ma presenta un margine anteriore appianato e piegheltato, il posteriore stretto e depresso, la superlitie presentasi rugosa per prominenze irregolari ed infossamenti interposti, il margine ventrale è un fro' concavo.

$$
\text { Langhezza 0,9.mm Largheza } 0,19 . \mathrm{mm} \quad \text { i. R. R. }
$$


430. C. con resa Baird $=$ C. arborescens Brads. Un po" variabile nella sunlum. i. r. R. - s. c. Bo, V,

431. C. quadridentatar Bard. Var. tenuis n.

Questa forma ì ben distinta dal tipo, essa manca di circna sulle valre, ha una scultura fina e quasi regolare, la regione anterioro quasi marginatil o finamente dentata dal lato ventrale, i quattro denti della regione posteriore hen distinti quautunçue pì̀ tosto piccoli.

Liughezza 0,51. ${ }^{\text {mm }}$ Larghezza 0,27. mm Spessore 0,2 mm i. R. R. V. - - . 1 . Bo. V. 432. C. emaciata Brady. Risponde bene alle fignre date dall'antore e piir specialmente alla forma che porta il margine anteriore fornito di fine dentellature. A. r. Bo. V. - 433. C. Whiteii Baird (Cythereis). Questa specie differisce lievemente dalle figmre date dal Brady, solo perche to due serio di grrossi twhercoli che ornano lo valre, sono un po"meno appariscenti, perche meno grossi e meno prominenti i tubercoli stessi. $\leftrightarrow, r . B 0$. V. - 434. C. antiquat a Bamb (Cythereis). Questa importante specie risponde bone alla vivente che ha sì larea distribuzione nel Nord, nell'Atlantico come nel Mediteraneo. s. c. Bo. V. -435. C. Edwards i Roemer (Cypridina). Var. subinermis r. Questa rarieta differisce dal tipo perchè le dentellature del margine anteriore sono ottuse e poco visibili, inoltre per le due carene o costole meno estese, più oblique e molto sporgenti. S. R. Bo. - 436. C. plicatula Reuss (Cyprilina). L'unico esemplare raceolto risponde esattamente alle figme date dal Brady della forma trovata rivente a Smirne e in Oriente. $\subseteq$. R. Bo, V. - 437. C. senilis R. Jones (Cylhereis). I miei pochissimi esemplari rispondono medioeremente alle figure date dal Terquem. n. I. Br. I.

438. C. rugosa n. sp. Tar. XVII. fig. 55.

Questa Cythere ricorda in qualcho modo la C. fabellata dol Tortoniano, pol margine radialmente preghettato e per Ia scultura analoga; ma lil forma del Quaternario è piì allungata, colle regioni estreme areuate e prive d'ogni maniera d'angolosità, col margine più stretto e senza denti alla regione inferioro.

Lunghezza $0,6 .^{\mathrm{mm}}$ Larghezza $0,28 .^{\mathrm{mm}} \approx \mathrm{r} . \mathrm{B}$.

Cytherillea. - 439. C. angulosa n. sp. 'Tir. IVII. Aig. 47, 47亿

Questa specie si arvicina molto alla virente C. papillosa Bosquet, ma distinguesi assai bene per lo augolositit piì mareate e per la diversa scultura. Difatti la forma generale è ovato-quadrangola, due angoli ottusi sulla regione dorsale, li regione posteriore ì molto sporgente in forma angolosa coll'estremitil rotondatil, Ia regione anteriore è meno prominente o piì rotonlata, il margine ventrale un po'flessuoso, la superficio regolarmente convessia ed ormata di pustoletto rinte, d'una finissima e foltissina puntegriatura.

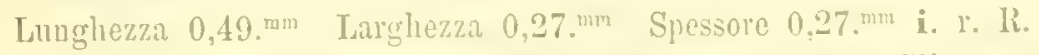
440. C. punctillata Budy = Cuprieleis proxima G. O. Sars. Gli csemplari raccolti ricoldano le Vitrie figure e le diverse forme descritte dal Brady. i. r. R. V. 441. C. elongata Brady = Cylhere anguseala Baird. Due soli esmmplari lierissimamente differenti dalla forma del Nord figurata daI Braly, -. r. Bo. V.

442. C. vitroa u. sp. 'Tar. XVL. fig. 18, $48 \pi$. 
Questir specie distinguesi per In sua forma ellittico-oblonga, compressa, e per il suo aspetto ritreo, perlochè la covchiglia è trislucida; la regione anteriore è piì larga della posteriore ed entrambe ben arrotondate, l'ultima presenta delle rugositia obliquo-trasserse; il margine rentrale è un po' concaro, la superficic finamente papillosia.

Lunghezza $0,49{ }^{\text {mmm }}$ Larghezza $0,24 .^{\mathrm{mm}}$ Spessore $0,15 .^{\mathrm{mm}}$ i. r. R. V.

443. C. exilis $11 . \mathrm{sp}$.

Questa e molto affine alla $C$. clongata, e si distingue bene per la sua pieciolezza, e più aucoril per ambe le estremitì consilererolmente piir assottigliate; il margine rentrale presenta rerso lis metì ma leggiera simuositì.

Lunghezzal $0,52 .^{\mathrm{mm}}$ Larghezz $0,16 \mathrm{~m}^{\mathrm{mm}}$ Spessne $0,15 \mathrm{~m}^{\mathrm{mm}}$ i. r. R.

Loxnconchn. - 444. I. implessa Baird (Cythere). Questa specie raccogliesi con tutte le rarie modificazioni che suole offrire, i. 1 . R. V. - - - C. Bo. V. 445. L. granulata Sars. La forma che riferisco a questa specio è veramente affine alla precedente, come dico il Brady, ma la scultura i formata di esili macchiette o granuli bianchi che spiccano assai bene sul fondo traslucido della esile sostanza della conchiglia. i. 1. R. - - s. c. Bo. V. - 446. L. ellipicica Brady. Ben distinta pel margine stretto, e per la fina junteggiatura dello valve, oltre le grandi lustolette della snperficie. i. r. R. - s. c. Bo. V.

Xestoleberis. - 447. X. depres a G. 0. Sars. Questa comunissima specie risponte esattamente nui snoi caratteri e melle sue modificazioni alla rivente fipica dei mari del Norid. i. r. R. - s. C. Bo. V.

448. X. testudo ш. sp. Tav. XVII. fig. 50, 50 a.

Questa nuova specio è molto affine alla preceleute e punteggiati come quella, ma ne ì distintissima jei seguenti caratteri. La regione ventrale è perfettamente appiamata in modo che tale porzione è distintamente angolosa, guardata dal dorso o dal rentre la regione anteriore è pressochè ugualmente larga della posteriore e quindi l'insicme delli forma quasi ellittica. Guadata lateralmente la conchiglia ha la regione ventrale retta, due ottusi angoli sul dorso, che risulta appianato al centro, c gli estremi troneati obliquamente si terminano in angnli un po' rotonlati ayli estremi delia linea rentrale, dei quali l'anteriore più prominente

Lunghez7a 0,58.m Larghezza 0,29. ${ }^{\mathrm{mm}}$ Spessore 0,35. $\mathrm{mm}$ i. r. R.. 449. X. pustulosa u. sp. Tar. XVII. fig. 31, $31 a$.

Per la descriziono vedi i fossili lel plioceno superiore. Questa comunissima specic dul nostro Quatemario mostria lo piu grandi relazioni di afliniti colla l. labiala Brany, della quale non ha prominente l'angolo postero-ventrale, invece lo prosenta rotondato, nel resto conriene quasi esattamente. $\mathrm{*}$. C. Bo. - 450. X. a ur antia

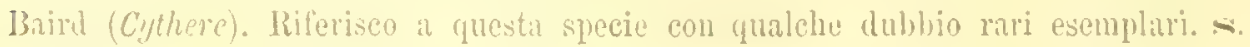
r. 130. V.

Gycherura. - 451. C. lincata 3ridy Var. subaptera 11.

Il mio mien esemplare rispoude henissimo alle figure date dall'antore ed alla descrizinne che le accompagna, ia furma alluugata della conchiglia indica che trattasi l'un individno masehio, del resto le costelle, le punteggiature cee. sono precisamente rispondenti asli esemplari inglesi, a la varietid da me stabilita i fondata 
soltanto sulla minore sporgenza ilelle prominenze laterili dello ralve, ol invec: sul maggiore prominenza dello sperone posteriore, il quale inoltre ò un po' meno ottuso.

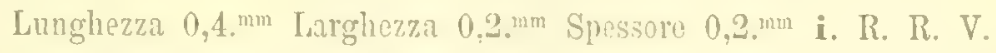

152. C. inversa n. sp. Tav. XVIr. fig. 51, 51a.

Questa elegante specie lia talune alliniti colla $C$. cuncuta Braty e specialmente quanto alla scultura essa l'imita esattamente essendo ornati di fima punteggiatura e di linee esili disposto in forma di roto irregolare, ma se ne distingue benissimo per la forma. Guardata lateralmente, il margino dorsale è fort.mente arcuato, la regione anteriore si restringe grado grado, la posteriore si prolunga in mu forte sperone, risulta cosi la regione mediana fortemente allargata; se gumilasi joi dal dorso ovvero dalla regione rentrale la conchiglia si presenta egualuente larga in tutta la lunghezza, rotondata all' estremo anteriore, vicino il quale sul dorso sono due granuli ben distinti; la regione posteriore mostra un piccolo ed acuto sperone mediano. Da questi caratteri ne ho derivato il nome specifico, dipppoichè la C. cuneata mostrasi nella sua lunghezza pressochè ngualmente larga guardata lateralmente, e cuneata alloreho osservasi dalla regiono dorsale o dalla ventrale, ed inrece arviene l'inverso nella $C$. inverse.

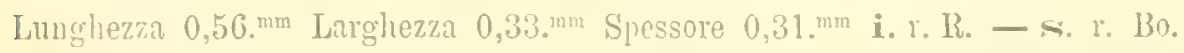

453. C. producta Brady. Var. micropiera n. La forma che denomino cosi nftre esnttimente la scultura della specie nelle sne punteggiature e nelle sue costole dorsali e sulamente diversifica per estere un pachino più lreve o specialunento per una maggior brevita delle ali laterili. i. R. R. V.

454. C. nevroptera n. sp. Tar. XVLr. fig. 52, 52a.

Questa mova specie è molto afline alla C. striata G. O. Sill's alla quale snmiglia principalmente per la forma, ma se ne listingue benissimo perchè porta due ale in forma di angoli acuti assai presso lo sperone posterioro e per la diveria conltura formata di nervature rilevate e reticolate.

Lunghezza 0,55 . $^{\text {mm }}$ Larghezza $0,25 .^{\mathrm{mm}}$ Spessore $0,25 . \mathrm{mm}$ i. R. R.

455. C. a e nticostata G. O. Sars. In raceolto alenne delle forme ligurate dal Brady tra gli Entomostracei riventi d'[nghilterra. i. 1. R. T.

Cytheropteron. - 456. C. calcaratum n. sp. Tar. XTIT. fig. 53, 5:3a.

Questa specie e ben distinta per la particolare forma dello sue valve che i) quella d'un triangolo sealeno molto allungato, il piccolo lato forma lia regione anteriore ohliqua e poco curva cogli angoli adiacenti rotondati, l'angolo opposto forma lo sperone robusto e prominente dulla regione posteriore, l'ala è prominente rolusta e forma un angolo ottuso, cinto dil un margine spesso e rugoso; la superticie i pruteggriato-rugosa.

Lunghezza 0,5. mm Spessore 0,27.mm Larghluzza $0,27 \mathrm{~mm}^{\mathrm{mm}}$ i. R. IR. 457. C. Bovettens is 11. sp. 'Tiv. XVII. fig. 54. 54a.

Questa specie si arvicina alquanto alla precerlento per l'andamento generale della sua forma incarata e come carenatia sulla regione dorsale, colle ali forti prominenti e marginate, e colla superticie rugoso-scabra, ma si listingue perfettamente perche le valve invece di essere triangolari sono arcuate anteriormente, 
pressochè d' nguale larghezza nolla loro lunghezza, si protent? no poi posteriormente in forma di sperone, formando due sinuosita alla regione supero-posteriore, ner le quali ne risulta un angolo molto sporgente tra le ali e lo sperone.

Lunghezza 0,56. mm Larghezza 0,25.mm Spessore $0,38$. mm $^{\mathrm{mm}}$ s. 1 . Bo.

Cytherideis. - 458. C. sub ul ata Braly. Vilr. fasciata Brady ot Robertson.

Il comune entomostriceo che denomino così rispondo esattamente alla forma illustrata dai due antori predetti (On Ostracola taken amongt. the Scilly Jslanis). Difatti la conchiglia risponde perfettamente nei particolari della forma delle sue varie parti; essa lia crenato il margine anteriore delle ralve, le quali variano solamente nella scultura, la quale sovente é formata da rare e distinte punteggiature. \& c. IB. V.

Pradoxostoma. - 459. P. ensiforme Brady. Var. tenue. L'mico esemplare raccolto differisce dal tipo per essere alquanto più stretto nella sua maggior larghezza, pel quale carattere costituisce la nominata rarietì. i. R. R. V.

Cstherelln. - 460. C. calabra n. sp. Tar. XVII. fig. 56, 56a.

Questa specie distingnesi dalle congeneri per nou essere angolosa, ma di forma orato-ohlonga colla regione posteriore rotondata ed alquanto più larga dell'anteriore, che si restringe gradatamente e si arrotonda anch'essa, un largo margine depresso cinge (nest'nltima estremitì offrendo delle strie ridianti esilissime, tale depressione piì o meno distinta si estende cingenlo ambe le ralre. Grarilata la conchiglia dal lato dorsale o dalla regione rentrale redesi che il suo maggiore spessore nou è come nel maggior numero delle specie presso la estremitì posteriole, ma si allontana da essa per cirea i due quinti della totale lunghezza. Ia stuperficie is sparsi li rare e fine punteggiature. Taluni esemplari sono pio breri e piì spessi degli altri, trattasi probabilmente d'individui femminei.

Lunghezza $0,84 .^{\mathrm{mm}}$ Larghezza $0,44{ }^{\mathrm{mm}}$ Spessore $0,36{ }^{\mathrm{nm}}$

Comune nella zona superiore, i) rarissima nell'inferiore. i. R. R. - S. c. Bo.

\section{Ordine. Cirripedi.}

RaIanus. - 461. B. tulip iformis Ellis. Rari esemplari che conservano il colo. rito. i. r. R. - s. r. Bo. V. - 462. B. spongicola Brome. Bei gruppi di individui impiantati sul Hurex trunculus. s. r. Bo. V.

Chramalus. - 463. C. stellatus Phil. Var. Di questo cimipedo s'incontrano le ralvo disgiunte, esso non trovasi in veruna zona o piano precedente, invece ì comme nel Mediterraneo ed in alti mari. s. r. Rr. V.

pachylasma. - 464. P. giganteum Philippi (Chtamalus). S'incontra qualche valra isolata. i. l. R. V.

Vermen. - 465. V. stromia Muller (Lepas). Trorasi in ralre staceate orrero in belli esemplari aderenti a varie conchiglie e sovente colle valve opercolari in posto. Giace sul Pecten opercularis o sulla Janira Jacobea. La forma comune is la tipiea, colle valve radialmente piegate. i. r. R. - s. Anco nella zona superiore si trovano belli esempari alerenti alle conchiglie e forniti di opercoli. Spettano allat forma tipiea ed incrostano la Venus casina, la Janira Jacobea ece. r. IBก. Ri. II. V. 


\section{Tipo. VERMI.}

Classe. Anetumi.

Psymobranclius. - 466. P. protensus Gmelin (Scrpulce). i. r. R. - - i. I3.. II. I

Filigrana. - 467. F, implexa Berkeley. Trovasi libera ovvero werente a varie specio di conchiglie. i. r. R. Gra. - $\leq$. 1". Bo. M. V.

Spirorbis. - 468. S. e $0 \mathrm{mmu}$ is Fleming = Serpula spirorbis. Donoran. i. 1 . R. - S. I. Bo. M. V. - 469. So laevis Quatr. i. c. R. - A. c. Bo. II. V. - 470. S. colnu-arietis Gube (Serpula). ì la specie più comune. i. C. R. - S. C. Bo. M. Ra. V. - 471. S. granulatus Lin. (Serpula). s. I. Bo. V.

Forterassa - 472. D. subulata Deshayes (Dentalium). i.c. R. Mo.— _. c. Bo. Ra. V.

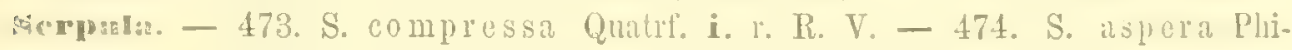
lippi. i. r. R. V.

Vermulia. - 475. V. infund ibulum Philipir. i. R. R. V. - 476. V. clongata Philippi. i. T. R. - s. e. Bo. M. Ra. V. - 477. V. trifida Quatrf. $=$ Serpula vermicularis Cuvier. i. c. R. - s. c. Bo. M. V. -478 . V. tricuspis Grube (Serpula). Forma degli ammassi agglomerati di molti indivilui fissi sopra ciottoli e sopra conchiglie. i. c. R. V. - 479. V. pectinata Grube (Serpula). i. r. R. V.

Bisogna avvertire che tutte le specie di Anellidi a conchiglia fissa frecelen. temente ricordate in ambe le zone si trovano indifferentemente attacente alle conchiglie varie o ad altri fossili, ma più comunemente alle grandi bivalvi.

Inoltre fil d'uopo avvertire che le specie entmerate sono quelle soltanto che ho creluto di poter uneglio riconoscero specificamente, dapnoichè non pocho altru restano dubbiamente definite yer la grave difilcoltir cle s'incontra ordinariamento nella determinazione specilica dei tubi degli anellidi.

Classe. Briozoarir.

Snficornaria. - 480. S. falciminoides Johnst. i. C. R. Ga. - R. C. Bo. Ra. II. $V$.

Serupucellaria. - 481. S. serupea Busk. i. r. R. - s. l. Bo. V. - 482. S. scruposa Lin. (Sertularia). S. 1. Bo. V.

Cellaria. - 483. C. cereoides Sol. et Ellis. i. 1. R. - A. I. Bo. V.

vyriozoon. - 484. M. truncitum Pallas (Jillepora). Questa comunissima specic del Mediterraneo trovasi anco comme nel Quatemario, i. c. R. Ga. - s. c. Bo. M. V.

Kripothon. - 485. H. caten ularia Jameson (Tubipora). Sulla Dosinia exoleta. i. r. R. - s. Sulle Cytherea Chione, Fenus cusina. I' effossa, Pechnoulus pilosus. P. bimaculatus, c. M. V. - 486. H. diraricati Isamour. Sul Curdium Norregicum. i. 1. R. - S. R. M. V. - 487. H. fligg 11 mm Manzoni. i. R. R. - - Inerosta le Fissurelle costariu, Cytherea Chione. Astarte sulcalu. Pichunculus bimaculatus. c. M. V. 


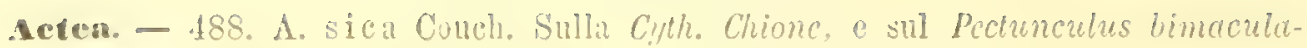
pus. s. I. M. V.

Calverea. - 489. C. B ory i Audouin (Crisia). s. r. Bo. V.

Membramipora. - 490. M. angulosa Reuss. Incrosta le segucnti specie, Cytherea Chione, Pecten opercularis, Eschara corvicornis ece. i, 1. R. Ga. - s. Incrosta le specie segnenti; Conus .... Triton corrugatus, Turbo rugosus, Vonus cllosse, Cyth. Chione, Pechunculus pilosus, P. violucescens ecc. e. Bo. Ra. M. V. 491. M. aperta Busk. Incrosta le specie seguenti: Cytherea Chione, Cardium aculeatum, Pechnculus pilosus, e violacescens, Myriozoon ece. i. c. Bo. MI. 192. 11. Flemingii Busk. Sul Buccinum striatum. i. r. R. - s. Sui Pectunculus violacescens, Ostrea ..... ece. r. Bo. Mr. V. - 493. II. irregularis D'Orbigny. Parmi doversi associare alla forme cosi denominata dal Manzoni una colonial Che trotasi su l'un' Ostrea. s. R. II. V. - 494. M. lineata Lim. Sulla Vemes linsterucii. i. r. R. - S. Sullo Strombus coronatus, e sulle IIactru trigona, Cythereu Chione, Pectunculus violacesecns. Dytrupe subulate ece. C. Bo. Ra. MI. T. - 495. M. Sararti A Audouin. Forse questa non ì che rarieti della II. Lacroixii Sitrigny. Inerosti il Cardium cchinatum a la Cytherea chione. s. i. Bo.V. - 496. M. trifolium S. Wool. Sul Cardium echinatum. Questa specio vive nei mari atiei. i. R. R. V. - 497. M. Rossolit Audouin. Sulla denire Jacobea. i. R. R. - s. Incrosta lir C'ytherea Chione. i Pectunculus bimaculatus c violacescens e la Junira, Jacobea. c. Bo. M. V. - 498. M. bidens Hag. Io credo di dovere riguardare come tali varie colonie di tenuissime cellule che incrostann il Trochus sizyphinus, la Venus casina, la V. Rusterucii, il Carlium oblongum, il Mytilus, il Myjiozonn esc. i. 1. R. - s. Anco nella zona superiore del Quatermario si umpagal cuesta specie, la quale redesi inerostare la l'enus effosse, lir Tapes elulis, la Cypheren Chione, i Pechunculus pilosus a bimacu. letus. r. M. - 499. II. Sinithii Manzoni. Snl Pecten operculuris. i. R. R 500. M. a ndegavousis Michelin Var. Questa forma incrosta la Cyprina islandica, il Pecton operculuris. i. 1. R. Ga. - 501. M. calpons is Busk. Sul Pe-

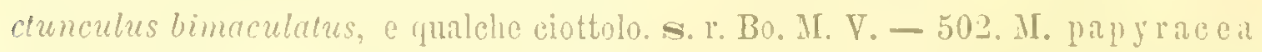
Rouss. Il Waters righarda questa forma siccome varietì della M. andegavensis, ma parmi che essa distiugresi per la forma allargati o romboidale delle cellule, pel difetto di collule trasformate in avicolari, e per altri particolari. Incrosta lo Cytherea Chione. Venus Rusterucii, Arcabarbata, Pectunculus glycimeris, Ostrea ..... cece. \&. 1. M.

Lepralia. - 503. L. coecin a Junston. Le colonie di questa specio nel Quaternario soro idontiche allo vivonti, esse inerostano lit Venus Rasterucii, il Myriozoon, i ciottolí. i. r. R. Ga. - - Incrosta le I'enus cffosse, Cylh. Chione, Pectunculus pilosus c bimuculatus, Ostrea cochlert. c. Bo. N. V. - 504. I. innom iunta Conch. Sulla ienus Busterucii. i. r. R. - s. Inerosta Ia Cytherea Chone. i Pechunculus pilosus e bimuculatus e l'Ostrea cochlear. C. Bo. II. V. - 505. L.

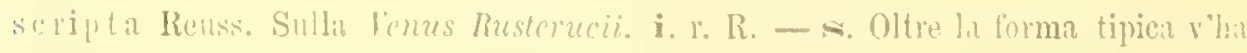
melegante rarieti, nrmita li gresse perfur.zioni disposte con regolariti negli spazi

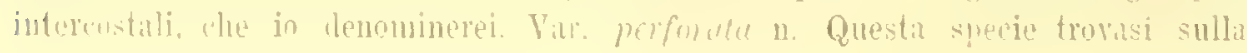


Cythrea Chione, il Pechnculus bimaculatus e violacescens. costrea cochlear. c. Bo. Mr, V.

506. L. planicosta n. \$1. = L. scripte? Manzuni. Come nel plinceno anco nel Quaternario redesi questa forma di Lopruliu ehe credo distinta dalli $L$. scripta. Tropata sulla Venus. Rusterucii on il Pechunculus bimuculatus. i. 1. R. - 507. L. ansata Jonston. Al solito si presenta mollo variabile nella forma angolosa o rotomiata dello cellute, nd llit prescnza di due o di un solo aviculario ece. Inerosta le sprecie seguenti: Brochia sinuosa. Cytherea Chione, Dosinia cxoleta. Vonus Rusterucii, V. Brongniartii, C'arlium Noreegioum, Chamu gryphoides, Lawina borechis, Pechunculus pilosus. Pecten opercularis ece. i. c. R. - - - Giace sullo Strombus coronatus, la lienus effossa, lil Cytherea Chione, il Peciunculus bimaculatus e pilnsus, 10 Spomlylus gaciteropus, 1'()strea ece. c. 130. Ra. M. Y. 508. 1. unicornis Johnston. Questa forma vieno da talino asschata alla precerlente, da altri all. L. spinifere, in la mantengo distinta perehi essi si presenta costinte uella sua forma con cellule piu grandi della precedente, con ariculari ancor piu grandi di quelli rappresentati hal Busk e disposti diversamente di come nella L. ansala, ordiuariamente un soln. Sulla Cytherea Chione, e l'Anomia patelliformis. i. 1. R. - S. Inorosta il Triton corrugalus, il Turborugosus. i

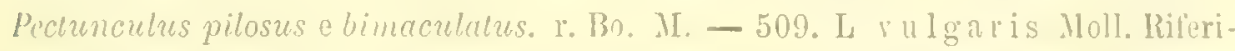
sen a questa specie varie colonio che incrustano lit Modinle modiolus, il Pectunculus pilosus. i. 1. R. - - \$. Sullit Fissurelle costaria, Cytherea Chione, Pectunculus bimaculatus, Spondylus gaedcropus, Os'rea cochlear. c. Bo. M. V. 510. L. Bronguiartii Audoniu. Sulla Turritella communis e la lenus Brongniurtii. i. r. R. - S. Inernstr le specie seguenti: C'ylherea Chione. l'enus cusina, Tapes celulis, Pectunculus bimaculatus, Jinira Jacobea. r. Bo. .I. V. - 511. L. a u r i cu lat a Hass. Questa specie presentil le diverse forme illustrate dal sig. Waters, lo cellule oria fornite el ora siomite di oricello e del grande aviculare, che sovente giace da un 1oto. In una grande colonia si passa per gratarioni verso lat varieti che il Waturs dhiamò Leonliniensis. Trovasi sul Peclunculus violacescens, la Vylyerea Chione, il Pectunculus bimaculatus, la Janira Jacobea cce. - - I. Bu. II. V. 512. L. violacea Johnst. Incrostit eon liughe colnnie il Buccinum undatum, lit Turritella triplieate, la tenus verrucosa, la I: Rusterucii, la Cythered Chione. il Cardium Worvegicum, la i)osinia exoleta, la Tupes cdulis, il Mytilus coe. i. C. R. - s. Sul Conus ..., il Titon corrugatus, lo Strombus coronatus. Io Cylheren Chione, Dosinia exoleta. Tapes ednlis, Cardium Porregicum, Pectunculus pilosus, P. bimaculatus, P. violacescens, Janira Jacobea ece. C. Bo. M. Ra. V. 513. L. ciliata Pallas. Variabile come suole essere questa specie l'ho raceolto sul Cardium oblongum, e sul Pecten upercularis. i. 1. 1R. - s. Trorasi sulla Cy. therea Chione. lia Vonus Rusterucii, la Tapes alulis, il Pectunculus Limuculalus, lo Spondylus gaceleropus. e. II. V.

514. I. Calabra 11. sp. (vedi fossili zaneleani). Sul Mytilus galloprovinciclis.

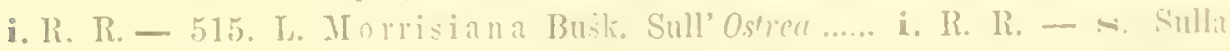

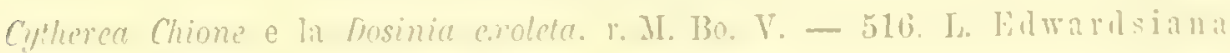

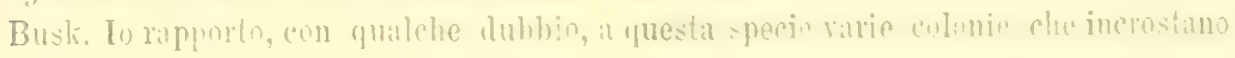




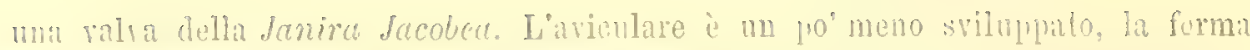
dellapatura e l'oricallo presso a poco rispontono, la superficio è con incasi o prominenze, e dubluimente perforatit. s. R. Bo. - 517. L. II alusii dul. Questa distinta specie incrosta lia r. Rusterucii, il Cardium echunatum, il Car. dium oblongum, lir Modidu modiolus, il Mylilus ecc.i. I. R. - S. Sulle Cytherea Chione. Curlizun Norvegicum. Pechnoulus bimaculatus, Ostrea cochlear. I. Ii. II. I

518. L. corouata n. spr. Tar. XTII. tig. 14 (reali lossili astiuni). Questa è specie molto affine alla precerlent: Una colonia sull'Ared barbuta. $\leadsto$. R. M. V. -519 . L. linearis Hass. È ben ran, no trovai una sola colnnia sul Murcxomunculus. s. R. Bo. V. - 520. L. le eticulata MIaeg. Comomissima e molto variabilu questa specie trorasi somma quanque specie di conchiglia e di fosili mani. $i$ C. R. - s. Così anenra nella zona supuriore rariando incrosta ogui maniera di fossili. C. Bo. Ra. MI. V. - 521. L. pratensis n. sp. Tar. XV. tig. 11 (ruli fossili zaneleani). Questa specie è molto affine alla precelente, le cellule sono multo conresse e prominenti. Sul Trochus magus. i. R. R. - s. Sull'Area barbata. R. M.522. L. bicornis Busk. Riferiseo a questa forma del Crug inglese una sola picenla colonia, sulla Cytherea Chione, che rami riprodume bene i calratteri. S. R. Bo, - 523. L. cucullatia I3usk. Le poche colonie raccolte ricorilano h forma vivente illustrata dal Waters, o parmi si allontanano verciò dalla forma pliocenica che vi riferise il Manzoni. Sullit Vemus Rusterucii. i. R. IR. - - s. Trovata sulla C'mherea Chione esul Pecunculus violacescens. I. Bo. M. V. 524. L. Pallasiana Moll. i. R. R. - - . Ralceolta sullat Cytherea Chione ed il Pectunculus pilosus. r. M. V. - 525. L. systolostomi Manzoni. Questo hriozoo come hene diee it sno scouritore non i che uno shato particolure in forma di Lepratia hella Celleporaria omonoma. Sullia Cylherea Chione, ed il Peannculus bimaculatus. $\approx$. I. M.

526. L. thiara n. sl!. Tar. XVlí. tig. 57.

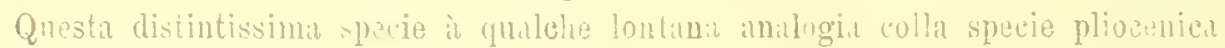
L. mitrate ma ne distintissima. Le cellule ovali sono fornite l'una carena longitu. linale, più 0 meno distinta dir dove irradiuno delle costole al numero di 90 di 11 , fiù o meno prominenti en irte di aspezze, cogl'interstizî forniti di rari e grossi forami. La bocer è pressochè semicireolare con un grosso labro e prominente dal lato inferiore, il quale porta ai fianchi ine ariculari lancenleti e prominenti; l'ovicello

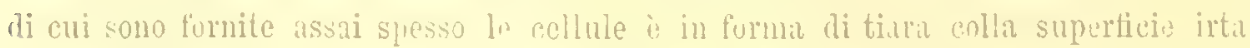
di prominenze e di asprezse o prota un terzo avicolure alla sommitì eles è di forma ruasi ugnale aggli altri due. Trovasi su virî Pechunculus, lenus. Cerdiumed

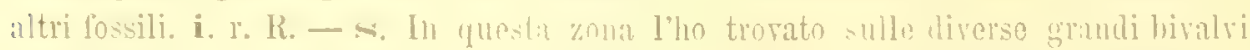
tanto comuni. 1. Bu. II. - 527. L. P'ea chi Jonst. Lu colonie riferite a questa specte farmi che rispondinn bene. esse incrnstano il Mytilus galloprovincialis a

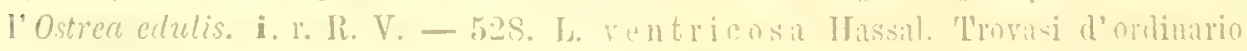
nua varieti di quosta smerie a collule poes rignntio o disposto in serio. Sulle

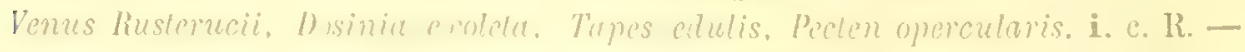
s. Sulle Cytherea Chione, Tenus Rusterucii, Pechunoulus binuculutus. C. MI. V. - 
529. L. pertusa Espur. Sublo Turriellu lriplicala, Venuscusinu, V. Rusterucii, I. effossu, Hodiola moliolus, Mytilus galloprovincialis, Ostrea .... i. c. R. - s. Sulle Sytherea Chione, Dosinia cxoleta, Pectunoulus bimaculatus ece. 3. II. V. 530. L. rudis Manzoni. Rapporto at questa specio talune colonie incrostanti la lenus Rustemacii e la Lucinu borealis. i. 1. R. - s. Sulla Cypherea Chione ed il Pectunculus binaculatus. P. MI. - 531. L. Iignlatia Manzoni. Salla Cytherea Chione e sul Pectunculne bimucul itus. s. I. M. V. - 532. L. stellata? n. sp. (vedi fossili zancleani). Sull'Ostro plicala. s. R. B3n. - 533. I. rugn ulosa Renss. Riferiseo con qualehe hubbio at questu suecio qualehe colonia che in erosta li lenus Rusterucii ed il Pecten opercularis. i. 1: R. - 53t. Id. lata Busk. Snlla Turritella triplicata en il Hylibus galloprovincialis. i. I: R. - - - . Incrosta la Cancellariu cancellata ed il Pectunculies pilosus. I. B). M. V. - 535. L. cunnlata Manzoni. Questa Corma crede il Waters che debiba riunirsi alli precedente per gradnali transizioni. Incrostic 1, Strombus coronalus. \&. R. R.. V.

Celleponara. - 536. C. t uligera Busk. Sulla Calyptraen chinensis e lit lénus Rusterncii. i. c. R. Pa. - s. Sulla Cyherea Chiono e sul Pechnoulus bimaculatus. \%. Bo. In. M. T. - 537. C. coronolus S. Wond. i. I. R. - s. r. Bo. T. - 538 C. edax Busk. Questa distinta specie a ma e poen hen conservata.i.r.R. V. - 539. C. systolostomia Manzoni. Sul Pectunculus bimeculalus. \&. r. M. - 540. C. rinmlosa Lin. i. r. R. - s. r. Bo. V.

Eschara. - 541. E. foliacen Lank, i. r. Ga. R. - S. c. R. Bo. V. - 5.42. E. lichenoites Junk. i. r. R. - - s. r. Ril. Bo. V. - 543. E. cerricornis

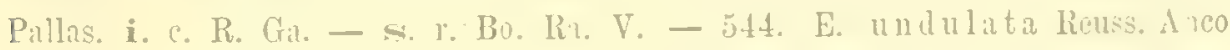

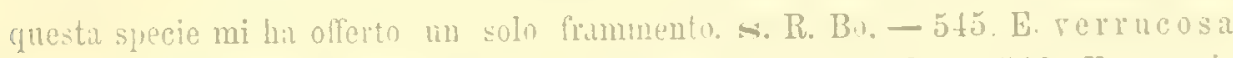
Peack =E. Lunaris Waters. i. r. R. - S. r. Bo. Ra. V. - 540. L. moniIifera M. Eurards. Questa forma tanto comuse uel nlioceno inferiore mi ha offerto nu solo frammento in questa zona del Quatemario.s. R. B. .

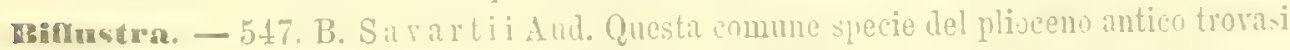
rarissima in questit rona. - R. Bo. V. - 518. B. rynelotir Waters. Un solo frammento un $100^{\prime}$ dubbio. $\rightarrow$. R. Bo. V.

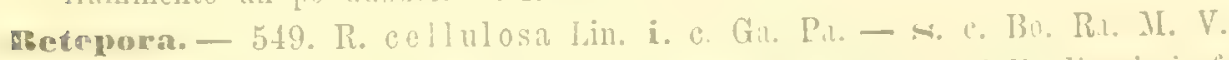

Cupalaria. - 550. C. unbollata Defr. Questa specie tronsi l'ordinurio in fram-

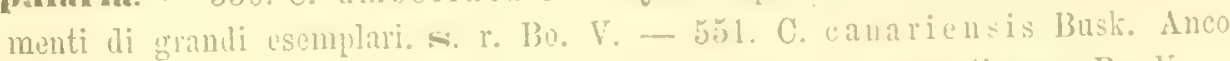
questa specie propria dei mari dello Canarie trovasi in frammenti. s. I. Bo. I. 552. C. Owe n i Gray. Riferisco a questui specic una fíceolal Cupulariu, comune nol giacimento di Borettu. Questa specie vive nel Mediterraneo sulle coste d'Algeria. s. C. Bo, V.

Crisia. - 553. C. fistulasa Heller. s. C. Bo. T. - 55t. C. Ilentienluta Lamx. $\therefore$ r. Bo. V. - 555. C. e hurnea Lin. \&. r. Bo. V.

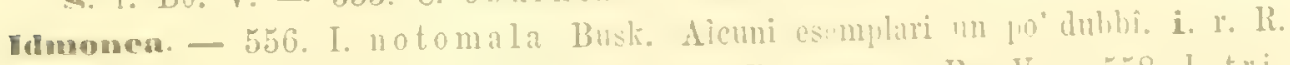
V. - 557. I. iregularis Mengh. i. 1. I. - - - 1. Bo. V. - 55s. 1. tri foris Heller. i. r. R. - s. c. Bo. Y. - 559. I. cuncara lemss. s. c. Bo. V.

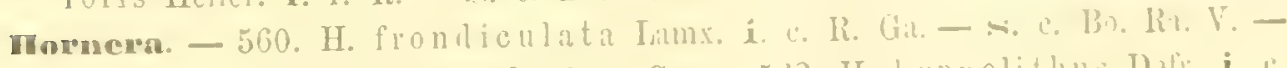

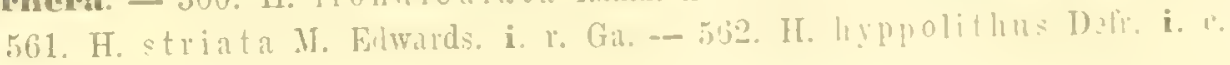


Ga. - Quest'ultime due specie nel Quaternario di Gallina possono benissimo ripetere Ia loro origine dall'Astiano, il quale veniva denudato in parte nel tempo quaternario. Hoisparsa. - 563. F. ralians Reuss. i. 1. R. - s. 1. Bo. - 564. F. tubulosa Busk (Hornera). i. r. R. - A. 1: Bo. V.

Pristulopora. - 565. P. proboscillea Forbes. i. r. R. - S. r. Bo. V. - 566. P. deflexi Conch. (Tubulipora). i. r. R. - S. c. Bo, V. - 567. P. palmata Busk. Specie del Crag inglese. i. 1: Bo. - 508: P. pulchella Reuss (Cricopora). Con qualche dubbio riferiseo alcuni esemplari a questa specie. i. r. R. - 569. P. rugosi D'Orbigny (Entalophora). S. r. Bก. V.

'Tububora. - 570. 'T. flabellaris Fabr. i. 1. R. - s. Sulla Cytheren Chione ed il Pechunculus glycimeris. I. 130. Ra. M. V. - 571. T. phalangea Conch. Sullo Spondylus gacderopus. s. 1. Bo. M. V. - 572. T. ser pens Limn. Sulla Venus Brongniartii, e Mytilus galloprovincialis, i. 1. R. - \$. Incrosta la Cytherea Chione, Ia Venus casina, il Pectunculus pilosus e bimaculatus e l'Ostrea cochlcar. e. Bo. M. V. - 573. T. palmata Smith. Trovasi sulle Cylherec Chione, Pechun. culus glycimeris, violacescens e l'Ostrea cochleat. S. c. Bo. M. V. - 574. T. foliacea Reuss. È rimarchevole questa specie che si dilata molto sulla superficie delle conchiglie che incrosta. Trovasi sulla Venus effossa e lo Spontylus gaederopus. s. I. M.

Alecto. - 575. A. repens Vood. Incrosta il Turbo rugosus, la Cylherea Chione. Ia l'enus Rustcruciz, il Cardium oblongum, il Pecten opercularis, il Mytilus. i. c. R. - s. Sulie Cyhherea Chione, I'enus casina. Dosinic exoleta, Tapes edulis, Pechunculus bimaculatus, pilosus, violacescens, Ostreu cochlear, Anomia ephippium. c. Bo. M. V.

576. D. Iatomarginata D’Orb. Sulla Venus Rusterucii. i. 1. R. - s. Sui C'ytherea Chione. Pecunculus pilosus, bimaculatus, Cardium Norvericum, Ostrea cuchlear. c. M. Bo. V. - 577. D. simplex Busk.Sul Cartium oblongum e l'Anomia ephippium. i. 1. R. - s. Sulla Cytherea Chione, Dosinia exolete, Candium Norvegicum, Pectunculus bimuculatus. 1. Bo. M. - 578. D. obelia Jolust. Sul Carlium Norvegicum e la Tenus Rusterucii. i. I. R. - - S. Sul Pectunculus bimaculaius il Hylilus gulloprovincialis a la Cylherea Chione. I: Bo. V.

Discoporena. - 579. D. radiata Aul. (Melobesia). Sulla Cytherea Chione, la l'enus verrucosa, il Pectunculus bimaculatus o violacescens, Janira Jacobea, Ostrea cochlear. s. c. Bo. M. V. - 580. D. h ispill il Flem. Sulla Dosinia cxoleta, il Cardium Norvegicum. i. r. R. - s. Sulla Cylherea Chione, i Petunculus pilosus, bimaculatns e violacescens, l' Ostrea cochlear, l'Anomia ephipium ece. c. Bo. Ra. II. V. - 581. D. Moditerlanea Blainv. s. r. Bo. V.

madiopora. - 582. Ri pustulosir D'Orbigny. Sulla Celleporaria tubigera.

Riferisco a questa specie aleune colonic che gindico a norma delle redute del sig. Waters, che lia pescato somiglianti esomplari nel Golfo di Napoli. s. r. Bo. V.

Froudipors. - 583. F. reticulata Blainville. i, c. R. - s. c. Bo. Ra. V. 
Tipo. HCHINODERJI.

Classe. Ecminidi...- Ordine. Regulari.

Dorocidaris. - 584. D. lypillata Leske (Cidaris). Parte del guscio e taluni radioli. i. r. R. Ga. - S. r. 130. Ra. M. V.

Centrostephanus. - 585. C. Iongispinus Philippi (Diarlena) = Diudemue e ropaeum Agrassis. Si mecolgnno frammenti dei ralioli. i. 1. R. V.

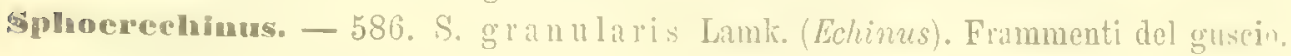
i. I. I. T.

Srrongylocentrotus. - 587. S. Iividus Lank. (Echinus). Gusci intieri.e ralioli sparsi. i. c. R. Gi. V.

\section{Oriline. Cuipeastroid.}

Echimoeganus. - 588. E. pusillus Muller (spatagus). Esemplaretti hen ennserrati. i. I. R. V.

\section{Ordine. Spatancordi,}

Spatangus. - 589. S. pulpuleus Leske. Si rinvengno non di raho tei frummenti e delle spine. Ho raccolto vari amni andietro, e conservo con cura, un evemplare completissimo di questa specie, ed esso è più tostis unico che raro, perehia quasi completamente ricoperto dai molioli ennecratissimi come il guscio. Giaecra nello sabbie quatermarie che formano le collinette soprastanti alla contrula Arehi. i. I. R. V.

\section{Tipo. CELENTERATI.}

\section{Classe. Antozoarit. - Ordine. Zonntarit.}

Corallium. - 590. C. ruhrum Lin. Questa specie trovasi piì tosto raranente nei dintorni di Regroio, mil i molto comme nelle colline di Gallien, dose spesso conserva tuttavia una legeriera tinta rosea. i. c. R. V.

Caryphyllia. - 591. C. clavus Seachit. i. c. R. - - Sul Pechnculus bimaculatus. r. MI. V.

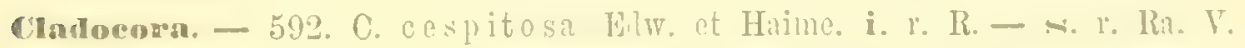

Dendrophyllia. - 593. D. colnigera Bhanrille. i. r. R. V.

Astroilles. - 594. A. cal yeular is Pallas (Iludrepora). Trovasi meno ram sulle colline di Gallico. i. 1. R. V.

\section{Classe. Spongiann.}

Sprngne perforanti varie, che riehiedono stulio comparatirn ateurate.

Tipo. PROTOZOARL.

Classe. Rizoponi. - Ordine. Fornamifen.

Angena. - 595. L. globosa Wallier (Serpula). i. R. R. - - r. Bo. V. - 59ti.

T. vulgaris Williamson。 i. r. R. - - I. I. Bu, T. 
597. L. elapato-punetata 11. sp. Tar. XVII. fig. 58.

Questa forma ricorda per la sua generale conformazione la $L$. clavata; ma la parete della conchiglia is nella nuovir specie elegantemente puntergiat, ed il lungo tnbo clee lia sormonta è fornito di mominenti rugositi traspersali.

$$
\text { Lunghezzal 0,63.nm Dinmetro 0,23.mm s. r. Bo. }
$$

598. L. Striata D'Ortrigny (Oolina). S. C. Bo. V. - 599. L. Haidingeri Crizek. i. R. R. - 600. I. filicosta Renss. \&. r. Bo. V. - 601. I. suleata Segnenza. i. r. I. - S. I. Bo. V. - 602. L. erenat a Parker et Jones. Questa specie è statia trovata rirente in Australia e fossile nel Miocene medio di Bordeanx ed a Nalaga. S. r. Bo. V. - 603. L. a piculata Renss (Oolina). s. r. Bo. V. 604. T. I yellii Seguenza (Amphorina). s. r. Bo. - 605. L. melo Dorbigng (Oolinu). s. r. Bo. V. - 606. L. geometrica Reuss. Un solo esemplare che parmi rispouda bene in tutti i caratteri. s. R. Bo. - 607. L. scalariformis Will. s. r. Bo. V. - 608. L. farosa Reuss. - r. Bo. - 609. L. reticulata Macsill. i. r. R. - s. r. Bo. V. - 610. I. margillata Walk. (Serpula). Diverse varieta. i. c. R. - - i. I in questa zona che li specie in parola presenta numerose e dicersissime raricti ver la forma piu o meno rotondata, pel margine variamente largo, per loapertura prolungatu in tubo ecc. occ. C. Bo. V.

Nodosaria. - 611. N. ra pha istrum Lin. s. R. Bo. V. - 612. N. Iongicauda D'Orbigny. La forma da me raccolta ricorda bene una piceola rarieti dj questil specie con poche logge e tennissime costelle. s. c. Bo. V.

Hingulina, - 613. L. carinata D'Orbigny. i. r. IR. - s, r. Bo. V.

Deutalina. - 614. D. guttifera D'Orbigny. S. R. Bo. V. - 615. D. p a u perata D'Orbigny. L'esemplate che vi riferisco i moltu solido e grosso.s. R. Bo. V. 616. D. n run la D'Orjigny. I pochi esemplari racelti sono eonservatissimi, himno quattro logge invece di tre e le costole piu numerose e piì sottili. Tali esem. plari sono molto eleganti. S. 1. 130.

Deatlemia. - 617. R'. compressa 11. sp. Tar. XVII. fig. 14 (recii fossili astiani). i. r. R.

Tonianima. - 618. N. sold an ii D'Orbigny. i. r. R. - 619. N. Labradorica D'Orh. S. R, Bo, V.

Dolystomella. - 620. P. crispa Linn. i. c. R. - $\$$ C. Bo. T. - 621. P. Fictelliana D'0ligny. s. r. Bo. V. - 622. P. striato-punetata Fichtell et Moll. (Nautilus). i. 1: R. - - , 1, BO, V.

Amplastegina. - 623. A. Ha ncriba D'orbigny. Io credo che questa speciu ri sia stata introdotta nel deposito quaternario allo stato fossile; ciò viene conferinato dall' essere gli esemplari incrostati della roccia mamosa o calcarea che li racchinde nello Zancleano. s. 1 . Bo.

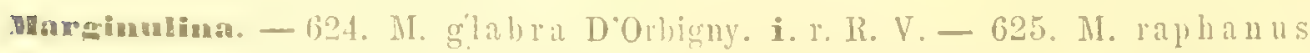
D'Orbigny. Var. Un solo espmplare consilerevolmente lungo. s. R. Bo. Y.

Crostellaria. - 626. U. crepidula Fichtell et Moll. (Nentilus). S. r. Bo. V.

IRobulina. - 627. R. cultrata DOrbigny. s. r. Bo. Y. - 628. R. rotulata Lamark. i. R. R. - . r. Bo. V. - 629. R. voltex Ficht et Moll. (Nautilus). i. l. R. - s. l. Bo, V. 
Folymorohina. - 630. P. la etea Walhep et Jicolj (Serpula). i. r. R. - s. c. Bo. V. - 631. P. commun is Dort). (Guthulina). i. s. R. - s.r. Bo. V. 632. P’. gibba D'OHigny. Var. Questa forma difleriseo dal tipo per essere di un andamento um po' orato. i. 1. R. V. - 633. P. problema D' Or. . - R. Bu. V. - 634. P. complosa D’orbigny. i. r. R. - s. r. Bo. V. - 635. P. complanata D'Orbigny. Vi riferisen m piccolo esemplare aualuge alla forma del Cray inglese, i. R. R.

Dimorphina. - 636. D. notosaria D'Orb, i R. R.

Capsulina. $\mathrm{n}$. gen.

Conchigliar elongata, costituita dall'associazione di tre ordini li logge, disposte parallelamente attorno un asse comune. Alla regione superiore sono tre aperture, che altemano con tre teniliture, le quali i ostendono sulla lunghezal della ennchiglia bipartendo tutte le logge.

Il nuovo genere ehe io descrivo per ha disposizione dello lusge somiglia alle Textularia e generi athini, ma i partionlari dolla sua costituzione lo rendono distiutissimo.

637. C. loculicida n. sp. Tar. Xvil. fig. 5!, 59a, $596,590$.

Conchiglia di forma obovato-cuneati, elargatia anteriormmte, ell alquanto prominente all" pstremiti, a sezions circolure allit regione anterine e distintannte trigona rerso l'estremo posteriore. Lu pareti sono fortemente porforite. Le tre aperture sono triangolari o marginate. Le fenditure longitudinali son ben manifeste e sinuose sopratutto posterioruente. Ciaseuna serie di logge ì eostituita da tre di cuí la superiore è molto piccola relativamente alle altre; i tramezzi che separano le tre serie sono spessi e disposti in lirozione delle aperture, esse si mani. festano esternamente per una linea impressa, cu altermano colle tre fenditure, che perciò dividoun le logge in due prarti esattamente uguali.

$$
\text { Lunghezza } 0,8 .^{\mathrm{mm}} \text { Diametro } 0,5 .^{\mathrm{mm}} \mathrm{r} \text {. R. }
$$

Burimina. - 638. B. maginata D'orb. i. R. R. - s. R. Bo, V. - 639. B. aculeata D'oubigny. s. R. B3o. V. - 610. B. ingeratrix? Karer. Limico esemplare che denomino cosi ì duhbio, ma per la forma globosa e la disposizione delle logge è a questa specie che piu somiglia. i. R. R. - 641. B. o rata D'Orbigny. \&. I. Bo. V. - 642. B. mutabilis Costa (Gullulina). i. 1. R. - - . r. Bo. - 643. B. tenera Renss. Riforise a questa specie alcuni escmpliri che parmi rispondano bene. i. r. R. - s. r. Bo. - 644. B. pyrula D'Orl). Insieme a variate forme. i. c. I. - s. C. Bo. V. - 645. B. prunella Custu (Guttulina). Molto variabile. i. c. R. - - B. Bo.

viroulina. - 646. V. squa mosal I) Orb. Specio ahbastanza variabile. i. I. R. V. Sphocroidina. - 647. S. bu 110 ilies J'Orì. i. r. R. - - c. 130. V.

aulvinulina. - 048. P. Partschiana D’orbigny (Rolalina). Un solo esem-

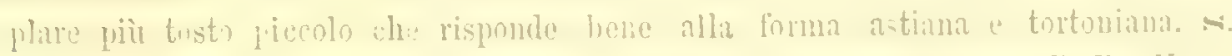

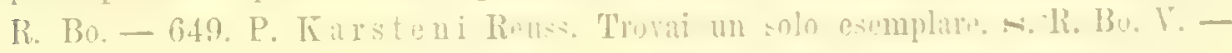

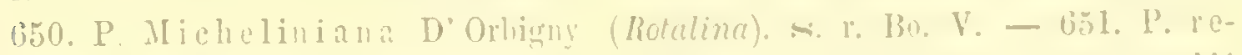

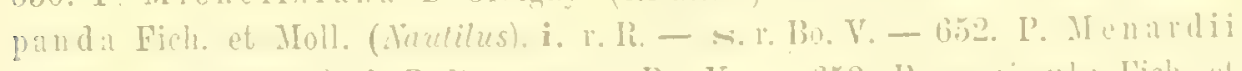

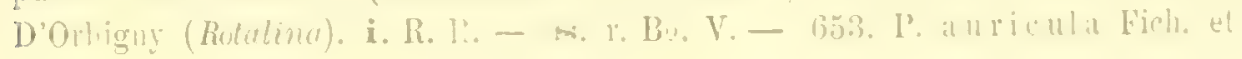


Mil1. (Nautilus). i. r. R. - S. R. Bo, V. - 654. P. communis D'orbigny. i. Ii. Ii. I?

IBotalia. - 655. R. Becearii Lin. (Xaulilus). Offre numerose variazinni ben note. i. c. R. - s. c. Bo, V. - 656. R. a m mon iform is D' Orb. Probabilmonte da doversi associare alla precedente specie. s. l' Bo. V.

Drônlima. - 657. 0. $n$ n i versa D'Orh. i. C. R. - \&. C. Bo. V.

Glolvigerina, - 658. G. bulloilles D'Orb. i. e. R. - - C. B?. V. - 659. (G. Aradasii Segnenza (Rotalina). i. r. R. - - r. Bo. - 660. G. luelicinil D'Orb. i. l'. R. V.

661. G. gomitulus n. sp. Tav. XVII. fig. 16 (redi fossili astiani). s. r, Bo. 662. G. oroidea n. sp. Tar. XVll. fig. 39 (redi fossili siciliani). - r. Bo.

Discorloina. 663. D. glo bularis D'Ort). (Rosalina). i, r, R. - s. C. Bo. V. 664. D. medituranensis D'Orbigny (Rusuma). i. R. R. V.

Truncatulius, - 665. T. lobatnla D'() b. i. c. R. - - c. Bo. V. - 666. T. Dutemplej D'Orb. (Rotalina). S. 1. Bo. V. - 667. T. Ungeriana D'0rb. (Rotrlina). s. r. Bn. Y.-668. T. Lelicina Costa (Tonionina?). Un solo esem. plute. s. R. Bo.

Cassidulina. - 669. C. l aerigata D Orb. i. r. R. V.

Plecnnium. - 670, P. siggittula Defince (Textularin), i. c. R. - s. C. Bo. V. - 671. P. agylutinas D'Orbigny (Textularia). S. R. Bo. V. 672. P. trochus D'Orbigny (Tertularia). i. r. R. - s. R. Bก. V. 673. P. gibbosum Dorliny. s. R. Bo. V. - 674. P. coucarum Karrer. Val. ilalicum 11. Dennmino cosi un piccolo Flecanium, il quale molto somiglia alla forma miocenica del Karrer, e colamente se ne allontana per essere un po' piì gracile en alquanto più compresso, e per avere le logge un po' piì distinte ussentoche le suture d'ortiuario si profontano riemmeglio, i. P. R. - s. r. Bo. Peneroplis. - 675. P. jertusus Forskal. Uir solo esemplare incompleto. i. R. R. V. mallowlina. - 676. B. bulloides D' Orbigny. i. 1. R. - s. e. Bo. V. 677. B. elongata D'Orbigny. i. r. R. - s. r. Bo. V. - o78. B. tubulosia Costa. Questal distinta specie lol la sua apertura prolungata in tubo, essil nifre quelle modificazioni illustrate dall'autore, nolle gruali una log gial, d'ordinario la penultima, non completandusi da l'aspetto alla conchiglia di ma Triloculina. s. 1. Bo. - 679. B. suhoera D'orbigny. Var. Calabra n. Denomino cosi una Biloculine che somiglia benissimo alla forma americana descritti lal D' Orbigny e solo differise per essere un po' meno ghbosil ed alquanto ovata. i. r. R. V. 650. B. depressa D'Orbigny. Non è sempre di forma ben arrotondatil, sorente assume un andamento orale, e bene spesso presentasi un po' gibhosa al centro delle valye. i. c. R. V. - 681. B. plina Karrer. Riferisen a questa forma miocenica alcuni pochi esemplari. i. l. R.

Spicoloculima. - 682. S. rotululata D'Orb. i. r. R. V. - 683. S. limbata

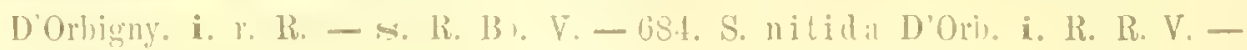
685. S. I la nulata Jamk. i. r. K. V.

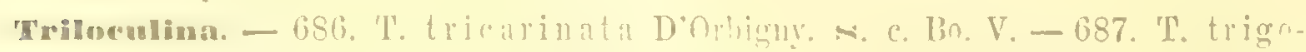
nula Lamk. s. r. Bn. V. - 688. 'T. gibh: D'0rh. i. c. R. V. - 689. 'T'. 
inflata D'orb. i. e. R. T. - 690. T. laevigata D'Orbigny, i. r. R. - 691. T. oblonga Montagu. (Serpula). i. r. R. - S. c. Bo. V.

Quinqueloculina - 69:. Q. seminulum Lin. (Serpula). i. 1. R. V. - 693. Q. Fulgaris Dorbigny. i. I. R. V. - 694. Q. triangularis Dorb. Trorasi colle rariate sne forme.s. c. Bo. V. - 695. Q. inflata D'orhigny, i, r. R s. r. Bo. V. - 690. Q. agglutinans D' Orligny. i. R. R. V. - 697. Q. subrotunda Montagu. i. R. R. V. - 698. Q. dopressa D'Orkigny. i. r. R. V. 690. Q. irregularis Dorb.s. r. Bo. V. - 700. Q. subcariuata Dorb. i. r. R. V. - 701. Q. Ferussacii D' Orb. i. r. R. - \&. r. Bo. V. - 702.Q. Bronguartii D'Orb. i. R. R. - «. r. Bo. V. - 703. Q. elegans D'Orb. Variabile molto nella forma, ma distinta per le sottili costelle di cui è elegantemente ornata. s.c. Bo. T. - 704. Q. costata D'Orb. i. r. R. - - s. H. Bo. V. 705. Q. pulchellí D'Orb. i. 1. R. - s. c. Bo. V.

Dall' elenco che precede risulta che le specie da me raccolte nel Quaternario del Reggiano ascendono a 702, essendochè nella zona inferiore ne trowai 497, e 515 nella zona superiore, essendorene di comune 310 . qunindi sono speciali alla prima 187 specie e 205 alla seconda.

La fauna della zona inforiore costa di un Mammifero, di 300 Molluschi, ciót 159 Gasteropodi, 6 Solenoconchi, 3 Pteropodi, 125 Lamellibranchi, 7 Brachiopodi, di 29 Ostracodi, dỉ 3 Cirripedi, di 13 Anellidi, di 68 Briozoarit, di 6 Echinili, di 5 Antozoarii, di 72 Foraminiferi.

Essa racchiude tra le specio viventi alente che più non virono nel prossimo mare, ma che attualmente ahitano i mari del settentrione d'Europa, tali sono le seguenti:

\section{Buccinum undatum \\ Natica Montacuti \\ Trochas Otta? \\ Cyprina islandica \\ Limopsis minuta}

\author{
Modiole modiolus \\ Pecten peslutrae \\ » ligrinus \\ Waldheimia cranium
}

Io mi astengo per ora di cnmmerare le specie appartenenti alle altre classi, essendochè difficilmente potrei fare utili raffronti e ricararne importanti dedurioni.

Qui fa d'uopo notare come gri Ostracodi del Mrediterraneo sono poco conoscinti, e quindi per le specie di questa classe non può contarsi con sicurezza l'emigrazione verso il nord, fino a che la fiuna mediterranea non sarì bene studiata; per ora bisogna dunque contare sui Molluschi soltanto, che bastuno da se soli a dimostrare in quel reriodo un clima a temperatura piì bassa dell'attuale dominante nel Mediterraneo.

Le specie che non conosconsi tra i viventi sono ben poche. e tra queste sonvi rarî Entomostracei, intorno ai quali milita l'osserrazione fatta precedentemente. Eeco i nomi di tali specie:

Elephas armeniacus liaphitoma Columnae. Yasse musiva Strombes curmulus
Odostomia lasvissima

Brocchia sinuosu

e'adulus cyalhus?

Limopeis pygmener Virt. 
La fauna della zona superiore costa di 309 Molluschi, di cui 163 Gasteropodi, 5 Solenoconchi, 4 Pteropodi, 133 Lamellibranchi, 4 Brachiopoli, di 23 Ostracodi, di 4 Cirripedi, di 9 Anellidi, di 87 Brozourii, di 1 Fchinids, di 2 Antozourii, di 79 Eoraminiferi.

Mancano afiatto in questo variato assembramento di specie quelle eschusive dei mari settentrionali ( $\left.{ }^{1}\right)$, siccome già notai, el invece si mostruno associate ad una fauna lutta mediterranea talune delle forme che aloitano oggi climi piu caldi.

Tali sono le seguenti specie:

Tornatina Knockeri Smith. Vive sulle coste dell'Africa occidentale.

Conus testudinarius Miartini Var. Abita le Isole del Capu Verte.

Terebra corrugata Lamk. Tar. Regina Desh. Vive allit Guinea.

Triton Ficoules Reere. Vire al Senegal.

Natica orientalis Gmel. Virente nell'Oconno imliano.

» porcellana D'Orbigny. Abita le Canario.

Iyyclaea quutrillentata Les. Vire allo Indie ocidentali e nel mare Rossm.

Diplodonte Squigny Vaillant. Vire nel Mfare liosso.

Loripes Smithii n. sp. Vive all' Isola Lancerotta (Conarie).

Cupularia umbellata Defrance. Vire forse all'Australiai.

» canariensis Busk. Abita il mare delle Canarie.

"Owenii Gray. Vire sulle coste dell'Algeria.

Lagena crenala Particr et Jones. Vive alla Nuova Olamla.

Como ben si vede dalla precolente enumerazione, sono quasi tutte queste specic viventi nei mari più o meno caldi delle coste orientili el occidentali dell'Afrien; sono quindi delle specie che vissero snl finire dellepocat quaternaria nella regione meditemanea e he quimli emigrarono rerso le regioni piu calde. o piu tosto vi esi steyano o si estinsero solo nilla rona temperatia.

I’ultima categoria di specio da ricorchare is ynella delle estinto, tra le quali con sicurezza ve ne sono di quelle che colle ulteriori ricerche si senoprimano ri. venti nei mari attuali, fueciahnente tra quelle classi che richiedno tuttaria accurate esplorazioni pej lo studio delle specie meditorrance, enm ad esempio i gruppi de. gli Ostracodi, dei Briozoi, dei Foraminiferi ece.

Eeco adunque l'elcueo delle speeie nou sconoscinte virenti:
Heterocetus sp.?
Actaron Bovellensis
Cylichme obssiuscula
Cyphoma Boveltensis
Conus subventricosus
\#hegimes
Mamlovani
Aitre Bronniz
» scrobiculata Var.
Strombus coronatus
Oilostomia comfusa
Arée diluvii?
Limopsis pygmaea. Vall. majur.
bairdia reniformis
Cothere subaerualis
$\gg$ Eiluarelsii
"rugosa
Raphitoma Columnac
lestoleberis pustulose
C'ylherura inversa

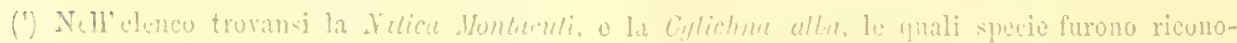

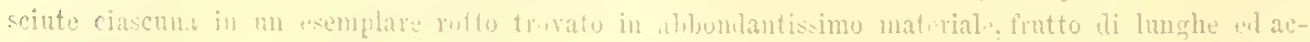
curate ricerche 
Cytherella Calubren

Membranipore uperta

$$
\text { " bidens }
$$

» puptruceu

Lepralice Elivarisiane

»unicornis

$\gg$ bicomis

$\gg$ systolostoma

$\gg$ coronater

$\gg$ pratensis

$»$ thiare

$\gg$ ruelis

$\gg$ stellate

Eschare monilifert

umelulata
Bifustial Rinchola

Filispensol verians

Tubulipora foliaced

Lagena clavato-punctate

$»$ geometrice

Dentalina urnula

Bulimina prunella tenera

Pulvinulina Porlschiana

Globigerina draclesii

»gomilulus

\ovnidea

Truncatulina helicind

Plccanium cencavam Var.

Biloculina tubulosa

Tra queste forme is limarcherole la riapparizione della bitra scrobiculata della Ir. Bronnii e iell' ahhoulante Strombus coronatus, lo quali, come feci già rimareare per una di esse, non conosceransi sinora che sino all'Astiano, ma non gì in Calabria, e mancuno aflatto nel plinceno recente, come nel Quateruario inferince. E notevole intanto cone la frima e la terza di queste specie non troppo rare a Bovetto si presentino costintemente ammiserite nelle loro forme, nou oltremasando inai le piccole dimensioni di cirea una metà o meno dei grandi esemulari che ci formiscono il Tortoniano ed il plioceno.

Cosi bisogna ancolia notare, con molta riserva, Ia rienmparsa di Ostracodi, Briozoi, Foraminiferi attendendo the nuovi e minuziosi studî sui fossili e sui viventi di tali Classi venissero a confermare i fatti ai quali aecenuo. Sarebhero dunque di talo eategoria le seguenti specie: Cylhere belwardait, Lischare monilifera. E. undulata. Filisparsa varians, Tubulipora foliacea, Dentalina urnula, P'ulvinulina Partschiana. Plecanizur concarum.

Ed inoltre talume specie tuttavia virenti mostrano un falto rimarcherole cli riapparizione e di ulleriore emigrazione. 'Tali surebbero la Cupularia umbellata e la $C$. canariensis; queste duo speciu sono comuni nel mineeno li molti lwoghi, rissero aneo in Italia nel plinceno antico e mancano completamente nel plioceno superiore e nel Quatemario inferiore per riapparive nel Quaternario suburore o quindi finalmente emigrare nuovamente verso le revioni piì enlde maneindo orgi alfatto nel Mediterraneo.

E benanco noterole la Ciphoma boretensis, che quintumque sennoseinta, pure si appartiene ad un gruppo di forme che sono proprie dei mari calli, siccome le nuove specio di Coni.

Questo fatto, anch'esso molto rimarcherole, ielia riapparizione nel Quaternario recente di specie clie vissero nel Tortosiamo e nel plioceno e che mancirono attatto in Italia nel plioceno recente e nel Quatemario inferiore, trova a mio moun di vedere unat spiegazione analoga a quella per cui le specie elei mari sultentrionali abitarono la regione meliterramea nul periodo glauiale e pni emiggamo verso il wom, allorchè il clima divene piu mite. Cosi lo specie plioceniche yni sopra rientiats, al cominciare del periolo glaciale hamno dovnto emigrare verso regioni pia ralue. e quindi verso il sud, o poi allat tine del freddo periodo ritornare nei mari llome si mano dipartiti. 
Ma insieme ad esse renivano ad abitare queste latitudini varie delle forme tropicali per essere piì tardi estinte con esse.

Il Quaternario marins deile Calabrie trova dei risentri in terreni analoghi, e coetanei in Sicilia, presso Tinmo, Livomo ece. e poi al Capo Gibilintu in Ispagna, come nei depositi mariui quaternarii d'Inghiltera, di Norvegin ece. ece.

Così ancora l'alluvione quaternaria, jer dir breve, trova aualogo riscontro quasi dapertutto in Europa.

Solamente per la zona recente del Quaternario marino io non conoseo riscontro di sorta, il quale offrisse quei fatti speciali nella fauna che sono stati gia esposti e sopratutto quelio della comparsa di specie tropicali.

Dopo tutto quanto abbiamo esaminito vediamo quali deduzioni possano derivame.

Primicramente risulta evidentissimo che tutta l'epoea quaternaria fu pel Reggiano un periodo di lento e graduale sullevamento, e quindi di consecutiva emersione, per la quale era gia venuta fuori in gran parte la zona inferiore quando si deponevano gl' importantissimi striti di Boyetto, Raragnese ecc.

Un secoudo arvenimento dell'epoca quatormaria si è quello molto rimarcherole del mutarsi del elima con nu imalzamento di temperatura. Difatti dall'Astiano al Quateruario inferiore abbiamo reduto una serio di specie tuttaria vivonti, ma che più non abitano le regioni medituranee, perchè emigrate rerso il nord: quindi questo lungo periodo che comprende parte dell'Astiano, il Siciliano ed il Quaternario inferiore ha dovuto offrire un clima fredio, quello della cosi detta epoea glaciale, la quale ha potuto benissimo presentare delle oscillazioni orvero dei priodi d'incremento o di diminuzione, una l'aumento definitiro della tomperatura ú quindi un considererole mutamento di clima si è gradualmente operato nel lungo periodo quaternario; ce lo attestano ad evidenza quegl'immani depositi marini, costituiti di sabbie e di ciottoli, c quelle estese alluvioni e potenti, prodotte dalle immense correnti terrestri moltiplicatesi ed enormemente ingrossate dal fondere delle nevi: ce lo dicono chiaro quei grandi e variati molluschi che vissero sino al primo periodo del Quaternario e pai emigrarono verso regioni piì fredde, dimodochè fiì non si trovano nei dopositi del Quaternanio superiore. E evidente quindi che l'aumento della temperatura cominciato collepoea quaternaria, o anco prina, si è compito lungo tale periodo e jria che si depronesse l'ultima zona.

Ma is poi questa zour ultima che ci othie un nuovo probleme, quello cioè di specie quaternarie mediteranee emigrate verso il mezzogioruo o a dir meglio verso regioni più calde.

Senza dubbio anco in questo caso potrebbonsi invocare come causa determinante l'arrivo o l'allontanamento di tali specie lo oscillarioni di tomperatura, e quindi le mutazioni subite dal clima; ma a mio credere non fa d' wo ro ricorrero a siffatti mutamenti per ispiegare completamente il caso nostro.

E di vero, pria che fosse cominciato il secondo periodo quaternario, la tempera. tura si era gia inmalzata talmente, che le specie che oggi vivono nei mari settentrionali erano gial scomparse dill Meditermes, sicchè noi non ne troviamo più traccia alcuna nei depositi posteriori; allura il sullamento graduale che in tuth l'epoea quaternarja elevo sino ald oltwe ottocento metri l'Italia meridionale, si era giil arrerato in 
gran rarte, ma non intieramente, e priò calcolarsi a circa 250 metri l' innalzamento arvenuto nel secondo periodo del Quateruario, essendochè gli strati di Boretto trovansi elevati a circa 80 metri e quelli di Musala al oltre 200. Da cii) ne consogute che il Mediterraneo allargara allora i suoi confini su quelle basse terre, uhe cingono yua e là i continenti e le regioni tutte circostanti, e che percio la sua estensione er., relatiramente all'attuale, molto vasta, la sua conformazione ben diversa. Esso jrobabilmente invaleva ancora i grandi deserti dell'Africa settentrionale; ma ciò che piì interessa al caso nostro si è che larghe commicazioni, jer questa sua maggiore glamdezza, doreano di molto accescere ed estendere le relazioni tra il Mediterranco e i mari tropicali, tanto della costa orientale quanto dell' oscilentale del continente afrieano. E questia diversissima topografia, influendo necessiriamente sul corso delle correnti marine e sulla loro distribuzione, ha dovuto agire riscaldando le acque del Afoliterraneo per mezzo ai correnti calde, che arrifurano dai mari tropiculi, e che tenderano in pari tempo ad introdurvi le specie di quei climi: vario infatti se ne sono introlotte.

Col progredire poi dell' innalzamento il Mediterraneo si andò restringendo ne' snoi confini, le dirette comunicazioni coi mari caldi si andarono mano mamo ostruendo finchè cessarono del tutto, le calde correnti non piì vi aflluironn; ma incece un freddo fume comincio a versarvi l'Atlantico, ed ecco creale giil gladatamente nuve e ben diverse condizioni d' esistenza, cioè quelle attuali, alle quali non potevano certo adattarsi quei viventi la cui vita stava legata al caldo ambiente che l'involgera, cessinto il quale furono necessariamente condanuati a perire; cosi quelle specie che noi troviamo ora fossili nel Quaternario superione e che virono tuttavia nei mari tropicali, quelle altre che piu non si conoscono viventi (Strombus coronabus, Mitra scrobiculata, Mitra Bronnii ecc.) rennero distrutte mano mano dal modificarsi successivo e graduale dell ambiente, ed invece il maggior numero delle specie si accostumara gradatamente a tali mutazioni e resistera alle nuove condizioni d'esistenza.

\section{CAPO TERZO}

Considerazioni intorno ai fatti geologici precedentemente esposti ed alle deduzioni alle quali conducono.

1. La serie teraiariu considerata nel suo insicme e nei suoi vari membri.

Eccomi al termine del mio compito, alla tine del lavoro impostomi: non git perchè esaurito il campo delle ricerche e dello studin, ma perebe non mi vien hato per ora di protrarre le mie indagini: mi accontentero quindi a dedure dai latti as:itloc le conseguenze cui legittimamente dan hrogo.

E dissi che il campo degli studî non è ancora csaurito, direi anzi che esso ì assai vasto e quasi illimitato, dal perchè nella l'rovincia di Reggio l'estensione dello formazioni terziarie è notevolissima, gramile la potenza e la rarieti dei loro strati, 


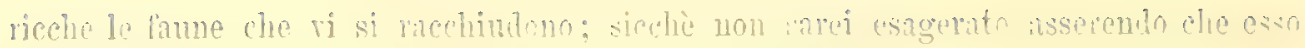
si offra whertoso alle reiterate ricercho di molti genlosi.

E printeramente la determinazione cronolorica di tutti i piani terziarî, la loro sincronizzarione colle varie fomazioni d' Europa ci dit evitentemente il dritto di conchiulere che i terreni terziari del Regriano formano ma sorie non interotta, nella guale percio ogni periodo viene rapmesentato in guisa da ofrirci documenti d'ogni manitra, che ralgono ad attestraci le condizioni fisiche e biologiche, che regnavano nel mare e sulle terre emerse.

Però se mò dirsi continua li serie terziaria lel Reggiano, se jù̀ ritenersi non interrotta da lacune, non siamo ancora al caso di dichiararla completissima. Come giì ho fatto velere nel principio di questo laroro, alla base lel Bartoniano. (il piì antico memliro cho ho potuto sicuramente determinare e riconoscere in posto) trivasi quella massa calcarea presso Stilo, nella quale si solo scoperte Orbitoili e Nummuliti, e cle probabilmente a mio crelere rapresenta il prii antico Terriario o forse taluni periodi di esso. Daltromie i massi calcarei a graudi nummuliti macolti nei dintorni di Reggio dimostrano, come ahiramo veduto, che anco il piano Parigino vi deve essere rappresentato. Quindi bisogua conchintere che se per ora non puo dichiararsi assolutamente completa lit serie terziaria che esaminn, is soltanto alla base che ci othie qualche difettn. comechè abbiansi via lei dati abbustanzi importanti per potere affermase sin da ora che lo ulteriori ricereho allevieranno le difícoltà e probabilissimamente colmeramn una tale lacuna.

Non occorrerebbe poi confermare qui un fatto oggimai dimostrato ar oltranza. riconosciuto lit dove la serie serlimentaria o stati studiata con ema, o costituente

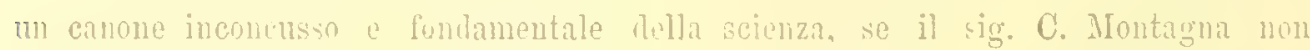
l'avesse voluto mettere in duhbio a proposito della geologia della Provineia di Reggio.

il fatto da lui messo in dubhio a tal proposito è lordine cronologico dei vari geologici periodi in veluaione colle faune e colle flore che le diverse vocce rachiu. dono: ei crede che nelle Calabrie, e mopriamente nej territori di Gerace, li Agnana e di Stilo l'ordinamento stratigrafico non Fiuda concordo con quiluto hamo rivelato Gli studî fatti nelle più classiclıe localitì d' Eurofra e del mondo intiero; ogli af. ferma che in Calabria le fanne e Ie fore dei dirersi nerindi grologici sieguano ben altro ordinamento di quello stabilito dalla cronoloria stratigrafiea, risultameuto inronensso dei lavori e deghli studi di tanti lotti, di tante menti elevate, di quanti furono geologi siuo al giono l'oggi. Ed il Montagua credo di aver dimostrato il suo assunto in due opere, l'una generale e l'altri che tratta del deposito carbonifero di Agnana ('). Io mi sento nel dorere, trattando dei medesimi terreni, di conviucer di falso quanto ha seritto il sig. Montagna, poichic i miei risultamenti sono in perfotto accordo con guanto sinora ci viene dettato dallal scienza.

11 sig. Montagna morendo dall'esame degli slrati carboniferi di Agnana, nei ynali avea egrli stesso raceolto le ussia e i denti dell'Anhracolerium magnum, en a questo dato positivo ed importantissimo associando una serie direi di allueinazioni,

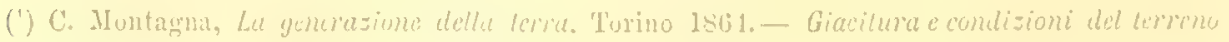
rethonifro d' Igmane or dintomi. $185 \%$. 
come l'esistenza d' nua flora secondaria nel cartone stosso, la sommposizione di strati con Ammoniti (che ne egli ne altri ha pointo velere mai al dgnana o al Autoni-

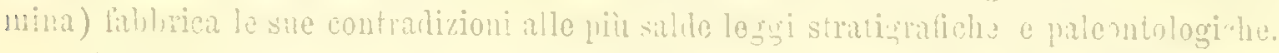

II lettore che non si trova al caso di smentire i preteni dali positivi, ne resta sopraffitto, e cedendo all'autoriti di cs-i verri tratto dall'insimno e presturi fede alle eccezioni, alle anomaliv delle leg fi prelette. Le mis osservazioni intanto non solo famo ginstizia delle rolnte dol sig. Montagna, mil aneo di quilehe lato positiro ohe egli assume per hase thell, sue strane enclusioni.

I terreui di Agnana, di Antonimina, di Gerace, come gia ho espostn, risultimn

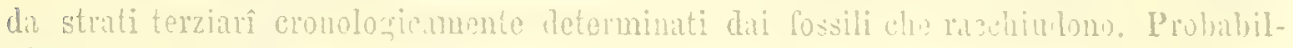

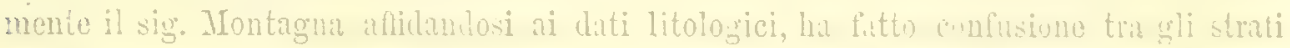
cho si accompagmano a quelli unu ombustibile e gli altri che a Brancaleone, a Fer-

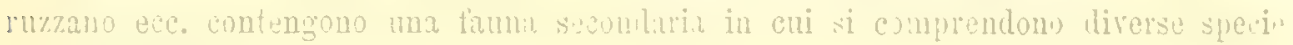
li smmonilimli.

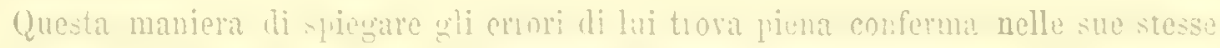

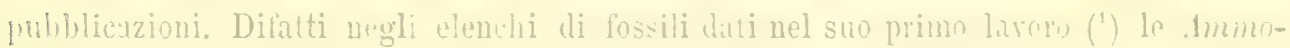

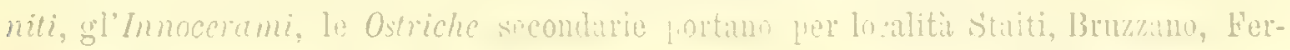

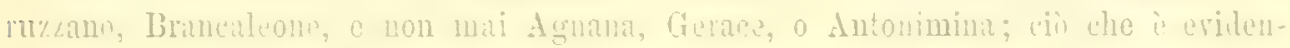
tumente un dichiarare li non arere raponlto Ammoniti nè altri fossili secombatî in guesti due ultimi territolî.

Daltronde il sig. Montagna rignadando quasi tutti i fissili ume sperie seo-

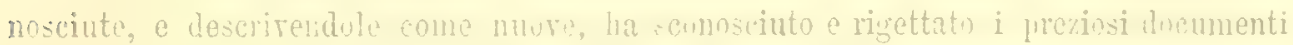

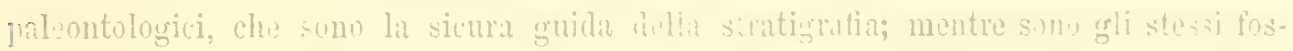
sili da lui enumerati, che sudati e deteminati acematumente famo riconose res pre

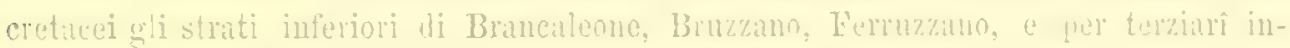
rece i terreni a carbone di Agnama e di Antmimina.

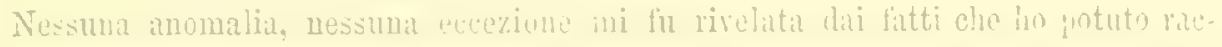
cogliere studiando la selie teraiaria tel Reggiano: anci ssi sono in pertetto alceordo colle legri foulamentali della stratigrafia o della faleontologia, nel esst io ho protuto riconoscere e siucronizance azesolusente ogni piano, njni zonia terziaria cogli strati coetunci di tuttil cuanta Buropa.

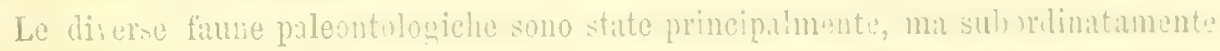

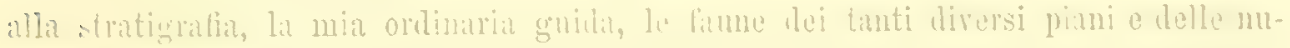

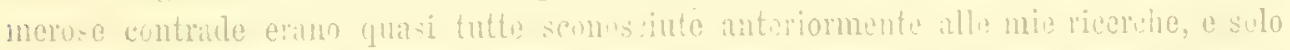

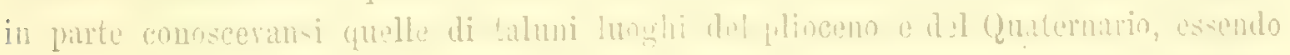

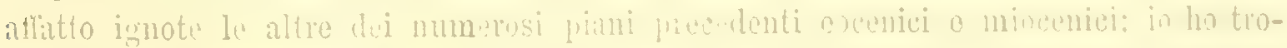

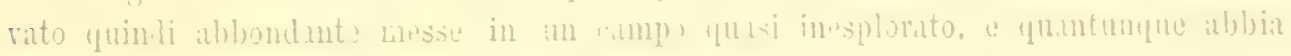

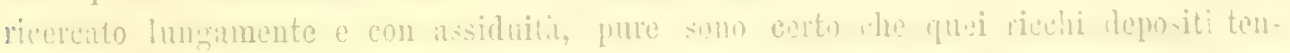

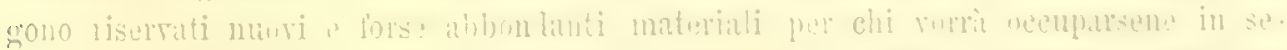

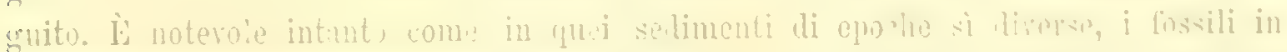

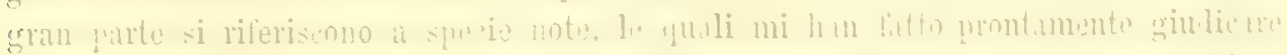

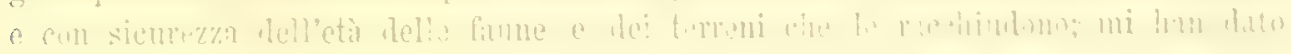

$\because \quad$ edi vprese citate 
l'agio inoltre di comparare queste alle coetanee dei rarî luoghi e di fane ntili raffronti sotto il punto di vista della cronologia biologica.

Come gria risulta dai fatti esposti, la formazion eocenica offe tre periodi certi e distinti: il Parigino, il Bartoniano, ol il Liguriano, ma i fossili si rilueono a poche specie di Rizopodi soltanto.

La formazione miocenica è quella al certo che si presenta, oltrechè molto sriIuppati, la piì rariata nei suoi strati, nelle sue rocee e-nei suoi fossili. I sei periodi ben distinti in cui essa naturalmente si riparte si dividono in zone, e tutto è caratterizzato da fossili numerosi, da faune differenti, le quali rispondono a capello con lo coetaneo d'altre Iocalità ilaliane ed curopee. Il Tongriano, l'Aquitaniano, il Langhiano, l'Elreziano, il Tortoniano ed il Messiniano, che sono i sci periodi o piani rel Terziario medio, non sono men caratterizati nel Reggiano di quanto lo sienu nelle più classiche terre ore accuratamente sono stati esplorati da chiari geologi.

Il plioceno poi vastamente esteso, e molto potente ci offre il complemento necessario del plioceno classico, di quello che formatosi quasi sempre a jiecole o mediocri profomlitì contiene la ben nota fauna propria di tali condizioni di esistenza; il nostro invece, coi suoi depositi di mare assai profondo, che sono i più comuni, offre una fanna che comparata alh prima risulta diversissima, ma siccome è coetanea, associata al essa la completa. I tre piani di cui costa, cioè lo Zancleano, l'Astiano, il Siciliano sono distintissimi e discordanti, trattasi di tre periodi che offrono condizioni di animalizzazione assai diverse.

Il Quaternario amb'esso coi suoi depositi mariui c terrestri e colle sue faume richiama l'attenzione del geologe, trattandosi di periodi al nostro assai vicini. E mentro gli strati più antichi, che hamno ofterto l'Elephas armeniacus racchiudono profusamente il Peclen pes-lutrae colla sua forma proprio nordiea, gli strati pii recenti invece contengono li fauma, che più somiglia a quella del Meditermeo, mista a talune specie tuttoria virenti sotto latitudini molto piu calde; cio che ci fa credore ragionevolmente ad un'antica e più diretta riunione del. Nediterraneo coi mari tropicali.

Queste somiglianze o queste mistioni reclamano al certo uno studio miunioso e comprativo delle ultime faune fossili colle viventi, che potrà condurre a conclusioni molto importanti intorno alle ulteriori modificazioni topografiche, batimetriche e climatologiche arrenute nelle nostré regioni.

\section{Esame dei materiali litolonici che costiluiscono la serie dei terreni tersiarî del Reggiano.}

Non i mio intendimento di esporre qui minutamente e comparativamente la litologia stratigrafica del Terziario, crenlendo sufliciente quanto fu detto per ciascuna zona in particolare; mi limiterò a trattare taluni speciali argomenti che reputo abbian:o l'unpo di essere sviluppati meglio di quanto siasi fatto antecedentemente e di essure considerati sotto altro punto di vista.

Mi arcontentero quindi di quanto is stato già esposto in particolare delle aryille, dello arenarie, delle salhie, dei calcari delle diverse etil. e parlero soltanto dei rmin flomerati farî, telle argille scigliose, o delle marne plioceniche. 
Direi quasi che in ogni periodo occorro di trovare un conglomerato; tali roccic varie per la potenza, per l'estensione, per la diversa grossezza decli elementi cle le costituiscono, e per la resistenza più o meno grande possono dirsi uniformi por la natura dei ciottoli di cui risultano.

Difatti abbiamo veduto nell' eoceno un conglomerato, solo od altemante con arenarie ed argille costituire il. Bartoniano: un conglomerato alternare colle arenario dell'Aquitauiano; un potente conglomorato formare gran parte del Langhiano; un altro stare alla base del plioceno; uno infine sostituire talvolta lo sabbio quatornarie marine, come ancora formare l'alluvione antica, o tutti poi risultare dall'associazione di ciottoli di rocee cristalline, anzi per lo piu di granito. Tutti i conglomerati duncue sono costituiti presso a poco dai medesimi materiali.

Non fa d'uopo andare lungi per rintracciare le rocee in posto, che col loro disfacimento, colla denudazione loro hanno somministrato il materiale per la costruzione dei terreni terziarî. Io ho già accennato nel principio di questo laroro, che tutto il centro della provincia, la giogaia della Serria, che si continua ad Aspromonte, risulta della formazione cristallina, ed in grim parte di granito; or al di li di Catanzaro ancora, nella vasta regione della Sila, abbiamo i materiali medesimi, siccome risulta beno dalle recenti esplorazioni del prof. Lovisato $\left({ }^{1}\right)$; quindi l'erosiono di tali terreni primitivi è la sorgente donde lamo attinto i conglomerati non solo, ma benanco le arenarie e le stesse argille, materiali tutti, che per la loro natura e costituziono, per l'abbondante mica che contengono, e tilvolta anco pel feldspato (come visibilissimo è in talune arenario tongriane (ii Stilo) attestano evidentemente la loro provenienza.

Secondo me il conglomerato piì antico studiato nei suoi dettagli a nella sua provenienza, risolve quasi ogni quistione; poichè tutti gli altri, almeno in gran parte, possono essere derivati dal disfacimento del primo. La loro identica naturia conferma la mia idea, l'immensa denudaziove cui ha doruto soggiacere il conglomerato cocenico, e come esso successiramente tuttí gli altri, ce ne dà poi quasi la certezza.

Ma tanto nell'eoceno come nei conglomerati di eti posteriore, tra i materiali che li costituiscono quasi tutti di rocee cristalline F'ha una roccia, in taluni luoghi abbondantemento sparsa, di cui sinora mi era proprio sconosciuta l'origine, perelic non trovata mai in posto nella provineia di Reggio, èil porficlo dioritico, il qualc colla sua variata costituzione, col suo colorito diverso, colle sue variazioni multiformi, como già abbiamo reduto, ci annuncia che proviene dai dintomi di Catanzaro, dove giace estesamente in posto, ed è stato recentemente studiato dal jrof. Ratlı $\left({ }^{2}\right)$, quindi dal sig. ing. V. Rambotti $\left({ }^{3}\right)$, che ne hanno esaminato la posizione, la costituzione, le modificazioni varie che esso subisce; cd ultimamento dal prof. D. Lorisato (") che indicara tale roccia in altri lnoghi della vasta regione della Sila.

Il non conoscersi, per quanto io sappia, simil roccia in altri luoghi dell'Italia

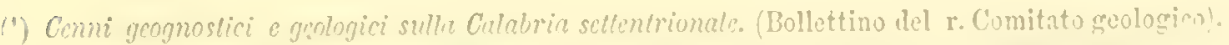

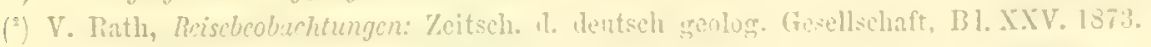

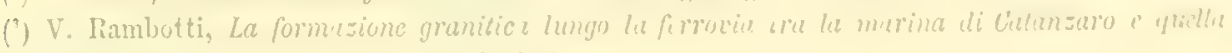
di Soveralo. (Bollett. del r. Comitato geologico).

(1) I). Luvisiatu. Memurias rifata. 
meridionalo, ed il somigliarsi dei ciottoli con la roccia in posto, parmi che confermi la provenionza suddetta.

Nei conglomerati terziarî del lato orientale e settentrionalo della Sicilia, coetanei a quelli delle Calabrie, s'incontrimo piì tosto abhondantemente i medesimi ciottoli. Essi sono stati segmalati dal prof. C. Gemmelluro ( $\left.{ }^{1}\right)$, dal dott. G. Denatile $\left({ }^{2}\right)$, da mo stesso $\left({ }^{3}\right)$; ma no resta tuttavia affatto ignota l'origine.

Or io non dubito punto ehe la provenienza del porfido dioritico, in Sicilia sia la stessa di quella dei ciottoli, che trovansi nei conglomerati di Calabria; che ne sia lo stesso l'agente di trasporto la stessa l'epoca poichè i caratteri tutti della roccia, le condizioni di giacimento, $\theta$ tutte le altre circostanze sono affatto identiche nelle due regioni.

Sarebbe da determinarsi l'agente cho spinse sì enorme materiale a sì grandi distanze ed in massi talora tanto voluminosi da raggiungere in taluni luoghi, per esempio nelle valli sopri Capo delle Armi, pressochè il diametro di due metri. Sarebbe da ricercarsi dunquo se correnti acque, se ghiacciai o piuttosto ghiacci galleggianti o altro poderoso agente, o parecchi insieme, hanuo operato il trasporto di questa ingente massa di rocce a distanze tanto cousiderevoli; ma tale ardua ricerca richiede apposite, svariate e protratte esplorazioni: quindi io non ardisco pel momento emettere nni mia opinione che non potrei certamente sorreggere con valevoli argomenti.

Aitro tema importante che voglio brevemente trattare è quello dell'età vari delle argille scagliose, che nell'Italia meridionale sono sempre evidentemente stratificate. In Calabria basta studinre per" poco siffatti terreni per convincersi del fatto sienrissimo della loro stratificazione, sia essa regolare come presso Stilo, presso Ferruzzano, nelle pianure di Brancaleone ec., sieno ancora gli strati lipiegati, contorti, sconvolti o rimestati come si mostrano in cento luoghi. Dorunque gli straterelli interposti calcarei, marnosi, arenosi, siderolitici ec., ora nella posizione originaria, ora rotti e spostati, ori frantumati e sparsi in seno alle argille od alla loro superficie, dimostrano colla piir spechiata eviclenza, e persuadono chicchessia della regolire stratificazione originuria di tali rocce. Quindi parmi che le argille seagliose delle Calabrie differiscano por talo riguardo da quelle dell'alta e modia Italia, sempre descritte siccome rocce in cui la stratificazione rarissimamente pù̀ essero con evidenza constatata.

Quanto poi spetta all'eti loro, assai discussa ed ancora indeterminata, or creduta secondaria, or riferita secondo i luoghi a varî periodi del Terziario, bisogna ormai anmunciare che l'Italin meridionale è chiamata a diradare i molti dubbî ed a risolvore definitivamente il problema.

Vi sono in Calabria, come giì abbiamo veduto, argille scagliose del Cretaceo medio (Cenomaniano D'Orbigny), che nello loro gradazioni presentano aspetti rarî che talvolta non possono distinguer'si dalle argille scagliose terziaric, e famno passargrio ad una forma, che parmi ricordi la scaglia dell'Italia media rapportatia al Cretaceo superiore. Queste argille sono caratterizzate da una fauna ricen di specio che ne

(') C. (iemmellaro, Gcologia della Provincie di Messina (Atti Acc. Giocnia).

() (i. Denitale, Riccrehe genynostiche sui terreni del distrelto di Wessina. 1851.

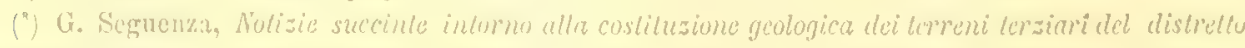

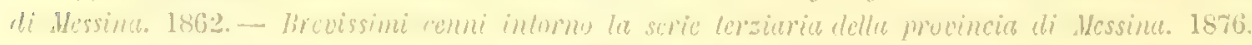


precisano beno l'etil: cosi mostransi nei temitorî di Brancaleone, di Bova, di Bruzzano di Ferruzzano ec, come in molti luoghi di Sieilia.

Vi sono argille scagliose che s'interpougono agli strati delle arenarie e del conglomerato bartoniani, come ha luogo a Stilo, e che perla loro posizione stratigrafica spettano a quel periodo.

Vi sono argille scagliose con istrati a Nummuliti ed Alreoline, che costituiscono il Flysch e che spettano all' eoceno superiore, cioè al piano liguriano.

Ve ne ha, come vedemmo senza indizio di fossili che si collegano al Tongriano. al quale pure spettano certe molasse scagliose della zona $E$ di tal piano che alle argille grandemente somigliano, ed alle quali fanno un rero graduato passaggio.

E qui non bisogna omottere che quantuaque tali rocee di periodi liversissimi possano benissimo indicarsi col comune appellativo di argille seagliose, pure in ciascum periodo geologico presentano dei particolari aspetti, doi caratteri speciali più o meno marcati. Quindi stratigraficamente e paleontologricamente nolla Calabria meridionale il problema è risoluto. Ci sono argille scagliose che spettano all'cpoca miocenica, come ve ne ha di quelle che spettano all' eoceno ed altre che sono cretacee.

Quanto poi all'origine di tali depositi argillosi, sicuramente stratificati ed accumulatisi in fondo al mare, io non ho verun dato da aggiungere a quanto gria si conosce. Mi resta a far notare che nelle Calabrie meridionali non si rede niente che parli in favore o contro la teoria, che fa derivare il materiale delle arcille scagliose dalle salse o dai vuleani fangosi.

Le mame del plioceno infine, sieno del periodo zancleano ovrero dell'astiano, hamo una grande importanza nella Calabria, vioi per la loro vasta estensione, ruoi por la loro costituzione speciale, cho insieme alla fiana racchiusivi, ammunciano essero stata ben grande la profonditi del mare in cui esse si costituivano, a differenza del plioceno classico dell'alta Italia, e d'altri lnoghi alle falde dell'Appennino, che rappresenta d'ordinario i depositi littorali di quell'opoca.

Uno studio minnzioso della costitnzione di quelle rocce maruose, che hanno una potenza talvolta enorme, come uresso Bianco-nuovo, Gerace ce, ci rivela che la loro origine è quasi completamente organica.

Stemprate nell'acqua lasciano galleggiare una miriale di piccolissimi Rizopodi calcarei, e trattate poi per lovigazione lasciano un resicho sabbioso cho talrolta raggiunge o supora la metà della massa, e che è in gran parte costituito dalle spoglic calcaree di Foraminiferi variatissimi, e specialmente di Orbuline e di Globigerine ai quali si aggiungono in minor proporzione gli Ostracodi e presso Ardore i Radiolarii.

L'abbondanza di tali spoglie fr presumero a ragione che la parte piì sottile di questo deposito dipenda dal detrito delle spoglic di ruegli organismi; o che quindi lo marne pliocenicho sieno formazione tutta organica, costituitasi negli abissi doi mari di quell'epoca, a quella guisa che oggi si forma il fango delle graudi profonditi oceanicho.

$$
\text { 3. Le oscillazioni del fondo marino nelle cpoche terziarie. }
$$

A determinare quali o quanti sieno stati i morimenti di ascensione e di depressione subiti dalla regione studiata, nelle epoche sottoposte all'esame geolegico, occorre precisare l'elevazione cui pervieno ciascum terreno, quindi seguirlo iappertutto ed 
esplorarno la cstensione; ma a riconoscere quanto piil esattamente i possibile il ralore di ciaseuna oscillazione, occorrono ben altri dati, più minuziose ricerche. Il raltionto tra le diverse profonditi delle acque marine nelle quali si originarono gli strati successivi della serie, è al certo uno dei piu importanti dati da ricerenrsi con molta curn; e i documenti per Ia determinazione di tali profonditi si hamo nella naturia e costituzione della roccia e moglio ancora nei caratteri tutti dellia fauna in essa racehiusid. Conosciute colla maggior possibile approssimazione le condizioni batimetriche di ogni piano geologico, e meglio di ogni strato, riuscirib agevole determinare per difforenza le oscillazioni arrenute nel fondo marino, precisare il loro valore, riconoscere lia loro eti, la durata relatira di ciascuma, il momento in cui al periodo di ascensione successe quello di abbassamento, la rapiditi o la lentezza del movimento. l'uniformitì o la difformita sopra estesa superficie, gli aceidenti rarî a cui diede origine e cento altri fatti relatiri, conclusioni tutte che sono come altrettanti corollarî che derirano legittimamente dallo studio stratigrafico, completo di m praese.

Con tali idee io rengo ad esporre brevemente in questo paragrafo quali e quante furono le oscillazioni e le loro varie accilcutaliti, a cui ando sogegetto nelle epoche terziarie il foudo sottomarino nella prorineia di Reggio, desumendole dal grato di profonditi del mare terziario nei periodi suecessiri, quale viene stabilito dalla natura delle rocce e delle faune.

Comincerò dal neriolo più antico per seguire l'ordine cronologico.

Le roce che spettano alla grande epoca cocenica mancano, quasi tutto di fossili: rien meno quindi il piì importante documento per determinare la profonditic delle acque nelle quali si originarono quei varî e potenti dępositi. Sono soltanto i calcari a Nummuliti, ben rari nel Regrgiano, che ci oftrono lei fossili eoconici.

E primo il Parigino, che ci si ofire soltanto in forma di massi isolati costituiti đi un calcare compatto-granoso, ricehissimo di grandi e piccoli Nummuliti, certamente ha dovuto deporsi a profonditi un po" considerevoli.

Immediatamente sieguono le argille bartoniaue di Stilo, che nella loro parte superiore alteruaro con arenarie, e quindi con istrati di conglomerato, alle quali rocec cedono finalunente il posto, ed entrambe si sviluppano cnormemente sul lato umeridionale della provincia, dore gli elementi direngono in taluni luoghi assai rolmminosi. Quantmuque siari completo difetto di fossili in questi potenti depositi, non puo farsi a meno di riconoscervi evideutemento un progressivo imalzamento del fondo marino, allorche si considerin che le argille, derositi delle profonditì, stanno al basso, in alto si mescolano alle arenaric ai conglomerati, o finalmente cedono il posto a quest'ultimo rocee, ed il conglomerato, deposito delle piccole prolomliti, termina la serie. Non r'ha dubbio quindi che dal calcare parigino al conglomerato bartoniano furri imalzamento stel fondo sottomarino.

Le argille scagliose dol Liguriano, succedono immediatamente c troransi dappertutto sovrapposte alla precedente serie: quindi poggiamo sul conglomerato a Stilo, al Capo Bruzzano e nel territorio di Motta, altermando con straterelli di calcare compatto, gramoso, suberistallino, o con calcuri cyusi intieramente formati di Orbitoidi, di Alveoline e di piecoli Nummuliti. Questi depositi sono senza dubbio di mare protondo, siccome sempre meglio ranne dimostrando lo recenti esplorazioni delle profonditi 
oceaniche. Quindi una grande iegressione si arreris nllorquando cominciara il periodo liguriano che e rappresentato in tutte lo contrade uniformemente.

Le argille scagliose si continuano per un certo tratto ancora nel minceno inferiore; ma ben tosto alternano con arenaria quarzosa, la quale finalmente diviene sviluppatissima in taluni luoghi. Cii) mostra che il mioceno comincia con un neriodo r'innalzanento del fonto marino, il qualo in taluni luoghi, come al Agnana ed Antonimina, riceve una serie di depositi alternanti palustri e d'estuario, tra i quali costituivasi il comlustibilo del territorio di Gerace. Ma non terminava ancoria il Iungo periodo tongriano, cle il mare si stendeva nuovamente su ruello contrade formando potenti depositi juetta. mente marini con Pellini, Clipeastri, Nummuliti, Orbiloidi ec.

Il nuovo periodo di depressione cominciato sul finire lell'epoen tongriana, si ì continuato nell'epoca aquitaniana: ce lo attestano i comuni depositi di mare profondo clic la rappresentano generalmente, quali sono i calcari a Briozoi, che soltanto rerso Stilo vengono sostituiti da depositi di mare meno profondo, ricchi di una famma molto variata.

Lo argille langhiane a Pteropodic Coralli attestano che ancora il mare mantenevasi tutlavia profondo, o che quindi, il fondo s'innalzava lo dimostra la fauna a Gasteropodi c Lamellibranchi che succede a Stilo e i potenti conglomerati e le arenarie che terminano dovunque Ia seric langhiana.

La debole prolondita delle acque attestata eridentemente dai conglomerati langhiani non si confa colla fauna delle sabbio o dei calcari clveziani, che a quelli imnsediatamente succedono; difatti in essa ai grandi Jamellibranchi ed ai commi e voluminosi Clipeastri si associano dei J3rachiopodi, degli Ostracodi, abbondanti Foraminiferi ed una serie imprortante di Briozoi che incrosta osni maniera di conchiglie, resti tutti cho attestano una frofondita marina almeno mediocre. Dopo il periodo langhiann dunque avvenne una nuova depressione; ma bentosto s'inizio un nuoro periodo d'innalzamento, cui attesta la minor profonditi delle açue riconosciuta nella rariti dei Brachiopodi e dei Briozoi delle argille tortoniane, e piir ancora nolla fauna littorale dello soprastanti sablie. I depositi palustri o d"estuario del territorio di IIontelcone non funıo che confirmare le sopra esposte deduzioni. Il sollevamento si continuo ancora per tutto il periodo mossiniano, quando dorunque in Italia ed altrove stendevansi-laghi, paludi c lagune in senn ai quali depositaransi gessi e combustibili, e nel Reggiano costituivansi le rnece gessose di Benestare, di Siderno, di Mileto oc., e i soprastanti calcari cellulari di Gerace o di tanti altri luoghi.

Il sollevamento dunque sul finire della grande epoca miocenicu convertiva in recioni paludose quelle dove libero e tranrunillo stendevasi il mate tortoniano, in fondo al qualo poco fa rigogliosa fervea la vita di una fauna rariatissima o propria di un clima abbastanza caldo.

Mra ecco bentosto al cominciare dell'epoca pliocenica avverarsi un grando mut?mento: ai depositi palustri o littoranei snecedere le ingenti masse di mame o salubie zancleane, clie depositatesi in mare molto jurofondo si estendono rastamente cul invadono sin le regroni elevate, dove sedimenti anteriori, secondari a terziari, non giunscro mai, el il plioceno vedesi percio joogrgaro sulle filladi jaleozoiche o sugli schisti cristallini raggiungendo l'altezza di 1200 metri sul livello del mare. 
Ecco alunque la piì grande oscillazione che dobbiamo recistrare, por la quale tutta cuanta l'Italia meridiomale profondarasi negli abissi del maro, venendo risparmiate appena le più alte cime dell'Aspromonte.

Difatti i potenti depositi mamosi dollo Zancleano sono veri fanghi degli abissi oceanici: un ammasso di Orbuline, Globigerine e tanti altri Eoraminiferi, fanghi quali oggi prouluconsi nelle grandi profonditi. A questa grande oseillazione, come è naturale, corrisponde la pì̀ grande denudazione. Difatti abbiamo veduto come il Messiniano ed il Tortoniano sono appena rappresentati da piccoli lembi nella provincia di Reggio; o l'Elveziano, quantunque alquanto piì esteso, pure siegue ussai da vicino gli altri due membri del mioceno superiore, trovandosi limitato a certe contrade soltanto. Erano questi i tre piani piì recenti di quolli gia costituiti allorquando la grande depressione avveniva e dal loro difetto generalo dipende il fatto che il plioceno comunemente poggia sul conglomerato lamghiano. Altro fatto di grande importanza si è quello che i lembi assai piecoli dei tre piani Elveziano, Tortoniano, o Messiniano si collegano insieme in taluno contrade specialissime, dovo si presentano allo studioso nei loro relativi rapporti stratigrafici. Così a Benestare, ad Ambuti, al colle Falcò presso Siderno, e nel territorio di Nonteleone: invano si cercherebbe altrove un lembo isolato dell' Elveziano che vadi disgiunto dalle argille tortoniane, o vicoversa, non occon'e mai d'incontrare queste senza di quello. Cio dimostra sino all'eridenza che la distruzione quasi completa degli ultimi tre piani del mioceno devesi ad unica e medesima causa, la qualo agendo contemporaneamente sugli strati dei tre piani, li distrusso generalmente risparmiandoli soltanto in poche e limitate contrale, fa conosccre inoltre che tale causa comincio ad agire dopo l'epoca tortoniana e probabilmento la sua azione si protrasse per lungo tempo. La coincidenza intanto della grande denudazione colla maguiore delle oscillazioni, svela lo relazioni che passano tra questi due fenomeni, fa bene intendere come la prima è dipendente dalla seconda. Ed in vero il movimento ascensionale cominciato sin dall'epoca elveziana si continuò per Intta l'epoca tortoniana, ma la rasta emersione delle terre avveravasi allorcuando nel periodo messiniano laghi, paludi e lagume apparivano dapertutto, ed intanto in sì lungo periodo di lenta emersione i sedimenti renivano mano mano esposti all'aziono distruttrice dalle onde marine, che credo sia stata la cansa precipua della vasta denudazione arvenuta sul finire della grande oposa miocenica.

Ma intanto il movimento s'invertiva al cominciare dell'epoca pliocenica, e i terreni emersi mano mano ritornavano in seno alle onde, che reiterando così la loro azione denudatrice finivano di distruggoro intiermento quegli strati che nel periodo di enersione erano stati abbastanza corrosi. Di tanta cosi imponente demolizione fanno ampia testimonianza i conglomerati colossali che in molti luoghi stanno alla base della formazione pliocenica, come nei dintorni di Siderno di Benestare ec. ma la loro costituzione risultante principalmente di grossi ciottoli granitiei dimostra più di nuanto bisogna; essa dichiara evidentemente che la denudaziono è andata ancol piì profonda. ha intaceato $\mathrm{i}$ conglomerati langhiani e le stesse rocce cristalline in posto, i terreni cioè che potevano somministrare i materiali di cui risulta il conglomerato pliocenico, non potondo essi provenire dai fini sedimenti di cui costano i tres piani miocenici denndati mossoche completamente. D'altrondo, aflinchè gli strati 
pliocenici avessero potuto deporsi sino alla elevazione di 1200 motri sul livello del mare, dovea il progressivo abbassamento esporre mano mano all' azione dello onde non solo tutti i sedimenti terziarî, ma, oltrepassato il livello doi piì elevati tra questi, anco la formazione cristallina; la quale dovea ancor piiu lungamente soggiacere all'azione demolitrice, ben lungamento essendosi protratto il periodo di depressione.

Allo Zancleano costituito per intiero di depositi di grandi profondita, fatta astrazione dei conglomerati della base, succede 1Astiano, parimenti formato di marno ricche d'una fauna abissicola; quindi il periodo di depressione si è continuato per tutta l'epoca astiana.

Sul finire di questa seconda epoca pliocenica troviamo gli strati sabbiosi di Gallina e d'altri luoghi ricchi d' nna fauna che accenna ad una diminuziono di profondità; quindi ricominciava sin d'allora mn nuovo periodo d'emersione, che lungamente perdurando, come quello di depressione cui seguiva, cra destinato a daro alla provincia reggiana il rilievo e la conformazione attuale. Difatti gli strati del plioceno recente di Villa S. Gicvanui e del territorio di Motta coi Ioro Briozoi abbondanti, e le argille di Monosterace accennano tuttavia ad un mare alquanto pro. fondo. Siffatta profondità diminuisce ancora nel primo periodo del Quatemario, i cui strati si elevano intanto a considerevoli altezze, mentrechè il Quaternario superiore depostosi in mare meno profondo, non ha subito che lieve innalzamento, ed i aranzato di molto dalle alluvioni anticho. Bisogna ritenere quindi che il movimento d'ascensione comincinto sul finire dell'epoca astiana si ì continuato sino al più rocente periodo geologico, o forse anche tuttavia si continua, avendo innalzato que. st'estremo della penisola italiana per'oltre mille e trecento motri.

\section{Altimetria dei terreni teraiari e conseguenae che ne derivano.}

Nell'esame speciale di ciascun piano terzilurio ho segnalato l'elevazione sul livello del mare cui sia porvenuta ciascuna roceia. Questi dati altimetrici potranno iudirizzarci nella determinazione dell'area emersa e delli sommersa in ciascuma epoca, potendo mettersi a profitto per dedurne i movimenti di ascensione o di albassamento arreratisi sull' intiera regione nei rarî perioli cenozoici o neozoici; e se tali risultamenti saranno concordi allo deduzioni tratte dalla natura litologica e dalla storia biologica degli strati, arremo una piena conferma dei risultamenti che precelono, porche l'elevarsi o l'abbassarsi della terri emersit concorda coi movimonti del mossimo fondo del mare, ed cntrambi si traducono nell'inmalzamento o l'abbassamento della costa.

A cominciare dal conglomerato eocenico, troviamo cho questo non s'imualza gran fatto sul livello del mare: di fatti il monte Pentedattilo, e le clerazioni circostanti raggiungono pressochio i 400 metri; la stessa clevazione ha il conglomerato bartoniano presso Stilo, ma si eleva di piì ancora nol territorio di MIotta dovo sui fanchi della fiumara di Lazaro, verso la metì del suo corso, esso raggiungo i 600 metri.

Tali depositi ossendo costieri per eccollenza e non raggiungendo in cloriziono nemmeno il terzo della massima altezza dei monti reggiani, ne ensegue che quella provineia nel periodo bartoniano cra abbastanza cstesa, e i depusiti di quell'epoea roreano costiture originariamente unil cintura che si cstmolera senza intermzione suj lati orientale e meridionale. 
Le argille scagliose del Liguriano, che succedono al conglomerato, nceupano d'ordinario le regioni basse, e le depressioni ma presso Motta ascendono al disopra del conglomerato, innalzandosi ancora piu del conglomerato stesso.

Cio dice che il fondo marino si deprimeva per ricevere quei sedimenti proprî dei mari profondi, e che perciò la terra emersa subiva una restrinzione.

Alle argille scagliose succede l'arenaria quarzosa del Tongriano, la quale sviluppasi considerevolmente in talımi luoghi del lato orientale della provincia; là imalzasi al di sopra delle argille scagliose, raggitungendo per massima elevazione 400 metri sul livello del mare. Così a Ferruzzano, a Ciminì ed in altri luoghi. Lo che importa che l'arenaria si mantiene ad un livello considerefolmente inferiore a quello delle sottostanti argille, che oltrepassano presso Motta i 650 metri.

Quindi al cominciare del Tongrimo il movimento è divenuto ascensionale, $\theta$ la parte emersa della jrovincia di Reggio si è andata clargando. A conferma di ciò stanuo i seguenti fatti: $1^{\circ}$ la mancanza dell'arenaria (quarzosa al di sopra delle argille scagliose nelli regione elevata del territorio di Motta; $2^{\circ}$ la natura di grossolano sedimento dell'arenaria stessa; $3^{\circ}$ Ia successione nei territorî di Agnana, e di Antonimina all'arenaria quarzosa di strati palustri a combustibile, i quali alternano con strati marini.

Tutto ciò concorda a meraviglia con un periodo di leuto e graduale innalzamento.

Al di sopra dogli strati a combnstibile il Tongriano si continua con una sorio di strati marini, che acquistano un granuo sviluppo el una limarchevolissima potenza nei monti che sovrastano a Gerace o ad Antonimina, raggiungendo l'elevaziono di oltre 800 metri sul livello del mare. Quegli strati sono di argille scagliose, di arenarie più o meno fine e calcarifere, che racchiudono un'importante fauna con Pettini, Clipeastri, Nummuliti, ed Orbitoidi. Eccoci adunque ad un nuero periodo di abbassamento, confirmato dall'apparire degli strati marini ultimi del Tongriano anco sopra le argille liguriane del territorio di Motta, dove l'arenaria quarzosa non si depose.

L'Aquitaniano in forma di calcare a Briozoi, deposito di mare profondo, vedesi in varî lnoghi sormontare in forma di piceoli lembỉ il Tongriano, e se prosso Stilo sotto forma di arenarie a Clipeastri, Nolluschi, o Coralli, raggiunge appena in qualche lnogo i 400 metri di elevazione, il calcare a Briozoi presso Antonimina sale a 600 metri; nel territorio di Motta, dovo offre il suo massimo sviluppo, oltrepassa i 700 motri, c lungo la rotabile che da Geraco va a Cittànova, nel luogo doro la strada è presso a raggiungere il pianalto, trovasi un lembo di calcare a briozoi, probabilmente aquitaniano, che sormonti il Tongriano e perviene quasi a 900 metri d'elevazione. Tutto cio dimostra che il periodo di abbassamento cominciato nell'epoca tongriana si è continuato per tutta l'epocil aquitaniama, o quindi che la parte emer'sa del Reggiano si è ristretti cousidererolmente.

Il Langhiano formato di argille e l'arenario alla baso, o d'un potente conglomerato in alto, ovvero di questo varie roce alternanti, non raggiunge generalmento l'elovazione dell' $\Lambda$ quitaniano: esso s'innalza pressochè 400 metri presso Stilo, 650 al monte Gonia presso Motta, ed oltre 600 a S. Auno e da Ortí, addimostrando, anco coi grossolani depositi littorali, che v'ebbe in sul finire di quollepoca un inmalzamento.

Gli ultimi tre piani miocenici essondo stati si profondamento denudati, non lascilrono, enme givi ho esposto, che lembi di ben piccolia mole, perchè potessero formirei 
valevoli argomenti nella ralutazione degl'impulsi subiti dalla regione cho esamino nei periodi da essi rappresentati.

Ad Ambutì dove l'Elveziano ì il più esteso, innalzasi a circa 360 metri, uguagliando presso a poco l'altezza del precedente conglomerato; c sono soltanto le considerazioni intorno la natura dei sedimenti e la costituriono della fuuna che depongono in favore di un abbassamento.

Della stessa manicra, niente ci rivelerebbero i piccoli lembi del Tortoniano e dol Messiniano, che ad Ambuti si mantengono ad un livello inferiore del precedente terreno, ed a Benesture invece s'imalzano molto su di esso raggiumgendo i 400 metri, se le considerazioni iutorno ai lorn caratteri non ei avessero spelato eridentemente un periodo d'innalzamento.

Ia bentosto rediamo succedere ai niceoli lembi e dimessi che completano la serie miocenicn, i vasti, potenti ed elevati strati pliocenici: il conglomorato cho presso Benestare raggiunge i 660 metri, e le sahbie e le marne che si elevano 400 metri presso Stilo, cirea 600 nei monti di Sidermo, 450 a Gerice, 750 presso Terreti, 750 ad Ortì, 600 sui piani della Melia, 900 sopra Canolo, 1200 nei piani sopra Reggio.

Ecco dunque un cumulo di dati che depongono con grande evidenza in farore dell'imponente e grandioso abbassamento, che alla fine dell'epoca miocenica operò la depressione maggiore che si sia mai avverata di tutta quanta la provincia di Reggio.

I depositi calcarei, marnosi e sabbiosi dell'Astiano sieguono molto da presso gli strati zancleani, quantunque non raggiungano le maggiori elerizioni di questi ultimi.

Ciò dimostra che non solo nell'epoca zancleana, ma ancora nell'astiana la regione era grandemente abbassata.

E tale abbassamento, che comincio a diminuire sul fiure del periodo astiano, come dimostrano gli ultimi strati sabbiosi e ghiaiosi di Gallina e d'altri luoghi, non crat scemato gran fatto, allorehè deponeransi lo sabbie del plioceno superiore, che elerate sino ai pianalti cho si estendono solna BIotta, raggiungono l'alterza di mille metri circa.

Il periodo pliocenico adunque fu quello della massima deprossione per la provincia reggiana; e tale abbassamento ha dovuto ridurre di molto la parto omersa; sicchè non potè rimanere all'ascint tn che un breve tratto, il gruppo centrale dell'd spromonte, quasi uno scoglio in mezzo a rasto mare. Onde a mio credero quell'idea cmessa dal Pilla, ripetnta dal Philippi e recentemente dal prof. Rath, che cioc la Calabria meridionale nellepoca pliocenica fosso disgiunta dalla parte continentale da uno strotto esteso da Squillace a S. Eufemia, ra considerevolmente modificata; dappoicche meglio che un'isola, essa non formava allora che uno scoglio assui lontano dalla terra forma.

Mentre dumque attorno quel cucuzzolo, che sporgevil dal foudo marino, si costiturvano a considererole profonditì crli strati del primo e del secondo perindo pliocenico, nell'acque si succederano quelle fiume clie oggi attestano cloquentements lit loro origine abissicola, el intanto attormo all'Appennino dell'alta o melia Italia rivea quella classica e ricea fama piì o meno littorale, clse troviamo oggi negli strati pliocenici costituitisi nllora a piecole o mediocri profonditid.

Le grossolane sahbie del Quatermario antico, quantunque non si elerano quanto il plioceno recente, pure raggrimgono altezze rigguarderoli. Ad Ortì o S. Aumn cirea 750 motri. mel territorio di Motta 830. Non cosi il Quatemarin recente, il 
quale invece si clera beu joco sul livello del mare; a Musala infatti s'immalca più di 200 metri, a Boveto ragginuge i 150 metri, a Ravagneso gli 80.

Tutto cio dimostra a dovere che l'innalzamento cominciato :ol periodo astiano, si è continuato nei varî e luughi periodi successivi sino all'ultimo che è ben recente, precedendo immediatamente i tempi attuali.

Ma diamo ancora un'utile occhiata agli ultimi periodi goologici nell'alta Italia, raffrontando ai nostri depositi i coetanei di quella regione. Nell' Italia meridionale erano in generale assai profondi i mari nei periodi zancleano al astiano: bisognò quindi lungo rolger di tempo, perchè la massa principale di quei depositi venisse portata fuori dalle acque dal morimento ascensionalo. Trascorsero quiudi e il periodo dol plioceno recente e il Quaterario; e i sedimenti marini che in tali epoche si costituirouo, poggiarono piì o meno estesamente sugli strati del plioceno antico. Nell'alta Italia invece, essendo generalmente joco profondo il mare pliocenico, al cominciare del movimento ascensionale i sodimenti sono venuti fuori dalle acque; quindi non poterono su di essi ricevere sedimenti marini di età più recente: ecco la ragione per cui in quelle contrade all'Astiano marino succedono depositi lacustri e terrestri a rapplesentare parte del plioceno, più il recente ed il Quaternario.

Da quanto abliamo ricavato dallo studio altimetrico intorno ai movimenti arveratisi nei successivi periodi terziari sul suolo della regione studiata, bisogna pur conchiudere che tali risultamenti concordano a meraviglia con quelli ottenuti dall'esame delle rocece e delle faune in esse racchiuse.

Nell'ultimo periodo di emersione adunque, che è il maggiore tra quanti se ne avverarono nelle epoche terziarie, dobbiamo riconoscervi quello, che dando alla Calabria l'attuale rilievo, vi ha prodotto insiome una delle più poderose deuudazioni; per la quale il plioceno come il Quatemario hanuo dovuto perdere sopra vasta scala gran parte dei loro depositi, ed il suolo di raste contrade trovasi oggi privo dei sedimenti degli ultimi periodi, come sni pianalti il plioceno corroso o smemurato trovasi ridotto a lembi e talvolta a massi staccati, e quelle spiauate alte od estese redonsi solcate da scoscesi burroni $\theta$ da valli che s'inabissano sino a parecehie centinaia di metri di jrofondita, efletti tutti doruti all'ulteriore denudazione.

L'innalzamonto intanto si è continuato nei periodi assaí recenti ed ultimi, come provano abbastanza gli strati di Boveto o di Ravagnese, e probabilmente si continua ancolia.

\section{Uno sguardo comprensivo sullo faune tersiarie della provincia di Reggio c sul loro valore.}

Nogli studî stratigrafici precelentemente esposti, i fatti piì vileranti dobbiamo necessariamente riconoscerli nei dati paleontologici che ci si offrirono a dovizia; sono i fossili, le riche fanme scoperte, che ei hamno porto il destro al importantissime alplienzioni, che ci hamo indirizzato in talune vie di ricerche che vano sareblue statn il tentarle senza l'ainto della paleontologia; in fine le più importanti deduzioni che oggi presento unale risultato ultimo di questi miei studî, le conclusioni princimali, o più tosto il maggior numero di esce, dorivano dal minurioso esame delle faume, che gli strati terziari del leggriano racchitulono, dallit discussione acenrata ilelle variate 
forme specifich di cui esse risulturo, dalla comparnzinne lnin colle foune precedenti, coetanee eri attuali.

Ma gl'importauissimi risultamenti si derono sopratutto alla ricchezzit delle stesse faune terziarie della provincia di Reggio; ricchezza uell'abbondante ummero delle specie non solo, ma ancora beno spesso nella profusione degl'indiridui, nella grande estensione topografica della magowior parte delle funo medesime, o finalmente nella loro costituzione, racchindendo d'ondinario rappresentanti di quasi tutte le classi animali, che mi sono ingegnato di mettero in evidenza studiando o definendo specificamente qualumqne siasi residuo.

Certamente il vastissimo campo delle esplorazioni paleontologiche, non ì stato da me esaurito: sono taluni piani, alcune zone, o certi strati, ortero delle contrade cho richiedono nuove e reiterate esplorazioni, sopratutto per quelle classi che sono costituite da minimi organismi, quali gli Ostracodi, i Brozoi, i Foraniniferi, i Radiolarii; ed io, in questa generale rivista del materiale paleontologico raccolto estudiato, nel mentre mi fard ad indicare quali sono le faune, overo le classi, che pel primo ho studiato nella Calabria meridiomale, siccome quelle cho erano state precedentemente esplorate đa altri, non trasanderò di additare i piani geologici, le classi animali, orrero le contrade che richiedono tuttavia move a reiterate ricerche, e che percio offrono tuttavia campo ben vasto pegli studî paleontologici.

E qui torna utile accennare un mio apprezzamento, cioè, che sotto il doppio punto di vista della dovizia delle faune e del loro concatenamento, certo la Calabria meridionale offee un campo di studio di grande importanza, e che divorrì senza dubhio classico; essendochè ivi, come i terreni terziarî, cosi lo ricche fiune che essi linchindono, formano una serie non interrotta, sino proprio al coneatenamento colle formazioni e colla fauma attuale. Difatti è a questo concatenamento, a queste successive o graduali modificazioni delle fane, che io voglio dare principalmente uno sguardo, considerando sopratutto le classi piì importanti.

La serie eocenica in rero entra per poco in quoste considerazioni, come quella che non offre altro clue spoglie della sola classe doi Rizopoli, e queste pure vi si contengono in numero ben linitato di specie.

Sono i numerosi piani che sovrastano all' eoceno che ci offrono le grandi ricchezze paleontologiche; lo quali, suecedendosi di periorlo in prriodo, formano un concatenamento quasi non interrotto, sino alla più recente zona del Qunternario.

Le doviziose faune dei piani miocenici calabresi si ofliono affitto muove allo studioso, come quelle che nou furono mai osplorate, quantunquo il Montagna (') abhir conosciuto taluni lnoghi dei piani inforiori, disconoscendone non per tanto l'otic dei depositi, che ha creduto secondaria, nonchè i fossili, cho ha definito tutte por nuove specie, e quantunque il Costa abbia deseritto qualcho dente di Curchurodon o qualche Cerizio di Montelcone $\left({ }^{2}\right)$.

La fauma del Tongriano quantunque poco ricca, pure è importantissima, essendo la prima dei piani terziarî che si presenta alquanto rariata, cinè costituita di rappresentanti di vario classi; difatti dei Mammiferi, dei Pesci, dei Molluschi, dei Briozoi,

(') Montagna, op. citate.

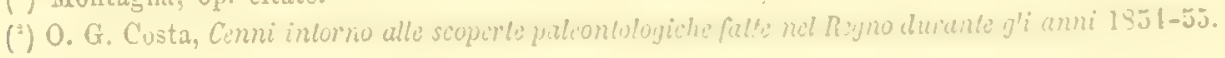


legli Echinodermi, dei Foraminiferi vi si trovano per formare un tutto abbastanza caratteristico; difatti oltre le specie riconosciute come tongriane, abbiamo rinvenuto degli strati ricchi di Nummuliti e di grandi Orbitoidi, siccome sunle d'ordinario osserrarsi altrove.

L'Aquitaniano l'abbiamo riconosciuto con un facies proprio dei mari profondi nel calcare a Briozoi, e con facies littorale nelle sabbie che lo rappresentano nel territorio di Stilo; quindi con due faune distinte ma complementari. Quella dei Briozoi che resta ad esplorarsi, e ne sarì ardua l'impresa; l'altra costituita di Molluschi ben noti, che caratterizzano lo stesso piano nella collina di Torino ed altrove, di Echinidi, e specialmente di grandi Clipeastri, e li Coralli o Foraminiferi anch'essi di specie note.

Le argille langbiane sono alla loro volta benissimo caratterizzate dai Molluschi, dai Coralli o dai Foraminiferi quasi tutti noti, e tra essi specialmeute dalla Vaginella depressa molto comune.

La fauna elveziana è delle più ragguardevoli senza dubbio, perchè in essa sono rappresentate quasi tutte le classi, non esclusi i Mammiferi e i Pesci. In essa i Briozoi e gli Ostracodi ci ofrrono gia un considerevole numero di specie, siccome i Clipeastri dapertutto abbondanti si presentano generalmente con forme molto elevate.

La fauva tortoniana poi è come dapertutto caratterizzata da molti Molluschi, ed è ricca assai di specie ben conosciute, spettanti alle varie classi; oltre dei MIolluschi, abbondano Crostacei (Ostracodi, Cirripedi), Briozoi, Anellidi, Echinidi, Antozoarî, Rizopodi.

Il piano messiniano ci offre una vera interruzione per riçuardo al concatenamento biologico, cssendochè i pochi lembi di rocce che vi si rapportano, oltrechè molto limitati e ristrotti, non hamo offerto funora reruno indizio dei resti organici di quell' epoca.

Le faume dei piani pliocenici, per ricchezza o varieti di gruppi e di forme, non sono da meno di quelle sinoria ricordate dei piani miocenici'; esse sono state precedentemente esplorate in alcune localiti e per talune classi soltanto. Il Philippi vi ha ricercato i Molluschi ('), il Costa, oltre di qualche Mollusco, piju specialmente vi ha esaminato i Foraminiferi dei dintomi di Reggio.

La fauna dello Zancleano renne dal Philippi esplorata pei soli Molluschi nelle localiti di Terreti e di Nasiti; essa invece ci offre rappresentanti di numerose classi. Dei Vertebrati, qualche Mammifero e taluni Pesci; dei Molluschi, rari Gasteronodi e conuni Lamellibranchi e Brachiopodi; dei Crostacei, numerosi Ostricoui e Cirripedi; dei Vormi, oltre taluni Auellidi, una ricca fauna di Briozoarî che forma uua rimarcherole caratteristica di questo piano; degli Echinodermi, alcuni Echinidi; dei Rizopodi, profusissimi i Foraminifuri, ammassati specialmento nei dopositi marnosi delle grandi profonditi, o i Radiolarii svariati, quantunque sinora conoscinti in un sol luogo.

'I'ra lo più attraenti fiune deresi al corto annoverare la nostra dell'Astiano; la quale, esseulo in generale di mari profondi, ci ofire la più rimarchevolo o la più 
importante serie di Molluschi, di cui taluni rirono oggi nei mari settentrionali, or un numero ben considerevole, che si accresce sempre piir, va scoprendosi nolle profonditit mediterranee ed nceaniche.

Il Philippi area già studiato un certo numero di tali Molluschi in varî luoghi, quali Bianco, Monosterace, Valle Lamato, Cutro, Cotrone S. Severina ec. ec. o perciò un certo numero di forme sono descritte da lui.

La fauna astiana costa dunque di qualche resto di Mammifero, dei residui di numerose specie di Pesci, di Molluschi (Gasteropodi, Solenoconchi, Pteropodi, Lamelliuranchi, e Brachiopodi) quasi tutti abissicoli, di Crostacei (Ostracodi e Cirripedi), di Vermi (Anellidi e specialmente Briozoi), di Echinodermi (Crinoidi ed Echinidi), di Zoantarii caratteristici e comuni, e finalmente da immensi ammassi di spoglie di Foraminiferi, che costituiscono d'ordinario gran parte della roccia.

Il plioceno superiore ha una fauma che dimostra la transizione rerso il Quaternario: in essa è rimarchovolo sopra tutto l'immenso ammasso di Briozoi esistente a Pezzo presso Villa S. Giovanni, del quale un certo numero di specie furono descritte dal sig. Manzoni.

Il Quaternario da ultimo nelle sue due zone, ci offre delle faune che hanno la più grande analogia colla mediterranea, essendochè hanno di comune con essa il maggior numero di specie di tutte lo classi.

Il Philippi avea già esaminato i Molluschi delle vicinanze di Reggio, c spe. cialmente della ricca localiti di Carrubare. In ambo lo zone quasi tutte lo classi animali vi hanno rappresentanti più o meno numerosi, e, come gì fu dimostrato, la zona inferiore offre delle specie proprie dei mari frecldi; invece la fauna della zona superiore, che non ela stata per lo innanzi esplorata, contiene delle specie dei mari caldi.

Avendo considerato sin qui complessivamente le faune terziario in ordine cronologico, bisogna ora cho diamo un rapido sgruardo alle siugole chassi por seguirne il loro successivo sviluppo nella regione da me esplorata, affine di apprezzarne la loro importanza, sopratutto relativamente agli strati che li contengono, o quindi ai piani geologici che devono rappresentare.

I Vertebrati ci offrono rapuresentanti di due classi soltanto: dei Mammiferi e dei Pesci; entrambe hanno dei lesti in quasi tutti i piani a cominciare dal Tongriano.

I Mammiferi infatti ci hanno ofterto l'Anthracoterium magnum nol Tongriano; degli ossami indeterminabili nell'Aquituniano o nel Langhiano; nell' E'lreziano l'Heterocetus Guiscardii ed il Palacodelphis minutus; nessun resto nel T'ortoniano e nel Messiniano; un Heterocetus? nello 'Zilncleano; un Delphinus nell'Astiano; l'Elephas armeniacus nel Quaternario inferiore; e resti d'una balena nella sua zona superiore.

I Pesci si offrono, como ì maturale molto piì comunemente: ecco un quadro numerico delle specie che ho raccolto e definito:

\begin{tabular}{|c|c|c|c|c|c|c|c|}
\hline Tongriano & Generi & 2 Specio & 4 & Messiniano & Generi & 0 & Specie \\
\hline Aquitaniano & $\gg$ & 3 & 5 & Zancleano & $»$ & 4 & » \\
\hline Langhiano & " & 0 & 0 & Astiano & " & 5 & » \\
\hline veziano & 》 & $»$ & 11 & Siciliano & $"$ & 0 & » \\
\hline ortoniano & $\gg$ & $»$ & 3 & Saariano & $"$ & 0 & $\gg$ \\
\hline
\end{tabular}


I numeri qui riportati riguardano soltanto i pesci tla me definili specifica. mente sullo studio dei denti raceolti, le quali forme sono tutte nuove pel Reggiano, meno il Charcharadon megalodon, che il Costir raccolse a Nontelcone; ma le faune ittiologiche dei terreni la me esplorati somo ben più ricche di quanto non appare dal precedente elenco; esse comprendono un numero di specie molto considerevole, rapuresentato soltanto dagli Otoliti, che tuttavia non siamo al caso di definire specificamente. Tali resti, come abbiamo veduto, divengono abbontantissimi rell'Astiano e di forme assai variate o numerose.

I Molluschi formano al certo il tipo piì ragơuardevole, essendo nel Reggiano rappresentati con grande profusione nel maggior numero dei piani terziarî, e riferendosi per la maggior parte a suecie gia ben note, che controdistinguono a meraviglia i piuni che li racchiudono.

I Cefalopodi non offrono che qualche raro frammento o residuo, tra i quali è ben notevole l'Aturia Aturi raccolta nel Langhiano di Stilo.

I Gasteropodi sono distribuiti disugualmente nei diversi piani: ne sono ricchi per esempio il Tortoniano, l'Astiano, il Quaternario, ed invece porerissimi l'Elveziano e lo Zancleano. Eccone l'elonco numerico:

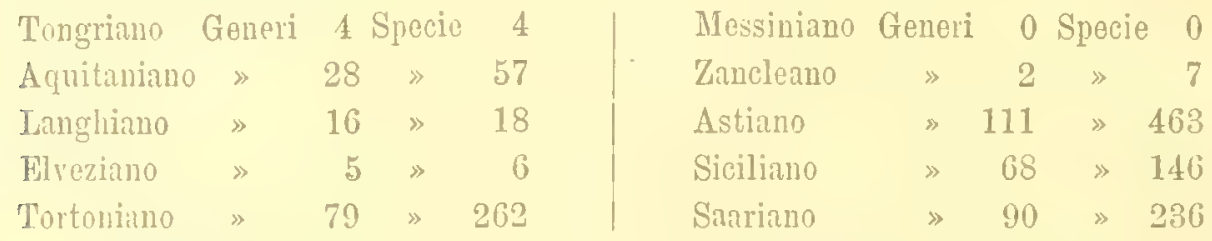

Gli Scafopodi, che formano la Classe dei Solenoconchi, hanno anch' essi dei rappresentanti in molti piani, come dice l'elenco seguente:

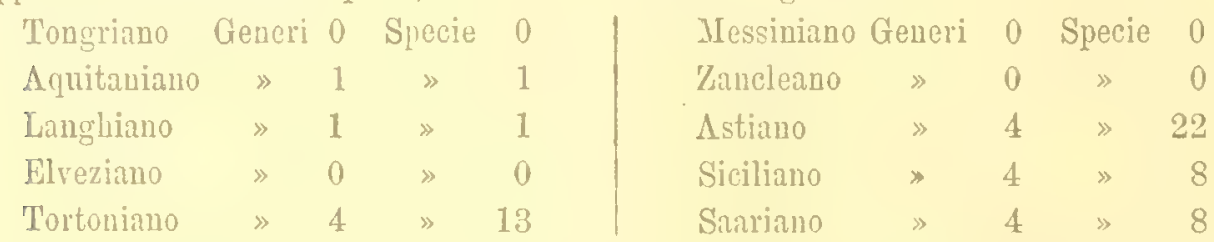

1 Pteropodi presentano ma distribuzione ancor piì varia, essendo profusamente sparsi in qualche piano, e mancando affitto in taluni; il numero delle specie poi ne è sempre ben limitato, come indica la seguente lista:

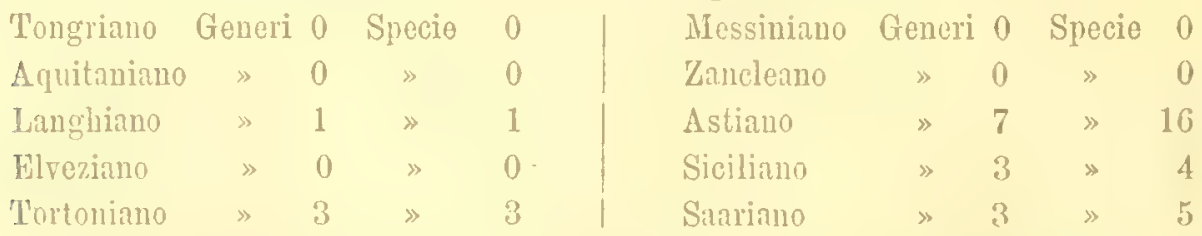

1 Lamellibranchi ci offrono invece una distribuzione nei successivi piani molto più uniforme di quella delle classi precodenti; l'elenco che siegue lo dimostra perfettamente:

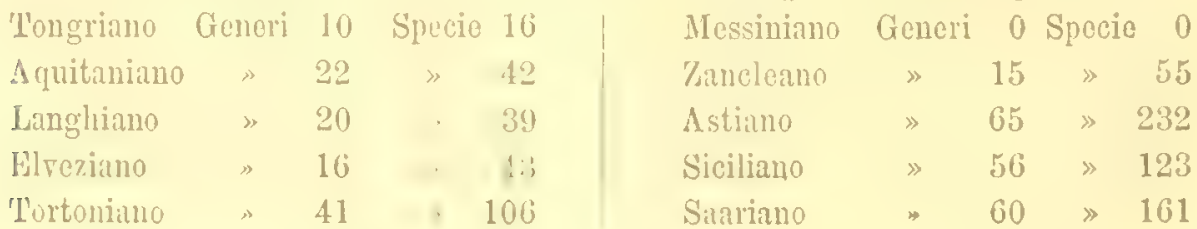


I Brachiopodi finalmonte, trovandosi soltanto nei dopositi di considerorole profondità, caratterizznno solamente tanto quei piani che comprendono sedimenti ditale natu'a: è perciò che mancano affatto nel Tongriano, nell'A quitaniano o nel Langhiuno, come risulta dall'elenco seguente:

$\begin{array}{llll}\text { Tongriano Generi } & 0 & \text { Specio } & 0 \\ \text { Aquitaniano } & 0 & & 0 \\ \text { Langhiano } & 0 & & 0 \\ \text { Elveziano } & 3 & & 0 \\ \text { I'ortoniano } & 2 & & 3 \\ 2 & & 2\end{array}$

$\begin{array}{lcccc}\text { Messiniano } & \text { Gencri } & 0 & \text { Specic } & 0 \\ \text { Zancleano } & » & 8 & » & 11 \\ \text { Astiano } & » & 9 & » & 19 \\ \text { Siciliano } & » & 6 & \gg & 8 \\ \text { Saariano } & » & 6 & » & 7\end{array}$

I Molluschi dunque presentano delle serie importantissime, costituite di specic abbondanti e comunemente sparse, formando così anco il gruppo che piì interessa il geologo nella cronologia stratigrafica, come quello che è stato studiato sopra ogui altio, e che offre spoglie ben consorrate, abbondanti, o che non famuo quasi mai difetto.

Delle faune malacologiche studiate in questo laroro erano affatto sconoscinte nel Reggiano le sei piir antiche che spettano ad altrettanti piani del mioceno; quindi tutti quanti i numerosi Molluschi miocenici $\left({ }^{1}\right)$, lo fun pliocenicho $\theta$ quaternarie erano state soltanto in parte esaminate in diversi larori dal Philippi, dal Costa (0. G.), da me stesso e più recentemente lal Mantovini: ma nel presente lavoro le suecie si sono moltiplicate a dismisura collo studio di numerose locilità per lo immanzi sconosciute, colla scoperta di unovi ed importantissimi luoghi fossiliferi.

A comiuciare dal plioceno antico si fil vedere tra i Molluschi qualche spocie che oggi vive nei mari del nord: nell'Astiano il numero di tali specio cresce di molto, nel Siciliano e nel Quaternario inferiore si ha pure un moderato numero di specie nordiche, ed invece poi è rimarchevolissima la scoperta di specie dei mari caldi nel Quatemario superior.

Il tipo degli Artropodi si mostra importante per due gruppi della classo dei Crostacei, cioè pregri Ostracodi e pei Cimpedi.

Gli Ostracodi terziarî dolle Calabrie non furono sin oggi menomamonte studiati: essi cominciano a farsi velere nel Langhiano, crescono nell'Flveziano o nel Tortoniano, ed abbondino benaneo nel plioceno o uel Quaternario, siccome dal seguente qualio risulta.

\begin{tabular}{|c|c|c|c|c|c|c|c|c|}
\hline Langhiano & Generi & 1 & Specie & 2 & Zancleano & Gonori & 9 & Specic 3 \\
\hline Elveziano & $»$ & 3 & $»$ & 10 & Astiano & $\gg$ & 12 & $\gg$ \\
\hline Tortoniano & $》$ & 6 & 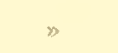 & 28 & Siciliano & » & 10 & $»$ \\
\hline Messiniano & $»$ & 0 & $\ll$ & 0 & Sarriano & $》$ & 12 & " \\
\hline
\end{tabular}

Questo gruppo di minimi organismi, al pari delle pir importanti chassi, cilratterizza colle sue specie i piani che le racehiulono; difatti le forme del mioceno superiore si riferiscono per la magrior parte allo specie del bacino di Vienua; quelle poi del plioceno e del Quaternario comprentono delle forme identiche alle viventi, che crescono mano mano in numero dagli striti piì antichi ai piu recenti.

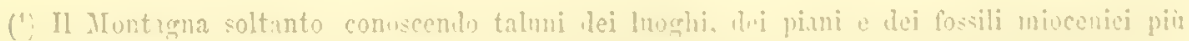

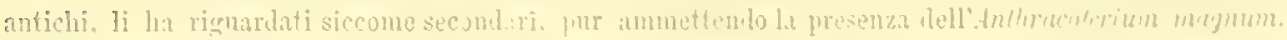


I risultamenti che io qui oflro intorno all'ordine degli Ostracodi, devono riguardursi siccome il prodotto di un primo saggio di ricerche, dappoichè sono estesissimi i terreni e le roce che bisogna tuttavia esplorare con perseverante cura.

Lordine dei Cirripedi era stato già da me studiato, e furono pubblicati i risultamenti in un lavoro speciale $\left({ }^{1}\right)$ : esso offre pochi resti nel mioceno superiore, e diriene invece importantissimo nel plioceno per l'abbondanza e varietà delle forme. Il plioceno inferiore offre grande abbondanza di Cirripedi sessili spettanti principalmente alla famiglia dei Balanidi; l'Astiano invece ci presenta, come nel Messinese. una serie di Cimipedi peduncolati molto importanti, per le loro speciali affinitì: a tali forme si associano e Verrucidi e Balanidi. Eccone il quadro numerico:

\begin{tabular}{|c|c|c|c|c|c|c|c|c|c|}
\hline Elveziano & Generi & 2 & Specie & 3 & Astiano & Generi & 8 & Specie & 21 \\
\hline Tortoniano & $»$ & 2 & $»$ & 3 & Siciliano & $\gg$ & 3 & » & 3 \\
\hline essiniano & $\gg$ & 0 & $»$ & 0 & Saariano & $\gg$ & 4 & $\gg$ & \\
\hline incleano & $»$ & 4 & $»$ & 13 & & & & & \\
\hline
\end{tabular}

Del tipo doi Vermi, le due classi degli Anellidi o dei Briozoarii mresentano ben differente importanza.

Gli Anellidi pei tubi calcarei che hanno lasciato nei nostri strati terziarî, offrono uno speciale interesse; ma per le gravi e sovente insormontabili difficolta che si incontrano nella definizione specifica di tali resti, che bene spesso rimangonó d'incerta determinazione, non possono interessare troppo il geologo.

Le specie cho parmi di arer potuto riconoscere con qualche grado di sicurozza sono distribuite come segue:

\begin{tabular}{|c|c|c|c|c|c|c|c|c|}
\hline Langhiano & Generi & 1 & Specie & 1 & Zancleano & Generi & 6 & Specie \\
\hline Elveziano & $»$ & 3 & $»$ & 4 & Astiano & $»$ & & $\gg$ \\
\hline Tortoniano & $»$ & 5 & " & 6 & Siciliano & , & & $\gg$ \\
\hline Messiniano & $»$ & 0 & $\gg$ & 0 & Saariano & $»$ & & \\
\hline
\end{tabular}

Non cosi accade dei Briozoarii; i quali, sparsi con grande profusione in molti piani del Terziario superiore, o d'ordinario assai ben conservati, costituiscono un gruppo paleontologico molto importante, che caratterizza assai bene, al pari di qualunque altra classe, gli strati che ne conservano i resti.

I Briozoi del Reggiano numerosi e variati si ripartono in rieche faune spettanti a molti e successivi periodi del Terziario; essi sono nuovi affatto per l'Italia meridionale, perchè non mai stuliati nei terreni di tale regione, se si eccettuino le poche specie descritte dal Manzoni, che furono raccolti nei recenti strati di Pezzo o dei tintorui di Reggio.

I risultamenti da me presentati in questo laroro possono ben riguardarsi siccome un saggio di esplorazione del vasto o vergine campo, che si stende nei siccessivi priani terziarî del mez\%ogiono d'Italia. Le prime spoglie di questa classe raccolgonsi nel Tongriano, dove lil cattiva conservazione fa ostacolo alla ricognizione specifica. Succelono i banchi calcarei dell'Aquitaniano formati dall'mmmassarsi di Briozoi e di Litotamnie direnuti irrieonoscibili per lia compattezza della roceia. In cattivo stato trovansi ancora i pochi fossili e rari del Langhiano. L'Flveziano

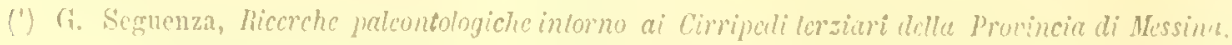


ed il Tortoniano invece ci presentano giil due ricche faune ben conservate e ben distinte, lo cui specie in gran parte sono comuni agli strati sincronici del bacino di Vienna. Lo Zameleano poi ci offre l'assembramento più riceo di Briozoi che io conosen. nel Regghiano. Le località di Terreti, di Nasiti e di Vigna di Mare ridondano di spoglie siffatte: ivi non v'ha conchiglia, nou sunglia di qualunque natura che vada priva dall'incrostazione di quei minimi gusci. La varieti dolle forme poi sorprende non poco; tra le tante specie, molte re ne ha di comune col mioceno, e vi si rinvengono quasi tutte quello che il Manzoni raceoglieva nei sincroni strati di Castrocaro. L'Astiano ha pure i suoi strati ricchi di Briozoi, ed a tale riguario sono rimarchevoli alcune speciali contrade, come Gallina e Valanidi, che ci presentano una considerevole fauna. Il plioceno recente ì ammirevole a Pozzo presso Villa S. Gioranni, perchè i suoi strati risultano dall'assembramento di Brio\%oi tanto ab)bondanti da formare essi soli quasi per intiero la roccia. Il Quaternario ne è anche esso molto ricco in tutti i suoi strati.

Ecco adunque la listribuzione numerica delle specio di Briozoi:

\begin{tabular}{|c|c|c|c|c|c|c|c|}
\hline Tongriano & Generi & 4 & Specie 7 & Messiniano & Generi & 0 & Specie 0 \\
\hline Aquitaniano & $0 \gg$ & 4 & 5 & Zancleano & $»$ & 31 & $\gg 165$ \\
\hline Langhiano & $»$ & 2 & 3 & Astiano & $»$ & 24 & 77 \\
\hline Elveziano & $»$ & 28 & $» 118$ & Siciliano & $»$ & 21 & 82 \\
\hline 'Tortoniano & $»$ & 29 & 81 & Saariano & " & 24 & 101 \\
\hline
\end{tabular}

Viene quindi il tipo degli Echinodermi, il quale nella classe dei Crinoidi non ci offre che rarissimi resti; inrece gli Echinidi sono rappresentati abbastanza bene e anco da specio caratteristiche nei rarî piani. Eceo l'elenco numerico delle specie:

\begin{tabular}{|c|c|c|c|c|c|c|c|c|}
\hline Tongriano & Generi & 7 & Specie & 11 & Messiniano & Generi & 0 & Specic \\
\hline Aquitaniano & 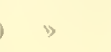 & 2 & $\gg$ & 13 & Zancleano & $\gg$ & 8 & $»$ \\
\hline Langhiano & $"$ & 0 & $"$ & $\cdot 0$ & Astiano & $»$ & & $»$ \\
\hline Ely & $»$ & 2 & $\gg$ & 12 & Siciliano & $»$ & & » \\
\hline Tortoniano & $\gg$ & 3 & $\gg$ & 3 & Saariano & $\gg$ & 5 & $»$ \\
\hline
\end{tabular}

Ia nella classe degli Echinidi deve attirar molto l'attenzione del palcontologo, siccome ha attirato la mia, l'ordino dei Clipeastroidi, e propriamente il genere Clypeaster, tanto sparso nelle Calulnie in varie formazioni terziarie. Dallo studio delle numerose specie da me riconosciuto ho dovuto convincermi, che generalmente ogni specic di questo genere è propria di un piamo terziario, alla quale legge lamo eccezione poche forme che s'incontrano in due piani ordinariamente successivi.

Cosi tutte lo specie da me incontrate sono distribuite nei piani del mioceno. el una caratterizza lo Zancleano. Esco il modo di loro ripartizione:

Tongriano:

C'ypeaster latirostris Agass.

»Antoniminensis n. sp.

Ayritanimo:

Clyperster pyramialalis Mich.

intermedius Des Moulins Var. Calubrus n.

"cuminalus Desol: Var. devians. n. 
Aquitaniano :

Clypeaster petaliferus 1. sp.

» Stilensis n. sp.

» gibbosus Marcel de Serres.

» Michelottii Agissiz.

Clypeaster tenuis n. sp.

$\gg$ folium Agassiz.

" meittensis Mich. Var. elegans $\mathrm{n}$.

planatus 11. sp. ( $\left.{ }^{2}\right)$

Langhiano:

Rari frammenti indeterminabili; senza dubbio ulteriori ricerche scopriranno le forme speciticte di questo piano.

Elveziano:

Clypeaster pyramidalis Micl.

* portentosus Des Moulius.

» allicostatus Mich.

» altus (Leske)

Clypeaster insignis n. sp.

* Philippii 11. sp.

$\gg$ marginatus Lamk.

Tortoniano:

Var. tenuipetalus n.

\section{Zancleano:}

Clypeaster marginatus Lamk.

\section{Clypeaster pliocenicus n. sp.}

(\%) Il prof. D. Lovisato nelle sne recentissine ricerche geologiche esplorando le provincie di Catanzaro e di Cosenza s"imbatte sovente in un terreno a Clipeastri, il quale forma quasi una cintura attorno il massiccio cristallino della Sila. Così sono le sabbie di Fiumarella presso Catanzaro, di Rossano, del fiune Alli, di Beleastro, il conglomerato di Tiusia ec. Dai belli esemplari di Clipeastri da lui comunicatimi gentilmente, ho potuto riconoscere che in taluni luoghi di quella regione quei fussili sono molto abbundanti, di bella conservazione, e li furme gigantesche: tale si è il territorio di Belcastro.

Quanto alla eti di tali depositi risulta evidentemente dalla lista seguente delle specie che vi ho riconoscinto:

Glypeaster pyrainidalis Michelin.

» intcrmedius Des Moulins Var. Gulabrus. n.

" sp.? Un esemplare incompleto che per la generale forma si approssima al C. acgypticcus, ma il margine ne è più largo e più depresso.

»Lnvisati n. sp. Bella specie aftine al $C$. alnu, dal quale si distingue jer essere grandissima, cogli anbulacri relativamente molto piri brevi, col margine molto piì largo e per la forma generale più depressa; i quali caratteri l'avricinerebboro al $C$. pliocenicus ma se ne distacea pel suo contorno decisamente ruinguangolato.

" I'urtskii Michelin.

» Revii Wright, Var, derressus n.

$\gg$ gibbosus Marcel de Nerres.

» Sriller: Des Munlins.

Varie di queste speeie sono commi ai luorlhi della Sila el alldrunitaniano della provincia di

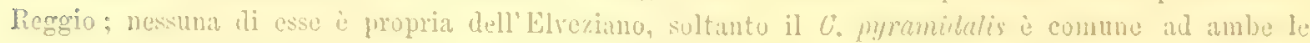
formazioni. Quiudi ì per me indulitato che il terreno a Clipeastri che cinge la sila spetta al piano

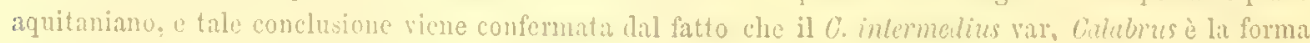
pii comune dell'Aquitanimo del lieggiano como di lieleastro.

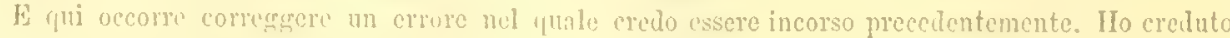
che i Clipeastri di Barclice pusseduti tall' Universitit di Napoli fossero elvezimi, e quazlche nuova

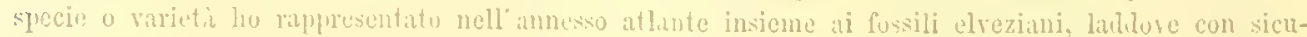

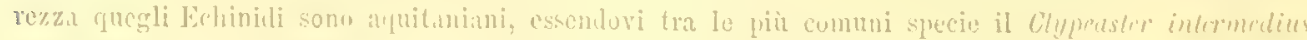

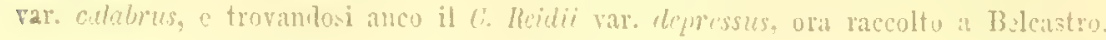


Da questa enumerazione risulta evidento che quasi osni furma di clipeastro reggiano è limitata ad un sol piano geologico, o che quindi le specie raccolte ralgono benissimo a caratterizzare i diversi periodi del mioceno, come l'antico plinceno.

Questo importantissimo genere, come tutti gli Echinidi delle rocce terziarie delle Calabrie, non erano state precedontemente studiate, se ne escludi tre Clipeastri di MIonteleone descritti dal Philippi, ai quali fu d'uopo mutare i nomi per ragione di priorità.

Ed eccoci ormai al tipo dei Celenterati anch'esso valevolissimo alla distinzione cronologica delle rocce.

La classe degli Antozoarî, rappresentata soltanto dall'ordine dei Zoantarî, quancumque nou ricea di forme, pure caratterizza a meraviglia colle sue specie quasi tutti i piani dal Tongriano al Saariano. Io vi ho raccolto infatti nelle vario zone del Tongriano qualche specie propria di Cassinelle, Dego, Cilcare; nell'Aquitaniano o nel Langhiano le specie proprie della Superga presso Torino; nell' Elveziano qualche resto poco riconoscibile; nel Tortoniano le forme proprio del Tortonese del Modenese e del bacino di Vienna; qualche reshlno nello Zancleano: abbondanti forme e speciali caratterizzano l'Astiano in Calabria come nel Messinese; le ultime zone terziarie e le quaternarie poi offrono poche specie tuttavia viventi nel Mediterraneo.

Ecco la distribuzione numerica delle specie:

\begin{tabular}{|c|c|c|c|c|c|c|c|c|}
\hline Tongriano & Generi & 2 & Specie & 2 & Messiniano & Generi & 0 & Specie \\
\hline Aquitaniano & $\gg$ & 6 & $»$ & 9 & Zancleano & » & 1 & $\gg$ \\
\hline Langhiano & » & 6 & $»$ & 17 & Astiano & 》 & 20 & $\gg$ \\
\hline Elreziano & $»$ & 1 & $»$ & 1 & Siciliano & i) & 2 & $»$ \\
\hline ortoniano & $»$ & 11 & $"$ & 18 & Saariano & $\gg$ & 5 & $»$ \\
\hline
\end{tabular}

Tutte queste forme di Coralli won erano state riconoseiute sinora nelle Callabrie: solamente il Philippi ne area descritto due solo specie plioceniche.

Gli Spongianî perforanti hamo lasciato dapertutto nelle conchiglie tarlatr, nei coralli forati i testimonî della loro esistenza in tutti i periodi terziarî; ma allorfunando imprendesi la loro specifica definizione, allora sì che s'incontrano seriissime difficoltit, e sorente fa d'uopo desistere dall'impresa.

Finalmente eccoci all'immenso tipo dei Protozoarî rappresentato da quellia miriade di Foraminiferi che tu incontri profusissime dapertutto, che non mancano in verun piano, che abbondano ugualmente nei calcari como nelle sabbio, nelle argille come nelle marne, che quasi da se sole fomano colossali dopositi, estesi terreni, poterti rocce. Qua il campo è davvoro immenso e direi quasi illimitato; le ricerche sono appena iniziate, e per quanto saramo parientemente protratte, resterì sempre ben lungo il cammino da percorrero pria che si possano dichiarare esaurite.

Se si eschudono le poche specie ricordate diul Costa in qualehe suo laroro e quelle da me rinvenute nel Plioceno e nel Quaternario, tutte le altre moltissime onumerate o descritte in runesto lavoro sono mure affatto pel Reggiano, e spettuno a quasi tutti i piani a contare dal Terziario piì antico.

Le Nummuliti sono in genere quelle che caratterizzano i rarî piani dell'Eoceno; ma esse bene spesso si associano ad Orbitoidi ed Alreoline. Nel 'Iongriano sono ancora le Nummuliti e le Orbitoidi ele rappresentano la classe; nell'dquitaniano i l'oraminiferi divengono rari, e poi crescono considerevolmente in numero di gemeri o di 
specie nel Langhiane, dove sono piccoli e variati di forma. Tale aumento di forme l'abbiamo aucora nell'Elveziano, che diviene poi stragrande nel Tortoniano dove le argille ridondano di cosi immenso numero di generi e specie da costituire una fauna davvero sorprendento. Il plioceno poi coi stoi depositi di mare profondo non è che un cumulo di spoglie di.Foraminiferi. Le marne dello Zancleano sovente potentissime e di vasta estensione risultano in gran parte di Orbuline, di Globigerine e di tanti generi e specie, che colle loro spoglie e coi tritumi di esse, hanno ammassato tanta mole di rocue da formare colline e monti, che quasi dapertutto nel Reggiano cingono il centrale Appenuino. Le sabbie poi, meno ricche delle marne tra i molti resti di questa classe, offrono molto comune le Amphistegine.

L'Astiano anch'esso potente, estesissimo e di mare profondo, risulta per la magoior parte formato dalle spoglie di variatissimi Foraminiferi tanto negli strati marnosi quanto nelle sabbie.

Il plioceno superiore poi e le zone quaternarie non maucano di questa classe, che viene rappresentata da specie quasi tutte viventi.

Ecco l'elenco numerico dei generi e delle specie di Foraminiferi raccolti nei piani terziarî reggiani:

\begin{tabular}{|c|c|c|c|}
\hline Parigino & Generi & 1 & Specie \\
\hline Bartoniano & $»$ & 0 & $\gg$ \\
\hline Liguriano & $»$ & 4 & 》 \\
\hline Tongriano & $»$ & 5 & » \\
\hline Aquitaniano & ) & 7 & » \\
\hline Langhiano & $\gg$ & 29 & $"$ \\
\hline Elveziano & $»$ & 40 & 》 \\
\hline
\end{tabular}

Tortoniano Generi 57 Specie 337

Messiniano » 0 » 0

Zancleano 》 45 》 282

Astiano » $41 \Rightarrow 190$

Siciliano » 35 » 132

Sariano » 30 » 111

Una sola localiti dello Zancleano mi la ofeerto i resti silicei di numerosi Radiolari, che formano una fauna ben distinta, pliocenica, che richiede accurato stuclio e pazienti ricerche, e che potrì valere moltissimo nelli storia di questi minimi organismi. A tale fauna si associano numerose Diatomee di eleganti e variate forme, che attendono anch'esse chi si facei a studiarle.

Da quanto abbiamo considerato risulta eridentissimo, che ciascun piano teriario ¿ perfettamente caratterizzato di una fauna distinta, la quale ha comuni tante suo specie coi più classici terreni coetanei. Ogni piano quindi viene distinto assai bene dai molti fossili che racchinde.

Dal precedente esame risulta inoltre come ciascuna classe animale, dalle piì elevate alle infime, ha il suo valore nella determinazione dei terreni. F se le clissi superiori offrono speciale interesse e dati più precisi per la limitazione delle loro specie nel tempo, le classi inferiori non attirano meno l'attenzione del paleontologo per l'abbondanza, la varietà e la profusione delle forme che comprenilono. Così gli Ostracodi, i Briozoarî e i Forimminiferi ci hamo of’erto nel Reggiano una ricea messe di forme, che si moltiplicherit a dismisura reiterando le ricerche e perseverando nello studio. 


\section{CONCLUSIONI}

Pei dati precedenti o per lo considerazioni che vi ho fatto si possono trarre dunque le seguenti deduzioni:

$1^{\circ}$ Che $\mathrm{i}$ terreni terziarî della Calabria Ultria prima ranuo intieramente esenti da ogni anomalia e da ogni eccezione, e formano una serie non interrotta, forse anco completa, comparabile alla serie terziaria di qualunque altro luogo, e contradistinta nei suoi molti piani da faune caratteristiche ed in gran parte giil note altrove.

$2^{\circ}$ Che della serie torziaria della provincia di Reggio era conosciuto in parte soltanto il plioceno e grli striti piì recenti, con porzione delle loro faune studiate. dal Philippi, dal Costa, dal Manzoni.

$3^{\circ}$ Che percio la serie dei prani eocenici e miocenici era affatto sconoscinta, e quindi riescono completamente nnore per le Calabrie le tanto ricche faune racchinse in si numerosi piani, che vengono da esse perfettumente caratterizati.

$4^{\circ}$ Tali faune tutte, non escluse la pliocenica e la quaternaria, mi hanno offerto una serie molto ricea di specie nuove appartenenti a tutte le classi animali. Pure bisogna ritenere che resta ancora molto da studiare sui fossili, e sopratutto sono veramente incomplete le ricerche intorno le clissi dei Crostacei, dei Briozoarî. degli Spongiarî e dei Rizopoli.

$5^{\circ}$ Le direrse zone dei terreni terziari si sono costituite a profonditi varissime, perchè una serie di oscillazioni inalzando ed abbassando alteruativamento il fondo marino nei successivi periodi, Io ha portato a livelli diversissimi di unita alla por. zione emersa, che or guadagnando ed or perdendo in altezza gual ignava aneoria e perdera in estensione. Tra la serio delle oscillazioni, determinato dallo studio delle rocco e delle faune e confirmate dall'altimetria degli strati; una è addirittura quella che dee riguardarsi siccome massima ed importantissima. Fssa è l'ultima da une segnalata: cominciava col perindo pliocenico inabbissando la maggior parte dellit provincia, che percio ricoprivasi dei depositi zancleani, quindi coll'Astiano s'invertiva il movimento in ascendente, che perilurando lungamente nel periodo siciliano o per tutto il quatemario, e forse aneo sin oggi, ha dato alla regione calabrese il riliero attuale, che is il massimo che questa abbia mai raggiunto.

$6^{\circ} \mathrm{Per}$ le ultime oscillazioni, ehe si arverarono evidentemente con grande lentezza, devono enumerarsi tre periuli di grumle denud uinne per la provincia di Reggio. Nel periodo di emersione arveratosi dall' opoca clveziana sino alla messiniana le rocee di tali formazioni, costituite in un periodo, veniramo sottoposte all' azione erosiva delle onde nei sussegnenti, c poscir cominciato l'abbassamento, la denuda. zione si dovea reiterare ancoril piu energica su tutti i piani del minecno; ma distruggeva quasi completamente gli strati del Messimiano e del Tortoniano, che allori erano i più recenti e quindi i superiori, e l'Elveziano veniva ancora in gran parte denudato. Tostochè poi l'emersione ricomineiara, e mano mano che gli strati sabbiosi e marnosi del plioceno e dol quatemario si presentarano al fiotto del mare il loro decadimento, cominciava e progrediva con grando energia.

$7^{\circ}$ Le fame dei periodi astiano, e siciliano e dell antico quateruario raceliudono fra le altre una serie di specie che oggi piu non rirono nelle nostre latitudini, 
ma che invece sono emigrate verso il nord, e quindi attualmente abitano quei mari. Questo fatto dimostra che probabilmente dallopoca astiana ebbe lnogo nelle uostre regioni un'abbassanento di temperatura, che si continuò lungo il periodo siciliano, c sino al un primo periodo quaternario.

$8^{\circ}$ È notevole, che l'abbassamento di temperatura s'iniziasse allorquando cominciava l'ultimo morimento di emersione, e che esso terminasse col deposito di quel colossale ammasso di.sabbie quater"uarie, che redonsi elevare tant'alte e dominare quasi tutte le formazioni terziarie. E in questi limiti che si racchiudo il periolo glaciale; e quelle potenti sabbie dimostrano apertamente damprima le profusissime piogge, e poscia il ritorno del calore: esse sono i testimoni prarlanti della fusione dei ghiacci e delle nevi, nonchè degl' immani torrenti e della imponente denudazione da loro operata.

9. 11 Quaternario superiore manca aflatto di specie proprie dei mari settentrionali, ed invece si trorano in osso $i$ resti di animali che oggi vivono in mari piu caldi, siccome talune specie estinte, che sono proprie del plioceno antico. Quindi il clima era già divenuto caldo abbastanza, le specie dei mari settentrionali erano scomparse per cedere il posto ad una fauma, che nel suo insieme è quella che attualmente abita il Mediterraneo: ma vi si aggiungerano talune specie di mari più caldi, e specialmente delle coste occidentali dell' Africa, che ri furono introdotte certamente per lo larghe comunicazioni, che in quel periodo il Mediterraneo si area cogli altri mari, e contribnendovi probabilmente correnti calde che venivano dal lato meridionale.

$10^{\circ}$ Quanto alle poche specie plioceniche che la fauna del Quatemario superiore racchinde, niente di piì semplice del credere che esse nell'epoca glaciale sieno emigrate verso mari più caldi, e clıe siano ritornate nella primiera abitazione quando il climi si è fatto piir mite; in quella guisa che specie del nord, sono venute contemporaneamente ad abitare il Mediterraueo, ed al riscaldare del clima sono emigrate verso i mari settentrionali. Così lo Strombus coronatus, le Mitra scrobiculata e Bronni, vissuti in mari piu caldi, nell'epoca glaciale, maneando affatto nelle zone del siciliano e del quaternario inferiore, ritomavano poi al Mediteraneo, da dore si erano dipartiti, allorquando le specie nordiche emigravano verso i mari settentrionali, ma vi ritornarano ammiseriti molto nelle forme e gia presso ad estinguersí.

11. La grande elerazione del plioceno, che sorpassando di molto le altre formazioni terziarie, oltrepassa i 1200 metri, dà la speciale fisonomia di regione appianata a quell'alta porzione che circonda il centrale gruppo dell'Aspromonte; essa mena a conchindere evidentissimamente che nei periodi zancleano ed astiano l'intiero estremo della penisola italiana, nonchè un' isola, come si è creduto, formava un vero scoglio, sicchè appena il centrale gruppo dell'Aspromonte afficciava fuori dalle acque.

$12^{\circ}$ Il graduale innalzamento cominciato nel periodo astiano, andò mano mano ingrandendo quello scoglio nel mentre lo elerava. Ma sino al periodo del plioceno recente esso dovea presentare linitati estensione: si fu quindi nell'epoca quaternaria che quest'estremo meridionale d'Itilia is andato emergendo e considerevolmente allargandosi; ma fu poi in epoca molto recente che esso assunse la parte principale sel suo attuale rilicro e della sua estensione, e tramutato in alta ed imponente giogaia, ando a congiungersi alla terra ferma. 


\title{
INDICE DELLE SPECIE FOSSILI
}

\author{
RACCOLTE NEI PIANI 'JERZIARI DELLA PROTINCIA DI TELGGIO \\ E DESCRITTE O ENUMERATE LA QUESTU LAVORO.
}

X. b. - Ciascma specie porta l'iulicnzione dei piani in cui è stata raccolta e delle prane in cui ¿ ricordata o descritta; lo lettere che la siegruno in licano i piani, i numeri le pagine. I piani sono indicati nel modo semente: P. Parigino: Li. Liguriano: T'u. I'ungrano; Aq. Aquitiniano: L. Langhiano; E. Elveziano; T. 'lortoniano: Z. Zancleano; A. Astiano: S. Siciliano; Sa. Sıariano. - L'agginnzione della lettera V. indica che la specic ì tuttavia vivente.

Acanthochites Teach.

discrepans (Brown) 1. 2\%.. S. 321. V. fascicularis (Lin.) Sa. 35\%. V.

Aeanthonetrin Mruller.

longispina n. sp. Z. 233.

regularis n. $\mathrm{s} \%$. Z. 233 .

Acasta Loucli.

muricata Seg. A. 2 ?2.

Acirsa Morch.

sublerussata (Cantraine' Sa. 355. V.

Aclis Lovèn.

hicincta n. sp. A. 26(6).

Fraunfeldi (Hoern.) 'T. 114.

umbilicaris Seg. A. 266 .

Walleri tetì: A. 266\%. V.

Actaeon Irontfort.

Boretensis n. sp. S., on 1. - Tav. XVII. fig. (1)

exilis . reffr. 1. 2il. T.

foveolatus n. sp. A. 2.] - 'Tav. XVI. fig. s.

globulinus (Furbes) A. 251. V.

finguis Dorligny T. 100.

gusillns (Forbes) 1. 251. V.

comistriatus Ferrutac. 'T. 1000 .

tonnatilis (Lin.) A. 251. S. 318. Sa.3.31. I

Iet inom ma Haerkel.

diacinthus и. sp. Z. 231.

ellipticum Stolur. Z. 237.

entactinia Iihrembere. 7. 2:31. V.

hirtum $11.8 \mathrm{p}, 1 \% 231$.

pliocenicum 3. sp. Z. 20.31.

cfi. Selowageri Stohx. \%. 231 .

simplex n. ep. \%. 2:31.

stohrii n. sp. \%. 2.31.
Aleorbis S. Whorl.

subcarinatus (MIontg.) Sa. 35\%. V.

Woolii Hoern. '1'. 117.

Leter Lamouroux.

anguina (Lin.) S. $327 . \mathrm{T}$.

sicia Conch. E. 79. T. 127. \%. 197. 1. 294.

s. $32 \%$. S., 3198. Y.

Alecto Iammumix.

Castmearencis Manzoni. \%. 213. . 1. 29\%.

dilatans IV. Thompson. \%. 213. V.

celimata (V. Munster) F. 86.

majner Johnston. 1. 297. V.

repens Wnorl. 7. 2133. 1. 297. S.930.5.3.372. V.

rugulosa Risus: 1'. 133,

Inxiat Leach.

Firminii (1'wrauleau) 1. 21?. V.

mrosetis (I)rapmanand) A. $219 . \mathrm{V}$.

I rania Risuro.

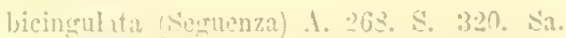
:356. Y.

"alithns (Furtes ot llanley) 1. 2189. V.

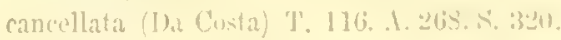

sa. sists. V.

cimer (lin.) T. 11 (i. 1. 202. . .820. sa. 3hti. V.

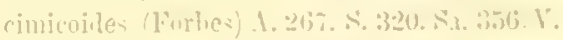

clathratil (Ihilipui) A. 20\%. S. .200. V.

costata (.dauns) 1. $267 . \mathrm{V}$.

dialmun (Inoterlein) '1'. 116. A. 20's.

$"$ Var. 1. 2utis,

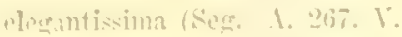

Latchesis (basteret) T'. 116. A. 265

"Var. laevis Hown. 'T, 111 .

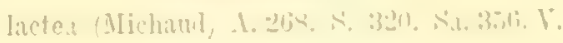


Dliania lixsu.

lineata Risste. A. 26\% I.

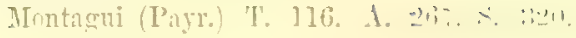
Sa. 356. V.

obliquesculyta n. sp. 1. 116. Tav. XI. fig. 46. pronctura (Montg. S. 320. Sa. 356. V.

reticulati (Montg.) T.? 116. 1. 268. \$.320. Sa. $30 \%$. V.

reticulato-punctata n. sp. A. 268 .

seaturn (Phil.) A. 26\%. V.

sentrella (Doterl.) T. 116.

snroreula (Granata) 1. 268. V.

sulereminlata Schwartz 1.268. N.320, sil.350.V.

* mbsoluta (Ararlas; Sia. $950 . \mathrm{V}$.

teruicosta (Seg.) S. 3200. V.

Testae (Arail.) T. 116. A. 26\%. S. 320. V.

trrutelloides n. sp. S. 320, - Tav. XVII. fig. 20.

Venus (D'orb.) T. 116.

Zetlandic (Montg.) 'T. 116. sa. 35(i. V.

Aveolina DOrbigny.

Haneri Dorb, T. 15\%.

melo D'Orb. F. (y2. T. 15\%2.

oroidea Diorl, I,i. 30.

sphoeroilea (Lamk.) Ti. 2?. 30.

subulosa (Montf.) Li. 20. 30.

Amphile lia Filwarts et Hame.

mincenica Seg. A. 302.

oculata (Lin.) A. 302. V.

sculpta? Seg. A. 302.

Amphistegina Dorbigny.

Complelli? Karrer. S. 89. T. 139

Hanerina DOH. Z. 222, A. 30\%. Sil. 3\%.

vulgaris D'Orb. Ar. 56.

Ancillaria Lamarek.

nlamliformis J amk. Aq. 50. I, 59. F. .3. T. 104. obsoleta (Brocehi) T. 101.

Annmalina Dorhigny.

alstriaca Dorh. T. 150 .

enronata Park.et.innes, E. 01.7.229. 1.309. V.

polymorpha Costa. Z. 225. 1. 309.

rotula DoOrh. Yar. ammonifomis n. T. 150.

7. 2209

Anomin Limnen.

acule at a Monto. 1'.123.\%.194.1.286. S..32:3.V.

Bnroligalensis Defrance. 'I'. 123.

costita Jinece. Ir. 5:3. I. 631. E. 76. Z. 190.

1. 286 .

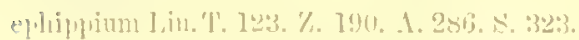
sit. $:$ iri. V.

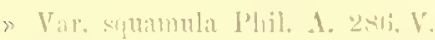

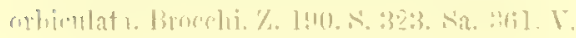

Anom is Limeo.

patelliformis Lir. E. 76. \%. 190. A. 286. S $323.53 .301 . \mathrm{V}$.

striati Broce. E. 76. T. 123. 7. 190. A. 286.

$\therefore$. 32:3. S1:3631.

Intliocyrtis Ehrenberg.

Ehrenheryii Stohr var. nliocenica n. Z. 232.

sphoeroilemin 11. sp. Z. 232.

Inthracoterium Cnvier. magnum Cuv. To. 39.

Aplanitnona Bellardi.

Bellardii n. 8p. A. 257.- Tav. XVI. fig. 18. Graeci (Phil.) d. 25\%. S. 318. Sa. 353. V. » Var. cingulata n. A. 25\%. - Tav. XVI. fig. 10.

Marinii (Libassi) A. $95 \%$.

Philipyii (Seg.) A. 257.

Arca Limen.

Altavillensis Seg, A. 282.

asperi Plül. A. 2282. S. 323.

barbat. Lin. T. 156. A. 282. S. 323. Sa. 360. V. biangulina D'Orb. To. 4 .

clathrati Tefr. T. $120.15 \%$.

cuculliformis Eichwali. 'T. 120.

dichotoma Hoern. T. 120.

diluvii Lamk. Aq. 52. L. 60. T. 120. \$a.? \$60. helretica? Mayer. T. 120.

lacter. T.? 156. A. 282. S. 323. Sa. 360. V.

Noae I.in. I. 6ก. 1. 2จ2. Sa. 36 ก. V.

nbliqua Phil. A. 282. S. 323. Si. 360. V.

pectinata Broce. A. 282.

pectunculoides Scacchi T. 120. A. 232. S. 323.

Si. $360 . \mathrm{V}$.

Polii Mayer. A. 282. Sa. 360. V.

pulchella Reere A. 282. S. 323. Si. 360. V

scahria Poli. A. 252. Si. 360. V.

Syracusensis Mayed. T. 120.

tetracona Poli. 1. 242. S. 3233 . S3. 360. V. munnata Lamk. E. 74. T. 156.

Areoplagiat.

balantina (Ijin.) A. 279. Sa. 358 . V.

crassa (Pennant) S. 322. Sa. 358. V.

Argiope F. Deslongchamps.

lecollata (Chomm.) 7. 190. 1. 28:. S. 324. S.1. 31. V.

Astarte howerloy.

lipirtita (I'hil.) A. 220. S. 322. Sa. 359. V. fusca (I'oli) 1. 279. 8. 32.2. Sa. :359. V.

scalizis $($ Desh. $)$ A. 5.2.

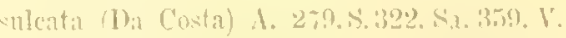

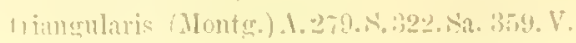


Asterigerina D Orlugny.

planorbis Dorbigny L. 65. 1\%. 91. T. 150. 2. 229.

Astroides Eitwards et Haime. calycularis (Pallasj A.301.S.3:31. Sa.373. V.

Astropecten Linck. sp.? To. 44.

Atlanta Lesueur. Peronii Les. A. 249. V.

Atoma Ballardi. hypothetica (Bell.) 'T. 104.

Aturia Bronn. Aturi (Bast.) L. 59.

Avicula kilein. merlia? Sow. Z. $18 \%$. tarentina? Lamk. A. 285 . V.

A sinus Sowerby. angulatus? Sow. L. 60. Croulinensis Jeftreys. A. 281. S. 322. V. ferruginosus (Forbes) T. 120. 1. 281. S. 322.V. flexuosus (MIontg.) A. 281. S. 359. V. urinulosus Jeffr. var. rotundatus. A. 281. V. rostratus (Pecchioli) A. $2 \varangle 1$.

Bactridium Reuss. Manzonii n. sp. T. 127. - Tav. XII. fig. 15.

Bairdia MI. Coy. arcuata (v. Munster) E. 7\%. T. 124. complanata Brady. Z. 191. A. 288. Y. $\star$ Var. simuata n. A. 288. obtusata Sars. Z. 191. A. 2s8. S. 324. V. »Var. producta n. Z. 191. A. 288.

" „ angulosa n. S. 324. Tar. XVII. fig. 21.

recta $11 . \mathrm{sp}$. A. 288 .

reniformis n. sp. Sa. 362. -Tiv. XVII. fig. 46. subdeltoidea (v. Munster) E. 7\%. T. 124. Z. 191.

A. 288. S. 324. Sa. 36\%. V.

Balanoply ylia S. Woou. caryophylloides n. sp. A. 303. - Tav. XVII. fig. 9 .

circularis n. su. 1. 303. - Tav. IVII. fig. 10, compressa n. sp. A. 303. - Tav. XVII. fig. 11. irregularis Seg. 'j'. 135. A. 303. italica (Michelotti) A. 303. V. Menerhinii E. Sismonda. L. 62. praelonga Mich.) 'T'o. 56. L. 62.

Balantium Icach. acutissimum n. sp. 1. 276. - Tav. XVI. fig. :35.

Balanus Auctorm. lisulentus Darwin. '/. 165.5. ralceolus l'allas. 1. 2az. V. balan us inctorum.

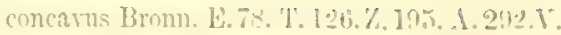
Darwinii Seg. Var. Calabra Seg. \%. 195.

Mylensis Seg. Z. 195. 1. 292. V. perforatus Brug. "Z. 195. A. 292. V.

»Var. Atavillensis Seg. \%. 195.

scutorum Seguenza. Z. 195. 1. 292.

spongicola Brown. Sa. 366 . V.

"Var. pliocenica Seg. Z. 195. 1. 292.

stellaris (Broce.) Z. 19\%. A. 29\%.

»Var. miocenica. Seg. E. 7s.

tintinnabulum (Lin.) Z. 195. V.

tulipiformis Ellis. Z. 195. 1. 292. s. $32 t^{\circ}$. Sa. $\$ 36$. $\mathrm{r}$.

"Var. arenaria Seg. Z. 195.

sp.? 'T. 126.

Barleia Clark.

rubra (Montg.) A. 26\%. S. 319. V.

Batopora Reuss. conica n. sp. To. 42. - Tar. IV. lis. 10 rosula (Reuss) E. 84. T. 130.

Bela Leach.

septangularis (Mnnter.) 1. 255. V

$\gg$ Var. B. secalina (1'hil.) 1. 255. Na. 35:. V.

Biflustra D' Orbigny.

Sarartii Aul. Z. 209. 1. 296. Sa. 3i1. V.

rynchota Waters. Sil. 3r1. V.

Bifrontia Deshayes.

minima n. sp̣. T. 110.-Tay. XI. tig. 2?n.

? Zanelea Phil. 'T. 111. V.

Bigenerina L'Orbigny.

agglutinans D'Orb. 'T. 152. ' Z. 2:30. 1. 310. nnilosaria? D’Orb. L. 65. \%. 230. 1. 310. s. $334 . \mathrm{V}$.

Biloculina D'Orbigny. aftinis D'Orb. 'I'. 15\%.

amphiconica Reuss. L. 65. E. 92. 'T' 153. 1. 311. S. 331.

bulloides D'Orb. E. 92. 'T'. 152. A. 310. S. 331. sa. 376. V.

»Var, inornata D'Orb. truncata lieuss. F. 92. 'I'. 152.

》Var.calnstoma Karrer. T. 152.

circumclausa Costa. A. 311.

compressa D'Orb. Z. 230. V.

contraria 1)' Orl). 1'. 153. 1. 310.

Iepressa Dorb. T. 153. 1. 311. \. ::31 หra. :376. V.

lisciunta n. sp. T. 153. - Tar. XIV. fig. 11. clongata 1) Orh. s. 331 . Sa. :376. Y. 
Biloculina Dorbigny.

larvata Reuss. var, breviuseula n. Т. 153. Inbata Reuss. T. 15:.

lumula D'Orb. T. 153. 1. 311. S. 331.

plana Fiarer. Sa. 370.

simplex I'Or]. E. 92. 'T. 15\%.

sphoera Dorb. var. Calabra. 12. Sa. 33r. I. tulmiosa Costa. 7. 230. 1. 311. Sir. 376. ventricosa Reuss. T. 153.

Bolivina Dorbignt.

antiqua D01h. E. 91. T. 150.

punctata 100rh. 'L. 2229. A. 309. S. $3 . ; 1$. I.

Bomia Philippi.

(ombuloiles Plit. A. 238. Sa. V.

Geoflroyi (Fayraud.) A. 282. Sa. 359. V.

Brachyrliyuchus Van Beneden.

teretirnstris V. Beneiten. E. 72.

Brocelia Bronn.

Bellariii 13iondi. 1. 273.

sinuosa Jronn. Sa. 35\%.

Buccinum Linneo.

Humplreysianum Bennet var. 1. 263. S. 319.

Sa. :353. V.

uniatum Lin. S. 319. Sa. 353. V.

Bufonaria Selumacher. scrobiculator (Lin.) S. 319. Sa. 353. V.

Bulimina Dorbigny.

aculeata DOrb. T. 146. S. 3:33. Sa. :375. V.

Buchiana D Orb. I. 61. Z. 227. A. 308. s. 333. V.

»Var. Calalura.n.T.116. Tav.XIII. fig.34.

$\gg$ Var. E. 90.

hulliformis n. sp. T. 141\%, - Tav. XIll. fig. 3i. (alcarata n. sp. T. 146. - Tav. XIII. fieg. :) (j. inperatris Farr. 'I. 146. A. 308. Sa.? 375. incrassata Karr. Var. clongata n. T. 146. marginata Toris. 1. 30S. S. 333. Sa. 375. T. mutabilis (Costa). 7. 227. S. 333. Sa. 375.

ovata D'Orb. 'I'. 110. 7., 2.27. A. 308. S. 33. '. Sir. 375. V.

*Var. inflata 11. T. 116.

funella (Costa). \%. 227. A. 308. 5. 3:33.

sa. 375.

punoides worb. E. ถo.

"Var. hreris. '1'. 146.

matulosa Costa S. 333.

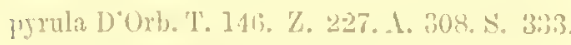

$$
\text { Sa. :375. V. }
$$

"Var. lata n. T. T.16;

》Var. spinosia n. 'Т. 146.

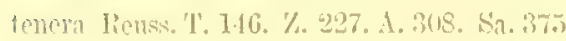

Bulla lilein.

cylindracea 1r. sp. A. 251. - Tav. XVI. fig. 6. grandis n. sp. A. 250.- Tar. XVI. fig. 4.

miliaris Broce. T. 100.

pinguicula Jefti. A. 250. V.-Tav. XVI. fig. I.

semilaevis Jeftr. A. 25I. V. - Tav. XVI. fig. 5.

ntricultus Brocc. T. 100.A.251.S.318. Sa. 351.V.

sil? Aq. 50.

Bullina Ferrussac.

molata (Delle Chiaie) A. 251. V. - Tav. IVI. liu. !

Burseolina n. gen.

Calabra n. sp. T. 133. - Tav. XIII. fig. 7.

Bythinia Gray. stagnalis (Bast.) T. 155.

Caberea Lamourous.

Boryi (Audouin) Z. 196. S. 327. Sa. 368. V.

Cadnlus Philippi.

cyathus (De Christ. et Jan.) T. 118. 1. $2 \% 6 . \mathrm{Sa}$ ? $35 \%$.

diploconus Seg. A. 276.

ovilum (Phil.) A. 276. S. 321.

» Var. gibbus 11. A. 276. .

Salicensis n. sp. A. 2\%6.

Calyptriea Lamarck. chinensis (Lin.) T. 11\%. A. 273. S. 321. Sa. 3is. V.

Cancellaria Lamarek.

Brocchii Crosse. A. 263.

ealcarata (Brocc.) T. 110.

cancellata (Lin.) T. 110. Sa. 354. V.

coronata Scacchi. A. 263. V.

Italica I)'Aneoma var. crispata n. T. 110.

lyrata (Brocc.) T. 110. A. 263.

Michelini Bell. e Michel. T. 110.

mitraeformis (Broce.) T. 110. V.

nassiformis n. sp. 'T. 110, - Tav. XI. tig. 28.

spinifera Grat. T. 110.

scruta Bronn. T. 110.

varicosa (Broce.) 1. 110.

Westiana? Grat. T. 110.

Capsulina n. gen.

loculicida n. sp. Sa. 375. - Tav. ATII. fis. 59.

Qnjulus Montfort.

Humgricus (Linn.) A. 273. S. 320. Sa. 375. V.

sulcatus (Borson) 'l'. 11\%.

Caveharodon Agassiz..

megalodon Agassiz. Iq. 19.

„Var. siculus Gemmellarn. T'o. 40.

"Var. subauriculatus. Ag. 'To. 39.

proluctus Ag. F. F. 
Carcharadon Agasciz. recticlens Ag. Aq. 4!? sulcictens Ag. Z. 185. A. $21 \%$. V.

Carlita Bruguière. aculeata (Poli) A. 280. S. 322. Sa. 359. V. antiquata (Lin.) Sa. 35\%. V.

Arituini Brongn. To. 41. calyculata (Lin.) A. 280 . V. corbis Phil. A. 280. S. 322. Sa. 3.4. V. crassicosta Lamk. A. 280. clongata Bronn. L. 60. intermedia (Brocc.) A. 280. Jomanneti Bast. E. 7t. T. 120.

Laurae (Brongn.) Tn. 41.

Partschii Golelf. A. 280. pectinata (Broce.) A. 280 ). revoluta Seg. A. 280. - Tar. XVI. fig. 40. rhomboilea (Brocc.) A. 280 . rudista Lamk. E. 74. T. 120. scaluricosta Michelotti. T. 120. trapezia (Lin.) A. 280. Sa. 359. V.

Caritum Iinneo.

acrileatum Lin. Sa. 359. V. discrepans Bast. Aq. 5\%. L. 60. E. 74. T. 120, echinatuin Lin. A. 280. S. 322. S . 359. V. »Var. Deshayesii Payr. S. 322. Sa. 3.0. V.

crinacem Lin. A. 280 . Sa. 359. V.

cxisum Gm. T.? 120. S. 322. Sa. 3ะ2. V. fnsciatum MIontg. T. 120. A. 281. S. 322. Sa. $359 . \mathrm{V}$.

frasgile Broce. E. 7t. T. 120. A. 281.

lians Broec. L. 60. E. Tt. V.

hirsutum Bronn. A. 280 .

Tamarkii Reere. A. 281. \$. 322. Sa. 359. T. lunnlatum n. \$1\%. 1. 280.

minimum Plil. A. 281. Sa. 359. V.

multicostatum Broc. Aq. 5\%. L. 60. F. \%. T. 120. A. 281.

Norvegicum Spengl, A. 281. S. 322. Sa. 359. V.

oblongum Chemn. S. 322. Si. 359. V. papillosum Poli A. 281. S. 322. Sit. 359. V. varvum 1'hil. 1. 281. V.

pancicostatum Sow. Sil. 359 . V. prectinatum. Lin. T. 120. 1. $281 . \mathrm{V}$. roseum Lamk. 1. 281. S2. $359 . \mathrm{V}$. taurinium Michelotti. L. (60). T'. tulberculatum Lin. 1. 280. Si. 35:) V. turnicum Mayer. F. 71. T. 120. s.1 ? L. 60.
Carpocanium Ehrenbere.

lagena n. sp. 7. .31.

minimum n. s]. Z. 231.

spinescens. n. s1. '7. 231.

Carsophyllia Lamarcl.

clatus seace, A. 300). Sin. 373 . V.

commresa Seg. A. 300.

geniculata Seg. A. :300.

Zanclea Seg. A. 300.

Cassillaria Lamarck. echinophora (Lin.) T. 107. A. 261. S. 315.

Sa. 3ัง $\mathrm{V}$.

tenuicincta n. sp. 1. 261.

thyrrena (Chemn.) A. 201. S. 31S. Y.

Cassidulina D'Orbigny. alata n. sp. L. 65. - Tar. VII. fig. 5.

laesigata D'Orb. S. 334. Sa. 37t. V.

margareta Karrax. T. 151.

oblonga Reuss. E. 91. 'T. 151.

punctata Reuss. I. 65. E. 91. T. 151.

Cassis Tamarck.

laevigata Defrance. A. 261.

manmillaris Grat. T. 107.

saburon (Brug.) Aq. 50.I, 50. A.261.Sa.35:3. V.

» Var. a Cocconi. T. 107.

unlulata (Linn). Sa. 353. V.

Cellaria Lamarck.

cereoirles Solander et Ellis. \%. 196. A. 20.4.

Sia. $36 \%$ V.

Celleporaria Lamomroux.

colonopus S. TFood. S. 32?. Sa. 371. T

crassin Manzoni. T. 12\%.

dieitati IVaters. S. :329. V.

eilax Busli. T. 129. 7. 207. Sia. 3\%1. T.

globularis (Bromm.) I.. 81. '1. 123.

Hassalii Johmston. S. 32?n. Y.

Inbatula Waters. S. 32?. V.

meralostoma? Reuss. T/. 61.

polythele Reuss. Aq. 53. I. 61. F. 81.\%. 207.

pulchrin Mriehelotti. 'I', lo9.

ramulosa T,in. \%.207. 1. -996.5 .329 .82 .371 .5$.

retusa Miunz. E. 81. Z. 207. 1. 206.

systolostoma Manz. E. 84. 'T. 1:20. 1. "3!ni.

S. 32?. Sit. :371.

tuluigera Busk.\%.207. 1.296. S. 329. Sa.371. 1\%

verruro:a Reuts. 'I'. 129.

Cenosphatera Zittel.

celinus $12 . \mathrm{sp} . \mathrm{Z} .230$.

microspina n. sp. \%. 23:).

mucronata. n. sp. \%. 2.33).

plutonis Fhrouly. \%. 23:3U. I'. 
Centrustephanus Pelers. longispius (Phil.) Z. 214. 1. 299 Sa.373. V. primigenius n. sp. T. 133

Ceratocyatlus Seguenza. acriticostatus Seg. A. 301.

aftinis ses. A. 3̋00.

communis Seg. 1. 300.

compressus Seg. A. 500 .

conulus Seg. A. 300.

elegans Seg. A. 300.

laterocristatus (Elw. et H.). I. 62.

polyedrus Seg. A. 301.

nolymorphus Seg. A. 300.

ponderosus Seg. 1. 300.

rectus Seg. A. 300.

Romettensis Seg. A. 300.

Scillac Seg. A. 300.

simplex Seg. A. 300.

subcristatus (Ediw. et H.) L. 62 .

verrucosus (Mich.) L. 56. L。 6\%.

versicostatus (Mich.) L. 6.2.

Ceratotrochus Edwark et $\mathrm{H}$.

anceps Michelotti. A. 30?.

dnodecimeostatus (Goldf.) T. 134.

multiserialis (Michelotti) I. 6 ?

» var. multicostatus 11. 'T. I34.

Ceriopora Goldfuss.

arbusculum Reuss. E. 86.

glotulus lieuss. L. 36. T. 133. \%. 214. A. 297.

S. 330 .

Cerithiolum Tiberi.

lacteum (Phil.) A. 263. \$. 319. Sa. 35t. V. pusillum (Jeltr.) A. 263. S. 319. Sa.351.V. reticulatum (Angl.) A. 263. s. 319. V. scabrum (Olivi). T. 109. A. 203. S. 319. Sa. 3.54. V.

Schwartii (Inocn.j T. 109.

scupptum n. sp. T', 10\%. - Tav. XI. fig. 26. spina (1'artsk.) T. 109. 1. 263.

Cerithiopsis Forbes.

bicarinata n. sp. T. 109. - Taw. XI. tig. 27.

bilineata (Hoemes) 1. 263. V.

Metrae (Delle Chiaie) 1. 263. Sia. 351. I. sealaris Monteros. 1. 2033. V.

tnbercularis (Monte.)'L. 109. A. 263.S. 319 Sa. 35. V.

Cerithium Bruguiere.

articulatum O. (X. Costa.' 'L. 155. Tav. XI. fig. 24.

* Var. lreve e tricinctum 12. 'I'. 155.

bisulcatum n. sp. In. 51. - 'lav. IV. fig. 13.

Bmuni Partsck 'l' lom.
Cerit lium Brugniere.

Dubuisii Нoern. T. 155.

granulinum Bonelli. T. 109.

lignitarum Eichw. T. 154.

margaritaceum (Broce.) To. 40.

minutum II. de Serres. T. 109. T. 15\%.

obliquistoma n. sp. T. 155. - Tav. XI. fig. 25.

rupestre Risso. 1. 263. Sa. 354. V.

varicosim (Brocc.) A. 263.

vulgatum Brug. Aq. 51. A. 263. S. 319. Sa. 351. V.

Chama Bruguière.

Rustriaca Hoern. E. 74.

cireinnata Monterosato. A. 280. V.

dissimilis Bronn. 1. 280.

gryphina Lamk. Aq. 280. V.

gryphoides Lamk. E. 74. T. 120. 1. 280. S. $32.2 .5 a .359 . \mathrm{V}$

Chenopus Philippi. pesgraculi (Bronn) T. 109. pespelicani (Lin.) S. 319. Sa. 354. V.

» Var. minor. n. T. 109.

Serresianus (Michaul) A. 263. S. 31?. Y

Chilostomella Reuss.

cylindrica Retıs. A. 309.

oroilea Reuss. T. 151. A. 309. V.

Chiton Linneo.

Altarillensis Seg. A. 274.

Cajetanus Poli. 1. 274. V.

corallinus Risso A. 274. V.

mincenicns Michelotti. A. 274 .

olivaceus Spencl. A. 274. S. :321. Sa.357. Y.

Polii Phil. Si. 357. V.

Chthamalus Ranzani.

stellatus Plil var. Sa. 366. Y.

Cidaris Flcin.

Desmonlinsii Sism. A. 298.

margheritifera Menegh. Z.? 214.

Mezzoana Taube To. 42.

Munsteri E. Sismonda. T. 133. 7. 214. A. 298. rosaria Bronn. E. 86. Z. 214.

signati Sism. E. 86.

Soldanii Menegh. 7.? 214.

tessurata Menemh. T. 156.

》Var. major. Menegh. E. 86. 7. 214.

('ingula Fleming.

grtamulum (Phil.) A. 267. S. 320. Sa. 356.V. obtusa (Cintr.) 1. 267. S. 320. Sa. 356. Y. obtusispira Seg. 1. 267

rulis (Phil.) A. $267 . \mathrm{V}$.

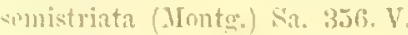


Cioniscus Jefress. miocenicus n. sp. T. 114. - Tav. XI. fig. 40.

Circe Schumacher. minima (Montg.) T. 119. 1. 279. S. 322. Sa. 359. V. solida Brugn. A. 279.

Civeulus Jellieys. striatus (1'hil.) T.117.A.272.\$. 320. Sa.350, V.

Cistella Davidson. cistelluli (S. Wool.). S. :24. V. costulata (Seg.) E. 76 . cuneata (Risso) A. 237. Sa. 361. V. laevis (Seg.) T. 123. Z.? 190.

Cladocora Fdwards et Haime. cespitos a Elw. et H. Sa. 373. V.

Prevostana Edw. et H. A. 30\% stellaria Fdw. et H. A. 303. V.

CIanculus Montert. corallinus (Gm.) 1. 270. S. 320. Sa. 356. V. cruciatus (Lin.) A. 270. S. 320. Sa. 3506. V. Jeussieui (1'ayr.) A. 270. Sa. 356. I.

Clathurella Carp. emarginata (Donoran) A. 257. V. gracilis (Montg.). Sa. 352. V.

Clavatula Lamarek.

Coppii Bell. T. 10:3. granulato-cincta? (Munst.) T. 101. Jonanneti (Grat.) T. 104.

Monsleonensis n. sp. T. 103. - T. XI. fig. 0. Schreibersii (Hoern.) 'T. 103. semimarginata (Lauk.). T. 104. Sotterii? (Michelotti). T. 103.

Clavella Swainson. filosa Seg. A. 262. Klipsteini (Mich.) T. 107.

Clavulina D'Orbiony. communis D'Orb. E.91.T.151.7.229. A.309.V. cylindrica Hantk. L. 65. T. 151. Z. 229. A. 309.

„Var. major. ㅁ. 'T. 151.

» inflata n. A. 309.

imegularis Costa. T. 151. Z. 229. A. 309.

('leodora Peron. cuspidata (Lamk.) 1.276. V. pyramilata (Lin.). T. 118. 1. 276. \$. 321. sa. $35 \%$. Y.

Clinura Bellarii. clathrata n. sp. A. 256. - Tav. XVT. fig. 17. Gallinae n. sp. A. 2.,6. - 'T'ar. XVI. fig. $16^{\circ}$ tenuisculpta (Seg.). A. 20\%.

»Var. inflata n. 1. 250.

$"$ "major. n. .1. 2.5t).
Cliona Givent.

faluniea Eischer. Aq. 56. L. 63. F. 88. T. 135. micropora n. sp. T. 135. - 1'av. XI. fig. 31. oostoma n. sp. T. 135. - 'lav. XII. fig. 32. tubulosian. sp. E. 89. 'I. 133.5. - Tav. XII. fics. 29. vermicularis n. sp. T. 1:35. - Tav. XII. tie. : 30 . sp. ? 'To. 14.

Gypeaster Lamarck.

aetuninatus Desor. Var. devians n. Aq. \$1.-

Tav. V. fig. 2.

alticastatus Mich. F. S?.

altus (Leske) E. 87. - Tav. VIIl. fig. 17.

Intoniminensis n. sp. To. 43. - 'lav. IV.

fig. 6 .

folium Agass. Aq. 55.

formosus n. sp. E. 88, - T'av. X. fig. 4.

ribbosus Mare. de serres. Aq. 55.

insignis n. s]. E. S.. - 'Tav. IX. fig. 2.

»Var.acuminatus n. sp. E. 87.- Tav. IV. fig. 2.

intermelius Desm. var. Calabra n. Aq. 51. -

'Tar. V. fig. :3.

latirostris Agass. Tn. 43.

marginatus Lank. E. 85. T. 1333.

"Var. tenuipetalus n. L. 88. - 'l'ar. X. fig. 3.

melitensis Michelin. Ar. 55.

"Var. clegins. n. Aq. 5.5.-Tav. VI. fig. -1.

Michclottii Igass. Ir. 5.).

petaliferus n. sp. Aq. 5.. - Tas. VI. fig. 2. Philippii n. sp. E. 8\%. - Tav. X. fig. 1, ld.

»Var. merlia n. E. Ss. - 'T'av. X'. fin. $1 a, 1 b, 1 c$.

planatus n. sp. Aq. 55. - Tiv. VI. fig. 1

pliocenicus n. sp. \%. 215. - Tar. XV. tig. 27. portentosus I) ssm. E. 80 .

$\gg$ Vir. elatior. n. E. 8t;,-Tav. IX. fie. 3. pyramilalis Michelin 1!. J\%. E. 86. Tav, 1.̌. fig. 1, la.

"Var. lnevior. n. H. S6. - Tav. IX. fies. $1 b, 1 c$.

Reilii Wright. var. lepressa. E. 8S. - Tav. X. fice. 2 .

Stilensis n. alv. Ar. 51. - Th\%. V. fig. 4.

„Var. explanata n. Aq. 5. - Tav. V. fig. 16 .

tenuis ル. sp. Aq. 55. - '12r. VI. fị. 3.

Cochloulesma Conthouy. luntenuis (Pult.) S. 321. Sa. 3ัญ. Y.

Coecum Flemin.

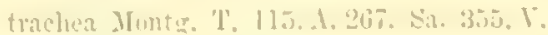


Columbella Lamarek.

Bellardii Seg. T. 105. - Tar. XI. fig. 20. Borsonii Bell. A. 260.

Calcarne Seg. T. 105. - Tar. XI. fig. 18. coronata n. sp. T. 105 - Tav. XI. fig. 15.

»Var. gracilior e striata. T. 106. comugata (Broce). T. 105. - Tar. XI. fig. 16. costulata (Cantraine) A. 259. Sa. 353. V. degans 11. sp. A. 259.

Gervillii (Payr.) A. 259. Sa. 353. V. inflata 11. sp. T. 105. - Tav. XI. fig. 13. interposita n. sp. T. 105. - Tav. XI. fig. 14. minor Seace. T. 105. A. 260. S. 318 . Sa. 353. V.-

Tar. XI. fig. 1!

nassoides (Grat.) Aq. 50. - Tav. XI. fig. 1\%

$»$ Var. A. Bell. T. 105.

rustica (Lin.) S. 318. Sa. 353. V.

scripta (Lin.) A. 259. S. 318. Sa. 353. V.

semicaudata Bon. rax. inflata n. A. 260.

semicostata (Cantr.) A. $25 ?$.

subulati (Broce.) A. 260.

tureidula Bell. A. 260.

Conocrinus Dorbigny.

pyriformis $v$. Munster. To, 44.

Seguenzai Meneglı. Z. 216. A. 299.

Conotroclius Seguenza.

typus Seg. T. 134. 1. 302.

Conus Tinneo.

antediluvianus Brug. Aq. 50. T. 102. A. 251.

Bergausii Michelotti. Aq. 50. T. 102.

betulinoides Lamk. Aq. 50 .

Broccliii Brom. Ar.? 50. T. 102.

catenulatus Sow. Ar. 50.

Dujardini Desh. Aq. 50.

fuscocingulatus Bronm. E. 7. T. T02.

Hoemesii Dol. Ar. 50. E. 173.

Mantovani n. sp. Sa. 352.

mediterraneus Brug. A. 254. Sa. 352. V.

Merenti Broce. Aq. 50. T. 102.

nisus Dorb. T. 102.

Puschii Michelotti. Aq. 50.

jyrula Broce. T. 102. A. 254.

Rheginus n. sp. Sa. 352.

striatulus 13roce. T. 102. A. 251.

subrentricosus n. sp. Sa. 352.

Tarbellianns? Grat. Aq. 50 .

tostudinarius Martini. Tar. Sa. 35\%. V

ventricosus Bromn. Aq. 50. T'. 11$)_{2}$.

Corallitum Tinneo.

rubrum (Lim.) s. :331. . ง.2. 33:3. V.
Corbula Bruguière.

gibba Olivi. Ar. 52. T. 118. A. 278. S. 321. Sa. $35 \%$ V.

Corbulom ra Nyst. mediterranea (Costa) S. 321. Sa. 35\%. V.

Cornuspira Schultze.

Bornemanni Reuss. T. 152.

carinata (Costa) A. 310. S. 334.

foliacea (Phil.) T. 152. A. :310, S. 334. V.

involvens (Reuss.) T. 152.

plicata (Czizeli). T. 152.

Corouula Lamarck.

Jificla Bronn. A. 292.

Crania Retzius.

anomala (Muller). Z. 191. A. 287. V.

lamellosa? Seg. A. $28 \%$.

Crassatella Lamarck.

concentrica? Dujarlin. 'T'. 119.

Michelottii n. sp. To. 40. - Tar. IV. fig. 2.

larva n. s1. 1. 2ร9. - Tav. XVI. fig 39.

planata (Calcara). S. 322. Sa. 35.9. Y.

C'renaster Luidius.

crenulatus Nichelotti. T. 133.

foveolatus Neneg. T. 133.

ormatus Meneg. T. 133.

Soluanii Meneg. T. 133.

Crepidula Lamarck.

gibbosa Defr. T. 117.

Moulinsii Michand. A. 273. \$. 35\% V. uneruformis Lamk, T. 117. A. 273. V.

Crepiemarginula n. gen. reticulata n. sp. A. 274.

Crese is Tang: acicula Rang. A. 276. V. subulata Quoy e Gaim. 1. 276. V.

Crisia Lamouroux.

dentieulata Lamarck. Sa. 371. V.

eburnea (Lin.) T. 132. S. 330. Sa. 3\%1. V.

litwardsii Reuss. E. 84. T. 132. \%. 208.

A. 296.

clongata M. Eilw. S. 330. V:

fistulosi Heller. Z. 208. A. 296. S. 330.

Sa. 3il. V.

Ifoernesii Reuss. E. 84. T. 132. Z. 208. A.2.6. marginata n. sp. T. 132. - Tav. XII. fig. 26.

Cristellaria Dorbigny.

arenata DOOrh. T. 140. Z. 223. S. 333.

articulata n. sp. T. 140.- Tar. XIII. fige. I1. aurenla Karr. T. 140.

Beyrichii IBom. T. 110. 
Cristellaria borbigny. cassis Lamk. Ar. 56. E. 90. T. 141. 7. 224.

A. 30\%. V.-Tar. XIII. fig. 14.

compressa D'Orb. Z. 223.

concima Reuss. Z. 223. A.? 307.

crassa D'Orb. T. 141. Z, 2293.

crepidula (Fich. et Moll.) Z. 223. 1. $30 \%$. S. 333. Sa. 375. V.

cymboiles D'Orb. T. 140. Z. 223.

disco-granulata n. sp. 'l'. 111. - Tar. XIII. fig. 15 .

clongata D'Orb. Z. 223.

Raleata? Reuss. Z. $2: 3$.

Iosephina D'Orb. Z. 224.

irregularis Hantken. Z. 223.

Italica $\mathrm{D}^{\circ} \mathrm{Or} \mathrm{b}$. T. 110. 7. 223. V.

"Var. granulata Karr, Z. 224.

lata Reuss. T. 140. Z. 223.

legmmen n. sp. T. 141.-Tav. XIII, fig. 12.

lenticula Reuss. T. 141.

Messanensis n. sp. Z. 223.

minuta n. sp. T., 223.

navicularis (Montf.) A. 307 .

paucisepta 11. sp. T. 141. - Tav. XIII. fig. 13.

nygmaea Reuss. T. 140.

reniformis D'Orb. T, 140. 7. 223.

»Var. pliocenica n. Z. 223.

simpler D'Orb. Z. 223.

striatissima n. s1. 7. 224.

sulcata (Costa) T. 140. Z. 223.

virgata D'Orb. S. 333. V.

sp? L. 63 .

Cryptangia Elwarts et Haime. parasita? (Mich.) E. S8.

Cumulipora $V$. Munster. granosa n. s]. T. 130.- Tar. XII. fig. 21. transilvanica Reuss. T. 130.

Cujularia Lamouroux.

canariensis Busk. T. 131. Sa, 371. V.

Haidingeri lieuss. E. 81. 'T', 131.

intermectia Michelotti. Aq. 53. L.? 61.

Owenii Gray. Sa. 371. V.

Renssiana Manzoni. 'T. 131. Z. 208.

umbellata Defi. 'T'. 1:31. 1.? 296. Sa.371. V. sp.? E. 84.

Cuvieria Rang. conica n. sl. 'I. 118. - Tay. XI. fig. 5l. striolata n. sp. 1. 277. - 'av. XVI. fig. 36.

Cyclonassa Aorassiz. neritea (Lin.) 1. 260. S. 318. Sa. 353. V. pellucida (lís:o) A. $260 . \mathrm{V}$.
Cyclostremil Maryat.

Cutlerianum (Clark.) 1. 272. Sa. 330. V.

lucislum Seg. A. $2 \pi 2$.

nitens (Phil.) Sa. 356. V.

C'ylichun Lören.

allua (Brown.) A. 252. Sa, 351. V.

Brocchii (Michelutti) Ar. 50.

clathrata? (Defr.) 'T. 100.

convoluta (Brocc.) Ar. 50. A. 252.

cylinilracea (Pem.) A. 252. S. 318. Sa. :3es?. V.

Jeflreysii Weinkauft. Sa. 3iI. V.

nana n. sp. 'T. 100. - Tar. XI. fig. I.

nitidula Loven. A. 25\%. $s .318 . V$.

» Var. major. Sa. 35I. V.

obesiuscula Brugn. A. 252. Sa. 3j].

ovata Jeffr. A. 252 . V.

striatula (Forbes) Sa. 351. V.

strigella Lovèn. S. 318. Sa 3.1. V.

subappennina (D'Ancona) A. 252.

subconulus? (D’Orb.) T. 100.

umbilicata (Montg.) T. 100. 1. 252. S. 318. Sa. 351. V.

》Var. pyrifomis. Sa. 351. V.

volvulaeformis n. sp. A. 25\%. 'Iav. XVI. Gig.11.

Cyplioma Bolten.

Buretensis n. sp. sa. 351. - Tav. XVII. fig. 41.

Cypraea Linneo.

achatilea Gray. Sa. 351. V.

amygdalum? Brocc. L. 5 .

s].? A. 252.

Cypricardia Lamarck.

lithophagella Lamk. \&. 32?. Sa. 330. V.

cyprina Lamareli.

Islandica (Lin.) s. :323. Sit. 339. V.

Cy pris Muller.

! angulosin n. sl. T. 123. - Tav. XII lig. :3.

!recta (licuss.) T. 123.

Cyrtocal pis Haeckel.

longilens n. : $51 . \%$. 2331.

cli. urua. stohr. \%. 231.

Cythere Muller.

antiquat: (Bairk. sa. :36:3. 1\%

asperrima (lieuss.) 1. 121. \. 32-1.

avirostris 11. 8p. 1. 28\% - Ti2\% XVI. fig. 4\%

bisinuata? 'I'erquem. A. '2s8.

Bralyi n. sp. A. 289).

calcarata n. sp. \%. 19:3.

ceratoptern (\%. Munst.) 'T. 125.

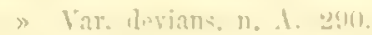

cicatricosa (licuss,) \%. 191. 1. 208:

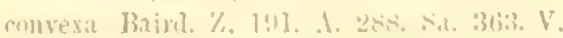


Cytlexe IIuller.

coxdiformis Terquen. S. 325.

coronata Roemer H. 7\%.

corrugata (Reuss.) T. 121.

Edwarlsii (Roem.) T. 125. S. 325.

»Var, radiato-plicata n. 'Z. 192.

» $\gg$ subinemis n. Sa. 363.

dongata n. sp. Z. 191.

emaciata Brady. Sa. 363. V.

flabellata n. sp. T. 125. - Tav. XII. fig. 8.

foliacer n. sp. S. 325. - Tav. XVII. fig. 2\%.

foveolata n. sp. S. 324.-Tav. XVII. fig. 23.

gibboso-foveolata n. sp. T. 121. Tav, XII. fig. 5.

Haneri (Renss) L. 61. T. 124.

listrix (Reuss) 1. 124.

》Var. elungata n. T. 121.

» scaberrima n. Z. 102.

humilis n. sp. A. 28\%. - "l'av. XVI. fig. 46. interposita n. S1\% Sa. 362.

Jonesiana Bosquet. T. 121.

Kostelensis (Reuss) T. 124.

microtuberculata 11. sp. E. 7\%.

oblonga Braly. Sa. 362. V.

"Var. eximia. 11. Sa. 362.

parva n. sp. S. 325, - Tav. XVII. fig. 28.

plicata (v. Munst.) E. \%ั. T. 124.

plicatula (Reuss) E. 77. T. 121. A. 289. Sa 363. V.

pliocenica n. sp. 'Z. 192.

»Var, minor. n. \%. 192.

punctata (v. Munst.) E. 78. - 'T. 124. 1. 288.

s. 324 .

quatridentata Baird. Var, tenuis, 11. Sa. 363. V. radiatopora n. sp. Z. 193. A. 289. - Tav. XVI. tig. 18.

\Var. inornata. A. 289.

" seulpta. Z. 193.

rarepunctata n. sp. Z. 325. - I'av. XVII. fig. 25. rostrata n. sp. S. 325. - Tav. XVII. fig. 26.

mugosa n. sp. Sa. 303. - Tav. XVII. fig. 55. scabra (v. Munst.) T. 125. Z. 192. A. 289. V.

"Var. minor. n. Z. 19?.

semilunata n. sp. T. 125. Z. 193. - Tav. XII. lig. $\%$.

seminulum 11. sp. T. 124. - Tav. XII. fig. 4.

senilis I. Junes. Sa. 36i3. V.

similis (Reuss) E. 7\%.

sororcula n. sp. '/. 19.2. 1. 289. - 'T'iv. XIV. 1ig. 18 .

„Var. minnr. 11. 1. $28 !$.
Cytlere AIuller.

striato-punctata Roem. T'. 124.

»Var. elonerata Eger. T. 124.

stibnequalis n. sp. S. 324. Sa. 362. - Tav. XVII.

fìg. 21.

sulutrigona n. sp. L. 61. E. 77. T. 125. 'L. 193. Tav. VIII. fig. 2.

"Var. marginato-striata n. T. 125. - Tav. XII. fig. 6.

terebrata Terquem. 'Z. 192.

tetraptera n. sp. T. 125. - Tav. XII. fig. 9.

»Var. angustata n. Z. 193.

$\gg$ dentata ı. Z. 193.

trigonata n. sp. S. 324. - Tav. XVII. fig. 22.

Witheii (Baird.) Sa. 363. V.

Cytherea Lamarck.

Chione (Lin.) A. 279. S. 322. Sa. 358. V.

erycinoides Lamk. Aq. 52. L. 60. T. 119.

Pelemontama Lamk. Aq. 52. L. 60. T. 119.

Cytherella Bosquet.

bipartita 11. s.. Z. 194. A. 29\%.

Brailyi n. sp. S. 326 .

Calabra n. sp. S. 326. Sa. 366. - 'Tav. XVII. fig. 56.

compressa (V. Hunst.) E. 78. 'T. 126. Z. 194. 1. 292 .

consanguinea n. sp. Z. 194.

hispida n. sp. A. 292. - Tav. XVII. fig. 4.

Jonesana Bosquet. T. 126.

lucila n. sp. Z. 194.

»Var. oblonga n. Z. 195.

Cytheridea Busquet.

angulosa n. sp. Sa. 363. - Tav. XVII. fig. 47.

clongata Brady. Si. 363. V.

cxilis n. sp. Z. 194. A.290. Sa. 361. - Tav. XVII.

fig. 49 .

foreolata 3. sp. A. 290. - Tav. XVI. fis. 4?.

lucida n. sp. Z. 193. A. 290. - Tar. XVI. fig. 51.

minima n. sp. A. 290. - T'av. XVII. fig. 2.

punctato-compressa n. sp. A. 290.-Tav. XVI. fig. 50 .

punctillata Brady. Sa. 363. V.

similis n. sp. \%. 193. - Tav. XIV. fic. 20.

subrostrat?? (Costa) S. 325.

tonuis (Renss) A. 290.

vitrea n. sp. Sa. 36:. - Tav. XVII. fig. 48.

Cytherideis Jones.

subulata Brady. Var. fasciata Braly of Roliertson. Sa. 3rj6. V.

('ytlueropteron G. O. Sars.

Buvetensis 11. sp. Sa.:365. - Jiv. IVII. lig. 54. 
Cytheropteron G. O. Sars. calcaratum n. sp. Si. 365. - Tav. XVIl. fis. 53. laevis n. 1 \%. A 292.

Cytheruxa G. O. Sars. acuticostata G. O. Sars. Sa. B 36.). V. cuneat. Brady. A. 291. V.

》Var. tenuisculta. n. 1. 229.2.

inversa n. s1. Sa. 365. - Tar. VII. fig. 51. lincata Brialy. rar. subaptera n. Sa. 361. V. nevroptera 3. sp. Sa. 365. - Tav. XVII. fig. 5?. prulucta Brals. var. mi popteria n. Sa. $36^{\circ}$. V. striata G. 0. Sars. S. $326 . \mathrm{V}$.

Japhuella Hinds. Rumanii (Libassi.) 1. 258.

Defrancia Dorbigny. simples Roemer. T'. I33.

Delphinus Linneo. s1)? A. 247 .

Deltucyathus Edwards et Haime. Itilicus (Nich.) T. 134.

Dendrophyllia Blainvilie. cornigera (Lamk.) A. 304. Sa. 373. V.

Dentalina D'Orbigny. acicularis Custa. Z. 220. A. 306. aciculata D'Orb. Z. 220. V. acutia DOrb. E. 89. T. 137. Z. 21\%. S. 332. $\gg$ Var. major. n. Z. 219. acuticosta Reuss. T. 13\%. V.

» Var. Hoemesii Neugeboren. T. 13\%. Alolphina D'Orb. Z. 220. alunca Costa. Z. 2020. annulata (Reuss) Vanden Broeck. 7. 2.21. V. Bartenensis I).0rb. Z. 221. A. 306.

Benestarensis n. sj. T. 13\%. Z. 2-30. - Tav. XIII. tin. 4.

bifureata D'Orb. E. 89. T. 13\%.

Bomeana D०Orb. 2/. 2.21.

brevis D'Orb. E. S9. Z. 220. S. 332. T.

calcarita n. sp. Z. 220.

communis D'Orb. Z. 221. A. 306. S. 333. V. consibrina D'Orb. E. 89. Z. 220.

cornicula 10orb. T. 13\%. 7. 220. V.

corniculata n. sp. \%. 2.21.

crissicautia n. sp. T. 138. - Tar. XIII. fig. 万. crebricosta? Neng. E. 89. 13iscretia Reus. \%. 220. V. elegams D'Orbigng. L. (i3. E. 8?. T. 13\%.\%. 220. V.

elegantissima 1)'Orb. 'Z. 른. V.

Ferstlinna Czizek. 'I'. 138. Z. 231.

filum 11. s1). \%. 2200. bentalia a Jorbing:

somphuiles Custa. T'. 1:3, \%. 2?1.

guttifera borb. T. 13\%. \% 220. Sa, 3it. V

Haidingeri Neug. T. 137. Z. 220.

inditterens Reuss. 'I', 1:3\%.

» Var. slobifera n. 'T. 137\%. \%, 221.

incruis Cziz. L. 63. T'. 1:38.

inoruata I'Ur', T', 1:38. Z.221. 1. 306. S.? 33??

intermelia Hantl. T. $13 \%$.

inacrocephala n. sp. Z. 221.

mucronata Neug. 'I'. 135. \%. 220.

nejos Costa. Z. 2200.

norlosa DUr7. T. 13\%. 7. *20. S. 333:2. V.

obliqua D.Orl. Z. 22 1. A. 306. V.

opaci. 11. sp. Z. ¿2.21.

Orbignjana Neug. E. 89. T. 138.Z. 22 1. 1. 306i

ovularis Custi. A. 306.

pauperata DOrb. L. 63. Z. 220. S. 332.

Sa. 3\%4. $\mathrm{V}$.

pungens Renss. T. 13i. Z. 220. 1. 306.

punformis Karrer. T. 18\%.

lecta n. sp. Z. :-21.

lieussii Neug. 'T. 13\%. Z. 220.

Roemeri Neug. T. 138. Z. 2*1.

rostratin n. sp. Z. 2221.

scabric lieuss. L. 6:3.

S'charbersana Neng. L. 6:3. T. 1:37. \%. 220.

schwatii Karr. T. 13\%.

seripta D'Orb. T. 1:3\%. \%, 2:0.

semicostati n. sp. T. 13\%. - T'av. NIII. tig. :3

seminula Reuss. 7. 22007.

solidir n. sp. T. 137. Z. 221. - Tav. IIII. fiv. 6 .

strigosa Costa. 7. 220. A. 30ti.

subinflata (Costo). 'Z. 220. 1. 306.

sulomata Renss. T. $13 \%$.

substriata Dorb. A :306. V.

sulutilis Neug. 'Z. 220.

stulcata (Nilsun) Vauden Broeck. \%. 220. V'.

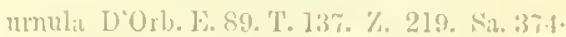

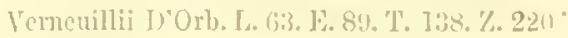
sp? Iq. 56.

1)entalinm limneo.

acile Sars. A. 275. S. :321. Sa. 357. V.

Balense L'artsh. I. 60, T. 117. A. 275.

Inelesertianmm Chenu. A. 275. S. 321.

dentalis Lin. T. 11\%. Sa. 357. V.

clephantinum Lin. A. 275. V.

filum (i. B. sow. 1. $275, \mathrm{~V}$.

forsile I,in. Iq. 5.2.

inaequale Bronn. 'T. $11 \%$ 
Dentalinm limuon.

inaequicosta n. s1). T. 117. - Tav. XI. fier. 48. irregulare n. s1. A 235. - Tav. XVI. fig. 33. laevigntum Ponzi. T. 11\%. 1. ¿ :

Michelottii Hoerm. T. 117.

norem-costatum Lamk. S. :321. Sia. 357. T.

Panomemur Clenu. 1. ำ. S. 321. V.

Passuninamen Coce. 1. 2\%̃.

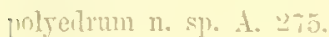

prismaticum n. sp. T. 117. - Tav. NT. fig. 10.

rubescens Desh. 1. 275. Sa. 35\%. Y.

vulgare Da Costa. A. 275. S. 321. Sa. $35 \%$. V.

Desmophyllam Ehrenbore.

yiganteum n. sp. 1. 301.

Diachoris Busk. patellaria Moll. S. $32 \%$ V.

Diastoporia Johnston. congesta? D Orb. Z. 213. V.

fi.tuellum Reass, E. 85. 7. 213.

latomarginata $\mathrm{D}^{\circ} \mathrm{OH}$ ). Z. 212. A. $29 \%$ S. 3:30. Sa. $932 . \mathrm{V}$.

obelia (Jolmston) S. 3\%. T.

patina Smitl. 7. 212. V.

simples Busk. 7. 213. S. 330. Sa. 372. V.

spiarsa Reuss, E. 8.5. Т. 133.

Dictyocha Fhrenbers.

aculeata Whrbes. Z. 233 .

Dictyomitra Zittel.

cristallini n. sp. Z. 232.

punctatella i. sp. Z. 232.

ventricosa stohr. 7, 2332 .

Dimorplina Dorbignr.

nulusiaria 1'Orlo. Sa. 375.

tuluerosa? D Orb. T. $110 . \mathrm{V}$.

Diplodonta Brom.

apienlis (Jhil.) A. 281. S. 322. 359. V.

intermerli, Bionti. 1. 281. S1. 359. V.

rotunilata (Monte.) 1\%. 52. A. 281. Sa. 359. V.

Savienyi? Vaillant. Sa. 35. V.

trisunula Brumn. T. 120.

1) iptohelin Eilwikts et Haime.

Doterloiniana Seg. A. 30.2.

Jenegliniana Sig. 1. 302.

retlexa (Michelotti) 1. 302.

sismoniliana Seç. 1302 .

Dised parella Gray.

celimulata (fienss) T: 85.

furmusa (Retus: E. 8.

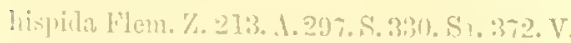

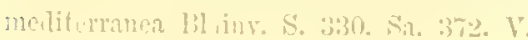

ratiata (1ud.) \%, 2 I3. I. 3301. Sia. V.
Discolyorellat Firy.

stelliformis Reuss. \%. 213.

Terucaria Fabr. '2. 21:3. S. 330. T.

sp. ? To. t2.

Discorbina I'arker et Junes.

globigerinoiles? l'ark. et Jones. Z. 228.

globularis (D* Orb.) E. 9I. 7. 228. A. 304.

S. 334. Sa. 37t. T.

granusa 1. sp. T. 148. - Tar. XIV. fic. '?

metiteranensis Dorb.j Sa. 376. V.

minuta 22. sp. T. 148.

minutissima n. sp. T. 149.-Tav. XIV. fig. 1.

oltusa (D'Orb.) 'T'. 148.

patella (Reuss.) E. 91.

perfurata n. sp. T. 118. A. 309. - Tav. XIV.

fig. 3.

semiorbis? Karr. E. !1.

solarium n. sp. L. 64. - Tav. VIJ. fi@. !?

restita n. sp. T. 148. - Tav. XIII. fig. :39.

»Var. pliogenica n. Z. 22:.

Ditrupa Brkeley.

incmia (lienier) E. 78. T. 12\% \%. 196. A. $294 . \therefore .32 \%$

? siphunculus (Costx) A. 294.

sulunlata (Dewl.) 1. 293. S. 32\%. Sa. 36i: V.

Dolichotoma Bellari.

catainiracta (Broce.) T. 101.

1) olinm Lamarek.

lenticulatum Desh. Ay. 50.

Domopora Dorbigny.

truncata (Jamesun. Z. 21. Y.

1) onax Limeo.

polita P'uli. Náa. 358. I.

semistriata Poli. S'a. 3.,8. V.

venusta Poli. Sa. :-s. V.

1) orucilaris A. Agassiz.

avperrima n. sp. A. 218.

papillata, Leske) \%. 214. A. 298. S. 330. Sia. 3\%3. V.

Dosinia siopuli.

cxoletir (Lin.) 1\%? 52. L. 60. 1. 279. \$. 32.2. sia. :358. V.

lineta (Pnlt.) 1. $=79$. Sa. 35s. V.

lupinus (Poli) . I .? 5\%. 1. 259. S. 32\%. Sa. 3.8. V.

urbicularis 1 gass. T. 119.

Drill i a Gray.

confusa n. เp. A. 25. S. 318. Sa. 35ะ. V.

(onsinguinea (Sin.s. A. 25.5.

(rispa (sig.) 1. 2yo.

"rispata (Jan.) '1'. 103. 
Drillia Gray.

emendata (Monter.) A. 255. V

galeritit (Phil.) A. 25\%.

»Var. minor ท. 1. 255.

globulifera n. sp. T. 103. - Tav. XI. fig. $\%$

inerassita (Dujardin) Sa. 3ュ2. V.

Loprestiana (Calc.) 1. 255. S. 318. Sa. 352. V.

Luciac 1. sp. T. 103. - 'Таv. XI. fis. 6.

minor 11. sp. T. I03. - Tav. XI. fig. 8.

moliola (Jan.) T. 102. A. 255.

ubtusangulus (Broce.) 'T? 102.

oritita Bell. T. 103.

Paretii (Maser) T. 10 ?.

pumila n. sp. A. 25 h.

Seillae Bell. T. 10\%.

sejuncta Bell. T. 10\%.

sigmoidea (Bronn.) '1. 103. A. 251.

„V Var. major. 13. A. 254 .

Eilsurna Lamarck.

eburnolites (JIath.) Aq. 50.

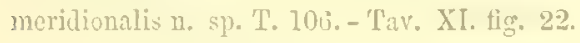

》Var. oblonga n. '1'. 107.

Echinocyamus Agassiz.

Costac n. sp. Z. 21\%.

prrsillus (Muller; Z. 210ั. S. 330 . Sa. 373. V.

Echinolampas Gray.

hemisphaericus (Laml.) 'To. 43. A.1. 5\%.

intlatus Laube. To. 4:3.

scutifomis (Leske) 1r. 55. Z. 216.

Fic hinus Limneo.

acutu: Lank. A. $299 . \mathrm{V}$.

maximus n. sp. 1. 299.

melo Iamk. A. 299. V.

mierutuberculatus Blainv. Var. pliocenica n.

\%. 2I4. V.

pulchellus (1gass.) A. 29\%. V.

Ponanus. MTerian. Z. 215.

s31.? A. 299 ,

Fomesus Philippi.

fungiaeformis Phil. T. 131. A. 301.

Eleplias Linneo.

Armeniacus Falconer. Sa. 3.su.

Ellipsoidina Semuenza.

ablureviati Seg. Z. 2266.

ellipsoides Ser. 7. 2)26\%.

ollonga Seg. Z. 2206.

sphoeroilalis n. s1). Z. 22.2t.

E.mareinula Lamarel.

Arriatica Costa. A. 20 1. S. 321. V.

cancellata 1'hil. A. 2\%.t. V.

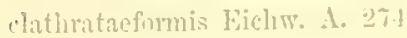

Fimarginula Iramarek.

confusa Seg. 1. 2il. V.

ennica Schumaher. A. 27.1. S. 321.1 .

decussata I'hil. 1. 274.

elongata Custa. 1. 2i1. 'V.

fissura Lin.j A. 274. S. 392. Sia. 35\% V.

Huzardi I'ayx, 1. 27. . V.

pileolus Michand. 1. 2\%1. V.

soliclula Costa. 1. 2\% \%. S.'321. Sir. 35\%. V.

Embolus Jetrieys.

belleroplina n. sp. \& $27 \%$. - 'l'av. XVI. fig. 31.

rostralis (soul.) 1. 27\%. \$. 321. Si. 35\%. V.

Enallopsaminia sismonda.

Scillie (Ses.) A. 3ut.

Entalophora Lamouroux. anomala (Reuss) F. 8\%. 7. 211. 1. 20\%.

attenuata Stoliczlia. E. 85. 'T'. 133..

Enidromus Klein.

reticulatus (De Blainv.) A. 262. S. :31\%. Sa. 353. V

Erato Risso.

laevis (Don.) e rarictiv. T. 101. A. 2\%3. S. 318. V.

Ervilia Turton.

castanea (Montg.) A. 279. S. 321. Six.358. V. jusilla (Phil.) T. 118.

Esclana Iay.

cervienrnis Lamk. \%. 2208. 1. 29(;. S. 33!! Sia. 3\%1. V.

columnaris .an\%. 7. 208. 1. 290.

monferta Reuss. E. 84.

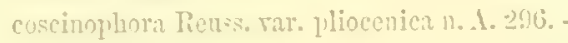

Tav. XVII. fig. $\%$

fistulnsa? lienss. To. 12.

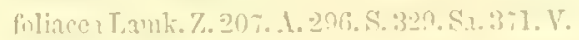

lichemnides Lamk. \%. 208. 1. 296. S. :32\%. Sa. :3\%1. V.

macromelilu Renss. F. 81.

microtheca n. sp. \%. -20\%.-Tav. XV. fis. 1 !.

monilifera .1. Fitw. 1'. 1:31. \%. 205. A. 23!4\%.

Sa. $3 \% 1$.

pertusa .I. Fdw. \%. 2U7.

inlystomelta Renss. L.st.

quatrilatera n. sp. \%. 20\%. - Tar. XV. ti:r. 15.

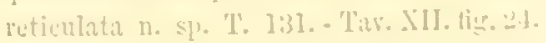

semlewichii M. Eilw. \%. 20\%.

tesinlata lienss. H. st.

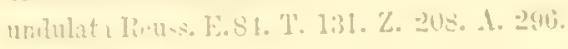

sia. :37.

variolata n. sp. F. \&.1. - Thas. VIJ1. lis. 15.

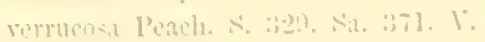


Eschara Tay.

s.? ? To. 42.

sp. ? To. 42.

Fuchitonia Ehrenberg. triangnlum 11. \$1). Z. 233.

Encyrtilinm Ehreubero. acmnimatum Ehrelsg. Z. 233.

calyx n. sp. Z. 23?.

inliolum n. sp. 7. 23:。

pliocenicum n. \$p. Z. 232.

tenuiporum n. $\mathrm{sp}$. Z. 232 .

tripartitum n. $\mathrm{sp}$. 7. 232.

Enlima Risso

hilineat, Alder. Sa. 3r.4. V.

breviuscula n. sp. T. 111. - Tav. XI. fig. 31.

conien Seg. A. 2064.

Fichwaldi Hoern. T. 111.

fusiformis Ses. A. 264.

internertia Cantr. A. 204. V.

Jeflieysina (Brus.) A. $264 . \mathrm{V}$.

lactea D'Orb. T. 111.

Philipuin Weinle. 1. 264. Sa. 354. V.

polita (Lin.) A. $261 . \mathrm{V}$.

nolygiri Seg. A. 264. V.

stenostoma .Tefti. T. 111. V.

subuluta (Don.) T. 111. A. 264. V.

Fulimella Forbes.

acicula (Phil.) T. 112.A. 264. S. 319. S2. 35 1. V.

confuna Sug. T. 112.

nitilissima (Jonter.) Seg. 319. V.

olsscura (Reas4.) T. 11:.

Scillae (Scace.) T. 112. A. 261. S. 319. V.

subumbilicata (Grat.) T. 11․

superflua (MIonter.) A. 264. V.

ventricosia Forbes T. 112. Sa. 351. V.

Eupsammia Elwarls et Haime.

compres $\times a$ Michelotti. Aq. 56. L. 62.

Sismondiana Michelin. Aq. 56. L. 62.

Euthria Gray.

comer (Lin.) A . 50. T. 10\%. A. 26\%. S.318.

Sia. $35 \%$. V,

mama Bell. 'L'. 10\%

》 Var. striata. T. $10 \%$

Fascinlaria Immarel.

Caliura n. sp. 'T'. 109.

fintriat. (Broce.) A. 202.

Tarbelliana Grat. 1y. 51. T. 109.

Ficula Swainson.

clathrata (Limk.) I. $5 . \%$

emelita lBrongm.) Aq. 51. '1. 109.

monnetra (Bors.) Aq. 51. 'T'. 109.
Ficula Swainson. intermedia (Sism.) T. 109.

Filigrana Berkeley. implexa Berkeley. S. 32\%. Sa. 36\%. V.

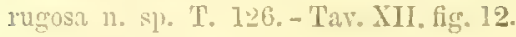

Filisparsa Dorbigny. biloba (Reuss.) E. 85. lata n. sp. Z.'210. - Tav. XV. fig. 22. tululasa (Busk.) A. 29\%. Sa. 3\%2. V. varians Reuss. E. S5. T. 13\%. Z. 210. A. $29 \%$. Sa. 3\%.

Fissurella Bruguière. costaria Bast. A. 273. S. 321. Sin. 35\%. V. dorsata Monter. 1. 273. S. 321. V. gibua Phil. 1. 273. . . 321 . Sa. 35\%. V. Graeca (Lin.) A. 273. V. neglecta Desh. e rar. b. Coce. A. 273.

Fissurina Reuss. acuta Reusi. T. 135. A. 305. alata Reuss. T. 135. Z. $21 \%$. apiculata? Reuss. Z. 217.

Biancae Seg. T. 135.

bieaulata Seg. A. 305.

Bonei Karr. T. 135.

carinata Renss. T. 136. 7. $21 \%$

communis Seg. A. 305.

Costae Seg. A. 306.

diaphana n. sl. A. 305.

diptera n. sp. S. 332 - Tav. XVII. fig. 36.

foliacea n. sp. A. 306. - Tav. XVII. fig. 13.

.Haeckelii Seg. T. 136.

laevigata Reuss. 'T. 135.

laevis Seg. T. 136 .

latimarginis 11. s1. Z. 21\%.

latistoma 1. 305.

longirostris Seg. Z. 21\%.

Lyellii Seg. A. 306.

obvia Seg. A. 305.

ovata Seg. A. 305.

Pecchiolii Seg. A. 305.

Peloritana Seg. A. 306.

punctata n. sp. T. 136. - Tar. XIII. figr. I.

racliata Seg. Z. 21\%. 1. 306.

raliatn-marcinata (Park. e Jon.) T'. 136. V.

recta $\mathrm{Seg}$. A. 305 .

regularis Seg. 1. 300 .

rugrosa Seg. A. 306.

simplex Seg. A. 305.

solicia Seg. 1. 305.

squamoso-mareinata (Park. e Jones 'l'. 136. S. 3332. V. 
Fissurina Reuso.

sulcata Seg. T. 136.

tubulosa Reuss. T. 136.

Fissurisepta Seguenza. papillosa Seg. A. 273. S. 321. V.

Flabellina Dorbigny.

foliacea $\mathrm{H}$. Bruly. Z. 225. V.

striolata n. 81. Z. 225.

Flabellum Iseson.

acutum Edwarils e H. T. 134.

aricula (Michalin) L. 6․

compressum? (Lamk.) A. 30\%. V.

deperitum Michelotti. Ag:5:

estensum Mielelin. Ar. 56. L. 6.2.

"Var. costatum 12. 'T. 131.

$\gg \gg$ pliocenicum n. 1. 302.

intermedium Filw. erl Haim. 1. 62. 1. 134. laciniatum (Pliil.) A. 302.

Messanense Ser. A. 302.

Michelini kilw. et $H$. 1. 30\%.

Roissianum Eilw. et H. T. 131.

Sieiliense Eilr. et H. A. 302.

»Var, crassitheea n. 1. 302.

Stilense n. \$1. Aq. 56. - Tav. VII. fig. 1.

sp.? Z. 226 .

Flustra Limen.

denticulata n. sp. E. ซอ. - Tav. VIII. fig. 6.

Frondicularia Defrance.

acuminata Costr. T. 136. Z. 21:1.

acuminato-striata n. s1). 7. 니․

alata D'Orb. F. 89. Z. 219. V.

anmularis D'Oris. L. 63.

compressa Costa. Z. 219.

corlata n. sp. E. 89. T. 13\%. - Tav. IX. fic. 5 .

Ienticulata Costa. Z. 219.

filicostata n. sp. Z. 219.

inaequalis Costa. '2. 219.

laevigata Karr. Z. $21 \%$.

Iedelongensis Kary. Z. 221!.

rhombohlalis $\mathrm{D}^{\circ} \mathrm{Or}$ ). E. 89. T. 1:36. V.

sculpta? Karr. 1'. 136.

Frondipora Inperato.

reticulata 13lainv. 7.214. S. 330. Sa. :772. V.

Fusus Iamarek.

crispus Bors. T. IUS.

glomoikes Genc. A1. 50. L. 51.

Iamellosus Bors. T. 108.

longiroster (Broce.) 'L'. 10\%, 1. 262.2.

pulchellus Phil. A. 26\%. S.. 319. I

rostratus (Olivi) 1. 201\%. s. $31 ! \%$ sia. 35:3. V.
F'usus Iamarck.

Valenciennesii Grateloup. T. 10s. sp.? 'T'o.

Gadinia Gray.

Garnoti Payr. 1. 249. T.

Galeocerilus Arassiz.

Pantanelli Lawley. T. 9g.

Ciastrochaena Lamarek.

dubia I'enn. 1. 27\%. S. 331. Sa. 35\%. V.

Gaulryina Dorbigns.

butenensis Remss. T. 153.

chilostoma Reuss. E. 92.

textilaroiles? Hantk. H. 92.

Gemellaria Sar.

punctata n. sp. T. 12\%.-Ta. X1I. fig. 14.

Genota II. et A. Arlams.

Craverii Bell. T. 102.

MLunsteri (Bell. e Mich.) T. 102.

Glandulina D'Orbigny.

acuminata Costa. A. 30 B.

nitunca Costr. S. 332.

apiculata Costa. Z. 218. 1. 306.

discretiz Reuss. \%. -18. A. 306.

elliptica Reuss. T. 136. \%. 218.

elongata 13nmen. T. 136.

globulus Reuss. T. 136.

encracilis n. sp. A. 305 .

intlata l3om.m. T. 136 .

linerigata D'()rb. E. 89. T. 131\%, \%. 21\%. A 3016.S. 33:2. T.

efr. olitusa Cocta. 1. 300 .

olutusissima Jietz:. T. 136. \%. 218.

ovifomis Teryuem. A. 306 .

Globigerina $\mathrm{D}^{\circ}$ Orbigny.

Amlasii (ser. E. 91. Z. 22-2s. 1. 30s. s.

3:31. Sa. 3\% 6 .

hilolin 1)(0rt. T'. 148.

Imliniles Dorh. I. 61. 1\%. !1. T'. 118. 7.

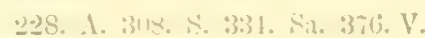

enncinna? Tienss. I., 61 .

conglumeratia schwager. \%. 2.28.

. 11

gomitulus n. sp. \%. 2.25. 1. 308. S. 331. Sit. 376. - 'Lay. XVII. fig. 16.

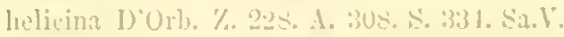

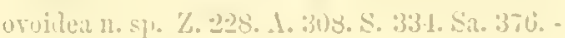

Tav. Alll. dic. 39.

quatriloba D'Orb. L. 61. L. (1. T. 1.18. Z. 22.28.

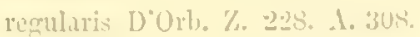

mima I'Urb. .1. :30s. V.

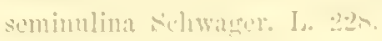


filobigerina D'Orbigny.

triloba Rems. T. 64. E. !1. 'T'. 118. \%. 228.

A. 308 .

Haliomma Hreckel.

liexacantlum Minll. Z. 2:30. V.

efr. lonritum. Stohr. '7. 2230.

cfr. molestum Stohr. Z. 230.

mucronatun. in sp. Z. 230.

Halintis Linneo.

lamellosa Lamli. A. 273. S. 320. Sa.33\%. V.

Volhinica Fichw. T. 150.

Haminea Teach.

hylatis (Lin.) Sa. 351.V.

varicosir (Ponzi) 1. 250.

II aplostiche Tieuss. compressa n. sp. A. 309. - Tav. XVII. fig. $1 \%$

Hela Jeflireys. tenella (Jefir.) A. 268. Sa. :356. V.

Helinstraca Edrards et Haime.

Reuscana Et. et H. T. 131. 157.

IIeliolineus Hacckel. pliocenicus n. sp. Z. 230.

Heliosplanera Hiweliel. rudis n. sp. Z. 230.

Irelonyx Stimpon. gadulus (Dorl.) T. 118. 1. 275.

Jeffreysii Monteros. 1. - -75. V.

subfusifomis (M. Sars.) S. 321. Sa. 35\%. V. tenuis n. sp. 'T'. 118. - TaY. IT. fig. 50.

rantricosa (Bronn.) T. 118. A. 275. V.

Hemieschara Busk.

imtellis Busk. $1 / 2$. 208.

trapezoilter Ficuss. T. 130.

varians и. s1. T. 131. - Tar. XII. fig. 23.

Heterocetus Tim Beneilen.

(tuiscartii Capellini. E. 71 .

s]1.? \%. 184.

sp.? Sa. 350 .

If cteropora Blainville.

clavata Bukk. Z. 2I4.

stellulata Reuss. E. 8f.

Iroternstegina D'orbigny.

mostata D'Orb. F. 94. T'. T:39.

japyracea n. s1. E. 90.- Tav. IX. fie. 1.

»Var.grigantea 13.Aq. 56. - I'av.VII. Aim. @2.

ap.? To. 15.

Il innites l)efrance.

erispus (Broce.) \%. 189. 1. 286.

Defineci? Mich. 'I'. Isif.

Frenlanianus Cnceni. \%. 1s!. 1. 286\%

lacviusculus I'hil. \%, 18:1. 1. 286.
IIinnites Defrance.

tenuis 11, s17. E. 76. - 'T'ar. VII. fig. 16.

Hippothon Lamourous.

catenularia (Tameson) S. 32\%. Sa. 36\%. V.

disaricata Lamouroux. S. 32\%. Sa. 36\%. V.

flagellum .Janz.Z. 19\%.A.294.S.32\%. Sa.36\%. V.

Homotoma Bellarti.

anceps (Eiclw.) S. 31S. A. 259. V.

cinct. 21. S1. A. 25:- Tav. YVI. fig. 20.

Cortieri (Parr.) A. 25\%. V.

»Var. hirta. A. $25 \%$

eleguns (Don.) A. 258. V.

hystrix (De Crist. et Jan.) S. 25\%. V.

inflata (De Crist. et Jan.) A. 258. V.

Leufunyi (Mich.) A. 258. T.

linearis (Montg.) Sa. 352. V.

multicingul z n.sp. A. 25S. - Tav. XVI. tig. 21.

purpurea (Montg.) A. 25\%. V.

reticulata (Renier) A. $257 . \mathrm{V}$.

rulis (Scacc.) - Sa. 352. $\mathrm{r}$.

scalberrima 11. s1. T. 101.- Tav. XI. fig. 10.

stria (Calc.) 1. 258.

textilis (Broce.) A. 258.

turitelloirles (Bell.) T. 104.

Zanclea (Seg.) A. 257.

"Var. lata 1. A. 25\%.

Hornera Lamourour.

enneatenati Rensz. T. 132. A. 29\%.

cilindracea 11. sp. e var. prominens n. \%.210.-

Tav. IV. fig. 20.

frondiculata Iamour. F. 81. T. 132. Z. 209. A. 29 \%. S.r. 371 . V.

"Var. rugosa. 11. A. 297 .

hyppolithus Defi. E. S1. 7.? 219. A. 297. Sล. :3\%1.

Reussii n. sp. F. 84. T. 132.Z.209. - Tar. VIII. fig. 16 .

serrata Renss. Var. pliocenica n. Z. 210. Tax. XV. fig. 19.

simplex 11. sp. T. 132. - Tav. XI. 1ig. 2\%.

»Var. impressa n. Z. 210.

striata IT. Etwarts, 7. 209. A. 297. S:2. 3:1.

II y I ca Lamarck.

Calataluimensis Seg. A. -276 .

inflexi Leseur. 1. 2ะ6. V.

peraflinis Seg. A. 270.

quatrilentati Les. Sil. $35 \%$ V.

Seillate Seg. A. 276.

triblentata (Forscl.) 1. 276. V.

trispinosa T.esmetr. . 1. 27io. Sa. 35\%. V.

s].? '1'. 118. 


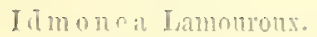

atlantica Forles. 1. 200 . S. 3:30. V.

bacillaris n. sp. A. 29\%. - Tar. XYII. fig. E.

cancellata (Golelf.) E. 8.,

carinata? Rom. T. 13:2.

concuva lieuss. E.? 85. Z. 20!. 1.'2)7. S. 330. Sil. 37 I. V.

conferta n. sp. Z. 209. - Tav. XV. fieg. 1\%. crassa 11. sp. Z. 208. - Tav. XV. fig. 16.

distichn? Gollf. T. 13\%.

fenestrata Busk. T. 13:2.

sricilis Menegh. Z. 20\%, V.

»Var. exilis e teretiuscula n, Z. 2009.

imegularis Menegh. Z. 209. 1. 29\%. S. 330.

Sa. 2ั1. $\mathrm{r}$.

lineata (Hag.) MLanz. Z. 209. T.

Meneghinỉ Hellr. S. 330 . V.

motomalu Busk. S. 33\%. Sa. 3\%1. V.

pertus. Rouss. E. 85. T. 132. A. 296.

protuctia n. sp. Z. 209. - Tay. IV. Aig. 18.

spice. n. s1. T'. 13.. - T'ar. XIl. fig. 28.

triforis Heller. 7. 209. A. 297. Sa. 3i1. V.

Ilyobates G. O. Sars.

bartonensis Jones. var. Monnstericensis. 7. 191.

A. 200 . S. 325.V. - Tav. XVII. fig. 29.

$\gg$ Var. brevis. A. 2!u.

compressa n.sp.Z.194.S.3.25.-Tar. IVII. fig.30.

"Vir. antiqua n. Z. 194.

Isis Iamouroux.

compressa Seg. A. 300.

melitensis Goldf. T. 134. 1. 299.

pelorituna Serg. A. 292.

Isocardia Lamarek.

cor. (Lin.) T. 119. A. 280 . S. 322. V.

Jagonia Reclus.

reticulata (Poli) A. $281.5 .322 .53 .359 . \mathrm{V}$.

fanira Albers.

adunca (Eichw.) T. 122.

Alessii (Phil.) Z. 188. A. 285.

areuata (Broce) To. 11.

Besseri (Anc1.) Aq. 53. L. 61. E. 7\%.

Beudanti (Bast.) Aq. 5.3. E. 75. T. 122.

bipartitit n. Sp. Z. 18S.

Burdigalensis (Bast.) T. 122.

Calabran.sp. E. 75. T. 122.-Thw. XIII. fig. 1:3.

flabelliformis (Broce.) \%. 185. A. 285.

》Vir. sulcata 11. Z. 183.

Grayi Michelotti) To.? 11. Mg. i3. L. (il. 1. . . . 1:

Jacobnea (Lin.) \%. 188. A. 255. ‥ 323. - 1. . *il. Y.
T an in Allors.

Jacoluen Var. simplex n. Sit. 3391

» "strittisim! linesti, \%. 188.

linevicostata 13. si. Z. 18S. - 1av. XIV. fig. 16. maxima (Lin.) \% 1/. 18s. S. 323. Sa. 361. V. pumil.s n. sp. .. 75. 'l'. 122. - Tav. XI. lig. 26. Rhegiensis n. sp. 7.. 188. - Tiv. XIV. fig. 1\%. rerolutir Michelutti. Aq. 53. L. 61. F. 55. Rollei (Hocrues) L'. 75. 'T'. 122.

subruliata n. sp. I. 61. E. 75. - T22. VII. fig. 12.

Inncella Valencienno. antiqua seg. A. 29?.

Ke ellia 'Inton. suborbicularis (Montg.) S. 322. Sit. 360. V.

Kelliella sars. miliaris (Phil.) T. 139. 1. 280. S. 322. V.

Lachesis Tisso.

arcoluta Tiberi. A. 25\%. Y.

canclidissime (Phil.) A. $255 . \mathrm{V}$.

custulata n. $11 \%$ A. 255.

Folineae (I)elle Chiaic) 1. 25\%. V.

lineolatı? (Tib.) A. 255. V.

mammillat, Risso. A. 25.5. V.

minima (Montg.) A. $255 . \mathrm{V}$.

rulpecula Jinnteros. A. $255 . \mathrm{V}$.

Lacena Wallicr.

aflinis (Seg.) A. 30\%.

aniculata Peuss \%. 21\%. 1. 305. \&. 331. șa. :3it.

appeniliculata Will. 1. 305. V.

eatenulata Will. T. 135. V.

cauclatir (D'Orlo.) S. 331. V.

clavata (I) (0)\%.) \%. 217. 1. 305. \$. 331. V.

clavato-punctata n. sp. Sa. 3\%1. - Tar. IVII. lis.s. 58.

crenata Partier c Ton. Sat. 37\%. V.

cucturlyita 11. sil). \%. :31\%.

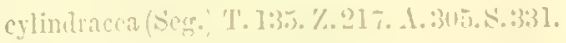

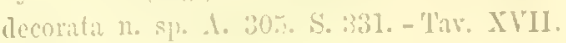

1iv. 1:-

tistomm l'ark. e Jon. S. :3:31. V.

llistm :-polita I'ark, c Jon. \%. 21 \%. S. 3331. V.

eloneratia Costat 1. Bus.).

emaciatia (lienss \%. $21 \%$. A. 33,5. S. 331.

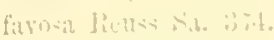

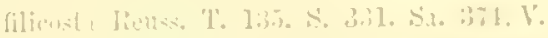

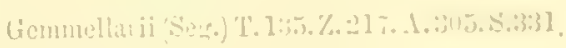

geometrie: lienso. s.t. :3it.

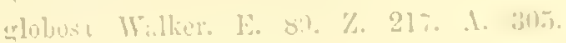

$\therefore$ :33il. Ait, : : i: V. 
Lagena Walker.

gracilis (Costa) A. 335 .

gracilis Will. S. 3:31. V.

sracillina (Sor.) Z. 21\% 1. $305 . \mathrm{V}$.

Haidingeri (Cziz.) Sil. 371.

»Var. clolosa 11. 1. 305.

lagenointes (Will.) S. 33:2. V.

Incilla Will. T. 135. Z. 217. 1. 305. S. 332. V.

»Var. qualrata. Z. 217. A. 305. V.

Lyellii (Seg.) T. L35. Z. 217. A. 30.5. Sa.374. V.

maculato-punetata 11. sp. S. 331. - Tav. XVII.

fig. 33.

marinata (Walk.) L. 89. T. 135. Z. 217.

1. 305. S. 331. Sir. 3\%t. V.

marerinato-perfuratia n. sp. S. 332. - Tav. XVII.

fig. 31.

marginato-raliata n. sp. S. 332. - Tav. XVII.

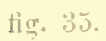

melo (I) Oris.) S. 3331. S.a. 37. V.

ornata ('̌eg.) '1. 135.

geticulata Hacgill. Sa. 371. V.

scalarifurmis, Will.) S. 332. Sa. 3\%4. V.

striate (D'Orls.) Z. 217. A. 305. S. 331.

Sa. 374. V.

striatula (Beg.) 1 :305.

sulcata (Seg.) Z. 21\%. A.305. s..331. Sa.3\%. V.

tenuis Bornemann. A. 305. V.

tenuistriata Seg. A. 30\%.

vulgaris Will. T. 135:Z. 217. A. 305. S.331.

$$
\text { : } 1 .: 2,: \text {. Y }
$$

》Var. semistriata Will. T. 135. Z. 217.

$$
\text { 1. } 305 \text {. S. 3331. V. }
$$

Lamellaxia MIntagu.

perspicua (Lin.) A. 263. V.

L'amna Cuvier.

crassidens Igass. E. 73. T. 105. A 247.

Lasaen Lench.

rubri (Montes.) S. 322. V.

Leda sehumacher.

cuspilata (1'hil.) A. 283.

Hoemesii Bell. T. 121. 1. 233.

Lemlulus lisso.

Bonellii (Bell.). T. 121.

commutatus (Phil.) T'. 121. 1. 281. S. 323. Sin. $360 . \mathrm{V}$.

concasus (Bromno). L. 234.

ribluns (Bers.) 1. 281.

innequilaterus (Ser.) 1. 284.

Meswanensis (Sego) A. 23i. V.

\Var. intlatus 1). 1. 231.

Nicotrac (Seg.). A. 23.1.
L e en b) Ins risiso. pella (Lin.) \$. 323. Sa. 360. V. peraftinis (Seg.) T. 121. pusio (Plil.) A. 2S4. V. pustulasus (Jeffi.) A. 284. V. seminulum (Seg.) A. 284.

trigonus (Seg.) 1. 284.

Lepas Limeo.

sigmata n. sp. A. 293.

Leprialia Jolneton.

alpressir 11. sp. Z. 203. - Tav. XV. fig. 10. anivostuma Reuss. T. 129.

ansata Juhnst. E. 81. T. 129. Z.“201. A. 295. S. 328. Sa. 369. V.

arenlata? Renss. Z. 201.

arrecta lieuss. E. 83.

amiculata Hassal. Sa. 369. V.

Barmanclei Renss. E. 81.

biaperta Michelin. E. 81. Z. 202.

bicornis Busk. Sa. 370.

brachicephala n. sp. E. 82. T. 120.

Bronguiartii Indonin. E. 83. Z. 201. 1. 295. S. 323. Sa. 36\%. V.

Calalira n. sp. Z. 201. S. 328. Sa. 36\%. liuv. IV. fig. 6.

ceritomorpha Reuss. Z. 205.

chilopora Reuss. Z. 206.

ciliata (Lin.) E. 81. T. 129. Z. 202. 1. 29J. ง. 3노. Sa. 369. V.

meciner Johnst. E. 81. A. 294. S. 328. Sa. 36s. V.

"Var. antiqua n. Z. 109.

$》 \quad 》$ gracilis n. E. 81 .

congesta n. sp. Z. 202. - lav. XV. tig. . . coronata 11. sp. A. 295. Sa. 3\%0. - T'av. XVII.

fig. 6 .

crassa Relis. E. S3. 1.? 295.

crassilabra Manz. E. 81. Z. 202.

rribrillina? Manz. Z. 203.

cucullati Busk. E. 83. ‥ 320. Sa. 371. V. cupulata MIanz. Z. 205. S. 309. Sa. 3i1. V. lecorata Reuss. E. 81. Z. 190?. 1. 204.

leltostoma n. sp. Z. 206. - 'Tav. XV. dig. 13. Iidwarksiana Busk. Sa. 360. V.

elegintissima n. sp. E. 83. - Tav, VIII. fig. 11. eximia n. sp. \%. 203. - Tav. XIV. fig. 23. furmosa n. sp. E. 82. - Tav. VIII. fig. 12. \Var. biarmata n. Z. 199. - Tav. IIV. tig. 2 -2.

fnlgmans MLanz. Z. 200 .

gistropora Reuss. E. 8:. 
Levialia Johnston.

Gittyae Lands. 1. 29\%. T.

cribbosuld IIanz. Z̈. 204.

"Vararine sa.biturifata.erectan.7.20 H.

cuniostonia fieusz. E. 83.

Gunversi Petus: Fi. S?.

Er.untis n. sp. \%. 199. - Tav. AV. fis. 1.

Enunoto-prosia Renss. 'T. 12?.

Haneri liencs. E. 83. Z. 201.

inamena Renks, F. 81. T'. Ion.

incisa lienss. L. 83.

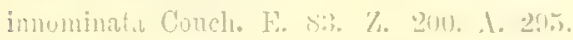
s. 338. ง ง. 368. V.

incimnis Renss. E. 83.

intricata n. sp. $\therefore$. 32?n- Tar. XVII. fig. 3:.

lata Pusk. 7. 204. 1. 29, . :320, sa. 371. V.

lignl tia Manz. Z. 205. S. 329. Sa. 371. V.

linearis Hassal. F. 8.2. \%. 202. 5. 3328. S.a. 3\%O. Y.

lncermula Manz. Van. F. S.1.

macrocephal. n. sj. Z. 201. - Thv. XV. fig. ?)

Halusii Induin. A. 205. S. 328. Sa. 350. V.

marionensis Manz. Z. y202.

uncgalota Reass. E, 81.

micans MIanz. '/ $20 \%$.

mintissima n. sp. E. 82. - Tav. VIIJ. fig. 13.

mitrata n. s1). Z. 203. - Tav. XV. fig. \&.

monocerus Reuss. E. 83. \%. 201.

Morriciana Busk. Z. 202. A. 295. K. 328.

ลื่ $36^{2} \% \mathrm{~V}$.

obeliscus Manz. E. 84. T. 12! Z. 20) \& $8.39 ! 9$

olvia? IIan\%. Z. 20) t. A 295 .

utophora Reuss. E. 82. 'T. 12.).

Pallasiana 15oll. Z. 205. A. 245.82 . 370. V.

Partschii Reuss. E. 83.

Peachii Johust. S. 32\%. Sia. 330. V.

porturit Johnst. E. 83. Z. 20) S. :32!?

Sir. 3i1. V.

planata MEunz. Z. 2.12. 1. 295.

planiceps Peu-s. E. 8:3.

planicosta n. sp. Z. 21)0. S. 328. Sa. 369.

plenropura Reuse. E. 81. '7. 21) 2.

Pratensis n. s\%. 7. 205. \$a. 3\%0. - Tiw. XV. fig. 11.

pustulosiz n. kj. F. 82. - Tav, VIII, fig. 14. prrifurmis S. Whoml. \%. $\therefore$ (1)

rallato-foveulata n. s. T. 12!). - Tis. XIJ. tig. 20 ,

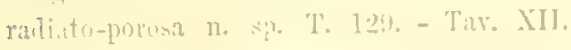

Jìn. 19 .

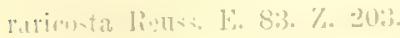

Lepralin Julustion

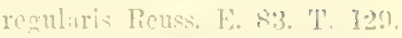

resizimata ILan\%. 5.81. \%. 201.

reticulati Bnsk. E. 8\%. 1. 125. \%。.205. 1.295. 328. Sa. 3 $30 . \mathrm{V}$.

$\gg$ Var. Alistincta 11. 1. 20y5.

limusil.mu Busk. F. 8:3.

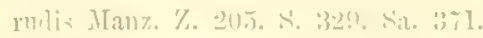

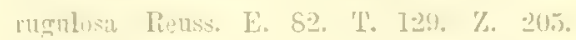
Si. : :3i1

schizusaster Reur. L. 8.. 1. 295.

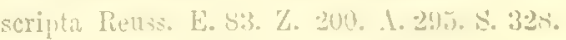

$$
\text { S.t. 36s. V. }
$$

» Tor. perfurata n. \$... 3168.

sernulata Renss. F. 833. \%.. 20:3.

sunumbitea fien-s. 'L'. 12!\%

stellatia n. sp. Z. 206. S.? 320. Sa.? 371.-

Tar. XV. fig. 12.

tremis .[a:1z. Z. 21)0. 1. 29)1.

"Var'. laciniat. n. Z. :00). - Tikr. XV.

$$
\text { fig. } 5 \text {. }
$$

Sturii Rents. F. 82.

surgens MIanz. 7. 201. 1. 291.

systulostoun Manz. Z. 20\%. șa. 330.

tem.lla Feuss. E. 8\%. Z. 202.

tenera Pienss. T. :3:?

thiara 11. sp. s. 329. Sa. 370. - liw. IVII.

five 57 .

tiqgonata n. sp. 7. 200 \%

111\}a Janz. 7. עu6.

tumicla Janz. Z. 20)-2.

mubonata Nan7. \%. 205 .

unicomis, Jolusst. S.2. $369 \%$

varolosa Johnst. Var. \%. -203.

vaceula J[an\%. F. 8.3. \%. $20 \% 3$.

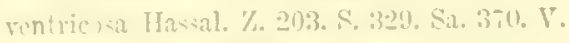

venusta Eichw. 1. 205 J.

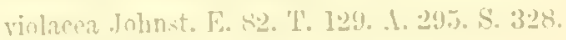

sil. 3ris. V.

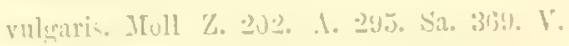

sp.? 'To. 12.

sp.? To. to.

sp.? A. wis.

sp.? Aq. 53.s.

I. cpeton 'Tirton.

nitilum (Turt. T. 1ะ0. S. 3320. Sa. :3t5). Y.

lima Briguiere.

excavita (Chemun.) 1. 205\% V.

hians (tim. \& :12:3. V.

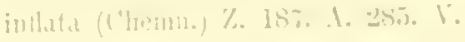


Is ima Bruguière.

T)scombii G. B. Sow. T. 18\%. A. 28\%, S. 323. Sa. $3(0)$ V.

miocenica sismonda. Tu. 11.

squamosa Tamk. T. 156. Z. 18\%. A. 2心i. S. 323. Sa. 360. V.

tenera Turton. A. 285. Sa. $360 . \mathrm{V}$.

Limea Brons.

crassa Forlies. 'T. 121. Z. 187. A. 285. V.

elliutica Jeffr. Z. 18\%. V.

Hoemesii n. sp. L. (j1. E. 74. - Tav. VII. fig. 1.1. niven (Ren.) \& $323.5 a .3 i 0 . V$.

ovatis S. Vool. 'T. 121. Z. 187. S. 323. V.

reticulata seg. A. 285 .

otrigilata (Broce) E. 74. T. 121. 1. 285.

subauriculata (Montg.) F. 74. S.? 323. V.

s1.? T. 121.

Limopsis Sasí.

anomalir (Eichw.) T. 121. A. 282.

Aradasii (Teta) T. 1:0. A. 282.

aurita (Broce) A. 282. V.

"Var. radiata. A. 282. S. 323. Sa. 360.

Calabra 11. sp. 'T. 120. - Tav. XI. fig. 51.

clathrata Seg. A. 28\%. - Tut. XVI. fig. 4\%

fragilis Se?. 1. 283.

minuta (Plil.) 1. 28: S. 323. Sa. 360 . V.

pygmaea (Phil.) T. 121. A. 28\%. s.. 323.

»Var. maiur. 11. 1. 25:3. Sa. 360.

Reinwartii Cantr. 1. -82.

"Var. obsoleta n. A. 282.

tonmis Seg. A. 283. S. 323. Sa. 360. V.

Ling ulina D'Orloigny.

cariuata Dorb. Z. 219. A. 306. Sa. 37t. V.

(costata I)'Orb. E. 89. 'Г. 136.

Ijithoircus. J. Nunler.

denctato-punctatus n. sp. Z. 233 .

Lithomelissa Ehrenbero.

meliterranea Mruller: 7. 232. V.

Littorina Fermsac.

neritoiles (Lim.) A. 268. S. 320. Sa. 356. V. peregrina n. sp. A. 268.

lituolas Iamarck,

Canariensis. D'Orb. T'. 15I. A. 309. V. dubia (I) Orl).) Z. 229 . V.

Flobigerinifomis Park. o Jon. A. 30\%. V.

scorpiums (MIontf.) \%.,2029. V.

Soldanii Park. e Jon. F. !) I. V.

I. oligo Iamarck.

vulgaris? (Lin.) T'. 100. 1\%. 219. V.

tonphohelia tilw. of Tiame.

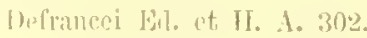

Lophohelia Fitw, et Haime. prolifera (Pallas). A. 302. V.

Lophophana Ehrenberg. cfr. amphora Stohr. Z. 232.

Loripes Poli.

divaricatus (Lin.) A. 282. S. 322. Sa. 359. V. fragilis (Phil.) A. 282. Sa. 359. V.

grandis n. sp. Z. 187.

lacteus (Lin.) A. 28\%. 32\%. Sa. 3:0. V.

Smithii 11. sp. S. 359. V. - Tav. XVII. fig. $\$ 1$.

Loxoenncha G. O. Sars.

elliptica Brady. S. 330. Sa. 361. V.

fabacea n. sp. A. 291. - Tav. XVI. fig. 53.

granulata Sars. S. 320. Sa. 361. V.

impressia (Baird.) Z. 191. A. 290. S. 3:6. Sa. 364. V.

lemumen 11. sp. A. 291. - Tav. XYI, fig. 52. maculatn-junctata 11. sp. A. 291. - Tar. XVII. fig. 1.

obliquata ı. sp. T. 126. - Tav. XII. tie. 10. junctatella (Tieuss.) T. 126.

tamarindus (Jones) A. 291. S. 320. V.

Lucina Bruguiere.

Agasizizii Michelotti L. 60. T'. 120.

Aspromontana Ses. A. 281. - Tav. XVI. tig. 11. borealis (Lin.) T. 120. A. 281. S. 322. ș. $354 . \mathrm{V}$.

Bromii Mayer. T. 120. A. 281.

»Var. major n. A. 281.

rircularis n. sp. A. 281 .

columbella Lamk. \$ q. 52. L. 60. 'Г. 120.

rentata Baster. 'T. 120 .

Dujarlini Desll. L. 60.

miocenica? Michelotti. L. 60.

umata Agass. Aq. 52 .

spinifera (Honto.) L. 60. T. 120. 1. 281. s. 321. Sล. 359. V.

"Var. hiatelloiles. L. 60. 'T. 120.

" dilatata n. A. 281.

I, unulites Lamouronx.

antrosaces Al. T. 131 .

I utriuja Iamarck.

elliptica Laml. 1. 279. S. 321. Sit. 368. V.

Lythodomus Curier.

appenliculatus Phil. T. 156. V.

sp.? T. $15 \%$.

IIacrocypris Brasly.

Cialabra n. s7. \%. 191. A. 28\%.

minna ([aird.) L. [9]. V.

Min ropmonstes Adussi\%.

hrissiformis n. sp. 'To. 4t. - T'av. IV. Jig. \&. 
Iractia Limmen.

(on)allina Lin. S. 32T. Sa. 335. Y.

wlanea Born. A. 279. V.

solida Lin. S. $358 . \mathrm{V}$.

subtruncata (Da Costa) T. 118. A. 279. S. 331. Sa. 358. V.

I alletia Desmoulins.

Bellardi Seg. T. 121. A. 284.

II angelia Lench.

angusta (Jan.) T. 10 f.

Bortrandi (Payr.) 1. 258. V.

clithrata (De Serr.) 1. 258. S. 318. Si. 352. V.

contracti Bell. T. 104.

costatia (Donor.) A. 2.58. Si. 352. V.

multilineolata (Desh.) A. 258. V.

mgnlosa (Pli1.) Sa. 352. V.

tomuicostatia (Seg.) A. 25:

Mar in ella Lamarck.

Benestarensis 2. sp. T. 101. - Tav. XI. fig. 2.

clanlestina (Brnce). 1. 253. S. 318. Sa. 351. V.

Deshryesii Michnotti. T. 101.

miliacea Lamk. T. 101. 1. 253. V.

ncculta Mnnteros. A. 25.. Sa. 3й1. V.

ovnlaeformis n. sp. 1. 25.. - Tay, XVI. fiצ。 12.

Philiunii Ironteros. A. 253. S. 318. Sa. 351. V.

secalina Plil. .1. 253. V.

subovulatia Dorh. Aq. 50.

Ma reinulina Dorbimy.

compressa n. sp. 7. 222.

contraria Cziz. T. 139. S. $33 \%$.

Costiz n. sp. Z. 22:3.

cristellarinikes Cziz. T. I40. 7. 222.

glabra DOrb. Z. 222. S. 33 ?. Sa. 3\%4. V.

hirsuta DOrb. E. 20. T. 140. 7. 222. V.

liturs $D^{\circ} \mathrm{Orh} .7 .292 . \mathrm{V}$.

moitosa n. sp. T. 139. - Tav. XIIT. fig. 11.

perliformis Born. T. 139.

jupoirles n. sp. T. 139. - Tav. XIII. fig. 9. raphanus Lin. E. 90. T. 140. Z. 283. Sa. 374. V.

»Var. crebricosta n.E.90.T. 110.Z.223.-

Tav, IX. fig. 6 .

» parva n. L. 63.

regularis D'Orb. Z. 222.

siliqua n. sp. Z. 222.

similis $\mathrm{D}^{\circ} \mathrm{Orb}, \mathrm{Z}, 2 \mathrm{2} 2 \mathrm{2}$. S. 33:3.

spinulosa Karr. T. 110. T. 22.2.

spleniens Hantk. T. 1:3?.

striata n. $57,7.222$.

striatisima n. sp. \%. 223.

cfr. subullata Hantk. Z. 22.20.

triangularis $\mathrm{D}^{\circ} \mathrm{Or}^{\mathrm{r}} \mathrm{3} .7 .222$.
Mathilda somper.

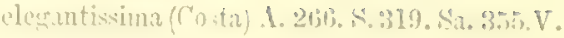

» Tar. tonuisenlpta n. T'. 113.

qutricarinata (Broce) T. 113. A. 2b6. S. $319 . \mathrm{V}$.

retusa? Brngn. Sa. 35\%. V.

Megerlia King.

ensticta (Phil.) 7. 190. A. 237.

truncata (Lin.) A. $23 \%$. S. 321. Sia. 3il. V. »Var. granosa n. Z. 190.

Melicerita M. Ectward:

Charleswartii MI. Elw. 7. 203

Membranipora Blainville. andegavensis (Mich.) E. 80. T. 123. S4. 3438.

»Var. incisa. n.\%. 193. - Tav. XV. fi.y. 2. angulosa Peuss. E. 81. 'T. 12.3. Z. 193. .1. 294. S. 3288 . Sin. $368 . \mathrm{V}$.

annulus JIanz. E. 80. Z. 199. 1. 294. s. 3:3. aperta Busk. T. 193. Z. 197. S. 327. .4.6. 3 ' appendiculat

bicornis a. sp. E. 80. - Tay. VIII. fig. 10. birlens v. Hag. E. 80. 'I'. 193. \%. 193. Sa. 36198. calpensis Bust. 'I'. 128. A. 2y1. S. :320. Si. 36i8. V.

catenularia Jamesol. 7. 197. V.

crispia n. мp. 'T'. 122. - Tar. XII. tig. 1s.

riadema Reuss. E. 79. 7. 197.

elliptica v. Hag. E. 80.

exngona n. sp. 7. 193. - 'I'av, XV. fig. 3.

fenestrata Renss. E. 80. Z. 19\%

fissura 11. sp. E. 80. - Tar. VHI. fin. T.

Fleningii Busk. Z. 19\%. Sa. 368. V.

formosil Reuss. E. 81. Z. 198.

»Var. conferta n. F. 81. - Tav. VIII. tig. 8.

mracilis Rettss. E. 81. T. 122. \%. 1!1:.

incomputa lieuss. \%. 193.

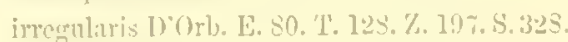
sa. :36s. V.

Lacmixii? (Sav.) Aq. F3. F. 70. \%. 197. V. lincatia Lin. E. 80. \%. 19\%. A. 294. s. 32s. Sa. $368 . \mathrm{V}$.

loxopma licus. F. 81). T. 123.

nerivalis n. sy. E. 80. '1'. 128. - T'uv. VIII. fig. s.

papyracea Retrss. K. 81. '1'. 128. 7. 10\%. 1.

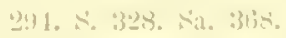

Pouilleti Autonin. \&. S0. \%. 197. S. 328. V.

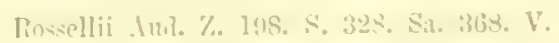

Savartii Aul. Sa, :3t\%. V.

semiapertar lieuss. 1'. 125.

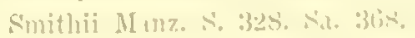


Membran ipora Blaimille. stennstoma Retas. F. 81. 'T. 128. 7. 198. trifolium S. Wond. E. 80. Sa. 368. V.

Menestho Moller. Hunbolltii (Risso). A. 200. I.

Mesenteripora Blainyille. eurlesiana? II. Hilw. T. l:3..

II esouesma Deshayes. cornea (Poli). S. 321. V.

Miriozoon Donati. truneatum Pallas. E. 79. 7. 197. A. 294. S. $32 \%$. S . $36 \%$. V.

IL itra Lamarek.

bicoronata 11. s1. T. 102.- Tav. X1. fie.. ร.

Borsonii Bell. T. 101.

Bromii Michelotti. Sa. :351.

urressina (Broce) A. 2.3.

chenns Lamk. A. 253. \&. 318. S2. $351 . \mathrm{V}$. "Vir. plicatula. 1. 253. V.

Ellicasta n. $810^{\circ}$ A. 25:3.

fusiformi: (Broce.) A. 283.

lutesens Lamk. A. 25:3. S. 318. Sa. 351. V. minima n. sp. 'I'. 191.- 'lav. XI. lig 4.

obsoleta (Broce.) 1. 253.

jyramidella (Broce.) T. 101. 1. 253.

recticosta Bell. 'T'. 101.

Sivignyi Payx. A. 253. V.

scrobiculatı (Broce.) 'T. 101.

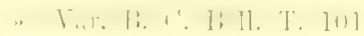

$» \gg$ Sa. 3ri.

striatinla (Broce) T. 101. A. 253.

"Var. 1. 13ell. 'T. 101.

trienlor (Gm.) A. 253. L. 318. Sa. 3is. T.

Modinla Lamarck.

alvintica Lamk. \%. 187. V.

barbata (Lin.) S. 32:3. Sa. 360. V.

molinlus (Lin.) Sa. $300 . \mathrm{V}$.

phaseolina. Phil. A. 284. S. 323. Sa. 360. V.

Moliolinin Beck.

costulata lisso. 1. 2*4t. V.

disenrs (Lin.) A. 281 . Sa. $: 600 . \mathrm{V}$.

mamorata Forlies. Sa. :36u. V.

subelavat libassi $A .281 . V$.

Montacuta furton.

bidentata (Montes) \&. 332.2. Sit. $360 . \mathrm{V}$.

ferruginowir (Hontg.) A. 28\%. V.

sulustriata (Monte.) 1. 252. Sa. $360, \mathrm{~V}$.

Montlivanltia Lamonum.

carearusis Miehelotti. T'o, 41.

Murex Limnen.

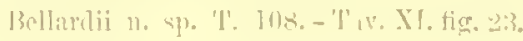

MI nex I,inner.

Ibainvillei (Payo) 1. 20?. V.

Trandaris Limu. \$. 31!9. Sa. 353. V.

Brocelii Monterns. A. $26 \%$ V.

corallinus Seace. 1. 262 sa. 35:3. V.

craliculatus (Broce.) '1'. 1 ns.

rristatns Broce. A. 262. S. 319.

Dertonensis Mtayer. T. 108.

Eilwardsii (1'ayr.) A. 262. \$. 319. Sa.353. V.

crimacens Lin. A. 262. S. 319. Sa. 3533. V.

funiculnsus Bors. T. 108.

Hocrusii U'Anconn. A. $2,2$.

lamellusus. (Jan.) A. $262 . \mathrm{V}$.

rudis Bors. T. 108. A. $26 \%$.

scalarioiles de Blainv. A. 262. V.

scaliuris Buce. A. $26 \%$

Fismotrlae Bell. Ar. 5u.

'T'tplyaronii Bell. '1'. los'.

torulıxitu Jannk. 'T. 108. A. 262.

trunculus Lili.. S. 319. Sil. 353. V.

sp)? Ar. 50 .

Ityliobates Dumeril. michrohizus Delfurtrie E. 73.

Myristica Swainson.

colnuta (Agis:- A 50.

Nytilu; Linneo.

fuscus Hoern. Ay. 5).

gallomorineialis Lamk. A. 285. S. 323. Sa. :360. V.

ohlitus Michlotti. A. 28 \%.

Nassa Lamarck.

angulata? (Broce.) A. 261.

asperata Cocc. A. 261.

Brocehii Mayer. T. 106. 1. 260.

clathrata (Broce.) A. 201.

conic i 11.81 . A. 261 .

comiculum (olivi) A. 260. V.

erenaticosta n. sp. T. 106. - T'uv. XI. fig. 21.

(uvieri (I'ayr.) A. 260. S. 318. Sa. 353. V.

»Var. simplex 12. 1. 260.

grimularis Bors. T. 10i.

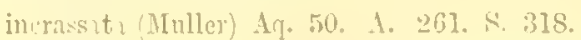
Sir. 35:3.

limata (Chemm.) 1. 260. \$. 31s. \$a. 353. V. musiva (Broce) 1. 260). ¿. 318. Sa. 3533.

mutabilis (Liu.) A. 260. Sa. 353. V.

obliquat: (Broce. 1. 260.

prismatica (Broce.) A\%. 50. 1'. 106. s. :318.

jumila n. s1\%. 1. 261.

pusill. (1'ltil.) A. 261. S. 318.

jygunten (Latuk.) 353. V. 
Nizssi Lanumek.

re orata? Inmterus. A. 251, V.

reticulat, (Lin!. A. 200. Sir. 35.3. I.

sumistriat a (Broce) T. 106. A. 200. S. 318. V. serraticustar Bromn.) T. 100 .

sprusulosi (I'hil.) 1. 201.

"Vir. spirata n. 1. 26il.

turbinellir (Broce) T. 106.

turbinelluiles 3. sp. A. 260.-Tav. AVT. tis. 23.

Natica Arianson.

auropunctat.r Menegh. 1'. 111.

catena I)، Custia. 1. 261. V.

compressa? Bast. A\%. 51.

crasia Njst. 'I? 111.

Dillwynii Payr. I. 59. T. 111. V.

elongata? Michelotti. Aq. 51.

flammulata Rey. A. 261. Sa. 35j. V.

fusea De Blaint. I.? 59. T'. 111. A. 264. S. 319.

Si. 3.) . V.

Guillemini Payr. A. 201\% Siro 351. V

Hebraea (Martyn.) Sa. :351. V.

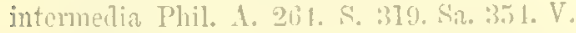

intricata Donoy. 1. 261. S. 319. Sa. 334. V.

Josephina (Rissu) L. 5!). 1. 20 1. Sa. 3.4. V.

macil nta Phil. A. 261. Sa. 351. V.

maculata Desh. A. $261 . \mathrm{V}$.

millepuctata Lamk. Aq.? 51. T. 111. 1. 261.

$$
\text { s. 319. Sa. 351. V. }
$$

» Tar, uninor. n. 'T. 111.

minor. n. sp. T. 111.

Montacuti Forbes. 1. 261. S. 3I!) Sa. 35.t. V. orimtalis, (rmel. Sa. $351 . \mathrm{K}$.

Mlocenica seg. T. 111. A. 2obt.

plobrema n. sp. T. 111. Tar. XI. :30.

porcellana Ivorls. Sa. 3.st. V.

jseuto-epigluttina sism. T. 111. A. 261.

redempta Hichsolti. '1. 111.

Sismondiana? Dour. .1. ol.

tigrina Definnce $A$.

Neacra Gray.

custellata (Desh.) A. 2\%. Y.

crispata (reace) T. 118. 1. 278.

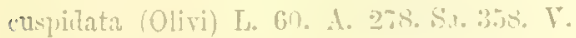

lameilinsa M. Sars. 1. 3\%. V.

whesa loven. A. 2\%: V.

Philippii sea. A. 2is.

rostrata (spenel.) A. 2-is. V.

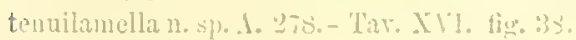

Neilo II. et A. diams.

dilintatus (1hil.) A. 281.

excistn (l)hil. 1. 20st. L.
Nentunnaliten. cutraria Lin, 1, 263. l

Nerita lambrik. virilis Lin. Sa. 350 t. Y

Niso likino.

churiea liks. I.? 5\%. T. 1I2.

Noulosaria I)Orbieny.

acul ata i) (Orh, I: I"'i.

acutechtata Silvestri. I, bis.

anomala fienss. I. 63.

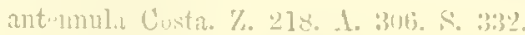

asp ria silvestri. 'T. 1:36. \%. 2ys.

conic sily, \%, 218. A. 301.

fnsifurmis vilt. \%. 218.

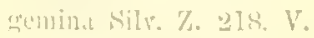

slabra D"()rl. A. 206. V.

hispita I) Orts. \%, 218. 1. 306. T

in ertil silt. 'L. 2218.

inturruptia Silv. \%. 2ls.

itregularis D'0.l]. 'T. $1: 36$.

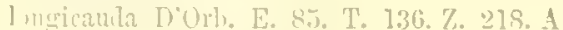
$306, \times 332,81,3 \div 1,5$.

$"$ Var. imperfecte-eustatia.

$» »$ sily. Z. 21\%. Y.

longiscata DOrls. Z. 2.18. . 1. :314. Y.

marginuluirles silv. E. 89 .

Mariac I) (Urb. '/s, 218.

munilis silvestri. Z. 218 . T.

» Var. Inerigata silv. \%. 218.

"vieula !)"(1)t). \%. 21s. I.

mpillusa silv. \%. 21s. 1. :3.6.

perfurata n. sp. s. 332. Tav. Xvll. fig. :37. proxima silk. T', 132. \%. 21s.

fun Lars. 'T'. lïr.

pupuiles silv, Z. 219

"Var. custatat n. \%. 2210

rmlieula (lin.) $\%$. 2.13. S. 33:2\%. V.

raphanistrmn (hin.) I. 63. L. S4. 'T. 136.

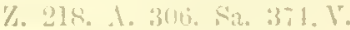

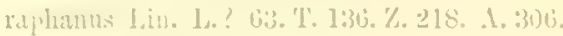
$\therefore \therefore .1$

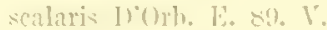

simplex sils. '\%. '21s.

subaequalis Costia. Z. 2218. A. 306. S. 332.

subtertenuata sichwager. '/a. 218,

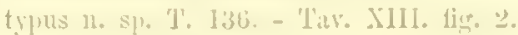

Nonionina lonbigny.

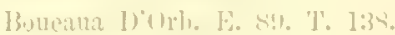

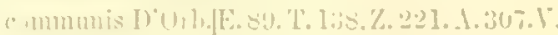

fals Cri\%, 'T'. l:3

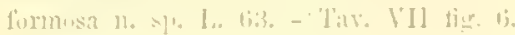


Nonionina Dorluigny.

mranusa [) Orb. L. 6)3. 1 .

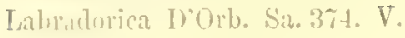

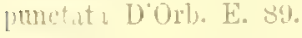

quatrilobi n. sp). 'Tay. XYII. fig. 15 ().

sapha (Fich, e M[o]l., L. 6:3. Z. 22.2. V.

Sulranii Do(1). E. 89. T'. 135. 7. 222. A.

307. \$. 33.2. \$่า.:374.

sulucarinatil Seg. S. 332 .

umbilienta Doorb. T. 138. V.

umbilicatula (MIonts.) Z.222. A. 302. S. 332. V.

Ynbecularia Defrnee.

papill. -a11.sp.E. 9 ะ. T. 152.Z.230-Tav.X.fig.6.

Nucinellis. Troot.

clabra Neg. 'T. 121.

nvalis (S. Wornd.) d. 283.

Nu $\operatorname{cula}$ Tamarck.

Intuniminensis Seg. To. 11. - Tav. IV. fig. 5. corbuloites Ser. A. 24\%. V.

confusa n. sp. A. $28 \%$ - Tav. XVI. fig. 43.

deciriens Phil. A. $28 \%$.

"Var. aeceensis Forbes. S. 323. Sa. 360. V.

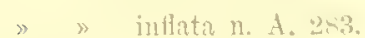

delphinnitonte Migh. A. 283. V.

clabra Phil e var. clati Seg. A. 283.

inflat. \%. sp. A. 283. Tav. XVI fig. 41.

Maveri Hoern. T. 1:1.

nitila Sow. A. 28:3. S. 3233. Sib. $360 . \mathrm{V}$.

nucleus Lin.) T. 121. 1.2833. S.323. Sa. 360. V.

Plicentin Lamk. A. 283. S. 323.

sulenta, Brunn. A. 28:3. S. 323. Sa. $360 . \mathrm{V}$.

triguna Sex. A. 283.

nmbonata Seg. 1. 283.

sp.? I. 61.

Num mulites Is unarek.

romplanata Lomk. P. 22.

curvispira Menegh. Li. 29.

Giransensis Joly. e Lem. To. 45.

mranosi n. sp). T. 139.

Gnettarii D'Arehiac. Li. 29.

intermelia d'Arch. To. 45.

Molli D'Areh. P. 22.

planuleti D'Orl). Li. 29. 30.

striatia T)(orb. I,i. :30.

T'rhibutehefli W'Arch. P. 2.?. varioluria? Sow. T'u. 45.

() dontaspis Amasi\%

dubia $A$ exs. Is. 73. 'T'. 13.

sp.? A. 217.

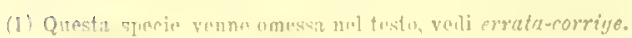

Odostomia Hleming. anta Jefir. T. 113, \&. 319, Sa, 3\%, V. amgulata 11. sp. T. 11\%. - Tav. XI. fig 38. confu*a n. sp. Sa. 35\%. - Tav. XVII. fig. 43. conoilen (Broce.) T. 113. 1. 265. S. 319. Sa. 35. V. - Tav. XI. fig. 53. clavula (Lorèn) A. 265. Sa. 355. V. laerissima n. sp. Si. 35ั. - Tar. XVII. 42. obliqua Alier. Sa. 355. V. pallita (Montor) A. 265. Sa. 355. V. planulata (Jฉท.) T. 113. plicata (Montg.) A. 265. Sa. 355. V. polita (Biv.) Sa. 355. V. rissoides Hanley. S. 319 . Sa. 355. V. "Var. rubia. Sa. 35... V.

Sismondae Seg. T. 113. A. 265. - Tar. XI. fig. 52.

striata Hoem. I'. 113.

suturalis (Bnnelli) A. 265.

thiara seg. A. 265.

nnilentata Jeffr. A. 265. V.

Venus n. sp. T. 113. - Tav. XI. fig. 39.

Warreni (Thompson) Sa. 355. V.

Oetobates Blainville.

Seguenziae R. Lawley. E. 73. - Tav. VII. fig. 11.

Oligntoma Bellardi. pannus (Bast.) T. 101.

O liva Brugnière. cyliniracea Bors. Aq. 50. T. 104.

Olivia Cantraine.

Tinei (Calcara) A. 270. S. 320. Sa. 356. V. Ommatocam $\mathrm{l}^{\text {, e Ehrenberg. }}$ trinacria stoln: Z. 231.

Oniscia Sowerby. Calabra n. s1\%. T. 10\% cithara (Broce) E. 73.

Operculina D'Orbigny. ammonoiles Gronovius. A. 307. V. camalifera? D'Arch. Li. 29. complanata (Bast.) To. 45. Ar. 56. L. 63. Orbitoicles D'Orbigny. dispansa (J. e C. Sow.) Li. 29. mlolulina? Michelutti. To. 45. Gumbelii n. sp. To. 45. - T'av. IV. fig.9. marginata Michelotti. T. 151.

Orbituli pora Stoliczka. uxcentrica n. s1. T. 130. - Tav. XII. fig. 22.2. Orbulina Dorbigny. niversa Doth. L. C4. E. 91. 'T. 1.8. \%. =2- 4. A. 308. ง. 334. Sa. 376. V. 
(j) streil Limen.

acuticostata 11, sp. E. F\%, T, 122.2. - Tav. XII. fig. 2.

Arnitanica Maser. Z. 190.

Boblay Desl. Aq. 53. I. 61. E. 76. 7. 189.

Brongniartii Montagna. To. 41.

cataplasma Hayer: Z. 1s9.

cochlear Poli. 7. 189. 1. 284. S. 323. Sa. $331 . V$.

(ymusii Payp. S. 323. Sa. 361. V.

digitalina Dubois. T. 122.

cululis. Lin. Z. 189. S. $3 \geq 2$. Sa. $361 . V$.

Lamarckii Mayer. Z. 189.

lamelinsa Broce. Z. 18:\%. A. 286.

laticurdinis Ser. A. 286.

minima 11. sp. Z. 189.

navicularis Broce. E. 76. 'I'. 122. Z. 189.

1. 280.

neglecta Michel. T. 12.2.

platicarelinis no spe. 1. 286 .

plicata Chemm. Ac.? 53. Z. 189. V.

plicatula Gmel. I. $76 . \mathrm{V}$.

tenuiplicata 11. sp. Aq. 53. L. 61. E. 76. T.

123. Z. 190, A. 286. - Tav. XII. fig. 1.

sp. ? L. 61.

Ovula Bruguière.

sprelta (Lin.) A. 25:. T.

Oxyrhina Agrassiz.

crassa .1g. To. 40. E. 7․․

Devorii 1g. To. 10. A1. 49. 1. 247.

hastalis Ag. E. \%2. Z. 15i.

trisonston $\mathrm{Ag}$. E. 72 .

tmmitula Costa. E. i-

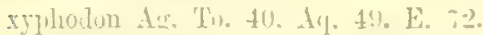

Pachrlasma Darwin.

giganteum (Phil. Z. 195. 1. 202. S. : ' Sa. 366. V.

Pagrus C'uvier.

sp.? 'T. 100 .

Palooodelplis Tan Beneden. ininutus In IBus. E. F.

Panidora Solanitur. inaeyuivalvis (Lin.) Sa. :3.,8. V

Panopara Menarl. Menarili Desh. Aq. 52.

Paracyathus Eriwarts et Haime. striatns (Plil., 1. 301. V.

Paracyuris G. O. Sars. polita (i. O. Sars. Var. Unbia. n. Sa. 3łil. V".

Paraloxnstoma fis her. arcuatum Braly. A. 202, V.
Pardorostoma Fischer.

cniforme Braly. 1. 292 . Y »Var. tenuc n. Sa. stifi.

hithernicum.? Brady. S. 326. V.

l'atella Limmen.

asper. Lamk. Sa. 3\%). V.

coerulea Lamk. \%. 186. 1. 2\%4. Sa. 35\%. V.

lusitanica Gmel. 1, 271. V.

Patinella Gray.

Manzonii n. \$1. 7. 213. - Tav. XY. fig. 26.

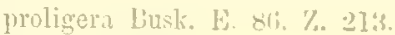

l'eeten Bruguitre.

Bruei Payr. A. 285. Sia, :3ti1. V.

commutatus II unter, A. 28\%. S. 33-23. Sa. 361, V.

demmlatus lienss, T. I-y.2. \%, lis.

elegans? Andr. 'I'. 1\%2. 13\%.

Hexuosus Poli. Z. 1ns. 1. 2s.s. s.a. 361. V.

Ifoskynsii lorbes. A. $285 . \mathrm{V}$.

intlexus ( Poli) 7.185. 1.285.5. 32:3. Sa.36'1. V.

latissimns Broec. 'T. 12.2. \%. 188.

Nalvinae Dub. T', l:32.

miocenicus Mieholotti. 'I'o. \&1.

multistriatus (Poli) Z. 15\%. A. 28\%. \$. 3233.

Sil. $360, \mathrm{Y}$.

ollitus Michelotti. To. 41.

operenlaris (Lin.) Z. 16\%. A. 235. S. 323. viz. $340 . V$.

»Var. singuinet. Sa. 330\%. V.

pesfelis (Lin.) \%. 188. A. 28\%. S. 332\%. Sa. 360. Y. sia.:360. V.

jeslutrae (Lin.) A. 250. ^. 32:3. Sa. 361. V. Pammulini Montagua. 'J'o. 41. - Tav. IS. fig.3. "Var. dilatata n. To. 11.

Reussii Hnern. T. Iski.

scalmellus Lamk. Ar. 5.3. E. T.1. T. 12.3. Z.

$18 \%$. 1. $25 \%$.

septemradiatus MIuller. 'T. 1\%l\%, I.

similis Iaskey. H. 71. 'T. 122. Z. 18S. A.

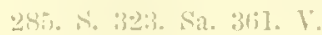

simplex Alichelotti. To. H. - Tar. IV. fig. A. solitrium Jamk. At?. 5:3.

spinulosus พ. Munst. T. 1?2.

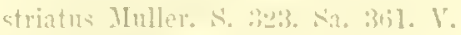

subaser ILontagna. 'T'o, 4l.

subsinulosu; $11.89 \%$ \%. 18\%.

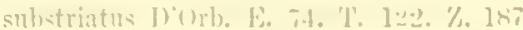

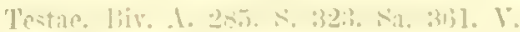

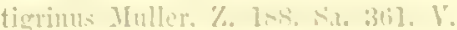

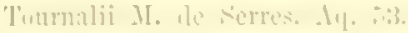

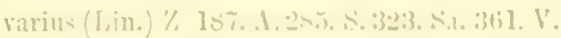

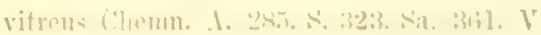


Poctunculus I Imarek.

himaculatu* (Poli) 1. 282. \$. 32.3. . . . 360. V.

Fichtelii Thil. H. It.

intlitus? (Broce.) Is. bu.

insuljricus (broce) Ar. 52. 'T. 121. A. 282.

obtusatus Partsk. Ac. 52.

filosis (Lin.) A. 252. Sin. $360 . \mathrm{V}$.

stellatui (Gmel.) Aq. 52. I, 60. E. 74. T

$1 \div 1 . \therefore: \because \%$

vinlacescens I amnk, 1. 242. S. 3233. Sa. 360. V

Peneroplis Montiort.

pertusus Forskal. Sa. 3\%

Pentarerin us Miller.

(iastalki Micholotti. Tis, 44.

Periaster v'orloweng.

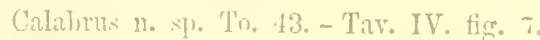

Capellinii Lambe. 'Tr. 13.

Periclany lium Ehrenliere.

lilitatum n. s1. Z. $23 \%$.

itruentare n. sp. \%. 233.

Peringielia Muntemato.

viclosseriana (Jirts.) A. 200\% V.

Perna Bruguière.

Solitanii I)eshayes. Z. $18 \%$.

Petricola curier.

subcarinata 11. sy). 1. $27 \%$.

Plasianella lamark.

intemerlia scarc. Sa. 356. T.

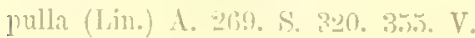

tennis Miclank. 1. $299.8 .320 .355 . \mathrm{V}$.

Pliasianema Woml.

cinctum n. $81 \%$ A. 264.

costatum (13roce.) A. $209 . \mathrm{V}$.

» Vax. patulum e minutum. 1. 209?. V.

Pli iline Ismanias.

catena Monter. Sin 3.1]. V.

involrens n. s\}. 1. 249.

Iruveni Nalm. A. 24!?. V.

junetata (Clath.) A. 2219. V.

gruatrata S. Wonl. A. $249 . \mathrm{V}$.

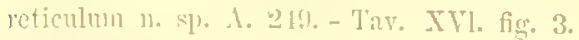

scabria (MIuller) A. 245. Sa. :35]. V

Plins Mnntfort.

molygonns. (Broce.) I. 5.). 'J'. 104.

l'inna Timmin.

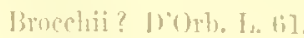

denulata n. sp. Aq. 5.2. - J'av. V. fig. I.

infundibulum n. s1). A . 5*. - Tax. IV. fig. I4.

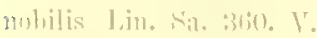

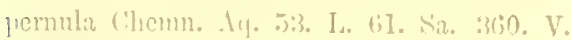

tetragentil broce. Ir. sis.
Pisinut Monterusato.

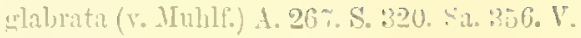

Placopsilina I'Orbigny. cenumana To()rb. To, 45.

I'lanispirina no gen. (ariuata 3. s1. A. 310. - Tav. XVII. 1ig. 19. commxnis 11. sp. A. 310. - Tav. XVII. tig. I8.

'lanorbis Gnettant.

sp.? Tn. 11\%.

I'lanurbulina D'Orbigny. mentitermensis Dort. F. 91. T. 150. S. 3:34. V.

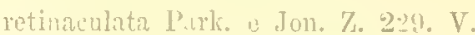

Planularia Deframee.

angustata (Costa) T. 111. Z. 2021.

anris I lefrance. 'T. 141. \%. 224. V.

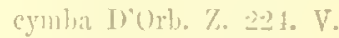

falcata 11. sp. T. 111. \%. 2-3. - Tav. XIII. fig. 1\%. lancenlata (D'()rb.) Z. 221.

hevis n. s1). 'I'. 141. - Tav. XIII. fig. 16 .

fungiusenlit (Costa) 7.234 .

rustrata 100rb. \%. פot.

semiluma (D'()ris.) T. 111. Z. 2.)4.

simili= (Costa) Z. 224 .

simplex 11 . sp. Z. 202.2.

sublialcata (Costa \%. 221.

tropica (Costa) 7. 221.

Planulifua Dorbiony.

ariminensis Dorl. E. 4) . T. 154, \%, 200

1. $30 \div$. S. 33 \%. T.

Platilia Costa. anomiviles (sicacelii) Z. 190). V.

P'lecanium Re'uss. ablorevintum (I)Orl," Z. 65. F. 1.2. T. 152. \%. $22.9 .1 .309 . \mathrm{T}$.

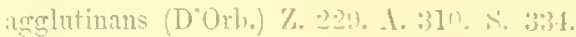
S.1. 37,6 . T.

acumi!natum ท. sp. 1.. 92. T. 151,- Tav. X. fiæ. 5. ncutum? (Iieuss.) H. 9-2. T. 151.

Brut niamm I'Orh. 'T. 151 .

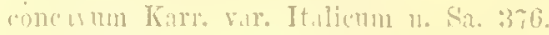
rost.ıtum 3. sp. T. 151. - Tar. XIV. fig. S. cumatum 13. sp. T. 151. - Tav. X. fic. 5.

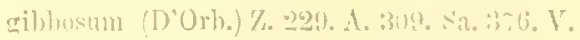

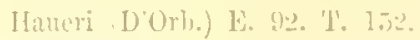

imeculare 11. sp. T'. 151. 1. 310. '"as. XIV. fig. :

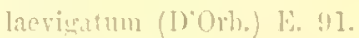

Mariae (1) ( $0 \%$ m.) A. 310 .

» Vill. imprume lienes, I , (6).

ball (l'zi\%) .1. $300 \%$

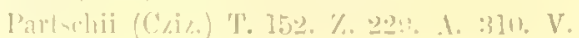


Plecanim Renss.

Mggmacum D'Orb. S. 334. T.

rotundatum (Costa) A. 310 .

rugosum? Renss. T. 15?.

saggittula (Defr.) E. 92. T'. 151. 2. 229. 1. 310.

S. 334. Sa. 376. V.

Sinyeri? Reuss" 1'. 152.

spinulosum Peus'. 1. :309.

subacutum n. sp. Z. 22:3.

subangulatum D'Orb. E. 92. T. 15\%. 1. 309.

trochus (Lin.) E. 92. S., 3\%6, V.

tuberifurme 11. s1\%. T. 152. A. 309. - Tar. XIV. tig. 9.

Pleuronecti s Swainson.

cristata (Bruce) L. 6 . E. 76. T. 12.2. A. 285. lifformis Sec. 1. 285. - Tas. XVI. fig. 45.

inorlecim-lamellata (Broun) 1. 285.

fenestrata (Furb.) L. 76 1. 122. Z. 189. A. 285.

S. 32:3. $\mathrm{Y}$.

Plenrostomella.

Costae 12. $51 . \% .226$.

cylintracea n. \$1). Z. 22:6.

intlata n. sp. \%. 22\%.

"Var. oblonga. \%. 227.

involiens n. s!n. Z. $22 \%$.

"Var. clongata n. Z. $22 \%$.

$\gg \gg$ inflita n. Z. $22 \%$.

noclosaria n. sp. Z. 2206.

ubtusi n. sp. A. 30\%

Plenrotoma Lamarck.

coutigur Broce. T. 102.

»Vir. granosa n. T. 102.

" "lamellosa n. T. 102.

coronata Munster. T. 102.

rotata (Broce) A. 25.

turricula (Broces) T. 102.

Pleurotomaria Defiance. nengenita n. sp. To. 40. - Tar. I1. fig. 1.

Plicatula Lamarck. mytilina Phil. Z. 189. 1. 286. S. 32ְ̣:3.

Polli Gray.

Bellarili n. slı. T. 10\%.

bicolor Cantraiue. A 291. S. 319. V.

D'Orbigny (Payr) A. 261. S. 319. Sa. 35:3. V.

fusulus (Bruce) A. 261.

plicata (Broce.) A. 26 l.

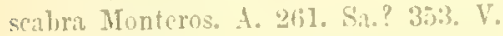

Sparlae (Libassi) A. $262 . \mathrm{V}$.

Polymorphina Dorlyigng.

aruta D०Orlo. 'T. 1 1\%.

in. glualis Dorb. I\%. $\%$.
Polymorplina Dorbigny.

amygitaloides Teryuem. 1. 30\%. \$. :33:3.

angusta Reuss, \%o. 2206.

anceps? Phil. F. 90.

austriace (D'Orl..) L. 6 !. T. 145.

commu is (DOrl). E. 90. 'T.145.Z.225.1.30\% .

s. $33: 3.3$. Sa. 375. V.

complanata D'Orb. T. 145. S. 333. Sil. 375.

compress. DOrb. Z. 22. . 1. 307. \$. 333.

Si. 3\%5. V.

costita Eigier. 'T. 140 .

cyliudrica Born. '1'. 1.15.

depauperata Reuss. T. I 16 .

digit.lis D'Orl. L. 63.

dimorjha Burıs. '1'. 145.

discreta lieus: T. 145.

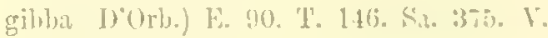

gutta I)(Orl. Z. 225. A. :307. S. 3333. V.

inuegualis Reuss. T. 146. Z. 225.

involvens $11.81 \%$ \%. 2.26.

lacter (Woilch.) 'T', 146. S. 3333. Sa. 375. I.

lanceolnta lieuss. T'. 145.

lata Bom. T. 146.

leprosa Reuss. 'I'. 116.

noxlusaria Renss. 'T. 115.

oblunga Will. Z. 22.25. A. 307. S. :3333. V.

obtusia B.rit. 'T' $1+6$.

oratil r'Orb. F. 90. T. 145.

problema (D'Orb.) F. 90. '1. 145. A. 30\%.

Sia. 3\%. V.

punctita (D'Orb.) E. 90. T. 146.

rugesa D'Orl.) T'. 146.

Sollanii D'Orb. 'Z. 2206.

suroria Reuss. 'l. 145.

spinosia (D'Orb.) T' 140.

tenera Karr. 'T. 145.

tuberculutia 'J0'Orb.). 'I'. 146.

tubulosa (I) Orb.) T. 1.15. S. 33:3. V.

variata l'ark. e Jon. e Brady. '\%. y.2t.

Polystumella Dorbigny.

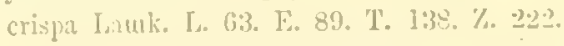

A. 30\%. S. :33:3. Sa. 37. Y.

Fichtelliana D'Orb. I. 63. '1. 1:38. А. $30 \%$

Sa. 37.1.

macella (Fich. e X[oll.) S. 333. V

minima 11. s1. S. 333. - Tav. XVII. tị. 35.

obtusa I)'(Orb. E. 8!.

rugesa I) Orb. T'. 13:.

stritto-punctata (Fich. c M[nll.) S. :33:3.

Sil. sĩl. b.

smbumbilicatal Crizck. L. $603 . \mathrm{s} .333 \%$. 
l'olytrema Blainville. rnbra Lamk. A. 309. V.

Poin a toceros Philippi. triquetroides (D. Chiric) Z. 196. V.

Pontocypris G. O. Sirs. compressi n. sp. Z. 191. - Tav. XIV. fig. 19. lactylus (Egger) A. 28\%.

lucida (Reuss) A. $28 \%$

mytiloiles (Norman) Z. 191. Sa. 361. V. »Vir. pliocenica. Z. 191.

saggittula 'Terquem. A. $28 \%$.

》Var. Calabra 11. S. 324. Sa. 36\%.

trigonella Sars. 1. 285. Sa. 362. V.

variulata n. sp. Sa. 36\%. - Tar. IVII. fig. 45.

Porites Lamarck.

incrustams. (Defr.) T. 135. e 15\%.

stratiformis 11. sp. T. $15 \%$

Poromy a Forbes.

granulata (Ajst. c West.) A. 278. V.

neaeroides. Seg. A. 278. V.

'ropilidium Furbes. ancyloiles (Forlies) S. 321. V.

Psammoli ia lamarck.

costulata 'Inuton A. 279. S. 321. Sa. 358. V.

ferruensis (Chemn.) S. $321 . \mathrm{Sa} .358 . \mathrm{V}$.

uniradista (Bruce.) E. 73.

respertina (Chemn.) A. ะ7๕. Sa. 3.8. V.

Psucadium Feuss.

ovatum 11. sp. T. 133. - Tav. XIII. fig. 8.

Pseurlotoma Bellarli.

inevis (Bell.) A. 25\%.

I's y gmo branchus P'hilippi,

firmus 1. sp. '. 126. A. 293. - Tav. XII. fig. 11.

protensus Auct. 'T. 195. 1. 293. S. 32\%. Sa. $36 \%$ V.

Pterocanium Ehrenberg. cliarybdeum Muller. Z. 233. V.

diceras n. sp. Z. 2.33.

l'ullenia Parlier e Jones.

bulloides (W0rb.) T. 138. A. :30\%.

cumpressa 11. sp. Z. .21. A. 30\%. S. 3320. Sa. 37. 'l'av. XVII. fig. 14.

sphoeruiles (D'Orlu.) s. 332. V.

l'ulvinulina Williamsun.

acutimargo (lieuss.) E. 90.

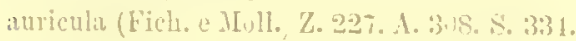
Sa. 3... V.

Buncana (I) (orb.) T. 117. \%。.220\%.

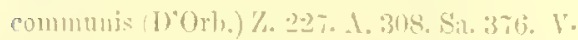
olemans 100rls.) 1. 30s. V.
Pulvimulina Williamon.

erinacea. Kart 'T. 147.

Fihlenbergensis ( $\mathrm{D}^{\circ} \mathrm{Or}$.). E. 90.

Karsteni (Reuss.) Z. 22\%. A. 308. Sa. 375. V.

Menardii (DOr\%.) 1. 14\%. Z. 22\% A. 308. sia. $3 i v . T$.

Mricheliniana (D’Orb.) A. 308. Sa. 375. V.

Partschiana (DOH.) L. 61. E. 90. T. 14\%. 7. 22\%. A. 308. Si. 375.

punctulata (D'Orlo.) S. :334. V.

relanda (Fich. e MI,11.) E. 90. T. 14\%. A. 308. Sa. 375. V.

scaphoidea (Reuss.) 'T' 14\%.

unlunata Reuss. 'T' 14\%.

Puncturella Lowe. noachiua (Lin.) A. 273. V.

Pnrpura Bruguière.

elata Blainv. L. 5!.

exilis Fart-h. T. 10!?.

hemastuma (Lin.) Sir. 354. V.

Pustulopora Blainville.

rlavaefurmis Busk. Z. 211. V.

clarata Bnsk. \%. 211.

clavula Reuss. F. 85. \%. 211.

deflexa (Cunch.) A. 2\%). Sa. V.

palnuata Busk. E. S5. Sa. 372.

probuscider (Juhnston) Z. 211 S. 320 . Sa. $3 ; \therefore 1$.

urubuscina Manz. 'T'. 132. Z.? 211. 1. 297. pulchella (Reuss.) F. 85. T. 132. Sa. 372. lugosa (D'Orb.) A. 29\%. Sa. 3\%2. V. rugulusa Manz. Z. 211.

suarsa Reuss. T. 132.

subcompressa Reuss. E. 85.

subverticillata Busk, A. 29\%.

I'yramiclella Lamarck.

minuscula Monter. A. 266. V.

plicosa Bronn. A. 266.

Pyrgulina A. Atams.

brevicula (Monter.) A. 265. S. 319. V.

curvicosta n. sp. 'T'. 113. - T'av. XI. fig. 36 .

decussata (MIontg.) T. 113. 1.

excavatia (Phil.) 1. 26.5. Sir. 351. V.

fenestrata (Forb.) 'l'. 113. A. 265. V.

furnosa n. sp. T' 11:3 - Tav. XI. 1ig. 37.

interstincta (Monte.) Sir. 354. r.

monozona (Brus.) sa. 3.j. I.

pyomaer (Grat.) '1'. 113. V.

scularis (Phil.) sit. 354. V.

L'yulat Ismatrek.

fancounitana Hont:r. Sal. 3353. V. 
Quinqueloculina Dơbions. agglutinns Dorb. Sa. 3\% Aknerina Dorb. E. 9.2. T. 153. asperula Sec. E. 92. T. 154.Z.230.1.311.S.335. balenensis Dorlo, I. fง̃. T. 151 . Boueana Dor?. T. 154.

Brongniartii D'Orb. Sa.371.V. Buchiana Dorb. F. 92. T. 153. bulloides $D^{\circ} \mathrm{Orb}$. S. $835 . \mathrm{V}$. concinna Reuss. T. 6.). F.? 92. T. 153. contorta Dorts. T. 151. costata D'Orb. S. 335. S2. 37\%. V. Tepressa DOrb. S. 335. Sa. 37\%. elegans D०OH. Sa. 3\% . V. Ferrussacii Dorb. S. 333. Sa. 377. V. focilir Reltss. T. 154.

Hailingeri D'Orb. T. 154.

Hanerina D'Orb. T. $15 \% 4$. incrassata Karl. Var. A. 311. inflata D’Orb. Sa. 3\%. irregularis Dorb. Sa. 3\%\%. V. Josephina N"Orb. E. 92. T. 154. .Tuleana Dorb. T. IJ4. latilorsata Reuss. I. 65. Iongirostra D'Grb. T. 153 . Incilla Karr. S. 335. lyria Dorls. S. 335. T. oblonga (Montg.) T. 153. Partslii DOOrb. T. 15\%. jlana D'Ori. S. 33\%. V. pulchella D'orb. S. 335. Sa.3\%\%. V. Schreibersii DOrb. E. 92. T. 154. seminulum Lin.) A. 311. Sa. 3\%\%: V. Skroekingeri Tarres. 'T. 15t. S. 33\%.

» Var. Calabrot T. 154.- Ta\%. XIV. fig. 13. subcarinata Dorb. S.2. 37\%. V. subrotumila (Montg.) Sik :37\%. V. tenuis Cziz. T. 15ั4. V. triangularis Dorb. T. 154. Z. 230. A. 311. S. 335. S.7. $37 \%$ V.

Ungeriana Dorb. E. 92. 1. 153. vulgaris Dorb. S. 335. Sa. 37\%. Y.

Rablocilaris Desmoulins. oxyrine Menegh. A. 299.

ritbiogonium. Russ. tricarinatum (Dorb.) 7. 218. V.

Radiopora Dorbigny.

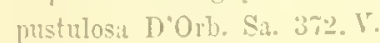

Ranclla. Lamarek. gigantea Lamk. 1. $26 \%$. S. 319. V. murcinata (Martin.) Aq. 50. 'I. los.
Ri ane lla Tamarck. tulberosi Bonel: A'. 5u.

Raphitomin Bell sudi. attentiata (Mont.) A. 25\%. S.t. 353. V. brach.stoma (Phil.) T. 104. A. 259. Sa. :isi.i. Y.

Jrevis 17. sp. T. 104. - Tav. XI. fig. 11. Columnir (Scacc.) A. 259. S. 318. Sa. 353. costulatia (Blainr.) Sa. 352. V.

echinata n. sp. 1. 2ป8, - T'เพ. XVI. fig. 22. larpula (Brocc.) A. 25.).

hatpul eformis n. sp. T'. 104. - Tav. XI. fig. 1‥

hispida Bell. 'T. 10 !.

hispirlula (Jan.' 104. 1. 25:9).

mesastomin (Brugn.) A. 259.

nevroplenra (Brugn.) A. 2.99.

nupesrima (Tiberi) \$. 259. V.

"Va\% subangulata n. A. 259.

plicatella $\left(J_{i:} \mathrm{n}_{*}\right)$ T. 104. $\mathrm{V}$.

sulumarginata (Bon.) A. 259.

sulertula (Bon.) A. 259. „Var. Calilira u. A. 259.

turgitic (Forbes) A. 25\%. V.

Ray a Limneo. aniliua Igassiz. 7. 185.

Reteunra Imjerato.

cellulnar Lin. F. 81. \%. 208. 1. 296. \$. 330. S..3\%I. V.

simplex Busk. Z. 20 s.

Rhizocrinus? G. O. Sars. *1.? \%. 216.

Rlynchonella Fischer. bipartitic (Biocc.) \%. 190. 1. 287. plicato-lentatia Costa. K. 76.

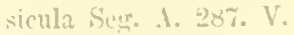

Rimu 1 a defrance. capuliformis 1'ecchioli. A. 27:3.

Ringienta Deshryes.

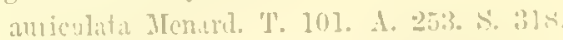
sil. 351.1 .

biplicata n. sp. A. 253. - Taw. XYT. fig. 13. "Var. elongata n. A. 253.

" inlata n. A. 2.-33.

buceine. (Broce.) Vitr. 1. $25 \%$

Calubra 31. sp. T. 101 - 'Ta\%. XI. tig. 3. * Tar. nruata n. 'T'. 101. conformis Monter. S.l. 35I. Y. leptochesila 13rugru. A. 2:3. I'. mareinata Desh. 'I'. IU1.

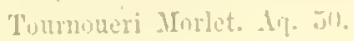


Rissos Frémensille (')

aurisealpium (Lin.) 4. 268. S. 319. F. costulati thler. A. 26s. Sia. 355. Y inconspicu Aler. S. 320. Sa. 355. V.

$\$$ Var. laevis Sı. 355. V.

oblongar Desm. A. 208. S.t. 355. V. monolonta Biv. Sa. 35J. V. Jurra Da Costa A. 26s. Sa. 35j. V pulchella Plit. 1. 265. Sa. 355. V. ymilla Plit. Sa. 35.5. T. raliata Phil. A. 2983. S. 320. Sa. 355. V. imilis Scace. A. 268. S. 320 . Sa. 355. V. simplex Phil. A. $=68$. S. 319. Sa. 355. V. mlentila Eichw. 1. 268. s. 320. sa. 35) V. V. ninltzeriana Sisn. A. 268. variabilis (v. Miullff.) A.263. S. 320. Sa. 356. V. ventricosa D.sm. 1. 268. Sa. 356. Y. violacea Desm. A. 268. Sa. 356. V.

Rissoina Dorloigny.

Brugnièri (Payr.) S. 319. Sa. 356. $\mathrm{V}$.

decussata (Monto.) 1. 267.

olsoleta Partsch. T'. 11:

pusilla (Broce.) 1. 26\%.

Rabertina D'orbigny. austriaca Renss. var. mutica n. T. 151.

Robulina D'Orbigny. areuato-striati Hantl. 'T. 142. ariminensis $\mathrm{D}^{\circ} \mathrm{Or} \mathrm{r}, \mathrm{T}, \mathrm{7} .2 \mathrm{2}-\mathrm{2} 5$.

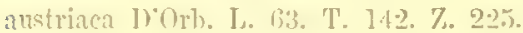
calcar. ((im.) T. 03. F. 90. T. 144. \%. 2.25. 1. $307.5 .3333 . \mathrm{V}$

$\triangle$ Var. lacera ef integra n. 1.145. 1..22\%. Nyopifommis Donrb. T. 143. \%. 22:\% V. confusa n. sp. T. 142. - Tav. XIII. fig. 21. mitrata T) Trl. T. 63. F. 90. T. 143. \%. 225.

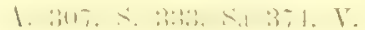
curricosta n. sp. T. 144.-Tav. XIII. fig. 31. curvisepta 11. s1. 'T. 142. - Tav. Xill. fig. 20. currispira n. s\}. T. 114. - Tav. XII1. fig. 28.

》 Var. gibloa n. T, 14 .

depauperata lieuss. T. 112. 7. 225.

dil.ecta n. sp. c var. denulata T. 145. Tav. XII. fig. 333

》Var. compressa Z, 2.25.

Aubia n. sp. 'T'. 141. - 'Tay. XIII. fig. 30. rehinata 1$)^{\circ}(0)$, $T, 145 . \% .225$.

»Var. cervicosta n. e var. laovis. 11.

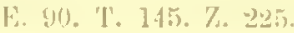

1) Le sumcip del Turtoniano appartengono e trovanci

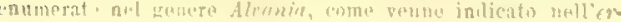
ratamenrige.
Robulina Dorkigny. festonati Costz A. 30 . formosissima n. sp. T. 145. - Tav. XIII. fig. 32. cravida n. sp. e Var. paucisepta, multisepta y discoidma. anormalis. 'T. 142. - Tav. XIII. fic. 23.

Helenac Karrer Var. Italica. n. Z. 225. imperaturia $D^{\circ} 0$ rb. L. 63. E. 90 . T. 143. 7. 225. inornata $D^{\circ}$ Orb. Ar.? 56. L. 63. E. 90. T'. 142.

$$
\text { 7. 225. 1. } 30 \% \text {. }
$$

intermedia E'Orb. F. 90.

limbata Bur. T. 142.

limhosa Renss. T. 143.

lucila n. sp. T. 14\%. Tav. XIII. fig. 19.

nitida Penss. F. . 00.

obtus I Renss. F. 90.

olfusimargo $\%$. sp. T. 14\%.-Tar. XIII. fig. $2 \%$. ornat 2 DOr7\%. F. 90. 7. 225. V.

" Var. ineertia et cincta n. T. 144.

princels Burn. T. 14 t.

ralliata Borı. T. 143. 7. 225.

ristrata n. sp. T. 113. - Tav. XIII. fig. 24. rotulata (Lamk.) L. 63. E. 90. Z. 225. A. $\therefore 1^{\circ}$. $\therefore$ : : :

"Var. pliocenica. \%. 225. Sa. 374.

semiimpressa Renss. T. 142.

serpens n. sp. T. 143. \%.225.-Tav. XIII. fig. 25.

similis Dort). E. 90, T. 143. \%. 225. A. 30\% simplex D'Orb. T. 142. Z. 225. A. $30 \%$

》Var. paucisepta Z. 225.

simplicissima n.sp. 'T. 141.-Taץ. XIII. fig. 18. stellata n. sp.'1'. 144. Z. 2-26.-Tav. IIII. fig. 29. striolata Cziz. var. F. 90.

subangulata Reuss. E. 90. T. 142.

tenuis n. sp. '1'. 143. 7.225. - Tav. XIII. fig. 26. vitrea n. sp. T. 144. - Tav. XIII. fig. 27.

rortex (Fich. e Moll.) L. 63. E. 90. T. 143. Z. 2.25. A. 30\%. Sa, 374. V.

"Var. laminifera n. T. 143.

liotalia Lamarels.

aculeata IOHl. var. L. 64 .

ammoniformis (DOrb.) T. 147. \%. 22.8. S. 334. Sal. $336 . \mathrm{V}$.

Becearii (Lim.) I. 61. F. 90. \%. 2.28. A. 308. S. 33 1. Sa. 376. V.

Broechiana? Karr. T. 148.

conoidea Cziz. T. 148.

Erita Reus?. T. 11\%.

inflata (Seg.) 'T. 147.

lobata n. sp. T. 115. - Tav. XlIl. fig. :34.

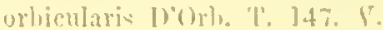


Rotalia Lamanck.

maecincta Kar1. 1q. 56. I. (4. F. 90. T. 14\%. punctato-granosa II. s]?. 'L'. 14\%. - Tar. XIII. กin. 37.

simplex (D)(t).) T. 11\%

Solitanii LOrl. E. 90. T. 148. 7. 2.28. A. 308. S. 331. V.

tenuimargo Reuss. L. fit.

Sulicornaria Curier.

farciminoirles John. E. 79. T. 12\%. '2.196. A.291.

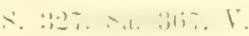

mammillatic n. sp. A. 294. - Tav. XVII. fig. 5.

Saxicara Fleuriau.

Norvergica? (Spengler) \%. 186. V.

rugoa (Lin.) Var. aretica (Lin.) A. :- :

321. Sa. $35 \%$. T.

scacchia Philippi.

exigua Brugn. Sa. 340 .

Sealinia I, marek.

Aspromontana n. sp. \%. 18i. - Tar. XIV. fig. ?4.

Bombieciana Coce. A. 260 .

Bronnii Seg. A. 26ti.

Cantrainei Weink. Sa. 3\%. V.

Coceni Seg. A. 266.

communis Tamk. A. 266. S. 319. Sa. 355. V.

»Var. Boveten is n. Sa. 3\%\%。

cormerata (Broce.) Var. Calabra n. A. 266. crenata Lin. A. 266. V.

filicosti n. sp. T. 115. - Tar. XI. fig. 13.

fromlicula S. Woul. A. $266 . \mathrm{V}$.

lamellos (Broce. Var. gracilis n, 7. 180.

Ianceolati (Broce) var. miocenica n. T. 111.

longissima Kien. A. 266 .

Mantovani n. sp. A. 267. - Tav. XVI. fig. 26. plicosa Phil. 1. 266.

pseudo-scalaris (Broce) 1. 266.

pulchella Bir. Z. 186. A. 266. V.

raricosta n. sp. T. 114. - Tav. XI. fig. 42.

retusi (Broce) Z. 186.

Rhegiensis 11. 51, 7. 186. - Tax. XIT. fig. 15.

rissoides. n. sp. T. 114. - Tar. XI. fis. 11.

Salicensis $\operatorname{Sec}$. A. $2(36)$

soluta Tiberi A. 266. Sa. "55\%. I:

sublamellosa Seg. A. 266 .

Trevelyana Leach. 'I'. 114. A. 266t. V.

Turtonae (Turton) Var, tenuicustati. Michanl.

7. 186. A. 266. Sa. 3ృ\%. V.

varicula Seg. 'T'. 114.

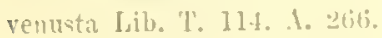

- Var. Seg. 1. elbl. sealpellum leach.

magnum D) avin. \%. I95 A.? :93.

Micheluttianum Seg. 1. 29:3.

Malinianum Seg. F. 78. T. 1:67.

Zancleaum sieg. 1. 2933.

Sicaphander Hontfurt.

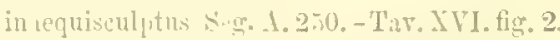

Jitreysii n. sp. 1. 250. - Tilv. XYI, fig. 1.

lignarius (Lin.) T. 100. A. 250. V.

sublign.ırius L'Orb. L. 59.

Schizaster Igussiz.

sp.? 'T'u. 14.

schizuphora lieuss.

Citlabro-sicula n. sp. \%. 2.29.

Scillate le pas Seguenza.

varimata (Phil.) 1. 20y3.

wruata Ses. 1. 293.

Scissurella I) Orbinis:

argutecosta n. \$1. A. 273. - Tav. XVI. fin. 30.

inpera Phil. 1. 272. V. - Tar. XVI. fig. 31.

rispata Flem.) 1.2,2. S. 3:0. Y.

osimia n. sp. 1. 22-2.- - lav. IVI. fige. 32.

t.misculptia n. sp. 1. 273. S.320.-Tar. XVI. fier, -2 ).

serupocellaria Vin. Beneden.

nliptica Renss. E. 79. \%. 156. A. 291.

scrupea Busk. S. 2\%ะ. Sa. 36\% V.

aprupusa (Lin.) Z. 1945. .1. 2991. \$. 327. S..366. I.

Scutell i Lamarck.

Paulensis der.ss. To. 12. - Tav. IV. tig. 11.

subrotumla Isunk. 'T'n. 42.

Scutulum MIonterusatu

tiussunii (). (i. Custa. 1. 219. Sa. 350. V.

Seuruen ia Jefireys.

monucinsulati (Sers: 1'. 111. A. 22\%. V.

》Var. elegans 11. A. 272.

selenaria Busk.

miocenica n. s1. '1'. 131. - Tav. XII. fig. 25.

Serpula I inneo.

articulati 11. sf. E. - A. - Tar. VIII. tig. 3.

asperir Phil. Sa. $36 \% \mathrm{~V}$.

cumpressa Quatrefige \%. 196. Sa. 36\%. V.

liscu-helix n. sp. L. is. - l'ar. VIII. tim. 5.

vermicularis Lit. \%. 196. 1. 294. V.

sp.? I. 61 .

sp.! 'I'. 12\%.

Setia H. e A. Mlams,

amabilis Munter. 1. 267. S. :3201). Sa. 35. ।

fulgrila (Adams) 1. 207.15

fuscia (I'l.) S.a. 3\%) 1 .

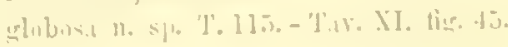


Sutia II 0 . Alitms

pulchrrim (Jetti.) 1. 2nit. V.

Silicula Jeftreys.

ovata Jefti. A. 281. V.

silic|uaria Bruguiere. anguima (Lil.) '1'. 115. Sa. 35\%. V.

siphonina Reus:

fimluriat \& Reuss. L. 65. T. 150. A. 309. S. 3334.

sipluonollentalium Sars.

intermedium (Copli) '1'. 118.

I fotense. II. Surs, d. 275. Sa. 35\%. V

t.tragonum (Broce.) T. 117. A. 275. S.321. V.

triquetrum (Broce) A. 275.

Stienea Fleming.

planorbis (Fabricius) A. 26\% V.

Solarium Lamark.

Alleryi Seg. A. 203. S. 319. V.

contertum Seg. 1. 263.

fallaciosum Tilueri. T. 110. A. 2033. Sa. 354. V.

Gallinae 11. sp. A. 263.

granuliferum Bronn. 'I'. 110.

millesranum Laml. 'T. 110.

semisquamosum Bronn. 'T'. 110. A. 263.

simplex Bromn. 'T. 110.

bolecutus Blaintille.

antiqnatus (Pult.) Sa. 35s. V.

cambilus Remier. A. 227-. Sa. 3-8. V.

strigilatus (Lin.) Ar. 32. 1. 278. Sa, 308. V sp.? L. 60.

Solen Linneo.

"usis Lin. Sa. 3os. V.

silinga I.in. 1. 278. V.

subfragilis? Eichw. 'T. 15\%.

ragina Lin. I. 118. V.

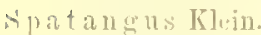

wrpurets I ske. Sa. 3753. V.

sp.? .1. 299.

Sipatipora lischer.

lasa 11. s!. T. 128. - Tay. XII. fig. $1 \%$

s'pheni a Turton.

cariuata 11. sp. d. 278. - Tav. XVI. fig. 37.

"Uyluerechinus Desort.

granularis (Lamk.) Sa. 3783. V.

splioeroll us Agassi\%.

annulatus Agass. Ay. 50.

vinetus Agmis. A. 2.17.

spluoeroidina borbieny.

anstriaca I) Orbigny I. 61. Fo S10. T'. 147. A. 308

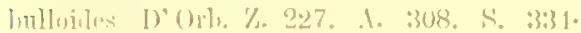
s.ง. $375 . \mathrm{V}$
Suirialis Fonlevet.

diversa Monterus. A. 22.5. \$. 321. V.

globulosa seg. A. 27i.

retropersa Fleming. S. 321. Sa. 35\%. V.

spirillina Junes.

punctata (lieuss) T. 150.

spiroloculina Dorluigny.

harienensis D'Orb. 'T. 152.

camaliculata I) Orb. T. 15:. A. 311. S. 33 t. V.

crassa n. sp. T. 152. - Tav. AIV. fig. 10.

dilatata D'Orb. 'T. 152.

excavata I)"(orl). T'. 15:- A. 311. S. 331.

limbata I'0rlo. A. 311. Sa. 376. V.

nitila 1)0r]. T. 152. S. 334. Sa. 376. V.

plamulata D*Orb. S. 331. Sa. 376. V.

rotunkata D)(Orb. S. 334. Sa. 376. V.

temuis Czizek. A. 311 . V.

Spiropora Lamouroux.

pulchella Rieuss. E. 85.

Spirorbis Lamarck.

communis Flem. Sa. 367. V.

cornu-arietis (Phil.) T'. 1.27. Sa. 367. V.

corugatus (IIontg.) S. 32\% V.

granulatus (Lin.). A. 2.)3. S. 32\%. Sa. 36\%.V.

laevis Quatref. A. 293. S. 327. Sa. 36\% V.

mantiloiles Jamki. A. 29!3. V.

obtectus n. sp. 'Г. 12\%. - Tax. XII. fig. 13.

Pagenstecheri Quatref. 7. 196. V.

plicatus n. \$p. Z. 196. 1. 293.

Spond y lus Lamarck.

crasicosta Iamk. E. 76. T. 122. \%. 189.

Deslayesii? Michelotti 5:3.

gaceleropus T. 122. Z.? 189. A. ¿80. S. 323. Sa. 3ri1. V.

Gusionii Scacc. A. 286. V.

spon eocyclia Hacelel.

circularis n. sp. Z. 233 .

s pongurus Haeckel.

cilintricus Elurenberg. Z. 2:3:3.

Steplianocyat li s seguenza.

elegans Seg. A. 301 .

»Var. sulsapinosus. A. 301 .

umbrella? Ponzi. A. 301.

Stephanophyllia Michelin. agraricoiles (lisso). 'I. 134.

elegans (Bronn.) 'T. 1:3\%.

śtiloplıora schwaiger. annulata Reuss. To, 14.

Stirechinus Jesmoulins.

precursur n. sp. Z. 21.

sillate (Desmonl.). 1. eng. 
strombus Linnow.

coronatus Defr. T. 10?. Sa. 354.

Strongylocentrotus Bromn. lividus (Lamk.) Sa. 373. V.

Sty la et is Ehrenberg.

triangulum Ehrenb. L. 333 .

surcula H. et. A. Ailame.

Timidiata (Brocc.) 'T. 102. 1.251.

»Var. minor n. A. 25t.

intermedir (Bronn). T. 10\%.

Isamarckii (Bell.). 'I'. 102.

Mercati (Bell.). T. 102.

Monostera zensis n. s!. A. 254. - Tav. XVI. li... 1 .

notulifera Phil. A. 2.44.

»Var. plicifura n. A. $25 \%$

» distinctr n. A. 251.

pomaer (Phil.) 1. 25t. - Tav. XVI. fig. I1.

» Var. Tittomis n. 1. 254.

$\gg$ unilormis 11. A. 254.

similis (Biv. f.) Sa. 3-2. V.

torquati (Phil.) A. 25. V. V.

Syndosmin Recluz.

alba (W. Wood) 1. 278. \$. 321. Sa. 358. V.

»Var. transversa. Sa. 3อง. V.

longricallis (Scacc.) A. 278. V.

ovatı? (Phil.). T. 118. V.

jrismatic. (Jontg.) 1.279. S. 321. Sa. 358. V. similis (Phil.) A. 279.

Tapes Megerle.

edulis (Chemn.) A. ำ9. Sa. 358. V.

lecussata (Ijin.) S.a. $358 . \mathrm{V}$.

vetula (Bist.) Aq. 52. T. 118.

Taranis Morck. cirrata (Brugn.) A. 262. V.

Tectura Aulouin.

unicolor Forbes. A. 274. Sa. 35\%. V.

Tellina Linneo.

compressa Brocc. Na. 35. V.

distorta Poli. S. :32.2. Sia. 359. V.

donacin $\mathrm{Lin}$. 1. 279. S. 322. Sa. 358. V.

elliptica Broce. L. 60.

exigua Poli. A. 279. V.

lineata (Montagna) To. 40.

nitila Poli. Sa. 358. V.

ovat., Broce. A. 27!

planata Lin. Aq. 5\%. T. 118. Sa. 3.5. V.

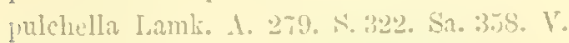
pusilla P'hil. 1. 279. S. 32-2. .4. $35 \%$ V. serrata Broce. 1. (io, T. 118. Sa, 3is. V. strigosa? (imel. Ay. : 2.
'L' cllin ia Linneo. tumila Broce. E. Fis.

Terebra Isimarel. acuminat: Bors. A\% : 0. 'I. 10\%.

Basteroti Nyst. Aq. 50. T. 10\%.

corruguta Lamk. var. Regina Desh. Sa. 353. V.

fuscati (Broce.) T. 10\%

pertusi Bast. T: 10\%.

》Var. crispata n. 1. 10\%

Scrabelli Dod. "T. 10\%.

'Terehratella D'Orbigny. septata (Phil.). A. $28 \%$.

Terebratula Lirgil.

Cilabra Seg. Z. 190.

Costae Seg. E. 7ti.

minor. Phil. A. 22: \$. 32t. S.. 361. V.

Philippii Seg. 7. 190.

Regnolii Menegh. A. 286.

Scillae Seg. A. 2286. S. 3ㄹ․

simunsa? (Broec). T. I233.

sphoenoitea Phil. 1. $28 \%$. V.

vitren (Born.). A. 287. S. 324. Sa 361. V.

Terebratulina Dorbigny.

caput-serpentis (Lin.). \%. 100. A. 28\% S. 324. Sa. 361. V.

granoso-radiata Seg. A. 28\%.

sinuesir n. sp. Z. 190.

'Terebripora D'Orbigny.

Archiaci Fiacher. E. 79. 'T'. 1\%- 7. 19\%.

Orbignyana Fischer. T. 1ะ8.

tenuis n. sp. T'. 128. - T'iv. XII. fig. 16.

T'eredo Iinnen.

sp.? Aq. 52. I. 60.

'Tetrapile J. Muller.

octnacanthum Mnll. '/. 2:31. V.

cfi. quadriloba Fhrenber. \%. 2031.

'l'extilaria Defrance.

marinata U)(brb. E. .1. 1. 1:1. I

» Vir. minns. L. li.,

granulat. (conta; S. :3:31.

palia (yis. T. 15u)

pectinatia la uss. 'T', 15\%.

Tharacia Ieach.

convexa (IV. Wuml.) 1. 20-s. s.a. 335. V.

corlunloiles Ihsh. 1. 278. .

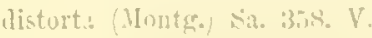

yapyrace a (l'oli) s. 321. S.. 3.5s. 1.

pubese ns l'ult. . 'T.? 11s. ... 35s. V.

Tindiaria li llareli.

onlita seco. 1. 284.10

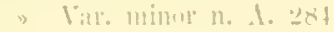


Tornatina A. Aitams.

Knocheri Smith. Sit. 351. V.

spirita (Brocc.). A. 2.2.

Tracliysm a Jettreys.

relicatum (Phil.' \$. 26?. V.

Tremato riscus Haeckel.

pliocenicus n. sp. Z. 233.

Triforis Deshayes.

adversa (Montg.) A. 263. V.

pervers. Lin.) T. 109. A.263.S. 319.Sa.351.V.

"Var, Benoitiana Aralas. 1. 263. \$. $31 \cap . V$.

Triloculina D'Orbiuny.

anceps Reuss. Var, intlata n. T. 153.

Anstriaca DOOrb. T. 15:3. 7. 230.

consobrina D'Orb. T. 153.

gibua D'Orb. T. 153. Sa. 376. V.

inilata Dorb. T. 15:3. S. 335. Sa. 3\%7. V.

inomatr Dorb. T. 15\%。

laevigati Dorb. Sa. :3 \%. V.

nitens lienss. T. 153.

oblonera Monte.) S. 335. Sa. 37\%. V.

pulchella Reuss. T. 153.

scapha D'0rb. T. 15\%3.

selene Karr. T'. 153. S. ? 3:35.

striarella n. sp. T. 153. - Tav. XIV. fig. 12.

tricarinata Dorb. S. 334. Sa. 3\%6. V.

trigonula Lamk. s. 3:34. Sa. 37\%. V.

Triton Lamarek.

appenninicum Sassi. T. 108. A. 262.

» Var. B. Bellardi. Aq. 51.

corrugatus Lamk. \$. 319. Sa. 353. V.

cutacens (Lin.) A. 262. V.

listurtus (Broce.) T. 108.

ficoides Reere. Sa. 353. V.

norliferns Lamk. A. 292. V.

nlearius (Lin). T. 108. V.

Parthenoreus 'v. Salis.) S. 319. Sa. 353. V.

Trivia Gray.

aflinis (Dujard.) A. 252.

europaea. (Montr.) A.25\%.s. 318. Sa. 351. V.

gibba n. sp. A. 252.

pmlex (Solander) A. 252. Sa. :351. V.

retusal (Sisw.) T. 101.

'Truchocyathus Elward et Haime.

Bellingerii? Eilw. et 1 . Aq. 56. L. 62.

T. 134 .

granulatus (Golde.) T. 131.

mitratus (Golif.) I. 6\%2. 'T. 131.

prismaticns n. $5 \%$. L. 62. - Tav. VII. fig. 3.

lyramiditus (Miclelotti) L. 62.
T'rochocyathus Eilward et Haims. Stilensis n. sp. Is (iz. - Tav. VIl. tig. 1. tintracselus 11. \$1). A. 301.

Trnehus Linneo.

Adnsonii Pnyr. A. 270. Sar. 356. V.

angulosus (Seg.). A. 2\%0. V.

bullatus Phil. A. 2-il.

rinctus Phil. A. 270.

"V Var. amabilis Jeffr. A. 270. V.

» depressus n. A. $2 \% 0$.

Cocehii D'Ancona. A. 271.

comulus I.in. 1. 271. S. 320 . Sa. $356 . \mathrm{V}$.

distinctus n. sp. A. 271. - Tav. XVI. fig. 28.

itubius Phil. A. 271. V.

elegantulus (Phil) S. 320 .

cxasperatus Pemm. A. 272. S. 320. Si. 356. V.

»Var. granulatus n. A. 272.

fanulum Gm. A. 270 . V.

gemmulatus Phil. A. 270. V.

Fermonii Payx. d. 2\%0. Sa 356. V.

granulatus Born. Sa. 356. V.

"Var, laevis Brugn. A. 2テl.

Gualterianus Phil. A. 271. S. $3 \geq 0$. Sa. 35h. V.

Guttulauri Plil. A. 궁. S. 320. Sa. :3.6. V.

laterisimus n. sp. A. วт0. - Tav. XVI. fir. $2 \%$.

Laugeri Payr. A. 271. Sa. 356. V.

magns Lin. 1. 270. S. 320. Sa. 356. V.

marginatus n. su. A. $2 \pi 1$.

"Var. crispatus n. dilatatus n. 1. 2il.

marginulatus Phil. 1. 270. V.

Michelottii n. sp. Aq. 51, L. 60.

millegrants Phil. A. 27 I. S. 320. Sa. 356. V.

Ottoi Phil. A. 271. S. 320. Sa. :356. V.

" var. major. n. 1. 271.

farvulus Plil. A. 2\%:.

patulus Brocc. A. 2\%0.

peregrinus (Lil).) T. 11\%. 1. 27(\%)

reticulatus (THil.) A. 270. V.

Richardii Payr. Sa. 356. V.

rotellaris Michelotti. F. 73. T'. 116.

Sayanus Seg. A. $2 \pi 1$.

》 Yar. striatulus n. A. 2. 1 .

scabrellus n. sp. T., 116.

"Var. semiomatus n. 'T'. 11 i.

sularioines Seg. A. 2-0.

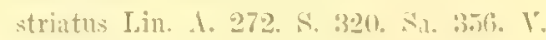

suturalis Phil. A. 207. V.

tumilulus . Irut. 1. 272. S: 3. 356. $V$.

turhinatus burn. 1. 2;0. 1 .

turbinoiles Dosh. 1. 2-il । 
Troehus Iinneo.

turgilulus Brocc. Au. 51. A. 272. S. 320. Sa. 3ั56. V.

nmbilicaris Lin. Sa. 35\% $6 . \mathrm{V}$.

midentatus Phil. A. 272. V

varius Lin. A. 270. Sa. 3\%6. V.

villicus Phil, A. 2\%0, V.

zizyphimus Lin. A. 271. S. 320. Sa. 356. V. 》Var. turbinnites Lank. A. 271. V.

'T'op hon Montfort.

Barvicensis Johnst. Sia. 35.3. V.

multilamellinsts (Plill.) 1. 262. Sa. 353. V.

"Var. elegans. n. A. 262.

muricatus (AIontg.) 1. 262. S. 319. Sa. 353. V.

squamulatus (Broce.) A. 262.

Faginatus (De Crist. e Jan.) 1.262. V.

Truncatulina Dorhigny.

aflinis (Cziz.) F. 91. T. 149. Z. 228. 1. 30\%.

Alneriana (1) Orb.) E. 91. T. 150.

Batenensis (D'Orb.) E. 91. T. 150. Z. 228. A. 309.

Birtensis (Cziz.) L. (11. E. 1). T. 149.

Boneana (D'Orb.) L. 64.

Brongniartii (D'Orb.) E. 91.

communis Roem. L. 6.4 .

Dutemplei (DOrb.) L. 64. E. 91. T. 1.19. \%. 2.28. A. :309. Sa. :376. V.

elegantissima n. sp. L. 91. - Tav. IX. Hg. 7.

formosa n. sp. T. 149. Z. 2.2S. A. 309. - Taw

XIV. fig.

Hailingeri (D०Otb.) E. 91. T. 149. Z. 228. V. helicina (Costa) 7. 225. 1. 309. Sa. 376. Kinteri n. sp. '1'. 150. - Tav. XIV. fig. 6. » Var. alepressiuscula n. T. 150.

limbata 11. s1. L. 61. - Tar. VII. fig. ว.

lobatula (Montg.) I. 61. E. 91. T. 150. \%. 228. A. :309. ล. 334. Sa. 37\%. V.

lncila lieuss, F. 91. T. 149. A. 30!1. marcinata n. s]. I, 64.'1.14!. - Tav.VII. fig.10. nuclenta 11. s]. T. 61. - Tav. VII. fig. 8. peraflinis (Costa) \%. 2.28. A. 3us.

propinqua (lieuss) L. 61. '1'. 1.19.

niemaca Hantk. 'I'. 149.

refulgens (1Iontf.) 7. 2.28. A. 309. S. 331. V. regularis Kar1. I. G4.

S'cheibersii (I) Orb.) L. G.t. T. I1!). 7. 22.28. V. spirata 11. sp. E. 91. T. 149. '1. 248. 1. 309. -

Tav. XIV. tis. 4.

\Var. eribba. Z. 2.23.

tulocrosa (Fich. c M[nll.) \%. 229. 1. "309. s.. 3:31. V.
Truncatulina J Orbigny.

Ungeriana (D'Orb.) E. 91. 'T. 149. Z. 228.

1. 309. S. 331. Sa. 37i, V.

variolata ( $0^{\circ}$ Orb.) L. (\$4. E. 91. 'T. 150. Z.

2.28. A. 309. V.

vortex ฉ. 517. E. 91. 'T. 150. Z. 228. - 'Г2V.

IX. fig. 8 .

Tubulipora Lamarck.

finsciculata n. . N1\%. Z. 2212. - 'T'av. XV. fig. 25.

Haluellaris Faljr. E. 85. Z. 212. 1. 29\%. . :330. Sia. 372. V.

foliace Reuss. E. s5. T. 132. Z. 211. Śa. 372..-

Tav. XY. fig. 21.

palmata sinitl. Z. 211. S. 330. Sa. 3\%2. V. phalangea Couch. Z. 212. S. 330. Sa. 372. V. pluma (licuss) E. 85.

seriatopora n. s]. Z. "211. - 'Iav. XV. fig. 23. suren Lin. \%. 211. S. 330. Sa. 3\%2. V. ventricosa IBusk. Z. 211. S. 330. V.

Turbinaria Oken. cyathiformis (Blainv.) Aq. $\breve{b}$.

' $\mathrm{ur}$ l, o Linueo.

carinatus Bors. Is. 60 .

crisputits n. s]". Ar. 51. - 'Tav. IV. fig. 12.

fimbriatus Bors. 'T'. 116 .

mranulatus n. sp. A. $26 \%$.

mamilla (Indrz.) .1. $26 \%$

mincenicus Michelotti. Ar. 51.

ploritanus Cintr. A. 209. V.

»Var. filosins e glabratus Phil. 1. 269.

reticulatus I. sp. 'I'. 116. - Tav. XI. fig. 4\%.

liomettensis Seg. 1. 270. V.

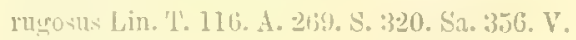
siutumeus Linn. S. 320. Sa. 356 . V.

sueciosiss Michelotti. T. 116.

T'u ronnilla rivso.

amnena (Honter.) 1. 261. Sa. 351. V.

brevis n. $81 \%$ 1. $26 \%$.

»Var. obsoleta n. A. 265.

costelluta ((irat.) '1'. 112.

lecussinta (Bon.) '1. 112.

Relicata (MInnter.) A. 205. V.

dimistiatia 1)or. 'I'. 11:.

elegans Seg. T. 112.

clemantissina (Mnntg.) A. 265 . Sa. 334. V.

cxilis seg. '1'. 11\%.

aracilis (Broce.) 1. 112.

”Var. ulubia n. '12.112. - Tar. XI. ti.s. 34.

Lanciae (Lib.) '1'. 112. A. 20(5.t.

manifiea n. sp. A. 261. - Tar. XVI. tig. 2a.

"Vax. simplex n. A. 265. 
Turbonilla Tísto.

minima 11. sp. T. 112. - Tav. XI. fig. 33.

meleata n. sp. T. 112. - Tav. XI. fig. 35.

ubliqueplicata 11. sp. A. 265.

rufa (Phil.) e var. Sa. 35\%. V.

scalariformis n. sp. A. $265 .-$ Tav. XVI. fig. 24.

striatula (Lin.) A. 261 . S. 319. V.

subplicata n. sp. 'I. 11\%. - Tav. XI. fig. 32.

varicusia Ind. T. 112. A. 264 .

Turritella Lamarck.

Archimedis A. Brungn. Aq. 51. I. 60. F. 73.

$$
\text { T. } 115 \text {. }
$$

bicarinata Fichw. T. 115.

Broccliii Bromn. 'I. 115.

cathedulis Brongr. Aq. 51 .

communis Risso. 1. 26\%. S. 31!. Sa. 355. V. exasperati I)ot. T. 115.

gradita Menke Aq. 51.

inaequisculpta 11. sp. T. 115. - Tav. XI. fisp. 41.

marginalis (Bruce) T. 115.

Rieppelii Hoern. Ay. 51. T. 115.

striatissima Dorl. 1. $26 \%$

subangulata (Broce.) Ar. 51. T. 11\%. A. 26\%.

terebralis Iamk. Ar. 51.

tornata (Broce.) A. 267.

tricarinata (Broce.) 1. 26\%. S. 319. Sa. 35\%. V.

triplicatia (13ruce.) 1. 26\%. S. 319. Sa. 35\%. V.

tmris Jast. var. minor. n. T. 115.

vermicnlaris (Hoce) A(p. 51. A. $20 \%$

Typhis Muntfort.

fistulostls (Broce.) 'T. 108. V.

homidus (Brocc.) 'T? 108.

Utriculus Brown.

Jel sii Seg. 1. 2ir. - 'linv. XVI. fig. 10.

Lajonkerianus ([hat.) T. 100. A. 251.

manmillatus (1'hil.j 1. 25I. Sa. 3isl. V.

truncatulus (13rug.) '., 100. A. 25. S. 318.

Sa. 351. V.

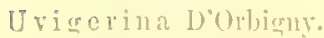

angulesia Will. \%. 226. 1. $830 \mathrm{7}$. V.

asperulit Crisck. 'T', 186, \%. 22:30. 1. 30\%.

coclearis Karr. T', $11 \%$.

nolosa (I) Orb.) S. 333. V.

pygmaer (D'Orb.) I. 6.4. F. 90. 'T' $116 . \%$. 226. 1. 30\% S. 3333. V.

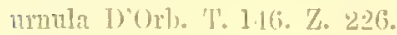

Varinella I)aurlin.

depressia Dami. Is. (jo).

Vaginulina 1) Orbigny.

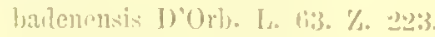

rlavatia Costa. \%. we:3.
Vagiunlina D'Orbigny.

Italica Costa. Z. 223.

legunco (Lin.) L. 63. T. 140. V.

lens Costa. T. 140. '2. 223.

linearis (Montg.) E. 90. T. 140. V.

Vonerupis Lamark.

irus (Lin.) A. 2\%. S. 321. Sa. 35\%. V.

Venus Linneo.

Aglaurie? (Brong.) Aq. 5\%.

Brougnartii Pajt. A. 279. s. 32.2. \$a. 358. V. casina I.in. A. 27\%. S. 322. Sa. 358. V.

dubir? Michelotti. 'T'o. 40.

Dujarlini Hoem. A(1. 52. L. 60 .

etlusia Biv. S. 322. Sa. 358. V.

grillinil Lin. S. 322. Sa. 3318. V.

grandis n. sp. T. 119.

Haneri Huem. E. 73.

insiguis 11. 41. E. 73. 'I. 119. - Taץ. VIII. fic.. I.

Nuliterranea (lib.) d. 279. Sa. 358. T.

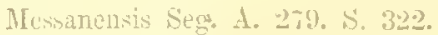

Imultilumella Lamk. L. 74. 'T. 119. A. 2:-9. V.

orata Penn. Ar. 52. T'. 119. 1. 2-0. S. :32?.

sir. $358 . \mathrm{V}$.

jlicat. Gmel. T. 119. V.

1)mleron 11. Sp. T. 119.

mulis Puli '1'. 119. A. 279. S. 322. Sa. 358. 1.

linsterucii Payr. 1. 290. \$. 322. Sa. 358. V:

scalaris Lirom. Ar. 52. I. 60. T. 119.

monbonata Lamk. 'I'. 118. 156.

vertucosa lin. 1. 229. 5. 322. Sa. 358. V.

Vermetus Adanson.

gigas Biv. 1. 25\%. S่a. 355. V.

» Var. srantulatus n. 'T. 115.

- intortus Lamk. A. 20\%\%

Sognentiants Arml. e Bmuit. 1. 26\% V.

semisurrectus Jiv, A. $06 \%$. Sin. 3\%). V.

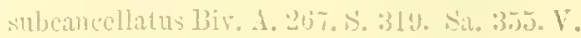
triupeter Bir. 1. 26\%. S. 31!. Sa. 35\%. V.

lermili a Lamarck.

calyptratia (Grube \%. 196. A. 299\%. V.

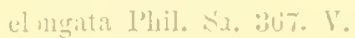

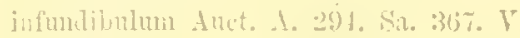

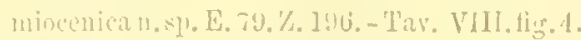
pectinata (Grube) s.t. $36 \%$. Y.

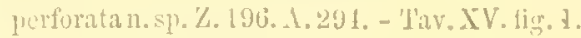

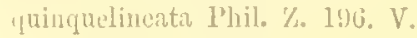

tricuspis (Grube) Sir. 36\% V.

tritida Quatri. Sa. 36\%. V.

Verruea tehumacher.

crebricosta seg. 1. 2.9:3.

liomettensis siog. 1. 293. V. 
Vorruea schmmacher.

stromia (Juzler ) \%. 195. A. 293. s. 32\%. S.z. 3i6. $\mathrm{V}$.

》Var. laeris Z. 195. V.

Zanclea Seg. A. 293.

Verticorias. Woort.

acuticostatit (Pliil.) 1. $280, \mathrm{~V}$.

arenosa (Rayneval) A. 280 .

argentea (Miriti) 1. 280.

gramulatu Seg. A. $280 . \mathrm{V}$.

trapezoiden Seg. T. 119. 1. 280. V.

Vincularia Defrance.

cucullata Renss: E. 81.

Virgulina Dorbiugry.

longissima Costa. A. 30s.

Sclureilsersii Cziz. T. 147. 7. 2.27. V.

stuano:a DUrl). Sa. 3\%ั. V.

Volut a Limeo.

ficulina Lamk. Aq. 50.

Volvula 1. Ailams.

acuninata Bruguiere) \$. 31\%. Sa. 351. r.

Vulvuliua D'Orbigny.

pectinata Hantk. E. 91. T. 150.

Valitheimia. King.

cranium (Mull.) Sa, 301. V.

Daridsuniana Seg. A. $28 \%$.

cuthira (Phil.) T. $28 \%$.

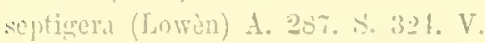

Woodia D slizyes.

ligitaria (Lin.) \&. 322. S... 35?. V.
Xenophora Fiscler von Waldheim.

cummlans (Brong.) Ir. 51. I. 59.

Deshayesii (Michelotti) Aq. 51. '1, 110.

infumliłulum (Broce.) T. 110.

testigera (Broce.) 'T'. 110.

Xestuleberis G. O. Sirs.

ancustata Terquem. 1. 201)1. ‥326.

aurantia (B.iri.) 1. 291. s. 326. Sa. 3f t. V.

depressa G. O. Sars. \%. 191. 1. 29I. S, 336\%. Sa. $31 j 4 . \mathrm{V}$.

prociucta n. sp. A. 201 .

pustulosia n. sp. S. 320. Si. 361.- Iav. XVII.

tig. : 31 .

spimulosil nl. sp. A. 291. - Tav. XVII. fig. :3.

testudis n. sp. Si. 301.- Tiv. XVII, fig. .01.

tminliz (Rutlss.) T. 120.

Syloyllaga Turton.

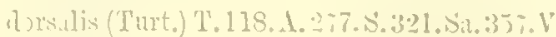

Ynlatia Moller.

abyssicola Torell. A. 284. V:

confusa Seg. 1. -281 .

frigitla Torell. '1. 121, 1. $231, .2 .323 .1$.

Incida Lorèn. 1. 2) 1 .

meritionalis seg. 1. 281.

nitili (Truec.) T. 121.

ublonga? Jefir. 1. 2s1, V.

pellucida (Plil., 1. 2-2.1.

Philipuii Bell. o ku. striatia ß. T. Iel.

sinuws I Seg. T', Iㄹ.

temis (1'hil.) 1. 284. S. 323. Sa. 360. V.

Dal precedente elenco di tutte le specie terziarie raceolte nel Reggiano, fatta la riduzione di quelle poche che fanno doppio impiego, come risulta dall' erralacorrige, si ha che le forme specifiche riconoscinte ascentono al 2686 , che aprartengono a 495 generi. Meno di una terza parte di tali specic cioè $99 \pm$ spettano alla fauna attuale e virono per la maggior parte nel Mediterrineo.

Del numero totale delle specie sono soltanto 1.15 quelle riconoscinte siccome nuove nella seienza, cioè cirea un sesto. Le altre poi, cioe yis $\$ 1$, spettino a forme note e valgono assai bene a caratterizzare, come abbiamo veluto, lo roce e gli strati rarî che le racchindono. 


\section{N D I O H}

DELLE MATERIE CONTENUTE IN QUESTA MEAORLA.

Prefazine. . . . . I . Ing. storia bibliografica selle ruce terziarie dellit

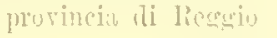

\section{GATO P'RIBI}

Nozioni seognostiche sencrali intorno all'estremo meritionale della penisola italiama . . . . . . . 》

I. Generaliti inturno all r costituzione topo. graticar e seologica delia provincia di fi $\ldots i, \ldots$. ivi

II. Esane tella suceessione stratigrafica dei terreni terziarii desunta dallo sturlio di una serie li sezioni nuturali . . . » 16

\section{CATO SIEONDO}

Descrizione sistematica delle formazioni terziaric tella provincia di lieggio. . ” 211

1. Formazione Focenic . . . . . . 》 ivi

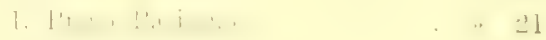

Pulcontologia . . . . . \$ i:i

Fiseneo rei tossili. . . . * 2.2

'Tipo. Protuzonii . . . " ini

2. I'iano Partuniano . . . . \

a. Argille urigie. . . " j.

b. Conglomerato. . . " ivi

c Arenaria. . . . . \$

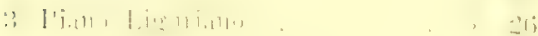

a. Argille reagliusc. . . . " in

J'aleontologia . . . . " \$

Elenco tei fissili. . . . \ …

'ija. l', ili . " it

b. Calcare numilitieo. . 》 isi

P'aleontologia . . . . . " , "

Eilenco dei foxili. . . . 》

Tipo. I'motuzuatij . . . . \ 1,1
II. Formazione diocenica . . . I'.... : : 1

1. Pisno Tousrianu . , , .

11. Narne binnehe in fucuili. , I

b. Sehisti Jituninosi .. . i.i

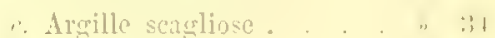

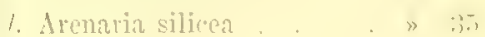

- Arenaria cun striti di combnstilile. . .

f. Aremaria a sentellit. . . . . :

Palentologia

Elenco dei fosili..$\quad \mathrm{ini}$

Tipo. Vertebrati . . » ivi

"Mollnechi. . . . . . 11

$"$ Vemi.

"Echinostermi. . , " is $\mathrm{i}$

"Celentrati . $1 \mathrm{i}$

"Protoznarii. . . li,

ב Piano Aquitaniano . . . . " ,i:

Paleontoluria . . I"

Elenco dei fursili. . . . . . .

Tium. Vertebrati...

"Holluschi. …

$\$$ Vemi, $\quad, \quad \ldots$

- Evbinotermi : :

. Celentera! i ..

»Protonorii . .. ivi

:3. Piano Lanchiano . . :

a. Mlulasse.

b. Conglomerato. ..

l'alecntulogia $\quad \ldots . .$.

Elene, Rei fiscili . . . . $\mathrm{i} i$

Tipo. Vertebrati. . . . is i

"Inlluschi. . . . isi

$»$ Artropocli. . i il

. Vermi. $\quad 1, i$

Hollinulenni. 
Tipu Celenteriti. . . Pag. 62

$\gg$ Protozoniii . . . . \$ 033

1. Pimo Elvezirno . . . . \$66

a. Sabluie . . . . . \$ ivi

b. Calcare. . . . . 》 ivi

Paleontulogia . . . . . » 70

Elenco dei fossili. . . . ” 71

Tipo. Vertelurati . . . " ivi

, Mr.llun hi , , i.;

$"$ lithmmi. . "

$\$$ Vermi. . . . . \$ 78

"Eclinodermi. . . . " 86

»Celenterati. . . . \ 88

»Protozoarii . . . . \$ 89

5. Piano Tortuniano. . . . \ 45

P'aleontologia . . . . . \$ 98

Elenco dei fossili di Benestare » 99

Tipo. Vertebrati . . . . » ivi

$\gg$ DLulluschi. . . . . \$100

$\$$ Artropodi. . . . . \$123

$»$ Vermi. . . . . « 126

Echinolermi. . . . . "133

$\gg$ Celenternti . . . . » 131

1'rotozoarii . . . 》135

Fossili di Cessaniti . . . 》15!

》 di Palmi ..... » 150

6. Piano Messiniano . . . . 》161

u. Ammassi li gressu . . . " 103

b. Calcare cellulare. . . \$ $16 t$

1II. Furmazione Pliocenica . . . . » 168

1. Piano Zancleano ..... " $17 \%$

a. Conglomerato. . . . " ivi

b. Salulie e marne. . . " 17:3

Palcontolomia ....... . ITst

Elenco dei fossili. . . . »18!

Tipo. Vertebrati...... ivi

» Molluschi. . . . . \186

$\gg$ Artropodi. . . . \$1.91

$»$ Vermi. . . . . . \$195

„Echinodermi. . . . \$214

"Celenterati . . . . " 210

$\gg$ Protozonrii . . . . \ 217

2. Pinno Astiano. . . . . „237

Paleontologia . . . . \241

Elenco dei fossili . . . \ 217

Tipo. Vertebrati . . . . » ivi

》Molluschi. . . . . \ 21!

$\$$ Artropodi. . . . . $\$ 28 \%$

, Vinll1. , :
Tipm Echinotnmi. . . Pag.

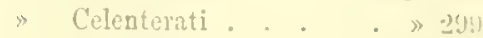

$»$ Prutozonrii . . . . »:30.

3. Piano Siciliano... . . „315

Paleontologia . . . . . »317

Elenco dei-fussili . . . . 》318

Tipo. Vertelorati . . . . . » ivi

"Mulluschi. . . . . " ivi

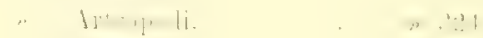

fini. . , : $: 3 \%$

Echinolemi . . . \:3:30

》Celenterati.... . \$331

$»$ Protozonrii . . . . » ivi

IV. Furmarione Quaternaria . . . . »336

P'iano Sarriano . . . . . " ivi

4. Sabbie marine inferiori . " 338

b. Subbic marine superiori . 》3 311

c. Alluvioni antichc. . . . " 312

Puleontologia . . . . . . 》 315

Elenco dei fossili . . . . \$350

Tipo. Vertebrati . . . . » iri

$\gg$ inolluschi. . . . . \ ivi

» Artropoli. . . . . . \$361

»Vermi. . . . . \$367

"Echinontermi. . . . . \$37:3

$"$ Celenterati. . . . . » iri

» Protozoarii . . . . 》 ivi

\section{Caro Terzo}

Consilerazioni intorno ai fatti geolorici precelentemente exposti ell alle deduzioni alle quali conducono. . . . . . \$ BS.

1. La serie tersiaria considerata nel suo insieme e nei suui varî membri » ivi

2. Escime dei materiali litolorici che costituiscuno la serie dei terreni terziarii del Regreiano . . ” $38 t$

3. T.e oscillazioni del funto marino nelle epoche terziaric. . . "3si

4. Altimetria lei terreni teriarii e consegnenze che ne lerivano. \391

5. Uno sruardo eomprensivo sullo faune terziaric alla provinci.u di lieggio e sul loro valore. . . " 391

Conclusioni . . . . . . . . 》 4u

Indice delle snecie fossili raceolte nei piani terziarii della l'rovincia di liegerio c leseritte o entmerate in ruesto lavoro. » IUT 
Conrezione di taluni crrari pià rimarchevali.

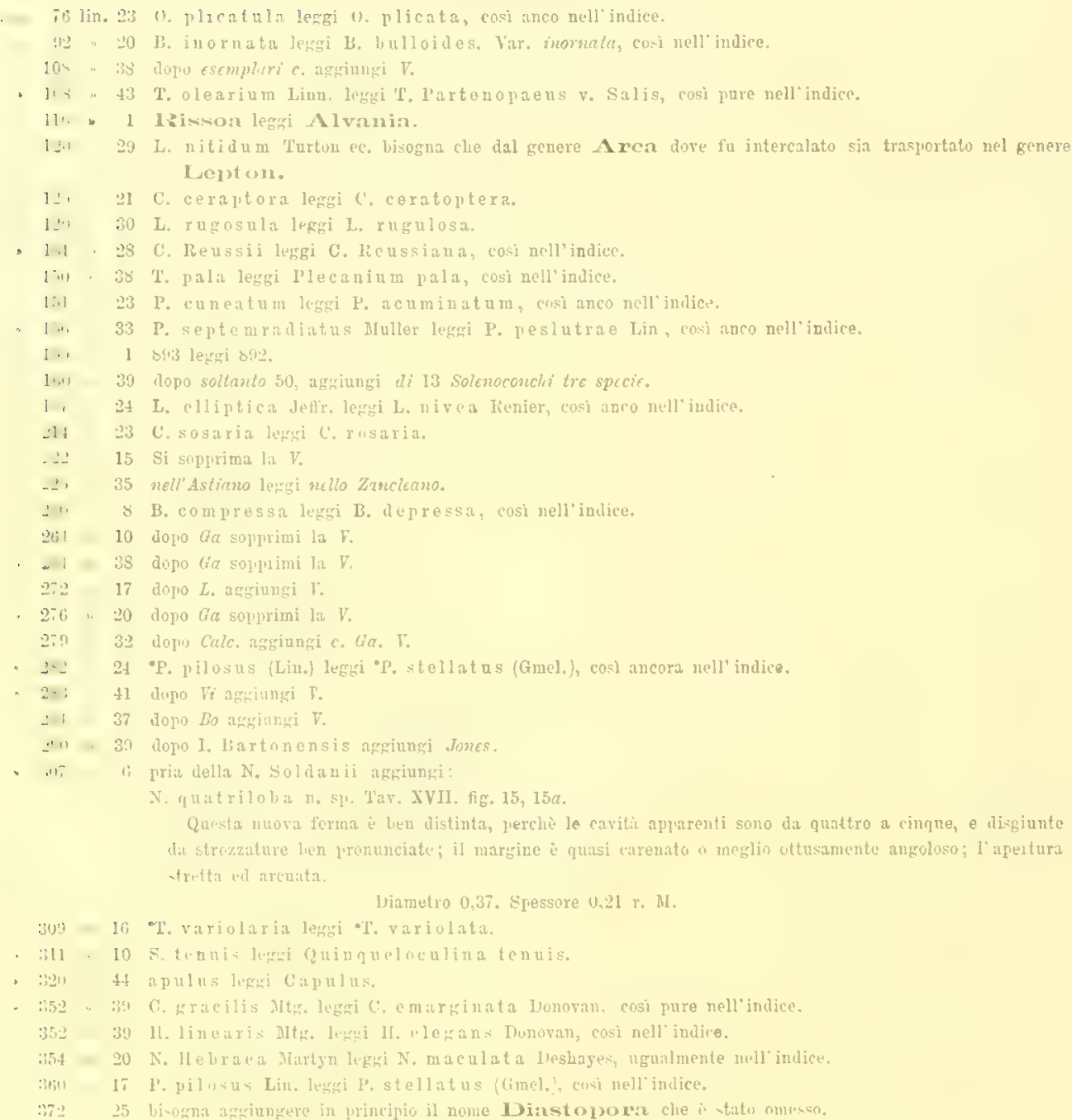

Nella spiegraione della earta di liugrin.

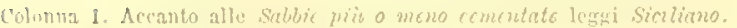

$\therefore$. Toneriono logeci Tunuriano.

Nella spiegarione della earta ti stiln.

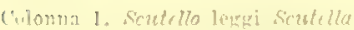

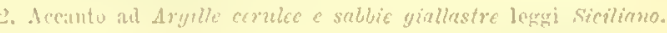

virele leggi Nirculo.

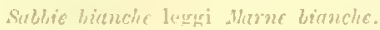

Nella tavola delle serimst.

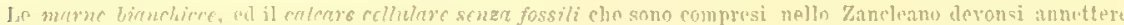

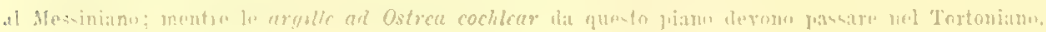




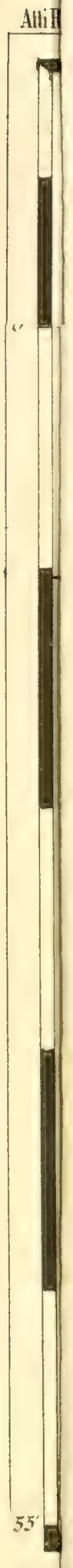





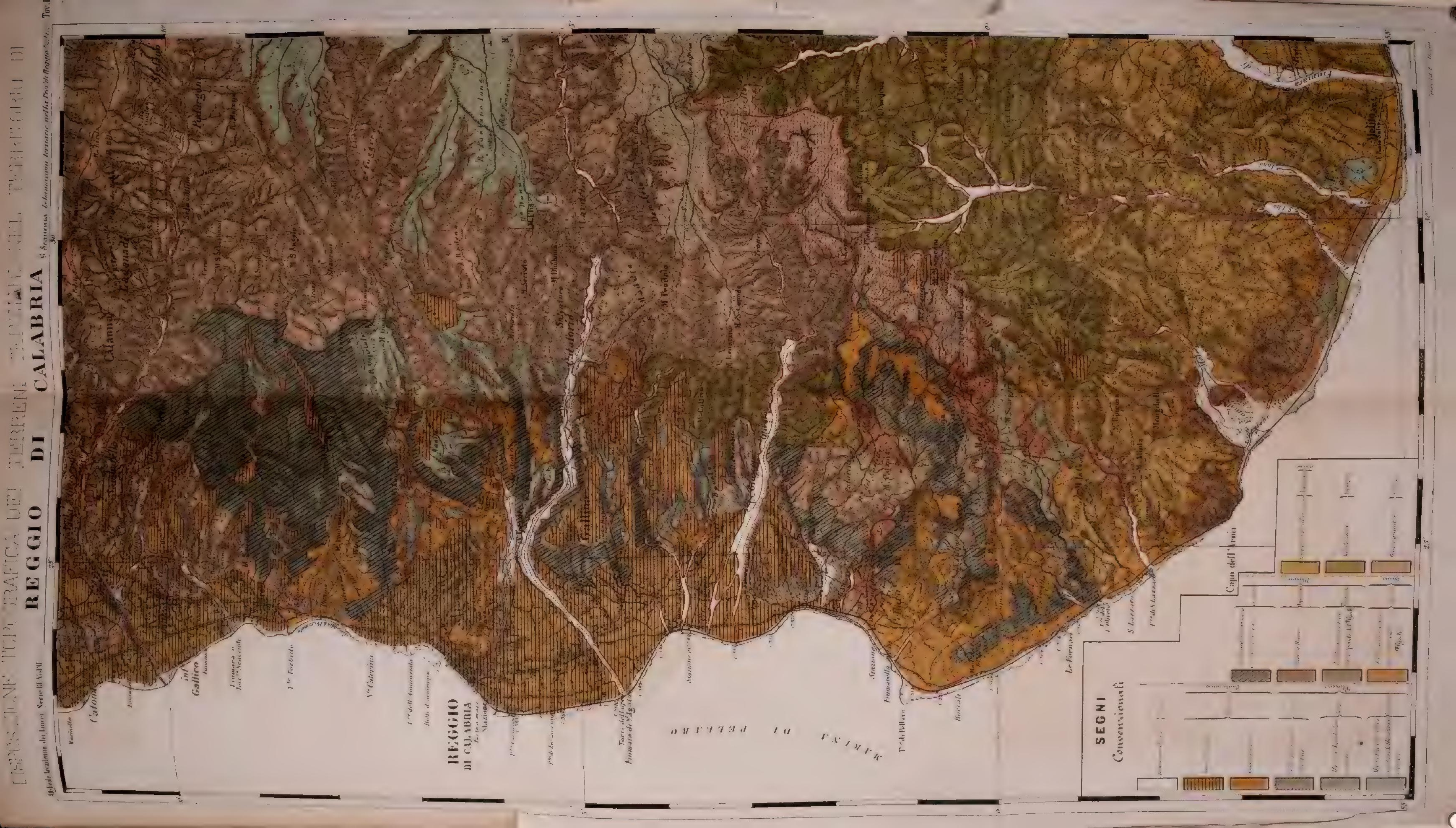






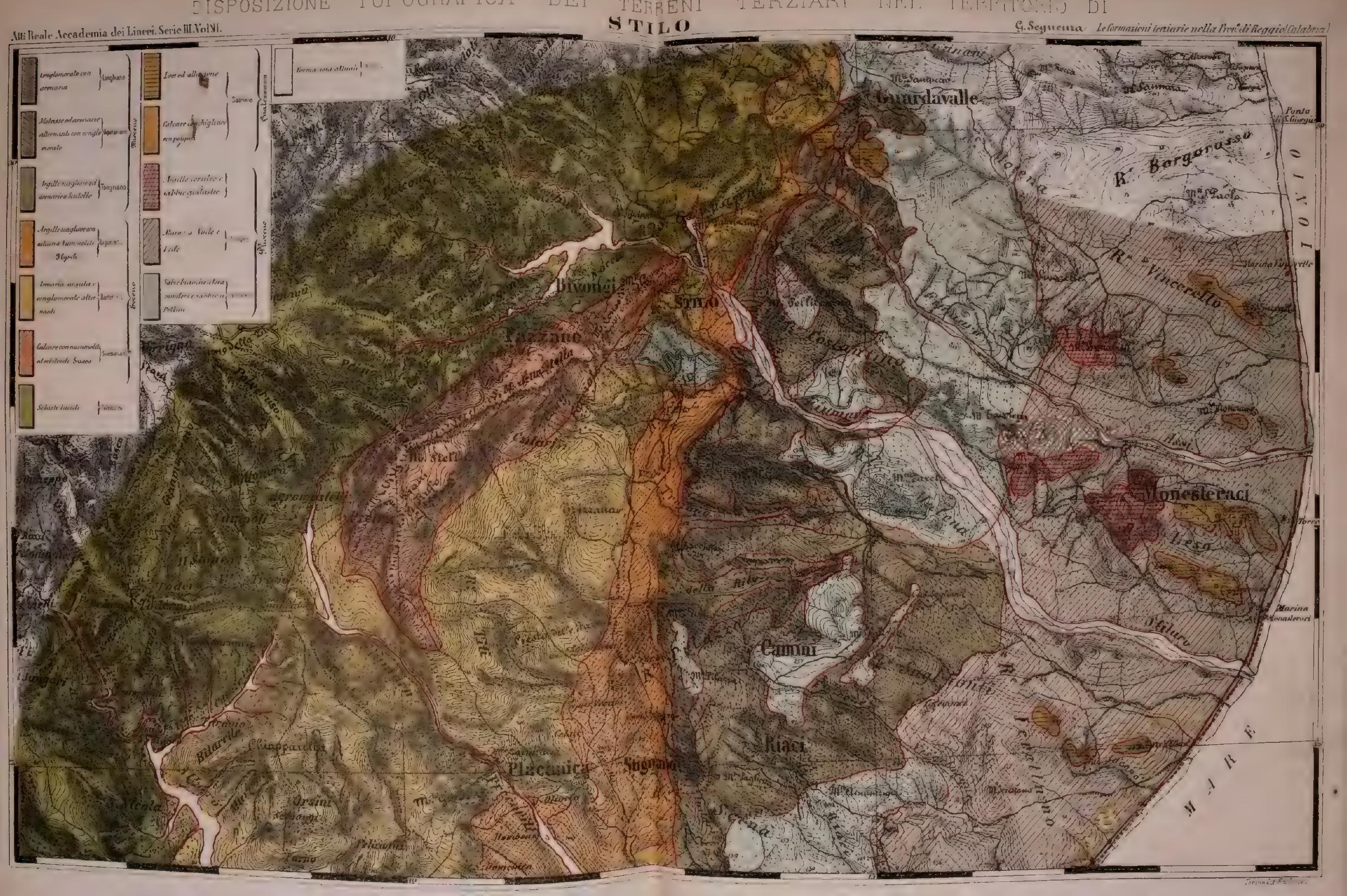






\section{SEZIONI NATURALI TRATTE DA. VIRII LUOGHI DEL REGGIANO}

SEGNI CONVENZIONALI

$x$ Micerale di Serro.

]1 Cristallino.

Dir. 2 Fillaje palconoica.

3 ialcare giuracsico?

4 Cretaceo (Cenomaniano)

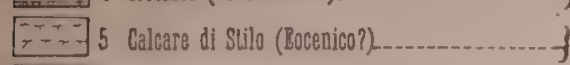

D 6 Argille grige...-...-

L 7 Conglomerato ed arenaria____ Bartoniano.

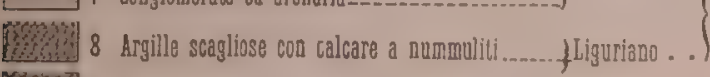

Ge Marne a fucoidi

9b Schistí bituminosi.

$\square$ gc Argille scagliose _

gd Arenaria silicea

Cla Arenarie e molssese

In Arenaria a Seutella

712 Arearie e conglomerationtan a Briozol

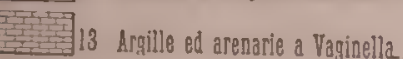

IA 14 Congglomerato con al ternanza di gres

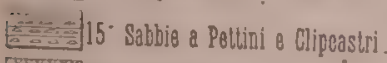

Wingrif 16 Argille azzure,

ITa hryllie al 0etres cochlear

J176-Ammassi di gesso

18 Harne bianchicce

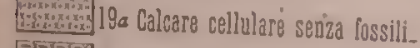

$=-196$ Conglomerats de cuoctoli cristallinit

Jisc iotbie e marne

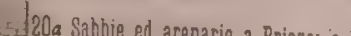

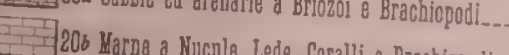

$\square$ Astiano.

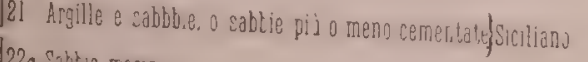

-

$=-1] 226$ Argill:

- 222c Alluviere.

J32d buteco

Tongrianc .

Lannghiano.

|jilveriano

\} Tortoniano

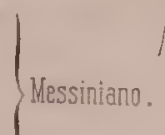

Alli Reale Accademia dei Lincei. Serie MII.VivI:

G. Seguenza. Formazioni Terziarie in Reygyo Calabria
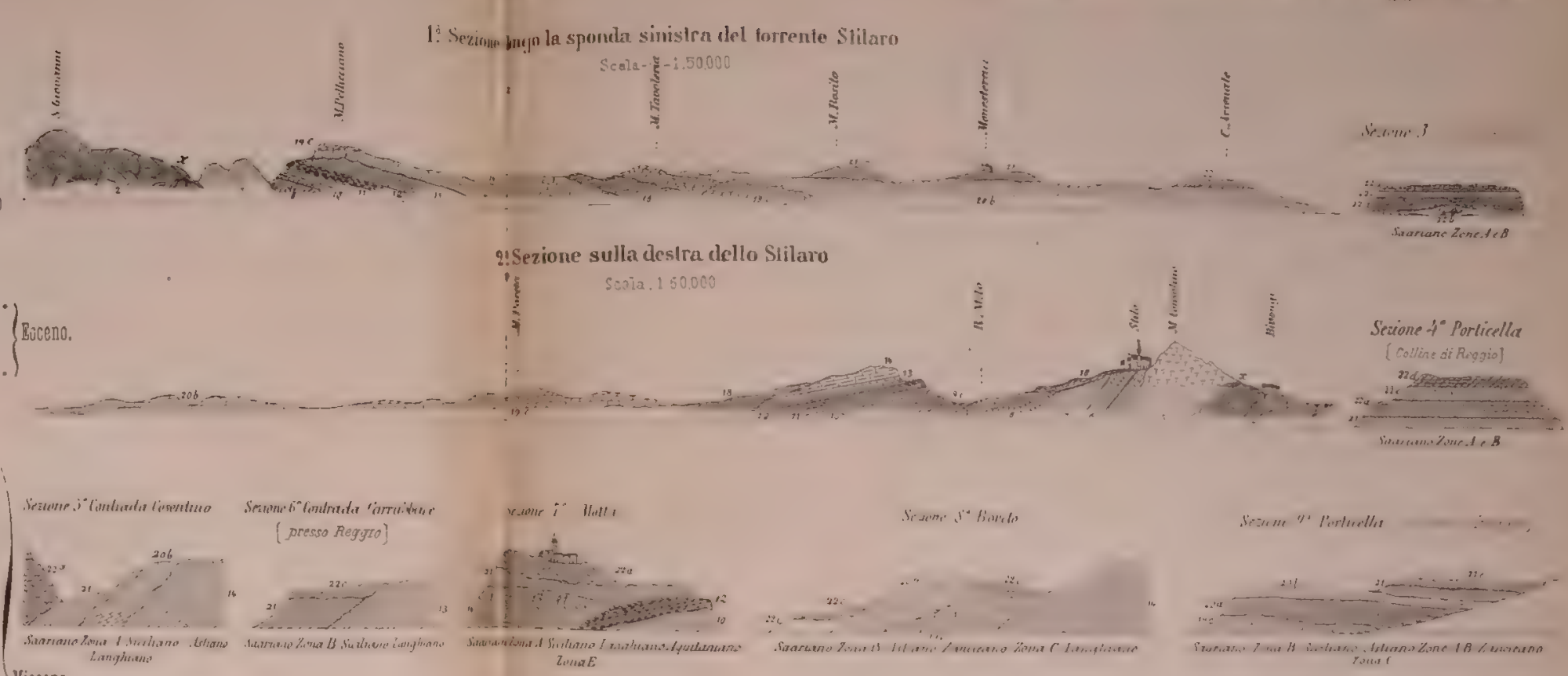
Hioceno.

Serime 10: Rasti

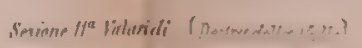

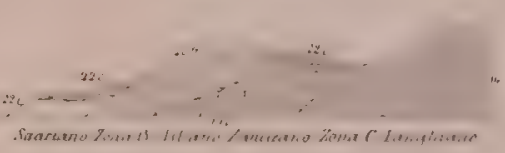

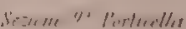

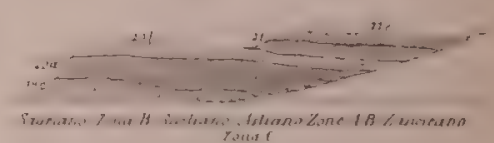

Frim. F:" Rometiut

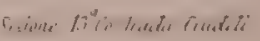

accos.

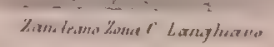

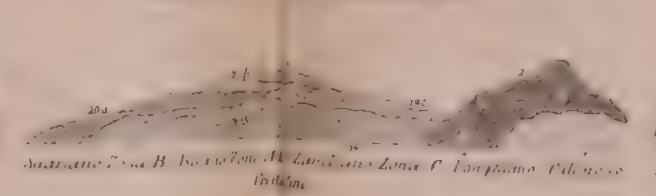

$4 \ldots$

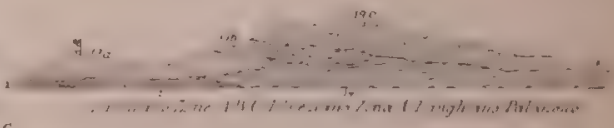

Sevint 14:Tälanidi (Sinistradella valle)

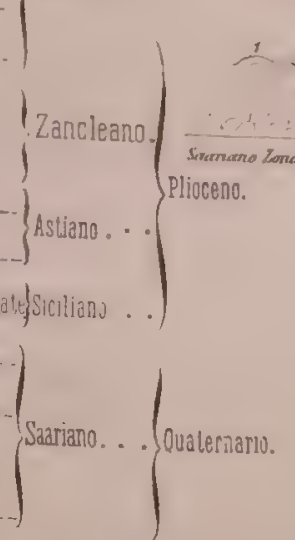

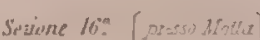

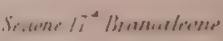

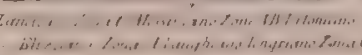
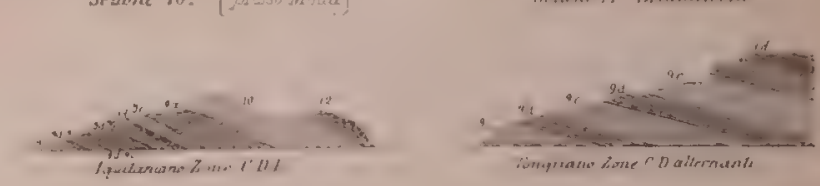

Spyime fy: syito 



\section{TATOLI IT.}

\section{FONSILI TONGIIANI}

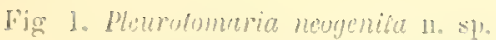

Un esemplaxe un po' lepresio del Tungriano di Anturimina.

». Urassatella Nichclotlii n. sp.

Un molello del Tongriano di Intonimina.

"3. Pecten Ramondini Montagna.

3. Un esemplare del T'ongriano di Antoninina. :3a. I sil scultura multu ingrandita. :3b. Cinnformazione tel margine.

». Peicn simplex Michelotti.

Un esemplare del Tongriano di Antonimina.

" 5. Wucula Antoniminensis n: sp.

Un esemplare delle colline tongrine di Antonimina.

"6. blypeaster intoniminensis n. sp.

Tre esemplari rappresentati in posizioni liverse, racolti mi monti tungriani di Intuninina.

» 7. Puriaster Cidabrus n. sp.

Un esemplare del Tongriano di Antunimina.

»\&. Hucropneustes brissiformis n. sp.

Un esemplare del Tongriano di Antunimina.

"!. Orbitwides Gumbelii n. s].

3. Un esemplare del Tonghiano di Antunimina. Ya. Sezione di un esemplare del medesinn, Inogo e terreno. 96. 96. Scultura variabile della superficie dell'esemplare della die. 9.

"1(1. Butopora canica n. sp.

Un escumiare racculto nel Tongriano dei monti di Antonimina.

" 11. Seutelle Paulensis Agassiz.

Un esemplate dellarenaria superioro di stilo che sta tra il Tougriano e l'A Iuitunianu

\section{FUSSILI AQUI'TANIANI}

\12. Turbo crispuluts $11 . \mathrm{sp}$.

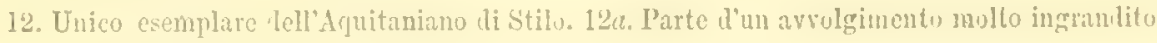
pur vederne bene In scultura.

$\gg$ 13. Quilhium bisulcatum no sp.

Dall Aquitaniano di Stilo.

" It. Pinne infundibulun n. sp.

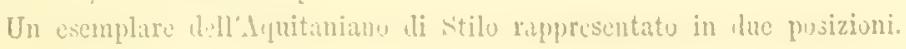


FOSSTLI TONGRIANI ED AQTTTANIANT DFI REGGIANO
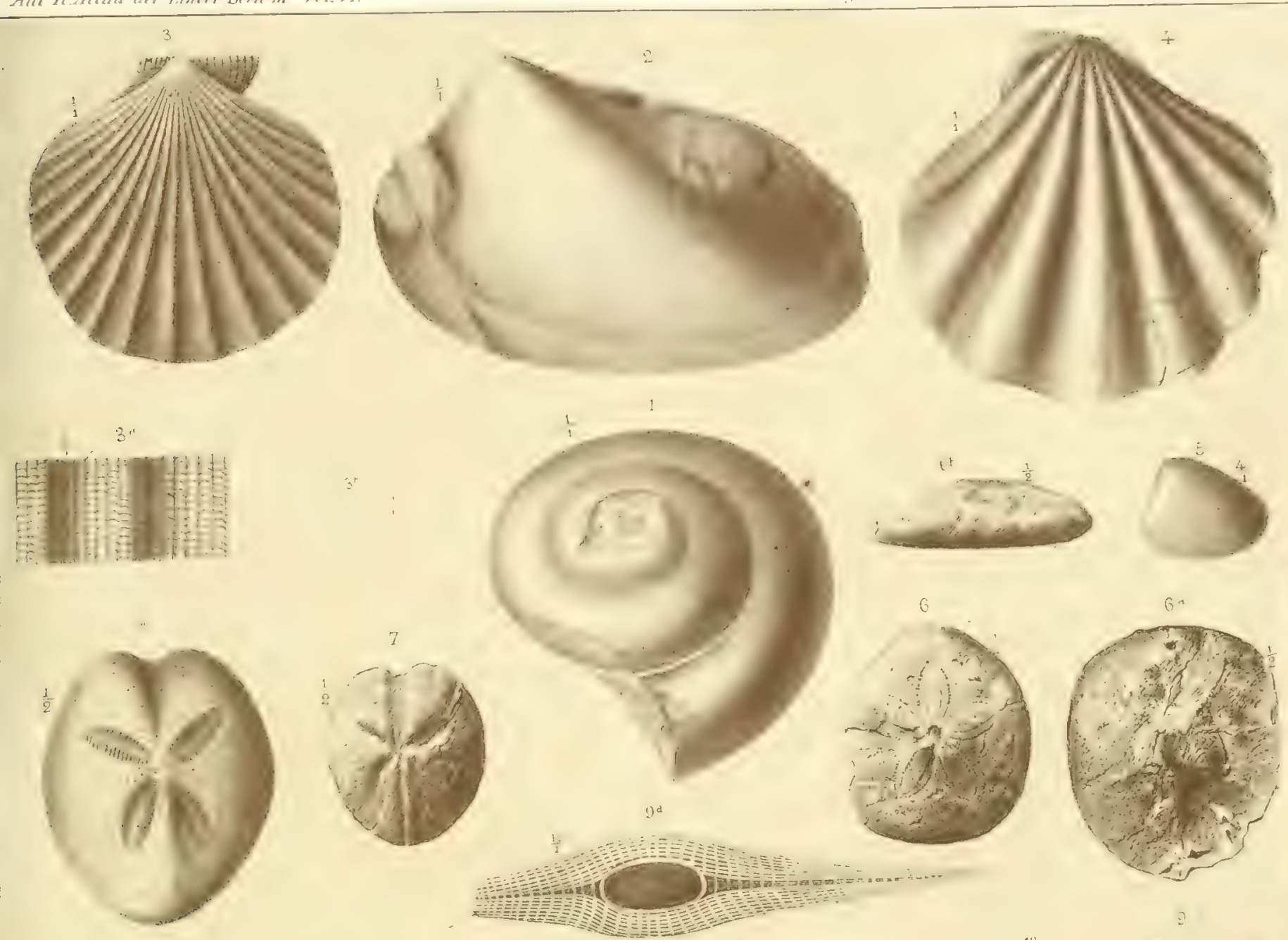

$$
10
$$
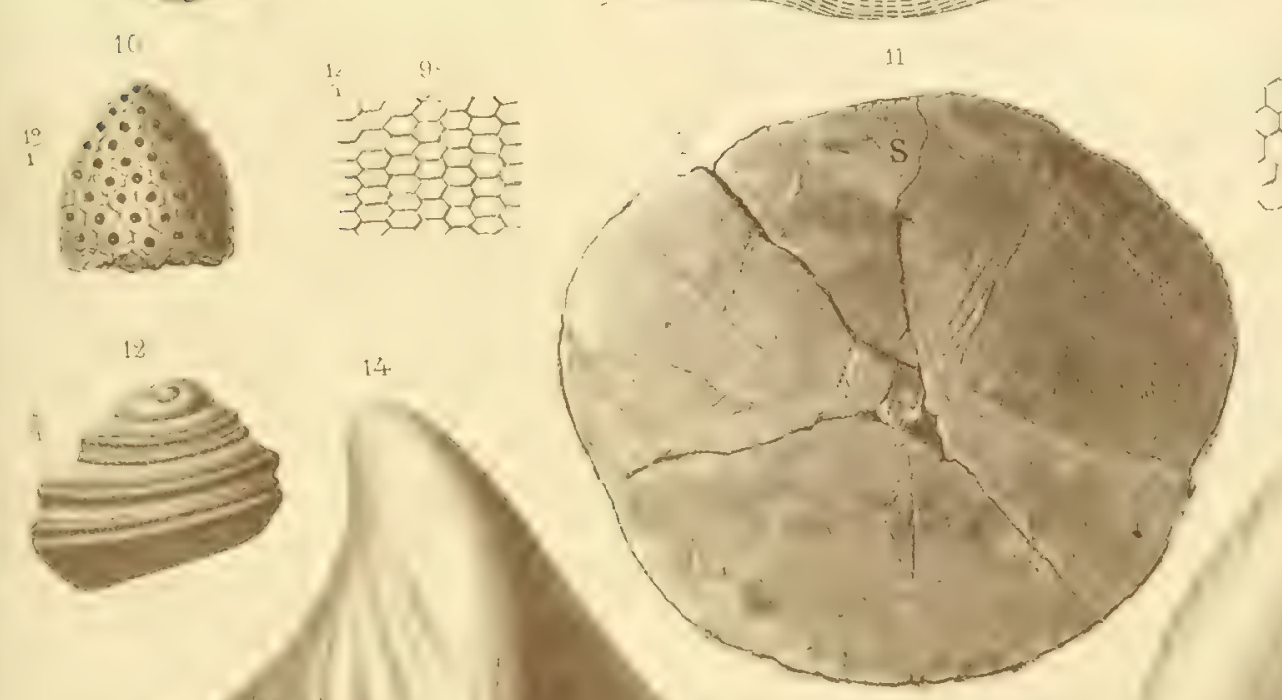

Tavola $\mathbf{V}$

\section{FOSSILI AQUITANIANI}

Eig. 1. Pinna denudala n. sp.

Un esemplare dell'Aquitaniano del territorio di Stilo rappresentato in slue posizioni.

»2. Clypasier acuminulus Desor. Var. devians n.

Un esemplare del territorio di Stilo, raccolto uel piauo aquitauiano e rappresentato in tro posizioni.

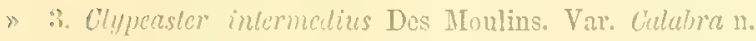

Un esemplare raceolto nell'A quitanimo di stilo rappresentatu in tre diverse posizioni.

-1. Clypeaster Stilensis n. sp.

t e 4a. Un esemplare dell"Aquitaniano di Stilo verluto in due posizioni. 4h. Yar. crplammie n.

Un esemplare dell'Aquitaniano di stilo. 

Tavola VI.

\section{FOSSILI AQUITANIANI}

Fig. 1. Clypeaster planalus n. sp.

Un esemplare rappresentato in tre diverse posizioni, raccolto nell'Aquitaniano cli stilo.

2. Clypeaster petaliferus $\mathrm{n}$. sp.

Un esemplare rappresentato in tre liverse posizioni, raccolto nell'Aquitaniano di Stili.

»3. Clypeaster tenuis n. sp.

Il solo esemplare raccolto nell'Aquitaniano di stilo, figurato in tre diverse posizioni.

4. Clypeaster melitensis Michelin. Var. clegans n.

Un esernplare dell'dquitaniano del territorio di Stilo, rappresentato in tre differenti posizioni. 



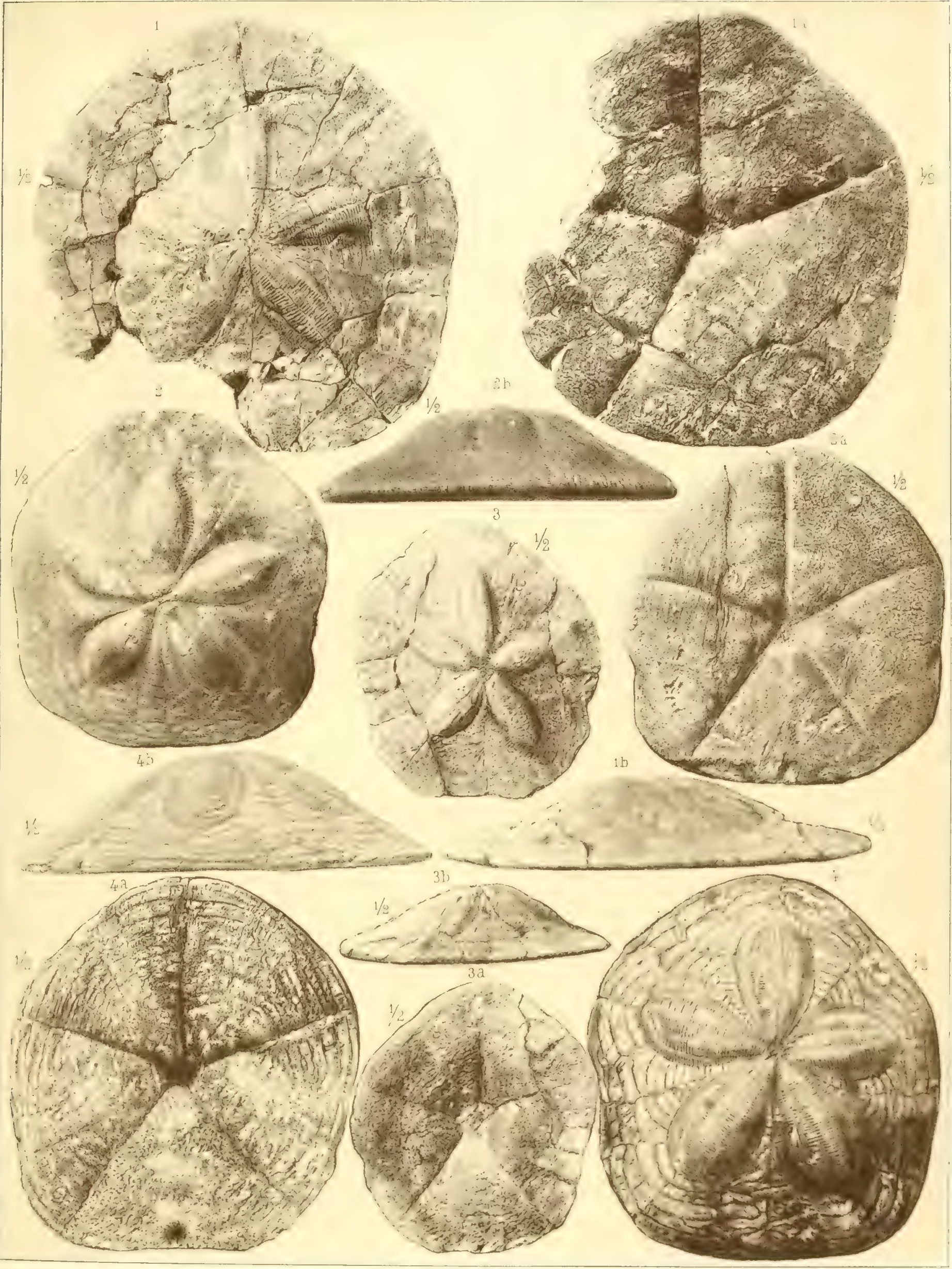





\section{Tavola VII.}

\section{FOSSILI AQUITANIANI}

Fig. 1. Flabellum Stilensis n. sp.

Un esemplare dei dintorni di Stilo.

" ¿ Helerostegina papyracea n. sp. Var. giganlea n.

Un esemplare dei dintorni di Stilo.

\section{FOSSILI IAANGHIANI}

" ‥ Truchocyuthus prismaticus घ. sp.

Un esemplare lelle argille sabbiose sulla sinistra dello Stilaro

1. Trochocyathus Stilonsis n. sp.

Un individuo dalle argille sabbiose dello stilaro.

5. Cassidutina ulula n. sp.

Dalle argille dello Stilaro. 5. Esemplare veduto di ficcia. $5 a$. Lu stesso veluto lateralmente.

" ". Nonionina formosa 13. sp.

Dalle argille dello Stilaro. 6. Esemellare vertuto di faccia. Gu. Lo stesso dal lato dell'aperturi.

7. Truncatulina limbata n. sp.

Dalle argille dello Stilaro. 7. Veluta dal lato superiore. $7 a$. Dal lato della spira. 76 . Guardata latexalmente.

- Truncatulina nucleabe n. sp.

Dalle argille dello Stilaro. 8. Un esemplare vedufo dal lato inforiore. sir. Dal lato superiore. $\delta b$. Verluto laterilmente.

?. Disconbina solarium n. sp.

Dalle argille dello Stilaro. 9. Un escmplare cuardato dal lato superiore. "u. Veluto ial lato della spira. 96. Lateralmente.

11. Truncalulina marginati 11. sp.

Dalle argille dello Stilaro. 10. Escmplare guarlato lal litu superiore. 10u. Lo stesso lal lato della spira. 10b. Veduto lateralmente,

\section{FOSSII I ELVEZIANI}

1. Aptobates Seyuenzate Lawley (M. S.)

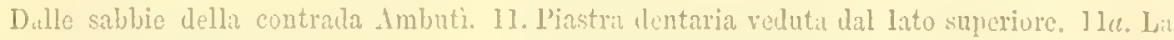
stessa dalla faceia inferiore. $11 \mathrm{~b}$. Kappresentata lateralnente in una fratturia naturale.

". 1.. Janira subradiate 13. sp.

Dalle sabbie di Ambnti. 12. Una valva inferiore veluta lal lato esterno. 12a. Esterno d'una valva superiore. 12b. Interno hella stessa. 12ce. L'rofilo d'un esemplare inticro.

" 1.3. Jamira culabra n. sp.

Dalle sabbie di Ambuti. 13. Valva inferiore veduta dal lato esterno. 13a. Esterno d'una valval superiore. 13b. Interno della stessa. 13c. Profilo d'un esemullare intieru.

Limea llormesii n. sp.

Una valva ritcolta nelle sabbie quareose di Ambuti.

15. llimites lenuis a. sp.

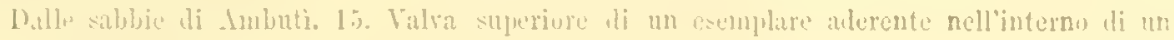

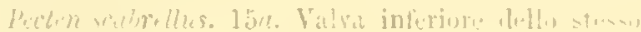



FOSSILI AQUITANIANI LANGHIANI ED ELVEZIANI DEL REGGIANO

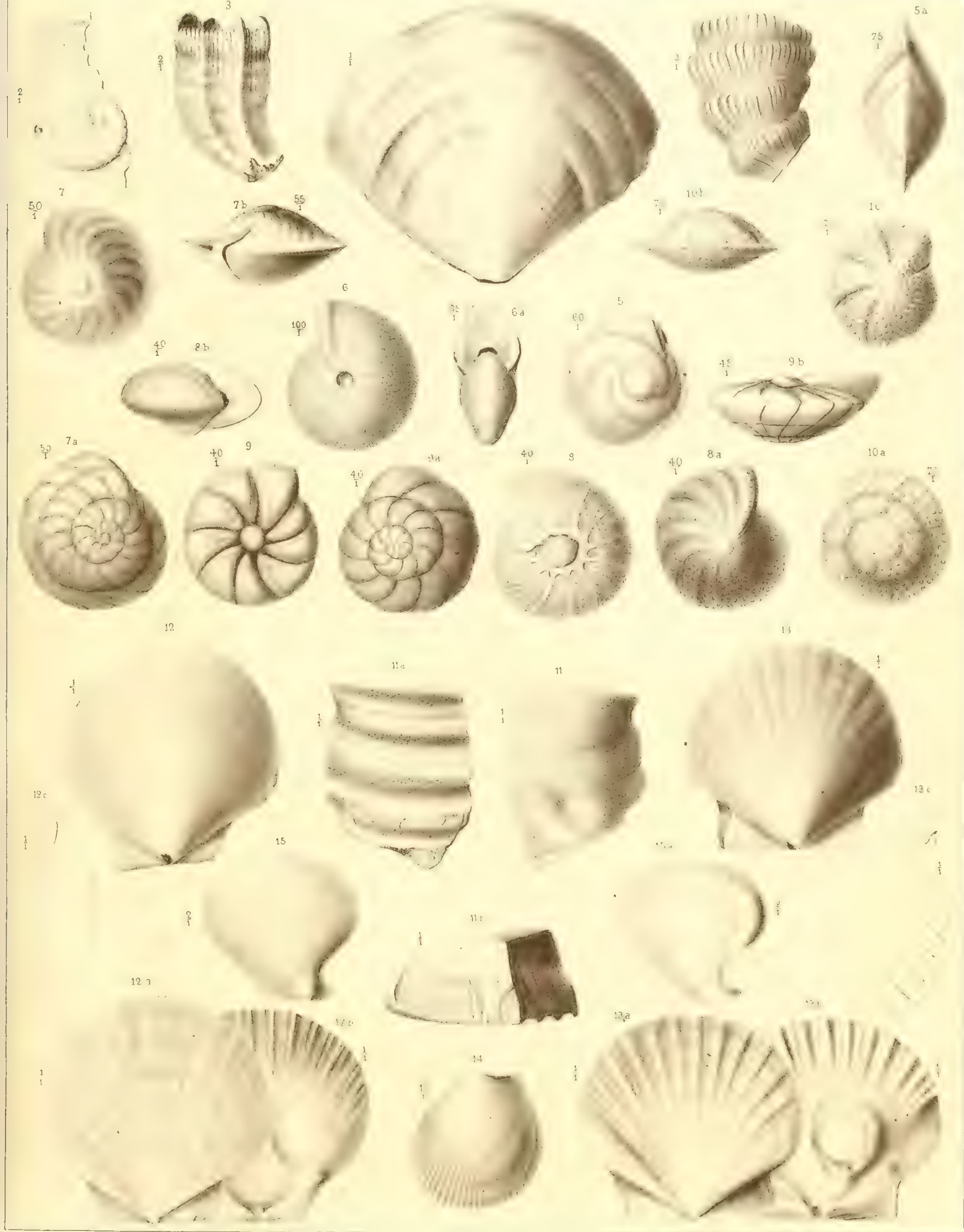




\section{Tavola VIII.}

\section{FOSSLL ELVEZLINI}

Fi. 1. Temes insignis w. sp.

Un modello dei varì rucculti au Imbuti, con un frammento delia conchiglia del liortoniano di Benestitre.

¿2. Cylliere subbrigona n. sp.

Una valva dalle sabbie di Ambuti.

$\therefore$ Serpula articulatio u. sp.

Un esemplare fisso su di un'Anomia, raccolta nelle subloie di Aubuti.

1. Vermilia miocenica n. sp.

Esemplare aderente alla Janira Besseri dalle sibbie di Ambuti.

" i. Serpula discohelix 11. sp.

Due esemplari aderenti alla valva superiore della Janira Beubanli dalla contrala Ambuti.

i. Flustra denticulala n. sp.

Un frammento dall'Elveziano di Benestare.

"7. Membranipora fissura n. sp.

Colonia aderente al Clypeaster mramidalis della contrada Ambuti.

" S. Membranipora formosa Revss. var. conferta $\mathrm{n}$.

Colonia fissa ad una Terebratula Cosfae delle sabbic di dmbuti.

- $\therefore$ Membranipora ogivalis $\mathrm{n}$. $\mathrm{sp}$.

Colonia arlerente ad un Pecten scabrellus di Ambuti.

\% 11. Membranipora bicornis n. sp.

10. Forma tipica. 10\%. Forma estrema della me lesima colonia impiantata su d'und valva superiore della Janiru Beudenti, raccolta ad Ambuti.

11. Lepralia elcgantissima n. $\mathrm{sp}$.

Colonia su d'una Rhynconella plicato-ilentula, raccolta nelle sabluie di Ambuti.

"1:. Lepralia tormosa n. sp.

Colonia sulla Terebratula Costae di Ambuti.

, 1:. Lernalia minutissima $\mathrm{n}$. sp.

Colonia sull'Ostrer ..... da Ambuti.

》14. Lepralia pustulosa n. sp.

Aderente al Pecten scabrellus da Ambuti.

"15. Eschara variolala n. sp.

Da un esemplare raccolto nelle sabbie elveziane di Benestare.

"16. Hornera Reussii n. sp.

Esemplari dell'Elreziano di Benestar*. 16. Uno veduto ral lato relle cellule. 16re. Un altro dal lato opposto.

"17. Clypeaster allus Lamarck.

Un esemplare li Baselice vidutu in tre liverse posizioni. 



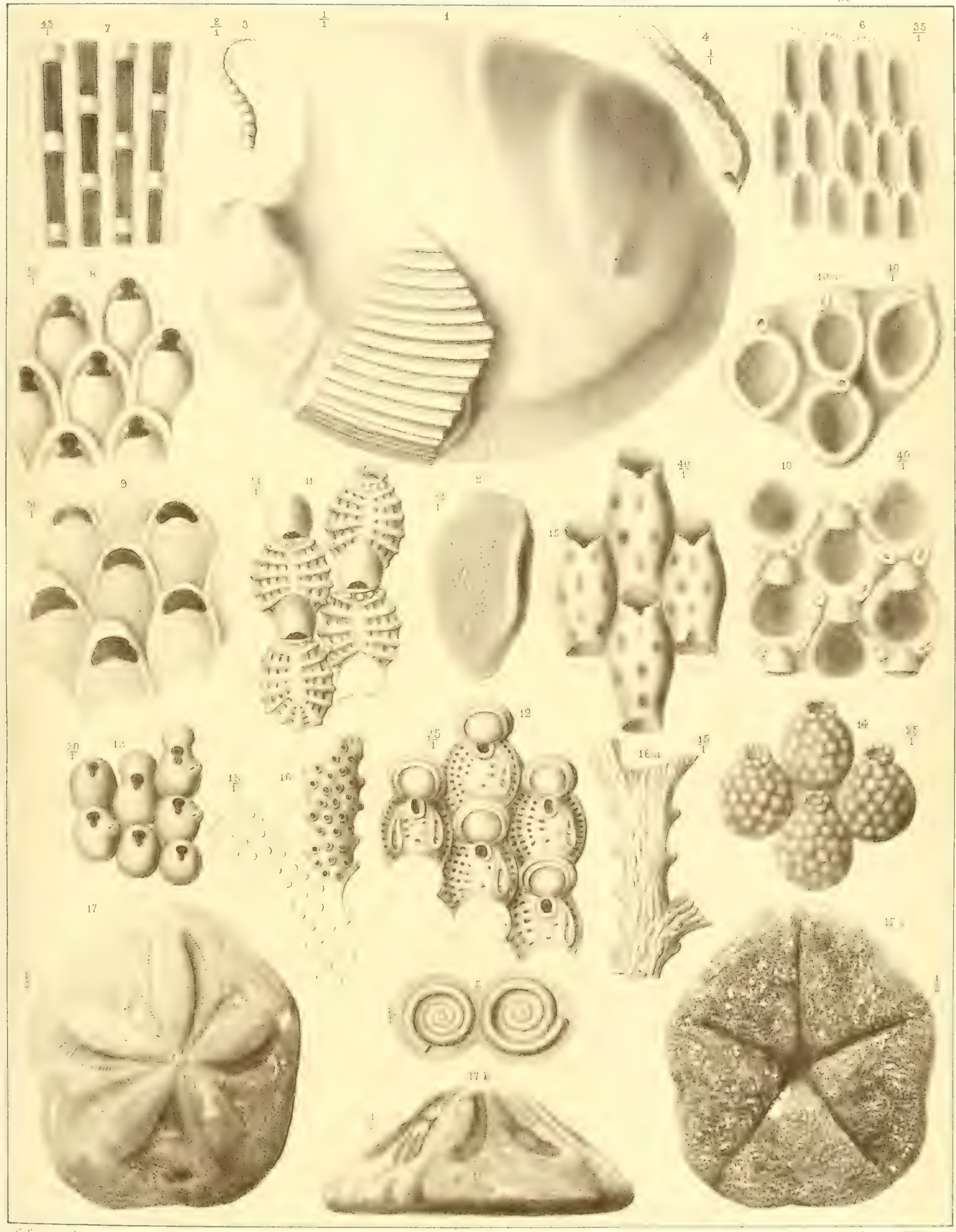




\section{Tavola IX.}

\section{FOSSILI FIUEZIANI}

Fig. 1. Clypeaster pyramilalis Michelin.

]. 1a. Un esemplare della forma tipica dell'Elveziano di Mlonteleone, veduto lateralmente e da sotto. 1b, 1c. Var. brevior n. Un indiciduo rappresentato da lato e da sopra, raccolto ad Ambuti.

" Ulypeaster insignis n. sp.

$2 a, 2 c, 2 l$. Un bello esemplare raccolto a Monteleone figurato in tre diverse posizioni 2, 2b. Var: ccuminatus n. Altro esemplare da Monteleone veduto di sopra e lateralmente.

»:Clypeaster portencosus Des Moulins. Var. elulior $\mathrm{n}$.

Un eseinplare raccolto a Monteleone veduto lateralmente.

"4. Helerostegina papracea n. sp.

Un esemplare dalle sabbic di Ambuti veduto di fronte o lateralmente.

„. Frondicularia cordala n. sp.

Un individuo raccolto a Benestare veduto di frunte.

" 1.. Marginulina raphanus Lin. Var. crebricosth $\mathrm{n}$.

Un esemplare dalle sabbie di Ambuti.

" . Truncatulina clegantissima n. sp.

Esemplare d'Ambuti veduto in tre posizioni.

" . Truncatulina vortix n. sp.

Un esemplare da Benestare raprresentato in tre posizinni. 

FOSSILI ELVEZIANY DEL REGGIANO
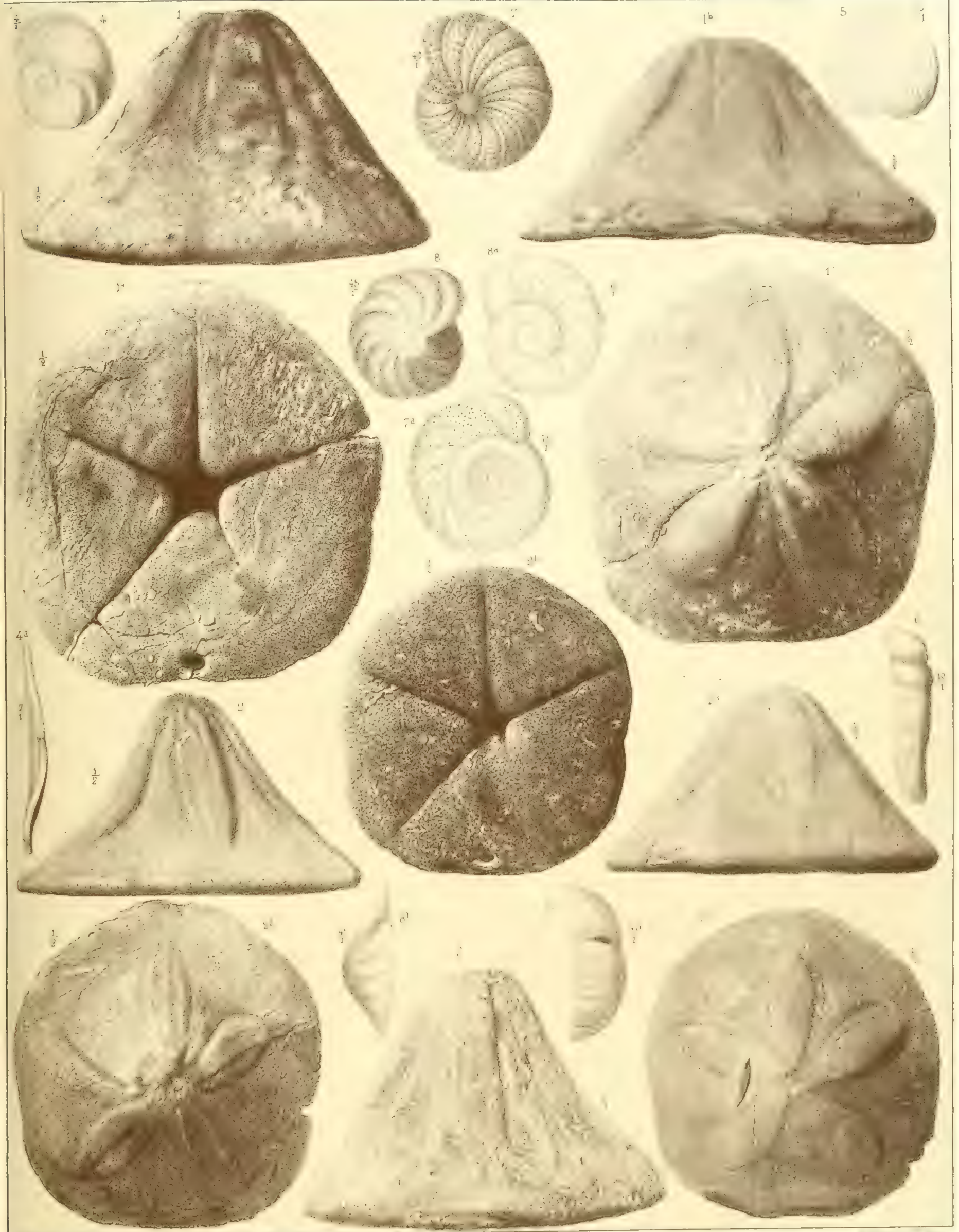


\section{Tavola X.}

\section{FOSSTII EITFZIIANI}

Fig. 1. Clypeaster Philippii n. sp.

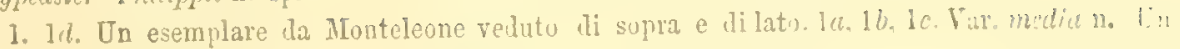
esemplare da Nontelenne rappresentato in tre posizioni.

» 2. Clypeaster Reidii Wright. Var. depressa n.

Un esemplare da Baselice veduto in tre pusizioni.

》3. Clypeastco marginalus Lamarck. Var. Lernuigetulu n.

Un esemplare dalla contrala Milochis rappresentato in lle pusiziuni.

\4. Clyperster farmosus n. sp.

Un esemplare da Buselice veduto in tre posizioni.

\$. Plecanium acuminatum n. sp.

Un esemplare da Milochia reduto in tre posizioni.

》6. Nubecularia papillose n. sp.

Tre esemplari di Ambuti, Milochia. Monteleone, li cui lib sinionate. 

FOSSILI ELVEZIANT DEL REGGIANO

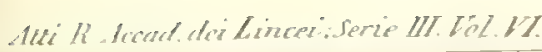

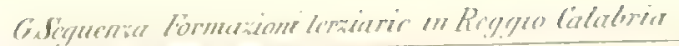

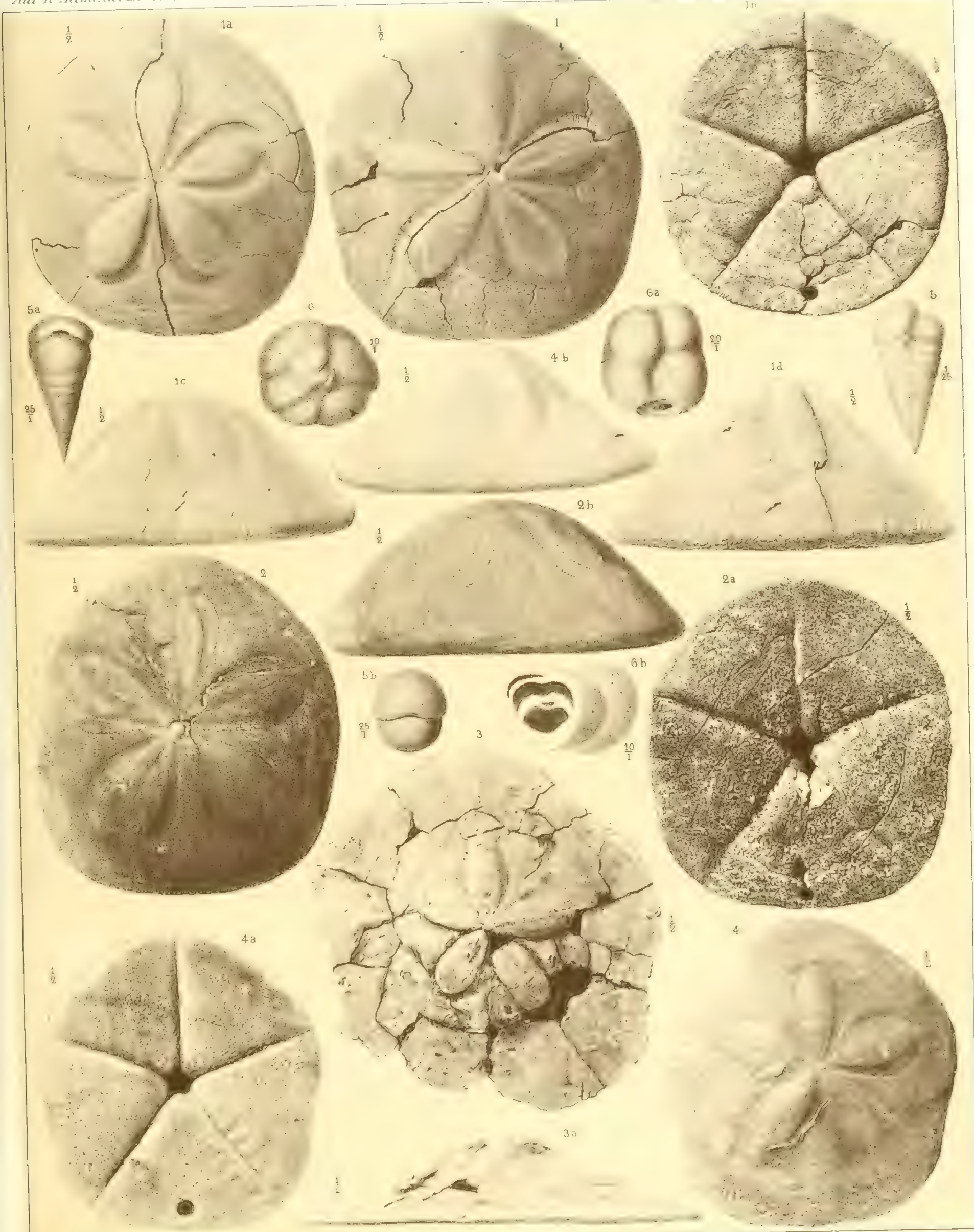




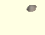




\section{Tavola XI.}

\section{EOSSILI TORTONIANI}

(Le specie di cui non è indicata la provenienza sono d't Benestare).

Fir. 1. Gylichna nana n. sp.

1. Un esemplare veduto dal lato dellapertura. la. Un altro guardato dalla regione dorsale.

¿. Marginella Benestarensis 13 . Sp.

2. Esemplare dal lato dorsale. 2u. Lo stesso veduto dal lato della bocc.

w. Ringicula calabro n. sp.

Uu esemplare guardato dal lato ilella bocca.

1. Mitra minima n. sp.

Esemplare rappresentato dal lato della bocca.

" כ. Mitra bicoronata n. sp.

Un esemplare veduto dal lato della bocca.

" 6. Drillia Luciae n. sp.

Ưn esemplare veduto dal lato dorsale.

7. Drillia globulifora n. sp.

Un incompleto esemplare.

- Drillia minor n. sp.

Un individuo guardato dal lato dorsale.

". Clavalula Monsleonensis n. sp.

Il solo esemplare raccolto presso Monteleone, rappresentato dal lato dorsale.

"11). Humotoma scaberrima n. sp.

Un esemplare dal lato del dorso.

"11. Raphitomu brevis n. sp.

Esemplare veduto dal lato della bocea.

" 1:. Rephitome harmulaeformis $\mathrm{n}$. sp.

Unico indiviluo figurito dalla regione dorsile.

"1:. Columbella inflata n. sp.

13. Un esemplare veduto dal lato della bocca. 13 2 . Apice dello stesso molto ingrandito.

"11. Columbella interposita 11. sp.

1.1. Unico esemplare figurato dil lato della bocca. 14a. Apice dello stesso molto più ingrandito.

》15. Cohumbella coronata 11 . Sp.

15. Un esemplare tipico. 15a. Un indiviluo della Var. striatu. 15b. Apice molto ingrandito.

"11. Columbella corrugata Brocchi.

Il solo apice molto ingrandito.

"17. Columbella nassoides Bellardi.

Apice ingrandito multo.

" I: Columbella Calcarae Seguenza.

Lipice molto ingrandito.

" 1:1 Columbella minor Scacchi.

Eapice di molto ingramlito.

‥ Culumbella Bollardii Seguenza.

Il solo apice molto ingramidit.. 
[ri... -21. Nassa crenatirosta v. sp.

Un esemplare guardato dallia regione boceale.

".... Eburna meridionalis n. sp.

22.2. Un esemplare guardato dal lato boccale. 2:a. Lo stesso rappresentato dal lato opposto.

"?3. Hurex Bellandii n. sp.

Un esemplare alquanto mutilato veduto dal lato della bocea.

21. Grithimm urliculalum 0. F. Costa.

24. Un esemplare tipico del territoriu di Monteleone. 24u. Un esemplare della l'ur. Iricingulın. delli stessa provenienzi.

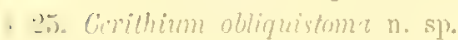

Un indivituo dal territorio di Monteleone.

- i: Cerithiolum simhum n. sp.

Un escmplare rapmesentato tal lato della bocca.

$\therefore \therefore$. Uithiopsis bicarinale n. sp.

Linxicu escmplare inutilate clse fin raccolto.

$\because$ Cuncell tric nussiformis n. sp.

Unico esemplare.

".9. bifrontia minima n. sp.

Liunico indiviluo racculto.

" in. Natica problema n. sp.

Un esemplare rappresentato dal linto dellapertura.

":1. Eulima lrevinscula n. sp.

Un esemplare gonardato dal latu dilla bucea.

. '. Turborillie sulpplicala n. sp.

Un esemplare mutilato all'apice.

".... Thubonilic minimu a. sj".

33. Un esemplare e mpleto veluto dal lato della bocca 33 . Lapice molta ingranditu.

":i1. Turbonilla grealis Brocchi. Var. dubia ns.

Un solo frammento, lounico raccolto.

$\gg \therefore$ Turbonilla méentu n. sp.

35. Inlividur veluto dal lato della bocea. 35a. Apice molto ingrandito.

.: i. Pyrrgulina curvicostu n. sir.

Esemplare incompleto.

.... Py/rgulines formosa n. sTr.

Ijusico esemplare merolto.

": . Olostimir angulosa n. sp.

38. Un exemplare veduto dal lato della boeca. 33 a. Apice dello stesso molto ingrandito.

. '." Olloslomice Fenus n. sp.

39. Il solo esemplare raccolto. $39 \%$. Apice dellu stesso molto ingrandito

" i". Cioniscus miocenicus us. sp.

Un esemplare intierissimo rulutu dal lato dolla bucca.

" 1. Scalaria rissoilles $n$. sp.

Un inclividno dal lato dellis boeca.

1'. Scalenia raricosen 11. sp.

L'unico esmplure incompleto raccolt.

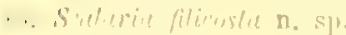

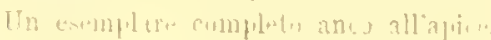


Fig. 44. Turrilella inacquisculpla n. sp).

Un esemplare un po' mutilato.

" 45. Setia globosa n. sp.

Un esemplare completo veduto dal lato dell'apertura.

» 46. Alvania obliquisculpta n. sp.

Esemplare intierissimo reduto dal lato della bocea.

" 1 . T. Turbo? reliculalus $\mathrm{n}$. $\mathrm{sp}$.

Esemplare rappresentato dal lato della bocca.

"18. Dentalizm inaequicosta n. sy.

48 e 48a. Due porzioni diverse associate insicme per che chisra idea della furma generale di questa specie.

"1?. Dentalium prismaticum n. $\mathrm{sp}$.

49 e 49a. Due porzioni associate insieme per clure la forma totale della specie.

"il. Helonyx tenuis n. sp.

Un completo esemplare.

" il. Cuvieria conica n. sp.

Un incompleto esemplare.

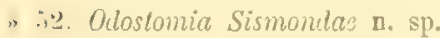

Il solo apice ingrandito molto.

"jii. Orlostomia conoillar Brocchi.

Il solo apice ingrandito di molto.

"51. Limopsis calabra n. sp.

54. Una valva veduta all'esterno. 54a. Una valva veduta lall'interuo.

"5.). Lepton lamellosum n. sp.

5.5. Una valva veduta clall'interno. $55 a$ lai stessa guarlata d.l lato esterno.

"56. Janira pumilu n. sp.

56. Una valva inferiore verluti all cuterno. 56a. Porzione marginale della stessa molto ingrandita. 56b. Una ralva superiore rappresentata dalla superficie esterna. $56 c$. Un frammento marginale della stessa molto ingranditu. 

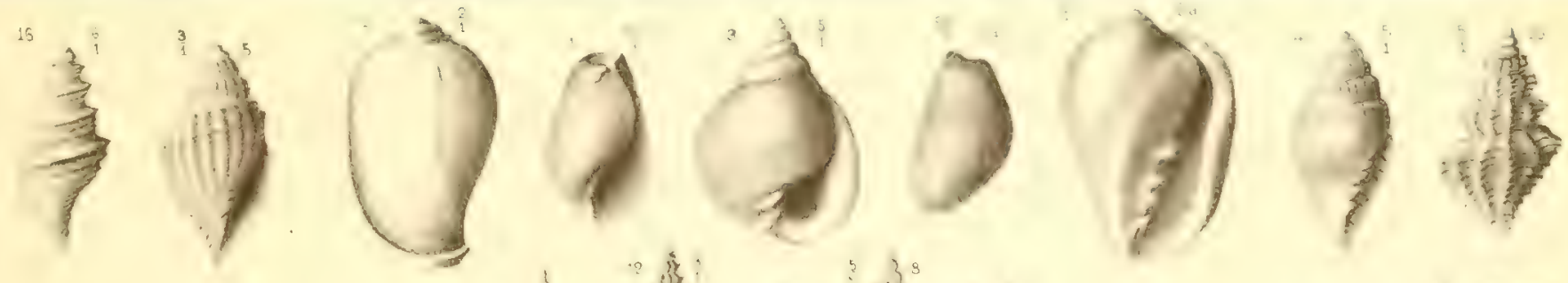

He

(1) 13

12

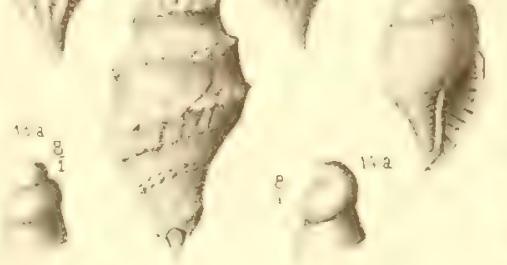

敉

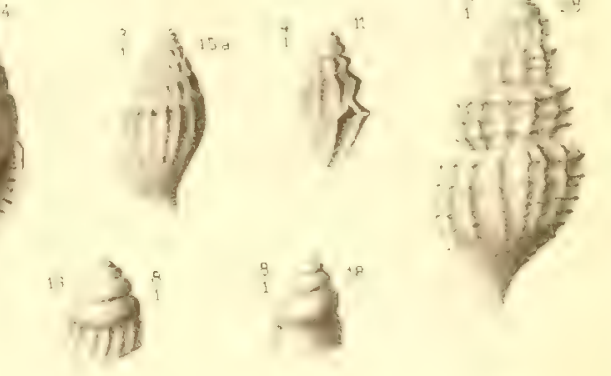

$\left.11\right|^{25}$

in

$\int_{0}^{3}$
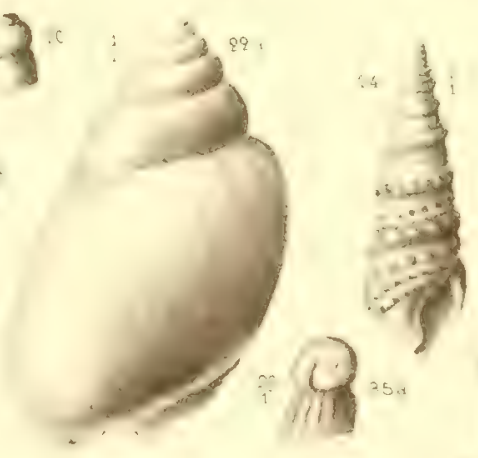

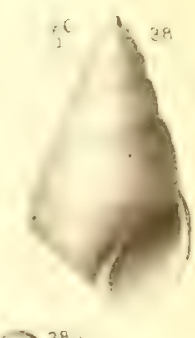

$\left.\left(f^{32 a}+1\right)^{52}\right)$

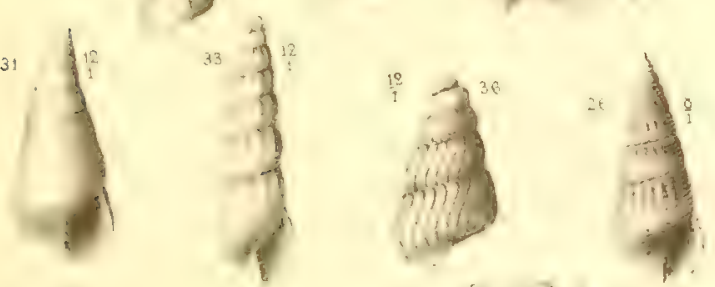

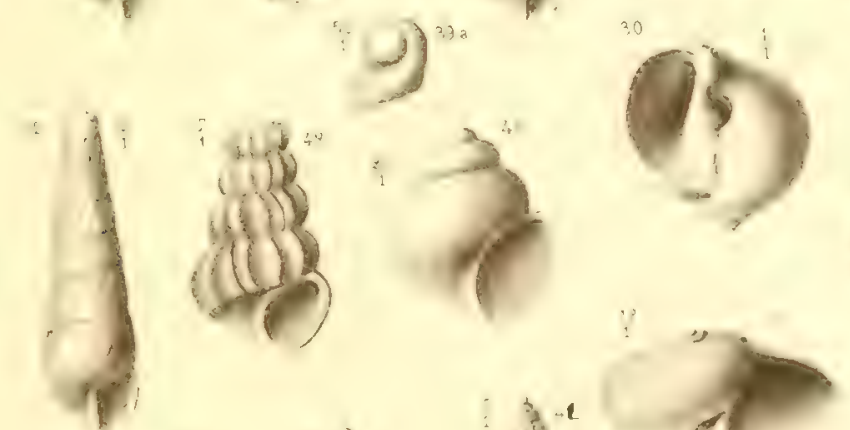

11

(ค)

19

1) 5

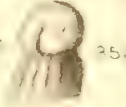

$183^{28}$

i $3 y^{3}$
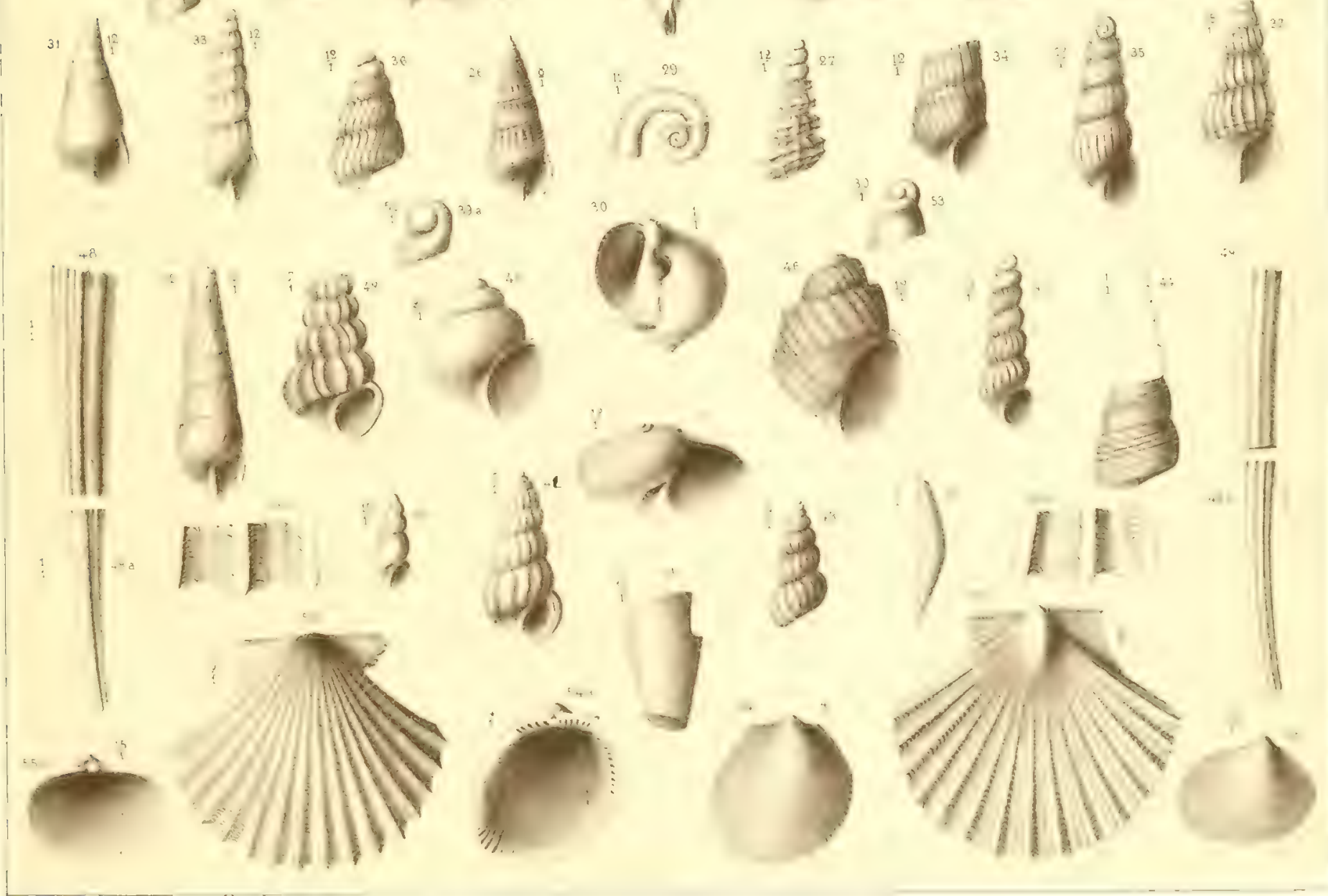



\section{Tavola XII.}

\section{FOSSILI TORTONIANI}

(Le specic di cui non è indicata la provenienza sono lia Renestare).

liig. 1. Ostrca lenuiplicale n. sp.

1. Valva superiore reduta dall"esterno, 1a. Valra inferiore dall"interno. 1b. Valva infuriure dall'esterno.

.. Ostrece acuticosta n. sp.

2. Valva superiore guardata all'esterno. $2 a$. La stessa reduta all'interno.

$\therefore$ C'ypris angulosa 11 . sp.

Unica ralva raccolta, rappresentata dall'esterno.

4. Cythro senuinulun n. sp.

4. Veduta lateralmente. 4a. Veluta dal lato superiore.

$\therefore$ Cythere gibboso-foveolalie n. sp.

5. Rappresentrita dal lato inferiore. 5a. Veduta lateralmente.

》 t. Cuthere sublrigone n. sp. Var. marginato-slriala n.

6. Guartata dalla regione inferiore. 6a. Rappresentata lateralmente.

i. Cythere semilunatu n. sp.

Veituta lateraimente.

$\therefore$ Cythere flabellaia n. sp.

Rapiresentata lateralmente.

»: Cylhere letraptera n. sp.

9. Veluta lateralmente. 9u. Guariata dalla regione inferiore.

"11". Loroconcha obliquak n. sp.

Veduta laterilmente.

. 11.. I'sygmobrancius firmus 11. sp.

11. Un frammento. 11a. Lo stesio veduto dall'apertura.

" I.:. Filigrema rugosu n. sp.

Indivilui varî insieme aggruppati.

" li. Syirortis ublectus n. sp.

Un esemplare fisso sull'Ancillarin grandiformis.

11. Gemellerie punctulu n. sp.

11. Linico esemplare raccolto veduto lateralmente. 14 . Lo stesso veduto di fronte.

- 12. Bactridirm Hensonti n. sp.

15. Uı esemplare rappresentato dul lato delle cellule. $15 a$. Lo stesso veduto dal lato posteriore. 1;. Terebripure tenuis n. sp.

Una colonia che perfora un fommento di l'usus.

"17. Spulipora luxu n. sp.

Una colonia sulla interna superficie dell'Ancillaria glandifurmis.

"1-. Membranipora crispa n. sp.

Una colonia che incrosta il Dentalium inuequicosti.

"19. Lepralie radialo-porosa $\mathrm{n}$. sp.

l'iccola porzione d'una grande colonia che giace sopr.h un frammento di un tiasteropodo. 
Fis. 20. Lepretia rediats-foveolala $\mathrm{n}$. sp.

Parte d'ma piccola colonia.

"?!. Cumulipora grunosa n. sp.

2L. Porzione d'una colonia a cellule non prolifere. 21 4 . Cellule jrolifere d'un'altra colonia.

"22. Urbilulipora execnlrica n. sp.

22. Un esemplare completo. 22a. Lo stesso veduto lateralmente.

"2:3. Ihomieschara varians n. sp.

I'arte di un frammento di colonia.

》24. Eschara reticulata n, sp.

Poche cellule di una colonia incompleti.

- 2.r. Selenaria miocenica s. sp.

25. Parte superiore d'un frammento. '25a. Iato inferiore dello stesso.

2.: C'risia marginala 11. sp.

Livnico esemplare raccolto.

":- Hornerel simplex n. sp.

-27. Colonia reduta dal lato delle cellule, 27a. La stessa dal lato posteriore.

" $\because 3$. ldmonca spica n. sp.

2s. Un esemplare rappresentato dal lato delle cellule. 2sa. Lu stesso veduto dal lato opposto.

》29. Cliona lubulosa n. sp.

* 29. Una colonia giacente sul Pecten Besseri, dellelvezinno di Ambuti. 29a. Varie colonio cho perfurano un frammento di couchiglia del Tortoniano di Benesture.

》30. Cliona vermicularis n. $\mathrm{sp}$.

Dalla superficie di un Conus che è perfurato dapertutto.

31. Cliona micropora n. sp.

Dalla sunefficie di un frammento di conchiglia di (1)nsteropolo.

》32. Cliona oostoma n. sp.

Di unita alla precedeute. 

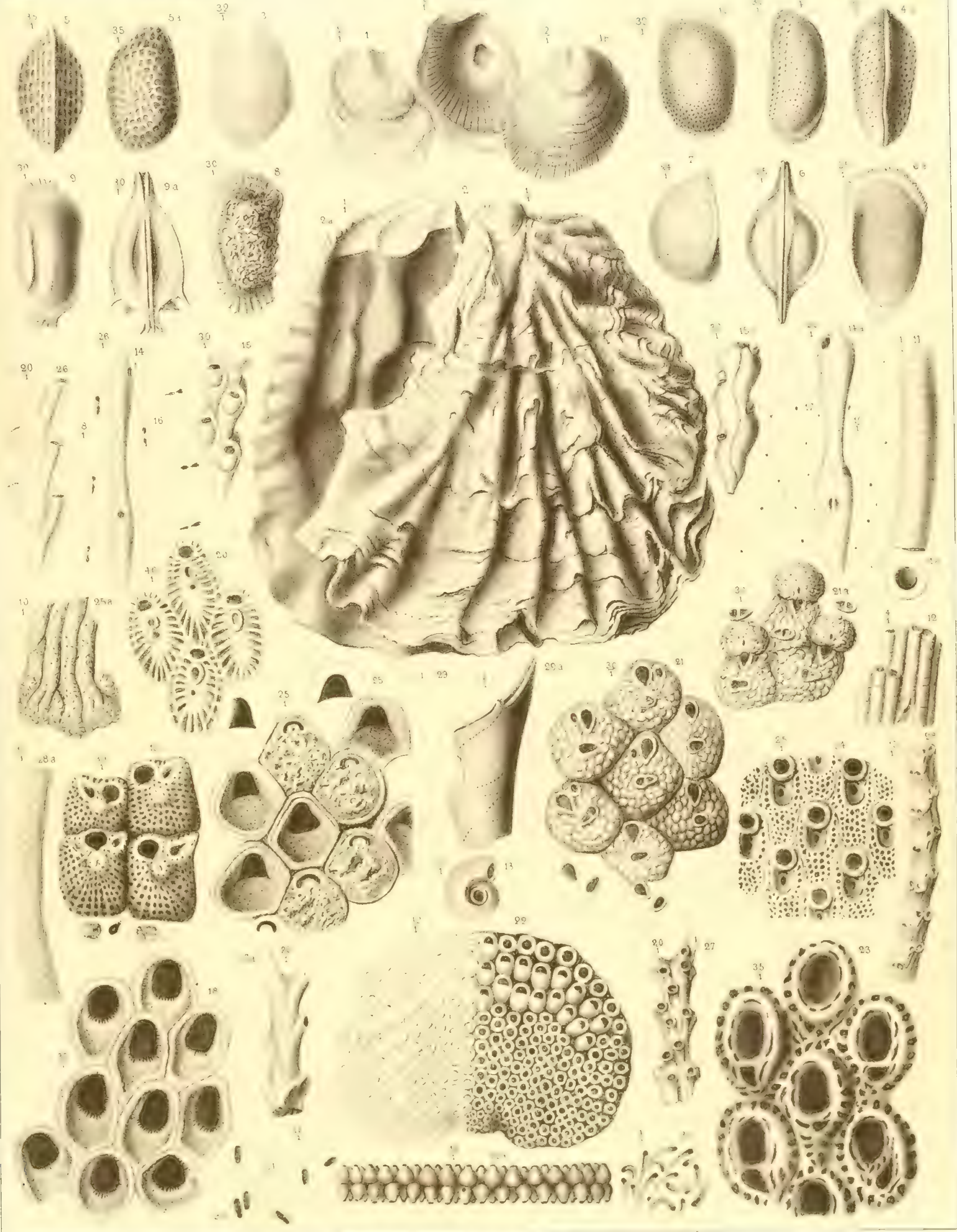



\section{Tavola XII.}

\section{FOSSILI TORTONIANI}

(Le specie di cui non è indicata la provenienza suno da Benestare).

Fig. 1. Fissurina punctata n. sp.

Un esemplare guardato di fronte.

"2. Tolnsaria typus n. sp.

Un individuo completo.

3. Denlalina Bemicostala n. sp.

Un esemplare considerevolmente curvo.

- 4. Dintalina binestarensis n. sp.

Un esemplare completissimo e traslucido.

\5. Dentalina crassicamla n. sp.

Un esemplare intiero ed opaco.

" f Dentalina solida n. sp.

Un individuo completo.

7. Burseolina Calabra n. sp.

7. Un esemplare verluto dal Iato della bocea. $7 a$. Lo stesso veduto dal lato opposto. $7 b$. Lo stesso rapprescntato lateralmente.

》8. Psecadium ovalum n. sp.

Il solo esemplare raccolto.

๑) Marginulina pupoides $\mathrm{n}$. sp.

9. Un esemplare conservatissimo. Sa. Lo stesso dal lato dell'apertura.

"10. Cristellaria articulata n. sp.

10. Un individuo veluto lateralmente. $10 a$. I ${ }_{0}$ stesso veduto dal lato convessos.

》11. Marginulina nodosa n. sp.

11. Un completo esemplare. 11 $\alpha$. Sezione trasversale dello stesso.

》12. Crisicllaria legumen n. sp.

12. Un esemplare intierissimo. 12 . Una sezione della regione posteriore.

"13. Cristellaria paucisenta n. sp.

13. Un esemplare reluto lateralmente. 13a. Lo stes:o dalla regione dell'apertura.

"14. Cristellaria cassis Lamarck. Var.

Un eseimplare reduto lateralmente.

\$15. Cristcllaria disco-granulata n. sp.

Un esemplare rappresentato lateralmente.

"16. Planularia lacvis n. sp.

16. Un esemplare veduto lateralmente. $16 a$. Lo stesso dal lato dell'apertura.

》17. Planularia falcala n. sp.

Un esemplare veluto lateralmente.

\#18. Robulina simplicissima n. sp.

18. Fsemplare rappresentato di lato. 18a. Lo stesso veduto dal lato dell'apertura.

$\gg$ 19. Robulina lucida n. sp.

19. Un esemplare veluto di lato. 19a. Lo stesso veduto dal lato delliapertura.

"20. Robulina curvisepta n. $\mathrm{sp}$.

20. Un esemplare vedutu lateralmente. 20a. Lo stesso dall'apertura. 
Fis. 21. Robulina confusa n. sp.

21. Un csemplare figurato da un lato. 21 a. Lo stesso veduto dalla regione dell' apertura.

त22. Robulina oblusimargo n. sp.

22. Esemplare figurato da un lato, 22a. Lo stesso dal lato delli pocca.

»23 Robulina gravida n. sp.

23 e 23 . Un esemplare giovane rappresentato in due nosizioni. $23 b$ e 23c. Var. A. paucisepta n. Un esemplare veduto in due posizioni. $23 d$ e $23 c$. Var. B. multisepta n. Un esemplare in due posizioni. 23f. Var. $C$. discoidea $n$. Un solo esemplare veluto di lato.

2) 21. Robulina rostrata $\mathrm{n}$. sp.

24. Esemplare reauto lateralmente. $21 \%$. Lo stesso dal lato dellapertura.

"… Kobulina serpens 11 . sp.

25. Un esemplare veduto lateralmente. 25a. Lo stesso dalla regione dell'apertura.

»2ti. Robuline temuis n. sp.

26. Un esemplare veduto lateralmente. 26a. Lo stesso dalla regione dell'aperturia.

" 2 . Robulina vilrea n. sp.

27. Esumplare reituto di lato. $27 a$. Lo stesso dal lato dell'apertura.

" $\cdots$. lobulina curvispira n. sp.

$28,25 \%$. Forma tipica in due posizioni. 28b, 28c. Var. gibba. Un esemplare in due posizioni.

. 2!! Robulinu stollate n. sp.

Esemplare rapresentato lateralmente.

, : Robulina dubic n sp.

30. Un inliviluo veluto lateralmente. $30 a$. Lo stesso dal lato dellapertura.

":i1. Robulina curvicostu n. sp.

31. Esemplare veluto di lato. 31a. Lo stesso dill'apertura.

" ¿.. Robuline formosissina n. sp.

32. Femplaro rappresentato lateralmente. $32 a$. Lo stesso dalla regione dell'apertura.

":3:3. limbul na dilecta n. sp.

33. Un bello esemplure veduto di lato. 33a. Lo stesso dal lato dell'apertura.

"::1. Bulimina Burhiana Dorbigny. Var. Calabra n.

Un esemplare completissimo.

". Bullimina bubiformis 11. s1).

Un esemplare veduto dal lato dell'aperturia.

"30. Bulimine calcurala n. sp.

Escmplare con sperone trilobo.

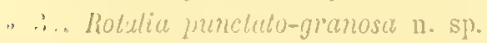

37. Un srande csemplare veduto dal lato della spirale. 37a. Lo stesso veluto lateralmente. 3ib. Un altro individuo rapipresentato dal lato superiore.

»in. Rioluclia lobata 11. sp.

38. Un esemplare dal lato superiore. $3 \$ a$. Lo stesso dal lato inferiore. 3sb. Il medesino individuo rappreseritato lateralmente.

39. Discorlina veslite n. sp.

:9. Un piccolo esemplare clalla regione superiore. $39 a$. Un esemplare più grande dal lato inferiore. $39 b$. Lo stesso veduto di lato. 


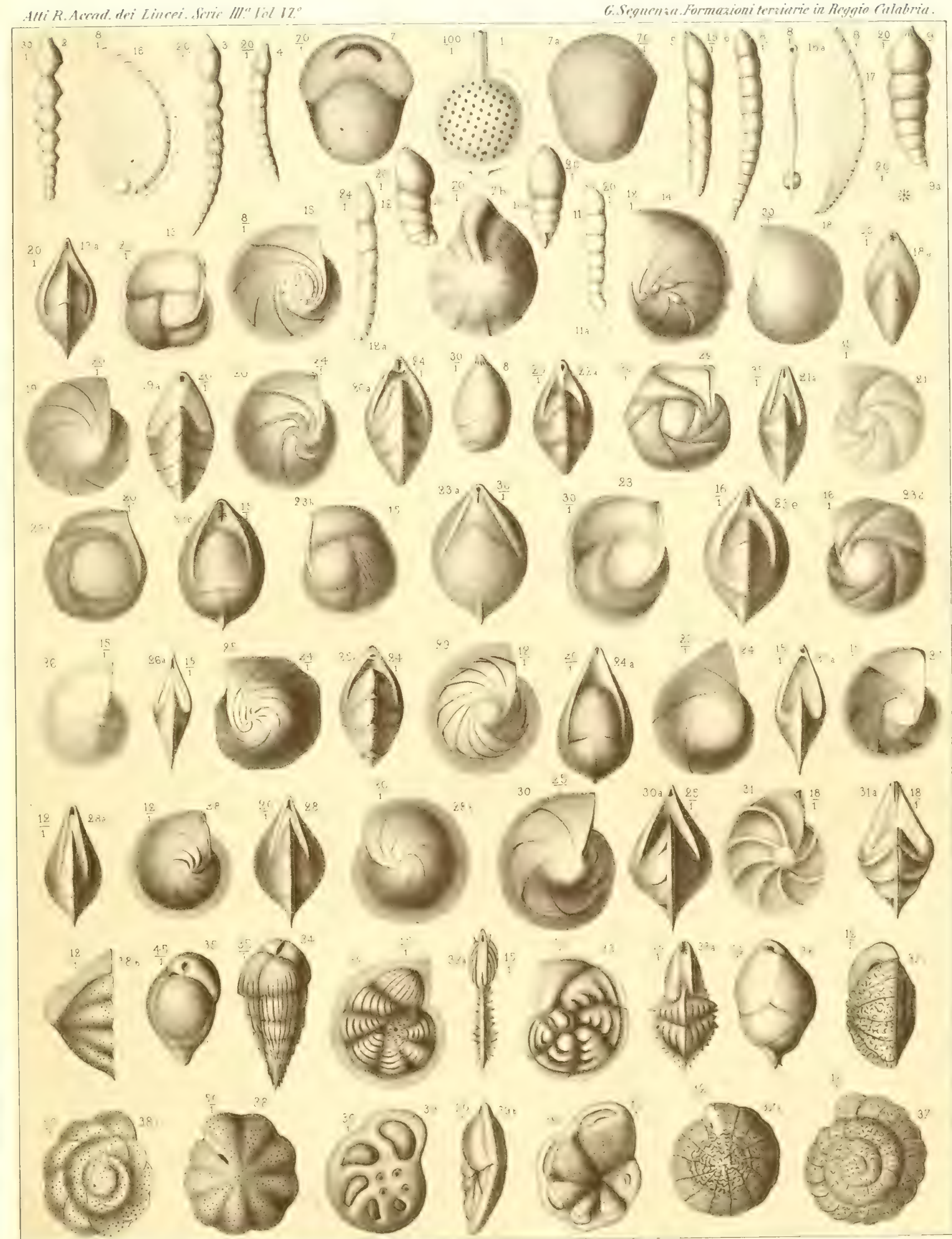





\section{Tavola KIV.}

\section{FOSSILI TORTONIANI}

(Tutti di Benestare)

I.j r. 1. Discorbina minutissima घ. sp.

1. Un esemplare veduto dal lato dell'aperturic. 1a. Lo stesso dal lato della spirale. 1h. Io stesso guardato lateralmente.

" $\therefore$ Discorbina granose $\mathrm{B}$. Sp.

2. Un esemplare rappresentato dal lato dellapertura. 2u. Lo stesso veduto dal lato dellı spirale.

* Discorbina perforata n. sp.

3. Un esemplare irregolarmente sviluppato perchè fisso su d"un corpo cilindrico e gracile, veduto dal lato dellir spirale. $3 a$. Lo stesso rappresentato dal lato opposto.

1. Truncatulina spirata n. sp.

4. Un esemplare veduto dal lato superiore. $4 a$. Lo stesso rappresentato dal lato della spirale. 4b. Lo stesso dato lateralmente.

" i. Truncululina formosa n. Sp.

5. Un esemplare osservato dal lato superiore. 5a. L'esemplare stesso guardato di lato. 5h. Lo stesso individuo vecuto dal lato della spirale.

i. Truncatulina Karreri is. \$p.

6. Esemplare guardato dal lato superiore. 6a. Lo stesso dal lato della spirale. 6b. Loindividu stesso veduto lateralmente.

i. Plecunium irregulare $\mathrm{n}$. $\mathrm{sp}$.

7. Individuo veduto anteriormente. 7↔. Lo stesso dal Iato dell'apertura.

. Plecenium costatum n. sp.

8. Un esemplare veduto di fronte. 8 . Lo stesso veduto dal hato superiore.

11. Plecunium tuberiforme 11. sp.

9. Un esemplare veduto di fronte. 9a. Lo stesso guardato lateralmente. $5 b$. Un giovane esemplare.

× 10. Spiroloculina crassa 1]. sp.

10. Un individuo guardato di fronte. 10a. Lo stesso dal lato dell'apertura.

- 11. Biluculina disgiunta $\mathrm{ns}$. sp.

11. Un esemplire veluto dalliapertura. 11 $u$. Lo stesso di fronte.

12. Triloculina striarella n. sp.

12. Esemplare guardato da un lato. 12a. Lo stesso dal lato oppusto. I2b. Lo stesso dal lato dell'apertura.

13. Quinqueloculina Schrokingorii Karrer. Var. Galabra n.

13. Esemplare veduto di fronte. $13 \%$. Lo stesso dallaperturil.

\section{FOSSILI \%ANCLEANI}

- 14. Scalaria Aspromontana n. sp.

Un esemplare raccolto presso Terreti.

1.i. Scaleria Rhegiensis n. sp.

Un esemplare raccolto a Valanidi sull destra lella valle. 
Fig. 1i. Janima laevicostata n. sp.

16. Individuo di Terreti guardato dalla sua valva inferiore. 16a. Profilo laterale dello stesso.

"17. Janira Rhegionsis u. sp.

1\%. Valva inferiore da Terreti. 17a. Valva superiore dello stesșo luogo. 17b. P'rofilo laterale Iel melesimo inlividuo.

li. Cythere sororcula n. sp.

18. Un esemplare veduto da una valva raccolta a Nasiti. 184. Lo stesso guardato lateralmente.

"1?. Pontocypris compressa n. sp.

19. Un esemplare che mostra una valva. 19a. Lo stesso guardato dalla commissura.

"211. Culheridea similis 11 . sp.

20. Un individuo racolto a Terreti. $20 a$. Lo stesso mostrato dal lato della commissura.

$\gg: 1$. Cuberca Boryi Auduin.

21. Un esemplare da Testa del Prato veduto di fronte. $21 a$. Lo stesso osservato dal lato opposto ove sono gli aricularii.

.. 1..). Linmeliu furmose 11. sp. Var. Liamate n.

I'urte d"una colonia incrostante la Janira fubellifurmis, raccolta a Terreti.

»3. Le prolia cximia 11. sp. .

Cellule d'ma colonia che incrosta m Ostrica meculta a Terreti. 

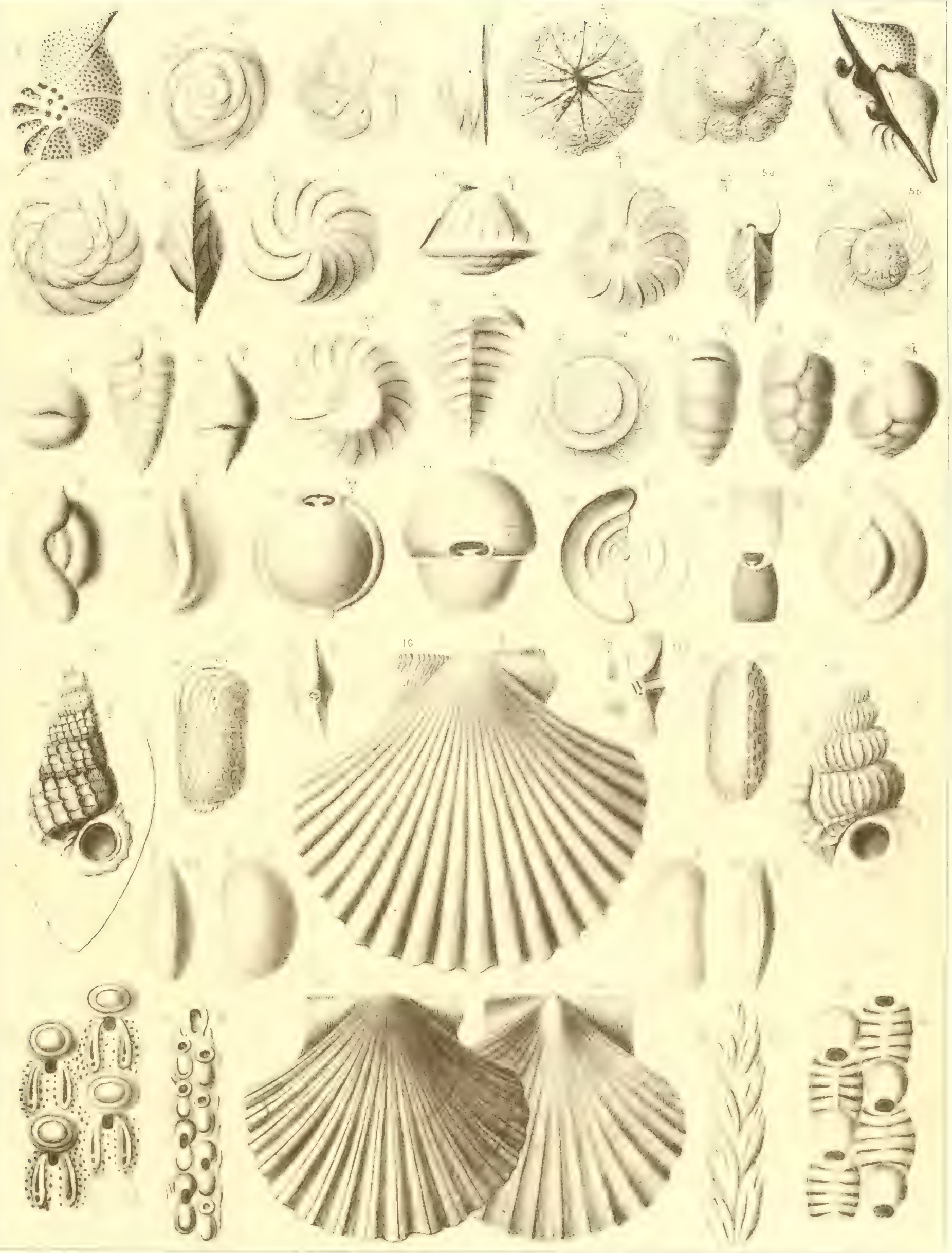



\section{Tavola XV.}

\section{FOSSILI ZANCLEANI}

Fig. 1. I'crmilit perforata n. sp.

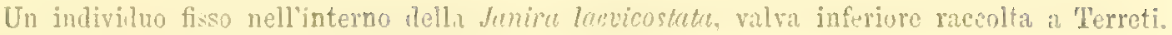

"2. Membranipora andogavensis (Michelin). Var. incise $\mathrm{n}$.

Piccola porzione d'ana grancle culonia che incrusta la valva piana della deniru flubellifurmis raccolt.r a Terreti.

"3. Mombranipore exagona $\mathrm{n}$. sp.

Parte d'una colonia aderente alla Janira flebelliformis da Terreti.

1. Lepralia gramlis n. sp.

Da una colonia sulla Janira flabelliformis raccolta a Terreti.

». Lejmulit strenuis Manzoni. Var. Laciniata n.

Cellule d'una colomin allerente al Pecten senlmillus da 'T'erreti. .

\%. Leprolie Culubre no sp.

6. Parte d'una colunia prolifera che incrosta una valva rel Bulanus concruus liteculta a l'esta del Prato. Go. Da una culonia priva di ovicelli arlenente al $L$. tulipiformis ricculto a 'Testit del Prato.

"7. Lemalia congesha n. sp.

Porzione d'una colonia sull'interno d'una valva della Terebratula Calabra raccoltis a Terreti. ¿. Lepralia milrula n, sp.

8. Franmento d'una grande colonia cho incrosta lostrea Boblay racenlta a Testa del Prato. Sa. Var. radiuns n. Da una colonia sul Piclen sezhrollus riccolto a Terreti.

"9. Lemalia marrocephala $\mathrm{n}$. sp.

Da colonia inerostante la Janira flabelliformis raccolta a Terreti.

»10. Lepratia arlpressa n. sp.

I'arte d"una srande colonia che incrosta l'interno d'una valva del pecten scabrellu. dia Terreti.

"I Lepralia Pralensis n.sp.

11. Porzione radiante d'una completa colonia aderente alla Jomira flabellifurmis raccolta a Testa del rrato. Ila. Disposizione radiato-licotoma che assume costantemente in guesta specie l'associazione delle ccllule.

"12. Lepratia slcilula n. sp.

12. Frazione d"ma colonia che incrosta il Balamus cmanus raceolto a lesta ilel Prato. 12ie. Figura teorica del molo come si dispongono costantissimamente le serie di cellule in questa specie.

"13. Lepralia deltostoma $\mathrm{n}$. sp.

l'arte d'una colonia che giace su d'una Amira flubellifurmis da Terreti.

》11. Eschare microlhece 11. sp.

Frazione d'un esemplare raccolto a 'Testa del Prato.

»15. Eschara quitrilatora n. sp.

P'arte dell'unico escmplare raccolto a 'l'ista del l'rato.

"16. Lelinanca crussa $11 . \mathrm{sp}$.

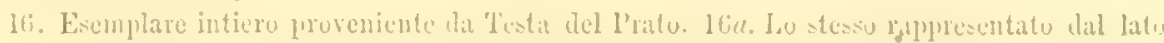
posteriore. 
Fig. 17. Idmonea conforla n. sp.

1\%. Un frammento veduto ital lato ielle cellnle racculto a Teveti. 1\%a. Lo stesso grardato dal lato posteriore. 17b. Sezione di un ramo. 17c. Colonia pressochè completa della stessa provenienza.

"18. Ilmonea producta n. sp.

18. Un ramo dal lato delle cellule proveniente da Terreti. 18a. Altro ramo reduto dal lato pusteriore. 18b. Sezione trasversale. 18c. Due colonie da Terreti e da Tusta del Prato.

"16. Hornera serrala lienss. Var. pliocenica n.

19. Un ramo dal lito delle cellule, raccolto a Terreti. 19a. Lo stesso veluto dal lato posteriore. "2. Hornera cylindrucea n. sp.

20. Un ramo raccolto a Testa del Prato. 20a. Altro ramo reduto dal lato posteriore. Var. prominens $\mathrm{n}$.

"21. Un ramo raccolto coi precelenti.

$\gg 2.2$. Filisparsa lata n. sp.

22. Parte di un ramo dei numerosi raccolti a Testa del Prato. 22 2 . Lo stesso veluto dal lato posteriore.

"23. Tubulipora seriutopora n. sp.

Una parte l'una colonia che incrosta una valva del Pecten scabrellus raccolto a Terreti.

"21. Tubulipora foliacer (Reuss.)

Piccola porzione duna grande colonia che incrosta l'interno di un Bulanus tulipiformis raccolto a Terreti.

"25. Tubulipora fasciculata n. sp.

Una intiera culonia che giace sulla faccia interna d'una Ostrica insieme ad altra colonia rilccolti a 'Terreti.

"26. Palinclla Manzonii u. sp.

26. Mezza colonia veluta dal lato superiore raccolta a Testa del Prato. $26 a$. Una delle lamine radianti costituita dall'associazione di tubi pressuchè retti. 26b. L'esterno della stessa colonia.

"־. Clypeaster pliocenicus n. sp.

2\%. Lato superiore d'un esemplare raceolto a Testa lel Prato. 27a. Lato inferiore dello stesso. $2 \%$. Il medesimo esemplare guarlato lateralmente. 


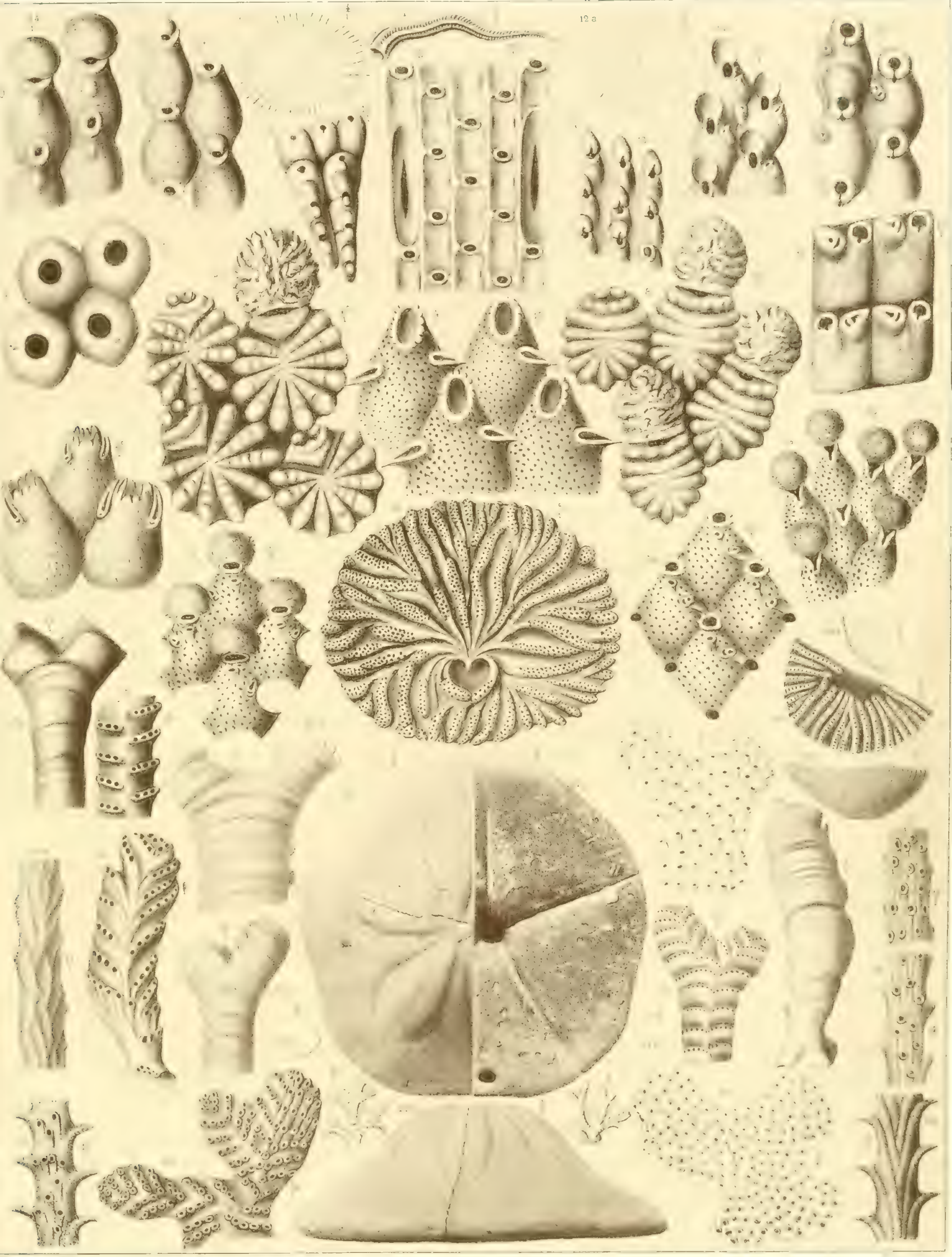




\section{Tavola XVI.}

\section{FOSSILI ASTIANI}

Fig. 1. Scaphander Jefreysii n. sp.

1. L'csemplare piư grande che è stato mecolto a Gallina rappresentato dal lato dell'aperturil.

la. Lo stesso reduto dal torso. Ib. La scultura molto ingranclita.

".. Scaphander inaequiseulptus 17. sp.

2. Un esemplare dei più grandi di Gallina, reduto dal lato dell'ipertura. "2u. La scultura ingrandita.

$\because$ Philine reliculum $\mathrm{n}$. sp.

3. Un individuo guardato dal lato della bocea raccolto a Gallina. Je. La scultura molto ingrandita.

1. Bulla grandis $11 . \mathrm{sp}$.

Un esemplare completo rappresentato dal lato dell'apertura raccolto insieme a molti frammenti presso Gallina.

„. Bulla semilaetis Jeffr.

Un individuo completo raccolto di unita a molti alla contrada Gallina.

* 1). Bulla cylindracea n. sp.

L'unico esemplare raccolto a Gallina e rappresentato dal lato della bocer.

" - Bulla pinguicula Jeftr.

Uno dei molti esemplari raccolti a Gallina.

" Actacon foveolalus n. sp.

8. Unico esemplare raccolto a Gallina. 8a. Scultura ingrandita.

. $\therefore$ Bullina undata. Delle Chiaie.

Un indiviluo dei molti raccolti a Gallina.

"1". Utriculus Jelasii n. sp.

L'unico esemplare raccolto presso Bianco-muoro, reduto dal lato della bocea.

" I. Cylichna volvulaeformis n. sp.

Un individuo dal lato dell'apertura raccolto a Gallina.

* H. Marginella ovulaeformis n. sp.

Uno dei comunissimi esemplari di Gallina.

"1:. Ringicula biplicata n. sp.

13. Un esemplare dei molto comuni di Gallina. 13a. Un indiriduo della Var. dongalu n.

- 11. Surcula pugnea Phil. Var. difformis n.

Un esemplare dell'Astiano di Monosterace.

" 1i. Surcula Monosteracensis n. sp.

Un esemplare di Monosterace.

- 11. Clinura Gallinae n. sp.

Un individuo della contrada Gallina veduto dal lato della bucea.

" T. Clinura clethata n. sp.

Il solo esemplare raccolto a Sillermo.

- I. Aphanioma Bellardii n. sp.

Esemplare raccolto a Gallina. 
Fig. 19. Aphanitoma firacei (Philippi) Var. cingulate n.

Un esemplare di Gallina veluto (hll lato della boccilo

,20. Homocoma cincta $11 . \mathrm{sp}$.

Esemplare raccolto presso Bovalino.

»21. Homoloma multicingula n. s1.

Il piil graule esemplare raccolto a Gallina.

"2.2. Ruphitoma cchinale 11. sp.

Limico esemplare riccolto a Monosterace.

"2\%. Nussa turbinclloides n. sp.

Un individuo dei moltissimi che racolgonsi alla contradı Gallina.

"24. Turbonilla scalariformis n. sp.

Unico esemplare raccolto pressu Gallina.

"25. Turbonilla magnifica $\mathrm{n.} \mathrm{sp.}$

Uno legli inlividui raccolti presso Gallina

"26. Scalaria Mantovani 11. sp.

Un esemplare raccolto a (iallina.

27. Trochus lacvissimus n. sp.

Un individuo dell'Astiano di Gallina

"28. Trochus distincius n. sp.

Uno degli escmplari rinvenuti a Gallina.

"29. Scissurclla temisculpla n. sp.

Un indiviluo di quelli raecolti a tiallius.

":31). Srissurelle argutaccusluta n. sp.

Un esemplare dal lato dellapertura meculto a siderno.

31. Scissurella aspera Philippi.

Un esemplare lei varî raceolti a riallina.

.32. Scissurclla eximia n. sp.

Un esemplare raccolto a Gallina.

.. 3\%. Uentalizm irregulare 13. sp.

33. Un individuo completo dell'Astiano di (iallina. 339a. Listremiti pusteriore della stesso.

"3:. Embolus bellerophina n. sil.

31. Un esemplare di quelli raccolti a Gallina. 34 a. 316 . Lo stesso veluto in un altre posizioni. "35. Butantium acutissimun n. sp.

35. Un esemplare quasi completo raccolto a Gallina. 35a. Lo stesso veluto lateralmente.

.":36. Cuvieria striolala 3 . हp.

Un individuo raccolte a Gallina.

"37. Spheniu carinala 11. sp.

37 e $37 a$. Una valva raccoltá a Găllina veluta all'estermo ed all'interno.

".8. Nenere tenuilamella n. sp.

33 e $38 a$. Due valve provenienti d.a Gallina e velute all'interno una. e l'altra all'esterno.

"34. Grassalplla jarva 11.81 .

39 e $39 a$. Una valva raccolta a Gallina rappresentata dal lato intemo e lal lato estomo.

"11. Carilia rovoluke Seg.

10 e $40 a$. Una valva raccolta a Gallini rappresentata dai lati esterno ed interno

"11. Lacina Aspromonlana n. sp.

$41 \mathrm{e}$ kl. Un esemplare di s. ${ }^{2}$ Cristina veluto da un Iato e dall'apice.

* 12. Limopsis clathrala 3. sp.

12 e $12 \alpha$. Una valva da liace veluti all'estemo ed all'interno. 
Fin. 43. Nucula confusa n. sp.

43. Un esemplare raccolto a Gallina voluto lateralmente. $43 a$. Lo stesso guardato all interno di una valva.

》44. Nucula inflata 13. sp.

44 e 4 a. Un esemplare di G.ullina guardato literalmente e dal lato della lunula.

"15. Pleuronectia difformis $\mathrm{n}$. $\mathrm{sp}$.

45 e $45 a$. Le due valve mecolte a liace rappresentate all'estemo. 45b. Una li esse veduta all'interno.

"46. Cigchere humilis n. sp.

46 e 46 . Un inlividuo dell'Astiano di dillina veluto in due posizioni.

\% 47. Cythere avirostris n. sp.

47 e $47 u$. Un esemplare di Gallina verluto in due posiziuni.

"18. Cythere raliatopora n. sp.

48 e 48 a. Una valva da Vialanidi reluta in due posizioni.

"19. Cylherideu foveolato $\mathrm{us}$. sp.

19 e $49 a$. Un esemplare di (iallina rilluresentatu in the posizioni.

"50. Cytherielea junctatu-compressa n. sp.

50 e 50a. Un indiviluo raccolto a (rillina e figurato in the posiaioni.

"51. Cytheridea lueich n. $\mathrm{sp}$.

51 e 5la. Una valva da Riace in due pusizioni.

"ì. Loxoconcha legumen. n. sp.

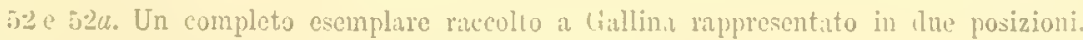

》53. Luroconchue fabacea n. sp.

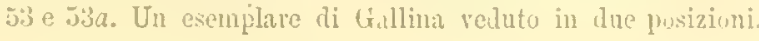





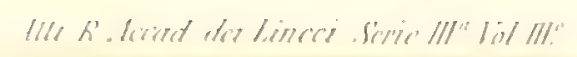
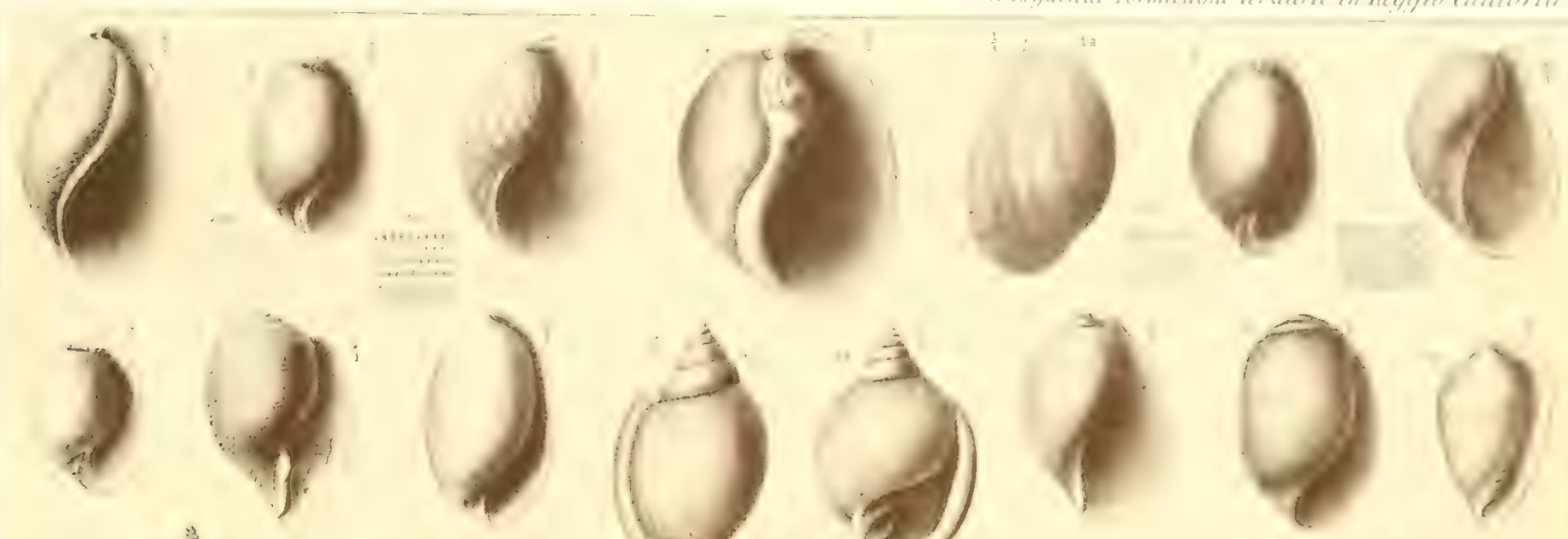

A

-
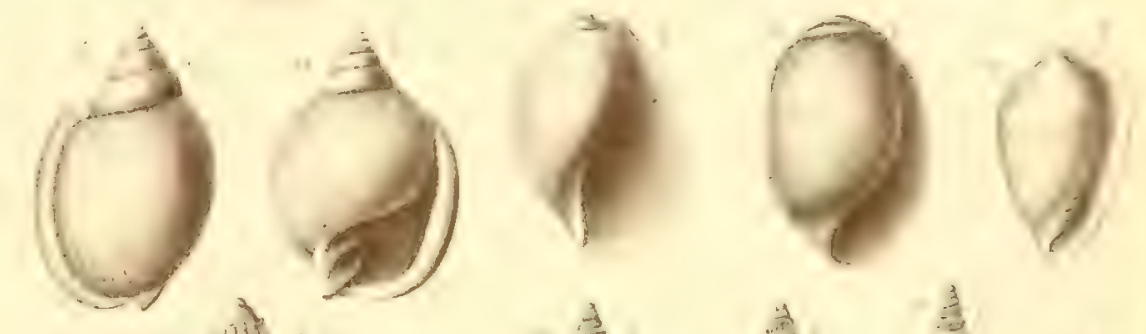

7
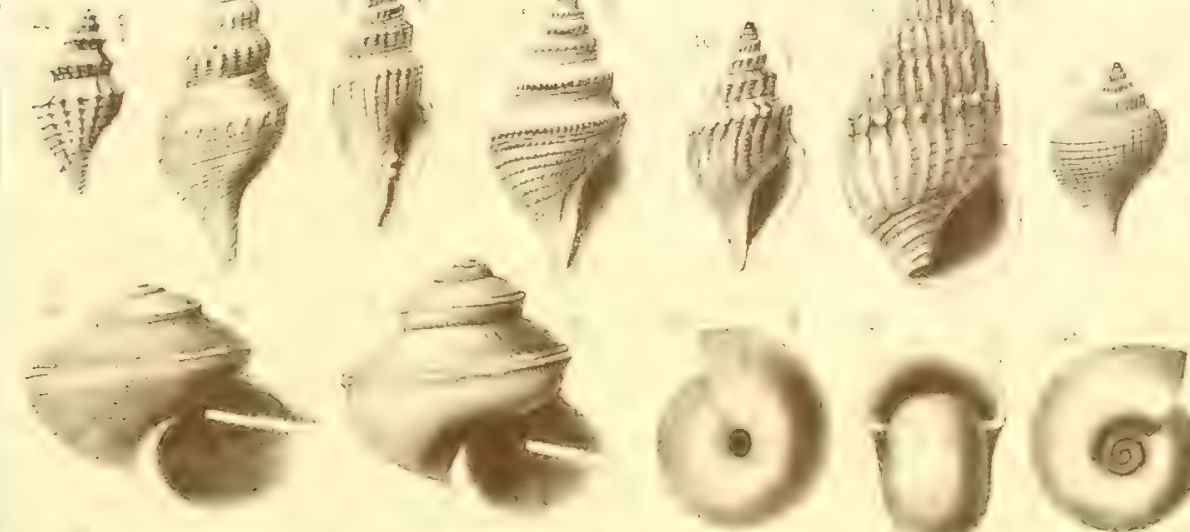

$+3$

17
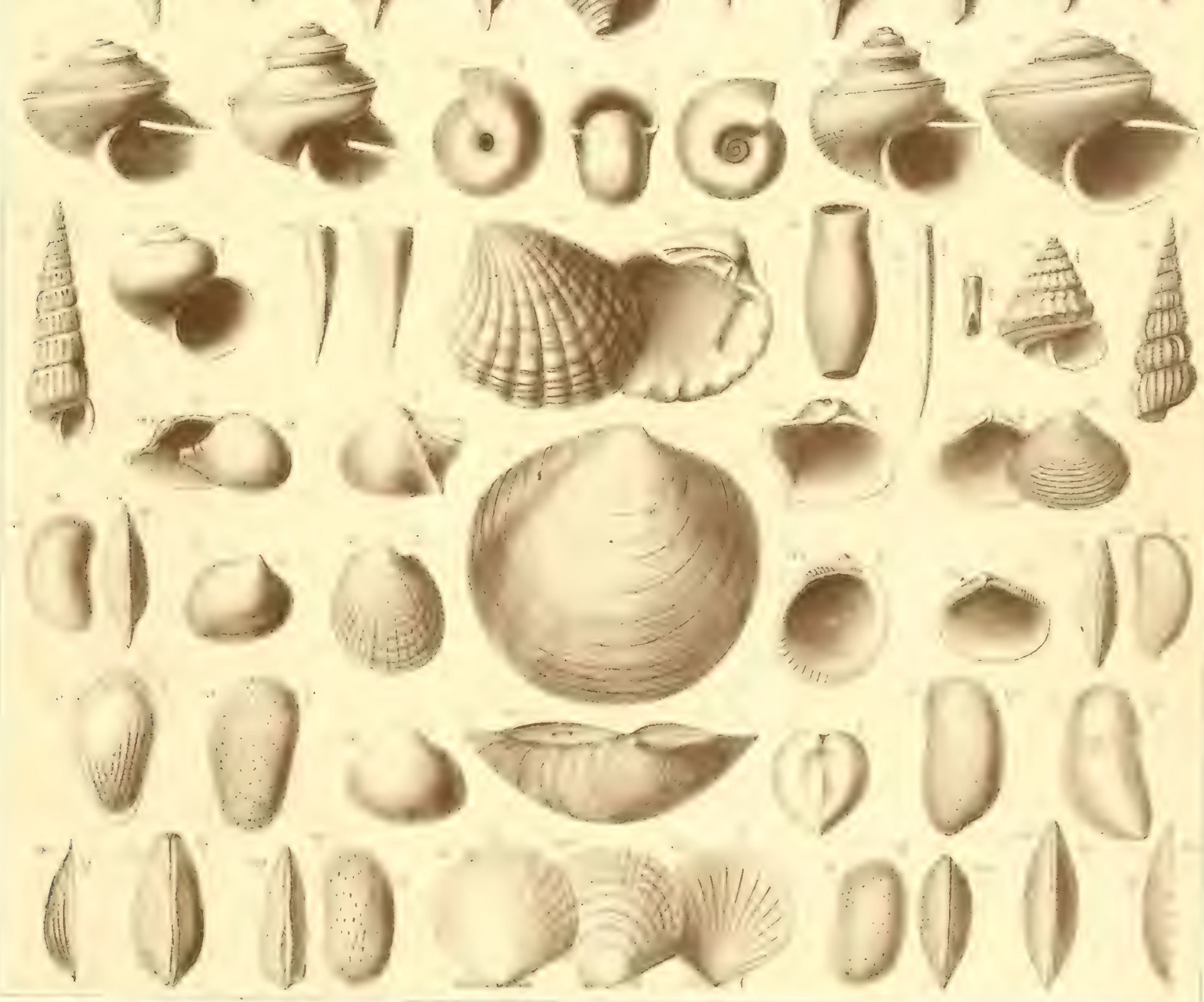


\section{Tavola XVII.}

\section{FOSSIII ASTTANI}

Ii. 1. Loroconcha maculatu-punctata n. sp.

1. Un esemplare completo riccolto a Gallina. la. Lo stesso vechutu in altra josizione.

". Cylheridea minime n. sp.

2. Una valva reluta allesterno raccolta a Gallina. 2a. La stessa rapresentata di profilo.

". Testolebcris spinulose n. sp.

3. Una valva reduta dall'esterno raccolta a Riace. 3a. La stessa guardata di profilo.

1. Cytherella hispida n. sp.

4. Una vialva la Riace rappresentata all'esterno. 4a. Profilo della stessa.

"5. Salicornaria mammillata n. sp.

5. Un articolo incompleto dei varî raccolti a Gallina. 5a. Alcune cellule molto iugrandite.

" i. Lepratia coronata n. sp.

Parte di uma colonia incrostante racenlta il Gallina.

》. Eschara coscinophora Renss. Var. pliocenica n.

7. Parte di un giovine ramo raccolto il Gillina. 7a. Parte di un ramo adulto della stessa provenienza.

" Idmonea bacillaris n. sp.

\& e $E$ a. Un ramo veduto in due posizioni raccolto a Gallina.

" ". Balonophyllia caryophylloides n. sp.

9. Un completo esemplare raccolto a Gallina, 9a. Calice dello stesso.

"10. Batinophyllia circularis n. sp.

10. Un esemplare raccolto a Gillina. 10a. Calice dello stesso.

"11. Balainophyllia compmessa n. ep.

11. Unico esemplare raccolto ar Gallin i. 11a. Calice dello stesso

\12. Lagena lecorala n. sp.

Unico esemplare raccolto nei dintomi di Regcrio.

"13 Fissurina foliacea n. sp

13, 13a, 13b. Un esemplare rappresentato in tre diverse posizioni raccolto ad Ardore.

"14. Pullenic compresse n. sp.

14. Un indiviluo raccolto a Mrnosterace. $14 \alpha$. Lo stesso veluto lal lato ilelliapertura.

"15. Nonionine quatribba n. sp.

15. Un escmplare raccolto a Monosterace. 15ire. Lo stesso veluto ial lato ilellilyertura.

"16. Globigerina gomilulus n. sp.

It e $16 a$. Un esemplare raccolto in Riace rappresentato in due posizioni.

"17. Laplostiche compressa n. sp.

17 e $17 a$. Un individun veluto in due posizioni raccolto presso Gallina.

"18. Manispirina commuis n. sp.

18 e $18 a$. Fsemplari raccolti in dne luoghi, cioè Sidexnn e liace, rappresentati in due diverse posizioni.

, 19. Manispirina carinabu $11 . \mathrm{s}$.

Un esemplare raccolto pressio Buvalius. 


\section{FOSSILI SICILIANI}

Fig. : Alvania turrilolloides $\mathrm{n} . \mathrm{sp}$.

Esemplare mecolto preso Villas. Giovami.

- 21. Bairlia oblusabe G. O. Sars. Var. angulasa n.

21 e. Ia. Un esemplare racenltn presso Momestrace rappresentisto in ine posizioni.

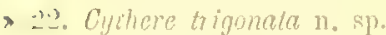

Un esemplare dalle argille di Monosterace.

"23. Cinlhere foreolata n. sp.

Una ralva dia inonosternee.

"21. Ciyllere subaryalis n. $\mathrm{xp}$.

24 e $21 a$. Un indivituo da Nonosterace rappresentato in the divere pocizioni.

"25. Culler" garemunctala n. sp.

25 e 25a. Fsemplare in clue posizioni, raccolto a Monosterace.

" sti. ("ythere rostrula $13 . \mathrm{sp}$.

26 e $26 a$. Individuo mecolto a Monosterace rappresentato in due posizioni.

"27. Cithere foliacra n. sp.

27 e $27 a$. Due diverse posizioni di un esemplare proveniente da Nonosterace.

s:- Ciythere perte n. sp.

28 e 48 . Individuo delle argille di Monosterace in the direrse posizioni.

"wo. llyoluates barlonensis Jones Vin. Honosteracensis n.

29 c 2 ?a Esemplure raccolto a Monosterace figurato in the josizioni.

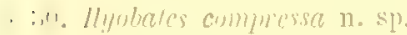

30 e $30 a$. Un individuo delle argille di Monosterace rappresentito in due prosizioni.

" il. destuleheris pustulusa n. sp.

:I c üla. Un esemplare da Monosterace in due pnsizioni.

:?. Lepralie intricula n. sp).

Parte di ma colonia, che incrosta il Mylilus gallomrovincialis raccolt i Pez.n presso Villa s. Giovanni.

"... Lagena maculato-punclata n. sp.

Esemplare delle arogille di MInnosterace.

" :1. Lagme marginato-perforata s1. sp.

Un indiviolun da Mnonsterice.

"Y. Lagena marginab-raliata un. sp.

Un escmplare raceolto nelle argille di Monosterace.

"3r. Fissurine diplere n. su.

Fsemplare seoperto a Mnnosterace.

"37. Nolosarice perforala n. sp.

Intivitun trovato a Monnsterace.

": :R. Pulystonella minima n. sp.

Esempliare raccolto a Mrometriace.

$\because \because$ Ghbigerino nevidera n, sp.

Un individno delle argille di MLnosterace. 


\section{FOSSILI SAARIANI}

Fig. 10. Actacon Lovetonsis n. sp.

Un esemplare raccolto a Boveto.

"11. Cyphoma Bovelensis n. sp.

41 e 41 a. Individuo di Boveto rapuresentat, in lue posizioni.

"42. Odosiomia lacvissima n. sp.

Esemplare raccolto a Carrubbare.

"43. Odostomia confusa n. sp.

Un indivisluo (li Bureto.

"14. Loripes Similhii n. sp.

Una valva delle tante che siraccolgono a Boveto.

»4.) Pontocypris variolale 11. sp.

Escmplare raccolto a Carrubbare.

"46. Bairdia reniformis n. sp.

46 e $46 a$. Completo esemplare trovato a Boreto clisegnato in clue posizioni.

$\therefore$ 17. Cylheridea angulosa n. sp.

47 e $47 a$. Una delle valve che trovansi a Carrubbare rapuresentata in due posizioni.

》48. Cylleridea vilrea n. sp.

48 e $48 a$. Esemplare raccolto a Carrubbare veluto in due posizioni.

"49. Cytheridect exilis $\mathrm{n}$. $\mathrm{sp}$.

49 e $49 a$. Esemplare raccolt, a Curubbare e rappresentato in due diverse posizioni.

"5o. Xestoleberis tesludo n. sp.

50 e 50a. Un individuo da Carrubbare rappresentato in due posizioni.

》51. Cybherara inversa n. sp.

51 e 5la. Un esemplare di Carrubbare veduto in due pasizioni.

".52. Cytherura nevroptera n. sp.

52 e $52 a$. Un completo individuo raccolto a Carrubbare e rappresentato in lue posizioni.

"in. Uyblhoropteron calcaratum n. $\mathrm{sp}$.

53 c 53 a. Una valva raccolta a Boveto e rappresentata in due diverse posizioni.

"is. Cytheropteron Bovellensis n. sp.

Ju e J $t a$. Un completo esemplare rli Boveto rappresentato in due posizimi.

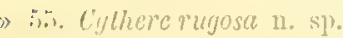

Una valva raccolta a Boveto.

"is. Cytherella Calabra n. sp.

56 e $56 a$. Un inlividno delle sabbie li Boveto figurato in due diverse pnsinioni.

\$.;. Lepralia thiara n. sp.

Parte lima colonia che incrosta una valva del Carlium Norveryicum, racenlta presso MIusalil.

»i. Lagena clavalo-punclata n. sp.

Essemplare raccolto a Boveto.

".". Cipusulina loculicida n. sp.

51!. Uno legli evemplari rnceolti it Carrubbare, s.m. Un segmento che forma un terzo della conchiglia e mostria le interne caviti e sepimenti; racenlto a Carrublare. $59 l$. Lievemflare della tig. 59 veiluto dall'estremo anteriore che porta le aperture. $59 c$. Lo stesso veluto dall'estremo opposto. 


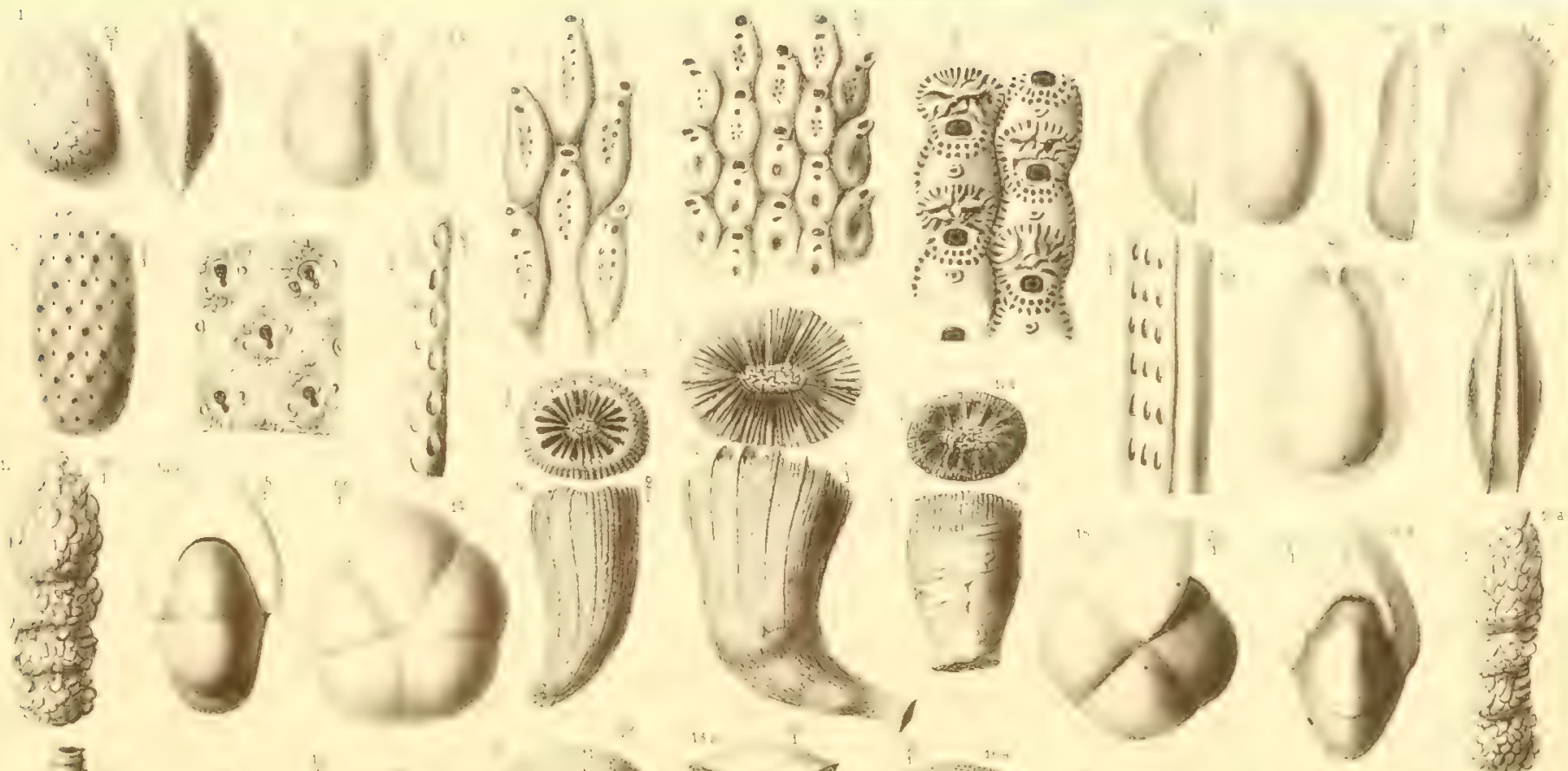

\& U B
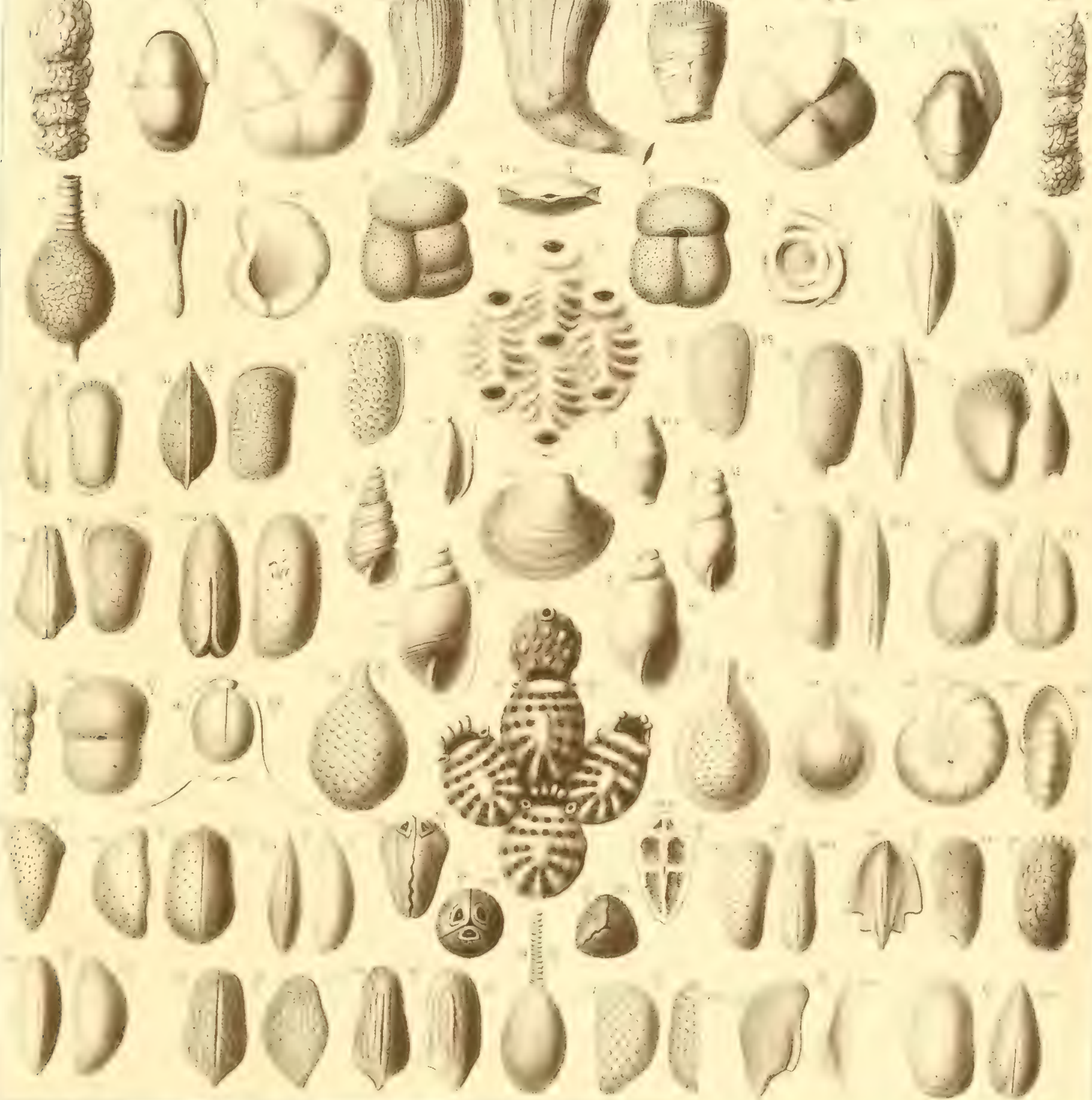



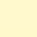


. 


23

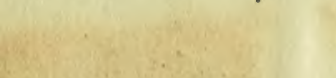




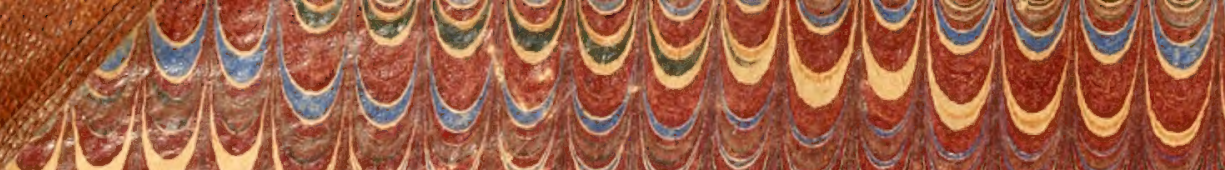
2029 e e e e

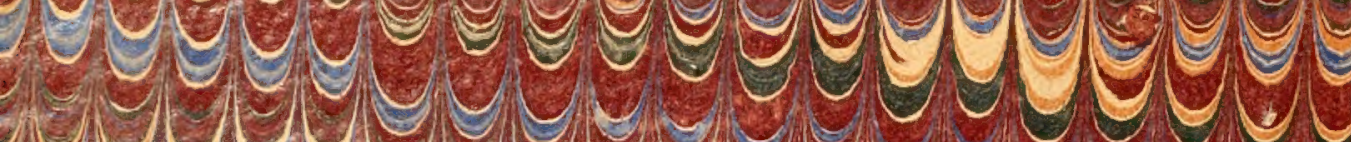

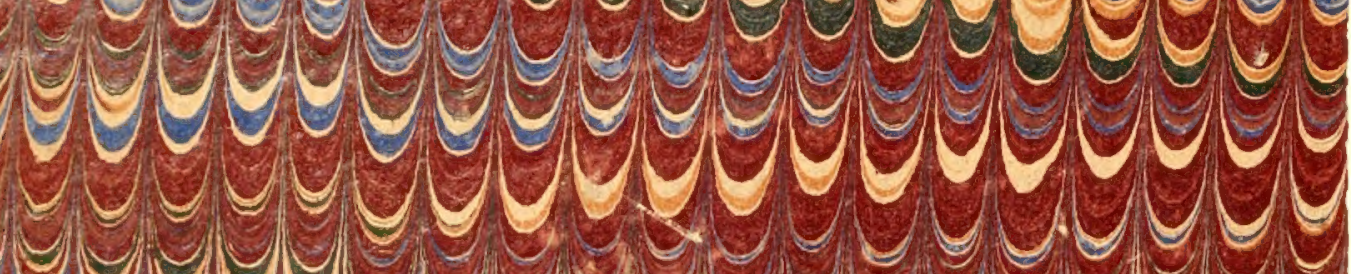

C E C

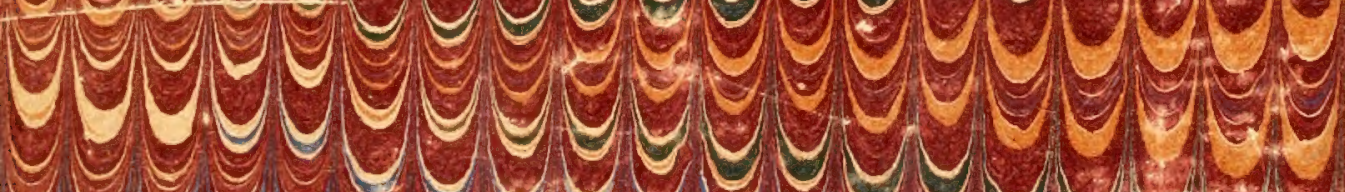

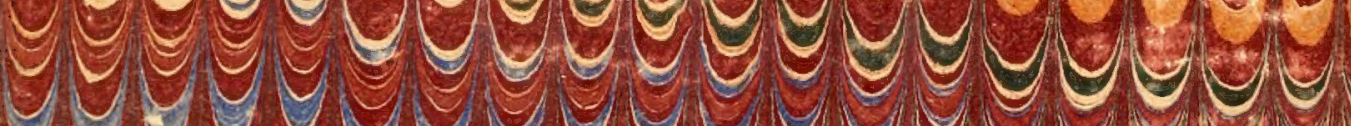

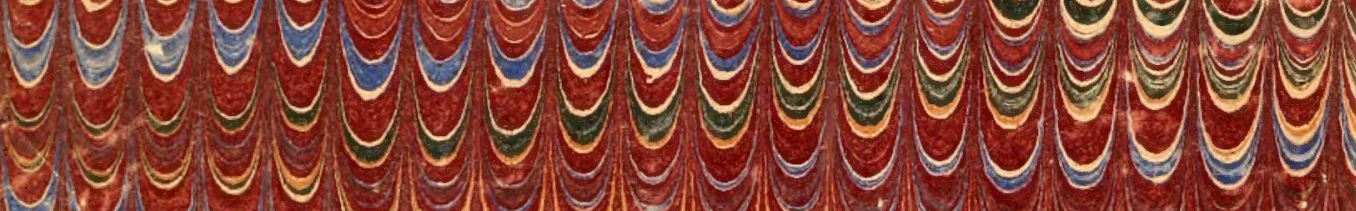
ar

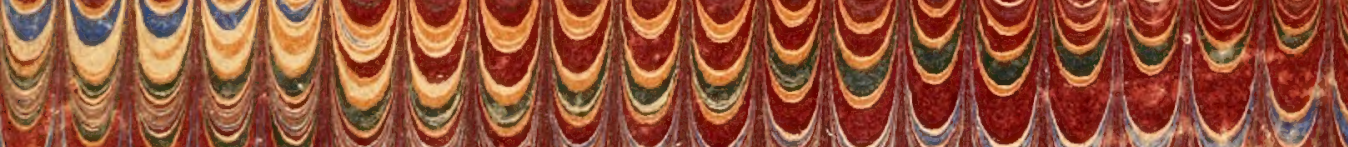
.

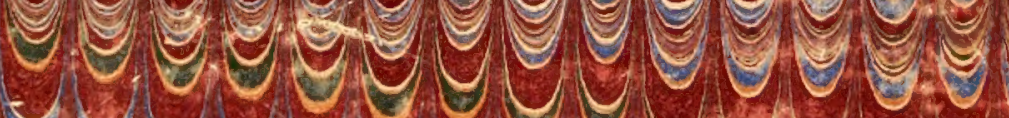

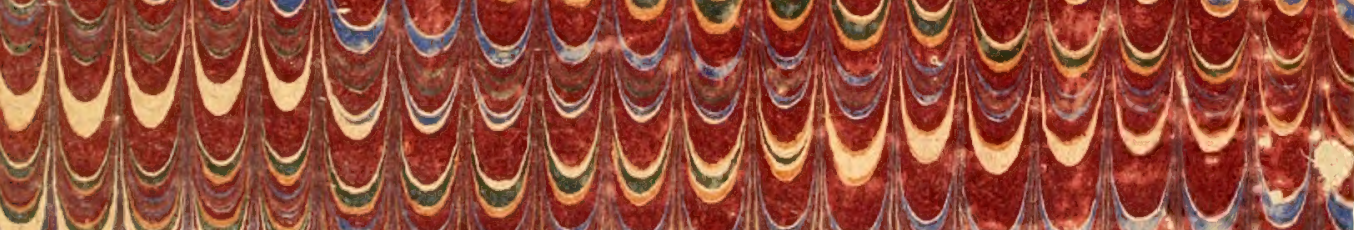
y 政

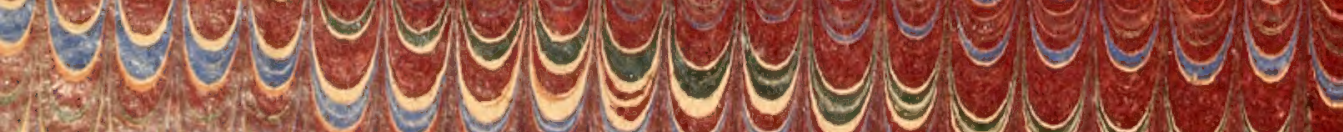
aras o

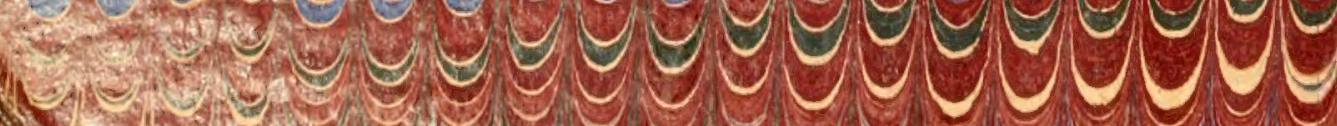
1.4. S8 8

- 